La conquête de la montagne : des premières occupations humaines à l'anthropisation du milieu

Marianne Deschamps, Sandrine Costamagno, Pierre-Yves Milcent, Jean-Marc Pétillon, Caroline Renard, Nicolas Valdeyron (dir.)

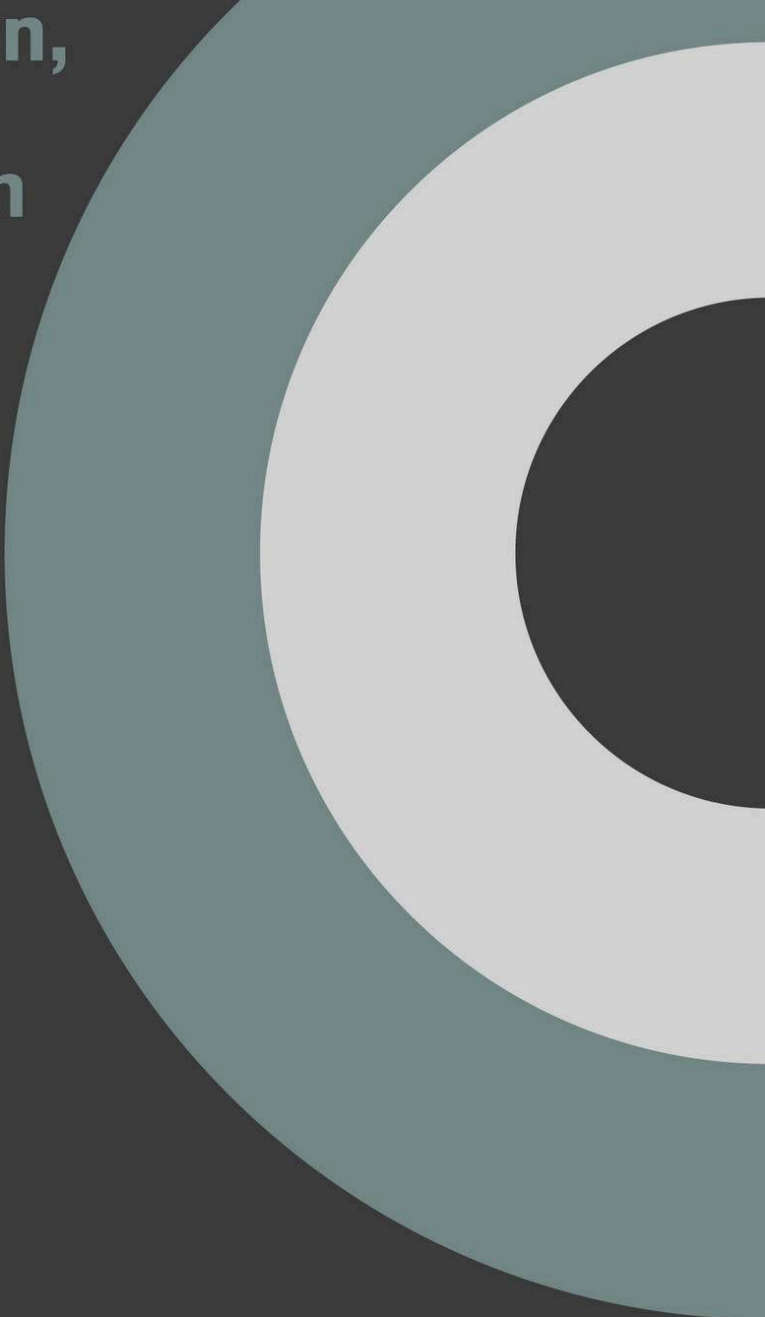




\title{
La conquête de la montagne : des premières occupations humaines à l'anthropisation du milieu
}

\author{
Marianne Deschamps, Sandrine Costamagno, Pierre-Yves Milcent, Jean- \\ Marc Pétillon, Caroline Renard et Nicolas Valdeyron (dir.)
}

DOI : $10.4000 /$ books.cths. 6152

Éditeur : Éditions du Comité des travaux historiques et scientifiques Année d'édition : 2019

Date de mise en ligne : 20 décembre 2019

Collection : Actes des congrès nationaux des sociétés historiques et scientifiques

EAN électronique : 9782735508846

\section{Sbooks}

http://books.openedition.org

Référence électronique

DESCHAMPS, Marianne (dir.) ; et al. La conquête de la montagne : des premières occupations humaines à l'anthropisation du milieu. Nouvelle édition [en ligne]. Paris : Éditions du Comité des travaux historiques et scientifiques, 2019 (généré le 21 septembre 2021). Disponible sur Internet : <http://

books.openedition.org/cths/6152>. ISBN : 9782735508846. DOI : https://doi.org/10.4000/books.cths 6152.

Ce document a été généré automatiquement le 21 septembre 2021.

(C) Éditions du Comité des travaux historiques et scientifiques, 2019

Conditions d'utilisation

http://www.openedition.org/6540 
Les montagnes sont souvent perçues comme des espaces peu et tardivement peuplés, en marge des grands axes d'échanges. Cependant, les recherches récentes ne cessent de faire reculer dans le temps et augmenter en altitude les plus anciennes traces de présence humaine en milieu montagnard. De nombreuses études environnementales et archéologiques ont permis de mieux appréhender les différentes modalités de la gestion des milieux montagnards par les populations pré- et protohistoriques. Du Paléolithique à l'âge du Bronze, au travers d'exemples d'occupations dans les Pyrénées, les Alpes, le Jura, le Massif central et le Morvan, les textes réunis dans cet ouvrage envisagent la montagne comme territoire d'approvisionnement, territoire culturel et territoire d'échange.

Le Congrès national des sociétés historiques et scientifiques rassemble chaque année universitaires, membres de sociétés savantes et jeunes chercheurs. Ce recueil est issu de travaux présentés lors $\mathrm{du} 142^{\mathrm{e}}$ Congrès sur le thème «Circulations montagnardes, circulations européennes ».

\section{MARIANNE DESCHAMPS}

Chercheuse, Centro de Arqueologia da Universidade de Lisboa (UNIARQ), membre associée du laboratoire Travaux et recherches archéologiques sur les cultures, les espaces et les sociétés (TRACES, UMR 5608, université Toulouse - Jean-Jaurès/CNRS)

\section{SANDRINE COSTAMAGNO}

Directrice de recherche au CNRS, laboratoire Travaux et recherches archéologiques sur les cultures, les espaces et les sociétés (TRACES, UMR 5608, université Toulouse - JeanJaurès/CNRS), secrétaire de la section Préhistoire et protohistoire du CTHS

\section{PIERRE-YVES MILCENT}

Maître de conférences habilité à diriger les recherches, laboratoire Travaux et recherches archéologiques sur les cultures, les espaces et les sociétés (TRACES, UMR 5608, université Toulouse - Jean-Jaurès/CNRS)

\section{JEAN-MARC PÉTILLON}

Chargé de recherche au CNRS, laboratoire Travaux et recherches archéologiques sur les cultures, les espaces et les sociétés (TRACES, UMR 5608, université Toulouse - JeanJaurès/CNRS)

\section{CAROLINE RENARD}

Chargée de recherche au CNRS, laboratoire Travaux et recherches archéologiques sur les cultures, les espaces et les sociétés (TRACES, UMR 5608, université Toulouse - JeanJaurès/CNRS) 
NICOLAS VALDEYRON

Professeur, directeur du laboratoire Travaux et recherches archéologiques sur les cultures, les espaces et les sociétés (TRACES, UMR 5608, université Toulouse - JeanJaurès/CNRS) 
SOMMAIRE

Introduction

Marianne Deschamps, Sandrine Costamagno, Pierre-Yves Milcent, Jean-Marc Pétillon, Caroline Renard et Nicolas Valdeyron

Occupation et exploitation du milieu montagnard

Approches multiproxy

Géographie et échanges culturels

\section{Occupation et exploitation du milieu montagnard}

Mobilité territoriale pendant le Paléolithique moyen en contextes discoïde et Levallois : exemple du site de l'Abric Romaní (Capellades, Barcelona, Espagne), niveau M et sousniveau $\mathrm{Oa}$

Bruno Gómez de Soler, María Gema Chacón, Amelia Bargalló, Francesca Romagnoli, María Soto, Josep Vallverdú et Manuel Vaquero

Le site de l'Abric Romaní

Matériel d'étude

Méthodologie

Résultats

Discussion

Conclusions

Paléolithique moyen récent et Paléolithique supérieur initial en contexte pyrénéen : les industries lithiques de la grotte de Gatzarria (Ossas-Suhare, Pyrénées-Atlantiques) et leurs implications régionales

Marianne Deschamps et Damien Flas

Présentation du site

Anciennes collections, nouvelles études

Implications régionales

Conclusion

The Llonin Cave (Peñamellera Alta, Asturias, Spain), level III (Galería): techno-typological characterisation of the Badegoulian lithic and bone assemblages

Marco de la Rasilla Vives, Elsa Duarte Matías, Joan Emili Aura Tortosa, Alfred Sanchis Serra, Yolanda Carrión Marco, Manuel Pérez Ripoll et Vicente Rodríguez Otero

Archeological data

Discussion

Conclusions

Les occupations humaines sur le site de plein air du Paléolithique supérieur de Montlleó (Prats i Sansor, Lérida, Espagne) : nouvelles données

Xavier Mangado, Marta Sánchez de la Torre, Mathieu Langlais, Núria Rodriguez, Jordi Nadal, Lluis Lloveras, José-Miguel Tejero, Gala García-Argudo, Oriol Mercadal et Josep Maria Fullola

Introduction : les conditions paléo-environnementales

Le site de Montlleó

L'industrie lithique

L'industrie osseuse

La parure

Les vestiges fauniques

Discussion

Conclusions 
Sur la piste d'un peuplement pionnier de l'Azilien en Pyrénées : l'exemple des industries en roches volcaniques de La Balma de la Margineda (Andorre)

Michel Martzluff, Valentí Turu, Gérard Remolins-Zamora et Jean Guilaine

Rappel des données acquises sur le site de La Margineda

Origine des roches volcaniques employées dans l'Azilien en Andorre

Conclusion

L'abri de L'Esplugón (Villobas-Sabiñánigo, Huesca, Espagne) : apports des données à la question de la transition Mésolithique-Néolithique dans les Pré-Pyrénées méridionales Alberto Obón Zúñiga, Abel Berdejo Arcéiz, Rafael Laborda Martínez, Alejandro Sierra Sainz-Aja, Marta Alcolea Gracia, Manuel Bea, Rafael Domingo Martínez et Pilar Utrilla Miranda

Le site préhistorique de L’Esplugón

Le matériel archéologique

Conclusions

De l'arolle ou du chêne? Mobilité verticale et exploitation des ressources végétales au

Néolithique dans les Alpes occidentales

Lucie Martin, Claire Delhon, Alexa Dufraisse, Stéphanie Thiébault et Marie Besse

Introduction

Des occupations humaines à toutes les altitudes

Approche archéobotanique : cadre géographique et chronoculturel des sites étudiés

Matériel et méthode

Résultats et discussion

Conclusion

Économie animale et territoire au Néolithique dans les Alpes occidentales : un même son de cloche? Les sites de La Grande Rivoire (Sassenage, Isère, France), Le Chenet des Pierres (Bozel, Savoie, France) et La Soie (Savièse, Valais, Suisse)

Patricia Chiquet

Méthodes et matériel

Les sites

Discussion

Conclusion

Des structures d'habitat en haute montagne de la fin du Campaniforme et du Bronze ancien (2 300-2 000 avant notre ère) au cirque de Troumouse (La Haille de Pout, Gèdre, Hautes-

Pyrénées) : premiers résultats

Guillaume Saint-Sever et Maxime Remicourt

Les données physiques et environnementales

Contexte archéologique

Les premiers résultats archéologiques

Les datations radiométriques

Le mobilier archéologique

Pour conclure

\section{Approches multiproxy}

Le canyon de la Pardina et ses estives : approche archéologique d'un territoire de haute montagne dans le parc national d'Ordesa et du mont Perdu (Fanlo, Huesca, Espagne) Lourdes Montes, Rafael Domingo Martínez, Rafael Laborda Lorente, Paloma Lanau, Vanessa Villalba-Mouco, Mario Gisbert et María Sebastián

La zone d'étude : caractéristiques géographiques et environnementales d'Ordesa Les travaux archéologiques : méthodologie et synthèse des résultats obtenus

Les sites les plus intéressants et leur répartition dans l'espace

Premières réflexions sur le peuplement du territoire

Conclusion 
Occupation et anthropisation des espaces de haute montagne dans les vallées de Nuria et de Coma de Vaca (Gerona, Espagne) : résultats des recherches archéologiques et patrimoniales Josep Maria Palet, Pau Olmos, Arnau Garcia, Tania Polonio et Hèctor A. Orengo

Les premières traces d'occupation des espaces de haute montagne au Néolithique et à l'âge du Bronze

La période romaine et l'Antiquité tardive

Rome et les territoires de montagne

Pour une mise en valeur du patrimoine archéologique de haute montagne dans les vallées de Nuria et de Coma de Vaca

Conclusions

Essai de géographie protohistorique en contexte de moyenne montagne : enquête en HauteAuvergne et sur les plateaux limousins (Massif central, France)

Florie-Anne Auxerre-Géron

Le cadre de l'étude

Étude de cas en Haute-Auvergne : le maillage des sites de hauteur du Bronze moyen à la fin du premier âge du Fer

Étude de cas en haute Corrèze : esquisse de l'organisation du territoire à La Tène finale

Conclusion

Peuplements et paysages anciens dans les massifs du Morvan et du Jura : confrontation de données paléo-environnementales, historiques et archéologiques

Valentin Chevassu, Émilie Gauthier, Pierre Nouvel, Hervé Richard, Vincent Bichet et Isabelle Jouffroy-Bapicot

Méthodologie et données utilisées

Premiers éléments de synthèse

Conclusion

\section{Géographie et échanges culturels}

Exploitation des matières premières lithiques locales et allochtones au Paléolithique moyen récent sur le versant nord-occidental des Pyrénées : le cas des grottes du Noisetier (FréchetAure, Hautes-Pyrénées) et de Gatzarria (Ossas-Suhare, Pyrénées-Atlantiques)

Marianne Deschamps, Théo Minet, Pierre Chalard, David Colonge, Vincent Mourre, Christian Servelle et Marc Thomas

Présentation des sites

Résultats concernant l'origine des matières premières

Synthèse et discussion

Conclusion

Montlleó (Prats i Sansor, Lérida, Espagne) : le passage du symbolisme à travers les montagnes

Juan Luis Fernández-Marchena, Gala García-Argudo, Xavier Mangado, Oriol Mercadal et Josep Maria Fullola

Les objets symboliques et culturels

Matériaux et méthodes

Conclusions

Les Pyrénées, une frontière pré-historiographique pour le Magdalénien ? Réflexions à partir du Magdalénien moyen récent de la grotte Tastet (Sainte-Colome, Pyrénées-Atlantiques) Mathieu Langlais et Jean-Marc Pétillon

Caractéristiques du Magdalénien moyen récent (MMR)

Le MMR dans le bassin d'Arudy : la grotte Tastet

La variabilité du MMR

Discussion 
Circulation à longue distance des matières premières lithiques et des objets de parure au Magdalénien moyen en Auvergne : exemple du site d'Enval-Moliard (Vic-le-Comte, Puy-deDôme)

Frédéric Surmely, Sandrine Costamagno, Jay Franklin, Raphaël Angevin, François Chevrier, Stéphane Madelaine et Maureen Hays

Le site d'Enval-Moliard

Circulation des matières premières lithiques

Objets de parure

Discussion

Conclusion

Les montagnes du Jura : entre contrainte topographique et vecteur de diffusion à la fin du Paléolithique supérieur (15 000-12 000 avant le présent)

Gérald Béreiziat

Le massif du Jura

Unité et originalité des cultures matérielles

Conclusion et discussion

Le Néolithique dans les Pyrénées nord-occidentales : circulation et complémentarité entre le piémont et la moyenne montagne

Patrice Dumontier

Les premières implantations du Néolithique ancien : entre 5800/5300 et 4500 avant notre ère

Le Néolithique moyen et récent (entre 4600/4500 et 3400/3200 avant notre ère)

Quel Néolithique final?

Conclusions

Vestiges graphiques, culture matérielle et matières premières : circulations du Néolithique aux âges des métaux dans les Alpes du sud. Les exemples de l'abri Faravel (Freissinières, Hautes-Alpes), de l'abri des Oullas (Saint-Paul-sur-Ubaye, Alpes-de-Haute-Provence) et du tertre des Sagnes (Jausiers, Alpes-de-Haute-Provence)

Claudia Defrasne, Florence Mocci, Kevin Walsh, Stéfan Tzortzis, Brigitte Talon, Thibault Lachenal et Vincent Dumas

Une circulation en altitude entre la préhistoire et l'âge du Fer : les sites de l'abri Faravel, des Sagnes et des Oullas

Vestiges graphiques et culture matérielle : territoires en jeu et circulation des idées au cœur des massifs alpins

Conclusion

Nouvelle lecture des rapports interculturels entre les communautés aux marges de l'Apennin méridional (régions Campania et Puglia, Italie) à partir de découvertes récentes Claude Albore Livadie, Anna Maria Tunzi, Elena Soriano, Nicola Gasperi et Francesco Matteo Martino

Chronologie, faciès culturel et impact volcanique

Stratégies d'implantation et formes de l'habitat

Mobilier

Conclusion

Essai de modélisation des échanges et des réseaux de circulation dans les Alpes centrales au premier âge du Fer

Veronica Cicolani et Thomas Huet

Les Alpes centrales : au carrefour de domaines culturels et géographiques différents

Le corpus : productions ordinaires sud-alpines et importations méditerranéennes

Méthodologie

Les communautés alpines et sud-alpines au prisme des échanges protohistoriques

Discussion 
Mobilité des individus et des biens dans la vallée de l'Ubaye (Alpes-de-Haute-Provence) et le Guillestrois (Hautes-Alpes) à l'âge du Fer

Delphine Isoardi et Laurie Tremblay Cormier

Cadre historiographique et méthodologique

État de la documentation archéologique : des sépultures peu documentées, mais un costume funéraire objet de toutes les attentions

Une première approche du genre des inhumés de l'âge du Fer en Ubaye-Guillestrois

Les interactions extrarégionales au travers de la parure funéraire

Synthèse et conclusion 


\section{NOTE DE L'ÉDITEUR}

Les articles de cet ouvrage ont été validés par le comité de lecture des Éditions du Comité des travaux historiques et scientifiques dans le cadre de la publication des actes du $142^{\mathrm{e}}$ Congrès national des sociétés historiques et scientifiques tenu à Pau en 2017. 


\title{
Introduction
}

\author{
Marianne Deschamps, Sandrine Costamagno, Pierre-Yves Milcent, Jean- \\ Marc Pétillon, Caroline Renard et Nicolas Valdeyron
}

1 Les montagnes, souvent perçues comme des espaces en marge des zones densément peuplées ou des grands axes de communication et de circulation, sont généralement considérées comme des territoires difficilement pénétrables, porteurs de traditions singulières, voire même mystérieux ou légendaires. Les reliefs sont aussi communément associés à l'idée de frontières naturelles, difficilement franchissables en raison de l'escarpement général de leur topographie et d'écarts climatiques saisonniers et altitudinaux importants. Pourtant, si la circulation et la communication dans ces espaces doivent certainement s'opérer de manière plus segmentée qu'en plaine, il n'en demeure pas moins que les récentes recherches ne cessent de faire reculer dans le temps et augmenter en altitude les plus anciennes traces de présence humaine en milieu montagnard. En témoigne notamment la toute dernière découverte d'un fragment humain ayant appartenu à un Dénisovien il y a environ 160000 ans sur le plateau tibétain, à 3280 mètres d'altitude (Chen et al. 2019).

2 Pour ceux qui s'intéressent de longue date aux occupations humaines anciennes dans les massifs montagneux, la faiblesse relative des données apparaît souvent bien plus liée aux difficultés de prospection et aux phénomènes érosifs intenses qu'à l'absence réelle d'occupation humaine. En dépit et en toute conscience de ces difficultés supplémentaires, le monde montagnard et ses abords offrent un terrain de recherche sans pareil, où les comportements humains peuvent être évalués à l'aune des contraintes naturelles, souvent plus aisément identifiables que dans d'autres types de milieux.

3 Cette thématique pose également la question des différentes échelles de résolution qui définissent le territoire: "territoire d'approvisionnement», où l'on puise dans les ressources du milieu ; «territoire culturel », où évoluent des groupes unis par un mode de pensée et d'expression symbolique; "territoire d'échange ", où s'opère la transmission de matières premières, de savoir-faire, de nouvelles idées (Bourgeot 1991).

4 Lorsque le Comité des travaux historiques et scientifiques (CTHS) a proposé les «circulations montagnardes, circulations européennes» comme thématique du $142^{\mathrm{e}}$ 
Congrès national des sociétés historiques et scientifiques, tenu en 2017 à Pau (Pyrénées-Atlantiques), la résonance de ce sujet pour de nombreux membres du laboratoire TRACES (UMR 5608 du CNRS, université Toulouse - Jean-Jaurès) a été le moteur naturel d'une participation active. C'était également l'occasion de proposer un bilan des avancées des connaissances depuis le $118^{\mathrm{e}}$ congrès du CTHS, organisé à Pau en 1993, et la publication du volume d'actes Pyrénées préhistoriques : arts et sociétés (Delporte et Clottes 1996).

En 2017, deux sessions complémentaires de communications ont ainsi été proposées, couvrant une vaste diachronie et articulées autour de deux axes de réflexion: «la conquête de la montagne, des premières occupations humaines à l'anthropisation du milieu » et «les montagnes, frontières naturelles, frontières culturelles ». Ce second titre faisait d'ailleurs écho à un précédent ouvrage collectif concernant les Pyrénées préhistoriques (Cazals et al. 2007). La participation aux deux sessions a été importante, regroupant près de quarante communications concernant différentes régions montagneuses. Le massif pyrénéen était le plus représenté, faisant l'objet de vingt-deux présentations, dont la moitié a été proposée par des collègues espagnols.

6 Les vingt-trois contributions réunies dans le présent volume regroupent les deux sessions ouvertes lors du congrès et se répartissent selon trois thématiques générales. Une première partie vise à comprendre les modes d'occupation et d'exploitation du milieu montagnard. Des contributions de synthèse régionales sont, quant à elles, liées au croisement et à l'interprétation de plusieurs types de données via des approches multiproxy. Enfin, des contributions à échelle macrorégionale au sein du thème "géographie et échanges culturels" mettent en avant les interactions et/ou les obstacles entre l'occupation du milieu montagneux et d'autres types de milieux.

\section{Occupation et exploitation du milieu montagnard}

7 Le premier thème regroupe neuf articles couvrant une très longue diachronie, depuis le Paléolithique moyen jusqu'au début du Bronze ancien, dans un espace couvrant principalement les Pyrénées et, dans une moindre mesure, le massif alpin. Abordées selon différents angles, les questions liées à l'occupation et à l'exploitation des montagnes sont principalement traitées en termes de présence/absence des traditions techniques, d'acquisition et d'utilisation des ressources, en particulier des matières premières lithiques. Avec l'avènement des sociétés agropastorales, les sources de documentation tendent à se multiplier et les questionnements se tournent alors vers les formes et la pérennité des habitats ainsi que vers la variété des structures liées à l'activité d'élevage.

8 Pour la Préhistoire ancienne, la rareté des occupations anthropiques, voire l'absence de représentation de certaines phases chronoculturelles, se prête à diverses interprétations. Si l'espace montagnard pyrénéen peut être associé à l'image d'un véritable «désert culturel» s'agissant de certaines traditions techniques du Paléolithique récent, on doit prendre en compte le rôle de phénomènes érosifs particulièrement importants, qui ont pu affecter les niveaux d'occupation et brouiller ainsi une part de la réalité archéologique. Dans ce cadre, la révision de séquences de référence et les analyses taphonomiques s'avèrent des axes de recherche fructueux permettant de renouveler nos connaissances des traditions techniques qui se sont développées dans ces territoires montagnards. 
9 C'est ce que montre par exemple l'article de M. Deschamps et D. Flas concernant la révision des collections anciennes du Paléolithique moyen et du Paléolithique supérieur initial issues des fouilles menées par G. Laplace à la grotte de Gatzarria, située dans le piémont nord-occidental des Pyrénées. L'intégrité de certains niveaux (niveau Cjn1) est remise en question tandis que d'autres ensembles (au sein du Paléolithique moyen) sont subdivisés sur la base de la répartition spatiale des attributs typotechnologiques et des remontages. Ces analyses aboutissent à un renouvellement des connaissances des industries du Paléolithique moyen récent et supérieur initial dans le monde pyrénéen.

10 Les analyses taphonomiques menées sur les gisements de Montlleó (Cerdagne, Espagne) et Llonín (Asturies, Espagne), localisés aux deux extrémités de la chaîne pyrénéenne, montrent l'existence de traditions techniques peu documentées - voire considérées comme absentes - dans cet espace géographique.

11 Ainsi, l'analyse taphonomique de la séquence de Montlleó, corrélée aux mesures radiométriques, permet à X. Mangado et al. de valider l'existence de deux niveaux archéologiques dont le plus important, au sommet, est attribué au Magdalénien inférieur. Ces travaux attestent par la même occasion les plus anciennes occupations humaines dans la zone des Pyrénées méridionales, contemporaines du Dernier Maximum glaciaire, et notamment la présence d'industries du Badegoulien.

12 À l'opposé de la chaîne pyrénéenne, c'est en exposant très précisément la nature et le contenu de la couche III du site de Llonín que M. de la Rasilla Vives et al. proposent un nouvel éclairage de la transition solutréo-magdalénienne dans les Asturies (Espagne). En mettant en œuvre une réflexion sur l'intégrité stratigraphique de cette couche et des éléments archéologiques qu'elle renferme, les auteurs, qui s'appuient également sur un cadre radiométrique renouvelé, montrent clairement l'existence d'une tradition badegoulienne dans cette aire géographique.

13 Une autre transition est également documentée par les travaux de A. Obón et al., celle entre les derniers chasseurs-collecteurs mésolithiques et les premières traces d'activités agropastorales identifiées à l'abri de l'Esplugón, dans la vallée de l’Èbre. Du début $d u \mathrm{VII}^{\mathrm{e}}$ au début $\mathrm{du} \mathrm{v}^{\mathrm{e}}$ millénaire $\mathrm{BC}$, cette séquence documente à la fois l'impact local des événements climatiques (recul des taxons mésophiles lié au 8.2 kevent), l'évolution typotechnologique $d u$ Mésolithique (rôle accru des influences ultrapyrénéennes dans la phase tardive) et les premières traces d'activités agropastorales au Néolithique ancien.

14 L'acquisition et la gestion des ressources - en particulier des matières premières lithiques - constituent également un axe important des recherches développées sur l'occupation et l'exploitation du milieu montagnard durant la Préhistoire ancienne.

15 À l'abri Romaní, gisement localisé sur les derniers contreforts de la cordillère du prélittoral espagnol, B. Gomez de Soler et al. montrent que la sélection et la gestion des matériaux lithiques employés dans deux niveaux du Paléolithique moyen récent restent identiques en dépit de la mise en œuvre de chaînes opératoires distinctes (Discoïde versus Levallois). Ce constat amène les auteurs à penser que, dans ce contexte, les matières premières lithiques ne conditionnent pas les choix technologiques, qui seraient davantage guidés par des facteurs socio-économiques.

16 Les matières premières lithiques sont aussi source d'information quant aux voies de circulation empruntées par les sociétés nomades qui ont parcouru ces espaces 
montagnards. C'est notamment ce que proposent M. Martzluff et al. dans leur contribution portant sur la révision de l'origine des laves abondamment utilisées dans l'Azilien de La Margineda. L'identification d'un approvisionnement dans la Serra del Cadí, couplée à de récentes études montrant que les cols alentour sont restés englacés tardivement, modifie notre vision de ces occupations. Ainsi les premiers peuplements des hautes vallées andorranes, supposés venus du nord des Pyrénées, auraient emprunté un trajet moins direct et auraient eu un ancrage plus pérenne au sud du site, dans le bassin du Sègre.

17 Avec l'avènement des sociétés agropastorales, les occupations au sein du monde montagnard s'intensifient et se diversifient. Ceci se traduit notamment par une appropriation des espaces d'altitude, résultant notamment de la généralisation de l'estivage. Cependant, il ne s'agit pas d'un processus uniforme, comme le montrent les recherches de P. Chiquet ou encore celles de L. Martin.

Une analyse archéozoologique d'ensembles osseux issus de sites d'altitude des Alpes occidentales conduit $\mathrm{P}$. Chiquet à mettre en évidence des différences dans la mise en place des premières communautés agropastorales du bassin de l'Isère et de celles de la haute vallée du Rhône. Si, dans le bassin de l'Isère, les populations autochtones tirent parti des zones d'altitude dès le Néolithique ancien, ce n'est qu'à partir du IV ${ }^{e}$ millénaire avant notre ère que l'estivage se généralise, montrant une véritable appropriation de cet espace par les groupes humains néolithiques dans le développement de leurs activités agropastorales.

Les ressources végétales, de par leur étagement altitudinal, sont aussi des matériaux de choix pour s'interroger sur le contrôle de l'espace montagnard par les populations néolithiques. Plantes sauvages, plantes cultivées et bois de feu permettent ainsi à L. Martin et al. d'explorer la diversité et la complexité de la gestion des territoires montagnards tout au long du Néolithique. Dans les Alpes du nord françaises, divers indices témoignent de l'exploitation d'un vaste territoire intégrant pleinement l'étage montagnard, voire subalpin, alors que dans la haute vallée du Rhône, sur le plateau suisse, l'économie des ressources végétales atteste une installation et une exploitation des étages altitudinaux les plus bas (étage collinéen principalement).

Enfin, la découverte de structures d'habitat datées du Campaniforme et du début du Bronze ancien à plus de 2000 mètres d'altitude dans le cirque de Troumouse, sur le versant septentrional des Pyrénées occidentales, amène G. Saint-Sever à considérer l'existence vraisemblable d'occupations saisonnières potentiellement liées à l'exploitation du minerai de cuivre. L'ouverture du milieu, qui s'accentue durant le Bronze ancien, semble aller dans le sens d'une diversification des activités dans ces habitats de haute montagne, avec notamment le développement d'activités agropastorales. Ces travaux viennent aussi abonder les conclusions de P. Dumontier évoquant une occupation plus pérenne de l'étage subalpin du massif pyrénéen durant le Néolithique final.

\section{Approches multiproxy}

21 Le second thème regroupe quatre contributions qui mettent en œuvre des approches multiproxy. Classiquement, l'archéologie se positionne à la croisée de plusieurs champs disciplinaires, et c'est généralement la confluence des résultats issus de différents types 
d'analyses qui permet d'aboutir à des interprétations plus fines, en même temps que de proposer des synthèses régionales diachroniques.

Les travaux de thèse conduits par F.-A. Auxerre-Géron en sont un bon exemple. Ces recherches sur la Protohistoire en Haute-Auvergne et sur les plateaux limousins sont présentées au travers des résultats obtenus dans deux fenêtres d'étude. En croisant études paléo-environnementales, données archéologiques et analyses spatiales, les modèles d'occupation du sol qui se dégagent de ces milieux de moyenne montagne montrent une profonde anthropisation dès l'âge du Bronze moyen et présentent des similitudes avec d'autres territoires du Massif central.

Transposées aux massifs du Morvan et du Jura, les recherches de V. Chevassu et al. sont conduites dans le même esprit. Le spectre chronologique est large, avec une extension jusqu'à l'époque moderne, ce qui permet de confronter les archives écrites aux vestiges matériels. Principalement à partir du haut Moyen Âge, une coévolution complexe des paysages et des structures de peuplement se dessine.

24 Un programme de prospection présenté par L. Montes et al. en haute montagne, sur le territoire du parc national d'Ordesa, permet également d'identifier une soixantaine de points d'intérêt archéologique ; le sondage ou la fouille de certains d'entre eux montre l'existence de trois épisodes de fréquentation humaine, tous liés au pastoralisme - un dès le $\mathrm{III}^{\mathrm{e}}$ millénaire $\mathrm{BC}$ (Néolithique final/Chalcolithique), un au Moyen Âge et un d'époque moderne et contemporaine.

Enfin, pour J. Palet et al., l'archéologie du paysage fournit des données importantes sur la transformation anthropique des paysages de haute montagne et leur évolution en Cerdagne. Une approche croisée utilisant systèmes d'information géographique (SIG), fouilles archéologiques et données paléo-environnementales leur permet de dresser un bilan de l'occupation du sol et de la nature de l'exploration des ressources entre le Néolithique et la période contemporaine. Un objectif conservatoire vient ici doubler l'objectif scientifique grâce à l'élaboration d'outils de gestion pour la conservation des espaces de haute montagne.

\section{Géographie et échanges culturels}

26 Le troisième thème aborde des comparaisons à plus large échelle faisant ressortir l'unité, les contacts, les complémentarités ou encore les spécificités des occupations en milieu montagnard face à celles qui se développent en plaine, dans le piémont ou même dans d'autres vallées d'altitude. Ces dix contributions démontrent que des preuves de contacts sur de longues distances peuvent être mises en évidence, même pour les périodes les plus anciennes (peuplement néandertalien). Ainsi la vision fantasmée d'un monde montagnard comme un système isolé et enclavé est-elle très majoritairement mise à mal.

Les travaux de M. Deschamps et al. vont dans ce sens, procédant à une caractérisation de l'origine des matières premières locales et allochtones dans deux sites attribués au Paléolithique moyen du versant nord-occidental des Pyrénées: Le Noisetier et Gatzarria. Des approvisionnements sur de longues distances viennent connecter les territoires lithologiques des deux sites et démontrent également la présence d'importations extrarégionales depuis le bassin de l'Èbre. Ces résultats ouvrent une 
réflexion sur la question des voies de circulation à travers les cols du Pays basque intérieur.

À l'autre extrémité de la chaîne, la vallée du Sègre demeure la seule vallée non englacée durant le Dernier Maximum glaciaire et la possibilité qu'elle représente un axe de circulation transpyrénéen entre la vallée de l'Èbre et le golfe du Lion est discutée par J.L. Fernandez-Marchena et al. La présence, dans le niveau Magdalénien inférieur, de nombreux éléments de parure (coquilles marines méditerranéennes et atlantiques), de minéraux rares (quartz et prismes) et de matières colorantes parfois d'origine lointaine pousse les auteurs à s'interroger sur les échanges et les voies de circulation pratiqués par ces sociétés.

Un autre exemple de circulation transmontagnarde est proposé dans l'article de G. Béreiziat, qui regroupe les données relatives aux sphères techniques et symboliques des groupes ayant fréquenté l'arc jurassien depuis le Magdalénien moyen jusqu'au début de l'Azilien. À partir d'un recensement exhaustif des sites présents dans cette entité géographique, l'objectif est de définir en quoi les caractéristiques topographiques de ce massif et des axes fluviaux ont pu alternativement faciliter, freiner ou empêcher la diffusion des objets et la circulation des groupes et des idées au Magdalénien.

30 La question des contacts sur de longues distances implique souvent une réflexion sur la notion d'échange entre divers groupes appartenant à une même tradition culturelle plutôt que celle de vastes territoires intégralement parcourus par ces groupes. La distinction entre un approvisionnement lointain direct et un approvisionnement par échanges de proche en proche entre groupes est relativement délicate à mettre en évidence du point de vue archéologique. La distance, la spécificité et la quantité des denrées qui voyagent peuvent cependant constituer un argument pour alimenter cette idée d'échange.

31 C'est notamment ce que propose l'étude du site nouvellement découvert d'EnvalMoliard. F. Surmely et al. abordent l'origine des différents matériaux mis au jour sur ce site. Certaines matières premières (lithiques, osseuses et coquilles), également identifiées sur d'autres sites magdaléniens du Massif central, documentent parfaitement les liens étroits entretenus avec d'autres régions du centre de la France, alors que d'autres attestent de contacts probables avec les régions alpines. Au regard des distances en jeu pour les matières premières les plus lointaines, les auteurs proposent un accès indirect par le biais d'échanges, ce qui semble induire une forte cohésion culturelle entre ces groupes.

Durant les phases plus récentes de l'âge du Fer, des réseaux de circulation à travers les Alpes sont documentés par les contributions de V. Cicolani et T. Huet et de D. Isoardi et L. Tremblay Cormier. À l'aide d'une modélisation des réseaux de circulation qui unissent au premier âge du Fer le nord de l'Italie à l'Europe centrale, à travers les Alpes centrales, V. Cicolani et T. Huet s'appuient sur l'identification de productions banales de la culture de Golasecca aussi bien que sur des objets prestigieux méditerranéens pour cartographier des réseaux de déplacements théoriques. SIG et tracés de graphes sont combinés pour identifier ces réseaux, leur structuration et leur évolution spatiotemporelle. D. Isoardi et L. Tremblay Cormier interrogent, quant à elles, l'identité culturelle des populations de l'âge du Fer dans la vallée de l'Ubaye, qui forme un espace topographiquement enclavé. Elles reprennent ainsi l'étude des nombreux éléments de costume déposés dans les tombes. Objets propres à la région ou d'origine exogène 
permettent d'avancer des hypothèses quant au degré variable d'isolement et d'intégration de cette région par rapport aux réseaux de contacts interrégionaux.

Dans d'autres cas, c'est également sous la forme d'un accès à des ressources et/ou à des saisons spécifiques que les sites montagnards se caractérisent. Une économie basée sur la complémentarité des types de ressources à l'interface de plusieurs écosystèmes peut être mise en évidence à certaines périodes. Ainsi, s'appuyant sur les premiers résultats des fouilles de la grotte Tastet, M. Langlais et J.-M. Pétillon livrent un bilan de la variabilité des industries lithiques du Magdalénien moyen récent tout au long de la chaîne pyrénéo-cantabrique. La présence de traditions techniques similaires dans l'ensemble de cet espace illustre les relations étroites tissées à cette période par les groupes humains et remet en cause la pertinence de différences terminologiques héritées de l'histoire des recherches.

Les évidences d'une association entre plaine et montagne sont plus marquées encore pour les sociétés agropastorales. P. Dumontier fournit notamment un bilan très détaillé du Néolithique du nord-ouest des Pyrénées. Une économie agropastorale s'y diffuse, sans doute depuis le sud des Pyrénées, à partir de la deuxième moitié du $\mathrm{VI}^{\mathrm{e}}$ millénaire $\mathrm{BC}$; puis l'anthropisation, liée à l'essor de l'élevage, augmente. Outre les nombreux sites funéraires, les « habitats » sont tous des occupations sous abri naturel ou des campements : ceci évoque une mobilité qui pourrait être en partie liée à un pastoralisme couvrant piémont, moyenne et haute montagne.

C. Defrasne et al. interrogent, quant à eux, la place des Alpes méridionales dans les larges réseaux de circulation qui se font jour à partir du Néolithique. Situés à 2000 mètres d'altitude, les sites pris en compte témoignent d'occupations saisonnières en lien avec des occupations de piémont, comme en atteste l'origine des matières premières, presque exclusivement allochtones. Si le mobilier céramique renvoie à une production régionale, les vestiges graphiques d'Oullas et de Faravel attestent en revanche de circulations transalpines à large échelle. Ils permettent de mettre en évidence une géographie culturelle aux contours mouvants du Néolithique à l'âge du Fer.

Un dernier exemple concerne l'Italie méridionale, où C. Albore Livadie et al. abordent la culture matérielle des occupations du Bronze ancien dans les montagnes de Campanie, parfois exceptionnellement conservées suite à des éruptions volcaniques. Les affinités étroites décelées avec des habitats des plaines des Pouilles sont interprétées comme la manifestation d'une mobilité saisonnière de populations dans le cadre d'une économie pastorale.

Nous espérons que la variété des thèmes et la large diachronie regroupée ici montreront à quel point les massifs montagneux représentent des environnements à la fois importants dans les modes de vie des populations anciennes et riches d'informations. Nous en profitons pour remercier l'ensemble des auteurs ayant contribué à l'élaboration de ce recueil et qui en font la richesse.

Ce volume est le fruit d'un travail collectif, et c'est pourquoi nous tenons à remercier les membres de la section de Préhistoire et protohistoire du CTHS, ainsi que l'ensemble des organisateurs du $142^{e}$ Congrès national des sociétés historiques et scientifiques, qui 
ont permis le bon déroulement des deux sessions organisées. Nous sommes également particulièrement reconnaissants envers l'ensemble des personnes qui nous ont accompagnés et aidés durant la publication de ces actes: Francine Fourmaux, David Simon et Isabelle Tarier.

Enfin, nos plus sincères remerciements s'adressent à nos collègues Rose-Marie Arbogast, François Bon, Delphine Bousquet, Céline Bressy-Léandri, François-Xavier Chauvière, Laure Dayet, Fabien Delrieu, Vincent Delvigne, Bertrand Dousteyssier, Sylvain Ducasse, Carole Dudognon, Célia Fat Cheung, Karim Gernigon, José Gomez de Soto, Alexis Gorgues, Auréade Henry, Jacques Jaubert, Thibault Lachenal, Mathieu Langlais, Xavier Mangado, Grégor Marchand, Liliane Meignen, Jean-Paul Métailié, Ludovic Mevel, Yannick Miras, Claude Mordant, Nicolas Naudinot, Kewin PêcheQuilichini, Jean-François Piningre, Thomas Perrin, Nicolas Poirier, Christine Rendu, Hervé Richard, Solange Rigaud, Guillaume Saint-Sever, Frédéric Séara, Antonin Tomasso et Jean Vaquer, qui ont accepté d'effectuer une relecture des différentes contributions.

\section{BIBLIOGRAPHIE}

BOURGEOT A., 1991, « Territoire », dans Bonte P. et Izard M. (dir.), Dictionnaire de l'ethnologie et de l'anthropologie, Paris, Presses universitaires de France, p. 704-705.

CAZALS N., GONZALEZ URQUIJO J., TERRADAS X. (dir.), 2007, Fronteras naturales y fronteras culturales en los Pirineos prehistóricos, Santander, PUbliCan, $354 \mathrm{p}$.

CHEN F., WELKER F., SHEN C.-C., BAILEY S. E., BERGMANN I., DAVIS S., XIA H., WANG H., FISCHER R., FREIDLINE S. E., YU T.-L., SKINNER M. M., STELZER S., DONG G., FU Q., DONG G., WANG J., ZHANG D., HUBlin J.-J., 2019, «A late Middle Pleistocene Denisovan mandible from the Tibetan Plateau », Nature, $\mathrm{n}^{\circ} 569$, vol. 7756, p. 409-412.

DELPORTE H. et CLOTTES J., 1996, Pyrénées préhistoriques : arts et sociétés. Actes du $118^{e}$ Congrès national des sociétés savantes [commission de pré- et protohistoire, Pau, 25-29 octobre 1993], Paris, Éditions du CTHS, $613 \mathrm{p}$.

\section{AUTEURS}

\section{MARIANNE DESCHAMPS}

Chercheuse, Centro de Arqueologia da Universidade de Lisboa (UNIARQ), membre associée du laboratoire Travaux et recherches archéologiques sur les cultures, les espaces et les sociétés (TRACES, UMR 5608, université Toulouse - Jean-Jaurès/CNRS) 


\section{SANDRINE COSTAMAGNO}

Directrice de recherche au CNRS, laboratoire Travaux et recherches archéologiques sur les cultures, les espaces et les sociétés (TRACES, UMR 5608, université Toulouse - Jean-Jaurès/CNRS), secrétaire de la section Préhistoire et protohistoire du CTHS

\section{PIERRE-YVES MILCENT}

Maître de conférences habilité à diriger les recherches, laboratoire Travaux et recherches archéologiques sur les cultures, les espaces et les sociétés (TRACES, UMR 5608, université Toulouse - Jean-Jaurès/CNRS)

\section{JEAN-MARC PÉTILLON}

Chargé de recherche au CNRS, laboratoire Travaux et recherches archéologiques sur les cultures, les espaces et les sociétés (TRACES, UMR 5608, université Toulouse - Jean-Jaurès/CNRS)

\section{CAROLINE RENARD}

Chargée de recherche au CNRS, laboratoire Travaux et recherches archéologiques sur les cultures, les espaces et les sociétés (TRACES, UMR 5608, université Toulouse - Jean-Jaurès/CNRS)

\section{NICOLAS VALDEYRON}

Professeur, directeur du laboratoire Travaux et recherches archéologiques sur les cultures, les espaces et les sociétés (TRACES, UMR 5608, université Toulouse - Jean-Jaurès/CNRS) 
Occupation et exploitation du milieu montagnard 


\title{
Mobilité territoriale pendant le Paléolithique moyen en contextes discoïde et Levallois : exemple du site de l'Abric Romaní (Capellades, Barcelona, Espagne), niveau $\mathrm{M}$ et sous-niveau Oa
}

\author{
Territorial mobility during the Middle Paleolithic in Discoid and \\ Levallois contexts: the case of the Abric Romani site (Capellades, \\ Barcelona, Spain), level $\mathrm{M}$ and sub-level Oa
}

Bruno Gómez de Soler, María Gema Chacón, Amelia Bargalló, Francesca Romagnoli, María Soto, Josep Vallverdú et Manuel Vaquero

\begin{abstract}
Nous remercions tous les archéologues et spécialistes qui ont participé dans les différentes campagnes de fouille ; le Departament de Cultura de la Generalitat de Catalunya, avec l'attribution du projet quadriennal « Abric Romaní-Cinglera del Capelló » (2014-2017) ; la mairie de Capellades et à Tallers Gràfics Romanyà-Valls S. A., ainsi que les groupes de recherche SGR2017-859 et SGR2017-836 (AGAUR) et les projets du MINECO HAR2013-48784-C3-1-P, CGL2016-80000-P et CGL2015-65387-C3-1-P (MINECO/FEDER). La recherche de Bruno Gómez de Soler, María Gema Chacón, Josep Vallverdú et Manuel Vaquero est financée par le "CERCA Programme/Generalitat de Catalunya ». Amelia Bargalló a reçu une bourse du European Union's Horizon 2020 Research and Innovation Programme (Marie Sklodowska-Curie Action grant agreement PREKARN n 702584). María Soto a reçu une bourse postdoctorale du Social Sciences and Humanities Research Council (fondation fédérale canadienne pour la recherche), liée au projet «Stone tools, Diet Sociality at Olduvai Gorge ». Merci à Gerard Campeny pour l'adaptation de certaines des figures, à Elvira Dominguez qui a réalisé la révision et correction du français écrit de l'article.
\end{abstract}


1 L'analyse des matières premières lithiques peut servir de base pour connaitre la mobilité territoriale des groupes de chasseurs-cueilleurs. La présente étude s'intéresse à l'utilisation du territoire et aux dynamiques d'approvisionnement en silex (en tant que matériau prédominant dans l'ensemble) par les Néandertaliens qui ont occupé l'Abric Romaní, dans le niveau $\mathrm{M}$ et le sous-niveau Oa.

2 Ce travail s'inscrit dans un cadre ethnologique centré sur le mode d'approvisionnement (foraging model) qui caractérise les sociétés de chasseurs-cueilleurs. Dans ce modèle, un élément important est le rayon d'approvisionnement, c'est-à-dire le trajet aller-retour pouvant être effectué, en une seule journée, entre le camp de base et le lieu d'extraction des ressources. Grâce à de multiples études ethnographiques (Binford 2001), ce rayon est évalué à environ 8 kilomètres ; une distance qui, dans notre étude, a été étendue à 10 kilomètres, avec l'intention de déterminer la zone d'approvisionnement locale et régionale et de connaître la disponibilité du silex dans ce territoire avec une approche actualisée. Ceci nous conduira à l'évaluation d'un rayon d'approvisionnement spécifique pour chaque assemblage archéologique, grâce auquel nous déduirons les modèles de mobilité et leur direction.

3 L'étude comparative du niveau $\mathrm{M}$ et du sous-niveau Oa de l'abri est justifiée par leur proximité temporelle et par les différences observées au sein des chaînes opératoires et des systèmes d'exploitation. Tout au long de la séquence de l'Abric Romaní, les chaînes opératoires lithiques sont plutôt expéditives et basées sur des systèmes discoïdes centripètes, comme dans le cas du niveau $\mathrm{M}$; le niveau $\mathrm{O}$ et le sous-niveau Oa montrent au contraire, pour la première fois, une prédominance manifeste des stratégies hiérarchisées de type Levallois. Notre hypothèse de travail s'articule autour de la signification de ces différences. Correspondent-elles au type ou à la qualité de la matière première lithique utilisée, ou bien à d'autres aspects qui ne sont pas strictement techno-économiques?

4 Nous nous sommes fondés sur une étude de terrain focalisée sur l'emplacement des aires d'approvisionnement d'origine siliceuse. Leur identification a été faite au moyen de critères visuels morphoscopiques, à l'aide d'un microscope stéréoscopique, afin d'établir les groupes principaux de matières premières. Une étude pétrographique a ensuite été réalisée à travers l'analyse de 88 lames minces (28 échantillons archéologiques et 60 échantillons géologiques de silex et roches mères) pour lesquelles ont été décrits les aspects minéralogiques, texturaux et diagénétiques. Enfin, plusieurs analyses complémentaires ont été réalisées pour mieux comprendre les composantes tant géologiques qu'archéologiques.

5 L'objectif final était de corréler le matériel archéologique avec son aire d'approvisionnement, afin de déterminer les stratégies d'exploitation du territoire et les itinéraires de mobilité mis en œuvre, de façon à contribuer à la connaissance de la relation de l'Homme avec son environnement naturel.

\section{Le site de l'Abric Romaní}

6 L'Abric Romaní est situé dans la commune de Capellades, dans la province de Barcelona, au nord-est de la péninsule Ibérique. Ses coordonnées UTM (ETRS89) sont $390566 \mathrm{E}$ et $459874 \mathrm{~N}$; il se situe à 310 mètres au-dessus du niveau de la mer (fig. 1). Il s'agit d'un abri ouvert au sein de la formation de travertin connue sous le nom de 
Cinglera del Capelló, dans un étroit passage ou couloir formé à la suite d'une faille de direction NNO/SSE, à travers laquelle coule la rivière Anoia. Ce passage naturel met en contact l'intérieur de la Catalogne avec la côte, ainsi qu'avec les trois grandes unités géomorphologiques composant ce territoire: la dépression de l'Èbre, la cordillère prélittorale et la dépression prélittorale. Cela représente un emplacement stratégique pour le site de l'Abric Romaní, en tant que point d'accès à différents écotones.

Fig. 1. - Localisation du site de l'Abric Romaní (Capellades, Barcelona, Espagne).
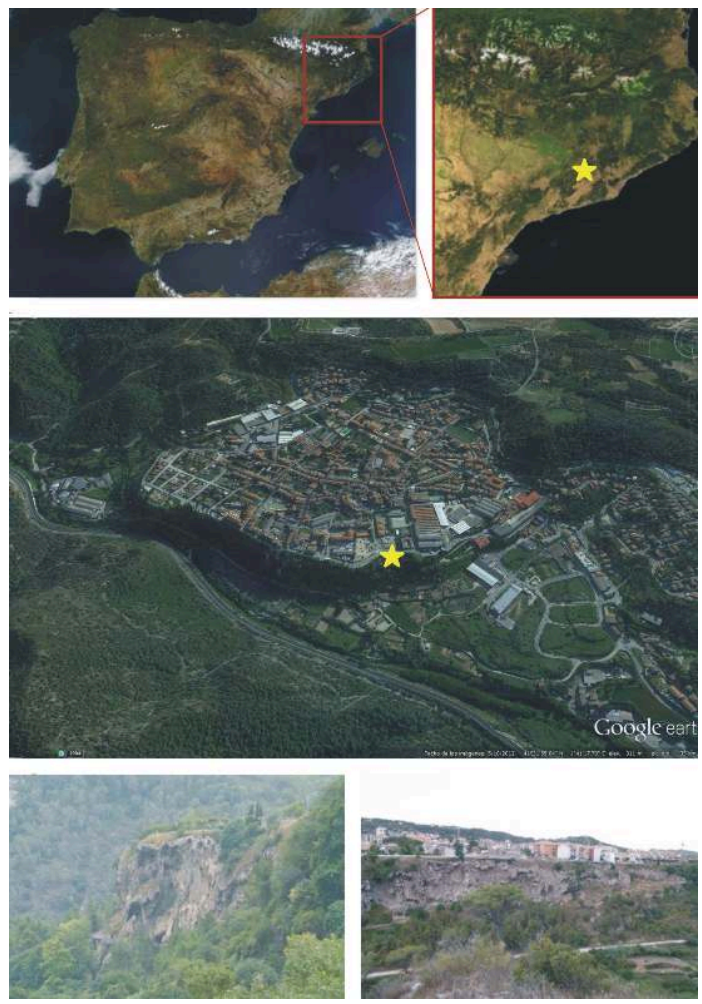

EN HAUT : emplacement dans la péninsule lbérique. AU CENTRE : vue aérienne montrant le cours naturel de la rivière Anoia et la formation de travertin où se trouve l'Abric Romaní. EN BAS : détail du cingle du Capelló, avec ses abris-sous-roches caractéristiques.

Photos Institut Català de Paleoecologia humana i Evolució Social. Fond de carte NASA.

7 La séquence lithostratigraphique de l'Abric Romaní, de plus de 50 mètres de puissance, est principalement composée de travertin, sables et limons, dans lesquels ont été documentés jusqu'à 27 niveaux d'occupations humaines (Carbonell et al. 1994, Sharp et al. 2016). Plus de 80 dates obtenues par U/Th et ${ }^{14} \mathrm{C}$ AMS fournissent un cadre chronologique allant de $110 \mathrm{ka}$ cal. BP à la base à $39 \mathrm{ka}$ cal. BP au sommet, situant la séquence dans les stades isotopiques 5, 4 et 3 (fig. 2). À l'exception du niveau A, associé au Paléolithique supérieur, les niveaux archéologiques correspondent à des occupations humaines appartenant au Paléolithique moyen (Vallverdú et al. 2012, Vaquero et al. 2013). 
Fig. 2. - Abric Romaní (Capellades, Barcelona, Espagne) : stratigraphie et datations.

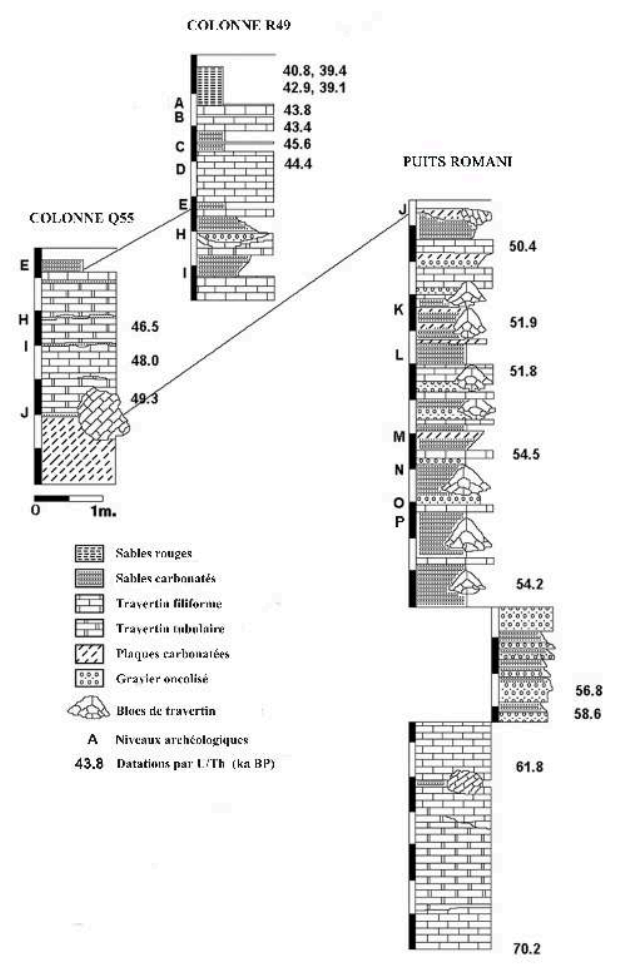

D’après Carbonell et al. 1994.

8 Au niveau paléo-environnemental, la séquence de l'Abric Romaní présente cinq phases climatiques, avec des périodes chaudes et d'autres froides et sèches. Les taxons les plus représentés sont Artemisa, Poaceae et Pinus. Les forêts de pins du type pin rouge sont prédominantes dans toute la séquence stratigraphique (Burjachs et al. 2012).

\section{Matériel d'étude}

\section{Le niveau $\mathrm{M}$}

9 Ce niveau a été fouillé sur une surface de $231 \mathrm{~m}^{2}$ entre 1997 et 2007. Il est daté entre $51,8 \pm 1,4 \mathrm{kaBP}$ et $54,9 \pm 1,7 \mathrm{kaBP}$. L'assemblage archéologique est constitué de 18946 vestiges.

10 La faune est représentée par 7656 restes, dont un pourcentage élevé d'os fracturés et altérés thermiquement à cause de l'intense activité anthropique. Cela rend leur identification anatomique et taxonomique difficile, et seulement $10 \%$ de l'ensemble a pu être identifié. Les profils squelettiques des ongulés indiquent que les Néandertaliens ont développé différentes stratégies pour transporter les animaux des sites d'abattage (kill sites) vers le camp de base. On peut supposer que le nombre de porteurs était important, indice d'une forte coopération entre les différents membres du groupe (Marín et al. 2017a et 2017b).

11 Les espèces les plus représentées sont Cervus elaphus $(\mathrm{n}=711)$, Equus ferus $(\mathrm{n}=84)$ et Bos primigenius $(\mathrm{n}=31)$. En outre, 144 remontages des os de macromammifères ont été réalisés, regroupant un total de 349 objets, soit 4,5\% (Fernández-Laso 2010, Marín 
2014). Les liens de connexion des remontages sont généralement inférieurs à 1 mètre et n'impliquent que des fragments brûlés. Les remontages des os en association avec l'analyse taphonomique des surfaces osseuses suggèrent l'origine anthropique de l'assemblage et apportent des informations sur la formation de zones multifonctionnelles liées aux foyers (Vaquero et al. 2017).

12 En ce qui concerne les structures de combustion, 37 foyers ont été documentés et fouillés suivant les limites structurelles qui constituent le niveau, formant une série de trois lignes plus ou moins parallèles entre la paroi de l'abri et la ligne de surplomb de la voûte. Évidemment, comme cela a été le cas dans tous les niveaux de l'Abric Romaní, le registre archéologique est structuré à partir des foyers (Vaquero et Pastó 2001), et organisé en six zones autour de ceux-ci (Vaquero et al. 2015 et 2017).

13 L'industrie lithique est composée de 6084 objets. Le silex est la matière première prédominante $(80,8 \%)$, suivi du calcaire $(9,3 \%)$, du quartz $(5,3 \%)$ et de l'ardoise $(3,9 \%)$, tandis que d'autres matériaux (grès, granites, quartzites et porphyres) ont des valeurs inférieures à $1 \%$ (tabl. 1). La méthode de taille utilisée est le Discoïde et les produits de taille, éclats, fragments d'éclats et éclats fracturés sont les objets prédominants (fig. 3.2 et 3.3), principalement de taille moyenne et petite. En outre, 120 remontages ont été réalisés, regroupant 803 objets lithiques, soit $20 \%$ du total (Chacón 2009, Vaquero et al. 2015 et 2017).

Tabl. 1. - Abric Romaní (Capellades, Barcelona, Espagne), niveau M : vestiges lithiques classés par matières premières et par catégories technologiques.

\begin{tabular}{|c|c|c|c|c|c|c|c|c|c|c|}
\hline & $\begin{array}{c}\text { Base } \\
\text { naturelle }\end{array}$ & $\begin{array}{l}\text { Outils } \\
\text { retouchés }\end{array}$ & Nucléus & $\begin{array}{l}\text { Fragments de } \\
\text { nucléus }\end{array}$ & Éclats & $\begin{array}{c}\text { Éclats } \\
\text { fracturés }\end{array}$ & $\begin{array}{l}\text { Fragments } \\
\text { d'éclats }\end{array}$ & Fragments & \multicolumn{2}{|c|}{ Total } \\
\hline Silex & & 34 & 40 & 9 & 2694 & 658 & 1468 & 15 & 4918 & $80,85 \%$ \\
\hline Calcaire & 29 & 1 & 6 & 2 & 141 & 70 & 226 & 91 & 566 & $9,3 \%$ \\
\hline Quartz & & 1 & & & 28 & 7 & 110 & 179 & 325 & $5,34 \%$ \\
\hline Schiste & 1 & 3 & & & 15 & 6 & 95 & 115 & 235 & $3,86 \%$ \\
\hline Grès & 4 & & 1 & & 3 & 1 & 1 & 3 & 13 & $0,21 \%$ \\
\hline Granite & & & & & 6 & 2 & & 1 & 9 & $0,15 \%$ \\
\hline Quartzite & & & & & 5 & 1 & 1 & & 7 & $0,12 \%$ \\
\hline Agate & & & & & 3 & 1 & & & 4 & $0,07 \%$ \\
\hline Porphyre & & & & & 3 & & & & 3 & $0,05 \%$ \\
\hline Calcarénite & & & & & 1 & & & 1 & 2 & $0,03 \%$ \\
\hline Stalagmite & & 1 & & & & & & & 1 & $0,02 \%$ \\
\hline \multirow{2}{*}{ Total } & 34 & 40 & 47 & 11 & 2899 & 746 & 1901 & 405 & \multirow[t]{2}{*}{6083} & \\
\hline & $0,56 \%$ & $0,66 \%$ & $0,77 \%$ & $0,18 \%$ & $47,65 \%$ & $12,26 \%$ & $31,25 \%$ & $6,66 \%$ & & $100 \%$ \\
\hline
\end{tabular}


Fig. 3. - Abric Romaní (Capellades, Barcelona, Espagne), niveau M : exemples d'industrie lithique.

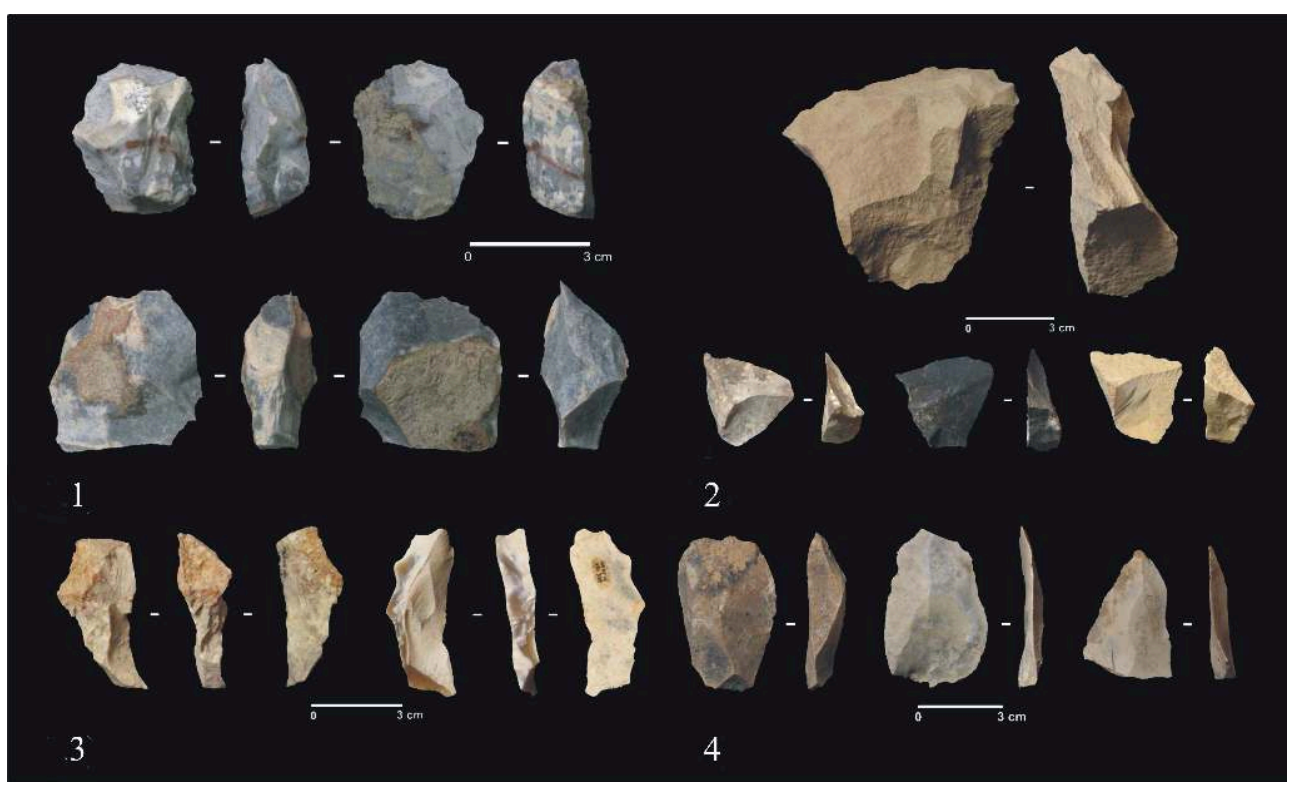

1 : nucléus discoïdes. 2 : éclats pseudo-Levallois. 3 : éclats débordants. 4 : éclats ordinaires. Photos María Gema Chacón.

Bien que le niveau soit globalement caractérisé par des zones d'activité liées au foyer et par un regroupement discret des restes sur toute la surface, l'analyse technologique et spatiale des remontages a montré des répartitions spatiales différentes. La partie intérieure de l'abri, près de la paroi, mieux protégée des agents climatiques, a été occupée pendant une longue période - avec les mêmes comportements technologiques et spatiaux pendant toute la période -, créant un palimpseste développé. La zone centrale a été occupée pendant deux épisodes distincts et utilisait souvent la partie interne de l'abri pour l'approvisionnement en matière première. La partie extérieure a été utilisée à la fin de l'occupation du niveau pour la réalisation de deux courts événements de taille (Vaquero et al. 2015, Romagnoli et Vaquero 2016).

La production lithique dans le niveau $\mathrm{M}$ est caractérisée par des séquences discoïdes (fig. 3.1). Le faible degré du contrôle volumétrique lors du débitage a permis aux Néandertaliens de l'Abric Romaní de s'adapter aux contraintes morphologiques des blocs et de sélectionner des ressources indépendamment de leurs qualités physiques (Chacón et al. 2013). Dans ce niveau, le silex se caractérise principalement par un faible degré d'homogénéité induit par la présence de géodes et de surfaces internes fissurées, et par des blocs à grain moyen/grand. L'analyse technologique et les remontages suggèrent que la qualité de la matière première n'a pas influé sur le développement de stratégies de taille plus complexes (Romagnoli et al. 2016).

Régulièrement, des blocs complets ont été transportés sur le site. De longues séquences de production ont été effectuées, attestant d'une faible fragmentation de la chaîne opératoire. Néanmoins, l'identification du transport d'outils destinés à la taille (toolkits) suggère un apport complémentaire sur le site de grands éclats discoïdes typiques, tels que les éclats à dos et les pointes pseudo-Levallois (fig. 3.3). Les remontages ont également montré que des outils ont été produits sur le site mais utilisés et abandonnés ailleurs. De plus, grâce aux remontages, il a été possible de mettre en évidence le rôle socio-économique de la séquence de production des petits éclats, productions issues de 
chaînes opératoires ramifiées. Dans la couche $M$, un comportement expéditif, identifié par la flexibilité du système technique, fut plus probablement destiné à résoudre les contraintes de matières premières et les besoins immédiats dans le site, et ne répondait pas à une stratégie planifiée de la mobilité humaine comme dans les autres niveaux de l'abri (Romagnoli et al. 2017).

Les outils retouchés sont rares tout au long de la séquence stratigraphique du site. Dans la couche $\mathrm{M}$, ils représentent moins de $1 \%$ et n'ont pas de relation avec les remontages et la répartition spatiale identifiée pour le niveau $\mathrm{M}$.

\section{Le sous-niveau Oa}

Le sous-niveau Oa fait partie du niveau O. Il a été fouillé entre les années 2004 et 2009, sur une surface d'environ $200 \mathrm{~m}^{2}$. Les dates obtenues par les séries d'Uranium sont, sur la partie supérieure du niveau 0 , de $54,6 \pm 0,4 \mathrm{Ka} \mathrm{BP}$ et sur la partie supérieure du niveau P, le niveau suivant, de $54,24 \pm 0,42 \mathrm{Ka} \mathrm{BP}$; on évalue donc l'âge du sousniveau $\mathrm{Oa}$ aux alentours de $54 \mathrm{Ka}$ BP.

La faune est représentée par 486 restes, avec un pourcentage élevé d'os fracturés à la suite d'un traitement intensif d'origine anthropique (Gabucio 2014). Seuls $9 \%$ de l'ensemble ont pu être identifiés, avec une prédominance de Cervus elaphus $(\mathrm{n}=18)$, Bos primigenius $(n=16)$, Oryctolagus cuniculus $(n=8)$ et Equus ferus $(n=4) .12$ remontages ont été réalisés, regroupant 31 objets $(6,4 \%)$. L'abondance de parties squelettiques à fort contenu nutritionnel, tels que les éléments appendiculaires proximaux, suggère un accès primaire et immédiat aux carcasses par les groupes néandertaliens. Ce schéma a été également confirmé par la localisation des marques de découpes et par les éléments diagnostiques des fractures anthropiques dans les diaphyses et les métaphyses, pour l'accès à la moelle osseuse (Gabucio et al. 2014).

Dix structures de combustion ont été documentées dans ce sous-niveau. Elles sont disposées sur deux lignes, l'une très proche de la paroi de l'abri et l'autre en parallèle vers l'extérieur, dans laquelle tout le matériel archéologique a été structuré, formant six accumulations principales.

21 L'industrie lithique est composée de 1496 restes. Le silex est le matériau prédominant, avec $91,57 \%$ du total, suivi par le calcaire (5,3\%), le reste des matériaux ne dépassant pas $1 \%$ : quartz, grès, quartzite et autres roches (tabl. 2).

Tabl. 2. - Abric Romaní (Capellades, Barcelona, Espagne), sous-niveau Oa : vestiges lithiques répartis par matières premières et par catégories technologiques.

\begin{tabular}{|c|c|c|c|c|c|c|c|c|c|}
\hline & $\begin{array}{c}\text { Base } \\
\text { naturelle }\end{array}$ & $\begin{array}{l}\text { Outils } \\
\text { retouchés }\end{array}$ & Nucléus & Éclats & $\begin{array}{l}\text { Éclats } \\
\text { fracturés }\end{array}$ & $\begin{array}{c}\text { Fragments } \\
\text { d'éclat }\end{array}$ & Fragments & Total & \\
\hline Silex & & 17 & 7 & 528 & 237 & 447 & 134 & 1370 & $91,57 \%$ \\
\hline Calcaire & 7 & & 2 & 19 & 22 & 15 & 14 & 79 & $5,28 \%$ \\
\hline Quartz & & & & 1 & 2 & 2 & 10 & 15 & $1,00 \%$ \\
\hline Ardoise & & & & 1 & 2 & & 7 & 10 & $0,70 \%$ \\
\hline Agate & & & & 4 & 3 & 2 & & 9 & $0,60 \%$ \\
\hline Grès & 4 & & & & & & 1 & 5 & $0,33 \%$ \\
\hline Autres roches & & & & & & & 5 & 5 & $0,33 \%$ \\
\hline Quartzite & & & & 1 & & 1 & & 2 & $0,13 \%$ \\
\hline Galène & 1 & & & & & & & 1 & $0,06 \%$ \\
\hline \multirow{2}{*}{ Total } & 12 & 17 & 9 & 554 & 266 & 467 & 171 & \multirow[t]{2}{*}{1496} & \\
\hline & $0,80 \%$ & $1,14 \%$ & $0,60 \%$ & $37,03 \%$ & $17,78 \%$ & $31,22 \%$ & $11,43 \%$ & & $100 \%$ \\
\hline
\end{tabular}

La méthode de taille utilisée pour obtenir des éclats est principalement Levallois : méthode centripète récurrente (Bargalló 2014). La plus grande part des nucléus 
analysés, 77,8\%, présente une exploitation bifaciale hiérarchisée (fig. 4.1). La surface de plan de frappe conserve généralement une bonne quantité du cortex jusqu'aux derniers moments de son exploitation. Dans ces cas, la hiérarchisation est basée sur l'exploitation préférentielle de l'une des surfaces par rapport à l'autre. La deuxième surface aura un rôle secondaire et subordonné, présentant peu d'extractions, très marginales et s'adaptant parfaitement à la production Levallois décrite dans la bibliographie (Boëda 1993, 1994 et 1995).

23 En ce qui concerne les produits obtenus (fig. 4.2), l'analyse technologique indique que les éclats débordants sont presque inexistants : deux éléments seulement. Aucun éclat Kombewa n'a été identifié, bien qu'ils constituent un autre produit habituel dans la taille Levallois. Cependant, quatre pointes Levallois ont été documentées.

24 Les types d'artefacts représentés et l'analyse des chaînes opératoires indiquent que l'assemblage est fragmenté et incomplet, et qu'il manque une bonne partie des produits attendus dans une production Levallois (fig. 4). Les 32 remontages réalisés correspondent à la reconstitution d'éléments fracturés pendant la taille ou au remontage proprement dit de deux ou trois éclats successifs, regroupant 77 objets lithiques, soit 5,1\% du total (Bargalló 2014). Nous n'avons pu réaliser aucun remontage entre le nucléus et l'éclat, ce qui confirme la forte fragmentation de la chaîne opératoire.

En ce qui concerne les outils retouchés de ce sous-niveau, 17 objets seulement ont été documentés (fig. 4.3). Des éclats de dimension moyenne à grande ont été sélectionnés. La retouche est principalement localisée sur l'un des bords, principalement sur les bords latéraux, dans la même proportion sur le bord gauche que sur le bord droit, et dans quelques cas sur le tranchant transversal distal. Les types d'objets retouchés sont pour la plupart des racloirs $(58,8 \%)$, les denticulés représentent $29,4 \%$ et le reste des aménagements correspond à des retouches abruptes et/ou marginales. 
Fig. 4. - Abric Romaní (Capellades, Barcelona, Espagne), sous-niveau Oa : exemples d'industrie lithique.

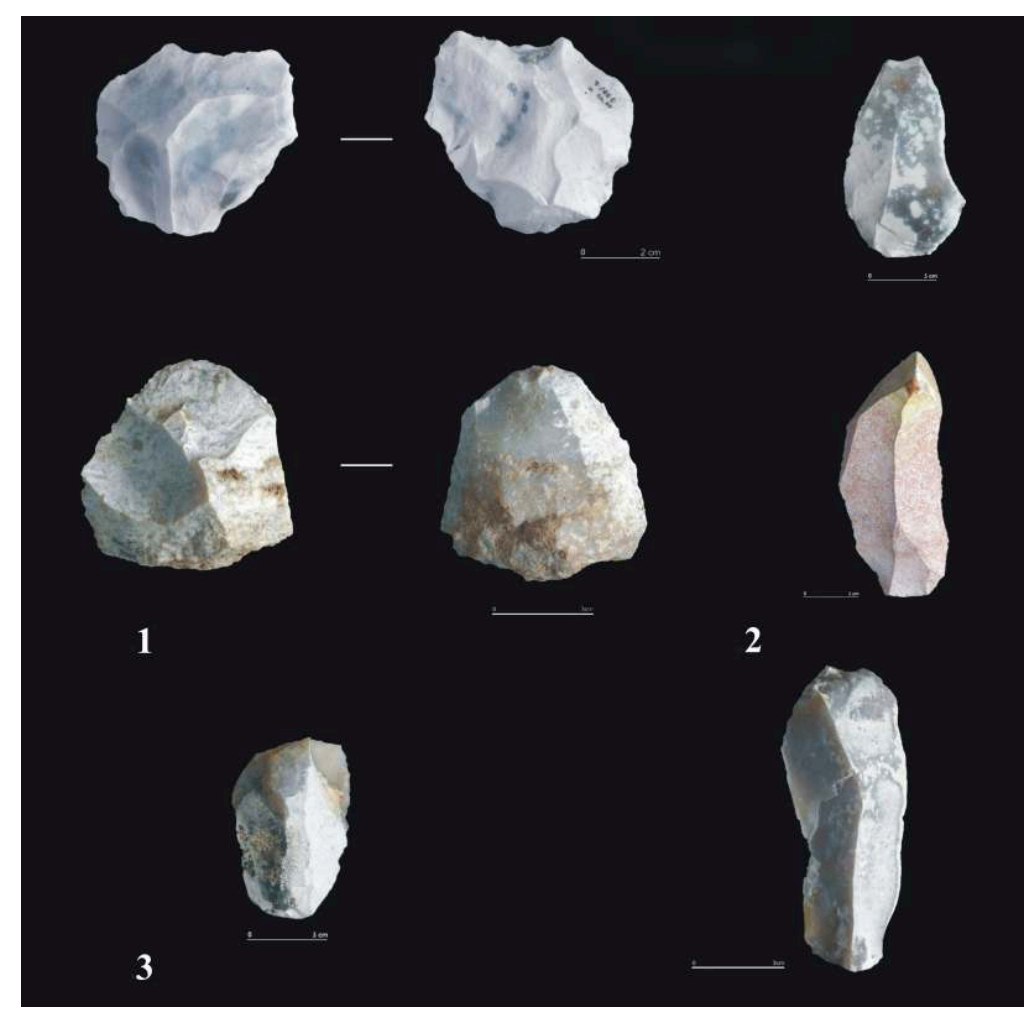

1 : nucléus Levallois. 2 : éclats. 3 : outils retouchés.

Photos Amelia Bargalló.

\section{Contexte géologique des silicifications}

Comme nous l'avons déjà mentionné, la zone d'étude comprend trois grandes unités géomorphologiques qui conditionnent l'obtention de ressources abiotiques (fig. 5). 
Fig. 5. - Localisation de l'Abric Romaní (Capellades, Barcelona, Espagne), et des trois unités géomorphologiques qui définissent son environnement géologique : dépression de l'Ėbre, cordillère prélittorale et dépression prélittorale.

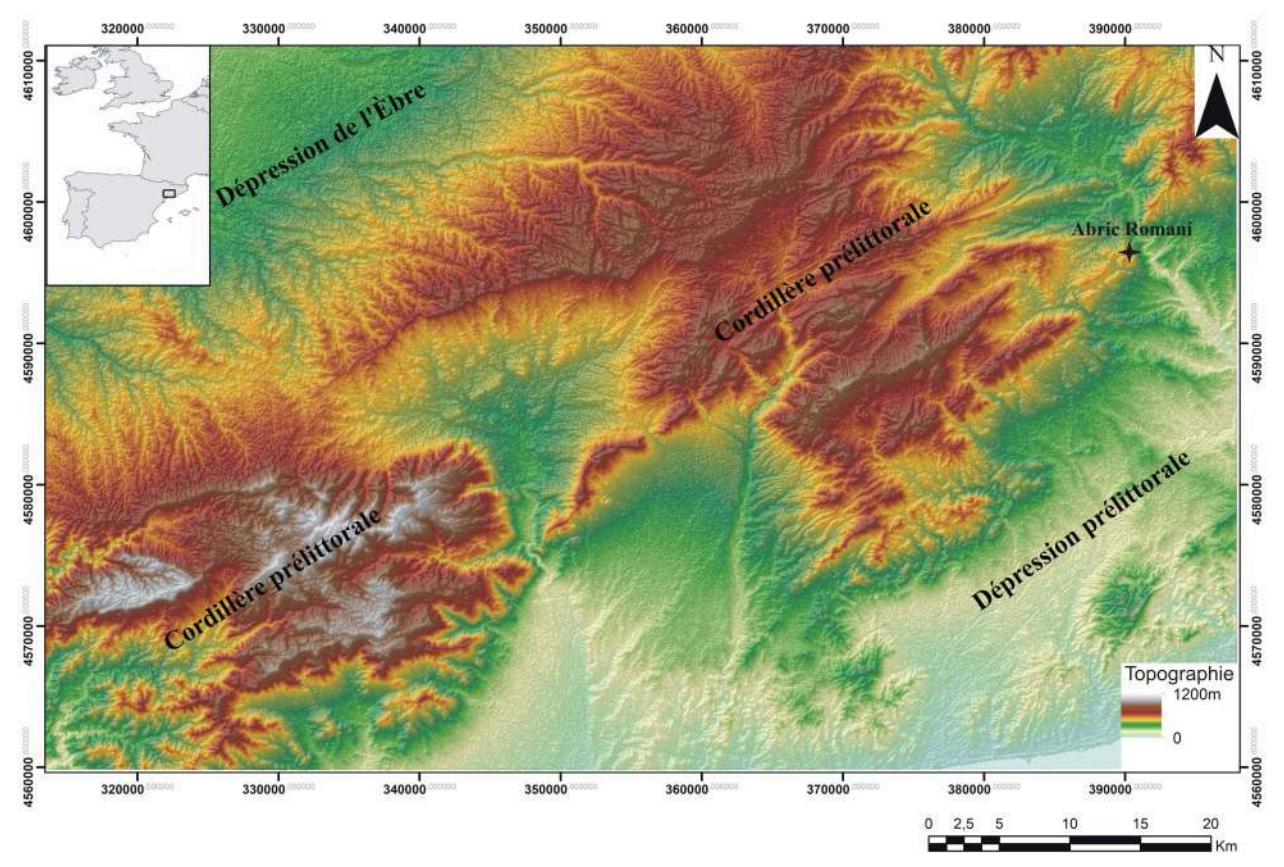

PAO : Bruno Gómez de Soler. Fond de carte : ArcGIS10.2.

La dépression de l'Èbre est l'unité géomorphologique qui concentre la plus grande quantité de silicifications dans deux de ses bassins marginaux, le bassin de Gaià et le bassin d'Anoia. Les formations qui contiennent du silex sont issues du Paléogène et sont principalement d'âge éocène et oligocène, et occasionnellement paléocène. Les gisements de silex sont situés dans les formations lacustres évaporitiques et fluviatiles formées par l'alternance de lutites, de gypses, de marne, de calcaires et de conglomérats. Dans l'ordre chronologique, les formations à silicifications sont les formations Mediona, Santa Càndia, Pobla de Claramunt, Valldeperes, Bosc d'en Borràs, Sant Genís, Santa Coloma et Montmaneu (Gómez de Soler 2016).

Dans la cordillère prélittorale, des silicifications se trouvent dans les dépôts carbonatés d'origine marine (téthys) du Muschelkalk, plus précisément dans les étages inférieurs et supérieurs. Le premier, datant de l'Anisien supérieur, est formé par des calcaires et dolomites de plateforme côtière et de boues évaporitiques. Le Muschelkalk supérieur, datant du Ladinien supérieur, correspond à des environnements marins superficiels formés par des calcaires dolomitiques (Gómez de Soler 2016).

Enfin, dans la dépression prélittorale, plus précisément dans la dépression du Penedés, les silicifications se situent dans les dépôts alluviaux pliocènes, en raison du système dispersif des formations évaporitiques du bassin de l'Èbre (formation Santa Càndia del Cuisiense). La formation contenant du silex est la série de La Guixera, une formation d'origine continentale et de caractère détritique formée par des alternances de poudingues, de grès et d'argiles (Gómez de Soler 2016). 


\section{Méthodologie}

\section{Prospections}

30 Pour cette étude, une zone de 30 kilomètres de rayon a été définie autour du site de l'Abric Romaní. Selon différentes études archéologiques, ethnographiques et pétroarchéologiques (Binford 1982 et 2001, Geneste 1989, Turq 1989, Kuhn 1995, Slimak 1999, Zilhao 2001, Bicho 2004, Dibble et al. 2009, Eixea et al. 2014, Grimaldi et Santaniello 2014, Aubry et al. 2016), la plupart des matériaux lithiques des assemblages du Paléolithique moyen proviennent de 10 kilomètres au plus du site, avec un maximum de 20 kilomètres. Dans certains cas, la distance ne dépasse pas 5 kilomètres, comme pour certains exemples aquitains. L'approvisionnement en matières premières au Paléolithique moyen est caractérisé par le faible pourcentage de matériaux provenant de longues distances (Féblot-Augustins 1999), bien qu'on ne puisse nier l'existence de cas d'approvisionnement lithique opportuniste à longue distance (Slimak et Giraud 2007, Spinapolice 2012, Thiébaut et al. 2012, Tarriño et al 2015, Delvigne et al. 2016, Deschamps 2017).

31 Grâce à la compilation de la bibliographie géologique et archéologique relative aux affleurements présentant potentiellement du silex (Gómez de Soler 2009 et 2016, Soto et al. 2014) et aux ressources cartographiques disponibles (cartes géologiques, cartographiques, orthophotocartes et photographies aériennes), il a été possible de sélectionner les zones à prospecter (IGME 1975, 1982a, 1982b et 1998).

Les affleurements de silex ont été enregistrés dans des bases de données où étaient saisies leurs principales caractéristiques: localisation, accessibilité, contexte géologique et lithostratigraphique, etc. L'emplacement des affleurements a été importé en format vectoriel sur une carte numérisée avec les données géologiques et cartographiques (échelle 1:50 000), pour créer une cartographie spécifique pour le silex.

\section{Calcul du taux de présence de silex ou chert abundance ratio (CAR)}

Nous avons créé une méthode de calcul du taux de présence de silex dans l'environnement, en tant qu'approche objective de la disponibilité de cette matière première (Soto et al. 2018). Ces données sont obtenues grâce à une série de mesures :

- La première mesure concerne l'épaisseur apparente de l'affleurement (OaT), la distance linéaire entre le toit et la base de l'affleurement observée au cours de la prospection.

- La deuxième mesure est l'estimation de la surface du silex dans l'affleurement (Aa). Elle est calculée en multipliant la superficie de la formation géologique contenant du silex par la moyenne des différentes épaisseurs apparentes contenant du silex dans cette formation.

- La troisième mesure est l'épaisseur réelle de l'affleurement (OrT). Elle correspond à la dimension maximale de la couche géologique contenant du silex. Dans les zones à pendage horizontal $\left(\beta=0^{\circ}\right)$, cette épaisseur correspond à la différence entre le toit et la base de la couche de l'affleurement. Dans les affleurements à pendage vertical $\left(\beta=90^{\circ}\right)$, l'épaisseur calculée est considérée comme étant identique à l'épaisseur mesurable de la cartographie multipliée par le dénominateur de l'échelle numérique cartographique. Dans les affleurements avec des pendages différents, l'épaisseur réelle est calculée en multipliant l'épaisseur mesurable par le sinus du pendage. 
D'après ces mesures, nous calculons ensuite le taux de présence de silex (CAR) de chaque formation. D'abord à travers l'indice de teneur en silex (Its), qui est le calcul du ratio en $\mathrm{cm}^{2}$ de silex par $\mathrm{m}^{2}$ de roche hôte. Puis à travers l'abondance, qui est la multiplication du silex total pour chaque affleurement (indice de teneur en silex) par l'épaisseur apparente de l'affleurement. La moyenne de l'indice de teneur moyenne en silex multipliée par l'abondance donnera l'abondance de silex dans le territoire (CAR).

La formule pour le calcul du taux de présence de silex (CAR) sera la suivante :

Index total de silex $($ Its $)=$ Ics $\times$ OaT

Affleurement $(\mathrm{Aa})=$ superficie $\times \mathrm{OaT}$

Taux de présence de silex $(\mathrm{CAR})=$ Its $\times \mathrm{Aa}$

Si nous prenons comme exemple la formation de Montmaneu et son silex (PAN) pour le calcul du CAR, le calcul sera le suivant :

- Si on a un index de contenu de silex (Ics) de $0,15 \mathrm{~m}^{2}$ dans cette formation, l'index total du silex (Its) sera la multiplication de l'Ics par l'épaisseur apparente (OaT), dans notre cas 3,5 $\mathrm{m}$. Ainsi, l'Its = 0,15 × 3,5, donnant un résultat de 0,53 $\mathrm{m}^{2}$.

- L'étape suivante est d'obtenir la valeur de l'affleurement (Aa) de la formation géologique avec silex, et ainsi de multiplier la surface de la formation en $\mathrm{m}^{2}$ par l'OaT, ici : $242000 \mathrm{~m}^{2} \times$ 3,5 m, ce qui nous donne un Aa de $847000 \mathrm{~m}^{2}$.

- Enfin, dans le but de connaître le volume en $\mathrm{m}^{3}$ de silex sur le territoire, le calcul du CAR sera obtenu à partir de la multiplication de l'Its $(0,53)$ par l'Aa $(847000)$, donnant un résultat de $444675 \mathrm{~m}^{3}$ de silex sur le territoire de type PAN.

\section{Analyses pétrographiques}

Lorsque les informations obtenues n'étaient pas suffisantes pour une bonne caractérisation, les analyses pétrographiques ont été basées sur des études macroscopiques, des lames minces et des analyses complémentaires. La diffraction et microdiffraction des rayons $\mathrm{X}$ et la microscopie électronique à balayage ont également été utilisées (Soto et al. 2014, Gómez de Soler 2016).

La description morphoscopique des matériaux a été effectuée de visu et à l'aide d'un microscope stéréoscopique (ZEISS Stemi DV4 8-32x). D'une part, nous avons analysé les aspects externes du matériau, tels que le type de support et la zone corticale; d'autre part, les aspects internes, tels que la couleur et sa distribution, la transparence, la texture, la présence de structures sédimentaires qui nous informent sur les milieux de dépôt, la présence de fissures et de fractures, les altérations post-dépositionnelles comme les patines, la présence d'impuretés et le contenu en microfossiles.

L'observation des silex en lame mince en lumière polarisée (Nikon Eclipse E400POL de 40-400x) a pour objectif de déterminer la composition minérale, les caractéristiques de la texture et la teneur en impuretés des silex. Ainsi, grâce à l'analyse microscopique, nous avons décrit la matrice siliceuse des silex, ainsi que la présence ou l'absence de reliquats minéraux et authigènes et d'éventuelles altérations ou compactages.

Des analyses complémentaires nous ont permis de réaliser une identification minéralogique rapide et non destructive grâce à la microdiffraction des rayons $\mathrm{X}$ (Bruker-AXS D8-Discover) et au microscope électronique à balayage (FEI Quanta 600), avec lesquels nous avons également pu décrire les tailles de grain et des zones 
corticales. Pour une meilleure identification des phases minéralogiques, nous avons utilisé la diffraction des rayons X (Siemens EM-10110BU D5000).

\section{Résultats}

$\mathrm{Au}$ cours des prospections, nous avons localisé plus de 30 affleurements contenant du silex dans un rayon de 30 kilomètres aux alentours de l'Abric Romaní. Les affleurements siliceux sont situés à l'ouest du site, dans les formations évaporitiques éocènes situées en marge de la dépression de l'Èbre, principalement dans deux de ses bassins marginaux, les bassins des rivières Gaià et Anoia; au nord-ouest, dans les systèmes lacustres oligocènes du secteur oriental du bassin de l'Èbre et dans les dépôts fluviaux pliocènes de la dépression prélittorale catalane. De plus, les prospections effectuées dans les cours d'eau proches de l'Abric Romaní ont exclu la présence significative de matériel en silex, celui-ci n'étant localisé avec une certaine abondance que dans la rivière de Tous, à proximité des affleurements de silex (Gómez de Soler 2016). Dans les sites archéologiques, on trouve un pourcentage de corticalité d'origine secondaire qu'on ne peut pas mettre en relation avec les cours fluviaux (terrasses actuelles et anciennes). Compte tenu du rôle des systèmes dispersifs des formations primaires, est-il possible de différencier le sous-primaire du secondaire ? Et dans ce cas, comment les systèmes dispersifs des formations primaires avec silex se sont-ils comportés au fil du temps? Pour répondre à ces questions, nous avons tenté de comprendre son affleurement primaire ainsi que sa dispersion dans la zone d'abondance siliceuse, et d'obtenir une approximation de la valeur réelle des silicifications dans un territoire en utilisant le taux de présence de silex (CAR). Ces dernières années, des études sur la corticalité du silex décrite au microscope électronique à balayage ont permis une approche plus précise de la chaîne évolutive du silex (Fernandes 2012, Delvigne 2016), un aspect à prendre en compte pour les études futures de la corticalité du silex du site de l'Abric Romaní.

Si on regroupe les affleurements de silex selon leur origine géographique, sept zones sources sont décrites, d'un rayon d'approvisionnement local ou régional :

- zone de La Serra (type SER);

- zone de faciès Muschelkalk (type MUSCH) ;

- zone de Mediona (type MED) ;

- zone de Sant Martí de Tous (type SMT) ;

- zone de Panadella (type PAN) ;

- zone de Cal Salvet (type SAL);

-zone de Ca l'Alemany (type ALE).

En comparant le matériel archéologique et géologique, seuls quatre de ces types sont représentés dans le matériel archéologique : SER, MUSCH, SMT et PAN (fig. 6 et tabl. 3). 
Fig. 6. - Localisation des affleurements de silex prospectés dans un rayon de 10 et 30 kilomètres autour de l'Abric Romaní (Capellades, Barcelona, Espagne) et des quatre aires d'approvisionnement documentées pour le niveau $\mathrm{M}$ et le sous-niveau $\mathrm{Oa}$.

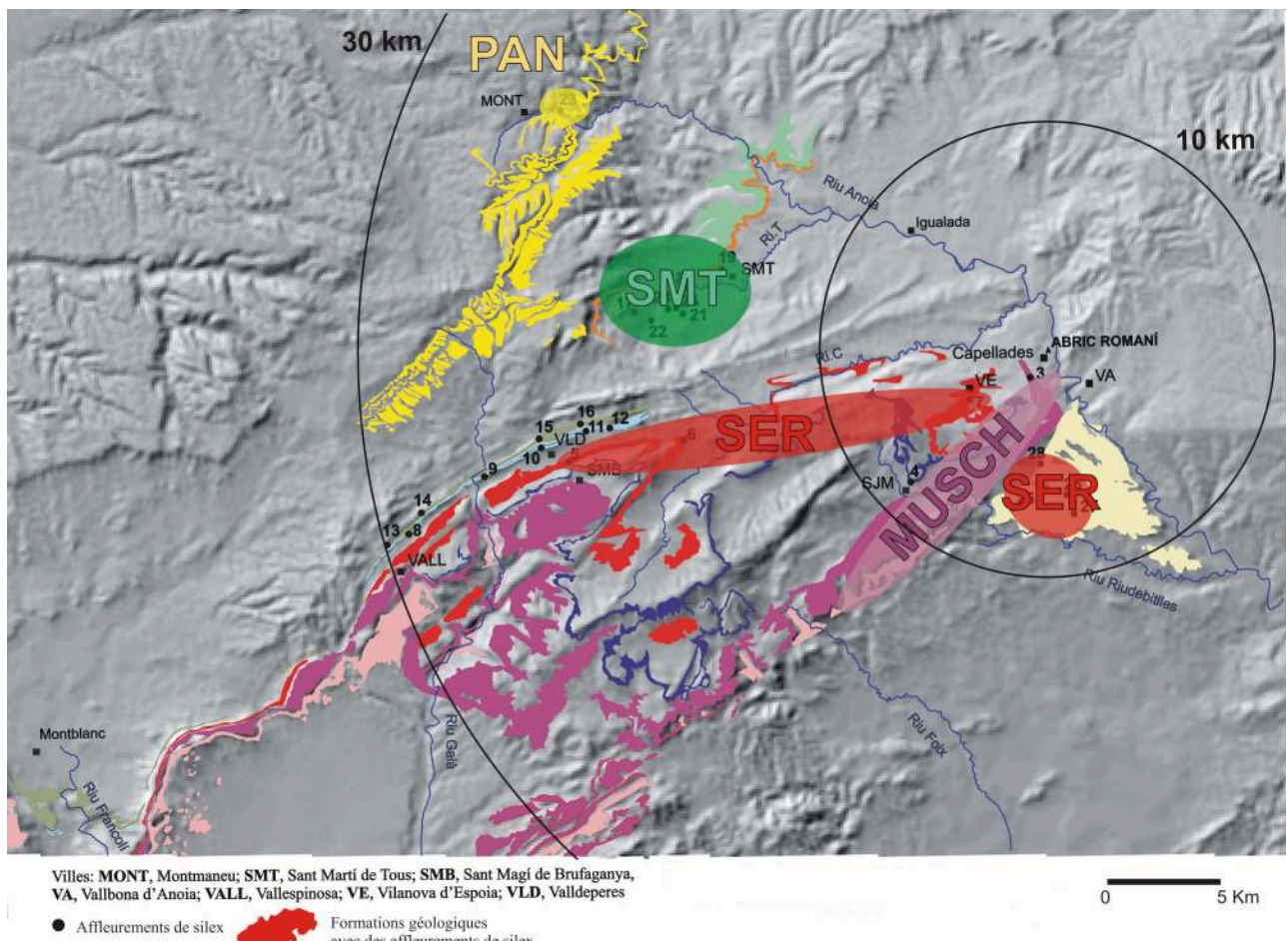

Superposition du modèle numérique d'élévation du terrain (1:50 000) avec la numérisation des formations géologiques contenant du silex. SER : zone de récolte du silex de type La Serra. PAN : zone de récolte du silex de type Panadella. SMт : zone de récolte du silex de type Sant Martí de Tous. Musch : zone de récolte du silex de type Muschelkalk. 
Tabl. 3. - Abric Romaní (Capellades, Barcelona, Espagne) : synthèse des types de silex représentés.

\begin{tabular}{|c|c|c|c|c|}
\hline Type de silex & $\begin{array}{l}\text { La Serra } \\
\text { ISER; }\end{array}$ & $\begin{array}{l}\begin{array}{c}\text { Muschelkalk } \\
\text { (MUSCCH) }\end{array} \\
\text { (M) }\end{array}$ & $\begin{array}{l}\text { Sant Marti de Tous } \\
\text { [5MT) }\end{array}$ & $\begin{array}{l}\text { Panadella } \\
\text { [PAN: }\end{array}$ \\
\hline Séries et agges & $\begin{array}{l}\text { Éocène (Cuisicn) } \\
\text { et Pliocène }\end{array}$ & $\begin{array}{l}\text { Triasique (Anisicn supéricur } \\
\text { et Ladinien supérieur) }\end{array}$ & $\begin{array}{c}\text { Eocène } \\
\text { (Priabonien) }\end{array}$ & $\begin{array}{l}\text { Oligocène } \\
\text { (Stampien) }\end{array}$ \\
\hline $\begin{array}{l}\text { Unités litho- } \\
\text { stratigraphiques }\end{array}$ & 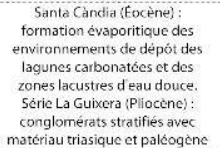 & 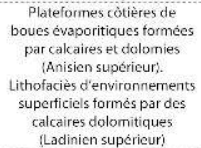 & $\begin{array}{c}\text { Formation } \\
\text { évaporitique } \\
\text { (scbkha) melant } \\
\text { niveauude gypse. } \\
\text { marnes } \\
\text { et gres }\end{array}$ & $\begin{array}{l}\text { Calcaires stratiticis } \\
\text { d'origine lacustre }\end{array}$ \\
\hline $\begin{array}{l}\text { Localité type et } \\
\text { distance du site. }\end{array}$ & $\begin{array}{c}\text { Lo Serra (SER) } \\
4.4 \mathrm{~km} \\
\end{array}$ & $\begin{array}{l}\text { Sant Quinti de Mediona } \\
\text { (MUSSCH17.6km }\end{array}$ & $\begin{array}{l}\text { Cal Perdut (PER) } \\
15,7 \mathrm{~km}\end{array}$ & $\begin{array}{l}\text { Montmaneu(PAN) } \\
\quad 24,3 \mathrm{~km}\end{array}$ \\
\hline Type de silicitication & $\begin{array}{l}\text { Siliex de calcaires } \\
\text { lagunaires } \\
\text { et tmarnes gyppifiteres }\end{array}$ & $\begin{array}{l}\text { Silex de depóts } \\
\text { carbonatés d'origine } \\
\text { marine (thétys }\end{array}$ & $\begin{array}{l}\text { Silex } \\
\text { évaporitique }\end{array}$ & $\begin{array}{l}\begin{array}{l}\text { Silex de calcaires } \\
\text { lacustres } \\
\text { lamines }\end{array}\end{array}$ \\
\hline Type d'encaissant & $\begin{array}{l}\text { Cálaires lagunaires. } \\
\text { matres gypsiferes } \\
\text { et conglomerats }\end{array}$ & $\begin{array}{l}\text { Calcaires et } \\
\text { dolomies }\end{array}$ & $\begin{array}{l}\text { Gypse, mames } \\
\text { et calcarenites }\end{array}$ & $\begin{array}{c}\text { Biomiccite } \\
\text { (Packstone) }\end{array}$ \\
\hline Habitus & Iréqulier & $\begin{array}{l}\text { Stratifiorme } \\
\text { discontinu }\end{array}$ & irrégulier & $\begin{array}{l}\text { Stratifiorme } \\
\text { discontinu }\end{array}$ \\
\hline Couleur & $\begin{array}{l}\text { Tonalités } \\
\text { de gris }\end{array}$ & Gris clair & $\begin{array}{l}\text { Hétérogóne: bleu, } \\
\text { gris, marron }\end{array}$ & $\begin{array}{l}\text { Uniforme } \\
\text { noir-vert }\end{array}$ \\
\hline Transparence & Opaque & Opaque & $\begin{array}{l}\text { Opaque et translucide } \\
\text { aux bords }\end{array}$ & $\begin{array}{l}\text { Opaque et translucide } \\
\text { aux bords }\end{array}$ \\
\hline $\begin{array}{l}\text { Texture } \\
\text { macroscopique }\end{array}$ & Fin & Fin a trés tin & Fin a moyen & Très fin \\
\hline 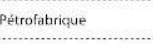 & Mudstone & $\begin{array}{l}\text { Wackestone } \\
\end{array}$ & $\begin{array}{l}\text { Micro- } \\
\text { cyptocristalline }\end{array}$ & $\begin{array}{l}\text { Mudstone- } \\
\text { Wackestone }\end{array}$ \\
\hline $\begin{array}{l}\text { Texture inicroscopique } \\
\text { dominante }\end{array}$ & $\begin{array}{l}\text { Quartz } \\
\text { microcristallin }\end{array}$ & $\begin{array}{l}\text { Quartz micro- } \\
\text { cryptocristallin }\end{array}$ & $\begin{array}{l}\text { Quartz } \\
\text { microcristallin }\end{array}$ & $\begin{array}{l}\text { Quartz micro- } \\
\text { cryptocristallin }\end{array}$ \\
\hline Porosité & $\begin{array}{l}\text { Porosités moldiques } \\
\text { remplies par mégaquartz } \\
\text { et calkédonite }\end{array}$ & $\begin{array}{l}\text { Porosités moldiques et } \\
\text { vacuoles remplies par } \\
\text { mégaquartzen mosatque } \\
\text { et calcedonite }\end{array}$ & $\begin{array}{l}\text { Anciennes porosités } \\
\text { remplies par calcédonite } \\
\text { spherolitique et } \\
\text { botryoidale }\end{array}$ & $\begin{array}{c}\text { Porosités moldiques } \\
\text { remplies par calcédonite } \\
\text { et mégaquartz en } \\
\text { mosalique }\end{array}$ \\
\hline $\begin{array}{l}\text { Composants non } \\
\text { siliceux }\end{array}$ & 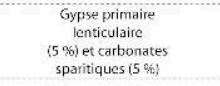 & $\begin{array}{l}\text { Micrite } \\
(20 \%)\end{array}$ & 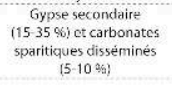 & $\underset{\substack{\text { Micrite } \\
(25-30 \%)}}{\text { (n) }}$ \\
\hline Elécments figurés & $\begin{array}{c}\begin{array}{c}\text { Grains squelettiques } \\
\text { (gastéropodes) } \\
<5 \%\end{array} \\
5 \%\end{array}$ & 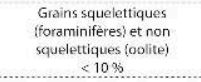 & & $\begin{array}{l}\text { Grains squelettiques } \\
\text { icharophyte, gasteropodes } \\
\text { et spicules) } \\
<10 \%\end{array}$ \\
\hline $\begin{array}{l}\text { Structures } \\
\text { sédimentaires }\end{array}$ & & 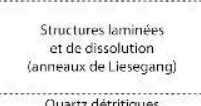 & $\begin{array}{l}\text { Structures de } \\
\text { dissolution- } \\
\text { granulation }\end{array}$ & $\begin{array}{l}\text { Structures laminees et } \\
\text { compactage mécanique : } \\
\text { ecrasement et de } \\
\text { réorientation des grains } \\
\text { squelettiques }\end{array}$ \\
\hline observations & $\begin{array}{l}\text { Reliques } \\
\text { Evaporitiques }\end{array}$ & $\begin{array}{l}\text { Ouartz detrtitiques } \\
\text { disséminés (1-3\%:i }\end{array}$ & $\begin{array}{l}\text { Reliques evaporitiques } \\
\text { atondantes }\end{array}$ & $\begin{array}{l}\text { Ouartz detritiques } \\
\text { disséminés }(1-3 \%)\end{array}$ \\
\hline
\end{tabular}

Pour utiliser le taux de présence de silex comme indicateur d'une meilleure connaissance du territoire et des ressources lithiques exploitables, il faut prendre en compte tous les silex présents dans la zone concernée, qu'ils aient ou non une représentation archéologique. La valeur totale de silex obtenue par le calcul du CAR n'est pas réelle, puisque la présence du silex dans un gisement n'est pas toujours continue, mais nous l'acceptons quand même, avec l'intention de créer un indice qui soit un outil de travail représentatif de la réalité du silex sur le territoire.

Pour le rayon local (inférieur à 10 kilomètres), trois types de silex sont représentés. Le silex SER est le plus abondant, avec $36146249 \mathrm{~m}^{3}$, soit près de $91 \%$ de la contribution locale, suivi du silex MUSCH avec $3678475 \mathrm{~m}^{3}$ et $9 \%$; le silex MED est presque inexistant, avec seulement $21199 \mathrm{~m}^{3}$ et un pourcentage de $0,04 \%$.

Pour le rayon régional (de 10 à 30 kilomètres), six types de silex sont représentés, puisque le silex SER comme le MUSCH couvrent les deux rayons d'approvisionnement. Le plus abondant sur le territoire est le silex SMT, avec $65283222 \mathrm{~m}^{3}$, soit $58 \%$. En second lieu, le silex MUSCH représente $25080162 \mathrm{~m}^{3}$ et un pourcentage de $27 \%$. Puis suivent le silex SAL (9 $777277 \mathrm{~m}^{3}$ et un peu plus de $6 \%$ ) et le silex ALE (9 $153404 \mathrm{~m}^{3}$ avec $6 \%$ ), et enfin le silex PAN, avec $127050 \mathrm{~m}^{3}$ et un pourcentage de $0,11 \%$.

$\mathrm{Au}$ niveau pétrographique, et en commençant par les gisements situés dans un rayon local, nous avons le silex SER, situé à une distance de 4 à 6 kilomètres de l'Abric Romaní. Il s'agit d'un silex résultant du remplacement des calcaires lacustres et des marnes gypsifères du Cuisien, et de son système dispersif: les conglomérats du Pliocène, de la série La Guixera, dans la dépression prélittorale catalane. Macroscopiquement, il est défini comme un silex de couleur grise, à texture fine et avec présence de bioclastes. Macroscopiquement, il est formé par du quartz microcristallin 
sur matrice, par du mégaquartz et de la calcédonite dans de vieilles porosités, et de gypse lenticulaire primaire (fig. 7). Ce silex présente des caractéristiques de régularité favorables à la taille, mais son principal défaut est qu'il se trouve sur des supports de petite taille dans les formations d'origine, et que sa texture en lame mince montre une prédominance du quartz microcristallin et de reliquats.

Fig. 7. - Silex géologique de La Serra (type SER).

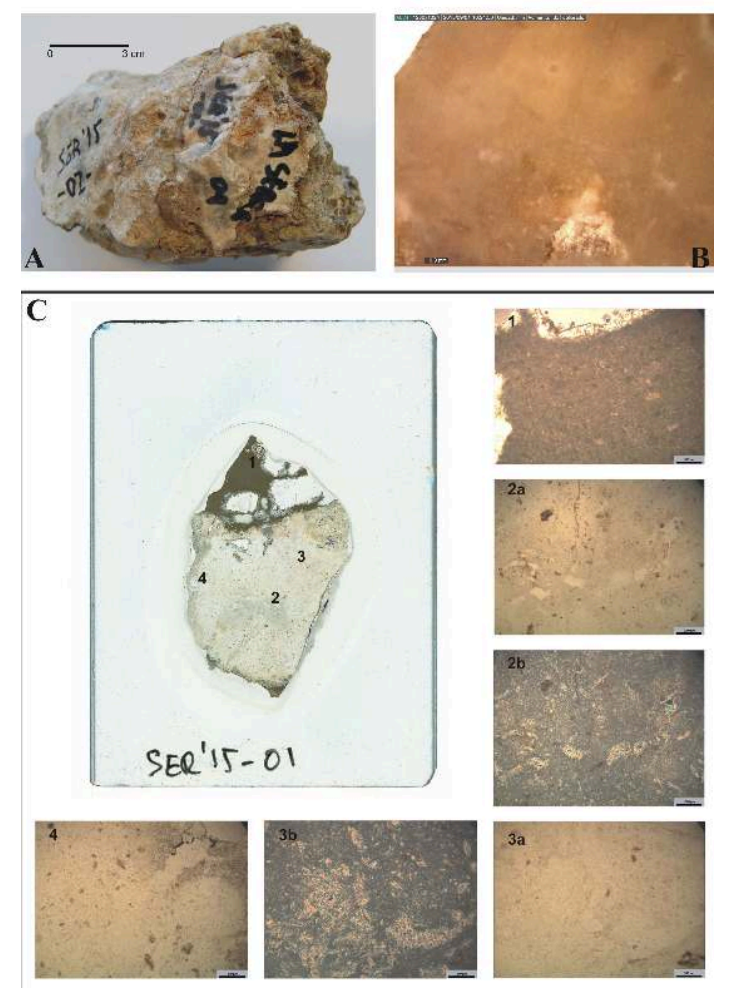

A : échantillon de silex géologique. B : détail au microscope stéréoscopique. c : lame mince scannée avec différentes images prises avec un microscope pétrographique.

Photos Bruno Gómez de Soler.

51 Le deuxième type de silex d'origine locale est le silex de type $\mathrm{MUSCH}$, dont le gisement est distant d'environ 7 kilomètres. Il est formé dans les calcaires marins silicifiés des dépôts triassiques du Muschelkalk inférieur et supérieur. Macroscopiquement, il présente une texture fine à très fine, avec des colorations grisâtres et la présence de bioclastes, générant des textures wackestone, des anneaux de Liesegang et des laminations comme textures sédimentaires. Les lames minces montrent un quartz micro-cryptocristallin en matrice, avec de la calcite micritique, de vieux grains squelettiques et non squelettiques et des structures sédimentaires abondantes (fig. 8). Malgré sa petite taille (nodules centimétriques), son aptitude à la taille est assez bonne, en raison de sa texture fine à très fine et de son caractère principalement microcryptocristallin. 
Fig. 8. - Silex géologique du Muschelkalk (type MUSCH).
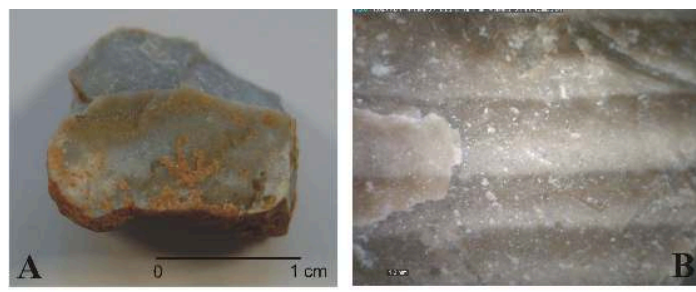

C
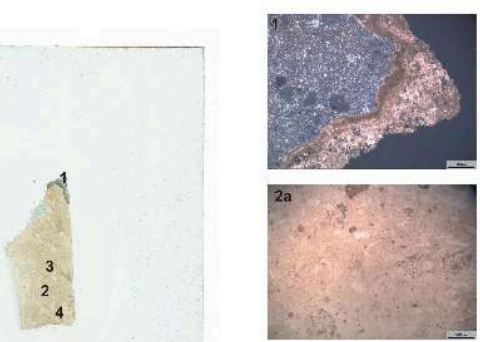

TS12 AR'99-M-QR2- 11
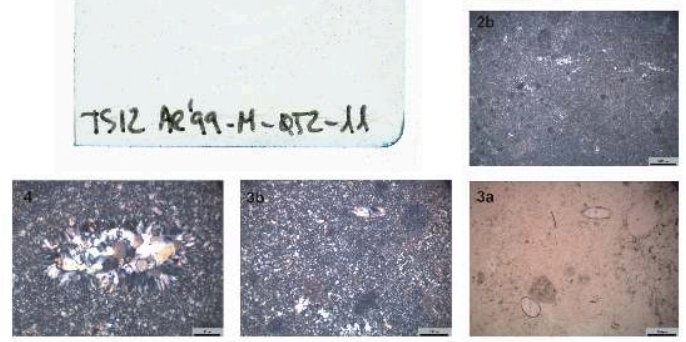

A : échantillon de silex géologique. B : détail au microscope stéréoscopique. c : lame mince scannée d'un silex archéologique (pièce AR'99-M-Q52-11) avec différentes images prises au microscope pétrographique.

Photos Bruno Gómez de Soler.

Dans la catégorie des silex d'origine régionale, le type SMT, situé à environ 16 kilomètres en ligne droite de l'Abric Romaní, figure en première place. Il s'agit d'un produit formé à la suite du remplacement des marnes gypsifères, des lutites et des gypses secondaires d'âge priabonien. En raison de sa grande variabilité, nous pouvons le définir comme un silex très hétérogène. Macroscopiquement, il se caractérise par une texture fine à moyenne, de couleur principalement bleuâtre, grisâtre et brunâtre, d'aspect translucide et présentant des reliquats évaporitiques. Macroscopiquement, il est formé par du quartz micro-cryptocristallin, avec du gypse secondaire, des carbonates sparitiques disséminés et avec des structures de dissolution-granulation (fig. 9). Ce caractère hétérogène représenté à la fois dans les formes, les tailles, les couleurs et les textures, lui confère également une aptitude très variée à la taille, en fonction du bloc ou du nodule choisi. 
Fig. 9. - Silex géologique de Sant Martí de Tous (type SAN).
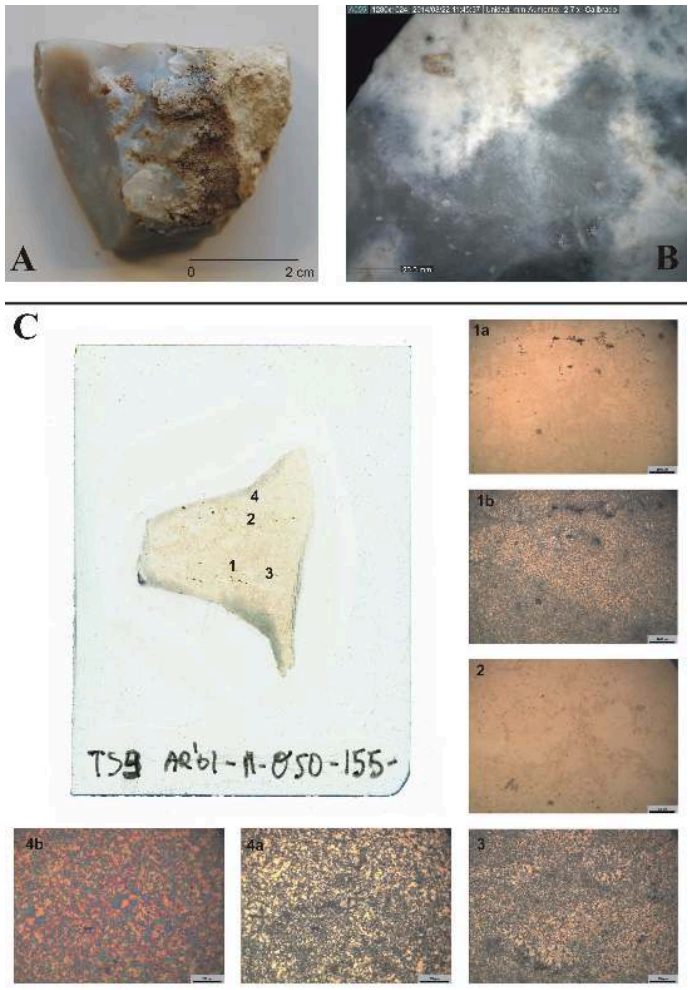

A : échantillon de silex. B : détail au microscope stéréoscopique d'un silex archéologique (pièce AR'04Oa-U47-1). c : lame mince d'un silex archéologique (pièce AR'01-M-050-155) avec différentes images prises au microscope pétrographique.

Photos Bruno Gómez de Soler.

53 Le silex de type PAN est situé à environ 24 kilomètres de l'Abric Romaní. Il est le résultat du remplacement des calcaires lacustres d'âge rupélien. Macroscopiquement, il se caractérise par une grande homogénéité, une couleur noirâtre et une transparence opaque, avec une texture très fine et la présence de certains bioclastes qui lui confèrent une texture de type mudstone-wackestone. En lame mince, il montre une matrice micro-cryptocristalline avec de la calcite micritique, des charophytes abondants et du quartz détritique disséminé (fig. 10). Toutes ces caractéristiques confèrent à ce silex des aptitudes optimales pour la taille. 
Fig. 10. - Silex géologique de La Panadella (type PAN).
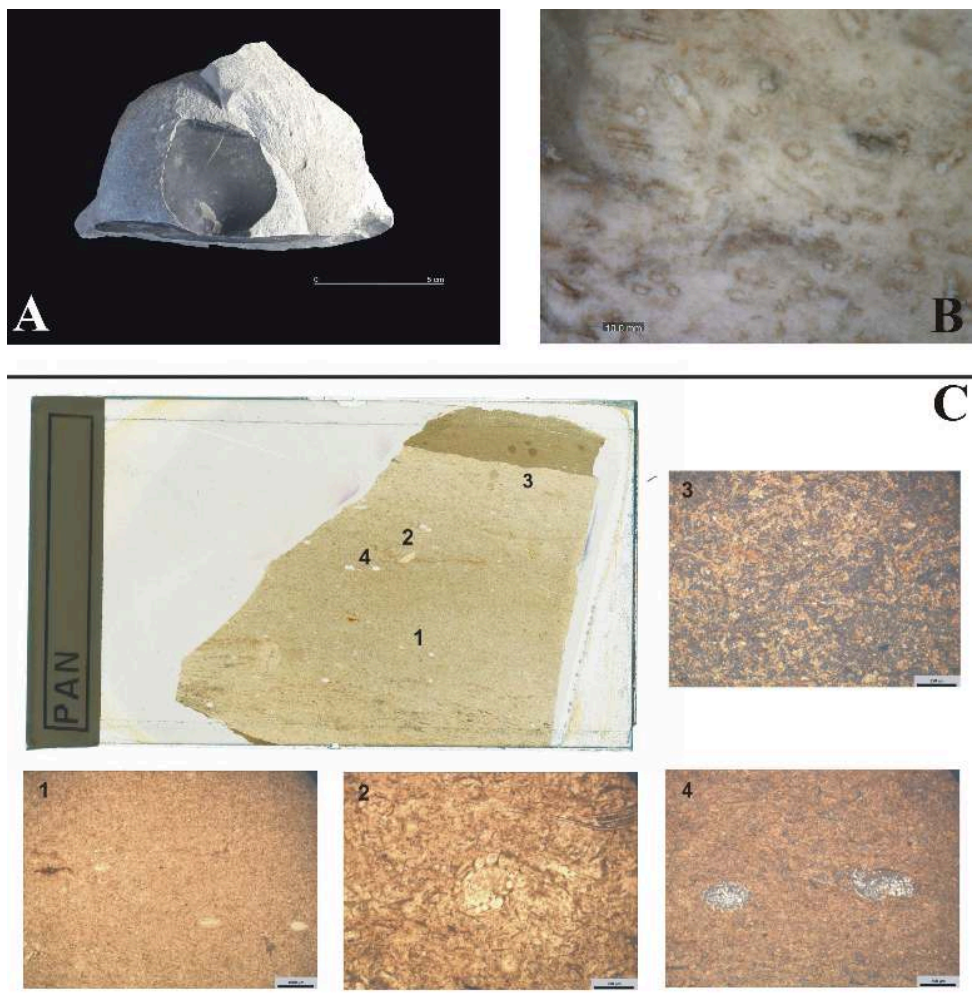

A : échantillon de silex. B : détail au microscope stéréoscopique d'un silex archéologique (pièce AR'02M-U49-47). C : lame mince scannée avec différentes images prises au microscope pétrographique. Photos Bruno Gómez de Soler.

Après avoir écarté toutes les pièces de silex mesurant moins d'un centimètre et celles montrant différents types d'altération, affectées soit par une patine totale, soit par des altérations thermiques, ou encore par des concrétions qui ne permettent pas une bonne identification géologique, nous avons pu analyser 2781 vestiges sur les $4922 \mathrm{du}$ niveau $\mathrm{M}$, soit $45,7 \%$. Les résultats montrent une nette prédominance du silex SMT, avec 2598 vestiges (93,5\%), suivi par le silex MUSCH, avec 69 pièces $(2,5 \%)$, puis par le silex PAN, avec 68 objets (2,4\%), et enfin par le silex SER, avec 46 éléments, soit 1,6\%. (tabl. 4).

Tabl. 4. - Abric Romaní (Capellades, Barcelona, Espagne), niveau M : catégories technologiques par lithotypes de silex.

\begin{tabular}{|c|c|c|c|c|c|c|c|c|}
\hline & $\begin{array}{c}\text { Outils } \\
\text { retouchés }\end{array}$ & Nucléus & $\begin{array}{l}\text { Fragments } \\
\text { de nucléus }\end{array}$ & Éclats & $\begin{array}{c}\text { Éclats } \\
\text { fracturés }\end{array}$ & $\begin{array}{c}\text { Fragments } \\
\text { d'éclats }\end{array}$ & Fragments & Total \\
\hline SMT & $\begin{array}{r}14 \\
(0,54 \%)\end{array}$ & $\begin{array}{r}42 \\
(1,62 \%)\end{array}$ & $\begin{array}{r}8 \\
(0,31 \%)\end{array}$ & $\begin{array}{r}1552 \\
(59,74 \%)\end{array}$ & $\begin{array}{r}361 \\
(13,89 \%)\end{array}$ & $\begin{array}{r}616 \\
(23,71 \%)\end{array}$ & $\begin{array}{r}5 \\
(0,19 \%)\end{array}$ & $\begin{array}{r}2598 \\
(93,5 \%)\end{array}$ \\
\hline MUSCH & $\begin{array}{r}2 \\
(2,90 \%)\end{array}$ & $\begin{array}{r}1 \\
(1,45 \%)\end{array}$ & & $\begin{array}{r}46 \\
(66,67 \%)\end{array}$ & $\begin{array}{r}10 \\
(14,49 \%)\end{array}$ & $\begin{array}{r}10 \\
(14,49 \%)\end{array}$ & & $\begin{array}{r}69 \\
(2,5 \%)\end{array}$ \\
\hline PAN & $\begin{array}{r}3 \\
(0,02 \%)\end{array}$ & $\begin{array}{r}1 \\
(1,45 \%)\end{array}$ & & $\begin{array}{r}42 \\
(0,46 \%)\end{array}$ & $\begin{array}{r}7 \\
(0,12 \%)\end{array}$ & $\begin{array}{r}15 \\
(1,81 \%)\end{array}$ & & $\begin{array}{r}68 \\
(2,4 \%)\end{array}$ \\
\hline SER & & & & $\begin{array}{r}30 \\
(65,22 \%)\end{array}$ & $\begin{array}{r}11 \\
(23,91 \%)\end{array}$ & $\begin{array}{r}5 \\
(10,87 \%)\end{array}$ & & $\begin{array}{r}46 \\
(1,6 \%)\end{array}$ \\
\hline Total & $\begin{array}{r}19 \\
(0,68 \%) \\
\end{array}$ & $\begin{array}{r}44 \\
1,58 \%) \\
\end{array}$ & $\begin{array}{r}8 \\
(0,29 \%) \\
\end{array}$ & $\begin{array}{r}1670 \\
(60,05 \%) \\
\end{array}$ & $\begin{array}{r}389 \\
(13,99 \%) \\
\end{array}$ & $\begin{array}{r}646 \\
(23,23 \%)\end{array}$ & $\begin{array}{r}5 \\
(0,18 \%) \\
\end{array}$ & $\begin{array}{r}2781 \\
(100 \%) \\
\end{array}$ \\
\hline
\end{tabular}

SMT : silex de type Sant Martí de Tous. MUsch : silex de type Muschelkalk. PAN : silex de type Panadella. SER : silex de type La Serra. 
Pour le sous-niveau Oa, sur les 1370 éléments de silex, 362 (24,4\%) ont été analysés : le silex SMT est également prédominant, avec 306 restes (84,5\%), suivi par le silex PAN, avec 45 objets $(12,4 \%)$ et le silex MUSCH, avec 11 pièces $(3,1 \%)$. Au niveau de la relation entre les catégories technologiques et les lithotypes, aucune différence notable n'est observée entre le niveau $\mathrm{M}$ et le sous-niveau Oa, en dehors du plus grand nombre d'éléments du silex SMT (tabl. 5).

Tabl. 5. - Abric Romaní (Capellades, Barcelona, Espagne), sous-niveau Oa : catégories technologiques par lithotypes de silex.

\begin{tabular}{|c|c|c|c|c|c|c|c|c|}
\hline & $\begin{array}{l}\text { Outils } \\
\text { retouchés }\end{array}$ & Nucléus & $\begin{array}{l}\text { Fragments } \\
\text { de nucléus }\end{array}$ & Éclats & $\begin{array}{l}\text { Éclats } \\
\text { fracturés }\end{array}$ & $\begin{array}{l}\text { Fragments } \\
\text { d'éclats }\end{array}$ & Fragments & Total \\
\hline SMT & $\begin{array}{r}11 \\
(3,59 \%)\end{array}$ & $\begin{array}{r}5 \\
(1,63 \%)\end{array}$ & $\begin{array}{r}2 \\
(0,65 \%)\end{array}$ & $\begin{array}{r}119 \\
(38,89 \%)\end{array}$ & $\begin{array}{r}67 \\
(21,89 \%)\end{array}$ & $\begin{array}{r}74 \\
(24,18 \%)\end{array}$ & $\begin{array}{r}28 \\
(9,15 \%)\end{array}$ & $\begin{array}{r}306 \\
(84,5 \%)\end{array}$ \\
\hline PAN & & & & $\begin{array}{r}14 \\
(31,11 \%)\end{array}$ & $\begin{array}{r}14 \\
(31,11 \%)\end{array}$ & $\begin{array}{r}15 \\
(33,34 \%)\end{array}$ & $\begin{array}{r}2 \\
(4,44 \%)\end{array}$ & $\begin{array}{r}45 \\
(12,4 \%)\end{array}$ \\
\hline MUSCH & & & & $\begin{array}{r}6 \\
(54,55 \%)\end{array}$ & $\begin{array}{r}2 \\
(18,18 \%)\end{array}$ & $\begin{array}{r}3 \\
(27,27 \%)\end{array}$ & & $\begin{array}{r}11 \\
(3,1 \%)\end{array}$ \\
\hline Total & $\begin{array}{r}11 \\
(3,04 \%)\end{array}$ & $\begin{array}{r}5 \\
(1,38 \%)\end{array}$ & $\begin{array}{r}2 \\
(0,55 \%)\end{array}$ & $\begin{array}{r}139 \\
(38,40 \%)\end{array}$ & $\begin{array}{r}83 \\
(22,93 \%)\end{array}$ & $\begin{array}{r}92 \\
(25,41 \%)\end{array}$ & $\begin{array}{r}30 \\
(8,29 \%) \\
\end{array}$ & $\begin{array}{r}362 \\
(100 \%)\end{array}$ \\
\hline
\end{tabular}

SMT : silex de type Sant Martí de Tous. PAN : silex de type Panadella. Musch : silex de type Muschelkalk.

\section{Discussion}

En premier lieu et compte tenu de l'abondance des ressources siliceuses sur le territoire, on pourrait s'attendre à ce que le silex le plus proche et le plus abondant soit le plus représenté dans le registre archéologique, conférant au silex SER un rôle prépondérant dans l'approvisionnement des ressources abiotiques par les communautés néandertaliennes qui occupaient l'Abric Romaní.

Dans le niveau $\mathrm{M}$, les silex locaux sont rares. Le silex SER représente $1,6 \%$ et le silex MUSCH 2,5\%. Quant au silex SMT, il est prédominant dans le registre archéologique, à $93,4 \%$, et c'est également le plus répandu au niveau régional. Si l'on ajoute que la rivière Anoia, lors de son passage par l'Abric Romaní, ne porte presque pas de matériel en silex, et que les prospections réalisées dans différentes sections de la rivière et de ses affluents (ruisseaux et torrents) permettent d'éliminer la possibilité d'un approvisionnement en position secondaire, nous pouvons en déduire que l'approvisionnement pour le niveau $\mathrm{M}$ a été réalisé principalement au niveau régional, à environ 16 kilomètres du site. Le silex PAN mérite une mention spéciale car, malgré sa faible présence dans le territoire $(0,11 \%$ du silex total), et son éloignement de 24 kilomètres, il représente $2,4 \%$ dans le registre archéologique du niveau $\mathrm{M}$ : un pourcentage similaire ou même supérieur à ceux des silex d'origine locale, qui sont pourtant beaucoup plus abondants. Cet approvisionnement spécifique peut s'expliquer par la très bonne qualité du silex PAN et son aptitude à la taille.

Si on se focalise sur le sous-niveau Oa, les conclusions sont similaires. Le silex le plus représenté est toujours celui de type SMT, à $84,5 \%$, ce qui implique que l'approvisionnement a été réalisé dans les zones d'abondance du niveau régional, les silex les plus abondants et les plus proches de l'Abric Romaní étant presque inexistants dans le registre archéologique. Dans ce sous-niveau, le silex SER est totalement absent, et le silex MUSCH, pourtant de bonne qualité, représente un faible pourcentage : 3,1 \%. Le silex PAN est plus fréquent que dans le niveau $\mathrm{M}$, avec un pourcentage de $12,4 \%$. 

une notion de prédétermination, favoriserait une utilisation plus importante des variétés de silex de qualité supérieure, dont la fracture est plus prévisible et contrôlable. On pouvait donc s'attendre à une augmentation de l'utilisation du silex PAN dans le sous-niveau $\mathrm{Oa}$, et à ne pas retrouver dans le niveau $\mathrm{M}$, caractérisé par un débitage discoïde, cette tendance à sélectionner des matériaux de bonne qualité pour la taille. Il est vrai que dans le sous-niveau Oa, l'augmentation du silex PAN est relativement modeste ; mais elle est plus manifeste dans d'autres niveaux actuellement encore en cours d'étude, comme dans le niveau $\mathrm{P}$, où les pourcentages élevés de silex PAN sont associés à des technologies élaborées avec un haut degré de prédétermination.

dant, afin d'aborder pleinement la relation entre la complexité de la technologie et la sélection des matières premières, il sera nécessaire d'obtenir plus de données, qui nous informeront sur les critères de sélection dans les zones sources caractérisées par une forte hétérogénéité dans la qualité des matériaux. C'est le cas du silex SMT, qui présente des variétés ayant des aptitudes à la taille très différentes. Il faudrait notamment déterminer si le silex SMT du sous-niveau Oa tend à être d'une qualité supérieure à celui utilisé dans le niveau $\mathrm{M}$, et pour cela caractériser les différentes 
variétés de silex SMT en termes d'aptitude à la taille, sur la base de la matière première : type de grain, géodes et fractures internes, etc. Cette approche qualitative est en cours d'étude.

En plus de ces facteurs strictement technologiques, on peut se demander dans quelle mesure les stratégies d'approvisionnement sont conditionnées par l'intensité et/ou la durée des occupations. Dans certaines études, il a été suggéré que le niveau M pourrait être un campement résidentiel de longue durée (Chacón et al. 2014, Fernández-Laso et al. 2010, Marín et al. 2017a et 2017b). À partir de l'étude de la répartition spatiale et des remontages identifiés, il a été possible de montrer qu'au sein du site lui-même existent des stratégies d'approvisionnement différentielles en matières premières. La partie centrale de l'abri est souvent caractérisée par le transport de nucléus et d'éclats depuis la zone la plus intérieure de l'abri, ce qui a déterminé des stratégies d'approvisionnement très différentes dans les unités domestiques de la partie centrale (Vaquero et al. 2015 et 2017), associées aux différentes intensités dans les activités réalisées et aux différents types d'occupation du site au fil du temps (Romagnoli et Vaquero 2016).

D'autre part, le sous-niveau Oa, dans lequel la distribution spatiale des activités est concentrée dans de petites zones de l'abri, où prédominent des chaînes opératoires très fragmentées et un faible nombre de vestiges, pourrait être interprété comme un camp résidentiel de courte durée (Bargalló 2014, Gabucio 2014). Cependant, ces interprétations se heurtent à la difficulté d'aborder la durée des occupations à partir du registre archéologique. En raison du caractère de palimpseste des unités archéologiques, les caractéristiques communément utilisées pour identifier les différences dans la durée des occupations (quantité de vestiges, variabilité du registre archéologique, etc.) pourraient être le résultat de la superposition d'événements d'occupation au fil du temps. En ce sens, la régularité des remontages identifiés dans le niveau $\mathrm{M}$ correspond à une dynamique de recyclage des vestiges lithiques selon une succession d'occupations (Vaquero et al. 2015 et 2017). Pour établir une relation entre les stratégies d'approvisionnement et les types d'occupation, nous devons disposer de données fiables sur la durée des occupations.

Le schéma de mobilité territoriale est très nettement identifiable pour les deux niveaux. La grande majorité de l'approvisionnement lithique est orienté vers le nordouest : il existe un axe unidirectionnel clair. À l'opposé, l'approvisionnement vers le sud et le sud-est, sur des affleurements contenant les silex SER et MUSCH, est sousreprésenté dans le registre archéologique ; le silex SER est même absent dans le sousniveau Oa.

68 Le fait que l'approvisionnement en silex ait lieu au niveau régional nous montre, d'une part, l'approvisionnement primaire des ressources abiotiques et, d'autre part, l'augmentation du rayon d'approvisionnement, allant d'un rayon de 10 kilomètres pour les sociétés de chasseurs-cueilleurs historiques à 16 kilomètres pour les communautés néandertaliennes occupant le niveau M et le sous-niveau Oa de l'Abric Romaní.

Comme nous l'avons déjà mentionné, bien qu'il existe de nombreux travaux sur l'approvisionnement en matières premières, peu d'entre eux étudient l'attribution du matériel archéologique aux zones sources à partir d'une base pétroarchéologique prenant en compte l'étude de lames minces, des analyses géochimiques complémentaires et un travail exhaustif de prospection géo-archéologique avec étude des unités lithostratigraphiques dans lesquelles se trouvent les silex. En nous fondant 
sur ces études, nous observons que même si la tendance de l'approvisionnement au Paléolithique moyen reste locale (environ 10 kilomètres), des sites où le silex provient d'une distance de 15 à 30 kilomètres peuvent également être identifiés, comme dans le cas de l'Abric Romaní.

Bien que la tendance générale pendant le Paléolithique moyen soit celle d'un approvisionnement local, il y a de plus en plus d'exemples dans le sud et le centre de l'Europe d'un approvisionnement d'envergure régionale, comme celui observé pour le site de l'Abric Romaní.

Les sites de la péninsule Ibérique ayant un rayon de mobilité similaire à ceux de l'Abric Romaní et qui ont été étudiés selon des critères pétroarchéologiques sont ceux d'Axlor et d'Amalda, au pays Basque. Dans le premier cas, l'approvisionnement en silex se produit dans un rayon de 15 à 30 kilomètres, et dans le second, de 30 kilomètres (Ríos 2008, Ríos et al. 2015). Le même modèle peut être observé pour le silex au Portugal, à La Gruta da Oliveira (Matias 2016) et sur des gisements côtiers et de plein air de l'Algarve (Praia da Galé, Vale Boi, Curva do Belixe, Vale Santo), distants d'environ 30 kilomètres des quelques affleurements de silex de la région (Bicho 2004).

Dans le sud-est de la France, toute une série de gisements montrent un approvisionnement au niveau régional: le site de Payre (Rompon, Ardèche), avec des distances allant de 8 à 50 kilomètres (Moncel et al. 2008), ou le site de l'abri du Maras (Saint-Martin-d'Ardèche, Ardèche), allant de 0 à 30 kilomètres (Moncel et al. 2014). De même pour le site du Bau de l'Aubesier (Monieux, Vaucluse) : Browne et Wilson (2011) situent le rayon d'approvisionnement à environ 20 kilomètres. Pour le site de la Baume de Néron (Soyons, Ardèche), L. Slimak (1999) établit un rayon d'approvisionnement allant de quelques mètres jusqu'à 60 kilomètres. Pour le site du l'abri du Rond (SaintArcons, Haute-Loire), l'approvisionnement en silex couvre un rayon de 15 à 40 kilomètres (Fernandes et al. 2008).

En Europe centrale, les dépôts présentant un rayon d'approvisionnement similaire à celui de l'Abric Romaní sont ceux de la grotte de Kulna (Moravie, République Tchèque) avec $80-90 \%$ du matériel provenant de 5 à 20 kilomètres, et de la grotte de Zowlen (Pologne) où $70 \%$ du matériel provient d'une vingtaine de kilomètres (Féblo-Augustins 1993 et 1999). Enfin, dans la grotte de Scladina, en Belgique, les sous-types de silex les plus abondants proviennent de 30 kilomètres (Di Modica 2010).

\section{Conclusions}

74 Tout d'abord, la localisation de plus de 30 affleurements de silex dans un rayon de 30 kilomètres autour du site de l'Abric Romaní nous permet de mieux connaître ce territoire et ses principales ressources abiotiques.

La représentation archéologique indique des zones d'approvisionnement situées au nord-ouest du site de l'Abric Romaní. La présence limitée de silex dans les cours d'eau et la prédominance de l'approvisionnement en silex SMT nous informe d'un approvisionnement régional, dans des zones où le silex est plus abondant. Cette prédominance marque un rayon d'approvisionnement d'environ 16 kilomètres, qui pourrait même atteindre 24 kilomètres pour le silex PAN, pour les communautés néandertaliennes qui ont occupé l'Abric Romaní pendant la formation du niveau $\mathrm{M}$ et du sous-niveau Oa. Cet approvisionnement nous fournit des modèles unidirectionnels 
très clairs, toujours du nord-ouest vers le sud-est. La route qui mettrait en contact l'intérieur catalan avec la côte (sud-sud-est), avec les silex SER et MUSCH serait quasi inexistante.

Les différences de technique de taille entre le niveau $M$ et le sous-niveau Oa ne semblent pas affecter les stratégies d'approvisionnement, ni par conséquent la mobilité territoriale. Cependant, il faut prendre en considération l'augmentation du silex PAN, et dans une moindre mesure du type $\mathrm{MUSCH}$, dans les niveaux où prédominent les méthodes de réduction plus complexes.

Le fait que le site joue également un rôle différent d'un niveau à l'autre pourrait également être lié à d'autres aspects, qui ne seraient pas exclusivement en lien avec la technologie. Compte tenu des stratégies d'approvisionnement et de la gestion du matériel lithique, la mobilité territoriale semble déterminée par des facteurs autres que techniques et technologiques, d'ordre plutôt socio-économique: parties de chasse, fonction différentielle du gisement ou même différentes populations de Néandertaliens ayant occupé le site de l'Abric Romaní.

\section{BIBLIOGRAPHIE}

AUBRY T., BARBOSA A. F., LUís L., SANTOS A. T., SILVESTRE M., 2016, « Quartz use in the absence of flint: Middle and Upper Palaeolithic raw material economy in the Côa Valley (North-eastern Portugal) », Quaternary International, n 424, p. 113-129.

BARGALLó A., 2014, « Anàlisi tecnològica del assentament neandertals del nivell o de l'Abric Romaní (Barcelona, Espanya)», thèse de doctorat, Tarragona, Universitat Rovira i Virgili. вісно N., 2004, « The Middle Paleolithic occupation of southern Portugal », dans Conard N. (dir.), Settlement Dynamics of the Middle Palaeolithic and Middle Stone Age, vol. 2, Tübingen, Kerns Verlag, p. 513-531.

BINFORD L.-R., 1982, « The Archaeology of place », Journal of Anthropological Archaeology, vol. 1, n 1 , p. 5-31.

BINFORD L.-R., 2001, Constructing Frames of Reference: An Analytical Method for Archaeological Theory Building Using Ethnographic and Environmental Data Sets, Berkeley, University of California Press.

BOËDA É., 1993, « Le débitage discoïde et le débitage levallois récurrent centripète ", Bulletin de la Société préhistorique française, vol. 90, nº 6, p. 392-404.

BOËDA É., 1994, Le concept Levallois : variabilité des méthodes, Paris, CNRS Éditions.

BOËDA É., 1995, «Levallois: A volumetric construction, methods, a technique », dans Dibble H.-L. et Bar-Yosef O. (dir.), The Definition and interpretation of Levallois technology, Madison, Prehistory Press (Monographs in World Archaeology), p. 41-68.

BURJACHS F., LÓPEZ-GARCÍA J.-M., ALLUÉ E., BLAIN H.-A., RIVALS F., BENNÀSAR M.-LL., EXPÓSITO I., 2012, «Palaeoecology of Neanderthals during Dansgaard-Oeschger cicles in northeastern Iberia (Abric Romaní): from regional to global scale », Quaternary International, $\mathrm{n}^{\circ} 247$, p. 26-37. 
BROWNE C.-L. et WILSON L., 2011, « Resource selection of lithic raw materials in the Middle Palaeolithic in southern France », Journal of Human Evolution, $n^{\circ}$ 61, p. 597-608.

CARBONELl E., GIRALT S., VAQUERO M., 1994, Abric Romaní (Capellades, Barcelona, Espagne): une importante séquence anthropisée du Pléistocène supérieur, Bulletin de la Société préhistorique française, vol. $91, \mathrm{n}^{\circ} 1$, p. 47-55.

CHACóN M. G., 2009, « El Paleolítico medio en el suroeste europeo: Abric Romaní (Capellades, Barcelona, España), Payre (Rompon, Ardèche, Francia) y Tournal (Bize, Aude, Francia). Análisis comparativo de los conjuntos líticos y los comportamientos humanos ", thèse de doctorat, Tarragona, Universitat Rovira i Virgili.

CHACÓN M. G., BARGALLÓ A., GÓMEZ DE SOLER B., PICIN A., VAQUERO M., CARBONELL E., 2013, « Continuity or Discontinuity of Neanderthal technological Behaviours during MIS 3: level M and level $O$ of the Abric Romaní Site (Capellades, Spain) », dans Pastoors A. et Auffermann B. (dir.), Pleistocene foragers on the Iberian Peninsula: their cultures and environment, Festschrift in honour of Gerd-Chritian Wenger for his sixtieth birthday, Mettmann, Neanderthal Museum, p. 55-84.

CHACÓN M. G., FERNÁNDEZ-LASO M. C., RIVALS F., 2014, « Comportements des populations néandertaliennes pendant le MIS 3 à l'Abric Romaní : les niveaux K, L et M. Variabilité ou continuité ? ", dans Jaubert J., Fourment N., Depaepe P. (dir.), Transitions, ruptures et continuité en Préhistoire, vol. 2 : Paléolithique et Mésolithique, Paris, Société préhistorique française, p. 207-228.

DI MODICA K., 2010, « Les productions lithiques du Paléolithique moyen de Belgique : variabilité des systèmes d'acquisition et des technologies en réponse à une mosaïque d'environnements contrastés ", thèse de doctorat, Paris, Muséum national d'histoire naturelle/Liège, université de Liège.

DIBBLE H.-L., BERNA F., GOLDBERG P., MCPHERRON S.-P., MENTZER S., NIVEN L., RICHTER D., SANDGATHE D., THÉRYPARISOT I., TURQ A., 2009, « A Preliminary Report on Pech de l'Azé IV, Layer 8 (Middle Paleolithic, France) », PaleoAnthropology, p. 182-219.

DELVIGNE V., 2016, « Géoressources et expressions technoculturelles dans le Sud du Massif central au Paléolithique supérieur : des déterminismes et des choix ", thèse de doctorat, Pessac, université de Bordeaux.

DELVIGNE V., FERNANDES P., PIBOULE M., CHOMETTE D., DEFIVE E., LAFARGE A., LIABEUF R., MONCEL M.-H., WRAGGSYKES R., RAYNAL J.-P., 2016, « Circulation du silex barrémo-bédoulien depuis le Paléolithique moyen de Vivarais en Velay par les monts du Mézenc ", Ardèche archéologie, nº 33, p. 11-18.

DESCHAMPS M., 2017, Late Middle Paleolithic assemblages with flake cleavers in the western Pyrenees : The Vasconian reconsidered, Quaternary International, $n^{\circ} 433$, p. 33-49.

EIXEA A., ROLDÁN C., VILLAVERDE V., ZILHÃo J., 2014, « Middle Palaeolithic flint procurement in Central Mediterranean Iberia: Implications for human mobility », Journal of Lithic Studies, vol. 1, $\mathrm{n}^{\circ} 1$, p. 103-115.

FÉBLOT-AUGUSTINS J., 1999, « Raw material transport patterns and settlement systems in the European Lower and Middle Palaeolithic: continuity, change and variability », dans Roebroeks W. et Gamble C. (dir.), The Middle Palaeolithic occupation of Europe, Leiden, Universiteit Leiden, p. 193-214.

FERNANDES P., 2012, «Itinéraires et transformations du silex : une pétroarchéologie refondée, application au Paléolithique moyen », thèse de doctorat, Pessac, université Bordeaux I. 
FERNANDES P., RAYNAL J.-P., MONCEL M.-H., 2008, « Middle Palaeolithic raw material gathering territories and human mobility in the southern Massif Central, France: first results from a petroarchaeological study on flint ", Journal of Archaeological Science, $n^{\circ} 35$, p. 2357-2370.

FERNÁNDEZ-LASO M. C., 2010, « Remontajes de restos faunísticos y relaciones entre áreas domésticas en los niveles K, L y M del Abric Romaní (Capellades, Barcelona, España) », thèse de doctorat, Tarragona, Universitat Rovira i Virgili.

FERNÁNDEZ-LASO M. C., RIVALS F., ROSELL J., 2010, « Intra-site changes in seasonality and their consequences on the faunal assemblages from Abric Romani (Middle Paleolithic, Spain) », Quaternaire, $\mathrm{n}^{\circ}$ 21, p. 155-163.

GABUCIO M.-J., 2014, « Estudi paleotemporal d'un plaimsest: anàlisi zooarqueològica i tafonòmica del nivell $\mathrm{O}$ de l'Abric Romaní (Capellades, Barcelona, Spain) », thèse de doctorat, Tarragona, Universitat Rovira i Virgili.

GABUCIO M.-J., CÁCERES I., ROSELL J., SALADIÉ P., VALLVERDÚ J., 2014, « From small bone fragments to Neanderthal activity areas: The case of Level $\mathrm{O}$ of the Abric Romaní (Capellades, Barcelona, Spain) », Quaternary International, $\mathrm{n}^{\circ} 330$, p. 36-51.

GENESTE J.-M., 1989, «Économie des ressources lithiques dans le Moustérien du Sud-Ouest de la France ", dans Otte M., Patou M., Freeman L. G. (dir.), L'homme de Néandertal : la subsistance, Liège, université de Liège (ERAUL, 6), p. 75-97.

GÓMEZ DE SOLER B., 2009, « Àrees de captació, tecnologia lítica i estràtegies d'aprovisionament de roques silicies en el nivell L de l'Abric Romaní (Capellades, Barcelona) », Quadern de Prehistòria Catalana, $\mathrm{n}^{\circ} 17$, p. 11-56.

GÓMEZ DE SOLER B., 2016, « Procedencia del aprovisionamiento lítico durante el Paleolítico medio en el yacimiento del Abric Romaní (Capellades, Barcelona) : Niveles M, Oa y P », thèse de doctorat, Tarragona, Universitat Rovira i Virgili.

GRIMALDI S. et SANTANIELLO F., 2014, « New insights into Final Mousterian lithic production in western Italy », Quaternary International, n³ 350, p. 116-129.

IGME (Instituto Geológico y Minero de España), 1975, Mapa Geológico de España a Escala 1:50.000, hoja n $^{\circ} 391$ : « Igualada », serie Magna, Madrid, IGME.

IGME (Instituto Geológico y Minero de España), 1982a, Mapa Geológico de España a Escala 1:50.000, hoja $\mathrm{n}^{\circ} 418$ : « Montblanch », serie Magna, Madrid, IGME.

IGME (Instituto Geológico y Minero de España), 1982b, Mapa Geológico de España a Escala 1:50.000, hoja ${ }^{\circ} 419$ : «Vilafranca del Panades », serie Magna, Madrid, IGME.

IGME (Instituto Geológico y Minero de España), 1998, Mapa Geológico de España a Escala 1:50.000, hoja $\mathrm{n}^{\circ} 390$ : «Cervera », serie Magna, Madrid, IGME.

KUHN S.-L., 1995, Mousterian lithic technology: an ecological perspective, Princeton, Princeton University Press.

MARÍN J., 2014, « Estrategias de transporte de carcasas de ungulados durante el Paleolítico Medio: el nivel M del Abric Romaní (Capellades, Barcelona) », mémoire de master, Tarragona, Universitat Rovira i Virgili.

MARÍN J., SALADIÉ P., RODRÍGUEZ-HIDALGO A., CARBONELL E., 2017a, « Ungulate carcass transport strategies at the Middle Palaeolithic site of Abric Romaní (Capellades, Spain) », Comptes rendus palevol, $\mathrm{n}^{\circ} 16$, p. 103-121. 
MARÍN J., SALADIÉ P., RODRÍGUEZ-HIDALGO A., CARBONELL E., 2017b, « Neanderthal hunting strategies inferred from mortality profiles within the Abric Romaní sequence », PlosOne, vol. 12, $\mathrm{n}^{\circ} 11$, p. 1-42.

MATIAS H., 2016, « Raw material sourcing in the Middle Paleolithic site of Gruta da Oliveira (Central Limestone Massif, Estremadura, Portugal) ", Journal of Lithic Studies vol. 3, n 2, doi: 10.2218/jls.v3i2.1452.

MONCEL M.-H., BOREL A., DE LOMBERA A., SALA R., DENIAUX B., 2008, « Quartz et quartzite dans le site de Payre (MIS 7 et 5 , Ardèche, France) : données techno-économiques sur la gestion de roches locales au Paléolithique moyen ", Comptes rendus palevol, n 7, p. 441-451.

MONCEL M.-H., CHACÓN M.-G., LA PORTA A., FERNANDES P., HARDY B., GALLOTTI R., 2014, « Fragmented reduction processes: Middle Palaeolithic technical behaviour in the Abri du Maras shelter, southeastern France », Quaternary International, nº 350, p. 180-204.

Ríos J., 2008, « Variabilidad tecnológica en el Paleolítico Medio de los Pirineos Occidentales: una expresión de las dinámicas históricas de las sociedades neandertales ", Treballs d'Arqueologia, $\mathrm{n}^{\circ}$ 14, p. 171-194.

RÍOS J., EIXEA A., VILLAVERDE V., 2015, « Ramification of lithic production and the search of small tools in Iberian Peninsula Middle Paleolithic », Quaternary International, nº 361, p. 188-199.

ROMAGNOLI F. et VAQUERO M., 2016, «Quantitative stone tools intra-site point and orientation patterns of a Middle Palaeolithic living floor: a GIS multi-scalar spatial and temporal approach », Quartär, $\mathrm{n}^{\circ}$ 63, p. 47-60.

ROMAGNOLI F., BARGALLó A., CHACóN M. G., GÓMEZ DE SOLER B., VAQUERO M., 2016, « Testing a hypothesis about the importance of the quality of raw material on technological changes at Abric Romaní (Capellades, Spain): Some considerations using a high-resolution techno-economic perspective », Journal of Lithic Studies, $\mathrm{n}^{\circ}$ 3, doi:10.2218/jls.v3i2.1443.

ROMAGNOLI F., GÓMEZ DE SOLER B., BARGALLó A., CHACóN M. G., VAQUERO M., 2017, « Here and now or a previously planned strategy? Rethinking the concept of ramification for micro-production in expedient contexts: implications for Neanderthal socio-economic behavior ", Quaternary International, $\mathrm{n}^{\circ}$ 474B, p. 168-181, doi :10.1016/j.quaint.2017.12.036

SHARP W. D., MERTZ-KRAUS R., VALLVERDÚ J., VAQUERO M., BURJACHS F., CARBONELL E., BISCHOFF J. L., 2016, « Archeological deposits at Abric Romaní extend to $110 \mathrm{ka}$ : U-series dating of a newly cored, 30 meter-thick section ", Journal of Archaeological Science Reports, n 5, p. 400-406.

SLIMAK L., 1999, « Pour une individualisation des Moustériens de type Quina dans le quart Sud-Est de la France ? La Baume Néron (Soyons, Ardèche) et le Champ Grand (Saint-Maurice-sur-Loire, Loire), premières données ", Bulletin de la Société préhistorique française, vol. 96, nº 2, p. 133-144.

SLIMAK L. et GIRAUD Y., 2007, « Circulations sur plusieurs centaines de kilomètres durant le Paléolithique moyen : contribution à la connaissance des sociétés néandertaliennes ", Comptes rendus palevol, vol. 6, $\mathrm{n}^{\circ}$ 5, p. 359-368.

SOTO M., GÓMEZ DE SOLER B., VALLVERDÚ J., VAQUERO M., 2014, « Potential siliceous sources during Prehistory: Results of prospecting in the East margin of the Ebro Basin (NE Iberian Peninsula) », Journal of Lithic Studies, vol. 1, n 1, p. 293-318.

SOTO M., GÓMEZ DE SOLER B., VALLVERDÚ J., 2018, « The chert abundance ratio (CAR): a new parameter for interpreting Palaeolithic raw material procurement », Archaeological Anthropological Science, vol. 10, nº 8, p. 2027-2046, doi :10.1007/s12520-017-0516-3. 
SPINAPOLICE E., 2012, « Raw material economy in Salento (Apulia, Italy): new perspectives on Neanderthal mobility patterns », Journal of Archaeological Science, vol. 39, n 3, p. 680-689.

TARRIÑO A., ELORRIETA I., GARCÍA-ROJAS M., 2015, « Flint as raw material in prehistoric times: Cantabrian Mountain and Western Pyrenees data », Quaternary International, $n^{\circ}$ 364, p. 94-108.

THIÉBAUT C., MOURRE V., CHALARD P., COLONGE D., COUDENNEAU A., DESCHAMPS M., SACCO-SONADOR A., 2012, « Lithic technology of the final Mousterian on both sides of the Pyrenees », Quaternary International, $\mathrm{n}^{\circ} 247$, p. 182-198.

TURQ A., 1989, « Exploitation des matières premières lithiques et exploitation du sol : l'exemple du Moustérien entre Dordogne et Lot », Cahiers du Quaternaire, n 13, p. 179-204.

VALLVERDÚ J., GÓMEZ DE SOLER B., VAQUERO M., BISHOFF J.-L., 2012, « The Abric Romaní Site and the Capellades Region ", dans Carbonell E. (dir.), High Resolution archaeology and Neandertal behavior: time and space in level J of Abric Romaní (Capellades, Spain), Dordrecht, Springer (Vertebrate Paleobiology and Paleoanthropology Book Series), p. 1-29.

VAQUERO M. et PASTÓ I., 2001, « The definition of spatial units in Middle Palaeolithic sites: the Herat-related assemblages », Journal of Archaeological Science, $n^{\circ}$ 28, p. 1209-1220.

VAQUERO M., ALLUÉ E., BISCHOFF J.-L., BURJACHS F., VALLVERDÚ J., 2013, « Environmental, depositional and cultural changes in the Upper Pleistocene and Early Holocene: the Cinglera del Capelló sequence (Capellades, Spain) », Quaternaire, vol. 24, n 1, p. 49-64.

VAQUERO M., BARGALLÓ A., CHACóN M. G., ROMAGNOLI F., SAÑUDO P., 2015, « Lithic recycling in a Middle Paleolithic expedient context: evidence from the Abric Romaní (Capellades, Spain) », Quaternary International, $\mathrm{n}^{\circ} 361$, p. 212-228.

VAQUERO M., FERNÁNDEZ-LASO M. C., CHACÓN M. G., ROMAGNOLI F., ROSELL J., SAÑUDO P., 2017, « Moving things: comparing lithic and bone refits from a Middle Paleolithic site », Journal of Anthropological Archaeology, $\mathrm{n}^{\circ}$ 48, p. 262-280.

ZILHĀo J., 2001, « Middle Paleolithic Settlement Patterns in Portugal », dans Conard N. (dir.), Settlement dynamics of the Middle Paleolithic and Middle Stone Age, Tübingen, Kerns Verlag, p. 597-608.

\section{RÉSUMÉS}

Le niveau M et le sous-niveau Oa du site de l'Abric Romaní (Capellades, Barcelona, Espagne), présentent différents types de contextes technologiques. Les chaînes opératoires du niveau M montrent des stratégies expéditives. L'assemblage lithique du sous-niveau Oa est associé à des stratégies hiérarchisées et à des chaînes opératoires Levallois. Le silex est la roche plus utilisée ( $80,8 \%$ pour le niveau M, 91,6\% pour le niveau Oa). Toutes les formations géologiques contenant du silex sont localisées dans un rayon de 30 kilomètres, les plus nombreuses étant les formations évaporitiques des marges de la dépression de l'Èbre. Le type de silex le plus représenté dans les deux niveaux provient d'un gisement situé à environ 16 kilomètres au nord-ouest du site. Ces rayons d'approvisionnements, identiques pour des systèmes techniques aussi différents, nous incitent à proposer l'hypothèse que les choix de matières premières sont majoritairement liés à des facteurs socio-économiques, et non uniquement à des aspects purement technologiques.

Level M and sub-level Oa at Abric Romaní (Capellades, Barcelona, Spain) are showing various types of technological contexts. The chaines opératoires of level $\mathrm{M}$ show expedient strategies. The lithic assemblage of sub-level $\mathrm{Oa}$ is associated to hierarchized strategies and Levallois 
chaines opératoires. Chert is the most used rock (level $\mathrm{M}=80.8 \%$; level $\mathrm{Oa}=91.6 \%$ ). All geological formation containing chert are located in a $30 \mathrm{~km}$ radius, the most numerous being the evaporite formations of the margins of the Ebro depression. The chert type most commonly found in both level is located about $16 \mathrm{~km}$ to the NW of the site. These identical supply distances for such different technological systems encourage us to consider that the raw material choices are mostly connected to socio-economic factors and not solely to technological aspects.

\section{INDEX}

Keywords : chert, raw material

Mots-clés : matière première, mobilité territoriale, silex

Index géographique : Abric Romaní

\section{AUTEURS}

\section{BRUNO GÓMEZ DE SOLER}

Institut Català de Paleoecologia Humana i Evolució Social (IPHES) ; Àrea de Prehistòria, Universitat Rovira i Virgili (URV)

\section{MARÍA GEMA CHACÓN}

Institut Català de Paleoecologia Humana i Evolució Social (IPHES) ; Àrea de Prehistòria, Universitat Rovira i Virgili (URV) ; laboratoire Histoire naturelle de l'homme préhistorique (HNHP, UMR 7194, Muséum national d'histoire naturelle/Université de Perpignan - Via Domitia/ Sorbonne universités/CNRS)

\section{AMELIA BARGALLÓ}

Institute of Archaeology, University College (Londres)

\section{FRANCESCA ROMAGNOLI}

Departamento de Prehistoria y Arqueología, Universidad Autónoma de Madrid

MARÍA SOTO

Department of Anthropology and Archaeology, University of Calgary

\section{JOSEP VALLVERDÚ}

Institut Català de Paleoecologia Humana i Evolució Social (IPHES) ; Àrea de Prehistòria, Universitat Rovira i Virgili (URV)

\section{MANUEL VAQUERO}

Àrea de Prehistòria, Universitat Rovira i Virgili (URV) ; Institut Català de Paleoecologia Humana i Evolució Social (IPHES) 


\section{Paléolithique moyen récent et Paléolithique supérieur initial en contexte pyrénéen : les industries lithiques de la grotte de Gatzarria (Ossas-Suhare, Pyrénées- Atlantiques) et leurs implications régionales}

Late Middle Paleolithic and Early Upper Paleolithic in Pyrenean context: lithic industries from Gatzarria cave (Ossas-Suhare, PyrénéesAtlantiques) and their regional implications

Marianne Deschamps et Damien Flas

1 Le secteur occidental des Pyrénées a souvent été décrit comme un point de passage privilégié reliant la péninsule Ibérique au reste de l'Europe occidentale (Arrizabalaga Valbuena et Ríos Garaizar 2012). Ce secteur s'avère en effet important du fait de sa position au croisement entre Bassin aquitain, Pyrénées, vallée de l'Èbre et cordillère cantabrique. En outre, les ressources minérales y sont nombreuses mais se répartissent de manière inégale sur ce territoire contrasté.

Dans le nord du pays Basque, l'historique régional des recherches concernant le Paléolithique se découpe principalement en deux temps. Les fouilles d'E. Passemard à l'abri Olha 1 et à Isturitz (Passemard 1924, 1936 et 1944) se déroulent au début du Xx siècle. Ses travaux font également écho à ceux en cours simultanément en Cantabrie, au Castillo, à Morín et à El Pendo (Breuil et Obermaier 1914, Obermaier 1924, Vega del Sella 1921). Les fouilles à Isturitz reprennent sous la direction de R. et S. de SaintPérier, de 1928 à 1958. C'est ensuite entre les années 1950 et 1970 que les recherches archéologiques régionales connaissent un regain d'intensité, avec les travaux de 
G. Laplace à Olha II et à Gatzarria (Laplace 1986, Laplace et Saenz de Buruaga 2000 et 2002-2003), mais également ceux de C. Chauchat et C. Thibault sur les gisements de plein air autour de Bayonne, notamment les stations du Basté et de Lestaulan (Chauchat 1968 et 1994, Chauchat et Thibault 1968, Jaubert 1995, Deschamps et al. 2016).

Depuis le début du $\mathrm{xxI}^{\mathrm{e}}$ siècle, on assiste à un nouveau développement de la recherche grâce à plusieurs opérations de terrain et/ou à de nouvelles études concernant le Paléolithique moyen et supérieur (Normand et al. 2007, Renard 2011, Dachary et al. 2010, Deschamps, 2014, Colonge et al. 2015, Deschamps et al. 2016, Ducasse et al. 2017, Pétillon et al. 2017, Langlais et Pétillon 2019).

4 Par ailleurs, la présence de spécificités régionales au sein des industries lithiques du Paléolithique moyen a notamment permis la définition d'un faciès régional, le Vasconien (Bordes 1953), dont l'élément emblématique était la présence de hachereaux. À partir des années 1980, la cohérence du Vasconien est cependant remise en cause par plusieurs auteurs, qui interprètent les hachereaux comme une perduration (Cabrera Valdés 1983) depuis l'Acheuléen dans différents types d'industries du Paléolithique moyen régional (pour un historique du Vasconien, voir Bordes 1953, Cabrera Valdés 1983 et 1984, Rodriguez Asensio et Arrizabalaga 2004, Deschamps et Mourre 2011, Deschamps 2014 et 2017). Pourtant, une révision récente de ces industries a permis d'en préciser les caractéristiques ainsi que la place dans la chronologie du Paléolithique moyen régional (Deschamps 2014 et 2017).

5 La grotte Gatzarria (Ossas-Suhare, Pyrénées-Atlantiques) représente notamment l'un des sites de référence régionaux pour le Paléolithique moyen et supérieur dans la partie occidentale des Pyrénées, en raison de sa séquence stratigraphique livrant des occupations qui documentent plusieurs phases du Paléolithique moyen, ainsi que le passage entre le Paléolithique moyen et plusieurs phases du Paléolithique supérieur ancien. La fouille de cette cavité et les premières études des industries lithiques qui y ont été identifiées ont principalement été menées par G. Laplace et A. Saenz de Buruaga selon les principes de la typologie analytique (Laplace 1957, 1966a, 1966b et 1971, Saenz de Buruaga 1987 et 1991, Laplace et Saenz de Buruaga 2002-2003).

6 Suite au décès de G. Laplace en 2004, les collections issues de ses fouilles ont été léguées au Musée national de préhistoire. Plusieurs nouvelles études se sont alors succédé, concernant la faune, l'industrie en matières dures animales, les industries lithiques et les datations (Tartar 2009, Deschamps 2009 et 2014, Barshay-Szmidt et al. 2012, Ready 2013, Ready et Morin 2013, Eizenberg comm. pers.). Ces révisions des anciennes collections ont permis de proposer de nouvelles interprétations concernant aussi bien la chronostratigraphie que la caractérisation des industries.

7 À partir de l'étude des industries lithiques issues des fouilles de G. Laplace, nous proposons dans cet article de nouvelles interprétations des différentes occupations de la séquence de Gatzarria, ainsi que de nouvelles hypothèses de découpage stratigraphique. La validité de ces hypothèses sera testée dans le cadre d'une nouvelle opération de terrain en cours, qui livrera dans l'avenir des résultats complémentaires.

\section{Présentation du site}

8 La grotte de Gatzarria se situe sur le versant nord de la partie occidentale de la chaîne pyrénéenne, en pays de Soule, au pays Basque. Elle s'ouvre sur le versant nord-est du 
mont Hargagne à une altitude d'environ 270 mètres, au pied du massif des Arbailles, qui possède des sommets entre 800 et 1200 mètres d'altitude (fig. 1).

Fig. 1. - Grotte de Gatzarria (Ossas-Suhare, Pyrénées-Atlantiques) : contexte.
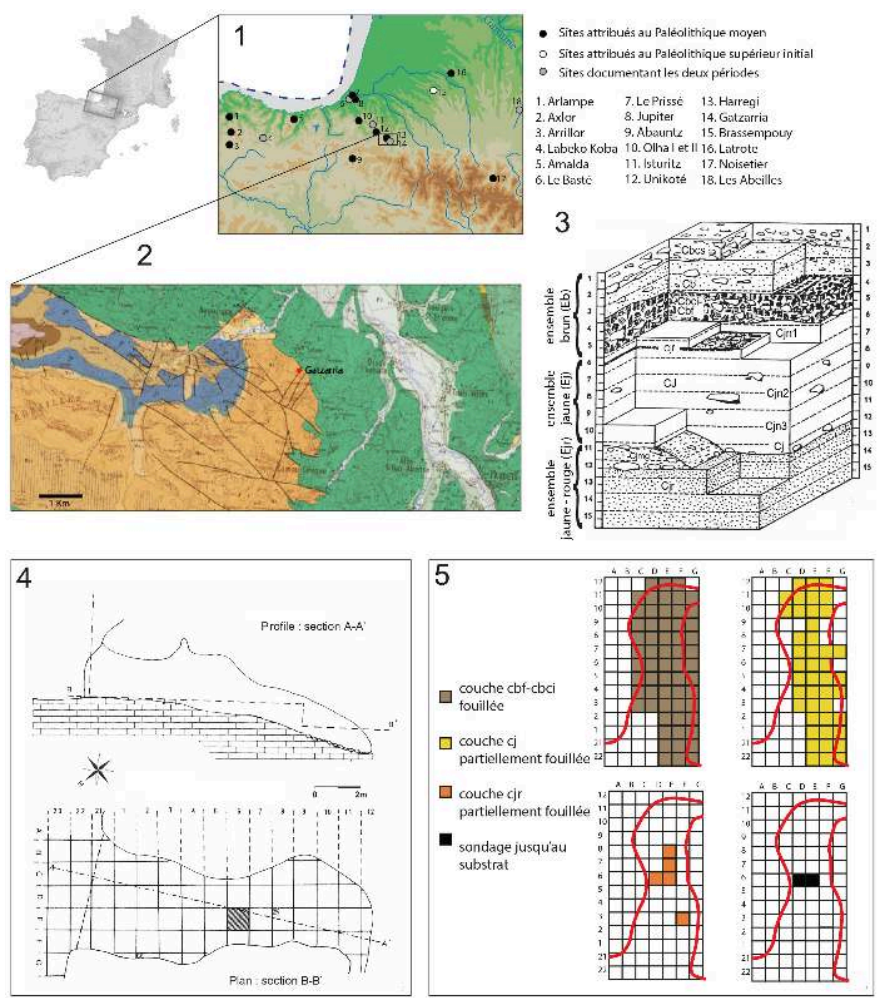

1 : localisation dans le contexte régional des autres sites documentant les phases du Paléolithique et du Paléolithique supérieur présentées dans le texte. $\mathbf{2}$ : localisation de la grotte Gatzarria sur la carte géologique au 1:25 000. $\mathbf{3}$ : stratigraphie théorique. 4 : plan de la grotte. 5 : représentation des différents niveaux fouillés par $\mathrm{G}$. Laplace.

PAO et dessin Marianne Deschamps. 3 : extrait de Laplace 1971. 5 : d'après les archives de fouilles, Musée national de préhistoire.

\section{Historique des recherches}

Si la grotte est connue depuis longtemps, son potentiel archéologique ne fut découvert qu'en 1950. Lors d'une tentative de désobstruction du boyau situé au fond de la cavité, des spéléologues accompagnés de P.Boucher, professeur et archéologue amateur, identifièrent des vestiges paléolithiques. Dès 1951 et jusqu'en 1953, des sondages y furent effectués avec l'aide de G. Laplace et F. Bordes. En 1956, de premières fouilles sont réalisées par Laplace ; interrompues en 1957, elles reprendront de 1960 à 1976.

Laplace fouille presque la totalité de l'intérieur de la cavité pour ce qui correspond aux niveaux du Paléolithique supérieur. En revanche, le Paléolithique moyen ne sera fouillé que partiellement dans des zones de sondage. Seule une zone à gauche, à l'entrée de la cavité, n'a pas du tout été affectée par ses fouilles. Laplace identifie plusieurs niveaux sédimentaires et archéologiques. Des problèmes de différenciation entre certains niveaux archéologiques ainsi que la présence de variations latérales l'amènent finalement à construire une stratigraphie schématique théorique a posteriori (fig. 1.4 ; 
Laplace 1971). Celle-ci comprend trois ensembles stratigraphiques, qui regroupent plusieurs couches archéologiques (tabl. 1). De haut en bas :

-L'ensemble supérieur se compose d'un sédiment argilo-sableux brun incluant un cailloutis cryoclastique. Il comprend un niveau gravettien, un niveau de l'Aurignacien récent, un niveau de l'Aurignacien ancien.

- L'ensemble moyen se caractérise par un sédiment jaune argileux compact, très homogène ; les niveaux archéologiques distingués dans cet ensemble l'ont été uniquement sur la base des changements identifiés dans les industries. Cet ensemble regroupe deux niveaux protoaurignaciens, des indices d'une occupation châtelperronienne, et le premier niveau attribué au Paléolithique moyen.

- Enfin, l'ensemble inférieur se caractérise par des niveaux argilo-sableux à dominante rouge comprenant des concentrations de manganèse assez importantes et variables. Deux niveaux archéologiques s'y regroupent: cjr et cr. Le substrat rocheux est finalement atteint uniquement dans les carrés 6D et 6E.

Tabl. 1. - Grotte de Gatzarria (Ossas-Suhare, Pyrénées-Atlantiques) : synthèse des observations de G. Laplace concernant les niveaux identifiés, leur caractérisation technoculturelle et leur description géologique.

\begin{tabular}{|c|c|c|c|}
\hline $\begin{array}{l}\text { Ensemble } \\
\text { stratigraphique }\end{array}$ & Couche & $\begin{array}{l}\text { Caractérisation } \\
\text { technoculturelle }\end{array}$ & $\begin{array}{l}\text { Description } \\
\text { géologique }\end{array}$ \\
\hline \multirow{4}{*}{ Eb } & $\mathrm{Cbn}-\mathrm{Cbr}$ & & Argile brune compacte humique remaniée, correspondant à un cône d'éboulis cryoclastique \\
\hline & Cbcs & Gravettien & Argile sableuse brune à cailloutis cryoclastique; elle est aussi partiellement remaniée. \\
\hline & $\mathrm{Cb}$ & $\begin{array}{l}\text { Aurignacien } \\
\text { récent }\end{array}$ & Argile sableuse brune emballant quelques éléments cryoclastiques et de rares blocs \\
\hline & Cbci-Cbf & $\begin{array}{l}\text { Aurignacien } \\
\text { ancien }\end{array}$ & $\begin{array}{l}\text { Argile sableuse brune emballant de nombreux éléments cryoclastiques, associée } \\
\qquad a ̀ \text { un niveau de foyers }\end{array}$ \\
\hline \multirow{5}{*}{ Ej } & C jn1 & Proto-aurignacien & $\begin{array}{l}\text { Couche jaune clair, argileuse, grasse, compacte, emballant de petits galets de schiste } \\
\text { décomposés et de rares éléments de calcaire corrodés. Cjn1 s'individualise par une ligne } \\
\text { de foyers ou d'éléments charbonneux diffus. }\end{array}$ \\
\hline & C jn2 & Proto-aurignacien & $\begin{array}{c}\text { Couche jaune clair, argileuse, grasse, compacte, emballant de petits galets de schiste } \\
\text { décomposés et de rares ééments de calcaire corrodés. Cjn2 s'individualise uniquement } \\
\text { par sa composante archéologique. }\end{array}$ \\
\hline & & & \\
\hline & $\mathrm{Cjn} 3$ & Châtelperronien & $\begin{array}{c}\text { Couche jaune clair, argileuse, grasse, compacte, emballant de petits galets de schiste } \\
\text { décomposés et de rares éléments de calcaire corrodés. Cjn3 s'índividualise uniquement } \\
\text { par sa composante archéologique. }\end{array}$ \\
\hline & $\mathrm{Cj}$ & $\begin{array}{l}\text { Moustérien } \\
\text { Levallois }\end{array}$ & $\begin{array}{c}\text { Couche jaune clair, argileuse, grasse, compacte, emballant de petits galets de schiste } \\
\text { décomposés et de rares éléments de calcaire corrodés. Cj s'individualise par sa composante } \\
\text { archéologique ainsi que par des lentilles localisées de manganèse. }\end{array}$ \\
\hline \multirow{3}{*}{ Ejr } & Cjmg & $\begin{array}{l}\text { Moustérien } \\
\text { indéterminé }\end{array}$ & $\begin{array}{l}\text { Sédiment concrétionné par endroit et comportant de nombreux éléments ferromanganiques. } \\
\text { Cette couche possède des limites très irrégulières et n'est pas présente dans tous les carrés. }\end{array}$ \\
\hline & $\mathrm{Cjr}$ & $\begin{array}{l}\text { Moustérien à } \\
\text { hachereaux }\end{array}$ & $\begin{array}{l}\text { Argile sableuse avec de petits galets de schistes souvent rubéfiés. Cette couche est à dominante } \\
\text { jaune ou rouge. A sa base, la couche Cjr est localement marquée (dans le fond de la cavité) } \\
\text { par une alternance desous-niveaux compacts et d'autres plus sableux, nommée Cjrs. }\end{array}$ \\
\hline & $\mathrm{Cr}$ & $\begin{array}{l}\text { Moustérien } \\
\text { indéterminé }\end{array}$ & $\begin{array}{l}\text { Argile rouge comportant des concentrations de manganèse localisées } \\
\text { et des concentrations osseuses }\end{array}$ \\
\hline
\end{tabular}

\section{Les vestiges fauniques}

11 Les vestiges fauniques issus de ces fouilles ont fait l'objet d'une étude paléontologique par F. Lavaud dans le cadre de sa thèse (Lavaud 1980). D'après cette étude, la faune est dominée par le cerf, suivi par le cheval et les bovidés, à l'exception des couches $\mathrm{Cb}$ et Cbf, où les bovidés sont mieux représentés (tabl.2). Quelques restes d'isard et de bouquetin ont aussi été identifiés; cependant ils restent rares tout au long de la séquence, excepté dans l'Aurignacien de Cbf. Leur présence est importante car, dans certains sites d'altitude, l'hypothèse d'une chasse spécialisée des espèces montagnardes 
comme l'isard ou le bouquetin a parfois été développée (Allard 1993, Altuna 1990). Toutefois, cela ne paraît pas être le cas ici, étant donné que ces espèces restent peu représentées.

La présence de carnivores en faible proportion est également signalée dans les niveaux inférieurs. En revanche, leur présence est beaucoup plus importante dans les niveaux attribuables à l'Aurignacien récent et ancien $\mathrm{Cb}$ et $\mathrm{Cbf}$, sans que leur rôle ni leur statut soient encore précisés.

Tabl. 2. - Grotte de Gatzarria (Ossas-Suhare, Pyrénées-Atlantiques) : représentation des taxons zoologiques dans les différents niveaux.

\begin{tabular}{|c|c|c|c|c|c|c|c|c|}
\hline & $\begin{array}{c}\text { Couche } \\
\mathrm{Cb}\end{array}$ & $\begin{array}{l}\text { Couche } \\
\text { Cbf }\end{array}$ & $\begin{array}{l}\text { Couche } \\
\text { Cjn1 }\end{array}$ & $\begin{array}{l}\text { Couche } \\
\text { Cjn2 }\end{array}$ & $\begin{array}{l}\text { Couche } \\
\text { Cjn3 }\end{array}$ & $\begin{array}{c}\text { Couche } \\
\text { Cj }\end{array}$ & $\begin{array}{c}\text { Couche } \\
\mathrm{Cjr}\end{array}$ & $\begin{array}{c}\text { Couche } \\
\mathrm{Cr}\end{array}$ \\
\hline \multicolumn{9}{|l|}{ HERBIVORES } \\
\hline Hot Cervus & 15 & 16 & $\cdot$ & - & 26 & 2 & 16 & 9 \\
\hline No Equus & 7 & 7 & & 3 & & 2 & 3 & 1 \\
\hline Bos/Bison & 10 & 32 & 1 & 3 & 1 & 1 & 1 & 2 \\
\hline Ringifer tarandus & 1 & 2 & - & - & - & - & - & - \\
\hline In Capreolus & - & - & - & - & - & 1 & - & - \\
\hline Ithe Rupicapra & 4 & 12 & - & 3 & 4 & - & 2 & 4 \\
\hline An Capraibex & 1 & 1 & 1 & - & - & & & - \\
\hline$s^{5}$ Megaceros sp. & 1 & 3 & - & - & - & - & - & - \\
\hline fins Mammuthus primigenius & - & - & - & - & 2 & - & - & - \\
\hline B Coelodonta antiq. & - & 1 & & & & & - & \\
\hline \multicolumn{9}{|l|}{ CARNIVORES } \\
\hline Tyes Canisfupus lupus & 7 & 11 & - & - & - & - & - & - \\
\hline Vulpes vulpes & 32 & 85 & & 4 & - & & 1 & - \\
\hline Alopexlagopus & & 1 & - & & & & & - \\
\hline Crocuta spelaea & 3 & 4 & & & 1 & & 1 & \\
\hline Ursus spelaeus & 5 & - & - & 2 & 2 & - & - & - \\
\hline Meles meles & 2 & - & - & - & - & - & - & - \\
\hline 3 Mustela nivalis & - & 1 & - & - & - & - & - & - \\
\hline
\end{tabular}

D’après Lavaud 1980.

\section{Les industries lithiques}

Laplace décrit une succession de niveaux archéologiques du début du Paléolithique supérieur et de la fin du Paléolithique moyen, qu'il considère comme homogènes et qui s'intègrent dans ses théories d'évolution transitionnelle depuis le substrat moustérien jusqu'aux industries leptolithiques aurignaciennes.

14 Au sommet de la séquence (couche Cbcs), il définit d'abord un niveau gravettien qui n'a été reconnu que dans un sondage, à l'entrée de la cavité. On peut cependant souligner la présence de burins de Noailles au sein de ce modeste ensemble gravettien, le rapportant au faciès noaillien, bien attesté sur le versant nord des Pyrénées (Foucher et al. 2008, Simonet 2010 et 2017).

Il identifie ensuite quatre niveaux, qu'il rapporte à différents stades évolutifs du technocomplexe aurignacien. Le matériel de la couche $\mathrm{Cb}$ est ainsi attribué à «l'Aurignacien évolué ». Sous-jacente, la couche Cbf/Cbci correspond à un Aurignacien 
ancien, notamment marqué par la présence de pointe en bois de cervidé de type « sagaie à base fendue ».

Ensuite, au sein de l'épaisse couche $\mathrm{Cj}$, il distingue un premier niveau (Cjn1) correspondant à un " Proto-Aurignacien à grattoirs carénés " présentant un caractère transitionnel entre les deux niveaux qui l'entourent (Cjn2 sous-jacent et Cbf/Cbci susjacent), puisqu'il présente à la fois une importante production lamellaire, habituelle au Proto-Aurignacien, et de nombreux grattoirs carénés comme dans l'Aurignacien ancien.

L'ensemble Cjn2 est décrit comme un "Proto-Aurignacien à pièces à dos marginal ", correspondant bien aux productions de lamelles Dufour connues lors de cette phase. Enfin, Cjn3 est un niveau complexe à appréhender en raison des caractéristiques technologiques hétérogènes de l'ensemble. G. Laplace (1966) proposait d'y voir un "Castelperronien évolué à caractère régressif " en raison de la présence conjointe d'éléments leptolithiques (pointes de Châtelperron, sur lames légères) et d'éléments rappelant le Moustérien à denticulés. Il n'excluait pas, cependant, que ces différentes composantes soient issues d'un mélange de plusieurs industries, mais sans retenir finalement cette hypothèse.

Concernant les niveaux attribués au Paléolithique moyen, Laplace et Saenz de Buruaga envisagent l'idée d'une "croissante complexité diachronique " (Laplace et Saenz de Buruaga 2002-2003). D'après eux, le spectre typologique identifié en Cjr connaît une diversification en $\mathrm{Cj}$, ainsi qu'une tendance aux formes leptolithiques qui se développe en Cj. Cependant, la possibilité d'un mélange stratigraphique existe entre les couches Cjn et le premier niveau moustérien Cj ; Laplace écrit d'ailleurs en 2002 : «Ce niveau est inséparablement associé à la partie inférieure de Cjn3», qu'il attribue au Châtelperronien.

En-dessous, l'industrie de Cjr se caractérise par des "racloirs carénoïdes», des denticulés nombreux, ainsi que par la présence de hachereaux en roches pyrénéennes.

Enfin, l'industrie du niveau $\mathrm{Cr}$, fouillé seulement sur 2 mètres carrés, ne comprend que trop peu d'outils pour effectuer une analyse typologique.

Finalement, Laplace et Saenz de Buruaga établissent une interprétation des dynamiques évolutives de la séquence moustérienne. Ils proposent un regroupement en «faciès morphotechniques " et distinguent un faciès «à hachereaux et à racloirs carénoïdes » qui correspond à Cjr, ainsi qu'un faciès "à racloirs plats et types leptolithiques » qui correspond à $\mathrm{Cj}$.

\section{Anciennes collections, nouvelles études}

\section{Les datations}

Depuis les fouilles Laplace, Gatzarria a fait l'objet de plusieurs tentatives récentes de datation, principalement en vue d'établir la chronologie des niveaux Cjn2 et Cbci-Cbf au sein de la séquence aurignacienne (Barshay-Szmidt et al. 2012, Ready et Morin 2013).

Les résultats vers 34-35000 BP (non calibré) pour la couche Cbci-Cbf sont tout à fait cohérents pour un ensemble de l'Aurignacien ancien. De même, la datation à ca. 36300 BP pour Cjn2 s'accorde bien à la chronologie connue du Proto-Aurignacien (Banks et al. 2013). Cependant, la seconde date pour ce niveau (vers 33800 BP) apparaît 
incohérente par rapport aux autres datations et laisse entrevoir la possibilité de mélanges plus importants que ce que l'on supposait dans cette zone.

Concernant le Paléolithique moyen, quatre datations ${ }^{14} \mathrm{C}$ du niveau $\mathrm{Cj}$, le plus récent, le placent au MIS 3, entre 44 et $47 \mathrm{ka}$ BP (Ready et Morin 2013). En revanche, les résultats des datations ${ }^{14} \mathrm{C}$ pour le niveau Cjr n'ont donné que des âges minimum de $>47400$ et $>50$ 300. Ainsi, les dépôts de base de Gatzarria sont antérieurs à la limite du champ d'application de la méthode ${ }^{14} \mathrm{C}$.

25 À la suite de nouveaux travaux menés en 2018, de nouvelles datations radiométriques viendront compléter celles qui sont déjà publiées (Deschamps et Flas 2018).

\section{Les industries attribuées au Paléolithique moyen}

\section{Nouvelles hypothèses de découpage stratigraphique de la séquence moustérienne}

À l'exception du premier niveau moustérien $\left(\mathrm{C}_{\mathrm{j}}\right)$, le reste de la séquence $\mathrm{du}$ Paléolithique moyen n'a été fouillé que sur une surface limitée, un carré dans l'entrée et trois dans le fond de la cavité, ce qui permet difficilement d'avoir une vision d'ensemble de ces niveaux.

27 L'aspect taphonomique des vestiges est différent entre l'entrée et le fond de la grotte (Barshay-Szmidt et al. 2012, Deschamps 2014). L'aspect émoussé, voire roulé des vestiges est très fréquent dans le fond de la cavité, alors qu'il est rare pour le matériel issu du carré 3F. Cela indique la présence de phénomènes postdépositionnels puissants dans le fond. Il faut préciser que cette différence de préservation du matériel est perceptible pour tous les niveaux archéologiques dans des proportions variables, et s'observe à partir de la bande 5 jusqu'au fond de la grotte.

28 Au delà de ces aspects taphonomiques, la composition typologique au sein de Cjr entre les carrés $3 \mathrm{~F}$ et $6 / 7-\mathrm{D} / \mathrm{E}$ semblait aussi relativement différente. Elle était notamment marquée par la présence, dans les carrés du fond de la grotte, de racloirs à retouche scalariforme se rapprochant du type Quina, déjà identifiés par Laplace sous le nom de «racloirs carénoïdes». Cela nous a incités à échantillonner d'abord seulement le carré 3F pour l'étude de son industrie. Cette concentration de vestiges de type Quina dans le fond de la grotte pouvait s'expliquer de deux manières : soit une répartition spatiale particulière des zones d'activités au sein de la couche Cjr, soit la succession de plusieurs niveaux archéologiques incluant du Quina, alors partiellement mélangés.

Afin d'évaluer ces deux hypothèses, nous avons réalisé des projections des éléments les plus discriminants des couches de l'ensemble inférieur (fig. 2). Les outils coordonnés ont été répartis en grands groupes typologiques. Leurs projections ont mis en évidence une distribution verticale différente de ces éléments. Si les racloirs latéraux ou transversaux, considérés comme ubiquistes, se répartissent tout au long de la séquence, les racloirs Quina et demi-Quina sont, à une exception près, concentrés à la base de la stratigraphie, alors que les denticulés et les hachereaux se répartissent principalement dans la partie supérieure de Cjr. La limite entre les deux ensembles reste diffuse, mais les projections transversales comme sagittales permettent d'identifier la même césure typologique à une profondeur d'environ 170-175 cm. 
Fig. 2. - Grotte de Gatzarria (Ossas-Suhare, Pyrénées-Atlantiques) : industrie lithique des couches moustériennes.

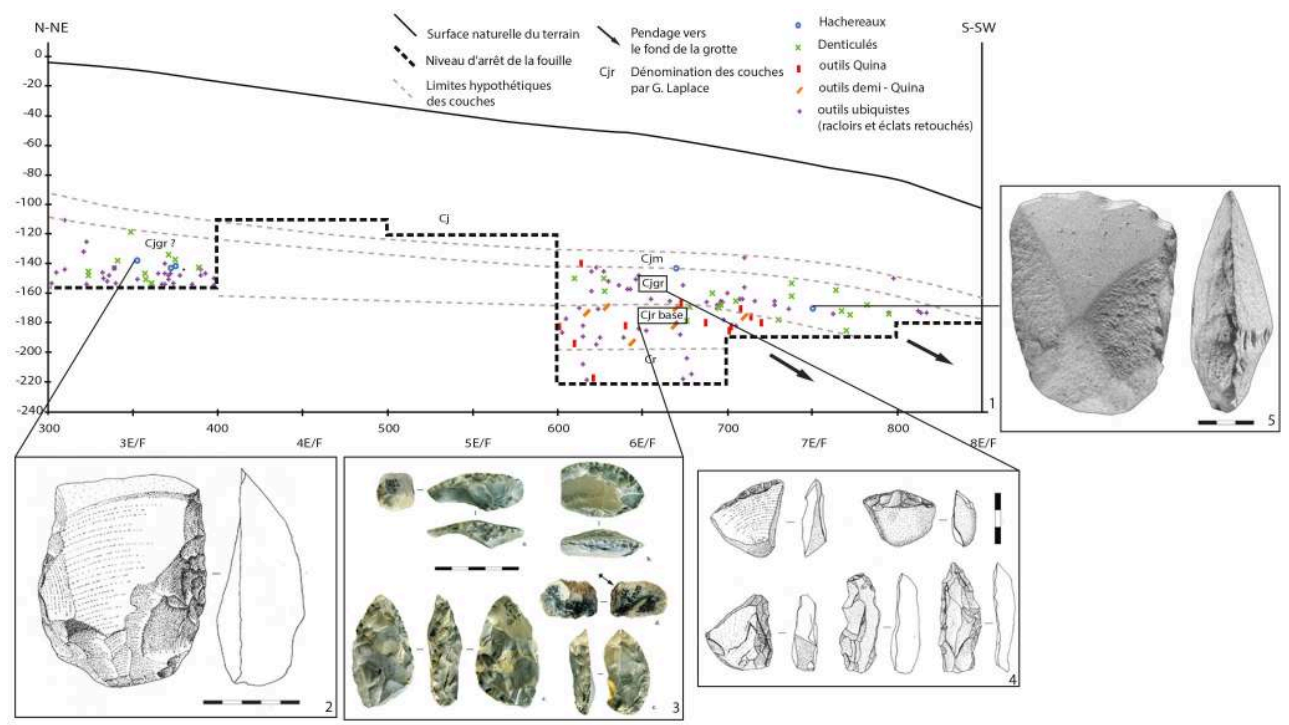

1 : projection sagittale des outils retouchés des couches moustériennes et hypothèse de séparation des niveaux archéologiques. 2 Eт 5 : hachereaux en ophite provenant du niveau Cjgr. $\mathbf{3}$ : racloirs à retouches scalariforme provenant du niveau Cjr-base. $\mathbf{4}$ : racloirs et denticulés provenant du niveau Cjgr.

PAO et dessins Marianne Deschamps. Photos Philippe Jugie (c) MNP Les Eyzies, dist. RMNX.

L'étude des carnets de fouille nous a permis de retrouver la mention d'une couche nommée « Cjgr » (couche jaune gris rouge), définie uniquement dans les carrés du fond. Celle-ci occupe la partie supérieure de la couche $\mathrm{Cjr}$, et ses altitudes correspondent à la césure typologique observée sur les projections. Cette couche Cjgr se caractérise par une texture proche de Cjr, mais incluant de petits dépôts argileux grisâtres et des taches de manganèse.

Mentionnée dans les carnets de fouille, la dénomination Cjgr n'a pas été conservée dans les stratigraphies théoriques publiées postérieurement, car elle a été considérée comme un phénomène local affectant Cjr. Ainsi, l'ensemble de ces industries a été regroupé au sein de l'ensemble Cjr. Au regard de ces projections, ce niveau paraît cependant constituer un véritable niveau archéologique et non un niveau de sédimentation de faciès local.

Dans les carrés du fond de la grotte, la couche Cjr semble donc correspondre en réalité à deux niveaux archéologiques distincts: un premier niveau caractérisé par l'abondance de racloirs à retouche scalariforme (que nous nommerons "Cjr-base»), auquel succède un niveau riche en racloirs ubiquistes et denticulés associés à des hachereaux (Cjgr). Ainsi, la couche nommée « Cjr » dans le carré 3F correspond, tant du point de vue du pendage général des couches que du point de vue typotechnologique, au niveau Cjgr du fond de la grotte.

\section{Le niveau Cjr-base}

Notre nouvelle hypothèse de travail consiste donc à penser que le niveau Cjr défini par G. Laplace contient en réalité deux niveaux archéologiques, dont le plus ancien, « Cjrbase ", se caractérise notamment par la présence de racloirs à retouche scalariforme de type Quina, de limaces et de racloirs bifaciaux (fig.3). Le pourcentage d'outils à 
retouche scalariforme est supérieur à $20 \%$ et l'outillage en silex prédomine sur celui en quartzite (Deschamps 2014 .

Les nucléus sont principalement de type Discoïde de modalité unifaciale et plus rarement bipyramidale. Lorsque le support a pu être identifié, on constate que le débitage est le plus souvent mis en œuvre sur éclat. Quatre nucléus en quartzite s'organisent en deux surfaces sécantes depuis lesquelles sont détachées des séquences unipolaires, et qui pourraient correspondre à un débitage Quina (sensu Bourguignon 1997). Deux nucléus en silex correspondent à un débitage Levallois. Au sein de ce niveau, les méthodes de débitage mises en œuvre indiquent donc une coexistence de différentes chaînes opératoires, comme cela a été proposé pour les niveaux rattachés au Moustérien de type Quina en Cantabrie (Carrión et al. 2008). Ce niveau n'ayant été fouillé que dans le fond de la grotte, il reste encore difficile d'évaluer avec certitude le degré d'intégrité de cette industrie.

Alors que les nucléus en silex sont rares $(n=4)$, les outils retouchés sont principalement réalisés dans cette matière $(48 \%)$; ils sont suivis par les outils en quartzite (42\%). Un important fractionnement spatiotemporel des chaînes opératoires est ainsi perceptible en ce qui concerne le silex. L'outillage retouché est riche pour ce niveau ( $23 \%$ de l'ensemble des vestiges) et clairement dominé par les racloirs. Le silex est la matière première la plus utilisée dans l'outillage, ce qui signe une importante différence avec le niveau Cjgr, où les outils en silex ne représentent que $39 \%$ du total des outils retouchés alors que ceux en quartzite atteignent $56 \%$. 
Fig. 3. - Grotte de Gatzarria (Ossas-Suhare, Pyrénées-Atlantiques) : industrie lithique du niveau Cjrbase.

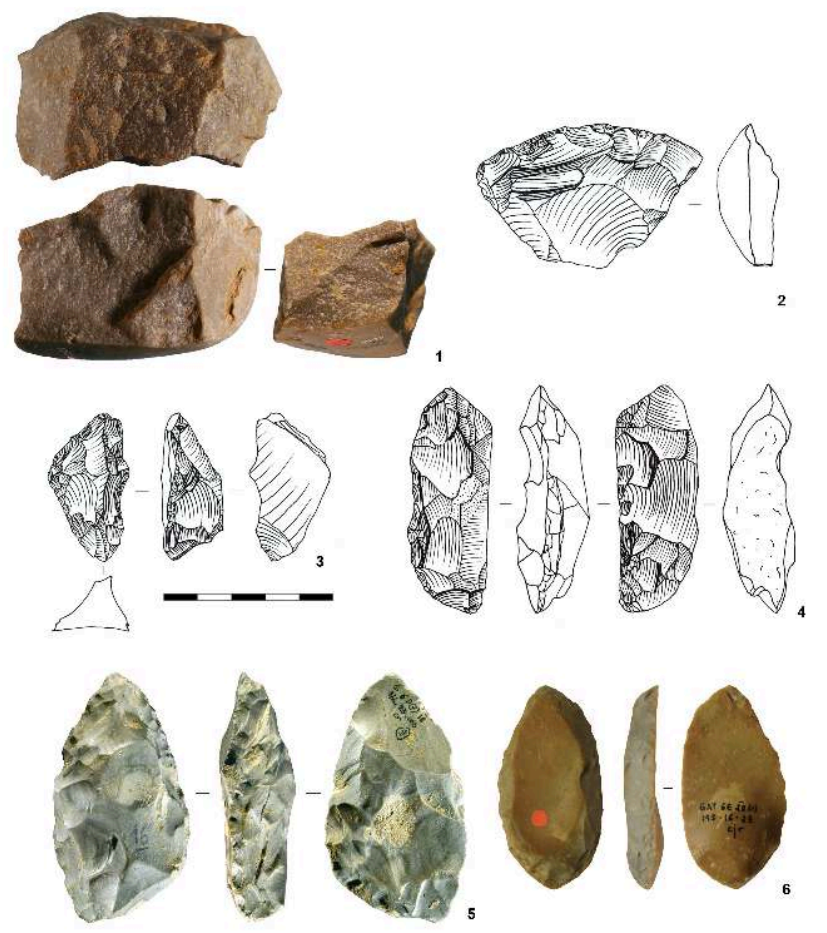

1 : nucléus à exploitations successives unipolaires de surfaces sécantes. $\mathbf{2}$ : racloir transversal à retouche scalariforme. $\mathbf{3}$ : limace. 4 ET $\mathbf{5}$ : racloirs bifaciaux planoconvexes. $\mathbf{6}$ : racloir simple latéral en silex de Chalosse.

Photos, dessins et DAO Marianne Deschamps, excepté n 5, clichés Philippe Jugie @ MNP Les Eyzies, dist. RMNX.

\section{Le niveau Cjgr}

Une fois la partie basale de Cjr séparée, la partie supérieure de la couche présente alors les mêmes caractéristiques typotechnologiques que l'industrie identifiée dans le carré 3F (nommé « Cjr » lors des fouilles Laplace).

Ce niveau, désormais renommé "Cjgr», se caractérise par un débitage Discoïde unifacial dominant sur quartzite (Deschamps 2014 et 2017). Les supports de nucléus sont majoritairement des éclats corticaux. La surface néocorticale est ainsi utilisée directement comme surface de plan de frappe.

Le débitage en silex est beaucoup moins bien représenté. De rares nucléus qui pourraient se rattacher au concept Levallois y sont représentés et ont été menés à un haut degré d'exhaustion. En revanche, le silex est bien présent au sein de l'outillage retouché, composé principalement de racloirs ( $40 \%)$ suivis par des denticulés (22\%). Ces derniers sont mieux représentés que dans l'industrie du niveau sous-jacent. De rares racloirs à retouche de type Quina ou demi-Quina sont également présents dans ce niveau; ils représentent $2 \%$ des outils. Le rapport dans l'utilisation des matières premières est inversé par rapport à Cjr-base, puisque les outils sont ici majoritairement confectionnés sur quartzite. 
Ce niveau se caractérise également par la présence de hachereaux en ophite (Claud et al. 2015, Deschamps 2017). Bien qu'ils soient en nombre limité $(n=5)$, ils représentent une caractéristique importante de ce niveau, puisqu'ils sont absents des niveaux qui l'encadrent (fig. 4).

Fig. 4. - Grotte de Gatzarria (Ossas-Suhare, Pyrénées-Atlantiques) : industrie lithique du niveau Cjgr.

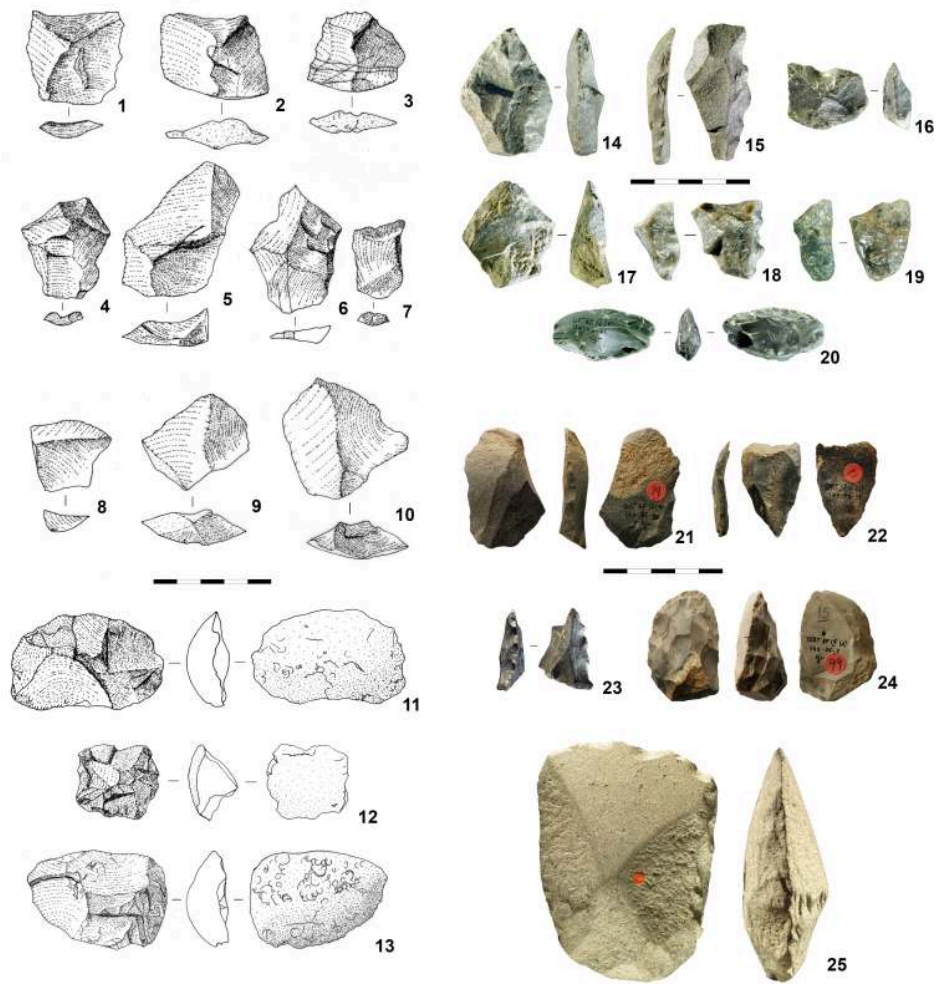

1 À 10 : éclats en quartzite issus d'un débitage discoïde. 11 À 13 : nucléus en quartzite. 14, 17, 19 Eт 20 racloirs en roches pyrénéennes. 15 Eт 18 : denticulés en quartzite. 16 : encoche en quartzite. 21, 22 ET $\mathbf{2 4}$ : racloirs en silex. $\mathbf{2 3}$ : denticulé en silex. $\mathbf{2 5}$ : hachereau en ophite.

Photos MNP Les Eyzies, dist. RMNX, clichés Philippe Jugie ; dessins et DAO Marianne Deschamps.

\section{Le niveau $\mathrm{Cj}$}

Enfin, le niveau $\mathrm{Cj}$, qui représente le dernier niveau attribué au Paléolithique moyen, est caractérisé par une industrie Levallois en quartzite différente des niveaux sousjacents caractérisés par un débitage Discoïde (Deschamps 2014). Les racloirs y sont aussi largement majoritaires (53\%), alors que les denticulés représentent $16 \%$ et que les hachereaux y sont absents (Deschamps et Flas 2018 ; fig. 5).

Comme cela a déjà été décrit, l'industrie de la couche $C j$ présente dans sa partie supérieure des intrusions de vestiges attribués au Châtelperronien et au ProtoAurignacien. Afin de définir les caractéristiques de l'industrie attribuée au Paléolithique moyen, nous avons choisi d'exclure la partie supérieure du niveau en fonction de la limite d'intrusion de ces éléments, en suivant ainsi les limites définies par une précédente étude de ce niveau (Ready 2013). On peut considérer qu'au-dessus de cette limite, l'intégrité des industries attribuables au Paléolithique moyen et aux phases initiales du Paléolithique supérieur peut être remise en question. La 
caractérisation des différentes composantes au sein de cet ensemble est en cours, dans le but d'identifier si la composante moustérienne est cohérente avec l'industrie du niveau Cj décrite précédemment, ou bien s'il s'agit d'une ultime occupation attribuée au Paléolithique moyen, à la charnière avec le Paléolithique supérieur.

Fig. 5. - Grotte de Gatzarria (Ossas-Suhare, Pyrénées-Atlantiques) : industrie lithique du niveau Cj.

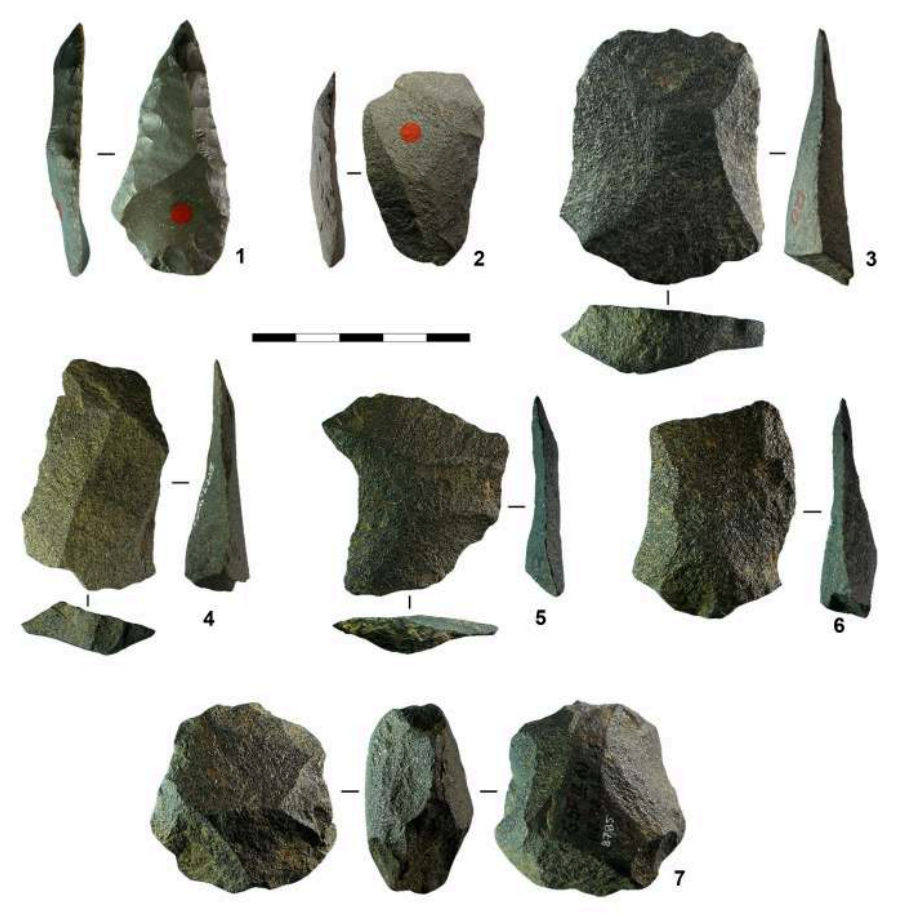

1 : pointe moustérienne en silex. 2 : racloir en quartzite. 3 À $\mathbf{6}$ : éclats Levallois en quartzite. $\mathbf{7}$ : nucléus Levallois en quartzite.

Photos, dessins et DAO Marianne Deschamps, excepté nos 1 et 2 : MNP Les Eyzies, dist. RMNX,

clichés Philippe Jugie.

\section{Les industries attribuées au Paléolithique supérieur}

\section{Cjn3 : des traces châtelperroniennes}

Dans la partie inférieure de la couche $\mathrm{Cj}$, G. Laplace avait défini un ensemble Cjn3 attribué à un « Castelperronien évolué à caractère régressif ». Cjn3 apparaît aujourd'hui comme un ensemble contenant principalement une industrie moustérienne, dont la séparation avec l'ensemble sus-jacent attribué au Proto-Aurignacien n'est par ailleurs pas évidente, en raison de l'absence de dépôt stérile ou de différences sédimentaires. Il est donc difficile, voire impossible, de définir un ensemble lithique homogène attribuable au Châtelperronien en dehors des fossiles directeurs classiques de ce complexe.

En effet, les fouilles Laplace ont bien livré un minimum de 11 pointes de Châtelperron (fig. 6.1). Celles des carrés de l'entrée de la grotte se trouvent toutes à la base de $\mathrm{Cj}$, sous la limite de répartition du matériel attribué au Proto-Aurignacien (Cjn2), à l'exception d'un fragment distal de pointe de Châtelperron provenant de cet ensemble Cjn2, mais 
qui se raccorde avec un fragment mésioproximal provenant de Cjn3. Ce raccord laisse penser que la géométrie des concentrations de matériel a été mal comprise. Il ne s'agit pas du seul remontage montrant une certaine amplitude altitudinale au sein du matériel de Cj (remontage entre Cjn1 et Cjn2 ; Barshay-Szmidt et al. 2012). Cela pourrait correspondre à la morphologie de l'assise calcaire, qui présente, à l'entrée de la grotte, un pendage transversal très marqué à partir de la paroi est, phénomène qui n'avait pas été reconnu lors des fouilles Laplace (Deschamps et Flas 2018).

Fig. 6. - Grotte de Gatzarria (Ossas-Suhare, Pyrénées-Atlantiques) : industries lithiques des niveaux Cjn2 et Cjn3.

\section{1/}
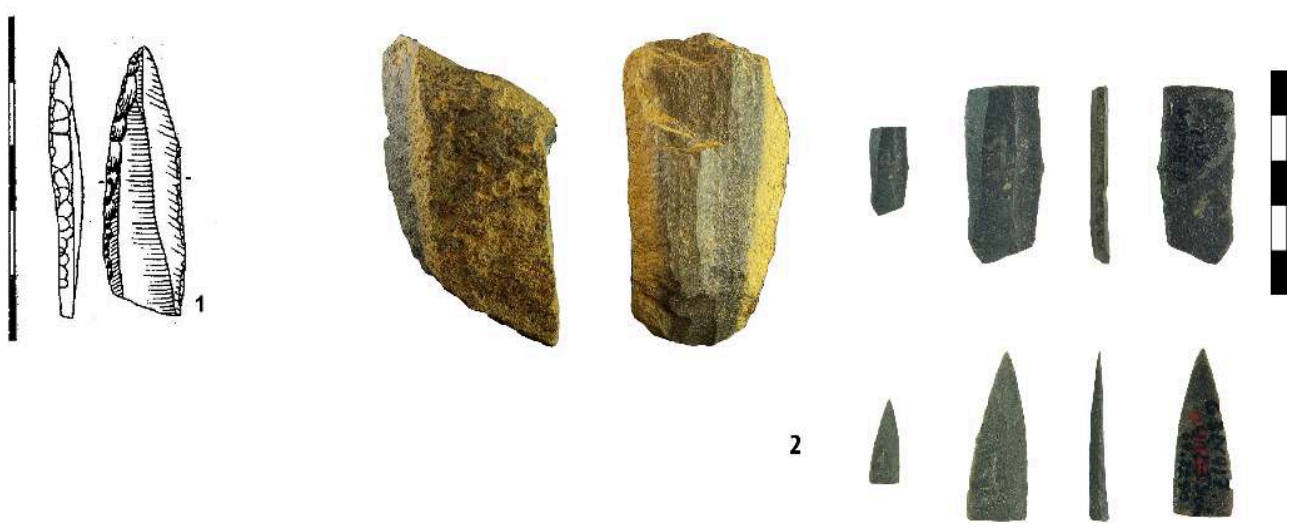

1 : pointe de Châtelperron du niveau Cjn3. 2 : nucléus et fragments de lamelles Dufour de l'ensemble Cjn2.

PAO Marianne Deschamps. 1 : extrait de Saenz de Buruaga 1987. 2 : extrait de Bachellerie et al. 2011.

\section{Cjn2 : un ensemble proto-aurignacien}

Comme on l'a déjà souligné, les trois ensembles définis par Laplace au sein de $\mathrm{Cj}$ semblent être basés sur des délimitations parfois arbitraires; ils paraissent aberrants pour les dépôts de l'intérieur de la grotte où les pendages, notamment, ont conduit à des mélanges importants de matériel d'époques différentes.

Cependant, si l'on se penche sur les carrés de l'entrée de la grotte, il est possible de reconnaître en Cjn2 un ensemble proto-aurignacien cohérent d'un point de vue typotechnologique et taphonomique (Barshay-Szmidt et al. 2012). Cet ensemble, ne dépassant pas 1800 pièces lithiques, est marqué par l'importance de la production lamellaire, essentiellement à partir de petits blocs et de tranches de plaquettes, production probablement menée à la percussion tendre organique, caractérisée par des talons lisses et abrasés (fig. 6.2). Plus de $70 \%$ de l'outillage correspond d'ailleurs à des lamelles retouchées, dont la moitié (37 sur 74) sont des lamelles Dufour. Le reste de l'outillage comprend notamment des grattoirs. La matière première majoritairement utilisée est le silex du flysch local, en particulier la variante la plus proche du site (silex d'Iholdy). Il est à souligner que le matériel lithique proto-aurignacien de Cjn2 est très rarement patiné. 


\section{Cjn1 : « Proto-aurignacien à grattoirs carénés »... ou Aurignacien ancien ?} dimensions, notamment utilisée pour l'aménagement de grattoirs et de lames retouchées (fig. 7.1-2). La production lamellaire est, elle, principalement réalisée sur des nucléus de type "grattoir caréné » $(\mathrm{n}=9$; tabl. 3 ; fig. 7.3) livrant des lamelles de profil courbe et de dimensions plus réduites $(<30 \mathrm{~mm})$ que celles du Proto-Aurignacien de Cjn2 (fig. 7.3-4). Certaines de ces petites lamelles courbes sont transformées en lamelles Dufour, mais elles sont rares $(n=3)$. D'autres éléments typologiques, comme l'importance des pièces esquillées, ou techniques, comme la préparation des talons de certaines lames, rapprochent également le matériel de Cjn1 de celui de l'Aurignacien ancien de la couche sus-jacente (Cbci-Cbf) et le distinguent du Proto-Aurignacien de Cjn2.

Fig. 7. - Grotte de Gatzarria (Ossas-Suhare, Pyrénées-Atlantiques) : industries du niveau Cjn 1.
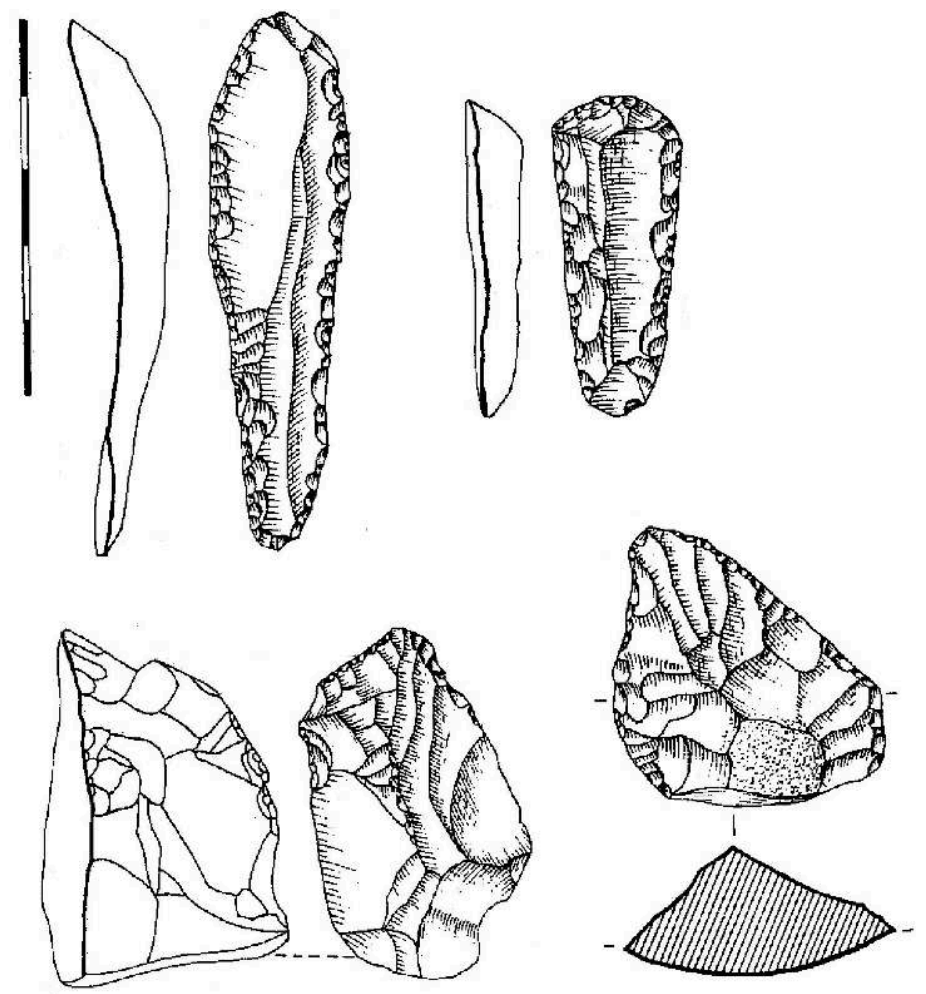

$\mathbf{1}$ : lame retouchée. $\mathbf{2}$ : grattoir sur lame retouchée. $\mathbf{3}$ : nucléus à lamelles de type « grattoir caréné ». 4 nucléus à lamelles de type « grattoir caréné à front rétréci ».

Extrait de Saenz de Buruaga 1991.

Les seuls éléments d'allure véritablement proto-aurignacienne classés en Cjn1 sont deux grandes lamelles Dufour de profil rectiligne, mais elles proviennent en fait de la limite de répartition entre le matériel classé en Cjn1 et celui classé en Cjn2 (carrés 3F et 
$3 \mathrm{G}, \mathrm{z}=65-70 \mathrm{~cm}$ ). Ces pièces pourraient donc tout à fait appartenir à l'ensemble protoaurignacien et s'être retrouvées indexées en Cjn1 de manière aléatoire.

D'ailleurs, les matières premières et l'état de conservation du matériel (patiné) de Cjn1 confirment cette similitude avec l'industrie aurignacienne de $\mathrm{Cbci-Cbf}$ et s'écartent de ceux décrits pour le Proto-Aurignacien de Cjn2. Tandis que le silex d'Iholdy, non patiné, dominait largement en Cjn2, le matériel de Cjn1 est constitué d'autres silex du flysch, comme le type de Bidache, et des silex encore plus lointains, comme ceux de Chalosse et de Salies-de-Béarn.

Par contre, dans le registre des matières dures animales, on peut signaler que Cjn1 n'a livré aucune pointe de sagaie à base fendue, mais plutôt des "sagaies plates", contrairement à Cbci-Cbf (Tartar 2009).

\section{Cbci-Cbf : Aurignacien ancien}

51 Le matériel lithique de la base de l'entité $\mathrm{Cb}$, la couche dénommée Cbci ou Cbf, est attribuable à l'Aurignacien ancien. L'observation des nucléus lamellaires et de leur production pour les carrés de l'entrée (bandes 1 à 4, C à G) le confirment (tabl. 3 ; Bordes 2005). Sur les 87 nucléus étudiés, 49 correspondent au type " grattoir caréné » et 26 à des grattoirs carénés dont la surface de débitage lamellaire est limitée par des retouches latérales (appelé ici "grattoir caréné à front rétréci » : Flas et al. 2013), sans aller jusqu'au dégagement d'un museau. Les grattoirs à museau ou à épaulement sont nettement plus rares $(\mathrm{n}=11)$.

Tabl. 3. - Grotte de Gatzarria (Ossas-Suhare, Pyrénées-Atlantiques), zone de l'entrée, bandes 21 et 1 à 4 : décompte des types de nucléus à lamelles pour les trois ensembles aurignaciens.

\begin{tabular}{|c|c|c|c|c|c|c|c|}
\hline & $\begin{array}{l}\text { Grattoir } \\
\text { caréné }\end{array}$ & $\begin{array}{l}\text { Grattoir } \\
\text { caréné à front } \\
\text { rétréci }\end{array}$ & $\begin{array}{c}\text { Grattoir à } \\
\text { museau }\end{array}$ & $\begin{array}{l}\text { Burin } \\
\text { caréné }\end{array}$ & $\begin{array}{l}\text { Burin } \\
\text { busqué }\end{array}$ & $\begin{array}{l}\text { Nucléus à } \\
\text { grattoir } \\
\text { caminade }\end{array}$ & $\begin{array}{c}\text { Burin } \\
\text { nucléiforme }\end{array}$ \\
\hline Couche $\mathrm{Cb}$ & 19 & 13 & 17 & 2 & 1 & 1 & 2 \\
\hline Couche Cbci-Cbf & 49 & 26 & 11 & 0 & 0 & 0 & 1 \\
\hline Couche Cjn1 & 9 & 13 & 0 & 0 & 0 & 0 & 1 \\
\hline
\end{tabular}

Comme en Cjn1, cette production lamellaire est accompagnée d'un débitage laminaire de grandes dimensions dont les supports, majoritairement importés sur le site, sont parfois retouchés latéralement ou transformés en grattoirs; les pièces esquillées sont également abondantes. Le matériel est très souvent patiné et les matières premières lointaines dominent (Bidache, Chalosse, Salies-de-Béarn).

\section{$\mathrm{Cb}:$ un Aurignacien récent peu abondant}

$53 \mathrm{Au}$ sommet de cette séquence aurignacienne, le matériel de la couche $\mathrm{Cb}$ a été attribué par G. Laplace à l'Aurignacien récent. Mais cette attribution se basait peut-être plus sur l'industrie osseuse que sur le matériel lithique : la présence de sagaies losangiques, et non plus de sagaies à base fendue, comme dans la couche sous-jacente Cbci-Cbf, conduisait alors à cette attribution chronoculturelle.

Si l'on examine les modalités de production lamellaire à partir de pièces carénées, les éléments des phases récentes de l'Aurignacien sont en effet présents, mais peu nombreux. Dans la catégorie des nucléus lamellaires de modalité "grattoir», les grattoirs à museaux et à épaulement sont mieux représentés $(n=17)$ que dans la couche 
sous-jacente, mais les grattoirs carénés, parfois à front étroit, sont toujours bien attestés. Les modalités de production lamellaire caractéristiques des phases les plus récentes, burins carénés et surtout burins busqués, restent très rares (tabl. 3 et fig. 8). Notons que parmi les grattoirs carénés, une pièce présente une morphologie de surface de débitage et de format d'enlèvements lamellaires qui pourrait tout à fait correspondre à un nucléus à support de grattoir Caminade, un type de pièces qui pourrait caractériser une phase de l'Aurignacien récent d'Aquitaine, jusqu'à présent très peu connu aux abords des Pyrénées (Morala et al. 2005, Anderson et al. 2016, Caux 2017). On peut d'ailleurs signaler qu'un fragment de grattoir Caminade a été identifié lors des fouilles 2017 à Gatzarria, mais dans la partie supérieure de la couche $\mathrm{Cj}$, ce qui pose question quant à la mise en place des dépôts et aux possibilités de remaniement du matériel.

Il est à noter qu'au moins un autre burin busqué provient des fouilles Laplace ; mais découvert dans le carré $21 \mathrm{~F}$, il a été classé comme appartenant à la couche $\mathrm{Cj}$, probablement en raison de la difficulté d'identification des couches dans certaines zones.

En résumé, le matériel de la couche $\mathrm{Cb}$ présente des traits qui correspondent en effet à des phases plus récentes de l'Aurignacien, mais dans un ensemble (palimpseste ?) englobant également du matériel identique à celui du niveau de l'Aurignacien ancien sous-jacent.

Fig. 8. - Grotte de Gatzarria (Ossas-Suhare, Pyrénées-Atlantiques) : éléments de l'ensemble Cb rattachables à l'Aurignacien récent.
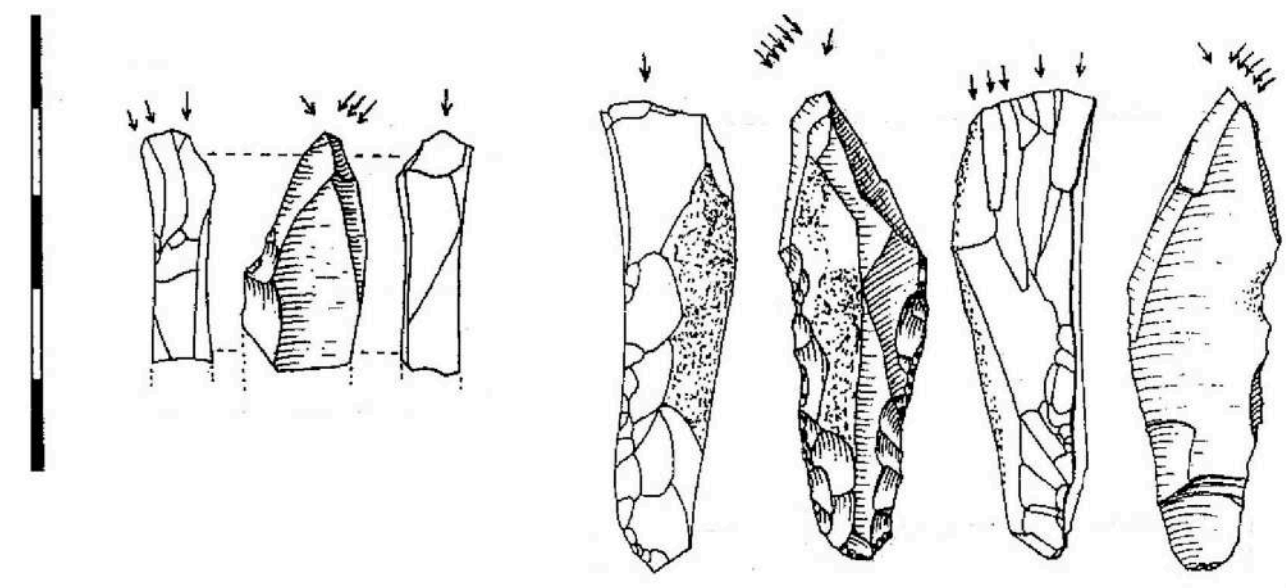

$\mathbf{1}$ : nucléus à lamelles de type «burin busqué ». $\mathbf{2}$ : nucléus à lamelles de type «burin caréné ».

Extrait de Saenz de Buruaga 1991.

\section{Implications régionales}

\section{Le Paléolithique moyen régional}

Cette nouvelle interprétation de l'archéo-séquence de Gatzarria remet en question l'interprétation initiale par G. Laplace de l'industrie de Cjr comme un ensemble «à racloirs carénoïdes et hachereaux » (Laplace et Saenz de Buruaga 2002-2003). Il s'agit en réalité d'un ensemble principalement caractérisé par des racloirs à retouche 
scalariforme, auquel succède un niveau comprenant une technologie Discoïde, composée de racloirs simples latéraux classiques, de denticulés et de hachereaux. Bien que demeurent des incertitudes concernant la stratigraphie de Gatzarria, notamment en ce qui concerne les interfaces entre les différents ensembles sédimentaires, deux ensembles archéologiques sont bien discernables à la base de la séquence. Ils se distinguent $\mathrm{du}$ point de vue stratigraphique, typotechnologique et également économique: importation de silex plus intense dans le niveau Cjr-base, gestion de l'outillage différente (Deschamps 2014).

Remettre en perspective les industries du Paléolithique moyen de Gatzarria dans leur cadre régional reste délicat, car la chronologie et la succession des technocomplexes dans la région pyrénéenne et cantabrique restent des questions complexes et débattues.

Sur la base de datations radiocarbone, certains auteurs ont notamment défendu l'hypothèse d'une chronologie postérieure à 50000 ans pour le Moustérien de type Quina dans cette région (Carrión Santafé et Baena 2002, Baena et al. 2005 et 2006, Ríos Garaizar 2012 et 2017). Il serait ainsi plus récent que dans le nord de l'Aquitaine, où il est attribué à la transition MIS 3/4, entre 55 et $60 \mathrm{ka} \mathrm{BP}$, sur la base de datations OSL (Guérin et al. 2012 et 2017, Jacobs et al. 2016, Frouin et al. 2017), à l'exception de Jonzac (Richter et al. 2013). La valeur des datations ${ }^{14} \mathrm{C}$ pour les niveaux archéologiques de Gatzarria si anciens ne doit cependant être considérée que comme un âge minimum.

Une tentative récente de construction d'une archéo-séquence théorique à l'échelle régionale place le Vasconien comme antérieur au Quina (Ríos Garaizar 2017). Pourtant, à Gatzarria, si l'hypothèse d'un niveau attribué au Quina se confirme, il apparaît comme plus ancien que le niveau comportant des hachereaux. Il s'avère également qu'aucun des gisements mobilisés dans cet article et venant soutenir cette hypothèse ne présente la succession de ces deux technocomplexes au sein d'une même séquence stratigraphique : cela renforce ainsi l'intérêt particulier de la séquence de Gatzarria pour ces questions. Un prélèvement de sédiment a été effectué en 2017 afin de tester le potentiel de datation par OSL du quartz de Gatzarria. Les premiers tests effectués semblent indiquer une composition du signal d'OSL adaptée à la datation (Guérin, comm. pers.) ; en conséquence, une campagne de datation du site par luminescence est prévue dans un avenir proche. La poursuite de ces recherches à Gatzarria pourra ainsi apporter prochainement de nouvelles réflexions concernant la chronologie régionale du Paléolithique moyen. La caractérisation des technocomplexes du Paléolithique moyen au sein de la séquence de Gatzarria permettra d'établir un lien pyrénéen avec les deux régions qui l'encadrent et qui sont mieux documentées pour ces périodes, le nord du Bassin aquitain et la Cantabrie.

\section{Le Paléolithique supérieur}

61 En ce qui concerne les complexes du début du Paléolithique supérieur, plusieurs facteurs viennent limiter les conclusions et comparaisons : difficulté de séparer des ensembles au sein de la couche $\mathrm{Cj}$; fouilles en planimétrie de nappes de vestiges et de couches sédimentaires subissant l'effet de pendages, non seulement vers l'intérieur de la grotte mais aussi latéralement (morphologie du substratum); nature et mise en place des dépôts mal comprise lors des fouilles Laplace. 
62 Ainsi, si le matériel châtelperronien pourrait évoquer une halte de chasse et correspondre à d'autres observations semblant indiquer la prévalence de ce mode d'occupation à cette période dans la zone franco-cantabrique pour les sites en grotte et sous abri (Bachellerie et al. 2011), on ne peut avoir aucune certitude à cet égard en l'absence d'une étude détaillée permettant d'exclure une occupation plus pérenne et moins spécialisée.

63 L'ensemble proto-aurignacien se délimite, lui, plus clairement, du moins pour quelques mètres carrés à l'entrée de la grotte. Et même s'il s'agit d'un ensemble assez restreint, il constitue néanmoins un jalon important dans notre connaissance de l'occupation des Pyrénées lors de cette phase, en parallèle à l'ensemble proto-aurignacien d'Isturitz, certes plus important (Normand et al. 2007), et en écho à de rares autres ensembles secondaires (Les Abeilles, Brassempouy; Bachellerie et al. 2011). Plus que la richesse et la préservation des ensembles, c'est la séquence d'occupation depuis le ProtoAurignacien jusqu'à l'Aurignacien ancien et récent, en passant par un niveau intermédiaire, transitionnel, qui fait le grand intérêt de Gatzarria. À cet égard, la révision de l'ensemble $\mathrm{Cjn} 1$ apporte une note légèrement décevante. Si cet ensemble confirme, une fois de plus, que l'Aurignacien ancien se développe bien toujours postérieurement au Proto-Aurignacien, on ne peut, cependant, y voir un ensemble «transitionnel » qui présenterait une mosaïque de traits techniques relevant des deux phases. Du point de vue de l'industrie lithique, il s'agit bien d'un ensemble relevant pleinement de l'Aurignacien ancien, et dont les rares éléments proto-aurignaciens sont probablement issus de $\mathrm{Cjn} 2$, en raison de la difficulté de séparer des phases d'occupation au sein de la couche $\mathrm{Cj}$. Il n'est pas impossible que ce petit ensemble Cjn1 dérive, en fait, de l'Aurignacien ancien de Cbci-Cbf, par infiltration de matériel entre les blocs d'éboulis au sommet de la couche $\mathrm{Cj}$.

En effet, l'ensemble sédimentaire sus-jacent $\mathrm{Cbci-Cbf}$, et même $\mathrm{Cb}$, se caractérise par l'importance des marqueurs de l'Aurignacien ancien, qui est certainement la période d'occupation principale, aux activités les plus variées - l'industrie osseuse, la parure, les restes de colorants, les galets et les restes de faune consommée y étant également abondants (Tartar 2009) - et sans doute la mieux préservée. Au sommet de cet Aurignacien ancien, des traces plus fugaces relevant des phases de l'Aurignacien récent (grattoir à museau, burin caréné, mais aussi burin busqué, voire production de grattoirs Caminade) montrent la présence dans les Pyrénées occidentales des tendances techniques particulières bien décrites dans le nord de l'Aquitaine (Michel 2010), même si elles ne semblent pas constituer ici des niveaux bien individualisés.

65 Le Gravettien, lui, découvert sur la terrasse, a été trop peu exploré lors des fouilles Laplace pour en tirer une quelconque conclusion. Mais il reste ici un potentiel prometteur à évaluer et à replacer dans son contexte régional, comme l'a montré la récente reprise des travaux à Gatzarria (Simonet 2018).

\section{Conclusion}

Finalement, la révision des collections issues des fouilles de G. Laplace a amené plusieurs nouvelles hypothèses concernant le découpage stratigraphique de la séquence, l'intégrité des différents niveaux archéologiques ainsi que leur signification en termes d'évolution diachronique comme au niveau des implications régionales. Cette approche confirme que Gatzarria constitue clairement l'une des séquences 
régionales clés pour les problématiques de recherche liées au Paléolithique moyen et au Paléolithique supérieur initial et ancien. Les nouvelles hypothèses de travail développées dans cet article sont désormais testées dans le cadre d'une reprise d'opération de terrain depuis l'été 2017 par les auteurs de cette contribution.

La révision des collections anciennes associée à cette nouvelle opération pourra ainsi apporter de nouveaux arguments permettant d'éclaircir la chronologie régionale des technocomplexes du Paléolithique moyen récent, ainsi que de faire le lien avec les deux régions qui l'entourent et qui sont mieux documentées pour ces périodes, le nord de l'Aquitaine et la Cantabrie. Cela permettra également de contribuer à la réflexion concernant le statut du Châtelperronien dans cette séquence, et plus largement au sein des sites du sud-ouest de la France. Par ailleurs, la remise en question de l'attribution du niveau Cjn1 au Proto-Aurignacien et une attribution à l'Aurignacien ancien permettent de réfléchir à la nature de la distinction de ces deux phases. Enfin, certains traits techniques de l'Aurignacien récent permettent de tracer les relations à longue distance, en particulier avec le nord de l'Aquitaine, lors de la phase finale de ce complexe.

\section{BIBLIOGRAPHIE}

ALLARD M., 1993, «Fréchet-Aure, grotte du Noisetier », dans Bilan scientifique 1992, Toulouse, Service régional de l'archéologie Midi-Pyrénées, p. 113-114.

ALtUNA J., 1990, « Caza y alimentación procedente de Macromamíferos durante el Paleolítico de Amalda », dans Altuna J., Baldeon A., Mariezkurrena K. (dir.), La cueva de Amalda (Zestoa, Pais Vasco), ocupaciones paleolíticas y postpaleolíticas, San Sebastián, Fundación José Miguel de Barandiaran/Eusko Ikaskuntza, p. 149-192.

ANDERSON L., CHESNAUX L., RUÉ M., PicAVet R., FERnANDes P., MORAla A., CAUX S., TAllet P., CAVERne J.-B., KAWALEK E., 2016, « Regards croisés sur la station aurignacienne de Brignol (Villeneuve-surLot, Lot-et-Garonne, France) : approches taphonomique, pétroarchéologique, technoéconomique et technofonctionnelle de l'industrie lithique », Paleo, $\mathrm{n}^{\circ} 27$, p. 11-42.

ARRIZABALAGA VALBUENA A. et Ríos GARAiZAR J., 2012, « The first human occupation of the Basque crossroads ", Journal of World Prehistory, $\mathrm{n}^{\circ} 25$, p. 157-181.

BACHELLERIE F., BON F., DESCHAMPS M., EIZENBERG L., HENRY-GAMBIER D., MOURRE V., NORMAND C., PELEGRIN J., PRIMAULT J., SCANDIUZZI R., THIÉBAUT C., 2011, « La signature archéologique de l'activité de chasse appliquée à la comparaison des industries moustériennes, châtelperroniennes et aurignaciennes des Pyrénées : nature des équipements et fonctions des sites ", dans Bon F., Costamagno S., Valdeyron N. (dir.), Haltes de chasse en Préhistoire : quelles réalités archéologiques? Actes du colloque international (13-15 mai 2009), université Toulouse II - Le Mirail, Toulouse, Presses universitaires du Midi (P@lethnologie, 3), p. 131-168.

BAENA J., CARRION E., RUIZ B., ELLWOOd B., SESÉ C., YRAVEDRA J., JORDÀ J., UZQUIANO OlLERO P., VELAZQUeZ R., MANZANO I., SANCHEZ-MARCO A., HERNANDEZ F., 2005, « Paleoecología y comportamiento humano durante en la comarca de Liébana: la secuencia de Esquilleu (Occidente de Cantabria, España) », 
dans Montes Barquín R. et Lasheras J. (dir.), Neandertalos cantábricos: estado de la cuestión, Santander, Museo nacional y centro de investigación de Altamira, p. 461-487.

BAENA J., CARRIÓN SANTAFÉ E., VELAZQUEZ R., 2006, « Tradición y coyuntura: claves sobre la variabilidad occidental a partir de la cueva del Esquilleu », dans Cabrera Valdés V., Bernaldo de Quirós F., Maíllo Fernández J.-M. (dir.), En el centenario de la cueva de el Castillo: El ocaso de los Neandertales, [s. 1.], UNED, p. 249-267.

BARSHAY-SZMIDT C., EIZENBERG L., DESCHAMPS M., 2012, « Radiocarbon (AMS) dating the classic Aurignacian, Proto-Aurignacian and Vasconian Mousterian at Gatzarria cave (PyrénéesAtlantiques, France) », Paleo, n 23, p. 11-38.

BORDES F., 1953, « Essai de classification des industries “moustériennes” ", Bulletin de la Société préhistorique française, $\mathrm{n}^{\circ}$ 50, p. 457-466.

BORDES J.-G., 2005, « La séquence aurignacienne du Nord de l'Aquitaine : variabilité des productions lamellaires à Caminade-Est, Roc-de-Combe, Le Piage et Corbiac-vignoble II », dans Le Brun-Ricalens F., Bordes J.-G., Bon F. (dir.), Productions lamellaires attribuées à l'Aurignacien : chaînes opératoires et perspectives technoculturelles. Actes du XIV congrès UISPP, Liège, 2-8 septembre 2001, Luxembourg, Musée national d'histoire et d'art (ArchéoLogiques, 1), p. 123-154.

BREUIL H. et OBERMAIER H., 1914, « Travaux en Espagne », L'Anthropologie, nº 25, p. 233-253.

CABRERA VALDÉS V., 1983, « Notas sobre el Musteriense cantábrico: el "Vasconiense” », dans Homenaje al Prof. Martín Almagro Basch, Madrid, Ministerio de Cultura, p. 131-141.

CABRERA VALDÉs V., 1984, El yacimiento de la cueva del Castillo (Puente Viesgo, Santander), Santander , Bibliotheca Praehistorica Hispana.

CARRIÓN SANTAFÉ E. et BAENA J., 2002, « La producción Quina del nivel XI de la cueva de Esquilleu: una gestión especializada de la producción », Trabajos de Prehistoria, nº 60, p. 35-52.

CARRIÓN SANTAFÉ E., BAENA J., CONDE C., CUARTERO F., ROCA M., 2008, « Variabilidad tecnológica en el musteriense de Cantabria », Treball's d'Arqueología, nº 14, p. 279-318.

CAUX S., 2017, «Étude typo-technologique et pétro-archéologique des grattoirs Caminade : première synthèse d'un outil caractéristique de l'Aurignacien récent du sud-ouest de la France », Bulletin de la Société préhistorique française, vol. 114, nº 2, p. 237-256.

CHAUсHAт C., 1968, «Les industries préhistoriques de la région de Bayonne, du Périgordien ancien à l'Asturien ", thèse, Pessac, université Bordeaux I.

CHAUCHAT C., 1994, « La station préhistorique de Lestaulan, quartier de Maignon, à Bayonne (Pyrénées-Atlantiques) », Muñibe, $n^{\circ}$ 46, p. 3-22.

CHAUCHAT C. et THiBAUlt C., 1968, « La station de plein air du Basté, à Saint-Pierre d'Irube (BassesPyrénées) : géologie, étude archéologique préliminaire », Bulletin de la Société préhistorique française, vol. $75, \mathrm{n}^{\circ} 10$, p. 314-326.

CLAUd É., DESCHAMPS M., COLONGE D., MOURRE V., THIÉBAUT C., 2015, « Experimental and functional analysis of late Middle Paleolithic cleavers in southwestern Europe (France and Spain) », Journal of Archaeological Science, $n^{\circ}$ 62, p. 105-127.

Colonge D., Claud É., Deschamps M., FouRloubey C., heRnANDEZ M., SElLAMi F., ANDERSON L., BusSeUil N., DEBENHAM N., GARON H., O'FARELL M., 2015, « Preliminary results from New Palaeolithic open-air sites near Bayonne (southwestern France) », Quaternary International, $\mathrm{n}^{\circ}$ 364, p. 109-125. 
DACHARY M., PLASSARD F., MERLET J.-C., BONNET-JACQUEMENT P., CHAUVIÈRE F.-X., 2014, « L'Azilien des Pyrénées occidentales : vers une révision de l'attribution chronoculturelle des séries archéologiques ", dans Jaubert J., Fourment N., Depaepe P. (dir.), Transitions, ruptures et continuité en Préhistoire: actes du XXVII Congrès préhistorique de France, Bordeaux-Les Eyzies 31 mai-5 juin 2010, vol. 1, Évolution des techniques, comportements funéraires, Néolithique ancien, Paris, Société préhistorique française (Mémoires de la Société préhistorique française, 2), p. 487-503.

DELPORTE H., 1974, « Le Moustérien d'Isturitz d'après la collection Passemard (Musée des antiquités nationales) », Zephyrus, $\mathrm{n}^{\circ} 25, \mathrm{p} .17-43$.

DESCHAMPS M., 2009, « Le Vasconien : révision de sa signification à partir des industries lithiques d'Olha I et II, d'Isturitz et de Gatzarria », Paleo, n² 21, p. 103-126.

DESCHAMPS M., 2014, « La diversité culturelle au Paléolithique moyen récent : le Vasconien et sa signification au sein des faciès moustériens ", thèse de doctorat, Toulouse, université Toulouse II - Le Mirail.

DESCHAMPS M., 2017, « Late Middle Palaeolithic assemblages with flake cleavers in the western Pyrenees: the Vasconian reconsidered », Quaternary International, $n^{\circ} 433$, p. 33-49.

DESCHAMPS M. et FLAS D. (dir.), 2018, « La grotte Gatzarria à Ossas-Suhare (Pyrénées-Atlantiques) », dans Rapport annuel d'opération programmée, Bordeaux, Service régional de l'archéologie NouvelleAquitaine, p. 127.

DESCHAMPS M. et MOURRE V., 2011, « Le Vasconien, un demi-siècle après sa définition par François Bordes ", dans Delpech F. et Jaubert J. (dir.), François Bordes et la Préhistoire : actes du $134^{e}$ Congrès national des sociétés historiques et scientifiques, Bordeaux, 22-24 avril 2009, Paris, Éditions du CTHS (Documents préhistoriques, 29), p. 269-279.

Deschamps M., ClaRK A.-E., ClAud É., Colonge D., HERnANDEZ M., NORMAND C., 2016, « Approche technoéconomique et fonctionnelle des occupations de plein air du Paléolithique moyen récent autour de Bayonne (Pyrénées-Atlantiques) », Bulletin de la Société préhistorique française, $\mathrm{n}^{\circ} 113$, p. 659-689.

DUCASSE S., RENARD C., COSTAMAGNO S., PÉTILLON J.-M., FOUCHER P., SAN JUAN-FOUCHER C., CAUX S., 2017, «Les Pyrénées au cours du Dernier Maximum Glaciaire : un no man's land badegoulien? Nouvelles données sur l'occupation du piémont pyrénéen à partir du réexamen des industries solutréennes de l'abri des Harpons (Lespugue, Haute-Garonne) », Bulletin de la Société préhistorique française, vol. 114, $\mathrm{n}^{\circ} 2$, p. 257-294.

FLAS D., TARTAR É., BORDES J.-G., LE BRUN-RICALENS F., ZWYNS N., 2013, « New looks on the Aurignacian from Spy: lithic assemblage, osseous artefacts and chronocultural sequence », dans Rougier H. et Semal P. (dir.), Spy cave: 125 years of multidisciplinary research at the Betche aux Rotches (Jemeppe-surSambre, Province of Namur, Belgium), vol. 1 : The Spy Cave context, Bruxelles, Société royale belge d'anthropologie et de préhistoire (Anthropologica et Praehistorica, 123), p. 231-256.

Foucher P., SAN JUAN C., SACCHI D., ARRizABAlaga A., 2008, « Le Gravettien des Pyrénées », dans Rigaud J.-P. (dir.), Le Gravettien : entités régionales d'une paléoculture européenne. Actes de la table ronde, Les Eyzies, juillet 2004, Les Eyzies-de-Tayac, Musée national de préhistoire (Paleo, $\mathrm{n}^{\circ}$ spécial 20), p. 99-124.

fROUIN M., LAHAYE C., MERCIER N., GUiBERT P., COUChOUd I., TEXIER J.-P., ROYER A., COSTAMAGNo S., BEAUVAL C., BOURGUIGNON L., 2017, « Chronologie du site moustérien de type Quina des Pradelles (Marillac-le-Franc, Charente, France) », Paleo, n² 28, p. 117-136. 
GUÉRIN G., DISCAMPS E., LAHAYE C., MERCIER N., GUIBERT P., TURQ A., DIBBLE H. L., MCPHERRON S. P., SANDGATHE D., GOLDBERG P., 2012, « Multi-method (TL and OSL), multi-material (quartz and flint) dating of the Mousterian site of Roc de Marsal (Dordogne, France): correlating Neanderthal occupations with the climatic variability of MIS 5-3 », Journal of Archaeological Science, $\mathrm{n}^{\circ} 39$, p. 3071-3084.

GUÉRIN G., FROUIN M., TUQUOI J., THOMSEN K. J., GOLDBERG P., ALDEIAS V., LAHAYE C., MERCIER N., GUIBERT P., JAIN M., 2017, « The complementarity of luminescence dating methods illustrated on the Mousterian sequence of the Roc de Marsal: A series of reindeer-dominated, Quina Mousterian layers dated to MIS 3 », Quaternary International, $n^{\circ} 433$, p. 102-115.

JACOBS Z., JANKOWSKI N. R., DiBble H. L., GOLDBERG P., MCPHERRON S. J., SANDGATHE D., SORESSI M., 2016, "The age of three Middle Palaeolithic sites: Single-grain optically stimulated luminescence chronologies for Pech de l'Azé I, II and IV in France ", Journal of Human Evolution, nº 95, p. 80-103.

JAUBERT J., 1995, « Datations numériques des gisements des Pyrénées centrales : Ariège, HauteGaronne (zone pyrénéenne) et Hautes-Pyrénées ", Bulletin de la Société préhistorique de l'Ariège, $n^{\circ}$ 50, p. 291-301.

LANGLAIS M. et PÉTILLON J.-M., 2019, « Les Pyrénées, une frontière pré-historiographique pour le Magdalénien ? Réflexions à partir du Magdalénien moyen récent de la grotte Tastet (SainteColome, Pyrénées-Atlantiques) », dans Deschamps M., Costamagno S., Milcent P.-Y., Pétillon J.-M., Renard C., Valdeyron N. (dir.), La conquête de la montagne : des premières occupations humaines à l'anthropisation du milieu. Actes du $142^{e}$ Congrès national des sociétés historiques et scientifiques, 24-28 avril 2017, Paris, Éditions du CTHS.

LAPLACE G., 1957, « Typologie analytique : application d'une nouvelle méthode d'étude des formes et des structures aux industries à lames et lamelles ", Quaternaria, $n^{\circ}$ 4, p. 133-164.

LAPLACE G., 1966a, Recherches sur l'origine et l'évolution des complexes leptolithiques, Rome, École française de Rome (Mélanges d'archéologie et d'histoire, suppl. 4).

LAPLACE G., 1966b, « Les niveaux castelperronien, protoaurignaciens et aurignaciens de la grotte Gatzarria à Suhare en pays Basque (fouilles 1961-1963) », Quartär, nº 17, p. 117-140.

LAPLACE G., 1971, « De l'application des coordonnées cartésiennes à la fouille stratigraphique », Munibe, $\mathrm{n}^{\circ} 2-3$, p. 223-236.

LAPLACE G., 1986, «À propos des gisements du pays Basque », Bulletin de la Société préhistorique française, $\mathrm{n}^{\circ} 83$, p. 106-112.

LAPLACE G. et SAENZ DE BURUAGA A., 2000, « Application de la typologie analytique et structurale à l'étude de l'outillage moustéroïde de l'abri Olha 2 à Cambo (Kanbo) en pays Basque ", Paleo, $\mathrm{n}^{\circ} 12$, p. 261-324.

LAPLACE G. et SAENZ DE BURUAGA A., 2002-2003, « Typologie analytique et structurale des complexes du Moustérien de la grotte de Gatzarria (Ossas-Suhare, pays Basque) et de leurs relations avec ceux de l'abri Olha 2 (Cambo, pays Basque) ", Pyrenae, $\mathrm{n}^{\circ}$ 33-34, p. 81-163.

LAVAUD F., 1980, « Les faunes paléolithiques du Würm II et III dans le sud-ouest et le centre-ouest de la France ", thèse de doctorat, Poitiers, université de Poitiers.

MICHEL A., 2010, « L'Aurignacien récent (post-ancien) dans le sud-ouest de la France : variabilité des productions lithiques. Révision taphonomiques et techno-économiques des sites de Caminade-Est, abri Pataud, Roc-de-Combe, Le Flageolet I, La Ferrassie et Combemenue », thèse de doctorat, université Bordeaux I. 
MORALA A., LENOIR M., TURQ A., 2005, « Production et utilisation de supports normalisés laminolamellaires dans les chaînes opératoires des grattoirs Caminade du site Pigeonnier à Gensac (Gironde, France) », dans Le Brun-Ricalens F., Bordes J.-G., Bon F. (dir.), Productions lamellaires attribuées à l'Aurignacien : chaînes opératoires et perspectives technoculturelles, actes du $14^{e}$ congrès UISPP (Liège, 2001), Luxembourg, Musée national d'histoire et d'art (ArchéoLogiques, 1), p. 257-271.

NORMAND C., BEAUnE S. A. de, COSTAMAgno S., DIOT M.-F., HENRY-GAMBIER D., GOUTAS N., LAROULANDiE V., LENOBLE A., O’FARRELl M., RENDU W., RÍOS GARAIZAR J., SCHWAB C., TARRIÑO VINAGRE A., TEXIER J.-P., WHITE R., 2007, « Nouvelles données sur la séquence aurignacienne de la grotte d'Isturitz (communes d'Isturitz et de Saint-Martin-d'Arberoue, Pyrénées-Atlantiques) », dans Évin J. (dir.), Congrès du centenaire de la Société préhistorique française : un siècle de construction du discours scientifique en Préhistoire, $26^{e}$ Congrès préhistorique de France, vol. 3 : Aux conceptions d'aujourd'hui, Paris, Société préhistorique française, p. 277-293.

OBERMAIER H., 1924, «Las diferentes facies del Musteriense espanol y especialmente de los yacimientos madrileños », Revista de la Biblioteca archivo y museo, vol. 1, nº 2, p. 143-177.

PASSEMARD E., 1924, « Les stations paléolithiques du pays Basque et leurs relations avec les terrasses d'alluvions », thèse de doctorat, Strasbourg, université de Strasbourg.

PASSEMARD E., 1936, « Le Moustérien à l'abri Olha en pays Basque », Revue lorraine d'anthropologie, $8^{\mathrm{e}}$ année, p. 117-160.

PASSEMARD E., 1944, « La caverne d'Isturitz en pays Basque », Préhistoire, n 9, p. 7-95.

PÉTILlON J.-M., LAROULANDIE V., BOUDADI-MALIGNE M., DUMONTIER P., FERRIER C., KUNTZ D., LANGLAIS M., MALLYE J.-B., MISTROT V., NORMAND C., 2017, « Occupations magdaléniennes entre 20000 et 15000 cal BP dans le piémont pyrénéen : la séquence paléolithique du sondage 4 de la grotte de Laa 2 (Arudy, Pyrénées-Atlantiques) », Gallia préhistoire, nº 57, p. 65-126.

READY E., 2013, « Neandertal foraging during the late Mousterian in the Pyrenees: new insight based on faunal remains from Gatzarria cave ", Journal of Archaeological Science, $n^{\circ} 40$, p. 1568-1578.

READY E. et MORIN E., 2013, « Revisiting the Middle to Upper Palaoelithic transition at Gatzarria Cave, France », poster non publié présenté au Paleoanthropology Society Annual Meeting, Honolulu, avril 2013.

RENARD C., 2011, « Continuity or discontinuity in the Late Glacial Maximum of south-western Europe: the formation of the Solutrean in France ", World Archaeology, vol. 43, n 4, p. 726-743.

RICHTER D., HUBLIN J.-J., JAUBERT J., MCPHERRON S. P., SORESSI M., TEXIER J.-P., 2013,

" Thermoluminescence dates for the Middle Palaeolithic site of Chez-Pinaud, Jonzac (France) », Journal of Archaeological Science, $\mathrm{n}^{\circ}$ 40, p. 1176-1185.

RÍOS GARAIZAR J., 2012, Industria lítica y sociedad en la Transición del Paleolítico Medio al Superior en torno al Golfo de Vizcaya, Santander, PUbliCan, Ediciones de la Universidad de Cantabria.

RÍOS GARAIZAR J., 2017, « A new chronological and technological synthesis for late Middle Palaeolithic of the Eastern Cantabrian Region », Quaternary International, n 433, p. 50-63. RODRÍGUEZ ASENSIO J. A. et ARRIZABALAGA A., 2004, « El poblamiento más antiguo de la región: las ocupaciones previas al IS4. Desde el inicio del poblamiento a circa 80.000 BP », dans Fano M. (dir.), La sociedad del Paleolítico en la región cantábrica, Vitoria-Gasteiz, Diputación Foral de Bizkaia (Kobie, série Anejos, 8) p. 51-90. 
SAEnz De BuRUaGA A., 1987, « La retouche sur os dans les niveaux du Paléolithique supérieur de la grotte Gatzarria à Suhare, en pays Basque ", Dialektikê, p. 22-26.

SAENZ DE BURUAGa A., 1991, El Paleolítico superior de la cueva de Gatzarria (Zuberoa, País Vasco), Bilbao, Universidad del País Vasco.

SAINT-PÉRIER R. de et SAINT-PÉRIER S. de, 1952, La grotte d'Isturitz III : les Solutréens, les Aurignaciens et les Moustériens, Paris, Masson (Archives de l'Institut de paléontologie humaine, mémoire 25).

SIMONET A., 2010, Typologie des armatures lithiques gravettiennes de la grotte d'Isturitz (PyrénéesAtlantiques, France), Oxford, Archaeopress (BAR International Series, 2156).

SIMONET A., 2017, « Gravettians at Brassempouy (Landes, France), 30,000 BP: a semi-sedentary territorial organization?», World Archaeology, n 49, p. 648-665.

SIMONET A., 2018, «L'industrie lithique gravettienne de Gatzarria », dans Deschamps M. et Flas D. (dir.), La grotte Gatzarria à Ossas-Suhare (Pyrénées-Atlantiques) : rapport annuel d'opération programmée, Service régional de l'archéologie Nouvelle-Aquitaine, p. 127.

TARTAR E., 2009, « De l'os à l'outil : caractérisation technique, économique et sociale de l'utilisation de l'os à l'Aurignacien ancien. Étude de trois sites : l'abri Castanet (secteurs nord et sud), Brassempouy (grotte des Hyènes et abri Dubalen) et Gatzarria », thèse de doctorat, université Paris I - Panthéon-Sorbonne.

VEGA DEL SELLA C., 1921, El Paleolítico de Cueva Morín (Santander) y notas para la climatologia cuaternaria, Madrid, Museo Nacional de Ciencias Naturales (Memoria de la Comisión de Investigaciones Paleontológicas y Prehistóricas, 29/Serie prehistórica, 25).

\section{RÉSUMÉS}

Dans le piémont nord-ouest des Pyrénées, peu de sites documentent les phases récentes du Paléolithique moyen et celles du Paléolithique supérieur initial au sein d'une même séquence stratigraphique. La grotte de Gatzarria (Ossas-Suhare, Pyrénées-Atlantiques), fouillée par G. Laplace entre 1951 et 1976, a révélé une stratigraphie complexe dont les industries documentent ce passage. Toutefois, des études récentes ont remis en question l'homogénéité des niveaux dans le secteur du fond de la cavité et de nouvelles interprétations stratigraphiques sont proposées pour le Paléolithique moyen, sur la base de l'analyse technologique et de la projection spatiale des vestiges. Les niveaux des débuts du Paléolithique supérieur, depuis le Châtelperronien jusqu'au Gravettien, sont également particulièrement importants, et de nouvelles hypothèses concernant l'évolution du Proto-Aurignacien à l'Aurignacien ancien peuvent désormais être proposées.

In the northwestern foothills of the Pyrenees, few sites document the late phases of the Middle Paleolithic and those of the early Upper Paleolithic within the same stratigraphic sequence. The Gatzarria cave (Ossas-Suhare, Pyrénées-Atlantiques), excavated by G. Laplace from 1951 to 1976, revealed a complex stratigraphy whose industries document this transition. But recent studies have questioned the homogeneity of the levels in the deeper part of the cave, and new stratigraphic interpretations are proposed for the Middle Paleolithic, based on technological analysis and spatial projection of the artifacts. The early Upper Paleolithic industries, from the Chatelperronian to the Gravettian, are also particularly significant, and new hypotheses concerning the Protoaurignacian and Aurignacian assemblages can now be proposed. 
INDEX

Mots-clés : Paléolithique moyen récent, séquence stratigraphique, Aurignacien

Keywords : Late Middle Paleolithic, stratigraphic sequence, Aurignacian

Index géographique : grotte de Gatzarria

\section{AUTEURS}

\section{MARIANNE DESCHAMPS}

Chercheuse, Centro de Arqueologia da Universidade de Lisboa (UNIARQ), membre associée du laboratoire Travaux et recherches archéologiques sur les cultures, les espaces et les sociétés

(TRACES, UMR 5608, université Toulouse - Jean-Jaurès/CNRS)

\section{DAMIEN FLAS}

Chercheur, service de Préhistoire, université de Liège 


\section{The Llonin Cave (Peñamellera Alta,} Asturias, Spain), level III (Galería): techno-typological characterisation of the Badegoulian lithic and bone assemblages

La grotte de Llonin (Peñamellera Alta, Asturias, Espagne), niveau III de la galerie : caractérisation techno-typologique des assemblages lithiques et osseux du Badegoulien

Marco de la Rasilla Vives, Elsa Duarte Matías, Joan Emili Aura Tortosa, Alfred Sanchis Serra, Yolanda Carrión Marco, Manuel Pérez Ripoll and Vicente Rodríguez Otero

To Gregorio Gil Álvarez (1926-2014), rural medicine doctor and humanist. To Manuel Hoyos Gómez (1944-1999) and Javier Fortea Pérez (1946-2009), in memoriam.

Aknowledgements to the Llonin excavation and research team, to María Borao (Universidad de Valencia), Jesús F. Jordá (UNED), Marc Tiffagom and to the editors and reviewers for their constructive critics.

1 Llonin cave is located in the Cares-Deva basin, at 112 m.a.s.l. and with ENE orientation. It is $\sim 23 \mathrm{~m}$ above the closest drainage basin (La Molinuca stream) and $\sim 18 \mathrm{~km}$ away from the Cantabrian Sea. The Cares-Deva valley is delimited by a mountainous relief with several mineral outcrops (i.e. iron, manganese and copper) and contains 13 other rock art caves or rock shelters from headwaters to estuary. El Pindal cave is in the coastline, close to the Deva River estuary. Situated on the Deva's right bank (Cantabria), Cueva Áurea's recently discovered art must also be added (Fig. 1). 
Fig. 1. - Asturias, Cantabria and Basque Country mentioned sites distribution and specific sites of the Cares-Deva basin.

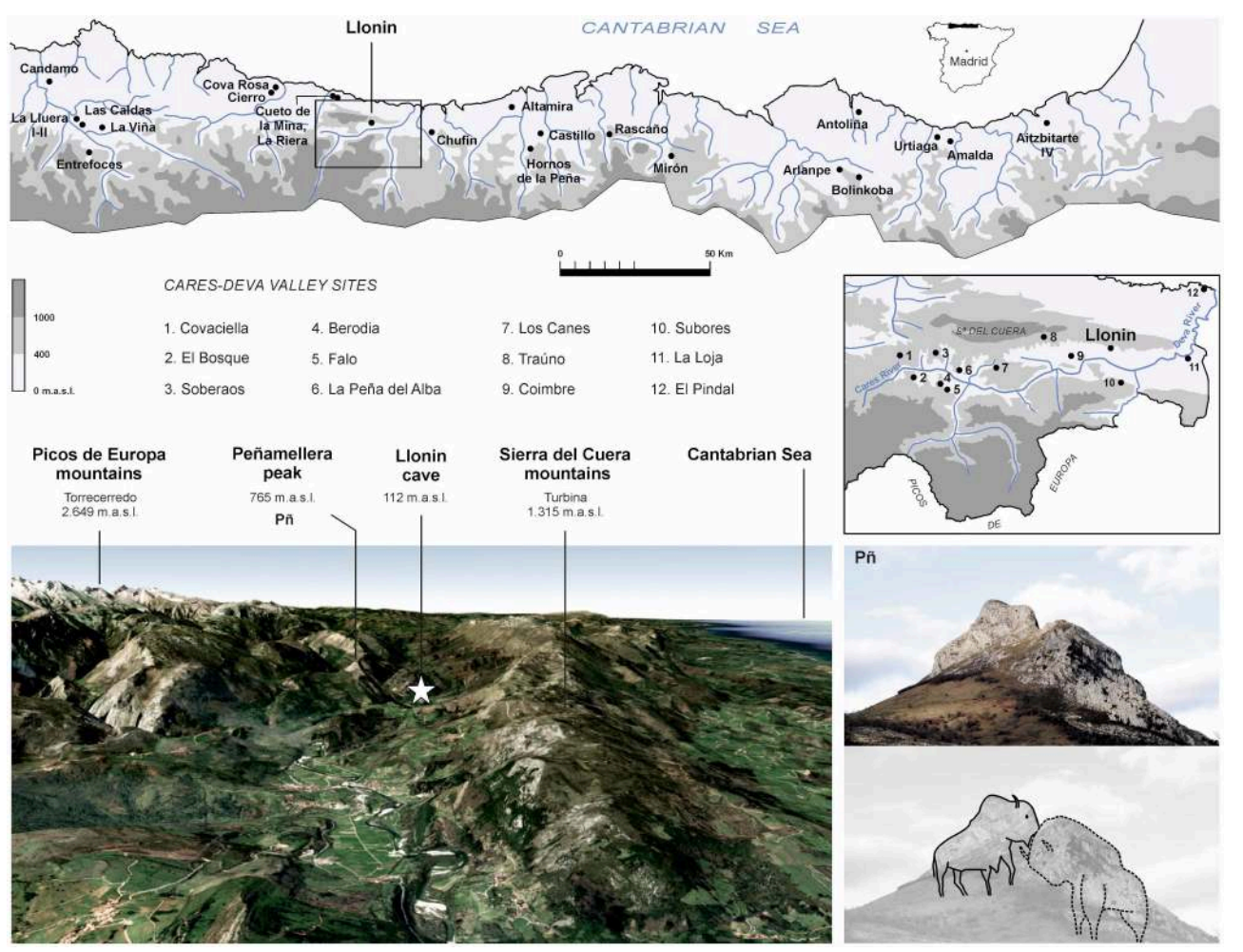

Left below: Llonin landscape with the main relief structures (east to west view). Right below: Peñamellera Peak bison forms.

Photo Elsa Duarte. Left below @ Digital Globe, 2017, Google, IGN.

2 Llonin's surrounding landscape is closed by mid-altitude mountains and the Peñamellera peak that constitutes a prominent relief feature, showing a singular form of two bisons when faced from the east (Fig. 1). The left bison's "head" points to La Molinuca valley and the cave. Undoubtedly this great "visual point", like for example the nearby Peña Tú rock or El Castillo Mountain in Cantabria, played an important role in the territory organization and also in the emotional/symbolic thinking (Rasilla and Duarte 2018).

The cave entrance was practically blocked by archeological deposits and calcite formations, but in 1957 it started being used for local cheese fermentation, which caused a partial destruction of the archeological layers. In 1971, its rock art was publicly presented and further research revealed a rich archeological sequence that included evidence of Middle and Upper Paleolithic (Gravettian, Upper Solutrean, Badegoulian, Middle Magdalenian, Upper Magdalenian), and to a lesser extent, Azilian and Bronze Age. This long-chronology parietal art is made up of several painting and engraving superimpositions, with a prominent use of multiple and striated lines engraving technique; there is a reasonable correlation between the artistic and cultural records (Fortea et al. 1995, 1999 and 2004, Rasilla 2014, Rasilla et al. 2014) (Figs. 2 and 3). 
Fig. 2. - Llonin Cave (Peñamellera Alta, Asturias, Spain): fence and vestibule (A). Galería excavation area (B). Plan of the cave with the excavation sectors and cave art panels (C).
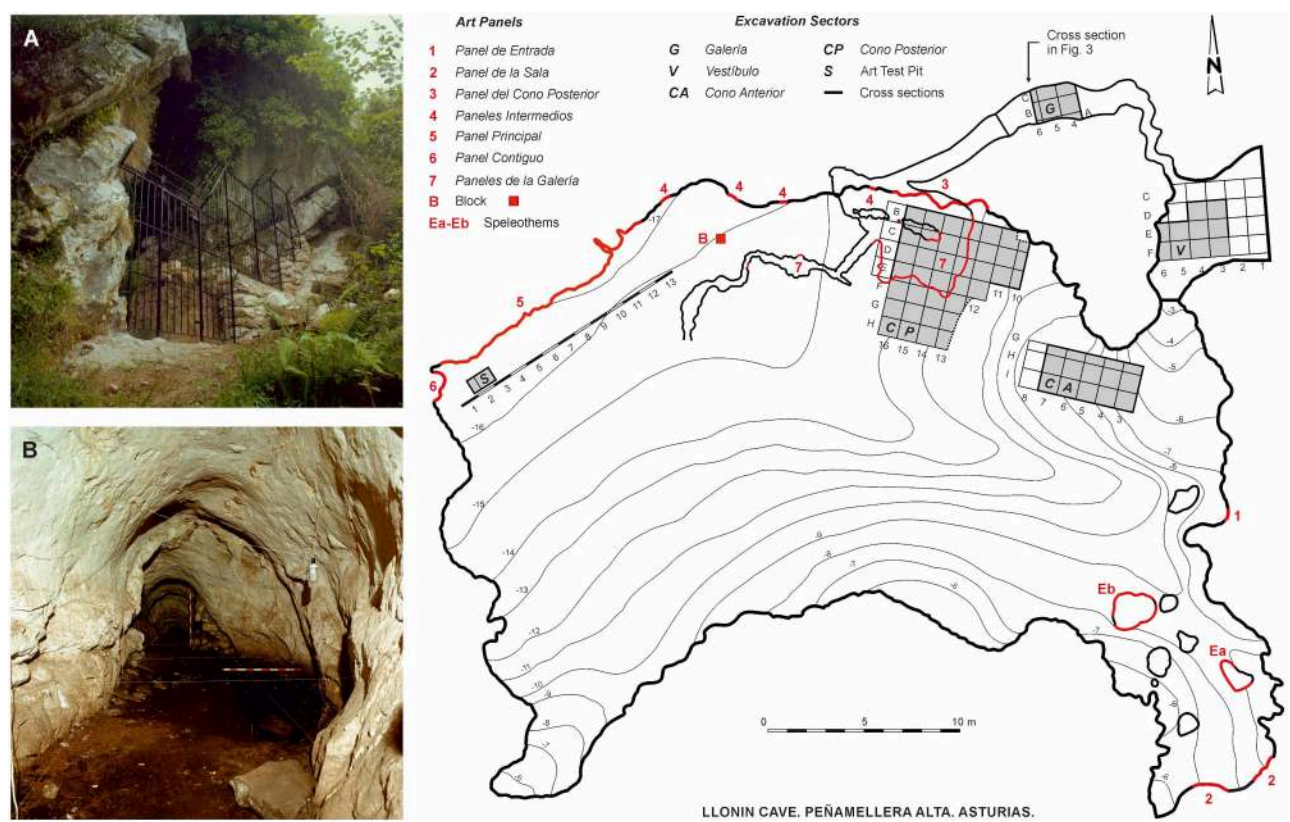

(Fortea et al. 2004).

Fig. 3. - Llonin Cave (Peñamellera Alta, Asturias, Spain): examples of rock art.
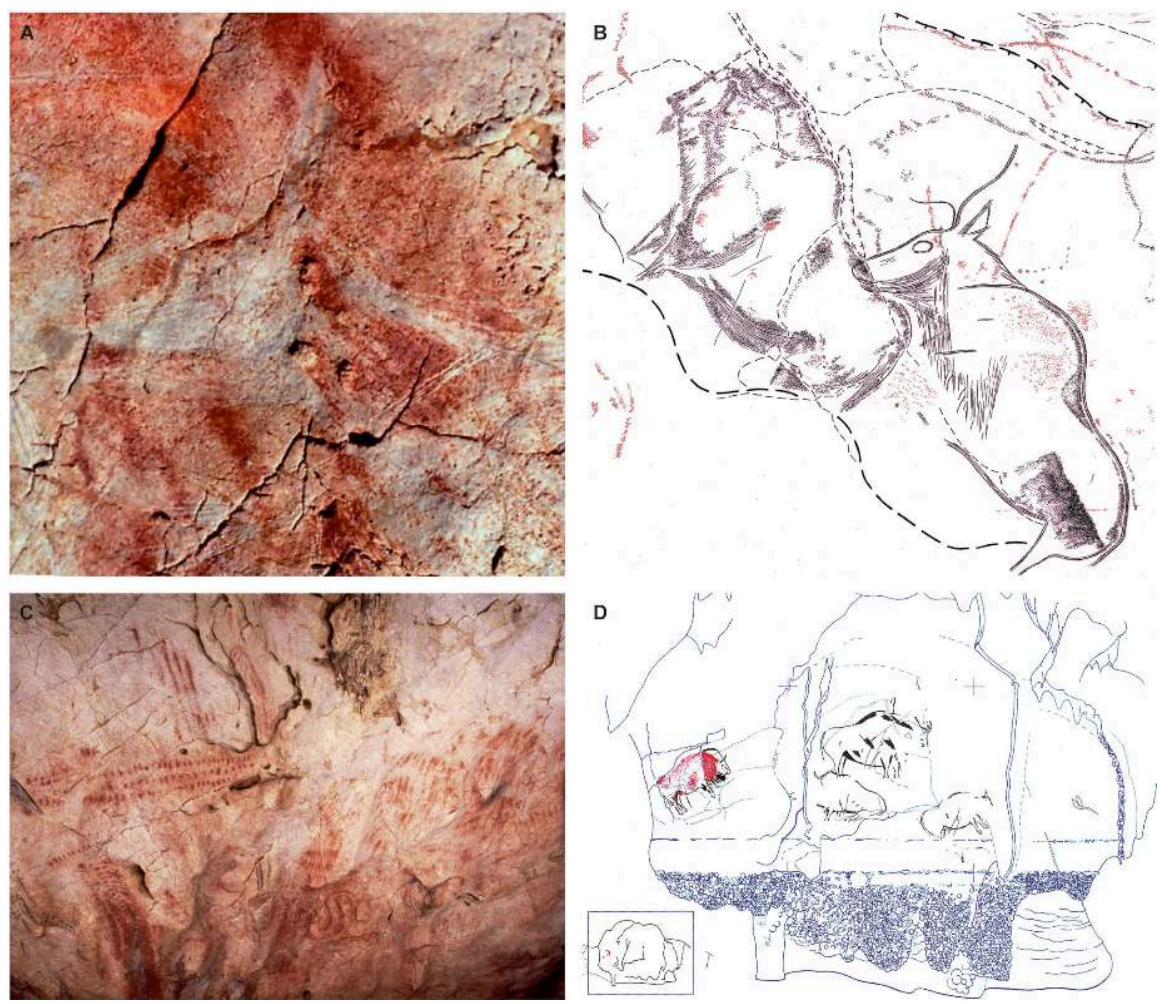

A: Panel Principal, engraved hind made by multiple and striate technique. B: Panel Principal, painted and engraved bisons, right bison overlapping a previous red deer. c: Panel Principal, overview of meters 3 to 5 with a red colour anthropomorphic feminine figure and several painted signs. D: Panel de la Sala, engraved bisons with fine lines and one partially painted.

Drawings : B : Alba Fernández Rey, D : Andrea Miranda. Photos Javier Fortea. Scales in Fortea et al. 2004. 


\section{Archeological data}

\section{Stratigraphy}

During the excavation works, we realized that a very thin red level delimited level III (Badegoulian) from level IV (Solutrean). It was constituted by fine-grained iron oxides and it filled up the whole excavated surface. Its importance is critical because it seals the top of level IV and we haven't noticed relevant taphonomical processes between levels III and IV. It also seems that iron oxides particles were sprinkled by the first individuals who arrived at the cave at the beginning of level III's formation. It could have involved a practical function directly related to the fire tasks documented in this level such as waterproofing, refractory base, etc., but it may also have been symbolic (Fig. 4).

Fig. 4. - Llonin Cave (Peñamellera Alta, Asturias, Spain): Galería. Stratigraphy (A); stratigraphic cross-section showing the different cultural units (B); level III detail (C, D).
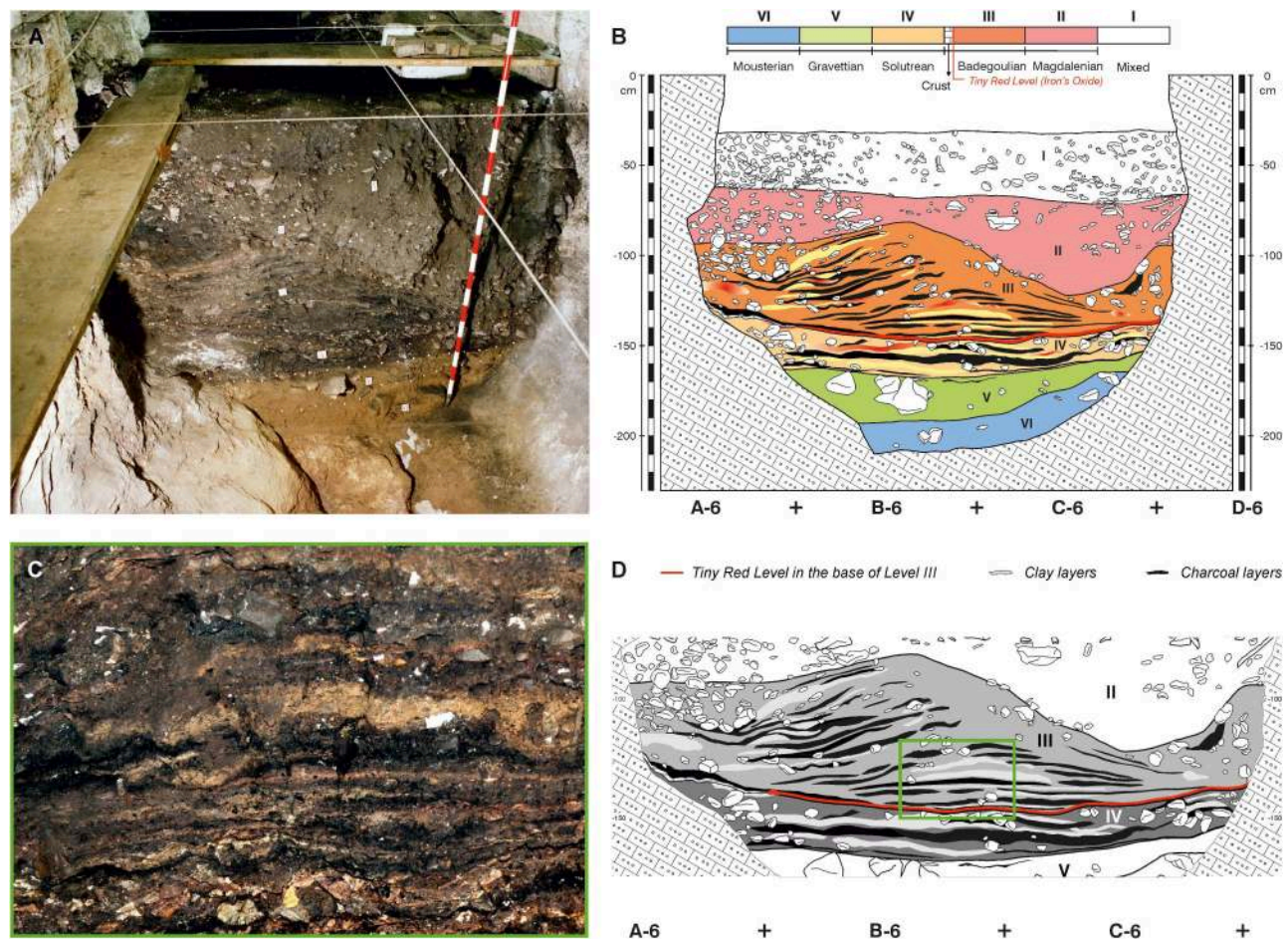

Photos Javier Fortea. Drawings Elsa Duarte.

Level III is 30 to $50 \mathrm{~cm}$ thick and it shows a central tumulus shape. It consists of clayeysandy sediment with black (charcoal, ashes) and yellow (clay) lenticular beds alternations (Fig. 4C, 4D). These clayey beds are highly compacted by fire action and they are usually beneath black lenses; they were in place before making fire. Sometimes there are sorts of "pits" full of ashes, charcoal and burnt and broken bones and lithics, beside a great quantity of broken and burnt Ordovician quartz-arenite and Devonian sandstone pebbles. There are also specific red (iron oxide) patches. Therefore, this level is mainly anthropic, without erosive discordances between levels III and IV. 


\section{Fauna and charcoal}

6 The preliminary faunal study indicates a predominance of chamois over red deer and Spanish ibex while horse and aurochs are occasional. The faunal record is in primary position, trampling evidence is scarce and no carnivore marks have been identified until now. On the contrary, bones have been highly transformed by humans. Incisions are more common than scraping and longitudinal incisions are more numerous than oblique or transversal ones. Defleshing traces are more common than disarticulation ones. Moreover, there is a strong fragmentation for marrow extraction and a high exploitation of large, short and flat bones.

7 Although wood charcoal analysis is still ongoing, the preliminary results reveal the presence of legume and heather (Ericaceae) species. Even though these families include a large number of genera and species of diverse ecological conditions, this combination is characteristic of the Eurosiberian cold moorlands and points to the existence of cold conditions and open, shrub-like landscapes, with a low arboreal component (only a fragment of Juniperus has been identified).

\section{Lithic assemblage}

It is formed of knapped materials, macro-lithic artifacts and partly modified rocks carried to the site (Table 1). Over an estimated total of $\sim 17,000$ knapped pieces, we are presenting here a sample of $31.90 \%(n=5,423)$. For the estimate and analysis, we have not taken into account the first centimeters of the level's top layer, nor sub-squares 1/4/7 from C/D-5/6 (Fig. 2), just to avoid possible archeological mix-ups.

Table 1. - Llonin Cave (Peñamellera Alta, Asturias, Spain), Galería, level III: general composition of the lithic assemblage.

\begin{tabular}{|c|c|c|c|c|c|c|c|c|c|c|c|c|}
\hline \multirow{2}{*}{ Lithic assemblage } & \multicolumn{2}{|c|}{ Quartzite } & \multicolumn{2}{|c|}{ Flint } & \multicolumn{2}{|c|}{ Lutite } & \multicolumn{2}{|c|}{ Subtotal } & \multicolumn{2}{|c|}{$\mathrm{Qa}+\mathrm{S}$} & \multicolumn{2}{|c|}{ Total } \\
\hline & $n$ & $\mathrm{~kg}$ & $n$ & $\mathrm{~kg}$ & $n$ & $\mathrm{~kg}$ & $n$ & $\mathrm{~kg}$ & $n$ & $\mathrm{~kg}$ & $n$ & $\mathrm{~kg}$ \\
\hline Flakes & 4,149 & 25.93 & 1,159 & 4.85 & 115 & 0.89 & 5,423 & 31.69 & 314 & 7.94 & 5,737 & 39.63 \\
\hline Estimated total & 13,000 & 82.00 & 3,600 & 15.20 & 400 & 2.80 & 17,000 & 100.00 & 1,000 & 26.00 & 18,000 & 126.00 \\
\hline Pebbles $>5 \mathrm{~cm}$ & & & & & & & & & 220 & 39.88 & 220 & 39.88 \\
\hline Estimated total & & & & & & & & & 750 & 150.00 & 750 & 150.00 \\
\hline Hammers/retouchers & 2 & 0.65 & & & 3 & 1.53 & 5 & 2.18 & & & 5 & 2.18 \\
\hline Anvils & & & & & & & & & 1 & 0.77 & 1 & 0.77 \\
\hline Total & 4,151 & 26.58 & 1,159 & 4.85 & 118 & 2.42 & 5,428 & 33.87 & 535 & 48.59 & 5,963 & 82.46 \\
\hline Estimated total & 13,000 & 82.00 & 3,600 & 15.20 & 400 & 2.80 & 17,000 & 100.00 & 1,750 & 176.00 & 18,750 & 276.00 \\
\hline
\end{tabular}

Sample of $31.90 \%(n=5,423)$ over an estimated total of $\sim 17,000$ knapped pieces. Qa + S: quartzarenite + sandstone? (studies in progress).

Quartz-arenite and sandstone make up parallel macro-lithic chaînes opératoires, and they consist of pebbles, anvils, hammers and few "large" flakes aimed at fire activity. They probably come from the stream and the outcrops just in front of the cave $(<100 \mathrm{~m}$ distance) (Fig. 5). 
Fig. 5. - Llonin Cave (Peñamellera Alta, Asturias, Spain): raw materials.
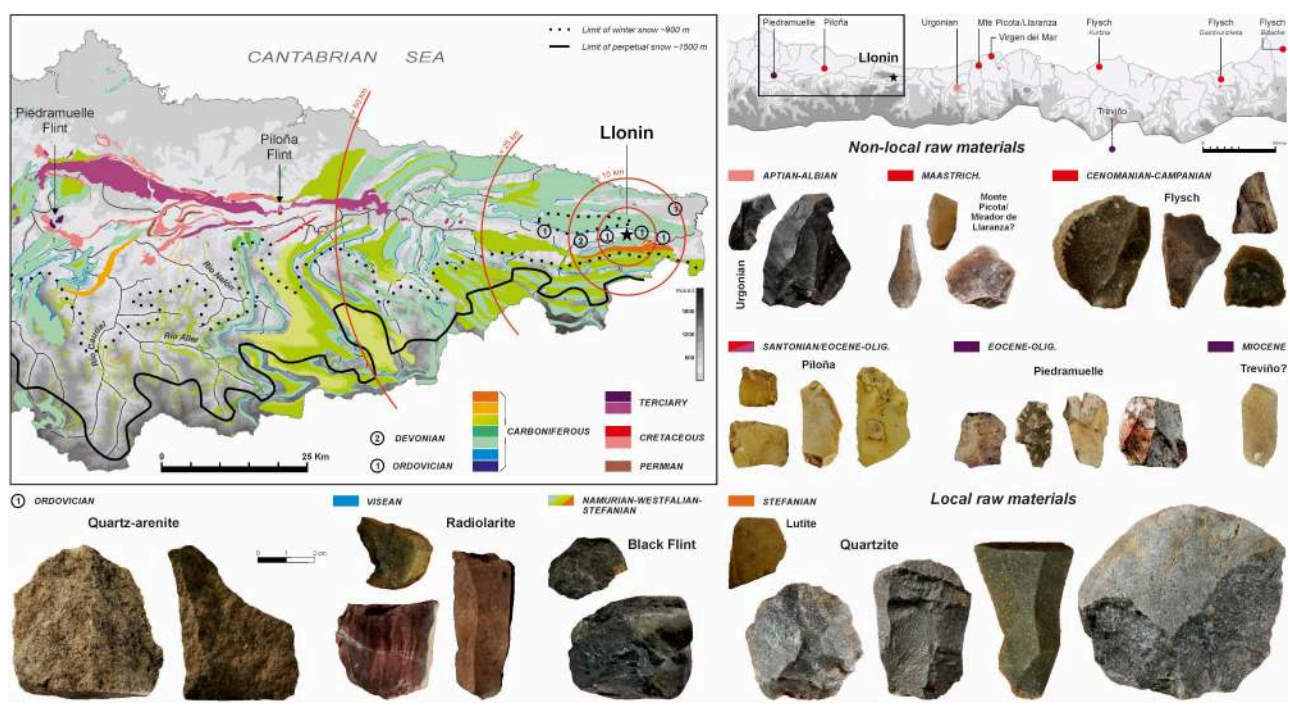

Left: local/semi-local (<10 km radius) and non-local origin. Right and above: main flint sources in the Cantabrian Region. Some flint identifications need further petrological analysis (cf. question marks).

Map, photos and PAO Elsa Duarte.

\section{Sample}

The sample is made up of all the tools, cores and blades/bladelets from squares C-4/5/6 (13.65\% of the total sample), with a random sample for the flakes and shatter ( $49.23 \%$ of the total sample). All sediments have been water-sieved in 2.38 and $1.41 \mathrm{~mm}$ mesh screens.

11 In addition, we have used a random sample for the rest of the excavated surface A-6, B-4/5/6 and D-5. We have studied all the pieces in each square/layer selected (37.12\% of the total sample). There are no significant differences regarding surface distribution between these two large groups, except for a higher material density in the sub-squares next to the walls.

\section{Assemblage composition and preservation}

12 It is formed by a majority of unretouched blanks ( $\sim 50 \%)$ over shatter, tools and cores (Table 2). For the technological groups, the shatter makes $\sim 40 \%$ and the blanks $\sim 60 \%$ (Table 3). This is a reverse proportion in comparison to a complete experimental and/ or archeological reduction sequence (Geneste 1988, Santamaría 2012). 
Table 2. - Llonin Cave (Peñamellera Alta, Asturias, Spain): general knapping groups frequencies.

\begin{tabular}{lrr}
\hline Knapping group & \multicolumn{1}{c}{$\mathrm{n}$} & \multicolumn{1}{c}{$\%$} \\
\hline Blanks & 2,430 & 44.81 \\
Shatter & 1,937 & 35.72 \\
Cores & 43 & 0.79 \\
Tool-cores & 16 & 0.30 \\
Tools & 997 & 18.38 \\
\hline Total & 5,423 & 100.00 \\
\hline
\end{tabular}

BLANKS: flakes (complete/fragments $\geq 20 \mathrm{~mm}$ ), blades-bladelets (complete/fragments), indeterminate fragments $(\geq 20 \mathrm{~mm}$ ); SHATTER: flakes (complete/fragments $<20 \mathrm{~mm}$ ), indeterminate fragments $(<20 \mathrm{~mm})$.

Table 3. - Llonin Cave (Peñamellera Alta, Asturias, Spain): technological group frequencies of cores and retouched/unretouched artefacts.

\begin{tabular}{llcccccc}
\hline & & Unretouched & \multicolumn{2}{c}{ Tools } & Tools/cores & Cores & \multicolumn{2}{c}{ Total } \\
& & $\mathrm{n}$ & $\mathrm{n}$ & $\mathrm{n}$ & $\mathrm{n}$ & $\mathrm{n}$ & $\%$ \\
\hline \multirow{3}{*}{ Blanks } & Flakes & 1,879 & 647 & 3 & 4 & 2,533 & 46.71 \\
& Blades & 182 & 50 & & & 232 & 4.28 \\
& Bladelets & 221 & 33 & & & 254 & 4.68 \\
Shatter & Indet.fragments & 148 & 106 & 13 & 12 & 279 & 5.14 \\
Pebbles & 1,937 & 161 & & & 2,098 & 38.69 \\
\hline Total & & & 997 & 16 & 43 & 5,423 & 100.00 \\
\hline
\end{tabular}

13 The already published levels V (Gravettian) and VI (Mousterian) from Llonin Galería are different from level III because of the lower object density in both levels $(<300)$ and a lower ( $13 \%)$ representation of tools (Martínez 2015, Rasilla and Santamaría 2011-12). These early occupations appear more episodic than levels IV-II, but the Solutrean and Magdalenian level analyses are still ongoing.

The Minimum Number of Blanks for the studied sample is $n=2,144$ (Hiscock 2002, Santamaría 2012) and in comparison to the number of studied blanks ( $n=3,012$, Table 3), the assemblage is relatively fragmented. We have assessed the stratigraphic integrity by comparing fragmentation rates between unretouched and retouched blanks (excluding tools under $20 \mathrm{~mm}$ ), and also between blank categories (excluding indeterminate fragments) and raw material categories (excluding lutite) by unretouched and retouched blanks (Santamaría 2012). The global fragmentation state is "moderate/tending to be moderate" in the evaluated cases and thus shows an internal coherence (Table 4). 
Table 4. - Llonin Cave (Peñamellera Alta, Asturias, Spain): blanks fragmentation and levels' conservation.

\begin{tabular}{|c|c|c|c|c|c|c|c|c|}
\hline Groups & $\begin{array}{c}\text { Complete } \\
+ \\
\text { marginal }\end{array}$ & $\begin{array}{c}\text { LL/LR + } \\
\text { TP/TD + } \\
\text { LT }\end{array}$ & $\begin{array}{c}\text { Minimum } \\
\text { number } \\
\text { of blanks } \\
\text { (MNB) }\end{array}$ & $\begin{array}{l}\text { Fragmented } \\
\text { blanks } \\
\text { (FB) }\end{array}$ & $\begin{array}{c}\text { Total } \\
\text { number } \\
\text { of blanks } \\
\text { (TNB) }\end{array}$ & $\begin{array}{l}\text { Representation } \\
\text { index }\end{array}$ & $\begin{array}{l}\text { Fragmentation } \\
\text { index }\end{array}$ & $\begin{array}{c}\begin{array}{c}\text { Fragmentation } \\
\text { index }\end{array} \\
\text { interpretation }\end{array}$ \\
\hline \multicolumn{9}{|c|}{ Unretouched/retouched: $n=2,93$} \\
\hline Unretouched & 1,010 & 523 & 1,533 & 1,201 & 2,211 & 0.69 & 0.54 & Moderate \\
\hline Retouched & 404 & 150 & 554 & 317 & 721 & 0.77 & 0.44 & Moderate \\
\hline Total & 1,414 & 673 & 2,087 & 1,518 & 2,932 & 0.73 & 0.49 & Moderate \\
\hline \multicolumn{9}{|c|}{ Unretouched/blanks: $n=2,211$} \\
\hline Flakes & 856 & 421 & 1,277 & 954 & 1,810 & 0.71 & 0.53 & Moderate \\
\hline Blades/bladelets & 154 & 102 & 256 & 247 & 401 & 0.64 & 0.62 & Strong \\
\hline Total & 1,010 & 523 & 1,533 & 1,201 & 2,211 & 0.68 & 0.58 & Moderate \\
\hline \multicolumn{9}{|c|}{ Unretouched/raw material: $\mathrm{n}=2,211$} \\
\hline Quartzite & 776 & 436 & 1,212 & 1,004 & 1,780 & 0.68 & 0.56 & Moderate \\
\hline Flint & 234 & 87 & 321 & 197 & 431 & 0.74 & 0.46 & Moderate \\
\hline Total & 1,010 & 523 & 1,533 & 1,201 & 2,211 & 0.71 & 0.51 & Moderate \\
\hline \multicolumn{9}{|c|}{ Retouched/blanks: $n=721$} \\
\hline Flakes & 366 & 124 & 490 & 271 & 637 & 0.77 & 0.43 & Moderate \\
\hline Blades/bladelets & 38 & 26 & 64 & 46 & 84 & 0.76 & 0.55 & Moderate \\
\hline Total & 404 & 150 & 554 & 317 & 721 & 0.77 & 0.49 & Moderate \\
\hline \multicolumn{9}{|c|}{ Retouched/raw material: $n=721$} \\
\hline Quartzite & 276 & 122 & 398 & 249 & 525 & 0.76 & 0.47 & Moderate \\
\hline Flint & 128 & 30 & 158 & 68 & 196 & 0.81 & 0.35 & Weak \\
\hline Total & 404 & 152 & 556 & 317 & 721 & 0.79 & 0.41 & Moderate \\
\hline
\end{tabular}

LL/LR+TD/TP+LT: LL Longitudinal left, LR Longitudinal right, TD Transversal distal, TP Transversal proximal, LT Longitudinal and transversal LIP/LDT/LID/LDD (morphological classification sensu Santamaría 2012). MINIMUM NUMBER OF BLANKS: sensu Santamaría 2012. REPRESENTATION INDEX: sensu Santamaría 2012: MNB/TNB. FRAgMENTATION INDEX: sensu Santamaría 2012: FB/TNB. Statistical differences are only significant (moderate according to V's Cramer test) when comparing flake/laminar blanks. UNRETOUCHED/RETOUCHED: $X^{2}(4)=33.792, p<0.000$, Cramer's $V=0.107$, independent. UNRETOUCHED/BLANK: $X^{2}(4)=393.024, p<0.000$, Cramer's $V=0.422$, moderate. UNRETOUCHED/RAW MATERIAL: $X^{2}(4)=40.792, p<0.000$, Cramer's $V=0.136$, independent. RETOUCHED/BLANK: $X^{2}(4)=54.234, p<0.000$, Cramer's $V=0.274$, moderate. RETOUCHED/RAW MATERIAL: $X^{2}(4)=19.785, p<0.001$, Cramer's $V=0.166$, independent.

In general, unretouched blanks are more fragmented (fragmentation index) than tools and both follow a similar fragments' distribution (complete > transversal > longitudinal > complex longitudinal), except for unretouched flakes among which longitudinal fragments are only $1 \%$ more than transversal ones. Laminar blanks are more fragmented than flakes and quartzites are more fragmented than flints.

These slight differences should be explained as intrinsic to the archeological level context:

- Laminar blanks break more than flakes due to their morphological and metrical features;

- Quartzite is highly related to splintered pieces and bipolar technique involves abundant and highly diverse fractures;

- Complex longitudinal fragments are over $2 \%$ in the five studied cases ( $\sim 8 \%$ of the studied sample) and they do not result from flaking activity but from others, such as trampling (Santamaría 2012) or more likely splintering and intentional fractures ("anvil type", $\mathrm{n}=73$ and $\sim 60 \%$ of them). So in the absence of direct refits we reject inter-stratigraphic artifact flows and therefore archeological contamination. 


\section{Raw materials}

17 The local knapped raw materials are of Carboniferous age: quartzite, lutite and different types of flint (mainly radiolarite and black flint). Up to date, Cretaceous and Tertiary flint sources are non-local and they are found to the east of Llonin $(40-85 \mathrm{~km}$ : Urgonian,Virgen del Mar and Monte Picota/Mirador de Llaranza: Risetto 2009, Fontes et al. 2016, Tarriño et al. 2015, Tarriño 2016) or to the west (60-100 km: Piloña and Piedramuelle: Fortea et al. 2010, Santamaría 2012, Tarriño et al. 2013, Rasilla et al. 2015, Duarte et al. 2016). Nonetheless, some of them involve macroscopic identification problems: Monte Picota/Mirador de Llaranza is a chalcedony-type flint similar to Piloña flint (Infiesto facies) and Piedramuelle (chalcedony facies). We are analyzing these features (Rasilla et al. 2018), but for the moment we have grouped them as a raw material unit called chalcedony. Urgonian flint (Tarriño 2016) and Kurtzia-Flysch flint (Flysch flint from now on) crop out $40 \mathrm{~km}$ and $120 \mathrm{~km}$ to the east respectively, and they also macroscopically resemble different varieties of black local flints (Fig. 5). We haven't identified local Pendueles-Flysch flint ( $\sim 8 \mathrm{~km}$ distant $)$ in the assemblage, but further studies are ongoing.

Quartzite is the most knapped raw material (76.5\%), followed by carboniferous flint varieties and mainly radiolarite (10.43\%) (Table 5).

Table 5. - Llonin Cave (Peñamellera Alta, Asturias, Spain): raw materials and number of pieces frequencies.

\begin{tabular}{ccccccccccc}
\hline Quartzite & Radiolarite & $\begin{array}{c}\text { Black } \\
\text { flint }\end{array}$ & $\begin{array}{c}\text { Urgonian } \\
\text { flint }\end{array}$ & $\begin{array}{c}\text { Pilona Chalcedony } \\
\text { flint }\end{array}$ & $\begin{array}{c}\text { Piedramuelle } \\
\text { flint }\end{array}$ & $\begin{array}{c}\text { Flysch } \\
\text { flint }\end{array}$ & $\begin{array}{c}\text { Jasper and } \\
\text { Treviño } \\
\text { flints }\end{array}$ & $\begin{array}{c}\text { Altered and } \\
\text { indeterminate } \\
\text { flints }\end{array}$ & $\begin{array}{c}\text { Lutite } \\
\text { and } \\
\text { quartz }\end{array}$ \\
4,149 & 566 & 155 & 11 & 42 & 22 & 17 & 201 & 4 & 140 & 116 \\
\hline
\end{tabular}

The rest of the flint types are scarce $(\sim 10 \%)$. Within them, Flysch flint is more abundant (3.70\%) than other flints from the neighborhood such as black flint $(2.85 \%)$. We have tentatively identified 2 blades and 1 flake as Treviño flint (0.05\%). The indeterminate and altered flints are scarce: $2.58 \%$. Heat alteration is spread all over the level but, as seen in the bone industry, few pieces have reached calcination state, so this doesn't distort the general macroscopic classification. On the contrary, this partial thermal change makes determining flint's features such as fossils or impurities stand out. Jaspers and quartz are poorly represented (1 flake and 1 shatter respectively) and lutite is $2.12 \%$.

Compared to weight data, quartzite and radiolarite are similar, but flint groups show an opposite ratio regarding Number of Specimens/Weight (Fig. 6A). Flysch flint contains the highest ratio and it is expressed by shorter module blanks, and therefore makes the largest bladelet assemblage production. Black flint is an outlier because its catchment area is similar to non-local flints, but it is found today in the Cares River alluviums.

Manuports or partially tested cores are nearly absent and cores tend to be highly reduced. They usually keep a cortical surface and pebble morphology, especially the centripetal ones $(\sim 70 \%)$. Their dimensions are small $(n=59$; medium length $49.85 \mathrm{~mm}-$ smaller dimension 12.89; medium width $40.57 \mathrm{~mm}$ - smaller dimension 10.88; medium thickness $26.98 \mathrm{~mm}$ - smaller dimension 7.88) and irregular flake-type negatives are common. The largest complete flake is a semi-cortical quartzite (denticulate) and its maximum measurement $(95.78 \times 79.49 \times 23.45 \mathrm{~mm})$ is $200 \%$ larger than cores' measurements. It is also the heaviest flake in the assemblage $(165.13 \mathrm{~g})$ and only a 
quartzite core is heavier $(178.95 \mathrm{~g})$. But this maximal module is smaller than some of the pebbles we collected in nearby alluviums (they can reach $300 \mathrm{~mm}$ in their longest axis). Cortical blanks make $23.45 \%$ of the total. They are larger in local raw materials, but quartzite is at intermediate level, as it presents a tendency to low cortex index (Fig. 6B). Blade-bladelet production and retouch is more common in distant-sources flints (Table 6, Fig. 6C).

Table 6. - Llonin Cave (Peñamellera Alta, Asturias, Spain): relative proportion of raw materials and blanks.

\begin{tabular}{|c|c|c|c|c|c|c|}
\hline & \multirow{2}{*}{$\begin{array}{c}\text { Flakes } \\
n\end{array}$} & \multirow{2}{*}{$\begin{array}{c}\text { Blades } \\
\mathrm{n}\end{array}$} & \multirow{2}{*}{$\begin{array}{c}\text { Bladelets } \\
\mathrm{n}\end{array}$} & \multirow{2}{*}{$\begin{array}{c}\text { Indeterminate } \\
\text { fragments } \\
n\end{array}$} & \multicolumn{2}{|c|}{ Total } \\
\hline & & & & & $\mathrm{n}$ & $\%$ \\
\hline Quartzite & 2,050 & 171 & 152 & 183 & 2,372 & 75.06 \\
\hline Radiolarite & 257 & 27 & 38 & 47 & 322 & 10.19 \\
\hline Black flint & 70 & 4 & 7 & 14 & 81 & 2.56 \\
\hline Urgonian flint & 6 & & & 2 & 6 & 0.19 \\
\hline Piloña flint & 21 & 5 & 6 & 3 & 32 & 1.01 \\
\hline Chalcedony & 9 & & 5 & 1 & 14 & 0.44 \\
\hline Piedramuelle flint & 12 & 1 & 2 & & 15 & 0.47 \\
\hline Flysch flint & 102 & 17 & 28 & 10 & 147 & 4.65 \\
\hline Other flints & 2 & 2 & & & 4 & 0.13 \\
\hline Indeterminate flint & 65 & 4 & 17 & 12 & 86 & 2.72 \\
\hline Lutite & 78 & 2 & & 11 & 80 & 2.53 \\
\hline Total & 2,672 & 233 & 255 & 283 & 3,160 & 100.00 \\
\hline$\%$ & 84.56 & 7.37 & 8.07 & 8.96 & 100 & \\
\hline
\end{tabular}

OTHER FLINTS: jasper and Treviño. Indeterminate flints: altered and indeterminate.

In general, flints are more retouched than quartzite (56\% versus $24 \%$ ) but there are two exceptions: radiolarite and chalcedony (Fig. 6D). Lutite shows marginal dynamics with a low number of flakes, higher cortex index and very few tools.

\section{Technology of blank production}

Unretouched complete blanks $(n=1,038)$ make $30.2 \%$ of the all the blanks. Their dimensions are the most accurate approach to core reduction strategies, since cores are exhausted. Complete flakes $(n=883)$ average dimensions are:

- Medium length: $28.08 \mathrm{~mm}$ - smaller dimension 11.53;

- Medium width: $28.09 \mathrm{~mm}$ - smaller dimension 10.62;

- Medium thickness: $8.98 \mathrm{~mm}$ - smaller dimension 6.15;

- Elongation index (L/W) 1.00;

- Careening index (W/T) 3.12.

Blade-bladelet (metric division: $12 \mathrm{~mm}$ wide) production shows a length and width continuum that ranges from $\sim 13-55 \mathrm{~mm}$ long and $\sim 2-20 \mathrm{~mm}$ wide and an elongation index of $\sim 3$ (Fig. $6 \mathrm{E}$ ). 
Fig. 6. - Llonin Cave (Peñamellera Alta, Asturias, Spain): lithic assemblage.

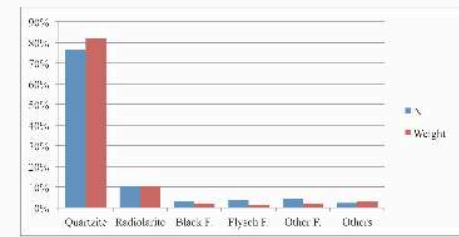

A

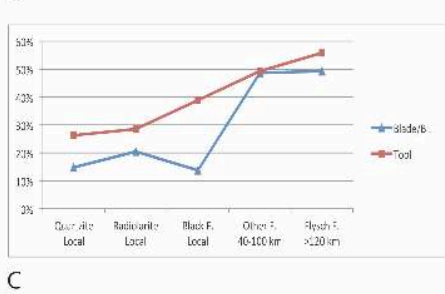

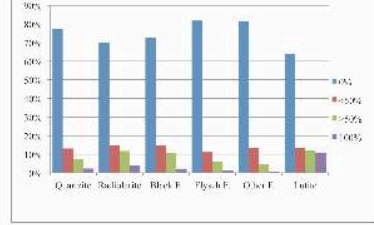

B

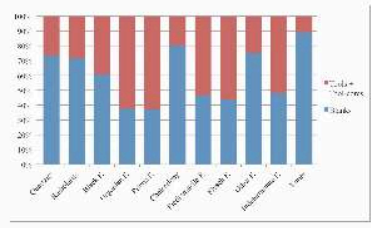

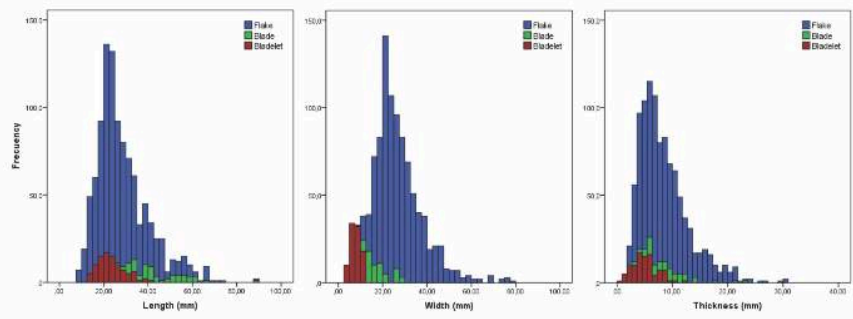

$E$

A: raw materials and number of pieces/weight proportion. Other F. (= flints): urgonian, chalcedony, Piloña, Piedramuelle, altered, indeterminate, jasper, Treviño. B: relative proportion of blanks' cortex and raw materials. c: intensity of laminar production/tools by raw material group. It increases in distant flints and is higher for tools. Laminar production: linear regression (except outlier black flint), $Y=4.14+9.71 \times, R^{2}$ (corrected) $=91.9 \%$. Tools: linear regression (except black flint), $Y=16.03+$ $7.98 \times, R^{2}$ (corrected) $=95.6 \%$. Other $F$. (= flints): jasper and Treviño. $\mathbf{D}$ : relative proportion of raw materials, blanks and tools/tool-cores. Indeterminate F. (= flints): altered and indeterminate. E: complete unretouched blanks measures and frequencies.

For raw materials, there are different flake modules (length or width) depending on their type: quartzite $\sim 29 \mathrm{~mm}$, local flints $\sim 26 \mathrm{~mm}$, non-local flints $22 \mathrm{~mm}$, Flysch $21 \mathrm{~mm}$. Standard deviation is higher in local raw materials $(\sim 10)$ than in non-local ones $(\sim 5)$. Blades over $21 \mathrm{~mm}$ wide are outliers because they are scarce $(n=13)$, mainly on quartzite $(n=11)$ and their elongation index is next to 2 , so they seem to belong to the large flake reduction phase. On the contrary, we have identified $10 \%$ quartzite bladelets as by-products from splintered pieces' use. Although they keep an inferior face, their dorsal face is slightly irregular and their proximal/distal edges are splintered. Their use as backed bladelets and also as bâtonnets-type indeterminate fragments will be assessed (Roda et al. 2015). Flysch flint would be the only raw material unit aimed at onsite bladelet production, since blanks are abundant and there are several types of flakes (such as cortical ones), blades-bladelets and two bladelet cores. They could be introduced as already prepared cores and/or tools. The rest of non-local flint knapping units are more fragmented; for example there are two Urgonian flint bladelet cores, but no bladelets.

In general, dorsal negatives are between 1 and 3 and they are unidirectional $(n=431$ over a sample of $n=868$ ) both in flakes and blades/bladelets, although centripetal negatives increase in flakes under $30 \mathrm{~mm}$. Moreover, technological features for arching and careening, such as ridges and backs, are quantitatively similar in flakes and 
bladelets $(\sim 22 \%$, sample $n=3,437)$ but they are comparatively more abundant in bladelets under $12 \mathrm{~mm}$ wide. These bladelets range between 9 and $12 \mathrm{~mm}$ wide and 6 to $9 \mathrm{~mm}$ thick, and these measurements match up burin's thicknesses (Table 7) so some bladelets could be related to burin manufacture.

Table 7. - Llonin Cave (Peñamellera Alta, Asturias, Spain): frequencies of tools and raw materials.

\begin{tabular}{|c|c|c|c|c|c|c|c|c|c|c|}
\hline & \multicolumn{2}{|c|}{ Quartzite } & \multicolumn{2}{|c|}{ Flint } & \multicolumn{2}{|c|}{ Lutite } & \multicolumn{2}{|c|}{ Total } & \multicolumn{2}{|c|}{ Flint variability } \\
\hline & $n$ & $\%$ & $n$ & $\%$ & $\mathrm{n}$ & $\%$ & $n$ & $\%$ & Local & Non-local \\
\hline Endscrapers & 47 & 4.71 & 24 & 2.41 & 1 & 0.10 & 72 & 7.22 & II & III \\
\hline Borers & 11 & 1.10 & 7 & 0.70 & & & 18 & 1.81 & "I & 1 \\
\hline Burins & 11 & 1.10 & 45 & 4.51 & 2 & 0.20 & 58 & 5.82 & "I & v \\
\hline Truncated pieces & 21 & 2.11 & 15 & 1.50 & & & 36 & 3.61 & 1 & IV \\
\hline Retouched blades & 14 & 1.40 & 5 & 0.50 & & & 19 & 1.91 & 1 & 11 \\
\hline $\begin{array}{l}\text { Retouched flakes/ } \\
\text { indeterminate fragments }\end{array}$ & 87 & 8.73 & 28 & 2.81 & 1 & 0.10 & 116 & 11.63 & "I & III \\
\hline Notches & 53 & 5.32 & 10 & 1.00 & 2 & 0.20 & 65 & 6.52 & "I & 11 \\
\hline Denticulates & 39 & 3.91 & 5 & 0.50 & & & 44 & 4.41 & 1 & 1 \\
\hline Splintered pieces & 339 & 34.00 & 132 & 13.24 & 2 & 0.20 & 473 & 47.44 & $\|$ & IV \\
\hline Sidescrapers & 42 & 4.21 & 3 & 0.30 & 2 & 0.20 & 47 & 4.71 & 1 & 1 \\
\hline Raclettes & & & 26 & 2.61 & & & 26 & 2.61 & "I & III \\
\hline $\begin{array}{l}\text { Abrupt retouched flakes/ } \\
\text { indeterminate fragments }\end{array}$ & 6 & 0.60 & 12 & 1.20 & & & 18 & 1.81 & $\|$ & 11 \\
\hline Retouched bladelets & & & 5 & 0.50 & & & 5 & 0.50 & 1 & 1 \\
\hline Total & 670 & 67.40 & 317 & 31.62 & 10 & 0.10 & 997 & 100.00 & & \\
\hline
\end{tabular}

Roman numbers: amount of flint types (radiolarite, black flint, Urgonian, calcedonitic, Piloña, Piedramuelle, Treviño). Tool-cores are not taken into account.

27 Cores are scarce and are exhausted. Their negatives' morphology is mainly small flakes, and they are centripetal $(n=30)$, orthogonal $(n=5)$ and indeterminate $(n=2)$. We have identified 16 pieces as tool-cores, which are pieces with a morphology that fits in the typological primary groups, but their thicknesses, negative series and negative dimensions make them susceptible to be cores. 3 denticulate tool-cores join the centripetal group and the rest are aimed at bladelet production such as thick endscrapers/sur front $(\mathrm{n}=6)$ or thick burins/sur tranche $(\mathrm{n}=5)$ (Ducasse and Langlais 2007, Santamaría 2012) or splintered pieces $(n=2)$, with a predominance of quartzite over flint. This raw material difference is similar to laminar prismatic cores, with bladelet $(n=3)$ or blade $(n=3)$ negatives.

\section{Tool production}

The tool transformation rate (i.e. percentage of blanks transformed into tools) is $29.1 \%$. Tools made on shatter are included here since they are scarce $(16.06 \%)$ and quite broken. Substratum tools (retouched flakes, notches, denticulates, sidescrapers and mainly splintered pieces) predominate (74.72\%), followed by endscrapers, burins (angle burins dominate over dihedral ones) and truncated pieces (Table 7, Figs. 7, 8 and 9). 
Fig. 7. - Llonin Cave (Peñamellera Alta, Asturias, Spain): tools and tool blanks frequencies.

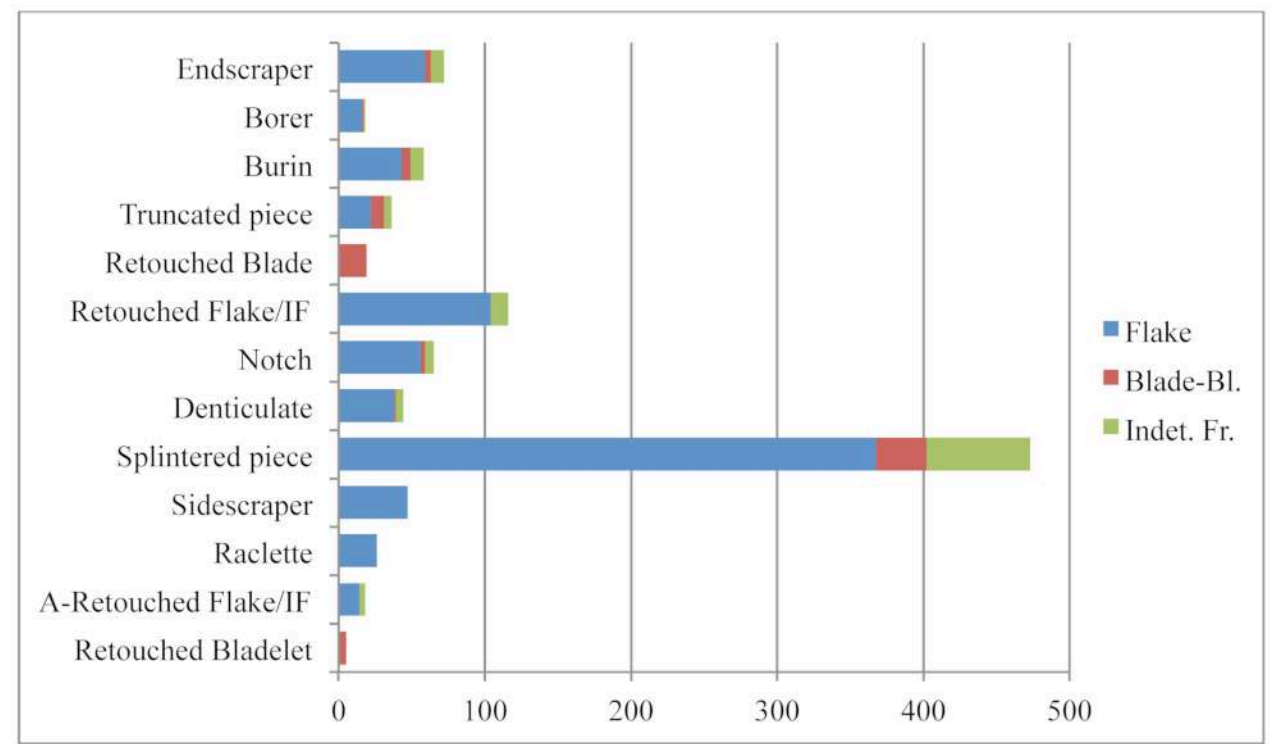

IF : indeterminate fragments.

Fig. 8. - Llonin Cave (Peñamellera Alta, Asturias, Spain): lithic toolkit.
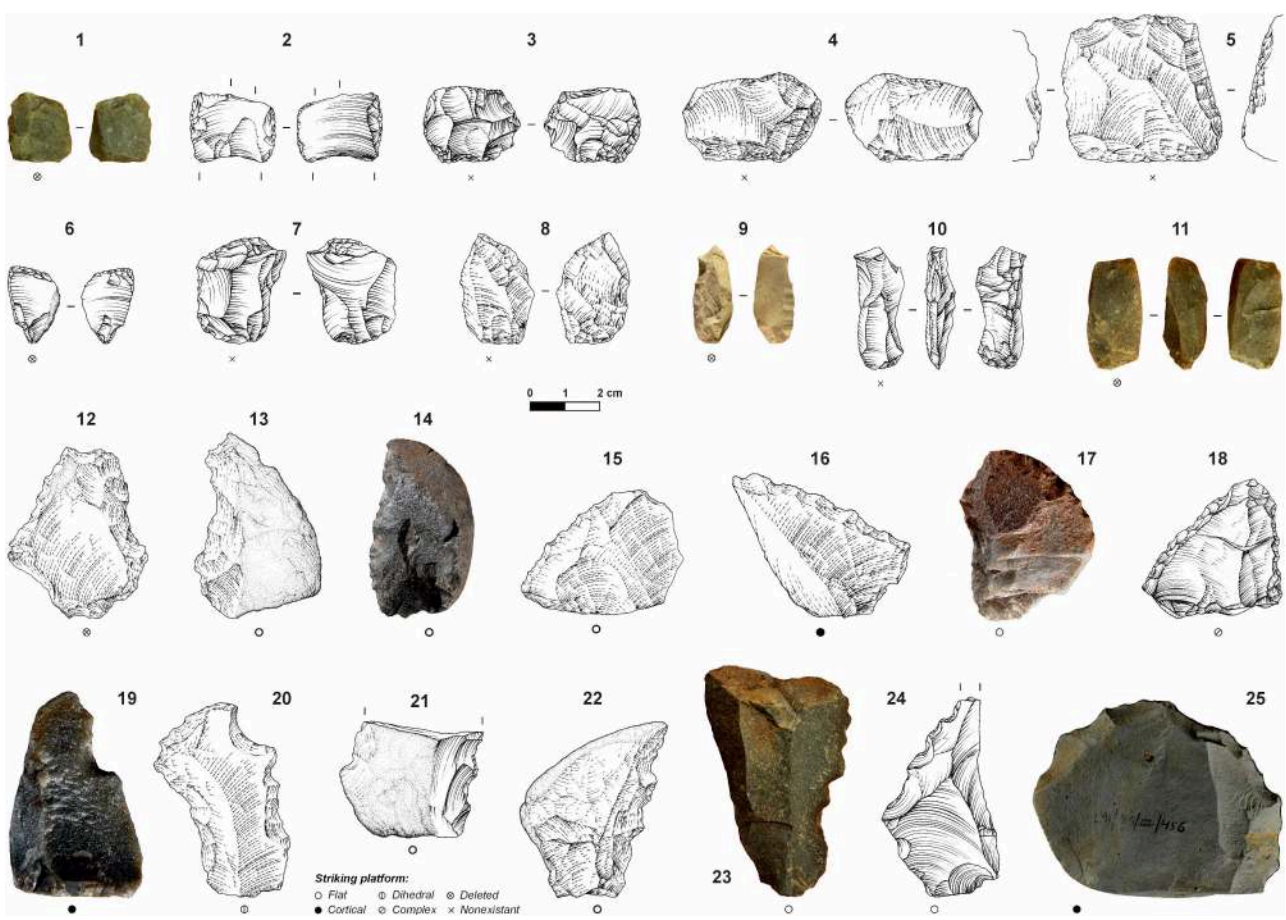

1-11: splintered pieces. 12-18: sidescrapers. 19-20: notches. 21-25: denticulates. Quartzite: 1, 4, 5, 8, 17, $12,13,14,15,16,17,19,20,22$; radiolarite: 10, 18, 24; lutite: 25; Piloña flint: 2, 3, 9; black flint: 21

Piedramuelle flint: 7 ; indeterminate: 6 .

Photos and drawings Elsa Duarte. 
Fig. 9. - Llonin Cave (Peñamellera Alta, Asturias, Spain): lithic toolkit and laminar blanks.

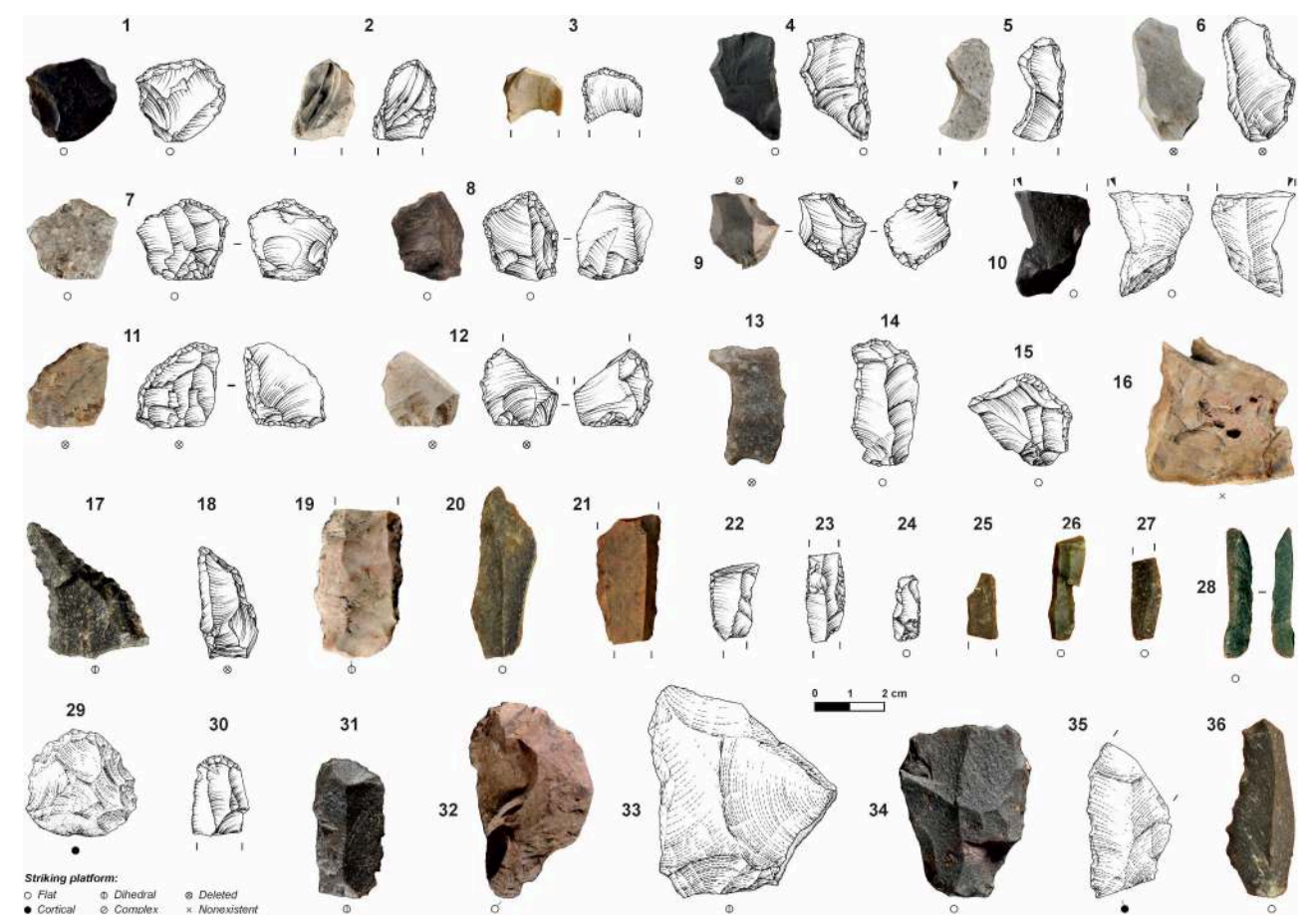

$\mathbf{1}, \mathbf{2}, \mathbf{3}, \mathbf{4}, \mathbf{5}, \mathbf{6}$ : raclettes. $\mathbf{7}, \mathbf{8}, \mathbf{1 1}, \mathbf{1 2}$ : raclettes and splintered pieces. $\mathbf{9}, \mathbf{1 0}$ : burins. $\mathbf{1 3}$ : abrupt retouch and splintered piece. 16: abrupt retouch. 14, 15 : truncated pieces. 17, 18: borers. 19, 35, 36: retouched blades. 20, 21: blades. 22, 23, 24: retouched bladelets. $\mathbf{2 5 , \mathbf { 2 6 }}$ : bladelets. $\mathbf{2 7}$, $\mathbf{2 8}$ : bladelets resulting from splintering. 29, 31, 32: Endscrapers. 33, 34: retouched flakes. Quartzite: 10, 17, 27, 28, 29, 37, 33, 34, 35, 36; radiolarite: 4, 8, 17, 14-15, 27, 23, 25, 32; Piloña flint: 3, 16, 19, 22; Urgonian flint: 1; Flysch: 5, 6, 9, 13, 18, 20, 30; indeterminate/altered: 2, 7, 12, 24, 26.

This transformation rate is biased by the predominance of splintered pieces ( $47.44 \%$ out of the total tools). So if we exclude them, the rate becomes $17.3 \%$. Given the abundance and high knapping quality of quartzite, main raw material used for these pieces (Table 7), we tend to consider splintered pieces as wedges instead of cores. For us negatives on these pieces reflect bipolar action but not a blank production. In fact, hypothetical blanks would be small and they wouldn't fit metrically for other tools (Table 8). However, by-products could be used again as wedges. Further studies are in progress in order to evaluate their on-site techno-functional implications. 
Table 8. - Llonin Cave (Peñamellera Alta, Asturias, Spain): mean and standard deviation of length, width and thickness for complete tools.

\begin{tabular}{|c|c|c|c|c|c|c|c|c|}
\hline & \multirow{3}{*}{$\begin{array}{c}\text { Fragmented } \\
\text { tools } \\
n\end{array}$} & \multirow{3}{*}{$\begin{array}{c}\text { Complete } \\
\text { tools } \\
n\end{array}$} & \multicolumn{6}{|c|}{ Complete tools measures } \\
\hline & & & \multicolumn{2}{|c|}{ Length $(\mathrm{mm})$} & \multicolumn{2}{|c|}{ Width $(\mathrm{mm})$} & \multicolumn{2}{|c|}{ Thickness (mm) } \\
\hline & & & Mean & Standard & Mean & Standard & Mean & Standard \\
\hline Endscrapers & 42 & 30 & 36.47 & 12.74 & 34.95 & 11.84 & 13.00 & 5.01 \\
\hline Borers & 6 & 12 & 39.63 & 13.00 & 30.00 & 11.41 & 10.31 & 4.46 \\
\hline Burins & 33 & 25 & 26.26 & 9.99 & 18.86 & 8.98 & 8.72 & 7.73 \\
\hline Truncated pieces & 21 & 15 & 26.52 & 9.72 & 20.83 & 8.04 & 8.13 & 11.04 \\
\hline Retouched blades & 14 & 5 & 46.78 & 15.76 & 19.39 & 5,65 & 7.43 & 16.47 \\
\hline $\begin{array}{l}\text { Retouched flakes/ } \\
\text { indeterminate fragments }\end{array}$ & 81 & 35 & 38.21 & 13.11 & 33.84 & 10.24 & 10.89 & 4.07 \\
\hline Notches & 36 & 29 & 38.14 & 14.57 & 36.79 & 13.55 & 12.40 & 5.07 \\
\hline Denticulates & 28 & 16 & 49.07 & 18.89 & 39.98 & 14.19 & 15.12 & 4.35 \\
\hline Splintered pieces & 225 & 248 & 28.15 & 10.11 & 22.90 & 10.08 & 9.40 & 26.43 \\
\hline Sidescrapers & 16 & 31 & 50.70 & 12.21 & 39.46 & 8.66 & 10.92 & 4.20 \\
\hline Raclettes & 10 & 17 & 18.88 & 5.22 & 17.74 & 5.24 & 5.73 & 1.42 \\
\hline $\begin{array}{l}\text { Abrupt retouched flakes/ } \\
\text { indeterminate fragments }\end{array}$ & 11 & 6 & 25.65 & 8.74 & 15.99 & 7.53 & 5.75 & 2.88 \\
\hline Retouched bladelets & 4 & 1 & 25.80 & & 9.73 & & 1.80 & \\
\hline Total & 527 & 470 & & & & & & \\
\hline
\end{tabular}

Raclettes are few and some abrupt retouched flakes/indeterminate fragments could likewise be raclettes being manufactured or fragmented. Moreover, raclettes are made of flint and show regular transverse sections and few negatives. Their thicknesses and type of retouch coincide with those from truncated pieces (Table 8), so it is probable that raclettes come from reduction and/or intentional fracture of truncated pieces (Fig. 9 No.14). As for the rest of the tools, they show a high formal variability and combination, thus $35 \%$ of raclettes show splintered edges (Fig. 9 Nos 7, 8, 11, 12). Almost $20 \%$ of the tools show several retouched edges, maybe as a result of recycling and/or improving prehension without hafting.

31 Tools are mainly made on quartzite and flint predominates only in burins, raclettes, abrupt retouched flakes/ indeterminate fragments and retouched bladelets, and several types of flint are used for this purpose. Burins join the highest flint variability of the assemblage and almost all the raw materials have been splintered (Table 7). Flint is almost never used for large tools such as sidescrapers, denticulates or notches. On the contrary, quartzite is not used for small tools such as retouched bladelets or raclettes and it is very little used in burins and abrupt retouched flakes (Table 8 and Fig. 7). Cortex index $(\sim 32 \%)$ is similar to unretouched blanks and it is only absent in retouched bladelets. There is a statistical association between tools and blanks $\left(\mathrm{X}^{2}(3)=\right.$ $68,307, \mathrm{p}<0.000)$ as they concentrate on flakes $(79.43 \%)$, and indeterminate fragments are the most retouched group (45.22\%, Fig. 7).

Definitely, the raw material procurement area is basically local under $5 \mathrm{~km} \mathrm{(92 \% )} \mathrm{and} \mathrm{it}$ is focused on quartzite (77\%) collected from the main river stream, the Cares River, less than $1 \mathrm{~km}$ away. Its knapping quality is very good, given the fact that it is possible to guide the knapping process and obtain large to small flakes and blades whereas local flints contain more natural fractures and impurities, and so a higher random breakage pattern. Moreover, the intensity of the production in local flint is lower, because these raw materials are rarer in the main alluvial catchment area. Non-local flints make mobile toolkits, and bladelets production increases as a way of technological investment. Flaking schemes are simple and focused on square flakes that are randomly converted into tools. Only measurements discriminate between tools: biggest flakes for common tool types and blades/smaller flakes for the rest. Splintered pieces are broad spectrum tools because they cover all the sizes and raw materials. Given the general low 
amount of shatter and the fact that splintering generates high shatter density, we hypothesize that flaking and retouching must have been done in another area of the site.

\section{Bone industry assemblage}

The bone industry assemblage consists of 108 pieces. Antler (50\%) dominates over bone $(\sim 30 \%)$ and animal teeth $(\sim 15 \%)$ as raw materials. There are more typological $(\sim 70 \%)$ than technological pieces and this could be due to the fact that we have based the present study on the bone industry selected in the field and inventory lists. A preview in B-6 has delivered 5 new antler technological pieces included here, so the whole faunal assemblage still has to be re-examined (Table 9).

Table 9. - Llonin Cave (Peñamellera Alta, Asturias, Spain), Galería, level II: bone assemblage general composition.

\begin{tabular}{|c|c|c|c|c|c|}
\hline & Antler & Bone & $\begin{array}{c}\text { Antler or } \\
\text { bone }\end{array}$ & Tooth & Total \\
\hline \multicolumn{6}{|c|}{ Unworked technological pieces } \\
\hline Waste products & 5 & & & & 5 \\
\hline Scraped pieces & & 4 & 1 & & 5 \\
\hline Tines & 4 & & & & 4 \\
\hline \multicolumn{6}{|c|}{ Partially worked splinters } \\
\hline Point preforms & & 1 & & & 1 \\
\hline Indeterminate preforms & 3 & 3 & & & 6 \\
\hline \multicolumn{6}{|c|}{ Finished objects } \\
\hline Projectile points & 38 & & 1 & & 39 \\
\hline Rods & 2 & & & & 2 \\
\hline Needles & & 6 & & & 6 \\
\hline Awls & 2 & 1 & & & 3 \\
\hline Ellipse & 1 & & & & 1 \\
\hline Pendants & & 2 & & 16 & 18 \\
\hline
\end{tabular}

\begin{tabular}{lccccc} 
Non-figurative engravings & 6 & & & 6 \\
Technical engravings & 12 & & & 12 \\
\hline Total & 55 & 36 & 1 & 16 & 108 \\
\hline
\end{tabular}

\section{Assemblage composition and preservation}

Bone objects are distributed all over the level, with a slight concentration in the intermediate and final layers, as is the case for the outstanding pieces. On the contrary, the surface distribution shows a high number of objects in B-6 $(n=15.5$ pieces/subsquare on average) in comparison with the rest (2 pieces/sub-square on average).

The assemblage is highly broken (91\%): 12 pieces show post-depositional or dry fractures, 8 projectile points show tongued fractures, 10 awls and pendants are broken in their active zones (use) and the rest (excluding the indeterminate fractures) are intentional. These ones are related to the technological knapping process, the reuse of the points and the general bone breakage pattern exposed above. We have only refitted 
2 point fragments (saw-tooth fracture), which come from the same square, sub-square, and layer (-135 m, B-4). The distance between them was under $30 \mathrm{~cm}$ (Fig. 10 No. 8).

Fig. 10. - Llonin Cave (Peñamellera Alta, Asturias, Spain): bone toolkit and technology.

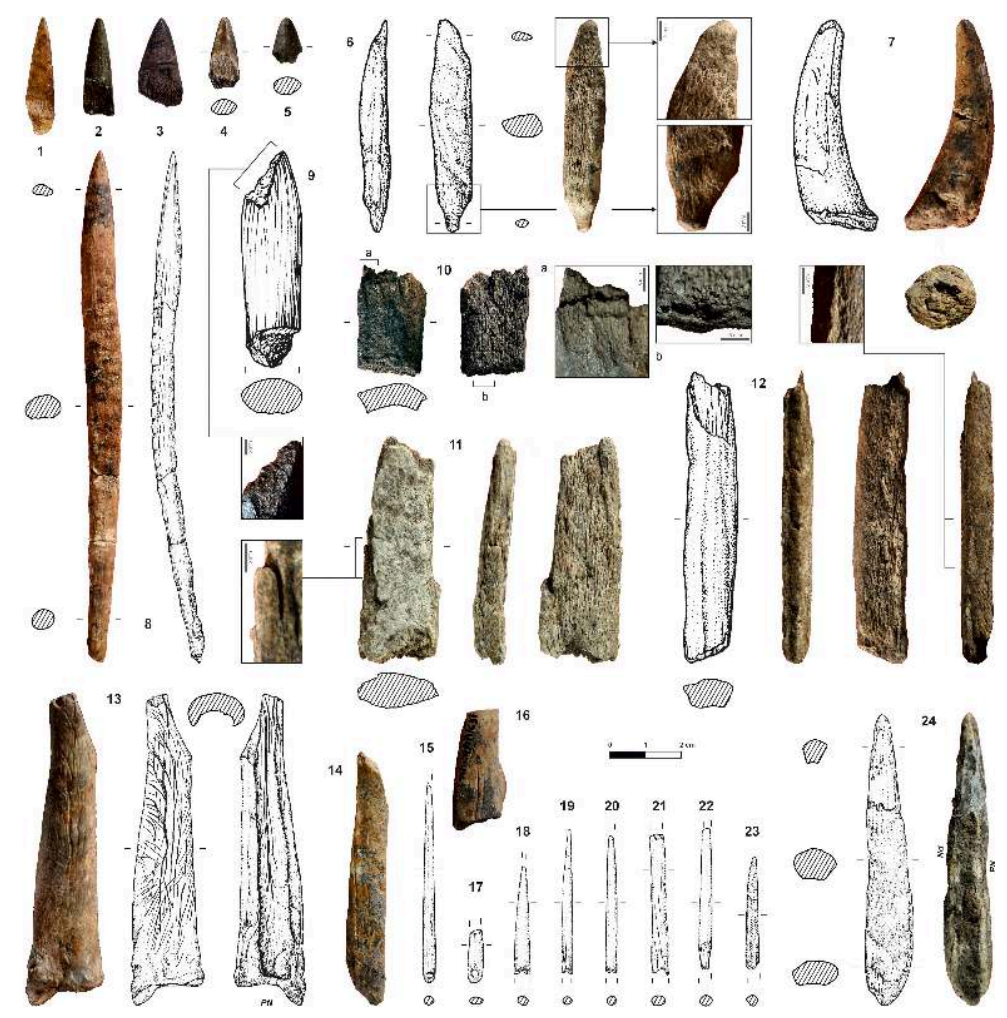

$\mathbf{1}, \mathbf{2}, \mathbf{3}, \mathbf{4}, \mathbf{5}$ : Projectile points' distal fragments. $\mathbf{6}$ : Antler splinter with lateral scraping, base raccourcie and flattened distal end. 7: Tine with transversal detaching marks. 8: Point-based point with rectilinear proximal end. 9: Rod with truncated distal end. 10: Antler waste product with bifacial splintered fractures. 11: Antler waste product with long lateral crack. 12: Antler splinter with partial lateral scraping. 13: Decorated bone, possibly recycled from a needle/awl matrix. 14, 16: Bones with parallel lines, possible needle/awl matrix. 15, 17, 18, 19, 20, 21, 22, 23: Needles. $\mathbf{2 4}$ : Bone splinter for projectile point/awl. PN: percussion notch.

The average preservation is good, but most of the pieces show alterations related to fire activities, such as colorations, ash coatings, fissures and thermal cracks. Anyway, very few seem to have reached calcination (Stiner et al. 1995, Lebon 2010) (Figs. 10 and 11). 
Fig. 11. - Llonin Cave (Peñamellera Alta, Asturias, Spain): bone toolkit and decorative/use engravings, pendants and portable art.

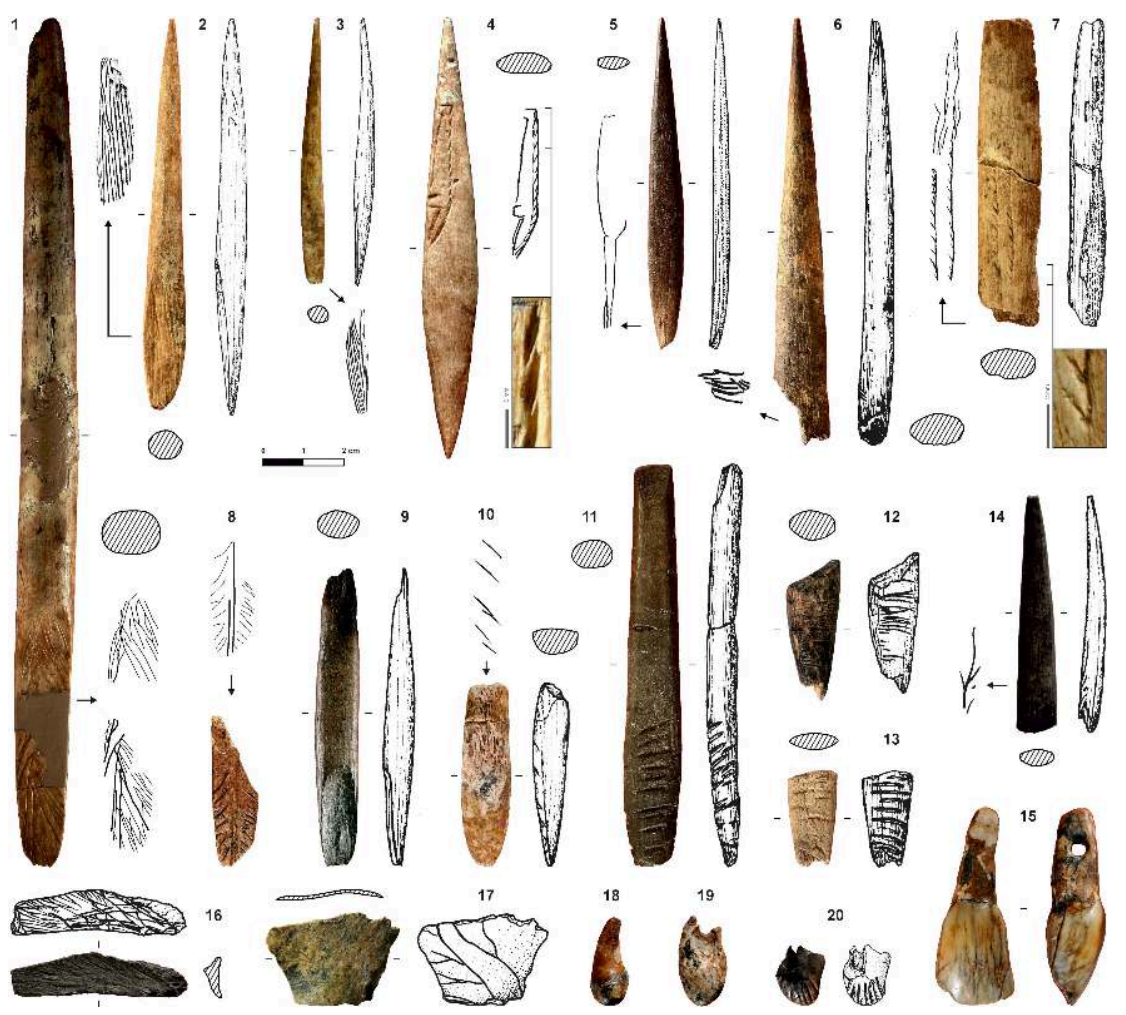

PROJeCtile Points, PLACARD TYPE: 2, 3, 9: single-beveled points with technical lines/scraping (No. 9 recycled). 4, 5: rhomboidal-type point-based points with pseudoexcisa decoration (No. 5 probable). $\mathbf{6}$ : distal fragment point with fine transversal fine lines. 10: single-beveled point with oblique line. 11, 13: flattened proximal end point with transversal incisions. 12: proximal end point with transversal fine lines. 14: point with carenated distal end and sharp edges with ramiforme engraving. ROD: 7: rod with pectiniform engraving. PENDANTS: 15: Herbivore incisive; 18, 19, 20 : Red deer canines. DECORATED BONES: 16: Multiple lines engraving. 17: ramiform engraving.

Photos Javier Fortea for Nos 1, 2, 5, 6, 7, 11, 13; Elsa Duarte for Nos 3, 4, 6, 8, 9, 10, 12, 14, 15-20. Drawings Elsa Duarte, except No 4: Alba Fernández Rey.

The differential burning is not focused on a typo/technological group or any raw material category, so we explain this as a random abandon of the pieces in the Gallery where fireplaces are placed all around the ground. Moreover, root etching and microfauna gnawing are very rare, apart from dissolution pits, desquamations, roundings and concretions that concentrate in the wall areas. This is further evidence in favor of the level's good preservation.

\section{Blank production}

Concerning the manufacturing process, antler dominates over bone and teeth (Table 9). There are no beams or defining anatomical parts to distinguish red deer from reindeer. Given the existence of red deer bones and canines at the site and the limited number of identified reindeer specimens in the Solutrean-Badegoulian-Magdalenian sites in the Cantabrian Region (Gómez-Olivencia et al. 2013), we suppose it is Cervus elaphus antler. The compact tissue ranges between 4 and $6.5 \mathrm{~mm}$ in the case of waste products and preforms, with little modification in cortical tissue. Nevertheless, it is more variable for the final products despite a higher concentration around 5 to $6.5 \mathrm{~mm}$, because some pieces are thinner $(\sim 4 \mathrm{~mm})$ and others $(\mathrm{n}=5)$ are very thick $(7-10 \mathrm{~mm})$. 
There is a lack of technological pieces (splinters) longer than the complete antler finished objects, and partially worked blanks are again shorter than finished objects. Within these preforms and waste products, there are 8 pieces obtained by knapping and 2 of them show diffuse notches. The other 6 objects show both lateral edges in oblique position, with a burr that runs along these edges next to the cortical tissue and a layered profile (Fig. 10 Nos. 10,11,12). In one piece (Fig. 10 No. 11), a crack runs along one of the steps that form the layered profile. It seems to be the result of applying hard force in order to split the blank, following the long axis of the antler, and not the result of scraping. So we tend to interpret these features as the use of splintered pieces in the knapping process (Rigaud 2004) such as coin-fente (David 2004). The large number of lithic splintered pieces and the variety of forms and measurements reinforce this possibility and it seems to be in relation with other type of actions such as coin-éclat, coin-éclat-fente and cassure sur enclume (David 2004). Moreover, even detaching and flattening could have been carried out by using splintered pieces. For example, a waste product resembles a lithic splinter and bears transverse fractures with a bifacially layered form and a medial salient area between both faces. It seems to have been laterally reduced with the aid of splintered pieces (or thick flakes resulting from the use of splintered pieces) and detached by bending (Fig. 10 No.10). Moreover, a tine shows deep and short incisions with $\mathrm{V}$ section, serrated profile and saw-tooth fracture, as a result of using splintered pieces for transversal detaching by knapping (Fig. 10 No. 7). There are four small tine fragments with tongue fractures.

Once the blanks obtained, the cortical and inner parts would be flattened by scraping, maybe starting by the lateral edges as we can see in two pieces, one unfinished (Fig. 10 No. 12) and another reconverted into a tool (Fig. 10 No.6). It bears scraped lateral edges, and the distal long bending fracture seems to have been rectified and maybe used as spatula, whereas the proximal end is raccourci and was maybe used as it has been proposed for Cuzoul de Vers (Le Guillou 2012). Antler finished objects usually bear spongy areas and scraped long sides with barely rounded sections so there is a lack of straightening of the edges, profiles and surfaces. Moreover, final polishing is barely used. Nevertheless, bone objects such as needles are highly worked and polished. Recycling process abounds and for example four points' distal ends show renewed oblique scrapings and another point shows a broken distal end in the process of being flattened and resharpened/pointed (Fig. 11 No. 9).

41 The bone products cover a large morphological variety (Table 9), but the whole chaine opératoire lacks. We have ruled out 42 bones with short and fine engraved marks as possible cut marks. These are ribs, scapulae and long bone fragments, between 20 and $60 \mathrm{~mm}$ in maximum length. Taking this as a small sample, does it represent a measurement template in bone breakage pattern intended for combustion tasks?

A selection of twelve long bones fragments $(3-6 \mathrm{~mm}$ thick) show parallel lines (separated by 1.7 to $5 \mathrm{~mm}$ ); they could be outlines or fragments of awl/needle production (Fig. 10 Nos. 14, 16). Thus, needles are 2 to $4 \mathrm{~mm}$ thick and 3 to $5 \mathrm{~mm}$ wide and two bone fragments would fit perfectly, whereas other tightly lined bones could be related to meat filleting (Castel 2012). Moreover, there is a metatarsus fragment split by percussion with parallel lines on its two faces. Given the irregularity of the lines, it could have been rejected as a preform and so restructured into a tool. It has scraped sides and the distal end has been scraped and polished/used. In addition, there is a 
possible but irregular use-break, so its use is enigmatic; it could fit as a handle or receptacle or even be decorative (Fig. 10 No. 13).

Another long bone fragment obtained by knapping has been converted into a sort of projectile point/awl. It has rectilinear convergent edges and the proximal end has been flattened by bifacial scraping, drawing a rounded form and so a general lozenge-shaped silhouette. The distal end is slightly rounded, maybe by use. There is strong measurement relationship between this preform (length $81 \mathrm{~mm}$; width $14 \mathrm{~mm}$; thickness $8 \mathrm{~mm}$ ) and a lozenge-shaped point-based point (length $80.69 \mathrm{~mm}$; width $8.89 \mathrm{~mm}$; thickness $4.68 \mathrm{~mm}$ ) (Fig. 10 No. 24; Fig. 11 No. 4), it could imply a direct reduction pattern. So the highly fire altered point-based point could be made of bone rather than antler as we had previously supposed (Duarte et al. 2014).

\section{Finished objects}

The group of projectile points consists of 39 pieces. The distal and mesio-distal fragments $(n=20,53.84 \%)$ dominate over the rest and some of them are very short and show tongue fractures. There are no longitudinal fractures. The sections vary between oval, rounded and biconvex (Fig. 10 Nos.1-5, 8; Fig. 11 Nos.1-14). Biconvex section points are usually distal fragments that have also been documented in Cuzoul de Vers; the origin of the break and the type of point they belong to are uncertain (Le Guillou 2012). Maybe these points were recovered with the game and the mesio-proximal fragments were recycled (Fig. 11 No. 9). In general, projectile points have rectilinear profiles -except for the long refitted point (Fig. 10 No. 8)- and diverse lengths for complete pieces (Fig. 10 No. 9). They have diverse silhouettes related to base types and sections. Thus single bevels show rectilinear silhouettes and rounded sections; flattened proximal end have lanceolate silhouette and oval section; pointed bases show forms that vary between lanceolate or rhomboidal and oval-biconvex sections. This has led us to propose six main templates, taking into account the maintenance/recycling processes and the fragmentary state of the assemblage:

- Point-based point (Fig. 11 No. 12);

- Point-based point with rectilinear proximal end (Fig. 10 No. 8);

- Rhomboidal-type point-based point (Fig. 11 No. 4);

- Flattened proximal end point with transverse incisions (Fig. 11 No. 11);

- Single-beveled point (Fig. 11 No. 1);

- Point with carenated distal end and sharp edges (Fig. 11 No. 14).

It is curious that the rhomboidal-type point-based point sare complete and decorated, so we hypothesized that they could be awls rather than projectile points, such as other with similar profile from Cuzoul de Vers (Le Guillou 2012). Could they otherwise be symbolic?

Rods are only two and they can be separated by their width and flattened section. They are broken (transverse-mesial) and their inferior faces are only scraped/abraded and lack oblique lines. One of them has a complex fracture and the opposite end shows a retouch, similar to a truncation (Fig. 10 No. 9; Fig. 11 No. 7).

Needles are broken at the hole, except for one. They show small round sections with a flattened proximal end and sharp edges (Fig. 10 Nos. 15, 17-23). Their width is different from the projectile points $(\sim 2-5 \mathrm{~mm}$ versus $>5-\sim 15 \mathrm{~mm})$, but from the three medial fragments $(3-5 \mathrm{~mm})$, provisionally awls. Their profile is rectilinear and rectified by 
polishing. The marginal fractures are very short-tongued, as a result of use or postdepositional processes. The length/width relationship shows that some of them could have been recycled (Fig. 10 Nos 10 and 18). They also show intense scraping in the distal ends. A decoration on the irregular awl stands out, made by oblique short lines that could help sewing, hafting, etc. (Fig. 10 No. 23).

There are three pendants made on herbivore teeth with perforation in the root (Fig. 11 No. 15). Red deer stags canines are perforated as well, one is decorated but partially broken, and hind red deer canines show fine transversal marks at the root as possible hafting means (Fig. 11 Nos. 18-20). There are two perforated bone fragments, but one of them is doubtful.

We have recorded several types of engravings, functional and/or decorative. For the projectile points, the "pike bevel" typical of Le Placard site (or tipo Placard: Utrilla 1981) stands out; it was recovered in other sites with similar culture/chronology such as Rascaño, Castillo, La Paloma, Lumentxa, El Gato 2 or Parpalló for the Iberian Peninsula. At Llonin Gallery, we find two types: one consists of two pairs of short oblique lines, one from left to right and the other the opposite, with long central line/s (Fig. 11 No. 8). The second consists of an irregular and linear beam, composed of longitudinal lines on the left and oblique lines on the right, all of them being convergent in the distal end (Fig. 11 No. 1). At the same time, there are other bevels with a less complex drawings such as parallel oblique lines, fine oblique-transverse lines, transverse mid-long incisions or intense scraping. All of them are rather ubiquitous in the Upper Paleolithic, but more numerous at least in the Cantabrian Solutrean and Archaic Magdalenian/ Badegoulian (Utrilla 1981, Corchón 1986) (Fig. 11 Nos. 2-3, 6, 9-13).

A bi-pointed piece shows an animal-like figure made by the engraving technique known as "pseudo-excise" (Barandiarán 1967 and 1973, Utrilla 1986, Duarte et al. 2014). From a morphological point of view, it consists of a series of short incision-like tracings ( $2 \mathrm{~mm}$ long $\times 1 \mathrm{~mm}$ wide on average), with an asymmetric V-shaped inner section on its long axis and a U-shaped section on its short axis. These tracings are organized in two ways, completely joined in the short axis or in oblique, touching the vertex and the short end (Fig. 11 No. 4, and probably No. 5).

So the defining features are:

- Series of short lines;

- Each line is linked to the other by the width edge or by one vertex;

- Each stroke shows an asymmetric V-shaped longitudinal section.

The technological process is tentatively determined; it would consist of the antler uplifting by each tracing, but experimentation is in process. Moreover, a similar technological process has been proposed for an Epigravettian bone of Poiana Ciresului (Romania) (Cârciumaru and Tutuianu-Cârciumaru 2009).

A mesial rod has a doubled pattern consisting of a long line combined with a series of transverse-oblique short tracings or "pectiniform" (Corchón 1986, Duarte et al. 2014) (Fig. 11 No. 7).

These functional/decorative designs are recorded in other sites and other similar patterns are added, like the series of longitudinal short tracings (i.e. Cuzoul de Vers, Le Placard). These combinations of short lines or with a long line seem to start in this period, making more complex the transverse short incisions series that are typical of 
Solutrean times and abundant in, for example, Llonin level IV. In Llonin level III, a bone fragment preserves a similar series of incisions but in an irregular outline.

Finally, there are three bone fragments with more complex decoration:

- Undulated line or "serpentiform" on a projectile point and a scapula fragment (Fig. 11 Nos. 14, 17): although broken, they seem to be vegetal patterns observed in this period (Duarte et al. 2014);

- Groups of short incisions similar to Magdalenian short lines for drawing an animal silhouette;

- Small rib fragment with several, irregular and interweaved lines; it could belong to the multiple and striated lines engravings (Fig. 11 No. 16). Although it is doubtful because it is a small fragment, it would be the only evidence of this engraving technique in portable art. On the other hand, in the Principal Rock art panel in Llonin's cave (Panel Principal) there are several hinds engraved with this technique/style (Fig. 3A).

\section{Level III functionality and spatial distribution}

While we await the results of the microstratigraphy, organic/inorganic soil constituents, fauna, charcoal and the use wear analysis, just to define the main on-site activity, we may highlight some elements about the level functionality that agree really well with a specialized activity.

Comparing all the site levels, it is clear that level III has a different characteristic. It is a generalized combustion area that was covered by spreading iron oxides before the beginning of the occupation (Fig. 4); this practice continued in some specific areas. The presence of iron oxides in Paleolithic sites is well known, as well as the combination of fire (hearth) and iron oxides. For example, among many others, the French Cuzoul de Vers rock shelter (Clottes et al. 2012) or the South African Sibudu Cave (Golberg et al. 2009).

Along with the massive presence of charcoal, ashes and iron oxides, the transport to the site of quartz-arenite and sandstone pebbles $(\sim 750$ pieces $/ \sim 200 \mathrm{~kg})$ is also relevant and extended all around the excavated area $\left(\sim 5 \mathrm{~m}^{2}\right)$.They are usually burnt, fractured/ fissured and dehydrated to different degrees (but not calcined): their heat exposure and their spatial distribution show that they were exceptionally used to structure hearths but rather as "hot stones": to maintain room temperature, to make vapour or smoke?

59 Another remarkable association contributes to support this evidence: faunal remains are abundant. Their manipulation through lithic and bone tools is intensive, from hunting to charcoal. Several domestic tasks would have been developed such as disarticulation, defleshing and intensive breaking, fur treatment (there are awls and needles), drying and/or smoking meat. The large amount of common tool types and mostly splintered pieces would serve these purposes as well as the preparation of wood and bone charcoal. Moreover, distal projectile points would have been recovered with the game. Non-utilitarian activities are absent. Several pendants and decorated objects are also in connection with the domestic sphere and the Mustelidae-type "pseudoexcise" decoration point could be related to Mustelidae clothing, extremely useful in changing climate contexts (Collard et al. 2016).

60 The distribution of the archeological record shows that Badegoulian lithic or bone typical tools are distributed all around the level III, confirming its homogeneity. 
Solutrean tools have an ample distribution through the level IV and there are no interstratigraphic contaminations with the upper level (Fig. 12).

Fig. 12. - Llonin Cave (Peñamellera Alta, Asturias, Spain): datation samples and main lithic and bone tools from level III (Badegoulian) and lithic points from level IV (Solutrean) projected in the stratigraphy.

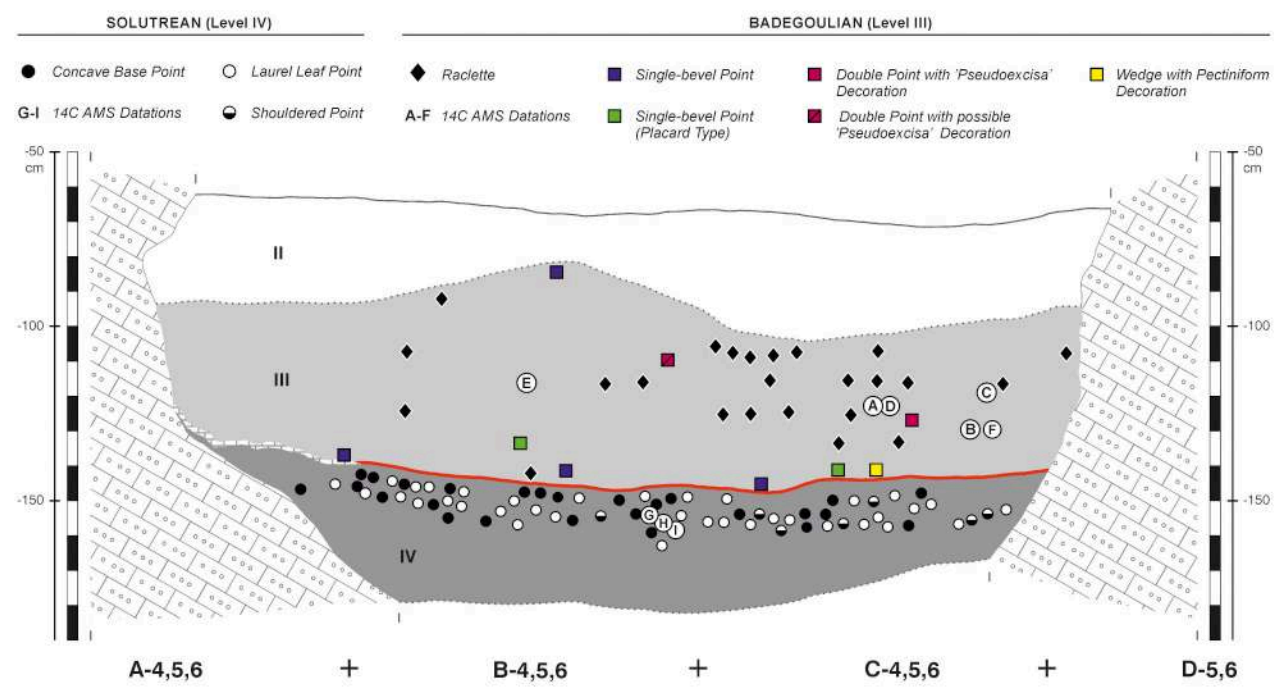

The Solutrean projected points come from the two first layers of that level just to illustrate its organisation next to the level III base. The levels and the artefacts are both projected over cave level 0 and over the maximum upper limit of level III and the lower limit of level IV (dotted line). The limit between both levels is uniform in squares $A$ and $B$, while in squares $C$ it is represented in the square $\mathrm{C} 4$ where the intersection reaches higher depth. The projected raclettes are the best examples, but there are some more in the collection distributed all over the level. A, B, C, D, E, F, G, H, I: samples references for ${ }^{\mathrm{C}} 14$ AMS datations - see Table 10.

\section{Chronology}

61 The dating is coherent (Table 10). Usually the samples were taken in the middle part of the level, to avoid contaminations from adjacent levels (Fig. 12). Focusing on the Badegoulian dates, they range between 18,400-17,500 years BP uncalibrated, so they are between the end of Older Dryas and the beginning of the Lascaux Interstadial. In the first phase, cold conditions were really significant with lower humidity compared with the previous phase (Laugerie Interstadial); the second phase was characterized by relatively "cool" conditions and a marked humidity. It is relevant to consider that usually the upper part of the levels corresponding to the Older Dryas have suffered from erosion processes caused by the increase of humidity during Lascaux, losing the information about that part of the sequence; in the last period mentioned the erosions, fluvial or flood deposits, are also present with the corresponding implications (Hoyos 1994 and 1995, Rasilla and Straus 2004). 
Table 10. - Llonin Cave (Peñamellera Alta, Asturias, Spain): ${ }^{14} \mathrm{C}$ AMS datations of Llonin Badegoulian and Upper Solutrean (Aura et al. 2012 and 2014, Bronk-Ramsey et al. 2015). Calibration IntCal 13 dataset (Radiocarbon 55 (4), 2013).

\begin{tabular}{cccccccc}
\hline $\begin{array}{c}\text { Fig. 12 } \\
\text { sample } \\
\text { reference }\end{array}$ & $\begin{array}{c}\text { Sample } \\
\text { number }\end{array}$ & $\begin{array}{c}\text { Laboratory } \\
\text { number }\end{array}$ & Date BP & SD & Material & $\begin{array}{c}\text { Cal age BP (95\%) } \\
\{0=\text { AD 1950 }\}\end{array}$ & $\begin{array}{c}\text { Cultural } \\
\text { phase }\end{array}$ \\
\hline A & LLO-71 & OXA-26042 & 17480 & 75 & Ericacea & $21520-20734$ & Badegoulian \\
B & LLO-70 & OXA-26041 & 17610 & 90 & Ericacea & $21630-20950$ & Badegoulian \\
C & LLO-68 & OXA-26338 & 17650 & 130 & Juniperus & $21628-21045$ & Badegoulian \\
D & LLO-71 & OXA-26340 & 17920 & 80 & Juniperus & $21540-21903$ & Badegoulian \\
E & LLO-31 & OXA-X-2559-11 & 18100 & 90 & Bone & $22241-21660$ & Badegoulian \\
F & LLO-69 & OXA-26339 & 18345 & 75 & Fabacea & $22418-21954$ & Badegoulian \\
G & LLO-28 & OXA-22700 & 19300 & 110 & Bone & $23460-22900$ & Upper Solutrean \\
H & LLO-27 & OXA-22699 & 19330 & 100 & Bone & $23460-22980$ & Upper Solutrean \\
I & LLO-26 & OXA-22698 & 19480 & 110 & Bone & $23550-23190$ & Upper Solutrean \\
\hline
\end{tabular}

Looking at the Cantabrian region sites involved in the above named interval radiocarbon dating, for instance: Las Caldas (levels: II-XIVc, Pasillo 3, I-11, Pasillo 7), Mirón (level 313), Aitzbitarte IV (level III), Altamira (level 6) and Las Aguas (level C2 and Hogar Inferior sector 3) (Aura et al. 2012: 70, Aura et al. 2014, Rasines del Río 2016: 113 and 139, Muñoz and Montes 2016: 802), we clearly verify that the sedimentological and taphonomical processes are disturbing the cultural attribution of the archaeological record. Fortunately, Llonin's level III didn't suffer such disturbances because of its particular location in a protected gallery (Fig. 2), so we expect that the evidence is correct.

\section{Discussion}

Actually the debate revolves around the features of Solutrean/Magdalenian transition $(\sim 18,300-17,000 \quad$ BP). Utrilla (2004) perfectly summarized the Magdalenian historiographical development in the Cantabrian Region, taking into account the research of Bosselin and Djindjian $(1999,2000)$ because they include the term Badegoulian in the sequence together with its general features. Besides the precisions added to that proposition, we may stress its significance now, because it renews a chrono-stratigraphy and a cultural systematization between the Solutrean and the Magdalenian (Utrilla 2004: 254).

Nevertheless, those facies/phases allow us to make out a changing cultural phase during a climate instability and therefore the existence of derived sedimentological processes that in many cases create biases in the archeo-stratigraphic levels' integrity. Moreover, soil morphology at the end of the Solutrean is normally irregular. The sediment is full of cryoclasts (Hoyos 1994 and 1995, Rasilla and Straus 2004), so tools belonging to next cultural groups would fill the remaining interstices. In the same way, trampling would make Solutrean previous tools come up into the upper level. Finally, different natural processes like removal, percolation, leaching and erosion would end up producing disruptions and interstratigraphic contaminations within these levels. That is why it is sometimes difficult to conclude that a particular collection belongs to one or another period. In Llonin case, the stratigraphic discontinuity is drastic, anthropically driven and isolated from this natural dynamics, so cultural mixing is to be rejected but for potential refits. 
What does Llonin level III (Galería) tell us?

- When the level is not disrupted and the occupational rate is intense (long stratigraphy and abundant archeological remains), there is a complete and specific lithic and bone assemblage.

- Despite the site's particular functionality, general features of the period are present: absence of flat and bifacial retouch and lithic projectile points, predominance of common tool types -including splintered pieces-, scarce bladelet production and microlithic tools, presence of raclettes, existence of antler single-beveled points, some of them of the Placard type, with a predominance of oval sections and pieces with "pseudo-excise" decoration, absence of art in non-utilitarian objects.

- Particularly here and generally in Asturias, the frequency of quartzite as main raw material is very important. Flaking is simple (orthogonal-centripetal) and it is focused on flake production. Nevertheless, non-local flints (from up to $200 \mathrm{~km}$ away) are carried to the site from both sides (western/eastern) of the Cantabrian Region as mobile toolkits, and in this case blade-bladelet production is notorious and entails a higher investment than local flints.

- Bone industry is made by percussion and not by grooving.

- The chronology dates fairly well the typo-technological change (or the change process) between the Solutrean and Magdalenian: 18,000-17,000 BP in round figures.

- As a hypothesis, the archeological sequence and its correlation with the rock art could modify, but just a little, the cultural assignation -at least the beginnings- of a specific and unique kind of rock engravings -and portable art?- found on the cave walls (Rasilla 2014: 116).

Therefore, are these elements enough to describe a cultural period? Are they different enough from previous and following periods? For us, Llonin level III contains more specific typological features -basically determined by the absence of- than those belonging to the Solutrean or the Magdalenian. These specificities can be related to the French and Iberian (for the moment less known) Badegoulian, as defined in cultural terms. Chronologically, it is also in relation to this period (Aura et al. 2012, Banks et al. 2011, Ducasse et al. 2014, Rasilla 2005, Raynal et al. 2014) and it is older than the Initial or Archaic Magdalenian (Straus et al. 2014, Utrilla et al. 2012).

In technological terms, Llonin level III would be defined by flaking and retouching simplification and microlithic discard. Obviously, the lithic variability is strong in comparison with other sites, because the raw material dimensions and quality are highly diverse. Anyway, it is more variable than in Solutrean or Magdalenian periods, given the higher normative and/or standardized characteristic of microlithic and microlaminar production and tools, and also for the antler grooving technique versus percussion. Overall tool groups are also in this fast-making dynamics. This technological change seems to overtake Llonin site's specificity and it takes part in all the technological and toolkit change (Aura et al. 2012, Banks et al. 2011, Borao et al. 2016, Ducasse 2010, Langlais et al. 2010, Pétillon and Ducasse 2012, Utrilla 2004, Utrilla et al. 2012). As to splintered pieces and bipolar reduction, it has been proposed as a more efficient utilization of raw material (Pargeter and Eren 2017) and an increase has been detected in other areas during the LGM as a technological response to climate instability and precarious access to raw materials (Marwick et al. 2016). Here these aspects need to be assessed, together with the whole archeological assemblage's data. In this unsteady atmosphere, we may bring to discussion how the relationship took place between, on the one hand, the size of the population and the kind of connections 
and the development of cultural accumulation and complex technologies (at least the change processes) and, on the other hand, climate and environmental variables in the distribution of human populations and its social and cultural evolution (Ducasse 2012, Burke et al. 2014 and 2017, Barton et al. 2018, Derek and Boyd 2016, Kobayashi et al. 2016, Schmidt et al. 2012).

Finally, it would be advisable to analyze again, with a new look, some levels located in the part of the archeological sequence that concerns us from sites like Las Caldas, Cova Rosa, Cueto de la Mina, La Riera, Rascaño, Antoliña and Aitzbitarte IV. If so, we could weigh the sedimentological, taphonomical and toolkit information to definitely precise its cultural attribution or the problems that make it difficult or prevent it (Rasilla and Duarte 2017).

\section{Conclusions}

In our opinion, the main question is not the term used (Archaic, Initial Magdalenian or Badegoulian) to define what is going on in the Cantabrian Region during the period we are considering. The point is that now we can better explain those problematic levels in the final part of the Solutrean or in the beginning of the Magdalenian. There are environmental (climate and sedimentological), taphonomical and cultural (technotypological change) combinations that mess up the archeological information and, sometimes, confound researchers. In this case, depending on the Solutrean or Magdalenian "eyes" of the participants, the prevalence of the cultural attribution goes on one or the other direction.

We think that Llonin clarifies sufficiently the main lines of the cultural development that coincides with shocking climatic episodes: the rattling of the LGM, at least in the Cantabrian region, continued by a real increase in humidity. Despite its main functionality, there are distinguishing elements equally observed, with their particular territorial specificities, in the same European and Iberian chronological context. Nevertheless, besides the conclusion of all the studies around this level and weaving all the data of what seems an isolate case in the Cantabrian general geological dynamics, the study of other sequences and their stratigraphic problems will allow us to better define the transition and evaluate its uni/multistep characteristics and the relationship with the possible French primary core and the Mediterranean world.

\section{BIBLIOGRAPHY}

AURA J.E., TIFFAGOM M., JORDÁ J.F., DUARTE E., FERNÁNDEZ DE LA VEGA J., SANTAMARÍA D., RASILLA M. de la, VADILLO M., PÉREZ RIPOLL M., 2012, The Solutrean-Magdalenian Transition: a view from Iberia, Quaternary International 272-273, 75-87. 
AURA J.E., RASILLA M. de la, SANTAMARÍA D., DUARTE E., JORDÁ J.F., PÉREZ RIPOLL M., SANCHís A., CARRIóN Y., wooD R., 2014, New dates for the Iberian Badegoulian: data from Cantabrian and Mediterranean regions, in: Abstracts Book XVII World UISPP Congress, Burgos 1-7 september 2014, pp. 250-251.

BANKS W.E., AUBRY T., D'ERRICO F., ZILHÃO J., LIRA-NORIEGA A., PETERSON A.T., 2011, Eco-cultural niches of the Badegoulian: Unravelling links between cultural adaptation and ecology during the Last Glacial Maximum in France, Journal of Anthropological Archaeology 30, 359-374.

BARANDIARÁN I., 1967, El Paleomesolítico del Pirineo occidental, Zaragoza, Universidad de Zaragoza (Monografías Arqueológicas, 2).

BARANDIARÁN I., 1973, Arte mueble del Paleolítico cantábrico, Zaragoza, Universidad de Zaragoza (Monografías Arqueológicas, 14).

BARTON C.M, AURA J.E., GARCíA-PUCHOL O., RIEL-SALVATORE J.G., GAUTHIER N., VADILLO M., POTHIER G., 2018, Risk and resilience in the late glacial: A case study from the western Mediterranean, Quaternary Science Reviews 184, 68-84.

BORAO M., VILLAVERDE V., AURA J.E., 2016, Debitage by fracturing in the osseous industry of Cova del Parpalló (Gandía-Valencia, Spain): A preliminary study, Quaternary International 403, 118-131.

BOSSELIN B. and DJINDJIAN F., 1999, Une révision de la séquence de la Riera (Asturies) et la question du Badegoulien cantabrique, Bulletin de la Société préhistorique française 96(2), 153-173.

BOSSELIN B. and DJINDJIAN F., 2000, Le Badegoulien en Europe sud-occidentale : faciès régionaux, paléoenvironment et filiations, in: Actas III Congresso de Arqueologia Peninsular, Vol. II : Paleolítico de la Península Ibérica, Oporto, ADECAP, pp. 363-401.

BRONK-RAMSEY C., HIGHAM T.F.G., BROCK F., BAKER D., DITCHFIELD P., STAFF R.A., 2015, Radiocarbon dates from the Oxford AMS system: Archaeometry Datelist 35*, Archaeometry 57(1), 177-216.

BURKE A., LEVAVASSEUR G., JAMES P.M.A., GUIDUCCI D., IZQUIERDO M.A., BOURGEON L., KAGEYAMA M., RAMSTEIN G., VRAC M., 2014, Exploring the impact of climate variability during the Last Glacial Maximum on the pattern of human occupation of Iberia, Journal of Human Evolution 73, 35-46.

BURKE A., KAGEYAMA M., LATOMBE G., FASEL M., VRAC M., RAMSTEIN G., JAMES P.M.A., 2017, Risky business: The impact of climate and climate variability on human population dynamics in Western Europe during the Last Glacial Maximum, Quaternary Science Reviews 164, 217-229.

CÂRCIUMARU M. and TUTUIANU-CÂRCIUMARU M., 2009, Étude technologique effectuée à l'aide du microscope digital VHX-600 sur un os gravé épigravettien de l'habitat de Poiana Ciresului-Piatra Neam, Annales d'Université “Valahia” Targoviste XI, 7-22.

CASTEL J.-C. 2012, Archéozoologie, in: Clottes J., Giraud J.-P., Chalard P. (Eds.), Solutréen et Badegoulien au Cuzoul de Vers : des chasseurs de rennes en Quercy, Liège, Université de Liège (ERAUL, 131), pp. 209-268.

CLOTTES J., GIRAUD J.-P., Chalard P. (Eds.), Solutréen et Badegoulien au Cuzoul de Vers : des chasseurs de rennes en Quercy, Liège, Université de Liège (ERAUL, 131).

COLLARD M.T.L., SANDGATHE D., ALLAN A., 2016, Fauna evidence for a difference in clothing use between Neanderthals and early modern humans in Europe, Journal of Anthropological Archaeology $44,235-246$.

CORCHÓN M.S., 1986, El arte mueble paleolítico cantábrico: Contexto y análisis interno, Santander, Ministerio de Cultura (Monografías del Centro de Investigación y Museo de Altamira, 16). 
DAVID É., 2004, Transformation des matières dures d'origine animale dans le Mésolithique de l'Europe du Nord, in: Ramseyer D. (Ed.), Industrie de l'os préhistorique, cahier XI : Matières et techniques, Paris, Société préhistorique française, pp. 113-149.

DEREK M. and BOYD R., 2016, Partial connectivity increases cultural accumulation within groups, Proceedings of the National Academy of Sciences 113, 2982-2987.

DUARTE E., RASILLA M. de la, AURA E., 2014, La técnica pseudoexcisa en el Badeguliense/

Magdaleniense arcaico de Asturias, Archivo de Prehistoria Levantina XXX, 27-55.

DUARTE E., SANTAMARÍA D., FORCELLEDO E., TARRIÑo A., RASILLA M. de la, 2016, El sílex como recurso mineral en la Prehistoria de Asturias, Cuadernos de Prehistoria y Arqueología de la Universidad de Granada 26, 11-28.

DUCASSE S., 2010, La " parenthèse » badegoulienne : fondements et statut d'une discordance industrielle au travers de l'analyse techno-économique de plusieurs ensembles lithiques méridionaux du Dernier Maximum Glaciaire, thesis, Toulouse, Université Toulouse II - Le Mirail.

DUCASSE S., 2012, What is left of the Badegoulian "interlude"? New data on cultural evolution in southern France between 23,500 and 20,500 cal. BP, Quaternary International 272-273, 150-165.

DUCASSE S. et LANGLAIS M., 2007, Entre Badegoulien et Magdalénien, nos cœurs balancent... Approche critique des industries lithiques du sud de la France et du Nord-Est espagnol entre 19000 et 16500 BP, Bulletin de la Société préhistorique française 104(4), 771-785.

DUCASSE S., PÉTILLON J.-M., RENARD C., 2014, Le cadre radiométrique de la séquence solutréobadegoulienne du Cuzoul de Vers (Lot, France) : lecture crique et compléments, Paleo 25, 37-58.

FONTES L.M., STRAUS L.G., GONZÁLEZ M.R., 2016, Lithic raw material conveyance and hunter-gatherer mobility during the Lower Magdalenian in Cantabria, Spain, Quaternary International 412, 66-81.

FORTEA J., RASILLA M. de la, RODRíGUEZ OTERo V., 1995, La Cueva de Llonin (Llonin, Peñamellera Alta): Campañas de 1991 a 1994, in: Excavaciones Arqueológicas en Asturias 1991-94, Oviedo, Gobierno del Principado de Asturias (Excavaciones Arqueológicas en Asturias, 3), pp. 33-43.

FORTEA J., RASILLA M. de la, RODRíGUEZ OTERO V., 1999, La Cueva de Llonin (Llonin, Peñamellera Alta): Campañas de 1995 a 1998, in: Excavaciones Arqueológicas en Asturias 1995-98, Oviedo, Gobierno del Principado de Asturias (Excavaciones Arqueológicas en Asturias, 4), pp. 59-68.

FORTEA J., RASILLA M. de la, RODRÍGUEZ OTERO V., 2004, L'art pariétal et la séquence archéologique paléolithique de la grotte de Llonin (Peñamellera Alta, Asturies, Espagne), Préhistoire, art et sociétés LIX, 7-29.

FORTEA J., RASILLA M. de la, SANTAMARÍA D., MARTíNEZ L., DUARTE E., FERNÁNDEZ DE LA VEGA J., 2010, El Paleolítico Superior en Asturias en los albores del siglo XXI, in: Mangado X. (ed.), Jornadas Internacionales sobre el Paleolítico Superior Peninsular: Novedades del siglo XXI. Homenaje al Prof. Javier Fortea, Barcelona, Universidad de Barcelona (Monografías del SERP, 8), pp. 271-289.

GENESTE J.-M., 1988, Les industries de la grotte Vaufrey : technologie du débitage, économie et circulation de la matière première lithique, in: Rigaud J.-P. (Ed.), La grotte Vaufrey à Cenac et SaintJulien (Dordogne) : paléoenvironnements, chronologie et activités humaines, Paris, Société préhistorique française (Mémoires de la Société préhistorique française, 19), pp. 441-518.

GOLDBERG P., MILLER C.E., SCHIEGL S., LIGOUIS B., BERNA F., CONARD N.J., WADLEY L., 2009, Bedding, hearths, and site maintenance in the Middle Stone Age of Sibudu Cave, KwaZulu-Natal, South Africa, Archaeological and Anthropological Sciences 1 (2), 95-122. 
GómeZ-OliVENCIA A., ARCEREDILLO D., ÁlVAREZ-LAo D.J., GÁrATE D., SAN PEDRO Z., CASTAÑos P., RÍOSGARAIZAR J., 2013, New evidence for the presence of reindeer (Rangifer tarandus) on the Iberian Peninsula in the Pleistocene: an archaeopalaeontological and chronological reassessment, Boreas, 10.1111/bor.12037.

HIScocк P., 2002, Quantifying the size of artefact assemblages, Journal of Archaeological Science 29, 251-258.

HOYOS M., 1994, Características sedimentokársticas y paleoclimáticas de los interestadios de Laugerie y Lascaux en la Cornisa Cantábrica, Férvedes 1, 21-37.

HOYOS M., 1995, Paleoclimatología del Tardiglaciar en la Cornisa cantábrica basada en los resultados sedimentológicos de yacimientos arqueológicos kársticos, in: Moure A. and González Sainz C. (Eds.), El final del Paleolítico cantábrico, Santander, Servicio de Publicaciones de la Universidad de Cantabria, pp. 15-75.

KOBAYASHI Y., OHTSUKI I., WAKANO J.Y., 2016, Population size vs. social connectedness: A gene-culture coevolutionary approach to cumulative cultural evolution, Theoretical Population Biology 111, 8795.

LANGLAIS M., PÉTILLON J.-M., DUCASSE S., LENOIR M., 2010, Badegoulien versus Magdalénien : entre choc culturel et lente transition dans l'Aquitaine paléolithique, in: Mestrot V. (Ed.), De Néandertal à l'homme moderne : l'Aquitaine préhistorique, vingt ans de découvertes (1990-2010), Bordeaux, Confluences, pp. 117-129.

LE GUILLOU Y., 2012, Premier regard sur la matière dure animale ouvragée, in: Clottes J., Giraud J.-P., Chalard P. (Eds.), Solutréen et Badegoulien au Cuzoul de Vers : des chasseurs de rennes en Quercy, Liège, Université de Liège (ERAUL, 131), pp. 279-354.

LEBON M., 2010, Caractérisation des ossements chauffés en contexte archéologique : étude comparative de matériel moderne et fossile par spectroscopie infrarouge, Palethnologie 2,149162.

MARTÍNEZ L., 2015, El Gravetiense en el sector occidental cantábrico y sus conexiones pirenaicas, Oviedo, Servicio de Publicaciones de la Universidad de Oviedo.

MARWICK B., CLARKSON C., O'CONNOR S., COLLINS S., 2016, Early modern human lithic technology from Jerimalai, East Timor, Journal of Human Evolution 101, 45-64.

MUÑOZ E. and MONTES R., 2016, Los datos culturales y su organización crono-estratigráfica: La secuencia crono-cultural de la zona estudiada, in: Lasheras J.A. (Ed.), Proyecto de Investigación "Los tiempos de Altamira": Actuaciones arqueológicas en las cuevas de Altamira, Cualventi, El Linar y Las Aguas (Alfoz de Lloredo, Cantabria, España), Madrid, Ministerio de Educación, Cultura y Deporte (Monografías del Museo y Centro Nacional de Altamira, 26), pp. 793-827.

PARGETER J. and EREN M.I., 2017, Quantifying and comparing bipolar versus freehand flake morphologies, production currencies, and reduction energetics during lithic miniaturization, Lithic Technology 42(2-3), 90-108.

PÉTILLON J.-M. and DUCASSE S., 2012, From flakes to grooves: A technical shift in antlerworking during the last glacial maximum in southwest France, Journal of Human Evolution 62(4), 435-465.

RASILLA M. de la, 2005, El Solutrense Cantábrico: reflexiones en torno a un diagnóstico recurrente, Lancia 5, 33-44. 
RASILLA M. de la, 2014, Los espacios rupestres paleolíticos de la cuenca de los ríos Cares-Deva (Asturias), in: Blas Cortina M.Á. de (Ed.), Expresión simbólica y territorial: los cursos fluviales y el arte paleolítico, Oviedo, Real Instituto de Estudios Asturianos, pp. 93-128.

RASILLA M. de la and DUARTE E., 2017, El final del Solutrense en la región cantábrica, in: Abstracts Book of the Solutrean: Third International Conference, 12-14 october 2017, ICArEHB-Universidad do Algarve, p. 53.

RASILLA M. de la and DUARTE E., 2018, ¿Casualidad o Estrategia? Las aguas termales y mineromedicinales en la configuración de los yacimientos con arte paleolítico de Asturias y su correlato cantábrico, Nailos 5, 43-64.

RASILla M. de la and SANTAMARÍA D., 2011-12, El Paleolítico Medio en Asturias, Mainake XXXIII, 3162.

RASILla M. de la and STRAus L.G., 2004, El Poblamiento de la Región Cantábrica durante el Último Máximo Glacial: Gravetiense y Solutrense, Kobie, series Anejos 8, 209-242.

RASilla M. de la, SANTAMARÍA D., RODRÍGuez OTERo V., 2014, Llonin Cave (Peñamellera Alta, Asturias), in: Sala R., Carbonell E., Bermúdez de Castro J.M., Arsuaga J.L. (Eds.), Los cazadores recolectores del Pleistoceno y del Holoceno en Iberia y el Estrecho de Gibraltar: Estado actual del conocimiento del registro arqueológico, Burgos, Universidad de Burgos y Fundación Atapuerca, pp. 663-665.

RASILLA M. de la, SANTAMARÍA D., DUARTE E., 2015, Asturias en la geografía neandertal y musteriense de la península ibérica, Espacio, Tiempo y Forma, series I, Prehistoria y Arqueología 8, 237-260.

RASILLA M. de la, DUARTE E., CAÑAVERAS J.C., SANTOS G., CARRIÓN Y., TORMO C., SÁNCHEZ-MORAL S., MARÍNARROYO A.B., JONES J.R., AGUDO L., GUTIÉRREZ I., SUÁREZ P., LÓPEZ C., GONZÁLEZ-PUMARIEGA M., 2018, El Abrigo de La Viña (La Manzaneda, Oviedo) 2013-2016, Excavaciones Arqueológicas en Asturias 2013-2016, Oviedo, Gobierno del Principado de Asturias (Excavaciones Arqueológicas en Asturias, 8), pp. 107-120.

RASINES DEL Río P., 2016, Cronología de los yacimientos arqueológicos de Altamira, Cualventi, El Linar y Las Aguas (Cantabria ), in: Lasheras J.A. (Ed.), Proyecto de Investigación "Los tiempos de Altamira": Actuaciones arqueológicas en las cuevas de Altamira, Cualventi, El Linar y Las Aguas (Alfoz de Lloredo, Cantabria, España), Madrid, Ministerio de Educación, Cultura y Deporte (Monografías del Museo y Centro Nacional de Altamira, 26), pp. 132-147.

RAYNAL J.-P., LAFARGe A., RÉmy D., DELVIGNe V., GUADELli J.-L., COSTAMAGNo S., LE GALl O., DAUJEARD C., VIVENT D., FERNANDES P., LE CORRE-LE BEUX M., VERNET G., BAZILE F., LEFÈVRE D. 2014, Datations SMA et nouveaux regards sur l'archéo-séquence du Rond-du-Barry (Polignac, Haute-Loire), Comptes rendus palevol 13(7), 623-636.

RIGAUD A., 2004, Transformation du bois de renne au Badegoulien : l'exemple de l'abri Fritsch (Indre, France), in: Ramseyer D. (Ed.), Industrie de l'os préhistorique, cahier XI : Matières et techniques, Paris, Société préhistorique française, pp. 75-78.

RISETTO J.D., 2009, Late Pleistocene Hunter-Gatherer Mobility Patterns and Lithic Exploitation in Eastern Cantabria (Spain), thesis, Albuquerque, University of New Mexico.

RODA X., MORA R., MARTÍNEZ-MORENO J., 2015, Identifying bipolar knapping in the Mesolithic of Font del Ros (northeast Iberia), Philosophical Transactions of the Royal Society, series B 370, 20140354.

SANTAMARÍA D., 2012, La transición del Paleolítico Medio al Superior en Asturias: El abrigo de La Viña (La Manzaneda, Oviedo) y la Cueva de El Sidrón (Borines, Piloña), Oviedo, Servicio de Publicaciones de la Universidad de Oviedo. 
SCHMIDT I., BRADTMÖLLER M., KEHL M., PASTOORS A., TAFELMAIER I., WENINGER B., WENIGER G.-C., 2012, Rapid climate change and variability of settlement patterns in Iberia during the Late Pleistocene, Quaternary International 274, 179-204.

STINER M.C., KUHN S.L., WEINER S., BAR-YOSEF O., 1995, Differential Burning, Recrystallization, and Fragmentation of Archaeological Bone, Journal of Archaeological Science 22, 223-237.

STRAUS L.G., GONZÁLEZ MORALES M.R., FONTES L.M., 2014, Initial Magdalenian artifact assemblages in El Mirón cave (Ramales de la Victoria, Cantabria, Spain): A preliminary report, Zephyrus LXXIII, 45-65.

TARRIÑo A., 2016, Procedencia de los sílex del proyecto Los tiempos de Altamira (yacimientos de Cualventi, El Linar y Las Aguas), in: Lasheras J.A. (Ed.), Proyecto de Investigación "Los tiempos de Altamira": Actuaciones arqueológicas en las cuevas de Altamira, Cualventi, El Linar y Las Aguas (Alfoz de Lloredo, Cantabria, España), Madrid, Ministerio de Educación, Cultura y Deporte (Monografías del Museo y Centro Nacional de Altamira, 26), pp. 457-476.

TARRIÑo A., DUARTE E., SANTAMARÍA D., MARTíNEZ L., FERNÁNDEZ DE LA VEGA J., SUÁREZ P., RODRÍGUEZ V., FORCELLEDO E., RASILLA M. de la, 2013, El Sílex de Piloña: Caracterización de una nueva fuente de materia prima en la Prehistoria de Asturias, in: Rasilla M. de la (Ed.), F. Javier Fortea Pérez, Universitatis Ovetensis Magister: Estudios en Homenaje, Oviedo, Ediciones de la Universidad de Oviedo y Ménsula Ediciones, pp. 115-132.

TARRIÑO A, ELORRIETA I., GARCÍA-ROJAS M., 2015, Flint as raw material in prehistoric times: Cantabrian Mountain and Western Pyrenees data, Quaternary International 364, 94-108.

UTRILLA P., 1981, El Magdaleniense Inferior y Medio en la Costa Cantábrica, Santander, Ministerio de Cultura (Monografías del Centro de Investigación y Museo de Altamira, 4).

UTRILLA P., 1986, La varilla 'pseudoexcisa' de Aitzbitarte IV y sus paralelos franceses, in: Estudios en homenaje al Dr. Antonio Beltrán Martínez, Zaragoza, Universidad de Zaragoza, pp. 205-225.

UTRILLA P., 2004, Evolución histórica de las sociedades cantábricas durante el Tardiglaciar: el Magdaleniense Inicial, Inferior y Medio (16.500-13000 BP), Kobie, series Anejos 8, 243-274.

UTRILLA P., DOMINGO R., MONTES L., MAZO C., RODANÉS J.M., BLASCO F., ALDAY A., 2012, The Ebro Basin in NE Spain: A crossroads during the Magdalenian, Quaternary International 272-273, 88-104.

\section{ABSTRACTS}

Llonin cave is located in the Cares river valley, between the sea and the Cantabrian Cordillera. In level III, hunted fauna comes from a rocky and mountainous biotope with chamois predominance over red deer and Spanish ibex. On top of this level there is an Upper Magdalenian level (II) and underneath an Upper Solutrean one (IV). Level III is formed by materials linked to fire, with a specific functionality, and there is an extraordinary association of elements: raclettes, singlebeveled points (Placard type) and "pseudoexcisa" decoration. In addition, the substrate tools dominate, beginning with the splintered pieces, which are the best represented, both in quartzite and flint, followed by notches and denticulates in quartzite. Flakes are the priority blanks; blade production is low and bladelets are scarce. Actually the archaeological record is not related to the Cantabrian Solutrean or the Magdalenian, but agrees with the Badegoulian. The level has been dated $\sim 18.000$ BP (21584-21935 cal BP).

La grotte de Llonin est située dans la vallée du Cares, entre la mer et la cordillère cantabrique. La faune chassée du niveau III correspond à celle d'un biotope rocheux et montagnard où le chamois 
prédomine sur le cerf et le bouquetin. Ce niveau est situé entre les niveaux IV (Solutréen supérieur) et II (Magdalénien supérieur). Il est constitué de matériaux liés au feu, avec une destination fonctionnelle très spécifique. Il a livré une association exceptionnelle d'éléments: raclettes, sagaies du type Placard et technique pseudo-excisée. Les outils lithiques du fonds commun sont majoritaires: les pièces esquillées sont les outils les plus représentés, tant en quartzite qu'en silex, suivies par les encoches et denticulés en quartzite. Les supports prioritaires sont les éclats, tandis que la production laminaire est réduite et que les lamelles sont rares. Sans rapport avec le Solutréen ou le Magdalénien cantabriques, ce niveau, daté d'environ 18000 BP (21 584-21 935 cal. BP) renvoie aux traditions techniques badegouliennes.

INDEX

Keywords: Last Glacial Maximum, chronology, fire, site functionality Mots-clés: chronologie, feu, fonctionnalité

Geographical index: Région cantabrique

\section{AUTHORS}

\section{MARCO DE LA RASILLA VIVES}

Área de Prehistoria, Universidad de Oviedo

ELSA DUARTE MATÍAS

Área de Prehistoria, Universidad de Oviedo

JOAN EMILI AURA TORTOSA

Departamento de Prehistoria y Arqueología, Universidad de Valencia

\section{ALFRED SANCHIS SERRA}

Servicio de Investigación Prehistórica (SIP), Museo de Prehistoria de Valencia

YOLANDA CARRIÓN MARCO

Departamento de Prehistoria y Arqueología, Universidad de Valencia

\section{MANUEL PÉREZ RIPOLL}

Departamento de Prehistoria y Arqueología, Universidad de Valencia

\section{VICENTE RODRÍGUEZ OTERO}

Área de Prehistoria, Universidad de Oviedo 
Les occupations humaines sur le site de plein air du Paléolithique supérieur de Montlleó (Prats i Sansor, Lérida, Espagne) : nouvelles données

\author{
Human occupations at the open air Upper Paleolithic site of Montlleó \\ (Prats i Sansor, Lérida, Spain): new data \\ Xavier Mangado, Marta Sánchez de la Torre, Mathieu Langlais, Núria \\ Rodriguez, Jordi Nadal, Lluis Lloveras, José-Miguel Tejero, Gala García- \\ Argudo, Oriol Mercadal et Josep Maria Fullola
}

En hommage à Oriol Mercadal

Ce travail fait partie du projet « La conca mitja i alta del Segre durant la Prehistòria » (2014/100479), financé par la Generalitat de Catalunya. Les travaux ont aussi reçu l'apport économique des projets HAR 2014-55131 du MICINN espagnol et SGR2017 de la Generalitat de Catalunya. M. Sánchez de la Torre bénéficie d'un contrat postdoctoral Juan de la Cierva du MEC espagnol (FJCI-2016-27911). Nous voudrions aussi remercier les réviseurs du travail pour tous leurs commentaires et corrections au texte.

\title{
Introduction : les conditions paléo-environnementales
}

1 Jusqu'aux années 1980, un vif débat animait les spécialistes quand il s'agissait d'établir si les conditions environnementales avaient permis l'installation humaine de chaque côté de la zone axiale pyrénéenne durant le Pléistocène supérieur. Aux conditions glaciaires rigoureuses du versant nord des Pyrénées s'opposait un versant sud où l'extension des glaciers était réduite, $d u$ fait d'un climat sous influence 
méditerranéenne, plus tempéré et plus ensoleillé. Deux glaciers principaux structuraient la vallée de la Cerdagne. Sur le versant nord, le glacier du Querol aurait atteint 26 kilomètres, avec une moraine terminale à 1200 mètres d'altitude (Calvet 2004), tandis que le glacier de la Têt mesurait moins de 20 kilomètres, avec une moraine terminale à 1500 mètres d'altitude (Delmas et al. 2008).

2 La chronologie du Dernier Maximum glaciaire pyrénéen montre une certaine diachronie par rapport au Dernier Maximum glaciaire global (Gillespie et Molnar 1995), les données récentes suggérant des divergences régionales significatives (Bordonau et al. 1992 et 1993, Pallàs et al. 2005, Jalut et Turu 2009). Les travaux sur le versant sud menés par des géologues spécialistes du Quaternaire (Bordonau et al. 1992) ont permis d'établir un maximum glaciaire vers $50000 \mathrm{BP}$, suivi d'une période assez rapide de retrait des glaciers. Ce contexte climatique lié aux caractéristiques physiques propres à la chaîne conditionne deux grandes périodes biogéographiques :

- Entre 30000 et $16900 \mathrm{cal}$. BP, un milieu typiquement glaciaire, avec un paysage ouvert à végétation steppique;

- Entre 16900 et 11700 cal. BP - période connue comme Last Termination -, un milieu caractérisé par l'alternance de périodes froides et tempérées, ces dernières permettant le développement d'une steppe plus herbacée et une mise en place progressive d'essences arborées (Jalut et Turu 2009). Cette proposition, définie dans un cadre régional large, semble bien s'appliquer au territoire de la Cerdagne.

3 Quoi qu'il en soit, avant la mise au jour du site de Montlleó, la seule indication d'un peuplement ancien en Cerdagne était apportée par la découverte hors stratigraphie de trois pièces lithiques en quartzite d'aspect moustéroïde dans la grotte B d'olopte (Girona, Espagne) (Fullola et Cebrià 1996).

\section{Le site de Montlleó}

En 1998, la découverte par un amateur du site de Montlleó (Prats i Sansor, Lérida, Espagne) au Coll de Saig, à une altitude de 1144 mètres, fournit la première preuve incontestable d'une occupation pléistocène en Cerdagne (fig. 1). 
Fig. 1. - Localisation des sites de Montlleó (Prats i Sansor, Lérida, Espagne) et d'Olopte (Girona, Espagne) et planimétrie du site de Montlleó avec les trois secteurs fouillés et la localisation du sondage mené en 2010.

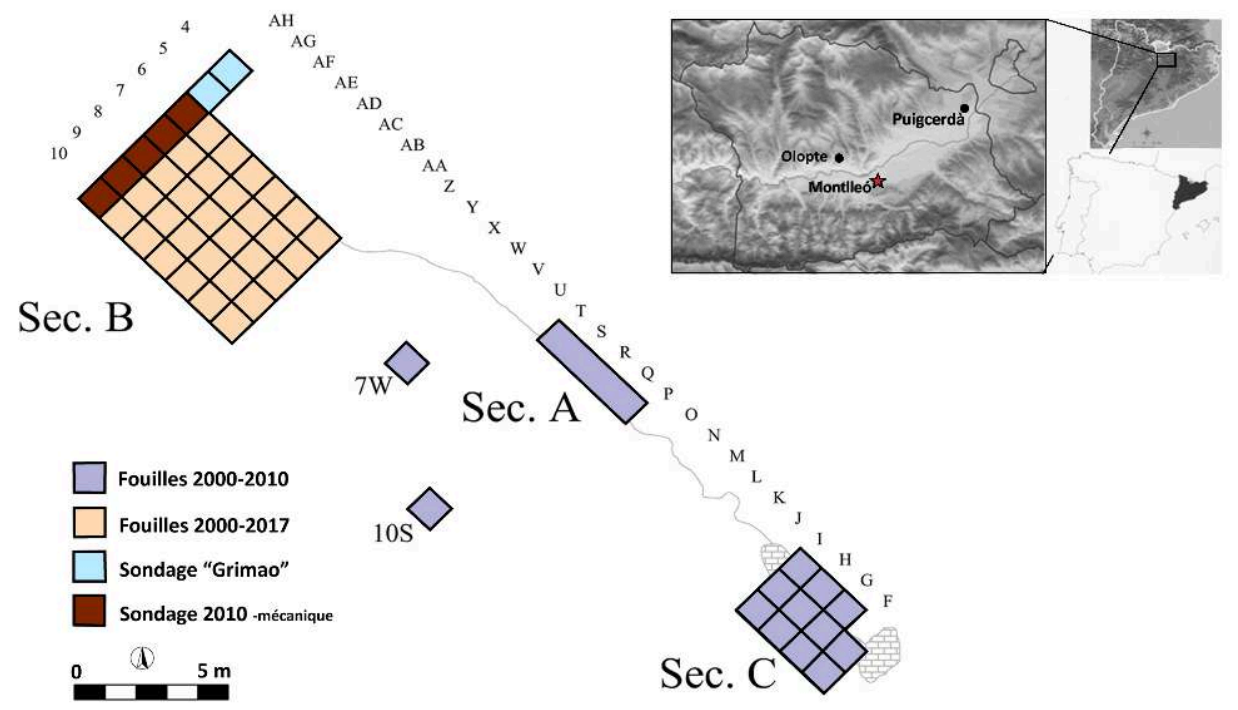

PAO Marta Sánchez de la Torre.

5 Le site, localisé sur une petite butte au cœur de la plaine, fut repéré grâce à une fracture sédimentaire liée à l'activité minière menée à proximité immédiate jusque dans les années 1980. Il s'agissait d'une exploitation en plein air de lignites issus de la bordure de l'ancien lac miocène de la Cerdagne. La coupe naturelle permit au découvreur de ramasser les premiers objets avant le démarrage des fouilles en 2000.

Depuis le début des fouilles, plusieurs dates ${ }^{14} \mathrm{C}$ ont confirmé l'ancienneté des occupations préhistoriques (Bronk Ramsey et al. 2000, Fullola 2001). Les deux premières datations, en provenance des secteurs $B$ et $C$, ont été considérées comme subcontemporaines du point de vue archéologique, confirmant l'âge magdalénien des industries. La troisième date, certes un peu plus ancienne, ne contredisait pas ce diagnostic. En 2010, la réalisation d'un sondage pour préciser la stratigraphie a permis de prélever, dans un ensemble jugé stérile, un charbon de bois que nous avons fait dater. Le résultat de cette quatrième date est sans appel $(18860 \pm 80 \mathrm{BP}$, soit 22 960-22 486 cal. BP), documentant une occupation à Montlleó antérieure au Magdalénien (tabl. 1, fig. 2). Cette datation nous a amenés à repenser la présence sur le site d'un certain nombre d'éléments.

Tabl. 1. - Site de Montlleó (Prats i Sansor, Lérida, Espagne) : dates ${ }^{14} \mathrm{C}$.

\begin{tabular}{cccc}
\hline Référence & Matériaux & Date BP & Date cal. BP \\
\hline OxA-9017 & Molaire de cheval & $15440 \pm 80$ & $18873-18538$ \\
OxA-14034 & Charbon de bois & $15550 \pm 140$ & $19134-18525$ \\
OxA-X2234-52 & Molaire de cheval & $16900 \pm 110$ & $20666-20073$ \\
OxA-23973 & Charbon de bois & $18860 \pm 80$ & $22960-22486$ \\
\hline
\end{tabular}

Calibrations obtenues avec le programme OxCal v4.3.2 Bronk Ramsey (2017). 
Fig. 2. - Site de Montlleó (Prats i Sansor, Lérida, Espagne) : calibration des quatre datations ${ }^{14} \mathrm{C}$.

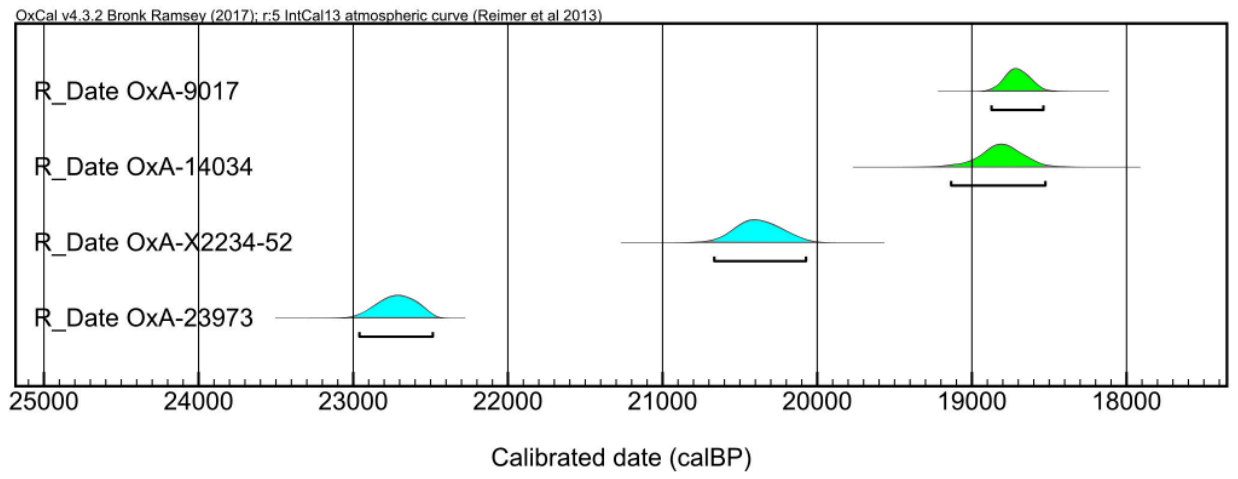

PAO Marta Sánchez de la Torre.

7 En effet, la révision et l'identification précise d'un certain nombre de matériaux lithiques à valeur typologique diagnostique (raclettes et pointes à cran), ainsi que la projection de la totalité des pièces coordonnées (fig. 3), mettent en évidence deux niveaux différents séparés par un ensemble quasi stérile au sein d'une séquence stratigraphique homogène du point de vue macroscopique. Ces deux subdivisions n'avaient pas pu être mises en évidence aussi clairement pendant les travaux de fouille. Dans l'ensemble supérieur, on retrouve principalement les armatures lamellaires caractéristiques du Magdalénien inférieur, et dans l'ensemble inférieur, plusieurs raclettes rappelant le Badegoulien ainsi que quatre pointes à cran attribuables au Solutréen final méditerranéen.

Fig. 3. - Site de Montlleó (Prats i Sansor, Lérida, Espagne) : projection sur un plan vertical de l'emplacement des vestiges lithiques, des charbons datés et de l'une des Tritia heynemanni du secteur $B$, où l'on peut observer les deux niveaux archéologiques.

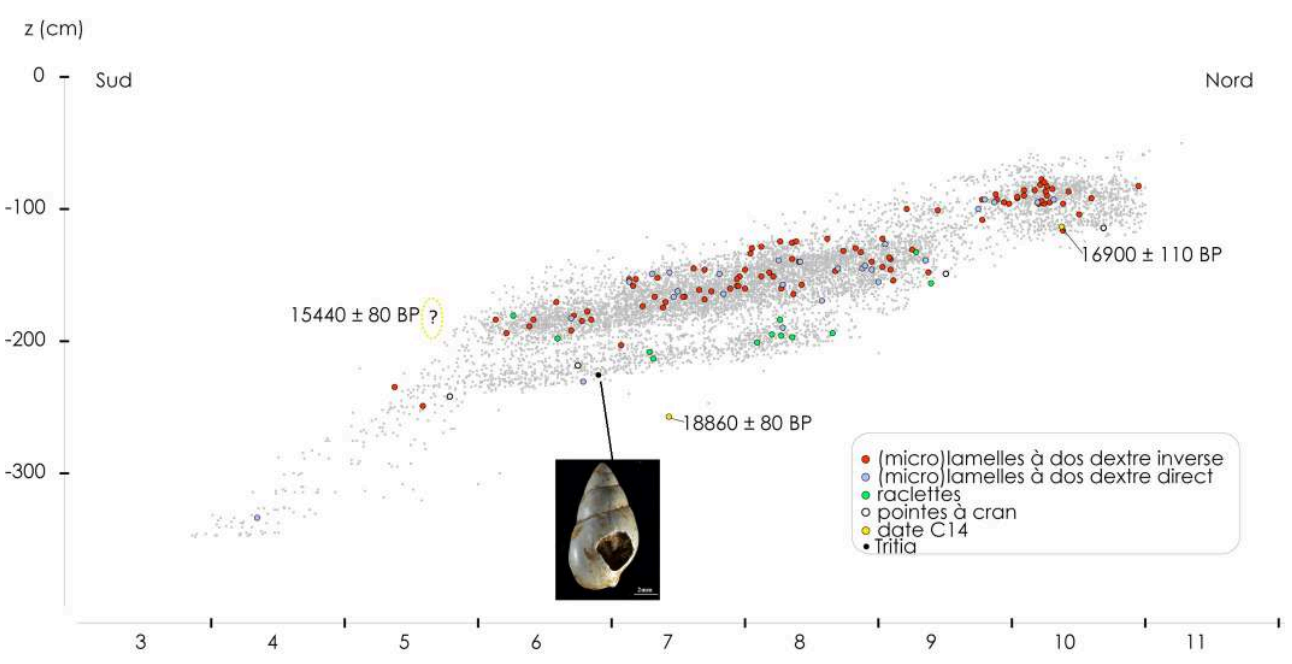

PAO Mathieu Langlais.

8 L'analyse détaillée des différents secteurs de fouille nous a fourni des informations sur le développement des occupations, lesquelles auraient eu lieu, selon l'analyse micromorphologique, sous des conditions climatiques froides, mais avec une certaine humidité. Ces occupations seraient donc contemporaines du stade glaciaire $2 \mathrm{~B} 2 \mathrm{~b}$, 
caractérisé par des processus édapho-sédimentaires de gélifraction et de cryoturbation du matériel détritique (Mangado et al. 2006, Bergadà et Serrat 2009).

9 Cette même analyse montre comment les processus taphonomiques ont mené à la perte d'une partie du remplissage sédimentaire original et à l'altération partielle du reste du dépôt par de légers mouvements de masse (solifluxion), qui n'empêchent pas cependant l'observation de la relation spatiale entre les différents éléments. Ces processus ont surtout été actifs dans les niveaux supérieurs; plus profondément dans la stratigraphie, les altérations sont largement moins significatives, comme le montrent notamment la disparition de la patine blanche des pièces lithiques et une meilleure conservation des ossements (Esteve 2009).

En attendant de pouvoir préciser la subdivision du matériel en deux niveaux, l'étude des vestiges est présentée dans cette étude comme un même ensemble. Si l'ensemble supérieur paraît homogène et attribuable au Magdalénien inférieur, en revanche il est pour le moment impossible de considérer l'ensemble inférieur comme un ensemble unique et homogène, l'étude taphonomique et archéostratigraphique restant à faire.

\section{L'industrie lithique}

11 Dans le cadre de ce travail, nous ne distinguerons pas les deux ensembles stratigraphiques et présenterons le matériel comme un tout, à l'exception de certains marqueurs particuliers.

L'analyse de l'approvisionnement en matières premières lithiques met en évidence une industrie lithique polylithologique. L'ensemble montre une bonne connaissance du territoire proche, à travers l'apport significatif de ressources lithiques disponibles localement dans la vallée : les rhyolites, les lydiennes, le quartz et les quartzites.

Par ailleurs, les analyses pétroarchéologiques ont mis en évidence l'existence d'un comportement d'anticipation des groupes humains qui ont fréquenté le site, et ce à travers la présence de silex d'origine lointaine (Sánchez de la Torre 2015). Grâce à ces nouvelles études, jusqu'à six types différents de silex ont pu être repérés, leurs origines précises étant actuellement discutées par le biais d'études pétrographiques et géochimiques. On sait notamment que certains silex proviennent du versant nord des Pyrénées : le silex du Flysch d'Hibarette-Montgaillard et le silex de Montsaunès-Buala, dont les sources se trouvent à une centaine de kilomètres au nord-ouest de Montlleó (Sánchez de la Torre et al. 2017). Des silex originaires du versant sud-pyrénéen sont également documentés : ce sont des silex marins de la formation Agua-Salenz, dont les gîtes les plus proches sont à quelque 80 kilomètres au sud-ouest du site (Sánchez de la Torre et Mangado 2016). La détermination de l'origine des silex lacustres, les plus nombreux, reste cependant incertaine, et des études géochimiques sont en cours afin de préciser leur lieu de collecte exact, ces matériaux pouvant tout autant provenir du nord que du sud de la chaîne pyrénéenne (fig. 4). 
Fig. 4. - Site de Montlleó (Prats i Sansor, Lérida, Espagne) : origines possibles des matières premières lithiques étudiées.

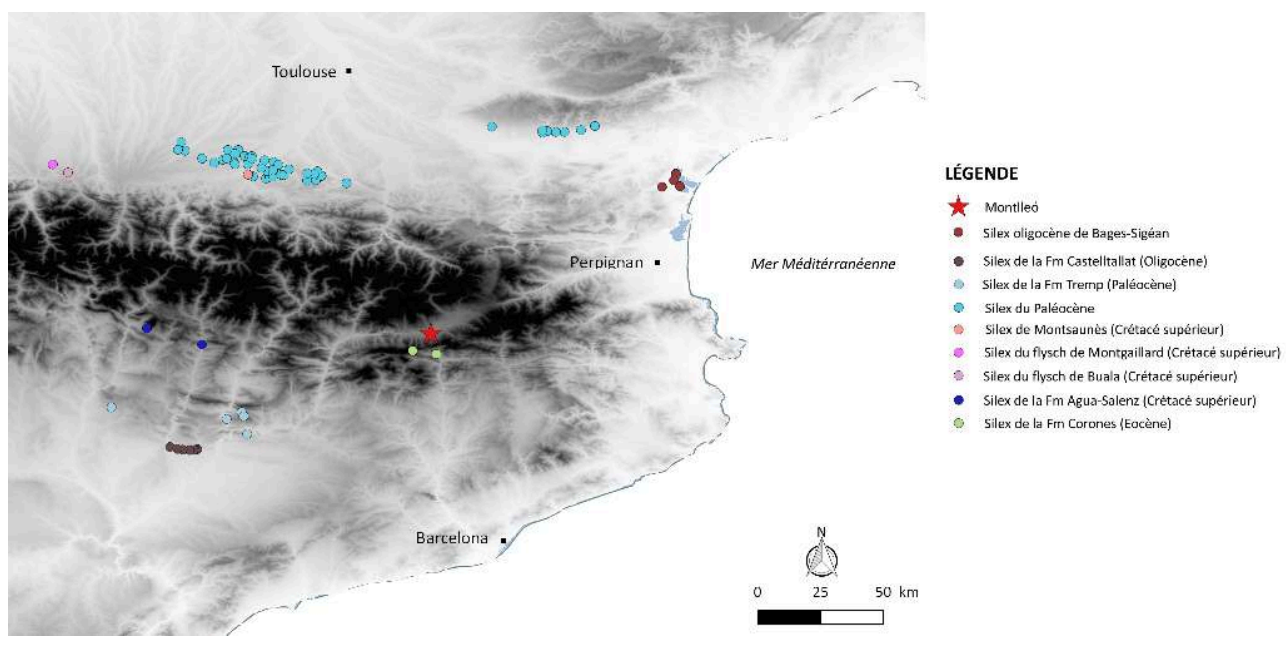

D’après Sánchez de la Torre 2015.

L'ensemble lithique récupéré sur le site de Montlleó dépasse les 20000 vestiges. Plusieurs chaînes opératoires sont mises en œuvre sur place (fig.5), comme en témoignent notamment les multiples déchets de débitage lamellaire.

Fig. 5. - Sous-système techno-économique lithique.
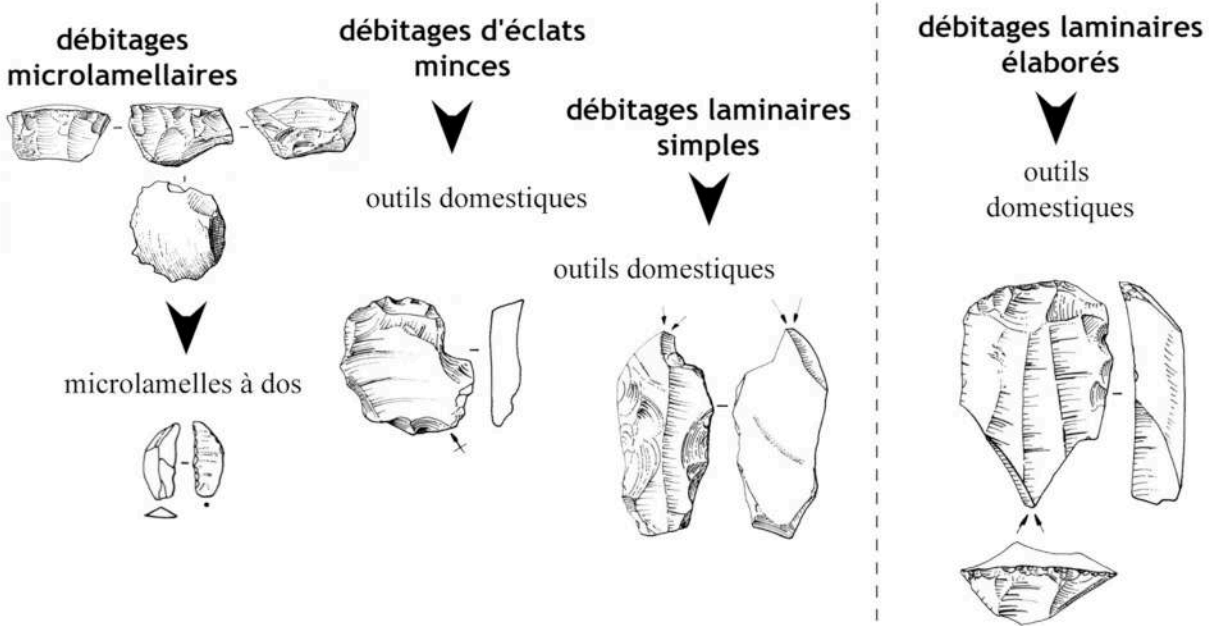

D’après Langlais 2010.

Un bon nombre d'outils sont réalisés sur éclats courts ou allongés. Certains correspondent à l'emploi de sous-produits issus des différentes séquences de débitage lamellaire (comme des tablettes ou des produits de flanc), tandis que d'autres proviennent d'un débitage d'éclats courts ou allongés effectué sur place (Langlais 2003, Mangado et al. 2010 : p. 141). Les éclats allongés récupérés ou débités (production de type laminaire simple) sont retouchés en grattoirs, perçoirs ou burins, tandis que les éclats courts et minces sont préférentiellement utilisés bruts comme tranchants, voire marginalement retouchés. En plus de ces deux types d'éclats recherchés, une production d'éclats épais est mise en œuvre afin de fournir des supports de nucléus à 
microlamelles (Langlais 2004). Il est pour le moment délicat de l'intégrer entièrement aux productions précédentes ou de la considérer comme une production autonome.

La place réservée aux lames dans l'outillage est relativement importante, surtout dans l'ensemble supérieur. Il s'agit pour une part de lames normalisées importées sur le site, et pour une autre part de lames et éclats laminaires débités sur place selon un schéma unipolaire simplifié (Langlais et Mangado 2007). Les lames régulières importées sont utilisées comme tranchants, comme l'indique leur aiguisage latéral, et souvent recyclées en grattoirs et burins. Dans certains cas, nous avons pu observer une fragmentation volontaire de ces lames par percussion (Langlais 2010, Mangado et al. 2010 et 2011). L'étude tracéologique n'a pour le moment pas permis de préciser ces hypothèses.

17 Les lamelles constituent l'essentiel des supports produits sur le site et sont destinées aux microlithes (Langlais 2004 et 2010, Mangado et al. 2010 et 2011). Elles sont produites de manière disjointe par rapport aux lames et aux éclats allongés. Différentes modalités opératoires sont mises en œuvre dans les deux ensembles :

- L'exploitation enveloppante pyramidale sur des rognons et sur tranche d'éclat pour des lamelles de profil rectiligne ;

- L'exploitation de type caréné d'éclats sur front ou sur tranche (notamment sur tranche à encoche) pour des microlamelles courbes (Langlais 2010).

Du point de vue typologique, les armatures majoritaires sont des lamelles à dos simples (retouche abrupte marginale ou profonde, LD11-LD21 selon la typologie de G. Laplace). Un morphotype original se distingue cependant dans l'ensemble stratigraphique supérieur : des microlamelles à dos dextre inverse (Langlais 2008, Mangado et al. 2010 : p. 142, Mangado et al. 2011).

19 Les productions lithiques de Montlleó peuvent pour la plupart être rapprochées du Magdalénien inférieur pour l'ensemble stratigraphique supérieur (Langlais 2010). Toutefois, les découvertes réalisées ces dernières années, notamment la présence de raclettes et de débitages lamellaires de type transversal sur encoche (cf. Badegoulien) et de pointes à cran dans le style du Solutréen supérieur et final méditerranéen (anciennement dénommé Solutréo-Gravettien ibérique: Fullola 1978 et 1979), permettent d'envisager l'existence d'occupations antérieures au Magdalénien dans l'ensemble inférieur (fig.6). Notons enfin, dans les deux ensembles, la présence récurrente de pièces esquillées. 
Fig. 6. - Site de Montlleó (Prats i Sansor, Lérida, Espagne) : exemples de pointes à cran (1-4) et raclettes (5-6).

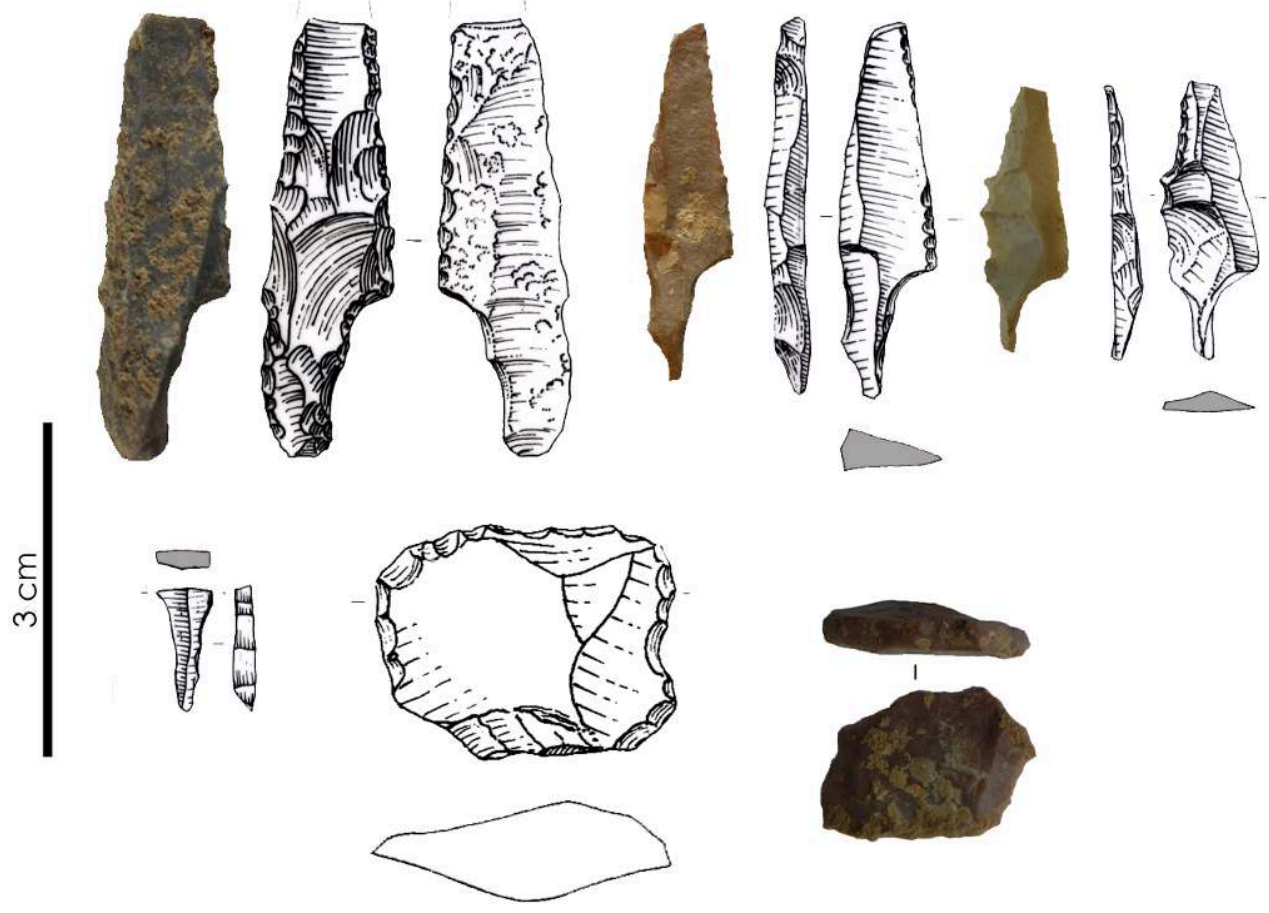

Dessin Ramon Álvarez. PAO Mathieu Langlais.

\section{L'industrie osseuse}

Considérée pour le moment comme un ensemble homogène, l'industrie osseuse de Montlleó est composée d'une dizaine d'éléments qui concernent trois sphères d'activités différentes : la chasse, les activités domestiques et la parure. En effet, des pointes de sagaies, des fragments probables de poinçons et des dents perforées destinées à être suspendues ou attachées aux vêtements comme ornement personnel (plusieurs canines résiduelles de cerf, Cervus elaphus), constituent les différents morphotypes documentés sur le site.

Malgré le faible nombre d'éléments, leur fragmentation et l'état de préservation de certaines pièces altérées par des processus post-dépositionnels (érosion des surfaces osseuses, vermiculations, concrétions sédimentaires), il reste possible de tirer de l'étude de l'ensemble de Montlleó des données intéressantes sur l'exploitation des matières dures animales pendant le Magdalénien au sud des Pyrénées. La première correspond à l'apparente adéquation entre matière première, morphotype et domaine d'activité auquel chaque objet est destiné. Le bois de cervidés a été utilisé par les Magdaléniens de Montlleó pour fabriquer leur équipement cynégétique. Ils ont en revanche privilégié l'os pour les objets utilitaires tels que les poinçons, tandis que la parure est façonnée sur des dents et des coquillages marins (Fernández-Marchena et al. 2019). Ce comportement, certes, n'est pas uniquement propre au Magdalénien du sud des Pyrénées ; il est très fréquent tout au long du Paléolithique supérieur sur les deux versants (Tartar et al. 2006). La reconstitution des schémas opératoires d'exploitation 
des matières dures animales reste en revanche à caractériser, par manque d'une série plus large et surtout d'éléments autres que les objets finis. baguette pourrait démontrer qu'une partie de l'équipement cynégétique a été fabriquée sur place, mais on ne peut pour autant pas exclure qu'il soit arrivé sur le site déjà fabriqué. En l'absence de déchets de fabrication en matières osseuses, nous ne sommes pas en mesure de trancher entre ces deux possibilités. Le procédé de débitage employé, d'après l'analyse de cette baguette, est celui du double rainurage longitudinal, bien connu des groupes de chasseurs-cueilleurs depuis le Gravettien (Averbouh 2000, Goutas 2004, Pétillon et Ducasse 2012).

que les conclusions sur l'exploitation des matières dures animales à Montlleó doivent être prises avec prudence compte tenu de la faiblesse quantitative et qualitative de l'échantillon, de l'absence de sites de plein air chronoculturellement contemporains au sud de la chaîne pyrénéenne ainsi que du manque d'études technologiques systématiques de l'industrie osseuse du Magdalénien régional (Tejero 2005, Tejero et Fullola 2008), les données issues de cet ensemble constituent une source importante d'informations.

\section{La parure}

L'ensemble malacologique récupéré à Montlleó jusqu'à aujourd'hui compte 58 exemplaires. Malgré cette faible importance numérique, sa variabilité taxonomique, la localisation du site et la provenance des matières premières en font un cas particulièrement intéressant. La majorité de l'ensemble est constituée de Tritia neritea ; sont aussi représentés des gastéropodes comme des Homalopoma sanguineum, Tritia incrassata et Tritia reticulata.

Dans les publications antérieures sur Montlleó (Mangado et al. 2015), plusieurs éléments malacologiques (une Littorina obtusata et deux Tritia heynemanni) avaient été considérés comme d'origine strictement atlantique (Eriksen 2002). Toutefois, l'idée que certains de ces éléments soient en fait d'âge prémagdalénien et datent de peu après le début du Dernier Maximum glaciaire $(22000 \mathrm{cal}$. BP) permet désormais d'envisager qu'ils proviennent de la côte méditerranéenne du sud de la péninsule Ibérique. En effet, pendant le Dernier Maximum glaciaire, ces espèces auraient également pu coloniser cette partie de la Méditerranée en arrivant jusqu'à la mer d'Alboran (Soler Mayor 2015).

Cependant, la présence des exemplaires d'Homalopoma sanguineum apporte une information supplémentaire, car nous sommes face à une espèce strictement méditerranéenne, avec un habitat limité à la région nord-est de la côte méditerranéenne de la péninsule. Ces caractéristiques très précises nous permettent de suggérer que leur abondance dans certains sites magdaléniens de la région cantabrique (tels que Tito Bustillo, El Horno ou El Mirón : Álvarez Fernández 2002, Vanhaeren et al. 2005, Varela 2004) est due à l'existence de contacts - directs ou indirects - avec des populations de la côte méditerranéenne. Ces données nous portent à reconsidérer l'hypothèse selon laquelle les exemplaires de Littorina obtusata et de Tritia heynemmani de Montlleó pourraient être des indices de l'existence de contacts avec des populations de la corniche cantabrique via la vallée de l'Èbre et le versant nord des Pyrénées. 


\section{Les vestiges fauniques}

27 Du point de vue économique, l'analyse de la faune est fondamentale pour appréhender la subsistance de ces populations de chasseurs-cueilleurs de la fin du Pléistocène. Nous présentons ici les vestiges correspondant à l'étude de l'occupation magdalénienne, l'étude des matériaux des niveaux inférieurs étant encore en cours. Malgré tout, le degré de détermination anatomique et taxonomique de la faune récupérée pendant les fouilles reste très faible, pour des raisons liées à la fois aux conditions de préservation du site (ruissellement, processus de gel et de dégel, action des racines ou acidité du sol) et aux comportements de subsistance des chasseurs-cueilleurs, les proies chassées étant exploitées de façon très intensive. C'est notamment ce que montrent les premières et deuxièmes phalanges des ongulés, qui présentent des fractures sagittales, obliques ou transversales, probablement liées à l'extraction de la moelle (Mangado et al. 2005).

L'origine anthropique de l'ensemble faunique est indiquée par la présence à la surface des ossements de différents types d'altération liés à l'exploitation des animaux, comme les traces de découpe (présentes sur 1,3\% des échantillons déterminés) ou les traces liées à la fragmentation, comme les impacts de percussion (présents sur $6,4 \%$ des restes). Les ossements ont été systématiquement fracturés, autant pour l'extraction de la moelle que très probablement pour l'obtention des graisses et protéines par le bouilli. La fragmentation intensive des restes fauniques de Montlleó peut être mise en relation avec la fragmentation déjà observée dans les études ethnographiques et ethnoarchéologiques des sociétés des chasseurs-collecteurs des zones tempérés et froides, où ces pratiques ont pour but de maximiser les ressources nutritives (Nelson 1973, Binford 1978, Costamagno et David 2009).

Dans certains cas, nous envisageons aussi l'utilisation des os comme combustible, car une préservation différentielle des éléments a été repérée (les diaphyses sont plus nombreuses que les épiphyses, ces dernières étant plutôt rares). Les épiphyses ne représentent que $0,92 \%$ de la totalité des os longs analysés ( $\mathrm{N}=3592$ fragments). Des travaux antérieurs ont démontré que les épiphyses, riches en graisse, peuvent être utilisées comme combustible dans des contextes où les ressources végétales sont rares (Costamagno et al. 2005 et 2009, Théry-Parisot et al. 2005, Yravedra et Uzquiano 2013). Seuls les ossements à moindre valeur nutritive, en particulier les plus durs (dents et os du basipode), moins altérés, ont permis l'identification taxonomique des espèces animales chassées.

La principale ressource animale chassée est le cheval (Equus sp.), suivi par le cerf (Cervus elaphus) (fig. 7). En prenant en compte les exigences environnementales de ces deux espèces, nous pensons que leur chasse avait lieu pendant la belle saison, entre la fin du printemps et le début de l'automne. Nous n'avons pas pour l'instant de données sur l'âge de mort des animaux, qui pourraient alimenter cette thèse, car les analyses cémentochronologiques n'ont pas été réalisées à cause de la mauvaise préservation des ossements; mais des études récentes sur les migrations saisonnières des chevaux sauvages et surtout des cerfs vont dans ce sens (King et Gurnell 2005, Luccarini et al. 2006, Kaczensky et Huber 2010). Le site est un emplacement stratégique du point de vue cynégétique, ce qui explique le choix des groupes qui y ont séjourné : lié à la chasse du cheval, Montlleó se situe sur sa route migratoire saisonnière entre la plaine de la Cerdagne et les piémonts pyrénéens. 
Fig. 7. - Site de Montlleó (Prats i Sansor, Lérida, Espagne) : restes fauniques.

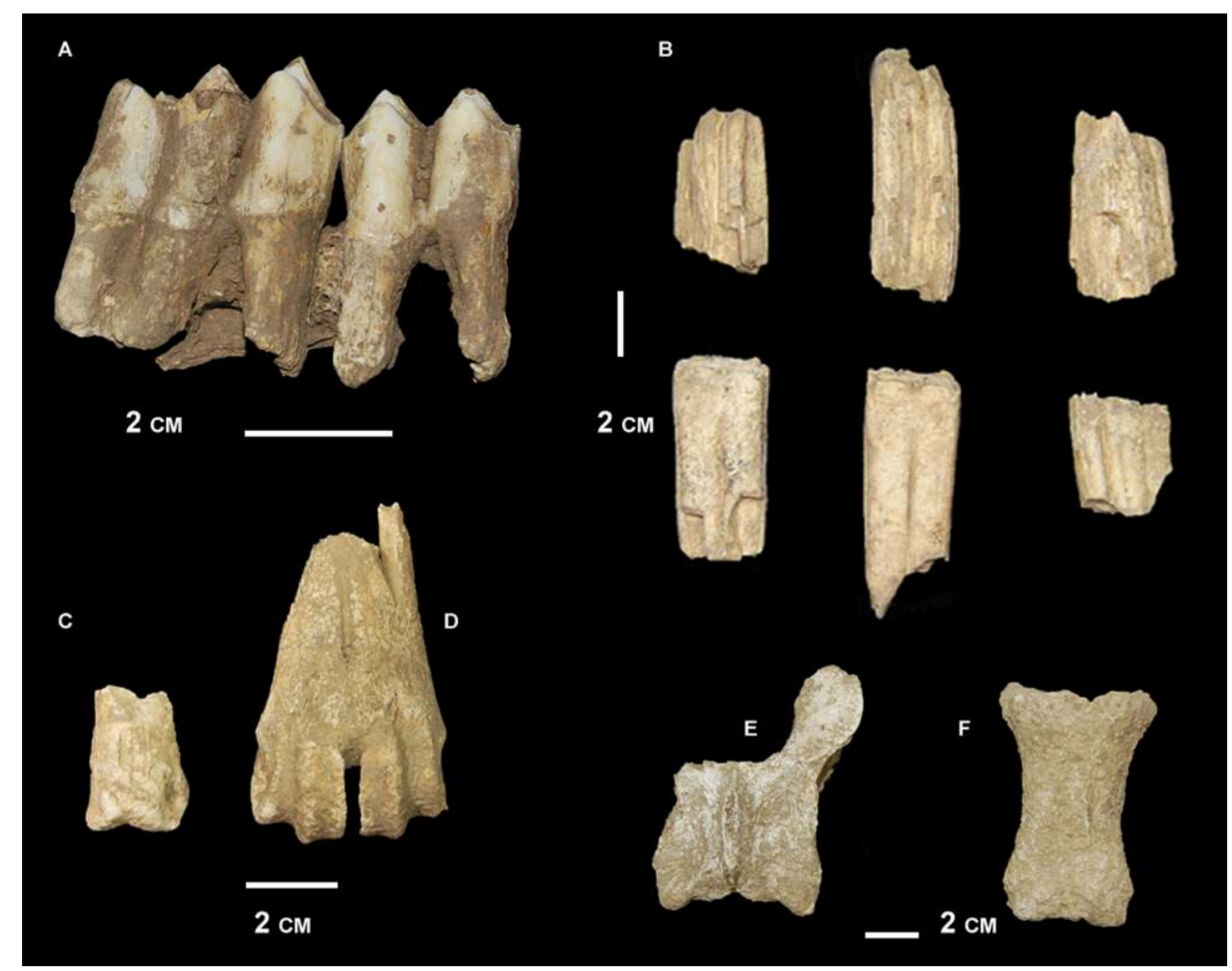

A : dents de cerf en connexion. B : dents de cheval. c : première phalange de cerf. D : extrémité distale de métapode de cerf. $\mathbf{E}$ : vertèbre de cheval. $\mathbf{F}$ : première phalange de cheval.

Photos Jordi Nadal et Lluis Lloveras.

31 Cette chasse qui visait les proies de grande taille était complétée par la capture sur les reliefs entourant le site d'autres espèces, comme le chamois (Rupicapra rupicapra) et dans une moindre mesure le bouquetin (Capra pyrenaica). Ainsi, la faune montre bien un paysage essentiellement ouvert, complété par des espèces rupicoles. En revanche, aucun reste de renne (Rangifer tarandus) n'a été mis au jour ; ce fait pourrait être lié à l'existence d'une " frontière bioclimatique ", démontrée par l'absence presque totale de cette espèce dans les sites paléolithiques ibériques - mis à part quelques exemplaires dans les extrémités occidentales et orientales du versant sud des Pyrénées -, qui contraste avec une importante présence du renne sur le versant nord jusqu'à la fin du Pléistocène (Costamagno et al. 2016). Enfin, à la différence de ce que l'on observe plus bas en altitude, les petites proies comme le lapin ou le lièvre ne sont guère représentées sur le site.

\section{Discussion}

Tandis que l'occupation du Magdalénien inférieur identifiée à Montlleó a bien été analysée et mise en relation avec d'autres occupations du nord-est ibérique pendant cette même période (Langlais 2010, Mangado et al. 2010, Sánchez de la Torre 2015), il est intéressant d'analyser ici les parallèles existants pour le niveau inférieur, récemment reconnu et daté par radiocarbone après le début du Dernier Maximum glaciaire, vers 22000 cal. BP. 
Pour cette période, la définition culturelle des sites ibériques est variable selon la région étudiée. Ainsi, en région cantabrique, on la dénomme Magdalénien archaïque, tandis que dans la partie méditerranéenne, elle est plutôt classée comme Badegoulien. De plus, l'analyse récente des datations radiocarbone de cette période (23 000-20 000 cal. BP) a montré l'existence d'une variation d'environ un millénaire entre les occupations culturelles similaires, selon la région d'étude (Aura et al. 2012).

Concernant l'analyse des éléments lithiques caractéristiques de cette période plus ancienne identifiée à Montlleó - notamment les pointes à cran et raclettes -, même si ces deux marqueurs typologiques pourraient signaler des périodes culturelles différentes, la présence de pointes à cran solutréennes dans les assemblages du Magdalénien archaïque/Solutréen final ou Badegoulien était déjà attestée anciennement dans la région cantabrique ainsi qu'en Méditerranée, à Parpalló (Gandía, Valencia, Espagne), ainsi qu'en France, sur des fouilles anciennes: abri Fritsch (Pouligny-Saint-Pierre, Indre), Laugerie-Haute (Les Eyzies, Dordogne), Badegoule (Beauregard-de-Terrasson, Dordogne) (Aura et al. 2012) ainsi que sur des fouilles plus récentes, comme le Cuzoul de Vers (Saint-Géry-Vers, Lot) (Clottes et al. 2012).

Ces éléments, ajoutés au fait qu'à Montlleó il n'est pas possible pour l'instant d'identifier des sous-niveaux dans la nappe basale reconnue lors des analyses de dispersion, nous poussent à considérer deux hypothèses :

- Soit cette couche inférieure correspond à un même groupe culturel, possédant raclettes et pointes à cran dans son outillage lithique ;

- Soit nous sommes face à deux moments culturels, l'un représenté par l'apparition des raclettes et l'autre par la présence des pointes à cran - mais nous ne sommes pas capables d'établir une différence au niveau stratigraphique, peut-être pour des raisons d'instabilité paléoclimatique, comme l'ont suggéré quelques auteurs (Aura et al. 2012).

Si on cherche des parallèles en se basant sur la quatrième datation radiocarbone obtenue lors du sondage réalisé en 2010 (18 $860 \pm 80$ BP, soit $22960-22486$ cal. BP : tabl. 1), on trouve en région méditerranéenne des datations similaires attribuées à des niveaux du Badegoulien et du Solutréen final : une datation du Parpalló attribuée au Badegoulien (T-11, OxA-22629: $18510 \pm 100 \mathrm{BP}$, soit 22 700-21 780 cal. BP : Aura et al. 2012), et une datation du niveau XIII de la grotte de Cendres (Teulada-Moraira, Valencia) attribuée au Solutréen final (Beta-118027 : $18750 \pm 130$ BP, soit 22 860-22 380 cal. BP : Villaverde et al. 1999). Enfin, une datation de Gato 2 (Épila, Zaragoza) se trouve aussi dans l'intervalle obtenu pour Montlleó, mais elle a été attribuée à des niveaux du Magdalénien archaïque (GrA-22505: $18650 \pm 140$ BP, soit 22 800-2 210 cal. BP : Blasco et Rodanés 2004). Il faut préciser que pour cette datation de Gato 2, le niveau daté n'a livré ni raclettes ni pointes à cran.

Si on essaye de mettre en connexion les pointes à cran identifiées à Montlleó avec celles qui ont été découvertes dans des régions voisines, on observe qu'elles présentent des parallèles avec les pointes à cran identifiées à Chaves (Bastaras, Huesca) et à Fuente del Trucho (Asque-Colungo, Huesca), celles-ci déjà étudiées et apparemment connectées avec le Salpêtrien du sud-est français (Bocaccio 2005, Domingo et al. 2012, Bocaccio et Utrilla 2013). Si les analyses détaillées de ces éléments, encore en cours, confirmaient cette similitude avec les pointes de Chaves, Trucho et la culture du Salpêtrien français, on disposerait alors d'un nouvel argument pour renforcer l'idée de mobilité humaine et des idées à travers l'axe Aude-Têt-Segre-Cinca pour ces moments du Dernier Maximum 
glaciaire. Toutefois, la proximité typologique des pointes à cran de Montlleó avec celles du site méditerranéen de Parpalló doit être considérée.

\section{Conclusions}

La constatation de l'existence de deux ensembles culturels clairement séparés dans la stratigraphie du site, la présence dans l'ensemble inférieur de plusieurs éléments lithiques distincts du Magdalénien inférieur de Montlleó, ainsi que d'une datation appartenant au $\mathrm{XIX}^{\mathrm{e}}$ millénaire $\mathrm{BP}$, doivent être interprétés comme des indices d'occupations humaines plus anciennes sur le site de Montlleó, diachronie jusqu'ici insoupçonnée. Les recherches à venir devront donc désormais distinguer le corpus issu de ces deux niveaux archéostratigraphiques afin de préciser les différences entre l'ensemble supérieur, attribuable au Magdalénien inférieur, et l'ensemble inférieur associant des attributs du Badegoulien récent (raclettes) et du Solutréen récent/final (pointes à cran).

\section{BIBLIOGRAPHIE}

ÁLVAREZ-FERNÁNDEZ E., 2002, « Perforated Homalopoma sanguineum from Tito Bustillo (Asturias): mobility of Magdalenian groups in northern Spain », Antiquity, nº 76, p. 641-646.

AURA J. E., TIFFAGOM M., JORDÁ PARDO J. F., DUARTE E., FERNÁNDEZ DE LA VEGA J., SANTAMARIA D., RASILLA M. DE LA, VADILLA M., PÉREZ RIPOLL M., 2012, « The Solutrean-Magdalenian transition: A view from Iberia », Quaternary International, $\mathrm{n}^{\circ}$ 272-273, p. 75-87.

AVERBOUH A., 2000, « Technologie de la matière osseuse travaillée et implications palethnologiques : l'exemple des chaînes d'exploitation du bois de cervidé chez les Magdaléniens des Pyrénées », thèse de doctorat, Paris, université Paris I - Panthéon-Sorbonne.

BERGADÀ M. et SERRAT D., 2009, « Episodis sedimentaris i paleoambientals en el vessant meridional dels Pirineus orientals entre els C.20-11,5 ka cal. BP », dans Fullola J. M., Valdeyron N., Langlais M. (dir.), Els Pirineus $i$ les àrees circumdants durant el Tardiglacial: Mutacions i filiacions tecnoculturals, evolució paleoambiental (16000-10000 BP). XIV Col-loqui Internacional d'Arqueologia de Puigcerdà. Homenatge al Professor George Laplace, Puigcerdà, Institut d'Estudis Ceretans, p. 105-128.

BINFORD L. R., 1978, Nunamiut Ehtnoarchaeology, New York, Academic Press.

BLASCO M. F. et RODANÉs J. M., 2004, « Las fases de ocupación de la Cueva del Gato-2 (Épila, Zaragoza) », Salduie, n 9, p. 311-334.

BOCACCIO G., 2005, «Les industries lithiques du Solutréen supérieur et du Salpêtrien ancien en Languedoc : ruptures et continuités des traditions techniques ", thèse, université Provence - AixMarseille I.

BOCACCIO G. et UTRILLA P., 2013, « Du Languedoc à l'Aragon : analyse technologique comparée du Salpêtrien de la vallée du Rhône et du Solutréen supérieur de la Cueva de Chaves ", dans Le 
Solutréen... 40 ans après Smith'66: congrès de Preuilly-sur-Claise, 2007, Tours, FERACF (Revue archéologique du centre de la France, supplément 47), p. 1-80.

BORDONAU J., SERRAT D., VILAPLANA J. M., 1992, « Las fases glaciares cuaternarias en los Pirineos », dans Cearreta A. et Ugarte F. M. (dir.), The late Quaternary in the western Pyrenean Region, Bilbao, Serv. Ed. Univ. País Vasco, p. 303-312.

BORDONAU J., VILAPLANA J. M., FONTUGNE M., 1993, « The glaciolacustrine complex of Llestui (Central Southern Pyrenees): A key-locality for the chronology of the last glacial cycle in the Pyrenees », Comptes rendus de l'Académie des sciences, vol. 316, nº II, p. 807-813.

BRONK RAMSEY C., PETTITT P. B., HEDGES R. E. M., HARDGINGS G. W. L., OWEN D. C., 2000, « Radiocarbon dates from the Oxford AMS system: Archaeometry datelist 30 ", Archaeometry, vol. 42, nº 2, p. 459-479. CALVET M., 2004, « The Quaternary glaciation of the Pyrenees », dans Ehlers J. et Gibbard P. L. (dir.), Quaternary Glaciations: Extent and Chronology, vol. 1 : Europe, Amsterdam/Boston, Elsevier Science, p. 119-128.

CLOTTES J., GIRAUD J.-P., CHALARD P. (dir.), 2012, Solutréen et Badegoulien au Cuzoul de Vers : des chasseurs de rennes en Quercy, Liège, université de Liège (ERAUL, 131).

COSTAMAGNO S. et DAVID F. 2009, « Comparaison des pratiques bouchères et culinaires des différents groupes sibériens vivant de la renniculture ", Archaeofauna, nº 18, p. 9-24.

COSTAMAGNO S., THÉRY-PARISOT I., BRUGAL J.-P., GUIBERT R., 2005, « Taphonomic consequences of the use of bones as fuel: Experimental data and archaeological applications », dans O'Connor T. (dir.), Biosphere to Lithosphere: new studies in vertebrate taphonomy, Oxford, Oxbow Books, p. 51-62.

COSTAMAGNO S., THÉRY-PARISOT I., CASTEL J.-C., BRUGAL J.-P., 2009, « Combustible ou non ? Analyse multifactorielle et modèles explicatifs ", dans Théry-Parisot I., Costamagno S., Henry A. (dir.), Gestion des combustibles au Paléolithique et au Mésolithique : nouveaux outils, nouvelles interprétations, Oxford, Archaeopress (BAR International Series, 1914), p. 65-84.

COSTAMAGNO S., BARSHAY-SZMIDT C., KUNTZ D., LAROULANDIE V., PÉTILLON J.-M., BOUDADI-MALIGNE M., LANGLAIS M., MALLYE J.-B., CHEVALIER A., 2016, « Reexamining the timing of reindeer disapperance in Southwestern France in the larger context of late glacial faunal turnover », Quaternary International, $\mathrm{n}^{\circ}$ 414, p. 34-61.

DELMAS M., YANNI G., BROCHER R., CALVET M., BOURLÈS D., 2008, « Exposure age chronology of the last glaciation in eastern Pyrenees ", Quaternary Research, $n^{\circ}$ 69, p. 231-241.

DOMINGO R., MONTES L., UTRILLA P., 2012, « Las puntas de escotadura solutrenses de Chaves y de Fuente del Trucho (Huesca, España) », Espacio, Tiempo y Forma, série I, Nueva época, Prehistoria y Arqueología, no 5, p. 507-516.

ERIKSEN B. V., 2002, « Fossil mollusks and exotic raw materials in Late glacial and early Postglacial find contexts: a complement to lithic studies ", dans Fisher L. E. et Eriksen B. V. (dir.), Lithic raw material economies in late glacial and early postglacial Europe, Oxford, Archaeopress (BAR International Series, 1093), p. 27-52.

ESTEVE X., 2009, « Resultats preliminars de les anàlisis de distribució espacial al jaciment de Montlleó (Prats i Sansor, Cerdanya) », dans Fullola J. M., Valdeyron N., Langlais M. (dir.), Els Pirineus i les àrees circumdants durant el Tardiglacial: Mutacions i filiacions tecnoculturals, evolució paleoambiental (16000-10000 BP). XIV Col-loqui Internacional d'Arqueologia de Puigcerdà. Homenatge al Professor George Laplace, Puigcerdà, Institut d'Estudis Ceretans, p. 527-535. 
FERNÁNDEZ-MARCHENA J. L., GARCÍA-ARGUDO G., MANGADO X., FULLOLA J. M., 2019, « Montlleó (Prats i Sansor, Lérida, Espagne) : le passage du symbolisme à travers les montagnes », dans Deschamps M., Costamagno S., Milcent P.-Y., Pétillon J.-M., Renard C., Valdeyron N., La conquête de la montagne : des premières occupations humaines à l'anthropisation du milieu, Paris, Éditions du CTHS.

FULLola J. M., 1978, « El Solútreo-Gravetiense o Parpallense, industria mediterránea », Zephyrus, $\mathrm{n}^{\circ}$ 28-29, p. 113-123.

FULlola J. M., 1979, Las industrias líticas del Paleolítico Superior ibérico, Valencia, Servicio de Investigación Prehistórica de la Diputación Provincial de Valencia (Trabajos Varios, 60).

fUllola J. M., 2001, « Recherches sur le Paléolithique supérieur dans le nord-est ibérique : la Catalogne (1996-2001) », dans UISPP, commission 8, Le Paléolithique supérieur européen : bilan quinquennal 1996-2001, Liège, université de Liège (ERAUL, 97), p. 141-148.

fUllola J. M. et CEBRià A., 1996, « Materials lítics prehistòrics de la Cerdanya », Pyrenae, nº 27, p. 271-277.

GILLESPIE A. et MOLNAR P., 1995, « Asynchronous maximum advances of mountain and continental glaciers », Reviews of Geophysics, vol. 33, n 3, p. 311-364.

GOUTAS N., 2004, « Caractérisation et évolution du Gravettien en France par l'approche technoéconomique des industries en matières dures animales (étude de six gisements du Sud-Ouest) ", thèse de doctorat, Paris, université Paris I - Panthéon-Sorbonne.

JALUT G. et TURU V., 2009, « La végétation des Pyrénées françaises lors du dernier épisode glaciaire et durant la transition glaciaire-interglaciaire (last termination) », dans Fullola J. M., Valdeyron N., Langlais M. (dir.), Els Pirineus i les àrees circumdants durant el Tardiglacial: Mutacions i filiacions tecnoculturals, evolució paleoambiental (16000-10000 BP). XIV Col-loqui Internacional d'Arqueologia de Puigcerdà. Homenatge al Professor George Laplace, Puigcerdà, Institut d'Estudis Ceretans, p. 129-149.

KACZENSKY P. et HUBER K., 2010, « The use of high frequency GPS data to classify main behavioural categories in a Przewalski's horse in the Mongolian Gobi », Erforschung Biologischer Resourcen der Mongolei, $\mathrm{n}^{\circ}$ 60, p. 281-289.

KING S. R. B. et GURNELL J., 2005, « Habitat use and spatial dynamics of takhi introduced to Hustai National Park, Mongolia », Biological Conservation, n 124, p. 277-290.

LANGLAIS M., 2003, « Réflexions sur la place des productions lamellaires au sein de la culture magdalénienne du Languedoc méditerranéen et pyrénéen de l'est : étude typo-technologique de quatre assemblages leptolithiques : Montlleó (Prats i Sansor, Lleida), Le Crès (Béziers, Hérault), Belvis (Aude) et les Piles Loins (Vauvert, Gard) ", mémoire de DEA, Université Toulouse II - Le Mirail.

LANGLAIS M., 2004, « Étude techno-économique comparative des productions lamellaires au Magdalénien : l'exemple du Languedoc méditerranéen et de la Catalogne », Pyrenae, vol. 35, $\mathrm{n}^{\circ} 1$, p. 45-73.

LANGLAIS M., 2008, « Magdalenian chronology and territories between the Rhone and the Ebro: the case of the lithic weapon elements/Chronologie et territoires au Magdalénien entre le Rhône et l'Ebre : l'exemple des armatures lithiques ", dans Pétillon J.-M., Dias-Meirinho M.-H., Cattelain P., Honegger M., Normand C., Valdeyron N. (dir.), Recherches sur les armatures de projectiles $d u$ Paléolithique supérieur au Néolithique : actes du colloque $83, X V^{e}$ congrès de l'IUSPP, Lisbonne, 4-9 septembre 2006, Toulouse, Presses universitaires du Midi (P@lethnologie, nº 1), p. 220-249. 
LANGLAIS M., 2010, Les sociétés magdaléniennes de l'isthme pyrénéen, Paris, Éditions du CTHS (Documents préhistoriques, 26).

LANGLAIS M. et MANGADO X., 2007, «Le Magdalénien entre le Rhône et l'Èbre : des frontières naturelles et culturelles vécues par les préhistoriques et perçues par les préhistoriens ? ", dans Cazals N., González J. E., Terradas X. (dir.), Frontières naturelles et frontières culturelles dans les Pyrénées préhistoriques, Santander, Universidad de Cantabria (Monografías del IIIPC, 2), p. 143-163.

LUCCARINI S., MAVRI L., CIUTI S., LAMBERTI P., APOLLONIO M., 2006, « Red deer (Cervus elaphus) spatial use in the Italian Alps: home range, patterns, seasonal migrations, and effects of snow and winter feeding ", Ethology, Ecology \& Evolution, n 18, p. 127-145.

MANGADO X., MERCADAL O., FULLOLA J. M., ESTEVE X., LANGLAIS M., NADAL J., ESTRADA A., BERGADÀ M. M., 2005, « Montlleó (La Cerdanya, Lleida): un yacimiento magdaleniense de alta montaña al aire libre en los Pirineos catalanes ", dans Bicho N. et Corchón M. S. (dir.), O Paleolítico: Actas do IV Congresso de Arqueologia Peninsular (Faro, 14 a 19 Setembro de 2004), Faro, Universidade do Algarve, p. 471-480.

MANGADO X., MERCADAL O., FULLOLA J. M., ESTEVE X., LANGLAIS M., NADAL J., ESTRADA A., SÁNCHEZ E., LACRUZ S., GRIMAO J., 2006, « Montlleó (Prats i Sansor, la Cerdanya): El primer jaciment a l'aire lliure magdalenià d'altitud al cor dels Pirineus », Tribuna d'Arqueologia, $\mathrm{n}^{\circ}$ 2003-2004, p. 23-44.

MANGADO X., TEJERO J. M., PETIT M. A., GARCÍA-ARGÜELLES P., GARCÍA M., SOLER N., VAQUERO M., 2010, « NuevoS territorios, nuevos grafismos: una visión del Paleolítico superior en Catalunya a inicios del siglo XXI », dans Mangado X. (dir.), El Paleolítico superior en Catalunya a inicios del siglo XXI, Barcelona, SERP (Monografías del SERP, 8), p. 63-83.

MANGADO X., MERCADAL O., BERGADÀ M. M., NADAL J., LANGLAIS M., TEJERO J. M., ESTEVE X., MEDINA B., RODRÍGUEZ N., GRIMAO J., FULLOLA J. M., 2011, « Montlleó (Prats i Sansor, Cerdanya): Balanç de 10 campanyes d'excavació », Tribuna d'Arqueologia, n² 2009-2010, p. 27-52.

MANGADO X., SÁNCHEZ DE LA TORRE M., FULLOLA J. M., MERCADAL O., RODRÍGUEZ N., GRIMAO J., LANGLAIS M., TEJERO J. M., NADAL J., BERGADÀ M., 2015, « Montlleó (Prats i Sansor, La Cerdanya): De la descoberta a la internacionalització », ERA, Revista Cerdana de Recerca, p. 25-36.

NELSON R., 1973, Hunters of the Northern Forest, Chicago, University of Chicago Press.

PALLÀS R., RODÉS A., BRAUCHER R., CARCAILLET J., ORTUÑO M., BORDONAU J., BOURLÈS D., VILAPLANA J. M., MASANA E., SANTANACH P., 2005, « The late Pleistocene and Holocene glaciation in the Pyrenees: new evidence from 10Be exposure ages, Noguera Ribagorçana Valley, south-central Pyrenean range », Quaternary Science Reviews, vol. 25, nº 21-22, p. 2937-2963.

PÉTILLON J.-M. et DUCASSE S., 2012, « From flakes to grooves: A technical shift in antlerworking during the last glacial maximum in southwest France ", Journal of Human Evolution, $\mathrm{n}^{\circ} 62$, p. 435-465.

SÁNCHEZ DE LA TORRE M., 2015, Las sociedades cazadoras-recolectoras del Paleolítico superior final pirenaico: Territorios económicos y sociales, Barcelona, SERP (Monografías del SERP, 11).

SÁNCHEZ DE LA TORRE M. et MANGADO X., 2016, « ¿De dónde vienen? Aprovisionamiento en rocas sedimentarias silíceas en el yacimiento magdaleniense al aire libre de Montlleó (Prats i Sansor, Lleida) », Trabajos de Prehistoria, vol. 73, n 1, p. 7-28.

SÁNCHEZ DE LA TORRE M., LE BOURDONNEC F.-X., GRATUZE B., 2017, « Reconsidering prehistoric chert catchment sources: new data from the Central Pyrenees (Western Europe) », Archaeological and Anthropological Sciences, https://doi.org/10.1007/s12520-017-0581-7. 
SOLER MAYOR B., 2015, «Elementos de adorno malacológicos de la secuencia Solutrense de la Cova del Parpalló (Gandia, València): Nuevos datos », dans Gutiérrez Zugasti I. et González Morales M. R. (dir.), La investigación arqueomalacológica en la Península Ibérica: Nuevas aportaciones. Actas de la IV Reunión de Arqueomalacología de la Península Ibérica, Santander, Nadir Ediciones, p. 13-25.

TARTAR É., TEYSSANDIER N., BON F., LIOLIOS D., 2006, «Équipement de chasse, équipement domestique : une distinction efficace ? Réflexion sur la notion d'investissement technique dans les industries aurignaciennes ", dans Astruc L., Bon F., Léa V., Milcent P.-Y., Philibert S. (dir.), Normes techniques et pratiques sociales : de la simplicité des outillages pré- et protohistoriques, Antibes, APDCA, p. 107-117. TEJERO J. M., 2005, El treball de l'os a la Prehistòria: Anàlisi tecnomorfològica de la indústria en matèries dures animals de la Cova del Parco (Alòs de Balaguer), Barcelona, Societat Catalana d'Arqueologia. TEJERO J. M. et FULLOLA J. M., 2008, « L'exploitation non alimentaire des ressources animales pendant le Magdalénien au nord-est de la péninsule Ibérique : l'exemple de la grotte du Parco (Alòs de Balaguer, Lleida, Espagne) ", L'Anthropologie, nº 112, p. 328-345.

THÉRY-PARISOT I., COSTAMAGNO S., BRUGAL J.-P., FOSSE P., GUILBERT R., 2005, « The use of bone as a fuel during the Paleolithic: experimental study of bone combustible properties », dans Mulville J. et Outram A. (dir.), The Archaeology of milk and fats, Oxford, Oxbow Books, p. 50-59.

VANHAEREN M., 2005, « Speaking with beads: the evolutionary significance of personal ornaments » dans D'Errico F. et Blackwell L. (dir.), From tools to symbols: from early hominids to modern humans, Johannesburg, Witwatersrand University Press, p. 525-553.

VARELA A. 2014, « Los colgantes magdalenienses del nivel 17 de la Cueva del Mirón: análisis y experimentación », inédit, Universidad de Cantabria.

VILLAVERDE V., MARTíNEZ R., BADAL E., GUILLEM P., GARCíA R., MENARGUES J., 1999, « El Paleolítico superior de la Cova de les Centres (Teulada, Moraira): Datos proporcionados por el sondeo efectuado en los cuadros A/B 17 ", Archivo de Prehistoria Levantina, n 23, p. 6-65.

YRAVEDRA J. et UZQUIANO P., 2013, «Burnt bone assemblage from El Esquileu Cave (Cantabria, Northern Spain): deliberate use for fuel or systematic disposal waste? », Quaternary Science Reviews, $\mathrm{n}^{\circ} 68$, p. 175-190.

\section{RÉSUMÉS}

Le site de plein air de Montlleó (Prats i Sansor, Lérida, Espagne) a été découvert en 1998 ; le SERP de l'université de Barcelone y fouille depuis l'année 2000. La présence d'industrie lithique et osseuse et de parure a montré l'importance du site pour des chasseurs du Magdalénien et le rôle de la haute vallée du Segre comme carrefour des échanges transpyrénéens de matières premières lithiques sur l'axe Segre-Têt via la Cerdagne. Des nouvelles dates radiométriques suggérant une occupation du site dès 22000 cal. BP, ainsi que la présence d'un outillage où les raclettes et les pointes à cran sont attestées, ouvrent la possibilité d'une occupation plus ancienne qu'on ne l'envisageait jusqu'ici. Les analyses spatiales de dispersion des vestiges montrent effectivement l'existence de deux niveaux archéologiques séparés par un bref hiatus stérile. Ces données montrent qu'il s'agit de la plus ancienne occupation de l'espace montagnard au cours du Dernier Maximum glaciaire dans la zone pyrénéenne méridionale.

The open air site of Montlleó (Prats i Sansor, Lérida, Spain) was discovered in 1998 and has been excavated since 2000 by a multidisciplinary team from the SERP research group, University of 
Barcelona. The presence of lithic and bone industries, as well as shell ornaments, have shown the importance of the site for hunter-gatherer Magdalenian groups and the role of the high Segre valley as a crossroad for lithic raw materials exchanges on the Segre-Têt axis through the Cerdanya valley. New radiometric dates (which situate the first occupations up to 22,000 cal BP) and the presence of new typological tools such as raclettes and Solutrean shouldered points lead us to think that human occupations were more ancient than first expected, going back up to the beginning of the Last Glacial maximum. The dispersion analyzes actually show the existence of two archeological levels separated by a short sterile hiatus. These data thus show that this site represents the oldest occupation of a mountain area during the LGM in the southeastern Pyrenean region.

\section{INDEX}

Keywords : hunter-gatherer, Lower Magdalenian, Late-Final Solutrean

Mots-clés : Magdalénien inférieur, chasseur-cueilleur, Solutréen récent-final

Index géographique : Pyrénées

\section{AUTEURS}

\section{XAVIER MANGADO}

Seminari d'Estudis i Recerques Prehistòriques (SERP), Secció de Prehistòria i Arqueologia, Universitat de Barcelona

\section{MARTA SÁNCHEZ DE LA TORRE}

Groupe de recherche Primeros Pobladores del Valle del Ebro (PPVE), Área de Prehistoria, Departamento de Ciencias de la Antigüedad, Universidad de Zaragoza ; Seminari d'Estudis i Recerques Prehistòriques (SERP), Secció de Prehistòria i Arqueologia, Universitat de Barcelona

\section{MATHIEU LANGLAIS}

Laboratoire De la Préhistoire à l'actuel : culture, environnement et anthropologie (PACEA, UMR 5199, université de Bordeaux/CNRS) ; Seminari d'Estudis i Recerques Prehistòriques (SERP), Secció de Prehistòria i Arqueologia, Universitat de Barcelona

\section{NÚRIA RODRIGUEZ}

Seminari d'Estudis i Recerques Prehistòriques (SERP), Secció de Prehistòria i Arqueologia, Universitat de Barcelona

\section{JORDI NADAL}

Seminari d'Estudis i Recerques Prehistòriques (SERP), Secció de Prehistòria i Arqueologia, Universitat de Barcelona

\section{LLUIS LLOVERAS}

Seminari d'Estudis i Recerques Prehistòriques (SERP), Secció de Prehistòria i Arqueologia, Universitat de Barcelona 


\section{JOSÉ-MIGUEL TEJERO}

Seminari d'Estudis i Recerques Prehistòriques (SERP), Secció de Prehistòria i Arqueologia, Universitat de Barcelona ; Laboratoire Archéologie et sciences de l'Antiquité (ARSCAN, UMR 7041, université Paris X - Paris-Nanterre/CNRS)

\section{GALA GARCÍA-ARGUDO}

Seminari d'Estudis i Recerques Prehistòriques (SERP), Secció de Prehistòria i Arqueologia, Universitat de Barcelona

\section{ORIOL MERCADAL}

† Museu Cerdà

JOSEP MARIA FULLOLA

Seminari d'Estudis i Recerques Prehistòriques (SERP), Secció de Prehistòria i Arqueologia, Universitat de Barcelona 
Sur la piste d'un peuplement pionnier de l'Azilien en Pyrénées : l'exemple des industries en roches volcaniques de La Balma de la Margineda (Andorre)

\author{
Pioneering Azilian settlement in Andorra: new data on the source of \\ volcanic rock industries
}

Michel Martzluff, Valentí Turu, Gérard Remolins-Zamora et Jean Guilaine

Nous tenons à remercier la fondation Marcel Chevalier (Andorre) et le laboratoire CEPAP (Centre d'Estudis del Patrimoni Arqueòlogic de la Prehistòria de l'Universitat Autònoma de Barcelona) pour l'aide matérielle qu'ils ont apportée à cette recherche. Que Pierre Giresse, géologue au laboratoire CEFREM (UMR CNRS 5110) de l'université de Perpignan - Via Domitia, soit également remercié pour ses conseils et l'examen des lames minces, de même que Bernard Laumonier (laboratoire GéoRessources, Université de Lorraine) pour la relecture du texte.

1 L'abri-sous-roche de la grotte de La Balma de la Margineda est le seul site azilien connu dans la zone axiale des Pyrénées. Cette situation originale dans le Paléozoïque des hautes vallées, vers 1000 mètres d'altitude, le place dans une zone totalement dépourvue des sources de silex, qui se trouvent bien plus loin sur les deux versants, dans les séries mésocénozoïques. Mais elle le positionne aussi à l'interface de deux grandes plaines sédimentaires et de deux influences climatiques qui se développent de part et d'autre de la haute chaîne. Prenant sa source à la frontière septentrionale de la co-principauté, l'Ariège relie en effet ce territoire au bassin de la Garonne et aux flux atlantiques. Toutefois, l'essentiel de cet espace, drainé par le cours de la rivière Valira, est naturellement tourné vers le sud et se rattache au bassin de l'Èbre, via le Sègre. L'Andorre est donc largement ouverte aux influences méditerranéennes et continentales qui caractérisent les « Pyrénées sèches » du versant méridional (fig. 1). Le rattachement à l'Azilien de tous les sites du Tardiglaciaire situés entre les oscillations 
GI 1 (Bølling-Allerød) et GS 1 (Younger Dryas) se fonde ici sur les datations par le radiocarbone ainsi que sur la structure de l'industrie, principalement caractérisée par un net relâchement technique dans le débitage laminaire au percuteur de pierre, par l'usage prononcé de roches locales et par la domination des grattoirs sur les burins ainsi que celle des pointes à bord abattu sur les lamelles « à dos».

Fig. 1. - Situation de la grotte de La Balma de la Margineda (Andorre) dans son contexte pyrénéen et du bassin de l'Èbre.

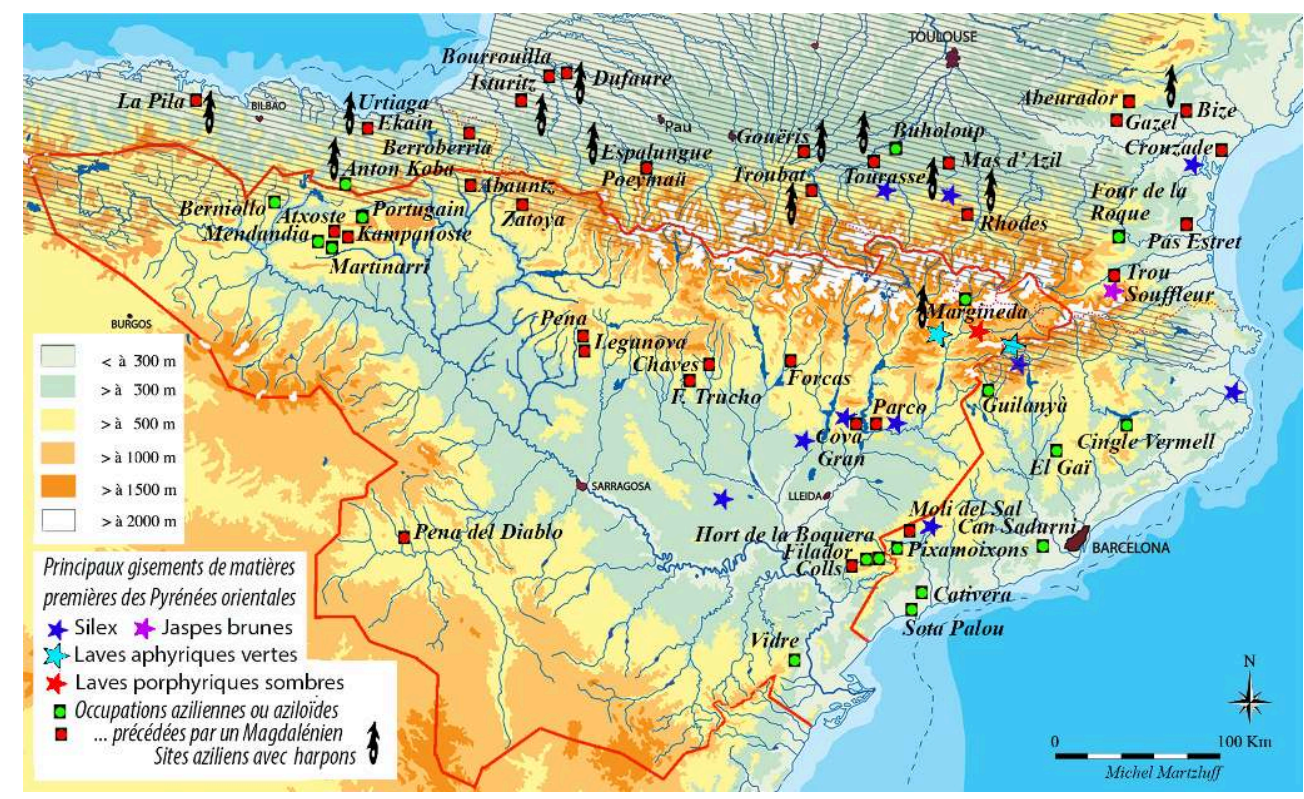

Le bassin de l'Ėbre est cerné d'un trait rouge. Les zones hachurées indiquent les influences océaniques qui baignent principalement la côte cantabrique et l'Aquitaine, où se trouve aussi l'aire de ponte du saumon atlantique (Salmo salar). La zone hachurée située à l'est des Pyrénées est celle de la "Catalogne humide » (orages estivaux venus de Méditerranée).

PAO et cartographie Michel Martzluff.

2 Les données recueillies dans le gisement ont été publiées de façon détaillée dans plusieurs ouvrages monographiques, dont celui de 2008 pour les premières occupations épipaléolithiques du site (couches 10 à 7 : Guilaine et al. 2008). Comme ce peuplement était associé à des harpons en bois de cerf à perforation en boutonnière et que cet outil typique a longtemps servi de fossile directeur pour définir l'Azilien à partir du site éponyme, il était admis qu'il s'agissait de brèves incursions venues directement du versant aquitain par la vallée de l'Ariège et le col du Port d'Envalira (fig. 2). 
Fig. 2. - Proche contexte de La Balma de la Margineda dans les Pyrénées de l'est.

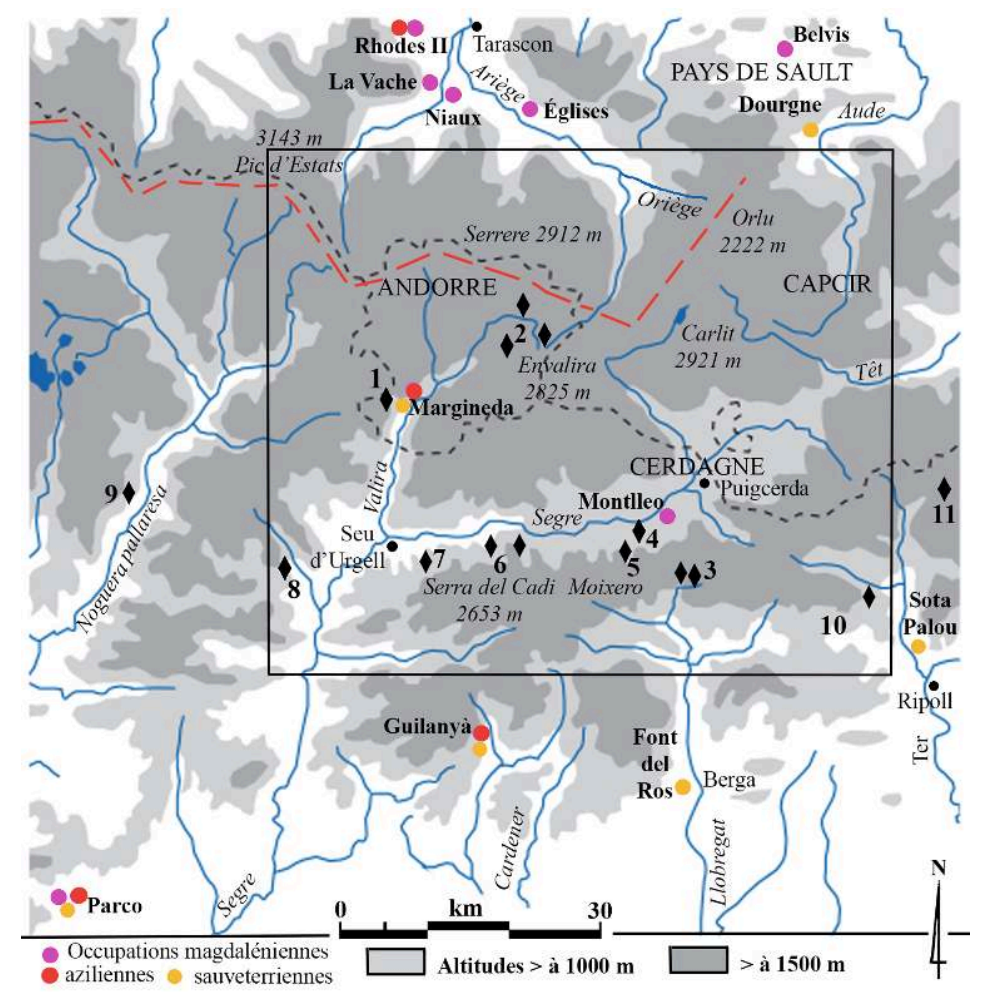

Le cadre renvoie à la présentation détaillée de la zone prospectée représentée fig. 3 et fig. 7. Les tiretés rouges signalent les secteurs infranchissables avant le début de l'Holocène. Les losanges pointent les principaux affleurements de roches volcaniques, ceux des Pallars et du Ripollès (n nos 9 et 11) se situant hors du cadre de cette étude.

PAO et cartographie Michel Martzluff.

Par ailleurs, la couche 8 ayant livré les petites têtes barbelées de ces armes se distinguait aussi par une industrie lithique tirée principalement de matériaux volcaniques difficiles à déterminer, en particulier des rhyolites et autres laves acides. Comme les affleurements de certaines de ces roches se trouvaient près du site, il était également convenu que ces Aziliens avaient puisé l'essentiel de leur ressource à proximité immédiate de leur campement. Ainsi, malgré une mise au point faite en 2009 sur les liens typologiques structurels qui unissent l'industrie de La Margineda aux complexes aziliens des deux versants de la chaîne (Martzluff 2009), les caractères particuliers qui s'expriment fortement dans la couche 8 (harpons, rusticité des pointes à bord abattu en roches volcaniques), peuvent expliquer qu'elle est le plus souvent restée ignorée des publications de synthèse concernant l'évolution post-magdalénienne dans le bassin de l'Èbre, là où les armes de chasse associables à l'aire de ponte du saumon atlantique n'existent pas et où l'ancienne notion d'Epipaleolítico microlaminar fut requalifiée en tant qu'Épimagdalénien (Román Monroig 2012 : p. 665, fig. 1). La notion d'Épimagdalénien, appliquée à l'ensemble des industries épipaléolithiques non géométriques au sud des Pyrénées et des Cantabres et, jusqu'à très récemment, à deux sites au nord de la chaîne (Troubat, dans les Hautes-Pyrénées et Gazel, à SallèlesCabardès, dans l'Aude), aboutit surtout à gommer les profonds changements qui affectent les modes de vie de l'Ouest européen à la fin du Tardiglaciaire, lors du brusque réchauffement climatique au GI 1-e, et à disqualifier l'impulsion qu'ont pu donner à ce processus les populations des péninsules méditerranéennes. Bien entendu, certains 
traits culturels de l'Azilien ancien du bassin de l'Èbre et des littoraux en Méditerranée nord-occidentale, issus de substrats magdaléniens ou épigravettiens régionaux, se distinguent bien de l'Azilien ancien dérivant des groupes magdaléniens du nord de l'Aquitaine ou du sud du Bassin parisien, et sans doute mieux par leur armement (absence des grands segments sur lame ou «bipointes à dos ", par exemple) que par la présence d'un art mobilier figuratif en voie de géométrisation, qu'ils ont en commun.

Plusieurs faits nouveaux nous ont poussé à reprendre les recherches sur cette question d'obédience culturelle, qui s'avère en réalité plus complexe qu'elle pouvait le paraitre il y a dix ans. D'une part, les récentes études géomorphologiques (Delmas et al. 2009, Turu et al. 2011) ont montré que le passage direct entre la vallée de l'Ariège et celle du Valira était barré par les glaces jusqu'au Dryas récent, et que l'accès aux hautes vallées andorranes à la fin du Tardiglaciaire depuis le bassin de Tarascon n'était possible que par le sud, à partir de la Seu d'Urgell, après avoir traversé le pays de Sault, le Capcir, la Cerdagne et la haute vallée du Sègre (fig. 3).

Fig. 3. - Englacement tardiglaciaire de la chaîne pyrénéenne au nord de l'Andorre.

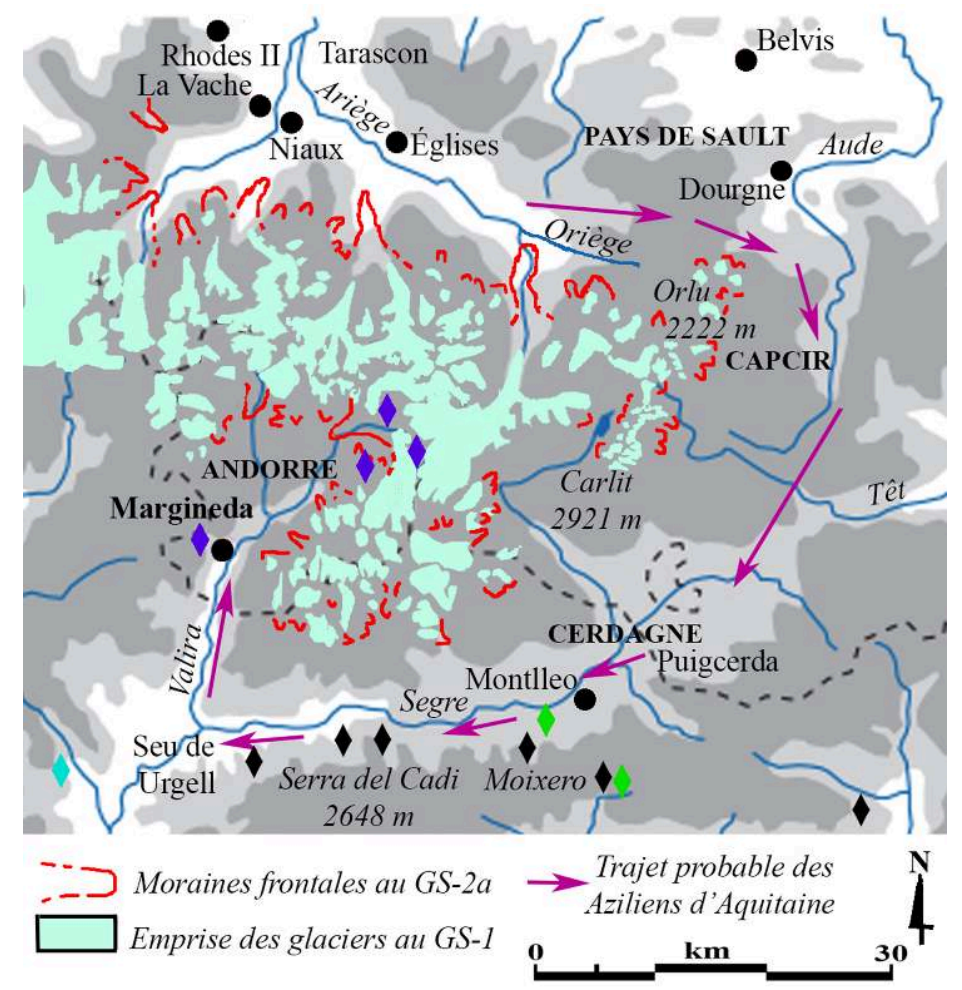

Losanges noirs : situation des laves porphyriques. Losanges bleus et verts : laves aphyriques. PAO et cartographie Michel Martzluff, d'après Delmas et al. 2009 et Turu et al. 2011.

D'autre part, alors que la découverte du campement de Montlleó (Prats i Sansor, Lérida) prouvait que ce passage par la Cerdagne était ouvert dès la fin du Dernier Maximum glaciaire, les récentes études sur la provenance des matériaux de ce site ont révélé que les chasseurs magdaléniens, éloignés de leur base, ont largement puisé dans les roches locales, parmi lesquelles des rhyolites (Sanchez de la Torre et Mangado Llach 2016). Enfin, une collaboration plus étroite avec les chercheurs fouillant des sites épipaléolithiques au sud des Pyrénées a permis d'affiner notre analyse des industries et des matériaux utilisés dans la région pour cette séquence (Martzluff et al. 2012). 
6 La gestion des matières premières par les Préhistoriques est une valeur qui compte surtout pour juger du stade culturel quand la ressource est anticipée sur de longues distances à partir de bons silex (lors du Magdalénien moyen, par exemple) ou, au contraire, quand elle l'est très peu, jusqu'à un paroxysme dans l'usage de roches immédiates de faibles propriétés clastiques (cas du Mésolithique au Boréal). Mais l'étude de ces matières premières pèse aussi sur notre appréciation des parcours saisonniers ou d'échanges intergroupes à leurs marges, et c'est ce qui nous intéresse ici. Généralement, la précision nécessaire pour assurer ces informations a surtout mis en avant l'étude des silex et des radiolarites. Sans négliger les données sur ces silexites, qui sont aujourd'hui mieux connues pour les Pyrénées de l'est qu'à l'époque où furent publiés les résultats des fouilles, nous rendrons compte ici des recherches récentes sur l'origine des laves utilisées par les Aziliens de la couche 8 en Andorre, car elles modifient sensiblement ce que nous avions avancé.

\section{Rappel des données acquises sur le site de La Margineda}

7 Avant le Néolithique, le peuplement de La Balma de la Margineda est attesté par deux séquences bien développées en stratigraphie : un Épipaléolithique azilien (couches 10 à 7 base), débutant à la fin du Bølling (GI 1-e) et surtout centré sur l'Allerød (GI 1-da) (fig. 4) et un Premier Mésolithique sauveterrien, qui apparaît précocement au cours du Yunger Dryas (GS 1) et se développe au Boréal (couches 7 à 4 base), le Second Mésolithique à armatures géométriques larges restant mal cerné en couche 4 . Les datations par le radiocarbone qui encadrent l'Azilien d'Andorre entre les couches 11 et 7 sup. s'étalent de $11870 \pm 110 \mathrm{BP}$ à $10340 \pm 130 \mathrm{BP}$, soit depuis la charnière conventionnelle Bølling-Allerød jusqu'à la charnière Dryas récent-Préboréal (fig. 4). 
Fig. 4. - La Balma de la Margineda (Andorre) : matières premières, modes de débitage et datations.
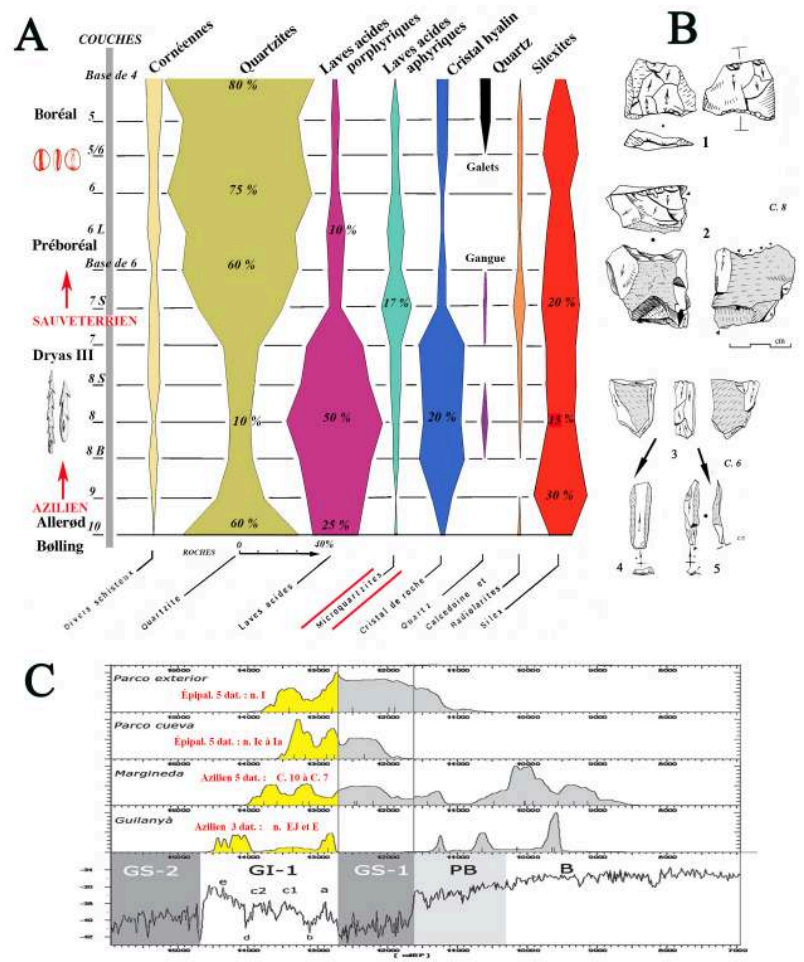

A : évolution des matières premières dans l'industrie lithique. Les anciennes déterminations sont notées au bas du graphique, avec le changement notable, souligné en rouge, des « microquartzites » en laves acides aphyriques. B : principaux modes de débitage sur les laves porphyriques. C : distribution des datations ${ }^{14} \mathrm{C}$ calibrées BP concernant la Margineda et deux sites épipaléolithiques proches. Datations ${ }^{14} \mathrm{C}$ calibrées BP CalPal (Weninger et al. 2006) ; les phases aziliennes du BøllingAllerød sont figurées en jaune.

PAO Michel Martzluff. c : d'après Martínez Moreno et al. 2006-2007.

Le Premier Mésolithique comprend deux stades. Le plus ancien (couches 7 et 6 base) est caractérisé - tout comme celui du Parco (Alòs de Balaguer, Lérida), situé au débouché de la vallée du Sègre, dans le bassin de l'Èbre (fig. 2 et fig. 4) - par l'hyper-microlithisme des armatures, majoritairement géométriques, obtenues à partir de lamelles recoupées par microburin ou par troncature oblique de minuscules éclats. Au Préboréal (couches 6 et 5/6), cet élassolithisme - vraisemblablement lié à la chasse exclusive à l'arc - est associé à de petits galets au décor peint ou gravé qui rattachent nettement ce Sauveterrien ancien à l'Epipaleolítico geométrico du Filador (Margalef de Montsan, Tarragona), situé près du delta de l'Èbre dans le même contexte chronotypologique (Martzluff 2009). Les niveaux 7 à 4 à microlithes sauveterriens et à galets peints du Filador couvrent un laps de temps assez resserré, qu'exprime l'ensemble de leurs datations ${ }^{14} \mathrm{C}$, soit cinq dates qui s'échelonnent entre $10020 \pm 80 \mathrm{BP}$ et $9130 \pm 230 \mathrm{BP}$, et qui se placent plutôt dans la première moitié du $\mathrm{X}^{\mathrm{e}}$ millénaire $\mathrm{BP}$ en datation conventionnelle, au début du Préboréal (fig. 4).

9 Au Boréal, le second stade mésolithique est caractérisé par la raréfaction (couche 5), puis par la disparition du débitage lamellaire et des armatures géométriques (couche 4 base), avec un recours quasi absolu aux roches locales proches, ce qui a pour effet d'accentuer le caractère archaïque de l'industrie déjà présente antérieurement : percussion posée, débitage clactonien d'éclats à la pierre dure et retouche épineuse sur 
les denticulés. Ces caractères récurrents sont aussi ceux des phases moyennes du Sauveterrien au nord des Pyrénées. Par contre, les armatures effilées hyperpygmées, tels les triangles de Montclus et les pointes de Sauveterre, qui caractérisent ce stade en Aquitaine, sont quasiment absentes dans son équivalent du bassin de l'Èbre, ce qui a lui valu, par défaut, l'appellation peu discriminante de complexe à muescas y denticulados. Il en résulte qu'à partir de la couche 7, en l'absence d'armatures pouvant évoquer l'influence du Laborien touchant le versant nord des Pyrénées au Dryas III et au Préboréal (Isturitz, Gouërris, Troubat, Mas d'Azil, Buholoup, Four de La Roque..., voir Fat Cheung et al. 2014), nous constatons qu'un même lien culturel fort relie les chasseurs-cueilleurs d'Andorre à ceux qui parcourent le bassin de l'Èbre et le sud des Pyrénées, depuis la Méditerranée (Corbières comprises) jusqu'à la cordillère Cantabrique. Or cette question d'ambiance culturelle s'avère plus complexe pour la séquence azilienne débutant vers 14000 cal. BP et marquée en stratigraphie par trois phases d'occupation au rythme séculaire (13 800-13 400-12 700 cal. BP) qu'isolent des phases d'abandon.

11 Les brèves stations saisonnières discontinues de la phase ancienne de La Margineda (couches 10 à 9) ont livré trop peu de matériel pour se montrer catégoriques. Mais ce premier peuplement épisodique montre des liens typologiques évidents avec des sites proches, sur le versant sud des Pyrénées, dont Guilanyà (Lérida) (Martínez Moreno et al. 2006-2007), où le processus d'azilianisation des industries est plus ancien dans le Bølling (fig. 4). Les principaux types de pointes à bord abattu y sont fusiformes, plus ou moins élancés, de type pointe d'Istres (voir ici pour la couche 8 de La Margineda fig. 5, $n^{\text {os }} 26$ et 27 et fig. $6, n^{\text {os }} 1$ et 2 ). 
Fig. 5. - La Balma de la Margineda (Andorre) : couche 8, aspect de l'armement azilien en « rhyolite 》.

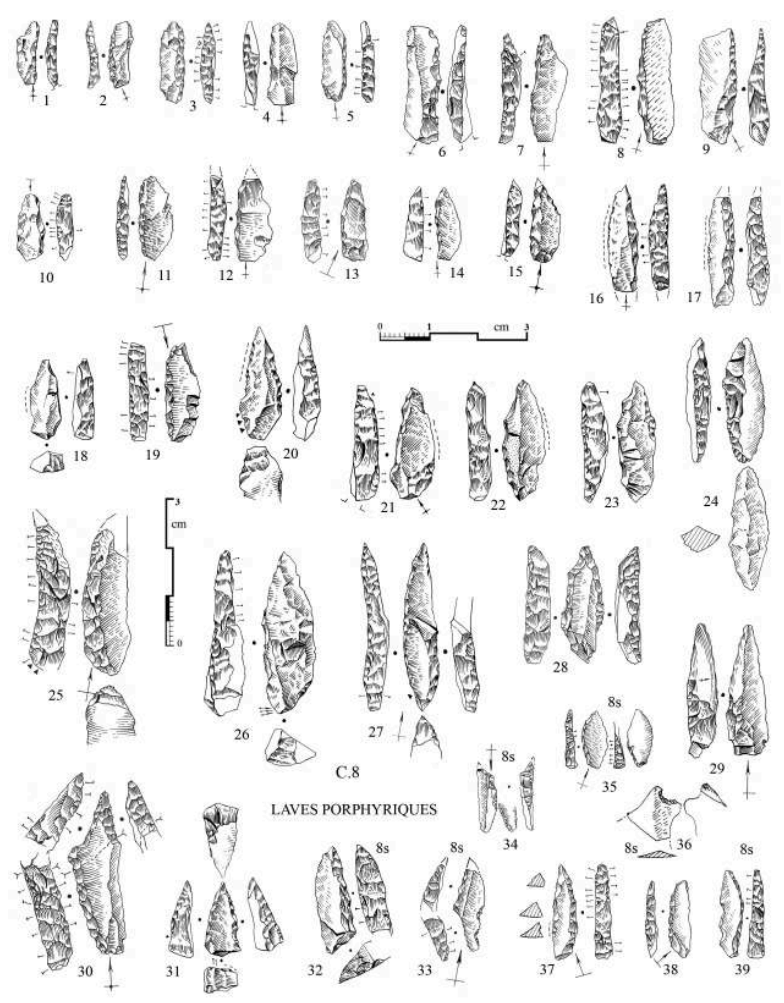

Les armatures issues du niveau supérieur sont notées 8S. 1 À 9 : lamelles à bord abattu ou à troncature très oblique $(8,9)$ sur supports peu normalisés. 10 A 12 : éclats à bord abattu $(11,12)$ ou tronqué prolongeant la série peu typique précédente. 13 A 28 : pointes à bord abattu rectiligne ou à troncature oblique (13) et pointes à bord abattu courbe caractérisant cet Azilien avec une majorité de pointes fusiformes courtes (19 à 23, 28) ou longues $(24,26,27)$. 29 : ébauche (?) de pointe fusiforme sur lamelle épaisse à dos de préparation (= face inverse) issu de la recoupe d'un éclat. $\mathbf{3 0}$ : pointe à dos gibbeux cassée en cours de fabrication. 31 Eт 32 : triangles non microlithiques pour l'épaisseur, malgré la retouche inverse rasante du $31 . \mathbf{3 3}$ : triangle à petite troncature croisée concave. $\mathbf{3 4}$ ET $\mathbf{3 7}$ À 39, pointes à troncature oblique et segments dissymétriques hyperpygmées. $\mathbf{3 5}$ : pointe fusiforme courte très diminutive. $\mathbf{3 6}$ : microburin.

Dessin Michel Martzluff. 
Fig. 6. - La Balma de la Margineda (Andorre) : couche 8, aspect de l'industrie azilienne : armatures effilées en « rhyolite » et leurs équivalents diminutifs en cristal de roche, plus nombreux et typiques.

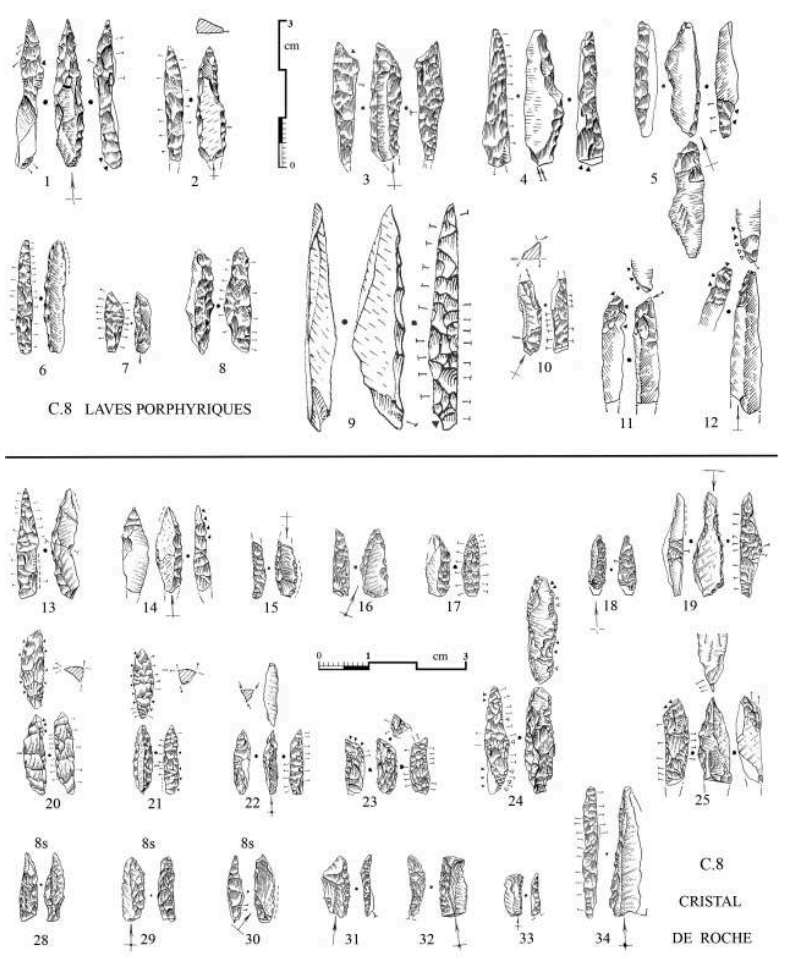

Les outils issus du niveau supérieur sont notés 8S. Sur ces pièces longues (c'est-à-dire relativement étroites) mais assez épaisses et souvent minuscules, le dos, obtenu par une retouche croisée, n'est pas vertical, mais prend une section arrondie caractéristique, le support étant posé sur le dièdre du tranchant et non pas sur la face d'éclatement (voir 8 ou 20 à 22). 1, 5 ET 19 : longues pointes à deux bords abattus courbes $(1,2)$ et leurs équivalents atypiques à dos gibbeux. $\mathbf{6}$ ET $\mathbf{1 3}$ : pointes segmentiformes. 9 : ébauche de pointe à bord abattu. 11 ET 12 : lamelles appointées sur chutes probables de la pièce esquillée. 10 ET 20 À 25 : minuscules dards (pointes triédriques aussi épaisses

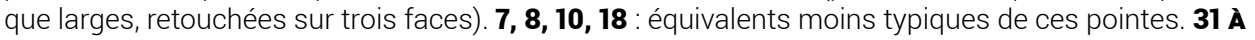
$\mathbf{3 3}$ : éclat et lamelles à bord abattu hyperpygmées. $\mathbf{3 4}$ : pointe à troncature très oblique.

Dessin Michel Martzluff.

C'est bien là l'un des caractères communs à l'ensemble de l'Azilien pyrénéen par la suite (Martzluff 2009, Fat Cheung et al. 2014). L'origine des silex, dont la proportion est la plus importante de la stratigraphie (fig. 4), dépend des affleurements qui se trouvent au sud (Guilaine et al. 2008 : étude de S. Lacombe, p. 552 et fig. 3), avec la présence notable d'une variété blanche que nous avions qualifiée de "calcédoine ». Nous savons désormais qu'elle provient des évaporites lacustres, de basse qualité pour le débitage laminaire (matrice fibreuse et fissurée), qui se trouvent dans les calcaires du Paléocène au débouché du Sègre, dans la plaine de l'Èbre (fig. 1). Cependant, les matériaux utilisés majoritairement lors de cette première phase sont principalement des quartzites et, pour une part bien moindre, des roches volcaniques.

Les occupations saisonnières s'intensifient dans la seconde phase (couche 8). C'est alors qu'apparaissent les éléments qui rattachent indubitablement cet Azilien à l'Azilien ariégeois du Mas d'Azil ou de Rhodes II (Arignac), avec les harpons bien sûr, mais aussi d'autres éléments typologiques plus discrets que sont de minuscules dards ou pointes triédriques (fig. 6, $\mathrm{n}^{\text {os }} 8$ et 20 à 24), outils spéciaux qui apparaissent en Andorre dans la couche 9 , qui sont bien présents dans l'Azilien de l'Ariège et bien plus rares, semble-t-il, 
sur le versant sud. Quelques silex, dont l'origine est vraisemblablement nordpyrénéenne, peuvent accentuer ce rapprochement : deux échantillons issus du flysch et une part moins congrue de silex noirs du Lias (Guilaine et al. 2008 : p. 562, échantillons T.119 et 77a), soit des silex noirs «schisteux " qui furent d'abord associés à un faciès «phtanite » du Paléozoïque en pays de Sault (Martzluff et Rouaud 1995) et par la suite rattachés en 2008 aux « silex noirs grenus » provenant du Lias nord-pyrénéen.

Cependant, les silex blancs calcédonieux venus du sud sont toujours bien présents et s'accompagnent de quelques silex à spicules provenant du Berguedà (formation Coronas). Mais ce qui change brusquement, c'est surtout la part des roches volcaniques, devenue prépondérante pour la fabrication des outillages. Elle s'accompagne de l'exploitation du cristal de roche hyalin, un bon succédané du silex pour certaines armatures pygmées (fig. 6) et dont les grands volumes sont ici associables à un encaissant magmatique.

Nous reviendrons plus loin sur la détermination des matériaux volcaniques plus ou moins altérés, qui peuvent encore conserver l'appellation générique de "rhyolites " que nous leur avions donnée sur la base d'un faciès porphyrique sombre ultramajoritaire, mais qui présentent en fait de plus nombreuses variétés, dont les origines ont été mal comprises. Retenons ici que toutes les roches éruptives de la stratigraphie possèdent un pseudocortex polyédrique formé de pans altérés par l'érosion lors d'un débit naturel à l'affleurement, suivant une fissuration structurale prismatique (rapide refroidissement ?). Sur les dièdres entre les surfaces planes de ces volumes prismatiques, la rareté des usures prouve que le ramassage s'est effectué près des gisements et non dans l'alluvion. Comme pour le cristal de roche, ces dièdres facilitent le débitage lamellaire. Mais ces laves ont, au contraire, de faibles propriétés clastiques, que nous avons testées à partir de gros cassons retrouvés dans les déblais des anciennes fouilles. Ce sont des roches très dures, mais peu fragiles, où l'onde de choc se propage difficilement, générant de fréquents rebroussements. De plus, bien qu'elles soient résistantes à la flexion dans les faibles épaisseurs, elles sont quand même cassantes au niveau des plus gros phénocristaux, qui créent une faiblesse dans la matrice.

propriétés ont eu une incidence forte sur le caractère de l'industrie et en particulier sur le contrôle du débitage, dont l'objectif est de produire de courtes lames minces et des lamelles à profil rectiligne. Elles favorisent les processus expéditifs déjà pratiqués dans l'Azilien ancien, avec l'usage intensif de la percussion posée (pièces esquillées, fig. $4, \mathrm{n}^{\circ} 1$ ) et avec l'utilisation de débris prismatiques où le plan de frappe est sommairement aménagé par une encoche en percussion lancée, de façon à obtenir des angles de chasse plus aigus dans l'axe de dièdres naturels (fig. $4, \mathrm{n}^{\circ} 2$ ). Ce principe se poursuit d'ailleurs sur les matériaux équivalents dans le Mésolithique, générant des déchets buriniformes, vite abandonnés (fig. $4, n^{\circ} 3$ à 5 ). Enfin, les piètres qualités mécaniques de ces laves - perceptibles sur des ébauches de pointes (fig. $5, \mathrm{n}^{\circ} 29$; fig. 6 , $n^{\circ} 9$ ), sur celles cassées en cours de confection (fig. $5, n^{\circ} 30$ ) ou sur les supports peu normalisés (fig. 5, $\mathrm{n}^{\mathrm{os}} 20,24,29$; fig. 6, $\mathrm{n}^{\text {os }} 4,5,9$ à 12 ) - induisent surtout une plus forte épaisseur des armatures, bon nombre atteignant ou dépassant la limite du microlithisme (>5 mm d'épaisseur : fig. $5, \mathrm{n}^{\mathrm{os}} 8,23$ à 26,28 à 32 ).

17 La troisième phase de cet Azilien (couche 8 sup. et couche 7 base de La Margineda) se signale, en fin d'Allerød/début Yunger Dryas, par un retour à des occupations discontinues et par une plus faible extension de l'aire habitée sous l'abri, sans doute 
associables à la péjoration climatique qui semble marquer par ailleurs l'abandon de sites montagnards situés à la même altitude (Martzluff et al. 2012). Les têtes de harpons disparaissent, et malgré la raréfaction des outillages, il est possible de constater une miniaturisation des pointes à bord abattu, une plus forte proportion de pointes taillées par troncature oblique sur éclats et l'apparition de microlithes géométriques fabriqués par microburin (fig. 5, nos 32 à 36). Avec ces éléments précurseurs du Mésolithique se développe aussi l'usage de roches microgrenues verdâtres, apparues en couche 8 avec les laves (fig. 4), mais qui ont posé des problèmes de détermination exposés ci-après.

\section{Origine des roches volcaniques employées dans l'Azilien en Andorre}

18 Les analyses concernant les sources d'approvisionnement de l'industrie complètent celles publiées précédemment et permettent de distinguer quatre groupes de roches volcaniques acides, deux pouvant se classer parmi les laves porphyriques et deux autres avec des pyroclastites aphyriques. Le groupe plus important est celui des laves porphyriques sombres (Martzluff et Rouaud 1995 : p. 153 et 156, échantillons 25, $\operatorname{lm} 10$; $26, \operatorname{lm} 5 ; 27 \mathrm{a}, \operatorname{lm} 9$ ), à pâte gris pâle de tonalité verdâtre ou gris foncé à noire (fig. 7, nos $1,8,9)$. 
Fig. 7. - Carte géologique simplifiée de la zone prospectée et secteurs des prélèvements.

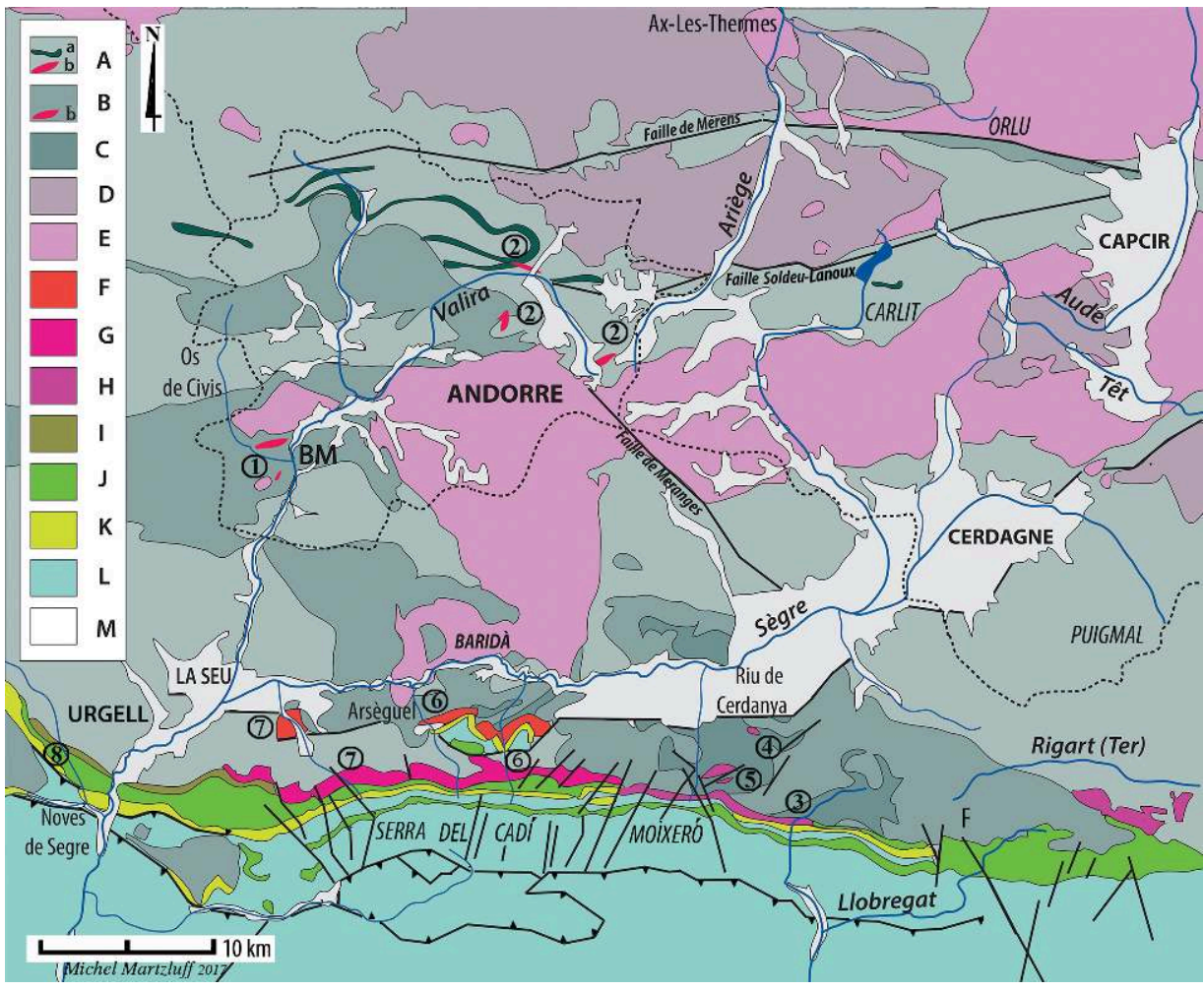

UG : unité grise ; UR : unité rouge. A : formations gréso-pélitiques schisteuses dominantes (séries préhercynienne, pré-Ordovicien supérieur et Ordovicien supérieur) ; intercalations (a) de bancs de quartzites gris sombres, (b) de métalaves acides et métatufs ryodacitiques. B : Siluro-Dévonien avec filons de paléovolcanites acides (b). c : conglomérats, grès, pélites et lydiennes de la formació de Bellver, au Carbonifère inférieur. D : orthogneiss ordoviciens (métagranites). E : plutons granitiques finicarbonifères (Stéphano-Autunien). F À H : complexe volcanique stéphano-autunien de la Serra del CadíMoixeró ; y sont distinguées les laves porphyriques verdâtres à noires plutôt andésitiques ( $F$ : UG, Stéphanien), les ignimbrites et laves porphyriques sombres plutôt rhyodacitiques (G : UG, Stéphanien), les pyroclastites de Gréixer et Riu : ignimbrites rhyolitiques souvent dévitrifiées, cinérites et laves aphyriques brunes ou vertes ( $H$, sommet de l'UG, Autunien du Carbonifère ?). I : transition de I'UG supérieure à l'UR (calcaires, grès et pélites). $\mathbf{J}$ : bancs de grès conglomératiques siliceux et de pélites rouge violacé du Permien, traversés de métatufs acides (UR inférieure, Autunien ?). $\mathbf{k}$ : conglomérats quartzeux rouges et pélites rutilantes du Trias inférieur, faciès Buntsandstein (UR supérieure). L : zone sud-pyrénéenne post-Keuper englobant les unités allochtones du Pedraforca, figurées ici par les chevauchements (séries alpines essentiellement calcaires du Mésozoïque au Paléogène compris). M : molasses néogènes (Mio-Pliocène) des bassins de la Seu et de Cerdagne; remplissages alluviaux et principales formations glaciaires du Quaternaire.

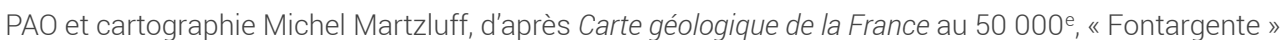
(1093) et «Saillagouse » (1098); Mapa geològic de Catalunya au 250000 e et Mapa geològic comarcal de Catalunya-Cerdanya au $50000^{\circ}$.

De gros phénocristaux blancs de feldspath potassique y sont très apparents, quoique souvent saussuritisés, ce qui témoigne de leur altération, tout comme la corrosion des quartz. La présence de clastes schisteux du Paléozoïque encaissant évoque le caractère parfois bréchique de ces ignimbrites rhyolitiques qui, lors des éruptions, ont pu être associées à la fusion de formations rocheuses déjà métamorphisées (fig. 8, nº 2). 
Fig. 8. - Vue des échantillons analysés sur surface sciée et sur lame mince.

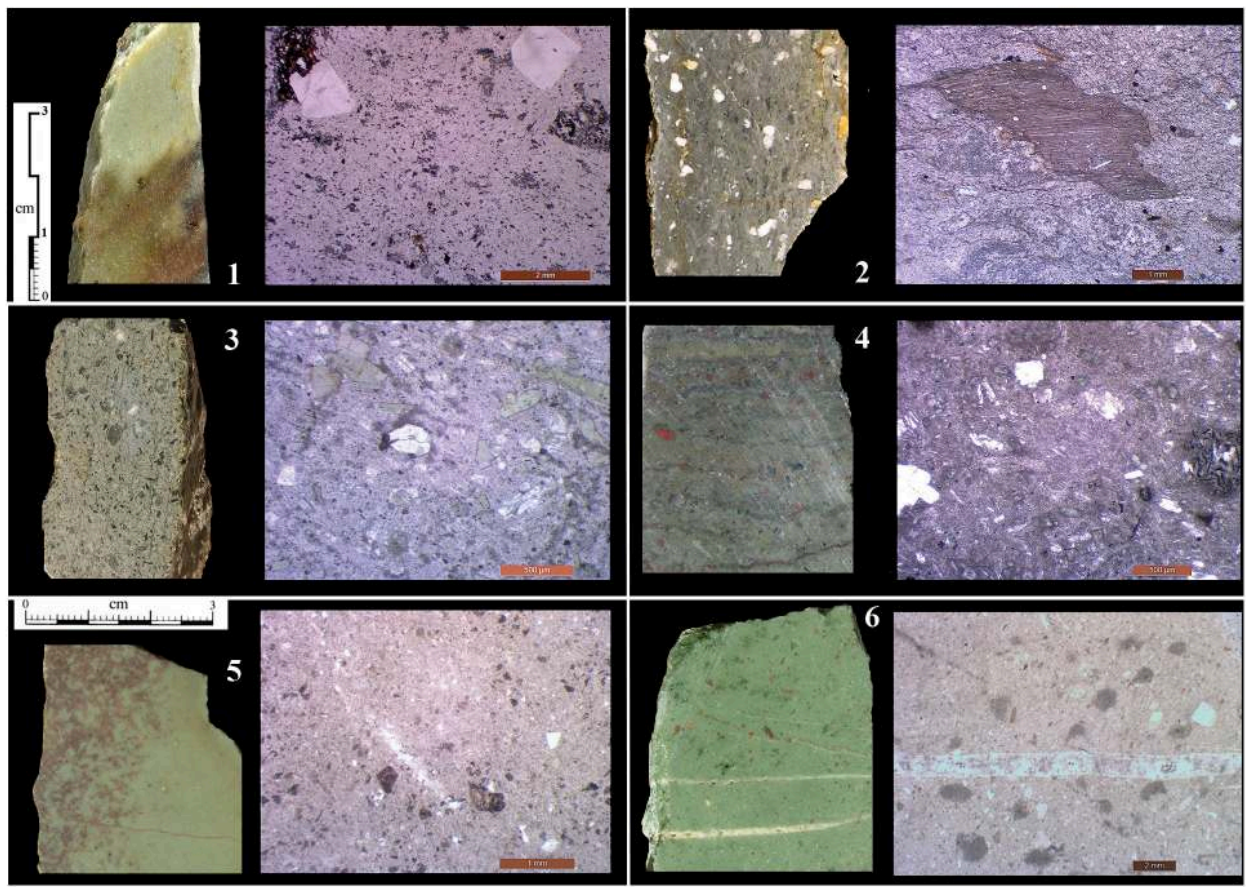

1 ANDORRA, BIXESARRI : roche gris pâle à verdâtre ; les parties les plus claires sont fortement altérées, les phénocristaux d'orthose souvent saussuritisés, avec présence de petits quartz dans la pâte microlithique et de nombreux grains ou masses noires indéterminables (fantômes d'orthose ?), métarhyolite (lame mince, éch. $2 \mathrm{~mm}$ ). 2 ANDORRA, LA MARgINEDA : Azilien de la couche 8, roche gris foncé à grands cristaux d'orthose ou sanidine (>5 mm), plutôt dégradés dans une structure subfluidale sans microlithes ; présence de minéraux fantômes très sombres, de quartz abondants et corrodés, de quelques zircons roses bipyramidés, mais aussi d'un grand claste ( 1 à $5 \mathrm{~mm}$ ) de micaschiste (au centre de la lame mince, éch. $1 \mathrm{~mm}$ ) ; une ignimbrite rhyolitique, vraisemblablement mobilisée à chaud après son dépôt. 3 ALT URgELL, SERRA DEL CADí, ARSÈguEL : roche grise à verdâtre à grands cristaux d'orthose blancs saussuritisés (> $5 \mathrm{~mm}$ ) dans une pâte microlithique sans lamines ; présence de prismes verts de feldspaths, de fantômes minéraux sombres (altération des orthoses ou des amphiboles) et de quelques petits quartz ; lave rhyolitique légèrement dégradée (lame mince vue en nicols croisés, éch. $500 \mu \mathrm{m}$ ). 4 ALt URgeLL, SERRA Del CADí, RIU CADí : roche gris foncé, presque noire, à cristaux prismatiques et brillants d'orthose ; structure microlithique bien conservée et légèrement laminée indiquant des épisodes d'accumulation fluidale de la lave, fréquents phénocristaux d'orthose (ou sanidine) dans une pâte microlithique (bâtonnets de feldspaths), minéraux opaques altérés (amphiboles probables), nombreux prismes de feldspaths verdis; ; la couleur très sombre de la pâte est due à une forte composante ferromagnésienne ; lave rhyolitique peu dégradée (lame mince, éch. $500 \mu \mathrm{m}$ ). 5 CERDANYA, MOIXeró, RIU DE CERDANYA : roche d'apparence hétérogène ; la partie grise à texture granulaire, d'aspect un peu vacuolaire, est assez riche en petits cristaux de quartz et les feldspaths potassiques y sont dégradés; présence de quelques veines quartzeuses de recristallisation secondaire ; la partie plus claire ne présente pas de phénocristaux, elle est essentiellement pélitique (pélites qualifiant ici des phyllosilicates type séricites-muscovites ou, dans ce cas, plutôt la chlorite résultant de la recristallisation d'autres alumino-silicates plus anciens, de type feldspath) ; en l'absence de structure microlithique conservée, la roche pyroclastique à la fois dégradée et recristallisée est difficile à défınir avec précision : métatuf rhyolitique ? (lame mince, éch. $1 \mathrm{~mm}$ ). 6 CERDANYA, MOIXERó, CANALS : roche gris verdâtre traversée de fissures remplies parfois incomplètement - de veines secondaires de quartz (0,5 à $1 \mathrm{~mm}$ de large) ; la matrice comprend de nombreux petits quartz et des feldspaths saussuritisés, mais pas de microlites, étant plutôt pélitique là aussi ; roche pyroclastique dégradée (lame mince, éch. $2 \mathrm{~mm}$ )

PAO Michel Martzluff. Déterminations et photos sur lames minces Pierre Giresse.

Ce groupe est suivi par celui des volcanites métamorphisées de tonalité claire et faiblement porphyriques, minoritaires (Martzluff et Rouaud 1995: p. 153, éch. 26, $\operatorname{lm} 12$; éch. 27b, $\operatorname{lm} 6$ ), dont l'origine avait déjà été détectée à proximité du site (fig. 2 et fig. $7, \mathrm{n}^{\circ} 1$; fig. $9, \mathrm{n}^{\circ} 7$ ). 
Fig. 9. - Principaux échantillons prélevés.

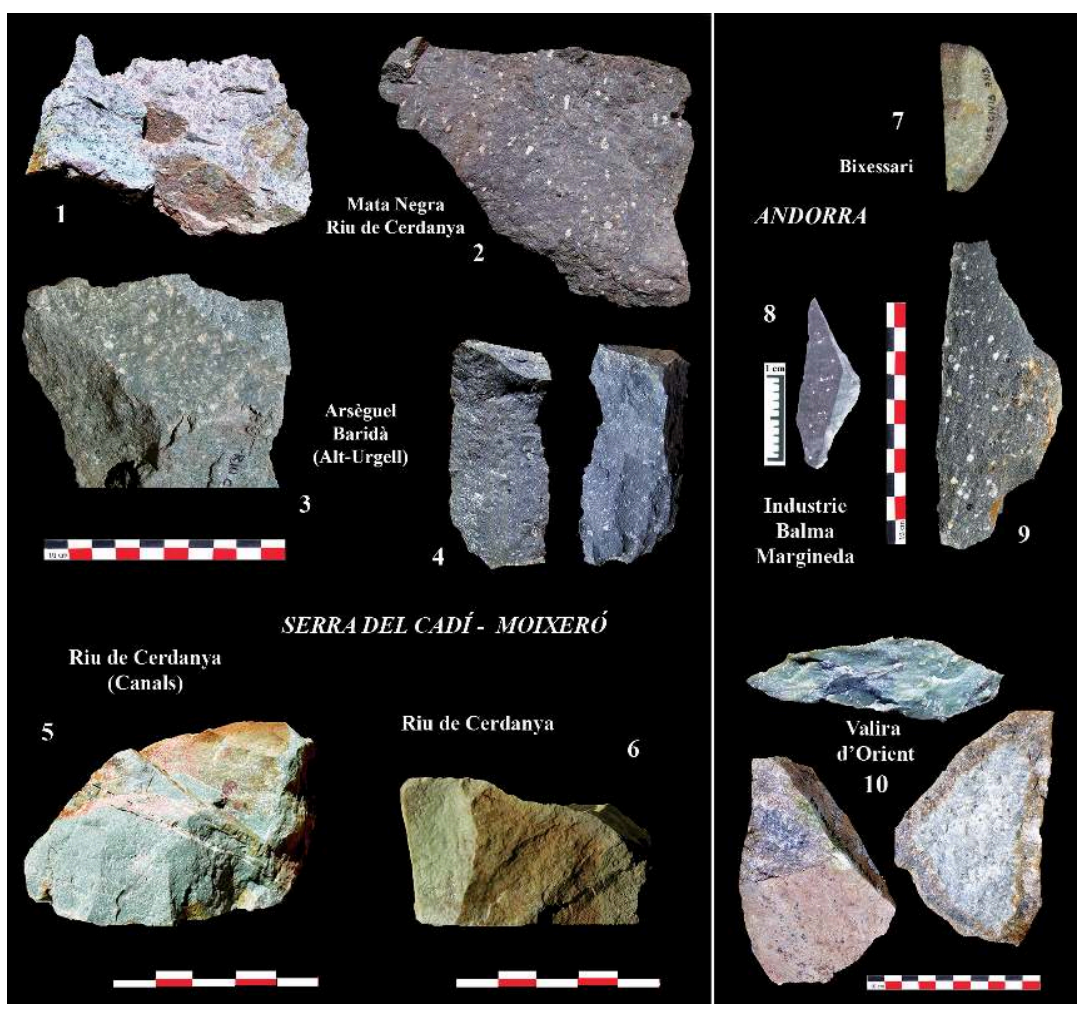

1 et 2 CERdANYA, SERRA DE MOIXeró, MATA NEgRA-Coll de PENDís : ignimbrite claire et rhyolite brun mauve. 3 ET 4 : BARIDÀ (ALT URgELL), SERRA DEL CADí, laves porphyriques verdâtres à noirâtres, éclat et lame (taille expérimentale). 5 ET 6 CERDANYA, SERRA DE MoIXERó, RIU DE CERDANYA : laves et tufs aphyriques verdâtres. 7 ANDORRA, RIU D'OS DE CIVIS, BIXESARRI : métarhyolite verdâtre faiblement porphyrique, avec oxydation brune à mauve due à l'altération. 8 ET 9 ANDORRA, BALMA DE LA MARgINEDA : lave porphyrique sombre à phénocristaux brillants d'orthose. 10 ANDORRA, COLL BLANC AU PORT D'ENVALIRA : métatuf aphyrique verdâtre et métarhyolite claire faiblement porphyrique, avec son auréole d'oxydation brune caractéristique.

Photos et PAO Michel Martzluff.

Les deux autres groupes concernent des roches volcaniques aphyriques, de texture microgrenue aphanitique, gris verdâtre pâle à vert olive, quelquefois beige à marron. Ces roches, dont le pseudocortex correspond aux fractures naturelles planes, oxydées en beige ou en brun, comme pour les laves, avaient été globalement qualifiées de «microquartzites » dans l'étude du Mésolithique en 1995, en raison de la forte teneur en grain de quartz, d'une zonation de la texture évoquant la schistosité et de la présence d'épidote signalant un métamorphisme, mais sans toutefois exclure de possibles laves séricitées (Martzluff et Rouaud 1995: p. 153, éch. 21, $\operatorname{lm} 23$ ). En 2008, pour les couches 10 à 7 , et avec les mêmes réserves concernant leur origine, des variétés de roches vertes aphanitiques, dont la cassure lisse conservait bien les stigmates du débitage (lancettes), avaient été classées parmi les silex. Il s'agit en fait dans les deux cas de roches volcaniques, dont les affleurements se trouvent au sud de l'Andorre avec les laves porphyriques sombres, ou bien associées aux grès rouges du Permien (fig. 7, $\mathrm{n}^{\text {os }} 3,4,8$; fig. 9, $\mathrm{n}^{\text {os }} 5,6$; fig. 10). 
Fig. 10. - Tufs et laves acides aphyriques (Autunien).

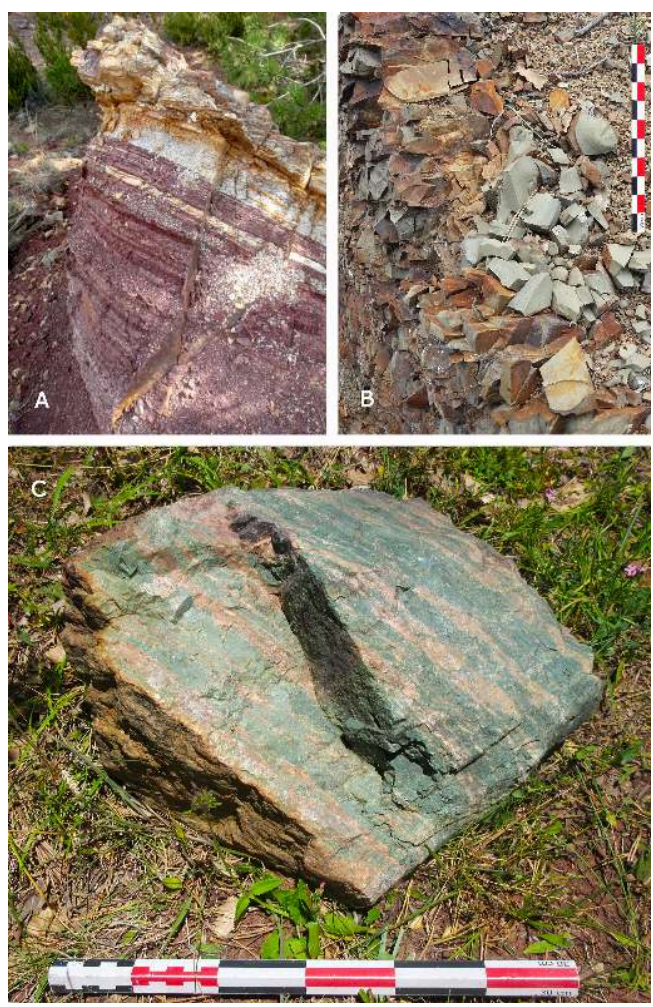

A : bancs de grès siliceux violacés de Noves de Segre (Alt-Urgell), où affleurent des métatufs acides verdâtres. B : détail du débit naturel. c : bloc rhyolitique vert et brun de Gréixer (Berguedà).

A et B, photos Gerard Remolins Zamora; C, photo Michel Martzluff.

Nos recherches de terrain pour localiser ces matériaux ont concerné deux types de gites. Au nord du Sègre, les intrusions de roches volcaniques felsitiques, faiblement porphyriques ou aphyriques, affleurent sous forme de dykes et de sills dans les vieilles formations paléozoïques de la chaîne axiale (fig. $7 \mathrm{~A}$ à C). Elles sont voisines du pluton granitique d'Andorre-Mont-Louis (fig. $7 \mathrm{E}$ ) qui se met en place vers $300 \mathrm{Ma}$ avec le magmatisme fini-carbonifère (Laumonier et al. 2014). Au sud, de bien plus vastes formations volcanoclastiques, également datables du Stéphano-Autunien (fig. $7 \mathrm{~F}$ à H), s'étirent d'est en ouest - depuis Camprodon jusqu'aux Nogueras du Pallars - en suivant une ligne où le socle paléozoïque entre en contact avec les formations de la zone sudpyrénéenne, substrats principalement calcaires du Mésozoïque et du début du Cénozoïque (fig. 1 et fig. 7 L). Aux formations éruptives de l'« unité grise » précédente succèdent les dépôts gréseux et conglomératiques rutilants de l'« unité rouge " du Permo-Trias (fig. $7 \mathrm{~J}-\mathrm{K}$ ) dont les galets de grès se retrouvent au nord de la chaîne dans le lit du Sègre, mais aussi, au sud, dans les alluvions des rivières ou bien en position secondaire vers l'aval, dans les conglomérats éocènes des Pré-Pyrénées. Ce sont ces grès siliceux rouges qui ont servi aux Aziliens pour réaliser leurs polissoirs à rainure et la plupart de leurs percuteurs (sauf pour débiter les laves tenaces, pour lesquelles de gros cassons de ces mêmes roches éruptives furent utilisés).

23 Entre la haute plaine cerdane et le bassin de la Seu d'Urgell, en rive gauche du Sègre, les paléovolcanites du Stéphano-Permien et les grès siliceux rouges du Permo-Trias forment plusieurs bandes dans les massifs du Moixeró et de la Serra del Cadí. Associables à un volcanisme explosif, les laves acides de cette zone et leurs équivalents 
pyroclastites (ignimbrites et tufs) forment de multiples faciès étroitement imbriqués. Ils ont subi des processus d'altération hydrothermale qui ont transformé leur minéralogie, leur texture et leur composition, si bien qu'il est difficile de préciser leur pétrographie sans avoir recours à des analyses chimiques, que nous n'avons pu effectuer sur nos échantillons. Díaz et al. (1996: p. 255) présentent une bonne synthèse de l'historique des recherches concernant ces roches éruptives des Pyrénées catalanes, sur leur description depuis les premiers travaux de M. San Miguel de la Cámara en 1935 et sur les hypothèses des principaux chercheurs sur ce volcanisme (en raison de la difficile détermination de ces roches, cet article déconseille de les utiliser pour une démonstration pédagogique dans les cours de pétrologie à l'université !).

Leur description macroscopique et leur détermination sur lame mince permettent cependant d'associer globalement les roches porphyriques sombres à des ignimbrites rhyolitiques, sous l'appellation finalement commode de métarhyolites. Bien que certains affleurements andésitiques ou dacitiques soient cartographiés (fig. $7 \mathrm{~F}$ et $\mathrm{G}$ ), les rapprochements avec la teneur de ces roches en silice sont donc incertains et notés avec un point d'interrogation dans les déterminations. Pour les mêmes raisons, les faciès aphyriques verts sont de détermination encore plus délicate entre les laves (métarhyolites) et les pyroclastites (métatufs). Leur rattachement aux cinérites demande à être précisé.

Notre diagnostic s'appuie aussi sur l'aptitude de ces roches dures à la taille au percuteur de pierre, c'est-à-dire sur leur fragilité et leur isotropie, ainsi que sur la résistance des produits minces à la flexion. Les rhyolites (au sens large) que livre le massif de la Serra del Cadí-Moixeró ont en effet une structure souvent bréchique et leur matrice, fréquemment perlitique, est le plus souvent dévitrifiée, ce qui rend impossible leur débitage contrôlé, en particulier pour obtenir des lames et lamelles. Dans ce cas, la source d'approvisionnement peut être écartée.

\section{Les paléovolcanites faiblement porphyriques ou aphyriques d'Andorre (peu utilisées en couche 8)}

De nombreux filons de roches éruptives affleurent au nord vers les sommets, principalement dans le Valira d'Orient : au Coll Blanc, près du Port d'Envalira, au Tosal de la Llosada et à Ransol, où ils touchent les bancs d'un excellent quartzite noir à grain fin (fig. $7, n^{\circ} 2$ ). Contrairement à d'autres variétés que livre par ailleurs le Paléozoïque régional, ce quartzite sombre est isotrope et fragile, relativement résistant dans les faibles épaisseurs, bien meilleur en tout cas pour produire des lamelles que les roches volcaniques. Les galets de ce quartzite que fournit l'érosion à partir des affleurements haut perchés sont très rares en Andorre dans les moraines basses, et absents sous forme manipulable dans les alluvions actuelles du cours du Valira au niveau du site. Ils ne sont bien attestés vers l'aval que sur les plus anciennes terrasses alluviales du Sègre. Il en est de même pour un faciès équivalent du pic Carlit, présent en Cerdagne dans les plus anciennes moraines, actuellement rarissime par ailleurs (fig. 7). Bien que ce quartzite ait servi au Préboréal pour l'essentiel de l'industrie sauveterrienne de La Margineda (couche 6), lorsque les hautes vallées septentrionales du Valira étaient facilement accessibles, il n'était sûrement pas disponible à proximité du site au Tardiglaciaire. Pour l'Azilien, on peut donc envisager des ramassages bien en aval, sur les hautes terrasses du Sègre. 
27 À ses côtés, les roches volcaniques du Valira d'Orient sont des métarhyolites très claires, blanches à verdâtres, faiblement porphyriques et des métatufs ryodacitiques verts, aphyriques (fig. 9, $\mathrm{n}^{\circ}$ 10). Quoiqu'elles soient compatibles avec certaines laves claires des industries de La Margineda, la place de ces roches dans les zones encore englacées au GS 1 et leur faible représentativité dans les alluvions et les déblais morainiques situés à plus basse altitude exclut pareillement cette source pour la période qui nous intéresse (fig. 3).

Dans la vallée d'Os Civis, des intrusions de roche volcanique aux tons gris pâle à verdâtre ont été cartographiées à Bixesarri dans le Silurien et aussi dans le Dévonien, au-dessus de La Margineda, d'abord en tant que "dyke d'aplite», puis comme «porphyre quartzitique» (Zwart et al. 1970, Besson et al. 1990). Ces roches faiblement porphyriques jouxtent le pluton granitique et sont fortement transformées (fig. $7, \mathrm{n}^{\circ} 1$ ). Elles présentent avec les précédentes les mêmes colorations claires, la même texture, le même débitage spontané en gros cassons prismatiques, avec les mêmes oxydations rougeâtres en périphérie de ces pseudo-cortex plans (fig. 9, $\mathrm{n}^{\circ} 7$ ). Il s'agit d'un matériau très dur, mais peu fragile, extrêmement difficile à débiter sous forme laminaire et dont on ne peut tirer que de petits éclats solides. Ces derniers sont légèrement translucides. Ces roches qualifiées de volcaniques ou de laves acides sp. dans les premières déterminations sur l'industrie sont classées désormais grâce à nos analyses avec les métarhyolites précédentes (fig. $8, \mathrm{n}^{\circ} 1$ ). Elles forment une part minoritaire dans la couche 8 et sont plutôt utilisées à la marge dans le Mésolithique de la couche 6 (fig. 4).

\section{Les laves porphyriques sombres de la Serra del Cadí-Moixeró (majoritairement exploitées en couche 8)}

Ces roches à gros phénocristaux blancs de feldspath se logent à une trentaine de kilomètres au sud de La Margineda (soit à une journée de marche environ), en rive gauche du Sègre. Nos recherches sur ce type de laves sont restées vaines en Andorre, bien que l'on nous ait signalé un petit affleurement de laves porphyriques sombres sous le pic de Carroi, dans le Silurien de la vallée de Sispony, non cartographié et introuvable ; il existe par ailleurs, dans les granites d'Andorre et de Cerdagne (secteur de Lles), des intrusions magmatiques noirâtres de lamprophyres. Ces roches filoniennes sombres, également porphyriques, mais mafiques, ne peuvent être confondues avec les roches effusives acides dont nous parlons.

Deux secteurs d'affleurements sont à exclure parmi ces zones d'approvisionnement potentielles. Vers l'est, le premier se situe loin en altitude, en Cerdagne, dans le massif du Moixeró, entre Mata Negra et le Coll de Pendís (fig. 7, n ${ }^{\circ}$ 5). Les pyroclastites ignimbritiques mauves à gris verdâtre, souvent bréchiques, et les laves rhyolitiques brunes ou violacées, y sont dévitrifiées et impropres au débitage contrôlé de produits minces (fig. $9, \mathrm{n}^{\circ} 1$ et 2 ). Plus proche vers l'ouest, en bordure du bassin de la Seu d'Urgell, le second secteur d'affleurements se trouve dans la Serra del Cadí, entre Cerc et $\mathrm{El} \mathrm{Ges} \mathrm{et} \mathrm{le} \mathrm{coll} \mathrm{de} \mathrm{Laguén} \mathrm{(fig.} 1$; fig. 7, $\mathrm{n}^{\circ}$ 7). Les roches éruptives y sont différentes (dacitiques et andésitiques), mais n'ont pas été retenues pour les mêmes raisons.

31 C'est finalement entre ces deux pôles, dans la région du Baridà, entre la Seu d'Urgell et Martinet, que les échantillons de laves sombres s'approchent le mieux - par leur propriétés clastiques et leur pétrographie - de celles massivement utilisées dans l'Azilien de couche 8 en Andorre. Ces roches traversent les vallées du Riu de Cadí, du 
Riu de Quer et du Torrent de Bastanist (fig. 1 ; fig. 7, $\mathrm{n}^{\circ}$ 6). Près d'Arsèguel, dans un secteur proche du Sègre et moins élevé en altitude, les affleurements volcaniques jouxtent le Dévonien dans une zone touchée par le métamorphisme du pluton granitique qui traverse le fleuve à cet endroit. Du reste, l'origine des gros cristaux de quartz hyalin automorphe associés à l'usage des roches volcaniques dans le site andorran pourrait aussi se trouver là.

Deux principaux types de laves rhyolitiques (au sens large) y sont compatibles avec l'industrie azilienne. Le premier est relativement altéré (andésite ? fig. 8, $\mathrm{n}^{\circ} 3$ ), parfois bréchique et de tonalité verdâtre dans le gris. Certains faciès permettent le débitage d'éclats, bien que le matériau soit assez peu fragile, générant des bulbes peu marqués ou plats (fig. $9, \mathrm{n}^{\circ}$ ). Le second, moins dégradé (fig. 9, $\mathrm{n}^{\circ} 4$ ), est un matériau gris sombre, aussi dur, mais plus fragile, qui autorise une taille laminaire. Cette lave noirâtre est celle qui s'approche le plus des roches rapportées à La Margineda (rhyodacite? fig. $8, \mathrm{n}^{\circ} 4$ ). Ces deux types de laves porphyriques taillables n'ont qu'une très faible représentativité dans l'alluvion du Sègre et paraissent absents sur le versant sud du massif du Cadí-Moixeró, en particulier dans les conglomérats tertiaires de Berga. Ils ne sont pas attestés dans le Magdalénien de Montlleó, ni dans l'Épipaléolithique-Mésolithique du Parco (comm. pers. M. Sánchez de la Torre). Il en est de même dans l'Azilien de Guilanyà, où un seul outil de la couche $\mathrm{E}$ nous paraît taillé dans ce type de lave (un racloir, BG-E $\mathrm{n}^{\circ} 4728$, observation M. Martzluff, étude inédite).

Notons que le secteur d'Arsèguel livre aussi de petits blocs de lydienne noire, probablement issus du Carbonifère basal du secteur (fig. $7 \mathrm{C}$ ), comme celles de la formation de Bellver, en Cerdagne. Cette variété de radiolarite fut aussi utilisée marginalement par les Magdaléniens de Montlleó et les Aziliens en Andorre.

\section{Les laves et tufs aphyriques verts du Moixeró (bien attestés en couche 8)}

C'est sur le versant sud du Moixeró, autour de Gréixer, dans le haut bassin du Llobregat, que ce complexe volcanique des Pyrénées catalanes est le mieux connu (fig. 7, $\mathrm{n}^{\circ} 3$ ). Les ignimbrites rhyolitiques brunes à mauves ou grises à verdâtres y sont le plus souvent bréchiques et dévitrifiées, inaptes à une taille dédiée aux industries préhistoriques. Mais à ces pyroclastites et laves porphyriques se trouvent mêlées des roches aphyriques: laves rhyolitiques, cinérites ou tufs de couleur vert olive ou beige à marron, mobilisés à chaud après leur dépôt et dont les émissions sont étroitement intriquées (fig. 10). Quoique très fissurées, ces roches dures plus ou moins aphanitiques, mais à cassure lisse, ont une bonne aptitude à la taille laminaire. Certaines avaient été anciennement classées comme "pétrosilex », terme qui qualifiait alors la cinérite (Díaz et al. 1996), ou comme hälleflinta pour quelques faciès à cassure brillante (porcelanita).

Un équivalent de ces laves rhyolitiques et métatufs acides se retrouve en Cerdagne, sur le flanc nord du Moixeró, au sud de Riu de Cerdanya (fig. 7, $\mathrm{n}^{\circ} 4$ ). Les affleurements de Riu et de Canals livrent un matériau légèrement grenu, gris clair à tonalité verdâtre ou franchement vert (fig. $9, \mathrm{n}^{\text {os }} 5$ et 6 ). Le débit prismatique naturel et la faible dimension du réseau issu de cette fissuration ne permettent d'extraire que de courtes lamelles. La plupart de ces roches vertes sont traversées de bandes plus claires avec changement de texture, parfois par des filets de quartz recristallisés (fig. 8, $\mathrm{n}^{\circ}$ 6). Certains échantillons sont localement ponctués de mouchetures oranges ou noirâtres, oxydations pouvant 
développer des digitations arboriformes de faciès dentritique (fig. 8, $\mathrm{n}^{\circ}$ 5). Ces laves aphyriques et ces métatufs verts ou beiges du Moixeró sont les rhyolites (au sens large) signalées dans le campement magdalénien de Montlléo (Sanchez de la Torre et Mangado Llach 2016). Elle correspondent en grande partie aux «silex verdâtres [...] imparfaitement définis » et parfois beiges qui apparaissent à partir de la couche 8 de La Margineda (Guilaine et al. 2008 : p. 562). Il conviendrait de vérifier si c'est bien ce type de roche verte qui est signalé dans l'Azilien de Rhodes II (Guilaine et al. $2008:$ p. 563, éch. T.19-19b-34-35-46-81-113 et T.53 pour le « silex beige » uniquement représenté en couche 8).

\section{Les pyroclastites aphyriques vertes (métatufs ou cinérites ?) de Noves de Segre (rares en couche 8 , très présentes en couche 7 )} trouvent en rive droite, près d'Argestues, des filons de roches verdâtres correspondant aux tufs acides associés à ces formations (fig. $7, \mathrm{n}^{\circ} 8$ et fig. 10). Ce matériau microgrenu opaque, à cassure mate, que l'érosion débite en «frites » selon les plans prismatiques de fissuration et dont les «cortex» sont beige clair à bruns, est tout à fait apte à la taille : les bulbes y sont bien marqués et la résistance dans les faibles épaisseurs est bonne. Toutefois, une légère anisotropie favorise l'onde de choc dans le sens des fissurations et la dimension modeste des débris naturels n'autorise qu'un débitage lamellaire. Lors des premières analyses sur le mobilier archéologique, nous l'avions classé parmi les «microquartzites verts ", avec d'autres roches microgrenues, tout en soulignant une possible origine volcanique (Martzluff et Rouaud $1995:$ p. 153, $1 \mathrm{~m} 20$ ). Il en est de même pour certains "silex gris verdâtre ou vert pâle indéterminés " des couches 8 et 7 (Guilaine et al. 2008 : p. 565, éch. T.36, T.102 et T.103).

En fait, cette roche reste difficile à séparer des autres émissions de laves et tufs verts rhyolitiques du Moixeró qui sont sub-contemporaines dans les débuts du Permien, en particulier des faciès microgrenus altérés de Riu de Cerdanya. En Andorre, c'est dans l'industrie du Sauveterrien ancien du Dryas III (couche 7 sup.) que ce métatuf acide subit une nette inflation (fig. 4), l'Azilien n'étant qu'assez peu concerné. Par contre, d'autres affleurements doivent pouvoir se trouver dans ces grès de l'unité rouge inférieure, au sud de la chaîne du Cadí-Moixeró, au sein de formations autuniennes (fig. $7 \mathrm{~J}$ ) et, par suite, dans les conglomérats cénozoïques des Pré-Pyrénées méridionales où les Aziliens de Guilanyà ont puisé leurs ressources lithiques, lesquelles comprennent une bonne part de roches vertes microgrenues d'aspect semblable.

\section{Conclusion}

Malgré des difficultés d'identification dues à la complexité des roches volcaniques dans la zone métamorphique de ces hautes montagnes et à la simplicité des moyens mis en œuvre pour les identifier, nous avons réussi à isoler quatre types qui constituent la source majeure des matériaux utilisés lors du premier peuplement azilien des hautes vallées andorranes et à retrouver les sites de provenance. Dans la couche 8 de La Margineda, les métarhyolites claires d'Andorre sont rares, de même que les pyroclastites rhyolitiques vertes qui proviennent de Cerdagne (Riu) ou que les métatufs acides de Noves de Segre. Par contre, l'usage intensif des laves sombres rhyolitiques (ou 
rhyodacitiques ?) a pour origine le Baridà, à proximité du bassin de la Seu de Urgell, sur le Sègre.

Cette exploitation représente-t-elle le simple témoignage d'un passage obligé sur le parcours qui conduisait épisodiquement un groupe azilien vers les hautes vallées andorranes depuis le bassin de Tarascon-sur-Ariège ? Sans doute, pour une part, mais peut-être pas si simplement. Outre le fait que ces affleurements étaient déjà connus de leurs prédécesseurs (couches 10 et 9), dont les trajets semblent différents lors des premières explorations de cette zone, le passage indirect depuis le nord, bien plus long que celui qui était envisagé, disqualifie l'hypothèse d'incursions légères avec allers-etretours rapides. Car c'est aussi pendant cette phase de l'Allerød que la fréquentation de l'abri andorran sur plusieurs décennies est continue à la belle saison. Un ancrage plus pérenne de ces chasseurs venus du nord dans le haut bassin du Sègre, avec des campements d'hivernage dans la cuvette d'Urgell, est donc une hypothèse envisageable, d'autant que des séjours prolongés peuvent expliquer leur adaptation au substrat volcanique local pour produire la plupart de leurs armes de chasse et de leurs outils domestiques. Ils ont même su trouver de gros cristaux de roche hyalins (fort difficiles à découvrir aujourd'hui malgré nos efforts) pour suppléer l'absence de silex.

Mais pourquoi ne retrouve-t-on pas d'outils en laves porphyriques, même à dose homéopathique semble-t-il, parmi les industries des autres sites contemporains connus, à la fois sur le versant nord (Rhodes II) et sur le versant sud (Guilanyà, Parco) ? Certes, ces roches coriaces ne sont pas un matériau pouvant susciter beaucoup d'intérêt par ailleurs, mais les chasseurs aziliens occupant le haut bassin du Sègre utilisaient aussi des silex lointains. Certains issus du versant nord, mais surtout les silex blancs calcédonieux affleurant bien en aval sur le fleuve, vers l'Èbre, silex qui ne sont pas de grande qualité non plus, mais qu'ils ont employés avec d'autres, tout aussi éloignés, sur le Llobregat. Ces matériaux balisent-ils de brefs parcours épisodiques à la marge d'un territoire de chasse assidûment fréquenté pendant une large partie de l'année, ou s'agit-il d'échanges plus normalisés avec d'autres groupes, échanges de bien matériels, dont des silex, et par conséquent, sociaux et culturels ?

Il serait périlleux de répondre à ces questions en l'état actuel de la recherche. Nous pouvons seulement constater que l'usage du harpon de type azilien ne dépasse pas l'Andorre vers l'Èbre. Au vu de la modeste taille des truites capturées en Andorre ( $30 \mathrm{~cm}$ pour les plus grosses, soit $250 \mathrm{~g}$ environ), la question se pose de l'utilité de cette arme sur le versant méridional de la chaîne, où l'aire de ponte du saumon atlantique n'existe pas. Cet armement en bois de cerf disparait d'ailleurs en couche $8 \mathrm{~S}$ et en couche $7 \mathrm{~b}$, alors qu'une partie de l'équipement lithique de ces mêmes groupes aziliens occupant le site andorran en fin d'Allerød semble se renouveler, avec la réduction de la dimension des pointes à bord abattu ou à troncature très oblique et la présence de rares microlithes géométriques taillés dans ces mêmes laves porphyriques. Cette évolution pourrait témoigner d'un influx caractérisant le Mésolithique - peut-être associable à l'usage de l'arc? - qui a précédé le développement stratigraphique des couches C.7 sup. et 6 à La Margineda, où le Sauveterrien est déjà précoce. Comme il est tout aussi précoce bien en aval sur le Sègre, à la grotte-abri du Parco, dans les niveaux EC 11 et 12, partie supérieure des niveaux Ia2 (Garcia-Argüelles et al. 1998-1999, Petit et al. 2009), ces innovations sauveterriennes semblent alors bien provenir du sud et du bassin de l'Èbre, dès le Dryas récent (Martzluff 2009). 


\section{BIBLIOGRAPHIE}

BesSon M., RAGUin E., ZWART H.-J., HARTEVelt J. J. A., AUTRAN A., VYAin R., KUMER J., 1990, Carte géologique de la France au 1/50 000, feuille n 1093, « Fontargente », Orléans, BRGM.

DELMAS M., CALVET M., GUNNEL Y., 2009, « Variability of Quaternary glacial erosion rates: A global perspective with special reference to the Eastern Pyrenees ", Quaternary Science Review, vol. 28, p. 484-498.

DíAZ N., GIMENO D., SEGURA C., 1996, « Revision de las colecciones de rocas rioliticas catalanas del Museu de Geologia y de la Facultat de Geologia de la Universitat de Barcelona », Treballs del Museu de Geologia de Barcelona, vol. 5, p. 255-281.

fat Cheung C., CheVAllier A., BONNET-JACQUement P., LANGLAis M., FERRiÉ J.-G., COSTAMAGNo S., KUnTZ D., LAROULANDIE V., MALlye J.-B., VALDEYRon N., BALISTA S., 2014, « Comparaison des séquences aziliennes entre Dordogne et Pyrénées : état des travaux en cours », dans Langlais M., Naudinot N., Peresani M. (dir.), Les groupes culturels de la transition Pléistocène-Holocène entre Atlantique et Adriatique, Paris, Société préhistorique française, p. 17-44.

GARCIA-ARGÜELLES ANDREU P., NADAL I LLORENZO J., FULLOLA I PERICOT J. M., 1998-1999, « Vingt anys d'excavacions a l'abric del Filador (Margalef de Montasant, Priorat, Tarragona) », Tribuna d'Arqueologia, Barcelona, Generalitat de Catalunya, p. 71-95.

GUILAINE J., BARBAZA M., MARTZLUFF M., 2008, Les escavacions a la Balma de la Margineda, t. IV [Azilien, textes bilingues catalan/français], Andorra la Vella, Ministeri d'Afers Socials i Cultura Principat d'Andorra.

LAUMONIER B., BARBEy P., DENÈLE Y., OLIVIER P., PAQUeTTE J.-L., 2014, « Réconcilier les données stratigraphiques, radiométriques, plutoniques, volcaniques et structurales au Pennsylvanien supérieur (Stéphanien-Autunien p.p.) dans l'est des Pyrénées hercyniennes (France, Espagne) », Hercynien, revue de géologie pyrénéenne, vol. 1, n² 2, 10 p. http://www.geologie-des-pyrenees.com/

MARTÍNEZ MORENO J., MORA TORCAL R., CASANOVA i MARTí J., 2006-2007, « El contexto cronométrico y tecno-tipológico durante el Tardiglaciar y Postglaciar de la vertiente sur de los Pirineos orientales ", Revista d'Arqueologia de Ponent, $\mathrm{n}^{\circ}$ 16-17, p. 7-44.

MARTZLUFF M., 2009, «L'azilien pyrénéen entre Garonne et Èbre : un état de la question », dans Fullola J. M., Valdeyron N., Langlais M. (dir.), Les Pyrénées et leurs marges durant le Tardiglaciaire: mutations et filiations technoculturelles, évolutions paléo-environnementales. Actes du XIV colloqui internacional d'arqueologia de Puigcerdà, Puigcerdà, Institut d'Estudis Ceretans, p. 375-422.

MARTZLUFF M. et ROUAUD M., 1995, «Les activitats de l'home prehistoric : els materials litics : natura i localitzacio », dans Guilaine J. et Martzluff M. (dir.), Les escavacions a la Balma de la Margineda, t. III, Andorra la Vella, Ministeri d'Afers Socials i Cultura Principat d'Andorra, p. 136-156.

MARTZLUFF M., MARTÍNEZ-MORENO J., GUILAINE J., MORA R., CASANOVA J., 2012, « Transformaciones culturales y cambios climáticos en los Pirineos catalanes entre el Tardiglaciar y Holoceno antiguo: el Aziliense y el Sauveterriense precoces de Balma de Margineda y Balma Guilanyà », Cuaternario y Geomorfología, vol. 26, nº 3-4, p. 61-78.

PETIT M. A., MANGADO X., FULLOLA J. M., BARTROLÍ R., BERGADÀ M.-M., ESTEVE X., 2009, « Els caçadorsrecol.lectors de la Cova del Parco (Alòs de Balaguer, La Noguera, Lleida). L’Epipaléolític microlaminar: continuïtat o canvi? », dans Fullola J. M., Valdeyron N., Langlais M. (dir.), Les 
Pyrénées et leurs marges durant le Tardiglaciaire : mutations et filiations techno-culturelles, évolutions paléo-environnementales. Actes du XIVè col.loqui internacional d'arqueologia de Puigcerdà, Puigcerdà, Institut d'Estudis Ceretans, p. 579-591.

ROMÁN MONROIG D., 2012, « Nouveautés sur la séquence Pléistocène final et l'Holocène initial dans le versant méditerranéen de la péninsule ibérique à travers l'industrie lithique ", L'Anthropologie, vol. 116, p. 665-679.

SANCHEZ DE LA TORRE M. et MANGADO LLACH X., 2016, « ¿De dónde vienen? Aprovisionamiento de rocas sedimentarias silíceas en el yacimiento magdaleniense al aire libre de Montlleó (Prats i Sansor, Lleida)», Trabajos de Prehistoria, vol. 73, $n^{\circ}$ 1, p. 7-28.

TURU V., VIDAL ROMANÍ J. R., FERNÁNDEZ MOSQUERA D., 2011, « Dataciones con isotopos coemogenicos: parte 1 ( $\left.{ }^{10} \mathrm{Be}\right)$ : el "LGM (Last Glacial Maximum)" y “Last Termination" en los valles del Gran Valira y La Valira del Nortd (Principado de Andorra, Pirineos Orientales) », dans Turu V. et Constante A. (dir.), El Cuaternario en España y areas afines, avances en 2011, Zaragoza, Sdad. Coop. De Artes Gràficas, p. 19-23.

ZWART H. J. et HARTEVELT J. J. A., 1970, Mapa geològic d'Andorra 1:50.000, Andorra la Vella, Arxiu Nacional d'Andorra.

\section{RÉSUMÉS}

L'Azilien est attesté à la grotte de La Balma de la Margineda (Andorre) dès la fin du Bølling. L'étude de l'industrie du site a montré que la source des silex des premiers occupants se trouvait dans le bassin de l'Èbre. Toutefois, les harpons ayant caractérisé cette période dans le site éponyme du Mas d'Azil ainsi qu'en Aquitaine apparaissent brusquement à l'Allerød, avec l'utilisation massive d'une lave porphyrique sombre ainsi que d'autres laves acides vertes situées en altitude, dans la zone axiale métamorphique des Pyrénées catalanes. Or de récentes études sur l'englacement indiquent que le passage direct depuis l'Ariège par les cols était alors impossible. De nouvelles recherches pétrographiques montrent qu'une zone d'approvisionnement en roches éruptives fut exploitée dans le piémont de la Serra del Cadí, entre Cerdagne et bassin d'Urgell. Cela renouvelle notre compréhension du parcours de ces chasseurs et interroge sur les contacts entre différents groupes aziliens des deux versants de la chaîne.

The Azilian culture is found at Balma de la Margineda (Andorra) as early as the end of the Bølling. The study of the industry has shown that the flint source of the early human occupation came from the Ebro basin. However, the harpoons that are characteristic of the Azilian period in the eponymous Mas d'Azil site and also in Aquitaine suddenly appear in the Allerød, together with the massive use of a dark porphyry lava, as well as other acid green lavas located at high altitude in the metamorphic area of the Catalan Pyrenees. Nevertheless, recent studies on glacial paleogeography suggest that the Ariège pass to Andorra was glaciated at that period. New petrographic evidences show that an eruptive rock supply was exploited in the foothills of the Serra del Cadí, in the Baridà. This renews our understanding about the routes used by Azilian hunters from the Aquitaine basin to Andorra and also the questioning about contacts between Azilian groups on both sides of the chain. 
INDEX

Mots-clés : Azilien, industrie lithique, rhyolite

Keywords : Azilian, lava porphyry industry, lithic industry

\section{AUTEURS}

\section{MICHEL MARTZLUFF}

Laboratoire Histoire naturelle de l'homme préhistorique (HNHP, UMR 7194, Muséum national d'histoire naturelle/Université de Perpignan - Via Domitia/Sorbonne universités/CNRS)

\section{VALENTÍ TURU}

Géologue, fondation Marcel Chevalier (Andorre)

\section{GÉRARD REMOLINS-ZAMORA}

Doctorant, Universidad de Barcelona ; fondation Marcel Chevalier (Andorre)

JEAN GUILAINE

Collège de France 
L'abri de L’Esplugón (VillobasSabiñánigo, Huesca, Espagne) : apports des données à la question de la transition MésolithiqueNéolithique dans les Pré-Pyrénées méridionales

The Esplugón rock shelter (Villobas-Sabiñánigo, Huesca, Spain): new data on the Mesolithic-Neolithic transition issue in the Spanish PrePyrenees

Alberto Obón Zúñiga, Abel Berdejo Arcéiz, Rafael Laborda Martínez, Alejandro Sierra Sainz-Aja, Marta Alcolea Gracia, Manuel Bea, Rafael Domingo Martínez et Pilar Utrilla Miranda

Nous remercions le groupe de recherche Primeros pobladores del Valle del Ebro (PPVE) du gouvernement d'Aragón - European Social Fund et l'Instituto Universitario de Investigación en Ciencias Ambientales (IUCA) de l'Université de Saragosse. Les travaux à L'Esplugón ont été partiellement financés par le projet de recherche Transiciones climáticas y adaptaciones sociales du Mineco (HAR2014-59042-P). Nous remercions les relecteurs pour leurs corrections. Nous tenons aussi à remercier les habitants des villages d'Aineto, Solanilla et de Molino Billobas, ainsi que le collectif CSO Kike Mur.

1 Les études sur le Mésolithique de la péninsule Ibérique se focalisent habituellement sur la côte cantabrique, la zone méditerranéenne et le Portugal. L'intérieur de la péninsule a longtemps été considéré comme un territoire marginal, ou même inoccupé. Cependant, grâce à divers projets de recherche développés par l'université de Saragosse et l'université du Pays basque, le bassin de l'Èbre est aujourd'hui l'une des régions les mieux connues de ce territoire pour cette période. En effet, 45 sites mésolithiques recélant d'importants dépôts stratifiés ont récemment été découverts et étudiés. 
Ces dernières découvertes prouvent que la vallée de l'Èbre n'est pas une frontière, mais plutôt une voie naturelle de communication entre la côte cantabrique et la côte méditerranéenne. C'est aussi la voie d'accès la plus facile vers la région de la Meseta, via la vallée du Jalon.

Un grand nombre de publications sont parues récemment sur ce sujet, dont quelques articles de synthèse et plusieurs monographies de sites, parmi lesquelles on peut souligner celles qui concernent en Aragon les sites de Botiquería de los Moros (Barandiarán 1978), Costalena (Barandiarán et Cava 1989), Secans (Rodanés et al. 1996), Los Baños (Utrilla et Rodanés 2004), Cabezo de la Cruz (Rodanés et Picazo 2013) et Forcas (Utrilla et Mazo 2014), et celles qui étudient dans la haute vallée de l'Èbre les sites de Kanpanoste Goikoa (Alday 1998), Kanpanoste (Cava 2004), Aizpea (Cava 2001) et Mendandia (Alday 2005). Nous mentionnerons enfin tout particulièrement la publication des actes de deux importants symposiums, celui de Vitoria sur les industries macrolithiques à denticulés (Alday 2006) et la conférence de Jaca sur les industries géométriques (Utrilla et Montes 2009).

Les sites du Mésolithique géométrique se concentrent en trois zones géographiques différentes (fig. 1), une au sud et deux au nord de l'Èbre. La première zone, le bas Aragon, se situe au sud de l'Èbre, près de la côte méditerranéenne; elle comprend une vallée d'une altitude inférieure à 400 mètres (fig. 1-1) et plus au sud, une zone plus haute appelée Maestrazgo-Els Ports (fig. 1-2) où se trouvent des sites au-dessus de 700 mètres. Au nord de l'Èbre, on distinguera deux autres zones bien différenciées : le haut bassin de l'Èbre (province d'Alava) avec une altitude de 500 à 900 mètres (fig. 1-3), et le versant sud des Pyrénées (région de Navarre, nord de la province de Saragosse et province de Huesca), avec une altitude entre 600 et 1000 mètres (fig. 1-4), où on connaît neuf abris avec des occupations de cette période.

Fig. 1. - Carte du Mésolithique géométrique dans la vallée de l'Èbre.

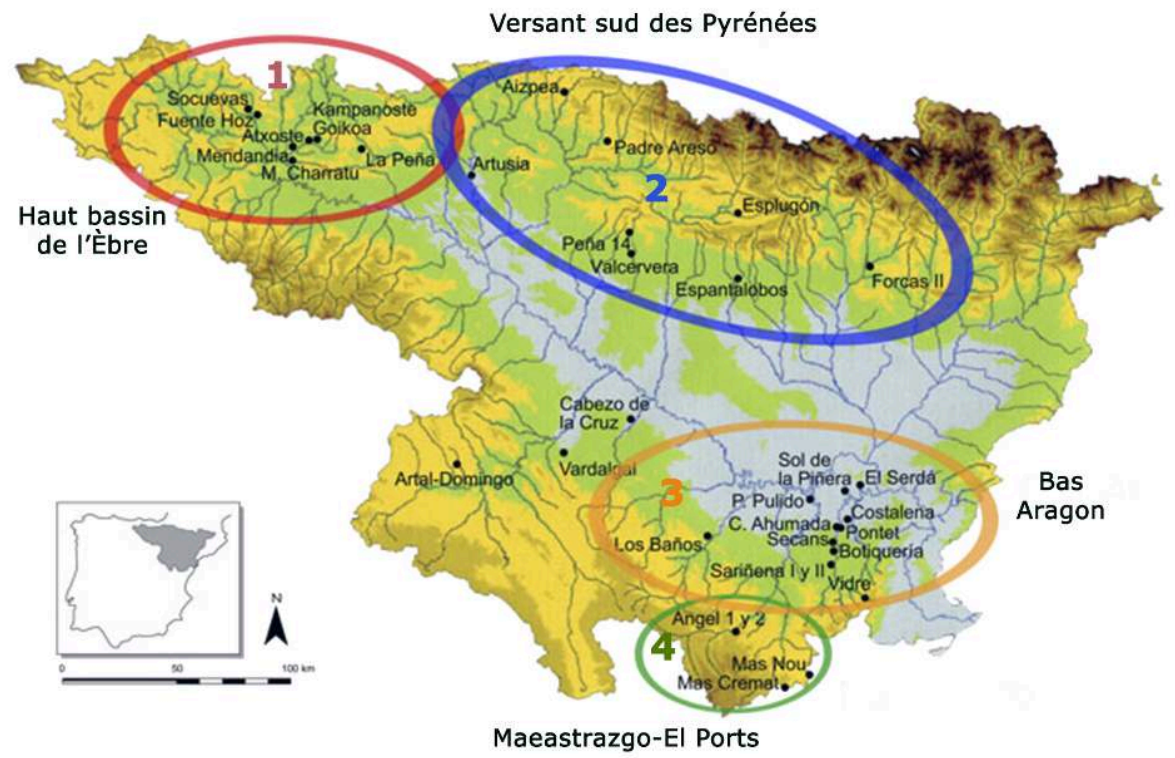

1 : haut bassin de l'Èbre (province d'Alava). 2 : versant sud des Pyrénées. 3 : bas Aragon. 4 Maestrazgo-Els Ports.

PAO et fond de carte Pilar Utrilla. 
5 Tous les sites des espaces mentionnés présentent une situation géographique similaire, en moyenne montagne, à des emplacements stratégiques permettant une position de contrôle sur la vallée, mais aussi de surveiller le passage du gibier. On remarque également la totale absence du Mésolithique géométrique en Catalogne, une zone qui, par ailleurs, révèle une forte présence du Mésolithique à denticulés (García-Argüelles et Vaquero 2009, Morales et Oms 2012).

\section{Le site préhistorique de L'Esplugón}

6 L'abri de L'Esplugón, le plus large et le plus imposant des abris connus pour ce cadre chronoculturel, est situé en plein cœur de la zone de Navarre-Huesca (versant sud des Pyrénées), et plus précisément dans le couloir transversal de la vallée du Guarga. C'est un grand abri-sous-roche orienté au sud-est. Ce site se distingue par sa position privilégiée dans la vallée, son bon état de conservation et sa richesse archéologique, avec six niveaux mésolithiques et néolithiques (fig. 2).

Fig. 2. - Situation de l'abri de L'Esplugón (Villobas-Sabiñánigo, Huesca, Espagne).

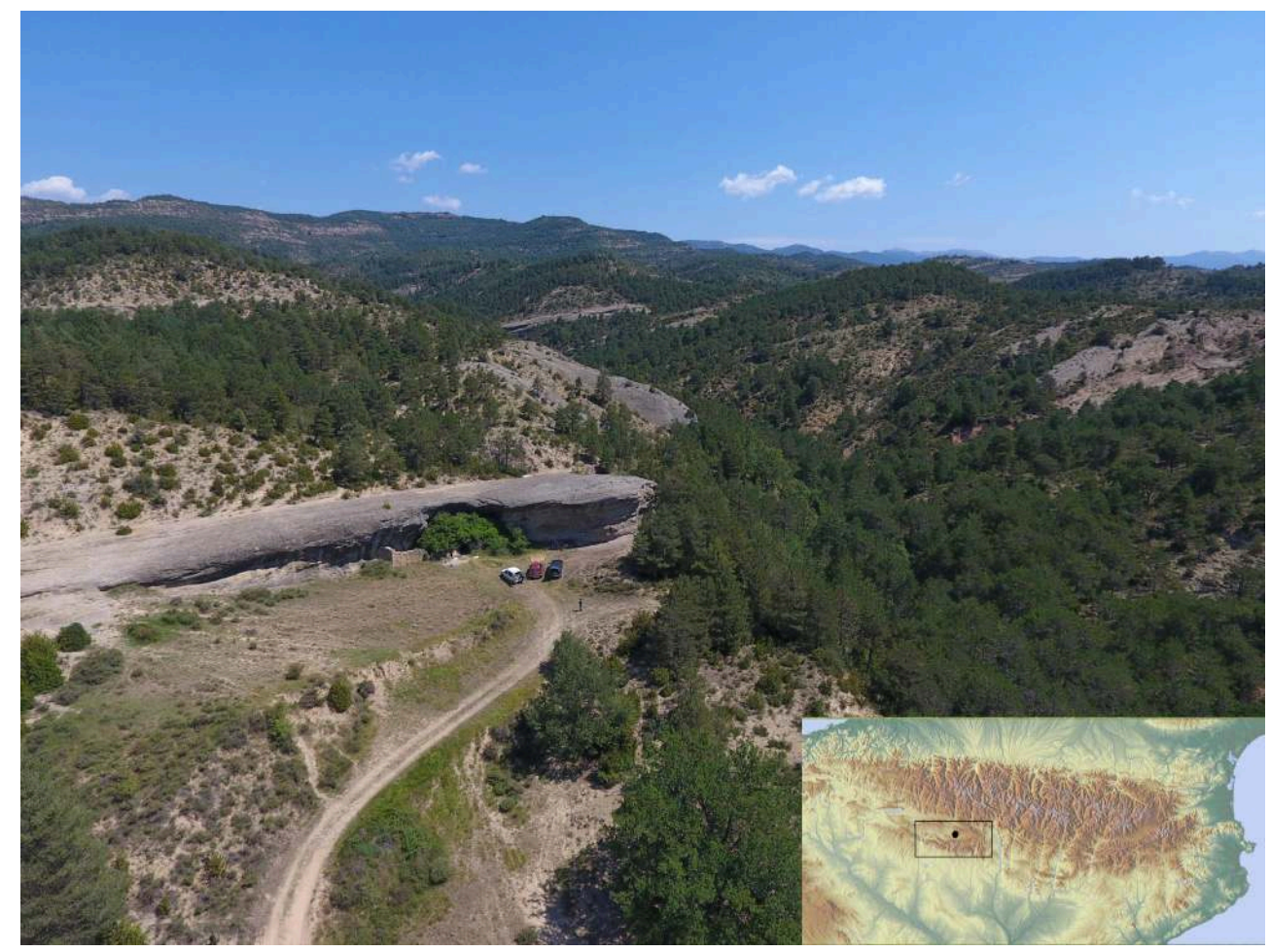

Photo José Luis Peña.

7 Même si actuellement la surface totale de notre intervention ne s'étend que sur quelques mètres carrés, on peut affirmer que L'Esplugón est déjà un des sites de référence pour comprendre le processus de néolithisation dans le bassin de l'Èbre. Les premières fouilles ont été réalisées entre 2009 et 2010 par A. Obón et A. Berdejo (Berdejo et Obón 2016). Ensuite P. Utrilla a rejoint l'équipe, ce qui a permis d'avoir le soutien de deux projets Mineco pour les campagnes de 2011, 2012 et 2013 (Utrilla et al. 2012 et 2016). Cette intervention s'intègre dans le contexte plus large d'une étude territoriale sur le peuplement préhistorique de la vallée du Guarga et du cours 
supérieur des rivières Isuela, Flumen, Guatizalema et Alcanadre (Obón et Berdejo 2016), et ce depuis 2008. Ces opérations sont coordonnées par le collectif indépendant De la Roca al Métal ainsi que par d'autres chercheurs indépendants.

Les résultats des prospections effectuées nous indiquent que le site de L'Esplugón fait partie d'un réseau d'abris répartis sur ce territoire, lesquels ont été utilisés traditionnellement pour abriter le bétail (Pallaruelo 1988). Ces abris présentent différents processus de genèse (Rapp et Hills 1988) et de colmatage caractéristiques de la formation géologique appelée Campodarbe (Puigdefábregas 1975), laquelle est constituée de grès, conglomérats et lutites d'origine continentale.

\section{La séquence stratigraphique}

En ce qui concerne la stratigraphie, nous avons identifié l'existence de six niveaux d'occupation (fig. 3), lesquels correspondent à quatre moments culturels :

-Phase I: une couche chalcolithique partiellement remaniée, dans laquelle nous avons constaté la présence de pointes de flèches foliacées (niveau 1);

- Phase II : une occupation du Néolithique ancien, qui comprend les niveaux 2 et 3 supérieur;

- Phase III : une occupation du Mésolithique géométrique, détectée dans les niveaux 3 inférieur (Mésolithique à triangles) et 4 (Mésolithique à trapèzes), ayant livré un ensemble lithique très riche en armatures microlithiques géométriques et en microburins ;

- Phase IV : une occupation mésolithique pauvre se caractérisant par un sédiment très foncé, qui comprend les niveaux 5 (noir) et 6 (brun foncé). Cette phase reste encore à définir culturellement, car les pièces retouchées recueillies dans le sondage sont en petit nombre. Cependant, nous considérons que le niveau 5 correspond à un niveau du Mésolithique à denticulés, et le niveau 6 à du Mésolithique microlaminaire, même si aucune datation ne concorde avec cette dernière période. Les niveaux 7 à 10 sont archéologiquement stériles.

Fig. 3. - Abri de l'Esplugón (Villobas-Sabiñánigo, Huesca, Espagne) : profil stratigraphique.

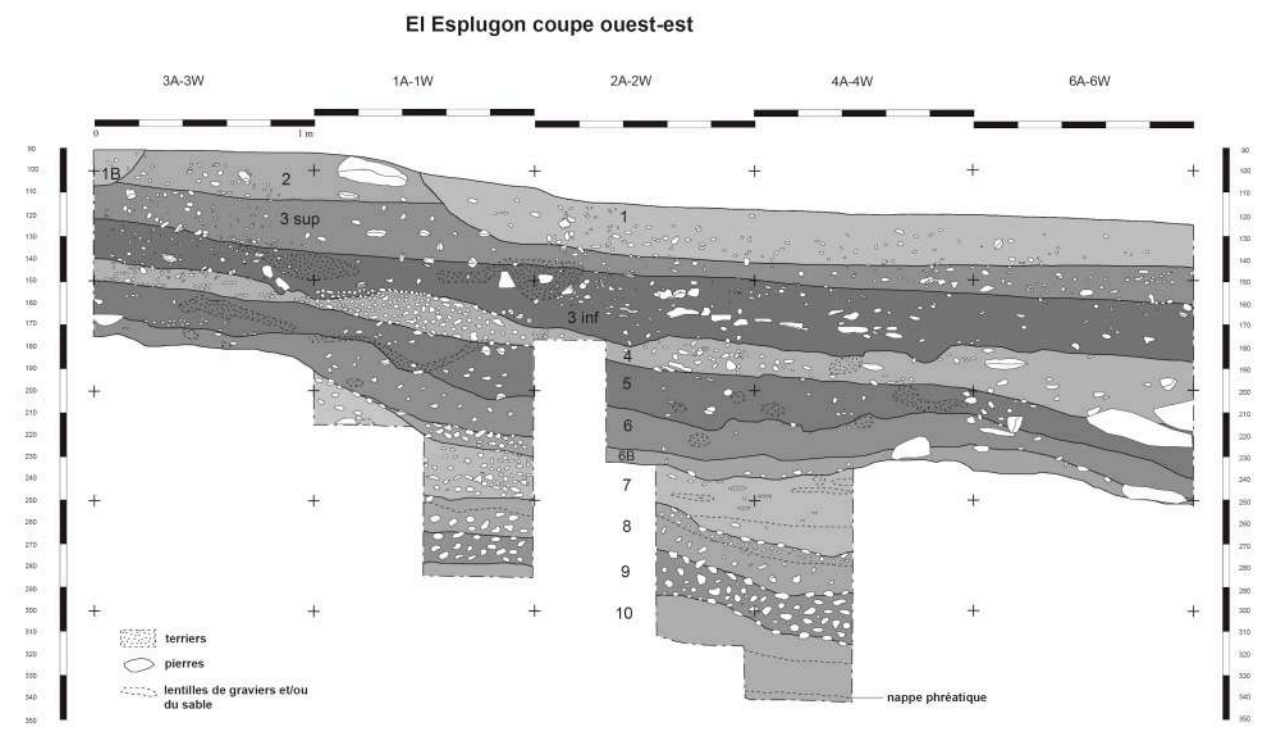

PAO Alberto Obón. 


\section{L'analyse anthracologique}

10 L'étude anthracologique réalisée par M. Alcolea a révélé la prédominance du pin sylvestre (Pinus sylvestris) dans toutes les couches archéologiques étudiées, mais aussi la présence d'autres espèces, comme le chêne (Quercus) à feuillage caduc et le genévrier (Juniperus sp.). Nous noterons l'identification exclusive de bois de pin dans le niveau 4 (Alcolea 2016, Utrilla et al. 2016). Cette couche est caractérisée par la présence d'horizons stratigraphiques constitués de galets et plaquettes anguleuses de grès, matériaux tombés de la paroi de conglomérat et de grès de l'abri, ce qui pourrait correspondre à un moment climatique plus froid et sec, en accord avec la datation de MAMS-30167 (7 $355 \pm 23$ BP, soit 6 340-6090 cal. BC). En effet, le froid et l'aridité du 8.2 kyr BP event provoquent une régression des taxons mésophiles présents dans le reste des couches archéologiques, principalement le chêne à feuillage caduc. À partir de ce moment, la chênaie commence à prendre de l'importance, suggérant un changement dans le régime des précipitations et l'existence de contrastes saisonniers plus marqués (fig. 4).

Fig. 4. - Abri de L'Esplugón (Villobas-Sabiñánigo, Huesca, Espagne) : diagramme anthracologique et image de la stratigraphie en $2 \mathrm{~A} / 2 \mathrm{~W}$.

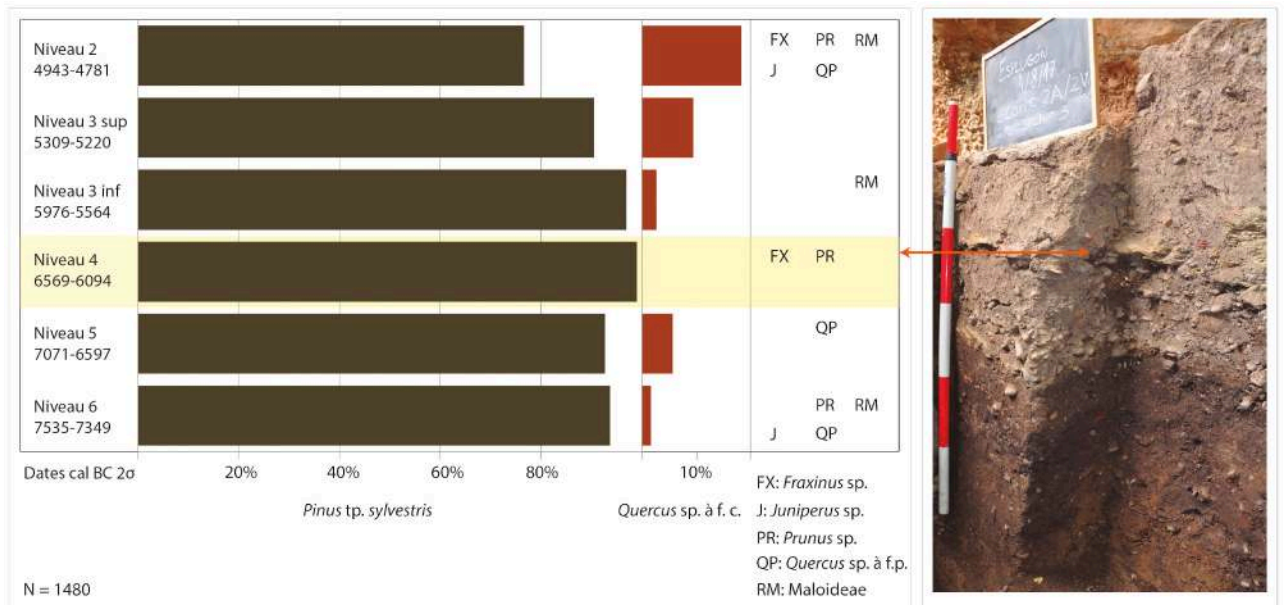

La flèche indique la correspondance entre les données anthracologiques et les plaquettes en haut du niveau 4.

PAO Marta Alcolea

\section{La datation radiocarbone}

11 Une série de datations a été obtenue par la technique $d{ }^{14} \mathrm{C}$-AMS, parmi lesquelles dix à partir d'échantillons osseux (quatre par le laboratoire de Mannheim avec ultrafiltration et six par le Beta-Analytic Laboratory), et trois autres effectuées à partir de fragments de charbon (Pinus nigra) par le laboratoire de l'université de Groningen (tabl. 1 et fig. 5). D'après la chronologie absolue obtenue, quatre datations appartiennent au Néolithique ancien, trois au Mésolithique à triangles, trois au Mésolithique à trapèzes et trois à un Mésolithique indéterminé. La séquence est donc presque continue et très riche en industrie lithique, mais il y a un écart chronologique de 450 années entre le niveau mésolithique ( 3 inf.) et le Néolithique ancien ( 2 et 3 sup.). Il n'existe aucune datation entre 5550 et $5300 \mathrm{cal}$. BC. 
Tabl. 1. - Abri de L’Esplugón (Villobas-Sabiñánigo, Huesca, Espagne) : datations radiocarbone.

\begin{tabular}{|c|c|c|c|c|c|c|}
\hline Laboratoire & z & Niveau & Dates BP & Cal. BC $2 \sigma$ & Matériau & $\begin{array}{c}\text { Phase } \\
\text { (d'après la mesure) }\end{array}$ \\
\hline Beta 338509 & 127 & $2 / 3$ sup. & $5970 \pm 30$ & $4943-4781$ & Os & Néolithique ancien \\
\hline Beta 283899 & 172 & 4 & $6120 \pm 40$ & $5209-4953$ & Os & Intrusion \\
\hline MAMS 30169 & 215 & 6 & $6166 \pm 23$ & $5213-5047$ & Os & Intrusion \\
\hline MAMS 30168 & 127 & 3 sup. & $6282 \pm 22$ & $5309-5220$ & Os & Néolithique ancien \\
\hline Beta 313517 & 128 & 3 inf. & $6730 \pm 40$ & $5718-5564$ & Os & Mésolithique à triangles \\
\hline MAMS 30166 & 117 & 2 & $6781 \pm 23$ & $5720-5638$ & Os & Intrusion? \\
\hline Beta 306723 & 165 & 3 inf. & $6950 \pm 50$ & $5976-5731$ & Os & Mésolithique à triangles \\
\hline MAMS 30167 & 175 & 4 & $7355 \pm 23$ & $6341-6094$ & Os & Mésolithique à trapèzes \\
\hline GrA-59632 & 182 & 4 & $7620 \pm 40$ & $6569-6416$ & c & Mésolithique à trapèzes \\
\hline GrA-59634 & 229 & 6 & $7715 \pm 45$ & $6635-6469$ & c & Intrusion \\
\hline Beta 306725 & 189 & 5 & $7860 \pm 40$ & $6984-6597$ & Os & Mésolithique à denticulés? \\
\hline GrA-59633 & 199 & 5 & $8015 \pm 45$ & $7071-6767$ & c & Mésolithique à denticulés? \\
\hline Beta 306722 & 218 & 6 & $8380 \pm 40$ & $7536-7350$ & Os & Mésolithique microlaminaire? \\
\hline
\end{tabular}

Sur fond gris, les dates qui ne sont pas en accord avec le niveau stratigraphique et correspondent à des intrusions dues à des bioturbations. 
Fig. 5. - Abri de L'Esplugón (Villobas-Sabiñánigo, Huesca, Espagne) : datations ${ }^{14} \mathrm{C}$-AMS cal. BP et courbe climatique du GRIP.

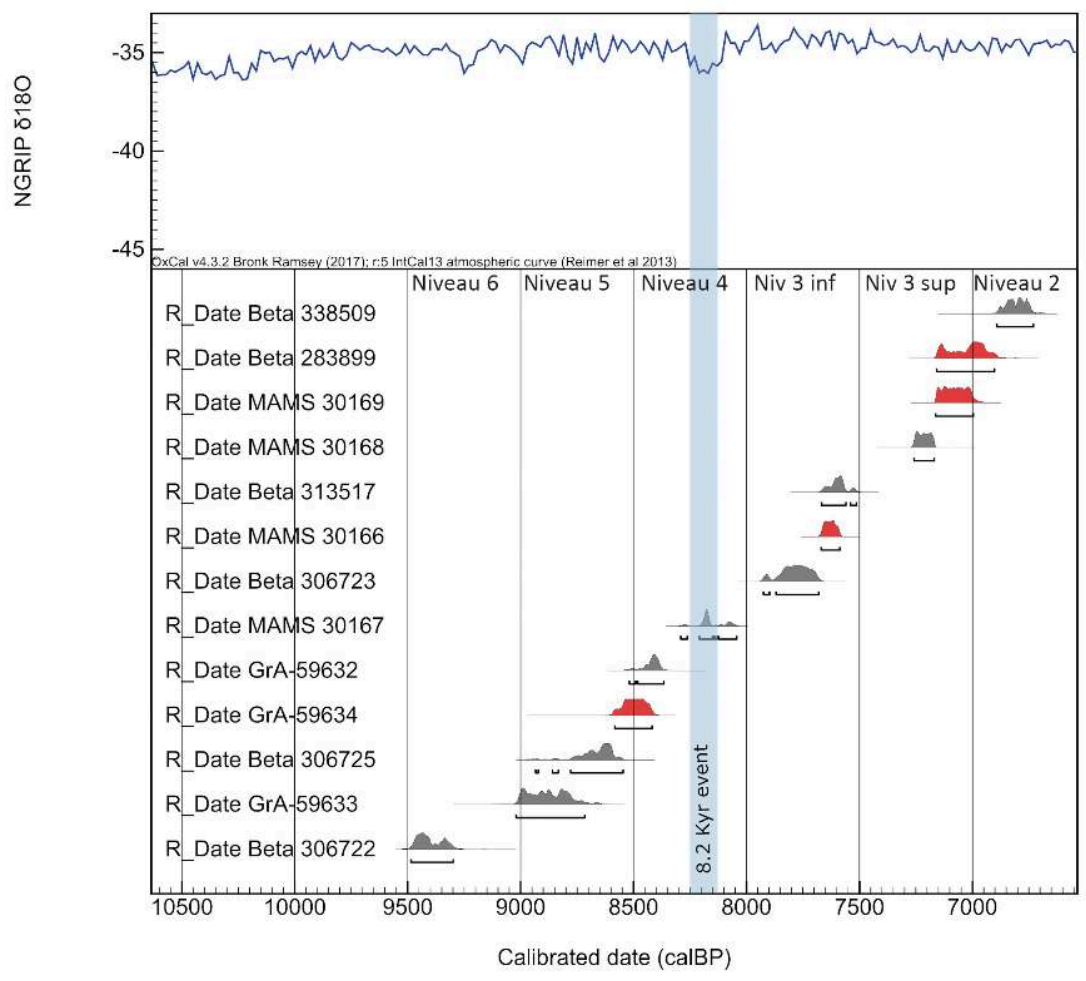

Les datations qui ne correspondent pas avec la position stratigraphique sont notées en rouge (OxCal v 4.3.2. IntCal13 - Reimer et al. 2013).

Extrait de Reimer et al. 2013.

12 Certaines datations ne coïncident pas avec le schéma de la typologie du mobilier lithique, en raison de l'existence de bioturbations (terriers principalement), ainsi que de possibles cuvettes anthropiques non détectées au cours des fouilles, qui ont pu altérer la position stratigraphique de quelques éléments. Ces datations, notées sur fond gris dans le tableau 1, seraient plus récentes qu'attendu. Malgré ces altérations, la séquence du mobilier archéologique reste cohérente chronologiquement avec les datations obtenues, d'après le corpus régional de ce cadre chronoculturel. D'autre part, il nous semble évident que chaque datation est le reflet d'un moment d'installation, quelle que soit la position de l'os ou du fragment de charbon dans la séquence.

En ce qui concerne la première occupation de l'abri, nous n'avons pas pu vérifier l'existence d'une occupation magdalénienne, malgré la présence de quelques burins assez atypiques.

\section{Le matériel archéologique}

\section{Le mobilier lithique}

14 La plupart des pièces lithiques typologiquement les plus remarquables ont déjà été publiées (Utrilla et al. 2016); on remarque la présence massive des armatures géométriques dans les niveaux du Néolithique ancien (niveaux 2 et 3 sup.) et du Mésolithique géométrique (niveaux 3 inf. et 4) (tabl. 2). Les pièces lithiques de la 
campagne de 2017 n'ont pas encore été intégrées. L'étude technologique est en cours de réalisation.

Tabl. 2. - Abri de L'Esplugón (Villobas-Sabiñánigo, Huesca, Espagne) : microlithes géométriques et microburins par niveaux.

\begin{tabular}{cccccccc}
\hline & Niveau 2 + 3 sup. & $\%$ & Niveau 3 inf. & $\%$ & Niveau 4 & $\%$ & Total \\
\hline Trapèzes & 5 & 15,6 & 27 & 26,2 & 17 & 28,3 & 49 \\
Triangles & $13(9 \mathrm{db}, 4 \mathrm{ab})$ & 40,6 & 33 & 32,0 & 6 & 10,0 & 52 \\
Segments & $3(\mathrm{db})$ & 9,3 & 2 & 1,9 & 1 & 1,6 & 6 \\
Microburins & 2 & 6,2 & 23 & 22,3 & 30 & 50,0 & 55 \\
Pointes à dos allongées & 5 & 15,6 & 5 & 4,8 & 1 & 1,6 & 11 \\
Troncatures & 4 & 12,5 & 13 & 12,6 & 5 & 8,3 & 22 \\
\hline
\end{tabular}

Du point de vue typologique, les pièces lithiques les plus significatives sont les suivantes :

- Dans le niveau 1, phase du Chalcolithique, deux pièces à retouche plate et une lame avec traces d'usure (patine de céréales sèches ; fig. 6).

Fig. 6. - Abri de L'Esplugón (Villobas-Sabiñánigo, Huesca, Espagne) : pièces lithiques du niveau 1 (Néolithique final-Chalcolithique).

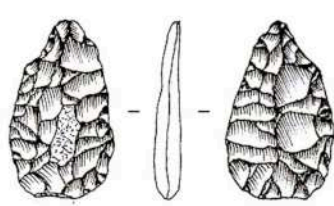

1
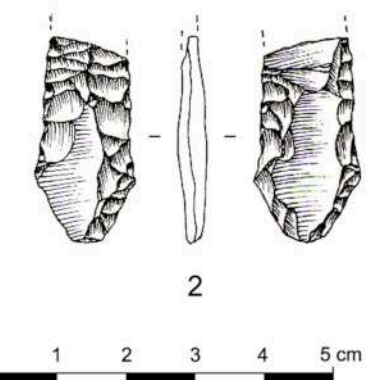

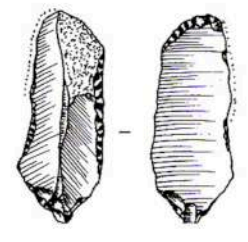

3

1 ET 2 : pièces à retouche plate. $\mathbf{3}$ : lame portant des traces d'usure.

Dessins Pilar Utrilla.

- Dans les niveaux 2 et 3 sup., correspondant au Néolithique ancien, on observe la présence de trois triangles à retouche en doble bisel (armatures à retouches bifaciales en double biseau, dites «du Bétey» (en France : Marchand et Manen $2006:$ p. 219) et retouche plate (fig. 7, $\mathrm{n}^{\circ}$ 1-3), d'une typologie similaire à ceux qui ont été découverts dans la grotte d'Aizpea (Navarra, Espagne), dans le niveau b, daté de 5 480-5 220 cal. BC (GrN-18421: $6370 \pm 70$ BP Cava 2001 : fig. 13.2), et qui existent aussi sur le versant nord des Pyrénées. En revanche, ce type de microlithe n'a été reconnu dans aucun des sites du bas Aragon. Nous avons aussi constaté l'existence de traces indiquant un usage comme élément de faucille (patine de céréales vertes) sur une première lame étudiée parmi un ensemble préliminaire de cinq exemplaires étudiés par R. Domingo (fig. 7, $\mathrm{n}^{\text {os }} 18$ à 22). Il est très intéressant de constater que la lame à lustre de céréales mûres, quoique anecdotique, provient du niveau chalcolithique, tandis que celle à lustre de céréales vertes est issue du niveau néolithique : les premières céréales domestiques devaient être fauchées à l'état vert pour éviter la chute des grains, ce qui n'arrive plus avec des variétés plus aptes à être moissonnées à maturité (Utrilla et al. 2016), telles qu'on les suppose pour le Chalcolithique. 
Fig. 7. - Abri de L'Esplugón (Villobas-Sabiñánigo, Huesca, Espagne) : pièces lithiques des niveaux néolithiques ( 2 et 3 sup.).

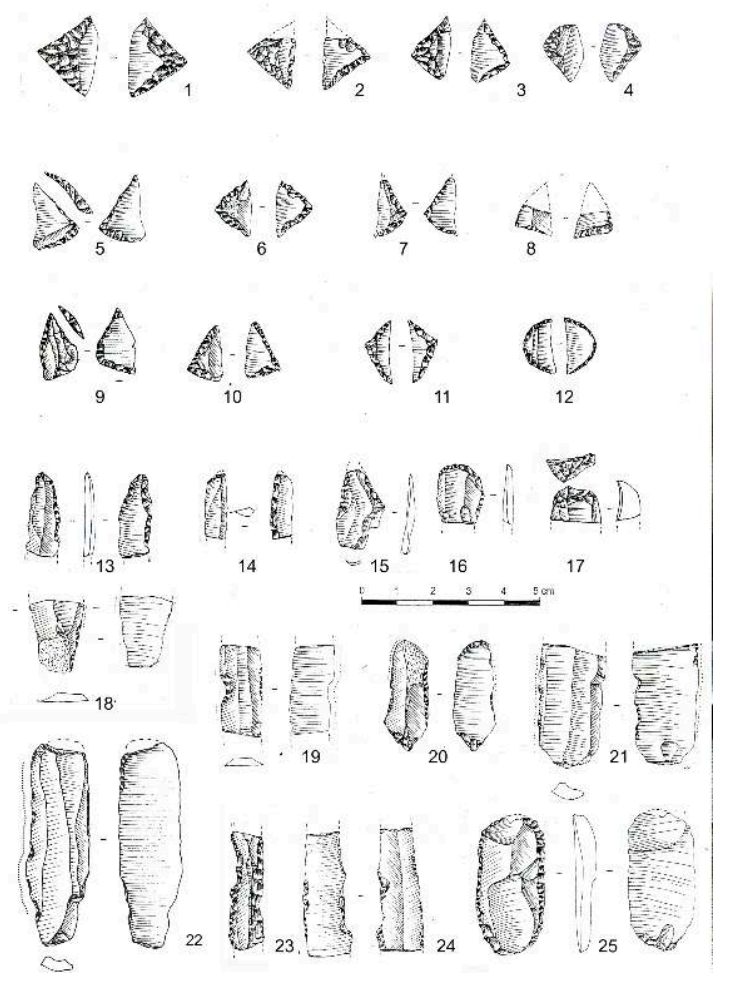

1 À 12 : triangles et segments à retouche bifaciale en doble bisel. 13 : perçoir. 18 À 22 : lames avec patine lustrale. 16 ET 17 : grattoirs. 23 ET 24 : lames denticulées. 14 : lamelle à dos. 15 ET 25 : lames à retouche simple.

Extrait de Utrilla et al. 2016.

- Dans les niveaux 3 inf. et 4, correspondant au Mésolithique géométrique, il faut signaler la prédominance des triangles sur les trapèzes dans le niveau 3 inf. (32\% versus $26 \%$ ) et des trapèzes sur les triangles dans le niveau 4 ( $28 \%$ versus $10 \%$ ). Parmi les points particuliers, il faut souligner la présence de la retouche inverse à la base de cinq triangles du niveau 3 inf., ce que l'on interprète habituellement comme une influence originaire du versant nord des Pyrénées. Ce phénomène a été également signalé pour les sites pré-pyrénéens d'Aizpea, niveau II (Cava 2001) et de La Peña de las Forcas (Graus, Huesca, Espagne), niveau IV (Utrilla et Mazo 2014), autour de 5900-5 700 cal. BC. Nous remarquerons la présence d'un petit tranchet (fig. $8, \mathrm{n}^{\mathrm{o}} 31$ ) et d'un triangle scalène allongé à petite base retouchée ( $\mathrm{n}^{\mathrm{o}} 32$ ), similaire à certains exemplaires de Costalena c3 (Maella, Zaragoza, Espagne - Barandiarán et Cava 1989 : fig. $12, \mathrm{n}^{\text {os }} 43$ et 44$)$. 
Fig. 8. - Abri de L'Esplugón (Villobas-Sabiñánigo, Huesca, Espagne) : triangles du niveau 3 inférieur.

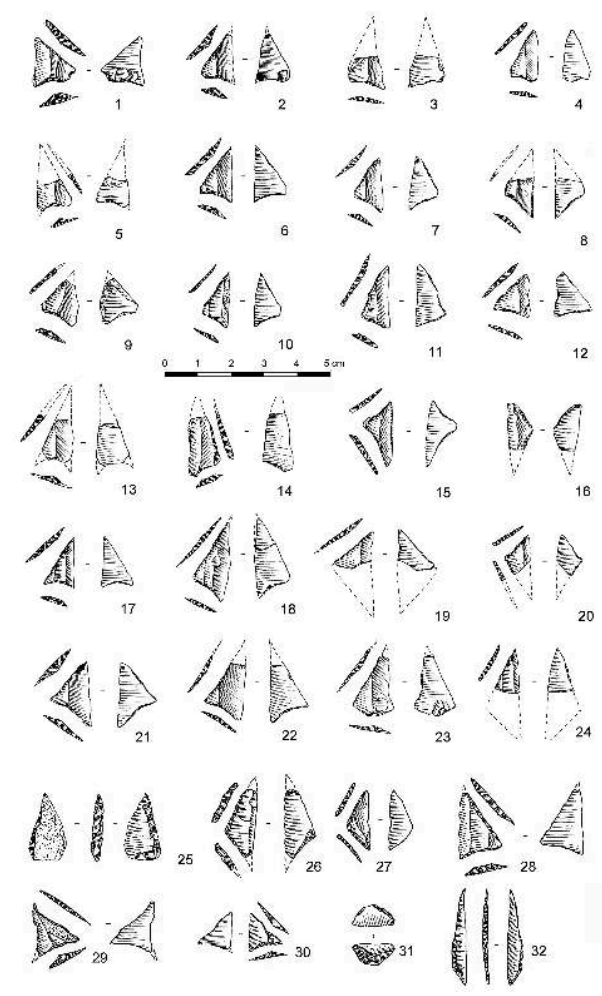

31 : petit tranchet. $\mathbf{3 2}$ : segment allongé à retouche abrupte alterne. Extrait de Utrilla et al. 2016.

16 En ce qui concerne les trapèzes, ceux qui ont un côté concave sont les plus nombreux, surtout dans le niveau 3 inf., avec 17 exemplaires (fig. 9). 
Fig. 9. - Abri de L’Esplugón (Villobas-Sabiñánigo, Huesca, Espagne) : trapèzes du niveau 3 inférieur.

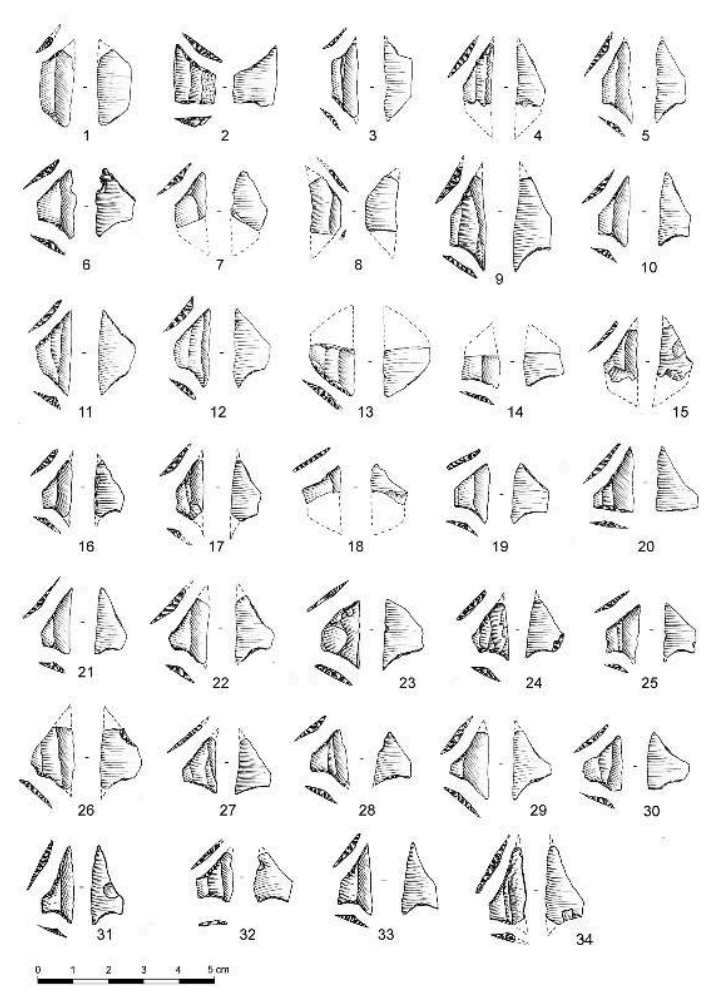

Extrait de Utrilla et al. 2016.

Dans le niveau 4 , l'ensemble est formé de 30 microlithes géométriques, dont 17 trapèzes $(56,6 \%)$ et 6 triangles ( $20 \%$ ), auxquels s'adjoignent 30 microburins, qui sont donc aussi nombreux que les géométriques eux-mêmes. Cette abondance de microburins atteste la fabrication des géométriques sur place. Ce niveau a également livré des pièces esquillées.

Dans l'abri de La Peña de las Forcas II, très similaire à l'abri de L'Esplugón, nous avions déjà signalé une évolution des armatures à partir des types classiques de triangles (niveau II) vers des types variés, comme les triangles à retouche inverse à la base dans le niveau IV, ce qui indique l'existence de possibles influences ultra-pyrénéennes (Utrilla et Mazo 2014). À cette période, autour de $5900-5700 \mathrm{cal}$. BC, se produirait le début d'une régionalisation du Mésolithique géométrique, avec des influences aquitaines et provençales, comme on le constate dans les sites prépyrénéens d'Aizpea et de Forcas. À la même période, dans la zone du bas Aragon-Maestrazgo, prédominent les triangles de type Cocina/Muge, avec deux côtés concaves et épine centrale, et les trapèzes allongés à petite base retouchée. Ces influences levantines, évoquées par les triangles du type Cocina et à angle retouché, apparaissent aussi au Pays basque, dans la plaine d'Alava, une zone qui reçoit l'influence des types du bas Aragon au moment de l'utilisation du silex évaporitique originaire du cours moyen de l'Èbre (Cava et al. 2007-2008 : p. 596). 


\section{Le mobilier céramique}

19 L'étude de la céramique a mis en évidence un minimum de 17 récipients. Un seul d'entre eux a un diamètre presque complet; nous avons donc un ensemble très fragmenté.

Parmi les décors sont présents les décors cardiaux (1 exemplaire), les décors d'impressions avec un instrument (7 ex.), les incisions (1 ex.), la céramique inciséeimprimée, les décors à cordon imprimé (4 ex.) (fig. 10) et à cordon lisse (3 ex.). Les formes les plus fréquentes sont globulaires : vases, terrines et marmites (fig. 11).

Fig. 10. - Abri de L'Esplugón (Villobas-Sabiñánigo, Huesca, Espagne) : décors sur céramique.

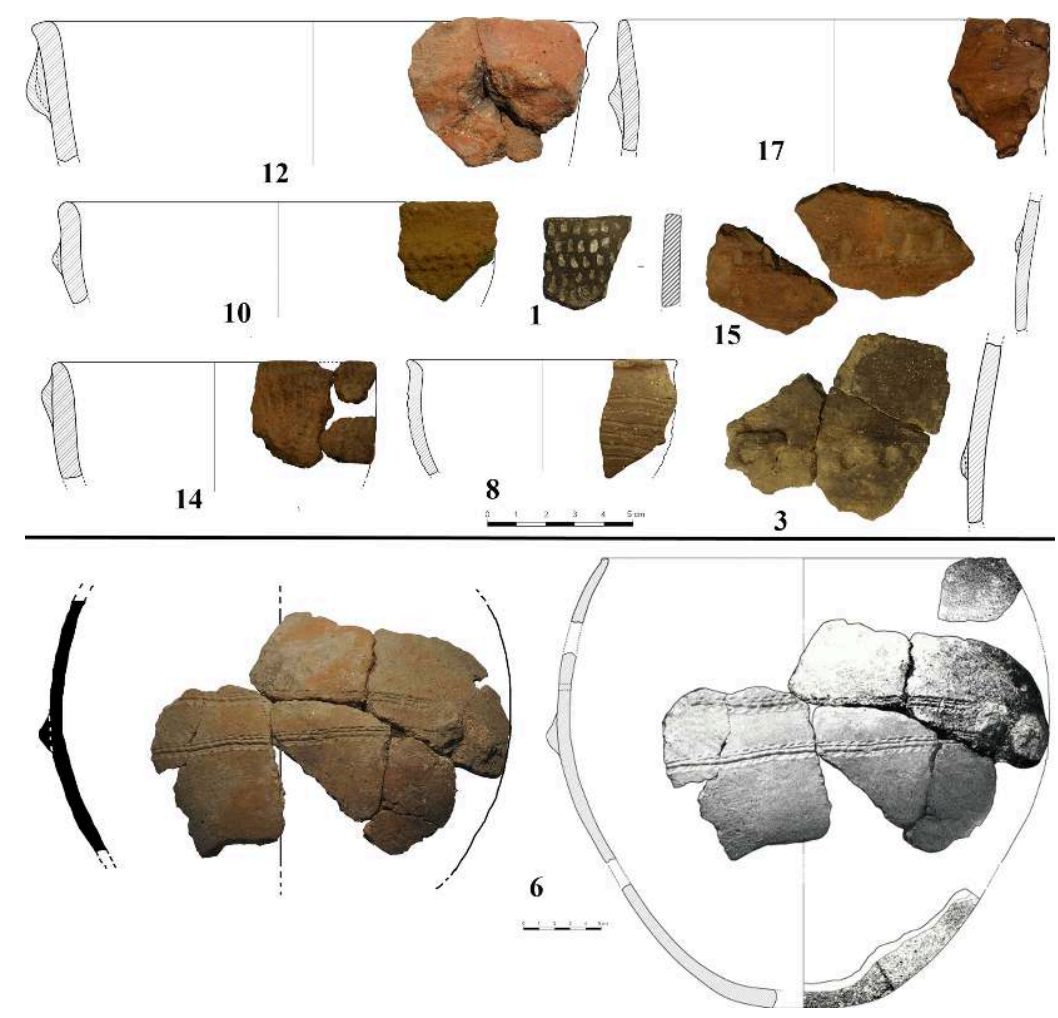

1, 6 ET 8 : décors réalisés par impression d'un instrument. 3, 10 ET 15 : décor à cordon imprimé. 14 décor cardial. 12 ET 17 : décor à cordon lisse.

PAO et photos Rafael Laborda. 
Fig. 11. - Abri de L'Esplugón (Villobas-Sabiñánigo, Huesca, Espagne) : céramiques de forme globulaire.
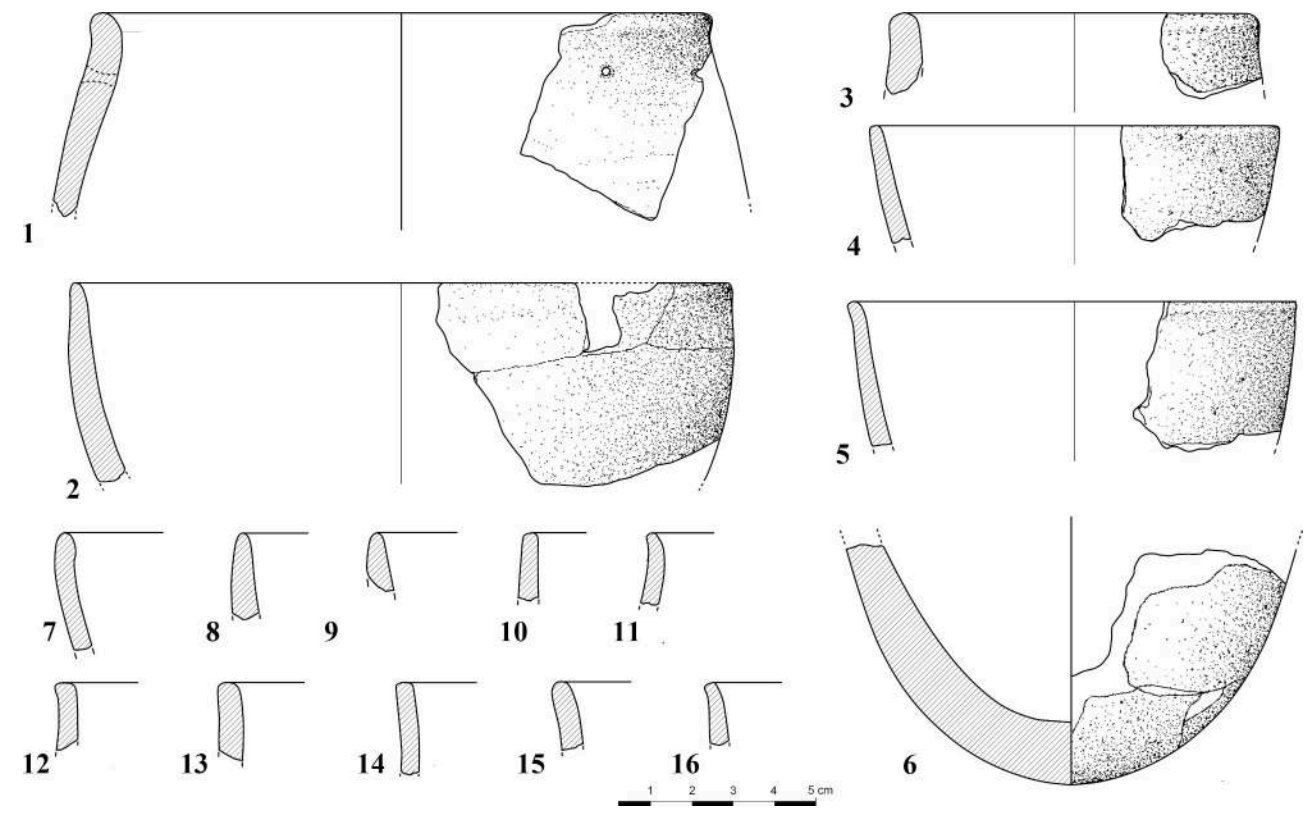

PAO et dessins Rafael Laborda.

Les caractéristiques technologiques sont la prédominance de la cuisson oxydante (10 exemplaires) sur la cuisson irrégulière ( 5 ex.) et la cuisson réductrice ( 2 ex.), et des finitions de surfacés lisses $(11$ ex.) sur les surfaces polies et spatulées (6 ex.). Comme dans tous les sites néolithiques de la vallée de l'Èbre (Gallart et López 1988, Gallart et Mata 1995, Lapuente et Igea 2014), le dégraissant est principalement constitué de mica et de quartz. Ces éléments peuvent provenir du concassage de granite, comme cela semble être le cas à Forcas II (Bea 2014). À L'Esplugón, la combinaison de mica et de quartz est observée sur 11 exemplaires, tandis que le quartz seul a été reconnu sur 4 individus et la calcite seule sur 2 .

L'ensemble des fragments de céramique des niveaux 2 et 3 sup. partage certaines caractéristiques avec les sites de la vallée du Cinca et du Sègre. On remarque une forte présence de décors d'impressions, comme on peut l'observer dans les sites de Olvena (Baldellou et Ramón 1995), La Miranda (Baldellou et Barril 1981), Forcon (Baldellou 1983b), Els Trocs (Rojo et al. 2013), Espluga de la Puyascada (Baldellou 1987) ou Cova Colomera (Oms 2008). Par ailleurs, à L'Esplugón, la technique appelée boquique est absente, et le décor cardial est présent sur un seul récipient. Ces caractéristiques sont similaires à celles de la couche $1 \mathrm{a}$ de la grotte de Chaves (Huesca), avec laquelle les niveaux mentionnés de L'Esplugón partagent d'autres similitudes, comme la chronologie et l'industrie lithique : armatures à retouche en doble bisel et perçoirs à longue pointe axiale (Cava 2000). La céramique cardiale est moins bien représentée que celle avec impressions faites à l'aide d'autres types d'outils (Baldellou 1983a). De même, dans le niveau 1n de Rambla de Legunova (Biel, Zaragoza), d'une chronologie similaire au niveau 2-3 sup. de L'Esplugón, apparaissent la céramique cardiale et les décors d'impressions avec outil, malgré la rareté de la céramique dans ce site (Montes et al. 2016). Nous ne pouvons pas établir de parallèle avec un site en particulier, car les motifs décoratifs sont si simples et si récurrents que l'on retrouve des similitudes avec la plupart des sites de la vallée du Cinca et du Sègre. 
23 En conclusion, même si les fragments de céramique de L'Esplugón proviennent de couches différentes, la plupart présentent une similitude d'élaboration (finitions, dégraissants et coctions) et de décors (motifs des impressions peu élaborés en général et applications plastiques parfois combinées avec des impressions digitées ou faites à l'aide d'autres instruments sur le cordon appliqué). Le site a aussi livré un fragment de céramique cardiale ( $\mathrm{n}^{\circ} 14$, fig. 10) appartenant au niveau à céramique plus ancien, ainsi que d'autres décors faits de cordons digités et d'impressions à l'aide d'instruments. Ces décors sont fréquents dans les ensembles de la péninsule Ibérique et s'inscrivent dans l'intervalle obtenu entre $5309-5220$ cal. BC (MAMS-30168) et $4943-4781$ cal. BC (Beta-338509), ce qui situe l'occupation dans un deuxième moment du Néolithique ancien régional.

\section{L'analyse de la faune}

À partir d'un nombre total de 3883 fragments osseux récupérées, l'étude de la faune a été réalisée sur une série de 938 fragments, dont 325 ont été attribués à une partie anatomique et à une espèce. On observe quelques différences entre le nombre de restes identifiés dans les niveaux néolithiques et mésolithiques, ce qui peut s'expliquer par une fracturation plus intense des os durant la période mésolithique.

Cette étude indique une abondance des espèces sauvages de milieu forestier, principalement le sanglier, le chevreuil et le cerf. En ce qui concerne la variabilité des espèces, on a pu déterminer que le chevreuil est l'espèce qui prédomine dans les niveaux néolithiques. En revanche, le cerf et l'isard sont plus abondants dans les niveaux mésolithiques.

Les espèces domestiques apparaissent seulement à partir des niveaux néolithiques. Ovis/Capra ont été détectés dans le niveau 2, tandis que Bos et Sus n'ont pas pu être identifiés comme des animaux domestiques. Ceci est dû à la difficulté de distinguer clairement les variétés sauvages des variétés domestiques (tabl.3). Nous devons souligner la découverte de deux grandes défenses de sanglier, disposées en position verticale dans le niveau 4, lesquelles ont été directement datées entre 6341 et $6094 \mathrm{cal}$. BC (MAMS-30167). 
Tabl. 3. - Abri de L'Esplugón (Villobas-Sabiñánigo, Huesca, Espagne) : espèces domestiques et sauvages par niveaux avec NR, NMI et biomasse.

\begin{tabular}{|c|c|c|c|c|c|c|c|c|c|c|c|c|}
\hline & \multicolumn{3}{|c|}{ NR } & \multicolumn{3}{|c|}{$\% \mathrm{NR}$} & \multicolumn{3}{|c|}{$\% \mathrm{NMI}$} & \multicolumn{3}{|c|}{$\%$ Biomasse } \\
\hline & $\begin{array}{l}\text { Niveau } \\
2\end{array}$ & $\begin{array}{l}\text { Niveau } \\
3 \text { sup. }\end{array}$ & $\begin{array}{l}\text { Niveau } \\
3 \text { inf. }\end{array}$ & $\begin{array}{l}\text { Niveau } \\
2\end{array}$ & $\begin{array}{l}\text { Niveau } \\
3 \text { sup. }\end{array}$ & $\begin{array}{l}\text { Niveau } \\
3 \text { inf. }\end{array}$ & $\begin{array}{l}\text { Niveau } \\
2\end{array}$ & $\begin{array}{c}\text { Niveau } \\
3 \text { sup. }\end{array}$ & $\begin{array}{c}\text { Niveau } \\
3 \text { inf }\end{array}$ & $\begin{array}{l}\text { Niveau } \\
2\end{array}$ & $\begin{array}{l}\text { Niveau } \\
3 \text { sup. }\end{array}$ & $\begin{array}{l}\text { Niveau } \\
3 \text { inf. }\end{array}$ \\
\hline Ovis/capra & 18 & - & - & 9,42 & - & - & 10,26 & - & - & 10,49 & & - \\
\hline Capra hircus & 3 & - & - & 1,57 & - & - & - & - & . & - & & - \\
\hline IOTAL DOMESTIQUES & 21 & - & - & 10,99 & - & - & 10,26 & - & - & - & - & - \\
\hline Capreolus capreolus & 83 & 29 & 5 & 43,46 & 35,8 & 11,63 & 15,38 & 10,71 & 12,50 & 13,54 & 7,09 & 4,02 \\
\hline Capra pirenaica & 7 & 5 & 1 & 3,66 & 6,17 & 2,33 & 5,13 & 3,57 & 12,50 & 6,77 & 4,73 & 8,05 \\
\hline Cervus elaphus & 14 & 20 & 9 & 7,33 & 24,69 & 20,93 & 2,56 & 3,57 & 12,50 & 16,92 & 15,75 & 26,82 \\
\hline Rupicapra rupicapra & 1 & 2 & 2 & 0,52 & 2,47 & 4,65 & 2,56 & 7,14 & 12,50 & 2,2 & 3,62 & 4,56 \\
\hline Lagomorfos & 9 & 1 & 1 & 4,71 & 1,23 & 2,33 & 2,56 & 3,57 & 12,50 & 0,07 & 0,06 & 0,13 \\
\hline Cervidés & 2 & 3 & - & 1,05 & 3,7 & 0 & - & - & - & - & & - \\
\hline $\begin{array}{r}\text { DOMESTIQUES / } \\
\text { SAUVAGES }\end{array}$ & 116 & 60 & 18 & 60,73 & 74,07 & 41,86 & 28,21 & 28,57 & 62,50 & 39,5 & 31,25 & \\
\hline Bos sp. & 6 & 4 & 6 & 3,14 & 4,94 & 13,95 & 2,56 & 7,14 & 12,50 & 29,62 & 47,25 & 46,93 \\
\hline Sus sp. & 22 & 11 & 13 & 11,52 & 13,58 & 30,23 & 5,13 & 10,71 & 12,50 & 20,31 & 21,42 & 21,45 \\
\hline Caprinés & 26 & 6 & 6 & 13,61 & 7,41 & 13,95 & - & - & - & - & - & - \\
\hline TOTAL SAUVAGES & 54 & 21 & 25 & 28,27 & 25,93 & 58,14 & 7,69 & 17,86 & 25 & 49,92 & 68,67 & - \\
\hline Felis silvestris & 3 & - & 1 & - & - & - & 2,56 & - & 12,50 & 0,08 & - & 0,11 \\
\hline Vulpes vulpes & - & 1 & - & - & - & - & - & 3,57 & - & - & - & - \\
\hline Lynx sp. & 1 & - & - & - & - & - & 2,56 & - & - & - & 0,08 & - \\
\hline Carnivore ND & 2 & - & - & - & - & - & - & - & - & - & - & - \\
\hline TOTAL CARNIVORES & 6 & 1 & 1 & - & - & - & 2,56 & 3,57 & 12,50 & 0,08 & 0,08 & - \\
\hline Testudo sp. & 1 & - & - & - & - & - & - & - & - & - & - & - \\
\hline Avifaune & 1 & 1 & - & - & - & - & - & - & - & - & - & - \\
\hline $\begin{array}{r}\text { TOTAL AUTRES } \\
\text { ESPEECES }\end{array}$ & 2 & 1 & - & - & - & - & - & - & - & - & - & - \\
\hline M. grand & 13 & 9 & 7 & - & - & - & - & - & - & - & - & - \\
\hline M. moyen & 257 & 41 & 89 & & - & - & - & - & - & - & & - \\
\hline M. petit & 5 & 2 & - & - & - & - & - & - & - & - & - & - \\
\hline TOTAL & 474 & 218 & 140 & 191 & 81 & 43 & 39 & 28 & 8 & 590,90 & 634,90 & 417,90 \\
\hline
\end{tabular}

27 La courbe de mortalité des différentes espèces révèle l'existence d'un abattage de jeunes individus dans les niveaux néolithiques et une préférence pour les adultes dans les niveaux mésolithiques (tabl. 4). Cela peut être interprété comme une gestion moins respectueuse de la ressource au Néolithique, en raison de la présence d'animaux domestiques. Parmi les espèces domestiques, on observe l'abattage d'animaux très jeunes, ce qui peut s'expliquer par l'exploitation du bétail pour la viande et le lait, fait clairement documenté pour cette période (Vigne et Helmer 2007). On a pu déterminer une occupation de la cavité du printemps jusqu'à l'automne pour la période néolithique. 
Tabl. 4. - Abri de L'Esplugón (Villobas-Sabiñánigo, Huesca, Espagne) : profils de mortalité de chaque espèce.

Néonatal Infantile Juvénile Subadulte Adulte

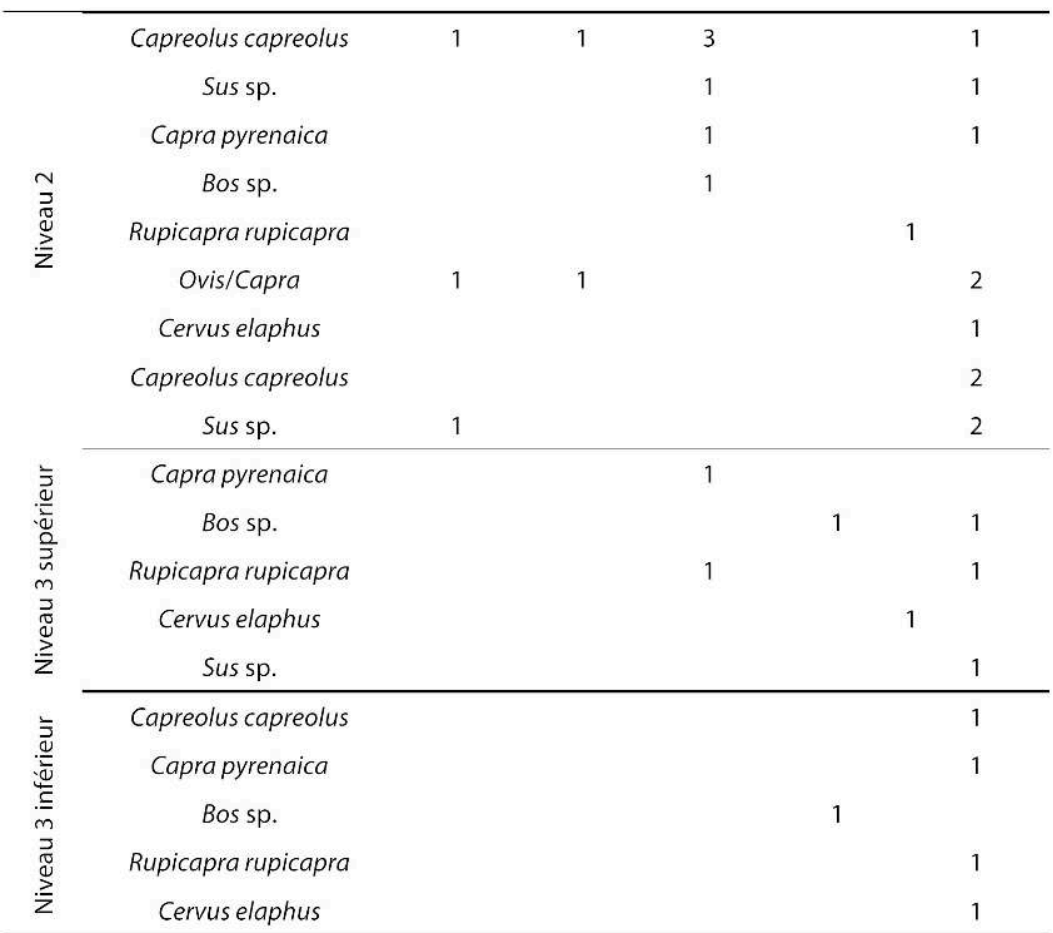

Quant à la gestion des animaux chassés, on observe une plus grande fracturation des os dans les niveaux mésolithiques, probablement liée à l'extraction de la moelle osseuse. En ce qui concerne la représentativité squelettique, aucune extrémité distale d'os long de cerf n'a été reconnue. À l'inverse, les os de Sus, Capreolus et des ovicaprinés sont complets. Ce constat paraît évoquer des pratiques de transport différentes pour le cerf.

\section{De possibles manifestations artistiques}

Parmi les objets décoratifs sont à signaler quelques exemplaires perforés de Columbellae rusticae découverts dans les niveaux du Mésolithique géométrique.

En ce qui concerne l'art, l'abri de L'Esplugón a livré plusieurs galets peints en rouge appartenant aux niveaux néolithiques (2 et 3 sup.). La figure 12 en reproduit deux, modifiés par l'application D-Strech du programme Image J. Le galet B semble représenter un bouquetin en course, mais ce n'est pas tout à fait clair. Les études à la loupe binoculaire et au microscope sont en cours pour le confirmer. 
Fig. 12. - Abri de L'Esplugón (Villobas-Sabiñánigo, Huesca, Espagne) : galets peints en rouge.
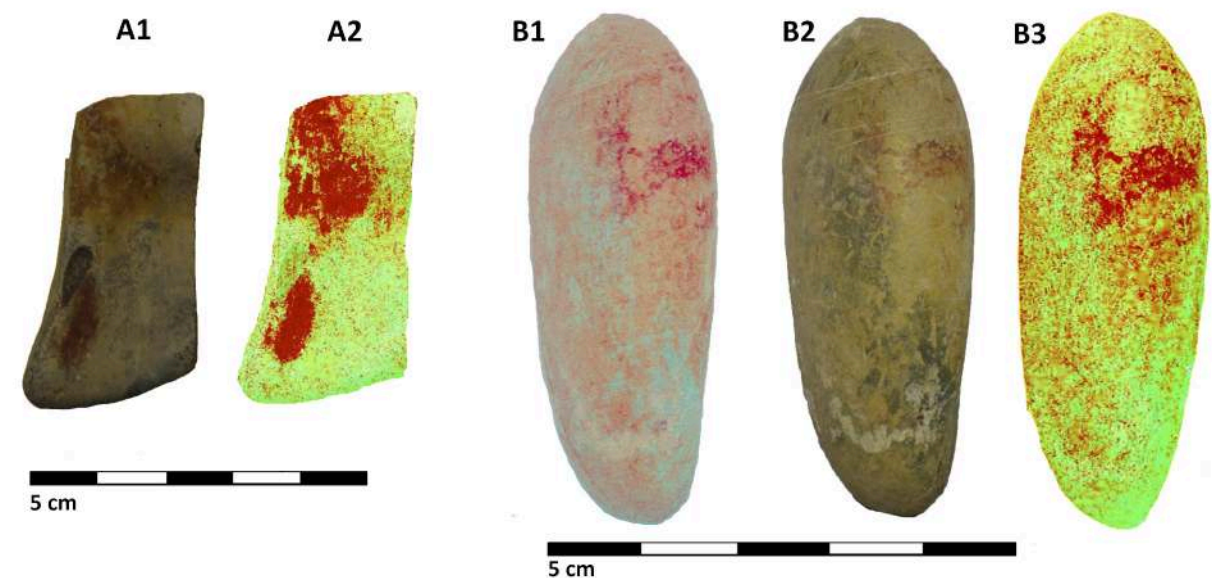

A1 ET B2 : images non modifiées. A2, B1 ET B3 : images modifiés par l'application D-Strech du programme Image $\mathrm{J}$.

PAO et photos Pilar Utrilla et Manuel Bea.

Les indices d'activité artistique les plus significatifs sont des gravures pariétales à hauteur d'homme. Il s'agit de trois figures géométriques, dont deux présentent une ligne horizontale et plusieurs verticales, tandis qu'une troisième se compose d'une ligne centrale avec d'autres lignes situées de chaque côté (fig. 13).

Fig. 13. - Abri de L'Esplugón (Villobas-Sabiñánigo, Huesca, Espagne) : tracé des gravures et schéma proposé en relation avec la possible position stratigraphique des créateurs des gravures.

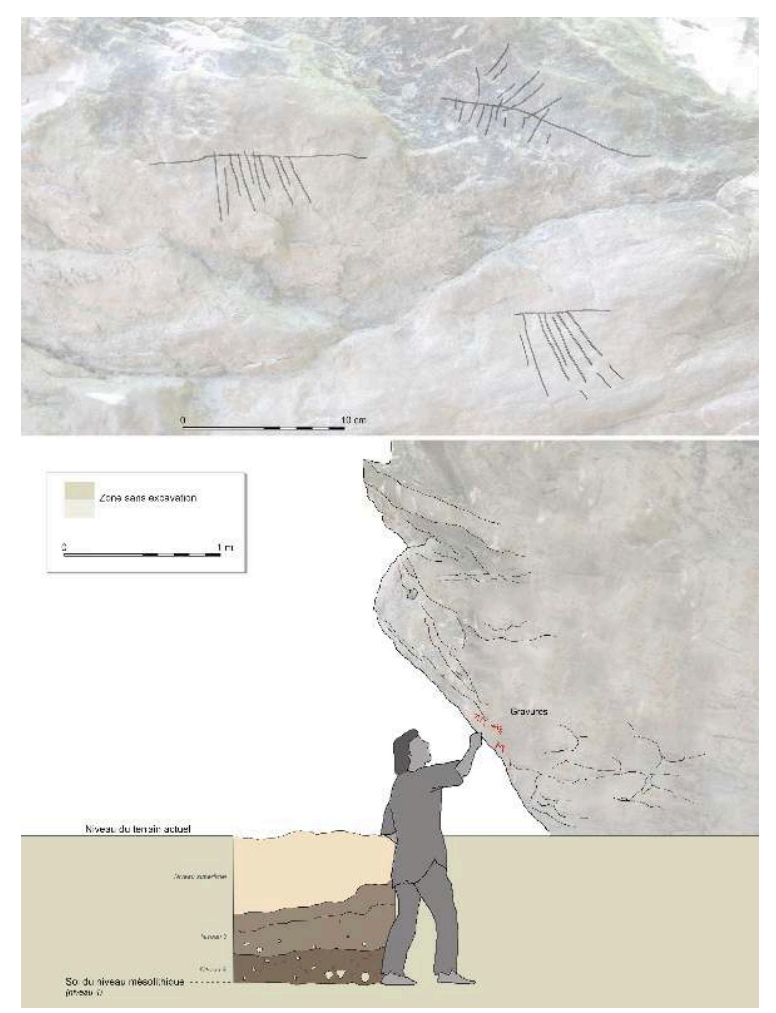

PAO, photos et dessin Manuel Bea. 
Rien ne permet d'affirmer que nous sommes en présence de gravures préhistoriques. Cette possibilité est cependant à retenir pour trois raisons :

- Leur position à hauteur d'homme (1,70 m), considérant qu'il dessine debout sur les niveaux mésolithiques (4 ou 3 inf.; fig. 13);

- La patine ancienne qui recouvre l'incision;

- Les similitudes de ces gravures avec des motifs géométriques mésolithiques, identifiés principalement dans le Bassin parisien (Buno-Bonneveaux, Ségognole, Canches, Villetard, grotte de Saint-Agnan, La Géode II de Bulou, et autres : Courty 1904, Nougier 1949, Hinout et Angelier 1968, Hinout 1998).

D'autre part, les parallèles de décors géométriques dans l'art mobilier du Mésolithique sont bien connus : par exemple, les plaquettes de la grotte de La Cocina ou, en haut Aragon, la plaquette de Forcas II, datée vers 6 210-6 030 cal. BC (GrN-22686: $7240 \pm$ $40 \mathrm{BP}$, niveau II) dans un niveau du Mésolithique géométrique avec des types ultrapyrénéens (Utrilla 2014, Utrilla et Domingo 2014) (fig. 14). En France, les plaquettes avec les motifs décoratifs les plus proches sont celles de l'abri Murat ou de Rochedane, dans le Doubs (Couraud 1985, D’Errico 1994, David et al. 1998), ces dernières attribuées à l'Azilien.

Fig. 14. - Abri de L’Esplugón (Villobas-Sabiñánigo, Huesca, Espagne) : comparaison avec des gravures provenant d'autres sites.
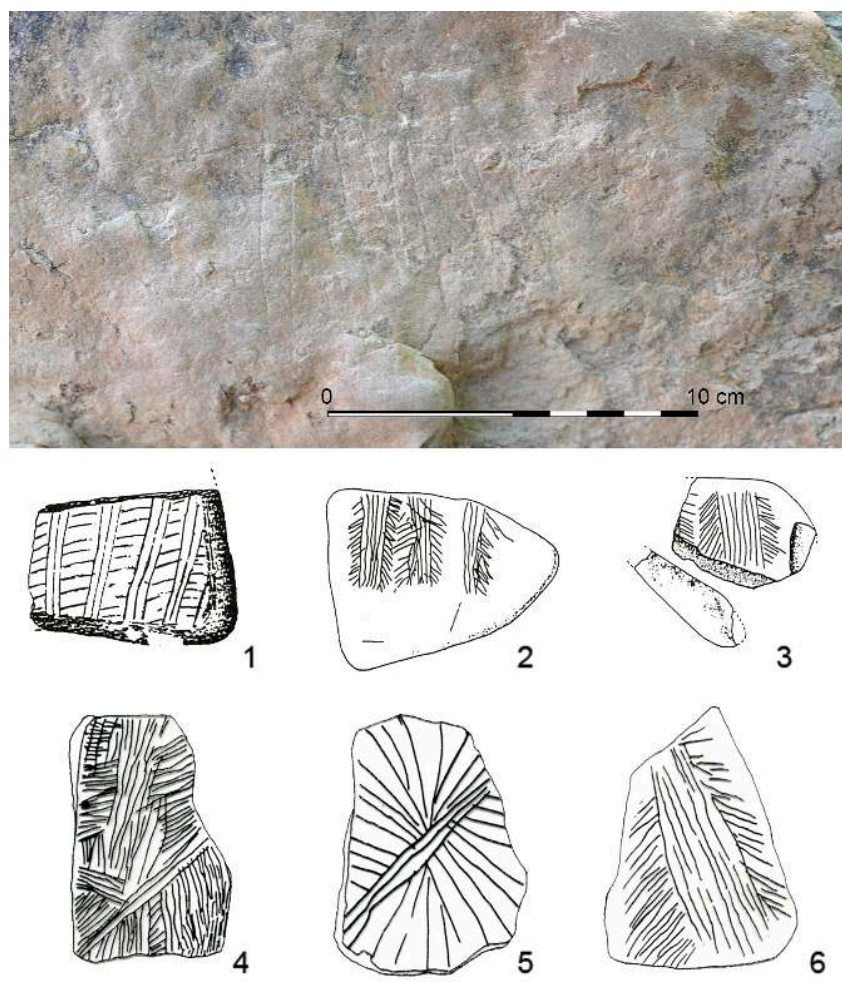

En haut : photographie de détail du motif 3 de L'Esplugón. En bas : gravures sur plaquettes mésolithiques. 1 : Forcas. 2-3 : abri Murat (Rocamadour, Lot). 4-6 : La Cocina (Dos Aguas, Valencia, Espagne).

1 : extrait de Utrilla 2014, 2-3 : extrait de D'Errico 1994. 4-6 : extrait de Fortea 1974. PAO et photo Manuel Bea. 


\section{Conclusions}

D'autres études sont en cours, principalement sur la sédimentologie, la micromorphologie, la palynologie, la carphologie, la technologie lithique et la dispersion spatiale des restes ; on sait cependant déjà que l'abri de L'Esplugón constitue un gisement de référence, pour six motifs principaux :

-L'existence d'une séquence de transition Mésolithique-Néolithique: niveau 4 à trapèzes; niveau 3 inf. à triangles; niveaux 3 sup. et 2, Néolithique ancien; niveau l, Chalcolithique. Les niveaux 5 et 6 , en cours de fouille, pourraient appartenir à l'Épipaléolithique à denticulés et/ou microlaminaire.

- La richesse de l'industrie lithique dans les niveaux mésolithiques, avec la mise au jour de plus de 200 armatures sur une petite surface fouillée (8 mètres carrés). La typologie montre des points communs avec les sites du versant sud des Pyrénées d'Aizpea et Forcas : triangles à retouche plate dans le Néolithique et présence de types d'au-delà des Pyrénées dans le Mésolithique géométrique tardif. En revanche, on note l'absence de triangles clairement attribuables au type Cocina.

- Avec l'abri d'Espantalobos (Huesca) (Montes et al. 2015), cette découverte vient combler un espace vide dans le haut Aragon entre le site de Forcas II, situé plus à l'est, et les sites plus occidentaux de la zone de Biel (Zaragoza, Espagne), tels que Peña 14 (Montes 2001-2002) et Rambla de Legunova (Montes 2005).

- L'Esplugón a livré des exemples d'art mobilier (galets peints en rouge des niveaux néolithiques) ainsi qu'un possible art pariétal (gravures à décor géométrique, probablement des niveaux mésolithiques).

- Dans les niveaux néolithiques, nous avons constaté la présence d'espèces domestiquées (ovicaprinés, et peut-être suidés et bovinés) et des indices d'activité agricole (lames avec patine de céréales).

- Dans le domaine de l'anthracologie, nous avons pu documenter le recul des taxons mésophiles (principalement Quercus sp. à feuillage caduc), ajouté à la présence de galets et de plaquettes anguleuses dans le niveau 4, qui pourrait être liée au froid et à l'aridité intense qui caractérise le 8,2 kyr BP event dans cette région.

\section{BIBLIOGRAPHIE}

ALCOLEA M., 2016, «El uso de los recursos vegetales leñosos en el abrigo de El Esplugón (BillobasSabiñánigo, Huesca): resultados preliminares », dans Rodanés J. M. et Lorenzo J. I. (dir.), Actas I Congreso de Arqueología y Patrimonio Aragonés, Zaragoza, Colegio Oficial de Doctores y Licenciados en Filosofía y Letras y en Ciencias de Aragón, p. 573-580.

ALDAY A., 1998, El depósito prehistórico de Kanpanoste Goikoa (Vírgala, Alava): memoria de las actuaciones arqueológicas, 1992-1993, Vitoria, Diputación Foral de Álava (Memorias de Yacimientos Alaveses, 5). 
ALDAY A. (dir.), 2005, El campamento prehistórico de Mendandia: ocupaciones mesolíticas y neolíticas entre el 8500 y el 6400 B.P., Vitoria, Fundación José Miguel de Barandiarán/Diputación Foral de Álava.

ALDAY A. (dir.), 2006, El Mesolítico de muescas y denticulados en la Cuenca del Ebro y el Litoral Mediterráneo Peninsular, Vitoria, Diputación Foral de Álava (Memorias de Yacimientos Alaveses, 11).

BALDELlou V., 1983a, « Comentario a los materiales neolíticos », Bolskan, nº 1, p. 67-94.

BALDELLou V., 1983b, « La cueva del Forcón (La Fueva-Huesca) », Bolskan, nº 1, p. 149-176.

BALDELLou V., 1987, « Avance al estudio de la Espluga de la Puyascada », Bolskan, nº 4, p. 3-42.

BALDELLOU V. et BARRIL M., 1981, « Los materiales arqueológicos de la Cueva de la Miranda (Palo, Huesca) en el Museo de Huesca ", Pyrenae, n 17, p. 55-82.

BALDELLOU V. et RAMÓN N., 1995, « Estudio de los materiales cerámicos neolíticos del conjunto de Olvena ", Bolskan, n 12, p. 105-169.

BARANDIARÁN I., 1978, « El abrigo de la Botiquería dels Moros, Mazaleón (Teruel): Excavaciones arqueológicas de 1974 », Cuadernos de Prehistoria y Arqueología Castellonense, n 5, p. 49-138.

BARANDIARÁN I. et CAVA A., 1989, La ocupación prehistórica del abrigo de Costalena (Maella, Zaragoza), Zaragoza, Diputación General de Aragón (Arqueología y Paleontología, 6).

BEA M., 2014, «Elementos líticos pulimentados y cantos con ocre de los abrigos de Forcas I y II », dans Utrilla P. et Mazo C. (dir.), La Peña de las Forcas. Graus, Huesca: Un asentamiento en la confluencia del Ésera y el Isábena, Zaragoza, Prensas Universitarias de Zaragoza (Monografías Arqueológicas, serie Prehistoria, 46), p. 227-236.

BERDEJO A. et OBÓN A., 2016, « Un nuevo yacimiento neolítico en las sierras exteriores del Pirineo central: el Esplugón (Villobas), sondeo de $2009 »$, Bolskan, n 24, p. 139-144.

CAVA A., 2000, « La industria lítica del Neolítico de Chaves (Huesca) », Salduie, nº 1, p. 75-162.

CAVA A., 2001, « La industria lítica », dans Barandiarán I. et Cava A. (dir.), Cazadores-recolectores en el Pirineo navaro El sitio de Aizpea entre 8.000 y 6.000 años antes de ahora, Vitoria, Universidad del País Vasco (Anejos de Veleia, serie Maior, 10), p. 63-148.

CAVA A. (dir.), 2004, La ocupación prehistórica de Kanpanoste en el contexto de los cazadores-recolectores del Mesolítico, Vitoria, Diputación Foral de Álava (Memorias de Yacimientos Alaveses, 9).

CAVA A., ALDAY A., TARRIÑo A., 2007-2008, « La circulación de materias primas líticas en la transición Mesolítico/Neolítico Antiguo en el País Vasco: Los abrigos de Mendandia, Kanpanoste y Aizpea », Veleia, $\mathrm{n}^{\circ}$ 24-25, p. 581-609.

COURAUD C., 1985, L'art azilien : origine-survivance, Paris, CNRS éditions (Gallia préhistoire, supplément XX).

COURTY G., 1904, « Les pétroglyphes de Seine-et-Oise », Bulletin de la Société préhistorique de France, vol. $1, \mathrm{n}^{\circ} 10$, p. 345-351.

D'ERRICO F., 1994, L'art gravé azilien : de la technique à la signification, Paris, CNRS éditions (Gallia préhistoire, supplément XXX).

DAVID S., D'ERRICO F., THEVENIN A., 1998, « L'art mobilier de Ranchot (Jura) et de Rochedane (Doubs) », dans Cupillard C. et Richard A. (dir.), Les derniers chasseurs-cueilleurs du massif jurassien et de ses marges (13000-5500 a. C.), Besançon, Centre jurassien du patrimoine, p. 192-200. 
FORTEA F. J., 1974, « Algunas aportaciones a los problemas del Arte levantino », Zephyrus, $\mathrm{n}^{\circ}$ 25, p. 225-257.

GALLART M. D. et LÓPEZ F., 1988, « Análisis mineralógico de las cerámicas neolíticas de la cueva de Chaves (Casbas, Huesca)», Bolskan, nº 5, p. 5-26.

GALLART M. D. et MATA M. P., 1995, « Análisis mineralógico de las cerámicas », Bolskan, n 12 , p. $171-180$.

GARCíA-ARGÜELLES P. et VAQUERo M., 2009, « Algunas reflexiones sobre la ausencia de Mesolítico geométrico en Cataluña », dans Utrilla P. et Montes L. (dir.), El Mesolítico geométrico en la Península Ibérica, Zaragoza, Universidad de Zaragoza, p. 191-204.

HINOUT J., 1998, « Essai de synthèse à propos de l'art schématique mésolithique dans les massifs gréseux du Bassin parisien », Bulletin de la Société préhistorique française, vol. 95, nº 4, p. 505-524.

HINOUT J. et ANGELIER J., 1968, « Abris gravés des massifs gréseux du Bassin parisien », Gallia préhistoire, vol. 11, $\mathrm{n}^{\circ} 2$, p. 235-246.

LAPUENTE P. et IGEA J., 2014, « Estudio petrológico de las cerámicas neolíticas de Forcas II y otros yacimientos del entorno », dans Utrilla P. et Mazo C. (dir.), La Peña de las Forcas II (Graus, Huesca): un asentamiento estratégico en la confluencia del Ésera y el Isábena, Zaragoza, Universidad de Zaragoza (Monografías Arqueológicas, serie Prehistoria, 46), p. 267-286.

MARCHAND G. et MANEN C., 2006, «Le rôle du Néolithique ancien méditerranéen dans la néolithisation de l'Europe atlantique ", dans $6^{e}$ Rencontres méridionales de préhistoire récente, Périgueux, 2004, Périgueux, ADRAHP/Préhistoire du Sud-Ouest, p. 213-232.

MONTES L., 2001-2002, « El abrigo Epipaleolítico de Peña 14 (Biel, Zaragoza): Excavaciones 1999 y $2000 »$ Salduie, $\mathrm{n}^{\circ}$ 2, p. 291-306.

MONTES L., 2005, « Abrigos de Legunova y Valcervera en Biel: Campaña de 2004 », Salduie, nº 5, p. 257-269.

MONTES L., DOMINGo R., CUCHI J. A., ALCOLEA M., sOlA C., 2015, « Completando el mapa de la Cuenca del Ebro: el Mesolítico del IX milenio cal BP de Espantalobos (Huesca, España) », Munibe, $\mathrm{n}^{\circ}$ 66, p. 119-133.

MONTES L., DOMINGO R., GONZÁLEZ-SAMPÉRIZ P., SEBASTIÁN M., ARANBARRI J., CASTAÑOS P., GARCÍA-SIMÓN L. M., ALCOLEA M., LABORDA R., 2016, « Landscape, resources and people during the Mesolithic and Neolithic times in NE Iberia: The Arba de Biel Basin », Quaternary International, $n^{\circ} 403$, p. 133-150. MORALES J. I. et OMS F. X., 2012, « Las últimas evidencias mesolíticas del NE peninsular y el vacío pre-neolítico », Rubricatum, $\mathrm{n}^{\circ}$ 5, p. 35-42.

NOUGIER L. R., 1949, « Remarques à propos des murs, enceintes et gravures de la forêt de Fontainebleau », Bulletin de la Société préhistorique française, vol. 46, nº 11, p. 418-427.

OBÓN A. et BERDEJO A., 2016, « Perspectivas para el estudio del poblamiento del valle del Guarga (Huesca) », dans Rodanés J. M. et Lorenzo J. I. (dir.), Actas I Congreso de Arqueología y Patrimonio Aragonés, Zaragoza, Colegio Oficial de Doctores y Licenciados en Filosofía y Letras y en Ciencias de Aragón, p. 169-177.

OMS F. X., 2008, «Caracterizació técnica, tipológica i cronológica de les ceràmiques del Neolític antic de la Cova Colomera (Prepirineu de Lleida) », Archivo de Prehistoria Levantina, $\mathrm{n}^{\circ}$ 27, p. 51-80. Pallaruelo S., 1988, Pastores del Pirineo, Madrid, Ministerio de Cultura, Dirección General de Artes y Archivos. 
PUIGDEFÁBREGAS C., 1975, La sedimentación molásica en la cuenca de Jaca, Jaca, Instituto de Estudios Pirenaicos-CSIC (Monografías, 104).

RAPP J. et HILLS C., 1998, Geoarchaeology: The Earth Science approach to archaeological interpretation, Yale, University Press.

REIMER P. J., BARD E., BAYLISS A., BECK J. W., BLACKWELl P. G., BRONK RAMSEY C., BUCK C. E., CHENG H., EDWARDS R. L., FRIEDRICH M., GROOTES P. M., GUILDERSON T. P., HAFLIDASON H., HAJDAS I., HATTE C., HEATON T. J., HOFFMANN D. L., HOGG A. G., HUGHEN K. A., KAISER K. F., KROMER B., MANNING S. W., NIU M., REIMER R. W., RICHARDS D. A., SCOTT E. M., SOUTHON J. R., STAFF R. A., TURNEY C. S. M., VAN DER PLICHT J., 2013, « IntCal13 and Marine13 radiocarbon age 22 calibration curves 0-50,000 years cal BP », Radiocarbon, vol. 55, $n^{\circ} 4$, p. 1869-1887.

RODANÉS J. M., TILO M. A., RAMÓN N., 1996, « El abrigo de Els Secans (Mazaleón, Teruel): La ocupación del Valle del Matarraña durante el Epipaleolítico y Neolítico Antiguo », Al-Qannis, nº 6, p. 3-107. RODANÉS J. M. et PICAZo J. V. (dir.), 2013, « El Campamento Mesolítico del Cabezo de la Cruz (La Muela, Zaragoza) », Zaragoza, Prensas Universitarias de Zaragoza (Monografías Arqueológicas, serie Prehistoria, 45).

ROJO M. A., PEÑA L., ROYO J. L., TEJEDOR C., GARCÍA-MARTINEZ I., ARCUSA H., GARRIDO R., MORENO M. MAZZUCCO N., GIBAJA J. F., ORTEGA D., KROMER B., ALT K. W., 2013, « Pastores trashumantes del neolítico antiguo en un entorno de alta montaña: secuencia crono-cultural de la Cova de Els Trocs (San Feliú de Veri, Huesca) », Boletín del Seminario de Estudios de Arte y Arqueología, n 79, p. 9-56. UTRILlA P., 2014, « La plaqueta decorada de Forcas II (Graus, Huesca) », dans Utrilla P. et Mazo C. (dir.), La Peña de las Forcas, Graus, Huesca: Un asentamiento en la confluencia del Ésera y el Isábena, Zaragoza, Prensas Universitarias de Zaragoza (Monografías Arqueológicas, serie Prehistoria, 46), p. 329-336.

UTRILLA P. et DOMINGo R., 2014, « La transition Mésolithique-Néolithique dans la vallée de l'Èbre », dans Guilaine J., Manen C., Perrin T. (dir.), La néolithisation de l'Ouest méditerranéen/The western Mediterranean Neolithization, Toulouse, Errance, p. 323-353.

UTRILla P. et MAzo C. (dir.), 2014, La Peña de las Forcas, Graus, Huesca: Un asentamiento en la confluencia del Ésera y el Isábena, Zaragoza, Prensas Universitarias de Zaragoza (Monografías Arqueológicas, serie Prehistoria, 46).

UTRILla P. et MONTES L. (dir.), 2009, El Mesolítico geométrico en la Península Ibérica, Zaragoza, Prensas Universitarias de Zaragoza (Monografías Arqueológicas, serie Prehistoria, 44).

UTRILLA P. et RODANÉS J. M. (dir.), 2004, Un asentamiento epipaleolítico en el valle del río Martín: El abrigo de los Baños (Ariño, Teruel), Zaragoza, Prensas Universitarias de Zaragoza (Monografías Arqueológicas, serie Prehistoria, 39)

UTRILLA P., BERDEJO A., OBÓN A., 2012, « El Esplugón: un abrigo mesolítico en el valle del Guarga (Huesca) », dans Muñiz J. R. (dir.), Ad Orientem: del final del Paleolítico en el Norte de España a las primeras civilizaciones del Oriente Próximo: estudios en homenaje a Juan Antonio Fernández-Tresguerres Velasco, Oviedo, Universidad de Oviedo, p. 235-252.

UTRILLA P., BERDEJO A., OBÓN A., LABORDA R., DOMINGo R., ALCOLEA M., 2016, « El abrigo de El Esplugón (Billobas-Sabiñánigo, Huesca): Un ejemplo de transición Mesolítico-Neolítico en el Prepirineo central ", dans Del neolític a l'edat del bronze en el Mediterrani occidental: Estudis en Homenatge a Bernat Martí Oliver, Valencia, Museo de Prehistoria de Valencia (Trabajos Varios, 119), p. 75-96. 
VIGNE J. D. et HELMER D., 2007, « Was milk a "secondary product” in The Old World Neolithisation process? Its role in the domestication of cattle, sheep and goats ", Anthropozoologica, vol. $42 \mathrm{n}^{\circ} 2$, p. 9-40.

\section{RÉSUMÉS}

Cet article présente les principaux résultats issus des récentes opérations de fouilles à l'abri de L'Esplugón (Billobas-Sabiñánigo, Huesca), ainsi que des diverses études réalisées. Ce site se distingue par son emplacement privilégié, son bon état de conservation et sa richesse archéologique, composée de différents niveaux mésolithiques géométriques et néolithiques. La surface fouillée concerne seulement quelques mètres carrés. Cependant, nous pouvons affirmer que L'Esplugón constitue d'ores et déjà un des gisements de référence dans ce cadre chronoculturel pour l'analyse des processus de néolithisation dans le bassin de l'Èbre.

In this article, we present the Mesolithic and Neolithic sequences of El Esplugón shelter (BillobasSabiñánigo, Huesca), as well as the main results of the various studies carried out after several archaeological fieldwork seasons in recent years: anthracology, lithic typology, use-wear analysis, pottery, fauna and art. This site, with good preservation, offers new data on the occupation in the Spanish Pre-Pyrenees, highlighting the geostrategic position of the Guarga river corridor. The rich archaeological sequence indicates a repeated occupation between the middle of the $8^{\text {th }}$ millennium cal BC and the beginning of the $5^{\text {th }}$ millennium cal BC, from the Microlaminar Mesolithic till the Early Neolithic. In short, it is one of the best reference settlements for this chrono-cultural framework in the analysis of Neolithic processes in the Ebro basin.

\section{INDEX}

Mots-clés : Mésolithique microlaminaire, gravure pariétale mésolithiques, Mésolithique géométrique, Néolithique ancien, Mésolithique

Keywords : Microlaminar Mesolithic, Geometric Mesolithic, Early Neolithic, painted pebble, Mesolithic

Index géographique : bassin de l’Èbre, Pré-Pyrénées de Huesca

\section{AUTEURS}

\section{ALBERTO OBÓN ZÚÑIGA}

Chercheur indépendant

\section{ABEL BERDEJO ARCÉIZ}

Chercheur indépendant, collectif De la Roca al Metal

\section{RAFAEL LABORDA MARTÍNEZ}

Departamento de Ciencias de la Antigüedad, Área de Prehistoria, Universidad de Zaragoza 


\section{ALEJANDRO SIERRA SAINZ-AJA}

Departamento de Ciencias de la Antigüedad, Área de Prehistoria, Grupo de investigación PPVE (Primeros pobladores del Valle del Ebro), Universidad de Zaragoza

\section{MARTA ALCOLEA GRACIA}

Área de Prehistoria, Universidade de Santiago de Compostela et Muséum national d'histoire naturelle, CNRS UMR 7209

\section{MANUEL BEA}

Departamento de Ciencias de la Antigüedad, Área de Prehistoria, Grupo de investigación PPVE (Primeros pobladores del Valle del Ebro), Universidad de Zaragoza

\section{RAFAEL DOMINGO MARTÍNEZ}

Chercheur « Ramón y Cajal », Departamento de Ciencias de la Antigüedad, Área de Prehistoria, Grupo de investigación PPVE (Primeros pobladores del Valle del Ebro), Instituto de Patrimonio y Humanidades (IPH), Universidad de Zaragoza

\section{PILAR UTRILLA MIRANDA}

Departamento de Ciencias de la Antigüedad, Área de Prehistoria, Grupo de investigación PPVE (Primeros pobladores del Valle del Ebro), Instituto de Patrimonio y Humanidades (IPH),

Universidad de Zaragoza 


\title{
De l'arolle ou du chêne ? Mobilité verticale et exploitation des ressources végétales au Néolithique dans les Alpes occidentales
}

\author{
Arolla pine or oak tree? Vertical mobility and plant resources \\ exploitation in the Neolithic in the western Alps \\ Lucie Martin, Claire Delhon, Alexa Dufraisse, Stéphanie Thiébault et Marie \\ Besse
}

\begin{abstract}
Nous remercions les organisateurs de la session « La conquête de la montagne: des premières occupations humaines à l'anthropisation du milieu » du $142^{e}$ Congrès des sociétés historiques et scientifiques à Pau en avril 2017 : Marianne Deschamps, Sandrine Costamagno, Pierre-Yves Milcent, Jean-Marc Pétillon, Caroline Renard et Nicolas Valdeyron. Nous tenons également à remercier les archéologues qui ont fouillé les différents sites évoqués, et qui nous ont permis de mener à bien nos analyses : Pierre-Yves Nicod, Régis Picavet, Pierre-Jérôme Rey, Joël Vital, Pierre Bintz et David Pelletier. Ce travail a été en parti soutenu grâce à des subsides du Fonds national suisse de la recherche scientifique (projets FNS PMPDP1 139632 et PZ00P1 161307).
\end{abstract}

\section{Introduction}

\section{Une végétation étagée}

Une des caractéristiques du milieu montagnard est le changement altitudinal de végétation, marqué notamment par la disparition des forêts, qui sont remplacées par des pelouses alpines entre 2000 et 2500 mètres d'altitude. Cet étagement de la végétation est dû à plusieurs facteurs écologiques : le premier est la température, à laquelle se joignent l'humidité, la composition du sol, le rayonnement solaire, la topographie, le vent, le degré de continentalité, etc. Les effets biogéographiques de ces différents facteurs se traduisent par une diminution progressive du couvert végétal, qui 
se ressent, d'une part, lorsque l'altitude augmente, et d'autre part en allant du sud vers le nord. Chaque étage de végétation regroupe ainsi un ensemble d'espèces végétales qui ont des affinités écologiques propres et qui forment par là même des groupements végétaux spécifiques. Aujourd'hui, en raison de multiples facteurs parmi lesquels ceux énumérés ci-dessus, ces étages sont irréguliers et variables. L'activité humaine a également eu un impact sur les dynamiques de végétation alpines. Les études paléoenvironnementales (pollen, spores, macro- et microcharbons) et archéobotaniques (macrorestes végétaux, charbons de bois archéologiques) ont montré l'effet du pastoralisme et des feux sur la végétation naturelle en montagne, et notamment sur la limite supérieure des forêts (Tinner 2007, Schwörer et al. 2015, Cabanat et al. 2017).

2 Dans les grandes lignes, chaque étage a une amplitude comprise entre 500 et 900 mètres, avec une moyenne de 650 à 700 mètres, et une fourchette de température qui couvre environ $3,8^{\circ} \mathrm{C}$ entre l'altitude la plus basse et la plus haute de chaque étage (fig. 1).

Fig. 1. - Étages de végétation dans les Alpes occidentales.

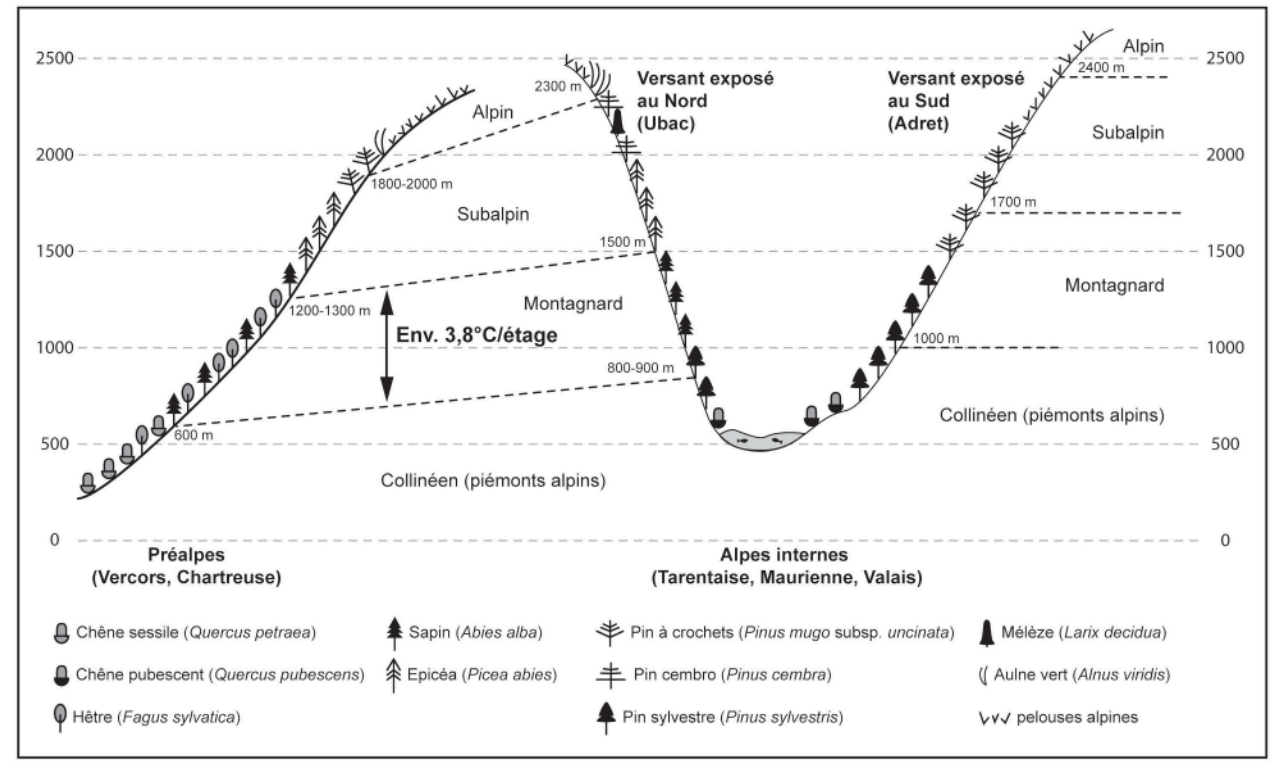

D’après Martin 2014, p. 28 et Rameau et al. 1993, p. 26.

3 Cinq étages de végétation peuvent être distingués dans les Alpes occidentales (Ozenda 1985, Rameau et al. 1993, Theurillat et al. 1998). Des plus basses aux plus hautes altitudes (fig. 1) :

- Le premier est l'étage collinéen, ou zone de piémont, qui atteint 600 mètres d'altitude dans les massifs subalpins (Chartreuse, Vercors, Bauges) à 1000 mètres dans les Alpes internes et les versants les mieux exposés au sud ; cet étage est défini comme celui des forêts de feuillus, en particulier des chênaies dominées par le chêne pubescent (Quercus pubescens), le chêne pédonculé ( $Q$. robur) et le chêne sessile (Q. petraea).

- Vient ensuite l'étage montagnard, jusqu'à 1200 à 1700 mètres d'altitude; dans les massifs calcaires des Alpes occidentales, il est occupé par des hêtraies et des hêtraies-sapinières (hêtre, Fagus sylvatica et sapin blanc, Abies alba). Les Alpes internes cristallines sont caractérisées par un climat plus continental et les formations végétales y sont dominées par 
des forêts de conifères, avec la série interne du sapin, de l'épicéa (Picea abies), et les séries mésophiles et xérophiles du pin sylvestre (Pinus sylvestris).

- L'étage subalpin lui succède. Sa végétation est plus complexe à décrire ; elle s'étend entre la limite supérieure des hêtraies ou du pin sylvestre et la limite supérieure des forêts, ou du moins de la végétation ligneuse (étage alpin). Dans les Alpes occidentales, cet étage se situe entre 1700 et 2400 mètres d'altitude; il est constitué de forêts de conifères adaptés à de rudes hivers avec l'épicéa, le mélèze (Larix decidua), le pin cembro ou arolle (Pinus cembra) et le pin à crochets (Pinus mugo subsp. uncinata ou P. uncinata), parfois accompagnés du sapin et $\mathrm{du}$ pin sylvestre.

-L'étage alpin commence entre 1900 et 2400 mètres; à ces altitudes, les communautés végétales sont considérées comme "spécialisées » pour s'adapter à cet environnement extrême.

- Quant à l'étage nival, entre 2400 et 3100 mètres, il est en théorie celui des neiges éternelles (glaciers), mais des communautés de plantes en coussinets peuvent se trouver sporadiquement, notamment dans les zones rocheuses (Theurillat et al. 1998).

\section{Étagements, modèles de peuplement et données archéobotaniques}

Grâce à cette succession de formations végétales, il est possible de restituer les différents biotopes exploités par les populations préhistoriques et de les situer selon un gradient altitudinal. Les archéologues ont par exemple utilisé cet étagement pour proposer des modèles de peuplement. Pour le Valais, A. Gallay et ses collaborateurs (département d'anthropologie de l'université de Genève) ont ainsi proposé un modèle théorique pour expliquer la relation entre l'économie des communautés néolithiques valaisannes et leur environnement. Ce système d'occupation du territoire est basé sur l'existence d'une forme de contrôle vertical des différentes zones altitudinales de production, à la manière du remuage, avec un habitat permanent à l'étage collinéen ou montagnard (Crotti et al. 1983, Gallay 1983). Ce modèle, repris ensuite avec une approche plus ethno-historique par O. May (1985), se fonde sur l'observation des communautés agropastorales traditionnelles, dont l'ensemble des faits socioéconomiques peuvent être appréhendés : la partition choisie ne tient plus compte des zones de végétation, comme l'avait fait A. Gallay, mais du type de cultures vivrières traditionnelles (fig. 2). Pour le Valais, ce modèle peut servir de postulat de départ pour comprendre l'éventuelle mise en place de ce contrôle vertical durant la Préhistoire. 
Fig. 2. - Modèle ethno-historique et comparatif proposé par 0 . May pour l'occupation du territoire par les communautés agropastorales en Valais au Néolithique moyen.

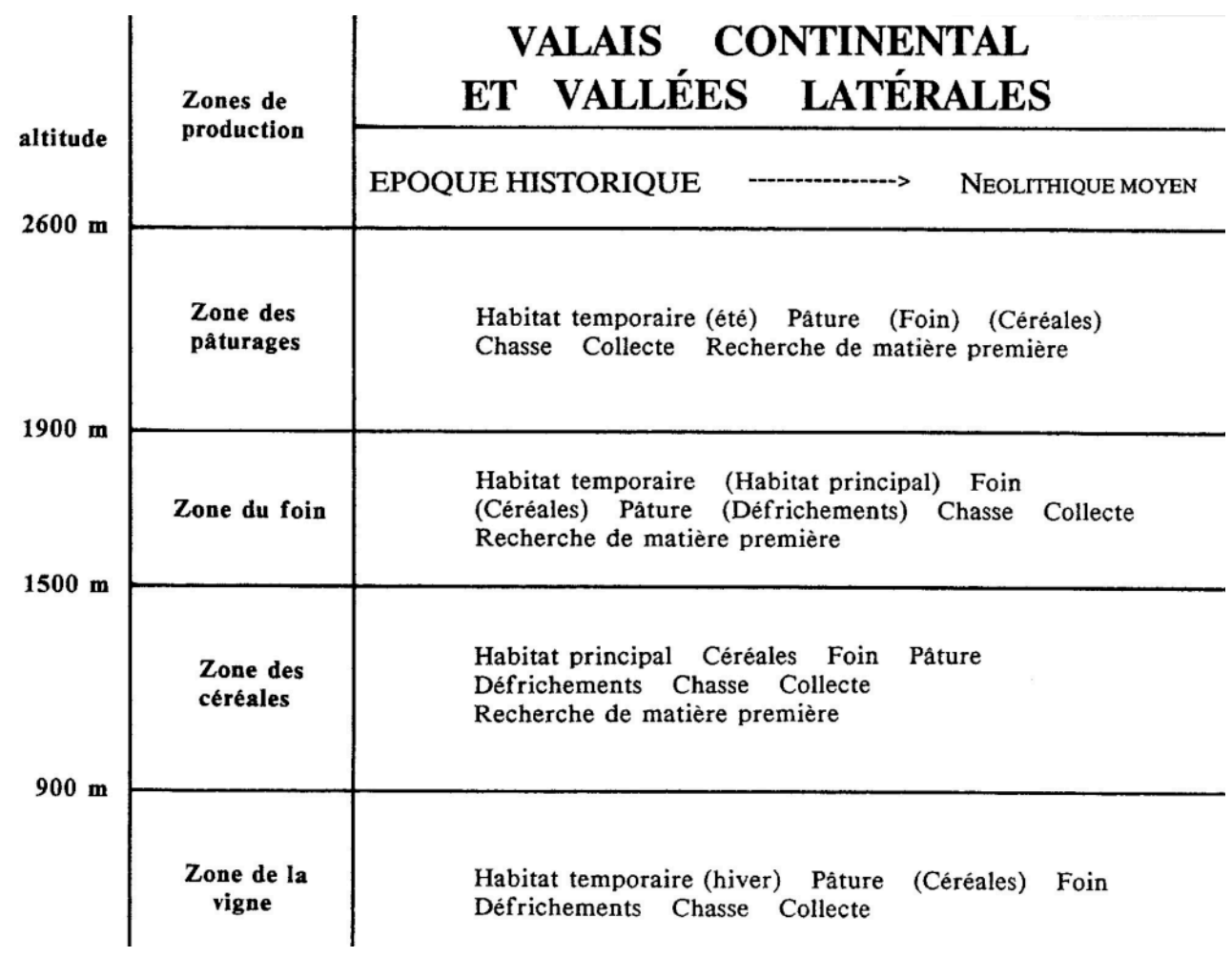

Extrait de Baudais et al. 1987, p. 4.

$5 \quad$ Les données archéobotaniques sont des indicateurs directs des biotopes exploités et de la manière dont les populations alpines néolithiques ont tiré profit de leurs ressources végétales. Cette contribution présente l'étude carpologique (graines, fruits et autres macrorestes végétaux) et anthracologique (charbons de bois) de quatre sites localisés dans les Alpes françaises du nord et d'un site dans les Alpes suisses, dont les résultats fournissent dans un premier temps un assemblage de taxons cultivés et sauvages, ligneux et herbacés. Les premières interprétations tirées de ces corpus renseignent sur la signification économique et écologique de ces plantes ainsi que sur les territoires parcourus et exploités par les communautés néolithiques. L'apport des céréales ou leur culture sur place, l'étendue de l'aire de cueillette ou celle de la récolte de bois apportent des éléments fondamentaux pour appréhender et préciser la fonction des sites, leur place au sein du territoire montagnard et décrire la mobilité verticale des populations de cette région. Ces différents aspects seront discutés après la présentation $\mathrm{du}$ cadre géographique, chronoculturel et méthodologique des cinq sites archéologiques utilisés ici comme exemples : en France, La Grande Rivoire (Sassenage, Isère), L'Aulp du Seuil (Saint-Bernard-du-Touvet, Isère), Le Chenet des Pierres (Bozel, Savoie) et Les Balmes (Sollières-Sardières, Savoie); en Suisse, Le Petit-Chasseur IV (Sion, Valais).

\section{Des occupations humaines à toutes les altitudes}

6 L'archéologie fournit de nombreux indices sur l'occupation de la montagne alpine, y compris à des altitudes élevées. Peu après le retrait du glacier würmien, à partir 
d'environ 15000 avant notre ère, les Alpes sont progressivement recolonisées au Paléolithique supérieur par des communautés magdaléniennes, qui en exploitent les ressources minérales et cynégétiques (Mevel 2013). Durant le Néolithique, dès 5500 avant notre ère, les populations alpines n'exploitent plus seulement les montagnes pour le gibier ou des matières premières, mais aussi pour y installer villages, champs et troupeaux.

7 Dans les Alpes occidentales, les hommes ont occupé l'espace des vallées jusqu'aux territoires d'altitude, qui offrent des milieux plus ouverts, propices à la chasse de grands herbivores grégaires comme le bouquetin ou le chamois. Les gisements temporaires, souvent en grotte, abri-sous-roche ou sous bloc, étaient généralement implantés à proximité d'un point d'eau et d'un gîte de matière première siliceuse (silex ou cristal de roche). Ces dernières décennies, de nombreuses campagnes de prospections et de sondages ont été menées dans plusieurs massifs (Vercors, Chartreuse, Dévoluy, Bauges, Maurienne, Tarentaise ou Valais) dans le cadre de programmes focalisés sur la fréquentation de la montagne dans les Alpes françaises du nord et en Valais.

8 Ces études ont fourni des indices archéologiques qui signalent une occupation des zones de moyenne montagne tout comme des étages supérieurs, au-delà de 1500 mètres d'altitude, et ce dès le Mésolithique (Bintz et al. 2008, Marguet et al. 2008, Rey et al. 2014, Rey 2015; programme PAVAC: Baudais et al. 1987 et 1990 ; bilan sur l'archéologie alpine: Thirault 2014). Elles montrent la diversité des implantations préhistoriques, que ce soit par leur fonction - halte de chasse, habitat, bergerie, ou site de peintures/gravures rupestres - ou par les environnements dans lesquels les communautés se sont installées: alpages, éperons rocheux, fond de vallée, hauts plateaux. Le programme de prospections et de sondages menés sous la direction de $\mathrm{P}$. -J. Rey autour du col du Petit-Saint-Bernard (projet Interreg IIIA Alpis Graia : Rey 2014) en est un excellent exemple. L'objectif était de mieux connaître les premiers peuplements de la montagne alpine et de préciser la dynamique des circulations transalpines autour d'un des principaux points de passage des Alpes occidentales. Avec une amplitude altitudinale importante (entre 750 et 3000 mètres d'altitude), près de 700 sondages renvoyant dans leur ensemble à toutes les périodes du Mésolithique à l'Antiquité ont livré de nombreuses occupations du Néolithique moyen et final, réparties à tous les étages et jusqu'à plus de 2000 mètres. Il s'agit de niveaux d'habitats, de concentrations d'indices ou d'indices isolés (Rey et al. 2014). L'étage alpin, à plus de 2500 mètres, était lui-même visité dès le Néolithique. En témoigne le cas bien connu d'ötzi, sujet masculin daté du Néolithique final (3300-3100 avant notre ère), dont le corps a été trouvé dans un glacier à la frontière austro-italienne (Spindler 1994). Plus récemment, les recherches menées sur le col englacé du Schnidejoch (Alpes bernoises, Suisse), à plus de 2750 mètres, ont livré, entre autres, des fragments de bols en bois, plusieurs pointes de flèches et un « kit » complet de chasseur comprenant un arc en if, sa corde, des hampes et des pointes de flèches.

9 Ces découvertes indiquent des occupations prolongées de l'étage alpin, tout au moins pour des activités de chasse (Hafner et Schwörer 2018). En Valais, un des rares sites de haute altitude occupé tout au long du Néolithique est l'abri d'Alp Hermettji, à 2600 mètres, au pied du Cervin, situé sur une voie de passage transalpine (col du Théodule au sud, col d'Hérens au nord). Les archéologues y ont trouvé des vestiges lithiques en cristal de roche et en silex, associés à des foyers. Le site a sporadiquement 
été occupé comme bivouac, il a pu servir de gîte pour des bergers, pour la recherche de matières premières comme le quartz ou des roches vertes, ou pour la chasse (May 1987, Curdy et al. 2003). Ces différentes découvertes illustrent bien l'existence au Néolithique d'une part de plusieurs voies de passage transalpines, d'autre part de fréquentes occupations à tous les étages, et ce jusqu’à des altitudes élevées.

\section{Approche archéobotanique : cadre géographique et chronoculturel des sites étudiés}

Cette contribution considère les niveaux néolithiques de cinq sites des Alpes françaises du nord et de la haute vallée du Rhône en Suisse (fig. 3). Chaque site profite d'un cadre chronoculturel solide grâce à des datations radiocarbone et des études chronotypologiques du matériel lithique et céramique (fig. 4).

Fig. 3. - Localisation des sites étudiés dans les Alpes nord-occidentales.

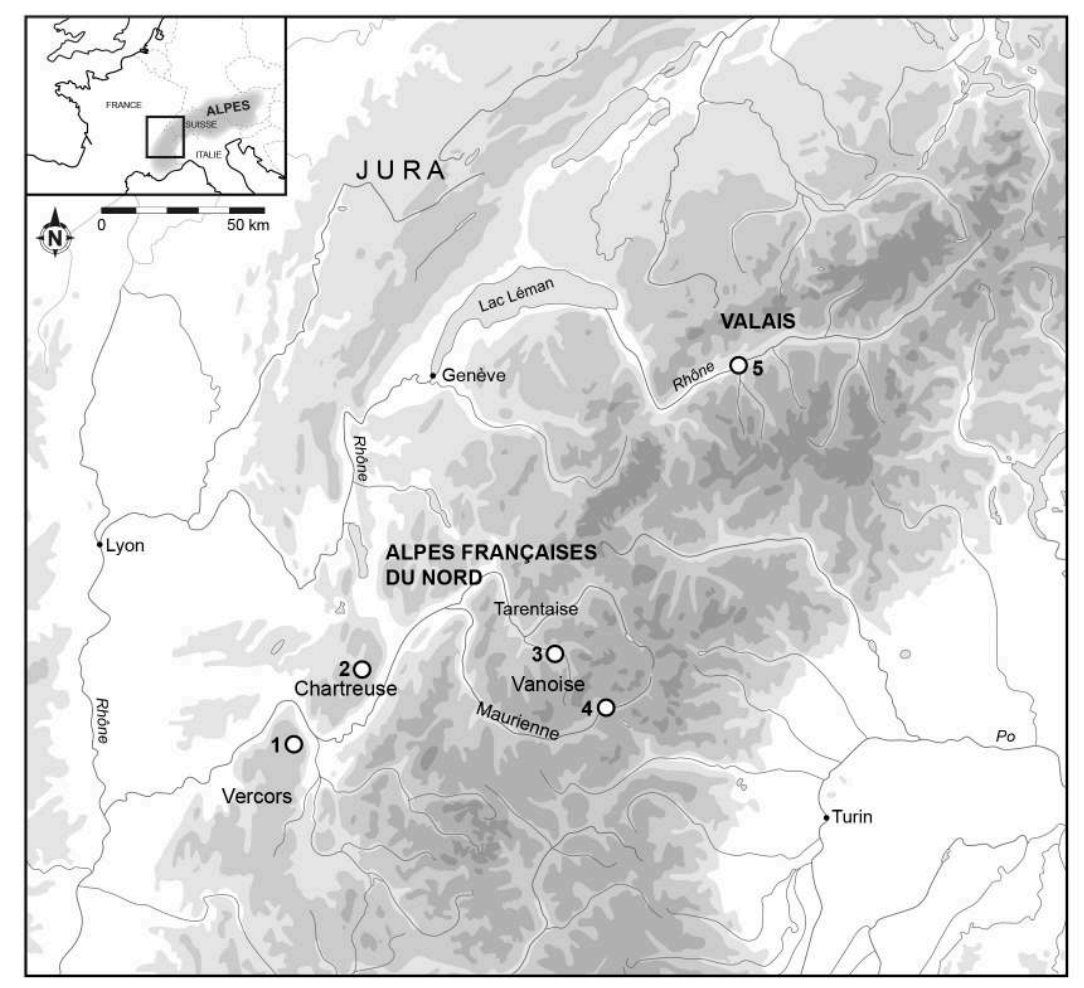

FRANCE : 1 : La Grande Rivoire (Sassenage, Isère). 2 : L'Aulp du Seuil (Saint-Bernard-du-Touvet, Isère). $\mathbf{3}$ : Le Chenet des Pierres (Bozel, Savoie). 4 : Les Balmes (Sollières-Sardières, Savoie). SuIsse : 5 : Le Petit-Chasseur IV (Sion, Valais).

PAO et cartographie Lucie Martin. 
Fig. 4. - Cadre chronoculturel des sites étudiés.

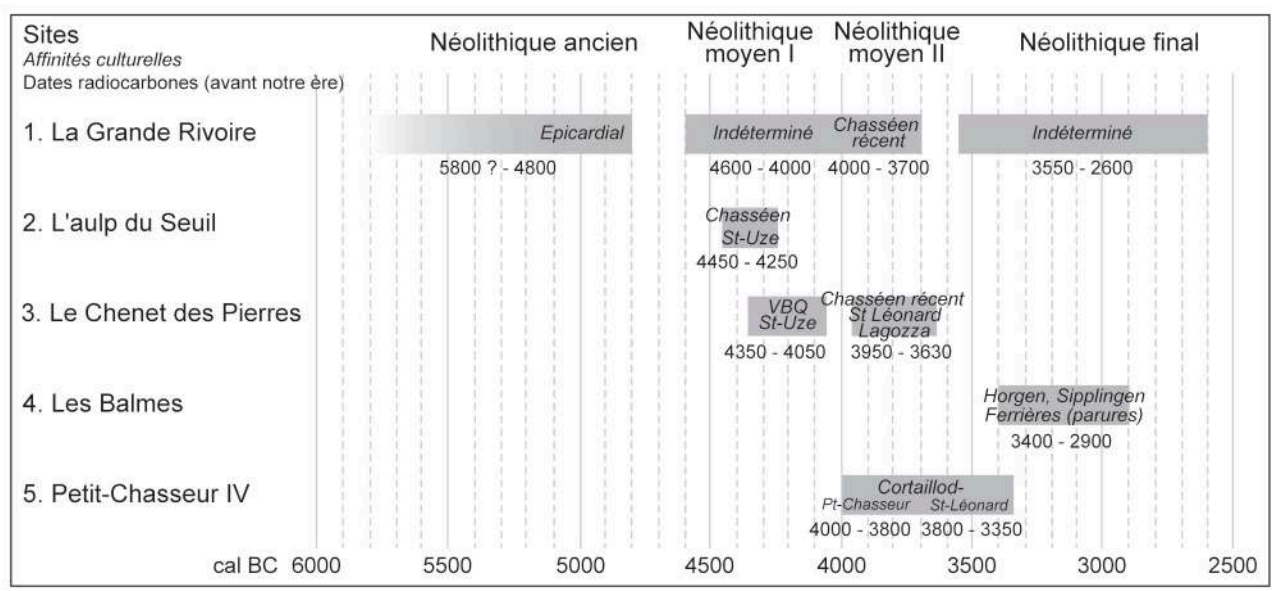

Les dates et ensembles culturels ne prennent en compte que les niveaux néolithiques qui ont fait l'objet d'analyses archéobotaniques. vBa : culture des Vasi a Boca Quadrata.

PAO Lucie Martin. Sources : 1, Nicod et al. 2010 ; 2 : Pelletier et al. 2000 ; 3 : Rey 2006 ; 4 : Vital 2012 ;

5 : Besse et Piguet 2011, Burri-Wyser et Jammet-Reynal 2014.

11 La Grande Rivoire est un abri-sous-roche localisé à 580 mètres d'altitude dans le nord du massif du Vercors (fig. 3, n ${ }^{\circ} 1$ ). Bien exposé au sud, au pied d'une falaise calcaire, le site se trouve actuellement entre l'étage collinéen, qui correspond à la série du chêne pubescent, ou "série delphino-jurassienne " (Ozenda 1985), et l'étage montagnard, dans la série mésophile du hêtre. Fouillé depuis 2000 par P. -Y. Nicod (université de Genève), le site de La Grande Rivoire présente une stratigraphie de cinq mètres d'épaisseur, qui couvre plusieurs millénaires d'occupation, du Mésolithique moyen à l'époque romaine. Une des séquences les plus intéressantes est celle du Néolithique, période pendant laquelle le site était utilisé comme bergerie. L'emploi de l'abri comme aire de parcage de petits ruminants a été mis en évidence par les études sédimentologiques (B. Moulin et J.-L. Brochier : Nicod et al. 2010) qui montrent dans les fractions fines la présence de sphérolites de calcite, des valeurs élevées en phosphate et de fortes teneurs en matière organique. Ces niveaux de bergerie sont une succession de couches de fumiers minéralisés, de cendres végétales, de fumiers brûlés et de faciès mixtes (Nicod et al. 2010). Parallèlement, l'étude archéobotanique (spores et pollen, phytolithes, charbons de bois et autres macrorestes végétaux) a permis de mettre en lumière la façon dont les bergers nourrissaient et soignaient leur bétail (Delhon et al. 2008, Martin 2011 et 2014).

Dans le massif de la Chartreuse, L'Aulp-du-Seuil est localisé à 1720 mètres d'altitude (fig. $3, n^{\circ} 2$ ), au sein de l'étage subalpin, dominé par des forêts clairsemées de pins à crochets. Le vallon de Marcieu, synclinal perché où se trouve le site, est composé en partie d'un chaos de gros blocs erratiques déposés lors du dernier retrait glaciaire. Les prospections archéologiques ont révélé de nombreuses occupations préhistoriques, dont six abris sous blocs et un site de plein air. Parmi eux, l'abri Alp1 a fait l'objet d'une fouille sous la direction de P. Bintz de 1993 à 1998 et de D. Pelletier de 1999 à 2005 (laboratoire ESEP, UMR 6636, Grenoble). Durant le Mésolithique et le Néolithique, L'Aulp-du-Seuil était une station résidentielle saisonnière, fréquemment occupée pour des activités cynégétiques. Sa fonction de halte de chasse est attestée par la présence au Néolithique ancien de très nombreuses armatures de flèches tranchantes et de restes osseux de faune sauvage (Pelletier et al. 2000, Pelletier 2005). Les données 
archéobotaniques proviennent des niveaux d'occupation datés du Néolithique moyen I (4400-4200 avant notre ère) (Martin et al. 2012, Martin 2014).

13 Le gisement du Chenet des Pierres se trouve dans la vallée de Bozel, entre le massif de la Vanoise et la vallée de la Tarentaise (fig. $3, \mathrm{n}^{\circ}$ 3). À près de 1000 mètres d'altitude, dans les Alpes internes, cet habitat de plein air est situé dans l'étage montagnard, au sein d'une hêtraie-sapinière. Le Chenet des Pierres comprend plusieurs occupations en terrasse, au milieu d'un chaos rocheux déposé lors du dernier retrait glaciaire. La fouille dirigée par P. -J. Rey entre 1999 et 2016 s'est concentrée principalement sur un secteur d'environ 30 mètres carrés, occupé au Néolithique moyen (4400-3600 avant notre ère). Les analyses archéobotaniques (charbons et autres macrorestes végétaux) sont en cours, mais les premiers résultats ont déjà livré un important spectre de restes végétaux cultivés et sauvages (Rey 2006, Martin et al. 2008, Martin 2014).

Les Balmes de Sollières-Sardières sont situées en haute Maurienne, à 1350 mètres d'altitude (fig. $3, \mathrm{n}^{\circ} 4$ ). Le site se trouve dans l'étage montagnard, qui correspond ici à la série intra-alpine de l'épicéa. Occupée entre le Néolithique final (3400-2900 avant notre ère) et l'âge du Bronze, cette grotte a été - comme La Grande Rivoire - utilisée comme bergerie. Les analyses archéobotaniques ont permis de mettre en évidence la présence de plusieurs stocks de céréales et de quelques plantes sauvages comestibles (Martin et Lundström-Baudais 2012, Thiébault 2012, Vital et Bennamour 2012, Martin 2014).

Dans les Alpes suisses, le site du Petit-Chasseur IV, localisé dans l'actuelle ville de Sion, en Valais, à 485 mètres d'altitude (fig. $3, \mathrm{n}^{\circ}$ 5), fait partie d'un vaste ensemble néolithique comprenant des habitats et plusieurs nécropoles mégalithiques exceptionnelles, fouillés entre 1961 et 2003 (Corboud et Curdy 2009, Mariéthoz 2009). L'habitat du Petit-Chasseur IV a été fouillé sous la direction de M. Besse en 1992 et 1993 (Besse et Piguet 2011). Les analyses archéobotaniques se sont principalement concentrées sur des échantillons provenant de fosses et de foyers issus de la couche 7 (Cortaillod type Petit-Chasseur, 4000-3800 avant notre ère), et en particulier de la " maison 3 ", et de la couche 6, légèrement antérieure (Cortaillod type Saint-Léonard, 3800-3350 avant notre ère) (Dufraisse 2011, Lundström-Baudais et Martin 2011).

\section{Matériel et méthode}

16 Les résultats présentés ici proviennent des analyses de vestiges botaniques issus de fouilles récentes sur lesquelles nous sommes directement intervenues (Grande Rivoire, Chenet des Pierres, Aulp-du-Seuil) et de fouilles plus anciennes (Petit-Chasseur IV, Les Balmes). Les protocoles d'échantillonnage et de traitement des restes archéobotaniques ont été respectés, en utilisant une maille minimum de $0,5 \mathrm{~mm}$ pour le tamisage à l'eau, excepté à L'Aulp-du-Seuil, où le sédiment a été préalablement tamisé à sec sur une maille de $6 \mathrm{~mm}$ (avant d'être à nouveau tamisé à l'eau selon le protocole), afin de réduire le volume des prélèvements, descendus en plaine à dos de mulet.

Les restes botaniques sont issus soit de couches d'habitat ou de niveaux de bergerie (fumiers fossiles), soit de structures telles que des foyers, des fosses ou des trous de poteaux (tabl. 1). 
Tabl. 1. - Description générale du matériel archéobotanique considéré pour chaque site.

\begin{tabular}{|c|c|c|c|c|c|}
\hline & La Grande Rivoire & $\begin{array}{l}\text { Le Chenet } \\
\text { des Pierres }\end{array}$ & Les Balmes & $\begin{array}{l}\text { L'Aulp- } \\
\text { du-Seuil }\end{array}$ & $\begin{array}{c}\text { Petit- } \\
\text { ChasseurIV }\end{array}$ \\
\hline $\begin{array}{l}\text { Sols/structures } \\
\text { échantillonnés }\end{array}$ & $\mathrm{FU}, \mathrm{OCC}, \mathrm{FOY}$ & OCC & $\begin{array}{c}1: \text { STO; } \\
2: \text { OCC, FU }\end{array}$ & OCC, FOY & FOY, FU \\
\hline $\begin{array}{l}\text { Nombre } \\
\text { d'échantillons } \\
\text { (éch.) et volume } \\
\text { total en litres (1.) }\end{array}$ & $\begin{array}{c}\text { Carpo.: } \\
65 \text { éch., 564.4L. } \\
\text { Anthraco.: } \\
\text { 37éch., 276 I. }\end{array}$ & $\begin{array}{l}38 \text { éch., } \\
3661 .\end{array}$ & $\begin{array}{l}\text { 1:5éch., env. } 5 \mathrm{I} \text {. } \\
\text { 2:10éch., } 520 \mathrm{I} \text {. }\end{array}$ & $\begin{array}{l}56 \text { éch., } \\
5971 .\end{array}$ & $\begin{array}{l}54 \text { éch., } \\
\text { env. } 150 \mathrm{I} .\end{array}$ \\
\hline \multicolumn{6}{|c|}{ Analyses carpologiques } \\
\hline $\begin{array}{l}\text { Céréales } \\
\text { (NR total) }\end{array}$ & 205 & 4227 & 87753 & 37 & 8225 \\
\hline $\begin{array}{l}\text { Céréale(s) } \\
\text { dominante(s), } \\
\text { en } \%\end{array}$ & $\begin{array}{c}\text { Cerealia }(72 \%) \\
\text { blé vêtu }(13 \%) \text {, blé } \\
\text { nu }(5 \%) \text {, orge }(5 \%)\end{array}$ & $\begin{array}{c}\text { Cerealia }(56,8 \%) \text {, } \\
\text { orge }(17,2 \%) \text {, } \\
\text { blé nu }(14 \%)\end{array}$ & $\begin{array}{c}\text { Engrain }(36,7 \%), \\
\text { orge }(13,9 \%) \\
\text { Cerealia }(12,8 \%)\end{array}$ & $\begin{array}{l}\text { Cerealia }(78,4 \%) \text {, } \\
\text { blé nu }(10,8 \%) \text {, } \\
\text { engrain }(8,1 \%)\end{array}$ & $\begin{array}{l}\text { Cerealia }(74,2 \%) \text {, } \\
\text { engrain }(15,2 \%)\end{array}$ \\
\hline $\begin{array}{l}\text { Autres plantes } \\
\text { cultivées (NR) }\end{array}$ & Non & $\begin{array}{l}\text { Pois cultivé (141), } \\
\text { pavot somnifère } \\
\text { (421) }\end{array}$ & Pois cultivé (3) & Non & Pois cultivé (2) \\
\hline $\begin{array}{l}\text { Taxons sauvages } \\
\text { (NR total) }\end{array}$ & 9071 & 2907 & 949 & 328 & 69 \\
\hline $\begin{array}{l}\text { Espèces } \\
\text { sauvages } \\
\text { dominantes }\end{array}$ & $\begin{array}{l}\text { Sapin, } \\
\text { if, sureau, } \\
\text { chénopode }\end{array}$ & $\begin{array}{l}\text { Chénopode, } \\
\text { sureau noisetier, } \\
\text { pin cembro, } \\
\text { vrillée faux-liseron, } \\
\text { ronce/framboise }\end{array}$ & $\begin{array}{l}\text { Renouée faux liseron, } \\
\text { sapin, noisetier, } \\
\text { raisin d'ours, } \\
\text { pin cembro }\end{array}$ & $\begin{array}{c}\text { Noisetier, } \\
\text { pin, } \\
\text { épiaire, } \\
\text { légumineuses }\end{array}$ & $\begin{array}{l}\text { Chénopode blanc, } \\
\text { uzerne, } \\
\text { lupuline }\end{array}$ \\
\hline $\begin{array}{l}\text { Rapport } \\
\text { cultivé/sauvage en } \%\end{array}$ & $2,2 / 97,8$ & $59,2 / 40,8$ & $98,9 / 1,1$ & $10,1 / 89,9$ & $99,2 / 0,8$ \\
\hline \multicolumn{6}{|c|}{ Analyses anthracologiques } \\
\hline $\begin{array}{l}\text { Nombre de } \\
\text { charbons identifiés } \\
\text { (nombre de taxons) }\end{array}$ & $\begin{array}{l}1730 \\
(32)\end{array}$ & $\begin{array}{l}1296 \\
(15)\end{array}$ & $\begin{array}{l}2571 \\
(16)\end{array}$ & $\begin{array}{l}1860 \\
(13)\end{array}$ & $\begin{array}{l}444 \\
(16)\end{array}$ \\
\hline $\begin{array}{l}\text { Espèces } \\
\text { dominantes } \\
\text { (soulignées > 50\%) }\end{array}$ & $\begin{array}{l}\text { If, chêne f. c., } \\
\text { noisetier, } \\
\text { frène }\end{array}$ & $\begin{array}{l}\text { Chênef. c., } \\
\text { frêne, } \\
\text { genévrier, pin, } \\
\text { bouleau }\end{array}$ & $\begin{array}{l}\frac{\text { Pin sylvestre, }}{\text { bouleau, }} \\
\text { épicéa/mélèze, } \\
\text { sapin }\end{array}$ & $\begin{array}{l}\text { Pin à crochet, } \\
\text { érable, } \\
\text { peuplier/saule, } \\
\text { aulne/bouleau }\end{array}$ & $\begin{array}{l}\text { Aulne blanc/glutineux, } \\
\text { pin sylvestrer } \\
\text { chênef. c. }\end{array}$ \\
\hline
\end{tabular}

FU : fumiers de bergerie. occ : couches d'occupation. For : foyer. sтo : concentration de céréales (stockage). Le nombre de restes (NR) est une estimation de restes entiers (comptage détaillé dans Martin 2010 : p. 75). Pour les périodes d'occupations concernées, se reporter à la fig. 3 . Résultat des analyses issus de Martin et al. 2008 et 2012, Dufraisse 2011, Lundström-Baudais et Martin 2011, Martin et Lundström-Baudais 2012, Thiébault 2012, Martin 2014.

Mis à part les premières fouilles des Balmes, le volume traité varie de 150 à presque 600 litres de sédiment. Pour l'ensemble des sites, les analyses carpologiques et anthracologiques proviennent des mêmes prélèvements et des mêmes structures. Le nombre de restes carpologiques est très variable d'un gisement à l'autre : un peu plus de 500 à L'Aulp-du-Seuil pour plusieurs dizaines de milliers aux Balmes. Cette variabilité dépend des conditions de conservation, de l'altitude, de la nature du sédiment, de l'utilisation du site et de sa durée de fréquentation, aspects qui ne seront pas détaillés ici, mais que le lecteur peut consulter dans la publication de chaque site (voir la légende du tableau 1).

19 Concernant la méthodologie, les macrorestes végétaux, hors charbons de bois, ont été identifiés avec une loupe binoculaire à grossissement $\times 6$ à $\times 40$, et avec l'aide de collections de référence: celle de L. Martin, à l'université de Genève, et celle du laboratoire d'archéobotanique de l'IPNA (Integrative Prähistorische und Naturwissenschaftliche Archäologie, université de Bâle, Suisse). La littérature spécialisée (atlas et catalogues) a été également utilisée (Anderberg 1994, Cappers et al. 2006). Les charbons de bois ont été identifiés sur la base de leur anatomie, observée au microscope à des grossissements de $\times 100$ à $\times 1000$, en utilisant également des collections de référence (collections du laboratoire AASPE, CNRS/MNHN, Paris et du CEPAM, CNRS/université de Nice), et des atlas d'anatomie (par exemple Schweingruber 1990). 


\section{Résultats et discussion}

\section{Résultats des analyses archéobotaniques}

20 Afin de montrer sur quels types d'assemblages les hypothèses d'exploitation du territoire sont fondées, les résultats archéobotaniques seront d'abord décrits de façon synthétique (tous ont fait l'objet d'une publication, au moins préliminaire). Tous les sites ont livré des plantes cultivées et des taxons sauvages, dans des proportions variables (tabl.1). Pour les céréales, souvent plus de la moitié, voire les trois quarts, n'ont pas pu être déterminées au niveau de l'espèce. Tous ces sites ont livré des restes carbonisés, dont la conservation est plus ou moins bonne. Parmi les céréales identifiées, trois dominent à cette époque : le blé nu (Triticum cestivum/durum/turgidum), le blé engrain (Triticum monococcum) et l'orge (Hordeum sp.). Ce dernier est souvent attesté sous sa forme nue, et parfois à six rangs (Hordeum vulgare var. nudum). Les autres plantes cultivées sont rares, mais on note la présence sur trois sites du pois cultivé (Pisum sativum) et celle du pavot somnifère (Papaver somniferum) au Chenet des Pierres. Les plantes sauvages sont nombreuses, largement majoritaires à La Grande Rivoire et à L'Aulp-du-Seuil, et très bien représentées au Chenet des Pierres ( $40 \%$ du corpus). Aux Balmes, il y a près de mille restes de plantes sauvages dans seulement dix échantillons, mais la surabondance de céréales les rend très minoritaires (1,1\%). Au Petit-Chasseur, bien que les céréales soient aussi surreprésentées (dans une seule fosse), il n'y a que 69 restes de taxons sauvages dans 54 échantillons. Sur tous les sites, des plantes rudérales très communes ont été identifiées, de type chénopode ou renouée (Chenopodium sp., Chenopodium album, Polygonum convolvulus); et uniquement dans les Alpes françaises du nord, des arbres et arbustes sous forme de fragments de coques de noisette, de pignons d'arolle, de graines d'if (Taxus baccata), de sureau (Sambucus sp.), de ronce ou de framboise (Rubus sp., R. idaeus) et de raisin d'ours (Arctostaphylos uva-ursi), et d'aiguilles de pin (Pinus sp.) et de sapin (Abies alba).

21 Concernant l'analyse des charbons de bois, entre 444 et 2571 charbons ont été identifiés, avec un nombre stable de taxons, entre 13 et 16 pour quatre sites, et jusqu'à 32 à La Grande Rivoire (tabl.1). Les principales espèces identifiées reflètent le plus souvent la végétation environnante de chaque occupation, selon l'étage dans lequel elle se trouve, mais pas toujours. Par exemple, au Chenet des Pierres, c'est le chêne caducifolié (Quercusf.c.), espèce de l'étage collinéen, qui domine, tandis que le gisement se trouve aujourd'hui au sein d'une hêtraie-sapinière de l'étage montagnard. Les conifères, courants dans le massif alpin, sont bien identifiés sur tous les sites: genévrier (Juniperus sp.), pin sylvestre et/ou à crochets, épicéa et/ou mélèze et sapin. Par ailleurs, les assemblages anthracologiques sont souvent complétés par des essences ripicoles appréciant l'humidité telles que le bouleau (Betula sp.), l'aulne blanc ou glutineux (Alnus incana/glutinosa), le frêne (Fraxinus excelsior), le peuplier et/ou le saule (Populus/Salix).

Les proportions des différentes espèces varient selon les sites : au Chenet des Pierres, il n'y a pas d'espèces prédominantes, aucun taxon ne dépassant les 30 à $35 \%$ des charbons identifiés dans les échantillons (Thiébault dans Martin et al. 2008), tout comme au Petit-Chasseur IV, avec une moyenne de $32 \%$ d'aulne, $23,9 \%$ de pin sylvestre et 12,6\% de chêne à feuillage caduc (Dufraisse 2011). À La Grande Rivoire, malgré une plus grande diversité de taxons, quatre espèces ressortent : l'if, le chêne, le noisetier et 
le frêne. En revanche, sur les deux sites les plus en altitude, une espèce domine largement : le pin de type sylvestre, qui représente, dans tous les échantillons, entre 70 et $90 \%$ des fragments aux Balmes et entre 73 et $99 \%$ à L'Aulp-du-Seuil, sauf dans un foyer où il n'atteint que 42,6\% (Thiébault et Delhon dans Martin et al. 2012, Thiébault 2012).

23 Cette présentation synthétique des résultats permet de discuter ci-dessous plusieurs exemples de mobilité verticale et d'occupation du territoire par les populations néolithiques alpines, sur la base des données archéologiques et archéobiologiques.

\section{La récolte des végétaux sauvages : un indicateur de l'étendue du territoire exploité}

Les cinq sites étudiés ont livré différentes espèces de végétaux sauvages, dont certaines sont comestibles et font potentiellement partie du spectre de cueillette à des fins alimentaires. Sous forme de graines et de fruits, la plupart des taxons identifiés sont attestés sur de nombreux sites néolithiques de la région, notamment sur les stations lacustres et palustres circum-alpines. Ces dernières, offrant des conditions anaérobies, ont livré de très grandes quantités de plantes sauvages de cueillette, parfois par dizaines de milliers de restes, conservés de manière exceptionnelle par imbibition (Jacomet 2006 et 2007). Il s'agit par exemple des noisettes, des glands de chêne, des baies de sureau, des framboises, des prunelles (Prunus spinosa), des pommes sauvages (Malus sylvestris), des poires sauvages (Pyrus pyraster) ou du raisin (Vitis vinifera subsp. sylvestris), pour ne citer que les plus courants. En revanche, la singularité des gisements alpins est l'exploitation de taxons montagnards et subalpins, comme les pignons d'arolle, les myrtilles ou les airelles rouges (Vaccinium myrtillus/vitis-idaea) et le raisin d'ours. La présence de ces taxons sur les sites étudiés montre que les populations des Alpes exploitaient un vaste territoire, de l'étage collinéen, avec le chêne, les pommes ou les prunelles, jusqu'à l'étage subalpin livrant les espèces mentionnées ci-dessus (fig. 5). 
Fig. 5. - Répartition altitudinale schématique des plantes récoltées sur les cinq sites mentionnés dans l'article sous forme de macrorestes végétaux, y compris les charbons de bois.

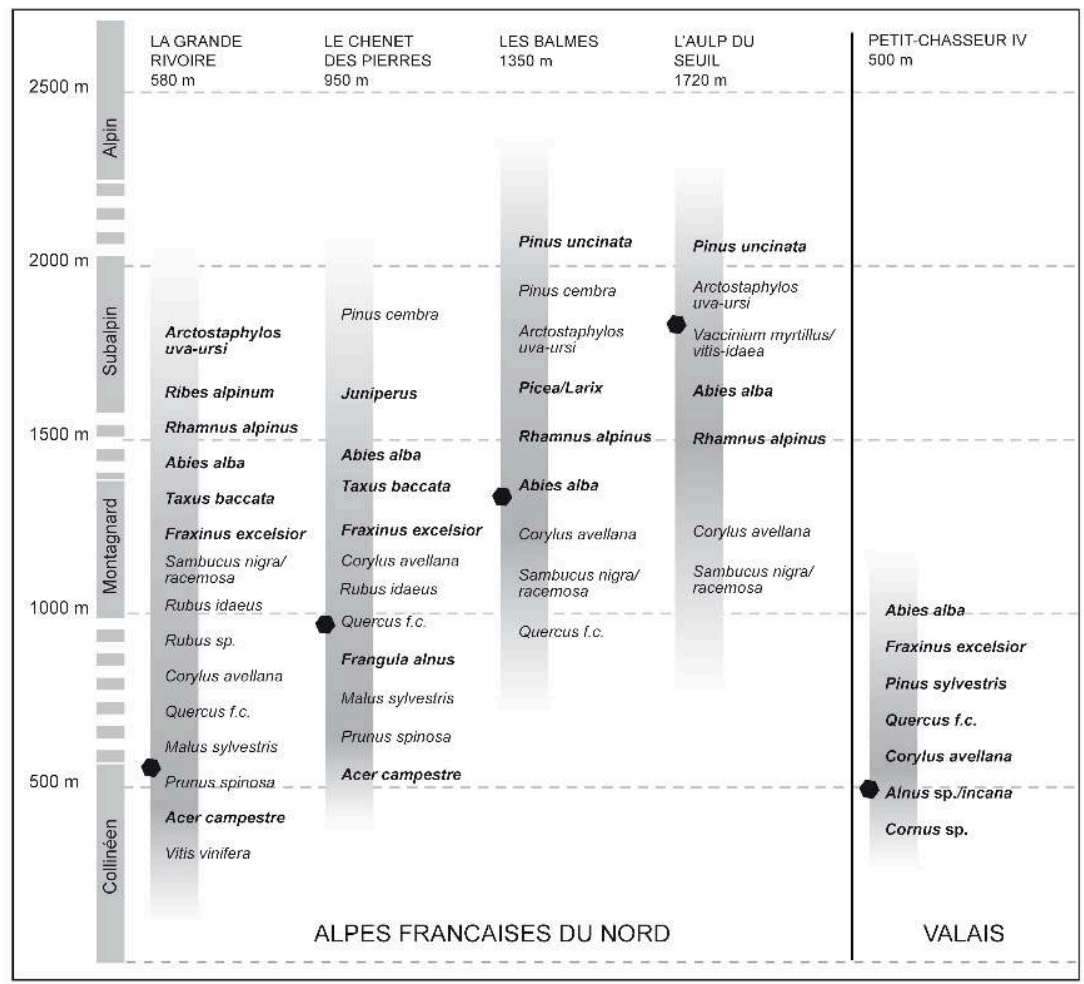

Les charbons sont figurés en gras ; les curseurs noirs indiquent la position des sites. Seuls les taxons ayant une répartition définie d'après Rameau et al. 1993 ont été pris en compte.

PAO Lucie Martin.

Les charbons de bois reflètent principalement la collecte de combustible, parfois de bois de construction, ainsi que de fourrage/litière dans certains cas, comme à La Grande Rivoire, et dans une moindre mesure aux Balmes. Les analyses anthracologiques permettent aussi d'appréhender l'étendue du territoire de récolte, par exemple sur des sites comme Le Petit-Chasseur IV, sur lequel les plantes de cueillette sont inexistantes dans les assemblages carpologiques. À La Grande Rivoire, de nombreuses espèces ligneuses de l'étage montagnard et subalpin, comme l'if, le sapin, le nerprun des Alpes ou le raisin d'ours, plaident en faveur de fréquentes visites des étages supérieurs (audessus des 580 mètres d'altitude) par les occupants (les bergers?). Dans les Alpes françaises du nord, les branchages d'arbres et d'arbustes étaient en général récoltés sur un vaste territoire, ce qui n'est pas le cas en Valais (fig. 5).

L'approvisionnement en bois de feu se fait aux abords immédiats du site, sans qu'il soit nécessaire de se rendre dans des zones ciblées où poussent des espèces particulières. Cette récolte peut rester locale, comme c'est le cas à L'Aulp-du-Seuil et aux Balmes : les abords immédiats des sites, et plus précisément les formations de pins, ont fourni la majeure partie du combustible. Dans les deux cas, il s'agit du pin, probablement du pin à crochets, espèce prédominante de nos jours autour des abris de L'Aulp-du-Seuil, en Chartreuse (série préalpine de Pinus uncinata, Ozenda 1985 : p. 219), et du pin sylvestre à la grotte des Balmes, en haute Maurienne (série xérophile de Pinus sylvestris, Ozenda 1985: p.193). Sur ces sites subalpins, il existe une complémentarité entre un approvisionnent massif et immédiat en combustible et bois de construction et des déplacements importants pour diverses activités (chasse, cueillette et recherche de 
matières premières), au cours desquels des ressources ligneuses complémentaires peuvent être collectées. À La Grande Rivoire et au Chenet des Pierres, les analyses anthracologiques indiquent une aire de récolte étendue entre l'étage collinéen/ montagnard (chêne, sureau, noisetier) et subalpin (arolle, pin à crochets), qui devait impliquer de plus longues distances à parcourir. La plus grande partie du bois de feu a pu être ramassée au cours de ces itinéraires journaliers (Carlstein 1981).

Cette gestion des ressources végétales sauvages n'est pas généralisable à l'ensemble des zones montagnardes. Par exemple, dans les gisements néolithiques pyrénéens situés entre 650 et 1790 mètres d'altitude, la carpologie enregistre une utilisation de taxons sauvages (présents dans $70 \%$ des échantillons) bien plus importante que dans les sites de plaine (seulement $20 \%$ des échantillons en contiennent). La cueillette des glands de chêne, des noisettes, des pommes/poires, fraises (Fragaria sp.) et ronces, y est nettement mieux représentée qu'à plus basse altitude, bien que ces taxons ne proviennent pas uniquement des étages montagnards et subalpins. Toutefois, cette importante utilisation des plantes sauvages ne permet pas de mesurer l'étendue du territoire de cueillette dans l'espace montagnard, à la différence des sites alpins (Antolín et Jacomet 2015, Antolín et al. 2018). En revanche, au nord des Alpes, les restes de plantes attestant l'exploitation des zones d'altitude sont présents de manière occasionnelle sur des sites de plaine. À Arbon Bleiche 3 (Thurgovie, Suisse), au bord du lac de Constance, au Néolithique final (Horgen, 3385-3370 avant notre ère), la présence de plusieurs taxons subalpins tels que l'arolle ou la véronique des Alpes (Veronica alpina) indique une fréquentation saisonnière des proches montagnes pour faire paitre le bétail en alpage ou pour la chasse (Hosch et Jacomet 2004). Ici encore, il est difficile d'extrapoler à partir de ces résultats un potentiel territoire de récolte. Ils montrent néanmoins une exploitation des zones d'altitude et illustrent l'existence, aussi bien dans les Pyrénées que dans les Alpes, de relations entre habitats de plaine et sites d'altitude.

\section{Les céréales : apportées ou cultivées en altitude?}

La présence de taxons cultivés contribue à mieux interpréter la fonction des sites et la place qu'ils occupent au sein du territoire montagnard, en permettant d'identifier de possibles cultures en altitude (Martin 2014). Toutefois, les données de l'archéobotanique ne permettent pas à elles seules d'établir si les occupants des sites alpins cultivaient à proximité de leur occupation ou s'ils apportaient les céréales depuis la plaine. Pour cela, plusieurs facteurs doivent être pris en compte :

- Les données carpologiques, et en particulier le spectre des céréales : quelles espèces sont identifiées? S'agit-il de vestiges isolés ou d'une concentration caractéristique d'un stockage, témoin d'une possible culture sur place? Les céréales sont-elles présentes sous forme de grains seuls ou avec leurs enveloppes, en épillets?

- La situation biogéographique du site: son emplacement est-il propice à la culture de céréales?

- Les données historiques et ethnographiques: pour des périodes plus récentes, leur utilisation fournit des indications sur les pratiques agricoles dans les régions qui nous intéressent, permettant ainsi de mieux interpréter les assemblages carpologiques.

Ainsi, sur certains sites, plusieurs indices suggèrent une culture de céréales autour des habitations, jusqu'à environ 1500 mètres d'altitude. Aux Balmes, de grandes quantités 
de blé engrain ont été découvertes (fig. 6), tout comme au Chenet des Pierres (Martin, inédit).

Fig. 6. - Blé engrain (Triticum monococcum) : dessins des restes provenant des Balmes de Sollières-Sardières, en Maurienne.

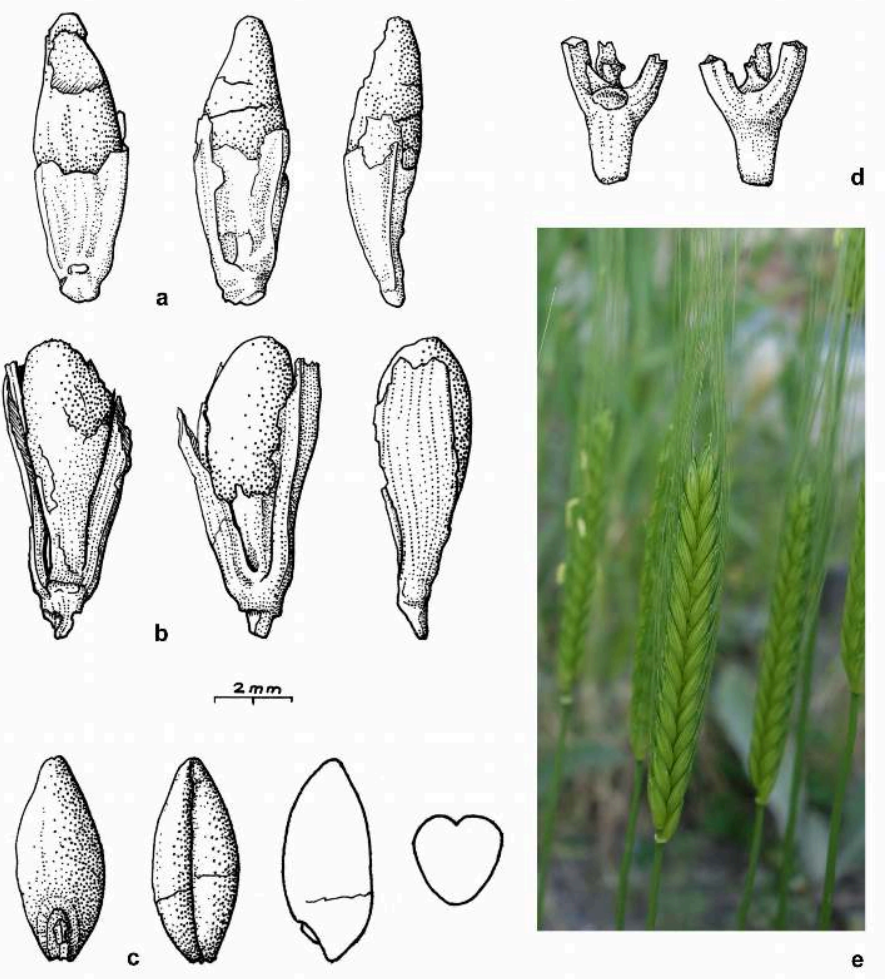

a et b : épillets ; c : caryopse ; d : base d'épillet ; e : engrain actuel.

Dessins Dominique Baudais, extraits de Martin et Lundström-Baudais 2012 : p. 243. Photo Lucie Martin.

Au Néolithique moyen et final - périodes d'occupation de ces deux sites alpins, entre 4400 et 3000 avant notre ère -, l'engrain est rare en plaine. Sur les nombreuses stations lacustres et palustres du plateau Suisse, qui constituent un très bon référentiel régional et dont les études archéobotaniques ont fait l'objet de plusieurs synthèses (par exemple Jacomet 2006 et 2007), cette céréale est toujours présente, mais avec un rôle d'abord secondaire sur les sites les plus anciens (4400-4300 avant notre ère), pour devenir tout à fait annexe par la suite. L'engrain est une céréale rustique, de petite taille (rarement plus de $70 \mathrm{~cm}$ de hauteur), qui supporte les sols pauvres, les terres sableuses et peu amendées, où d'autres espèces de blé se développent difficilement (Zohary et al. 2012). Les occupants de ces sites montagnards auraient choisi cette espèce pour sa rusticité, sa résistance aux hivers rigoureux et sa bonne adaptation au climat et à l'environnement alpin, et l'auraient cultivée en altitude, aux alentours des sites. En outre, cette céréale était stockée en épillets (fig. 6, a et b), de manière à mieux résister à l'humidité et aux attaques de rongeurs et des insectes. Le décorticage et la mouture se font donc plutôt au quotidien, au fur et à mesure des besoins. La découverte dans le même secteur d'une meule entière, très utilisée, conforte cette hypothèse (Thirault 2012).

La situation est différente à L'Aulp-du-Seuil : si peu de céréales ont été identifiées, elles sont malgré tout présentes sous forme de fragments de caryopses de blé engrain, de blé nu et d'orge. Ces céréales étaient sans doute apportées de la plaine, ou du moins depuis 
de plus basses altitudes. En Chartreuse, le climat, océanique et pluvieux (environ 2000 $\mathrm{mm} / \mathrm{an}$ ), est impropre à la culture de céréales. De plus, l'abri de L'Aulp-du-Seuil était occupé temporairement comme halte de chasse, ce qui est difficilement compatible avec des pratiques agricoles. La présence de ces plantes cultivées suggère plutôt une relation entre le site et des habitats permanents, ruraux, à basse altitude.

D'après des sources historiques et ethnographiques, les céréales peuvent être cultivées jusqu'à environ 1800 mètres, en particulier dans des vallées et massifs internes: certaines vallées ont un climat continental, qui autorise des cultures céréalières en altitude, comme la haute Durance et l'Ubaye, la haute Maurienne, où se situe la grotte des Balmes, ou le Valais, avec le site du Petit-Chasseur IV (Martin 2014 : p. 124, Niederer 1980, Dubuis 1990, Meilleur 2008).

\section{Un modèle d'exploitation montagnarde : l'exemple du Petit- Chasseur IV en Valais}

En Valais, les données archéobotaniques du Petit-Chasseur IV montrent une vision différente de l'exploitation du territoire et de la mobilité verticale par rapport aux quatre sites des Alpes françaises du nord. Les études anthracologiques indiquent l'exploitation d'un territoire centré principalement sur l'étage collinéen, avec une récolte de bois d'une part dans des forêts thermophiles de pins sylvestre et de chênes, et d'autre part dans des forêts alluviales à aulne blanc ou glutineux, frêne, peuplier ou saule (Dufraisse 2011). Cette stratégie bipolaire permettait d'exploiter de façon optimale les ressources de l'environnement tout en diversifiant la production. La présence de céréales reflète les pratiques agricoles autour du site, avec la prédominance du blé engrain, accompagné de blé amidonnier (Triticum dicoccum), de blé nu et d'orge. Dans cette vallée interne bénéficiant d'un climat continental propice à l'agriculture, les champs pouvaient être situés sur les cônes d'alluvions ou sur les replats en arrière des collines. La découverte d'une lame de houe en serpentinite illustre un travail manuel de la terre (Thirault et al. 2011). Parmi les taxons sauvages, des plantes adventices des cultures et des rudérales ont été identifiées, mais aucun taxon de cueillette (Lundström-Baudais et Martin 2011). Sur des sites plus anciens de la région sédunoise (Néolithique ancien et moyen 1, 5000-4200 avant notre ère), le constat est le même, avec une nette prédominance des plantes cultivées (blé nu, orge et pois) et de très rares plantes de cueillette représentées par quelques noisettes, des restes de poire, de pomme et de sureau (Martin 2015). Par exemple, 241 fragments de noisettes ont été identifiés sur plusieurs milliers de restes carpologiques provenant de cinq sites à Sion et Savièse (Martin 2015). C'est très peu, sachant que le noisetier est une essence très courante et que les coques de noisettes se conservent très bien et sont souvent surreprésentées par rapport à d'autres plantes cueillies.

Le croisement des données de la végétation actuelle (Werner 1988) et la végétation ancienne, d'après des analyses palynologiques réalisées à différentes altitudes (Rachoud-Schneider et Praz 2002, Tinner et Kaltenrieder 2005, Colombaroli et al. 2012, Thöle et al. 2015) a permis de proposer une reconstitution de la végétation de la région sédunoise au Néolithique. Les différentes espèces qui la composent permettent de localiser les territoires exploités par les habitants du Petit-Chasseur IV (fig. 7) : ils se situent principalement à l'étage collinéen et montagnard inférieur (forêts thermophiles et alluviales). 
Fig. 7. - Coupe schématique à travers la haute vallée du Rhône montrant les principales formations forestières telles qu'elles peuvent être évaluées au Néolithique moyen par l'archéobotanique, la palynologie et la végétation actuelle.

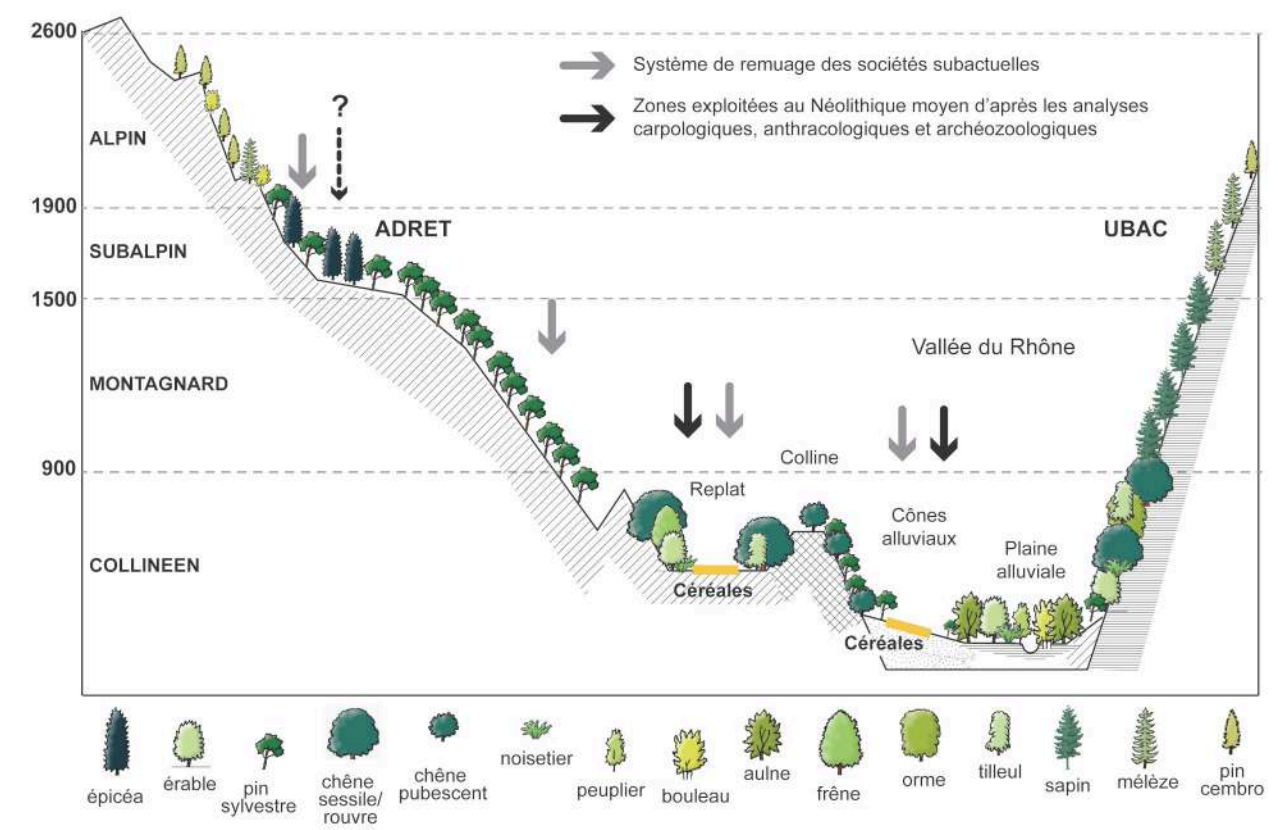

Les flèches noires indiquent les territoires exploités par les occupants du Petit-Chasseur IV au Néolithique moyen. Les flèches grises indiquent les quatre zones de production de contrôle vertical liées au système de remuage, tel qu'il a été décrit dans les sociétés subactuelles du Valais central.

PAO Alexa Dufraisse et Lucie Martin.

Les données archéozoologiques confirment l'hypothèse de l'absence d'exploitation des zones de moyenne ou de haute altitude, avec une forte prédominance des espèces domestiques, et la quasi-absence de gibier, notamment des espèces de montagne comme le bouquetin ou le chamois (Chiquet 2011). Les résultats obtenus au PetitChasseur font écho à ce qui a été décrit par L. Chaix à propos du Néolithique valaisan, à savoir une prééminence de l'élevage, en particulier du petit bétail (Chaix 2008). Cette prédilection pour les caprinés domestiques n'est pas un fait nouveau, puisqu'elle est attestée dès le Néolithique ancien; elle s'explique par la bonne adéquation de ces animaux à un environnement sec et montagnard. Au Petit-Chasseur, et sur d'autres sites néolithiques valaisans, la nette prédominance d'espèces domestiques végétales (céréales) et animales (mouton/chèvre), associée à l'absence ou quasi-absence de faune sauvage et d'espèces végétales de cueillette de moyenne et de haute altitude, montre que nous avons affaire à des communautés agropastorales dont l'économie de subsistance est principalement basée sur une agriculture pratiquée en plaine. Cela montre également que le système de remuage décrit plus haut (fig. 2), qui tend au contrôle vertical de quatre zones de production, ne semble pas encore être en place au Néolithique moyen. Cette stratégie bipolaire n'est peut-être qu'une première étape, où l'habitat se situerait entre deux niveaux d'exploitation, la plaine alluviale et les niveaux supérieurs. Dans un contexte similaire, un peu plus tardif, les analyses anthracologiques du site d'Airolo-Madrano "In Grop» (Tessin, Suisse) situé dans la vallée de la Lévantine, à 1175 mètres d'altitude et daté de l'âge du Bronze (1665-1422 
avant notre ère) indiquent une nette prédominance des aires d'approvisionnement situées vers les hauteurs (Dufraisse 2018).

Cela étant dit, en Valais, des indices de fréquentation néolithique existent toutefois en altitude, sur les glaciers et les cols assez proches du Petit-Chasseur, ainsi que dans de rares occupations comme le site d'Alp Hermettji (Zermatt, Valais, Suisse) : la poursuite des analyses sur d'autres sites contemporains permettra de préciser les modalités d'occupation de cette vallée alpine et peut-être le lien entre les nombreux habitats agricoles implantés en vallée du Rhône et les gisements d'altitude.

\section{Conclusion}

Cette contribution décrit une facette de la gestion du territoire montagnard durant le Néolithique et montre, avec ces quelques exemples, que les données archéobotaniques permettent d'aborder différents aspects comme l'économie des ressources végétales, la mobilité verticale et la place de ces sites au sein du territoire alpin :

- Les plantes récoltées pour l'alimentation humaine ou animale et le combustible identifient les différents étages de végétation fréquentés par les communautés alpines néolithiques dans les Alpes du nord ; le territoire exploité est vaste, de l'étage collinéen à l'étage subalpin (tabl.1), même lorsque le site se trouve à une altitude relativement basse (La Grande Rivoire) ; en Valais, l'économie végétale est limitée à l'étage collinéen/montagnard inférieur et à la plaine alluviale du Rhône, il n'y a guère d'indication d'exploitation des zones supérieures, que ce soit avec les données carpologiques, anthracologiques ou archéozoologiques,

- Les plantes cultivées, et en particulier les céréales, ont été semées et récoltées à proximité des sites, même en altitude (Le Chenet des Pierres, Les Balmes), ou apportées de la vallée (L'Aulp-du-Seuil), ce qui donne des indications sur la fonction des occupations et des contacts entre les communautés alpines et les établissements de plaine; la présence de céréales et leur culture in situ sont en lien direct avec le type de gisement et sa pérennité : les activités agricoles impliquent une occupation plus prolongée, et une occupation de courte durée ne permet, ni ne nécessite, une telle économie de production.

Ces observations montrent qu'il n'y a pas une dichotomie nette entre sites d'altitude occupés de manière saisonnière et habitats permanents en plaine. Un système probablement plus complexe, caractérisé par un ensemble de sites occupés pour différentes fonctions et de façon plus ou moins prolongée, même en altitude, existait dans les Alpes. C'est aussi le cas des Pyrénées : F. Antolín et ses collaborateurs ont bien démontré, grâce aux données couplées de l'archéobotanique et de l'archéozoologie, que les pratiques agricoles sont comparables entre sites d'altitude et de plaine, qu'une agriculture locale et des stratégies de subsistance à long terme (notamment de stockage) existent sur des sites montagnards (Antolín et al. 2018).

Ces travaux pionniers se poursuivent actuellement dans les Alpes occidentales et seront complétés par des approches bioarchéologiques couplées à la biogéochimie pour aborder les tendances alimentaires des populations humaines et de leurs troupeaux, les pratiques agraires et les questions de mobilité. Ce dernier point va de pair avec le pastoralisme, un élément clé de l'économie alpine dès le Néolithique, qui est mieux compris depuis quelques années grâce à l'étude approfondie de gisements utilisés comme bergeries au Néolithique et à l'âge du Bronze. Les études menées à La Grande 
Rivoire se sont révélées très positives pour aborder les questions d'alimentation du bétail et de mobilité (Delhon et al. 2008, Nicod et al. 2010). Des analyses archéobotaniques et pluridisciplinaires (archéozoologie, ADN sédimentaire, isotopes stables) sont en cours sur des contextes similaires, à la grotte Pertus II, à Méailles, dans les Alpes de Haute-Provence, dont l'analyse anthracologique a en partie déjà été réalisée (Battentier et al. 2016 et projet CoproArchéo « Apport de la bioarchéologie des dépôts coprogènes à la connaissance du pastoralisme Néolithique " porté par C. Delhon, financement CSI université de Nice - Sophia Antipolis).

Ces pistes de réflexion sont actuellement développées avec un jeu de données plus conséquent, afin d'affiner les comparaisons, en particulier du point de vue chronoculturel. En Valais, les études carpologiques et anthracologiques se poursuivent sur une dizaine de sites, en espérant à l'avenir préciser et repenser les modèles de peuplements existants et mieux comprendre les fonctionnements socioéconomiques des premières communautés agropastorales alpines.

\section{BIBLIOGRAPHIE}

ANDERBERG A. L., 1994, Atlas of seeds and small fruits of Northwest-European plant species with morphological descriptions, vol. 4 : Resedaceae - Umbelliferae, Uddevalla, Swedish Museum of Natural History.

ANTOLín F. et JACOMET S., 2015, « Wild fruit use among early farmers in the Neolithic (5400-2300 cal bc) in the north-east of the Iberian Peninsula: an intensive practice? », Vegetation History and Archaeobotany, vol. 24, p. 19-33.

ANTOLÍN F., NAVARRETE V., SAÑA M., VIÑERTA Á., GASSIOT E., 2018, « Herders in the mountains and farmers in the plains? A comparative evaluation of the archaeobiological record from Neolithic sites in the eastern Iberian Pyrenees and the southern lower lands ", Quaternary International, vol. 484, p. 75-93.

BATTENTIER J., LEPÈRE C., THÉRY-PARISOT I., CARRÉ A., DELHON C., 2016, « La grotte de Pertus II (Méailles, Alpes-de-Haute-Provence) : exploitation du couvert forestier au Chasséen récent (3850-3650 cal. BC) », dans Cauliez J., Sénépart I., Jallot L., Labriffe P.-A. de, Gilabert C., Gutherz X. (dir.), De la tombe au territoire et actualités de la recherche: actes des $11^{e}$ Rencontres méridionales de préhistoire récente, Montpellier, 25-27 septembre 2014, Toulouse, Archives d'écologie préhistorique, p. 223-232.

BAUDAIS D., CURDY P., DAVID-ELBIALI M., MAY O., 1987, « Prospection archéologique du Valais : une approche du peuplement préhistorique », Archéologie suisse, vol. 10, p. 2-12.

BAUDAIS D., CURDY P., DAVID-ELBIALI M., MAY O., 1990, « La néolithisation du Valais : modèles de peuplement et premier bilan de la prospection archéologique du Valais (Suisse) », dans Biagi P. (dir.), The neolithisation of the alpine region, Brescia, Museo Civico di Scienze Naturali di Brescia (Monografie di Natura Bresciana, 13), p. 159-174. 
BESSE M. et PIGUET M., 2011, Le site préhistorique du Petit-Chasseur à Sion (Valais, Suisse). 10 : Un hameau du Néolithique moyen, Lausanne, Office archéologique du Valais (Cahiers d'archéologie romande, 124 / Archaeologia Vallesiana, 6).

BINTZ P., MORIN A., PICAVET R., ARGANT J., BRESSY C., PELLETIER D., 2008, « Les fréquentations humaines de la montagne alpine au début de l'Holocène : l'exemple du Vercors et du Dévoluy ", dans Richard H. et Garcia D. (dir.), Le peuplement de l'arc alpin, Paris, Éditions du Comité des travaux historiques et scientifiques (Documents préhistoriques), p. 51-76.

BURRI-WYSER E. et JAMMET-REYNAL L., 2014, « La seconde partie du Néolithique moyen de Suisse occidentale (4000-3350 BC) : essai de synchronisation des cultures rhodaniennes et lacustres », dans Perrin T., Sénépart I., Leandri F., Cauliez J. (dir.), Chronologie de la préhistoire récente dans le sud de la France : acquis 1992-2012, actualités de la recherche. Actes des $10^{e}$ Rencontres méridionales de préhistoire récente, Porticcio, 2012, Toulouse, Archives d'écologie préhistorique, p. 75-86.

CABANAT A.-L., DAVID F., LATIL J.-L., PERRIER C., AUBERT S., 2017, « Vegetation cover changes during the last 7200 years at $2000 \mathrm{~m}$ in the Southwestern Alps (Lautaret Pass, France): A combined palynological and paleobotanical study ", Review of Palaeobotany and Palynology, vol. 246, p. 32-43.

CAPPERS R. T. J., BEKKER R. M., JANS J. E. A., 2006, Digital Seed Atlas of the Netherlands, Eelde, Barkhuis and Groningen University Library (Groningen Archaeological Studies, 4). DOI: 10.1017/ S0960258507708383.

CARLSTEIN T., 1981, Time resources society and ecology, Lund, Royal University of Lund, Department of Geography.

CHAIX L., 2008, «Les animaux domestiques dans les Alpes occidentales au Néolithique », dans Jospin J.-P. et Favrie T. (dir.), Premiers bergers des Alpes : de la Préhistoire à l'Antiquité, Gollion, Musée dauphinois/Infolio, p. 53-61.

CHIQUET P., 2011, « La faune du Petit-Chasseur à Sion (Valais) revisitée », dans Besse M. et Piguet M. (dir.), Le site préhistorique du Petit-Chasseur à Sion (Valais, Suisse). 10 : Un hameau du Néolithique moyen, Lausanne, Office archéologique du Valais (Cahiers d'archéologie romande, 124/ Archaeologia Vallesiana, 6), p. 217-254.

COLOMBAROLI D., BECKMANN M., VAN DER KNAAP O. W., CURDY P., TINNER W., 2012, « Changes in biodiversity and vegetation composition in the central Swiss Alps during the transition from pristine forest to first farming ", Diversity and Distributions, vol. 19, p. 157-170.

CORBOUd P. et CURDY P., 2009, Stèles préhistoriques : la nécropole préhistorique du Petit-Chasseur à Sion, Sion, Musées cantonaux du Valais.

CROTTI P., CURDY P., DAVID M., FARJON K., GALLAY A., PIGNAT G., STUDER J., WERMUS E., 1983, « Le territoire des sites du Néolithique moyen valaisan (Suisse) », dans Le peuplement de l'intérieur du Massif alpin de la Préhistoire à la fin de l'Antiquité, Aoste, Société de recherches et d'études préhistoriques alpines (Bulletin d'études préhistoriques alpines, $\mathrm{n}^{\circ}$ spécial XV), p. 56-80.

CURDY P., LEUZINGER-PICCAND C., LEUZINGER U., 2003, « Zermatt Alp Hermettji et les cols secondaires du Valais ", dans Besse M., Stahl Gretsch L.-I. et Curdy P. (dir.), ConstellaSion, Lausanne, Musée cantonal d'archéologie et d'histoire (Cahiers d'archéologie romande, 95), p. 73-88.

DELHON C., MARTIN L., ARGANT J., THIÉBAULT S., 2008, « Shepherds and plants in the Alps: Multi-proxy archaeobotanical analysis of neolithic dung from La Grande Rivoire (Isère, France) », Journal of Archaeological Science, vol. 35, p. 2937-2952. 
DUBUIS P., 1990, « Une économie alpine à la fin du Moyen Âge : Orsières, l'Entremont et les régions voisines, 1250-1500», Sion, Archives cantonales (Cahiers de Vallesia, 1).

DUFRAISSE A., 2011, « La composition des boisements et gestion du bois dans l'habitat néolithique moyen du Petit-Chasseur (Sion, Valais) », dans Besse M. et Piguet M. (dir.), Le site préhistorique du Petit-Chasseur à Sion (Valais, Suisse). 10 : Un hameau du Néolithique moyen, Lausanne, Office archéologique du Valais (Cahiers d'archéologie romande, 124/Archaeologia Vallesiana, 6), p. 269-278.

DUFRAISSE A., 2018, «Woodland Exploitation and Management in the Montane and Subalpine Zones of the Leventina Valley in the Bronze and Iron Ages ", dans Della Casa P. (dir.), The Leventina Prehistoric Landscape (Alpine Ticino Valley, Switzerland), Zurich, Chronos Verlag (Zurich Studies in Archaeology, 12), p. 191-206.

GALLAY A., 1983, De la chasse à l'économie de production en Valais : un bilan et un programme de recherche, Genève, Université de Genève (Documents du département d'anthropologie, 7).

HAFNER A. et SCHWÖRER C., 2018, « Vertical mobility around the high-alpine Schnidejoch Pass: Indications of Neolithic and Bronze Age pastoralism in the Swiss Alps from paleoecological and archaeological sources ", Quaternary International, vol. 484, p. 3-18.

HOSCH S. et JACOMET S., 2004, « Ackerbau und Sammelwirschaft: Ergebnisse der Untersuchund von Samen und Früchten », dans Jacomet S., Leuzinger U., Schibler J. (dir.), Die jungsteinzeitliche Seeufersiedlung Arbon Bleiche, T. 3 : Umwelt und Wirtschaft, Frauenfeld, [s.n.] (Umwelt und Wirtschaft Archäologie im Thurgau, 12), p. 112-157.

JACOMET S., 2006, «Plant economy of the northern Alpine lake dwellings, 3500-2400 cal. BC », dans Karg S., Baumeister R., Robinson D. E., Schlichtherle H. (dir.), Economic and environmental changes during the 4th and 3rd millenia BC, Sheffield, Association for Environmental Archaeology (Environmental Archaeology, vol. 11, n 1), p. 65-85.

JACOMET S., 2007, « Neolithic plant economies in the northern Alpine Foreland from 5500-3500 cal BC », dans Colledge S. et Conolly J. (dir.), The origins and spread of domestic plants in Southwest Asia and Europe, Londres, Institute of Archaeology, University College London/Left Coast Press, p. 221-258.

LUNDSTRÖM-BAUDAIS K. et MARTIN L., 2011, « Les paléosemences des fosses néolithiques du PetitChasseur IV », dans Besse M. et Piguet M. (dir.), Le site préhistorique du Petit-Chasseur à Sion (Valais, Suisse). 10 : Un hameau du Néolithique moyen, Lausanne, Office archéologique du Valais (Cahiers d'archéologie romande, 124/Archaeologia Vallesiana, 6), p. 261-267.

MARGUET A., BINTZ P., NICOD P.-Y., PICAVET R., REY P.-J., THIRAULT E., 2008, « Éléments pour une histoire du peuplement nord-alpin français entre 10000 et 2700 BP », dans Magny M., Desmet M., Mocci F. (dir.), Dynamique holocène de l'environnement dans le Jura et les Alpes : du climat à l'homme, Le Bourgetdu-Lac, Université de Savoie (Edytem, 6, Cahiers de paléoenvironnement), p. 225-252.

MARIÉTHOZ F., 2009, Les saisons du Petit-Chasseur, Sion, Sedunum Nostrum.

MARTIN L., 2010, « Agriculture et alimentation végétale en milieu montagnard au Néolithique : nouvelles données carpologiques dans les Alpes françaises du nord ", thèse de doctorat, Université Paris I - Panthéon-Sorbonne et université de Bâle.

MARTIN L., 2011, « Une bergerie néolithique dans le Vercors : analyse des macro-restes végétaux des "fumiers" fossiles de la Grande Rivoire (Isère, France) ", dans Wiethold J. (dir.), Carpologia : articles réunis à la mémoire de Karen Lundström-Baudais, Glux-en-Glenne, Centre archéologique européen (Bibracte, 20), p. 27-38. 
MARTIN L., 2014, Premiers paysans des Alpes : alimentation végétale et agriculture au Néolithique, Rennes, Presses universitaires de Rennes / Tours, Presses universitaires François-Rabelais.

MARTIN L., 2015, « Plant economy and territory exploitation in the Alps during the Neolithic (5000-4200 cal bc): first results of archaeobotanical studies in the Valais (Switzerland)», Vegetation History and Archaeobotany, vol. 24, p. 63-73.

MARTIN L. et LUNDSTRÖM-BAUDAIS K., 2012, « Analyses carpologiques : agriculture et alimentation végétale », dans Vital J. et Bennamour P. (dir.), Économies, sociétés et espaces en Alpe : la grotte des Balmes à Sollières-Sardières (Savoie), du Néolithique moyen 2 à l'âge du Fer, Lyon, Alpara (Documents d'archéologie en Rhône-Alpes et en Auvergne), p. 233-245.

MARTIN L., JACOMET S., THIÉBAULT S., 2008, «Plant economy during the Neolithic in a mountain context: the case of "Le Chenet des Pierres" in the French Alps (Bozel-Savoie, France) », Vegetation History and Archaeobotany, vol. 17, p. 113-122.

MARTIN L., DELHON C., THIÉBAULT S., PELLETIER D., 2012, « Plant exploitation and diet in altitude from Mesolithic to Neolithic: Archaeobotanical analysis from a hunting camp in the Chartreuse massif (Isère, France) », Review of Palaeobotany and Palynology, vol. 185, p. 26-34.

MAY O., 1985, «Économie et milieu montagnard dans le Valais Néolithique : essai de méthode comparative ethnoarchéologique et historique ", mémoire de diplôme, université de Genève, département d'anthropologie.

MAY O., 1987, «Zermatt VS, abri d'Alp Hermettji : un site néolithique à $2600 \mathrm{~m}$ d'altitude », Annuaire de la Société suisse de préhistoire et d'archéologie, vol. 70, p. 173-175.

MEILLEUR B., 2008, Terres de Vanoise : agriculture en montagne savoyarde, Grenoble, musée Dauphinois. MEVEL L., 2013, « Magdalenian pioneers in the northern French Alps, 17000 cal BP », Antiquity, vol. 87, p. 384-404.

NICOD P.-Y., PICAVET R., ARGANT J., BROCHIER J.-L., CHAIX L., DELHON C., MARTIN L., MOULIN B., SORDOILLET D., THIÉBAULT S., 2010, « Une économie pastorale dans le nord du Vercors : analyse pluridisciplinaire des "fumiers" néolithiques et protohistoriques de la Grande Rivoire (Sassenage, Isère) », dans Beeching A., Thirault E., Vital J. (dir.), Économie et société à la fin de la préhistoire, Lyon, Maison de l'Orient et de la Méditerranée (Documents d'archéologie en Rhône-Alpes et Auvergne, 34), p. 69-86.

NIEDERER A., 1980, «Économie et forme de vie traditionnelle dans les Alpes », dans Guichonnet P. (dir.), Histoire et civilisation des Alpes, destin humain, vol. 2, Lausanne/Toulouse, Payot/Privat, p. 8-76.

OZENDA P., 1985, La végétation de la chaîne alpine dans l'espace montagnard européen, Paris, Masson.

PELLETIER D., 2005, « Fouille programmée de l'abri n 1 (ALP 1) de l'Aulp du Seuil à Saint-Bernarddu-Touvet (Isère) », fouille programmée plurinannuelle (2003-2005), rapport intermédiaire, Lyon, Service régional de l'archéologie Rhône-Alpes.

PelLetier D., NATON H.-G., ARGANT J., Chaix L., thiÉBAult S., BRESSy C., COUSSERAN S., BRISOTTO V., 2000, « L'abri n ${ }^{\circ} 1$ de L'Aulp-du-Seuil (Isère, Chartreuse, Saint-Bernard-du-Touvet) : synthèse des résultats préliminaires et discussion sur les modalités d'exploitation territoriale au Mésolithique et au Néolithique ancien ", dans Tillet T. (dir.), Les Paléoalpins : hommage à Pierre Bintz, Grenoble, université Joseph-Fourier (Géologie alpine, numéro hors série 31), p. 165-177. 
RACHOUD-SCHNEIDER A.-M. et PRAZ J.-C., 2002, « Le climat et la végétation : l'exemple de la vallée du Rhône ", dans Curdy P. et Praz J.-C. (dir.), Premiers hommes dans les Alpes : de 50000 à 5000 avant Jésus-Christ, Sion/Lausanne, Musées cantonaux du Valais/Payot, p. 19-37.

RAMEAU J.-C., MANSION D., DUMÉ G., 1993, Flore forestière française, vol. 2 : Montagnes, Paris, Institut pour le développement forestier.

REY P.-J., 2006, « Le site du Chenet des Pierres aux Moulins de Bozel (Savoie, France) : une nouvelle séquence néolithique alpine ", dans Alpis Graia : archéologie sans frontières au col du PetitSaint-Bernard, séminaire de clôture, projet Interreg IIIA Alcotra 2000-2006 France-Italie, Aoste, 2-4 mars 2006, La Thuile, commune de La Thuile / SIVOM de haute Tarentaise et région autonome de la Vallée d'Aoste, p. 361-370.

REY P.-J., 2015, « Archéologie du massif des Bauges du Néolithique à l'âge du Bronze », Les Dossiers du musée Savoisien, vol. 1, revue numérique.

Rey P.-J., BATIGNe-VAllet C., COLLOMBet J., Delhon C., MARTin L., MOULin B., OBERLiN C., POULENARD J., ROBIN V., THIÉBAULT S., TREFFORT J.-M., 2014, « Approche d'un territoire de montagne : occupations humaines et contexte pédo-sédimentaire des versants du col du Petit-Saint-Bernard, de la Préhistoire à l'Antiquité ", dans Sénépart I., Billard C., Bostyn F., Praud I., Thirault E. (dir.), Méthodologie des recherches de terrain sur la préhistoire récente en France : nouveaux acquis, nouveaux outils, 1987-2012 : actes des premières Rencontres Nord-Sud de préhistoire récente, Toulouse, Archives d'écologie préhistorique, p. 73-90.

SCHWEINGRUBER F. H., 1990, Microscopic Wood Anatomy: Structural variability of stems and twigs in recent and subfossil woods from Central Europe, $3^{\mathrm{e}}$ éd., Birmensdorf, Eidgenössische Forschungsanstalt WSL.

SCHWÖRER C., COLOMBAROLI D., KALTENRIEDER P., REY F., TINNER W., 2015, « Early human impact (5000-3000 BC) affects mountain forest dynamics in the Alps », Journal of Ecology, vol. 103, p. 281-295.

SPINDLER K., 1994, The Man in the Ice, Londres, Weidenfeld and Nicolson.

THEURILlAT J.-P., FELBER F., GEISSLER P., GOBAT J.-M., FIERZ M., FISCHLIN A., KÜPFER P., SCHLÜSSEL A., VELLUTI C., ZHAO G.-F., 1998, « Sensitivity of plant and soil ecosystems of the Alps to climate change ", dans Cebon P., Dahinden U., Davies H. C., Imboden D., Jäger C. C. (dir.), Views from the Alps: regional perspectives on climate change, Londres, MIT Press, p. 225-308.

THIÉBAULt S., 2012, « Résultats de l'analyse anthracologique », dans Vital J. et Bennamour P. (dir.), Économies, sociétés et espaces en Alpe : la grotte des Balmes à Sollières-Sardières (Savoie), du Néolithique moyen 2 à l'âge du Fer, Lyon, Alpara (Documents d'archéologie en Rhône-Alpes et en Auvergne), p. 65-66.

THIRAUlT E., 2012, «L'industrie lithique du Néolithique moyen 2 NM2 (NF) », dans Vital J. et Bennamour P. (dir.), Économies, sociétés et espaces en Alpe : la grotte des Balmes à Sollières-Sardières (Savoie), du Néolithique moyen 2 à l'âge du Fer, Lyon, Alpara (Documents d'archéologie en RhôneAlpes et en Auvergne), p. 70-72.

THIRAULT E., 2014, « Trois décennies de terrain en préhistoire récente dans les Alpes françaises : pratiques, acteurs, perspectives ", dans Sénépart I., Billard C., Bostyn F., Praud I., Thirault E. (dir.), Méthodologie des recherches de terrain sur la préhistoire récente en France, nouveaux acquis, nouveaux outils, 1987-2012 : actes des premières Rencontres Nord-Sud de préhistoire récente, Toulouse, Archives d'écologie préhistorique, p. 377-393.

THIRAULT E. et SANTALLIER D., VÉRA R., 2011, « Le petit mobilier en pierre du site du Petit-Chasseur (Sion, Valais) ", dans Besse M. et Piguet M. (dir.), Le site préhistorique du Petit-Chasseur à Sion (Valais, 
Suisse). 10 : Un hameau du Néolithique moyen, Lausanne, office archéologique du Valais (Cahiers d'archéologie romande, 124/Archaeologia Vallesiana, 6), p. 183-191.

THÖLE L., SCHWÖRER C., COLOMBAROLI D., GOBET E., KALTENRIEDER P., VAN LEEUWEN J., TINNER W., 2015, « Reconstruction of Holocene vegetation dynamics at Lac de Bretaye, a high-mountain lake in the Swiss Alps », The Holocene, vol. 26, p. 380-396.

TINNER W., 2007, « Plant Macrofossil Methods and Studies: Treeline Studies », dans Elias S. A. (dir.), Encyclopedia of Quaternary Science, Oxford, Elsevier, vol. 3, p. 2374-2384.

TINNER W. et KALTENRIEDER P., 2005, « Rapid responses of high-mountain vegetation to early Holocene environmental changes in the Swiss Alps », Journal of Ecology, vol. 93, p. 936-947.

VITAL J. et BENNAMOUR P., 2012, Économies, sociétés et espaces en Alpe : la grotte des Balmes à SollièresSardières (Savoie), du Néolithique moyen 2 à l'âge du Fer, Lyon, Alpara (Documents d'archéologie en Rhône-Alpes et en Auvergne).

WERNER P., 1988, La flore, Martigny, Pillet (Connaître la nature en Valais).

ZOHARY D., HOPF M., WEISS E., 2012, Domestication of plants in the Old World: The origin and spread of cultivated plants in West Asia, Europe, and the Mediterranean Basin, $4^{\mathrm{e}}$ éd., Oxford, Oxford University Press.

\section{RÉSUMÉS}

$\mathrm{Au}$ Néolithique, les montagnes sont exploitées pour leurs ressources minérales, cynégétiques et pastorales. À partir de 5500 ans avant notre ère, les premières communautés agropastorales atteignent les Alpes depuis le nord de l'Italie et la vallée du Rhône et s'établissent dans les massifs subalpins comme dans les Alpes internes. Les études archéobotaniques (analyse des macrorestes végétaux, principalement des graines, des fruits et des charbons de bois) permettent de comprendre l'économie végétale de ces communautés néolithiques : quelles espèces, sauvages ou cultivées, étaient récoltées pour le fourrage, pour construire, se nourrir, se soigner, se chauffer? Les données de cinq sites néolithiques nous indiquent les différentes façons dont ces populations ont exploité leur territoire en tirant profit des ressources de divers biotopes, de l'étage collinéen à l'étage alpin, contribuant ainsi à mieux comprendre la mobilité verticale au Néolithique en contexte alpin.

During the Neolithic, mountains were exploited for their mineral, hunting and pastoral resources. The first agro-pastoral communities reached the Alps from Northern Italy and the Rhone valley and settled in the subalpine massifs and in the internal Alps. Archeobotanical studies (plant macroremains and charcoal analysis) conducted at five sites allow us to understand the plant economy of these Neolithic communities: they determine which crops were cultivated, used as fodder, or gathered for consumption, medicine or other purpose, such as firewood. In the present paper, we support that the use of plant resources and the exploitation of territory are very different for the same period from one region to another, depending on the activities carried out at each site but also on cultural backgrounds. Archeobotanical data indicate how these people took resources from various plant associations growing from the colline to the subalpine level, and thus contribute to the understanding of vertical mobility in alpine contexts. 
INDEX

Mots-clés : anthracologie, archéobotanique, carpologie, cueillette, Néolithique

Keywords : archaeobotany, carpology, charcoal analysis, gathered plants, vertical mobility, Neolithic

Index géographique: Alpes

\section{AUTEURS}

\section{LUCIE MARTIN}

Laboratoire d'archéologie préhistorique et anthropologie (département F. -A. Forel des sciences de l'environnement et de l'eau, Université de Genève), laboratoire Environnements, dynamiques et territoires de la montagne (Edytem, UMR 5204, université Savoie - Mont-Blanc/CNRS)

\section{CLAIRE DELHON}

Laboratoire Culture et environnements : préhistoire, Antiquité, Moyen Âge (CEPAM, UMR 7264, université Provence - Alpes - Côte d'Azur/CNRS)

\section{ALEXA DUFRAISSE}

Laboratoire Archéozoologie, archéobotanique : sociétés, pratiques et environnements (AASPE, UMR 7209, Muséum national d'histoire naturelle/CNRS)

\section{STÉPHANIE THIÉBAULT}

Laboratoire Archéozoologie, archéobotanique : sociétés, pratiques et environnements (AASPE, UMR 7209, Muséum national d'histoire naturelle/CNRS)

\section{MARIE BESSE}

Laboratoire d'archéologie préhistorique et anthropologie (département F. -A. Forel des sciences de l'environnement et de l'eau, Université de Genève) 


\section{Économie animale et territoire au} Néolithique dans les Alpes occidentales : un même son de cloche? Les sites de La Grande Rivoire (Sassenage, Isère, France), Le Chenet des Pierres (Bozel, Savoie, France) et La Soie (Savièse, Valais, Suisse)

Animal management and territory in the Neolithic in the Western Alps: same story? La Grande Rivoire (Sassenage, Isère, France), Le Chenet des Pierres (Bozel, Savoie, France) et La Soie (Savièse, Valais, Suisse).

Patricia Chiquet

Cet article présente les premiers résultats d'un projet financé par le Fonds national suisse (projet $n^{\circ}$ PMPDP1_173551/1) et intitulé "Aux origines du pastoralisme alpin : nouvelles recherches sur les productions animales et la gestion des troupeaux dans les Alpes valaisannes et les Alpes françaises du Nord au Néolithique ». Je remercie le Muséum d'histoire naturelle et l'université de Genève, les musées cantonaux et le service cantonal d'Archéologie du Valais ainsi que PierreYves Nicod, Jacqueline Studer, Marie Besse, Pierre-Jérôme Rey et Dominique Baudais, pour leur aide et le soutien apporté à ce projet.

« Ils se tenaient dans le silence devant cet arrangement qui est fait depuis toujours, devant ces choses bien trop grandes et auxquelles plus rien ne change, devant ce qui ne change pas, qui est l'arrangement d'ensemble ; l'ordre à l'arbre 
d'être plus bas que l'herbe, à l'herbe d'être audessus de l'arbre, aux rochers d'être au-dessus de

l'herbe, et aux neiges et à la glace d'être pardessus le rocher ; eux là-devant, devant ce qui est

commandé, mais eux aussi sont commandés. »

(Charles Ferdinand Ramuz, La Séparation des

races.)

1 L'appropriation de la montagne par les premiers paysans néolithiques a très tôt suscité des interrogations quant à la nature des relations qui se sont établies entre l'homme et l'animal dans ce milieu contrasté. Différents modèles socio-économiques ont été proposés pour expliquer les systèmes pastoraux et l'exploitation des territoires au cours du Néolithique dans les Alpes occidentales (Crotti et al. 1983, Baudais et al. 1987, Beeching et al. 2000).

2 C'est dans la perspective d'approfondir notre connaissance de l'économie animale alpine au Néolithique et d'appréhender plus finement l'organisation de l'élevage dans le temps et l'espace (alimentation, productions, saison des naissances, territoires pastoraux, etc.) que nous avons entrepris un projet de recherche financé par le Fonds national suisse de la recherche scientifique (FNS), dont les premiers résultats sont présentés ici. Cette recherche est basée sur l'analyse des restes osseux d'animaux de plusieurs sites archéologiques datés du Néolithique (5 500-2 200 av. J.-C.) et localisés dans deux secteurs des Alpes occidentales, d'une part dans la haute vallée du Rhône, qui correspond ici au canton suisse du Valais, d'autre part dans le bassin de l'Isère, localisé dans les Alpes françaises du nord (fig. 1). 
Fig. 1. - Localisation des sites intégrés au projet FNS avec, en blanc, les trois sites présentés dans l'article : La Soie (Savièse, Valais, Suisse), Le Chenet des Pierres (Bozel, Savoie), La Grande Rivoire (Sassenage, Isère).

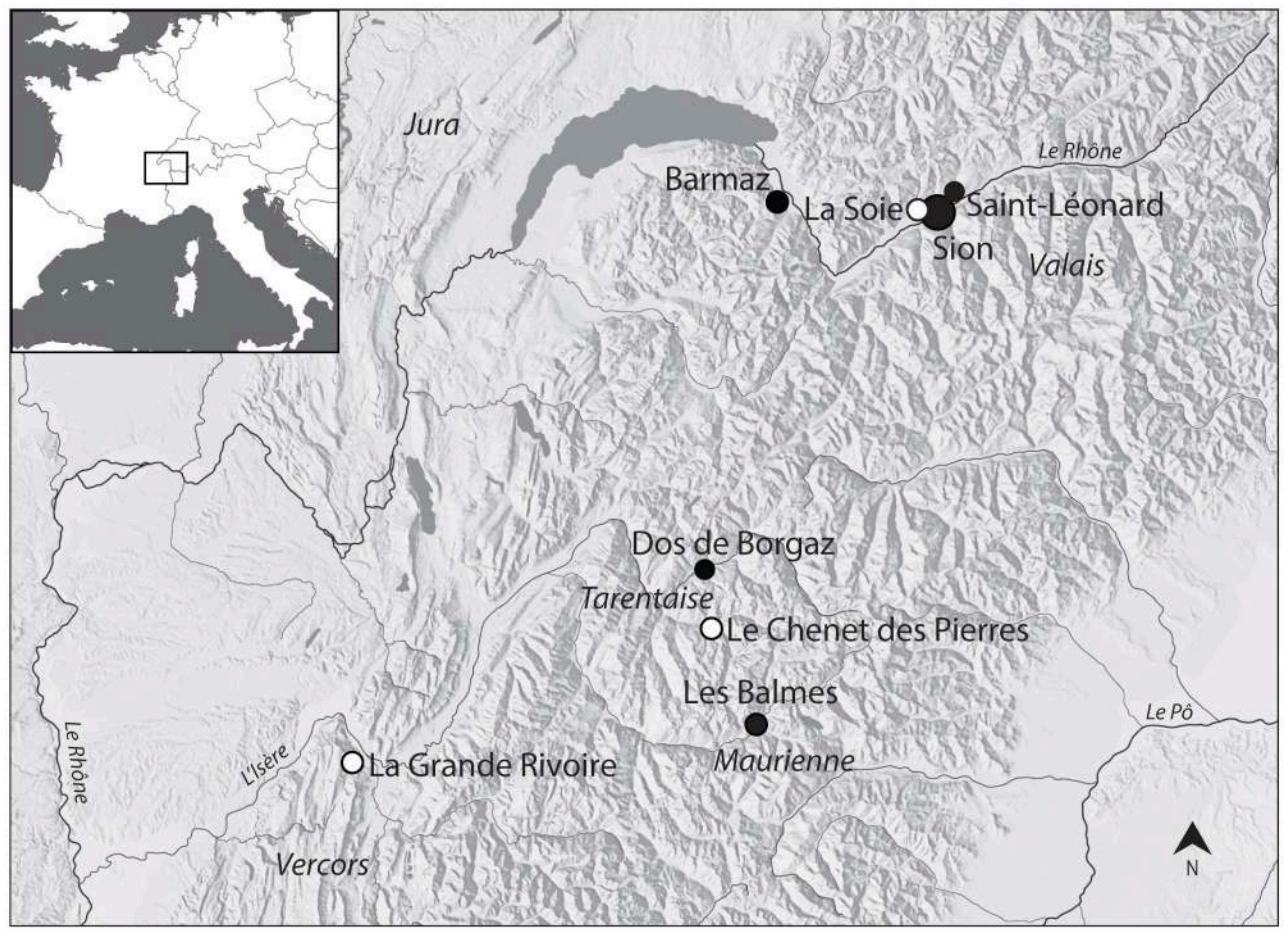

La grande pastille (Sion) rassemble différentes séries de la région sédunoise.

PAO Patricia Chiquet.

Ces secteurs montrent des variations topographiques et climatiques importantes, qui induisent une grande variété de paysages et par conséquent une grande diversité végétale et animale. L'étagement altitudinal des biotopes offre des ressources naturelles variées, susceptibles d'être exploitées par les hommes et leurs troupeaux. Le choix d'étudier ces deux secteurs découle d'une volonté d'approcher l'économie des premières sociétés agropastorales à une échelle suprarégionale et d'en examiner la mise en place et les développements dans des secteurs pour lesquels des fonctionnements socio-économiques différents ont été pressentis.

Dans le bassin de l'Isère, les composantes néolithiques semblent se manifester de façon asynchrone, suggérant une acculturation des sociétés autochtones de chasseurscueilleurs au contact des premières populations paysannes du midi de la France (Nicod 2008). Le Néolithique ancien demeure peu documenté, avec des ensembles qui apparaissent parfois comme ambigus (Bridault et Chaix 1999, Marguet et al. 2008, Nicod et al. 2012). Une économie de production ne semble attestée qu'à basse altitude, à Balme Rousse par exemple (alt. 650 m., Chaix et al. 1991), alors qu'en altitude, à l'Aulp du Seuil (alt. $1700 \mathrm{~m}$.), les espèces identifiées témoignent d'activités exclusivement cynégétiques et saisonnières (Bintz et al. 2015). La situation est sans doute plus complexe, puisqu'à La Grande Rivoire (alt. $580 \mathrm{~m}$.) un épisode épicardial présentant les caractéristiques d'une bergerie succède à un premier Néolithique où la chasse est pratiquée de façon exclusive (Marguet et al. 2008, Nicod et al. 2010 et 2012).

$\mathrm{Au}$ Néolithique moyen (4700-3500 av. J.-C.), l'implantation d'une économie agropastorale dans le nord-ouest des Alpes françaises se renforce et atteint désormais les vallées internes. Les travaux de prospection et de sondages réalisés depuis la fin des 
années 1990 ont permis d'accroître fortement notre connaissance du peuplement des vallées alpines, notamment celles de la Tarentaise et de la Maurienne (Marguet et al. 2008, fig. 24). La fréquentation de ces vallées prend diverses formes et témoigne d'affinités culturelles multiples, mais toujours clairement méridionales, avec par exemple les bassins rhodanien et padan (Denaire et al. 2011, Van Willigen et al. 2016, Rey 2016a et 2016b). Le modèle socio-économique envisagé pour la moyenne vallée du Rhône dès la fin du Néolithique ancien, et qui pourrait être étendu au bassin de l'Isère, insiste sur la mobilité des groupes humains au sein d'un vaste territoire s'articulant entre plaine et montagne et dont la gestion repose sur différents types de sites, aux fonctionnalités complémentaires (Beeching et al. 2000, Beeching 2003, Helmer et al. 2005, Brochier et Beeching 2006 et 2008). Des analyses archéozoologiques ont permis d'affiner ce modèle et d'envisager une segmentation des troupeaux de bovins et de caprinés au cours de l'année, en relation avec une spécialisation des lieux (grottebergerie ou site de plein air / place centrale), mais également des personnes en charge de différentes catégories d'animaux (Bréhard et al. 2010, Bréhard 2011).

Le Néolithique final nord-alpin (3 500-2 200 av. J.-C.) reste pour sa part encore mal défini, même s'il semble faire l'objet d'influences culturelles diverses avant d'être touché par le phénomène campaniforme. En moyenne vallée du Rhône, le système pastoral tend à se complexifier, sans rompre pour autant avec les pratiques antérieures (Blaise et al. 2010).

7 Contrairement au bassin de l'Isère, le Valais central concentre un grand nombre de gisements, avec une cinquantaine de sites néolithiques répertoriés dans la région de Sion et Saint-Léonard, dont certains sont parmi les plus anciens témoignages néolithiques de Suisse. Dès le Néolithique ancien (5 500-4 700 av. J.-C.), la région voit l'implantation de communautés agropastorales originaires d'Italie septentrionale, qui s'installent avec toute la "panoplie néolithique »: élevage, agriculture, céramique, pierre polie... (Gallay et al. 1983, Baudais et al. 1989-1990, Müller 1995, Besse et Piguet 2011, Curdy et al. 2015). Habitats et nécropoles vont se concentrer en basse altitude durant tout le Néolithique, principalement en bordure de la plaine du Rhône, avec une extension en direction des vallées latérales et une augmentation des indices archéologiques en altitude au Néolithique final (Curdy et al. 1999, Curdy 2007). Les recherches portant sur le Néolithique valaisan se cristallisent depuis plusieurs décennies autour de la question de l'exploitation de ce milieu montagnard et de la mobilité qui a pu en découler (Baudais et al. 1987 et 1989-1990, Crotti et al. 1983, Gallay 1983, Curdy et al. 1999, Curdy 2007, Curdy et Chaix 2013, Hafner 2015 : vol. 2 p. 174). Le modèle de peuplement proposé par A. Gallay en 1983 est bien différent de celui élaboré pour la moyenne vallée du Rhône, puisqu'il suppose un habitat néolithique sédentaire localisé uniquement à basse altitude et une économie agropastorale qui se cantonne à l'étage collinéen, avec toutefois la possibilité d'une utilisation des pâturages d'altitude. Les études des restes animaux et végétaux disponibles à ce jour indiquent effectivement le recours presque exclusif à une économie de production (Chaix 1976, Martin 2015). Des occupations temporaires ont néanmoins été mises au jour à haute altitude, mais n'ont pas livré de restes de faune. La découverte d'un bol en bois et de flèches datés du Néolithique moyen et final au col du Schnidejoch, situé à plus de 2750 mètres d'altitude et reliant la vallée du Rhône à l'Oberland bernois, témoigne d'une fréquentation de ces espaces d'altitude dès le début $d u v^{e}$ millénaire avant notre 
ère et pose sérieusement la question de l'emploi des pâturages d'altitude depuis la région de Sion (Hafner et Schwörer 2018).

Ainsi, ces deux modèles se distinguent notamment par le degré de mobilité du bétail (et des individus) qu'ils supposent, puisqu'en Valais une forte sédentarité est envisagée, avec une agriculture et un élevage qui se déploient à l'étage collinéen aux abords des habitats, tandis qu'un déplacement intramontagnard du bétail vers les pâturages d'altitude à la belle saison n'est que présumé ; en moyenne vallée du Rhône, ce sont au contraire les mouvements de l'homme et de ses troupeaux qui paraissent orchestrer l'organisation territoriale des communautés néolithiques entre plaine et montagne au cours de l'année.

9 Afin de prendre la mesure de ces différences, nous avons choisi de présenter ici trois séries archéozoologiques inédites et d'interroger leur place dans ces modèles généraux. Il s'agit du site de La Soie, localisé dans le Valais central, et de deux sites du bassin de l'Isère: l'abri de La Grande Rivoire, situé en bordure septentrionale du massif du Vercors, et le site du Chenets des Pierres, sis au cœur de la Savoie, à mi-parcours entre le Valais et la moyenne vallée du Rhône (fig. 1).

\section{Méthodes et matériel}

10 L'identification du matériel a eu lieu au Muséum d'histoire naturelle de Genève, à l'aide de la collection de référence du département d'archéozoologie. Divers articles et ouvrages ont également été mobilisés, afin d'identifier notamment les restes de caprinés (voir entre autres Boessneck et al. 1964, Fernandez 2001, Zeder et Pilaar 2010, Gillis et al. 2011). Il s'agit d'un des principaux enjeux de cette recherche, dans la mesure où cette sous-famille domine clairement le spectre des trois sites analysés, mais se manifeste sous la forme de quatre espèces distinctes : le chamois (Rupicapra rupicapra L., 1758), le bouquetin (Capra ibex L., 1758), la chèvre (Capra hircus L., 1758) et le mouton (Ovis aries L., 1758) (fig. 2). Cette étape d'attribution à l'une ou l'autre de ces espèces s'avère cruciale, si l'on veut pouvoir évaluer le rapport entre activités de chasse et d'élevage, mais aussi la contribution relative des différents animaux et les modes d'exploitation qui les caractérisent. 
Fig. 2. - Le Chenet des Pierres (Bozel, Savoie) : restes de caprinés du Néolithique moyen.

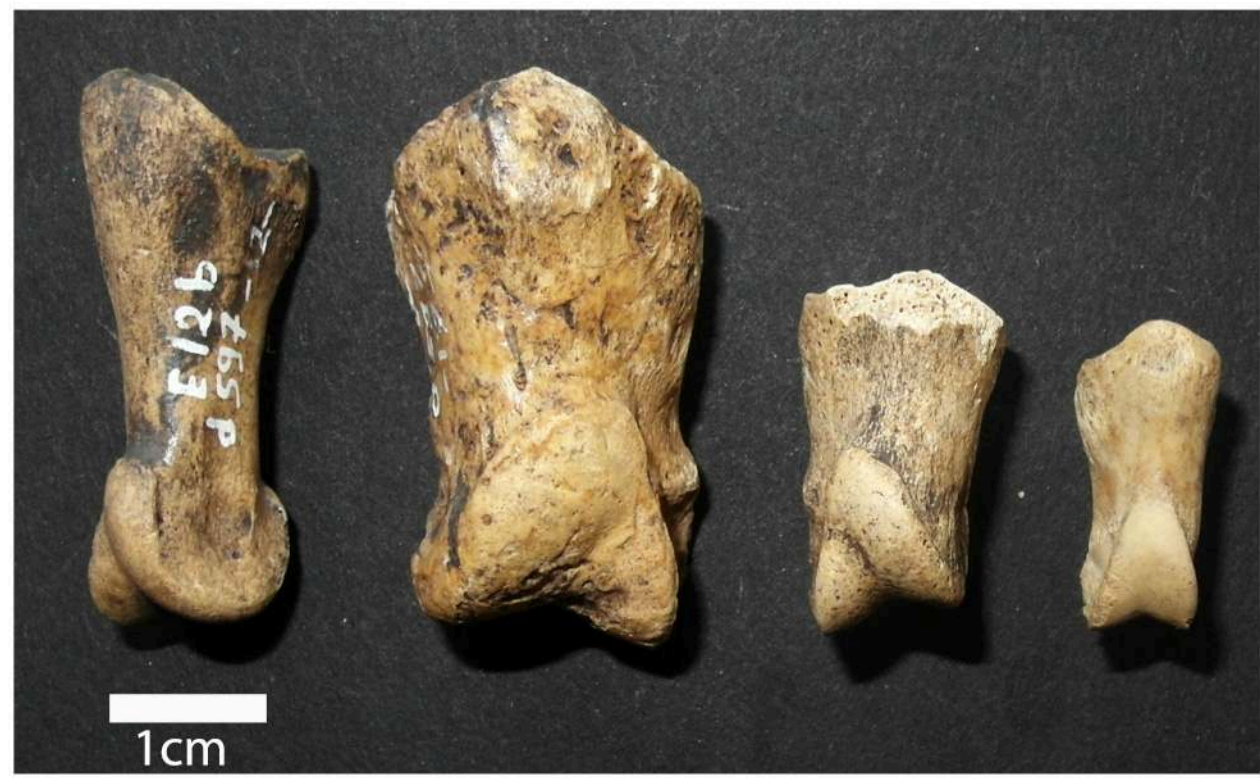

De gauche à droite : phalanges intermédiaires de chamois, bouquetin, chèvre et mouton.

Photos Patricia Chiquet.

11 En ce qui concerne les suinés, nous avons rencontré les mêmes difficultés à séparer la forme domestique et la forme sauvage, d'autant que les restes sont souvent issus de sujets en cours de croissance. C'est pourquoi une grande part des restes demeure attribuée à la catégorie générique Sus sp.

12 Un intérêt particulier a été porté à l'âge des sujets, puisque cette étude cherche notamment à établir la composition des cheptels. Seuls les caprinés du site de La Soie se prêtent pour l'instant à une telle approche. Sur les deux sites du bassin de l'Isère, où l'identification des restes n'est pas terminée, les restes osseux sont majoritairement des esquilles de taille réduite d'un poids moyen qui n'atteint pas le gramme. Le taux d'identification y est inférieur à $10 \%$ et les effectifs dentaires par ensemble chronologique demeurent à l'heure actuelle trop faibles, avec moins d'une centaine de dents de caprinés identifiées sur chaque site pour l'ensemble de leur séquence chronologique.

13 Les âges des caprinés ont été estimés en combinant l'observation de l'éruption et de l'usure dentaires et la mesure d'indice d'usure (Vigne et Helmer 2007) (tabl. 1). Les classes d'âge retenues (0-2 mois, 2-6 mois, 6-12 mois, 1-2- ans, 2-4 ans, 4-6 ans, > 6 ans) sont celles proposées par D. Helmer (2000, modifiées d'après Payne 1973).

14 La construction des profils d'abattage repose ici sur la fréquence du nombre de dents (supérieures et inférieures) attribuées à chaque classe d'âge. Les dents encore fixées dans la mandibule ou le maxillaire ont été décomptées au même titre que les dents isolées, afin d'atténuer les effets de la dissociation différentielle (Vigne 1988). Le nombre minimum d'individus (NMI) auquel elles peuvent se rapporter est également fourni dans les profils. Les classes d'âge ne présentant pas toutes la même amplitude, les fréquences ont été corrigées en fonction de la durée de chaque classe. Nous avons choisi de mettre également à disposition du lecteur le décompte précis du nombre de dents attribuées à chaque classe d'âge (tabl. 1). 
Tabl. 1. - La Soie (Savièse, Valais, Suisse), couche 6 , couche 5 et couche 4 : décompte du nombre de dents attribuées à chaque classe d'âge.

\begin{tabular}{llccc}
\hline & Classe d'âge & Couche 6 & Couche 5 & Couche 4 \\
A & (0-2 mois) & 0,00 & 0,00 & 0,00 \\
B & (2-6 mois) & 2,66 & 3,00 & 5,66 \\
C & (6-12 mois) & 11,65 & 4,33 & 24,64 \\
D & $(12-24$ mois $)$ & 14,97 & 11,66 & 17,30 \\
EF & (2-4 ans) & 28,49 & 9,00 & 11,16 \\
G & (4-6 ans) & 43,33 & 6,33 & 15,00 \\
HI & (>6 ans) & 10,76 & 5,66 & 25,16 \\
& & 112 & & 100 \\
\hline
\end{tabular}

Les valeurs présentant des décimales illustrent le fait que certaines dents n'ont pas pu être rattachées à une seule classe. Leur nombre a donc été divisé en conséquence.

L'interprétation de ces profils d'abattage en termes de production (lait, viande, toison, etc.) s'appuie principalement ici sur la typologie proposée par D. Helmer et J.-D. Vigne (Helmer et Vigne 2004, Vigne et Helmer 2007), qui distinguent 5 types principaux :

- Deux modes d'exploitation de la viande, l'un caractérisé par un abattage des bêtes âgées de 6 à 12 mois (classe $\mathrm{C}$ ) en vue d'obtenir de la viande tendre, l'autre centré sur des bêtes un peu plus âgées (classe D : 1-2 ans), ayant atteint leur maturité pondérale ;

- Deux modes d'exploitation du lait, le premier avec un abattage marqué des jeunes encore au pis (classe A : 0-2 mois), le second où les agneaux sont gardés sur pied, mais avec un accès restreint au pis. Dans ce dernier cas, le profil montre avant tout l'abattage des femelles réformées entre 2 et 6 ans (classes $\mathrm{EF}$ et $\mathrm{G}$ );

- Enfin, un type d'exploitation de la toison qui se traduit par un abattage des mâles comme des femelles âgés de plus de 4 ans (classes G et HI).

De plus, d'après une étude réalisée par E. Blaise (2006), un abattage des jeunes après sevrage (classe B : 2-6 mois) pourrait révéler une optimisation du rendement en viande des agneaux associée à une utilisation du lait, pour autant que l'accès des petits au pis soit restreint. Ce système traduirait également une régulation des troupeaux avant l'hiver, en admettant bien sûr des mises bas au printemps (Helmer et al. 2005, Blaise 2005).

\section{Les sites}

\section{La Grande Rivoire (Sassenage, Isère, France)}

17 L'abri de La Grande Rivoire est situé dans la vallée du Furon, près de Grenoble, dans le nord du massif du Vercors (fig. 1). Couvrant une surface d'environ $80 \mathrm{~m}^{2}$, il est exposé plein sud, à 580 mètres d'altitude. Le site a fait l'objet d'une fouille préventive entre 1986 et 1994 sous la direction de R. Picavet, puis d'une fouille programmée entre 2000 et 2017, sous la conduite de P.-Y. Nicod. Les niveaux du Néolithique qui nous 
intéressent ici sont exclusivement les niveaux de bergerie couvrant la période allant de 5000 à 2600 avant notre ère (fig. 3).

Fig. 3. - La Grande Rivoire (Sassenage, Isère) : coupe stratigraphique dans la séquence médiane et attribution chronoculturelle.

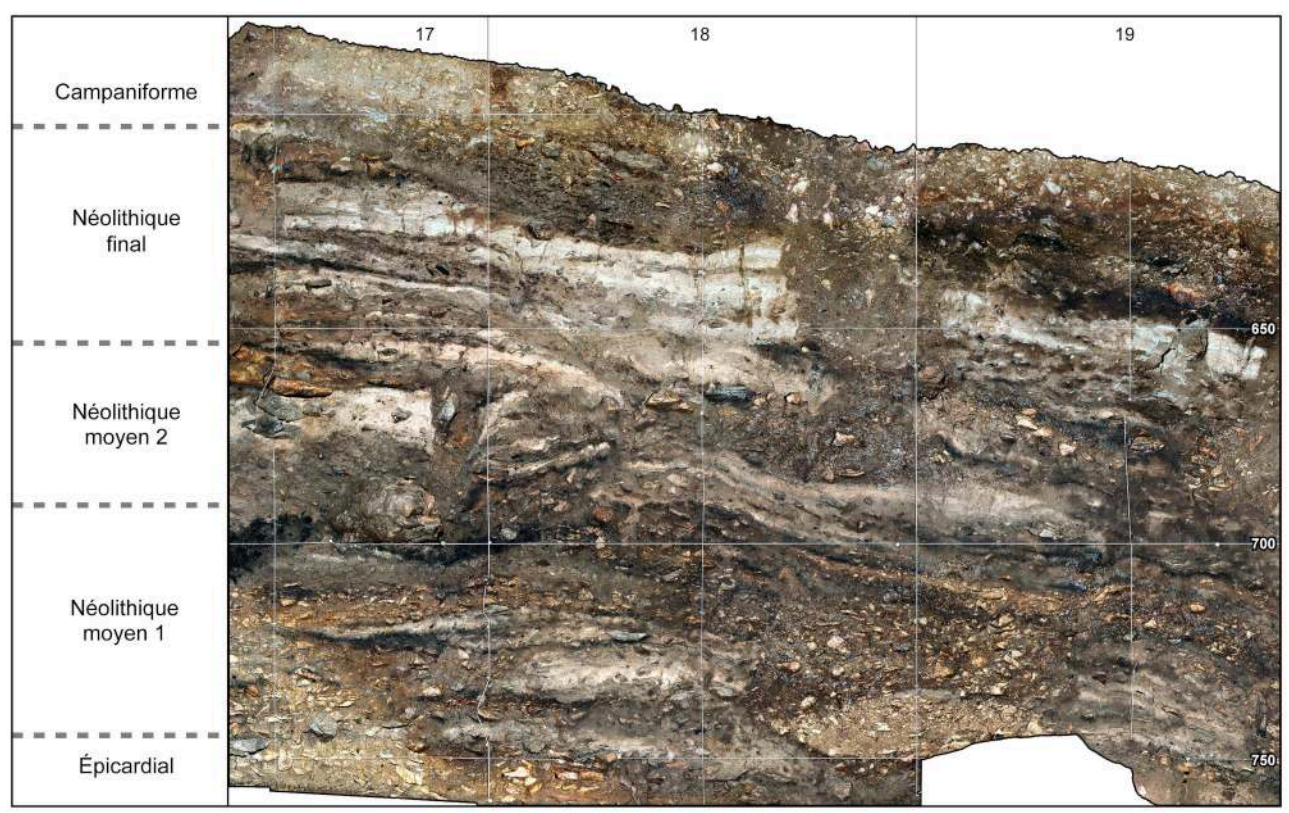

PAO Cyril Bernard

D'après les analyses sédimentologiques et micromorphologiques, ces dépôts accumulés sur 1,5 mètre d'épaisseur correspondent à une alternance de couches d'excréments d'herbivores fossilisés et de couches de cendres de bois, les premières étant liées au parcage d'animaux, les secondes résultant de feux de bois vraisemblablement allumés pour réduire le volume des fumiers et assainir le lieu (Nicod 2008, Nicod et al. 2010). Des crottes de caprinés (mouton et / ou chèvre) parfaitement conservées sont parfois encore visibles dans ces niveaux et viennent appuyer l'hypothèse d'une utilisation de l'abri comme bergerie.

Dans le cadre de cette hypothèse fonctionnelle, la découverte dans les niveaux du Néolithique moyen 1, autour de 4500 av. J.-C., de fragments de récipients perforés interprétés comme des fragments de faisselles, apparaît comme l'illustration d'un traitement du lait au sein même de la bergerie. Les analyses des restes végétaux suggèrent, pour leur part, une fréquentation entre le début du printemps et la fin de l'automne et un apport intentionnel de végétaux sur le site sous la forme de rameaux feuillus et fleuris pour l'entretien et l'alimentation des bêtes (Delhon et al. 2008). Les analyses palynologiques et phytolithologiques de deux coprolithes de caprinés du Néolithique moyen indiquent quant à elles une consommation, certes ponctuelle (compte tenu du matériel analysé), de feuillage recueilli à la fin du printemps ou en début d'été (Nicod et Picavet 2014, analyses effectuées par J. Argant et C. Delhon).

Plus de 10000 restes osseux ont été examinés à ce jour (tabl. 2). Il s'agit principalement du matériel recueilli lors de la fouille planimétrique d'un secteur d'environ $15 \mathrm{~m}^{2}$ (N 12-15) localisé entre la zone abritée et celle soumise aux intempéries, auquel est associé le matériel du secteur adjacent (NR 16-21), abrité par le surplomb de la falaise et dont l'étude préliminaire a été réalisée par L. Chaix (Nicod et al. 2010). Pour l'instant, 
seuls 500 vestiges ont été déterminés au niveau de l'espèce ou du genre (y compris ici " caprinés indéterminés »), ce qui représente $5 \%$ du nombre total de restes, mais tout de même $56 \%$ du poids correspondant. Une quinzaine d'espèces ont été reconnues, principalement des taxons sauvages qui témoignent d'une exploitation des alentours de l'abri, soit un milieu boisé présentant également des escarpements et des pentes herbeuses qui conviennent au chamois. La découverte de fragments de carapaces et d'ossements de cistude (Emys orbicularis L., 1758) évoque un prélèvement dans des eaux calmes, à faible altitude ( $<500 \mathrm{~m}$., plaine de l'Isère) et à la belle saison, puisqu'à l'automne les cistudes s'enfouissent dans la vase jusqu'au printemps (Duguy et Baron 1998).

Tabl. 2. - La Grande Rivoire (Sassenage, Isère) : spectre de faune par ensemble chronologique.

\begin{tabular}{|c|c|c|c|c|c|c|c|c|c|c|}
\hline & \multicolumn{2}{|c|}{$\begin{array}{c}5200-4700 \text { BC } \\
\text { Néolithique } \\
\text { ancien }\end{array}$} & \multicolumn{2}{|c|}{$\begin{array}{c}4700-4000 \mathrm{BC} \\
\text { Néolithique } \\
\text { moyen } 1\end{array}$} & \multicolumn{2}{|c|}{$\begin{array}{c}4000-3700 \text { BC } \\
\text { Nélithique } \\
\text { moyen 2 }\end{array}$} & \multicolumn{2}{|c|}{$\begin{array}{c}3650-2700 \mathrm{BC} \\
\text { Néolithique } \\
\text { final }\end{array}$} & \multicolumn{2}{|c|}{ Total } \\
\hline & NR & PR & NR & $P R$ & NR & PR & NR & PR & NR & $P R$ \\
\hline Mouton (Ovis aries) & 1 & 6,1 & 2 & 10,9 & & & & & 3 & 17,0 \\
\hline Chèvre (Copro hircus) & & & 1 & 22,3 & 2 & 93,5 & & & 3 & 115,8 \\
\hline Mouton/chèvre & 12 & 8,2 & 24 & 107,3 & 19 & 89,1 & 14 & 29,0 & 69 & 233,6 \\
\hline Chamois (Rupicapra rupicapra) & 5 & 27,7 & 2 & 8,5 & & & & & 7 & 36,2 \\
\hline Chevreuil (Capreolus capreoius) & 16 & 52,9 & 1 & 29,9 & & & & & 17 & 82,8 \\
\hline Petits ruminants indéterminés & 42 & 99,7 & 62 & 108,6 & 31 & 61,4 & 54 & 43,6 & 189 & 313,3 \\
\hline Total petits ruminants & 76 & 194,6 & 92 & 287,5 & 52 & 244,0 & 68 & 72,6 & 288 & 798,7 \\
\hline Bœeuf (Bos taurus) & 29 & 317,6 & 30 & 519,1 & 12 & 173,5 & 18 & 229,6 & 89 & 1239,8 \\
\hline Cerf (Cervus elaphus) & 59 & 781,3 & 28 & 507,8 & 13 & 135,5 & 2 & 0,8 & 102 & 1425,4 \\
\hline Grands ruminants indéterminés & 66 & 233,2 & 40 & 216,5 & 11 & 34,1 & 9 & 27,5 & 126 & 511,3 \\
\hline Total grands ruminants & 154 & 332,1 & 98 & 1243,4 & 36 & 343,1 & 29 & 257,9 & 317 & 3176,5 \\
\hline Porc (Sus domesticus) & & & 6 & 49,8 & & & 3 & 10,7 & 9 & 60,5 \\
\hline Sanglier (Sus scrofa) & 6 & 26,3 & 4 & 93,5 & & & 2 & 11,1 & 12 & 130,9 \\
\hline Suinés indéterminès & 25 & 65,1 & 35 & 81,4 & 9 & 143,2 & 16 & 23,2 & 85 & 312,9 \\
\hline Total suinés & 31 & 91,4 & 45 & 224,7 & 9 & 143,2 & 21 & 45,0 & 106 & 504,3 \\
\hline Chien (Conis familiaris) & & & 1 & 1,1 & 1 & 0,8 & & & 2 & 1,9 \\
\hline Total canidés & 0 & 0 & 1 & 1,1 & 1 & 0,8 & 0 & 0 & 2 & 1,9 \\
\hline Martre ou fouine (Martes sp.) & 2 & 0,6 & 23 & 14,8 & 6 & 4,4 & 8 & 8,1 & 39 & 27,9 \\
\hline Blaireau (Meles meles) & 7 & 34,4 & & & 1 & 5,5 & & & 8 & 39,9 \\
\hline Chat sauvage (felis silvestris) & 1 & 0,1 & 4 & 1,7 & & & 3 & 2,0 & 8 & 3,8 \\
\hline Lièvre (Lepus sp.) & & & 4 & 0,8 & & & & & 4 & 0,8 \\
\hline Hérisson (Erinaceus europaeus) & 6 & 2,1 & 3 & 0,3 & 3 & 1,4 & 1 & 1,2 & 13 & 5,0 \\
\hline Total divers sauvages & 16 & 37,2 & 34 & 17,6 & 10 & 11,3 & 12 & 11,3 & 72 & 77,4 \\
\hline Cistude (Emys orbicularis) & 53 & 18,3 & 2 & 0,4 & & & 1 & 0,3 & 56 & 19,0 \\
\hline Micromammifères & 3 & 0,21 & 5 & 0,2 & 1 & $<0,1$ & 4 & 0,3 & 13 & 0,7 \\
\hline Oiseaux & & & 15 & 0,8 & 2 & $<0,1$ & 4 & 0,4 & 21 & 1,2 \\
\hline Amphibiens & 1 & 0,1 & 1 & 0,2 & & & 2 & 0,2 & 4 & 0,5 \\
\hline Carnivores indetermines & 1 & 0,1 & 2 & 2,5 & & & 7 & 2,4 & 10 & 5,0 \\
\hline Indéterminés & 3563 & 56,48 & 1470 & 531,1 & 2883 & 475,9 & 1255 & 453,6 & 9171 & 2217,0 \\
\hline Total des lignes grisées & 3898 & 430,8 & 1765 & 2310,0 & 2994 & 1218,3 & 1403 & 844 & 10060 & 6802,3 \\
\hline
\end{tabular}

$N R$ : nombre de restes; PR : poids des restes en grammes.

D'un point de vue diachronique, le gibier tend à être moins abondant entre le Néolithique ancien et final, et ce recul touche tout particulièrement les ruminants, c'est-à-dire le cerf, mais aussi le chevreuil et le chamois (tabl. 2 ; fig. 4a). 
Fig. 4. - La Grande Rivoire (Sassenage, Isère), Le Chenet des Pierres (Bozel, Savoie) et La Soie (Savièse, Valais, Suisse) : contribution des animaux sauvages versus domestiques au Néolithique ancien, Néolithique moyen I et II et Néolithique final.

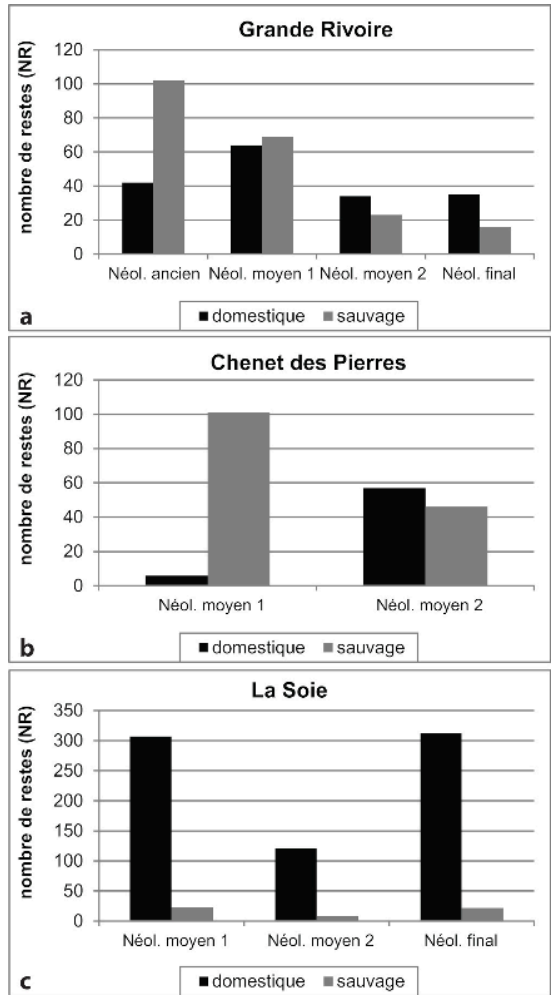

A : La Grande Rivoire. B : Le Chenet des Pierres. c : La Soie. PAO Patricia Chiquet.

22 La contribution des petits ruminants, dont l'identification spécifique pose souvent problème, devient plus évidente lorsque sont considérées des catégories d'animaux élargies (fig. 5a). L'image montre une nette diminution des grands ruminants au cours du temps, qui reproduit avant tout le recul de la chasse au cerf, tandis que l'exploitation des petits ruminants semble prendre le pas sur les autres catégories d'animaux à partir du Néolithique moyen 2. 
Fig. 5. - La Grande Rivoire (Sassenage, Isère), Le Chenet des Pierres (Bozel, Savoie) et La Soie (Savièse, Valais, Suisse) : contribution des diverses catégories de mammifères exploités sur le site au Néolithique ancien, Néolithique moyen I et II et Néolithique final.

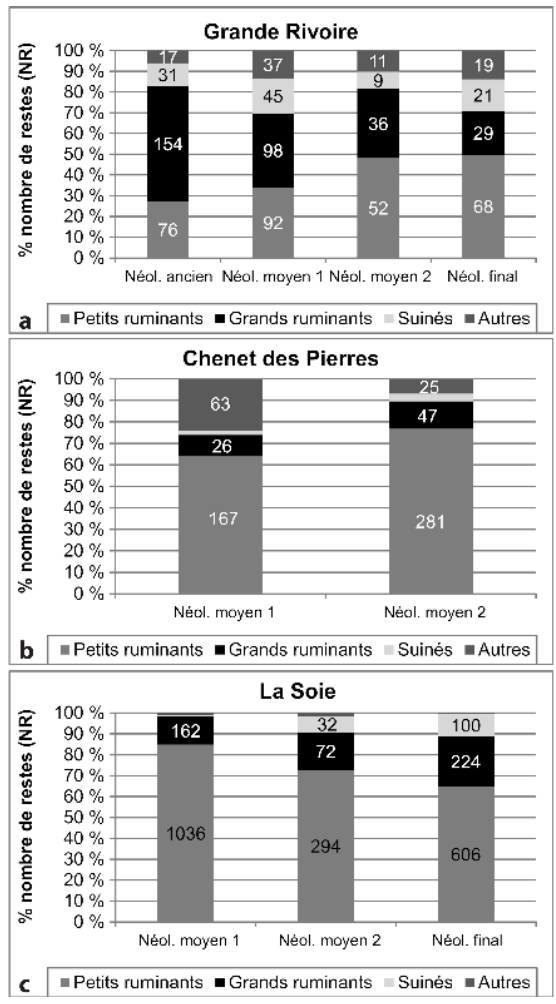

A : La Grande Rivoire. B : Le Chenet des Pierres. c : La Soie. La catégorie « autres » comprend les " divers sauvages » et les " carnivores indéterminés ».

PAO Patricia Chiquet.

Parmi le cheptel domestique, le bœuf et les caprinés sont les animaux qui apparaissent le plus régulièrement dans la séquence (tabl. 2). La présence du mouton et de la chèvre est confirmée. Une vingtaine de dents jugales de chute leur appartenant ont également été recueillies, plutôt dans les horizons les plus anciens du secteur le moins abrité (NR 12-15) (tabl. 3).

Tabl. 3. - La Grande Rivoire (Sassenage, Isère), secteur NR 12-15: décompte du nombre de dents de chute de mouton et de chèvre par ensemble chronologique.

\begin{tabular}{|c|c|c|c|c|c|c|c|c|}
\hline & $\begin{array}{l}\text { D2 } \\
\text { sup. }\end{array}$ & $\begin{array}{l}\text { D3 } \\
\text { sup. }\end{array}$ & $\begin{array}{l}\text { D2 } \\
\text { inf. }\end{array}$ & $\begin{array}{l}\text { D3 } \\
\text { inf. }\end{array}$ & $\begin{array}{l}\text { D4 } \\
\text { inf. }\end{array}$ & Indét. & $\begin{array}{l}\text { Total } \\
\text { chute }\end{array}$ & $\begin{array}{l}\text { Total } \\
\text { dents }\end{array}$ \\
\hline Néolithique final & - & 2 & - & - & 1 & - & 3 & 10 \\
\hline Néolithique moyen 2 & - & - & - & 1 & - & - & 1 & 4 \\
\hline Néolithique moyen 1 & - & 1 & - & 1 & 1 & 2 & 5 & 10 \\
\hline Néolithique ancien / moyen 1 & 1 & - & - & - & 2 & - & 3 & 12 \\
\hline Néolithique ancien & - & 1 & 1 & 2 & - & - & 4 & 5 \\
\hline Total & 1 & 4 & 1 & 4 & 4 & 2 & 16 & 41 \\
\hline
\end{tabular}

Rappelons ici que les dents de chute sont des dents de lait perdues du vivant de l'animal, au moment où les dents définitives se mettent en place. Leur découverte sur le site est donc à mettre en relation avec le fait que certains caprinés, âgés d'1 à 2 ans au moment du changement dentaire, passaient du temps sous l'abri, ce qui viendrait conforter l'hypothèse d'une utilisation de ce dernier ou d'une partie de celui-ci comme bergerie. Pourtant, alors que des niveaux de fumiers extrêmement développés et une 
forte fragmentation des vestiges suggèrent un parcage intense, leur nombre peut paraître faible par comparaison aux centaines de dents de chute évoquées dans certaines grottes bergeries du sud-est de la France, comme celle de Fontbrégoua (Helmer 1984). Dans cette dernière, les dents de chute représentent presque $70 \%$ des dents recueillies. Plus proche de La Grande Rivoire, la grotte de l'Abbaye, à ChazeyBons, dans l'Ain (alt. $270 \mathrm{~m}$.), a fourni un taux comparable (22/33) de dents de chute dans des niveaux datés entre 4300 et 3800 av. J.-C. (Chiquet, inédit). À La Grande Rivoire, dans les niveaux néolithiques du secteur NR 12-15, étudié intégralement, leur nombre correspond à plus du tiers des dents de caprinés identifiées (16/41). Si la proportion de dents de chute est moindre à La Grande Rivoire, elle n'en est pas moins le signe d'un parcage sur place de caprinés.

De tels vestiges sont totalement absents de sites d'habitat, comme nous avons pu l'observer par exemple en Valais ou sur le plateau suisse (Chiquet 2011 et 2012) et peuvent également faire défaut sur des sites où le parcage est attesté (Helmer 1984, Helmer et al. 2005). Diverses raisons peuvent être envisagées pour expliquer cette différence de proportion de dents de chute. La dimension des sites et leur capacité d'accueil, leur localisation et leur configuration (grotte profonde ou abri) sont des variables qui ont pu agir sur la taille et la composition des troupeaux. La durée de fréquentation de l'abri au cours de l'année intervient également sur la quantité de fumier accumulé par un troupeau, tandis que la période de fréquentation du site peut faire varier le nombre de dents de chute susceptibles d'être retrouvées. Rappelons en effet que les changements dentaires interviennent à des âges assez précis. Pour trouver des molaires de lait de chute, il faut que les animaux soient présents sous l'abri au moment du changement dentaire, qui a lieu un peu avant l'âge de 20 mois pour la chèvre, un peu après pour le mouton (Helmer et al. 2005), c'est-à-dire entre la fin de l'été et le début de l'hiver. Cela implique que la reproduction soit ajustée au cycle des saisons et que les naissances aient lieu entre la fin de l'hiver et le début du printemps, ce que l'on peut à notre avis envisager, compte tenu des données disponibles aujourd'hui sous nos latitudes pour le Néolithique européen (Balasse et al. 2017).

Une présence sous l'abri plutôt au printemps et en début d'été, c'est-à-dire en dehors de la période où s'effectue le remplacement des molaires de lait, pourrait donc s'accompagner d'un faible nombre de dents de chute. Notons encore que lorsque le troupeau est géré en plusieurs lots, parqués en divers lieux et rassemblant chacun une catégorie d'animaux (par exemple brebis et agneaux, femelles n'ayant pas encore mis bas...), certaines classes d'âge vont être sous-représentées, ce qui peut également conduire à l'absence de certains vestiges comme les dents de chute (Brochier et al. 1992).

27 Enfin, rappelons que le matériel analysé jusqu'à présent ne représente qu'une partie de la surface de l'abri et que ce dernier abritait des bêtes, mais également les personnes qui les accompagnaient. L'analyse de la distribution spatiale des vestiges permettra dans le futur de se faire une idée de l'aménagement de l'espace et de la place dédiée aux animaux.

Si les indices saisonniers sont ténus pour l'instant, la découverte, dans les niveaux du Néolithique ancien et moyen 1 , de divers ossements appartenant à des agneaux ou cabris $(\mathrm{NR}=20)$ et à des veaux $(\mathrm{NR}=3)$ morts aux alentours de la naissance et dans les mois qui suivent est à mettre en relation avec une présence de femelles (brebis ou chèvres, vaches) sous l'abri au moment des mises bas. Ces éléments témoignent là 
encore d'une fréquentation plutôt à la belle saison. De plus, la présence de femelles allaitantes rend également plausible l'hypothèse d'une exploitation du lait sur le site. Si les éléments dont nous disposons convergent vers une occupation à la belle saison, rien ne nous permet d'exclure une utilisation prolongée de l'abri à d'autres moments de l'année.

Pour le Néolithique moyen 2 et final, nous ne disposons pour l'instant d'aucune information probante sur la période de fréquentation du site.

\section{Le Chenet des Pierres (Bozel, Savoie, France)}

30 Le site du Chenet des Pierres, aux Moulins de Bozel, est localisé à l'intérieur du massif alpin, dans la vallée du Doron de Bozel, un affluent de l'Isère (fig. 1). Le site a été fouillé entre 1999 et 2016 sous la direction de P.-J. Rey. Les occupations humaines ont pris place dans un chaos de blocs rocheux, à une altitude de 940 mètres environ. Bien qu'il soit situé en pied d'ubac, le site jouit d'une très bonne insolation en été, alors qu'en hiver les conditions y sont difficiles. Ces observations laissent supposer une fréquentation plutôt saisonnière du site (Rey 2015). Le caractère remarquable du lieu où il est implanté est à souligner, de même que sa position géographique, à proximité de la vallée de la Tarentaise, l'une des principales voies de circulation ralliant les versants français et italien des Alpes.

31 Le matériel provient du secteur 3, correspondant à une terrasse d'une trentaine de mètres carrés, délimitée par deux grands blocs (fig. 6).

Fig. 6. - Le Chenet des Pierres (Bozel, Savoie) : vue générale du secteur 3.

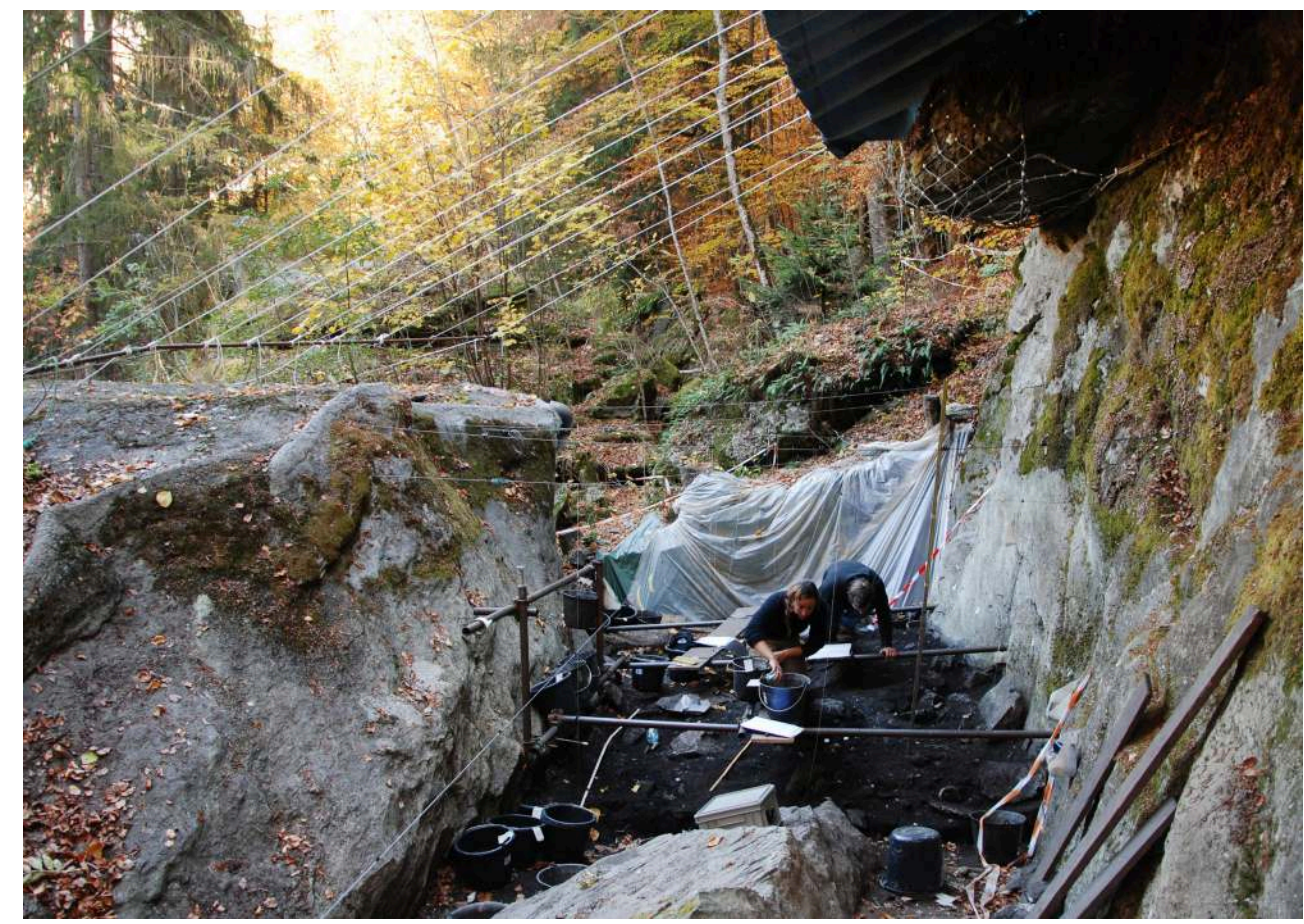

Photo Pierre-Jérôme Rey.

32 D'après la typologie céramique et les datations radiocarbone, il est possible de distinguer deux ensembles archéologiques principaux, attribuables tous deux au 
Néolithique moyen et comportant un matériel diversifié et abondant. L'ensemble 4, représenté par les niveaux 4II et 4I, regroupe des occupations de la seconde moitié du $\mathrm{V}^{\mathrm{e}}$ millénaire avant notre ère. S'y rapportent des éléments céramiques révélant des influences d'origine nord-italienne (VBQ, vasi a bocca quadrata) et rhodanienne (SaintUze récent) (Rey 2016b). L'ensemble 3, formé des niveaux 3III à 3I, témoigne de plusieurs fréquentations au cours des deux premiers tiers $d u \mathrm{IV}^{\mathrm{e}}$ millénaire avant notre ère. La céramique présente des caractéristiques qui la rapprochent ici encore du Piémont italien et de la vallée du Rhône (Rey 2016b). En ce qui concerne la nature des occupations, les indices sont discrets, mais suggèrent des changements dans les modalités d'utilisation du lieu au cours du temps. La présence d'une probable architecture en terre et bois au Néolithique moyen 1 est suspectée et parlerait en faveur d'occupations d'assez longue durée, de l'ordre de plusieurs mois, alors qu'au cours du Néolithique moyen 2, l'endroit semble fréquenté brièvement, mais de façon répétée (Rey 2015). L'analyse des restes végétaux montre, pour les deux ensembles, la présence de nombreuses céréales ainsi qu'une importante activité de cueillette, qui se déploie sur un large territoire (étages collinéen, montagnard et subalpin). La possibilité d'une culture locale d'altitude est envisagée pour certaines céréales, notamment au Néolithique moyen 2 (Martin 2014).

Plus de 4000 restes fauniques ont été analysés à ce jour (tabl. 4). Ils sont répartis assez équitablement entre les deux ensembles. La faune sauvage apparaît variée et reflète bien l'étage montagnard dans lequel s'inscrit le site, ainsi que les secteurs alentour. Tandis que certaines espèces répertoriées affectionnent les zones pentues, rocailleuses et plutôt ouvertes (marmotte, lièvre, bouquetin, chamois), d'autres recherchent un milieu plus forestier (cerf, lynx, écureuil, sanglier). Ces données font tout à fait écho aux résultats de l'étude des restes végétaux, montrant une prédation qui couvre toute la hauteur du versant. 
Tabl. 4. - Le Chenet des Pierres (Bozel, Savoie) : spectre de faune par ensemble chronologique.

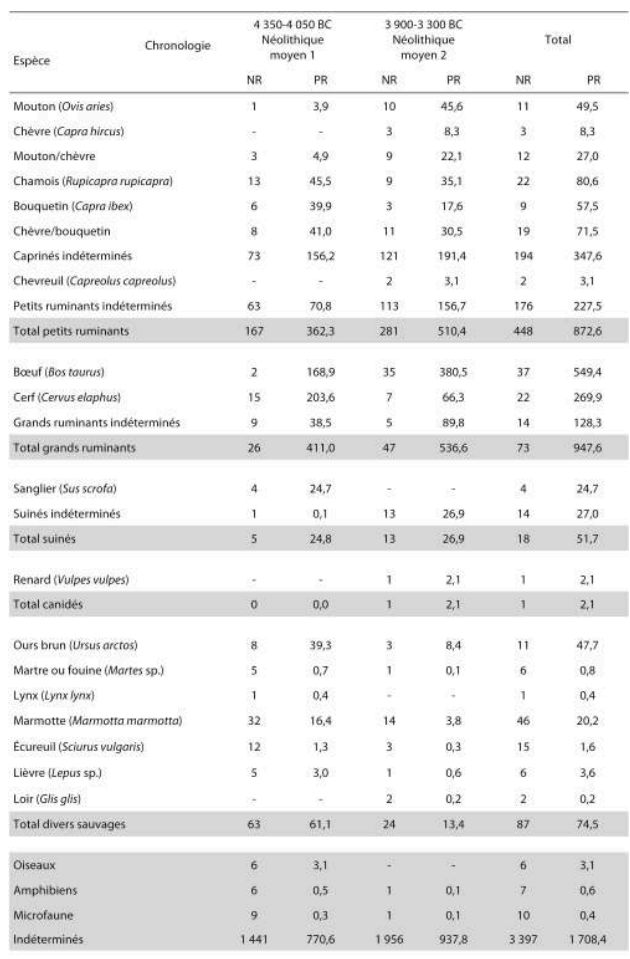

$\begin{array}{lllllll}\text { Total des lignes grisees } & 1723 & 1633,7 & 2324 & 2027,6 & 4047 & 3661\end{array}$

NR : nombre de restes. PR : poids des restes en grammes.

34 L'examen sous loupe binoculaire de l'ensemble des vestiges osseux a permis d'identifier des stries de désarticulation, décarnisation et écorchage sur des os de bœuf, caprinés, martre, marmotte et lièvre (fig. 7). 
Fig. 7. - Le Chenet des Pierres (Bozel, Savoie) : extrémité proximale d'un tibia de lièvre (Lepus sp.) portant des stries de découpe.

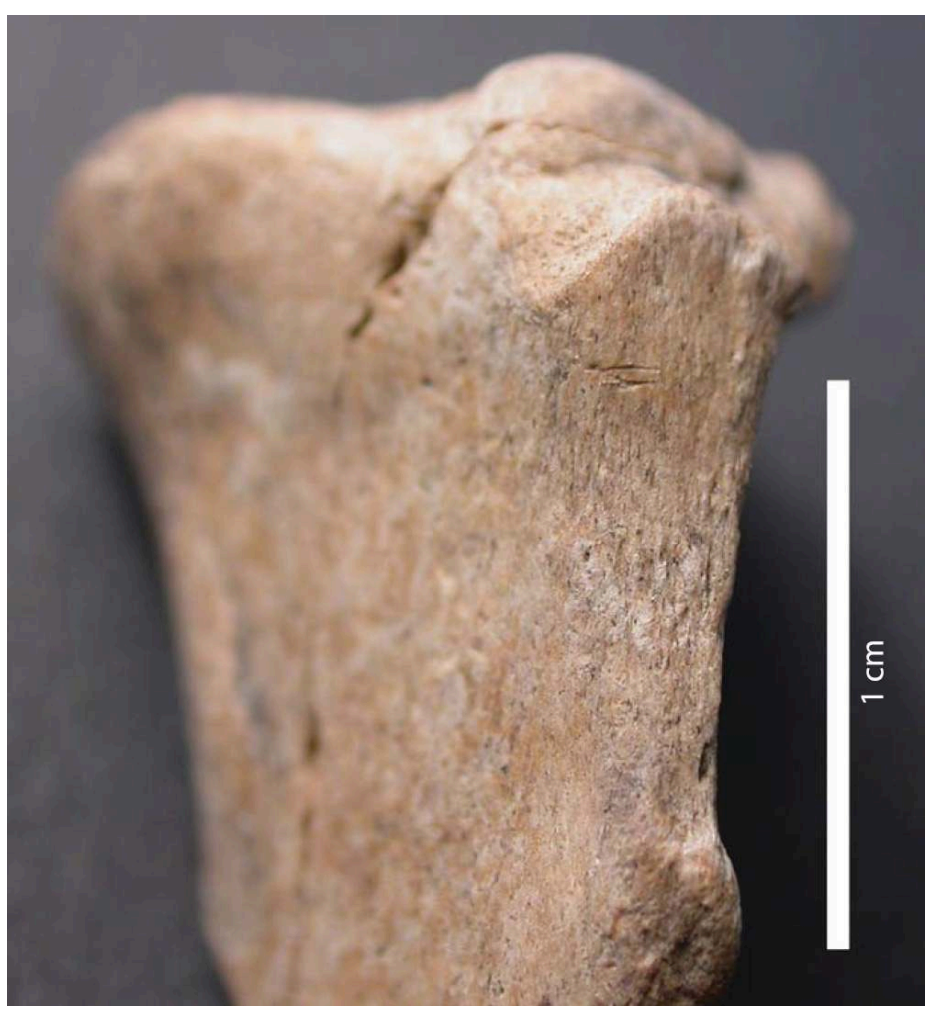

Photo Patricia Chiquet.

Quant au cheptel domestique, il est représenté au Chenet des Pierres par le bœuf, le mouton et la chèvre. La présence du chien, de même que celle du porc, n'est pas confirmée à l'heure actuelle. Des modifications assez nettes dans le choix des espèces sont perceptibles entre les deux ensembles chronologiques. C'est ainsi que la chasse enregistre un net recul au Néolithique moyen 2 (ensemble 3), tandis que le cheptel domestique, notamment le bœuf et le mouton, est plus clairement attesté (fig. 4b). Les caprinés, dont le caractère sauvage ou domestique n'a pas toujours été déterminé, sont majoritaires sur l'ensemble de la séquence et progressent également entre les deux ensembles (fig. 5b). De manière plus générale, l'intensification de l'exploitation des petits et grands ruminants au cours du Néolithique moyen semble s'effectuer au détriment des espèces dites à fourrure : carnivores, rongeurs et lièvre. Il faut cependant signaler ici que les niveaux 4II et 4I (ensemble 4) témoignent d'une grande similitude dans la liste des espèces identifiées comme dans l'importance octroyée au gibier, tandis que des différences parfois frappantes ont été observées au sein l'ensemble 3, comme par exemple la présence marquée du bœuf dans le niveau 3II, alors qu'il est totalement absent de l'ensemble suivant (3I). Si les effectifs sont aujourd'hui trop faibles pour pouvoir juger de la pertinence de ces observations, de futures analyses sont déjà prévues afin d'accroître les corpus de données et explorer ces questions.

Peu d'indices sont disponibles dans l'ensemble 4 pour déterminer la saison d'occupation. La présence fréquente de marmottes est toutefois l'indice clair d'une fréquentation du lieu à la fin de la belle saison. Les marmottes sont généralement recherchées pour leur fourrure, leur chair et leur graisse; leur chasse atteint son maximum de rentabilité entre septembre et mi-octobre, avant les premières chutes de 
neige et leur entrée en hibernation (Monin et al. 2010). L'ensemble 4 a également livré une phalange intermédiaire attribuée à un jeune ours mort au cours de sa première année, lui aussi plutôt entre l'été et l'automne. Quelques dents de caprinés se rapportent à des jeunes, morts entre le printemps et la fin de l'automne, en supposant ici aussi une mise bas au printemps. Si les âges dont nous disposons (6-9 et 6-12 mois) ne sont pas assez précis pour exclure totalement une fréquentation à la mauvaise saison, les caractéristiques du site sont toutefois peu propices à une installation hivernale. Ainsi, au cours de la deuxième moitié du ve millénaire avant notre ère (ensemble 4), le site semble occupé entre le printemps et l'automne par une communauté qui s'installe pour un certain temps, au vu notamment de l'architecture. Le groupe comprend des enfants, puisque plusieurs dents de chute humaines ont été identifiées parmi les restes osseux.

$\mathrm{Au}$ cours $\mathrm{du} \mathrm{IV}^{\mathrm{e}}$ millénaire avant notre ère (ensemble 3), les activités de chasse se restreignent, sans pour autant disparaître. Des restes de marmottes et de loirs suggèrent une présence humaine, toujours à la belle saison. L'élevage prend de l'importance, sans qu'il soit possible pour l'instant de mesurer son ampleur en ce qui concerne les moutons et les chèvres. La présence de sujets morts aux alentours de la naissance - il s'agit d'un veau $(\mathrm{NR}=2)$, mais également d'au moins deux caprinés $(\mathrm{NR}=10)$ - alors que cela n'est pas du tout le cas dans l'ensemble précédent, laisse entrevoir une présence humaine sur le site au moment des mises bas, envisagées ici encore entre la fin de l'hiver et le début du printemps, et qui concerneraient plutôt des animaux domestiques. L'absence de dents de chute de ruminants n'est pas surprenante, dans la mesure où la fouille porte sur une zone d'habitat. On ne peut par contre écarter la possibilité qu'une partie du chaos rocheux dans lequel s'inscrit la fouille ait pu servir à parquer des animaux. La présence d'un vaste replat (plateau de Praz, alt. $1220 \mathrm{~m}$ ) à une demi-heure de marche du site a pu constituer une belle attraction, tout comme les prairies d'altitude, que les hommes sur les traces des caprinés sauvages n'ont pas manqué de parcourir.

En ce qui concerne la plus grande discrétion des aménagements anthropiques au Néolithique moyen 2, découle-t-elle d'une fréquentation de plus courte durée, plus discontinue, ou de celle d'un groupe humain plus restreint? La question demeure ouverte pour l'instant. Compte tenu de l'abondance des artefacts lithiques retrouvés au Chenet des Pierres tout au long du Néolithique moyen et des nombreuses activités réalisées sur place dont ils témoignent, débitage, polissage, etc. (Rey 2006), mais également du caractère hors norme du site et de sa position stratégique au cœur du massif alpin, il faut en tout cas envisager une fréquentation qui n'a pas eu pour seuls mobile des activités de prédation ou la recherche de pâturages, mais s'inscrivait dans un mode d'appropriation plus large de la montagne. Toujours est-il que la fréquentation de ce lieu de façon saisonnière au cours du Néolithique moyen implique un autre lieu de résidence à la mauvaise saison, plus en aval, ou en tout cas dans un lieu mieux exposé.

\section{La Soie (Savièse, Valais, Suisse)}

Localisé non loin de la ville de Sion (fig. 1), sur la rive droite du Rhône, le site occupe un replat au sommet de la colline de La Soie, à 850 mètres d'altitude. Cette éminence jouit 
d'un ensoleillement intense et offre un large panorama sur la vallée du Rhône et l'ensemble du Valais central (fig. 8).

Fig. 8. - La Soie (Savièse, Valais, Suisse) : vue sur la vallée du Rhône en direction de Martigny.

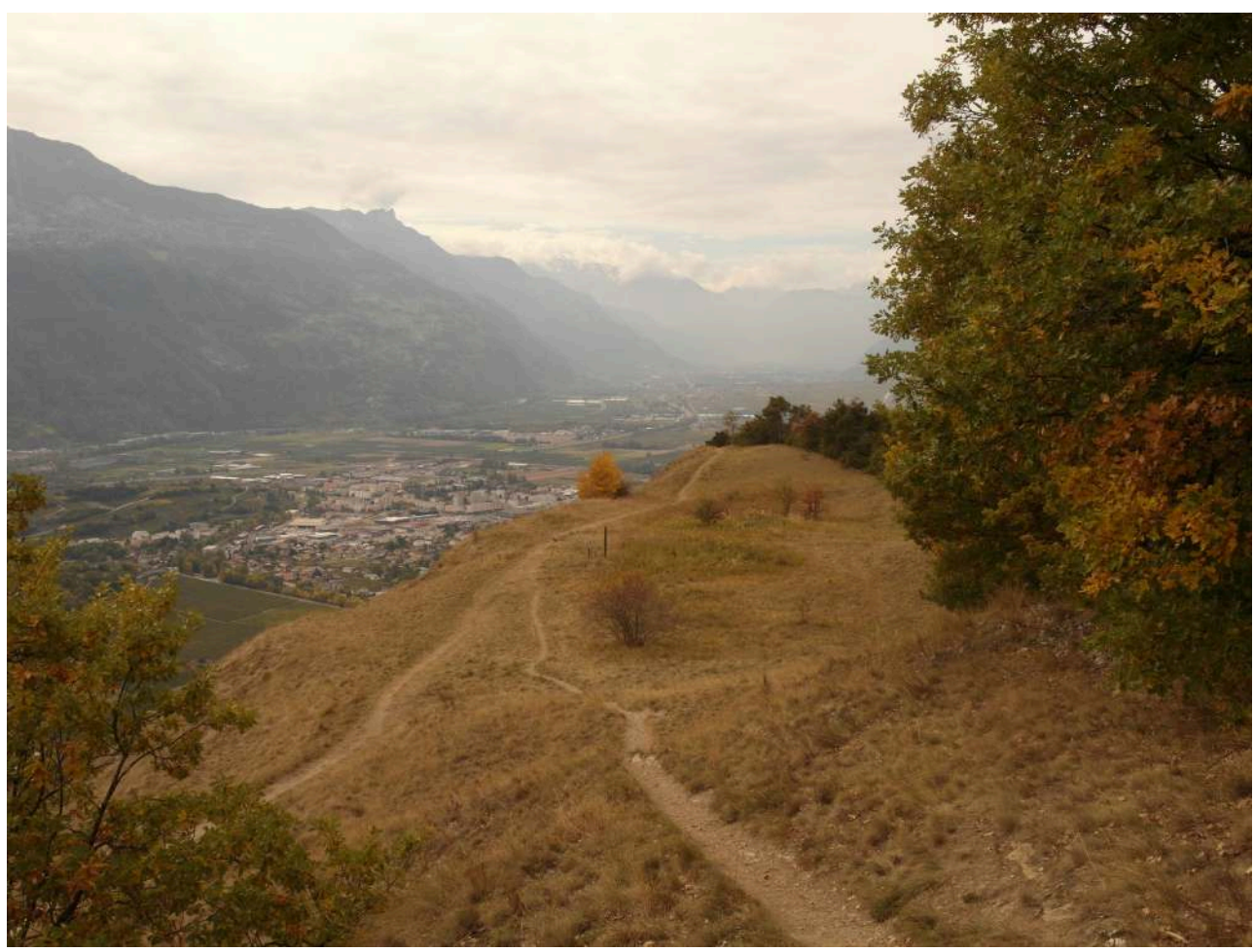

Une nuance nette dans la végétation au centre du replat marque l'emplacement des fouilles.

Photo Patricia Chiquet.

40 Repéré en 1986, puis fouillé sur une parcelle de $50 \mathrm{~m}^{2}$ au début des années 1990 sous la direction de D. Baudais, le site a livré de nombreux aménagements et des vestiges matériels se rapportant essentiellement à des occupations du Néolithique moyen et final (Baudais 1995). La première d'entre elles (couche 6), datée aux alentours de $4700-4250$ av. J.-C., a fourni une céramique se rapportant à un Néolithique moyen 1 valaisan, dont la dénomination est encore floue mais qui révèle des influences diverses (Egolzwil / Saint-Uze / culture des vases à bouche carrée ou VBQ; d'après Baudais et al. 1989-1990, Denaire et al. 2011). Les analyses archéobotaniques associées à ce niveau témoignent d'une culture des céréales prédominante et d'une exploitation du territoire qui se focalise sur l'étage collinéen (Martin 2015). Après une phase d'abandon, la colline est à nouveau fréquentée aux alentours de 3500-3 300 av. J.-C. (couche 5) et l'on y découvre une céramique attribuée à un facies régional, le Saint-Léonard (Baudais 1995, Burri-Wyser et Jammet-Reynal 2014). L'occupation du site semble se poursuivre sans véritable rupture au Néolithique final (couche 4), entre 3350 et 2950 av. J.-C., avec une céramique originale, sans équivalent pour l'instant.

41 Les niveaux du Néolithique ont livré près de 6700 restes osseux, avec une douzaine d'espèces reconnues (tabl. 5). 
Tabl. 5. - La Soie (Savièse, Valais, Suisse) : spectre de faune par ensemble chronologique.

\begin{tabular}{|c|c|c|c|c|c|c|c|c|}
\hline \multirow[t]{2}{*}{ Chronologie } & \multicolumn{2}{|c|}{$\begin{array}{c}4700-4250 / B C \\
\text { Néolithique } \\
\text { moyen } 1\end{array}$} & \multicolumn{2}{|c|}{$\begin{array}{c}\text { 3500-3300 BC } \\
\text { Néolithique } \\
\text { moyen } 2\end{array}$} & \multicolumn{3}{|c|}{$\begin{array}{l}3350-2950 \mathrm{BC} \\
\text { Néolithique } \\
\text { final }\end{array}$} & \multirow{2}{*}{$\begin{array}{l}\text { Total } \\
\text { PR }\end{array}$} \\
\hline & NR & $P R$ & NR & PR & NR & PR & NR & \\
\hline Mouton (Ovis aries) & 117 & 1451,7 & 39 & 308,1 & 35 & 318,0 & 191 & 2077,8 \\
\hline Chèvre (Capra hircus) & 29 & 226,1 & 13 & 56,6 & 32 & 556,8 & 74 & 839,5 \\
\hline Mouton/chèvre & 36 & 196,4 & 3 & 18,7 & 28 & 175,8 & 67 & 390,9 \\
\hline Chamois (Rupicapra rupicapra) & 4 & 61,9 & 2 & 12,2 & 11 & 83,3 & 17 & 157,4 \\
\hline Bouquetin (Capra ibex) & 4 & 31,3 & & - & 10 & 252,4 & 14 & 283,7 \\
\hline Chèvre/bouquetin & 4 & 28,7 & - & - & 20 & 154,9 & 24 & 183,6 \\
\hline Caprinés indéterminés & 443 & 1659 & 111 & 271,9 & 236 & 793,6 & 790 & 2724,5 \\
\hline Petits ruminants indéterminés & 399 & 864,4 & 126 & 315,1 & 234 & 580,4 & 759 & 1759,9 \\
\hline Total petits ruminants & 1036 & 4519,5 & 294 & 982,6 & 606 & 2915,2 & 1936 & 8417,3 \\
\hline Boeuf (Bos taurus) & 124 & 3820 & 55 & 746,8 & 175 & 3306,6 & 354 & 7873,4 \\
\hline Cerfélaphe (Cervus elaphus) & - & - & - & - & 1 & 48,3 & 1 & 48,3 \\
\hline Bossp. & - & - & - & - & 4 & 71,9 & 4 & 71,9 \\
\hline Grands ruminants indéterminès & 38 & 394,4 & 17 & 262,6 & 44 & 350,9 & 99 & 1007,9 \\
\hline Total grands ruminants & 162 & 4214,4 & 72 & 1009,4 & 224 & 3777,7 & 458 & 9001,5 \\
\hline Sanglier (Sus scrofa) & 4 & 116,6 & 3 & 84,4 & & . & 7 & 201,0 \\
\hline Porc (Sus domesticus) & - & - & 9 & 128,7 & 39 & 685,2 & 48 & 813,9 \\
\hline Sus sp. & 5 & 36,6 & 20 & 116,9 & 61 & 432,8 & 86 & 586,3 \\
\hline Total suinés & 9 & 153,2 & 32 & 330 & 100 & 1118 & 141 & 1601,2 \\
\hline Chien (Conis familiaris) & 1 & 0,2 & 2 & 6,3 & 3 & 17 & 6 & 23,5 \\
\hline Renard (Vulpes vulpes) & 2 & 7,2 & - & - & - & - & 2 & 7,2 \\
\hline Canidés indéterminés & 1 & 0,2 & 1 & 2,7 & 2 & 3,9 & 4 & 6,8 \\
\hline Total canidés & 4 & 7,6 & 3 & 9 & 5 & 20,9 & 12 & 37,5 \\
\hline Ours brun (Ursus arctos) & 9 & 164,4 & 2 & 8,8 & & & 11 & 173,2 \\
\hline Lynx (Lynx Iynx) & - & . & 1 & 1,6 & - & . & 1 & 1,6 \\
\hline Total divers sauvages & 9 & 164,4 & 3 & 10,4 & 0 & 0 & 12 & 174,8 \\
\hline Micromammifêres & 7 & 1,3 & 2 & $<0.1$ & 3 & 0,21 & 12 & 1,5 \\
\hline Oiseaux & 1 & $<0.1$ & - & - & 3 & 0,21 & 4 & 0,2 \\
\hline Amphibiens & 1 & 0,1 & - & - & 1 & 0.2 & 2 & 0,3 \\
\hline Microfaune & - & - & 1 & 0,1 & - & - & 1 & 0,1 \\
\hline Indéterminés & 1567 & 1812,8 & 740 & 995,6 & 1804 & 2662,2 & 4111 & 5470,6 \\
\hline Total des lignes grisées & 2796 & 10873,3 & 1147 & 3337,1 & 2746 & 10494,6 & 6689 & 24705,0 \\
\hline
\end{tabular}

NR : nombre de restes; PR : poids des restes en grammes.

Dans l'ensemble, la conservation est très bonne et plus de la moitié du matériel se trouve associée à des structures, dans la plupart des cas des fosses. Comme on le voit sur la figure $4 \mathrm{c}$, la faune identifiée à La Soie montre une présence presque exclusive d'animaux domestiques, et ce quel que soit le niveau considéré. Si les caprinés demeurent majoritaires en nombre de restes et d'individus tout au long de la séquence, ils enregistrent néanmoins un recul au cours du temps en faveur du bœuf et du porc (fig. 5c). Absent du Néolithique moyen 1, ce dernier voit en effet sa contribution dépasser les $10 \%$ au Néolithique final. Le bœuf progresse également au cours du temps, sa participation passant de 15 à $30 \%$ du nombre total de restes. Un recours à la force motrice des bovins est pressenti de façon un peu plus prononcée au Néolithique final, à travers la reconnaissance de diverses pathologies observées au niveau des phalanges et de restes appartenant à des individus âgés. La présence de veaux de quelques mois est attestée tout au long de l'occupation du site, et leur consommation est confirmée au Néolithique moyen 2. En outre, la découverte au Néolithique final de deux molaires de lait incomplètes ne présentant aucune usure et montrant une minéralisation encore limitée à l'extrémité des cuspides a permis d'identifier deux veaux morts au moment de la naissance, voire même un peu avant. Ces vestiges laissent supposer la présence des mères à proximité du site au moment des mises bas, vraisemblablement entre la fin de l'hiver et le printemps, afin de disposer des conditions optimales au moment de la lactation.

Les modes d'exploitation des caprinés témoignent également de changements notables au cours du temps. Au Néolithique moyen 1 (couche 6), la contribution des caprinés à l'alimentation carnée est notable et devait égaler celle du bœuf. Le rôle des autres espèces apparaît à ce titre tout à fait accessoire. L'élevage est principalement tourné 
vers le mouton et destiné à une production mixte de lait et de viande, si l'on se réfère aux types présentés plus haut. L'abattage se concentre d'une part sur des brebis en âge de se reproduire et réformées entre 2 et 6 ans, d'autre part sur des jeunes âgés de 6 à 24 mois, probablement en majorité des mâles, mis à mort entre leur premier et leur second automne (fig. 9a).

Fig. 9. - La Soie (Savièse, Valais, Suisse), couches 6,5 et 4 : profils d'abattage des caprinés.

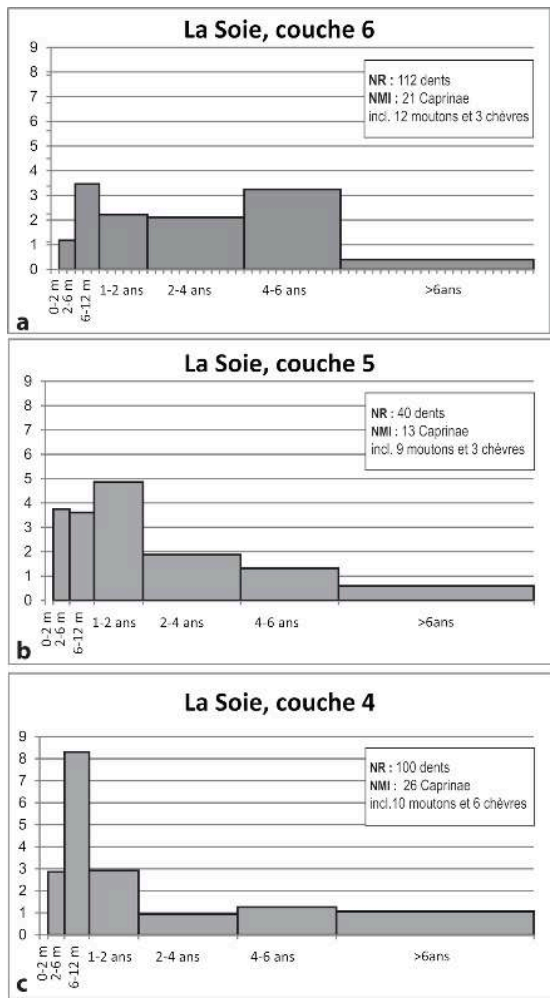

Les profils sont construits à partir du nombre de dents inférieures et supérieures (NR) décompté dans chaque classe d'âge par rapport à l'effectif total de la couche (\% des effectif), les valeurs calculées étant ensuite corrigées en fonction de la durée relative de la classe d'âge. NR : nombre de restes. NMI : nombre minimum d'individus.

PAO Patricia Chiquet.

L'histogramme indique également l'absence quasi totale de sujets âgés de moins de 6 mois. La mortalité naturelle durant la gestation et les premières semaines de vie est pourtant attestée dans ce niveau par une vingtaine d'ossements du squelette appendiculaire appartenant à trois sujets au moins, dont un fotus âgé d'environ 100 jours. Ce constat nous amène à proposer que des femelles gestantes sont présentes aux abords du site. En ce qui concerne la faible présence générale des agneaux de moins de 6 mois, elle peut s'expliquer par un maintien sur pied des jeunes tant que durent la lactation et la belle saison. Une découverte faite à Sion, avenue Ritz, un site localisé en plaine du Rhône, à une heure de marche de la colline de La Soie, nous amène également à envisager une autre possibilité. La découverte consiste en une fosse contemporaine de la couche 6, contenant du mobilier et les restes d'une quinzaine de moutons, soit six agneaux âgés de 2 à 3 mois, deux individus âgés de 9 à 15 mois et trois autres de 2 à 3 ans (Chenal-Velarde et al. 2002). Leur mort aurait eu lieu simultanément, entre mai et juin, en supposant une mise bas au printemps. La structure, localisée entre des niveaux d'habitat et une nécropole, a tout d'abord été interprétée comme le témoignage d'un 
ensevelissement suite à une épizootie (Chenal-Velarde et al. 2002). L'identification d'un fragment de calotte crânienne humaine à l'intérieur (Chiquet, inédit), remet en question cette interprétation et vient plutôt renforcer celle d'un geste rituel (repas funéraire, dépôt de fondation) proposée par d'autres auteurs (Moinat et al. 2007). Ce cas illustre bien le fait que l'abattage d'une partie du troupeau dans le cadre d'un événement ponctuel et le dépôt des restes dans une structure localisée à l'écart de l'habitat peuvent créer des manques dans les courbes d'abattage. Il permet également de se questionner sur la façon dont s'articule le site de La Soie avec la plaine du Rhône, où se concentrent les habitats et les nécropoles.

Entre 3500 et 3300 avant notre ère (couche 5), les caprinés demeurent majoritaires mais enregistrent un certain recul au profit du bœuf et des suinés. Le rapport chèvre / mouton se modifie légèrement, en faveur de la première (1/3). L'abattage concerne dans la moitié des cas des individus de moins de deux ans (fig. $9 b$ ) et suggère une exploitation plus marquée qu'auparavant de la viande, même si l'abattage plus prononcé des jeunes après sevrage (2-6 mois) dans ce niveau peut également être le signe d'une recherche d'équilibre entre productions de viande et de lait (Blaise 2005).

L'élevage préférentiel de moutons fait place au Néolithique final (couche 4) à un élevage faisant aussi bien appel au mouton qu'à la chèvre, comme l'attestent notamment plusieurs fragments de chevilles osseuses. L'élevage semble destiné avant tout à une production de viande tendre, issue d'agneaux principalement. Une réforme plus tardive des caprinés, au-delà de 6 ans, est également observable (fig. 9c). Il ne nous est pas possible de dire pour l'instant si ce phénomène est lié à la contribution bien plus marquée de la chèvre. Le fait qu'au sein de cette dernière espèce les femelles sont majoritaires alors que relativement peu de cabris sont identifiés est sans doute le signe que cet élevage est destiné à une production dont l'objectif principal n'est pas la viande tendre. Il pourrait s'agir d'une exploitation du lait, sachant que, dans les mêmes conditions d'élevage, la chèvre produit plus de lait qu'une brebis, que la lactation est plus longue et qu'elle peut donc être maintenue sur pied à un âge plus avancé, jusqu'à ce que sa productivité générale baisse significativement. Une exploitation des poils des moutons comme des chèvres est également envisageable ici, même si ce type de production peut aussi bien faire appel à des femelles qu'à des mâles maintenus à un âge avancé.

En ce qui concerne les saisons d'occupation du site, nous attendons encore les résultats des analyses isotopiques ( $\delta C$ et $\delta 0$ ) menées sur une sélection de dents de caprinés (J. Knockaert, Department of Archeology, University of York et M. Balasse, MNHN, UMR $7209 \mathrm{du}$ CNRS), qui vont permettre de préciser la saison des naissances et de mieux définir le calendrier des activités pastorales au cours du Néolithique. Une présence à différents moments de l'année, et notamment au moment des mises bas, est pour l'instant envisagée, quel que soit le niveau considéré.

\section{Discussion}

L'intérêt porté aux caprinés, même s'il varie passablement d'un site à l'autre et au cours du temps, se pose clairement en dénominateur commun de ces trois séries alpines, ce qui peut aisément s'expliquer par la bonne adéquation de ces animaux au milieu montagnard. Des images assez contrastées émergent pourtant et révèlent quelques éléments inédits. 
À La Grande Rivoire, nos résultats confortent ceux des autres approches (sédimentologie, micromorphologie, archéobotanique, archéologie) avec une présence de caprinés domestiques attestée sous l'abri dès le Néolithique ancien. Leur présence au moment des mises bas et dans les mois qui suivent s'accorde avec l'idée d'une exploitation sur place du lait. La découverte de restes de très jeunes veaux se rapportant au Néolithique ancien/ moyen 1 nécessite toutefois d'entrevoir la fréquentation du site par un troupeau mixte (caprinés-bœuf) à cette époque. Différents indices (dents de chute, périnataux...) laissent supposer une utilisation de l'abri à divers moments de l'année, de manière continue ou non, et qui associe une occupation humaine à un espace dédié au parcage des bêtes. Les occupants ont également su tirer profit des ressources sauvages dont ils disposaient dans l'environnement immédiat du site et jusque dans la plaine de l'Isère. Il est à noter que cette prédation, centrée avant tout sur le cerf, s'inscrit parfaitement dans la continuité de celle qui caractérise les niveaux antérieurs, et notamment le Néolithique ancien pré-bergerie (fig. 10).

Fig. 10. - La Grande Rivoire (Sassenage, Isère) : contribution des diverses catégories de mammifères et des tortues exploitées sur le site.

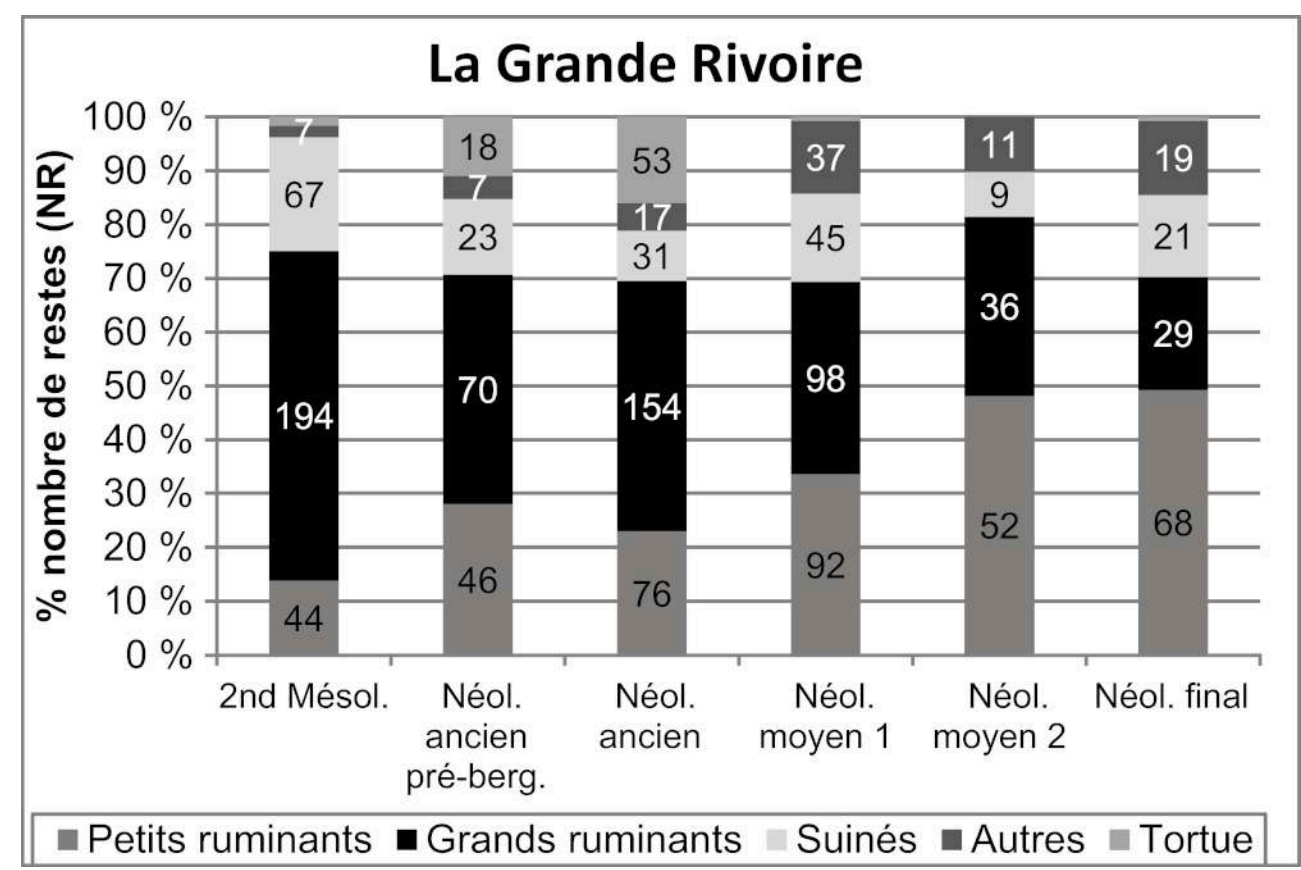

La catégorie « autres » comprend les « divers sauvages » et les « carnivores indéterminés ». Les données du Mésolithique et du Néolithique ancien pré-bergerie sont issues du travail de L. Chaix (Nicod et al. 2012).

PAO Patricia Chiquet.

Si les données demeurent encore ténues pour les niveaux datant du Néolithique moyen 2 et final, l'exploitation des petits ruminants semble cependant prendre le pas sur les autres catégories d'animaux à partir de $4000 \mathrm{av}$. J.-C., ce qui pourrait indiquer un recentrage des activités autour des caprinés domestiques, en l'absence de leurs homologues sauvages.

51 Les changements qui s'amorcent en altitude au Chenet des Pierres font d'une certaine manière écho à ceux qui s'opèrent à La Grande Rivoire, puisqu'à un approvisionnement diversifié qui mobilise largement les ressources sauvages, ici de l'étage montagnard et 
subalpin, succède au tournant du IV $V^{e}$ millénaire avant notre ère un mode d'exploitation désormais centré sur l'élevage des caprinés.

Les résultats obtenus à la grotte des Balmes, à Sollières-Sardières, en haute Maurienne (Savoie), à plus de 1350 mètres d'altitude, mettent également en évidence l'existence d'activités pastorales dans la zone interne des Alpes dès le Néolithique moyen 2 et indiquent que ce site était presque exclusivement dédié à une fonction de bergerie pendant le Néolithique final (Vital et Benamour 2012). La faune sauvage est néanmoins présente tout au long de la séquence et rappelle clairement celle identifiée au Chenet des Pierres.

Il est tentant de rapprocher les mutations économiques qui s'opèrent à La Grande Rivoire et au Chenet des Pierres du constat plus général d'une mobilité accrue des communautés durant le Néolithique moyen 2 à l'échelle des Alpes occidentales et de la vallée du Rhône. Les travaux archéozoologiques menés en moyenne vallée du Rhône suggèrent effectivement la dissociation spatiale de certaines étapes du cycle pastoral annuel au Chasséen récent (Bréhard et al. 2010, Bréhard 2011). Le système, qui repose sur l'existence de divers types de sites aux fonctionnalités différentes et qui implique un mouvement du bétail (caprinés et bovins), ou d'une partie de celui-ci, entre les sites au cours de l'année amène à envisager également l'émergence de groupes spécialisés (bergers, vachers) nécessaire à l'accompagnement des bêtes.

Dans son analyse approfondie des lames de haches en roches tenaces des Alpes occidentales et du bassin du Rhône, E. Thirault envisage également le déploiement spatial des activités pastorales comme l'un des maîtres mots de l'organisation de ces sociétés du Néolithique moyen 2. L'auteur relie le changement d'échelle de production et de diffusion des lames perceptible entre le Néolithique moyen 1 et 2 à une restructuration sociale qui témoignerait d'un nouveau rapport au territoire en lien avec les pratiques pastorales. Les réseaux d'échanges tisseraient une trame territoriale complexe, dont l'extension inégalée jusque-là reposerait sur la capacité à se mouvoir (Thirault 2004).

55 Du point de vue du mobilier céramique, une nouvelle dynamique serait perceptible au même moment dans les vallées internes et notamment au Chenet des Pierres, révélatrice d'une amplification des circulations transalpines (Rey 2016b).

À la lumière des éléments précédents, les données archéozoologiques disponibles pour le bassin de l'Isère, bien que ténues encore, nous amènent à envisager au Néolithique ancien et moyen 1 une fréquentation de l'espace montagnard prenant principalement appui sur l'exploitation des ressources naturelles, notamment la chasse, et qui permet de prendre la mesure de cet espace et des possibilités de circulations transalpines. À partir du Néolithique moyen 2, le rapport au territoire se modifie et le bétail devient peut-être le moyen d'imprimer de façon plus durable et plus tangible la marque des groupes humains fréquentant ces lieux élevés et reculés, dont le contrôle est précieux. On assisterait à une véritable appropriation de cet espace, tandis que les échanges se déploieraient à très large échelle.

De nombreuses questions demeurent à cette étape de l'étude, qu'il s'agisse par exemple de la façon dont s'articulent les sites - implantés à différentes altitudes, en bordure des massifs alpins ou dans les vallées internes, et souvent en position stratégique (Rey 2009) - ou des activités qui s'y déroulaient. Des différences fonctionnelles sont toutefois déjà perceptibles à ce stade, avec d'une part des sites sur lesquels des activités pastorales sont clairement enregistrées, que ce soit dès le Néolithique ancien en 
périphérie du massif, comme à La Grande Rivoire, ou plus tard dans les vallées internes, comme au Chenet des Pierres ou à la grotte des Balmes; d'autre part, des lieux d'altitude qui fonctionneraient davantage comme site relais ou de contrôle du territoire, avec une fréquentation de courte durée et une subsistance basée sur des activités de prédation.

Du côté de la haute vallée du Rhône, la faune du site de La Soie reproduit en apparence les données compilées jusqu'ici en Valais central pour le Néolithique, avec une économie animale reposant essentiellement sur l'élevage (Chaix 1976, Chiquet 2011, Reynaud Savioz et Chauvière 2011). Entre 4700 et 2950 avant notre ère, nous y observons toutefois très clairement une diversification de l'élevage et sans doute aussi des productions au cours du temps, avec notamment une contribution toujours plus importante de la chèvre aux côtés du mouton ainsi qu'une progression du bœuf et du porc.

Si la complémentarité entre moutons et chèvres pressentie dans la couche 4 est régulièrement envisagée au Néolithique, en Valais ou ailleurs en vallée du Rhône, en termes de production (Reynaud Savioz et Chauvière 2011, Helmer et Vigne 2004, Blaise et al. 2010), le recours aux deux taxons peut également être un moyen d'optimiser l'exploitation du milieu. En effet, les moutons et les chèvres présentent des préférences alimentaires qui les conduisent vers des espaces distincts : les premiers affectionnent les surfaces herbeuses, tandis que les secondes se nourrissent volontiers de feuillage et s'accommodent bien de secteurs embroussaillés, plutôt rocheux ou trop pentus, qui ne conviennent pas au mouton. À cet égard, l'intérêt croissant pour les chèvres observé à La Soie, qui trouve un certain écho sur le site de Pranoé, à Bramois, en plaine du Rhône, au sein de deux bâtiments semi-enterrés datant du Néolithique final (Reynaud Savioz et Chauvière 2011), s'il peut s'expliquer par un besoin croissant en produits laitiers, peut également traduire la nécessité de conquérir ou de débroussailler certains espaces. Dans un environnement relativement confiné, la mobilisation plus intensive du bœuf, dont la force et le fumier constituent de précieux alliés pour l'agriculteur, a pu effectivement conduire ce dernier à rechercher de nouveaux espaces pastoraux afin de répondre aux besoins accrus en fourrage. En ce qui concerne le porc, sa capacité de reproduction ainsi que son régime alimentaire omnivore présentent des avantages évidents par rapport aux ruminants, puisque son élevage peut être développé rapidement sans empiéter sur les terres arables. Le transfert d'une partie de la production de viande vers cette espèce au Néolithique final a pu constituer un véritable atout dans un contexte d'intensification agropastorale. Un phénomène comparable a été mis en évidence en Suisse occidentale à partir du XxxIv siècle avant notre ère, dans la région des Trois Lacs (Kerdy et al. 2019), et en moyenne vallée du Rhône sur les sites de plein air (Blaise et al. 2010).

Face à ces multiples changements, dont les premiers signes se font déjà sentir à la fin du Néolithique moyen 2, on est en droit de se demander s'ils ne sont pas l'illustration d'une restructuration des activités au sein d'un territoire où l'exploitation des ressources et de leur étagement est repensée. En combinant l'élevage de différentes espèces, les hommes ont pu chercher à se garantir une certaine marge de manœuvre face à des épisodes de crise (changement climatique, épizootie, appauvrissement des sols...) tout en assurant une nouvelle complémentarité entre le bas et le haut, le sec et l'humide, le boisé et l'herbagé. 
61 Cette hypothèse trouve peut-être un certain écho dans les découvertes faites aux abords du col du Schnidejoch, à 2750 mètres d'altitude (Hafner et Schwörer 2018). Si les auteurs de cette étude proposent un emploi de ces hauts pâturages dès le Néolithique moyen par des communautés agropastorales issues de la région de Sion, une amplification des témoignages n'est clairement perceptible qu'à partir du Néolithique final. À l'échelle du Valais, les trouvailles en altitude semblent elles aussi s'intensifier au Néolithique final, signe possible d'un développement des échanges et des communications transalpines (Curdy et al. 1999, Curdy 2007).

Sur la base des données archéobotaniques (Haas et al. 1998), l'occupation Néolithique final du site de La Soie (3350-2950 avant notre ère) se placerait plutôt au cours d'un épisode de dégradation ou du moins d'instabilité climatique. Ainsi, les changements qui s'opèrent au cours du IV millénaire avant notre ère sur le coteau de Savièse, soumis aujourd'hui à un climat plutôt chaud et sec et sur lequel est localisé le site de La Soie, pourraient être interprétés comme une réponse à des fluctuations climatiques qui ont dû agir sur la disponibilité des ressources végétales et la fréquentation de l'espace montagnard. La création relativement récente des "bisses " valaisans, ces canaux construits au prix de gros efforts afin d'irriguer les terres, témoigne de l'équilibre fragile instauré entre l'homme et son environnement dans la région.

Même si l'on ne peut exclure pour l'instant que l'élevage bovin se soit développé sans entrer en compétition avec celui des caprinés grâce à la mise à profit de la plaine alluviale, le fait que le chamois et surtout le bouquetin, espèce emblématique de la montagne, deviennent plus visible à La Soie durant le Néolithique final constitue peutêtre le signe d'une pression de plus en plus forte qui s'exerce en direction des prairies d'altitude. Combiné à un intérêt croissant pour le porc, perçu comme le marqueur d'une certaine sédentarité, n'aurait-on point ici l'illustration de ce " compromis entre la fixation des territoires et l'emprise mouvante et temporaire des troupeaux » (Rendu 2003 : p. 526), voire d'une dissociation saisonnière entre le bas et le haut?

\section{Conclusion}

Cette recherche, toujours en cours, a révélé que les différences observées en termes de moyens de subsistance entre la haute vallée du Rhône (Valais) et le bassin de l'Isère, différences qui ne sont certainement pas sans rapport avec la manière dont les premières communautés agropastorales se mettent en place (acculturation vs colonisation?), tendent à s'estomper progressivement au cours du Néolithique. Un recentrage des activités autour des chèvres et des moutons semble ainsi s'opérer dans le bassin de l'Isère au tournant du $\mathrm{IV}^{\mathrm{e}}$ millénaire avant notre ère tandis qu'en Valais, l'élevage des caprinés s'est imposé dès le Néolithique ancien. Une diversification de l'élevage au cours du temps est toutefois perceptible dans les deux régions et tend à se renforcer au Néolithique final. Reste à déterminer aujourd'hui si cette évolution n'indique pas une diversification, voire une complexification des pratiques d'élevage, en lien avec un ancrage au sol plus fort ou une pression démographique accrue, à l'instar de ce qui a été décrit pour le midi de la France (Blaise et al. 2010).

Pour l'instant, les changements économiques enregistrés à partir du Néolithique moyen 2 dans les trois établissements étudiés nous paraissent en tout cas illustrer un processus similaire, à savoir une (re)structuration progressive du territoire et une appropriation de toute la hauteur du versant, qui s'appuierait sur les activités 
pastorales. Seule la poursuite des analyses et l'intégration d'un plus grand nombre de séries permettront d'affiner notre grille de lecture et d'étayer ces premières hypothèses. Les résultats des analyses isotopiques $(\delta C$ et $\delta 0$ ) actuellement en cours sur une sélection de dents de caprinés (J. Knockaert, Department of Archeology, University of York et M. Balasse, MNHN, UMR 7209 du CNRS) seront également d'un soutien précieux dans la définition de l'organisation des activités pastorales au sein de ces communautés alpines.

\section{BIBLIOGRAPHIE}

BALASSE M., TRESSET A., BĂLĂșESCU A., BLAISE E., TORNERo C., GANDOIS H., FIORILlo D., NYERGES E. A., FRÉMONDEAU D., BANFFY E., IVANOVA M., 2017, « Animal Board Invited Review: Sheep birth distribution in past herds, a review for prehistoric Europe (6th to 3rd millenia BC) », Animal, vol. 11, n 2, p. 2229-2236.

BAUDAIS D., 1995, « Le camp néolithique de Savièse, La Soie », dans Gallay A. (dir.), Dans les Alpes à l'aube du métal : archéologie et bande dessinée, Sion, Musées cantonaux du Valais, p. 91-96.

BAUDAIS D., CURDY P., DAVID-ELBIALI M., MAY O., 1987, « Prospection archéologique du Valais : une approche du peuplement préhistorique », Archéologie suisse, vol. 10, nº 1, p. 2-12.

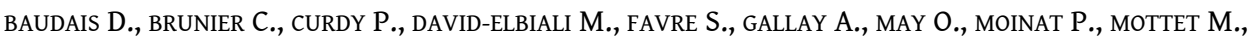
VORUZ J.-L., WINIGER A., 1989-1990, « Le Néolithique de la région de Sion (Valais) : un bilan », Bulletin du Centre genevois d'anthropologie, vol. 2, p. 5-56.

BEECHING A., 2003, « Mobilité et sociétés néolithiques dans les Alpes occidentales et la France méridionale », Preistoria alpina, vol. 39, p. 175-187.

BEECHING A., BERGER J.-F., BROCHIER J.-L., FERBER F., HELMER D., SIDI MAAMAR H., 2000, « Chasséens : agriculteurs ou éleveurs, sédentaires ou nomades? Quels types de milieux, d'économies et de sociétés ? » dans Leduc M., Valdeyron N., Vaquer J. (dir.), Sociétés et espaces : rencontres méridionales de préhistoire récente, Toulouse, Archives d'écologie préhistorique, p. 59-79.

BESSE M. et PIGUET M. (dir.), 2011, Le site préhistorique du Petit-Chasseur (Sion, Valais). 10 : un hameau du Néolithique moyen, Lausanne, Musée cantonal d'archéologie et d'histoire (Cahiers d'archéologie romande, 124).

BINTZ P., ARGANT J., CHAIX L., BRESSY C., COUSSERAN S., JEANNET M., MARTIN L., MORIN A., NATON H.-G., OZANNE J.-C., PELLETIER D., THIÉBAULT S., 2015, « Archéologie et paléoenvironnement dans la réserve des Hauts de Chartreuse : le site de l'Aulp du Seuil à Saint-Bernard-du-Touvet ", dans Collin A. (dir.), Archives environnementales et évolution des écosystèmes : étudier le passé pour comprendre le présent et éclairer l'avenir, Dijon, Réserves naturelles de France (Cahiers RNF, 5), p. 23-37.

BLAISE E., 2005, « L'élevage au Néolithique final dans le sud-est de la France : éléments de réflexion sur la gestion des troupeaux ", Anthropozoologica, vol. 40, n 1, p. 191-216. 
BLAISE E., 2006, « Référentiel actuel de brebis “Préalpes du sud” (Dignes, Alpes-de-HauteProvence, France) : pratiques d'élevage et âges dentaires », Anthropozoologica, vol. 41, n 2, p. 191-214.

BLAISE E., BRÉHARD S., CARRÈRE I., FAVRIE T., GOURICHON L., HELMER D., RIVIÈRE J., TRESSET A., VIGNE J.-D., 2010, « L'élevage du Néolithique moyen 2 au Néolithique final dans le midi méditerranéen de la France : état des données archéozoologiques », dans Lemercier O., Furestier R., Blaise E. (dir.), Quatrième millénaire: du Néolithique moyen au Néolithique final dans le sud-est de la France et les régions voisines, Lattes, Association pour le développement de l'archéologie en Languedoc-Roussillon (Monographies d'archéologie méditerranéenne, 27), p. 261-284.

BOESSNECK J., MÜLLER H.-H., TEICHERT M., 1964, Osteologische Unterscheidungsmerkmale zwischen Schaf (Ovis aries, Linné) und Ziege (Capra hircus, Linné), Berlin, Akademie-Verlag (Kühn-Archiv, 78).

BRÉHARD S., 2011, « Le complexe chasséen vu par l'archéozoologie : révision de la dichotomie Nord-Sud et confirmation de la partition fonctionnelle au sein de sites méridionaux ", Bulletin de la Société préhistorique française, vol. 108, $\mathrm{n}^{\circ} 1$, p. 73-92.

BRÉHARD S., BEECHING A., VIGNE J.-D., 2010, « Shepherds, cowherds and site function on middle Neolithic sites of the Rhône valley: an archaeological approach to the organization of territories and societies ", Journal of Anthropological Archaeology, n² 29, p. 179-188.

BRIDAULT A. et CHAIX L, 1999, « Contribution de l'archéozoologie à la caractérisation des modalités d'occupation des sites alpins et jurassiens, de l'Épipaléolithique au Néolithique », dans Thévenin A. et Bintz P. (dir.), L'Europe des derniers chasseurs : Épipaléolithique et Mésolithique. Actes du $5^{e}$ Colloque international UISPP, commission XII, Grenoble, 18-23 septembre 1995, Paris, Éditions du CTHS, p. 547-558.

BROCHIER J.-L. et BEECHING A., 2006, « Grottes bergeries, pastoralisme et mobilité dans les Alpes au Néolithique » dans Jourdain-Annequin C. et Duclos J.-C. (dir.), Aux origines de la transhumance : les Alpes et la vie pastorale d'hier à aujourd'hui, Paris, Picard, p. 131-157.

BROCHIER J.-L. et BEECHING A., 2008, « Les grottes bergeries dans le système pastoral », dans Jospin J.-P. et Favrie T. (dir.), Premiers bergers des Alpes : de la préhistoire à l'Antiquité, catalogue d'exposition (avril 2008-juin 2009, Grenoble, Musée dauphinois), Gollion, Infolio, p. 69-74.

BRoChier J.-E., VIlla P., GiacomarRa M., TAGLiacozzo A., 1992, « Shepherds and sediments : Geoethnoarchaeology of pastoral sites ", Journal of Anthropological Archaeology, n 11, p. 47-102.

BURRI-WYSER E. et JAMMET-REYNAL L., 2014, « La seconde partie du Néolithique moyen de Suisse occidentale (4000-3350 BC) : essai de synchronisation des cultures rhodaniennes et lacustres ", dans Sénépart I., Leandri F., Cauliez J., Perrin T., Thirault É. (dir.), Chronologie de la Préhistoire récente dans le sud de la France : acquis 1992-2012, actualité de la recherche, Toulouse, Archives d'écologie préhistorique, p. 75-86.

CHAIX L., 1976, La faune néolithique du Valais, Suisse : ses caractères et ses relations avec les faunes néolithiques des régions proches, Genève, Imprimerie nationale.

CHAIX L., GUINAND B., OLIVE C., 1991, « Aspects de la transition entre les populations de chasseurs et d'éleveurs dans les Alpes du nord et le sud du Jura : les données de l'archéozoologie » dans Mésolithique et néolithisation en France et dans les régions limitrophes, actes du $113^{e}$ Congrès national des sociétés savantes, Strasbourg 1988, Paris, Éditions du CTHS, p. 309-322.

CHENAL-VELARDE I., PUTELAT O., FERNÁNDEZ H., 2002, La faune du site néolithique de Sion-Avenue Ritz (Valais, Suisse) : histoire d'un élevage villageois il y a 5000 ans, Oxford, Archaeopress (BAR International Series, 1081). 
CHIQUET P., 2011, « La faune du Petit-Chasseur à Sion (Valais) revisitée », dans Besse M. et Piguet M. (dir.), Le site préhistorique du Petit-Chasseur (Sion, Valais), 10 : un hameau du Néolithique moyen, Lausanne, Musée cantonal d'archéologie et d'histoire (Cahiers d'archéologie romande, 124), p. 217-254.

CHIQUET P., 2012, La faune du Néolithique moyen de Concise (Vaud, Suisse) : analyse des modes d'exploitation des ressources animales et contribution à l'interprétation de l'espace villageois, Lausanne, s. n. (Cahiers d'archéologie romande, 131).

CROTTI P., CURDY P., DAVID M., FARJON K., GALLAY A., PIGNAT G., STUDER J., WERYMUS E., 1983, « Le territoire des sites du Néolithique moyen valaisan (Suisse) », Bulletin d'études préhistoriques alpines, $\mathrm{XV}$ ( $\mathrm{n}^{\circ}$ spécial Le peuplement de l'intérieur du massif alpin de la Préhistoire à la fin de l'Antiquité), p. 55-80.

CURDY P., 2007, « Prehistoric settlement in middle and high altitudes in the Upper Rhone Valley (Valais-Vaud, Switzerland): a summary of twenty years of research », Preistoria Alpina, $\mathrm{n}^{\circ} 42$, p. 99-108.

CURDY P. et CHAIX L., 2013, « Les premiers pasteurs du Valais (Suisse) », dans Borrello M. A. (dir.), Les hommes préhistoriques et les Alpes, Oxford, Archaeopress (BAR International Series, 2476), p. 85-94.

CURDY P., DAVID-ELBIALI M., HONEGGER M., 1999, « Le peuplement du Mésolithique à la fin de l'âge du Fer dans les Alpes de Suisse occidentale » dans Della Casa P. (dir.), Prehistoric alpine environment, society and economy, Bonn, R. Habelt, p. 47-59.

CURDY P., SUTER P. J., WIBLÉ F., 2015, « Les trouvailles préhistoriques, d'époque romaine et du haut Moyen Âge sur les versants nord et sud des Alpes bernoises ", dans Hafner A. (dir.), Schnidejoch et Lötschenpass : investigations archéologiques dans les Alpes bernoises, Berne, Service archéologique du canton de Berne, p. 130-223.

DELHON C., MARTIN L., ARGANT J., THIÉBAULT S., 2008, « Shepherds and plants in the Alps: Multi-proxy archaeobotanical analysis of neolithic dung from La Grande Rivoire (Isère, France) », Journal of Archaeological Science, $\mathrm{n}^{\circ}$ 35, p. 2937-2952.

DENAIRE A., DOPPLER T., NICOD P.-Y., VAN WILLIGEN S., 2011, « Espaces culturels, frontières et interactions au $5^{\mathrm{e}}$ millénaire entre la plaine du Rhin supérieur et les rivages de la Méditerranée », Annuaire d'archéologie suisse, $\mathrm{n}^{\circ}$ 94, p. 21-59.

DUGUY R. et BARON J.-P., 1998, « La cistude d'Europe, Emys orbicularis, dans le marais de Brouage (Char-Mar.) : cycle d'activité, thermorégulation, déplacements, reproduction et croissance ", Annales de la Société des sciences naturelles de la Charente-Maritime, t. VIII, nº 7, p. 781-803.

FERNANDEZ H., 2001, « Ostéologie comparée des petits ruminants eurasiatiques sauvages et domestiques (genres Rupicapra, Ovis, Capra et Capreolus) : diagnose différentielle du squelette appendiculaire ", thèse de doctorat en biologie (Sc. 3286), Genève, université de Genève.

GALLAY A., 1983, De la chasse à l'économie de production en Valais : un bilan et un programme de recherche, Genève, université de Genève (Documents du département d'anthropologie, 7).

Gallay A., olive P., CARAzZetti R., 1983, « Chronologie C14 de la séquence Néolithique-Bronze ancien du Valais (Suisse) », Annuaire de la Société suisse de préhistoire et d'archéologie, nº 66, p. 43-73. GILLIS R., CHAIX L., VIGNE J.-D., 2011, « An assessment of morphological criteria for discriminating sheep and goat mandibles on a large prehistoric archaeological assemblage (Kerma, Sudan) », Journal of Archaeological Science, $\mathrm{n}^{\circ}$ 38, p. 2324-2339. 
HAAS J. N., RICHOZ I., TINNER W., WICK L., 1998, « Synchronous Holocene climate oscillations recorded on the Swiss Plateau and at timberline in the Alps ", Holocene, $n^{\circ}$ 8, p. 301-309.

HAFNER A. (dir.), 2015, Schnidejoch et Lötschenpass : investigations archéologiques dans les Alpes bernoises, Berne, Service archéologique du canton de Berne.

HAFNER A. et SCHWÖRER C., 2018, « Vertical mobility around the high-alpine Schnidejoch Pass: indications of Neolithic and Bronze Age pastoralism in the Swiss Alps from paleoecological and archaeological sources ", Quaternary International, vol. 484, p. 3-18.

HELMER D., 1984, « Le parcage des moutons et des chèvres au Néolithique ancien et moyen dans le sud de la France ", dans Clutton-Brock J. et Grigson C. (dir.), Animals and Archaeology, 3: Early Herders and their Flocks, Oxford, Archaeopress (BAR International Series, 202), p. 39-45.

HELMER D., 2000, « Discrimination des genres Ovis et Capra à l'aide des prémolaires inférieures 3 et 4 et interprétation des âges d'abattage : l'exemple de Dikili Tash (Grèce) ", Anthropozoologica, vol. 3 / Ibex, vol. 5 ( $\mathrm{n}^{\circ}$ spécial La gestion démographique des animaux à travers le temps), p. 29-38.

HELMER D. et VIGNE J.-D., 2004, « La gestion des cheptels de caprinés au Néolithique dans le midi de la France », dans Bodu P. et Constantin C. (dir.), Approches fonctionnelles en préhistoire : actes du Congrès préhistorique de France, 24-26 novembre 2000, Nanterre, Paris, Société préhistorique française, p. 397-407.

HELMER D., GOURICHON L., SIDI MAAMAR H., VIGNE J.-D., 2005, « L'élevage des caprinés néolithiques dans le sud-est de la France : saisonnalité des abattages, relations entre grottes bergeries et sites de plein air ", Anthropozoologica, vol. 40, n 1, p. 167-189.

KERDY M., CHIQUET P., SCHIBLER J., 2019, « Hunting, husbandry, and Human-environment interactions in the Neolithic lakeshore sites of Western Switzerland », European Journal of Archaeology, vol. 1, no 19 (doi:10.1017/eaa.2018.32).

MARGUET A., BINTZ P., NICOD P.-Y., PICAVET R., REY P.-J., THIRAULT É., 2008, « Éléments pour une histoire du peuplement nord-alpin français entre 10000 et 2700 BP », dans Desmet M. (dir.), Du climat à l'homme : dynamique holocène de l'environnement dans le Jura et les Alpes. Actes du Colloque GDR JURALP, Le Bourget-du-Lac, université de Savoie, p. 225-252.

MARTIN L., 2014, Premiers paysans des Alpes : alimentation végétale et agriculture au Néolithique, Rennes, Presses universitaires de Rennes / Tours, Presses universitaires François Rabelais (Tables des Hommes).

MARTIN L., 2015, « Plant economy and territory exploitation in the Alps during the Neolithic (5000-4200 cal. BC): first results of archaeobotanical studies in the Valais (Switzerland)», Vegetation History and Archaeobotany, $\mathrm{n}^{\circ} 24$, p. 63-73.

MOINAT P., BAUDAIS D., BRUNIER C., 2007, « Les sites de l'avenue Ritz et du chemin des Collines : deux exemples de nécropoles en ville de Sion (Valais, Suisse) », dans Moinat P. et Chambon P. (dir.), Les cistes de Chamblandes et la place des coffres dans les pratiques funéraires du Néolithique moyen occidental : actes du colloque de Lausanne, 12-13 mai 2006, Lausanne, Cahiers d'archéologie romande (Cahiers d'archéologie romande, 110)/Paris, Société préhistorique française (Mémoires de la Société préhistorique française, XLIII), p. 277-296.

MONIN G., GRIGGO C., FOURNIER J., OBERLIN C., 2010, « Exploitation d'un écosystème alpin au Tardiglaciaire : les chasseurs de marmottes (Marmota marmota) du Vercors. Données environnementales, culturelles et économiques ", dans Tzortis S. et Delestre X. (dir.), Archéologie de la montagne européenne : actes de la table ronde internationale de Gap, Quétigny, Librairie archéologique (Bibliothèque d'archéologie méditerranéenne et africaine, 4), p. 171-185. 
MÜLLER K., 1995, « Le site de Sion-Torbillon (VS) : nouvelles données sur le Néolithique ancien valaisan », Archéologie suisse, vol. 18, $\mathrm{n}^{\circ}$ 3, p. 102-108.

NICOD P.-Y., 2008, «Les premières sociétés agropastorales dans les Alpes occidentales », dans Jospin J.-P. et Favrie T. (dir.), Premiers bergers des Alpes : de la préhistoire à l'Antiquité, Gollion, Infolio, p. 44-51.

NICOD P.-Y. et PICAVET R., 2014, Fouille archéologique de la Grande Rivoire à Sassenage (Isère) : rapport de fouille 2012-2014 (opération programmée pluriannuelle 2012-2014), Grenoble, Conseil général de l'Isère.

NICOD P.-Y., PICAVET R., ARGANT J., BROCHIER J.-L., CHAIX L., DELHON C., MARTIN L., MOULIN B., SORDOILLET D., THIÉBAULT S., 2010, « Une économie pastorale dans le nord du Vercors : analyse pluridisciplinaire des niveaux néolithiques et protohistoriques de la Grande Rivoire (Sassenage, Isère) », dans Beeching A., Thirault É., Vital J. (dir.), Économie et société à la fin de la préhistoire : actualité de la recherche. Actes des $7^{e}$ Rencontres méridionales de préhistoire, Lyon, Maison de l'Orient et de la Méditerranée, p. 69-86.

NICOD P.-Y., PERRIN T., BROCHIER J.-L., CHAIX L., MARQUEBIELLE B., PICAVET R., VANNIEUWENHUYSE D., 2012, «Continuités et ruptures culturelles entre chasseurs mésolithiques et chasseurs néolithiques en Vercors : analyse préliminaire des niveaux du Mésolithique récent et du Néolithique ancien ", dans Perrin T., Cauliez J., Sénépart I., Thirault É., Bonnardin S. (dir.), Dynamismes et rythmes évolutifs des sociétés de la Préhistoire récente : actes des $9^{e}$ Rencontres méridionales de préhistoire, Toulouse, Archives d'écologie préhistorique, p. 13-32.

PAYNE S., 1973, « Kill-off patterns in sheep and goats: the mandibules from Asvan Kale », Anatolian studies, $\mathrm{n}^{\circ} 23$, p. 281-303.

RENDU C., 2003, La montagne d'Enveig, une estive pyrénéenne dans la longue durée, Canet, Trabucaire.

REY P.-J., 2006, « Le site du Chenet des Pierres aux Moulins de Bozel (Savoie, France) : une nouvelle séquence néolithique alpine ", dans Alpis Graia : archéologie sans frontières au col du PetitSaint-Bernard. Séminaire de clôture, Aoste, 2-4 mars 2006, projet Interreg IIIA Alcotra 2000-2006, Aoste, Musumeci, p. 361-370.

REY P.-J., 2009, « Sociétés et fluctuations du climat dans les Alpes nord-occidentales au Néolithique moyen ", dans Deline P. et Ravanel L. (dir.), Neige et glace de montagne : reconstitution, dynamique, pratiques, Chambéry, Edytem (Cahiers Edytem, 8), p. 37-50.

REY P.-J., 2015, «Bozel, Chenet des Pierres, un site néolithique en contexte alpin », dans Journées archéologiques régionales, Saint-Vulbas, 2014 : le Néolithique en région Rhône-Alpes, dix ans de recherches archéologiques (2004-2013), Lyon, Service régional de l'archéologie Rhône-Alpes, vol. 2, p. 15-21.

REY P.-J., 2016a, « Les productions céramiques du Chenet des Pierres (Bozel, Savoie, France) dans le contexte des relations transalpines au Néolithique moyen ", Bulletin d'études préhistoriques et archéologiques alpines, t. XXVII (Archeologia del Movimiento, circulation des hommes et des biens dans les Alpes), p. 331-335.

REY P.-J., 2016b, « Éléments pour une approche de l'évolution des styles céramiques entre l'axe Saône-Rhône et les Alpes savoyardes, de 4500 à 3400 avant notre ère ", dans Perrin T., Chambon P., Gibaja J.-F., Goude G. (dir.), Le Chasséen, des Chasséens... Retour sur une culture nationale et ses parallèles, Sepulcres de fossa, Cortaillod, Lagozza, actes du colloque tenu à Paris, 18-20 novembre 2014, Toulouse, Archives d'écologie préhistorique, p. 501-539.

REYNAUD SAVIOZ N. et CHAUVIÈRE F.-X., 2011, « La faune et l'industrie sur matières dures d'origine animale », dans Mottet M., Gentizon A.-L., Haller M., Giozza G., Les bâtiments semi-enterrés de 
Bramois : un habitat du Néolithique final en Valais (Suisse), Lausanne, Cahiers d'archéologie romande (Cahiers d'archéologie romande, 126 / Archaeologia Vallesiana, 8), p. 77-122.

THIRAULT E., 2004, Échanges néolithiques : les haches alpines, Montagnac, Monique Mergoil (Préhistoires, 10).

VAN Willigen S., D’ANNA A., RENAUlt S., SARGiano J.-P., 2016, « Le Chasséen dans le midi de la France : questions de définition et de chronologie », dans Perrin T., Chambon P., Gibaja J.-F., Goude G. (dir.), Le Chasséen, des Chasséens... Retour sur une culture nationale et ses parallèles, Sepulcres de fossa, Cortaillod, Lagozza, actes du colloque tenu à Paris, 18-20 novembre 2014, Toulouse, Archives d'écologie préhistorique, p. 457-470.

VIGNE J.-D., 1988, Les mammifêres post-glaciaires de Corse :étude archéozoologique, Paris, CNRS Éditions, Gallia préhistoire (suppl. 26).

VIGNE J.-D. et HELMER D., 2007, « Was milk a "secondary product" in the Old World Neolithisation process? Its role in the domestication of cattle, sheep and goats ", Anthropozoologica, vol. 42, $\mathrm{n}^{\circ} 2$, p. 9-40.

VITAL J. et BENAMOUR P. (dir.), 2012, La grotte des Balmes à Sollières-Sardières (Savoie), du Néolithique moyen 2 à l'âge du Fer, Lyon, Maison de l'Orient et de la Méditerranée (DARA, 36).

ZEDER M. A. et PILAAR S. E., 2010, « Assessing the reliability of criteria used to identify mandibles and mandibular teeth in sheep, Ovis, and goats, Capra ", Journal of Archaeological Science, $\mathrm{n}^{\circ} 37$, p. $225-242$.

\section{RÉSUMÉS}

Cet article présente les premiers résultats de l'étude archéozoologique de trois sites localisés dans les Alpes occidentales et occupés au Néolithique: La Grande Rivoire (Sassenage, Isère, France), Le Chenet des Pierres (Bozel, Savoie, France) et La Soie (Savièse, Valais, Suisse). Les analyses indiquent un recours important au gibier dans le bassin de l'Isère, tandis qu'en Valais, l'élevage est pratiqué de manière quasi exclusive. Les différences observées en termes de moyens de subsistance tendent cependant à s'estomper au cours du Néolithique, puisqu'un recentrage des activités autour des caprinés domestiques s'opère dans le bassin de l'Isère au tournant du IV millénaire avant notre ère. Une diversification de l'élevage au cours du temps est perceptible dans les deux régions et tend à se renforcer au Néolithique final. Les mutations économiques enregistrées au cours du Néolithique paraissent illustrer un même processus, une appropriation progressive de l'espace montagnard prenant appui sur les activités pastorales.

Recent analyses have been conducted on animal remains from Neolithic settlements located in the Upper Rhone Valley (Valais, Switzerland) and in the Northern French Alps in order to characterize breeding practices. Initial results suggest that the two regions under review offer different economic systems, with a significant use of game in the Isère basin, whereas in the Valais region, breeding is practised almost exclusively. The differences observed in terms of means of subsistence between these regions, however, tend to fade during the Neolithic, since a refocusing of activities around goats and sheep seems to be taking place in the Isère basin at the turn of the 4th millennium BC. A diversification of breeding over time is perceptible in both regions and tends to strengthen in the Final Neolithic. The economic changes recorded seem to illustrate the same process, a progressive (re)structuring of the territory that reflects an appropriation of the mountain area based on pastoral activities. 
INDEX

Mots-clés : archéozoologie, élevage, Néolithique, pastoralisme, territoire, Vallais

Keywords : Archaeozoology, Neolithic, Western Alps, Herd management, Pastoralism, Territory, Isère basin, Valais region

Index géographique : bassin de l'Isère, Alpes occidentales

\section{AUTEUR}

\section{PATRICIA CHIQUET}

Chercheure associée au Muséum d'histoire naturelle de Genève, Archéozoologie 


\title{
Des structures d'habitat en haute
} montagne de la fin du Campaniforme et du Bronze ancien (2 300-2 000 avant notre ère) au cirque de Troumouse (La Haille de Pout, Gèdre, Hautes-Pyrénées) : premiers résultats

\author{
High-mountain settlement structures at the end of the Bell-Beaker \\ culture and Early Bronze Age (2,300-2,000 BC) at the Cirque de \\ Troumouse (La Haille de Pout, Gèdre, Hautes-Pyrénées): first results
}

Guillaume Saint-Sever et Maxime Remicourt

1 Depuis une trentaine d'années, de nombreux travaux ont permis de mieux appréhender les différentes modalités de la gestion des milieux montagnards par les populations pré- et protohistoriques, au travers d'études environnementales ou archéologiques. Cette contribution s'inscrit dans la continuité de ces recherches, à partir de la découverte de structures d'habitat à 2000 mètres d'altitude, dans le cirque de Troumouse, au lieu-dit La Haille de Pout, sur la commune de Gèdre (Hautes-Pyrénées), attribuables à la fin du Campaniforme et au début du Bronze ancien.

Les travaux sur le gisement en étant encore à leurs prémices, il n'est pas pour l'heure possible de déterminer tous les tenants et aboutissants qui ont motivé cette implantation de haute montagne. Il est toutefois possible de dégager quelques pistes, à partir des données paléo-environnementales ou encore des vestiges mobiliers et immobiliers mis au jour lors des premières campagnes de fouille. En corrélant ces données avec les résultats paléo-environnementaux plus généraux, qui indiquent une augmentation de la pression anthropique sur les espaces montagnards boisés pour 
cette période dans les Hautes-Pyrénées et des indices de pollutions métalliques, ainsi qu'en comparant les vestiges mobiliers issus du site de Troumouse à ceux de régions voisines, il est dès lors envisageable d'affiner les hypothèses sur la fonctionnalité du gisement et les relations culturelles de ces occupants.

Le site de La Haille de Pout a été découvert en 2015 par T. Perrin (2015) et son équipe, dans le cadre d'une campagne de prospections et de sondages visant à identifier d'éventuelles traces d'occupations attribuables à la Préhistoire récente dans le cirque de Troumouse, sur la commune de Gèdre, dans les Hautes-Pyrénées (fig. 1).

Fig. 1. - Localisation du cirque de Troumouse (Gèdre, Hautes-Pyrénées).

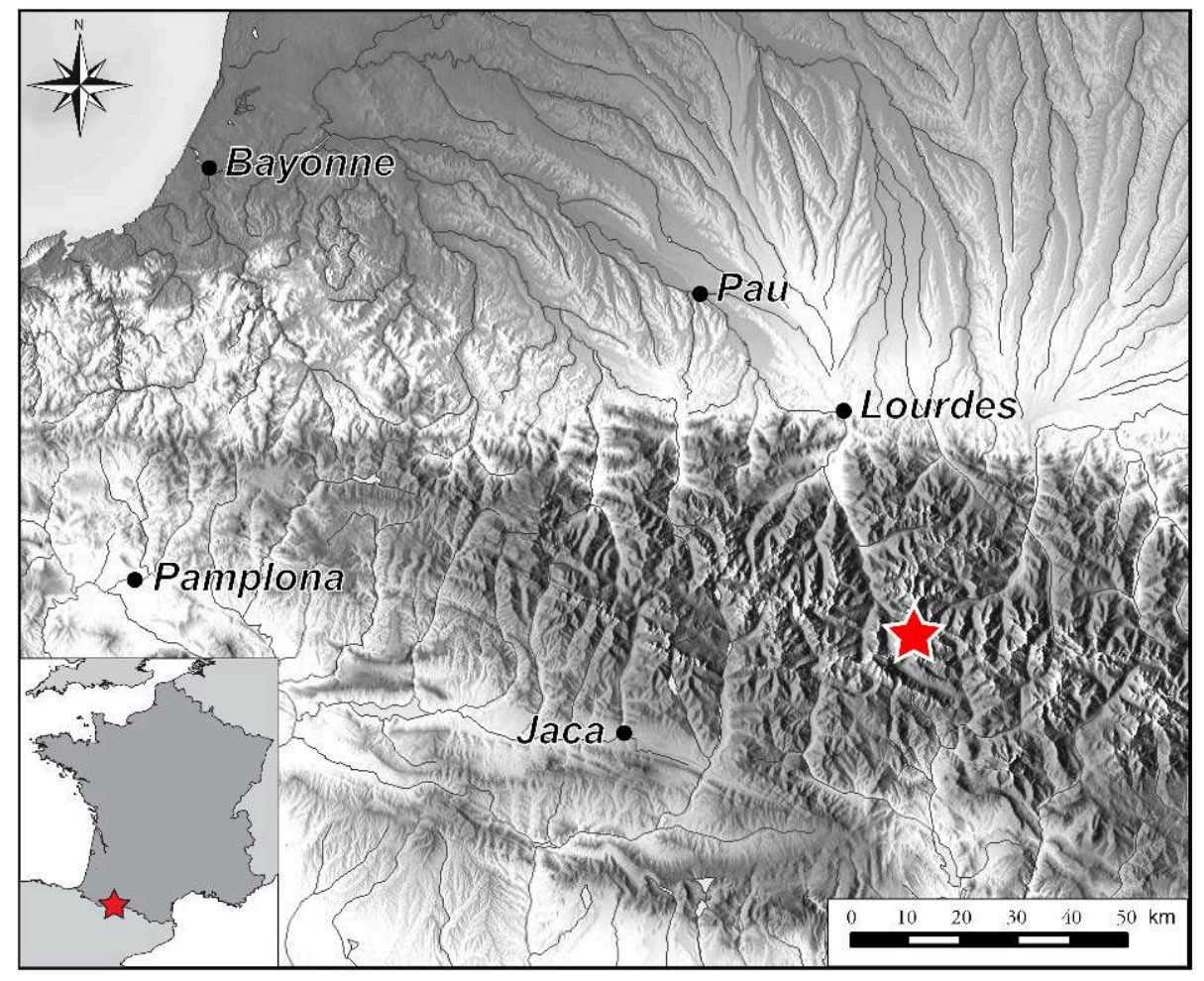

PAO Guillaume Saint-Sever. Fond de carte OpenStreetMap.

Ces travaux avaient été motivés par les données paléo-environnementales issues de carottages réalisés dans les tourbières du cirque et des environs par D. Galop et ses équipes (2001), qui suggéraient des indices de présence humaine pour ces périodes. Lors de la réalisation du sondage $\mathrm{n}^{\circ} 65$, un niveau de sol rubéfié a été mis au jour; il était associé à un mur en pierres sèches et a livré des vestiges céramiques attribuables au Bronze ancien. En raison de la bonne conservation des vestiges, cette découverte a motivé par la suite la réalisation d'une fouille programmée pour mieux déterminer le type d'occupation (domestique ou funéraire) auquel appartenaient ces éléments mobiliers et immobiliers. 


\section{Les données physiques et environnementales}

\section{Contexte géographique et géologique}

5 Le cirque de Troumouse est le plus grand cirque glaciaire des Pyrénées. Il a un diamètre moyen d'environ 4 kilomètres, son assise oscillant entre 2000 et 2200 mètres d'altitude, les pics culminant à une élévation moyenne de 3000 mètres. Le centre du cirque est marqué par une succession de collines et de combes formées par les érosions successives et les accumulations morainiques. Il est éventré dans sa partie centrale, du sud au nord, par le gave des Touyères, aux abords du lac des Aires. Au nord, une entaille d'orientation ouest-est permet l'écoulement du ruisseau de Maillet. Ces deux ruisseaux forment le gave d'Héas, qui suit ensuite les anciennes vallées glaciaires et rejoint les autres gaves du même bassin versant, des cirques d'Estaubé et de Gavarnie, pour initier le gave de Pau à Gèdre.

6 Le passage des cols vers les vallées espagnoles, au sud du cirque de Troumouse, est ardu mais largement praticable, et encore desservi par des chemins de randonnée, qui reprennent le tracé des chemins de contrebandiers. Ces vallées moins escarpées ont un accès plus direct aux piémonts méridionaux pyrénéens que les vallées des gaves, qui peuvent être fortement encaissées en direction du piémont français.

7 Le gisement se situe au sud du lieu-dit La Haille de Pout, en bordure du ravin des Touyères (fig. 2). Il est implanté dans une zone à plusieurs replats avec de petites combes sèches, en bordure de ruisseau. Cette étendue est abritée des vents dominants remontant la vallée, et sa position au centre du cirque lui confère un bon ensoleillement. Si l'on chemine le long du ravin en direction du sud, la falaise s'estompe et permet un accès au lit du gave des Touyères, en contrebas de la cascade de Matacas ; ce passage constitue un des principaux accès au centre du cirque et donc aux cols. 
Fig. 2. - Site de La Haille de Pout, cirque de Troumouse (Gèdre, Hautes-Pyrénées) : topographie et implantation des secteurs explorés.

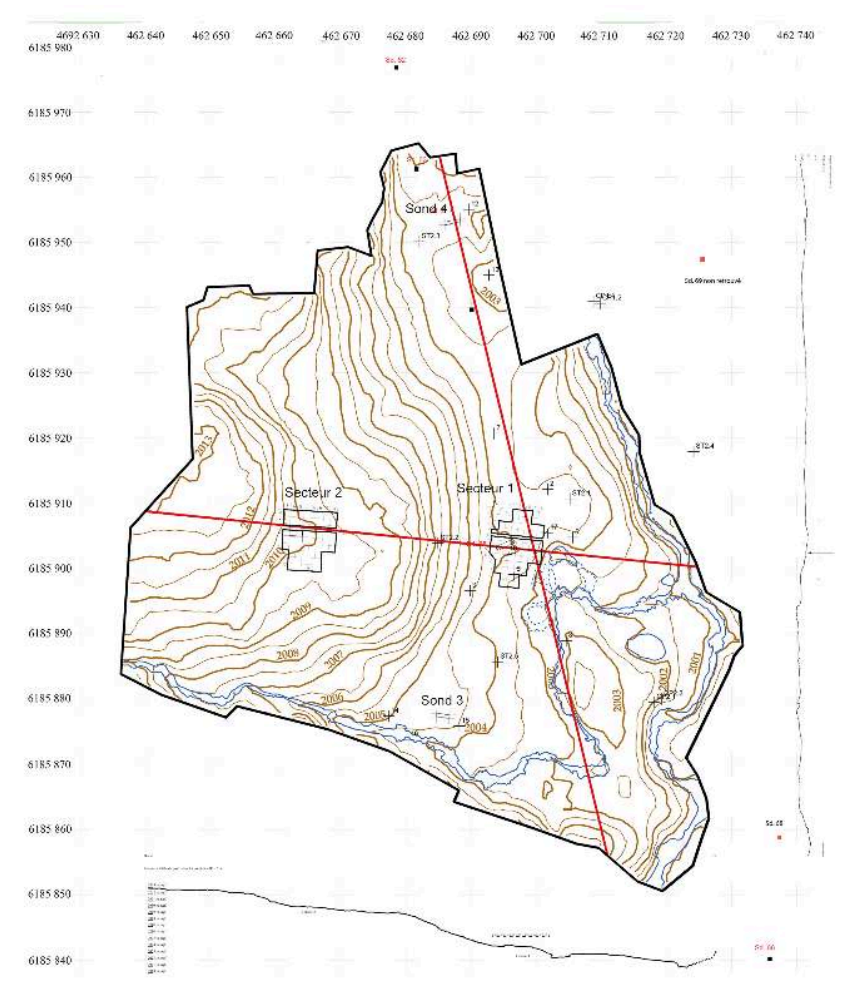

PAO Florian Soula.

8 L'environnement géologique du site est très varié et constitue pour les géologues un résumé de l'histoire de l'élévation des Pyrénées centrales. Les sommets et la corolle du cirque sont constitués par une alternance de calcaires et de pélites du Dévonien. Les formations métamorphiques sont illustrées par les diorites formant le socle du cirque. Elles sont issues d'un métamorphisme anatectique dû à la remontée de roches plutoniques lors de l'orogenèse varisque. Cet événement métamorphique du Carbonifère engendre la formation des granites à cordiérite au centre du cirque, des gneiss migmatitites, des calcaires gréseux et des schistes sur le pourtour. Le plissement principal des Pyrénées, du début du Cénozoïque, a façonné les montagnes actuelles. Le contexte hydrothermal de ces formations a permis la création de filons quartzeux au sein des différentes roches, avec précipitations de sulfures métalliques divers. Il en résulte que les bases du cirque et des pentes des vallées constituent un district polymétallifère où les gîtes de galène, blende et chalcopyrite ont été exploités par petits filons jusqu'à la fin du XVIII ${ }^{\mathrm{e}}$ siècle de notre ère (Dietrich 1786).

\section{Les données environnementales et paléo-environnementales}

9 Le gisement est situé dans l'étage subalpin, compris entre 1700-1900 mètres et 2 300-2 500 mètres d'altitude. En raison de l'exploitation du milieu comme zone d'estive pour les troupeaux, la végétation actuelle est surtout représentée par des pelouses d'altitude, les forêts - avec des essences comme le pin à crochets, caractéristique de cet étage - ayant été rasées au profit des prairies. Il existe toutefois toujours une strate arbustive, constituée de rhododendrons, myrtilliers, bruyères et genévriers. 
10 Les études paléo-environnementales sont à ce jour les meilleurs marqueurs pour étudier les dynamiques d'anthropisation de la montagne pyrénéenne pour la pré- et la protohistoire. En effet, pour ces périodes, les occupations d'altitude des étages montagnards à alpins sont difficilement identifiables, et impossibles à dater sans des sondages et des datations relatives ou absolues. D'une manière générale, les données paléo-environnementales permettent d'observer une exploitation plus conséquente des zones d'altitude pour la fin du Néolithique et le début de l'âge du Bronze dans les Pyrénées. Cette présence humaine se traduit par un recul de la forêt dominée par le bouleau et le pin à crochets dans l'étage subalpin (elle laisse la place à des clairières et prairies d'altitude qui pourraient être liées à des pratiques pastorales nouvelles), ainsi que par la présence de pollens de céréales, interprétés comme des indices de pratiques agricoles dans l'étage montagnard (Galop et al. 2007, Carozza et al. 2005). Les résultats des travaux en cours de D. Galop sur les tourbières du lac des Aires de Troumouse, celles de Gavarnie, de Saugé, et l'étude de carottages dans le lac de Barroude nous offriront une résolution des évolutions climatiques et des pratiques agrosylvicopastorales dans l'environnement proche du gisement. Ces travaux livreront des données sur différents étages altitudinaux au cours de la protohistoire locale, en particulier sur les phases climatiques du Bronze ancien et la courte péjoration du XXI siècle avant notre ère, bien identifiée dans les Alpes (Magny et al. 2007).

\section{Contexte archéologique}

11 Les données archéologiques fiables pour la fin du Néolithique et le début du Bronze ancien sont quasi absentes pour le versant septentrional des Pyrénées centrales, et seuls des indices issus de travaux anciens aux contextes peu assurés sont disponibles (Rouquerol 2004). En outre, ce sont essentiellement des ensembles à vocation funéraire qui documentent le paysage protohistorique montagnard, et la recherche archéologique sur l'occupation du sol est restée très lacunaire.

12 La documentation disponible est plus conséquente à partir de la deuxième phase du Bronze ancien. Pour les Hautes-Pyrénées, les gisements de l'âge du Bronze ancien et du Bronze moyen sont essentiellement des grottes ou abris sépulcraux - Gourgue d'Asque (Clot et al. 1978), Artigaou, à Esparros (Omnès 1980), Peyrère 3, à Fréchet-Aure (Le Guillou 2000) - et une sépulture multiple en coffre, fouillée et datée du Bronze moyen dans la vallée directement à l'ouest du cirque de Troumouse, à Aragnouet (Giraud et al. 1987). Par contre, les indices concernant l'habitat de vallée ou d'altitude sont relativement faibles en comparaison des données paléo-environnementales sur la pression anthropique pour ces périodes. Quelques habitats d'altitude avec des murs en pierres sèches sont toutefois reconnus grâce à des sondages. Ils sont attribuables à des phases de l'âge du Bronze plus récentes que celles illustrées sur le gisement de La Haille de Pout (Rendu et al. 2016).

\section{Les premiers résultats archéologiques}

13 Lors de la campagne de fouilles de 2016, la zone où était localisé le sondage $\mathrm{n}^{\circ} 65$, le secteur 1 (Perrin 2015) a fait l'objet d'un décapage extensif pour cerner les limites des niveaux archéologiques conservés. Ce secteur a livré les restes de plusieurs occupations successives correspondant à des structures d'habitat, des niveaux de sols et de 
destructions. En sus de ces travaux, trois sondages ont été réalisés dans des secteurs proches pour documenter d'éventuels autres indices d'occupations contemporains (fig. 2). Ces sondages exploratoires ont tous livré des éléments mobiliers et immobiliers, plus ou moins conséquents, attribuables au début du Bronze ancien. Le sondage 2 présente une succession d'occupations comparables à celles identifiées dans le secteur 1. Le sondage 3 a livré des fosses rubéfiées, quelques trous de poteau et un aménagement empierré. Le sondage 4 a fourni un niveau de sol et un petit muret en pierres sèches.

\section{Les premiers résultats de la fouille du secteur 1}

14 Le secteur 1 est situé sur un replat, en bordure du lit du ruisseau. Il est encadré à l'est et à l'ouest par des affleurements rocheux de migmatites friables. Au nord se développe une petite combe de 6 à 10 mètres de largeur, relativement plate, qui se prolonge en direction du sondage 4 et de la falaise, située à une centaine de mètres au nord. Avant la fouille, cette zone s'illustrait dans le paysage par un dôme et un empierrement d'une quarantaine de centimètres de haut, dont les plus gros blocs dépassaient de la prairie, limité par un dévers au sud et à l'est en direction du lit du ruisseau.

15 Les premiers décapages réalisés sur la totalité de l'empierrement et sur ses bordures extérieures ont permis de distinguer une zone extérieure à l'implantation avec de rares blocs, et une zone intérieure avec une accumulation importante de pierres, qui a protégé les couches anthropiques d'une érosion conséquente. Il est apparu que les niveaux extérieurs étaient constitués de phases successives de colluvionnements qui avaient détruit puis remplacé les traces anthropiques. Un gour intermittent borde actuellement la partie est de la zone. Il est inondé pendant les phases de fonte de neige et de fortes pluies, ce qui entraîne un phénomène de sape du côté est; les différents niveaux archéologiques se sont affaissés sur la pente, les parements et les empierrements ont disparu ou se retrouvent disloqués au niveau de cette dernière. Dans la partie sud, la fouille en cours ne permet pas encore de déterminer si l'implantation s'est effectuée au niveau de la pente actuelle ou si l'inclinaison a été accentuée par les diverses phases érosives reconnues sur le gisement.

\section{La dernière phase d'occupation}

16 La fouille du secteur 1 a permis de mettre au jour, dans sa moitié nord, les vestiges d'une habitation d'environ 5 mètres sur 4, d'orientation est-ouest, matérialisée par un mur à double parement (fig. 3). 
Fig. 3. - Site de La Haille de Pout, cirque de Troumouse (Gèdre, Hautes-Pyrénées) : secteur 1, plan de l'habitation la plus récente en début de fouille et coupe stratigraphique.

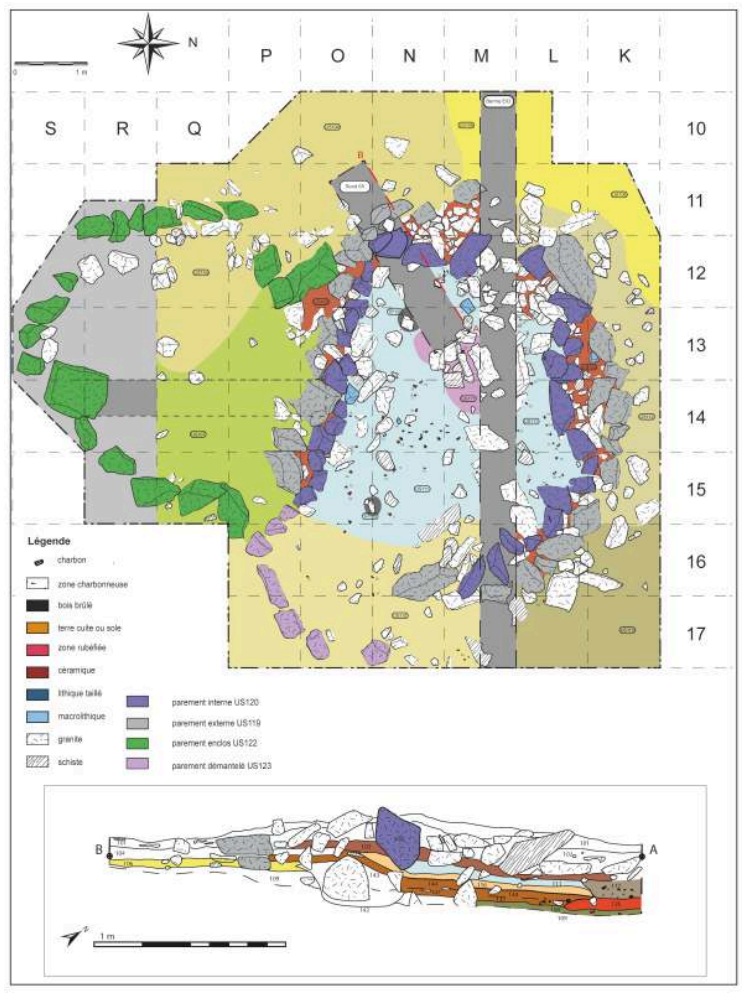

PAO Maxime Remicourt et Guillaume Saint-Sever.

Contre le mur sud, une structure subcirculaire de 4 mètres de diamètre est illustrée par un mur à un seul parement de gros blocs. D'après nos premières observations, la mise en place des parements a été réalisée de deux manières. Dans la partie nord-est, une fosse d'implantation a été préalablement aménagée et remplie de blocs de pierres et de terre, puis les parements y ont été ancrés superficiellement. Dans les parties sud et est, les parements sont calés contre un remblai de terre et de petites pierres. Le mur, qui présente une largeur moyenne de 0,8 mètre, est construit selon un système de double parement de blocs de granite (de 0,5 à 1,2 mètre de long) avec un remplissage interne de terre et de petites pierres (US 103). Les parements externes (US 119) sont légèrement plantés ou posés sur la tranche de leur côté long. Les blocs des parements internes (US 120), en moyenne moins volumineux, sont pour certains posés à plat ou plantés plus profondément sur leur petit côté. Quelques blocs traversants entre les deux parements ont pu servir à consolider la construction.

Les blocs issus de l'effondrement à l'intérieur de la structure sont essentiellement inclinés vers l'intérieur et certains sont directement au contact du parement interne. Dans sa partie la mieux conservée, l'éboulis voit une accumulation de quatre à six assises de pierres de 5 à 15 centimètres de haut, qui devait reposer sur une première assise d'environ 30 centimètres d'épaisseur. Ceci nous permet d'estimer la hauteur du mur entre 0,6 et 1 mètre.

Le niveau de circulation rubéfié de cette phase d'occupation (US 111) a livré deux trous de poteaux de 30 centimètres de diamètre et 20 centimètres de profondeur, avec des calages de pierres. Ils sont situés à environ 0,8 mètre du mur, le long du parement interne sud, et espacés de 2,5 mètres; si leurs équivalents existent le long du parement 
nord, ils devraient se trouver dans la berme témoin. Ces poteaux pourraient avoir porté une panne ventrière en lien avec une panne sablière posée sur le mur (US 119 et US 120), pour servir de support à la couverture, probablement un toit très pentu. Ce système doit permettre une résistance mécanique compatible avec le poids de la neige ; le gisement pouvant être recouvert actuellement, pendant la période hivernale, par 2 à 4 mètres de neige.

Au centre de la maison, un foyer (US 127) est constitué de plusieurs pierres en schiste très rubéfiées posées à plat, et rempli d'un sédiment cendreux très charbonneux. La partie nord de ce foyer, non fouillée, est localisée dans la berme.

\section{L'enclos}

21 Sur le dévers sud, un parement simple (US 122) forme une structure subcirculaire d'environ 4 mètres de diamètre. Il est constitué d'une seule assise de gros blocs de 0,4 à 1,2 mètre de long, plus massifs dans la partie est, où ils sont posés en milieu de pente. Ce parement s'appuie sur le parement extérieur de la dernière structure d'habitat (US 119). La faible accumulation de pierres du côté interne et la petite quantité de pierres en extérieur de la structure laissent supposer l'existence d'un muret de faible hauteur permettant le calage d'éléments végétaux. Pour l'instant, aucun niveau anthropique ni mobilier n'a été repéré à l'intérieur de cet espace. Ce possible enclos possède une éventuelle ouverture d'environ 0,6 mètre au contact des murs de la dernière unité d'habitation, à l'est, en P 15.

\section{Les occupations antérieures}

Lors de la première campagne, nous avons poursuivi l'exploration partielle des niveaux sous-jacents de l'intérieur de la dernière unité d'habitation, plutôt que de poursuivre une fouille extensive. Cela a permis de documenter plusieurs niveaux d'occupations rubéfiés, indiquant que des incendies ont détruit plusieurs constructions successives (fig. 3B).

23 Un niveau rubéfié (US 116) marque le second sol d'occupation. Il s'étend sous les parements internes de la dernière phase d'occupation et son extension s'inscrit dans la limite des parements externes de l'occupation sus-jacente. Une zone cendreuse et un probable foyer se développent sous la berme, en léger décalage vers l'ouest par rapport au foyer (US 127). Ce niveau rubéfié et charbonneux a livré des tessons de céramique posés à plat et des matériaux lithiques.

La fouille des niveaux sous-jacents (US 144-147) permet d'observer qu'ils s'étendent à l'extérieur des parements délimitant les dernières phases d'occupation. Ces niveaux, pour l'instant sans structures associées, ont été repérés au nord et au sud, dessinant une surface ovalaire d'environ 7 mètres sur 4, d'orientation nord-sud, perpendiculaire à celle observée pour l'habitation 1 . On constate, dans la coupe stratigraphique fournie par la berme, que cette implantation correspond à une excavation d'environ 15 à 20 centimètres de profondeur, qui tronque les niveaux de colluvions antérieurs (US 106-109). Les US 144 et 147 appartiennent à une même dynamique sédimentaire ; l'US 144 présente des concentrations denses de tessons de céramique, alors que l'US 147, parfois sous-jacente, est tapissée de charbons de grande dimension recouvrant pratiquement tout le sol, dont une planche carbonisée de 40 centimètres sur 15 et des 
fragments d'écorce appartenant à la structure du bâtiment et à d'éventuels récipients organiques.

Ces différents niveaux rubéfiés et charbonneux sont à mettre en lien avec un incendie qui a détruit une structure d'habitat. L'épaisseur et l'homogénéité du comblement interne laissent supposer que ce dernier provient probablement des parois de l'habitation en terre, qui se sont effondrées rapidement à l'intérieur de celle-ci. Ce recouvrement rapide des bois incandescents a permis une bonne conservation des restes anthracologiques. À la base de l'US 144, un foyer fait d'un petit dôme de terre rapportée est bordé par de petites pierres et présente en surface des branches carbonisées.

Enfin, un dernier niveau, non daté et repérable dans la coupe (US 108), livre des fragments de céramique et des microcharbons. Il illustre les premiers terrassements et creusements de fondation de la première installation dans le secteur 1 .

\section{Les sondages exploratoires}

\section{Secteur 2}

Le sondage 2 (2 mètres sur 0,5$)$ a été implanté sur une terrasse naturelle surplombant le secteur 1, à l'ouest, au niveau d'un dôme de forme ovalaire orienté est-ouest, d'environ 6 mètres sur 4 de long et délimité par de gros blocs de granite (fig. 4).

Fig. 4. - Site de La Haille de Pout, cirque de Troumouse (Gèdre, Hautes-Pyrénées) : coupes stratigraphiques des différents sondages.

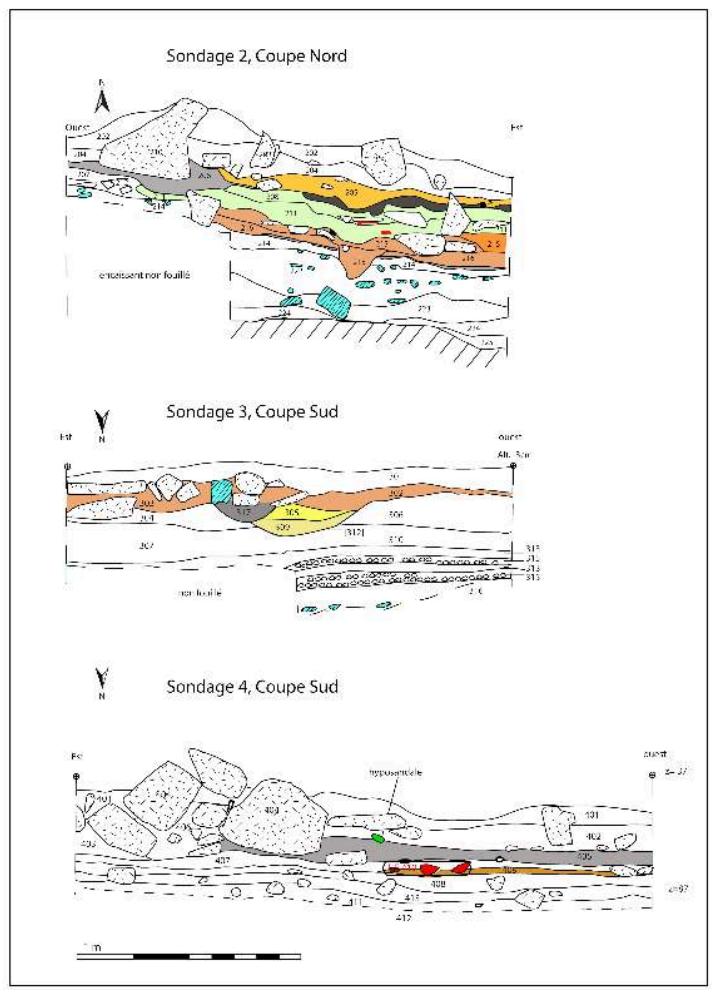

PAO Maxime Remicourt et Guillaume Saint-Sever. 

d'identifier quatre phases d'occupation successives, peu ou prou contemporaines de celles identifiées dans le secteur 1 (US 205, 211, 213, 216). Les premières données illustrent partiellement les modalités de construction mises en œuvre. On observe que la première implantation est semi-excavée, le creusement recoupant les colluvions naturelles de l'US 214. La couche interprétée comme le niveau de circulation (US 216) a livré du mobilier céramique et lithique posé à plat. La deuxième phase d'occupation (US 213) s'inscrit globalement dans les mêmes limites et présente un trou de poteau et ses pierres de calage, ainsi qu'un foyer limité par des meules de granite, marqué par des limons rubéfiés et de nombreux restes charbonneux. Le niveau de circulation sus-jacent (US 211/208) s'étend à l'ouest jusqu'à un trou de poteau qui pourrait appartenir au mur extérieur. Ce niveau a également livré du matériel macrolithique et des tessons de céramique posés à plat. L'ensemble le plus récent (US 205) est délimité par un parement de gros blocs de granite et s'inscrit dans une légère dépression.

Ces différentes phases d'occupations sont séparées par des niveaux de destruction en lien avec des incendies. Ils sont fortement rubéfiés et livrent de nombreux restes anthracologiques qui appartiennent aux éléments architecturaux en bois des murs porteurs ou de la toiture. La dernière phase d'occupation, puis de destruction, qui présente des niveaux moins remaniés par le réaménagement ultérieur de nouvelles structures d'habitat, a ainsi livré les vestiges d'une paroi ou d'un toit effondré sous la forme d'un treillage de branches et de nombreuses brindilles. et présente les mêmes caractéristiques.

\section{Secteur 4}

31 Le sondage 4 (2,5 mètres sur 0,5$)$ est situé au nord du secteur 1 , dans la même combe (fig. 4). Il a été réalisé à l'intérieur d'une structure rectangulaire d'apparence récente (6 mètres sur 5), marquée par un mur en pierres sèches encore en élévation d'une cinquantaine de centimètres de haut dans sa partie sud et effondré dans ses parties nord et est, d'environ 0,8 à 1 mètre de large, à double parement de gros blocs. Le niveau d'occupation, en lien avec cet aménagement, a livré du mobilier attribuable à la période antique ou au haut Moyen Âge, avec une hipposandale d'âne en fer et quelques tessons d'une céramique tournée.

Le niveau sous-jacent correspond à une phase de colluvionnements. Il recouvre un niveau de circulation ou de destruction peu épais (US 407) qui a livré des restes anthracologiques, des nodules de terre cuite et des tessons protohistoriques d'aspect proche de ceux du secteur 1, qui sont attribuables à l'âge du Bronze ancien. Ce niveau recouvre et englobe un alignement de petites pierres, encore empilées sur deux assises, d'environ 30 centimètres de large et d'orientation nord-sud (US 410), en partie démantelé au sud. Ce probable muret marque une limite entre un niveau anthropique (US 409) et la couche géologique (US 408) sur laquelle il repose. Ce petit aménagement doit marquer les bords d'une occupation ou d'un premier habitat érodé par les niveaux sus-jacents. Il n'a pas fourni de mobilier, mais il pourrait être attribuable au début du Bronze ancien ou à une phase antérieure, en raison de sa position stratigraphique sous un niveau du Bronze ancien. 


\section{Secteur 3} ruisseau, au centre d'un petit dôme de 6 mètres sur 5 orienté est-ouest, d'environ 40 centimètres de hauteur, aux contours peu réguliers et cerné de blocs de granite peu ordonnés (fig. 4).

Un empierrement de pierres posées à plat montrant une limite nette d'orientation nord-est/sud-ouest est apparu directement sous l'humus, dans la partie est du sondage. Dans cet ensemble, deux petites zones vides coïncident avec l'emplacement de deux structures en creux identifiées dans les niveaux sous-jacents comme des trous de poteaux avec des calages de pierres. Dans la partie ouest du sondage, au moins trois petites fosses qui se recoupent ont été identifiées, sans que le lien avec l'empierrement soit clairement établi. Ces dernières ont un diamètre d'une quarantaine de centimètres, pour 20 à 30 centimètres de profondeur. Elles présentent toutes des parois rubéfiées et un remplissage contenant de petits nodules de terre cuite et de petits charbons. Au contraire des autres secteurs, aucun niveau de destruction n'est illustré, ce secteur ne correspond donc pas à des structures d'habitat, mais plus probablement à une zone d'activités extérieures.

Le mobilier archéologique est peu présent ; néanmoins, quelques tessons retrouvés sous l'empierrement permettent de dater également ces occupations des débuts de l'âge du Bronze.

\section{Les datations radiométriques}

Nous disposons pour l'heure de cinq datations radiométriques pour les occupations des secteurs 1 et 2, réalisées sur des brindilles ou des caramels de cuisson présents sur les céramiques (fig. 5). 
Fig. 5. - Site de La Haille de Pout, cirque de Troumouse (Gèdre, Hautes-Pyrénées) : datations radiocarbone.

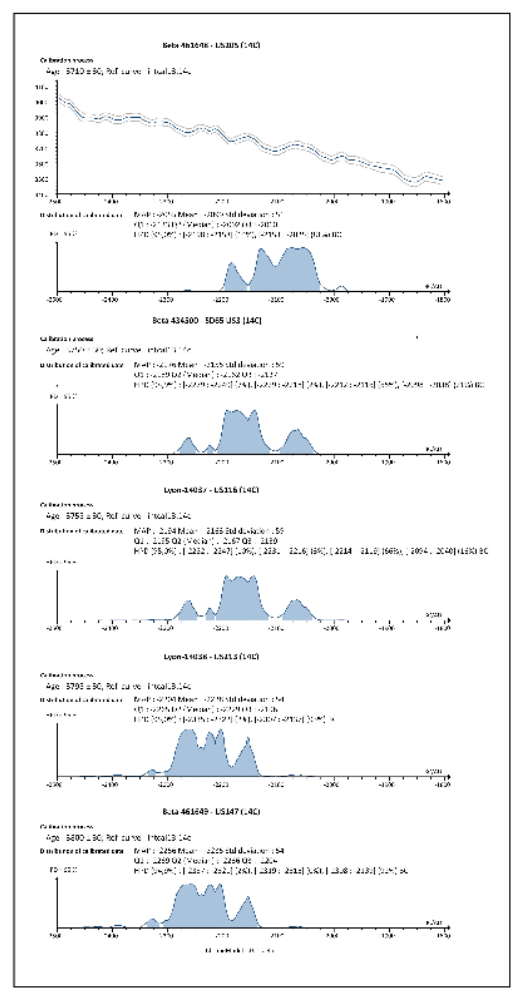

Calibration ChronoModel 2.0.2_beta et courbe intcal13.14c.

PAO Maxime Remicourt.

À l'image du mobilier céramique, ces datations pourraient illustrer la probable contemporanéité de certaines phases d'occupation entre les structures d'habitat de ces deux ensembles. La phase la plus ancienne n'a pas été datée, mais le deuxième temps de l'occupation des secteurs 1 et 2 est relativement proche :

- Secteur 1, US 147, Beta $461649: 3800 \pm 30$ BP, soit entre 2337 et 2139 av. J.-C., date calibrée à 2 sigma ;

- Secteur 2, US 213, Lyon-14038 : $3795 \pm 30$ BP, soit entre 2335 et 2137 av. J.-C., date calibrée à 2 sigma.

Le niveau de la troisième phase d'occupation a été daté dans deux zones du secteur 1 , avec la couche 3 du sondage $n^{\circ} 65$ (Perrin 2015) et avec une date dans l'US 116 :

- Secteur 1, SD 65 US 3, Beta 434500: $3750 \pm 30$ BP, soit entre 2279 et 2038 av. J.-C., date calibrée à 2 sigma ;

- Secteur 1, US 116, Lyon-14037 : $3755 \pm 30$ BP, soit entre 2282 et 2040 av. J.-C., date calibrée à 2 sigma.

La date de la dernière phase d'occupation a été obtenue dans le secteur 2, dans l'US 205 (Beta 461648: $3710 \pm 30 \mathrm{BP}$, soit entre 2198 et 2025 av. J.-C., date calibrée à 2 sigma).

De nouvelles datations à venir permettront peut-être de resserrer ces écarts, mais au vu des céramiques, il est probable que ces différentes occupations et réoccupations ne s'étalent pas sur beaucoup plus d'une centaine d'années, entre le XxIII ${ }^{e}$ et le début du $\mathrm{XXI}^{\mathrm{e}}$ siècle avant notre ère. 


\section{Le mobilier archéologique}

\section{La céramique}

41 À ce stade préliminaire de la fouille, deux ensembles céramiques principaux peuvent déjà être dégagés (fig. 6) ; la césure semble se situer entre le xxII et le xxI ${ }^{\mathrm{e}}$ siècle av. J.-C., avec des éléments attribuables d'une part à la fin du Campaniforme et d'autre part au début du Bronze ancien.

Fig. 6. - Site de La Haille de Pout, cirque de Troumouse (Gèdre, Hautes-Pyrénées) : mobilier céramique.

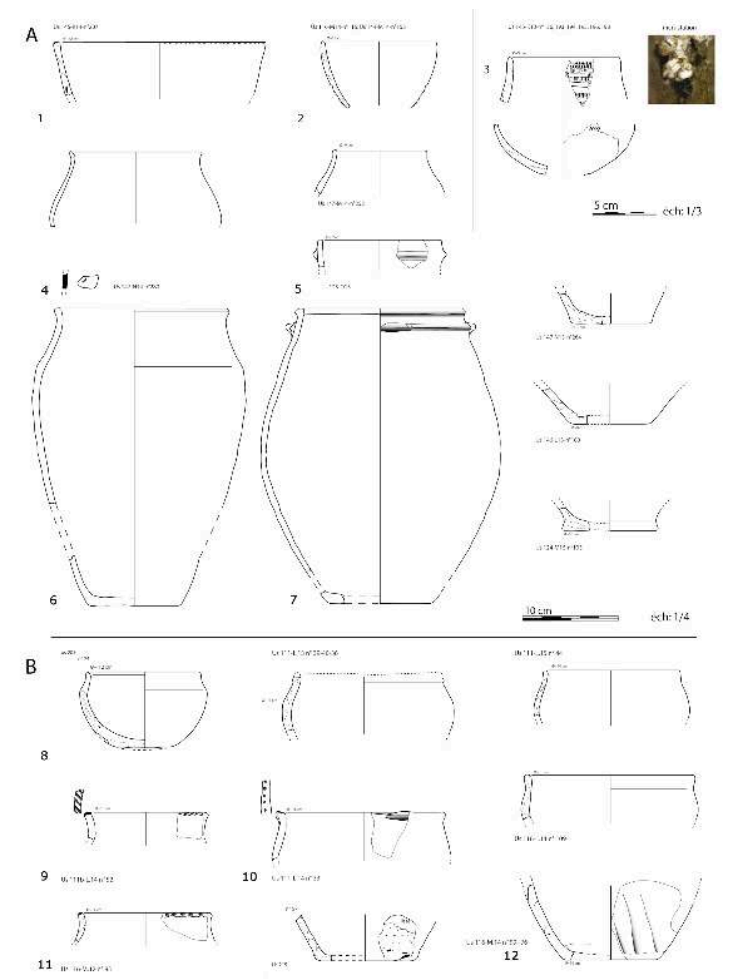

A : niveaux de la fin du Campaniforme (US 144-147, 124, 146). B : niveaux du début du Bronze ancien (US 205, 116, 111).

Dessins Guillaume Saint-Sever.

\section{La céramique de la fin du Campaniforme}

Les niveaux associés à l'habitation 2 du secteur 1 (US 145, 144-147) ont livré une petite série céramique qui peut se rattacher à la fin du Campaniforme pyrénéen (fig. 6A). Le gobelet à col concave et à panse légèrement carénée, décoré de petites impressions verticales inscrites dans des bandeaux horizontaux aux motifs d'échelles en quinconce remplis de matière blanche collée, en constitue l'élément le plus typique (fig. $6, \mathrm{n}^{\circ} 3$ ). Ce décor se retrouve sur des gobelets du Campaniforme pyrénéen (phase $3 \mathrm{du}$ Campaniforme ; Besse 1996), fréquents dans les séries des Pyrénées-Orientales (Claustre et Mazière 1998) et d'Ariège (Rouquerol 2004 : fig. 27 et 29), et que l'on rencontre également sur le site de Médor, à Ornaisons, dans l'Aude (Guilaine et al. 1989; Gascó 2004 : fig. 3, $n^{\circ} 5$ ) ou encore en Catalogne espagnole (Tarrus i Glater 1985 : fig. 2). Le 
profil de ce gobelet à carène naissante, d'aspect probablement trapu, pourrait évoquer une phase tardive, car il se rapproche de celui des gobelets épicampaniformes à décor barbelé, comme dans l'abri de Font Juvénal, à Conques-sur-Orbiel, dans l'Aude (Gascó 2004 : fig. $4, n^{\circ} 7$ ). Des coupes, une petite ainsi qu'une large et profonde qui possède un décor de très légères impressions sur l'extérieur de la lèvre (fig. $6, \mathrm{n}^{\circ} 1$ et 2 ), sont des formes répandues (type 12; Besse 1996) qui s'insèrent dans les typologies de la fin du Campaniforme, à l'image d'un petit fragment de céramique lustrée au décor d'impressions à l'ongle (fig. 6, no 4 ).

Le cordon sur le bord à lèvre équarrie (fig. $6, \mathrm{n}^{\circ} 5$ ) peut se rapporter au type 6 de M. Besse (1996) pour la fin du Campaniforme. Toutefois, pour les poteries de plus gros volume, on notera l'absence de perforations péri-orales, présentes par exemple dans les séries de La Pièce d'Alquier, à Fontiès-d'Aude (Aude), ou de Lapeyrère, à Muret, en Haute-Garonne (Bevilacqua 2015, Jolibert 1988).

Le pot au profil galbé et refermé ne trouve pas de comparaisons locales directes (fig. 6, $\left.\mathrm{n}^{\circ} 7\right)$; mais d'un point de vue typologique, il peut être postérieur à la céramique au profil en $\mathrm{S}$ plus marqué, à bord ouvert à cordon lisse et à lèvre épaissie rectangulaire, issue du tumulus de Cabout 5 à Pau, dans les Pyrénées-Atlantiques, que plusieurs dates radiocarbone permettent de caler dans le XxIII ${ }^{\mathrm{e}}$ siècle avant J.-C. (Marembert et al. 2008).

Les vases de la grotte d'Elzarreko Karbia, à Saint-Juste-Ibarre (Pyrénées-Atlantiques), qui sont attribués au groupe de Pont-Long 1 , moins galbés, à cordons digités et décors plastiques couvrants, préfigurent les vases tonnelets du Bronze ancien et moyen du Sud-Ouest. La série de La Haille de Pout est probablement antérieure aux céramiques attribuées à ce groupe, dont les datations radiocarbone, à fort écart type, s'inscrivent entre le $\mathrm{Xx}^{\mathrm{e}}$ et le $\mathrm{xvII}{ }^{\mathrm{e}}$ siècle avant J.-C. (Marembert 2000 : fig. $5, \mathrm{n}^{\circ} 1$ ). Le pot élancé à col concave et légère carène (fig. $6, \mathrm{n}^{\circ} 6$ ) ne se retrouve pas directement dans les formes du Pont-Long, mais sur des formes décorées plus basses.

\section{La céramique du Bronze ancien}

Les céramiques des niveaux supérieurs (US 205, US 116-111) ont des caractères typologiques que l'on ne retrouve pas dans les niveaux sous-jacents (fig. 6B). Les profils peuvent être carénés et légèrement fermés, aux bords droits légèrement concaves et à lèvres épaissies, légèrement déjetées, qui possèdent pour certaines un décor au poinçon (fig. $6, \mathrm{n}^{\circ} 10$ ) ou profondément imprimé (fig. $6, \mathrm{n}^{\text {os }} 9$ et 11 ). Des languettes peu protubérantes apparaissent sur l'extérieur de la lèvre (fig. $6, \mathrm{n}^{\circ} 10$ ), ainsi que des cordons digités. Le fond recuit (fig. $6, \mathrm{n}^{\circ} 12$ ) présente une surface passablement abîmée, sur laquelle on distingue les restes d'un revêtement de pâte étirée verticalement.

La forme de coupe carénée à col concave et à fond arrondi (fig. 6, $\mathrm{n}^{\circ} 8$ ) peut trouver des comparaisons dans des séries du Bronze ancien de Catalogne, par exemple dans la fosse CR 67 à Can Roqueta (Sabadell, Barcelona, Espagne), où elle est associée à un pot globulaire à languette sur la lèvre décorée au poinçon (Carlús et al. 2008), un type de pot que l'on retrouve dans la fosse CR 66 du même site. Les datations radiocarbone, malgré leur large écart type, couvrent tout de même le début du Bronze ancien (CR 66-1-8 = Beta $91583: 3570 \pm 140 \mathrm{BP}$, soit entre 2299 et 1742 av. J.-C., calibrée à deux sigma; CR 67 = Beta 91849: $3900 \pm 120 \mathrm{BP}$, soit entre 2693 et 2030 av. J.-C., calibrée à deux sigma). 

les Pyrénées centrales. Nos niveaux récents trouvent peu de comparaisons au nord ou à l'ouest des Pyrénées, les séries de référence pouvant être légèrement plus récentes. Le site de Cassagna 3 (Pons et al. 2003) présente des formes éloignées de celles de Troumouse. Elles sont à rapprocher de celles du Roussillon, avec un décor au poinçon sur la panse et des impressions digitées ou de baguette sur la carène (Claustre 1996). Pour les Pyrénées occidentales, les faciès du Pont-Long 1 , aux vases à formes carénées basses et à décors d'incisions ou d'impression de cordelettes, ne sont également pas représentés à Troumouse, et peu d'éléments peuvent s'y rattacher pour les Pyrénées centrales (Rouquerol 2004 : fig. 44). Ces ensembles paraissent appartenir à une phase légèrement plus récente ; mais même ainsi, il apparaît que les éléments typologiques les plus proches, outre les quelques éléments présents dans les Pyrénées centrales, se retrouvent principalement au nord-est de la Catalogne. Le niveau ancien est, pour sa part, plus ancré dans la tradition du Campaniforme pyrénéen, et l'extension géographique de celle-ci apparaît plus développée vers le nord des Pyrénées. Les datations radiocarbone disponibles semblent indiquer que le changement entre nos deux styles céramiques se produit rapidement, au tournant des $\mathrm{xXII}^{\mathrm{e}}$ et $\mathrm{xxI}^{\mathrm{e}}$ siècles avant notre ère.

\section{Le creuset}

51

ns l'US 144, au centre de l'habitation 2, un creuset en argile modelée a été découvert (fig. 7). Sa petite coupe ovalaire possède des bords légèrement rentrants, son manche s'accroche à une de ses extrémités ; à l'opposé, un petit bec verseur est façonné par encochage du bord. Ces deux éléments sont légèrement excentrés du même côté de l'objet, facilitant l'écoulement de biais (manche : 3,2 sur 1,9 cm ; coupe : hauteur $3 \mathrm{~cm}$, diamètres internes 1,8 et $2,6 \mathrm{~cm}$, profondeur $2,4 \mathrm{~cm}$ ). Sa petite contenance avoisine les 2,5 centilitres, ce qui doit le destiner à la refonte de métal. Cette pièce est constituée d'une argile dense, avec un dégraissant sableux abondant et des éléments siliceux noir indéterminés, qui ne correspondent pas aux dégraissants des vases céramiques (sables translucides clairs). La pièce est brute de façonnage, avec des traces de modelage apparentes, sans lissage particulier. L'objet, dans son ensemble, a fait l'objet de recuissons successives visibles sur toute sa surface. L'intérieur de la vasque a subi une 
chauffe réductrice importante, comme en atteste sa couleur grise et des bulles millimétriques. La moitié intérieure du fond est recouverte de plages de matière jaune à brune, parfois brillante, avec de nombreuses microbulles. Des analyses sont en cours pour en déterminer la composition.

Fig. 7. - Site de La Haille de Pout, cirque de Troumouse (Gèdre, Hautes-Pyrénées) : creuset, US 144.
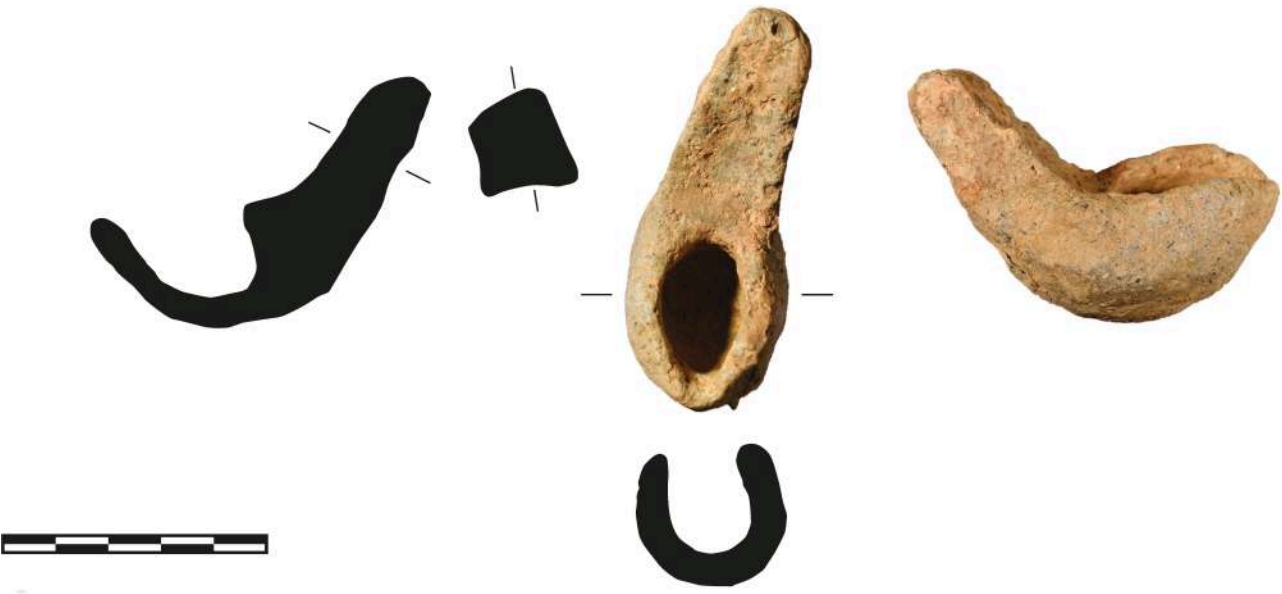

PAO, dessins et photos Guillaume Saint-Sever.

Aucun élément de comparaison typologique direct n'a pu être trouvé pour cet objet. Par contre, l'étude menée sur des creusets à préhension du Bronze ancien et moyen par I. Soriano et N. Escanilla (2016) en répertorie pour l'Europe de l'ouest. Ils possèdent des manches à creux destinés à insérer une hampe de bois et sont en général plus volumineux. À l'exemple de celui découvert dans des niveaux du Bronze ancien ou moyen de La Lède du Gurp, à Grayan-et-l'Hôpital, en Gironde (Roussot-Larroque 1997 : fig. 2), ils possèdent un manche creux de section arrondie et sont plus larges : de 10 à 15 centimètres de diamètre.

\section{L'industrie lithique taillée}

53 L'industrie lithique taillée de la campagne 2016 est représentée par une trentaine d'éléments en silex et en schiste dur, provenant des secteurs 1 et 2. La campagne de 2017 a plus que triplé la série. On reconnaît trois types distincts de silex (détermination P. Fernandes), qui sont tous présents au nord-ouest du gisement. Le silex du Flysch est originaire des niveaux du Turonien, dont les gîtes les plus proches sont distants de 40 à 60 kilomètres à vol d'oiseau, à Oloron-Sainte-Marie ou dans la forêt de Labaig, dans les Hautes-Pyrénées (Remicourt et al. 2010). Le deuxième et le troisième type sont disponibles dans les gites du Campanien et du Maastrichtien des Landes, aux environs de Tercis et dans le bassin d'Audignon, à une distance comprise entre 100 et 120 kilomètres de notre site (Remicourt et al. 2010). Il n'est pas possible de savoir si ce silex a été acquis par prélèvement direct par la population du site ou dans le cadre d'un système d'échanges. Dans tous les cas, on constate que cet approvisionnement appartient au bassin versant de l'Adour. 
Malgré l'effectif restreint, il est possible d'observer dans les différents niveaux un petit débitage local qui se traduit par une production de petits éclats par percussion dure directe lancée et/ou par percussion sur enclume. Les pièces transformées illustrées sont principalement des grattoirs et des pièces esquillées, ainsi que quelques pièces à retouches latérales (fig. 8A).

Fig. 8. - Site de La Haille de Pout, cirque de Troumouse (Gèdre, Hautes-Pyrénées) : industrie lithique.

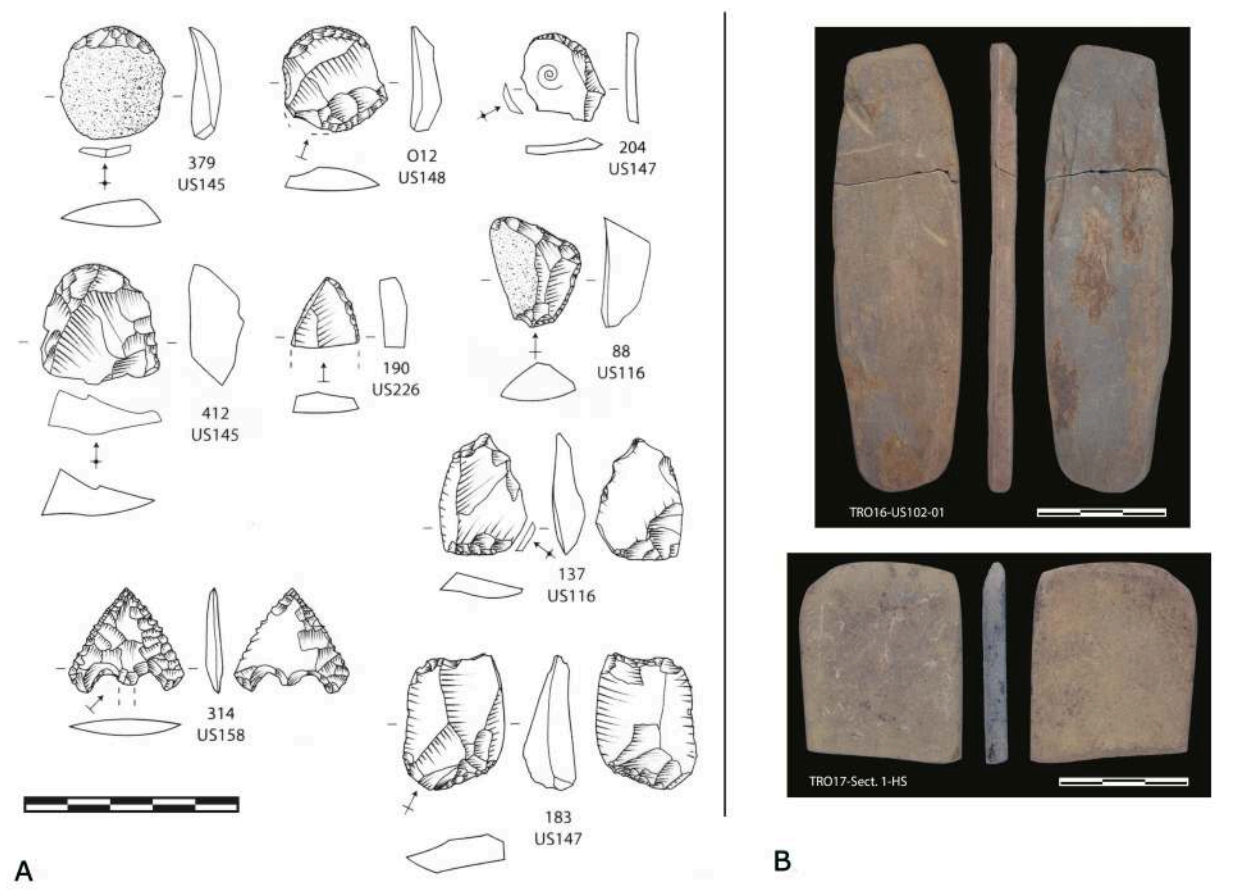

A : grattoirs, pièces esquillées, pièces à retouches latérales. B : aiguisoirs-lissoirs en schiste.

On peut signaler une armature à retouches bifaciales, à pédoncule et ailerons équarris, qui est caractéristique du Campaniforme et des débuts de l'âge du Bronze. Ces éléments technologiques ou typologiques s'inscrivent bien dans les caractéristiques reconnues dans le sud de la France, que ce soit en Languedoc (Escallon et al. 2008) ou en Provence (Furestier 2007, Donnelly et Furestier 2009, Remicourt et al. 2014). Sur le versant méridional des Pyrénées, les productions lithiques sont proches, mais elles comportent en sus une petite production laminaire, la présence de troncatures et l'utilisation du silex en plaquettes importées (García Gazólaz 1993, Equip Minferri 1997, Mujika et al. 2009); des éléments qui n'ont pas encore été identifiés à La Haille de Pout.

\section{Le mobilier pondéreux}

Au sein du mobilier lithique, deux petits lissoirs-aiguisoirs en schiste grenu ont pu être identifiés (fig. $8 \mathrm{~B})$. La pièce entière $(10,5$ sur $3 \mathrm{~cm}$, épaisseur $0,5 \mathrm{~cm})$ porte des stries perpendiculaires à la longueur sur l'une des faces et un émoussé sur l'un de ses petits côtés. Ces pièces, même si elles ne sont pas perforées comme les exemplaires 
septentrionaux de l'âge du Bronze, rappellent les aiguisoirs du centre-ouest de la France (Cordier 1964, Pautreau et Cassen 1975, Gomez 1976) ou de Bretagne et de Normandie (Marcigny et al. 2001). Des artefacts en schiste, non répertoriés comme aiguisoirs, mais présentant de nombreux points communs avec nos exemplaires, sont illustrés dans l'Aude et en Ariège. Ces éléments ont été mis au jour soit dans des grottes sépulcrales (grotte du Trou du Loup, à Armissan; grotte de la Palette, à Narbonne ; grotte I de Thèzan ; grotte de Jugnes, à La Nouvelle ; grotte de l'Aguzou, à Escouloubre), soit dans des occupations domestiques (grotte des Ratos Panados, à Montredon; La Pièce d'Alquier, à Fontiès-d'Aude ; grotte de Las Morts, à Benaix; grotte de Vals). Ces pièces, parfois considérées comme des palettes funéraires, appartiennent soit à des ensembles relevant du Campaniforme, soit au début du Bronze ancien (Durand 1968, Guilaine 1977, Bevilacqua 2015).

Le macro-outillage est relativement abondant sur le gisement. Pour la campagne de 2016, on recense dans les secteurs 1 et 2 une dizaine de pièces, principalement des fragments de meules, deux molettes et un percuteur. La majorité de ces éléments ont été découverts comme éléments constitutifs des murs en pierres sèches, ou parmi les éléments démantelés de ces derniers, ce qui témoigne d'un recyclage de ces pièces plus ou moins volumineuses. De ce fait, la plupart des restes macrolithiques sont brûlés, en raison de la destruction systématique des structures d'habitat par des incendies.

Une première diagnose des matières premières permet d'attribuer une origine locale au matériel de mouture ou de broyage. On identifie le schiste dur et le granite disponibles à proximité ou directement sur le gisement (Mirouse et Barrère 1993). Les blocs de granite présentent un caractère granuleux qui offre un mordant naturel à ces pièces, ce qui facilite la préparation de la surface active. Pour les meules ou molettes, les éléments d'origine sont des galets ou des blocs plus ou moins roulés, avec peu ou pas de traces spécifiques de préparation ou de mise en forme; les flancs et les extrémités restant bruts, sans régularisation. Les pièces sont abandonnées avec des surfaces actives lisses et le ravivage de ces dernières semble être anecdotique. Cette option de façonnage minimal, où seule la surface active est préparée, ainsi qu'un faible taux de ravivage de ces dernières et un abandon rapide, sont des caractéristiques qui se rencontrent également sur certains gisements néolithiques alpins ou jurassiens, lorsque la matière première est facilement disponible (Hamon et Milleville 2006, Milleville 2007).

\section{Pour conclure}

59 Les premières campagnes de fouille de La Haille de Pout ont fourni des résultats inédits sur les habitats de haute montagne de la fin du Campaniforme et du début de l'âge du Bronze et vont ainsi permettre de nouvelles réflexions sur l'exploitation des territoires montagnards. Il ressort en premier lieu que plusieurs structures d'habitations et/ou aires d'activités se sont succédé pendant ces périodes dans cette zone, et que certaines ont pu fonctionner de façon plus ou moins contemporaine, à la manière d'un petit hameau, d'après ce que l'on peut observer au niveau des vestiges mobiliers et immobiliers, ainsi qu'à partir des datations radiocarbone.

Les premiers éléments concernant l'architecture permettent de proposer au moins un modèle pour le type d'habitation le plus récent, avec une base semi-excavée bordée d'un mur bas en pierres sèches, à double parement, sur lequel pourrait reposer directement la panne sablière de la toiture. La découverte de nombreux restes 
carbonisés bien conservés, issus d'éléments architecturaux - cloisons ou toits clayonnés, planches et piquets - nous renseignera au cours des campagnes à venir sur les techniques de construction des superstructures en terre et bois, voire par extension sur certaines pratiques sylvicoles. Les structures d'habitation de l'âge du Bronze (plus récentes qu'à Troumouse) qui avaient été reconnues par des sondages dans les Pyrénées n'ont livré pour l'heure que des restes plus ou moins bien conservés de murs en pierres sèches, et les niveaux de sol étaient relativement érodés, comme à Enveig, dans les Pyrénées-Orientales (Rendu et al. 2012).

Le mobilier archéologique, outre son apport à l'attribution chronologique des ensembles, va permettre de documenter à la fois des phénomènes d'échanges et des affinités culturelles entre les deux versants des Pyrénées. En effet, en l'état actuel de nos recherches, les productions céramiques se rapprochent des ensembles du nord de la Catalogne et de l'est des Pyrénées (bassin collecteur du Sègre). Au contraire, l'industrie lithique taillée trahit un approvisionnement en matières premières en lien avec le bassin versant de l'Adour, dans les Pyrénées nord-occidentales et leurs piémonts.

Cette occupation de hauteur, probablement saisonnière, a été nécessairement en lien avec des implantations à plus basse altitude. Les indices de métallurgie (marteaux et creusets, rares en contexte campaniforme), pourraient permettre de proposer une destination utilitaire de cet établissement. En effet, en plus de ces indices mobiliers, le gisement se situe à proximité immédiate de filons de pyrites cuivreuses de petite dimension, partiellement disponibles en surface (Militon 1987). Il est dès lors possible de soupçonner qu'il s'agit d'un site producteur d'objets de cuivre, en attendant de trouver à proximité plus ou moins immédiate du gisement des zones évidentes de métallurgie, comme des foyers de réduction de minerai ou des indices d'extractions minières ou de haldes. Pour les débuts de l'âge du Bronze, les données paléoenvironnementales, issues des carottages polliniques réalisés dans le cirque et dans les environs, montrent des indices de pollution liés à la métallurgie, en plus des indices d'exploitation pastorale et sylvicole des zones d'altitude se traduisant par l'ouverture du milieu. Ces données pourraient alors traduire une diversité des activités réalisées dans ce milieu d'altitude. La poursuite des travaux devrait permettre d'appréhender plus précisément le quotidien de ces anciennes populations montagnardes, leurs relations avec les implantations de plus basse altitude et les enjeux de telles implantations.

\section{BIBLIOGRAPHIE}

BESSE M., 1996, Le Campaniforme en France : analyse de la céramique d'accompagnement, Oxford, Archaeopress (BAR International Series, 635).

BEVILACQUA R., 2015, La Pièce d'Alquier à Fontiès-d'Aude : un nouveau jalon pour l'étude du Campaniforme pyrénéen, Toulouse, Archives d'écologie préhistorique. 
CARLÚS X., LÓPEZ CACHERO F. J., TERRATS N., OLIVA M., PALOMO A., RODRÍGUEZ A., 2008, « Diacronia durant la Prehistoria recent a Can Roqueta (Sabadell-Barbera del Vallès, Vallès Occidental) entre el VII et I Milleni Cal. ANE », Cypsela, nº 17, p. 115-142.

CAROZZA L., GALOP D., MAREMBERT F., MONNA F., 2005, « Quel statut pour les espaces de montagne durant l'âge du Bronze ? Regards croisés sur les approches société-environnement dans les Pyrénées occidentales ", Documents d'archéologie méridionale, $\mathrm{n}^{\circ}$ 28, p. 7-23.

CLAUSTRE F., 1996, « Le Bronze ancien en Roussillon », dans Mordant C. et Gaiffe O. (dir.), Cultures et sociétés du Bronze ancien en Europe : actes du $117^{e}$ Congrès national des sociétés savantes, ClermontFerrand, Paris, Éditions du CTHS, p. 387-399.

CLAUSTRE F. et MAZIère F., 1998, « La céramique campaniforme des Pyrénées orientales », Bulletin de la Société préhistorique française, vol. 95, nº 3, p. 383-392.

CLOT A., COQUEREL R., OMNÈS J., 1978, « Une triple inhumation du Bronze ancien à la Gourgue d'Asque (Hautes-Pyrénées) », Bulletin de la Société d'histoire naturelle de Toulouse, vol. 114, nº 1-2, p. 93-114.

CORDIER G., 1964, « Aiguisoirs de l'âge du Bronze provenant de la Touraine », Revue archéologique du Centre, vol. $3, \mathrm{n}^{\circ} 1$, p. 49-53.

DIETRICH P.-F. de, 1786, Description des gîtes de minerai et des bouches à feu de la France, Paris, éd. Didot fils.

DONNELY G. et FURESTIER R., 2009, A8 Saint-Maximin, chemin d'Herbous à Saint-Maximin-la-Sainte-Baume (Var), région Provence-Alpes-Côte-d'Azur : rapport final d'opération, Aix-en-Provence, Service régional de l'archéologie PACA.

DURAND J.-M., 1968, La Préhistoire de l'Ariège du Néolithique I à la période La Tène, Foix, Société ariégeoise des sciences, lettres et arts.

EQUIP MINFERRI, 1997, « Noves dades per a la caracterizacio dels assentaments a l'aire lliure durant la primera meitat del II millenni cal. BC: primers resultats de les excavacions en el jaciment de Minferri (Juneda, Les Garrigues) », Revista d'Arqueologia de Ponent, nº 7, p. 161-211.

ESCALLON G., FURESTIER R., LACHENAL T., CONVERTINI F., FOREST V., 2008, « Le parc Georges Besse II : un site du Bronze ancien épicampaniforme à Nimes (Gard) », Bulletin de la Société préhistorique française, vol. 105, $\mathrm{n}^{\circ}$ 3, p. 517-537.

FURESTIER R., 2007, Les industries lithiques campaniformes du sud-est de la France, Oxford, Archaeopress (BAR International Series, 1684).

GALOP D., 2001, « La longue durée, une anthropisation croissante », dans Briffaud S. et Davasse B. (dir.), Paysage et politique du paysage dans le massif transfrontalier de Gavarnie/Mont-Perdu : analyse interdisciplinaire pour servir de fondement à la gestion durable d'un bien inscrit au patrimoine mondial : rapport final de recherche, Paris, Direction de l'architecture et du patrimoine, p. 46-62.

GALOP D., CAROZZA L., MAREMBERT F., BAL M.-C., 2007, « Activités agropastorales et climat durant l'Âge du Bronze dans les Pyrénées : l'état de la question à la lumière des données environnementales et archéologiques ", dans Mordant C., Richard H., Magny M. (dir.), Environnements et cultures à l'âge du Bronze en Europe occidentale, Paris, Éditions du CTHS (Documents préhistoriques, 21), p. 107-119. GARCíA GAZÓLAZ J., 1993, « Saso I y II: Reflejos de una economia de producción durante el Eneolitico final-Bronce antiguo en Navarra », Cuadernos de Arqueología de la Universidad de Navarra, $\mathrm{n}^{\circ} 1$, p. 17-52. 
GASCó J., 2004, « Les composantes de l'âge du Bronze, de la fin du Chalcolithique à l'âge du Bronze ancien en France méridionale », Cypsela, $\mathrm{n}^{\circ}$ 15, p. 30-72.

GIRAUD J.-P., MARTY B., VIDAL M., 1987, « La sépulture en coffre d'Aragnouet (Hautes-Pyrénées) », Préhistoire ariégeoise, bulletin de la Société préhistorique ariégeoise, $\mathrm{n}^{\circ} 42$, p. 189-245.

GOMEZ J., 1976, « Quelques aiguisoirs protohistoriques du Centre-Ouest de la France », Revue archéologique du centre de la France, $\mathrm{n}^{\circ}$ 59-60, p. 261-265.

GUILAINE J., 1977, « Hommages à P. Helena : le Néolithique, le Chalcolithique et l'âge du Bronze », Cahiers ligures de préhistoire et d'archéologie, n² 25-26, p. 109-350.

GUILAINE J., VAQUER J., COULAROU J., 1989, Ornaisons-Médor : archéologie et écologie d'un site de l'âge du Cuivre, de l'âge du Bronze final et de l'Antiquité tardive, Toulouse, Centre d'anthropologie des sociétés rurales / Carcassonne, Archéologie en terre d'Aude.

HAMON C. et MILLEVILLE A., 2006, « La meule rhabillée, le plus simple appareil ? Fabriquer et utiliser un moulin au Néolithique », dans Astruc L., Bon F., Léa V., Milcent P.-Y. et Philibert S. (dir.), Normes techniques et pratiques sociales : de la simplicité des outillages pré et protohistoriques. Actes des $26^{e}$ Rencontres internationales d'archéologie et d'histoire d'Antibes, Antibes, APDCA, p. 173-183.

JOLIBERT B., 1988, Le gisement campaniforme de Muret, Toulouse, Archives d'écologie préhistorique.

LE GUilLou Y., 2000, « Grotte de Peyrère-3 : une sépulture des débuts de l'âge du Bronze à FréchetAure (Hautes-Pyrénées) », Préhistoire ariégeoise, bulletin de la Société préhistorique ariégeoise, $\mathrm{n}^{\circ} 55$, p. 107-116.

MAGNY M., BOSSUET G., GAUTHIER E., RICHARD H., VANNIÈRE B., BILLAUD Y., MARGUET A., MOUTHON J., 2007, «Variations du climat pendant l'âge du Bronze au centre-ouest de l'Europe : vers l'établissement d'une chronologie à haute résolution », dans Mordant C., Richard H., Magny M. (dir.), Environnements et cultures à l'âge du Bronze en Europe occidentale, Paris, Éditions du CTHS (Documents préhistoriques, 21), p. 17-28.

MARCIGNY C., GHESQUIÈRE E., GAUMÉ E., MARE E., 2001, « Un habitat de l'âge du Bronze ancien à Guilberville Le Domaigne (Manche) », Bulletin de la Société préhistorique française, vol. 98, $\mathrm{n}^{\circ} 3$, p. 529-541.

MAREMBERT F., 2000, «Un faciès original : le groupe du Pont-Long au cours des phases anciennes de l'âge du Bronze dans les Pyrénées nord-occidentales ", Bulletin de la Société préhistorique française, vol. 97, $\mathrm{n}^{\circ}$ 4, p. 521-538.

MAREMBERT F., DUMONTIER P., DAVASSE B., WATTEZ J., 2008, « La transition Néolithique final/Bronze ancien sud Aquitaine à travers les tumulus Cabout 4 et 5 de Pau (Pyrénées-Atlantiques) », Archéologie des Pyrénées occidentales et des Landes, n² 27, p. 77-112.

MILITON C., 1987, « Métallogénie polyphasée à $\mathrm{Zn}, \mathrm{Pb}, \mathrm{Ba}, \mathrm{F}$ et Mg, Fe de la région de GèdreGavarnie-Barroude (Hautes-Pyrénées) », thèse de doctorat, Orléans, université d'Orléans.

MILLEVILLE A., 2007, « De la pierre à la meule durant le Néolithique, circulation et gestion des matières premières entre Rhin et Rhône ", thèse de doctorat, Besançon, université de FrancheComté.

MIROUSE R. et BARRÈre P., 1993, Notice explicative. Carte géologique France (1/50000), feuille Vielle-Aure (1083), Orléans, BRGM.

MUJIKA J.-A., PEÑALVER X., TARRIÑO A., TELLERIA E., 2009, « Haltzerreka (Gipuzkoa): un asentamiento del Bronce antiguo al aire libre en un medio de montaña », Kobie, $n^{\circ} 28$, p. 89-120. 
OMNÈs J., 1980, « L'ossuaire de la grotte d'Artigaou à Esparros (H.-P.), suivi d'un inventaire des grottes sépulcrales des Hautes-Pyrénées », Revue de Comminges, n 93, p. 161-174.

PAUTREAU J.-P. et CASSEN S., 1975, « Aiguisoirs inédits de l'âge du Bronze dans le Centre-Ouest », Revue archéologique du Centre, vol. 14, nº 1, p. 63-67.

PERRIN T., 2015, PRIMAP 2015: premiers impacts anthropiques dans les Pyrénées centrales, approches multi-proxy (archéologie, paléoenvironnement). Prospection-inventaire avec sondages à Gèdre (HautesPyrénées), rapport de prospection-inventaire, Toulouse, Service régional de l'archéologie MidiPyrénées.

PONS F., LAGARRIGUE A., COLONGE D., JARRY M., MARTIN H., 2003, « Un habitat de plein air du Bronze ancien dans le midi toulousain à Blagnac (Haute-Garonne) : le site de Cassagna 3 », Document d'archéologie méridionale, $\mathrm{n}^{\circ}$ 26, p. 7-41.

REMICOURT M., TALLET P., FERNANDES P., RUE M., BRIAND T., SIMONET A., PASQUINI A., FEDOROFF N., PICAVET R., BERNARD C., 2010, Les occupations gravettiennes de Hin de Diou, à Pujo-le-Plan (Landes), rapport final d'opération, Villard-de-Lans, Paléotime / Service régional de l'archéologie d'Aquitaine.

REMICOURT M., ANDRIEU-PONEL V., AUDIBERT C., BARADAT A., BATTENTIER J., BLAISE E., BONNARDIN S., CAVERNE J.-B., FERNANDES P., FURESTIER R., GIRARD B., LACHENAL T., LEPÈRE C., LOCATELLI C., MARTIN L., PARISOT N., PONEL P., POUSSET D., RUÉ M., SCHMITT A., SÉNÉPART I., THIRAULT E., 2014, « Les occupations pré et protohistoriques du Clos de Roque, Saint-Maximin-la-Sainte-Baume (Var) », dans $X^{e}$ Rencontres méridionales de préhistoire récente : actualité de la recherche, actes du colloque d'Ajaccio, Toulouse, Archives d'écologie préhistorique, p. 523-548.

RENDU C., CAMPMAJO P., CRABOL D., 2012, «Étagement, saisonnalité et exploitation des ressources agro-pastorales en montagne à l'âge du bronze : une possible "ferme d'altitude" à Enveig (Pyrénées-Orientales) », Bulletin de l'Association pour la promotion des recherches sur l'âge du Bronze, $n^{\circ} 10$, p. 58-61.

RENDU C., CALASTRENC C., LE COUÉDIC M., BERDOY A., 2016, Estive d'Ossau : 7000 ans de pastoralisme dans les Pyrénées, Toulouse, Le Pas d'Oiseau.

ROUQUerol N., 2004, Du Néolithique à l'âge du Bronze dans les Pyrénées centrales françaises, Toulouse, Archives d'écologie préhistorique.

ROUSSOT-LARROQUE J., 1997, « La Lède du Gurp et la métallurgie du Bronze moyen dans le Médoc », Revue archéologique de Bordeaux, nº 88, p. 35-56.

SORIANO I. et ESCANILLA N., 2016, « Can Mur (Barcelona): Crisoles con sistema de prensión y la metalurgia de la Edad del Bronce en el nordeste de la Península Ibérica », Trabajos de Prehistoria, vol. $73, \mathrm{n}^{\circ} 1$, p. 160-179.

TARRUS I GLATER J., 1985, « Consideracions sobre el Neolitic final-calcolitic a Catalunya

(2500-1800 a.C.) », Cypsela, $\mathrm{n}^{\circ}$ 5, p. 47-57.

TOLEDO I MUR A., 1998, « Els materials ceramics de les coves A i B d'Olope (Isovol, Cerdanya) », Cypsela, $\mathrm{n}^{\circ} 12$, p. 135-148.

\section{RÉSUMÉS}

La première campagne de fouille dans le cirque de Troumouse, sur le site de La Haille de Pout, a permis la découverte de plusieurs occupations de haute montagne datant du passage du Campaniforme aux premiers temps de l'âge du Bronze. Ce petit hameau a livré au moins deux 
habitations bien conservées et de probables zones d'activités extérieures. Si d'autres occupations pré- ou protohistoriques sont repérées au-delà de 2000 mètres d'altitude dans les Pyrénées, les premiers résultats obtenus ici montrent un site exceptionnellement bien conservé et sans équivalent. Ils permettront d'appréhender le quotidien de ces anciennes populations montagnardes, leurs relations avec les implantations de plus basse altitude et les enjeux économiques de telles occupations, donnant ainsi des précisions quant aux interprétations des nombreuses observations paléoenvironnementales disponibles.

The first excavation campaign in the Haille de Pout site (cirque of Troumouse) led to the discovery of several high-mountain occupations dated at the transition between the Bell-Beaker culture and the beginning of the Early Bronze Age. This small, high-altitude hamlet includes at least two well-preserved houses and several outdoor activity pens. Other pre-or protohistoric occupations above 2,000 m a.s.l. are known in the Pyrenees, but our first results show an exceptionally well-preserved open-air site, without parallel. Its study will shed light on the everyday life of these ancient mountain populations, their relationships with the lower altitude settlements and the economic status of this occupation. These data will allow us to more precisely interpret the numerous paleoenvironnemental observations.

INDEX

Mots-clés : Campaniforme, Bronze ancien, habitat, haute montagne

Keywords : Bell-Beaker Culture, Early Bronze Age, high mountain, settlement

Index géographique : Hautes-Pyrénées

\section{AUTEURS}

\section{GUILLAUME SAINT-SEVER}

Laboratoire Travaux et recherches archéologiques sur les cultures, les espaces et les sociétés (TRACES, UMR 5608, université Toulouse - Jean-Jaurès/CNRS), équipe Radhamante

\section{MAXIME REMICOURT}

Laboratoire Travaux et recherches archéologiques sur les cultures, les espaces et les sociétés (TRACES, UMR 5608, université Toulouse - Jean-Jaurès/CNRS), équipe Préhistoire récente du bassin méditerranéen 
Approches multiproxy 


\section{Le canyon de la Pardina et ses} estives : approche archéologique d'un territoire de haute montagne dans le parc national d'Ordesa et du mont Perdu (Fanlo, Huesca, Espagne)

The Pardina canyon and its summer pastures: archeological approach to a high-mountain territory in the National Park of Ordesa and Monte Perdido (Fanlo, Huesca, Spain)

Lourdes Montes, Rafael Domingo Martínez, Rafael Laborda Lorente, Paloma Lanau, Vanessa Villalba-Mouco, Mario Gisbert et María Sebastián

Ce travail a été développé dans le cadre du projet de l'Organismo Autónomo Parques Nacionales "Análisis ecológico de la culturización del paisaje de alta montaña desde el Neolitico: los Parques Nacionales de montaña como modelo " (Analyse écologique de la culture du paysage de haute montagne depuis le Néolithique : les parcs nationaux des montagnes en tant que modèles) (BOE $n^{\circ} 300,16 / 12 / 2013$, réf. 998), mais le soutien économique et institutionnel a été fourni par l'université de Saragosse à travers le projet HAR2014-59042, "Transiciones climáticas y adaptaciones sociales en la Prehistoria de la cuenca del Ebro " (Transitions climatiques et adaptations sociales pendant la préhistoire de la vallée de l'Èbre), et le groupe de recherche H07 "Primeros Pobladores del Valle del Ebro " (Premiers habitants de la vallée de l'Èbre) du gouvernement aragonais et du Fonds social européen. Nous renouvelons encore une fois nos sincères remerciements à la ville de Fanlo et au parc national d'Ordesa et du mont Perdu pour nous avoir fourni toute la documentation nécessaire pour mener à bien ce travail. Nous remercions enfin C. Rendu et $C$. Mordant, qui ont relu notre contribution, pour leurs commentaires sur l'orientation du texte ainsi que la révision approfondie de la rédaction en français. 
1 Bien que la recherche préhistorique ait débuté dès le xix ${ }^{e}$ siècle sur les piémonts de la chaîne pyrénéenne, c'est véritablement au début du xxi siècle que se consolident, au sein du massif, les études archéologiques liées à l'occupation préhistorique de la haute montagne. Avant la récente publication multidisciplinaire des estives d'Ossau (Rendu et al. 2016), on peut citer les travaux de plusieurs chercheurs en relation avec l'analyse du pastoralisme ou du passage entre les deux versants : sur la longue durée, ceux de D. Galop (1998 et 2006) sur l'évolution paysagère des Pyrénées, celui de C. Rendu (2003) sur la montagne d'Enveig et enfin celui de E. Gassiot (2016) sur la zone de Aigüestortes i Estany de Sant Maurici. À noter également des travaux focalisés sur certaines périodes historiques: ceux de J.-L. Ona et C. Calastrenc sur le couloir entre les hospices de Venasque et de Bagnères-de-Luchon (2009), ceux de l'équipe de J.-M. Palet sur le Cadí (Ejarque et al. 2009) et sur les Pyrénées romaines (Leveau et Palet 2010), ou la révision de D. Barraud et F. Réchin (2013) sur Oloron et ses alentours.

Dans les Pyrénées centrales espagnoles, notamment dans la province de Huesca, les occupations humaines préhistoriques de montagne ont fait l'objet de recherches spécifiques depuis des décennies. Ces travaux ont commencé dans les années 1970, avec les fouilles de V. Baldellou à Sierra Ferrera, à environ 1300 mètres d'altitude (Baldellou 1983 et 1987). Quelques années plus tard, la Cueva Drólica, située à un emplacement stratégique sur l'ancien chemin de Sevil, à 1200 mètres d'altitude (Montes et Martínez Bea 2007), a été fouillée dans le cadre d'un projet régional de recherche incluant d'autres cavités habitées (Cueva de la Carrasca) ou funéraires (Cueva de los Cristales) ainsi que trois monuments dolméniques (Montes et al. 2016). On peut aussi citer, dans les travaux sur le site de l'hôpital de Venasque, l'étude de structures d'habitation et funéraires datées de l'âge du Bronze, à 1750 mètres d'altitude (Ona et Calastrenc 2009). Les très récentes fouilles à la Cova dels Trocs, à 1560 mètres, ont dévoilé une occupation néolithique liée à une transhumance pionnière (Rojo Guerra et al. 2013). Les travaux encore en cours dans la grotte de Coro Trasito (alt. $1548 \mathrm{~m}$ ), à Tella, ont déjà révélé une occupation du Néolithique ancien (Clemente-Conte et al. 2016). Enfin, dans le parc national de Aigüestortes i Estany de Sant Maurici, dans la province de Lérida, la présence humaine est attestée au moins depuis le Mésolithique (abri de l'Estany de la Coveta, alt. $2430 \mathrm{~m}$ ) et le Néolithique ancien (Cova del Sardo, alt.1790 m) (Gassiot 2016).

3 Les altitudes de ces sites montrent que le terme "archéologie de montagne " ne peut pas être considéré comme un concept univoque, mais qu'il est fortement lié au gradient latitudinal et à l'environnement des sites : on peut qualifier de territoires de montagne des aires planes situées à haute altitude, mais aussi des reliefs prononcés très proches des zones côtières, d'à peine 200 mètres de hauteur. Le concept englobe donc des zones climatiques et des paysages dominants très variés, mais qui partagent toujours une grande sensibilité aux changements, même mineurs, en température et en précipitations (Grimaldi et al. 2016).

4 Ce travail présente une recherche archéologique conduite au sein du parc national d'Ordesa et du mont Perdu (PNOMP), entre 1700 et 2100 mètres d'altitude : il s'agit d'une véritable archéologie de haute montagne (Laborda et al. 2016). Trois campagnes de prospection (avec des sondages) se sont déroulées dans le cadre du projet de recherche 2014-2016 «Analyse écologique de la transformation culturelle du paysage de haute montagne à partir du Néolithique : les parcs nationaux de montagne comme modèles »(réf. 998 de l'Organismo Autónomo Parques Nacionales), coordonné par 
J. Catalán, biologiste de l'université autonome de Barcelone. L'objectif principal était de déceler l'origine de l'impact anthropique sur le paysage d'Ordesa, où le pastoralisme a abaissé la limite altitudinale des forêts alpines.

5 Après une première analyse de la carte du territoire du parc national, nous avons considéré que la zone du canyon (barranco) de la Pardina (Fanlo, Huesca, Espagne), dans le secteur de pâturages connus comme Puerto Bajo de Góriz (zone SE), serait idéale pour nos recherches. De 2014 à 2016, durant trois années, nos prospections l'ont totalement couverte, en rive droite (occidentale) du canyon d'Añisclo, en incluant l'estive. Le parc national nous a donné accès à une liste d'abris-sous-roche ou grottes utilisés traditionnellement comme des refuges (mallatas) par les bergers. Sans supposer une relation directe, nous avons posé l'hypothèse que les éleveurs pionniers du Néolithique ont pu choisir pour s'installer les mêmes refuges naturels; ils ont donc constitué les objectifs initiaux de nos prospections. Celles-ci ont ensuite, selon les résultats, donné lieu à des sondages et fouilles archéologiques. Les travaux sur le terrain ont mobilisé les auteurs de ce texte, avec l'appui de Mikel Etxebarría, Jorge Sevil et Guillermo Tena, mais aussi de Laureano Gómez et David Asenjo (Grupos de Rescate Especial de Intervención en Montaña de la Guardia Civil), que nous remercions de leur aide. Nous voulons exprimer enfin nos remerciements à Manuel Latre, ancien berger de la zone, qui nous a aidé à mieux connaître ce territoire.

\section{La zone d'étude : caractéristiques géographiques et environnementales d'Ordesa}

6 La vallée d'Ordesa se trouve au nord de la province de Huesca, dans les Pyrénées centrales espagnoles (fig. 1). Elle est devenue un parc national en 1918 en raison de ses caractéristiques géologiques, géomorphologiques et environnementales. Après un élargissement de la zone protégée en 1982, la surface totale du parc dépasse 15000 hectares, articulés autour de quatre vallées, celles des rivières Arazas (la vallée d'Ordesa elle-même), Bellós (canyon d'Añisclo), Cinca (Pineta) et Yaga (Escuaín). Le massif calcaire du mont Perdu (alt. $3355 \mathrm{~m}$ ) domine ce territoire, qui compte d'autres pics supérieurs à 3200 mètres d'altitude : Cilindro, Marboré et Soum de Ramond. 
Fig. 1. - Carte du parc national d'Ordesa et du mont Perdu, avec les sites archéologiques enregistrés aux environs du canyon de la Pardina, sur le Puerto Bajo de Góriz.

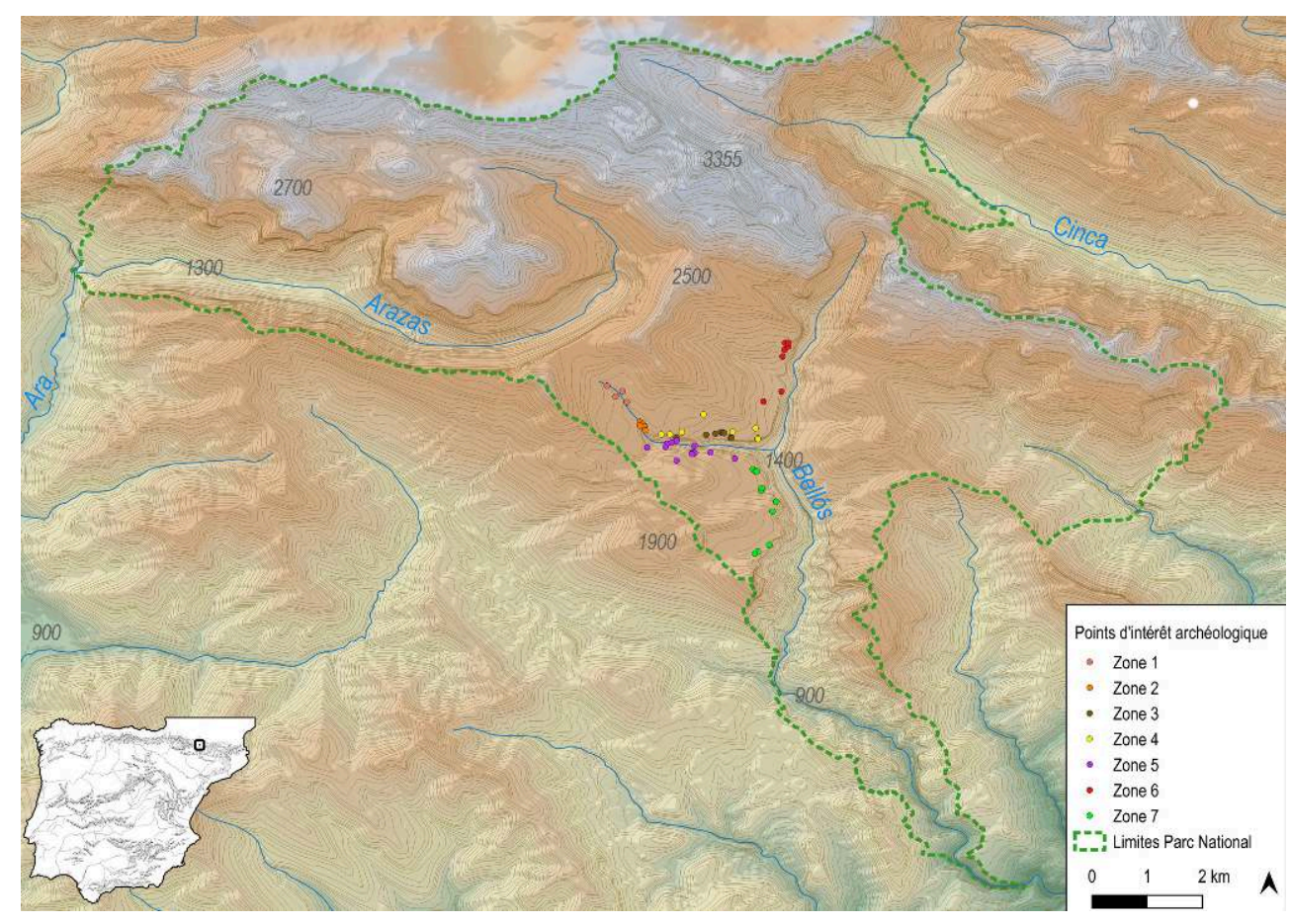

PAO et cartographie Rafael Domingo.

7 La lithologie calcaire a permis la présence de canyons abrupts de plusieurs centaines de mètres de profondeur (fig. 2). 
Fig. 2. - Un paysage typique de la zone étudiée : sur le profil étagé du canyon de la Pardina alternent des petits couloirs horizontaux (fajas) et des parois verticales. Au fond, le massif de Las Tres Marías et à gauche, la Punta de las Olas.

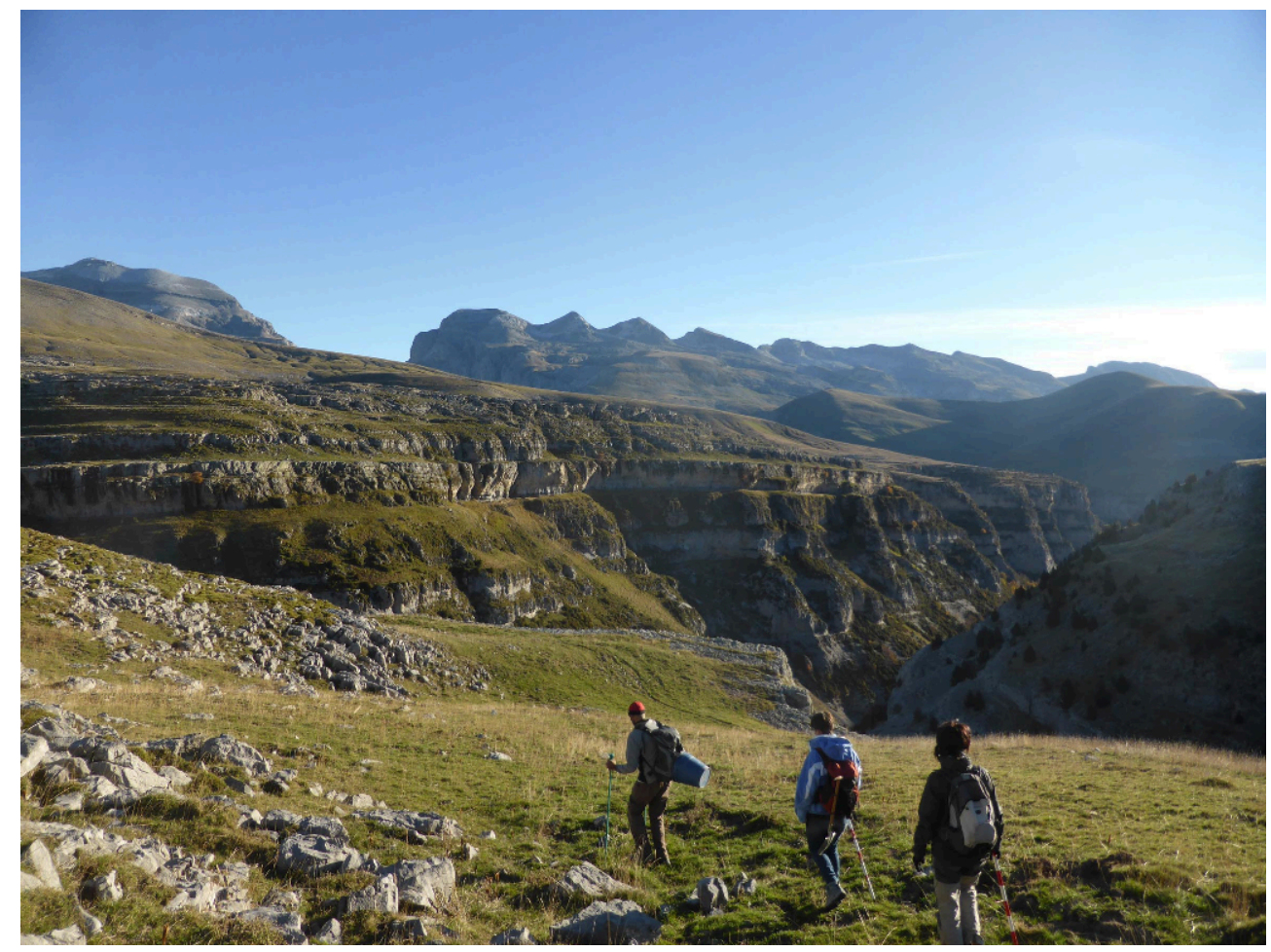

Photo Rafael Laborda

Le climat de haute montagne subit des influences méditerranéennes, avec une concentration des pluies au printemps et en automne. L'isotherme $0{ }^{\circ} \mathrm{C}$ est situé entre novembre et mai entre 1600 et 1700 mètres d'altitude; malgré les faibles précipitations hivernales, la neige conditionne fortement le paysage pendant plusieurs mois.

La zone sud-est du parc est dominée par le canyon d'Añisclo, dont la longueur (environ 10 kilomètres), l'orientation (N-S) et la profondeur (plus de 1000 mètres), ainsi que la présence de courtes vallées latérales, génèrent un paysage très contrasté. Le fort gradient altitudinal détermine un étagement de la végétation, caractérisé dans la partie basse par les forêts mixtes de noisetiers, chênes faginés et buis, mais aussi des groupements isolés de hêtres; une bordure de conifères (Pinus uncinata) occupe l'étage subalpin, qui cède ensuite la place, plus haut, aux pelouses alpines. L'abandon progressif des pratiques traditionnelles provoque la croissance de buissons dans la partie basse de l'étage subalpin, antérieurement géré par le feu et le pâturage.

Situé dans les pâturages du Puerto Bajo de Góriz, le canyon de la Pardina est une vallée latérale qui démarre à mi-parcours de la rivière Bellós (canyon d'Añisclo) ; il s'agit d'un canyon court et à forte pente, au parcours rythmé par des chutes d'eau liées à l'alternance de lithologies calcaires de duretés différentes (knickpoints). Sa longueur totale est de 4 kilomètres environ, dont les deux premiers, relativement peu pentus, suivent une orientation NW-SE, tandis que les deux derniers enregistrent une pente de plus de 400 mètres de dénivelé. Cette dernière partie est caractérisée par de hautes parois verticales calcaires et d'étroites faches (couloirs horizontaux appelés fajas du côté espagnol et faches dans les Pyrénées françaises) d'accès difficile (fig. 3). Dans la partie 
haute du canyon de la Pardina, l'ancienne déforestation destinée à créer des pâturages est à l'origine de processus érosifs provoquant des glissements de terrain (García-Ruiz et al. 2014).

Fig. 3. - Falaise de la partie finale du canyon de la Pardina (Fanlo, Huesca, Espagne) et son débouché sur le canyon d'Añisclo. Au fond, le col d'Añisclo sépare les massifs de Las Tres Sorores (ou Treserols, à gauche) et de Las Tres Marías. Le cercle montre la situation de la grotte Candón.

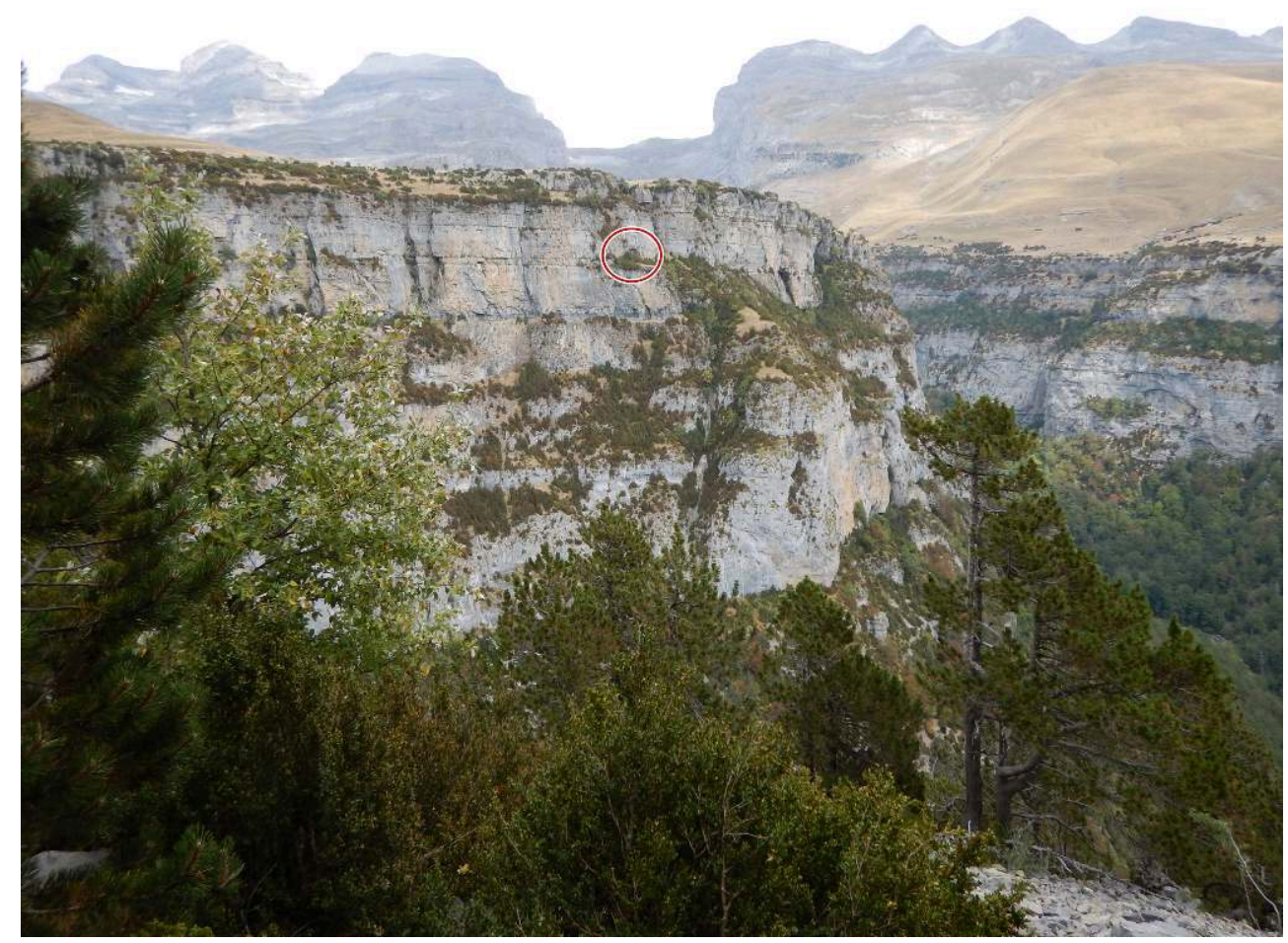

Photo Rafael Laborda.

11 La paléoclimatologie de la zone a commencé récemment à être décrite grâce à différents référentiels, dont ceux du lac de Marboré, les plus complets pour l'Holocène, et dont les deux premiers millénaires montrent encore une influence glaciaire très marquée (Leunda et al. 2017) ; puis les données suggèrent un contexte climatique plus humide jusqu'à environ 2200 cal. BC; les derniers siècles de cette période sont marqués par une augmentation de l'aridité, qui s'intensifie pendant les périodes suivantes. Les fluctuations hydrologiques sont fréquentes durant l'Antiquité romaine et le Moyen Âge, tandis que les impacts anthropogéniques ne peuvent être reconnus avant le Petit Âge glaciaire. Les données polliniques des sites de La Basa de la Mora (alt. $1914 \mathrm{~m}$ ) ou Marboré (alt. $2612 \mathrm{~m}$ ) montrent une forte augmentation, vers 900 A. D., de l'influence anthropique sur l'environnement, parallèlement à l'augmentation des conditions d'aridité jusque vers 1300, quand le début du Petit Âge glaciaire entraîne l'apparition d'un climat plus humide et plus froid (González-Sampériz et al. 2017, Leunda et al. 2017). À Tramacastilla (alt. $1640 \mathrm{~m}$ ), l'expansion de Plantago reconnue à partir des années 1000 montre, sans aucun doute, la transformation en pâturages de terres qui auparavant étaient de type forestier. Dans ces séquences, l'évolution de la végétation reflète les caractéristiques particulières de chaque période, avec une réponse rapide de la végétation régionale aux changements climatiques (García-Ruiz et al. 2014). 


\section{Les travaux archéologiques : méthodologie et synthèse des résultats obtenus}

12 Comme nous l'avons dit, l'hypothèse de départ s'appuie sur le réseau des refuges utilisés par les bergers jusqu'au $\mathrm{xx}^{\mathrm{e}}$ siècle (notamment les grottes, abris ou petites cavités), dont l'emplacement bénéficie de conditions favorables dans un environnement plutôt hostile. Du fait de ces caractéristiques optimales, les bergers préhistoriques auraient pu occuper les mêmes refuges naturels. Nous avons d'abord compilé les données sur les abris et les grottes utilisés comme refuges par les bergers jusqu'à une époque récente, à partir de la liste de mallatas fournie par le PNOMP, mais aussi de l'information présente dans les travaux de L. Briet (1910) et S. Pallaruelo (1988), ainsi que dans certains rapports spéléologiques (GIEG Granollers 1984 et 1985, GIE Peña Guara 1974).

13 La deuxième phase du travail a consisté à parcourir systématiquement l'aire délimitée (400 ha environ, entre 1700 et $2100 \mathrm{~m}$ d'altitude, divisés en 7 sous-zones) avec une attention particulière pour les points listés par le PNOMP, mais aussi pour les falaises rocheuses des deux versants du canyon de la Pardina, ainsi que de la rive droite du canyon d'Añisclo.

Plusieurs objectifs ont été définis :

- Explorer les plus anciennes occupations humaines dans le territoire du PNOMP, en les datant au moyen $d u{ }^{14} \mathrm{C}$ et de l'étude des matériels archéologiques trouvés lors des prospections et des sondages. Les dates sont données calibrées $\mathrm{BC}$ d'après le logiciel Oxcal 4.2 (IntCal 13 curve) (Bronk Ramsey 2009, Reimer et al. 2013);

- Fouiller quelques-uns des gisements préhistoriques identifiés, afin d'en appréhender l'activité principale, la saisonnalité des occupations, la composition des troupeaux, les activités complémentaires, etc.;

- Examiner l'évolution de l'impact anthropique sur le terrain par l'analyse anthracologique des charbons de bois des sites archéologiques, afin de mesurer la disponibilité (croissante/ décroissante) des espèces utilisées comme combustible. Nous avons décidé d'élargir ce type d'analyse aux dépôts charbonneux sans matériaux anthropiques associés (feux naturels?) ainsi que de les dater;

- Identifier si l'exploitation pastorale de cette zone de haute montagne est demeurée stable sur la longue durée, ou s'il s'agit plutôt d'un processus intermittent depuis la préhistoire jusqu'à nos jours ;

- Établir une éventuelle corrélation entre la typologie et la fonctionnalité des sites archéologiques et leur localisation (altitude, pente, insolation, etc.) au moyen d'un système d'information géographique (SIG) permettant, après avoir généré un modèle prédictif, de localiser des points dotés de caractéristiques semblables.

15 À chaque station déterminée, un protocole identique a été suivi :

- Enregistrement des coordonnées par GPS ;

- Sondage archéologique et topographie, pour les cavités renfermant des sédiments et pour d'autres sites présentant un intérêt ;

- Le cas échéant (sondage positif) : fouille en extension selon le temps disponible et l'intérêt archéologique ;

- Dans tous les cas, rédaction d'une fiche détaillée. 

archéologique (nul, faible, élevé, très élevé) selon plusieurs critères: orientation, altitude, ampleur de l'espace habitable, accessibilité, présence de sédiments, matériel trouvé en surface ou lors d'un premier sondage. Ce classement a guidé la stratégie d'intervention des années postérieures: nous avons exclu les endroits les moins favorables, sur lesquels nous ne sommes pas revenus, et favorisé ceux qui présentaient un plus grand intérêt.

Les trois campagnes de prospection sur le terrain ont été conduites en septembre ou octobre, quand l'affluence des touristes décroît et avant l'apparition de la neige. Un total de 59 sites d'intérêt archéologique a été recensé, dont 17 ont été sondés et 2 fouillés en extension (tabl. 1 et 2). Pour tous les sites visités (fig. 1), leurs noms, coordonnées, descriptions, ainsi que les travaux qui y ont été développés (sondage, fouille, topographie, photos, cartes, matériaux récupérés) figurent dans les rapports envoyés à la direction générale du Patrimoine culturel d'Aragón.

Tabl. 1. - Canyon de la Pardina (Fanlo, Huesca, Espagne) : sites d'intérêt archéologique.

\begin{tabular}{|c|c|c|c|c|c|}
\hline $\begin{array}{r}\text { Typologie } \\
\text { des sites }\end{array}$ & Cabane & $\begin{array}{c}\text { Falaise + } \\
\text { cabane/ } \\
\text { enclos }\end{array}$ & $\begin{array}{l}\text { Abri/ } \\
\text { cavité }\end{array}$ & $\begin{array}{l}\text { Grotte / } \\
\text { résurgence }\end{array}$ & Total \\
\hline Zone 1 (20 ha environ) & 0 & 2 & 1 & 1 & 4 \\
\hline Zone 2 ( 15 ha environ) & 0 & 0 & 7 & 0 & 7 \\
\hline Zone 3 (45 ha environ) & 0 & 1 & 3 & 4 & 8 \\
\hline Zone 4 (65 ha environ) & 1 & 2 & 2 & 4 & 9 \\
\hline Zone 5 ( 85 ha environ) & 2 & 5 & 3 & 3 & 13 \\
\hline Zone 6 ( 85 ha environ) & 3 & 0 & 3 & 2 & 8 \\
\hline Zone 7 (90 ha environ) & 0 & 3 & 5 & 2 & 10 \\
\hline Total sur 405 ha environ & 6 & 13 & 24 & 16 & 59 \\
\hline
\end{tabular}

Tabl. 2. - Canyon de la Pardina (Fanlo, Huesca, Espagne) : datations ${ }^{14} \mathrm{C}$.

\begin{tabular}{|c|c|c|c|c|c|}
\hline Site & $\begin{array}{c}\text { Type } \\
\text { de dépôt }\end{array}$ & Échantillon & $\begin{array}{l}\text { Référence } \\
\text { laboratoire }\end{array}$ & $\begin{array}{l}\text { Datation } \\
\text { BP }\end{array}$ & $\begin{array}{c}\text { Date } \\
\text { cal. BC/AD } \\
2 \text { sigma }\end{array}$ \\
\hline Grotte Candón & Surface & Bos taurus & D-AMS 12625 & $826 \pm 27$ & $1166-1261 \mathrm{AD}$ \\
\hline Abri VP1 & $\begin{array}{l}\text { Couche cendreuse } \\
\text { Feu naturel? }\end{array}$ & Buxus sp. & MAMS-29833 & $2995 \pm 21$ & $1367-1129 B C$ \\
\hline Abri FP5 & Foyer & Pinus sp. & D-AMS 15081 & $4030 \pm 33$ & $2631-2471$ BC \\
\hline Mallata & Foyer & Fraxinus sp. & D-AMS 22987 & $4091 \pm 28$ & 2859-2501 BC \\
\hline Valle Pardina & $\begin{array}{l}\text { Couche } \\
\text { extérieure }\end{array}$ & Abies sp. & MAMS-29834 & $4463 \pm 23$ & $3332-3027 \mathrm{BC}$ \\
\hline
\end{tabular}




\section{Les sites les plus intéressants et leur répartition dans l'espace}

\section{Zones 1 et 2}

Ces zones correspondent à la naissance du torrent de la Pardina. Elles n'ont pas livré de vestiges archéologiques, bien que leurs falaises ( $10 \mathrm{~m}$ de haut environ) montrent de très beaux exemples de cavités bien orientées (Fogaril, Güerdios) et quelques sources (Furicón). Dans cette première partie de son cours, le torrent coule en direction nordsud entre 2100 et 1900 mètres d'altitude (fig. 4).

Fig. 4. - Les premiers étages du canyon de la Pardina (zone 2) avec quelques abris-sous-roche, dont les sondages ont été négatifs.

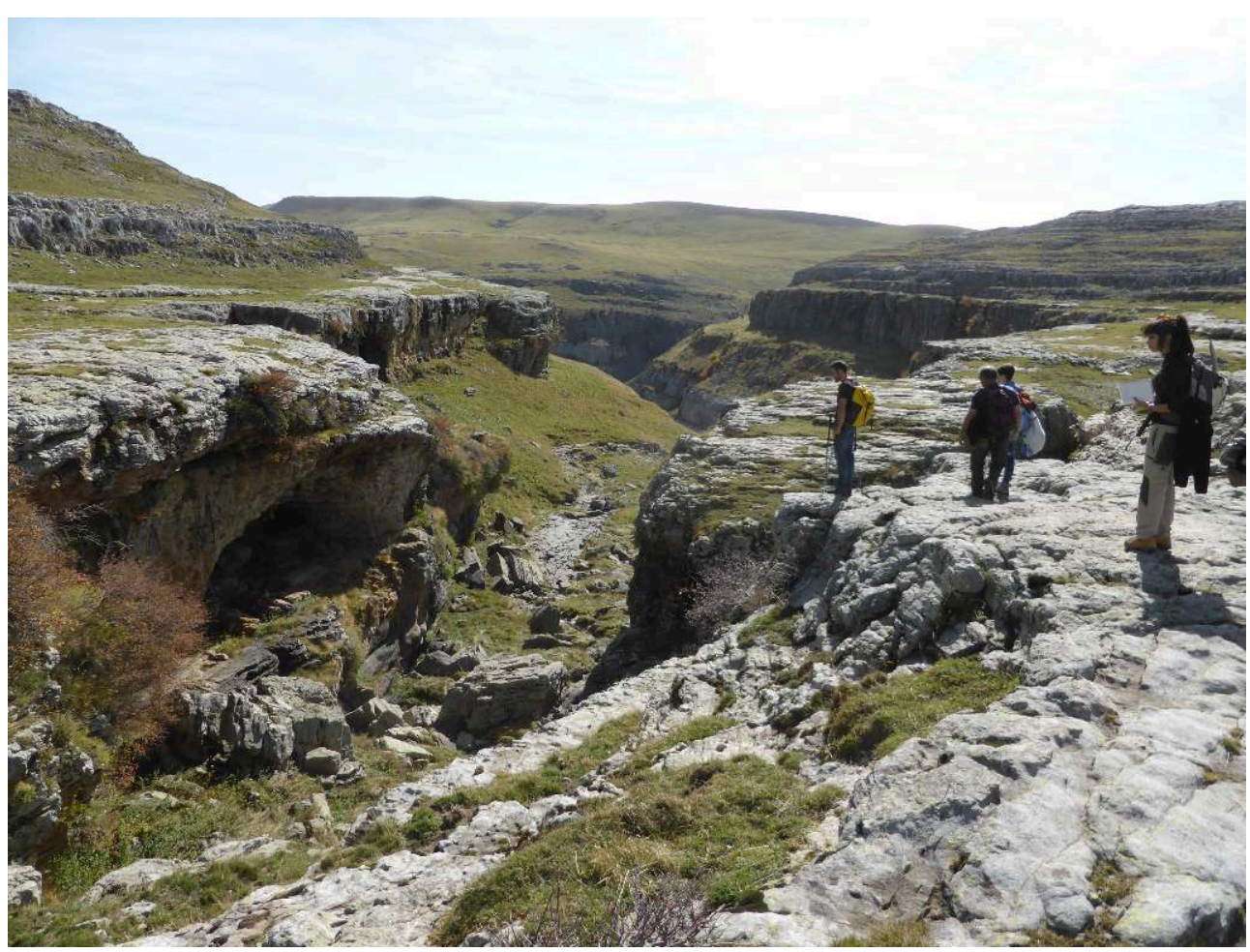

Photo Rafael Laborda.

\section{Zones 3 à 5}

Quand le canyon oblique vers l'est, en direction du cours du Bellós (canyon d'Añisclo), il se creuse profondément et son profil acquiert une allure étagée, marquée par l'alternance d'étroites plateformes rocheuses horizontales, les faches, et de falaises verticales. Les couloirs horizontaux de la rive gauche constituent la zone 3 , tandis que les plateaux en amont de ces falaises font partie de la zone 4 et que le fond de la vallée correspond à la zone 5. Quelques sites archéologiques (fig. 5) ont été répertoriés sur ces couloirs horizontaux, parmi lesquels les seuls sites préhistoriques connus à ce jour : l'abri FP-5, la grotte Candón, l'abri VP-1 et un petit abri sous un grand bloc rocheux dans la Mallata Valle Pardina. 
Fig. 5. - Carte de répartition des sites archéologiques sondés et décrits dans cette étude.

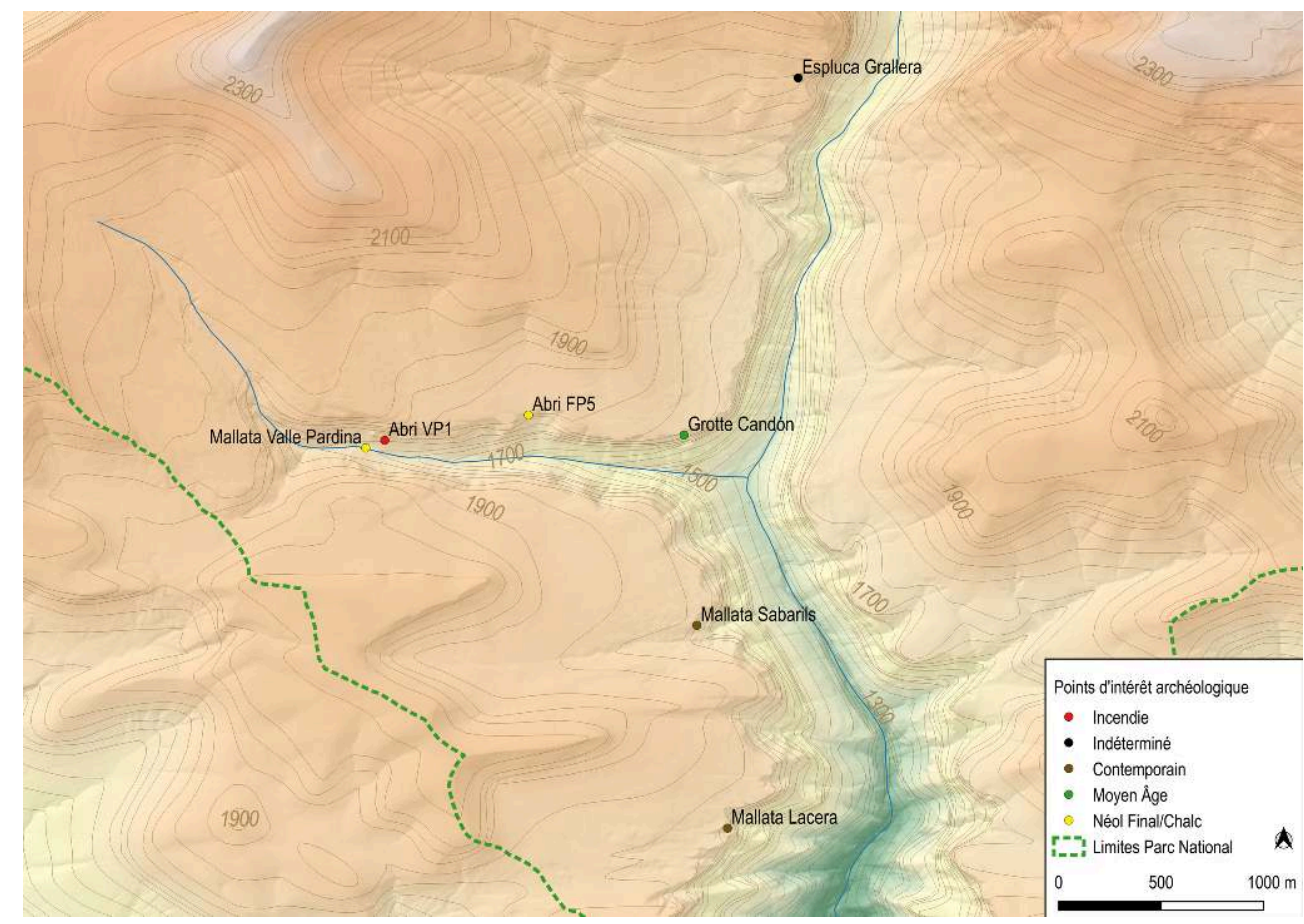

PAO et cartographie Rafael Domingo.

\section{Abri Faja Pardina 5 (abri FP-5)}

Situé dans la zone 3, il s'agit d'une petite cavité ouverte sur le sentier qui parcourt le couloir le plus développé (1 $820 \mathrm{~m}$ ). Elle montrait des taches de suie sur le plafond, de sorte qu'un sondage a été décidé au moment de sa découverte, en 2015. Les résultats positifs (fragments de poterie montée à la main, restes de faune brûlée, charbons) nous ont conduits à fouiller toute la cavité, puisque ses petites dimensions $\left(10 \mathrm{~m}^{2}\right.$ environ) permettaient de réaliser le travail dans le temps prévu pour la campagne de l'année. La plus grande partie de la surface était assez plate, mais marquée par une pente sensible en direction de l'extérieur, du côté de l'ouverture, jusqu'à la terrasse externe.

21 La stratigraphie commence par une couche superficielle de terre végétale avec des racines abondantes, pratiquement stérile. Immédiatement en dessous, une accumulation de blocs et de clastes scelle une nouvelle couche, le niveau 1, un sédiment compact de couleur claire qui repose directement sur le substrat rocheux. Jusqu'à environ 20 centimètres de profondeur, le niveau, assez pauvre, n'offre que quelques esquilles de faune. C'est à partir de cette profondeur que de nombreux tessons de poterie non tournée commencent à apparaître, ainsi que de plus grands fragments de faune et des charbons de bois. La majorité des fragments de céramique apparaissent autour de 22 à 24 centimètres de profondeur, groupés dans les carrés E6 et F6. Dans cette zone et à la base du niveau, un foyer en cuvette bien délimité s'appuie partiellement sur une marche du rocher. Il contenait des restes de faune brûlée, quelques fragments de céramique de taille modeste et des charbons abondants, qui ont été recueillis pour analyse anthracologique. Un de ces charbons du foyer, identifié d'après le diamètre de sa section comme une petite branche de Pinus sp., a été daté entre 2631-2471 cal. BC (D-AMS 015081: $4030 \pm 33$ ), datation qui se situe entre le 
Néolithique final et le Chalcolithique (tabl.2). Les fragments de céramique correspondent à trois récipients différents au moins, dont l'un présente un profil caréné, fermé, avec une anse en ruban près du bord (fig. 6-a) : dans la région, ces formes sont plutôt typiques de l'âge du Bronze. Certes, on connaît aussi des profils carénés au Chalcolithique, mais ils sont alors toujours associés à des décors campaniformes, du moins pour ceux que signalent les chercheurs. Il faut en outre tenir compte du fait que le charbon daté venait de l'intérieur du foyer, qui se situait à la base du niveau 1 , d'où provient le vase. Celui-ci pourrait donc être légèrement plus récent que le charbon daté.

Fig. 6. -Abri FP5, canyon de la Pardina (Fanlo, Huesca, Espagne) : en haut, récipients céramiques récupérés dans les fouilles de l'abri. En bas, section et plan de l'abri ; photos de l'intérieur et de l'ouverture de la cavité.

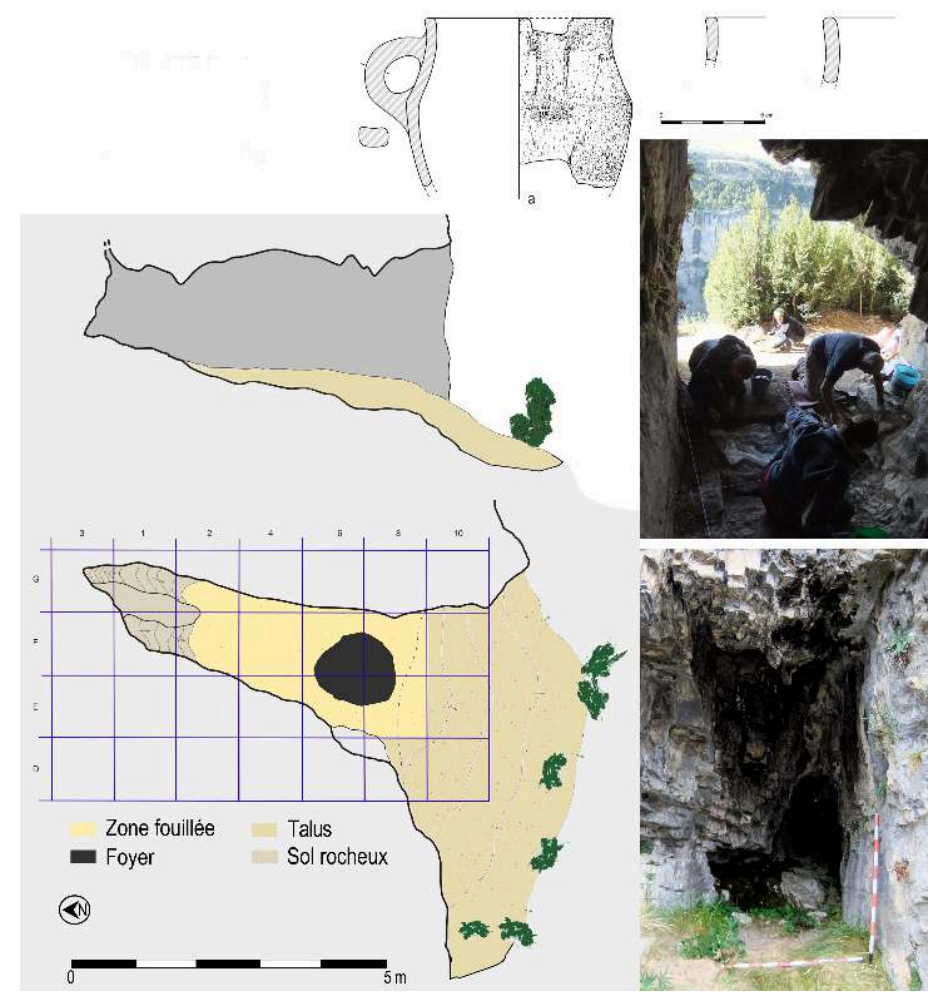

Dessin des matériaux Maricruz Sopena ; photos Rafael Laborda ; PAO et plan Mario Gisbert.

\section{Grotte Candón}

Connue aussi comme la grotte BP02 parmi les spéléologues, il s'agit une résurgence située à l'extrémité de la fache supérieure du canyon, à la confluence avec le canyon d'Añisclo (fig. 3). Elle est difficile d'accès et il faut pour la rejoindre descendre à travers une gorge depuis le plateau supérieur (donc depuis la zone 4). L'entrée, bien orientée au sud-est, est aujourd'hui cachée par des buissons. Dès l'ouverture, on accède à une pièce de dimensions suffisantes, mais au plafond bas, qui s'ouvre sur deux galeries. Celle de gauche fonctionne comme une résurgence des eaux souterraines: dans son sédiment boueux se trouvait un crâne de bovidé fortement patiné, sans doute charrié par l'eau, de sorte qu'il avait l'air ancien. L'animal, ou tout au moins ses restes, ont pu tomber dans le lapiaz qui se développe au-dessus de la grotte, puis s'être déplacés au fil des ans jusqu'à l'emplacement de leur découverte. Une fois identifié comme 
appartenant à l'espèce Bos taurus, nous avons décidé de dater ce crâne pour confirmer (ou pas) son ancienneté. Le résultat du laboratoire (D-AMS 12625: $826 \pm 27 \mathrm{BP}$ ) le place au cœur du Moyen Âge, entre 1166 et 1261 cal. AD (tabl. 2).

\section{Abri Valle Pardina 1 (abri VP-1)}

Il s'agit d'une petite cavité localisée dans la zone 5 , ouverte dans la partie inférieure de la falaise calcaire la plus profonde (alt.1790 m), juste au-dessus du fond de la vallée. Visité d'abord en 2014, il a fait l'objet d'un sondage en profondeur en 2016. Celui-ci a révélé une accumulation importante de charbons de bois à 80 centimètres sous la surface, dont il n'est pas possible de déterminer pour l'instant l'origine, anthropique ou naturelle : aucun reste archéologique n'a été trouvé, peut-être en raison de la surface limitée du sondage. Tous les sédiments ont été recueillis pour flottation, et 4 charbons de bois ont été déterminés pour l'instant par M. Alcolea : Rosacée indéterminée, Fagus sylvatica, Pinus sylvestris/uncinata et Buxus sempervirens, ce dernier ayant été daté de $2995 \pm 21$ (MAMS-29833), c'est-à-dire à l'âge du Bronze final : entre 1367 et 1129 cal. BC (tabl. 2).

\section{Mallata Valle Pardina}

Également situé dans la zone 5, ce site est un refuge engendré par un grand rocher tombé au fond du canyon (alt.1725 m). Le bloc, enfoncé sur l'un de ses sommets, a généré deux petits abris adjacents (fig.7). Un mur venant s'appuyer sur le rocher dessine un enclos pastoral d'environ $20 \times 12$ mètres. L'un des abris conserve encore une structure semi-circulaire simple en pierres sèches (de type brise-vent) entourant une zone habitable minuscule, aujourd'hui envahie par des buissons. L'autre, plus proche du cours du torrent et situé à un niveau inférieur, présente une surface couverte de graviers transportés par des arrivées répétées d'eau. Tous les deux ont été sondés simultanément en 2014, avec des résultats positifs pour le premier (lame en silex, quelques tessons de poterie, etc.) et négatifs pour le deuxième, dont le remplissage était composé seulement de cailloux. 
Fig. 7. - Site de Mallata Valle Pardina, canyon de la Pardina (Fanlo, Huesca, Espagne). En haut, vue depuis le nord du grand bloc rocheux au fond de la vallée et du parc à moutons en pierre. En bas à droite, céramiques et l'extrémité distale d'un poinçon en os $\left(n^{\circ} 4\right)$. En bas à gauche, plan topographique du site, avec le carroyage et l'enclos de l'abri (en jaune : les carrés fouillés).

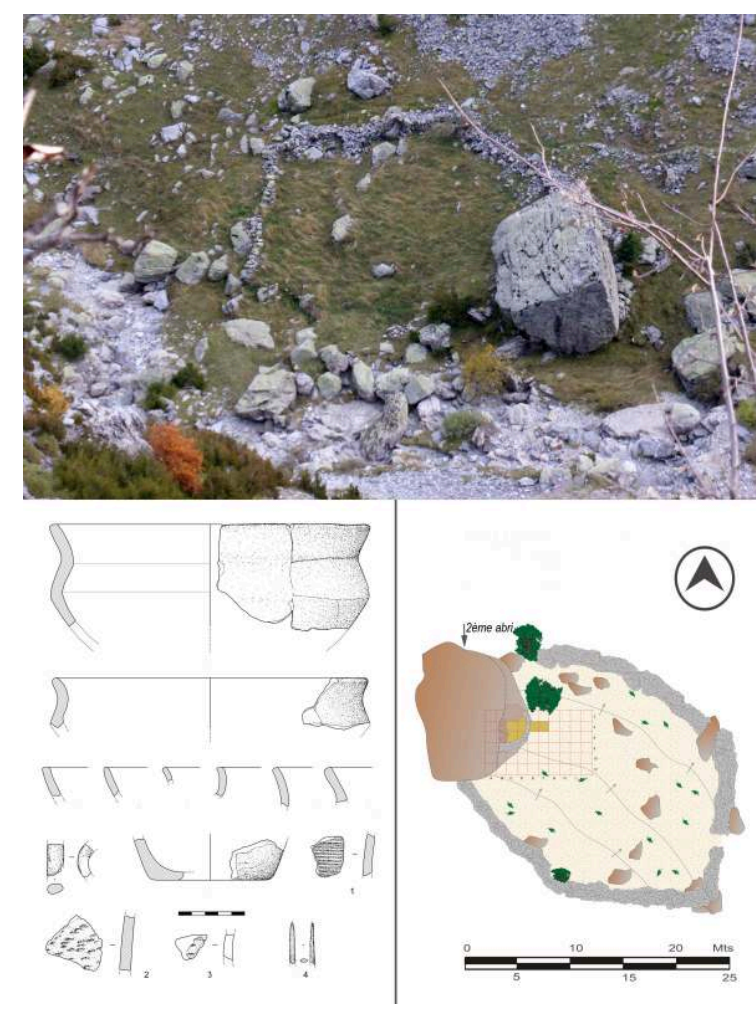

Dessin des matériaux Maricruz Sopena ; photos Rafael Laborda ; PAO et plan Mario Gisbert.

En 2016, le premier abri a été fouillé en extension et en dépassant la limite du mur de pierres qui enserre le petit refuge. Après un niveau superficiel à sédiment foncé et pulvérulent, marqué par des traces de foyers (cendres, charbons, etc.) et des matériaux modernes (céramiques glaçurées, une médaille religieuse, etc.), un niveau apparemment intact est apparu, plus compact, appelé niveau 1. Il s'agit d'une couche d'environ 20 centimètres d'épaisseur, parsemée de petits charbons, à l'intérieur de laquelle se trouvait une lentille de terre plus foncée en raison de l'augmentation de l'humidité (niveau 1b), ainsi qu'un foyer bien délimité (carré D4). Plusieurs tessons de poterie ont été dégagés de ce niveau, la plupart sans décor, dont quelques-uns à profil caréné (fig. 6). Deux fragment, décorés avec des impressions « à l'ongle » (fig. 7, nºs 2 et 3) et l'autre avec un décor au peigne $\left(n^{\circ} 1\right)$, ont également été récupérés, ainsi que l'extrémité distale d'un poinçon en os $\left(n^{\circ} 4\right)$.

Vers le fond de la fouille, le sédiment devient plus clair, et apparemment stérile du point de vue archéologique : il s'agit du niveau 2, dont la fouille s'est arrêtée après 5 centimètres de profondeur pour privilégier le travail à l'extérieur du refuge. Là, sans la protection du plafond rocheux, la stratigraphie s'avère un peu différente : le niveau superficiel repose directement sur une sorte de pavage de dalles de pierre qui scellent le dépôt inférieur. L'ensemble "sédiments superficiels + dalles" présente une puissance d'environ 20 centimètres. Au-dessous, une couche archéologique, appelée « niveau a » jusqu'à ce que sa relation avec l'intérieur de l'abri soit vérifiée, présente un sédiment moins compact et un peu plus riche en clastes que le niveau 1, mais qui livre les mêmes témoins archéologiques que celui-ci: des fragments de céramique non 
décorés permettant de reconstituer un vase caréné presque complet (fig. 6-a). La fouille a été interrompue à 25 centimètres de profondeur, faute de temps, sans avoir atteint le niveau de base.

27 Un charbon de Fraxinus sp. du foyer du niveau 1 de l'intérieur du petit refuge a été daté entre 2859 et 2501 cal. BC (D-AMS 22987: $4091 \pm 28$ BP), soit au Néolithique final/ Chalcolithique (tabl. 2). Il s'agit donc d'une datation très proche de celle de l'abri FP-5. Une deuxième datation a été obtenue dans la partie extérieure, sur un charbon de Abies sp. issu de la partie la plus profonde du niveau a et qui date du Néolithique final, entre 3332 et 3027 cal. BC (MAMS-29834: $4463 \pm 23 \mathrm{BP}$ ). Il reste encore à expliquer la différence, étant donné la similitude des poteries: peut-être une nouvelle couche à peine atteinte?

\section{Zones 6 et 7}

Le canyon de la Pardina termine son parcours en débouchant dans l'impressionnante gorge du canyon d'Añisclo. Nos prospections s'étendent au nord et au sud de ce point, les zones 6 et 7 respectivement, couvrant la rive droite de l'Añisclo. Ici, de petits ravins, dont les profils reproduisent à plus petite échelle l'alternance faches horizontales/ parois verticales, débouchent directement dans l'Añisclo. Ils accueillent une série de refuges.

\section{Espluca Grallera de Capradiza}

29 Comme son nom l'indique (espluca), c'est une grotte de grandes dimensions, qui s'ouvre dans la zone 6 à 1905 mètres d'altitude, face au sud-est. Elle domine le canyon d'Añisclo (fig. 8). 
Fig. 8. - Site de Espluca Grallera de Capradiza, canyon de la Pardina (Fanlo, Huesca, Espagne) : vue partielle de l'entrée et de la grande salle de la grotte.

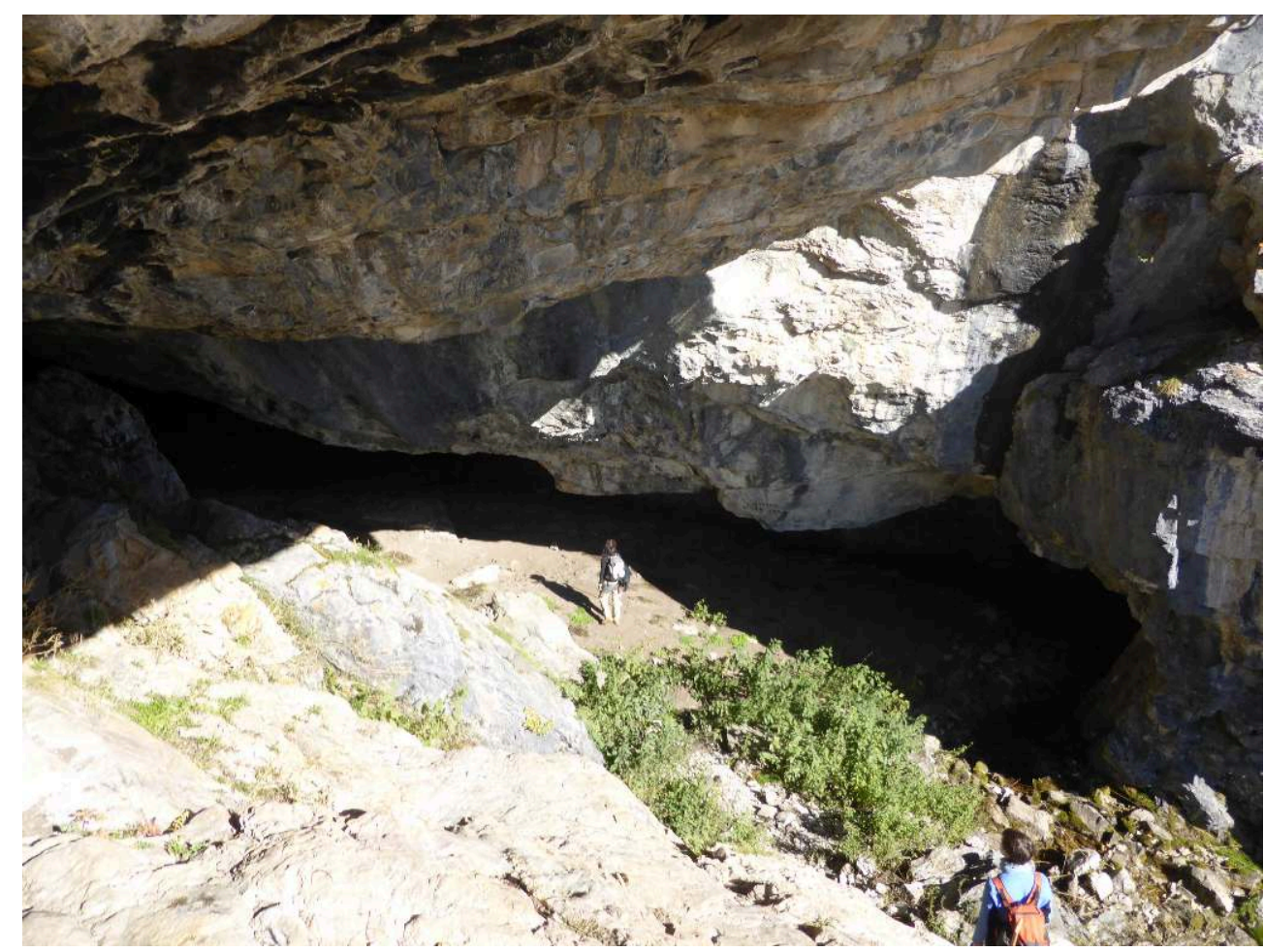

Photo Rafael Laborda.

Le sol de la grande salle de l'entrée, utilisée comme bergerie il y a quelques années encore, est recouvert d'une puissante couche de fumier récente. Un ruisseau d'origine souterraine traverse la grotte et draine un flux abondant dans la partie est de l'entrée. Actuellement, le cours d'eau est canalisé par des blocs de pierre, mais il est impossible de savoir comment il s'est comporté dans le passé. Certaines parties de la salle, situées en hauteur, ont toujours été protégées des inondations. De plus, au fond de la grotte, un plancher stalagmitique scelle un sédiment dans lequel s'observent plusieurs niveaux, différenciés par leur couleur. Tous ces aspects (dimensions, orientation, cours d'eau) ainsi que l'apparition de restes matériels épars sur la surface (pour la plupart modernes, mais aussi un fragment de poterie non tournée) suggèrent la présence d'un site archéologique. Il n'a pas encore été sondé, faute de temps, mais nous pensons le tester prochainement.

\section{Mallata Sabarils et grotte Sabarils}

31 Les deux gisements sont situés dans une petite gorge de la zone 7, qui est parallèle au canyon de la Pardina et située à 1 kilomètre au sud. Distants d'environ 20 mètres, ils sont tous deux situés sur la fache du même nom, à environ 1760 mètres d'altitude : la mallata (refuge) profite d'un surplomb de la falaise, qui protège un petit enclos entouré d'un mur de pierres sèches (fig. 9), tandis que la grotte, qui se développe en deux galeries subparallèles, présente des conditions d'habitabilité médiocres en raison de sa faible hauteur. 
Fig. 9. - Site de Mallata Sabarils, canyon de la Pardina (Fanlo, Huesca, Espagne) : vue générale. Au premier plan, le petit mur en pierre qui délimite l'espace de la Mallata Sabarils, sur la fache éponyme. Au fond, la paroi et les pâturages de la rive gauche du canyon d'Añisclo.

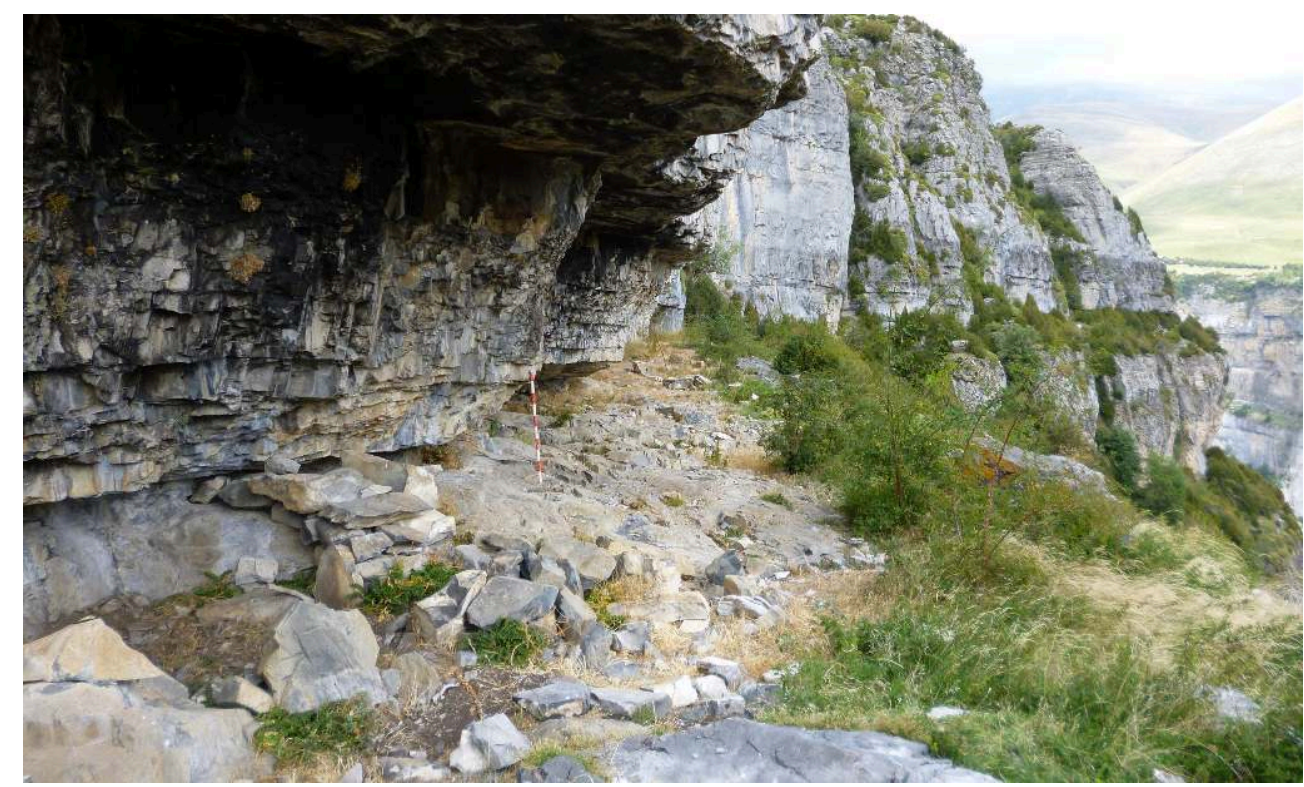

Photo Rafael Laborda.

Les deux sites ont été sondés: dans la mallata, il n'y avait pratiquement pas de sédiments ; une douille dont le culot portait les sigles FNTo (Fábrica Nacional de Toledo) et un battant de cloche en os, qui avait été brisé puis fixé avec un fil métallique, sont à signaler. Dans la grotte, deux sondages ont été faits à proximité d'un foyer situé au fond d'une des galeries, mais sans résultat. Tous les charbons du sédiment ont été collectés pour analyse anthracologique et datation. En surface, sur le sol de la grotte, deux battants de cloche en os ont été récupérés.

\section{Mallata Lacera (ou Lecera)}

33 Ce refuge est situé en zone 7, dans une extension au nord de la fache Lacunas, à 1737 mètres d'altitude. Bien que le site apparaisse dans les listes du parc national comme mallata, nous n'avons trouvé aucune trace de construction. Il est cependant possible d'observer différents motifs peints sur la paroi rocheuse (fig. 10), tous situés entre 140 et 150 centimètres du sol. Il s'agit dans la plupart des cas de traces informes (taches, traits allongés), dont la chronologie est difficile à déterminer pour le moment. Se distinguent néanmoins un cruciforme et quelques lettres, probablement des initiales des bergers qui ont utilisé les refuges à une époque subactuelle. 
Fig. 10. - Site de Mallata Lacera, canyon de la Pardina (Fanlo, Huesca, Espagne) : vue générale et motif cruciforme peint en rouge. En bas à gauche, photographie du motif cruciforme ; au centre, image traitée avec le logiciel DStretch pour ImageJ ; à droite, relevé digital du motif.
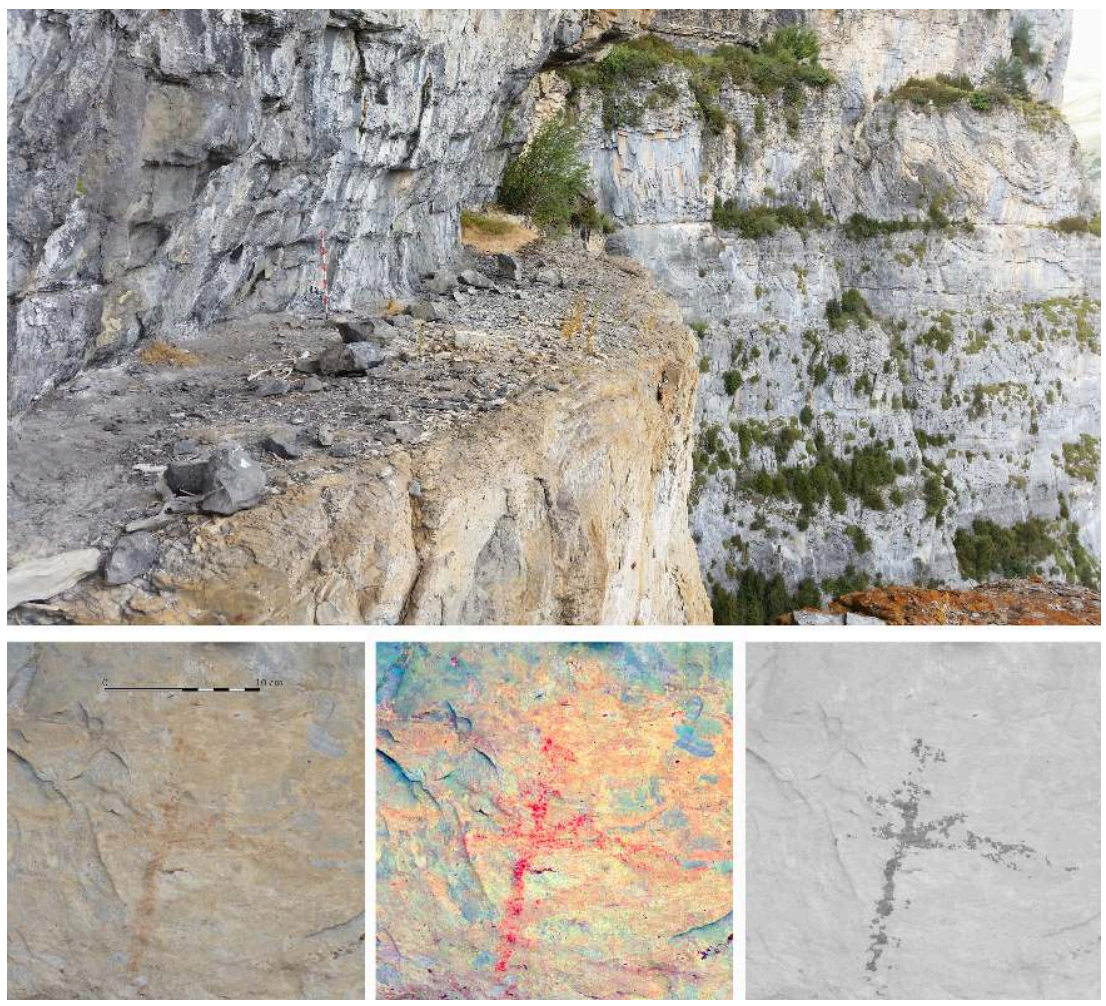

Photos Paloma Lanau

\section{Premières réflexions sur le peuplement du territoire}

archéologiques dans l'aire du canyon résultats intéressants. La recherche archéologique traditionnelle considérait ces zones de haute montagne comme inhospitalières et rarement visitées par les humains, donc, hors de son champ d'étude. S'il est vrai que la haute montagne pyrénéenne, au-dessus de 2000 mètres, constitue un milieu hostile pour l'homme pendant plusieurs mois de l'année (fortes chutes de neige et températures négatives), il est également certain que depuis le Néolithique, des paysans éleveurs ont apprécié la qualité de ses pâturages d'été.

Nous ne pouvons actuellement évaluer la fréquence de ces visites et leur effet réel sur l'environnement, mais il convient de souligner que c'est à partir du Chalcolithique et de l'âge du Bronze que les données polliniques acquises dans des zones relativement proches (González-Sampériz et al. 2017) semblent documenter les premiers impacts anthropiques : la réduction des forêts d'altitude aurait commencé à ce moment, peutêtre suite à des incendies visant à agrandir les prairies.

Le terrain prospecté demeure au-dessus de 1700 mètres d'altitude (fig. 1) : il ne semble pas facile d'y trouver des établissements préhistoriques permanents ou de grandes dimensions. Ces derniers pourraient se situer dans la partie basse des vallées, territoire encore vierge de recherches archéologiques et susceptible de livrer dans les années à venir des habitats protohistoriques. 

des données (Rojo Guerra et al. 2013, Clemente et al. 2014 et 2016, Rey et al. 2014) qui confirment ce qui a déjà été observé dans d'autres secteurs pyrénéens (Gassiot 2016, Rendu 2003, Rendu et al. 2016, Palet et al. 2016) : une présence humaine fréquente audelà de 1500 mètres d'altitude depuis le Néolithique, probablement limitée à cette époque à l'exploitation estivale des pâturages et d'autres ressources. Dans ce milieu difficile, des groupes humains réduits auraient cherché refuge dans des habitats de plein air et des cavités - faiblement aménagées-, dédiés à diverses activités de subsistance outre celles consacrées au soin du bétail. Les données de la grotte, déjà mentionnée, de Coro Trasito à Tella, très proche de la Pardina, mais à plus basse altitude (Clemente et al. 2016), suggèrent un modèle d'économie agropastorale mixte basé sur de petits établissements de montagne, que nous supposons localisés dans les vallées voisines, à partir desquels des déplacements de courte distance en altitude permettaient de profiter des pâturages naturels, mais aussi d'exploiter d'autres ressources. Les niveaux de fumier de la grotte montrent son utilisation comme bergerie, mais ils sont aussi associés à des structures de stockage et à des matériaux variés qui impliquent une occupation plusieurs mois par an par des groupes plus nombreux que quelques seuls bergers (Antolín et al. 2018). des pâturages à l'époque préhistorique. Le terme suppose en effet des déplacements beaucoup plus importants, liés à une régulation administrative très spécifique, née autour de la gestion intégrale d'un élevage spécialisé dans la production de laine du mouton au Moyen Âge (Pallaruelo 1988). Ce n'est pas le cas dans notre secteur, même aux époques récentes, où sont plutôt attestés des déplacements en hauteur (trasterminancia) de très courte portée, comme ceux pratiqués de nos jours avec le bétail bovin. D'après Pallaruelo (1988), les multiples règlements adoptés depuis l'époque médiévale pour encadrer la transhumance au sens propre semblent impliquer la nécessité d'un pouvoir politique fort garantissant le transit des animaux à travers les terres étrangères par une série de normes et de règlements, sans doute très loin des modes de vie préhistoriques. Ou, en d'autres termes, "Rien de ce que l'on sait des usages contemporains ou récents ne peut être transposé avec certitude dans ces sociétés autres que sont a priori les sociétés du passé » (Rendu $2016:$ p. 7). Les données de Coro Trasito, que l'on vient d'exposer, mais aussi, pensons-nous, celles de la Cova dels Trocs, dont l'occupation est toujours liée à la mobilité des animaux (Rojo Guerra et al. 2013 et 2014), sont en faveur de la thèse de ces courts déplacements en hauteur. Nous pensons que les centaines de kilogrammes de tessons de céramique utilisés pour paver la salle et isoler le sol de l'humidité n'ont pas été transportés sur une longue distance.

Après cette époque, Néolithique final/Chalcolithique, l'occupation humaine de ces zones de haute montagne du versant sud semble régresser, et la zone de la Pardina se comporte de la même manière (fig. 5), du moins d'après les datations. Aucun vestige archéologique permettant de retracer en toute certitude des passages de personnes n'a été trouvé (Gassiot 2016, Palet et al. 2016), mais cela peut être dû à un changement dans la sélection des habitats, qui évoluerait vers une préférence pour la construction de petits refuges au détriment de l'occupation de grottes, ce qui permettrait de choisir un site favorable sans dépendre de la disponibilité ou non de cavités. Du côté français, des travaux exhaustifs de documentation archéologique dans un environnement non 
karstique, donc sans cavités, tel que les estives d'Ossau (Rendu et al. 2016), ont fourni des résultats tout à fait intéressants: il n'y a pas de sites néolithiques absolument identifiés, mais jusqu'à 5 établissements de typologie variée (voire 8 possibles) datés entre l'âge du Bronze ancien et final. Qu'il s'agisse de cabanes isolées, d'un groupe de cabanes ou d'une couche archéologique sans structures conservées, ce sont toujours des vestiges très difficiles à découvrir lors d'un survol rapide de la région, comme nous l'avons fait dans notre zone d'étude avec l'objectif de localiser les cavités susceptibles d'avoir été habitées. Ces questions du "silence des dépôts archéologiques » et de la visibilité des sites nous intéressent particulièrement (Alday et al. 2018).

À cet égard, dans la zone du Puerto Bajo de Góriz, le profil caréné et ouvert de quelques vases céramiques de la Mallata Valle Pardina (fig. 6) pourrait suggérer une persistance de l'occupation pendant l'âge du Bronze, jusqu'à présent non confirmée par les dates ${ }^{14} \mathrm{C}$. En ce qui concerne le dépôt de charbons de la grotte VP1, daté du Bronze final, on ne peut pas le relier avec une occupation humaine car aucun matériau archéologique n'a été découvert sur le site. Même l'origine naturelle ou anthropique de cet incendie reste à déterminer : actuellement, environ $30 \%$ des feux qui se produisent dans les limites du PNOMP sont causés par la foudre (Jiménez-Ruano et al. sous presse) et nous ne pouvons donc pas établir directement une relation de cause à effet entre l'activité humaine et les feux enregistrés.

41 Dans l'état actuel du dossier archéologique des environs du canyon de la Pardina, limité à un enregistrement préliminaire et forcément partiel, nous n'avons pas d'évidence d'une présence humaine avant le Moyen Âge. On remarque une absence notable de données pour la période romaine et la fin de l'Antiquité, alors qu'elles sont relativement nombreuses dans les autres aires pyrénéennes (Aigües Tortes, vallée de Núria, Andorre). Il faut considérer que cette absence pourrait être un biais lié à notre méthode d'enquête centrée sur les grottes et les refuges rocheux.

En ce qui concerne le Moyen Âge, nous n'avons que la seule découverte des restes squelettiques d'un bovin domestique dans la grotte Candón, daté entre le $\mathrm{XII}^{\mathrm{e}}$ et le XIII ${ }^{\mathrm{e}}$ siècle de notre ère. Le dernier moment historique clairement identifié dans nos prospections correspond à la guerre civile espagnole. La découverte à la Mallata Sabarils (fig. 9) d'une douille de balle produite à l'usine nationale de Tolède en 1937 est liée sans doute aux opérations militaires de l'armée de Franco dans les hautes régions des Pyrénées, au cours de l'épisode connu sous le nom de Bolsa de Bielsa.

Un développement spécial mérite d'être consacré à l'ensemble de traits peints sur la paroi calcaire de Mallata Lecera. La plupart sont informes et très difficiles à encadrer chronologiquement. Il faut remarquer, parmi ces tracés, la représentation d'un motif cruciforme réalisé avec un pigment rouge orangé, actuellement imbibé dans le support rocheux (fig. 10). Les cruciformes constituent un motif très fréquent à toutes les époques, de l'art schématique préhistorique jusqu'à nos jours. Quelques chercheurs ont même évoqué une possible relation entre l'art rupestre préhistorique et les marques de berger actuelles (Acín Fanlo et Satué Oliván 1983, Violant i Simorra 1958 et 1997). Cependant, il faut noter qu'il s'agit en général de motifs élémentaires, que l'on trouve en divers endroits et différentes périodes, et qui n'ont pas forcément une origine commune (Fernández Otal 2001). Quoi qu'il en soit, malgré le fait qu'à notre avis il ne s'agit pas ici d'art préhistorique, la découverte récente de peintures de style naturaliste sur le site de $\mathrm{O}$ Lomar, au-dessus de 1600 mètres d'altitude et à peu de distance des 
limites du PNOMP (Ruiz-Redondo et al. 2016), ouvre la possibilité de trouver des peintures rupestres dans cette zone d'étude.

\section{Conclusion}

Nos connaissances sur le peuplement du canyon de la Pardina et de ses environs ont considérablement progressé au cours de ces trois premières campagnes : 59 points présentant un intérêt archéologique possible ont été documentés (fig. 1). Parmi ceux-ci, 17 sites ont été sondés et 2 fouillés en extension (abri FP5 et Mallata Valle Pardina). Du point de vue chronologique, nous avons identifiés trois moments bien définis (fig. 5 et tabl. 2) :

- Un épisode préhistorique, limité actuellement à une période comprise entre le Néolithique final et l'âge du Bronze ancien (abri FP5 et Mallata Valle Pardina);

- Des éléments médiévaux (grotte Candón), dont la date confirme l'exploitation du bétail de cet environnement depuis la fin du Moyen Âge ;

- Des fréquentations modernes/subactuelles (Mallata et grotte Sabarils, initiales peintes de Mallata Lacera).

Pour les premiers indices de fréquentation, il serait nécessaire de sonder davantage les abris et refuges présentant des caractéristiques similaires à celles de l'abri FP5 et d'élargir les fouilles de Mallata Valle Pardina pour déterminer si le site comporte des phases successives d'occupation. En outre, compte tenu de la datation obtenue dans l'accumulation de charbons de bois de l'abri VP1, il est nécessaire d'étendre la fouille pour comprendre la nature du dépôt. Le feu a été un élément de gestion commun dans de nombreux écosystèmes de montagne, où il a été utilisé pour éliminer la ceinture supérieure de la forêt et favoriser l'expansion des pâturages d'été, afin d'augmenter les effectifs des troupeaux et de prolonger leur séjour dans les pâturages supraforestiers (Villar et García-Ruiz 1977, Bertrand 1984). Malgré cela, comme nous l'avons signalé, 29,8 \% des feux enregistrés de 1974 à 2013 dans les limites actuelles du PNOMP ont été provoqués par la foudre (Jiménez-Ruano et al. sous presse); il faut donc prendre en compte cette information et ne pas considérer que le paysage actuel de cette partie du parc résulte uniquement d'incendies intentionnels. Dans tous les sites, des sédiments abondants ont été recueillis pour analyses anthracologiques après flottation, qui fourniront des informations sur le paléoenvironnement de la région entre le $\mathrm{III}^{\mathrm{e}}$ et le $\mathrm{II}^{\mathrm{e}}$ millénaire avant notre ère. Nous pensons que ces sites préhistoriques ne sont pas des points isolés au sein de cet environnement.

D'autre part, il est nécessaire de traiter et comparer plus d'informations se référant aux périodes médiévale, moderne et subactuelle. Il faut en effet déterminer s'il existe des stratégies de continuité dans l'utilisation pastorale des mallatas avec des persistances du Moyen Âge à nos jours, ou si au contraire nous observons des ruptures, qui peuvent être liées aux différentes stratégies d'élevage, avec des prédilections à différents moments pour les moutons ou les bovins, et aux fluctuations paléo-environnementales. Cela nous oblige à revenir sur ces points, à reprendre les enquêtes et à étendre ce type d'actions à d'autres lieux, notamment les zones de plein air côtoyant les canyons de la Pardina et d'Añisclo, travail que nous avons l'intention de poursuivre ces prochaines années. 


\section{BIBLIOGRAPHIE}

ACíN FANLO J. L. et SATUÉ OLIVÁN E., 1983, « Vida pastoril en una mallata de Sobremonte », Temas de Antropología Aragonesa, vol. 2, p. 9-29.

ALDAY A., DOMINGO R., SEBASTIÁN M., SOTO A., ARANBARRI J., GONZÁLEZ-SAMPÉRIZ P., SAMPIETRO-VATTUONE M. M., UTRILLA P., MONTES L., PEÑA-MONNÉ J. L., 2018, « The silence of the layers: Archaeological site visibility in the Pleistocene-Holocene transition at the Ebro Basin ", Quaternary Science Reviews, vol. 184, p. 85-106.

ANTOLÍN F., NAVARRETE V., SAÑA M., VIÑERTA A., GASSIOT E., 2018, « Herders in the mountains and farmers in the plains? A comparative evaluation of the archaeobiological record from Neolithic sites in the eastern Iberian Pyrenees and the southern lower lands ", Quaternary International, vol. 484, p. 75-93.

BALDELLou V., 1983, « La Cueva del Forcon (La Fueva - Huesca) », Bolskan, vol. 1, p. 49-176.

BALDELlou V., 1987, « Avance al Estudio de la Espluga de la Puyascada », Bolskan, vol. 4, p. 3-41.

BARRAUD D. et RÉCHIN F., 2013, D'Iluro à Oloron-Sainte-Marie : un millénaire d'histoire, Bordeaux, Fédération Aquitania (Aquitania, suppl. 29).

BERTRAND G., 1984, « Apogée et déclin d'un géosystème silvo-pastoral (montagne de León et de Palencia, Espagne du nord-ouest) ", Revue géographique des Pyrénées et du Sud-Ouest, vol. 55, $n^{\circ} 1$, p. 239-248.

BRIET L., 1910, Barrancos et cuevas (Haut-Aragon, Espagne), Paris, Société de spéléologie (Espelunca, t. VIII, $\mathrm{n}^{\text {os }} 61$ et 65$)$.

BRONK RAMSEY C., 2009, « Bayesian Analysis of Radiocarbon Dates », Radiocarbon, vol. 51, p. 337-360. CLEMENTE I., GASSIOT E., REY J., MAZZUCCO N., OBEA L., 2014, « “Cort o Transito” -Coro Trasito - o corral de tránsito: una cueva pastoril del Neolítico antiguo en el corazón de Sobrarbe », dans ClementeConte I., Gassiot Ballbè E., Rey Lanaspa J. (dir.), Sobrarbe Antes de Sobrarbe: Pinceladas de Historia de Los Pirineos, Boltaña, Centro de Estudios de Sobrarbe, p. 7-32.

CLEMENTE-CONTE I., GASSIOT E., REY J., ANTOLÍN F., OBEA L., VIÑERTA A., SAÑA SEGUí M., 2016, « Coro Trasito (Tella-Sin, HU) un asentamiento de pastores en el Pirineo Central con dataciones del Neolítico antiguo y del Bronce medio ", dans Lorenzo Lizalde L. et Rodanés Vicente J. M. (dir.) : Actas I Congreso de Arqueología y Patrimonio Aragonés, Zaragoza, Colegio Oficial de Doctores y Licenciados en Filosofía y Letras y Ciencias de Aragón, p. 75-84.

EJARQUE A., JULIÀ R., RIERA S., PALET J. M., ORENGO H. A., MIRAS Y., GASCóN C., 2009, « Tracing the history of highland human management in the Eastern Pre-Pyrenees (Spain): an interdisciplinary palaeoenvironmental study at the Pradell fen (Spain) », The Holocene, vol. 19, n 8, p. 1241-1255.

FERNÁNDEZ OTAL J. A. 2001, « Las marcas y señales de propiedad del ganado en Aragón », Temas de Antropología Aragonesa, vol. 11, p. 173-254.

GALOP D., 1998, La forêt, l'homme et le troupeau dans les Pyrénées : 6000 ans d'histoire de l'environnement entre Garonne et Méditerranée : contribution palynologique, Toulouse, Méridiennes.

GALOP D., 2006, « La conquête de la montagne pyrénéenne au Néolithique : chronologie, rythmes et transformations des paysages à partir des données polliniques », dans Guilaine J. (dir.) Populations néolithiques et environnement, Paris, Errance, p. 279-295. 
GARCÍA-RUIZ J. M., VALERO-GARCÉS B. L., BEGUERÍA S., LÓPEZ-MORENO J. I., MARTí-BONO C., SERRANO-MUELA P., SANJUAN Y., 2014, « The Ordesa and Monte Perdido National Park, Central Pyrenees », dans Gutiérrez F. et Gutiérrez M. (dir.), Landscapes and Landforms of Spain, Dordrecht, Springer, p. 165-172.

GASSIOT E. (dir.), 2016, Montañas humanizadas: Arqueología del pastoralismo en el Parque Nacional d 'Aîgüestortes i Estany de Sant Maurici, Madrid, Organismo Autónomo de Parques Nacionales. GIE PEÑA GUARA (Grupo de Investigaciones Espeleológicas Peña Guara de Huesca), 1974, Boletín de Contribución al Catálogo Espeleológico de la Provincia de Huesca, Huesca, GIE Peña Guara.

GIEG GRANOLLERS (Grup d'Investigacions Espeleològiques de Granollers), 1984, Informe “Campaña ESTIU/84 - Barranco de la Pardina", Barcelona, GIEG Granollers.

GIEG GRANOLLERS (Grup d'Investigacions Espeleològiques de Granollers), 1985, Informe “Campaña ESTIU/85 - Barranco de la Pardina", Barcelona, GIEG Granollers.

GONZÁLEZ-SAMPÉRIZ P., ARANBARRI J., PÉREZ-SANZ A., GIL-ROMERA G., MORENO A., LEUNDA M., SEVILLACALlEJO M., CORELlA J. P., MORELlóN M., OLIVA B., VALERO-GARCÉs B., 2017, « Environmental and climate change in the Southern Central Pyrenees since the Last Glacial Maximum: A view from the lake records ", Catena, vol. 149, p. 668-688.

GRIMALDI S., BANG-ANDERSEN S., CARRER F., CROTTI P., DELLA CASA P., FONTANA F., LEITNER W., MANSUR E., REINHOLD S., 2016, « Human occupations of mountain environments », Quaternary International, vol. 402 , p. 2-4.

JIMÉNEZ-RUANO A., RODRIGUES M., RIVA J. de la, sous presse, « How does wildfire work? A comprehensive analysis of fire regime features at mainland Spain ", Applied Geography.

LABORDA R., VILLALBA-MOUCO V., LANAU P., GISBERT M., SEBASTIÁN M., DOMINGO R., MONTES L., 2016, « El Puerto Bajo de Góriz (Parque Nacional de Ordesa y Monte Perdido): Ocupación y explotación de un paisaje de alta montaña desde la prehistoria hasta el siglo xx », Bolskan, vol. 26, p. 9-30.

LEUNDA M., GONZÁLEZ-SAMPÉRIZ P., GIL-ROMERA G., ARANBARRI J., MORENO A., OLIVA-URCIA B., SEVILLACALLEJO M., VALERO-GARCÉS B., 2017, « The Late-Glacial and Holocene Marboré Lake sequence (2612 m a.s.l., Central Pyrenees, Spain): Testing high altitude sites sensitivity to millennial scale vegetation and climate variability ", Global and Planetary Change, vol. 157, p. 214-231.

LEVEAU P. et PALET J. M., 2010, « Les Pyrénées romaines, la frontière, la ville et la montagne. L'apport de l'archéologie du paysage », Pallas, vol. 82, p. 171-198.

MONTES L. et MARTÍNEZ BEA M., 2007, « La cueva Drólica de Sarsa de Surta (Huesca): el arte rupestre que nunca fue y su yacimiento campaniforme », Veleia, vol. 24-25, p. 813-834.

MONTES L., BEA M., DOMINGO R., SÁNCHEZ P., ALCOLEA M., SEBASTIÁN M., 2016, « La gestión prehistórica de un territorio en la montaña Prepirenaica: Tierra Bucho (Huesca, España) », Munibe Antropología, vol. 67, p. 349-362.

ONA J. L. et CALASTRENC C., 2009, Los Hospitales de Benasque y Bañeras de Luchón: ocho siglos de hospitalidad al pie del Aneto / Les Hospices de Vénasque et Bagnères-de-Luchon, Benasque, Fundación Hospital de Benasque.

PALET J. M., GARCÍA A., ORENGO H. A., POLONIO T., 2016, « Ocupacions ramaderes altimontanes a les capçaleres del Ter (Vall de Núria i Coma de Vaca, Queralbs): resultats de les intervencions arqueològiques 2010-2015 », dans Frigola J. (dir.), Tretzenes Jornades d'Arqueologia de les comarques de Girona, Banyoles, Generalitat de Catalunya, p. 67-75. 
Pallaruelo S., 1988, Pastores del Pirineo, Madrid, Ministerio de Cultura, Dirección General de Bellas Artes y Archivos.

ReIMER P. J., BARD E., BAYLISS A., BeCK J. W., BLACKWELl P. G., BRONK M., GROOTES P. M., GUILDERSON T. P., HAFLIDASON H., HAJDAS I., HATTE C., HEATON T. J., hOFFMAN D. L., HOGG A. G., HUGHHEN K. A., KAISER J. F., KROMER B., MANNING S. W., NIU M., REIMER R. W., RICHARDS D. A., SCOTT E. M., SOUTHON J. R., STAFF R. A., TURNEY C. S. M., VAN DER PLICHT J., 2013, « IntCal 13 and Marine 13 radiocarbon age calibration curves 0-50,000 years cal BP », Radiocarbon, vol. 55, p. 1869-1887.

RENDU C., 2003, La montagne d'Enveig, une estive pyrénéenne dans la longue durée, Le Canet-enRoussillon, Trabucaire.

RENDU C., 2016, «Introduction », dans Rendu C., Calastrenc C., Le Couédic M., Berdoy A. (dir.), Estives d'Ossau : 7000 ans de pastoralisme dans les Pyrénées, Toulouse, Le Pas d'Oiseau, p. 7-11.

RENDU C., CALASTRENC C., LE COUÉDIC M., BERDOY A. (dir.), 2016, Estives d'Ossau : 7000 ans de pastoralisme dans les Pyrénées, Toulouse, Le Pas d'Oiseau.

REY J., CLEMENTE I., GASSIOT E., 2014, « Cueva Lobrica, hallazgo de un nuevo yacimiento del Neolítico en la orilla izquierda del río Bellós, en el Parque Nacional de Ordesa y Monte Perdido ", dans Clemente-Conte I., Gassiot Ballbè E., Rey Lanaspa J. (dir.), Sobrarbe antes de Sobrarbe: Pinceladas de Historia de Los Pirineos, Boltaña, Centro de Estudios de Sobrarbe, p. 55-61.

ROJO GUERRA M. A., PEÑA CHOCARRO L., ROYO GUILLÉN J. I., TEJEDOR RODRÍGUEZ C., GARCÍA MARTíNEZ DE LAGRÁN Í., ARCUSA MAGALLÓN H., GARRIDO PENA R., MORENO-GARCÍA M., MAZZUCO N., GIBAJA BAO J. F., ORTEGA D., KROMER B., ALT K. W., 2013, « Pastores trashumantes del Neolítico Antiguo en un entorno de alta montaña: secuencia crono-cultural de la Cova de Els Trocs (San Feliú de Veri, Huesca) », BSAA Arqueología, vol. 79, p. 9-55.

Rojo GUERRA M. A., ARCUSA MAGALlón H., PEÑa CHOCARRo L., ROYo GUILLEN J. I., TEJEDOR RODRÍGUEZ C., GARCÍA MARTÍNEZ DE LAGRÁN Í., GARRIDO PENA R., MORENO GARCÍA M., PIMIENTA C., MAZZUCO N., GIBAJA BAO J. F., PÉREZ JORDÁ G., JIMÉNEZ JIMÉNEZ I., IRIARTE E., ALT K. W., 2014, « Los primeros pastores trashumantes de la Alta Ribagorza », dans Clemente-Conte I., Gassiot Ballbè E., Rey Lanaspa J. (dir.), Sobrarbe antes de Sobrarbe: Pinceladas de Historia de Los Pirineos, Boltaña, Centro de Estudios de Sobrarbe, p. 127-151.

RUIZ-REDONDO A., REY LANASPA J., CLEMENTE-CONTE I., GASSIOT BALLBÉ E., 2016, « Arte Levantino En El Alto Pirineo: Las Pinturas Del Conjunto De O Lomar (Huesca, España) », dans Rivero Vilá O. et Ruiz Redondo A. (dir.), El Arte de las Sociedades Prehistóricas. V Encuentro Internacional de Doctorandos y Postdoctorandos, Santander, Universidad de Cantabria, p. 101-103.

VILLAR L. et GARCíA-RUIZ J. M. 1977, « Explotación del territorio y evolución de pastos en dos valles del Pirineo occidental », Publicaciones del Centro Pirenaico de Biología Experimental, vol. 8, p. 143-163.

VIOLANT I SIMORRA R., 1958, « Posible origen y significado de los principales motivos decorativos y de los signos de propiedad usados por los pastores pirenaicos », Revista de Dialectología y Tradiciones Populares, vol. 14, $\mathrm{n}^{\circ}$ 1-2, p. 77-163.

VIOLANT I SIMORRA R., 1997, El Pirineo español: Vida, usos, costumbres, creencias y tradiciones de una cultura milenaria que desaparece, Barcelona, Alta Fulla. 


\section{RÉSUMÉS}

Le Puerto Bajo de Góriz fait partie des vastes surfaces pastorales subalpines du parc national d'Ordesa et du mont Perdu. Le paysage actuel n'est pas strictement naturel, car il a été modifié tout au long du temps par des activités anthropiques, notamment l'élevage, qui a abaissé la limite des pâturages en les étendant sur des surfaces qui devraient être occupées par la forêt. Depuis 2014, des prospections et sondages archéologiques ont été engagés pour appréhender les premières manifestations de cet impact anthropique et voir si des transformations sont déjà perceptibles au cours de la préhistoire, antérieurement, donc, à la documentation médiévale bien connue. Trois campagnes ont permis de renseigner 59 points d'intérêt archéologique dont des grottes, abris, enclos et cabanes de bergers. Dix-sept d'entre eux ont été sondés et deux étudiés en fouilles extensives. Les premiers résultats confirment l'occupation et exploitation du territoire depuis le $\mathrm{III}^{\mathrm{e}}$ millénaire cal. BC.

The Puerto Bajo de Góriz is one of the pasture areas in the National Park of Ordesa and Monte Perdido, within the subalpine floor zone. The current landscape is not strictly natural: human activities (shepherding) have modified it, lowering the pastures level to altitudes that should be occupied by forests. Starting in 2014, we have carried out archaeological surveys and excavations in order to test when the human impact can be detected in the area and if those affections were already visible during prehistoric times, before the well-known medieval documentation. After three fieldwork campaigns we have explored 59 archaeologically relevant spots comprising caves, rockshelters, pens and herder huts; test-pits have been carried out in 17 of them, while 2 have been excavated in full. First results confirm the occupation and exploitation of this territory at least since the $3^{\text {rd }}$ millennium cal. BC.

INDEX

Keywords : anthropic landscape, early pastoralism, mountain archaeology

Mots-clés : archéologie de montagne, pastoralisme ancien, paysage anthropique

Index géographique : Pyrénées

\section{AUTEURS}

\section{LOURDES MONTES}

Área de Prehistoria, Instituto Universitario de Ciencias Ambientales, Universidad de Zaragoza

RAFAEL DOMINGO MARTÍNEZ

Área de Prehistoria, Instituto Universitario de Ciencias Ambientales, Universidad de Zaragoza

RAFAEL LABORDA LORENTE

Área de Prehistoria, Instituto Universitario de Ciencias Ambientales, Universidad de Zaragoza

PALOMA LANAU

Área de Prehistoria, Instituto Universitario de Ciencias Ambientales, Universidad de Zaragoza

\section{VANESSA VILLALBA-MOUCO}

Área de Prehistoria, Instituto Universitario de Ciencias Ambientales, Universidad de Zaragoza 


\section{MARIO GISBERT}

Centro de Espeleología de Aragón (CEA)

\section{MARÍA SEBASTIÁN}

Departamento de Didáctica de las Lenguas y de las Ciencias Humanas y Sociales, Instituto Universitario de Ciencias Ambientales, Universidad de Zaragoza 


\title{
Occupation et anthropisation des espaces de haute montagne dans les vallées de Nuria et de Coma de Vaca (Gerona, Espagne) : résultats des recherches archéologiques et patrimoniales
}

\author{
Occupation and anthropization of high-mountain spaces in the Nuria \\ and Coma de Vaca valleys (Gerona, Spain): results of archeological and \\ heritage research
}

Josep Maria Palet, Pau Olmos, Arnau Garcia, Tania Polonio et Hèctor A. Orengo

1 La recherche sur l'occupation et l'exploitation des zones de montagne a longtemps été conditionnée par le caractère marginal qu'attribuait traditionnellement l'historiographie à ces milieux. En outre, des facteurs tels que l'intensité des processus d'érosion, la topographie, la mauvaise conservation des vestiges archéologiques ou la densité du couvert forestier ont limité la recherche sur le terrain, ce qui a encore encouragé une perception des zones de montagne comme marginales en ce qui concerne les activités humaines.

Certes, cette situation a changé au cours des dernières décennies, grâce à un intérêt croissant pour l'occupation et l'exploitation des espaces de montagne européens au fil du temps. Les travaux pionniers développés par C. Rendu dans la vallée de la Cerdagne dans les années 1990 (Rendu 2003), par E. Gassiot dans les Pyrénées catalanes (Gassiot et Jiménez 2006) et par K. Walsh, F. Mocci et J. M. Palet dans les Alpes occidentales (Palet et al. 2003, Walsh et Mocci 2003, Walsh et al. 2005 et 2007, Segard 2009) constituent le point de départ d'une ligne de recherche qui a développé de nouveaux projets en Europe et enrichi les méthodes et techniques de l'archéologie du paysage (Palet et al. 
2013 et 2014, Gassiot et al. 2014, Orengo et al. 2014a et 2014b, Walsh et al. 2014, Gassiot 2016). Les études paléo-environnementales ont également eu un impact croissant, avec des approches multidisciplinaires et diachroniques (Galop 1998, Miras et al. 2007 et 2010, Pèlachs et al. 2009, Ejarque et al. 2009, 2010 et 2013).

3 Les résultats obtenus dans diverses zones de montagne européennes ont remis en question l'image traditionnelle, montrant que l'impact humain sur ces espaces a été intense et qu'ils constituent de véritables paysages culturels, façonnés dans le temps. Dans ce contexte, de « nouvelles » archéologies ont été définies, telles l'« archéologie de la montagne » ou l'« archéologie du pastoralisme ", avec des approches étroitement liées à l'archéologie du paysage. Ces études sont multidisciplinaires, basées sur la corrélation des données archéologiques, historiques, paléo-environnementales et ethnographiques. Les valeurs du paysage culturel sont également une ressource durable pour la société. En ce sens, les possibilités de transfert de connaissances sont importantes, car ces zones sont souvent protégées par des réglementations s'appliquant au patrimoine naturel et culturel. Les résultats peuvent, par exemple, être intégrés dans des plans sociaux et environnementaux et contribuer au développement de futures politiques de gestion et de patrimonialisation territoriale (Criado-Boado et al. 2015).

4 Dans ce cadre, depuis 2004, le Grup d'Investigació en Arqueologia del Paisatge (Groupe de recherche en archéologie du paysage) de l'Institut Català d'Arqueologia Clàsica (GIAP-ICAC) a développé un programme d'étude de l'occupation du sol dans les zones de haute montagne. Depuis 2010, cette recherche a été réalisée dans les vallées pyrénéennes supérieures du Ter : Nuria, Coma de Vaca et Coma del Freser (Palet et al. 2013, 2014 et 2016) (fig. 1). L'objectif est de caractériser la dynamique du peuplement, l'occupation du sol et la formation des paysages culturels de haute montagne. La recherche est axée sur une perspective interdisciplinaire, basée sur l'intégration des données d'archéologie du paysage. Cette approche de l'archéologie du paysage est fondée sur la pluridisciplinarité et la longue durée, et inclut des chercheurs des sciences historiques et paléo-environnementales. 
Fig. 1. - Localisation des zones étudiées dans les Pyrénées orientales.

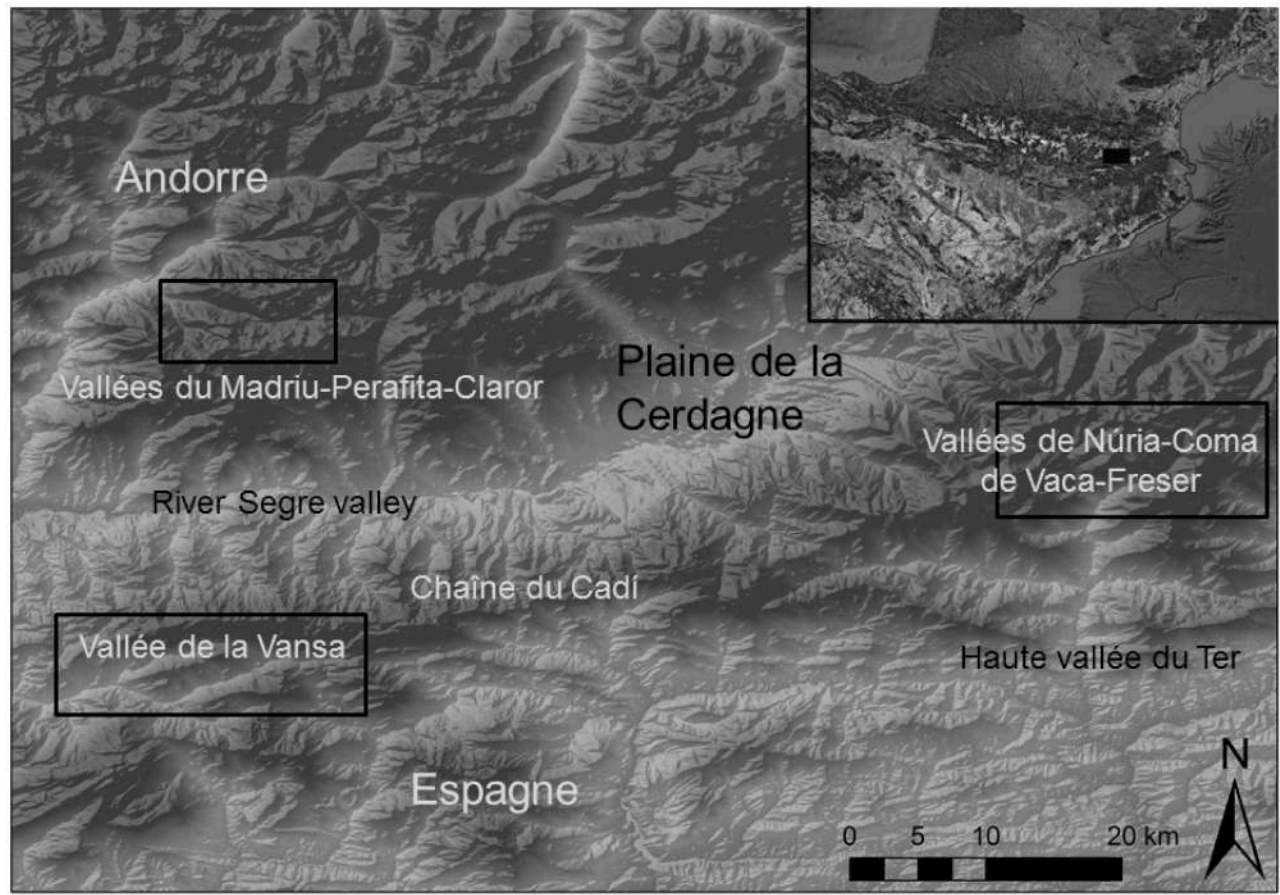

Extrait de Palet et al. 2017, p. 79.

5 Plusieurs tourbières, à partir desquelles des séquences paléo-environnementales ont été obtenues, sont associées à de nombreux sites archéologiques de différentes périodes situés à proximité. En ce sens, l'archéologie constitue une approche complémentaire de celles qu'offrent les sciences paléo-environnementales, qui apportent un type d'information très utile puisqu'elles peuvent fournir des données spécifiquement liées à l'exploitation que les humains font du paysage. Ces données sont référencées chronologiquement et spatialement. La caractérisation des données archéologiques permet de documenter des activités humaines spécifiques qui peuvent être la cause de perturbations dans le registre paléo-environnemental (Riera et al. 2017).

6 Un total de 430 structures ont été attestées dans les vallées de Nuria, de Coma de Vaca et de Coma del Freser, dont 45 ont fait l'objet de fouilles archéologiques. Une série de 38 datations radiocarbone ont été obtenues dans des séquences archéologiques. Les sites sont entièrement associés aux activités d'élevage : cabanes, enclos, couloirs de traite (Palet et al. 2016 et 2017). Le modèle chronologique obtenu à partir des datations situe les premières évidences d'activités pastorales vers la fin du Néolithique moyen. L'occupation du sol continue jusqu'à la période moderne, avec la présence d'une discontinuité entre l'âge du Bronze et la fin de l'âge du Fer.

7 Les résultats ont permis de développer une histoire des activités humaines menées dans ces vallées sur la longue durée. Ils permettent de dessiner un paysage densément exploité, démontrant une forte et ancienne occupation humaine de ces espaces de haute montagne. 


\section{Les premières traces d'occupation des espaces de haute montagne au Néolithique et à l'âge du Bronze}

Les recherches du GIAP dans les Pyrénées, au niveau des vallées du Madriu-Perafita Claror, en Andorre, ont documenté les premières évidences des activités de pâturage au début du Néolithique, au milieu du v $v^{\mathrm{e}}$ millénaire avant J.-C., liées à l'existence d'une fréquentation sur de petits espaces (Orengo et al. 2014a). Il convient de noter que les structures archéologiques documentées présentaient une corrélation avec les données paléo-environnementales, qui indiquaient un processus de déforestation avec une extension des prairies et des clairières boisées utilisées pour le pâturage, ainsi qu'une augmentation des indicateurs anthropiques (taxons nitrophiles et rudéraux, spores coprophiles) associés aux pratiques pastorales locales au début et au milieu du Néolithique.

9 Dans les vallées de Nuria et de Coma de Vaca, les premières activités d'élevage remontent au Néolithique (fig. 2), à la fin du $\mathrm{IV}^{\mathrm{e}}$ et au $\mathrm{III}^{\mathrm{e}}$ millénaire avant J.-C. (Palet et al. 2016 et 2017).

Fig. 2. - Vallées de Núria et de Coma de Vaca : localisation des sites archéologiques datés du Néolithique.

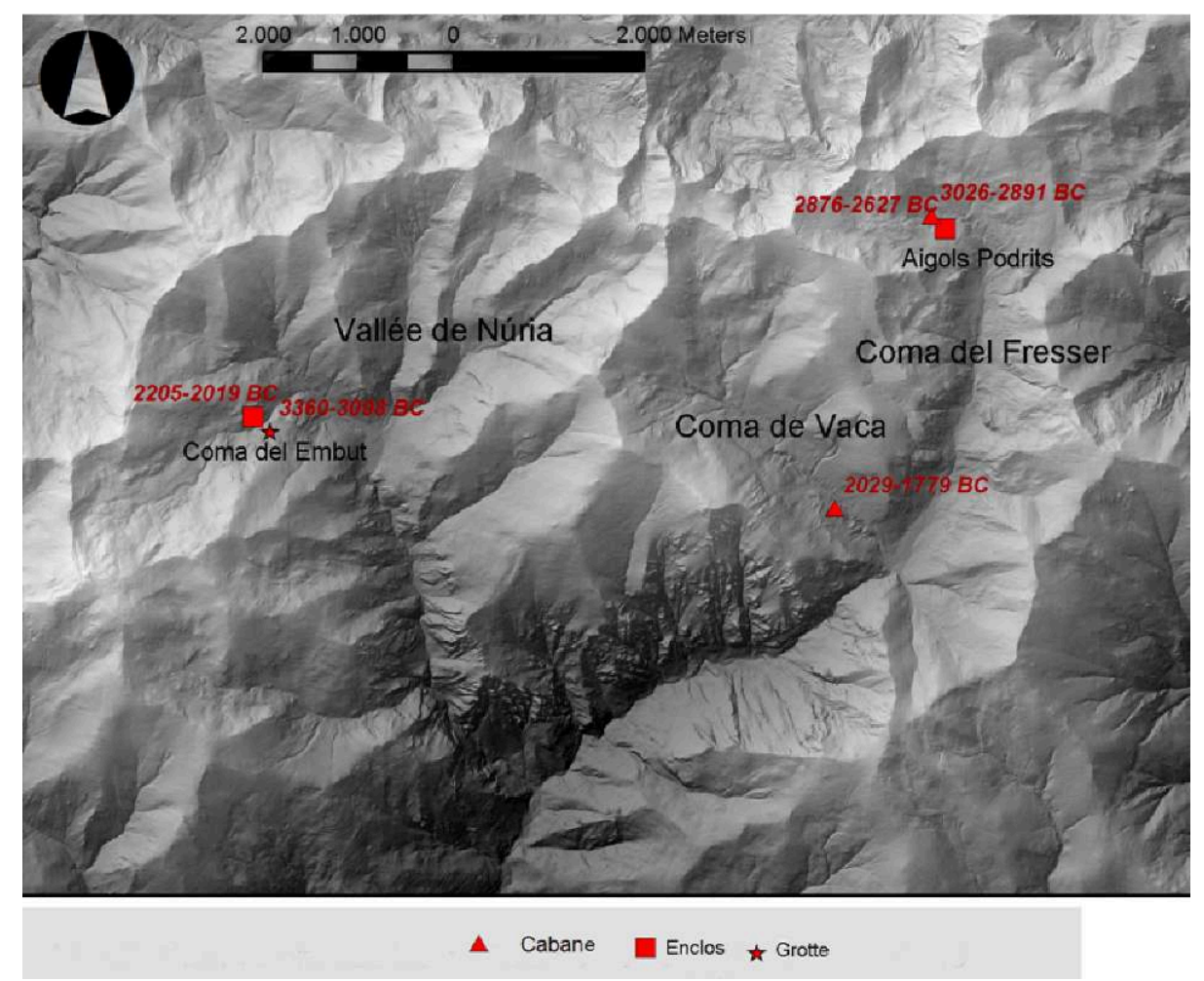

PAO et cartographie Arnau Garcia et Josep Maria Palet.

10 Il convient de mentionner une occupation en grotte sur le site de Coma de l'Embut (grotte 338), dans la vallée de Nuria, datée de la fin du IV millénaire avant J.-C. La grotte est située au bord d'un itinéraire qui mène au col de Finestrelles et à la plaine de Cerdagne, dans une zone de substrat calcaire (fig. 3). 
Fig. 3. - Site de Coma de l'Embut, grotte 338 (Gerona, Espagne) : vue générale.

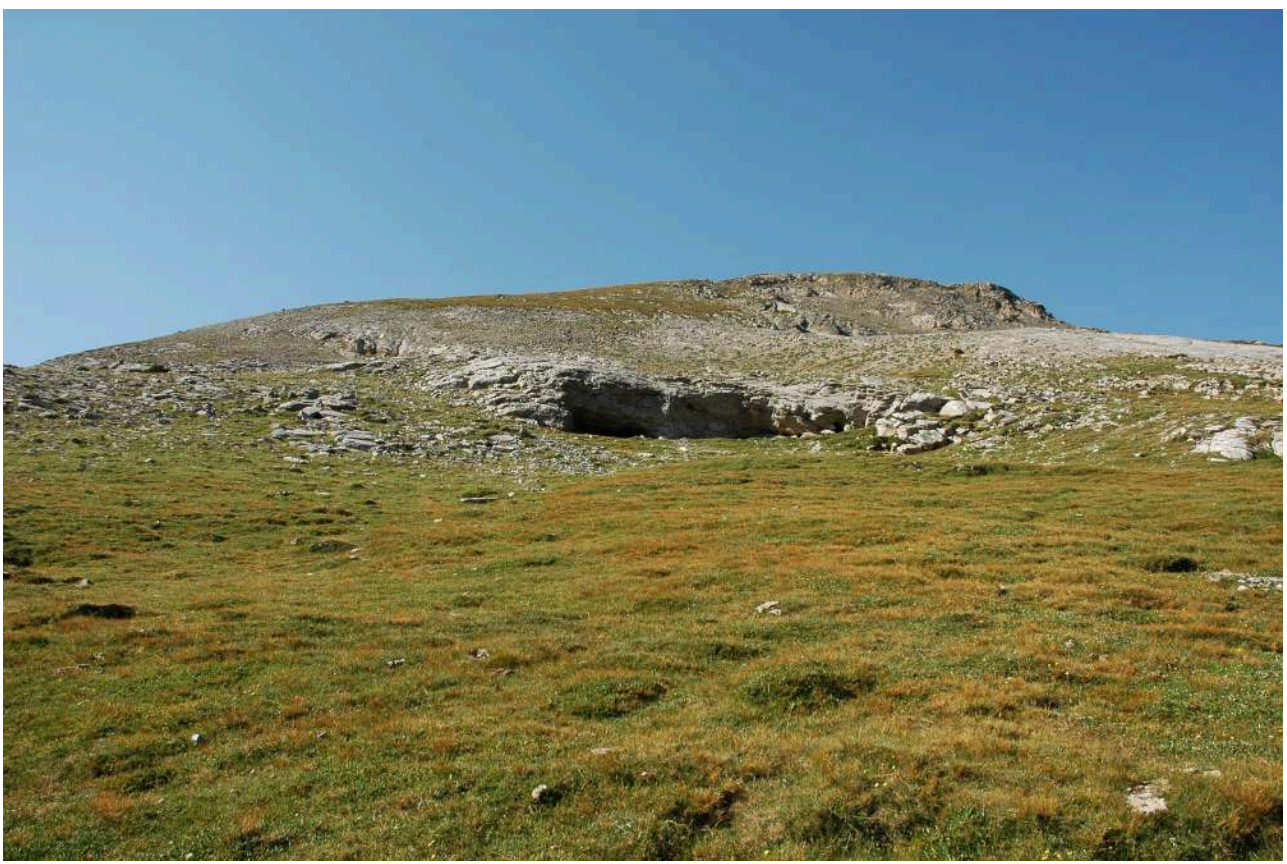

Photo Josep Maria Palet.

11 Les fouilles à l'entrée de la grotte ont fourni des charbons abondants, de la céramique non tournée et une faune très fragmentée. L'analyse anthracologique a indiqué la présence presque exclusive de Pinus uncinata, ce qui suggère une forêt de pins proche (Euba 2016). Dans ce même secteur, un niveau d'occupation daté du Néolithique tardif a été documenté (2 205-2019 cal. BC). Ce niveau a également fourni d'abondants charbons, parmi lesquels la présence de Pinus uncinata renforce l'idée d'un environnement forestier proche du site (Euba 2016).

12 L'occupation néolithique a également été attestée dans les vallées voisines étudiées dans ce secteur, celles de Coma de Vaca et de Coma del Freser, où les données paléoenvironnementales renforcent l'idée d'une extension des activités de pâturage, liée aux incendies locaux pendant cette période. Des structures d'élevage diverses sont associées aux activités de pâturage dans la haute vallée de Freser, une zone riche en eau et en alpages, bien reliée par un couloir est-ouest sous la ligne de crête principale (alt. env. $2500 \mathrm{~m}$ ).

Deux sites archéologiques ont été identifiés dans les pâturages entourant la tourbière d'Aigols Podrits, à 2468 mètres d'altitude (fig. 2). Le site d'Aigols Podrits I est caractérisé par un enclos dont l'occupation a été datée du Néolithique final (2 876-2 627 cal. BC). Cette structure délimite une superficie d'environ 100 mètres carrés. Le site d'Aigols Podrits II contient un foyer en cuvette arrangé avec des blocs de pierre, associé à un niveau d'occupation daté de la fin du Néolithique moyen (3 300-2 900 cal. BC). L'analyse anthracologique de ces niveaux (fig.4) indique également la présence exclusive de Pinus uncinata, associée à un paysage forestier dans cette partie supérieure de la vallée (Euba 2016). 
Fig. 4. - Site d'Aigols Podrits II (Gerona, Espagne), fin du Néolithique moyen : foyer en cuvette.

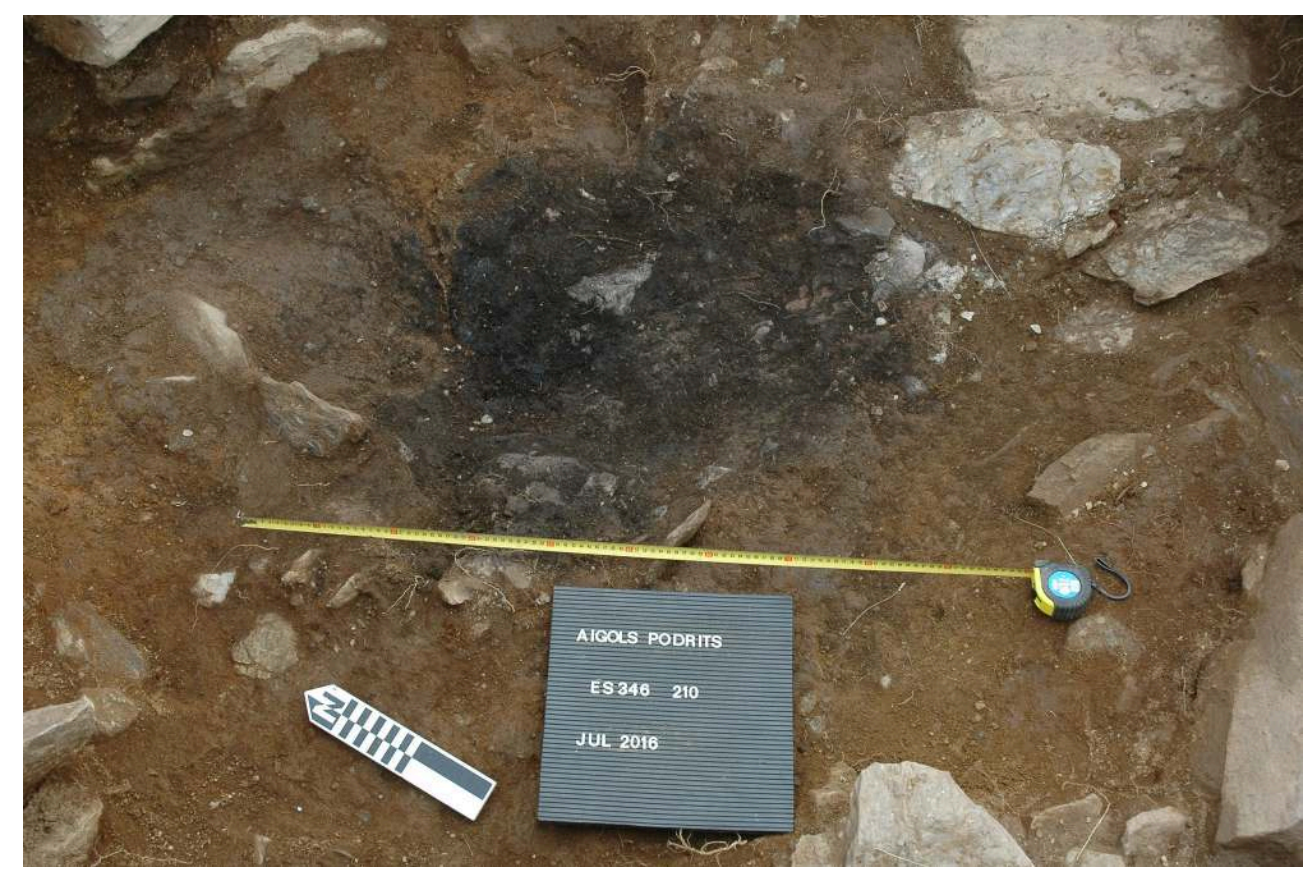

Photo Josep Maria Palet.

14 La présence d'activités d'élevage au Néolithique final est également documentée sur le site de Coma de Vaca I (alt. $2110 \mathrm{~m}$ ). Des niveaux liés à une occupation indéterminée du début de l'âge du Bronze ont aussi été attestés (2029-1779 cal. BC), avec la présence d'une céramique non tournée abondante (récipients, bols et pots), liée à un habitat détruit par des constructions postérieures. Ces données sont cohérentes avec les résultats obtenus dans les vallées du Madriu-Perafita-Claror, dans lesquelles l'importance des activités pastorales depuis la fin du IV millénaire avant notre ère et au Néolithique final a été bien attestée (Ejarque 2013, Orengo et al. 2014a).

Dans ces vallées, l'action anthropique devient, pour la première fois, assez intense pour aboutir à un changement du paysage durable. Les zones supérieures des vallées étudiées resteront déboisées depuis ce moment jusqu'à aujourd'hui, en raison de la pression humaine continue. Ces déboisements répondent au besoin de créer des zones de pâturage dans les hautes vallées (Riera et al. 2017). De ce fait, le feu se généralise en tant qu'outil de transformation du paysage.

\section{La période romaine et l'Antiquité tardive}

16 Comme dans d'autres régions des Pyrénées, la période allant de l'âge du Bronze à la fin de l'âge du Fer n'a été que rarement attestée dans le registre archéologique (Gassiot 2016 : p. 125). Il est probable que ce hiatus ne signifie pas l'abandon des activités humaines, mais plutôt un changement dans les formes d'habitat et la typologie des structures, car les données paléo-environnementales suggèrent une continuité des activités humaines.

17 L'anthropisation des paysages pyrénéens de haute montagne fait ainsi partie d'une dynamique de longue durée. En effet, l'Antiquité voit la naissance d'une nouvelle phase importante dans l'occupation du sol et l'intensification des implantations. D'une 
manière générale, les activités se diversifient à l'époque romaine, avec une exploitation paysagère plus spécialisée dans la haute vallée du Sègre (élevage, production de poix, de charbon de bois et de la métallurgie du fer), et une activité d'élevage plus intense dans la haute vallée du Ter (Orengo et al. 2013, Palet et al. 2014, 2016 et 2017).

Dans ce secteur, les premières occupations sont attestées dans le haut Freser sur le site d'Aigols Podrits II. Une cabane de berger quadrangulaire, caractérisée par un soubassement en pierre sèche et un trou de poteau à l'intérieur pour soutenir le toit, a fourni des niveaux d'occupation contenant du mobilier cohérent avec une datation radiocarbone des $\mathrm{II}^{\mathrm{e}}-\mathrm{I}^{\mathrm{er}}$ siècles av. J.-C. : un long clou de fer, de la céramique tournée de cuisine et de la céramique ibérique.

La vallée de Coma de Vaca montre une occupation pastorale intense pendant la période romaine (fig. 5).

Fig. 5. - Localisation des sites archéologiques de la période romaine et de l'Antiquité tardive dans les vallées de Núria et de Coma de Vaca.

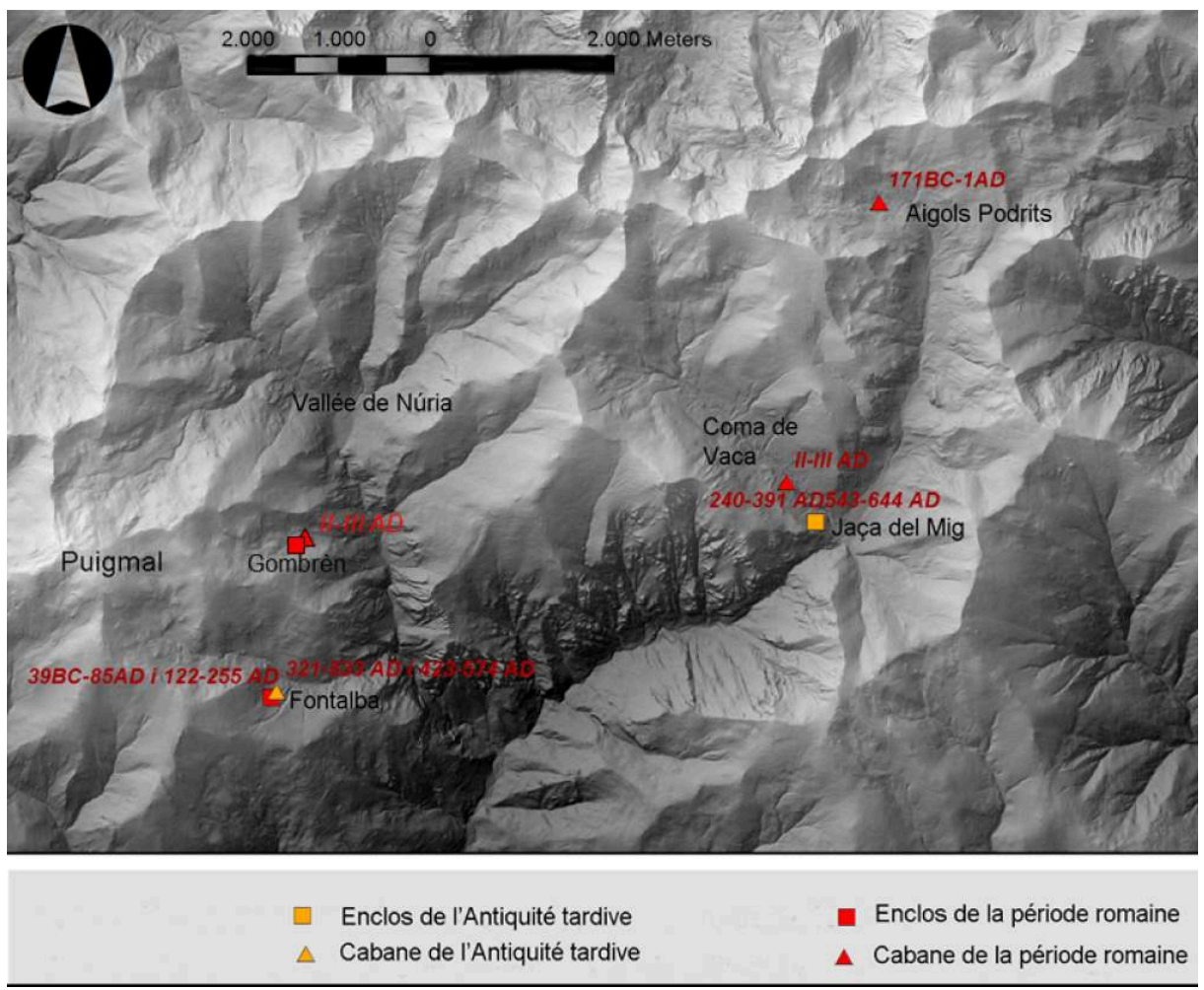

PAO et cartographie Arnau Garcia et Josep Maria Palet.

Dans le site de Coma de Vaca I, une cabane de forme quadrangulaire en pierres sèches a été fouillée en extension. Les couches d'occupation montrent de la céramique de vaisselle fine (terra sigillata hispanique) et de la céramique de cuisine africaine, qui datent l'occupation entre la fin du $\mathrm{I}^{\mathrm{er}}$ et le $\mathrm{II}^{\mathrm{e}}$ siècle. La structure, située dans un site pastoral à 2150 mètres d'altitude, définit une surface rectangulaire d'environ 20 mètres carrés. Cette cabane était probablement utilisée pour l'exploitation pastorale et forestière. Sa situation, en bordure d'un chemin qui traverse ce secteur des Pyrénées d'est en ouest, suggère qu'elle aurait aussi pu servir de point d'arrêt ou de contrôle (Palet et al. 2014, 2016 et 2017). 
21 Dans le massif du Puigmal, sur le site de Fontalba (alt. $2100 \mathrm{~m}$ ), la fouille d'une cabane de berger et d'un enclos a aussi fourni du mobilier de la période romaine (terra sigillata, céramique africaine), ce qui suggère une activité commerciale dans ces milieux de haute montagne, bien liée aux réseaux commerciaux romains (Palet et al. 2016).

L'élevage a aussi été une activité attestée dans les vallées du Madriu-Perafita-Claror, en Andorre. Des enclos de petite taille, situés à 2310 mètres d'altitude et datés du $\mathrm{I}^{\mathrm{er}}$ siècle, ont été retrouvés dans la haute vallée du Madriu (Palet et al. 2013). Dans la vallée de Perafita, la présence d'une cabane de berger et d'un couloir de traite datés des $\mathrm{III}^{\mathrm{e}}-\mathrm{IV}^{\mathrm{e}}$ siècles a montré la présence de l'exploitation du bétail à l'époque romaine (Orengo 2010 : p. 263). Les données paléo-environnementales recueillies dans ces vallées ont corroboré cette situation, documentant une augmentation générale des activités pastorales entre $300 \mathrm{cal} . \mathrm{BC}$ et $800 \mathrm{cal}$. $\mathrm{AD}$, avec un processus d'ouverture des forêts et d'expansion des pâturages indiqué par la présence de taxons nitrophiles et rudéraux et de spores de coprophiles (Ejarque 2013).

D'autre part, ces vallées ont montré une exploitation plus diversifiée, avec la présence de plusieurs fours de poix du pin (Pinus uncinata) datés entre le $\mathrm{I}^{\mathrm{er}}$ et le VII $\mathrm{VI}^{\mathrm{e}}$ siècle. En effet, la corrélation des dates et des données polliniques indique l'existence de trois épisodes de production de poix différents pendant cette période (Orengo et al. 2013). Ce type d'exploitation forestière intensive en haute montagne s'inscrit vraisemblablement dans une économie de marché dotée d'un réseau de distribution bien développé (Orengo 2010: p. 274). L'étude d'autres vallées proches permet de documenter une autre activité à l'époque romaine, caractéristique elle aussi des régions de haute montagne : l'extraction et le premier traitement du fer (Palet et al. 2013 et 2014). Cette activité a été attestée à l'ouest de la chaîne du Cadí, dans les sites de Goleró et Pradell, situés à environ 2030 mètres d'altitude et datés des $\mathrm{I}^{\mathrm{er}}$ et le $\mathrm{II}^{\mathrm{e}}$ siècles.

L'intensité des activités pastorales durant l'Antiquité tardive est très remarquable dans la haute vallée $d u$ Ter. Plusieurs structures ont été attestées au sud du massif du Puigmal (Fontalba, vallée de Nuria, Asturias), ainsi que sur le site du Jaça del Mig (alt. 2 $080 \mathrm{~m}$ ), dans la vallée de Coma de Vaca. Un ensemble de cabanes et d'enclos atteste l'expansion de cette activité à partir du IV siècle et pendant l'Antiquité tardive. Les deux sites montrent une continuité de l'occupation au début du Moyen Âge, liée à la transhumance à longue distance ( $\mathrm{IX}^{\mathrm{e}}-\mathrm{XI}^{\mathrm{e}}$ siècle). L'abondant matériel archéologique récupéré (céramique de cuisine, verre, objets métalliques) suggère que ces sites pastoraux étaient d'une certaine manière en relation avec l'importance des activités d'élevage dans les vallées. Les séquences paléo-environnementales dans la haute vallée du Ter enregistrent plusieurs phases de déforestation à partir du vie siècle, liées à l'exploitation des pâturages et à l'extension des activités d'élevage (Palet et al. 2014).

La période romaine témoigne donc d'une diversification, d'une spécialisation et d'une spatialisation des activités économiques. Les données obtenues suggèrent un contraste entre des zones d'étude proches, où les activités montrent une plus grande complémentarité : intensification des activités d'élevage dans la haute vallée du Ter, exploitation plus diversifiée dans les vallées du Madriu-Perafita-Claror, en Andorre, et dans la chaîne du Cadí (Palet et al. 2013 et 2014). Par conséquent, à l'époque romaine, les Pyrénées en général et les hautes montagnes en particulier constituaient des espaces complémentaires offrant des ressources spécifiques de grande importance. L'intensité de ces activités montre que ces secteurs étaient des zones accessibles et bien 
connectées, intégrées dans une économie et une société qui dépendaient en partie de ces ressources (Leveau et Palet 2010, Orengo et al. 2013).

\section{Rome et les territoires de montagne}

montagne des Pyrénées orientales étaient fortement occupées à l'époque romaine. $\mathrm{Ce}$ fait a également été attesté dans d'autres vallées pyrénéennes, en relation avec la métallurgie du fer (Gassiot et Jiménez 2006, Gassiot 2016). Pendant la période romaine, les zones étudiées faisaient partie de la Ceretania, qui selon Strabon (Géographie III.4.11) recouvrait la zone centrale des Pyrénées. Pline l'Ancien (Hist. nat. III.3.22-23) le confirme quand il décrit le territoire des Cerretani comme limitrophe de celui des Vascones. Iulia Libica, la ville actuelle de Llívia (Gerona, Espagne), en Cerdagne, était le chef-lieu des Cerretani. montagne d'Enveig, avaient proposé au contraire un recul des activités saisonnières d'élevage pendant la période romaine, une situation interprétée comme le reflet d'une certaine marginalité des activités de montagne, contrairement aux activités agricoles dans les basses plaines (Rendu 2003 : p. 520). De fait, des études du paysage dans les secteurs atlantiques pyrénéens (vallée d'Ossau: Rendu et al. 2013) ainsi que dans les Alpes occidentales (Walsh et al. 2014, Segard 2009) ont conclu que la période romaine ne correspond pas à une phase d'accroissement des activités d'élevage. Ce contraste n'est probablement pas lié au déclin des activités économiques dans les zones de montagne, mais à la spécialisation et à la diversification des activités au niveau régional et microrégional (Leveau et Palet 2010, Palet et al. 2014). En effet, les vallées étudiées étaient bien reliées par un ancien réseau routier pyrénéen entre la Gallia Narbonensis et la Hispania Tarraconensis. Au centre de ces vallées se situe la plaine de Cerdagne et la ville romaine de Iulia Libica (Llívia), fondée dans le dernier quart du $i^{\text {er }}$ siècle (Olesti 2014 : p. 357). Cette ville romaine était le centre d'un important réseau routier rattaché aux montagnes environnantes.

Il est important de noter que les données archéologiques et paléo-environnementales s'accordent en soulignant que depuis le bas Empire et surtout durant l'Antiquité tardive, l'anthropisation de ces zones de montagne s'intensifie en raison de l'augmentation des activités d'élevage. Parmi les zones étudiées, ceci est particulièrement sensible dans la haute vallée du Ter (Riera et al. 2017). L'action anthropique à cette période a été suffisamment importante pour créer une nouvelle configuration du paysage, qui aura une continuité à l'époque médiévale et moderne, avec une plus grande homogénéisation paysagère, caractérisée par l'expansion des activités transhumantes extensives.

\section{Pour une mise en valeur du patrimoine archéologique de haute montagne dans les vallées de Nuria et de Coma de Vaca}

Le patrimoine archéologique de haute montagne est un patrimoine souvent menacé à cause du changement climatique et de la pression anthropique. Dans le cas des sites de 
haute montagne, le recul des glaciers provoque actuellement la destruction de nombreux sites archéologiques désormais exposés à l'érosion et qui ont besoin de mesures de protection urgentes (Dixon et al. 2015, World Heritage Centre 2007). Des problèmes liés aux phénomènes érosifs, comme les avalanches ou les glissements de terrain, auront un impact direct sur la préservation du patrimoine archéologique. L'enregistrement des données patrimoniales et archéologiques est donc un objectif majeur. En parallèle, le tourisme a aujourd'hui un impact fort sur les paysages de haute montagne, et peut aussi constituer un des risques principaux de destruction du patrimoine archéologique, comme nous avons pu le constater pour les sites de notre aire d'étude, où la conservation est fortement menacée par l'action humaine, de façon souvent involontaire.

Dans notre zone d'étude, les phénomènes érosifs sont très présents, surtout en ce qui concerne l'érosion anthropique : soit à cause de la pression touristique, soit par l'action de l'élevage moderne. Grâce à leur facilité d'accès et au bon état de préservation de leur patrimoine naturel, ces vallées constituent l'une des plus importantes zones touristiques de montagne en Catalogne. Dans cette zone, le déclin des activités traditionnelles - l'exploitation forestière, l'agriculture et l'élevage d'ovins - et leur remplacement par l'industrie du tourisme de neige et de randonnée (plus de 150000 visiteurs pendant l'été 2016) sont les menaces principales pour la conservation du patrimoine.

31 La recherche archéologique nous a permis de constater la richesse du patrimoine archéologique de ces vallées, mais nous avons également noté une méconnaissance globale de ce patrimoine de la part des visiteurs du parc naturel. Notre objectif est donc double : d'une part dresser un bilan de l'état du patrimoine archéologique, et d'autre part mettre en place des actions de communication, de formation et de sensibilisation de la population locale.

De fait, la méconnaissance générale de la part du grand public ainsi que l'absence de mesures de protection nous ont incités à mieux faire connaître ce patrimoine montagnard. Pour cela, nous avons réalisé deux actions pédagogiques avec deux types d'acteurs : d'une part le grand public, notamment les randonneurs, et d'autre part les agents locaux (autorités publiques, gestionnaires et professionnels du secteur). Les actions ont pris la forme d'une présentation des résultats des recherches en cours sur les sites fouillés en 2017, et de l'évaluation du matériel pédagogique (fiches et cartes) créé pour la mise en valeur du patrimoine archéologique. Ces actions de terrain ont permis à la communauté locale d'identifier les différents types de vestiges et l'intérêt archéologique des occupations humaines dans ces vallées, jusqu'à présent pratiquement absent des guides et documents touristiques à destination des visiteurs du parc (fig. 6). 
Fig. 6. - Visite grand public des sites archéologiques du Forat de l'Embut (été 2017).

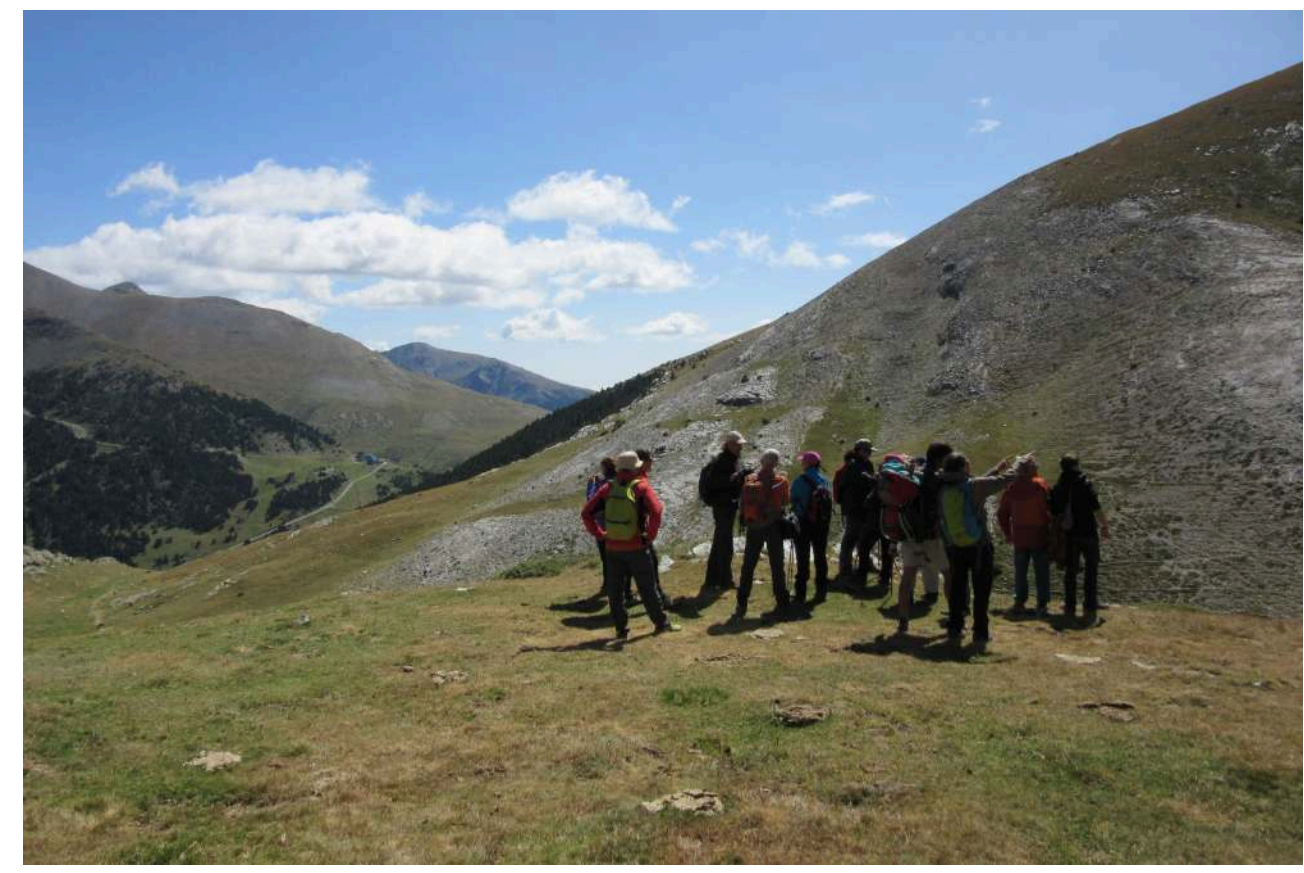

Photo Josep Maria Palet.

33 Ces actions de terrain ont été complétées par une formation théorique des acteurs locaux, qui a eu lieu au Musée ethnographique de Ripoll, et par la création de matériel pédagogique à destination du grand public. Nous proposons, à partir de nos recherches archéologiques, la mise en place d'une série de routes d'intérêt archéologique dans le parc naturel des sources du Ter et Freser. Ces routes seront bientôt accessibles à travers le site web du parc et permettront aux visiteurs de découvrir l'importante richesse archéologique de ces vallées.

34 Nous sommes pour l'instant au début du processus de transmission de la recherche archéologique dans ce secteur de montagne. Il s'agit d'un projet qui s'inscrit dans le long terme et s'appuie sur la coopération des chercheurs, des autorités, des gestionnaires du site, des professionnels du tourisme de la région et des associations de randonneurs.

\section{Conclusions}

Les Pyrénées et les zones de haute montagne ne peuvent pas être considérées comme des espaces isolés et marginaux, car les épisodes d'anthropisation liés aux activités d'élevage ont été documentés depuis le début du Néolithique. Le pastoralisme a donc joué un rôle décisif dans la formation et la dynamique des paysages culturels de montagne. À l'époque romaine, les hautes montagnes pyrénéennes constituaient un territoire accessible et bien relié aux voies de communication principales, pleinement intégré dans le complexe socioculturel romain et les réseaux commerciaux extrarégionaux. Pendant cette période, les Pyrénées et les hautes montagnes en particulier peuvent être considérées comme une zone complémentaire offrant des ressources de grande importance (Leveau et Palet 2010, Orengo et al. 2013). 

dynamiques paysagères attestent d'une nette expansion du pastoralisme des premiers temps médiévaux ( $\mathrm{x}^{\mathrm{e}}-\mathrm{X}^{\mathrm{e}}$ siècles), avec une réutilisation des structures romaines et l'utilisation de nouveaux espaces clairement spécialisés dans des activités d'élevage spécifiques (structures de production du fromage). Dans les vallées étudiées, cette expansion est bien attestée par la présence d'enclos et de cabanes des $\mathrm{IX}^{\mathrm{e}}$ et $\mathrm{X}^{\mathrm{e}}$ siècles. Pendant cette période, un paysage largement pâturé a entraîné une vaste déforestation.

Enfin, le potentiel de la recherche archéologique et environnementale dans les zones de montagne a été souligné afin de les définir comme "paysages culturels». Ceci est important pour indiquer que le patrimoine archéologique, en tant qu'outil de gestion et de ressource culturelle dans les zones protégées, a une valeur paysagère. En ce sens, l'histoire de ces paysages fournit de nouvelles données pour le développement durable des espaces de montagne méditerranéens.

\section{BIBLIOGRAPHIE}

CRIADO F., BARREIRO D., VARELA-POUSA R., 2015, « Sustainable archaeology in post-crisis scenarios », dans Van Den Dries M., Van Der Linde J., Strecker A. (dir.), Fernweh: Crossing borders and connecting people in archaeological heritage management. Essays in honour of prof. Willem J. H.Willems, Leiden, Sidestone Press, p. 56-60.

DIXON J., CALLANAN M., HAFNER A., HARE G., 2014, « The Emergence of Glacial Archaeology », Journal of Glacial Archaeology, vol. 1, p. 1-9.

EJARQUE A., 2013, La alta montaña pirenaica: génesis y configuración holocena de un paisaje cultural. Estudio paleoambiental en el valle del Madriu-Perafita-Claror (Andorra), Oxford, Archaeopress (BAR International Series, 2507).

EJARQUe A., JULIÀ R., RIERA S., PALET J.-M., ORENGo H. A., MIRAS Y., GASCóN C., 2009, « Tracing the history of highland human management in the Eastern Pre-Pyrenees (Spain): an interdisciplinary palaeoenvironmental approach ", The Holocene, vol. 19, nº 8, p. 1241-1255.

EJARQUE A., MIRAS Y., RIERA S., PALET J.-M., ORENGO H. A., 2010, « Testing microregional variability in the Holocene shaping of high mountain cultural landscapes: a palaeoenvironmental case-study in the Eastern Pyrenees ", Journal of Archaeological Science, vol. 37, n 7, p. 1468-1479.

EUBA I., 2016, Resultats de les análisis antracològiques de la vall de Núria i Coma de Vaca: campanyes 2011, 2012, 2013, i 2015, [rapport final de synthèse], Tarragona, Institut Català d'Arqueologia Clàssica.

FOSSIER R., 1994, « Les déviations économiques des Cisterciens », dans Pressouyre L. (dir.), L'espace cistercien, Paris, Éditions du CTHS, p. 39-44.

GALOP D., 1998, La forêt, l'homme et le troupeau dans les Pyrénées : 6000 ans d'histoire de l'environnement entre Garonne et méditerranée. Contribution palynologique, Toulouse, Méridiennes. 
GASSIOT E. et JIMÉNEZ J., 2006, « El poblament prefeudal de l'alta muntanya dels Pirineus occidentals catalans (Pallars Sobirà i Alta Ribagorça) », dans Tribuna d'Arqueologia 2004-2005, Barcelona, Generalitat de Catalunya, p. 89-122.

GASSIOT E., RODRÍGUEZ ANTÓN D., PÈLACHS A., PÉREZ-OBIOL R., JULIÀ BRUGUÉS R., BAL-SERIN M. C., MAZZUCCO N., 2014, « La alta montaña durante la Prehistoria: 10 años de investigación en el Pirineo catalán occidental », Trabajos de prehistoria, vol. 71, n 2, p. 261-281.

GASSIOT E. (dir.), 2016, Arqueología del pastoralismo en el Parque Nacional d'Aigüestortes $i$ Estany de sant maurici: Montañas humanizadas, Madrid, Consejo Superior de Investigaciones Científicas.

LEVEAu P. et PALET J. -M., 2010, « Les Pyrénées romaines, la frontière, la ville et la montagne :

l'apport de l'archéologie du paysage », Pallas, vol. 82, p. 171-198.

MIRAS Y., EJARQUE A., RIERA S., PALET J. -M., ORENGo H., EUBA I., 2007, « Dynamique holocène de la végétation et occupation des Pyrénées andorranes depuis le Néolithique ancien, d'après l'analyse pollinique de la tourbière de Bosc dels Estanyons (2180 m, Vall del Madriu, Andorre) ", Comptes rendus Palevol, vol. 6, p. 291-300.

MIRAS Y., EJARQUE A., ORENGO H., MORA S. R., PALET J.-M., POIRAUD A., 2010, « Prehistoric impact on landscape and vegetation at high altitudes: an integrated palaeoecological and archaeological approach in the eastern Pyrenees (Perafita valley, Andorra) », Plant Biosystems, vol. 144, $\mathrm{n}^{\circ} 4$, p. $946-961$.

OLESTI O., 2014, Paisajes de la Hispania romana: La explotación de los territorios del Imperio, Sabadell, Dstoria Edicions.

ORENGO H. A., 2010, « Arqueología de un paisaje cultural pirenaico de alta montaña: Dinámicas de ocupación del valle del Madriu-Perafita-Claror (Andorra) », thèse, Tarragona, Universitat Rovira i Virgili/Institut Català d'Arqueologia Clàssica.

ORENGO H. A., PALET J. -M., EJARQUE A., MIRAS Y., RIERA S., 2013, « Pitch production during the Roman period: an intensive mountain industry directed towards long distance trade? », Antiquity, vol. 87, $\mathrm{n}^{\circ} 337$, p. 802-814.

ORENGO H. A., PALET J. -M., EJARQUE A., MIRAS Y., RIERA S., 2014a, « Shifting occupation dynamics in the Madriu-Perafita-Claror valleys (Andorra) from the early Neolithic to the Chalcolithic: the onset of high mountain cultural landscapes ", Quaternary International, vol. 353, p. 140-152.

ORENGO H. A., PALET J. -M., EJARQUE A., MIRAS Y., RIERA S., 2014b, « The historical configuration of a UNESCO World Heritage Site: the Cultural Landscape of the Madriu-Perafita-Claror Valley ", Archeologia Postmedievale, vol. 17, p. 333-343.

PALET J. M., RICOU F., SEGARD M., 2003, « Prospections et sondages sur les sites d'altitude en Champsaur (Alpes du sud)» Archéologie du Midi médiéval, vol. 21, p. 199-210.

PALET J. M., ORENGO H. A., EJARQUE A., MIRAS Y., RIERA S., 2013, « Arqueología de paisajes altimontanos pirenaicos: formas de explotación y usos del medio en época romana en valle del MadriuPerafita-Claror (Andorra) y en la Sierra del Cadí (Alt Urgell) », dans Fiches J.-L., Plana R., Revilla V. (dir.), Paysages ruraux et territoires dans les cités de l'Occident romain : actes du colloque AGER IX, Barcelona, 24-25 mars 2010, Montpellier, Presses universitaires de la Méditerranée, p. 329-340.

PALET J. M., GARCIA A., ORENGO H. A., RIERA S., MIRAS Y., JULIÀ R., 2014, « Ocupación y explotación de espacios altimontanos pirenaicos en la Antigüedad: visiones desde la arqueología del paisaje », 
dans Dall'Aglio P. L., Franceschelli C., Maganzani L. (dir.), Atti del IV Convegno Internazionale di Studi Veleiati, Bologna, Ante Quem, p. 455-470.

PALET J. M., GARCIA A., ORENGO H. A., POLONIO T., 2016, « Ocupacions ramaderes altimontanes a les capçaleres del Ter (Vall de Núria i Coma de Vaca, Queralbs): resultats de les intervencions arqueològiques 2010-2015 ", dans XIII Tretzenes Jornades d'Arqueologia de les Comarques de Girona, Banyoles, Universitat de Girona, p. 67-75.

PALET J. M., GARCIA A., ORENGO H. A., POLONIO T., 2017, « Els espais altimontans pirenaics orientals a l'Antiguitat: 10 anys d'estudis en arqueologia del paisatge del GIAP-ICAC », Treballs d'Arqueologia, vol. 21, p. 77-97.

PÈLACHS A., NADAL J., SORIANO J. M., MOLINA D., CUNILL R., 2009, « Changes in Pyrenean woodlands as a result of the intensity of human exploitation: 2,000 years of metallurgy in Vallferrrera, northeast Iberian Peninsula », Vegetation History and Archaeobotany, vol. 18, n 5, p. 403-416.

RENDU C., 2003, La montagne d'Enveig : une estive pyrénéenne dans la longue durée, Perpignan, Trabucaire.

RENDU C., CALASTRENC C., LE COUÉDiC M., GALOP D., RIUS D., CUGNY C., BAL M., 2013, « Montagnes et campagnes d'Oloron dans la longue durée : premiers résultats d'un programme interdisciplinaire ", dans Baraud D. (dir.), D'Iluro à Oloron Sainte-Marie, un millénaire d'histoire : colloque des 7 au 9 décembre 2006, Bordeaux, Fédération Aquitania (Aquitania, supplément 29), p. 37-68.

RIERA S., JULIÀ R., MIRAS Y., PALET J.-M., POLONIO T., GARCÍA A., ORENGO H. A., 2017, « Climate variability, human use and landscape change of high mountain environments: Coma de Vaca and Ter valleys, Eastern Pyrenees ", dans M.-F. Loutre, M. N. Evans, S. C. Fritz, C. Tabor, H. Plumpton, R. Barnett, Y. Zhang, E. Razanatsoa, E. Dearing (dir.), Global Challenges for our Common Future: a paleoscience perspective, PAGES young Scientist meeting, Zaragoza, Institut Pinenaico de Ecología/Consejo Superior de Investigaciones Científicas.

SEGARD M., 2009, Les Alpes occidentales romaines : développement urbain et exploitation des ressources des régions de montagne (Gaule narbonnaise, Italie, provinces alpines), Aix-en-Provence, Université de Provence.

WALSH K., 2005, « Risk and marginality at high altitudes: new interpretations from fieldwork on the Faravel Plateau, Hautes-Alpes », Antiquity, vol. 79, n 304, p. 289-305.

WALSH K. et MOCCI F., 2003, « 9000 ans d'occupation du sol en moyenne et haute montagne : la vallée de Freissinières dans le Parc national des Écrins (Freissinières, Hautes-Alpes) », Archéologie du Midi médiéval, vol. 21, p. 185-198.

WALSH K., MOCCI F., PALET J. M., 2007, « Nine thousand years oh human/landscape dynamics in a high altitude zone in the southern French Alps (Parc national des Écrins, Hautes-Alpes, 05) ", Preistoria Alpina, vol. 42, p. 9-22.

WALSH K., MOCCI F., TZORTZIS S., PALET J. M., 2005, « Dynamique du peuplement et activités agropastorales durant l'âge du Bronze dans les massifs du Haut Champsaur et de l'Argentiérois (Hautes-Alpes) », Documents d'archéologie méridionale, vol. 28, p. 25-44.

WALSH K., COURT-PICON M., BEAULIEU J.-L. de, GUITER F., MOCCI F., RICHER S., SINET R., TALON B., TZORTZIS S., 2014, " A historical ecology of the Ecrins (Southern French Alps): Archaeology and palaeoecology of the Mesolithic to the Medieval period », Quaternary International, vol. 353, p. 52-73. 


\section{RÉSUMÉS}

Depuis 2010, un programme intégrant des recherches archéologiques et paléoenvironnementales a été développé dans les Pyrénées orientales (Catalogne). Le but était d'étudier la formation et l'origine des paysages de haute montagne méditerranéens. Ce programme comprenait des travaux de prospection, des systèmes d'information géographique, des fouilles archéologiques ainsi que l'intégration de données paléo-environnementales. Les résultats soulignent l'importance des activités d'élevage au cours des derniers millénaires dans les zones étudiées, depuis la première occupation humaine de ces espaces de haute montagne, attestée depuis le Néolithique moyen, jusqu'aux périodes modernes et contemporaines. Cette activité a conduit à la formation de paysages culturels complexes. L'archéologie du paysage fournit de nouvelles données pour l'élaboration des outils de gestion nécessaires au développement durable des espaces de haute montagne.

Since 2010, an integrated archaeological and paleoenvironmental research program has been developed in the Eastern Pyrenees (Catalonia), with the aim of studying the long-term landscape shaping of Mediterranean high-mountain environments. This program involved extensive surveying, geographical information systems, archaeological excavation and the integration of multi-proxy paleoenvironmental data. The results underline the incidence in these areas of grazing activities during the past millennia, from the first human occupation of the highlands, recorded in the Middle Neolithic, to the modern and contemporary periods. This activity has led to complex cultural landscapes in the high Pyrenean areas. Landscape history provides new data for the development of management tools for the sustainability of Mediterranean highlands.

\section{INDEX}

Mots-clés : archéologie du paysage, élevage, patrimoine, paysage culturel

Keywords : cultural landscape, heritage, landscape archaeology, livestock

Index géographique : Pyrénées orientales

\section{AUTEURS}

\section{JOSEP MARIA PALET}

Institut Català d'Arqueologia Clàssica, Grup d'Investigació en Arqueologia del Paisatge (GIAPICAC, Tarragona)

\section{PAU OLMOS}

Institut Català d'Arqueologia Clàssica, Grup d'Investigació en Arqueologia del Paisatge (GIAPICAC, Tarragona)

\section{ARNAU GARCIA}

McDonald Institute for Archaeological Research, University of Cambridge

\section{TANIA POLONIO}

Institut Català d'Arqueologia Clàssica, Grup d'Investigació en Arqueologia del Paisatge (GIAP-

ICAC, Tarragona) 
HÈCTOR A. ORENGO

Institut Català d'Arqueologia Clàssica, Grup d'Investigació en Arqueologia del Paisatge (GIAPICAC, Tarragona) 


\title{
Essai de géographie protohistorique en contexte de moyenne montagne : enquête en Haute-Auvergne et sur les plateaux limousins (Massif central, France)
}

\author{
Attempt at protohistoric geography in mid-mountain context: \\ investigations in Haute-Auvergne and on the Limoges plateaus (Massif \\ Central, France)
}

Florie-Anne Auxerre-Géron

1 Dans le cadre du congrès du Comité des travaux historiques qui s'est tenu à Pau en avril 2017 ont été présentés quelques résultats de la thèse de doctorat soutenue à la fin de la même année, qui porte sur le nord-ouest du Massif central (Auxerre-Géron 2017). Ce secteur de moyenne montagne est un terrain privilégié pour étudier l'occupation humaine au cours de la Protohistoire: les conditions de conservation remarquables sont en effet un des principaux avantages de ces contextes, conditions résultant en partie d'une tradition d'élevage extensif peu destructif, qui a permis de préserver les vestiges tels que les tertres de toutes périodes, dont des tumulus protohistoriques. De plus, de nombreuses études paléo-environnementales ont été effectuées ou sont encore possibles dans ce secteur où abondent zones humides et tourbières. Cette recherche s'est attelée à synthétiser les différentes sources d'informations disponibles aujourd'hui, afin de répondre aux questions relatives à l'occupation du sol et à l'interaction Homme/milieu dans un contexte particulier, où la topographie et le climat assez rude (températures moyennes peu élevées, précipitations importantes, etc.) ont nécessairement modulé la fréquentation humaine. L'étude de cette zone de moyenne montagne permet également de proposer une approche plus nuancée et équilibrée des sociétés protohistoriques du Massif central, connues essentiellement par les sites de plaine, en premier lieu de Grande Limagne d'Auvergne (département du Puy-de-Dôme). 
L'objet de cet article est donc de présenter certains aspects et résultats de cette recherche à travers des exemples concrets pris dans deux fenêtres d'études et centrés sur l'habitat. Ces données permettent en effet de proposer de premières interprétations relatives à l'organisation des territoires, grâce notamment à une approche spatiale.

\section{Le cadre de l'étude}

\section{Cadre géographique}

2 La zone géographique concernée par cette recherche est vaste, dans le but notamment de bénéficier de contextes variables, sur le plan topographique mais aussi culturel, et de permettre des comparaisons entre différents secteurs. Cette zone est située à cheval entre deux régions administratives, Auvergne-Rhône-Alpes et Nouvelle-Aquitaine, et sur cinq départements, le Puy-de-Dôme, le Cantal, la Corrèze, la Creuse et la HauteVienne (fig. 1).

Fig. 1. - Localisation de la zone étudiée et principales entités géographiques la composant.

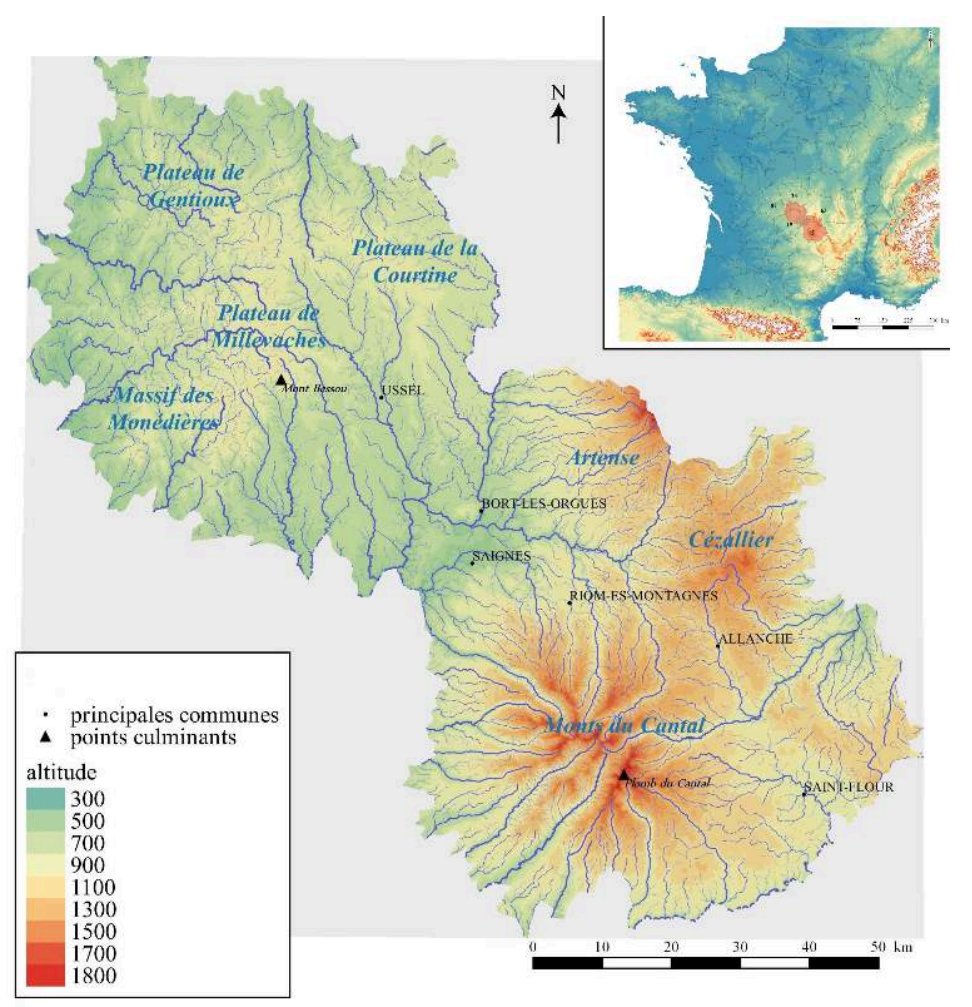

PAO Florie-Anne Auxerre-Géron (logiciel SIG QGIS), fond de carte SRTM, NASA/JPL-Caltech/National Geospatial Intelligence Agency.

3 La Haute-Auvergne est une des zones principales de nos recherches: elle correspond plus ou moins au département du Cantal, et est constituée essentiellement d'un important massif volcanique. Ce massif cantalien est découpé par une quinzaine de vallées encaissées qui rayonnent depuis les principaux sommets et crêtes, et dont le point culminant est le Plomb du Cantal, à une altitude de 1855 mètres. Les plateaux basaltiques grossièrement triangulaires, à déclivité douce, appelés planèzes, sont la composante principale du paysage cantalien: ils se développent entre 900 et 
1300 mètres d'altitude, et grâce à leur surface relativement plane, constituent aujourd'hui des secteurs de pâturages privilégiés. D'autre part, la Haute-Auvergne recouvre également les monts du Cézallier, anciennes coulées basaltiques provenant des différents massifs volcaniques environnants, qui revêtent l'aspect d'un vaste plateau bombé modelé par l'activité glaciaire. Ce secteur est également entaillé par de profondes vallées.

4 Aux côtés de ces espaces de hautes terres, une zone de contrefort au nord-ouest du département a été ajoutée à cette fenêtre d'étude, afin de faire le lien avec la zone d'étude limousine. En Limousin, l'étude s'est intéressée à la zone couramment appelée "Montagne limousine", d'altitude moyenne avoisinant 800 mètres. Cette entité géographique est composée en réalité de plusieurs plateaux granitiques : les plateaux de Millevaches, du Gentioux, de Pigerolles et du massif des Monédières. La « Montagne limousine » recouvre essentiellement le nord de la Corrèze, zone appelée haute Corrèze, et le sud de la Creuse. Elle est ponctuée par un réseau hydrographique dense et des vallées encaissées.

5 Ces territoires présentent donc essentiellement des contextes de moyenne montagne, au relief parfois chaotique, souvent contraignant pour les déplacements et les installations humaines, où le climat peut être capricieux et difficile: assez humide, caractérisé notamment par d'abondantes chutes de neige en hiver, en particulier sur les plateaux et des versants ouest exposés aux perturbations venues de l'Atlantique. La saison végétative est généralement courte, de cinq mois pour les secteurs les plus privilégiés à quatre mois, voire moins, dans d'autres. En «Montagne limousine », la température moyenne annuelle approche tout juste $9^{\circ} \mathrm{C}$, et les forts contrastes thermiques, tout au long de l'année, sont une particularité du climat. En HauteAuvergne, le climat est bien plus frais: au-dessus de 800 mètres d'altitude, la température annuelle moyenne avoisine $8^{\circ} \mathrm{C}$, et lorsque l'on dépasse 1000 mètres, cette température est comprise entre 5 et $7^{\circ} \mathrm{C}$. Ces quelques considérations générales témoignent du caractère montagnard des territoires étudiés.

\section{Bref historique des recherches et cadre chronoculturel}

6 Cette étude, menée rappelons-le dans le cadre d'un doctorat, a porté sur la totalité de la Protohistoire, cette fourchette chronologique permettant notamment d'appréhender les modalités d'occupation sur le long terme. Pour cet article, cependant, seront abordés essentiellement l'âge du Bronze moyen et final, ainsi que La Tène finale (La Tène $\mathrm{D}$ ). Les systèmes chronologiques employés dans l'étude sont le système français adapté à la France centrale pour l'âge du Bronze et le premier âge du Fer (Delrieu et Milcent 2012), et le système allemand pour le second âge du Fer.

7 L'historique des recherches doit être abordée, même brièvement, pour bien comprendre les enjeux propres à cette zone d'étude, car la recherche archéologique y est particulièrement contrastée. Les travaux anciens sont en effet relativement rares par rapport à d'autres régions, tandis que l'absence d'archéologie préventive récente est incontestablement dommageable. Les premiers travaux remontent à la première moitié du XIXe siècle : la Protohistoire est abordée dans un premier temps à travers les tumulus, nombreux grâce à de très bonnes conditions de conservation. L'engouement pour ces monuments est surtout fort dans le Cantal, où une quinzaine de tumulus sont explorés avant 1900. Ils seront particulièrement privilégiés à nouveau à partir des 
années 1960, recensés par centaines mais aussi fouillés. Ces vingt dernières années, les premiers essais de typologie et de classement de ces structures et des ensembles ont été proposés (Delrieu 2000, Milcent et Delrieu 2007). Par contraste, les habitats sont bien moins connus, et ils le sont essentiellement par le biais des sites de hauteur, dont certains sont étudiés dès la fin du XIX siècle (Pagès-Allary 1908). En «Montagne limousine ", quelques-uns de ces sites sont inventoriés, mais aucun ne fera l'objet de relevés précis ou de fouilles avant la fin des années 1950 (Cotton et Frere 1961). En revanche, dans cette zone, l'intérêt sera porté sur un autre type de sites, propres à la fin du second âge du Fer : il s'agit de sites à enclos rectangulaires, dont deux seront présentés dans cet article. En Haute-Auvergne, les sites de hauteur sont bien plus documentés, même si les fouilles assez conséquentes restent exceptionnelles et anciennes.

8 Ce peu d'intérêt pour les habitats d'une manière générale, et au contraire la focalisation sur les tertres et tumulus, seront à l'origine des premières hypothèses sur le peuplement protohistorique du Cantal : le schéma alors avancé est que ces territoires d'altitude n'étaient pas occupés toute l'année, et qu'ils accueillaient une activité de transhumance au cours de la belle saison (Millotte 1959, Tixier 1984). Dans ce fonctionnement, l'édification de tumulus correspondrait ainsi à un "marquage » du territoire. Cette hypothèse, assez tenace entre les années 1960 et 1990, sans qu'aucun véritable argument ait été avancé, a commencé à être mise à mal par de nombreuses analyses paléoenvironnementales. Ces dernières ont essentiellement été menées par Y. Miras en « Montagne limousine » (Miras 2004), mais aussi dans certaines tourbières cantaliennes, comme par exemple celle de La Borie à Saint-Saturnin, dans le nord du département, et proche de certains sites d'habitat mentionnés dans cet article (Miras et Guenet 2013). Ponctuellement dans le temps et l'espace, des traces évidentes d'agriculture permettent d'écarter l'idée de la pratique exclusive de l'élevage, et le couvert forestier assez important jusqu'à La Tène finale est loin du paysage actuel, que l'on pensait millénaire et propice presque uniquement à la pratique de l'estive.

9 Sans entrer dans les détails, il est nécessaire d'aborder succinctement le cadre chronoculturel afin de disposer de quelques jalons de compréhension. D'une manière générale, l'est de l'Auvergne est dès le début du Bronze ancien au carrefour de différentes influences, et tout particulièrement tournée vers le Rhône, le Languedoc et le midi de la France (Vital 2004 et 2014). Au début du Bronze moyen, le lien avec les groupes méridionaux est assez fort, ce qui transparaît notamment sur le site de hauteur du Roc de Chastel, dont il sera question ci-dessous, avant qu'un basculement des influences s'observe dans une deuxième phase. La région s'intègre alors au groupe centre-occidental des Duffaits (Gomez de Soto 1995). En Haute-Auvergne, le Bronze ancien et le début du Bronze moyen constituent la première séquence bien identifiée d'édification et d'utilisation de tumulus non mégalithiques (Delrieu et Milcent 2012). Les étapes les plus anciennes du Bronze final sont peu connues en Auvergne, et absentes en Limousin. Sur le plan funéraire toutefois, en Haute-Auvergne, le Bronze final 2 semble correspondre à une deuxième séquence d'utilisation des tumulus (Delrieu et Milcent 2012). En revanche, la fin du Bronze final est mieux représentée, notamment par plusieurs sites de hauteur.

10 Du point de vue de la céramique, une harmonisation des formes dans une grande partie du Massif central s'observe à partir du Bronze final 2. Les distinctions avec le groupe Rhin-Suisse-France orientale (RSFO) stricto sensu résident notamment dans l'absence de 
décor incisé et la présence de céramiques culinaires à carène haute. Les parallèles les plus forts sont de nouveau à trouver entre Languedoc et Garonne (Saint-Sever 2014, Vital et Benamour 2012). À la fin du Bronze final 3, les secteurs étudiés sont dans l'aire de répartition du faciès céramique de la France médiane, caractérisé notamment par des décors de signes réalisés au trait simple (Gomez de Soto et al. 2009).

11 Si l'on considère les objets métalliques, les productions relèvent surtout du faciès continental, tandis que le Limousin est pleinement intégré au domaine atlantique. La même situation prévaut au premier âge du Fer (Milcent 2004, Milcent et Delrieu 2007). En ce qui concerne la fin du second âge du Fer, abordé principalement par le biais des sites de haute Corrèze, la basse Auvergne a servi ponctuellement de référence pour l'étude des corpus céramiques, et ce faute de monographie récente disponible pour cette partie du Limousin : la récente publication issue d'un important programme de recherches dirigé par C. Mennessier-Jouannet a ainsi servi d'ouvrage de référence (Mennessier-Jouannet et Deberge 2017).

\section{Éléments de méthodologie}

12 La base de cette recherche a été la constitution de plusieurs inventaires thématiques. Recherches documentaires, prospections et sondages archéologiques, mais aussi étude de collections anciennes ont permis d'alimenter ces inventaires dans le but de disposer des informations les plus fiables possibles à l'heure actuelle et de procéder à un certain nombre d'analyses, spatiales mais aussi statistiques. L'étude de collections disponibles a ainsi permis de revoir les datations de nombreux sites et d'apporter un regard nouveau sur plusieurs d'entre eux.

13 Dans un second temps, c'est une approche spatiale qui a été privilégiée pour traiter les données : en effet, aux vues des caractéristiques des informations disponibles variées (habitats, mobilier métallique issu de dépôt non funéraire ou de découverte isolée, sites funéraires, mais aussi données paléoenvironnementales), et des particularités topographiques de la zone étudiée, des questionnements spécifiques ont nécessairement été posés. Cette zone d'étude est donc apparue comme pouvant constituer un laboratoire pour des analyses spatiales et des approches par ailleurs peu pratiquées. Certaines ont été menées en vue de répondre à quelques questions assez basiques, mais néanmoins délicates lorsque l'on s'intéresse à un territoire peu documenté, à savoir la question de l'occupation du sol, de son évolution dans le temps, mais aussi celle de l'origine possible des modulations observées (apparentes hausse ou baisse de la fréquentation, dynamique d'un secteur par rapport à un autre, etc.). D'autres analyses et modélisations spatiales ont été réalisées dans le but de comprendre au mieux les implantations des habitats en appréhendant leur environnement, qu'il soit naturel mais aussi humain.

En premier lieu, la question de l'occupation du sol et de son évolution dans le temps peut être d'abord traitée à l'aide de cartes de répartition, notamment thématiques. Celles-ci permettent de visualiser rapidement les caractéristiques des distributions des gisements, mais leur intérêt est limité car la dynamique temporelle est difficile à mettre en évidence, à moins de multiplier les cartes. A donc été utilisée une méthode qui consiste à mettre en place un maillage régulier de la zone d'étude, et à comptabiliser pour chaque période définie le nombre de sites par maille. Il est ensuite possible de comparer les maillages obtenus, d'une étape chronologique à une autre, par 
simple addition ou soustraction, et ainsi de mesurer les dynamiques d'implantation et éventuelles évolutions: on visualise clairement quels secteurs sont fréquentés, abandonnés ou, au contraire, connaissent une certaine continuité de l'occupation. À travers quelques cas concrets présentés dans cet article, nous verrons que cette méthode permet de mettre en lumière de nouvelles pistes de recherche. Certaines analyses ont été menées afin d'appréhender les sites dans leur environnement naturel, topographique mais aussi humain, c'est-à-dire dans le contexte archéologique connu aujourd'hui. Dans un premier temps, il est possible d'analyser plusieurs caractéristiques des positionnements topographiques : l'altitude, la situation dominante ou non par rapport à l'environnement direct, la pente et l'orientation principale du terrain où est installé l'habitat. L'implantation dans un paysage peut aussi s'étudier via la modélisation et l'analyse du champ de visibilité théorique depuis un site, calculé avec l'aide d'un logiciel de système d'information géographique (SIG) et d'un modèle numérique de terrain (MNT) précis. Enfin, il est possible d'approcher les liens avec les ressources disponibles dans l'environnement direct, comme par exemple la distance avec les cours d'eau, seuls éléments a priori peu changeants au cours des siècles. Les analyses spatiales peuvent également porter sur les relations entre les sites. Ainsi, le champ de visibilité théorique permet d'identifier d'éventuelles relations de covisibilité entre les sites.

De plus, cette approche a aussi consisté à calculer les distances intersites et ainsi les temps de parcours théoriques, en suivant les cheminements dits de "moindre coût " calculés grâce au logiciel de SIG. En effet, pour un point donné, il est possible de calculer le « coût » de déplacement autour de ce point, en fonction de la pente (appelée "facteur de rugosité »), et donc de mesurer l'impact sur un déplacement humain, notamment la réduction de la vitesse moyenne de marche, établie en l'occurrence pour l'étude à $4 \mathrm{~km} / \mathrm{h}$ en terrain plat. Il est ensuite possible de calculer les chemins les plus courts et surtout les moins « coûteux » en termes d'énergie déployée, entre deux points (calculs effectués sous le logiciel QGIS et la console Grass, avec laquelle il est notamment possible de générer des cartes de "coûts cumulés" sous forme d'isochrones). Les distances et profils des tracés théoriques obtenus permettent ensuite de calculer des temps de parcours théoriques, estimés après calcul de la vitesse de déplacement en fonction de la « rugosité » du trajet, c'est-à-dire dans notre cas la pente moyenne. Les cheminements calculés sont certes théoriques, car ils ne prennent pas en compte un certain nombre de facteurs dont l'importance est impossible à déterminer aujourd'hui, comme la végétation, les conditions climatiques ou les contraintes proprement humaines, mais ils constituent des éléments de réflexion qui permettent d'approcher un territoire "vécu ». Il est de plus assez intéressant de les coupler à l'environnement archéologique des habitats, ainsi qu'aux aires visibles en théorie depuis les sites. Les exemples présentés dans cet article montreront les apports de cette approche. 


\section{Étude de cas en Haute-Auvergne : le maillage des sites de hauteur du Bronze moyen à la fin du premier âge du Fer}

\section{Présentation de quelques sites de hauteur emblématiques}

\section{Le Roc de Chastel (Chastel-sur-Murat, Cantal)}

Sur les contreforts nord-est des monts du Cantal, culminant à 1190 mètres, le dyke basaltique du Roc de Chastel est un site connu depuis la toute fin du XIX ${ }^{e}$ siècle (fig. $2, \mathrm{n}^{\circ}$ 17).

Fig. 2. - Carte de répartition des sites occupés au cours de l'âge du Bronze et localisation des sites mentionnés dans l'article (astérisques blancs).

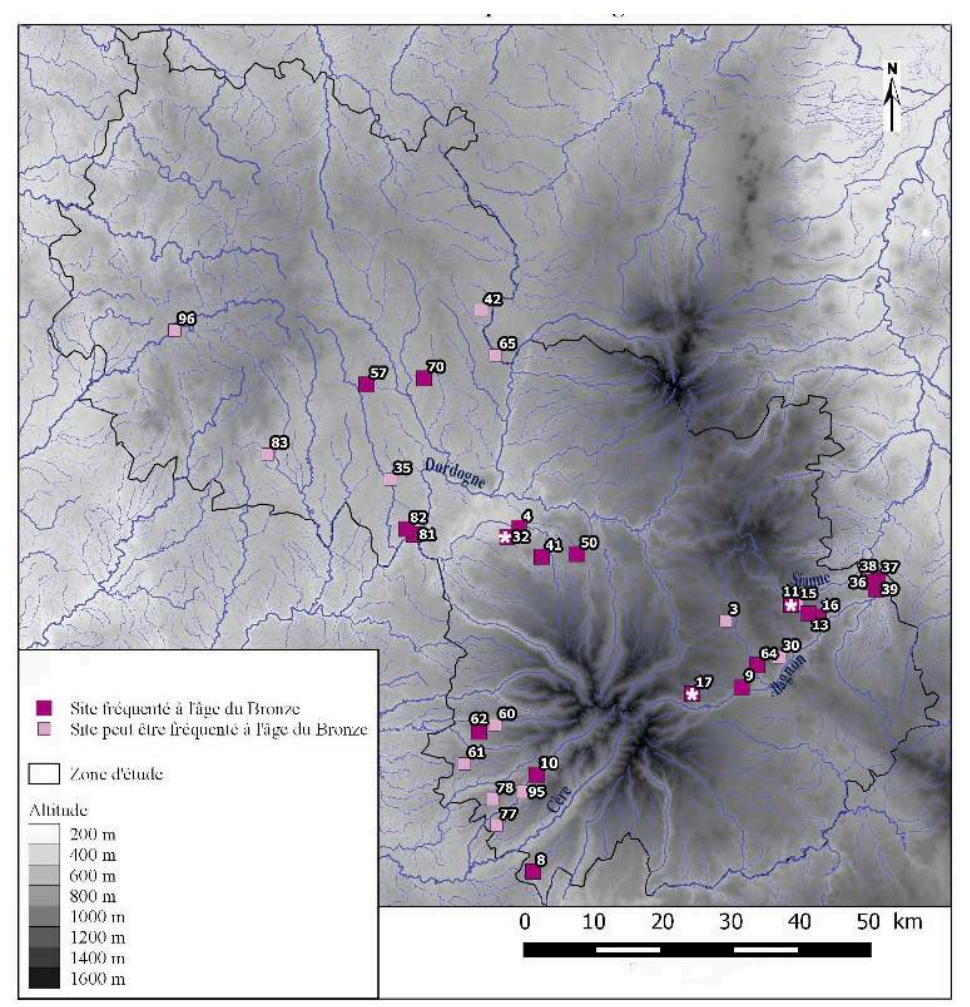

3 : Bois du Chay (Allanche, Cantal). 4 : Roc Vignonnet (Antignac, Cantal). 8 : Roc de Carlat (Carlat, Cantal). 9 : abri du Cheylat (Chalinargues, Cantal). 10 : abri de Roche-Rouge (Lascelle, Cantal). 11 : Suc de Lermu (Charmensac, Cantal). 13 : La Richard (Charmensac, Cantal). 15 : Les Malettes (Charmensac, Cantal). 16 : Le Couderc des Morts (Charmensac, Cantal). 17 : Roc de Chastel (Chastel-sur-Murat, Cantal). 30 : L'Arbre Lachat (Joursac, Cantal). 32 : Chastel-Marlhac (Le Monteil, Cantal). 35 : Station R4 (Liginiac, Corrèze). $\mathbf{3 6}, \mathbf{3 7}, \mathbf{3 8}, \mathbf{3 9}$ : Saint-Victor, Chalet, Prats des Riou d'Ouche, Berges de l'Alagnon (Massiac, Cantal). 41 : Puy de Menoire (Menet, Cantal). $\mathbf{4 2}$ : Les Vergnes (Merlines, Corrèze). $\mathbf{5 0}$ : Châteauneuf (Riom-ès-Montagnes, Cantal). $\mathbf{5 7}$ : Mont-Joly (Saint-Angel, Corrèze). 60, 60, 62 : abri de Roncaillade, La Combe du Troupier, Castel Marzes (Saint-Cernin, Cantal). $\mathbf{6 4}$ : Cuzes de Neussargues (Sainte-Anastasie, Cantal). 65 : Camp de Fontjaloux (Saint-Étienne-aux-Clos, Corrèze). 70 : Les Champs (Saint-Exupéry-les-Roches, Corrèze). 77, 78 : Mazeirac, Montagne du Carme (Saint-Simon, Cantal). 81, 82 : Belvédère de Gratte-Bruyère, Douniol (Sérandon, Corrèze). 83 : Le Cayre (Soudeilles, Corrèze). 95 : abri de Mousset (Velzic, Cantal). 96 : Le Bournazel (Viam, Corrèze).

PAO Florie-Anne Auxerre-Géron (logiciel SIG QGIS), fond de carte SRTM, NASA/JPL-Caltech/National Geospatial Intelligence Agency. 
D'une surface de 1,4 hectare, il est défendu en partie naturellement par des falaises à pic de près de 100 mètres de hauteur (fig. 3 a).

Fig. 3. - Contexte topographique des sites de hauteur de Haute-Auvergne mentionnés dans l'article.

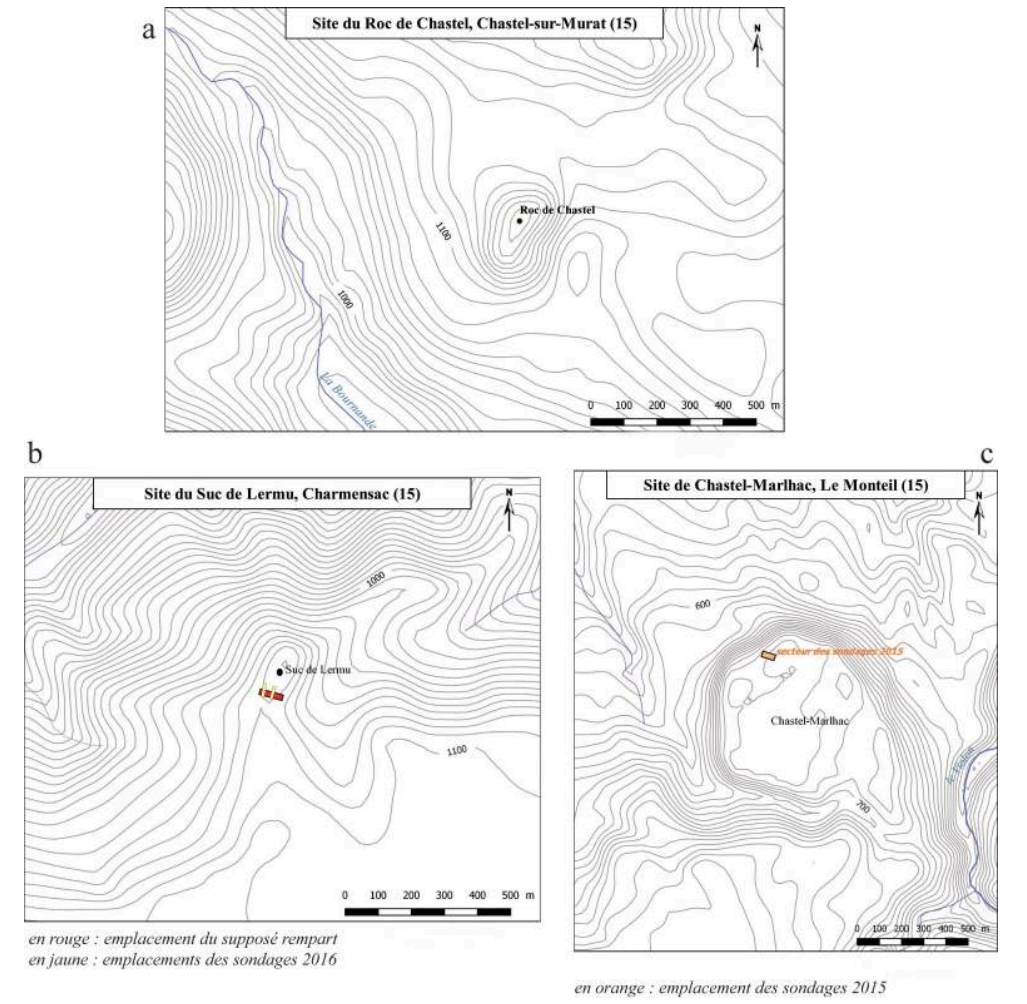

PAO Florie-Anne Auxerre-Géron (logiciel SIG QGIS), fond de carte issu du modèle numérique de terrain, pas $25 \mathrm{~m}$.

19 Une importante occupation du haut Moyen Âge a laissé des vestiges de constructions qui ont très vite interpellé les érudits : le site a été fouillé dès 1891 par J.-B. Delort, puis entre 1908 et 1914 par J. Pagès-Allary, figure importante de l'archéologie cantalienne. Ce dernier mentionne notamment, en fond de stratigraphie, un abondant mobilier néolithique et protohistorique (Pagès-Allary 1908). Ce mobilier atteste de plusieurs phases d'occupation, et J. Pagès-Allary a tenté dès 1910 de le classer et de le périodiser. Récemment, le mobilier a été réétudié en partie par J. Vital (Vital 2004), ce qui a permis de reconsidérer ces premiers classements proposés et d'identifier notamment du mobilier céramique du Bronze moyen 1.

Le Roc de Chastel est actuellement le seul habitat du Bronze moyen relativement bien documenté pour le Cantal, et plus largement pour la zone d'étude considérée. Les affinités culturelles avec le sud de la France sont assez nettes : les comparaisons de morphologies céramiques avec les corpus notamment des Grands Causses sont pertinentes, et les décors font quant à eux écho aux céramiques du groupe du Noyer, que l'on retrouve dans le Lot, le Tarn-et-Garonne et en Dordogne. Les parallèles moins francs avec certains sites de la Grande Limagne d'Auvergne (Puy-de-Dôme) montrent également que le Roc de Chastel entretient des liens avec des secteurs situés plus au nord (Vital 2014). 
21 En outre, quelques éléments de parure épars sont connus et attestaient jusqu'à maintenant d'occupations postérieures, datées notamment du premier âge du Fer. Un fragment d'anneau de jambe ou de bracelet en bronze incisé, daté du Hallstatt moyen, semble témoigner d'une troisième phase de fréquentation (Milcent 2004). Une autre phase d'occupation, sans doute plus conséquente, à la fin du premier âge du Fer et à La Tène A1 est quant à elle suggérée par la présence d'une fibule en fer et d'un bracelet de lignite (Milcent 2004). L'étude du mobilier céramique conservé au musée d'Aurillac a permis de confirmer ces occupations: quelques formes peuvent se rapporter au Hallstatt moyen, comme les bords de jattes ou coupes tronconiques, tandis qu'un vase à col vertical, à lèvre amincie et à cordon torsadé peut être attribué à cette période ou daté du Hallstatt D3-La Tène A1. Pour le tout début de La Tène, l'étude de la collection a également mis en évidence la présence de jattes à profil en $\mathrm{S}$ ainsi qu'un tesson de céramique à pâte claire peinte, semblable à ce qui a pu être mis au jour au Suc de Lermu (voir paragraphe suivant). Cette occupation au Roc de Chastel fait écho à la multiplication des fréquentations des sites de hauteur au cours de la période de transition entre le premier et le second âge du Fer, observée en Haute-Auvergne mais aussi en basse Auvergne et dans d'autres régions de France centrale (MennessierJouannet et Milcent 2007, Auxerre-Géron et al. 2017). Enfin, il est également à noter qu'une part importante du corpus céramique mais aussi de la parure et des monnaies provenant du Roc de Chastel se rapporte à une dernière phase d'occupation protohistorique, datée de La Tène $\mathrm{D}$.

\section{L'éperon barré du Suc de Lermu (Charmensac, Cantal)}

22 À une cinquantaine de kilomètre à vol d'oiseau du Roc de Chastel (fig. $2, \mathrm{n}^{\circ} 11$ ), le Suc de Lermu est un éperon, très probablement barré, surplombant la vallée de la Sianne (fig. $3 \mathrm{~b}$ ), dont les occupations protohistoriques sont repérées pour la première fois au début des années 1950. À des ramassages de mobilier succèdent quelques sondages, brièvement documentés ou même clandestins. L'intérêt principal de ce site est l'abondance du mobilier récolté et très peu étudié jusqu'ici, encore conservé dans les musées de Saint-Flour et d'Aurillac. Il s'agit d'un site aux dimensions plus modestes que le Roc de Chastel, puisque la surface disponible atteint tout juste $6000 \mathrm{~m}^{2}$, mais il semble présenter un aménagement défensif qui barre l'accès côté plateau, possiblement attribué à une des phases d'occupations protohistoriques. En effet, si un sondage mené en 2016 par F. Delrieu a permis de premières observations, d'autres opérations à venir sont nécessaires pour clarifier la chronologie de l'aménagement. Les occupations protohistoriques sont multiples l'une est datée de l'âge du Bronze moyen (assez hypothétique encore à l'heure actuelle), et une bien plus conséquente est datée du Bronze final 3. Une phase d'occupation datée du tout début de La Tène a aussi pu être mise en évidence au cours des sondages de l'été 2016 (Auxerre-Géron et al. 2017).

23 Pour le Bronze final 3, même si les sondages de 2016 n'ont pas permis d'atteindre les niveaux en place, un matériel assez conséquent se rencontre de manière résiduelle, et les collections anciennes mentionnées contiennent de nombreuses pièces : les éléments les plus caractéristiques correspondent à des fragments de gobelets à épaulement, des assiettes à marli ou de très nombreux bords facettés. Il faut signaler la présence de tessons à décor incisé (à un trait), représentant des motifs anthropomorphes et zoomorphes caractéristiques $\mathrm{du}$ Bronze final 3 récent, et plusieurs fragments d'assiettes à marli présentant des traces de peinture rouge et noire. Si la forme est 
caractéristique du Bronze final 3, ce type de décor peint perdure au début du premier âge du Fer: dans le Puy-de-Dôme, le site du Pâtural Redon/l'Ormeau de Bontemps (Lussat) a livré des coupes à rebords ornées de bandes peintes en rouge délimitées par des filets incisés, datées du Hallstatt ancien (Milcent 2004). Le métal est représenté par un fragment de faucille à languette en bronze, également attribuable au Bronze final 2 ou 3.

Quant à la phase d'occupation datée de La Tène $\mathrm{A}$, le matériel céramique s'illustre avant tout par la présence de jattes à bords rentrants et pots à profil ovoïde, ainsi que par de nombreux tessons de céramique à pâte claire peinte. Ce type de production était jusqu'alors inconnu en Auvergne, où les importations de céramiques tournées méditerranéennes sont par ailleurs très rares entre la fin $\mathrm{du} \mathrm{vI}^{\mathrm{e}}$ siècle et le $\mathrm{v}^{\mathrm{e}}$ siècle av. n. è., à l'exception de quelques sites comme Bègues, dans l'Allier (Milcent 2004), et la cathédrale Notre-Dame du Puy-en-Velay, en Haute-Loire (Milcent 2004). Rappelons toutefois qu'un exemplaire de pâte claire peinte a récemment été identifié dans le matériel céramique provenant du Roc de Chastel, ce qui a été évoqué précédemment.

Le Suc de Lermu se présente aujourd'hui comme un site phare de la Protohistoire en Haute-Auvergne, d'autant plus qu'il se situe dans un contexte archéologique assez riche. En effet, plusieurs nécropoles tumulaires ayant livré des sépultures contemporaines de certaines phases d'occupation du site sont localisées non loin : la nécropole de Lair, à Laurie, de la Croix de Baptiste sur les communes d'Allanche et de Vèze (Milcent 2004, Milcent et Delrieu 2007, Delrieu et Milcent 2012) ; mais aussi, sur la commune même de Charmensac, plusieurs gisements mis au jour à l'occasion de travaux de remembrement pourraient correspondre à des monuments funéraires arasés (Daugas et al. 1982, Auxerre-Géron 2017). D’autres sites de hauteur occupés à des périodes synchrones sont également situés à quelques dizaines de kilomètres, notamment les plateaux de Chalet et de Saint-Victor, à Massiac (Auxerre-Géron 2017 ; fig. $2, \mathrm{n}^{\text {os }} 36$ et 38 ). Enfin, la poursuite des opérations de sondages devrait notamment permettre d'apporter de nouveaux éléments sur le probable système défensif observé.

\section{Le plateau de Chastel-Marlhac (Le Monteil, Cantal)}

26 À la suite de prospections pédestres positives, le plateau de Chastel-Marlhac a fait l'objet de sondages archéologiques en août 2015, ce qui a permis de documenter des occupations protohistoriques inédites. Il s'agit d'un plateau basaltique quasiment circulaire, situé à l'extrémité nord de la commune du Monteil, dans le nord-ouest du Cantal (fig. 2, $\mathrm{n}^{\circ} 32$ ). D'une surface totale d'environ 40 hectares, le site est défendu naturellement par des orgues basaltiques de 25 à 30 mètres de hauteur, sur quasiment la totalité de son pourtour (fig. 3 c). L'accès naturel est possible au sud-est du plateau, dans un secteur en pente douce où prend place le petit bourg actuel. Le plateau culmine à 730 mètres et domine la plaine de Saignes, où coule la Sumène, affluent de la Dordogne. Il est situé également au pied de la planèze de Trizac, et donc aux portes des hautes terres du Cantal.

Le contexte archéologique est assez riche, puisque le site se place dans un secteur où les données disponibles offrent une vitrine diversifiée des âges des métaux dans le département: des dépôts de mobilier métallique attestent notamment d'une fréquentation du secteur dès le Bronze ancien: dépôt de haches de Châteauneuf à Riom-ès-Montagnes (Daugas 1976) ; au Bronze moyen : dépôt de haches de l'Étang de Mialet, à Monestier-Port-Dieu, en Corrèze, anciennement localisé à Beaulieu dans le 
Cantal (Daugas 1976); mais aussi au Bronze final, avec notamment la hache découverte dans la Dordogne, au lieu-dit Bois de Madic, à Bort-les-Orgues, en Corrèze (Daugas 1976, Hernandez et al. 1989); et surtout l'important dépôt de trois épées en bronze découvert à Aliès, sur la commune de Menet, proche du Monteil (Rames 1872). Ce dépôt est situé à 5 kilomètres à vol d'oiseau de Chastel-Marlhac, en amont du Violon, qui coule à l'est du site.

Le domaine funéraire est également documenté dans le secteur environnant: un des tumulus du Suc des Demoiselles, à Vebret, a livré une sépulture du Bronze ancien avec poignard en bronze de type rhodanien (Bouillet 1834) et à Menet, la fouille récente du tumulus de Fô-est a permis de mettre au jour les vestiges d'une sépulture du Hallstatt ancien 2 (Delrieu 2006).

Enfin, notons que deux autres sites de hauteur proches, particulièrement importants à la période médiévale, ont livré des indices d'occupations protohistoriques: le Roc Vignonnet, à Antignac (fig. 2, $\mathrm{n}^{\circ}$ 4), et le Puy de Menoire, à Menet (fig. 2, $\mathrm{n}^{\circ} 41$ ). Le site de Chastel-Marlhac en lui-même est connu à l'origine pour son occupation galloromaine, mais surtout mérovingienne. Des occupations protohistoriques étaient soupçonnées, sans pour autant que des découvertes en ce sens y aient été faites. Seule la mention d'une monnaie en or gauloise provenant du plateau laissait supposer une phase d'occupation à la fin du second âge du Fer (Provost et Vallat 1996).

En 2015, trois sondages de petites dimensions ont été ouverts sur la frange nord du plateau, là où avait été observée une concentration de matériel lors de prospections. Dans le sondage 1 a été mis au jour un important remblai d'origine anthropique, composé de blocs de basaltes rapportés, qui a comblé et recouvert une fosse circulaire peu profonde, creusée en partie dans le substrat et dans sa couche d'altération. Le mobilier mis au jour dans la fosse, notamment les fragments d'une jatte à profil en $\mathrm{S}$ et d'une céramique peinte en rouge, permet de la dater entre La Tène A2 et La Tène B1 (Auxerre-Géron 2015b). Cependant, du mobilier caractéristique de La Tène D mis au jour en surface permet d'identifier une dernière phase de comblement, résultant d'une volonté d'aplanissement, ou bien d'un niveau d'occupation. Dans ce sondage a été également récolté du mobilier résiduel à rapporter au Bronze final 3. Ce bruit de fond du Bronze final se retrouve également dans le sondage 2. Dans ce dernier a également été mis en évidence un important remblai, toutefois postérieur car bien daté de La Tène D par un mobilier abondant mêlé aux blocs de basalte. Cet aménagement témoigne d'une même volonté qu'au tout début du second âge du Fer d'assainir un secteur au sol trop humide et trop souvent gorgé d'eau, ce que les analyses micromorphologiques ont permis de confirmer (Auxerre-Géron 2015b).

31 Le troisième et dernier sondage, bien plus modeste, a permis de mettre en évidence une stratigraphie complexe et relevant d'une histoire de gestion des terrains différente. Le mobilier mis au jour dans deux unités stratigraphiques, bien que peu abondant, constituait cependant un lot homogène, où se distinguent notamment un fragment de fond d'assiette à surface polie arborant une cannelure, ainsi qu'un fragment d'une forme haute fermée à panse globulaire. Le Bronze final 3, rencontré de manière résiduelle dans les autres sondages, est représenté dans ce troisième sondage par deux unités stratigraphiques à part entière, peut-être relevant d'un niveau d'occupation. Le sondage était toutefois trop modeste pour que cette hypothèse ait pu être vérifiée.

32 Le site de Chastel-Marlhac a donc été fréquenté au moins à trois reprises au cours de la Protohistoire. Plus particulièrement, il semblerait qu'une occupation assez 
conséquente au Bronze final 3 se dessine déjà : la récurrence du mobilier résiduel dans les niveaux postérieurs atteste d'une implantation assez prégnante. Ces données inédites, d'autant plus précieuses dans la mesure où le contexte archéologique est relativement fourni, restent à confirmer et affiner par des opérations de terrain ultérieures. De plus, le potentiel du site en archives paléoenvironnementales, un unicum pour l'instant dans la zone, sera sans doute très intéressant à exploiter à l'avenir.

\section{Appréhender les rythmes d'occupation et les voies de circulation par l'étude des sites de hauteur}

Après cet aperçu de quelques sites, il est nécessaire de prendre du recul afin de tenter d'appréhender les rythmes d'occupation, en particulier en Haute-Auvergne. Cette zone se caractérise par une répartition contrastée des habitats protohistoriques connus, en grande partie du fait de l'historique des recherches. Ces sites se concentrent notamment dans les deux secteurs distincts abordés: dans le nord-ouest du département du Cantal, illustré par le site de Chastel-Marlhac (fig. 2, $\mathrm{n}^{\circ} 32$ ), et dans le nord-est, de part et d'autre de la vallée de l'Alagnon, illustré par le Suc de Lermu (fig. 2, $\mathrm{n}^{\circ} 11$ ) et le Roc de Chastel (fig. 2, $\mathrm{n}^{\circ} 17$ ). Grâce à la méthode, décrite précédemment, de décompte de sites par maille et de comparaisons par étapes chronologiques, l'occupation de la vallée de l'Alagnon est particulièrement intéressante à observer. Elle est assez variable dans le temps, rythmée par des abandons et parfois la réoccupation de certains sites. Mis en perspective avec ce qui se passe ailleurs, notamment dans le nord-ouest du Cantal, cela permet de comprendre la place de cette vallée dans un fonctionnement plus global. Ainsi, au Bronze final 3, un changement d'axes de communication semble apparaître : alors que toute la vallée était avant cela occupée (fig. 4 a), notamment au Bronze moyen, comme l'illustre le site du Roc de Chastel, la concentration de l'occupation dans la basse vallée au Bronze final, et aussi sur le plateau du Bru, d'axe est-ouest, compris entre les gorges de l'Alagnon et de la Sianne, peut sembler significative. En effet, en parallèle dans le nord-ouest du département, plusieurs sites de hauteur sont alors occupés. Il apparaît ainsi un axe orienté grossièrement est-ouest (fig. 4 b) qui pourrait matérialiser un axe d'échanges et de contacts contournant le massif cantalien par ses versants septentrionaux, tandis que la traversée du massif via les vallées de l'Alagnon et de la Cère, et donc par le biais des cols, pourrait avoir perdu en importance. Les changements d'affinités lisibles dans les corpus céramiques entre le Bronze moyen et la fin du Bronze final pourraient être vus comme des témoins de ces variations des axes d'échanges. 
Fig. 4. - Comparaison des zones fréquentées de l'âge du Bronze ancien au Bronze moyen (a) et du Bronze moyen au Bronze final (b) (méthode des sommes focales, décompte par maillage) et axes de concentration lisibles.

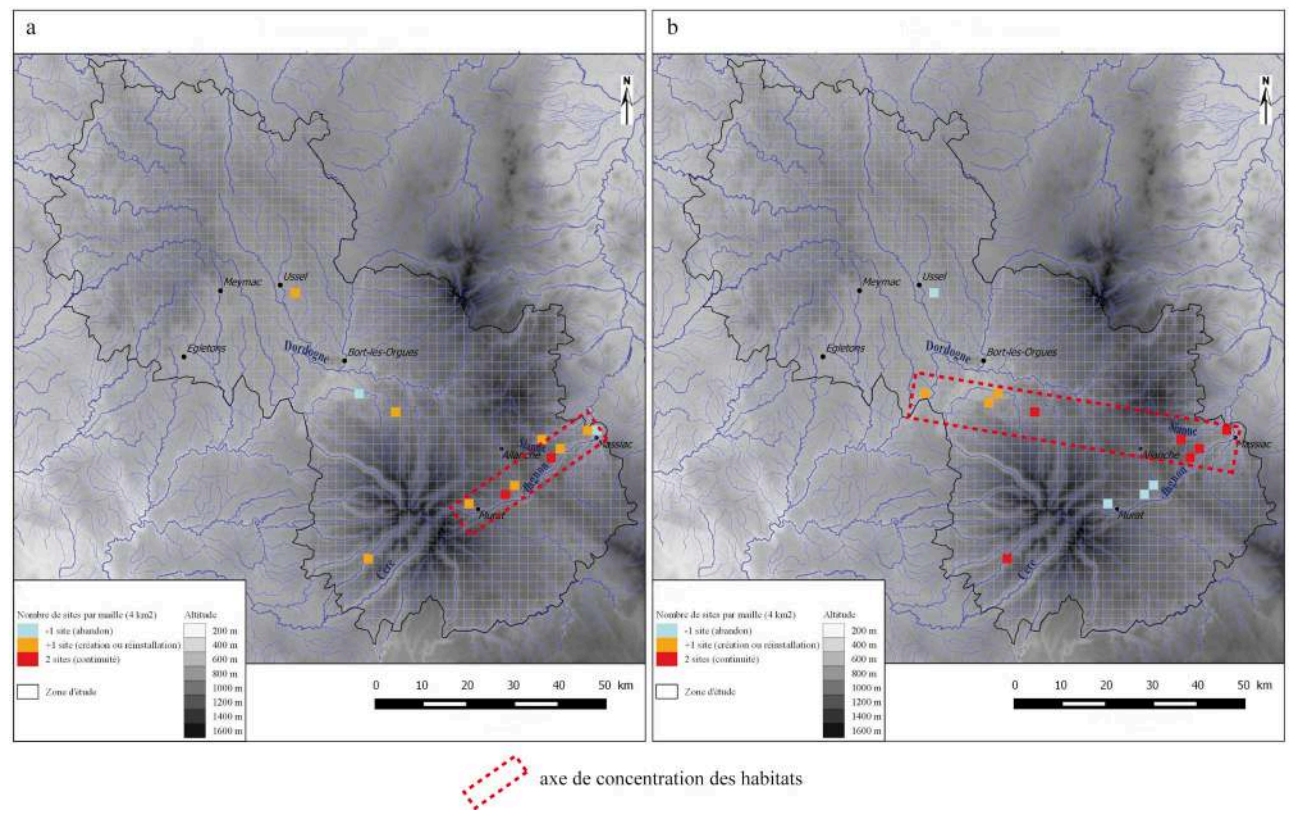

PAO Florie-Anne Auxerre-Géron (logiciel SIG QGIS), fond SRTM, NASA/JPL-Caltech/National Geospatial Intelligence Agency.

En plus de ces considérations générales sur l'évolution de l'occupation du sol, il est aussi primordial de tenter de comprendre les motivations à l'origine des implantations de ces habitats de hauteur, en les replaçant dans leur contexte géographique et archéologique. Dans cette optique, il est intéressant de considérer le relief, et en particulier son aspect plus ou moins contraignant pour les déplacements, en calculant le cheminement idéal entre deux sites donnés. À travers quelques exemples d'itinéraires théoriques, comme ceux reliant le Suc de Lermu (fig. $2, \mathrm{n}^{\circ} 11$ ) à d'autres sites très probablement contemporains (fig. 5), et les tracés partant du plateau de SaintVictor à Massiac (fig. $2, \mathrm{n}^{0} 36$; fig. 6), il apparait sans surprise que les vallées peuvent constituer des voies de circulation « naturelles ». 
Fig. 5. - Site de hauteur du Suc de Lermu (Charmensac, Cantal) : champ de visibilité théorique depuis le site et contexte archéologique.

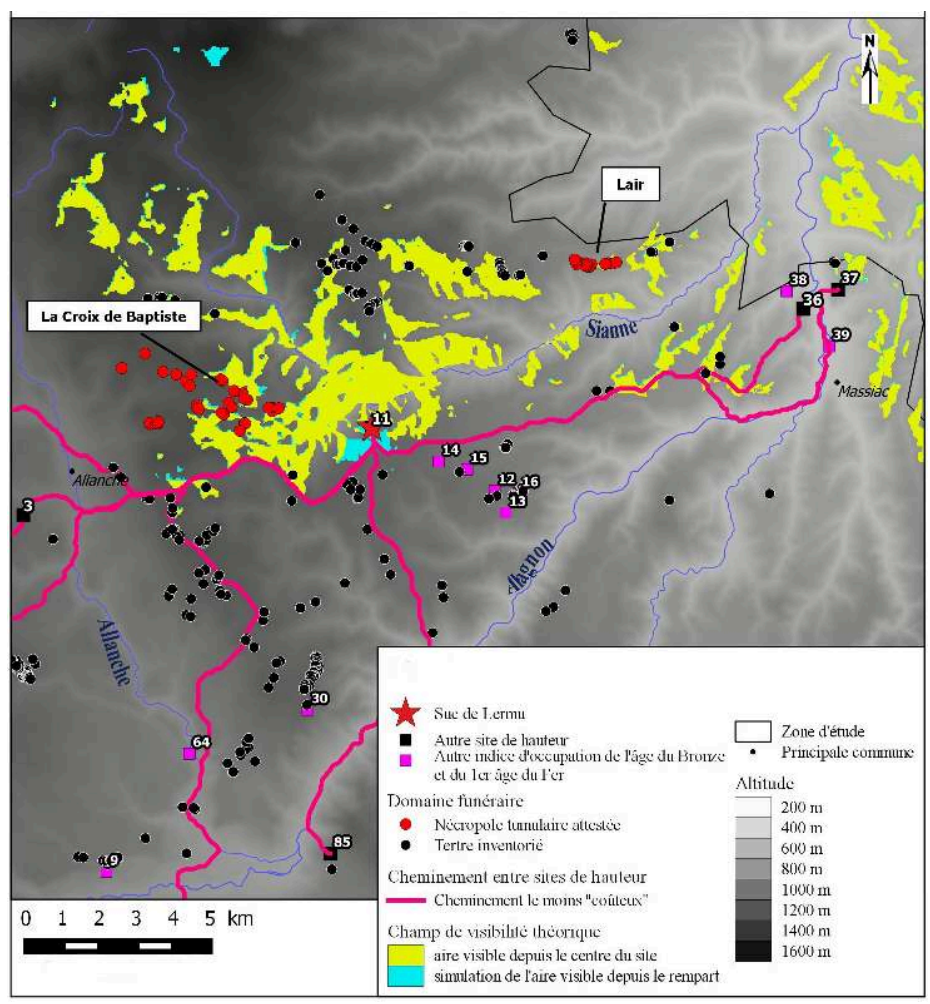

La visibilité depuis le rempart supposé a été calculée à partir d'un point central, en prenant 3 mètres comme élévation hypothétique. 3 : Bois du Chay (Allanche). 9 : abri du Cheylat (Chalinargues). 11, 12, 13, 14, 15, 16 : Suc de Lermu, Le Vau, La Richard, Les Alots, Les Malettes, Le Couderc des Morts (Charmensac). 30 : L'Arbre Lachat (Joursac). 36, 37, 38, 39 : Saint-Victor, Chalet, Prats des Riou d'Ouche, Berges de l'Alagnon (Massiac). 64 : Cuzes de Neussargues (Sainte-Anastasie). 85 : Les Charmilles (Talizat). Tous les sites sont dans le département du Cantal.

PAO Florie-Anne Auxerre-Géron (logiciel SIG QGIS), fond SRTM, NASA/JPL-Caltech/National Geospatial Intelligence Agency. 
Fig. 6. - Site de hauteur de Saint-Victor (Massiac, Cantal) : champ de visibilité théorique depuis le site et contexte archéologique.

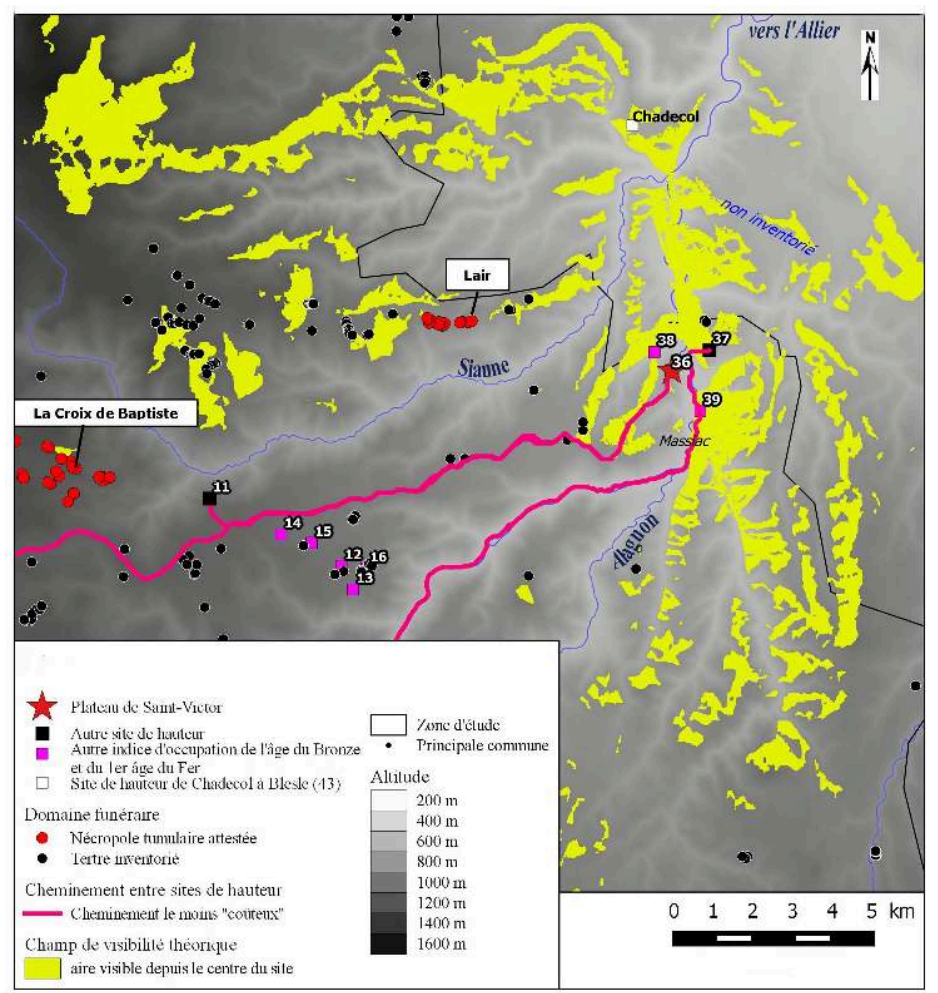

3 : Bois du Chay (Allanche). 9 : abri du Cheylat (Chalinargues). 11, 12, 13, 14, 15, 16 : Suc de Lermu, Le Vau, La Richard, Les Alots, Les Malettes, Le Couderc des Morts (Charmensac). 30 : L'Arbre Lachat (Joursac). 36, 37, 38, 39 : Saint-Victor, Chalet, Prats des Riou d'Ouche, Berges de l'Alagnon (Massiac). 64 : Cuzes de Neussargues (Sainte-Anastasie). 85 : Les Charmilles (Talizat). Tous les sites sont dans le département du Cantal.

PAO Florie-Anne Auxerre-Géron (logiciel SIG QGIS), fond SRTM, NASA/JPL-Caltech/National Geospatial Intelligence Agency.

Toutefois, dans la zone considérée ici, un autre axe se matérialise aussi sur le plateau triangulaire compris entre les cours de l'Allanche, de la Sianne et de l'Alagnon, entre les actuelles communes de Massiac et Allanche. Les cheminements présentés sont théoriques, mais il est assez intéressant de les coupler à l'environnement archéologique des habitats, d'observer par exemple la proximité de ces tracés avec d'autres sites contemporains, notamment funéraires, ainsi que de les confronter aux aires visibles en théorie depuis les sites. Si les sites de hauteur considérés bénéficient en général, et assez évidemment, d'un champ de visibilité très étendu, dans quelques cas des portions des cheminements théoriques vers des sites contemporains sont bien visibles. Il est donc envisageable que ces voies naturellement aisées à emprunter aient été en partie contrôlées visuellement par ces sites de hauteur. Le degré de "contrôle ", et la forme réelle que celui-ci pouvait prendre (protection, péage, etc.), sont des questionnements qui restent évidemment en suspens.

L'autre intérêt de ces cheminements est de pouvoir calculer le temps nécessaire, en théorie, pour relier un site à un autre à pied et de donner ainsi une envergure «humaine» au territoire. Ainsi, pour le Bronze final 3, en l'état actuel des connaissances, un maillage assez régulier peut s'observer, basé sur un temps de marche entre sites compris entre 4 et 5 heures, selon les secteurs. En partant du postulat qu'un site de hauteur est indépendant des habitats de même statut et rayonne d'une manière 
égale sur un territoire donné, à l'image de la théorie des places centrales de Christaller, souvent appliquée à l'archéologie (Olivier et al. 2002), il est envisageable que les habitats de hauteur du Bronze final 3 "possédaient " des territoires théoriques basés sur 2 à 3 heures de marche au maximum autour des sites. En modélisant puis figurant ces territoires délimités par 2 heures de marche autour de tous les sites de hauteur de cette période (fig. 7), il apparaît que les recoupements sont assez restreints, voire inexistants. Ces territoires sont même parfois jointifs, dans le nord-est du Cantal.

Fig. 7. - Territoires et cheminements théoriques entre les sites de hauteur du Bronze final de Haute-Auvergne : modélisation de territoires délimités par deux heures de marche autour des sites.

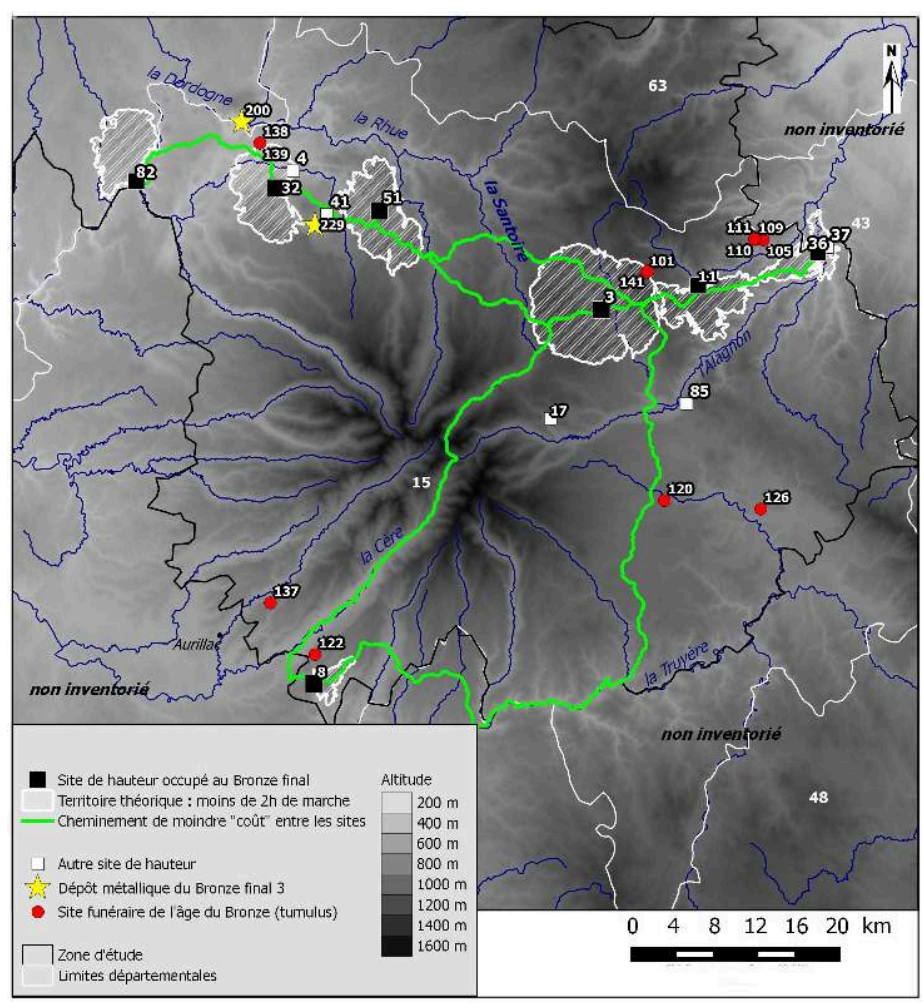

3 : Bois du Chay (Allanche). 4 : Roc Vignonnet (Antignac). 8 : Roc de Carlat (Carlat). 11, 15 : Suc de Lermu, Les Malettes (Charmensac). 17 : Roc de Chastel (Chastel-sur-Murat). $\mathbf{3 2}$ : Chastel-Marlhac (Le Monteil). 36, $\mathbf{3 7}$ : Saint-Victor, Chalet (Massiac). 41 : Puy de Menoire (Menet). 51 : Châteauneuf (Riom-ès-Montagnes). 82 : Douniol (Sérandon, Corrèze). $\mathbf{8 5}$ : Les Charmilles (Talizat). 101 : La Croix de Baptiste T409 (Allanche). 105, 109, 110, 111 : Lair T1, Lair T18, Lair T20, Lair T21 (Laurie). 120 Liozargues T2 (Roffiac). 122 : Le Puy des Arbres (Saint-Étienne-de-Carlat). 126 : Mons T3 (SaintGeorges). 137 : Salesse T4 (Saint-Simon). 138, 139 : Suc des Demoiselles, Suc des Demoiselles T2 (Vebret). 141 : La Croix de Baptiste T1 (Vèze). 200 : Bois de Madic (Bort-les-Orgues, Corrèze). 229 : Aliès (Menet). Les sites sont dans le département du Cantal sauf les nos 82 et 200 (Corrèze). PAO Florie-Anne Auxerre-Géron (logiciel SIG QGIS), fond SRTM, NASA/JPL-Caltech/National Geospatial Intelligence Agency.

37 Les territoires basés sur 3 heures de marche au maximum (fig. 8) se recoupent dans des proportions un peu plus conséquentes dans ce secteur nord-est du Cantal. 
Fig. 8. - Territoires et cheminements théoriques entre les sites de hauteur du Bronze final de Haute-Auvergne : modélisation de territoires délimités par trois heures de marche autour des sites.

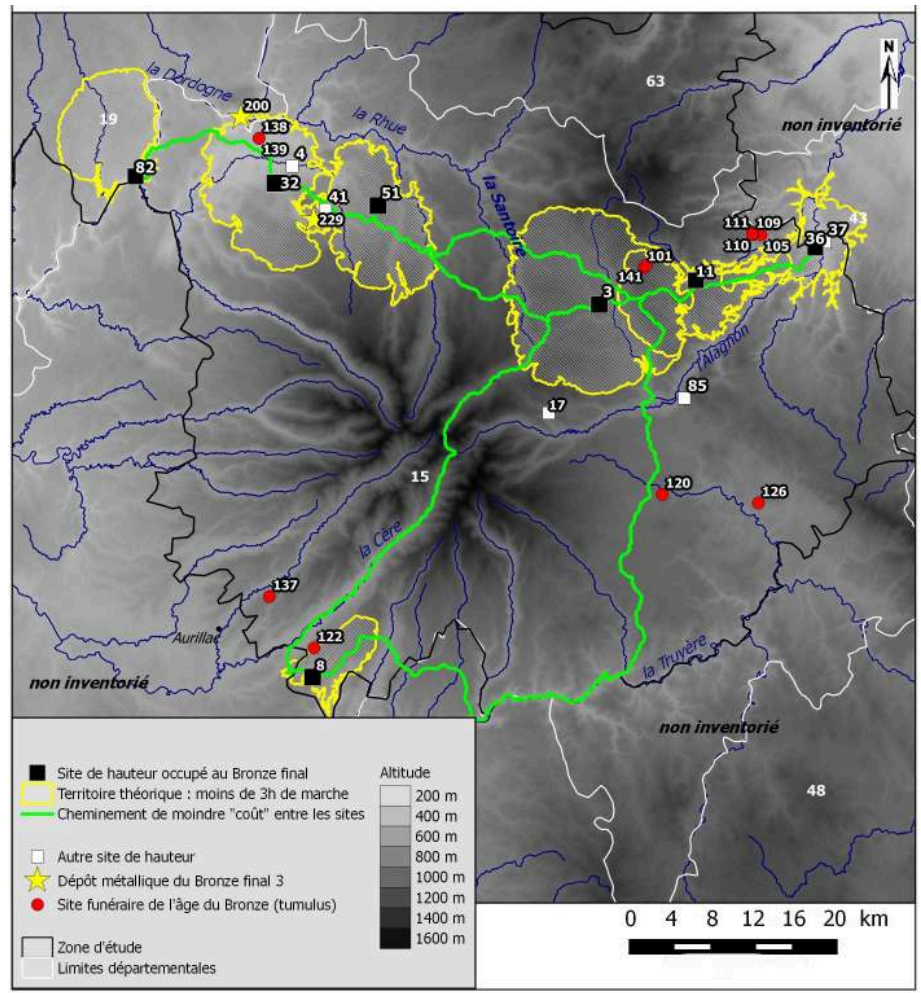

3 : Bois du Chay (Allanche). 4 : Roc Vignonnet (Antignac). 8 : Roc de Carlat (Carlat). 11, 15 : Suc de Lermu, Les Malettes (Charmensac). 17 : Roc de Chastel (Chastel-sur-Murat). $\mathbf{3 2}$ : Chastel-Marlhac (Le Monteil). 36, $\mathbf{3 7}$ : Saint-Victor, Chalet (Massiac). 41 : Puy de Menoire (Menet). $\mathbf{5 1}$ : Châteauneuf (Riom-ès-Montagnes). $\mathbf{8 2}$ : Douniol (Sérandon, Corrèze). $\mathbf{8 5}$ : Les Charmilles (Talizat). 101 : La Croix de Baptiste T409 (Allanche). 105, 109, 110, 111 : Lair T1, Lair T18, Lair T20, Lair T21 (Laurie). 120 Liozargues T2 (Roffiac). 122 : Le Puy des Arbres (Saint-Étienne-de-Carlat). 126 : Mons T3 (SaintGeorges). 137 : Salesse T4 (Saint-Simon). 138, 139 : Suc des Demoiselles, Suc des Demoiselles T2 (Vebret). 141 : La Croix de Baptiste T1 (Vèze). 200 : Bois de Madic (Bort-les-Orgues, Corrèze). 229 Aliès (Menet). Les sites sont dans le département du Cantal sauf les nos 82 et 200 (Corrèze). PAO Florie-Anne Auxerre-Géron (logiciel SIG QGIS), fond SRTM, NASA/JPL-Caltech/National Geospatial Intelligence Agency.

Ces schémas de territoires théoriques rayonnant depuis les sites sont bien entendu tributaires de l'état de la recherche et de la connaissance des sites, puisqu'il est possible que d'autres sites de hauteur restent à identifier. Ils permettent toutefois quelques observations intéressantes, et amènent en particulier à se poser la question des relations entre certains sites très proches, y compris les sites funéraires. Ainsi dans le nord-ouest du Cantal, dans la vallée de la Sumène, deux sites de hauteur très proches et occupés a priori tous les deux au Bronze final 3, Chastel-Marlhac (mentionné ci-dessus ; fig. 7 et $8, n^{\circ} 32$ ), et le Roc Vignonnet à Antignac (fig. 7 et $8, n^{\circ} 4$ ), témoigneraient soit de territoires beaucoup plus petits, peut-être même à l'origine de conflits, soit du caractère complémentaire de ces installations (un système habitat/vigie par exemple), ce qui n'est pas illogique si l'on considère les surfaces disponibles, bien différentes. La question du rôle de ces sites sur les voies de circulation naturelles se pose donc aussi, tandis que les zones de vide observées sur ces axes ne peuvent qu'interpeller : le cas du plateau du Limon, entre les deux zones de concentration définies par la vallée de la Sumène au nord-ouest et le secteur Sianne-Alagnon au nord-est, est le plus flagrant. Des opérations de terrain permettront à terme de définir s'il s'agit là d'un biais de la 
recherche ou d'une réalité historique qui infirmerait ainsi cette proposition de maillage territorial.

Certains secteurs de Haute-Auvergne apparaissent finalement comme "découpés » de façon optimisée pour l'Homme, puisque l'aller-retour entre les sites est souvent possible en une journée de marche. Ce maillage peut résulter de plusieurs origines ou avoir plusieurs fonctions : ces sites de hauteur peuvent avoir servi de sites-refuges sur une voie de circulation particulièrement difficile à certaines périodes de l'année, avoir été des sites-marchés, à la fois producteurs et consommateurs, et/ou des sites contrôlant des flux d'échanges et donc de marchandises. En l'état, il faut avant tout retenir que ces sites témoignent clairement d'une occupation réelle de cette partie septentrionale de la Haute-Auvergne. L'organisation de cet habitat semble mettre en évidence qu'il s'agit d'une occupation pérenne, établie et confortée par des facteurs multiples qui ont été à l'origine de modulations dans le temps. En revanche, cette organisation, telle qu'elle peut se percevoir aujourd'hui, semble difficilement découler d'une occupation basée uniquement sur une activité saisonnière d'élevage et de transhumance, comme cela a longtemps été supposé sans véritable argumentation.

\title{
Étude de cas en haute Corrèze : esquisse de l'organisation du territoire à La Tène finale
}

\section{Présentation de quelques sites d'habitat emblématiques}

\author{
Le Pont-Maure (Rosiers-d'Égletons) et La Moutte (Sérandon)
}

À Rosiers-d'Égletons (fig. 9, n 53), le site du Pont-Maure est situé dans un secteur humide, voire marécageux, et se présente comme une plateforme surélevée, rectangulaire, délimitée par un talus précédé d'un fossé (fig. 10 a). La hauteur de la levée de terre conservée aujourd'hui atteint 2 à 4 mètres par endroits, la longueur maximale est de 120 mètres et la largeur de 60 mètres. Une possible entrée se situe à peu près au milieu du côté oriental. Le site fut fouillé avant la Seconde Guerre mondiale et le matériel permet de le dater entre La Tène D1 et D2a. À Sérandon (fig. 9, $\mathrm{n}^{\circ} 80$ ), le site localisé au lieu-dit La Moutte est assez similaire, mais cependant un peu moins grand (fig. 10 b). Plusieurs sondages dans les années 1930 ont permis de mettre au jour de la céramique qui oriente d'une manière générale vers une datation à la fin du second âge du Fer. Les caractéristiques de ces sites, le plan quadrangulaire, l'emplacement de l'entrée, mais aussi la méthode de construction de l'enceinte, correspondent parfaitement aux sites appelés Viereckschanzen, connus notamment en Allemagne, et construits entre La Tène C2 et La Tène D1. Littéralement «retranchements quadrangulaires ", des établissements de ce type fouillés en France et en Allemagne se sont avérés être des fermes ou petits hameaux au statut particulier, qui reste à définir, ou bien des centres de village (Von Nicolai 2009). 
Fig. 9. - Carte de répartition des sites occupés à La Tène finale et localisation des sites mentionnés dans l'article (astérisques blancs).

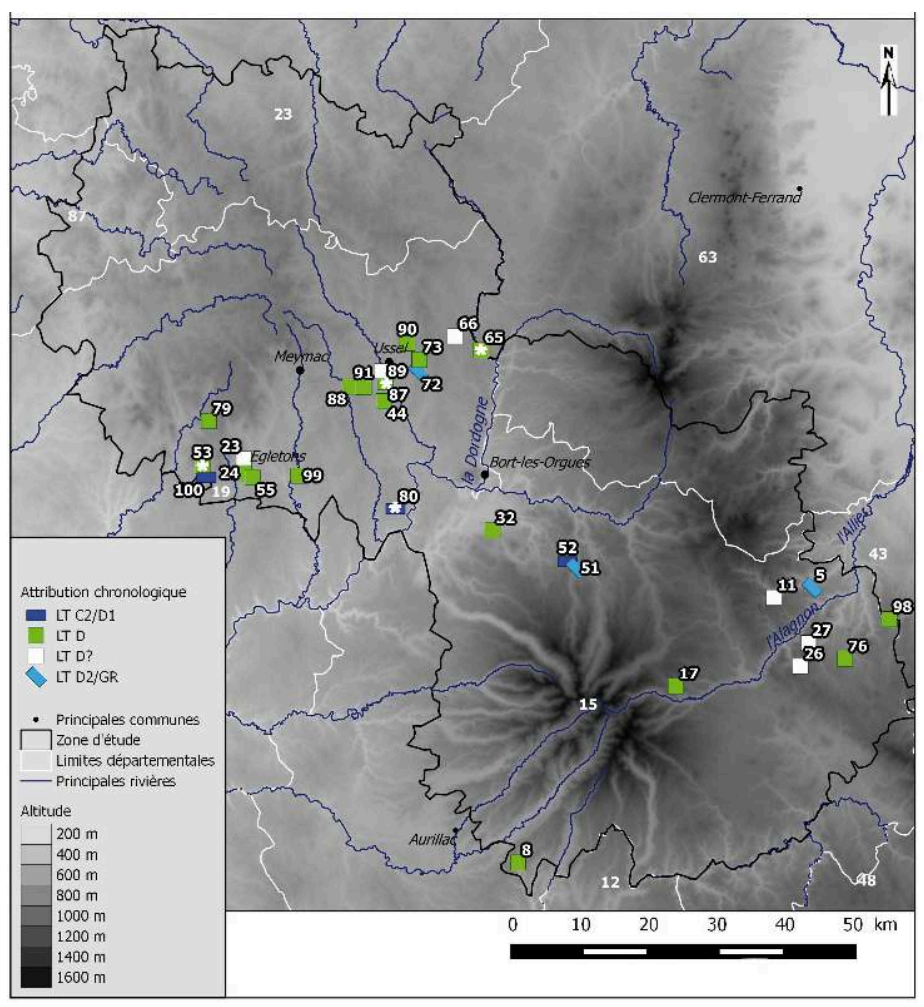

5 : Champ-Cairrat (Auriac-l'Église, Cantal). 8 : Roc de Carlat (Carlat, Cantal). 11 : Suc de Lermu (Charmensac, Cantal). 17 : Roc de Chastel (Chastel-sur-Murat, Cantal). 23, 24 : Naudou, Boulevard du Stade (Égletons, Corrèze). 26, 27 : plateau de Lusclade, La Peyre (Ferrières-Saint-Mary, Cantal). 32 Chastel-Marlhac (Le Monteil, Cantal). $\mathbf{4 4}$ : La Serre (Mestes, Corrèze). 51, $\mathbf{5 2}$ : Les Mazets, ZAC du Coudert (Riom-ès-Montagnes, Cantal). 53, $5 \mathbf{5}$ : Pont-Maure, Tra Le Bos (Rosiers-d'Égletons, Corrèze). 65, 66 : Camp de Fontjaloux, Le Fort (Saint-Étienne-aux-Clos, Corrèze). 72, 73 : La Croix Rouge, Champ-Derrière-la-Grange (Saint-Fréjoux, Corrèze). $\mathbf{7 9}$ : Commerly (Saint-Yrieix-le-Déjalat, Corrèze). 80 : La Moutte (Sérandon, Corrèze). 87, 88, 89, 90, 91 : Camp de Charlat, La Vergne des Soirs, Les Salles, Saint-Dézery, L'Estrade (Ussel, Corrèze). 98 : Rougeadit (La Chapelle-Laurent, Cantal). 99 : Le Châtelet (Lamazière-Basse, Corrèze). 100 : Bernotte 2 (Rosiers-d'Égletons, Corrèze).

PAO Florie-Anne Auxerre-Géron (logiciel SIG QGIS), fond SRTM, NASA/JPL-Caltech/National Geospatial Intelligence Agency. 
Fig. 10. - Sites corréziens de Pont-Maure (Rosiers-d'Égletons) et La Moutte (Sérandon) : plans des enclos quadrangulaires.

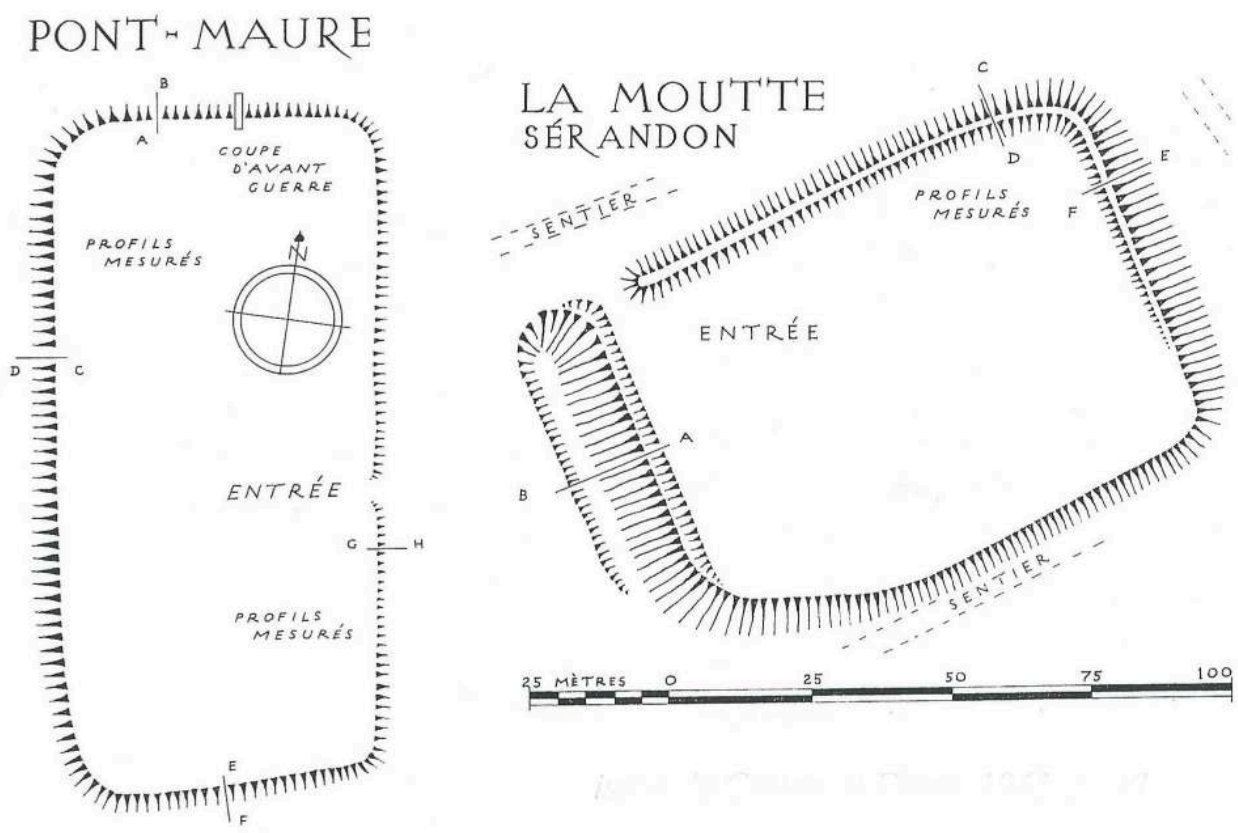

Extrait de Cotton et Frere 1961, p. 47

\section{Le Camp de Fontjaloux (Saint-Étienne-aux-Clos)}

$\mathrm{Au}$ nord des hauts plateaux corréziens (fig. 9, $\mathrm{n}^{\circ}$ 65), surplombant le Chavanon, affluent de la Dordogne, le Camp de Fontjaloux est un vaste éperon barré d'une surface plane avoisinant 2,5 hectares, situé à 700 mètres d'altitude (fig. 11 a).

Fig. 11. - Contexte topographique des sites de hauteur de haute Corrèze mentionnés dans l'article.

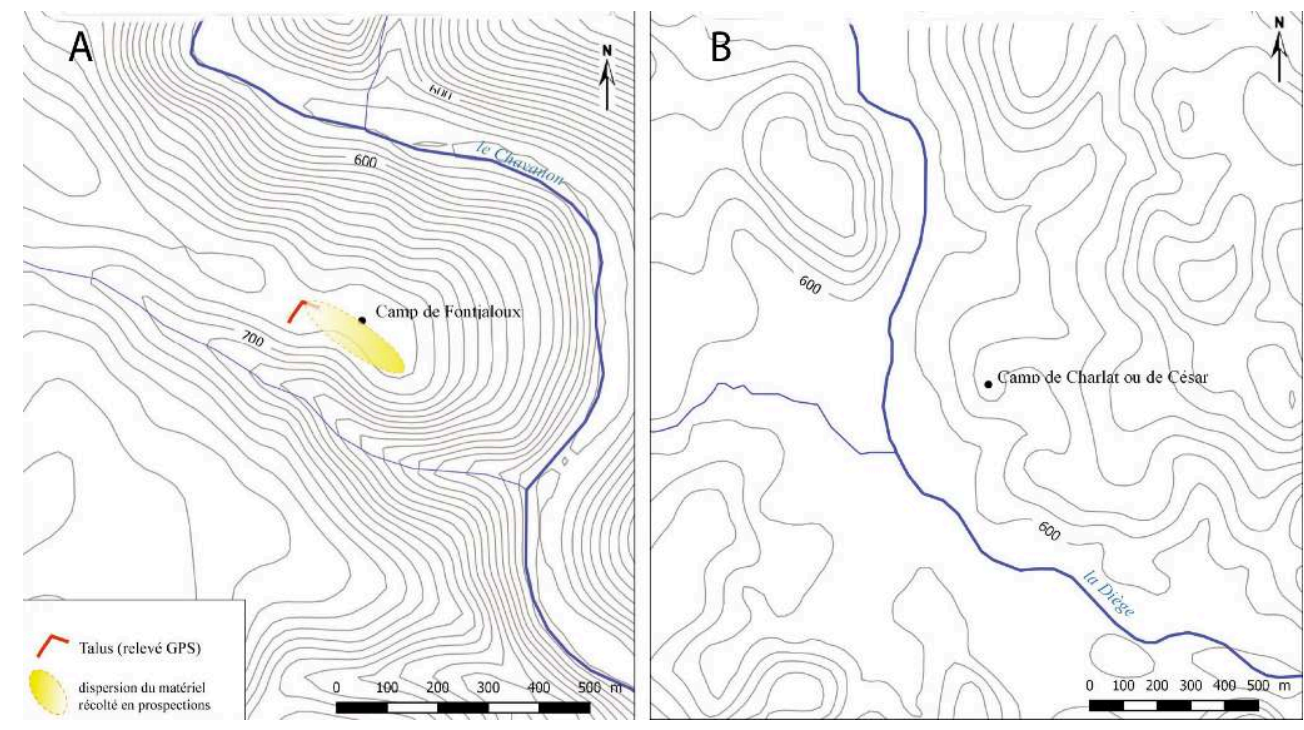

A : site du Camp de Fontjaloux (Saint-Étienne-aux-Clos, Corrèze). B : site du Camp de Charlat (Ussel, Corrèze).

PAO Florie-Anne Auxerre-Géron (logiciel SIG QGIS), fond de carte issu du modèle numérique de terrain, pas $25 \mathrm{~m}$. 
a d'abord été décrit par M. Vazeilles en 1954, qui mentionnait alors la présence d'un haut vallum conservé sur 30 mètres et haut de 4 à 5 mètres côté extérieur (Vazeilles, 1954). L'attribution à la Protohistoire a souvent été avancée, sans pour autant que des découvertes aient été faites en ce sens (seule une fiche en fer, dont le calibre rappelle celles utilisées dans les remparts de type murus gallicus, a été découverte il y a une quinzaine d'années; information Patriarche). Une prospection en mai 2015 a permis de récolter un peu de mobilier, laissant envisager effectivement une occupation à la fin de La Tène, mais aussi probablement une phase de fréquentation plus ancienne, à placer soit au Bronze final, soit au cours du premier âge du Fer. Le potentiel du site est réel, et de nouvelles prospections accompagnées de sondages pourraient permettre d'éclairer les différentes phases d'occupations perçues à travers le matériel, rare certes, mais assez varié (fragments d'amphores, tessons de céramique, dont l'un présente un décor de cordon torsadé rapporté ; Auxerre-Géron 2015a).

\section{Oppidum de Charlat (Ussel)}

Le site du Camp de Charlat à Ussel (fig. 9, $\mathrm{n}^{\circ}$ 87) est un site de hauteur avec fortification, le seul daté à ce jour dans la fenêtre d'étude corrézienne. Placé en rebord de plateau, il domine légèrement les alentours, le dénivelé des pentes n'étant pas très élevé (fig. 11 b). Il surplombe le cours de la Diège, et la surface totale disponible est modeste $(1,4$ ha). Le site est barré au sud par un rempart, assez massif puisque large de 7 mètres et haut de 4 à 5 mètres, qui a été sondé en 1957 dans sa partie occidentale. Les différents sondages ont permis de mettre en évidence que ce rempart principal présente, au moins dans sa partie occidentale, les caractéristiques du murus gallicus. Un deuxième rempart, qualifié de défense secondaire, a été documenté au nord-est du site : haut de 2 mètres, il est composé d'un noyau de pierres couvertes de sable et d'un parement en pierres sèches. Le matériel mis au jour atteste d'une fréquentation du site au cours de La Tène $\mathrm{D}$, et parmi les amphores, un bord semble plutôt caractéristique des Dressel 1B, et oriente donc plutôt vers la fin de la période. Un tesson de campanienne A se trouvait dans le rempart de pierre, ce qui permet de situer l'érection du système défensif au plus tard au tournant des $\mathrm{II}^{\mathrm{e}}$ et $\mathrm{I}^{\mathrm{er}}$ siècles av. n. è. Le Camp de Charlat est donc sans doute un site que l'on peut qualifier d'oppidum, au pied duquel plusieurs indices d'occupations témoignent d'une implantation assez conséquente dans le bassin d'Ussel.

\section{Organisation et genèse du réseau de communication à La Tène finale en territoire lémovice, sur les contreforts du plateau de Millevaches}

Le secteur des hauts plateaux corréziens, situés sur les contreforts sud-est du plateau de Millevaches, a la particularité de compter de nombreux sites de la fin de La Tène, implantés dans des contextes différents (plateau, rebord de plateau, mais aussi bassin) et présentant aussi des caractéristiques différentes. Ces sites sont, bien évidemment au vu de la topographie de la fenêtre d'étude, compris dans une fourchette altitudinale assez resserrée et basse, entre 600 et 685 mètres. En observant la position topographique relative, c'est-à-dire le positionnement par rapport à l'environnement direct, il apparait que la plupart de ces indices d'habitats sont en position presque neutre, c'est-à-dire ni dominée ni dominante, ou quelquefois en position très peu 
dominante. Les sites de La Moutte et du Pont-Maure, mentionnés plus haut, sont localisés tous deux dans un contexte largement plan (plateau d'altitude) et ne dominent pas les environs. Même l'oppidum de Charlat ne se démarque pas par un positionnement particulièrement dominant.

Concernant les expositions de ces sites, il s'avère qu'ils sont installés sur des terrains majoritairement orientés à l'est et à l'ouest. L'exposition sud est également recherchée; en revanche, le nord est très peu représenté, ce qui est certainement significatif : pour comparaison, en Limousin d'une manière générale, des études ont mis en évidence que «l'habitat rural d'origine antique est presque toujours implanté [...] face au sud-est, au sud ou au sud-ouest » (Desbordes 1997: p. 15). Il en est de même pour l'habitat d'origine médiévale, tandis que les expositions vers le nord sont quasiment inexistantes, et ce pour des raisons climatiques évidentes. Ces éléments permettent d'envisager que ces installations étaient essentiellement tributaires d'activités agropastorales, sans doute non saisonnières, comme le montrent les études paléoenvironnementales d'une part, et le matériel mis au jour sur certains sites d'autre part : présence de matériel de mouture, notamment sur le site de Tra le Bos, à Rosiersd'Égletons (Vial 2011).

Comme pour le Cantal, la rugosité du terrain en fonction des pentes a été modélisée, afin d'observer les conditions de circulation entre ces sites. Les cheminements les plus faciles à emprunter ont ainsi pu être calculés. En figurant tous ces cheminements, un maillage assez serré apparait (fig. 12) : des voies de passage naturelles apparaissent clairement comme incontournables, dont un axe entre les actuelles villes d'Ussel et Égletons, qui se présente comme un passage entre les vallées encaissées au sud-est et la "Montagne limousine» à proprement parler, au nord-ouest. En nous intéressant uniquement aux cheminements entre les sites remarquables, quelques observations intéressantes peuvent être faites. Ainsi, pour relier le site du Pont Maure à celui du Camp de Fontjaloux (fig. 12, $\mathrm{n}^{\text {os }} 53$ et 65 ), le passage le plus aisé se fait notamment au sud de l'oppidum de Charlat (fig. 12, $\mathrm{n}^{\circ}$ 87). Sur cette commune, il passe de plus à proximité de quelques indices d'occupation mis au jour à l'occasion de sondages (Toledo I Mur et al. 1997). Le tracé passe également au sud de la commune actuelle d'Égletons, où des indices d'occupations datés due La Tène $\mathrm{D}$ sont également connus. 
Fig. 12. - Cheminements théoriques entre les sites remarquables de La Tène finale des hauts plateaux corréziens et tracé de la voie gallo-romaine.

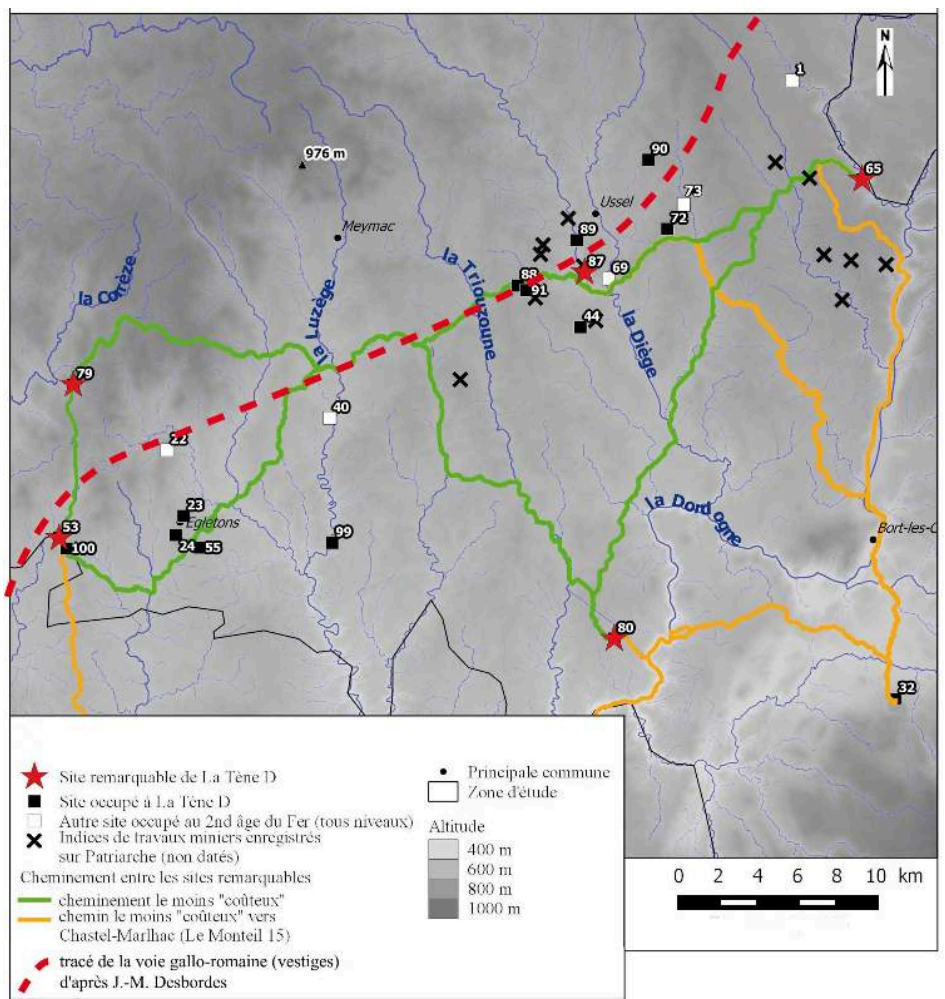

1 : Bergères-Barricades (Aix, Corrèze). 23 et $\mathbf{2 4}$ : Naudou, boulevard du Stade (Égletons, Corrèze). 32 Chastel-Marlhac (Le Monteil, Cantal). $\mathbf{4 0}$ : La Forêt (Maussac, Corrèze). $\mathbf{4 4}$ : La Serre (Mestes,

Corrèze). 53, 55 : Pont-Maure, Tra Le Bos (Rosiers-d'Égletons, Corrèze). 65 : Camp de Fontjaloux, (Saint-Étienne-aux-Clos, Corrèze). 69 : Entraygues (Saint-Exupéry-les-Roches, Corrèze). 72 et 73 : La Croix Rouge et Champ-Derrière-la-Grange (Saint-Fréjoux, Corrèze). 79 : Commerly (Saint-Yrieix-leDéjalat, Corrèze). $\mathbf{8 0}$ : La Moutte (Sérandon, Corrèze). 87, 88, 89, 90, 91 : Camp de Charlat, La Vergne des Soirs, Les Salles, Saint-Dézery, L'Estrade (Ussel, Corrèze). 99 : Le Châtelet (Lamazière-Basse, Corrèze), 100 : Bernotte 2 (Rosiers-d'Égletons, Corrèze).

PAO Florie-Anne Auxerre-Géron (logiciel SIG QGIS), fond SRTM, NASA/JPL-Caltech/National Geospatial Intelligence Agency.

Ces proximités ne sont sans doute pas une coïncidence, et il semble que l'habitat s'est bien installé et conforté en fonction des voies de passage naturelles, sans doute empruntées depuis le premier âge du Fer au regard des données par ailleurs disponibles pour cette période (Auxerre-Géron 2017). Cet axe de circulation naturel, orienté nordest/sud-ouest, entre les Combrailles auvergnates - et donc, plus largement, le bassin hydrographique de la Loire - et la Corrèze calcaire, ouvrant sur le bassin hydrographique de la Garonne, est par la suite emprunté par la voie romaine reliant Clermont-Ferrand à Bordeaux (Chevallier 1997, Dacko 2016). L'hypothèse que les axes de circulations laténiens aient servi d'ossature au réseau viaire gallo-romain est avancée dans plusieurs cités (Kasprzyk et Nouvel 2010, Dacko 2016), et le cas d'étude des hauts plateaux corréziens permet d'illustrer l'importance du facteur topographique dans la mise en place de ces itinéraires.

Enfin, en considérant la multitude des indices d'établissements ruraux connus pour la fin de l'âge du Fer, le maillage de site apparaît finalement comme assez dense et semble bien répondre à la pression anthropique plus forte perçue à cette période dans les tourbières du plateau de Millevaches (Miras 2004). On remarquera pour terminer que les deux seuls sites de hauteur localisés à Saint-Étienne-aux-Clos et Ussel, le Camp de 
Fontjaloux et l'oppidum de Charlat, sont distants d'un peu plus de 20 kilomètres, soit 5 heures et 10 minutes de marche pour un piéton, et moins d'une journée pour un animal attelé. Ces chiffres se rapprochent notamment de l'espacement mis en évidence entre les oppida de Bohème (Salač 2013).

\section{Conclusion}

Par le biais d'une approche spatiale, les premières esquisses de dynamique d'occupation dans l'ouest du Massif central à la Protohistoire peuvent aujourd'hui être proposées, et en particulier entre le Bronze moyen et La Tène ancienne pour la HauteAuvergne, alors que l'habitat de ce secteur était jusqu'ici peu étudié. La disposition des sites de hauteur n'apparaît pas comme anodine : elle s'appuie sur des voies de passages naturelles, plus ou moins utilisées au cours du temps, et un maillage régulier du territoire se dessine tout particulièrement au Bronze final 3.

À cette période, le développement des habitats concentrés et défendus montre que la Haute-Auvergne ne se différencie pas du reste de la région, de la France et de l'Europe. Cette caractéristique atteste d'une intégration de ces territoires de moyenne montagne dans des schémas d'occupation classiques, et donc qu'ils n'étaient en aucun cas en marge. Les données matérielles vont d'ailleurs dans le sens de cette parfaite intégration, les échanges avec le sud de la France notamment transparaissant dès le Bronze moyen sur le site du Roc de Chastel, mais aussi au début du second âge du Fer, comme le suggère la présence de céramique à pâte claire peinte sur plusieurs sites.

51 En "Montagne limousine ", en revanche, l'occupation au cours de l'âge du Bronze apparaît encore comme morcelée et ses modalités sont aujourd'hui difficilement appréhendables, du fait du manque de recherches. C'est à partir du premier âge du Fer qu'un signal archéologique plus net se lit, et une occupation, en lien notamment avec une voie de circulation naturelle, semble se mettre en place. Elle se confirmera tout particulièrement à la fin de La Tène.

\section{BIBLIOGRAPHIE}

AUXERRE-GÉRON F.-A., 2015a, « Prospection-inventaire thématique : les sites d'habitat supposés protohistoriques de Haute-Corrèze, communes de Bugeat, Chaumeil, Darnets, Davignac, Maussac, Meymac, Saint-Angel, Saint-Etienne-aux-Clos, Sérandon, Tarnac », Limoges, Service régional de l'archéologie du Limousin.

AUXERRE-GÉRON F.-A., 2015b, « Prospection thématique, sondage archéologique : site de hauteur de Chastel-Marlhac, commune du Monteil (15) », Clermont-Ferrand, Service régional de l'archéologie d'Auvergne.

AUXERRE-GÉRON F.-A., 2017, « L’Homme et la moyenne montagne durant la Protohistoire dans le Massif central : enquête en Haute-Auvergne et Limousin ", thèse de doctorat, Toulouse, université Toulouse - Jean Jaurès. 
AUXERRE-GÉRON F.-A., COUDERC F., DELRIEU F., 2017, « Les habitats de hauteur occupés au Hallstatt D3 et La Tène A en Auvergne : données récentes ", Bulletin de l'Association française pour l'étude de l'âge du Fer, $\mathrm{n}^{\circ} 35$, p. 17-22.

BOUILLET J.-B., 1834, Description historique et scientifique de la Haute-Auvergne (département du Cantal), suivi d'un tableau alphabétique des roches et des minéraux et accompagné d'un atlas de 35 pl., gravures et lithographie, Paris, J.-B. Baillière.

CHEVALLIER R., 1997, Les voies romaines, Paris, Picard.

COTTON A. et FRERE S., 1961, "Enceintes de l'âge du Fer au pays des Lémovice », Gallia, vol. 19, nº 1, p. 31-54.

DAСКо M., 2016, « Circuler dans le Massif central à l'époque romaine : réseaux, infrastructures et équipements routiers. Le cas des cités arverne et vellave ", thèse de doctorat, Clermont-Ferrand, université Blaise Pascal - Clermont II.

DAUGAS J.-P., 1976, « Les civilisations de l'âge du Bronze dans le Massif central », dans Guilaine J. (dir.), La Préhistoire française, Paris, CNRS Éditions, p. 506-522.

DAUGAS J.-P., MARS M., SABATIER L., THOMAS A., VINATIÉ A., 1982, « Archéologie et remembrement parcellaire : commune de Charmensac », Revue de la Haute-Auvergne, $\mathrm{n}^{\circ} 48$, octobre-décembre, p. 587-614.

DELRIEU F., 2000, « Étude spatiale et caractérisation des tertres funéraires protohistoriques du nord-est du Cantal », mémoire de maîtrise, Clermont-Ferrand, université de Clermont-Ferrand.

DELRIEU F., 2006, « Le tumulus de Fô-est à Menet : une incinération du début du I I $^{\text {r }}$ age du Fer sur le versant nord du Cantal ", Revue de la Haute-Auvergne, $n^{\circ}$ 68, p. 403-426.

DELRIEU F. et MILCENT P.-Y., 2012, « Les paysages tumulaires protohistoriques dans le Massif central (France) : les exemples du Cézallier et du Causse Noir ", dans Bérenger D., Bourgeois J., Talon M., Wirth S., Paysages funéraires de l'âge du Bronze : actes du Colloque international sur l'âge du Bronze (Herne, 15-18 octobre 2008), Darmstadt, P. von Zabern (Bodenaltertümer Westfalens, 51), p. 23-57.

DESBORDES J.-M., 1997, L'archéologie du paysage rural en Limousin, Limoges, Association des antiquités historiques du Limousin.

GOMEZ DE SOTO J., 1995, L’Âge du Bronze en France, vol. 5 : Le Bronze moyen en Occident, Paris, Picard.

GOMEZ DE SOTO J., KÉROUANTON I., MARCHADIER É., 2009, « La transition du Bronze final au Premier Âge du Fer (XIII ${ }^{\mathrm{e}}$-VII ${ }^{\mathrm{e}}$ siècle av. J.-C.) dans le centre-ouest de la France et sur ses marges ", dans Roulière-Lambert J., Daubigney A., Milcent P.-Y., Talon M., Vital J. (dir.), De l'âge du Bronze à l'âge du Fer en France et en Europe occidentale ( $X^{e}-V I I^{e}$ siècle av. J.-C.) : actes du $30^{e}$ Colloque international de l'AFEAF (Saint-Romain-en-Gal, 26-28 mai 2006), Besançon, Société archéologique de l'Est (Revue archéologique de l'Est, supplément 27), p. 267-282.

HERNANDEZ O., LÉGER P., VUAILLAT D., 1989, « Le Limousin à l'âge du Bronze : recensement synthétique des découvertes et première approche métallogénique », Revue archéologique du centre de la France, vol. 28, $\mathrm{n}^{\circ}$ 1, p. 55-76.

KASPRZYK M. et NOUVEL P., 2010, « Du Val de Saône au nord-ouest de la Gaule : le passage du Morvan de la fin de la Protohistoire au haut Moyen Âge », dans Le Bihan J.-P. et Guillaumet J.-P. (dir.), Routes du monde et passages obligés de la Protohistoire au haut Moyen Âge : actes du colloque international (Ouessant, 27-28 septembre 2007), Quimper, Centre de recherche archéologique du Finistère, p. 223-251. 
MENNESSIER-JOUANNET C. et DEBERGE Y., 2017, Chronologie du mobilier archéologique du second âge du Fer en Auvergne, vol. 1 : Monographies des ensembles de référence, Tours, Revue archéologique du centre de la France (suppl. 65).

MENNESSIER-JOUANNET C. et MILCENT P.-Y., 2007, « L'occupation du sol en basse Auvergne du Bronze final à la fin de La Tène ancienne », dans Mennessier-Jouannet C. et Deberge Y. (dir.), L'archéologie de l'âge du Fer en Auvergne : actes du $27^{e}$ colloque de l'Association française pour l'étude de l'âge du Fer (Clermont-Ferrand, mai-juin 2003), Lattes, Association pour le développement de l'archéologie en Languedoc-Roussillon (Monographie d'archéologie méditerranéenne), p. 71-98.

MILCENT P.-Y., 2004, Le premier âge du Fer en France centrale, Paris, Société préhistorique française (Mémoire de la Société préhistorique française, 34).

MILCENT P.-Y. et DELRIEU F., 2007, « Tertres et archéologie funéraire en Haute-Auvergne dans le contexte du premier âge du Fer en Gaule méridionale (vIII $-\mathrm{V}^{\mathrm{e}}$ s. av. J.-C.) », dans MennessierJouannet C. et Deberge Y. (dir.), L'archéologie de l'âge du Fer en Auvergne : actes du XXVII colloque de l'Association française pour l'étude de l'âge du Fer (Clermont-Ferrand, 29 mai-1 ${ }^{\text {er }}$ juin 2003), Lattes, Association pour le développement de l'archéologie en Languedoc-Roussillon (Monographies d'archéologie méridionale), p. 43-70.

MiLLOTTE J.-P., 1959, « Essai sur les relations entre l'est et l'ouest de la France aux âges des métaux », Ogam, n 11, p. 131-154.

MIRAS Y., 2004, « L'analyse pollinique du plateau de Millevaches (Massif central, France) et de sites périphériques limousins et auvergnats : approche des paléoenvironnements, des système agropastoraux et évolution des territoires ruraux ", thèse de doctorat, Besançon, université de Franche-Comté.

MIRAS Y. et GUENET P., 2013, « Une histoire plurimillénaire des paysages du Cézallier et ses liens avec les activités agrosylvopastorales depuis le Néolithique à partir de l'analyse pollinique de la tourbière de La Borie (1 170 m, Saint-Saturnin, Cantal) », dans Trément F. (dir.), Les Arvernes et leurs voisins du Massif central à l'époque romaine : une archéologie du développement du territoire, vol. 1 , Clermont-Ferrand, Société des amis des universités de Clermont-Ferrand (Revue d'Auvergne), p. 481-497.

OLIVIER L., WIRTZ B., TRIBOULOT B., 2002, « Assemblages funéraires et territoires dans le domaine hallstattien occidental », dans Garcia D. et Verdin F. (dir.), Territoires celtiques : espaces ethniques et territoires des agglomérations protohistoriques d'Europe occidentale. Actes du $24^{e}$ Colloque de l'AFEAF, Paris, Errance, p. 338-362.

PAGÈS-ALLARY J., 1908, « Notes de fouilles à Chastel-sur-Murat », Bulletin de la Société préhistorique française, $\mathrm{n}^{\circ}$ 5, p. 474-493.

PRovost M. et VAllat P., 1996, Carte archéologique de la Gaule : le Cantal, Paris, Académie des inscriptions et belles-lettres.

RAMES J.-B., 1872, « Découverte d'épées en bronze à Aliès (Cantal) », Revue archéologique, $\mathrm{n}^{\circ} 24$, p. 337-338 et pl. XXV.

SAINT-SEVER G., 2014, « De la production à l'utilisation des poteries de l'âge du Bronze final : dynamiques inter-régionales et évolutions locales en Quercy et Basse Auvergne ", thèse de doctorat, Toulouse, université Toulouse II - Le Mirail.

SALAČ V., 2013, « De la vitesse des transports à l'âge du Fer », dans Colin A. et Verdin F. (dir.), L'âge $d u$ Fer en Aquitaine et sur ses marges : actes du 35e colloque de l'AFEAF (Bordeaux, 2-5 juin 2011), Bordeaux, Fédération Aquitania (Aquitania, supplément 30), p. 489-512. 
TIXIER L., 1984, «L'activité pastorale dans les massifs volcaniques de l'Auvergne des temps protohistoriques au Moyen Âge ", dans Élevage et vie pastorale dans les montagnes d'Europe au Moyen Âge et à l'époque moderne: actes du colloque international, Clermont-Ferrand, Institut d'études du Massif central, p. 185-202.

TOledo i MUR A., CABEZUelo U., Milor F., CHEVReUSE F., TEXIER P., TERNON M., 1997, « A89 Ussel (19) Saint-Julien-Puy-Lavèze (63) : document final de synthèse de sondages et d'évaluation ", Limoges, AFAN/Service régional de l'archéologie du Limousin.

VAZEILLES M., 1954, « Enceintes, camps et stations antiques fortifiées en Haute et Moyenne Corrèze ", Bulletin de la Société des lettres, sciences et arts de la Corrèze, $\mathrm{n}^{\circ}$ 58, p. 23-28.

VIAL J., 2011, « Fouille préventive du site de Tra le Bos à Rosiers d'Égletons », Limoges, Service régional de l'Archéologie du Limousin.

VITAL J., 2004, « L'âge du Bronze moyen sur le roc de Chastel-sur-Murat », Revue de la HauteAuvergne, $\mathrm{n}^{\circ}$ 66, p. 299-316.

VITAL J., 2014, « La chronologie céramique du Bronze ancien et moyen du Massif central aux Alpes », dans Sénépart I., Leandri F., Cauliez J., Perrin T., Thirault É. (dir.), Chronologie de la préhistoire récente dans le sud de la France : actualité de la recherche: actes des $10^{e}$ Rencontres méridionales de préhistoire récente (Porticcio, 18-20 octobre 2012), Toulouse, Archives d'écologie préhistorique, p. 221-238.

VITAL J. et BENAMOUR P., 2012, Économies, sociétés et espaces en Alpe : la grotte des Balmes à SollièresSardières, Savoie : du Néolithique moyen 2 à l'âge du Fer, Lyon, Alpara.

VON NICOLAI C., 2009, « La question des Viereckschanzen d'Allemagne du sud revisitée », dans Bertrand I., Duval A., Gomez De Soto J., Maguer P. (dir.), Habitats et paysages ruraux en Gaule et regards sur d'autres régions du monde celtique : actes du 31 colloque de l'AFEAF (Chauvigny, 17-20 mai 2007), Chauvigny, Association des publications chauvinoises, p. 245-280.

\section{RÉSUMÉS}

Le nord-ouest du Massif central est un terrain privilégié pour étudier l'occupation au cours de la Protohistoire dans un contexte de moyenne montagne. Au cours d'un doctorat, plusieurs sites de hauteur de Haute-Auvergne (Cantal, Auvergne-Rhône-Alpes) et de haute Corrèze (NouvelleAquitaine) ont fait l'objet de prospections, de sondages et d'études de mobilier. Pour l'âge du Bronze et le premier âge du Fer, des données inédites permettent de reconsidérer les modalités d'occupation de ces territoires. À l'aide d'analyses spatiales, les rythmes d'occupation de ces sites et leurs caractéristiques d'implantation ont été examinés. Des esquisses de dynamique d'occupation peuvent être proposées, en particulier entre le Bronze moyen et La Tène ancienne. Ainsi, la disposition des sites de hauteur n'apparaît pas comme anodine : elle s'appuie sur des voies de passages naturelles, plus ou moins utilisées au cours du temps, et un maillage régulier du territoire se dessine à certaines périodes.

The Northwestern area of Massif Central is a privileged ground for the study of Protohistoric human occupation in a mid-mountain context. For the purpose of a $\mathrm{PhD}$, many entrenched or hilltop settlements of Haute-Auvergne (Cantal, Auvergne-Rhône-Alpes) and of Haute-Corrèze (Nouvelle-Aquitaine) have been subjected to prospections, surveys, or studies of collections. For Bronze Age and Early Iron Age, new data are now available, and allow us to reconsider the occupation modalities of these territories. With spatial analyses, the occupation rhythms of these sites and their characteristics can be observed and discussed. The first drafts of occupation 
dynamics in western Massif Central during Protohistory can be proposed, especially between the Middle Bronze age and La Tene I for the Haute-Auvergne. Thus, the positioning of hilltop settlements doesn't appear as random: it is based on more-or-less used in time natural passage ways, and designs a regular territorial network in certain periods.

\section{INDEX}

Mots-clés : âge du Bronze, analyse spatiale, moyenne montagne, premier âge du Fer, site de hauteur, territoire

Keywords : hilltop settlement, mid-mountain, spatial analysis, territory, Bronze age Index géographique : Cantal, Corrèze, Massif central

\section{AUTEUR}

\section{FLORIE-ANNE AUXERRE-GÉRON}

Membre associée du laboratoire Travaux et recherches archéologiques sur les cultures, les espaces et les sociétés (TRACES, UMR 5608, université Toulouse - Jean-Jaurès/CNRS) 


\section{Peuplements et paysages anciens} dans les massifs du Morvan et du Jura : confrontation de données paléo-environnementales, historiques et archéologiques

Early peopling and landscapes in the Morvan and Jura Massifs: comparing paleoenvironmental, historical and archeological data

Valentin Chevassu, Émilie Gauthier, Pierre Nouvel, Hervé Richard, Vincent Bichet et Isabelle Jouffroy-Bapicot

Depuis les années 1990, le développement des analyses paléo-environnementales et les recherches archéologiques menées dans plusieurs régions de haute montagne ont démontré que les milieux d'altitude, bien que contraignants, n'en étaient pas moins occupés et exploités par l'Homme à toutes époques. Toutefois, dans de nombreux massifs de moyenne montagne, l'histoire des paysages et des structures de peuplement reste associée au postulat d'une colonisation tardive, datée de la période médiévale. Les données archéologiques et paléo-environnementales récentes permettant de dépasser cette vision ancienne, il convient d'étudier plus objectivement les spécificités de l'anthropisation en moyenne montagne et d'en identifier les causes anthropiques ou environnementales.

Les massifs du Morvan et du Jura bénéficient dans ce domaine d'un corpus de données riche de perspectives: analyses paléo-environnementales variées, prospections archéologiques récentes, textes médiévaux et modernes abondants. Ils constituent par conséquent de bons terrains pour étudier les dynamiques de l'occupation et de l'exploitation du milieu dans la longue durée. La mise en parallèle des deux massifs permet également d'évaluer de quelle manière se manifeste l'influence du milieu montagnard au sein de deux régions dissemblables. Il s'agit ainsi de dissocier les particularités régionales et les spécificités liées au milieu montagnard, voire de 
déterminer les facteurs environnementaux ou humains expliquant ces rythmes différents d'anthropisation. Nous présentons ci-dessous quelques éléments de méthodologie, suivis d'une première synthèse issue de la confrontation de ces données pluridisciplinaires, plus particulièrement exploitables à propos des périodes médiévales et modernes.

\section{Méthodologie et données utilisées}

\section{Les espaces étudiés}

3 Le massif jurassien forme un arc séparant les plaines de Saône du bassin suisse, caractérisé par une succession de plateaux appuyés sur une haute chaine plissée. Ces espaces sont actuellement morcelés en diverses circonscriptions territoriales, de part et d'autre de la frontière franco-suisse. Nous nous concentrerons ici sur une portion du Jura central français, qui forme la partie montagneuse du département du Doubs, autour de la ville de Pontarlier (fig. 1). Ce secteur comporte des plateaux caractérisés par une topographie assez plane et des altitudes comprises entre 400 et 900 mètres, ainsi qu'une partie de la haute chaîne, où le relief plissé varie de 800 à 1400 mètres d'altitude. Un accident de relief transversal, la cluse de Joux, constitue enfin un point de passage privilégié qui a polarisé de tout temps les circulations humaines.

Fig. 1. - Le Jura central pontissalien : localisation du secteur étudié et des études paléoenvironnementales.

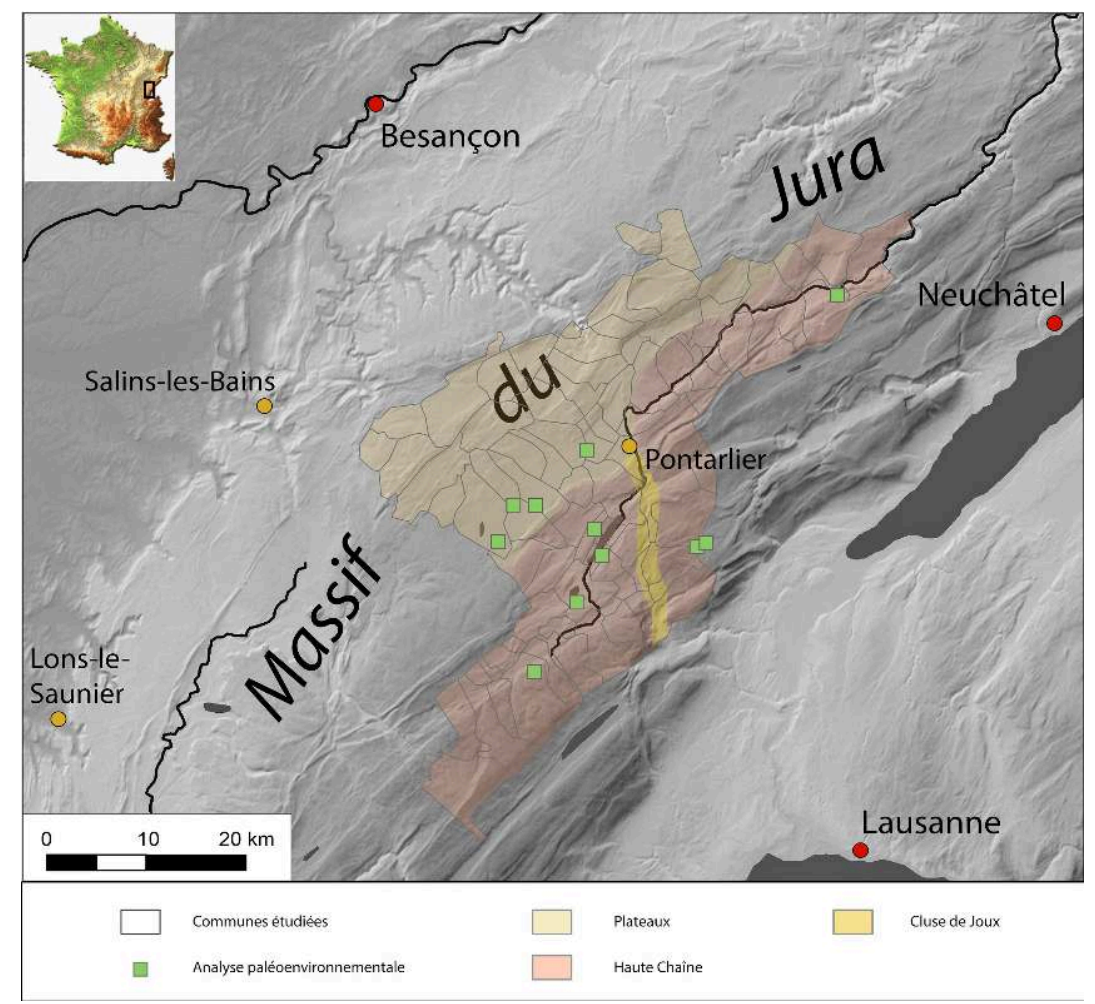

PAO Valentin Chevassu, fond de carte IGN 2017.

De l'autre côté du val de Saône, le Morvan forme un prolongement du Massif central au centre de la Bourgogne. Malgré des altitudes globalement modestes, la topographie et 
le climat du Morvan méridional présentent un réel caractère montagneux. C'est cette partie du massif qui a été prise en compte, autour des sites archéologiques majeurs de Bibracte et Autun, à la limite des départements de la Nièvre et de la Saône-et-Loire (fig. 2). Trois microrégions peuvent être distinguées : le haut Morvan, au relief encaissé culminant à 900 mètres; le Morvan collinéen, caractérisé par des vallées plus larges, entre 800 et 300 mètres d'altitude; et enfin les plaines et piémonts du bassin autunois et du val d'Arroux.

Fig. 2. - Le sud Morvan-Autunois, localisation du secteur d'étude, des études paléoenvironnementales et des microrégions : Autunois-val d'Arroux, Morvan collinéen, haut Morvan.

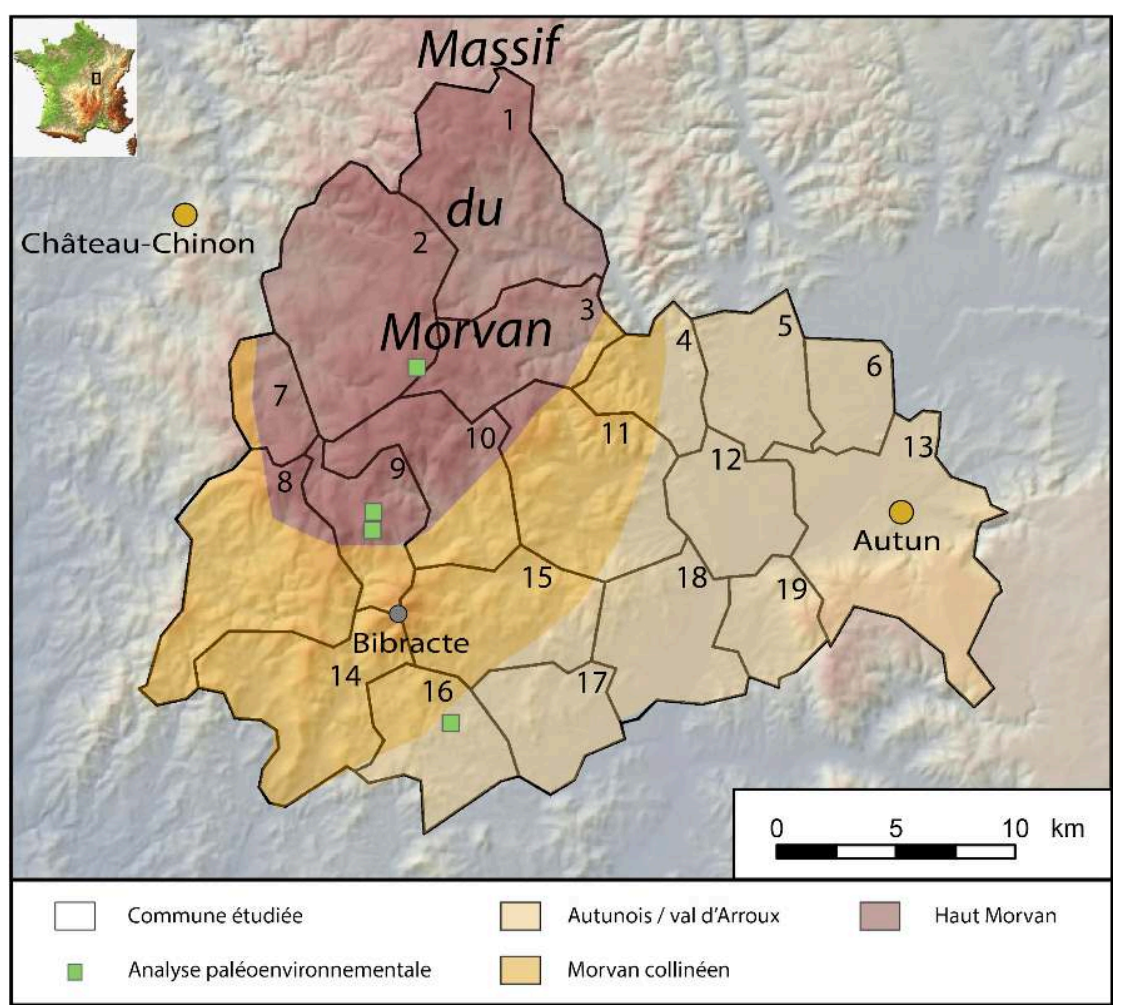

1 : Anost (Saône-et-Loire). 2 : Arleuf (Nièvre). 3 : Roussillon-en-Morvan (Saône-et-Loire). 4 : La Celle-enMorvan (Saône-et-Loire). 5 : Tavernay (Saône-et-Loire). 6 : Saint-Forgeot (Saône-et-Loire). 7 : Fâchin (Nièvre). 8 : Villapourçon (Nièvre). 9 : Glux-en-Glenne (Nièvre). 10 : Saint-Prix (Saône-et-Loire). 11 : La Grande-Verrière (Saône-et-Loire). 12 : Monthelon (Saône-et-Loire). 13 : Autun (Saône-et-Loire). 14 : Larochemillay (Nièvre). 15 : Saint-Léger-sous-Beuvray (Saône-et-Loire). 16 : Poil (Nièvre). 17 : La Comelle (Saône-et-Loire). 18 : Laizy (Saône-et-Loire). 19 : Brion (Saône-et-Loire).

PAO Valentin Chevassu, fond de carte IGN 2017.

5 Ces deux massifs, quoique nettement individualisés par rapport aux plaines environnantes, restent des montagnes aux altitudes moyennes et à la topographie assez peu accidentée. Ils sont soumis à des climats froids et très humides, qui ont pu s'avérer plus ou moins contraignants au fur et à mesure des variations climatiques anciennes. L'histoire de ces deux massifs, vus comme des milieux hostiles, a donc longtemps été construite autour du postulat d'un déboisement et d'un peuplement très tardif, principalement médiéval et moderne, censé expliquer les spécificités actuelles des paysages et de l'occupation humaine.

6 Toutefois, les deux régions ont également en commun d'avoir été documentées par de récentes recherches archéologiques et paléo-environnementales qui mettent en évidence l'ancienneté de l'occupation humaine et permettent de décrire son évolution 
dans la longue durée. Un troisième corpus d'informations s'ajoute à partir du haut Moyen Âge, grâce à la présence de nombreuses sources écrites inventoriées et publiées. Une nouvelle étude de l'anthropisation peut donc être envisageable, grâce à un travail de synthèse croisant ces trois sources d'informations complémentaires. La présence de jeux de données similaires dans les deux massifs permet par ailleurs d'envisager les réactions de différents espaces montagneux face à des rythmes d'évolution généraux. Il devient ainsi possible d'évaluer dans quelle mesure l'anthropisation présente des caractères spécifiques au sein de deux territoires de moyenne altitude liés à des contraintes naturelles, des cadres politiques et des potentialités économiques très divers.

\section{Les données utilisées}

7 Dans les deux massifs, l'activité de nombreux érudits locaux durant le $\mathrm{XIX}^{\mathrm{e}}$ siècle et le début $\mathrm{du} \mathrm{xx}^{\mathrm{e}}$ a laissé un premier corpus de données archéologiques. Cette documentation concerne principalement l'architecture religieuse et les sites fortifiés médiévaux, mais laisse de côté les occupations plus modestes et les zones d'altitude. L'archéologie préventive apporte assez peu d'informations supplémentaires dans ces secteurs, où les aménagements de grande ampleur restent rares. Notre connaissance de l'évolution du peuplement repose donc essentiellement sur plusieurs travaux bénévoles de prospection débutés dans les années 1980-1990, suivis et largement complétés par deux programmes de prospection et d'inventaire diachroniques. Les recherches menées sur 18 communes du sud Morvan se basent ainsi sur un inventaire des découvertes anciennes, complété par une prospection systématique des parcelles labourées et pâturées (coord. P. Nouvel). Elles ont abouti entre 2008 à 2018 à l'identification de plus de 300 points d'occupations anciennes datées entre la Préhistoire et la période moderne (Nouvel et al. 2016). Débutées en 2015, les prospections diachroniques sur le Jura central se sont appuyées sur l'exploitation de relevés LiDAR réalisés depuis 2010 par diverses collectivités territoriales, ainsi que sur le récolement des résultats de diverses prospections d'amateurs (coord. M. Thivet puis V. Bichet, H. Richard, V. Chevassu). Ces travaux ont pour le moment permis de repérer des voies anciennes, de nombreux sites d'exploitation des matières premières ainsi que quelques habitats et sites défensifs protohistoriques, antiques, altomédiévaux et modernes (Bichet et al. 2017).

8 Ces informations archéologiques peuvent être mises en relation avec l'évolution de la végétation ancienne grâce à un corpus d'analyses paléo-environnementales récentes. Le sud du Morvan est ainsi documenté par quatre analyses palynologiques intégrant ponctuellement la caractérisation des microfossiles non polliniques et des paléopollutions métallurgiques (Jouffroy-Bapicot 2010). La région du Jura central a, quant à elle, fait l'objet d'une quinzaine d'études paléo-environnementales entre 1980 et aujourd'hui. Les analyses les plus récentes utilisent des approches multiparamètres et des échantillonnages à haute résolution susceptibles de nombreux croisements avec les sources historiques et archéologiques (Gauthier 2004, Gauthier et Richard 2006, Leroux 2010, Murgia 2016).

9 Les deux massifs sont enfin concernés par un important lot d'archives médiévales et modernes, même si le haut Moyen Âge reste faiblement documenté si on le compare aux régions voisines. À partir des VIII $^{\mathrm{e}}$ et IX ${ }^{\mathrm{e}}$ siècles et jusqu'au XIII ${ }^{\mathrm{e}}$ siècle, les archives des évêchés, des grands monastères et des principaux lignages féodaux fournissent de 
nombreuses informations, qui se limitent toutefois à l'appréhension des possessions seigneuriales. La majeure partie de cette documentation a été transcrite et compilée grâce aux érudits des $\mathrm{XIX}^{\mathrm{e}}$ et $\mathrm{xx}^{\mathrm{e}}$ siècles et à quelques travaux universitaires récents. Après le XIv ${ }^{e}$ siècle, la documentation se précise et s'enrichit de nombreux documents liés à la gestion des grandes seigneuries par les ducs de Bourgogne dans le Morvan et la famille de Chalon-Arlay dans le Jura central. Elle permet alors une compréhension plus exhaustive des structures de peuplement et d'exploitation du territoire, complétée ensuite par les premiers travaux cartographiques des XVII et $\mathrm{XVIII}^{\mathrm{e}}$ siècles. On pourra enfin déplorer un manque d'études sur la foisonnante documentation du début de la période moderne, principalement abordée par le biais des inventaires d'archives.

\section{Traitement des informations}

Malgré la qualité et l'abondance de ces informations, il reste difficile d'intégrer à une même analyse des données qui se réfèrent à des chronologies et à des superficies géographiques très variées. Ainsi, la zone pollinique documentée par le palynologue donne une indication sur l'état de la végétation durant une période comprise entre quelques dizaines d'années et plusieurs siècles, selon la résolution de l'analyse, pour un espace plus ou moins vaste en fonction de la zone humide étudiée. Le signalement de vestiges archéologiques va démontrer la présence d'un ou plusieurs types d'occupations et d'activités humaines en un point géographique précis, mais pour une période plus ou moins longue, la datation pouvant également être d'une précision très variable. Enfin, un document d'archive, daté à l'année, peut contenir un ensemble d'informations variées, relatives à différents points géographiques, souvent précis mais parfois non localisés.

11 Par ailleurs, les données recueillies comprenant à la fois des découvertes anciennes et des travaux très récents, leur précision et leur fiabilité très variables restreignent les possibilités d'analyse. Les informations collectées dans la base de données se voient donc attribuer des descripteurs et un indice chiffré, associés à la qualité de l'information, permettant par exemple de différencier, pour des témoins archéologiques, une découverte fortuite mentionnée au XIX ${ }^{e}$ siècle et un site décrit par une fouille exhaustive. Les documents d'archives sont évalués de la même manière, en fonction de la connaissance du texte original (cité, mentionné dans un inventaire, transcrit de manière partielle ou intégrale), de même que les séquences polliniques, selon les paramètres de l'étude qui en a été faite (fréquence de l'échantillonnage, précision du modèle d'âge, types d'analyses appliqués à la séquence).

12 L'intégration à une même base de données suppose ensuite de décomposer ces informations diverses en éléments qui puissent être confrontés les uns aux autres. Chaque information est ainsi associée à une aire ou un point géolocalisé, de manière à pouvoir être intégrée dans un système d'information géographique (SIG). Des fourchettes chronologiques communes ont également été définies (siècles et phases chronologiques). Il devient alors possible de cartographier systématiquement les données dont l'on dispose concernant l'occupation et l'exploitation d'un territoire durant une période définie. Cela permet d'abord d'évaluer la répartition et la pertinence des informations disponibles pour documenter les différents aspects de l'anthropisation, ensuite de donner un aperçu des formes de l'occupation ancienne et 
de tester les corrélations entre les données paléo-environnementales, écrites et archéologiques.

De fait, des incohérences apparaissent au sein de cet ensemble de données, l'occupation humaine étant perçue de manière très différente selon les informations utilisées. Ainsi, dans le sud du Morvan, les indices archéologiques d'occupation se raréfient subitement entre le $\mathrm{IV}^{\mathrm{e}}$ et le $\mathrm{x}^{\mathrm{e}}$ siècle. Cela suggère une potentielle désertion du secteur, apparemment confirmée par le très faible nombre de mentions textuelles concernant la région avant le $\mathrm{XI}^{\mathrm{e}}$ siècle. Les analyses paléo-environnementales attestent au contraire d'activités agropastorales d'intensité égale durant toute la période altomédiévale, sans recul perceptible par rapport à la période antique. La difficulté de repérer des établissements altomédiévaux dans le cadre de prospections pédestres, ainsi que la piètre connaissance des productions céramiques de cette période dans l'AutunoisMorvan, paraissent donc expliquer cette apparente raréfaction des occupations humaines. À l'inverse, dans la seconde moitié $\mathrm{du} \mathrm{XVI}{ }^{\mathrm{e}}$ siècle, les troubles militaires liés aux guerres de Religion sont suivis par de nombreux cas de désertion et d'enfrichement mentionnés dans les textes, tandis que l'archéologie montre sur plusieurs sites des épisodes de destruction ou de mise en défense. Cette crise, peut-être trop ponctuelle chronologiquement ou géographiquement, n'est pourtant jamais visible dans les diagrammes polliniques concernant la région (Jouffroy-Bapicot et al. 2013). Outre ces quelques discordances ponctuelles, un certain nombre d'évolutions peuvent être mises en évidence et documentées de manière complémentaire à travers les trois jeux de données exploités.

\section{Premiers éléments de synthèse}

\section{Périodes protohistoriques et antiques}

Les prospections archéologiques mettent en évidence de nombreuses traces d'occupations humaines pré- et protohistoriques, les plus anciennes étant datées du Paléolithique ancien pour le Morvan et du Paléolithique supérieur pour le Jura central (Cupillard 2013, Nouvel et al. 2016). De même, les analyses paléo-environnementales documentent la présence de défrichements et d'activités agricoles dans les deux massifs dès le Néolithique, accentuées ensuite durant l'âge du Bronze, sur les piémonts comme dans les secteurs les plus en altitude. Malgré de nombreuses découvertes concernant la Protohistoire dans les deux massifs, il reste cependant difficile d'appréhender autre chose qu'une anthropisation diffuse pour les périodes antérieures au second âge du Fer.

Les témoins archéologiques d'occupation se multiplient ensuite pour la fin de l'âge du Fer et le Haut Empire, ce qui reflète sans doute en partie l'efficacité des prospections pédestres pour décrire l'habitat rural laténien et antique. Toutefois, la densité des points d'occupation reconnus dans le Morvan pour ces périodes coïncide bien avec le fort impact des activités agropastorales constaté dans les différents diagrammes polliniques. L'amélioration de la documentation archéologique permet par ailleurs de décrire, à partir du Haut Empire, des nuances dans les modes d'occupation des différentes microrégions (fig. 3). 
Fig. 3. - Répartition des points de peuplement connus et ouverture du milieu dans le sud du Morvan et le Jura central durant le Haut Empire ( (er-III $^{\mathrm{e}}$ siècle).
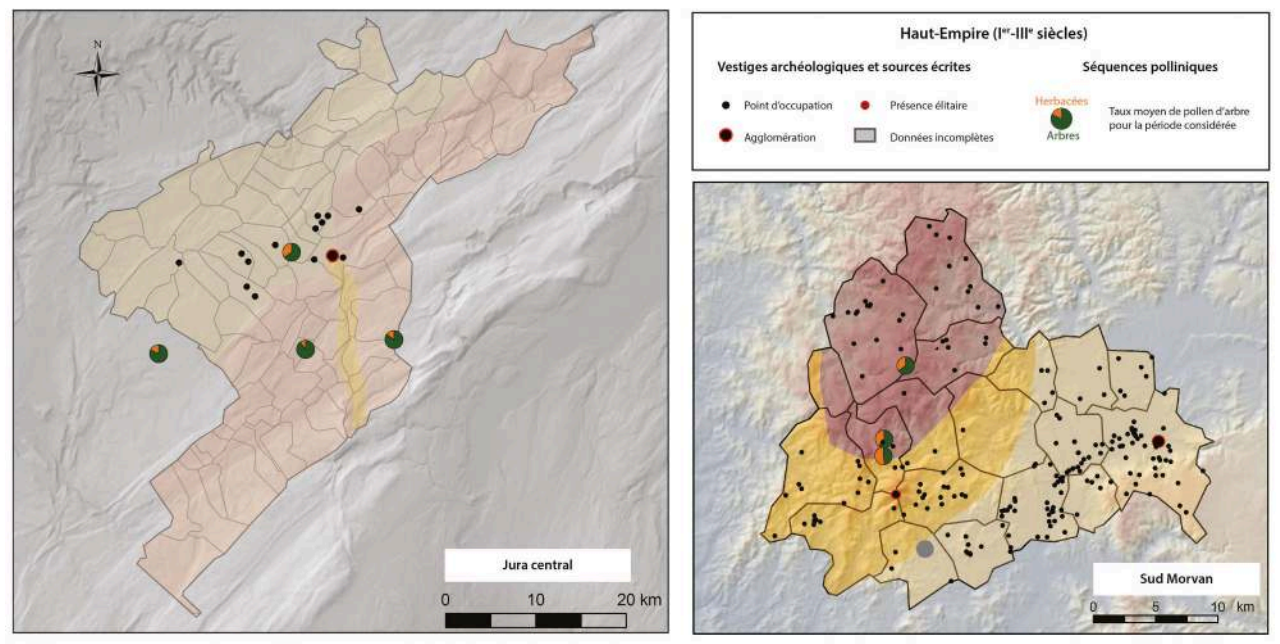

PAO Valentin Chevassu, fond de carte IGN 2017

L'occupation antique est ainsi plus facilement perceptible dans les zones de basse altitude, piémonts morvandiaux ou plateaux jurassiens, où la palynologie décrit des milieux très ouverts associés à un dense semis d'établissements privilégiés, bien reconnaissables archéologiquement. Les secteurs d'altitude des deux massifs présentent au contraire des milieux plus boisés, notamment dans la haute chaîne jurassienne, et des vestiges archéologiques de nature plus modeste.

\section{Antiquité tardive}

17 Comme cela a été décrit plus haut, le haut Moyen Âge n'est pas affecté en Morvan par une déprise agricole, même si la raréfaction des indices archéologiques laisse supposer un changement des modes d'occupation. L'impact anthropique reste d'intensité égale, voire croissante, durant l'Antiquité tardive. Dans le massif jurassien, les analyses palynologiques signalent au contraire une forte reforestation durant les $\mathrm{IV}^{\mathrm{e}}$ et $\mathrm{V}^{\mathrm{e}}$ siècles, qui paraît liée à une période de crise, ou tout au moins de déprise agricole. De même que dans le Morvan, la rareté des témoins archéologiques pour ces deux siècles ne permet guère d'apporter d'autres éléments de compréhension. Cette période semble donc correspondre à diverses mutations de l'occupation et de l'exploitation du territoire dans les deux massifs, occupation surtout marquée dans les zones d'altitude si l'on en croit la palynologie. Ces changements restent cependant très difficiles à appréhender dans l'état actuel de nos connaissances.

\section{Haut Moyen Âge}

Les données paléo-environnementales enregistrent à partir des $\mathrm{VII}^{\mathrm{e}}$ et $\mathrm{VIII}^{\mathrm{e}}$ siècles une reprise des défrichements en haut Morvan, apparemment liée à des indices d'activités métallurgiques, tandis que l'impact anthropique reste d'intensité égale dans le piémont (fig. 4). 
Fig. 4. - Répartition des points de peuplement connus et ouverture du milieu durant le haut Moyen Âge ( $v^{\mathrm{e}}-\mathrm{x}^{\mathrm{e}}$ siècle).
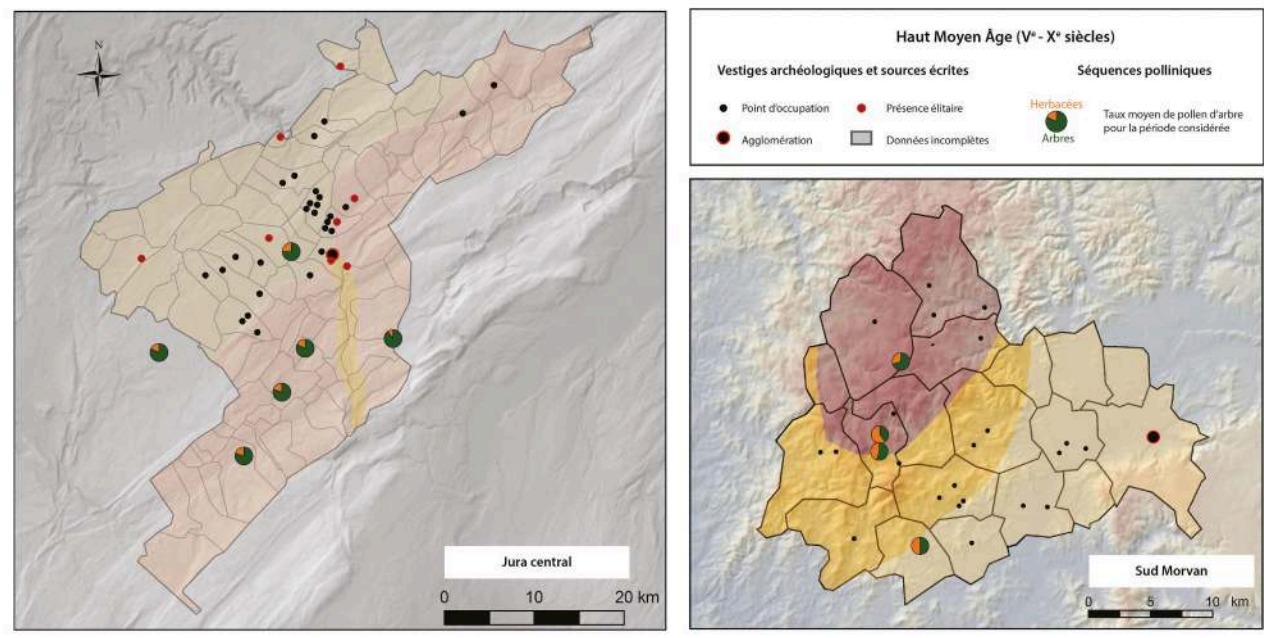

PAO Valentin Chevassu, fond de carte IGN 2017

D’une manière générale, la rareté persistante des textes et des indices archéologiques ne permet guère de statuer sur les formes de l'occupation pour cette période. La localisation de quelques nécropoles des $\mathrm{VII}^{\mathrm{e}}$ et $\mathrm{VIII}^{\mathrm{e}}$ siècles sous les villages actuels semble toutefois signaler une certaine stabilité des points de peuplement à partir de la période mérovingienne.

Le Jura central suit une évolution parallèle, caractérisée par une augmentation progressive mais généralisée de l'impact anthropique dès les $\mathrm{VI}^{\mathrm{e}}$ et $\mathrm{VII}^{\mathrm{e}}$ siècles. Les analyses polliniques montrent cependant une certaine dichotomie entre des plateaux très exploités et une haute chaîne aux spectres polliniques encore largement forestiers. Les données archéologiques, quoique de qualité inégale, insistent sur le dynamisme des zones de plateaux, particulièrement à proximité des itinéraires menant à la cluse de Joux, où se regroupent plusieurs sites de hauteur, habitats et riches nécropoles. Les textes, quant à eux, évoquent surtout les circulations et les possessions éparses de monastères et de lignages aristocratiques situés à l'extérieur du massif.

\section{Moyen Âge central}

Dans les deux massifs, les données polliniques suggèrent pour le Moyen Âge central une phase d'ouverture du milieu et de fort accroissement des activités agropastorales (fig. 5). 
Fig. 5. - Répartition des points de peuplement connus et ouverture du milieu durant le Moyen Âge central et tardif ( $\mathrm{xl}^{\mathrm{e}}-\mathrm{xV} \mathrm{e}^{\mathrm{e}}$ siècle).
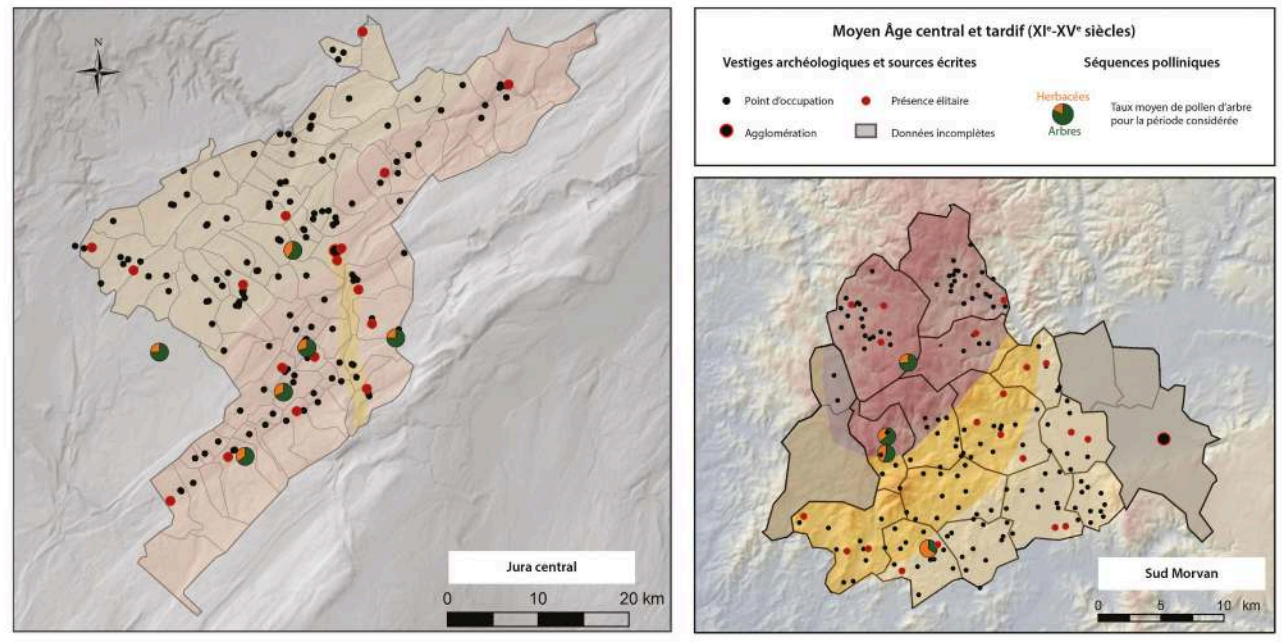

PAO Valentin Chevassu, fond de carte IGN 2017

Si cette mutation touche même les zones de basse altitude, déjà très déboisées, elle s'avère surtout marquante dans les secteurs montagneux. Ces derniers connaissent à la même période l'apparition de nouveaux pouvoirs locaux, monastères fondés dans la haute chaîne jurassienne ou lignages châtelains constructeurs de nombreuses fortifications de hauteur dans le haut Morvan (Locatelli 1999, Chevassu 2015). De telles créations peuvent être vues comme les marqueurs d'un nouveau dynamisme dans des régions qui semblaient rester jusque-là à l'écart des réseaux de pouvoirs. Les sources écrites et l'archéologie permettent également d'envisager l'influence de ces entités seigneuriales sur l'intensification locale des activités humaines, particulièrement dans la haute chaîne jurassienne, où les archives monastiques suggèrent la fixation de pratiques agricoles et d'occupations auparavant diffuses ou temporaires.

À partir des $\mathrm{XII}^{\mathrm{e}}$ et XIII ${ }^{\mathrm{e}}$ siècles, un semis de peuplement stable et assez dense est attesté dans les zones basses et les fonds de vallées montagnardes des deux massifs, associé à un maillage paroissial qui évoluera peu par la suite. En revanche, les reliefs et les terres d'altitude, moins documentés, restent mentionnés uniquement en tant que terres de parcours exploitées, de manière temporaire, pour le pacage des animaux et le prélèvement de ressources forestières.

\section{Moyen Âge tardif}

Les $\mathrm{XIV}^{\mathrm{e}}$ et $\mathrm{XV}^{\mathrm{e}}$ siècles sont caractérisés par une reforestation et une régression des marqueurs d'activités anthropiques dans les séquences polliniques morvandelles et jurassiennes. Si la fermeture du milieu est assez manifeste dans le haut Morvan, sur les plateaux et dans la haute chaîne jurassienne, elle ne semble pas en revanche apparaître dans le piémont morvandiau. Cette évolution paysagère est corrélée par plusieurs abandons de sites fortifiés et de petits habitats groupés, documentés à la fois par les textes et l'archéologie (Bouvard 1997, Chevassu 2015). Une partie de ces désertions peut être liée aux crises épidémiques, climatiques et militaires qui frappent alors toute l'Europe. Toutefois, la période est également marquée dans les deux massifs par la disparition ou la perte d'influence des lignages aristocratiques locaux au profit de 
grands ensembles territoriaux tels que le duché de Bourgogne. Ce nouvel encadrement seigneurial, intégrant les espaces de montagne à de plus vastes ensembles politiques, pourrait alors favoriser de nouvelles formes d'exploitation du territoire (voir notamment Beck 2008).

\section{Période moderne}

Les deux secteurs étudiés connaissent durant les $\mathrm{XVI}^{\mathrm{e}}$ et $\mathrm{XVII}^{\mathrm{e}}$ siècles une intense déforestation, sensible tant dans les séquences polliniques que dans les textes, à travers la multiplication des conflits concernant l'utilisation des boisements (fig. 6). Les dévastations entraînées par les conflits militaires survenus en Morvan dans la seconde moitié du XVI siècle et dans le Jura entre 1634 et 1644 ne semblent entamer que brièvement cette dynamique d'ouverture du milieu.

Fig. 6. - Répartition des points de peuplement connus et ouverture du milieu au début de la période moderne (XVI et $X V I I^{e}$ siècles).
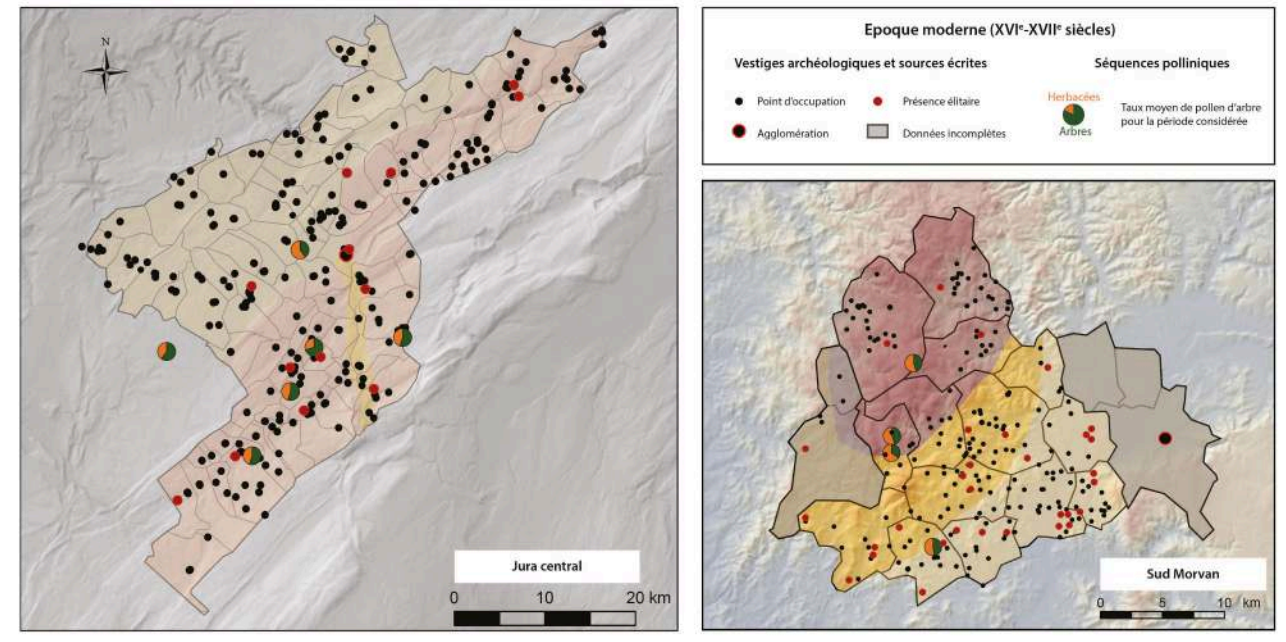

PAO Valentin Chevassu, fond de carte IGN 2017

Le haut Morvan et la haute chaîne jurassienne voient en effet la mise en place de nombreuses activités très consommatrices en bois, bénéficiant d'une ressource encore abondante dans ces espaces. Les créations de mines, d'industries hydrauliques et métallurgiques se multiplient ainsi dans le Jura central dès la fin du $\mathrm{xv}^{\mathrm{e}}$ siècle, tandis que le Morvan se spécialise dans l'export massif de bois de chauffe vers Paris à partir de la seconde moitié $\mathrm{du} \mathrm{xvI}^{\mathrm{e}}$ siècle. Les défrichements peuvent également être associés au développement croissant de l'élevage du gros bétail dans les deux régions.

Ces activités sont notamment liées aux investissements d'une petite bourgeoisie locale qui accapare une partie des revenus seigneuriaux par le biais des amodiations et se distingue par un habitat privilégié. Les reliefs du haut Morvan et de la haute chaîne jurassienne, dont l'occupation était jusque-là temporaire ou très difficile à percevoir, se parsèment alors de nombreux écarts, hameaux et granges d'estive qui témoignent d'une nouvelle dynamique d'appropriation des espaces d'altitude. 


\section{Différenciations régionales et microrégionales}

28 bien que les deux massifs présentent des reliefs assez peu élevés, on constate la forte influence des contraintes altitudinales et topographiques sur la mise en valeur du milieu. Les deux régions présentent en effet une dichotomie entre des zones basses, où l'impact anthropique est assez constant, et des secteurs d'altitude plus ou moins montagneux, où les évolutions sont plus contrastées. Les plateaux du Jura central, tout comme les piémonts du sud Morvan, connaissent ainsi de l'Antiquité à nos jours une exploitation agropastorale assez intense, liée à une densité d'occupation pérenne. La présence continue d'élites aisées apparaît chaque fois que les marqueurs archéologiques permettent de l'appréhender, successivement grâce à la présence d'établissements ruraux antiques de forts statuts, de nécropoles altomédiévales privilégiées, puis de nombreux petits sites fortifiés durant le Moyen Âge central et tardif. Des fluctuations marquées caractérisent au contraire la mise en valeur des secteurs montagneux, plus contraignants et sans doute plus dépendants du contexte économique et politique. Les analyses polliniques suggèrent ainsi que le haut Morvan et la haute chaîne jurassienne sont plus fortement affectés par les phases de déprise ou de recomposition territoriale de l'Antiquité tardive et de la fin du Moyen Âge. Ces espaces connaissent également un encadrement seigneurial différent de celui des zones basses, ainsi qu'une évolution spécifique du maillage paroissial. Les reliefs les plus en altitude, au-dessus de 600 mètres dans le Morvan et de 1100 mètres dans le Jura, sont enfin caractérisés par des modes d'occupation et d'exploitation spécifiques. Jusqu'à la fin du Moyen Âge, ces secteurs paraissent constituer des terres de parcours occupées de manière modeste ou temporaire par des communautés avoisinantes. Les $\mathrm{XVI}^{\mathrm{e}}$ et $\mathrm{XVII}^{\mathrm{e}}$ siècles amènent de nouvelles formes d'appropriation et de peuplement de ces espaces alors de plus en plus déboisés. Dans l'état actuel de nos connaissances, il faut attendre cette dernière période pour que l'occupation des zones de reliefs puisse être appréhendée correctement par la documentation écrite et archéologique.

La répartition des axes de circulation influence également l'évolution des activités humaines et les dynamiques de peuplement, qui semblent évoluer de manière différente dans les secteurs de passage. Les possibilités de relations avec les zones basses favorisent le développement précoce d'activités spécialisées, tandis que les pouvoirs locaux cherchent à contrôler les circulations. Tout au long de la période médiévale, les centres paroissiaux les plus précoces, les sites fortifiés ou encore les relais monastiques s'échelonnent le long des principales routes. Les déboisements et les activités artisanales s'y développent également de manière préférentielle. Ces phénomènes sont particulièrement sensibles autour des axes routiers transjurassiens, mais apparaissent également vers Autun et le long des itinéraires secondaires parcourant le haut Morvan.

La présence inégale des ressources d'origine minérale ou végétale constitue enfin un troisième facteur. L'existence de minerais variés dans certaines parties des deux massifs favorise ainsi le développement d'activités métallurgiques et minières d'intensité variable selon les périodes, de la Protohistoire au Moyen Âge central au sud du Morvan, durant le haut Moyen Âge et surtout du Xv $v^{e}$ au XIX $x^{e}$ siècle pour le Jura. Dans cette même région, l'abondance de forêts de résineux et de pierres calcaires permet la fabrication de poix et de chaux, activités attestées au moins à partir du Moyen Âge 
central et liées à l'exportation vers les plaines voisines dépourvues de ces ressources. De manière plus générale, la présence de vastes forêts conditionne à partir de la fin du Moyen Âge le développement d'industries consommatrices en combustibles dans tous les secteurs d'altitude.

Outre ces nuances localisées, les deux massifs présentent quelques différences notables. La phase de repli des activités humaines, qui caractérise l'Antiquité tardive dans la montagne jurassienne, reste ainsi inconnue dans le Morvan. Par ailleurs, la structure du peuplement adopte des formes très différentes dans les deux massifs. Le Jura central est en effet un pays d'habitat groupé majoritaire, excepté pour certains secteurs d'altitude, tandis que le sud du Morvan se caractérise par un éclatement très poussé de l'habitat en multiples hameaux, y compris en plaine. Ces formes d'habitat sont attestées de part et d'autre dès le Moyen Âge central et perdurent jusqu'à nos jours. Cette différence peut s'expliquer par des contraintes naturelles, telle l'hydrographie des régions concernées, mais également par des facteurs politiques, comme l'absence de regroupement médiéval de l'habitat autour des chefs-lieux paroissiaux ou seigneuriaux.

\section{Conclusion}

La confrontation des données présentées ici permet de décrire les rythmes et les modalités de l'anthropisation dans deux massifs aux spécificités marquées. Au-delà de divers biais engendrés par des états de connaissance variables, ces comparaisons mettent en évidence une évolution spécifique du peuplement dans les zones hautes des deux massifs, qui connaissent des mutations distinctes de celles décrites dans les plaines environnantes. Cette évolution est en grande partie comparable à ce qui a pu être observé par ailleurs dans d'autres montagnes, Alpes, Vosges, Massif central ou Pyrénées. On retrouve dans ces différents massifs un même accroissement progressif des activités humaines à partir de la période mérovingienne, ainsi que deux phases de forte augmentation de l'anthropisation durant le Moyen Âge central et la période moderne. Ces mutations semblent par ailleurs être directement associées à divers changements dans les formes d'occupation et d'encadrement politique de ces mêmes territoires.

Des particularités apparaissent cependant au sein de ces tendances communes, notamment pour les secteurs les plus montagneux, qui voient la mise en place de formes particulières de peuplement et de présence élitaire. Les zones de basse altitude et les zones de passage connaissent, elles, des évolutions moins contrastées. Cette différence pérenne explique quelques-unes des spécificités qui caractérisent la structuration des communautés humaines et de l'habitat dans le Morvan et le Jura, massifs dont l'aspect actuel est toutefois largement dû aux spécialisations forestières et pastorales de l'époque contemporaine. 


\section{BIBLIOGRAPHIE}

BECK C., 2008, Les eaux et forêts en Bourgogne ducale (vers 1350-vers 1480) : société et biodiversité, Paris, L'Harmattan.

BICHET V., RICHARD H., CHEVASSU V., 2017, Programme de recherche ArcheoPal haut Jura central : rapport d'activité 2017, secteur des Fourgs et des Hôpitaux-Vieux (Doubs, France), Besançon, université de Franche-Comté, UMR 6249 Chrono-environnement.

BOUVARD A., 1997, Châteaux et bourgs de la montagne du Doubs, Montbéliard, Société d'émulation de Montbéliard.

CHEVASSU V., 2015, « Les Roches de Glenne, la Tour de Vauteau et le Mont Touleur : châteaux et peuplements en Morvan médiéval », dans Mouillebouche H. (dir.), Chastels et maisons-fortes, vol. 5, Actes des Journées de castellologie de Bourgogne, Chagny, Centre de castellologie de Bourgogne, p. 43-65.

CUPILLARD C., 2013, « La haute vallée du Doubs entre 13000 et 5000 av. J.-C. : des derniers chasseurs de rennes aux premiers agriculteurs ", Mémoires de la Société d'émulation du Doubs, vol. 55, p. 188-227.

GAUTHIER É., 2004, Forêts et agriculteurs du Jura : les quatre derniers millénaires, Besançon, Presses universitaires franc-comtoises.

GAUTHIER É. et RICHARD H., 2006, « La forêt jurassienne au cours des deux derniers millénaires à la lumière de quelques diagrammes polliniques ", dans Dupouey J.-L., Dambrine E., Dardignac C., Georges-Leroy M., La mémoire des forêts : actes du colloque Forêt, archéologie et environnement, Paris : ONF et INRA / Metz : DRAC Lorraine, p. 36-47.

JOUFFROY-BAPICOT I., 2010, «Évolution de la végétation du massif du Morvan (Bourgogne, France) depuis la dernière glaciation à partir de l'analyse pollinique : variations climatiques et impact des activités anthropiques », thèse de doctorat, Besançon, université de Franche-Comté.

JOUFFROY-BAPICOT I., VANNIÈRE B., GAUTHIER É., RICHARD H., MONNA F., PETIT C., 2013, « 7000 years of vegetation history and land-use changes in the Morvan Mountains (France): A regional synthesis ", The Holocene, vol. 32, no 12, p. 1888-1902.

LEROUX A. 2010, « Caractérisation et évolution des flux détritiques et authigènes en contexte lacustre carbonate au cours du Tardiglaciaire et de l'Holocène (lac Saint-Point, haute chaîne du Jura) : implications paléoclimatiques et paléoenvironnementales ", thèse de doctorat, Besançon, université de Franche-Comté.

LOCATELLI R., 1999, L'abbaye de Mont-Sainte-Marie et le haut Doubs forestier : 800 ans d'histoire, Labergement-Sainte-Marie, Les Amis de l'abbaye de Mont-Sainte-Marie et de Saint-Théodule.

MURGIA L., 2016, « Mémoire des lacs et mémoire des sociétés du Moyen Âge à nos jours : approche palynologique et historique de la moyenne montagne jurassienne et alpine (lac de Remoray, Doubs ; glissement du mont Granier, Savoie) », thèse de doctorat, Besançon, université de Franche-Comté.

NOUVEL P., CHEVASSU V., IZRI S., STOCK A., THIVET M., 2016, L'occupation des territoires entre Morvan et Arroux de la Préhistoire au Moyen Âge : rapport de prospection-inventaire 2015, Besançon, université de Franche-Comté, UMR 6249 Chrono-environnement. 


\section{RÉSUMÉS}

La présence conjointe de nombreuses analyses paléo-environnementales et de plusieurs programmes de prospection archéologique vient renouveler notre compréhension des dynamiques anciennes d'occupation dans les montagnes du Morvan et du Jura. Ces informations peuvent également être croisées avec un important corpus d'archives médiévales et modernes jusqu'ici peu exploitées. Une mise en lien systématique de ces trois sources de données devient possible grâce à la spatialisation des informations et la définition de cadres chronologiques communs. L'étude des phases d'expansion ou de repli de l'anthropisation, notamment pour les périodes médiévales et modernes, permet d'évaluer une réelle spécificité des dynamiques d'occupation dans deux massifs de montagnes aux contraintes environnementales diverses. L'utilisation de données pluridisciplinaires met enfin en lien ces évolutions avec les mutations intervenant dans la structuration des occupations humaines et de leur encadrement politique.

The results of numerous paleoenvironmental analyses and recent archeological surveys allow us to renew our understanding of settlement and land-use evolution in the Morvan and Jura Mountains (eastern France). Furthermore, these data can be completed by a large and underused collection of medieval and modern archives. A systematic cross-reading between these different types of data has been carried out, using geolocation and association with common chronological frameworks. It becomes possible to describe the phases of growth and decrease of human activities, with a particular accuracy for medieval and modern periods. We will try to evaluate in which way this evolution reveals some specific features associated with mid-mountain areas, within two regions characterized by various environmental stresses. The use of multidisciplinary data also helps to connect land-use evolutions with other changes affecting settlement patterns and political networks.

\section{INDEX}

Keywords : archaeology, land-use, mid-mountain, Middle Ages, Modern period, paleoenvironment

Mots-clés : anthropisation, archéologie, Moyen Âge, moyenne montagne, paléo-environnement, période moderne

\section{AUTEURS}

\section{VALENTIN CHEVASSU}

Doctorant en archéologie, Maison des sciences de l'homme et de l'environnement Claude-Nicolas Ledoux, laboratoire Chrono-environnement (UMR 6249, université de Franche-Comté / CNRS)

\section{ÉMILIE GAUTHIER}

Laboratoire Chrono-environnement (UMR 6249, université de Franche-Comté / CNRS)

\section{PIERRE NOUVEL}

Laboratoire Chrono-environnement (UMR 6249, université de Franche-Comté / CNRS)

\section{HERVÉ RICHARD}

Laboratoire Chrono-environnement (UMR 6249, université de Franche-Comté / CNRS) ; membre de la section Préhistoire et protohistoire du CTHS 


\section{VINCENT BICHET}

Laboratoire Chrono-environnement (UMR 6249, université de Franche-Comté / CNRS)

ISABELLE JOUFFROY-BAPICOT

Laboratoire Chrono-environnement (UMR 6249, université de Franche-Comté / CNRS) 
Géographie et échanges culturels 
Exploitation des matières premières lithiques locales et allochtones au Paléolithique moyen récent sur le versant nord-occidental des Pyrénées : le cas des grottes du Noisetier (Fréchet-Aure, HautesPyrénées) et de Gatzarria (OssasSuhare, Pyrénées-Atlantiques)

Exploitation of local and allochtonous lithic raw materials in the Late Middle Paleolithic on the northwestern side of the Pyrenees: the case of Le Noisetier (Fréchet-Aure, Hautes-Pyrénées) and of Gatzarria (OssasSuhare, Pyrénées-Atlantiques) caves

Marianne Deschamps, Théo Minet, Pierre Chalard, David Colonge, Vincent Mourre, Christian Servelle et Marc Thomas

Ces dernières années, une succession d'opérations archéologiques menées sur le versant nord-ouest des Pyrénées a autorisé une relecture des modalités d'exploitation des matières premières lithiques au Paléolithique moyen récent (fig. 1). Ces travaux sur les ressources minérales et leurs exploitations visent à mieux caractériser les réseaux de circulations techno-économiques au Pléistocène supérieur et à mieux circonscrire les territoires fréquentés par les groupes. Ils constituent la première étape visant à restituer leurs schémas de mobilité dans l'espace pyrénéen. 
Fig. 1. - Grotte du Noisetier (Fréchet-Aure, Hautes-Pyrénées) : environnement local.

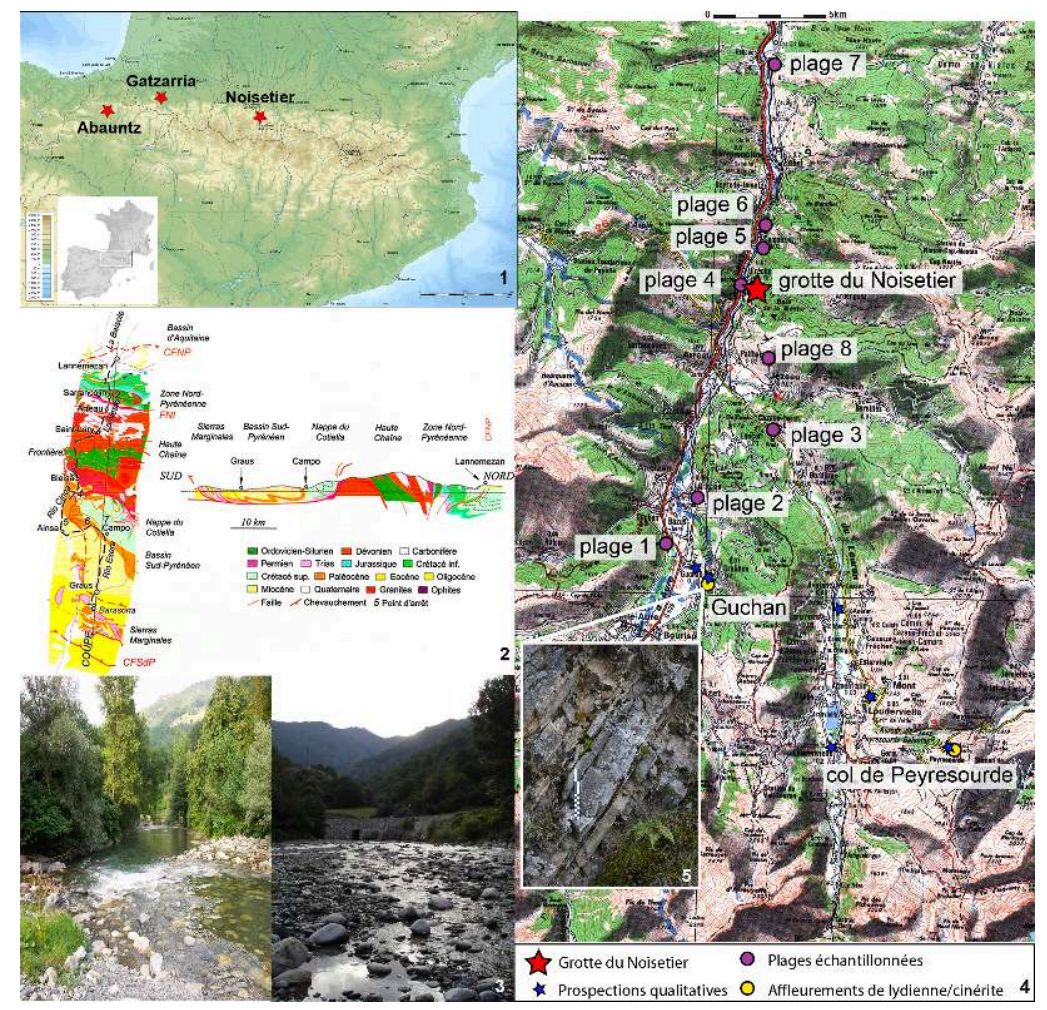

$\mathbf{1}$ : localisation des sites mentionnés dans le texte. $\mathbf{2}$ : carte géologique des vallées de la Neste d'Aure et de la rivière Ésera. $\mathbf{3}$ : vues de la Neste d'Aure. $\mathbf{4}$ : localisation des zones de prélèvements (1/50 000). $\mathbf{5}$ : exemple de cinérite en position primaire.

PAO Marianne Deschamps. 1 : fond de carte Eric Gaba (Sting). 2 : extrait de Canérot 2008. 3 : photos Marianne Deschamps. 4 : fond de carte IGN. 5 : photo Marianne Deschamps.

2 Le contexte montagnard est un secteur particulièrement révélateur pour aborder les questions comportementales liées aux types de mobilité des groupes, ce type d'environnement étant caractérisé par des contraintes naturelles marquées et variées.

3 Au niveau régional, l'aire d'étude est découpée en plusieurs entités géologiques structurales (Canérot 2008). Du nord au sud, ce sont le Bassin aquitain et la basse vallée de l'Adour, la zone nord-pyrénéenne, la chaîne primaire axiale, la zone sudpyrénéenne, aux pentes beaucoup plus douces que sur le versant nord, et enfin le bassin de l'Èbre. Dans la partie nord-ouest, il faut également évoquer la frange littorale $\mathrm{du}$ golfe de Gascogne et la zone sableuse des Landes (fig. 1.2). Ces importantes différences géomorphologiques reflètent des changements dans la distribution de la faune et de la flore et des variations climatiques saisonnières marquées. Il en résulte un territoire aux caractéristiques physiques très contrastées.

La distribution géographique des matières premières lithiques connues dans le secteur accentue l'hétérogénéité spatiale générale. Si les gîtes de silex se répartissent pour l'essentiel en zone nord et sous-pyrénéenne ou à proximité du littoral, les zones plus montagnardes en sont dépourvues. Elles offrent, en revanche, une grande diversité de roches dures aptes à la taille, principalement accessibles dans les alluvions des différents cours d'eau. Ce cortège de roches pyrénéennes est surtout constitué de quartzites, schistes, grès et granites, dont les proportions varient en fonction de la localisation dans les bassins versants. 
5 Les gîtes à silex connus dans l'aire étudiée sont nombreux et variés. Ces ressources sont documentées par une somme importante de recherches, systématisées dans la région depuis les années 1980 (Simonnet 1981 et 1999, Normand 1986 et 2002, Lacombe 1998, Barragué et al. 2001, Bon et al. 2002, Tarriño 2006 et 2007, Séronie-Vivien M. et al. 2006, Séronie-Vivien M.-R. et al. 2012, Chalard et al. 2010, Colonge et al. 2011, Minet 2013, Fernandes et al. 2013, Foucher 2015, Tarriño et al. 2015, Sánchez de la Torre et Mangado Llach 2016). Les secteurs plus particulièrement exploités et investis au Pléistocène correspondent aux séries silicifiées des flyschs, en particulier celles des formations des calcaires de Bidache. Les gîtes à silex des formations du Crétacé supérieur qui affleurent sur les localités de Tercis, de Salies-de-Béarn et en Chalosse fournissent également de nombreux indices d'exploitation. À l'est, ce sont principalement les gîtesateliers d'Hibarette, ceux des Petites Pyrénées et du Plantaurel, qui ont livré aux groupes de chasseurs-cueilleurs successifs des géoressources du Crétacé et du Paléocène.

6 Cette disparité des ressources et l'hétérogénéité des milieux amènent à s'interroger sur la manière d'investir le territoire montagnard et à s'intéresser aux relations qu'entretenaient les groupes néandertaliens avec l'avant-pays. Ces questions vont être appréhendées à travers les recherches récentes menées aux grottes du Noisetier et de Gatzarria. Le point commun de ces deux gisements est leur implantation aux abords des hauts-reliefs pyrénéens, à une certaine distance des ressources en silex de bonne qualité.

\section{Présentation des sites}

\section{La grotte du Noisetier (Fréchet-Aure, Hautes-Pyrénées)}

7 La grotte du Noisetier est une cavité située à environ 820 mètres d'altitude, dans la vallée de la Neste (fig. 1). Lors des premières opérations, entre 1987 et 1993, sous la direction de M. Allard, le site fut interprété comme une halte de chasse liée à l'exploitation des ongulés de montagne. La rareté des occupations attribuées au Paléolithique moyen au cœur de la chaîne des Pyrénées avait en effet laissé envisager qu'il s'agissait d'incursions brèves et ponctuelles, dans un milieu montagnard considéré alors comme peu fréquenté par les Néandertaliens. Cette interprétation de la fonction du site a depuis été remise en question (Costamagno et al. 2008, Mallye et al. 2012).

8 La reprise des fouilles à partir de 2004 sous la direction de V. Mourre a mis en évidence une séquence stratigraphique complexe, dont certains niveaux sont affectés par des processus post-dépositionnels tandis que d'autres sont mieux préservés (structure de combustion en place).

9 Le site a été occupé à plusieurs reprises au cours de l'OIS 3 d'après les ensembles fauniques mis en évidence (mammifères et micromammifères). En l'état actuel des données, les seules datations absolues disponibles pour la séquence sont des datations radiocarbone qui permettent de considérer que son âge s'échelonne entre environ 47 et 30 ka BP en âge conventionnel (Mourre et al. 2008). Nous avons choisi de ne présenter ici que les principaux ensembles reconnus au sein de la séquence : les couches 1 , gb et l'ensemble $2 / 33$.

10 De manière générale, l'industrie lithique se caractérise majoritairement par l'exploitation de matières premières locales, à près de 90 \% (Mourre et Thiébaut 2009, 
Thiébaut et al. 2012). Elles sont dominées par les quartzites, suivi des schistes et plus rarement des lydiennes et des cinérites. Le faible pourcentage restant correspond à des silex d'origine allochtone. Des différences dans les modalités d'exploitation de ces matériaux ont également pu être décelées dans la séquence. Les macro-outils (hachereaux, bifaces) sont présents dans la couche 1, associés à un débitage Discoïde à pointes pseudo-Levallois dominant (Discoïde stricto sensu). Les silex y sont présents, sous la forme d'éclats et d'outils retouchés. Les éclats liés aux activités de réaffûtage et de ravivage des tranchants sont plus particulièrement représentés dans la couche gb pour le silex. Dans l'ensemble 2/33, le silex se fait plus rare, au profit du quartzite.

\section{La grotte Gatzarria (Ossas-Suhare, Pyrénées-Atlantiques)}

11 La grotte Gatzarria se situe dans la partie occidentale de la chaîne pyrénéenne. Elle s'ouvre à une altitude de 270 mètres, au pied du versant nord-est du massif des Arbailles. Ce relief de moyenne montagne oscille entre 800 et 1200 mètres d'altitude. Si la grotte est connue depuis longtemps par les habitants de la région, son potentiel archéologique ne fut révélé qu'en 1950 par P. Boucher.

La séquence stratigraphique documentée par les fouilles de G. Laplace entre 1956 et 1976 comporte une succession de niveaux archéologiques attribués au Paléolithique moyen et au Paléolithique supérieur ancien. Cette séquence complexe est, au moins en partie, perturbée par des phénomènes post-dépositionnels (Deschamps et Flas 2019). Les travaux récents ont permis des datations qui placent le premier niveau moustérien, $\mathrm{Cj}$, entre 44 et $47 \mathrm{ka} \mathrm{BP}$ (Ready et Morin 2013). En revanche, les datations ${ }^{14} \mathrm{C}$ pour le niveau sous-jacent Cjgr n'ont donné que des âges minimums de $>47400$ et $>50300$ BP (Barshay-Szmidt et al. 2012).

13 L'industrie lithique des différents niveaux a été précédemment étudiée selon la méthode de la typologie analytique et structurale (Saenz de Buruaga 1991, Laplace et Saenz de Buruaga 2002-2003). Au sein de la séquence attribuée au Paléolithique moyen, trois niveaux archéologiques avaient été différenciés par G. Laplace. Une réévaluation récente a cependant mis en évidence la présence de niveaux supplémentaires (Deschamps, soumis; Deschamps et Flas 2019). Notre étude présente les résultats préliminaires de la caractérisation des silex du niveau Cjgr.

\section{Résultats concernant l'origine des matières premières}

\section{Exploitation des roches pyrénéennes dans l'environnement de la grotte du Noisetier}

14 L'éloignement des sources de silex n'a pas constitué un obstacle à l'implantation des groupes dans le milieu montagnard. D'autres types de roches issues de la chaîne axiale pyrénéenne ont été exploités (quartzite, schiste, lydienne, cinérite, quartz). Ces roches, disponibles dans l'ensemble des systèmes alluviaux de la région (Colonge et Mourre 2009, Colonge et al. 2012), sont généralement décrites comme provenant de l'environnement immédiat. $\mathrm{Si}$, à l'inverse du silex, l'absence de marqueurs micropaléontologiques ne permet pas de caractériser leur provenance avec précision, des travaux préliminaires comparant les cortèges alluviaux aux corpus archéologiques tendent à montrer un haut degré de sélection de ces matières, qui pour partie ne sont 
pas nécessairement issues de l'environnement immédiat des sites, jusqu'à 2 kilomètres (Deschamps et al. 2010 et 2011, Bruxelles et al. 2012, Roy Sunyer et al. 2017). L'idée selon laquelle les roches grenues comme le quartzite seraient utilisées de façon opportuniste uniquement lorsque le silex fait défaut constitue un postulat qu'il faut aujourd'hui dépasser.

15 À la grotte du Noisetier, la totalité des surfaces corticales observées sur les vestiges en matériaux pyrénéens correspondent à des néocortex fluviatiles. Une série de prélèvements tests systématiques a donc été effectuée sur les plages alluviales du cours principal de la Neste et d'affluents en amont et en aval du site. L'objectif était d'identifier l'apparition et la disparition de certaines roches le long de la vallée afin de cerner des zones d'approvisionnement potentielles et d'évaluer le degré de sélection des matériaux dans l'environnement. La présence en quantités limitées de certaines roches dans l'environnement pouvait aussi nous permettre d'identifier des lieux d'acquisition spécifiques ou un degré de sélection élevé, et donc d'évaluer la connaissance du territoire parcouru par les groupes néandertaliens en contexte montagnard.

Six prélèvements ont été effectués en différents points des alluvions du cours principal de la Neste. Un prélèvement complémentaire a été fait dans la vallée de la Neste de Louron (fig. 1.4, plage $\mathrm{n}^{\circ} 3$ ).

Des lambeaux d'anciennes terrasses sont à signaler dans l'environnement proche du site, mais ils sont généralement recouverts par des dépôts de versant qui les rendent inaccessibles. Le prélèvement $n^{\circ} 8$ constitue le seul lambeau de terrasse affleurant identifié dans le secteur. Les investigations de terrain ont donc concerné principalement les alluvions actuelles, bien que des modifications mineures du réseau hydrographique puissent constituer un possible biais dans l'interprétation des disponibilités gîtologiques pléistocènes.

Sur chaque plage, les galets d'un gabarit égal ou supérieur à dix centimètres ont été prélevés ou identifiés, ce qui correspond au gabarit des galets archéologiques. La zone de prélèvement avait un mètre de rayon. Chaque prélèvement a été constitué par un minimum de 100 échantillons. Parallèlement, les plages testées ont été systématiquement arpentées à la recherche de matériaux identifiés au sein des différents ensembles archéologiques, même s'ils y sont rares, et qui étaient absents ou rares au sein des prélèvements quantitatifs (lydiennes, cinérites ; fig. 2). Dans les alluvions, la diversité des roches s'est révélée importante. C'est pourquoi certaines catégories ont été regroupées par types généraux, en particulier celles qui ne possèdent pas de fracturation conchoïdale et/ou qui ne sont pas représentées dans la cavité. Les granites et granitoïdes ont également été éliminés des prélèvements car ils dominaient tous les spectres et leur décompte aurait occulté les données concernant les autres roches les plus rares. 
Fig. 2. - Grotte du Noisetier (Fréchet-Aure, Hautes-Pyrénées) : roches présentes dans l'environnement de la grotte.
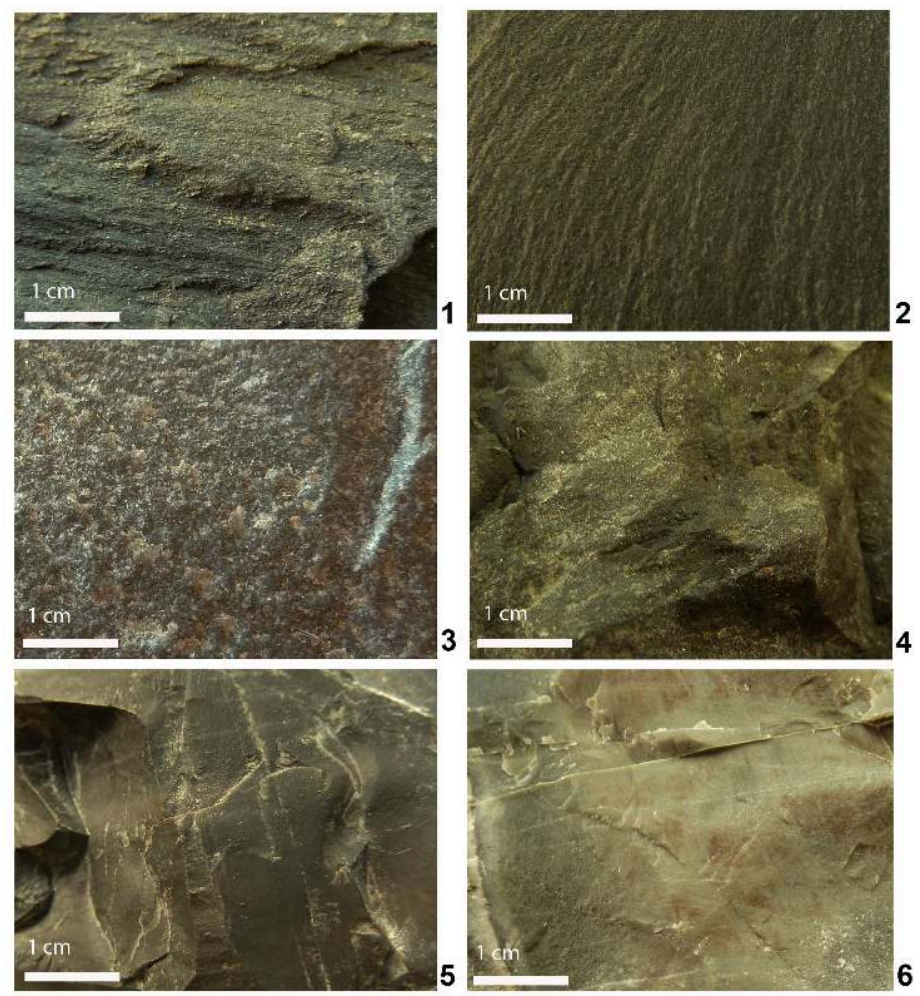

$\mathbf{1}$ : schiste lité. $\mathbf{2}$ : schiste tacheté. $\mathbf{3}$ : quartzite. 4 : cornéenne. $\mathbf{5}$ : lydienne. $\mathbf{6}$ : cinérite. Photos Marianne Deschamps.

19 La comparaison de ces prélèvements avec les vestiges archéologiques montre que les proportions de vestiges en quartzites et en schistes de la séquence archéologique correspondent sensiblement aux proportions identifiées dans les alluvions, sauf pour l'ensemble $2 / 33$, où les quartzites s'avèrent largement plus représentés (fig. 3). La schistosité est très marquée pour la plupart des schistes des alluvions, ce qui les rend inaptes à la taille. Seuls des schistes tachetés ont été importés dans la cavité. 
Fig. 3. - Grotte du Noisetier (Fréchet-Aure, Hautes-Pyrénées) : histogrammes cumulés de représentation des différents types de roches et de quartzite dans les plages alluviales et les couches archéologiques.
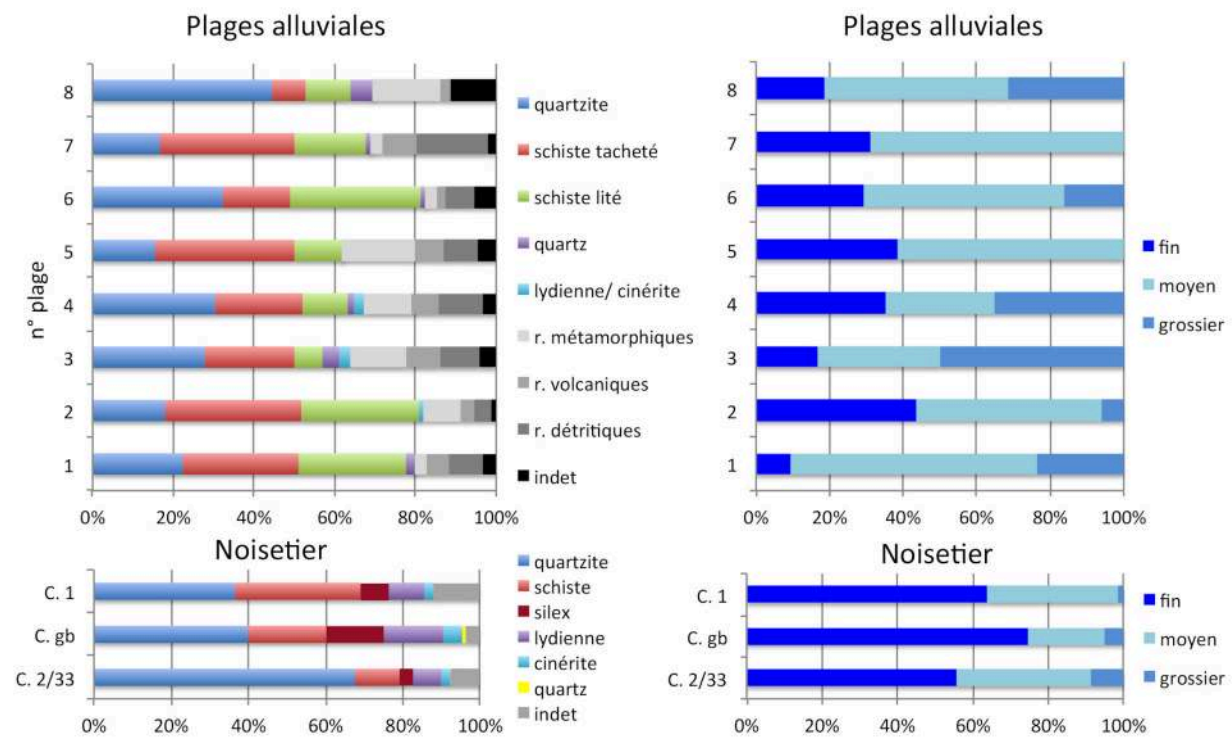

1 ET 2 : types de roches. 3 ET 4 : types de quartzite. PAO Marianne Deschamps.

Une autre différence importante entre les plages alluviales et les vestiges archéologiques concerne les lydiennes et les cinérites. En effet, les lydiennes représentent entre 7 et $15 \%$ des matériaux lithiques taillés au sein des ensembles archéologiques, les cinérites entre 2 et $4 \%$. Or dans les alluvions ces roches sont rares et uniquement sur les plages $\mathrm{n}^{\circ} 3$ et 4 , soit dans la Neste du Louron et directement en aval de la confluence des deux Neste. Les échantillons s'écartaient par ailleurs des matériaux recueillis dans les couches archéologiques, notamment par de plus petites dimensions et des diaclases fréquentes. Les modalités d'acquisition des lydiennes et des cinérites restent donc à déterminer. Il faut signaler que ces roches existent en amont, en position primaire dans les vallées d'Aure et du Louron, au sein de la formation des lydiennes à nodules phosphatés du Tournaisien moyen à supérieur (Carbonifère inférieur) (fig. 1.5). Elles sont donc potentiellement présentes dans les dépôts alluvionnaires anciens, même si elles n'alimentent que de façon rare les charges de fond de ces cours d'eau. Pourtant, les couches de lydiennes et des cinérites affleurent selon des bandes grossièrement ouest-est qui sont systématiquement recoupées par les cours d'eau orientés sud-nord. Mais les affleurements de cinérites représentent globalement un volume relativement restreint par rapport à d'autres formations géologiques. Par ailleurs, leur mode de fracturation favorise leur mobilisation dans les versants en contexte périglaciaire. Les cinérites peuvent aussi subir une décoloration et un émiettement. Tous ces éléments peuvent expliquer leur rareté dans les alluvions.

Les quartzites ont également été différenciés en fonction de la taille des grains de quartz cimentés en zones internes, en suivant trois catégories: les quartzites à grains fins, moyens et grossiers (fig. 3.3-4). En comparant les échantillons aux vestiges archéologiques, il apparaît une sélection manifeste : les quartzites à grains fins sont systématiquement majoritaires dans les différentes couches archéologiques, alors que cela n'est jamais le cas sur les différentes plages échantillonnées. 

comparaisons entre le référentiel actualiste et les vestiges archéologiques de la grotte du Noisetier démontrent la difficulté d'identifier avec certitude les origines d'approvisionnement pour les matériaux du cortège pyrénéen.

\section{Apports de silex dans la grotte du Noisetier}

Des apports de silex ont également été documentés tout au long de la séquence, en faibles proportions (fig. 3). L'accès à ces ressources et leur qualité sont étroitement dépendants de facteurs structuraux et climatiques dans les Pyrénées. Ces contraintes participent au choix de parcours paléogéographiques spécifiques associés aux matières premières. L'analyse a porté sur 339 vestiges cotés et issus du tamisage provenant des couches 1 , gb et $2 / 33$. Les résultats des déterminations présentées ici (fig. 4 ) ont été obtenus à partir d'observations macroscopiques et par l'analyse des microfaciès à faible grossissement (Cuvillier 1951). Le mode de présentation adopté se réfère aux contextes paléoenvironnementaux d'origine des dépôts silicifiés (Tarriño et al. 2015). En vue d'homogénéiser la présentation, et malgré des distorsions topographiques évidentes, les mesures de distance s'entendent sur des tracés à vol d'oiseau. Seules les ressources les plus proximales sont prises en compte.

Fig. 4. - Grotte du Noisetier (Fréchet-Aure, Hautes-Pyrénées) : proportions des principales variétés de silex identifiées dans la grotte selon les ensembles stratigraphiques sélectionnés.
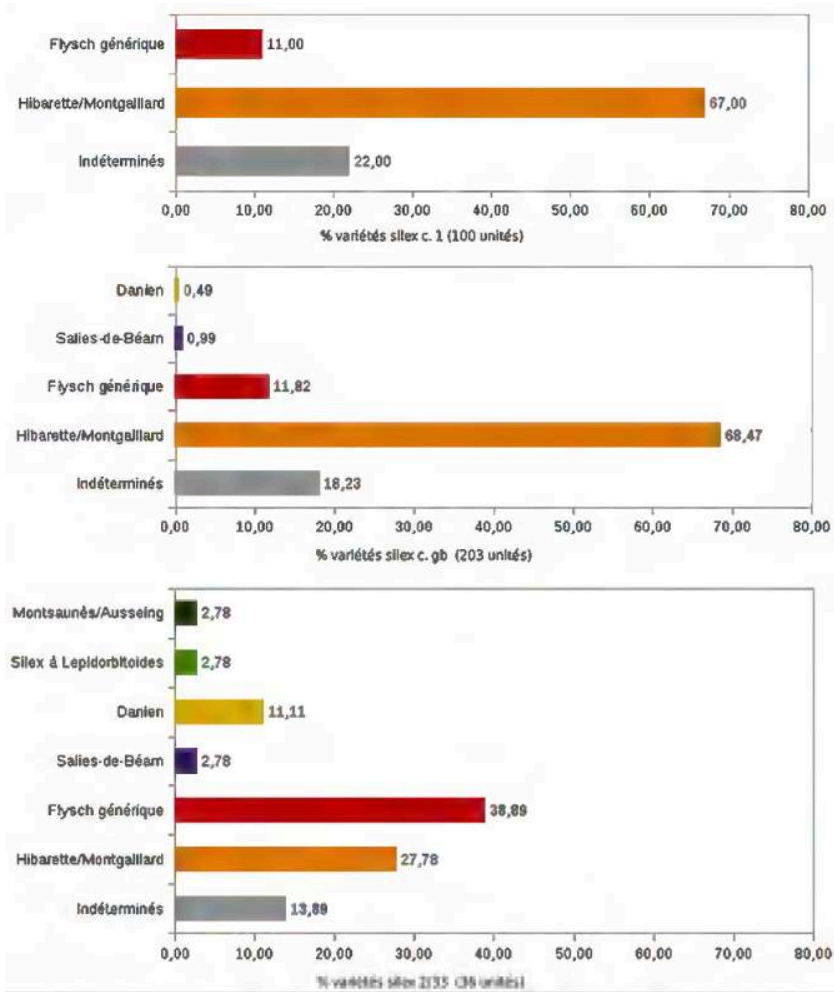

PAO Théo Minet.

\section{Les silex des flyschs}

La majorité des vestiges ont pu être rattachés aux différentes variétés de silex rencontrées dans les séries des flyschs pyrénéens du Crétacé supérieur $(78,17 \%$; 
$\mathrm{n}=265$ ), caractéristiques de séquences turbiditiques où les spicules d'éponges sont fréquents (fig. 5.1). Leurs structures, fréquemment poreuses (porogenèse par dissolution), peuvent comporter des veines de silice tardive (fig. 5.2). Elles comprennent des fragments de quartz détritiques et des oxydes métalliques, avec sur certaines surfaces un aspect dendritique (fig. 5.3). 216 de ces éléments ont pu être rapprochés des silex de type Hibarette-Montgaillard (Barragué et al. 2001), soit la majorité des vestiges $(63,72 \%)$. Leurs microfaciès, généralement oxydés et à pelloïdes plus ou moins défaits, s'apparentent à ceux documentés autour de ces localités des hautes Pyrénées (Barragué et al. 2001, Lacombe 1998, Foucher et al. 2016, Sánchez de la Torre et al. 2019). Les surfaces naturelles conservées sont celles de gîtes secondaires ou secondaires proches qui, dans l'ensemble, correspondent aux dépôts remaniés de la formation du poudingue de Palassou. Ces ressources sont accessibles non loin des affleurements des séries de flyschs turoniennes à maastrichtiennes où prennent place les silicifications, décrites à 30 kilomètres au nord-ouest du site (Azambre et al. 1989). Les phénomènes d'altération post-dépositionnels peuvent donner lieu à un blanchiment des surfaces sur un fond cristallin d'ordinaire brun orangé (fig. 5.4). Cet aspect lié à l'altération est commun à d'autres silex des flyschs des zones nord et souspyrénéennes plus occidentales. C'est probablement à ces formations plus distantes qu'il faut rattacher les autres éléments de l'ensemble générique des flyschs $(14,45 \%$ des vestiges). Ces silex diffèrent de ceux d'Hibarette-Montgaillard notamment par leur faciès plus sombre, gris à noir (fig. 5.5-6), souvent plus fourni en bioclastes, et par les surfaces naturelles conservées qui renvoient à des gîtes primaires ou subprimaires. Sans exclure une variabilité intragîte potentielle et en l'état actuel des données, il est possible de leur attribuer une provenance hypothétique entre la "bande d'Asson" (Lacombe 1998) et la région d'oloron, soit à plus de 50 kilomètres au nord-ouest du site. 
Fig. 5. - Grotte du Noisetier (Fréchet-Aure, Hautes-Pyrénées) : microfaciès des silex des flyschs
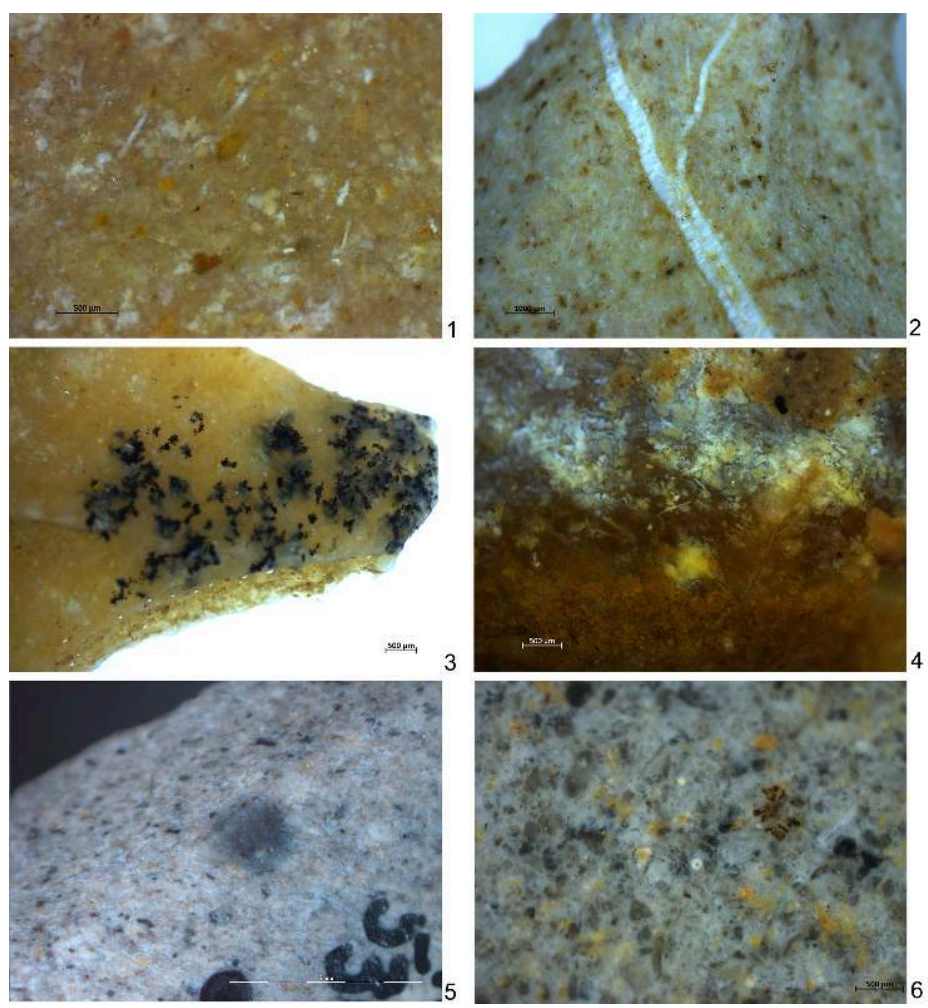

$\mathbf{1}$ : microfaciès à bioclastes dont spicules d'un silex des flyschs de type Hibarette-Montgaillard. $\mathbf{2}$ microfaciès à veines siliceuses d'un silex des flyschs de type Hibarette-Montgaillard. $\mathbf{3}$ : microfaciès oxydé à solidifications d'aspect dendritique d'un silex des flyschs de type Hibarette-Montgaillard. 4 : microfaciès altéré avec blanchiment d'un silex des flyschs de type Hibarette-Montgaillard. $\mathbf{5}$ : microfaciès altéré avec blanchiment d'un silex sombre de l'ensemble générique des flyschs. $\mathbf{6}$ : microfaciès altéré avec blanchiment d'un silex bioclastique de l'ensemble générique des flyschs.

Photos Théo Minet.

\section{Les silex des formations pélagiques}

Deux vestiges de la couche gb et un élément de l'ensemble $2 / 33$ ont pu être rattachés aux diverses variétés de silex rencontrées sur les terrains qui affleurent autour de la zone triasique de Salies-de-Béarn. Ce sont des silex caractéristiques d'une sédimentation pélagique, où les microsphères (pithonelles, incertae sedis; Odin 2008 et 2010) sont abondantes (fig. 6). Leur teinte est grisâtre et leurs structures comportent des zones plus bioturbées et carbonatées. Ils ont pu être rapprochés de types gîtologiques décrits dans les environs de Salies-de-Béarn et Sauveterre-de-Béarn (Normand 2002 et 2003, Tarriño 2007). La formation qui livre ces silex pourrait être campanienne (Henry et al. 1974). Un élément de la couche gb conserve une surface naturelle qui renvoie à un gîte secondaire ou secondaire proche. Il peut donc être établi que l'approvisionnement s'est effectué autour d'affleurements occidentaux à plus de 100 kilomètres du site, sur un axe de déplacement similaire à ceux mentionnés pour les silex des flyschs (Thiébaut et al. 2012). 
Fig. 6. - Grotte du Noisetier (Fréchet-Aure, Hautes-Pyrénées) : microfaciès des silex pélagiques
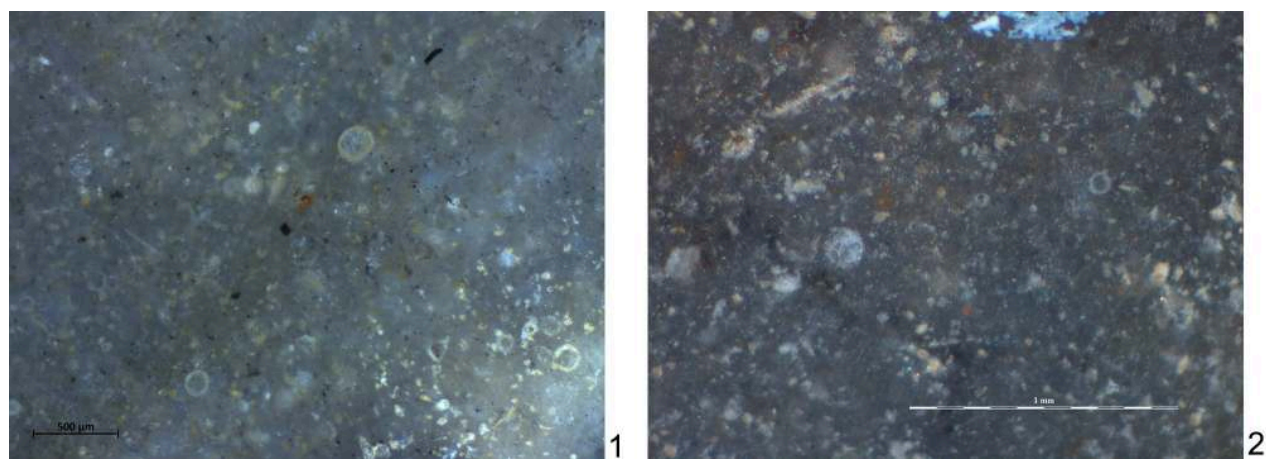

1 : microfaciès à bioclastes dont microsphères d'un silex pélagique de type Salies-de-Béarn. 2 microfaciès à microsphères et impuretés d'un silex pélagique de type Salies-de-Béarn.

Photos Théo Minet.

\section{Les silex de la plateforme aquitaine}

Deux vestiges de l'ensemble $2 / 33$ ont pu être rattachés aux variétés de silex rencontrées sur les terrains d'avant-pays issus de la plateforme aquitaine campanomaastrichtienne. Le premier comporte un cortège fossilifère où les genres Lepidorbitoides et Siderolites sont présents (fig. 7.1-2). Les propriétés structurelles de cet élément (translucidité), son microfaciès (faible représentation des éléments figurés) et son contenu bioclastique (absence d'Orbitoides media) permettent d'exclure en l'état une source orientale pour cette roche, l'origine des variétés de silex à Lepidorbitoides recueillies sur le site archéologique de Tarté (Séronie-Vivien et al. 2006, Foucher 2015) demeurant par ailleurs débattue. La structure affleurante la plus proche qui livre des silex avec ce même fond micropaléontologique est celle dite d'Audignon, en Chalosse (Bon et al. 2002). Des gîtes aux ressources comparables ont cependant été mis en évidence en amont, dans le bassin de l'Adour (Colonge et al. 2011, Séronie-Vivien et al. 2012), notamment sur la commune de Labarthète, à plus de 85 kilomètres au nord-ouest du site (Minet 2015). Ce silex ne conserve pas de surfaces naturelles observables mais présente un faciès oxydé en zone interne compatible avec des gîtes secondaires anciens. Le second élément présente un microfaciès avec de très nombreux petits foraminifères, notamment de l'ordre des Rotaliida (Nonionella, fig. 7.3-4). La nature des divers éléments figurés, leurs formes et leur agencement le rendent caractéristique des silex du secteur de Montsaunès-Ausseing, près de la cluse de Boussens (Simonnet 1999). Les ressources indiquées sont issues de formations du Crétacé supérieur, que l'on rencontre à plus de 50 kilomètres au nord-est du site.

\section{Les silex continentaux}

27 Quatre vestiges de l'ensemble $2 / 33$ et un élément de la couche gb ont pu être rattachés aux variétés de silex rencontrées sur les terrains cénozoïques de la zone souspyrénéenne et de l'avant-pays aquitain. Ce sont des silicifications qui intéressent des milieux continentaux, ou du moins margino-littoraux temporairement exondés. Les faciès documentés sont azoïques, translucides, avec parfois des concentrations d'oxydes de manganèse (fig. 7.5-6). Ils ont pu être rapprochés de ceux documentés dans les Petites Pyrénées comme relevant des variétés de silex du Danien (Simonnet 2002). Les formations susceptibles de livrer ces silex sont connues pour la qualité des 
silicifications autour de la cluse de Boussens, mais on ne peut exclure un approvisionnement depuis les gîtes des dômes annexes, à 40 kilomètres au nord-est du site (Rouquerol 2000). Les surfaces naturelles conservées sur deux éléments de l'ensemble 2/33 renvoient à des gites primaires ou sub-primaires.

Fig. 7. - Grotte du Noisetier (Fréchet-Aure, Hautes-Pyrénées) : microfaciès des silex de plateforme et continentaux.
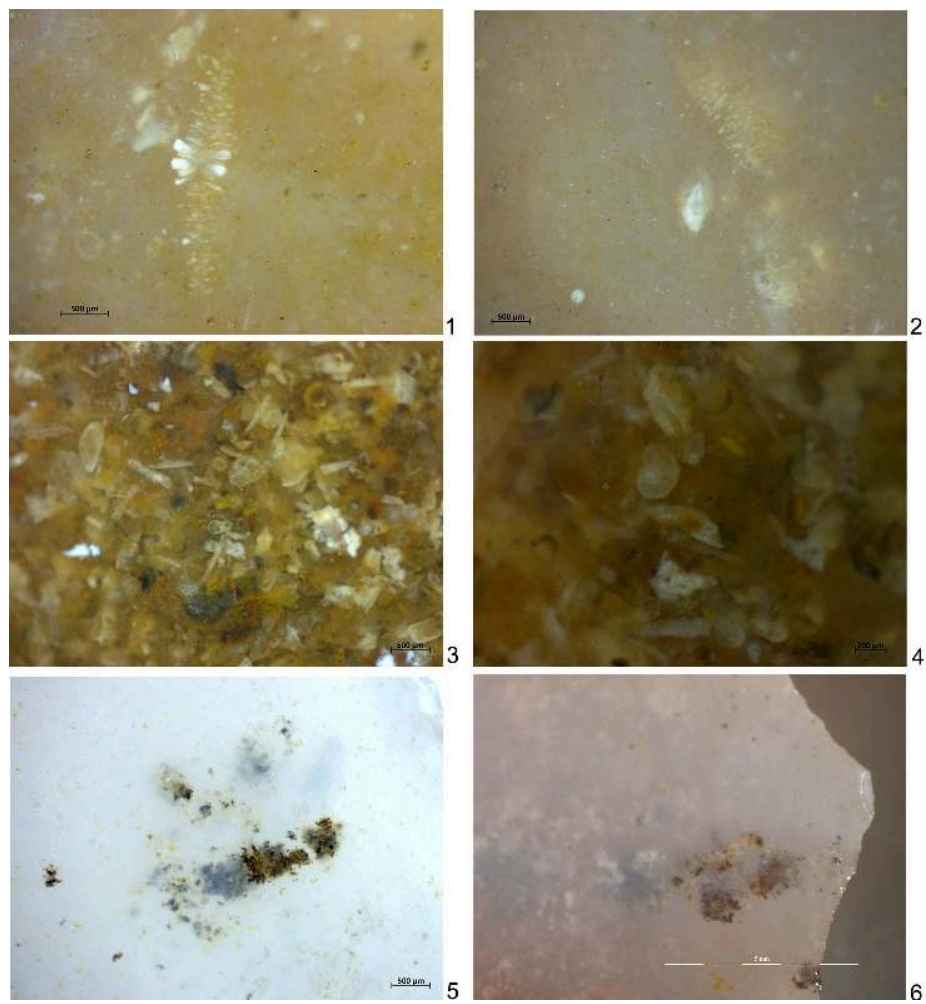

$\mathbf{1}$ : microfaciès à bioclastes (dont Lepidorbitoides sp.) d'un silex de plateforme. $\mathbf{2}$ : microfaciès à bioclastes (dont Siderolites sp.) d'un silex de plateforme ; $\mathbf{3}$ : microfaciès à nombreux petits bioclastes de l'ordre des Rotaliida d'un silex de plateforme de type Montsaunès-Ausseing. $\mathbf{4}$ : petit foraminifère de l'ordre des Rotaliida dans un silex de plateforme de type Montsaunès-Ausseing. $\mathbf{5}$ : microfaciès translucide avec concentration d'oxydes de manganèse d'un silex de type continental. $\mathbf{6}$ : microfaciès translucide avec concentration d'oxydes métalliques d'un silex de type continental.

Photos Théo Minet.

\section{Apports de silex dans la grotte Gatzarria}

L'étude des vestiges de la grotte Gatzarria a également permis de mettre en évidence l'apport de différents types de silex dans la séquence d'occupation moustérienne du site (Deschamps 2017). L'analyse porte sur 432 éléments (soit $11 \%$ de l'ensemble des vestiges lithiques) pour un total de 549 vestiges en silex issus des anciennes fouilles du niveau Cjgr défini sur la base de travaux récents (Deschamps 2014 et soumis). La majorité d'entre eux sont donc caractérisés $(78,69 \%$, fig. 8$)$ mais ces résultats restent préliminaires puisque tant l'étude des silex issus des anciennes collections que celle de ceux issus des nouvelles opérations de terrain débutées en 2017 sont à poursuivre (Deschamps et Flas 2018). 
Fig. 8. - Grotte Gatzarria (Ossas-Suhare, Pyrénées-Atlantiques) : proportions des principales variétés de silex identifiées dans l'ensemble stratigraphique Cjgr.

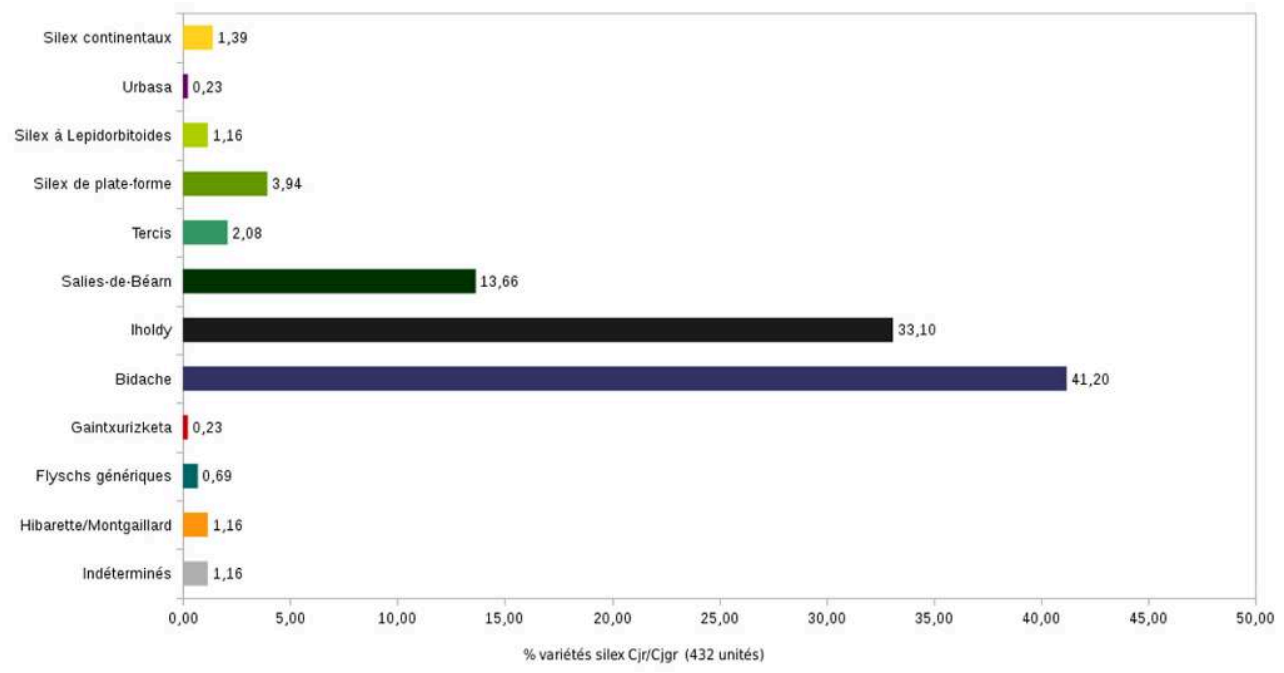

PAO Théo Minet.

\section{Les silex des flyschs}

$76,39 \%$ des vestiges $(n=330)$ ont pu être rattachés aux multiples variétés de silex rencontrées dans les séries des flyschs pyrénéens du Crétacé. Leurs microfaciès sont caractéristiques de séquences turbiditiques et comportent de très nombreux spicules, des oxydes métalliques et des quartz détritiques. Leurs structures apparaissent fréquemment poreuses et peuvent présenter un aspect laminaire. $43,33 \%$ de ces éléments $(\mathrm{n}=143)$ ont pu être rapprochés des silex de type Iholdy (Normand 2002). Ils correspondent à des silicifications plus ou moins grossières, sombres, similaires à celles documentées dans la formation du flysch à silex du bassin de Mauléon (Le Pochat et al. 1974). Les surfaces naturelles en présence renvoient dans l'ensemble à des gîtes primaires ou sub-primaires. Ces matières proviennent vraisemblablement de terrains rencontrés en aval, à une dizaine de kilomètres au nord-ouest du site. La plupart des autres silex (41,20\% de l'ensemble des vestiges) s'apparentent à ceux dits des calcaires de Bidache (Normand 2002). D'aspect plus hétérogène, ils relèvent de silicifications plus fines que les précédentes, grises et/ou bleutées et dont les teintes s'éclaircissent par altération opacifiante. De tels silex sont connus dans les formations turbiditiques de Bidache (Kieken et Thibault 1975a). Leurs affleurements sont signalés au nord du site, en aval du Saison, à une trentaine de kilomètres. Les matériaux y ont principalement été recueillis sous la forme de plaquettes ou de rognons. Il n'est pas exclu que d'autres silex des flyschs pyrénéens soient représentés dans cet ensemble, les processus génétiques étant similaires dans plusieurs séries néocrétacées des Pyrénées occidentales.

D'autres types ont par ailleurs pu être distingués du fait de certaines caractéristiques intrinsèques. Cinq silex correspondent aux types Hibarette-Montgaillard (fig. 9.1). Leurs microfaciès oxydés à pelloïdes et spicules s'apparentent à ceux documentés à plus de 70 kilomètres à l'est du site, dans les séries remaniées du poudingue de Palassou (Barragué et al. 2001). Parmi les autres silex des flyschs, une variété du type Gaintxurizketa a aussi pu être mise en évidence. Son faciès est sombre, à rhomboèdres 
de carbonates authigènes et à indices de bioturbations. Cet élément présente des similitudes avec les silex inclus dans les mégaturbidites du couloir Deba-Irun (Tarriño 2006), cette fois à plus de 70 kilomètres à l'ouest du site.

\section{Les silex des formations pélagiques}

$31 \quad 13,66 \%$ des vestiges analysés $(n=59)$ ont pu être rattachés aux diverses variétés de silex rencontrées sur les terrains du Crétacé supérieur de la région de Sauveterre-deBéarn et de Salies-de-Béarn. Le microfaciès de ces silex est caractéristique d'une sédimentation pélagique et renferme de nombreuses microsphères. Leur teinte d'ensemble est généralement grise et ils montrent fréquemment un aspect bioturbé. Les surfaces naturelles conservées renvoient pour l'essentiel à des gîtes primaires ou sub-primaires. Ces silex ont donc été rapprochés des ressources signalées à une trentaine de kilomètres au nord, en aval du site (Normand 2003). Neuf autres éléments présentent un faciès plus sombre, du gris au noir bleuté, translucide. Les spicules y sont fréquents, avec notamment des formes triaxones (fig. 9.2), ainsi que de nombreux corps blancs diffus (dont des fragments d'échinides). Ces caractéristiques permettent de rapprocher ces silex de ceux décrits dans les calcaires de faciès aturien du domaine de transition plateforme-bassin campano-maastrichtien. Les variétés les plus proches sont connues en contexte gîtologique autour de la ride anticlinale de Tercis (Kieken et Thibault 1975b). Les surfaces naturelles renvoient à des gîtes primaires à secondaires. L'approvisionnement a donc pu être réalisé suivant le cours d'un paléo-Adour et dans les environs de Tercis, à plus de 60 kilomètres au nord du site.

\section{Les silex de plateforme}

$5,32 \%$ des vestiges analysés $(n=23)$ ont pu être rattachés aux variétés de silex issues d'environnement de plateformes carbonatées. Leurs microfaciès comportent fréquemment des foraminifères plus ou moins identifiables. Cinq d'entre eux ont un cortège où le genre Lepidorbitoides est présent (fig.9.3). La seule surface naturelle observée sur ces éléments renvoie à un gîte sub-primaire. Les structures les plus proches susceptibles de livrer ces silex sont celles d'Audignon et de Bastennes-Gaujacq, en Chalosse (Le Pochat et Thibault 1977, Capdeville 1997). Une partie de l'approvisionnement a donc eu lieu à une soixantaine de kilomètres au nord du site. Parmi les autres silex de plateforme, une variété du type Urbasa a aussi pu être mise en évidence (Tarriño et al. 2007). Son faciès, éclairci par l'altération, comporte notamment une espèce du genre Discocyclina (fig. 9.4). La présence de ce grand foraminifère autorise un rapprochement avec les ressources du Thanétien documentées sur le plateau d'Urbasa (Tarriño et al. 2015), soit à plus de 100 kilomètres au sud-est du site, dans le bassin de l'Èbre.

\section{Les silex continentaux}

Six vestiges correspondent à des silicifications qui intéressent des milieux continentaux, lacustres ou palustres. Les faciès documentés sont variés, plus ou moins bréchoïdes, mats, parfois bioclastiques. Des fragments de gastéropodes et d'ostracodes ont notamment été mis en évidence sur l'un de ces éléments (fig. 9.5). Ils ont pu être rapprochés de silex documentés dans le bassin de l'Èbre, plus particulièrement ceux du synclinal de Miranda-Treviño. Les surfaces naturelles observées sur deux éléments 
renvoient pour l'une à un gîte sub-primaire, pour l'autre à un gîte secondaire. En l'état, ces silex sont donc rattachés aux variétés du type Treviño accessibles sur les terrains miocènes autour de cette localité (Tarriño 2006). L'aire d'approvisionnement autour du site s'étend ainsi sur plus de 150 kilomètres vers le haut bassin de l'Èbre.

Fig. 9. - Grotte Gatzarria (Ossas-Suhare, Pyrénées-Atlantiques) : microfaciès des silex.
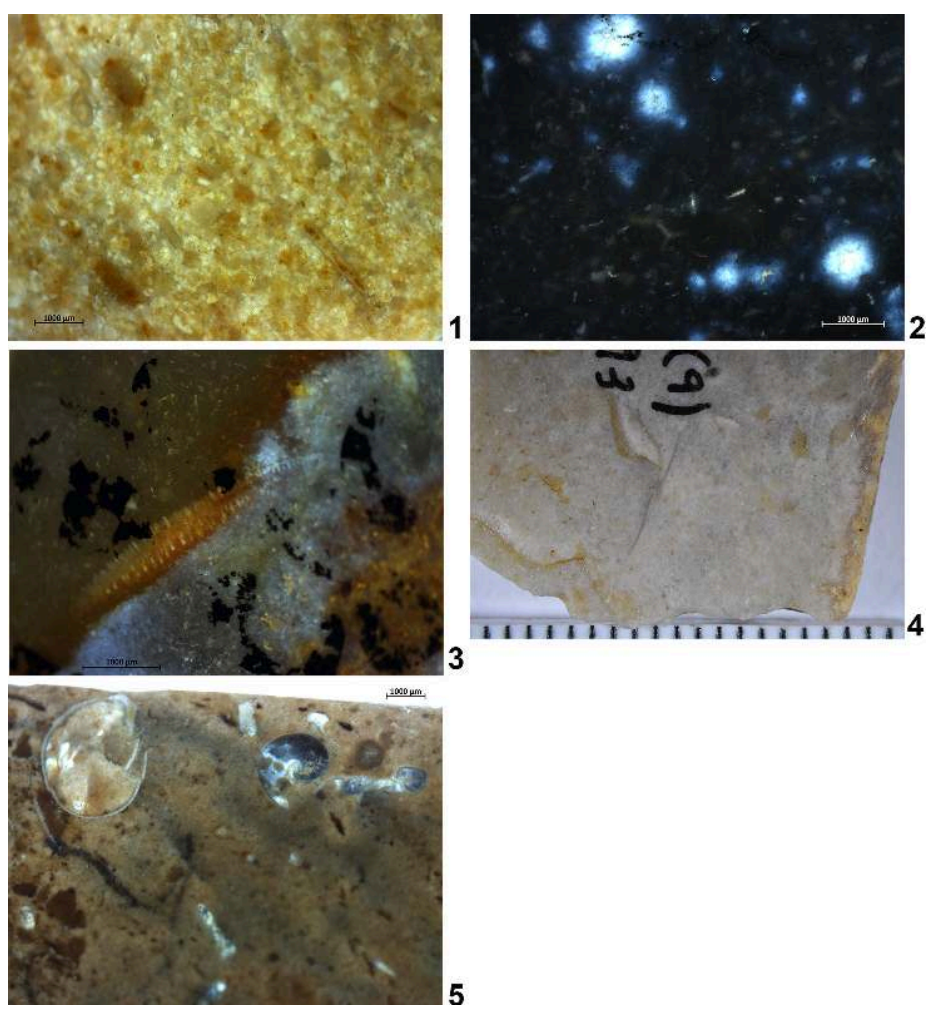

$\mathbf{1}$ : microfaciès oxydé à pellö̈des d'un silex des flyschs de type Hibarette-Montgaillard. $\mathbf{2}$ : microfaciès bioclastique à spicules dont triaxone d'un silex sombre de transition plateforme-bassin de type Tercis. 3 : microfaciès bioclastique à Lepidorbitoides sp. d'un silex de plateforme. $\mathbf{4}$ : microfaciès bioclastique à Discocyclina sp. d'un silex de plateforme de type Urbasa (échelle en millimètres). $\mathbf{5}$ : microfaciès bioclastique à gastéropodes et ostracodes d'un silex continental de type Treviño.

Photos Théo Minet.

\section{Synthèse et discussion}

Les travaux concernant les roches pyrénéennes de la grotte du Noisetier ont permis de mettre en évidence des différences importantes de représentation des matériaux entre les assemblages naturels de l'environnement local actuel et les trois ensembles archéologiques considérés. La lydienne et la cinérite sont ainsi nettement plus fréquentes dans les ensembles archéologiques que dans les formations alluviales échantillonnées, où elles se présentent sous forme de volumes aux qualités insuffisantes. D'autre part, la comparaison des proportions des variétés de quartzites selon la taille de leurs grains indique que ceux à grains fins sont surreprésentés dans les ensembles archéologiques par rapport aux alluvions. 
l'Adour et en particulier depuis les gites du secteur d'Hibarette-Montgaillard qui ont été identifiés à plusieurs dizaines de kilomètres du site. Ce lien est très fort pour la couche 1 , tandis que pour la couche gb des circulations sur de plus grandes distances ont pu être mises en évidence à travers le piémont occidental. Il s'agit notamment de deux racloirs en silex, aux microfaciès caractéristiques des ressources dites de Saliesde-Béarn, signalées à plus de 100 kilomètres du site.

Dans l'ensemble $2 / 33$, ce sont des apports occidentaux comparables qui ont été identifiés, avec à nouveau du silex de Salies-de-Béarn, ici un nucléus sur éclat à exhaustion. S'y ajoute un outil sur éclat altéré de silex à Lepidorbitoides et Siderolites, dont l'origine est à rechercher dans l'avant-pays septentrional, probablement à plus de 85 kilomètres du gisement. Cet ensemble révèle enfin des apports plus diversifiés, avec en particulier des déplacements sur 40 à 50 kilomètres depuis les Petites Pyrénées et 
leurs dômes annexes. Cela concerne deux racloirs et de petits fragments d'éclats en silex continentaux auxquels s'ajoute un petit éclat en silex de type MontsaunèsAusseing.

Un raccord effectué entre l'un des racloirs et le seul élément en silex continental identifié dans la couche gb, illustrant une opération de retouche/ravivage, permet de mettre en lumière de probables processus de remaniement après la première phase de dépôt de ces vestiges. Par ailleurs, ce petit éclat provient des abords immédiats de l'un des foyers explorés dans la cavité (Mourre et al. 2008). Ces observations permettent de relativiser la représentation de ressources sous-pyrénéennes orientales au sein de la couche gb. Les résultats obtenus sur la séquence sélectionnée sont donc en mesure d'illustrer des choix de parcours paléogéographiques différenciés entre l'ensemble 2/33 et les couches 1 et gb. Ces choix peuvent être associés à des articulations territoriales spécifiques aux différentes phases d'approche du milieu montagnard pendant le Pléistocène supérieur.

41 Dans la grotte de Gatzarria, les silex recueillis ont pour origine des gîtes principalement situés en aval de la vallée du Saison, sur quelques dizaines de kilomètres. Les silex locaux de type Iholdy ont été utilisés à plusieurs reprises, mais il faut surtout relever la forte proportion de matériaux issus du secteur de confluence entre le Saison et les gaves d'Oloron et de Pau (types Bidache et Salies-de-Béarn). D'autres silex indiquent des relations plus lointaines avec l'avant-pays : il s'agit de silex similaires à ceux rencontrés dans les structures anticlinales de Tercis, de Bastennes-Gaujacq et d'Audignon, à une soixantaine de kilomètres vers la vallée de l'Adour. Sur des axes de déplacement très différents, ont aussi été mis en évidence des indices de circulations tout au long des Pyrénées occidentales. Cela concerne à la fois l'aire littorale (type Gaintxurizketa) et l'intérieur des terres, en direction des Pyrénées centrales (type Hibarette-Montgaillard). Enfin, aux côtés de ces silex nord-pyrénéens et aquitains, des matériaux en provenance du sud ont également été documentés.

Cette étude préliminaire a en effet permis d'isoler d'autres éléments, dont l'un présente un contenu bioclastique caractéristique des silex de type Urbasa dans les massifs basques. Les autres présentent des microfaciès de silex continentaux et un fond micropaléontologique caractéristique des silex de type Treviño. Ces éléments sont révélateurs de contacts transpyrénéens en provenance du bassin de l'Èbre, sur plus de 150 kilomètres, ce qui ouvre de nouvelles perspectives. Les recherches pétroarchéologiques initiées autour de la grotte Gatzarria permettent ainsi de replacer le site dans un environnement pléistocène largement ouvert sur le bassin de l'Adour et qui s'articule avec d'autres unités territoriales en direction de l'espace ibérique (fig. 10).

43 Des travaux sont par ailleurs en cours pour explorer la possibilité de liens avec le Paléolithique moyen de la grotte d'Abauntz (Arraitz, Navarre). Cette cavité est située à une soixantaine de kilomètres de Gatzarria, sur le versant sud des Pyrénées, et se localise précisément sur l'axe reliant Gatzarria aux gites de Treviño et d'Urbasa.

\section{Conclusion}

44 À partir de ces nouvelles données concernant l'origine des matières premières sur le versant nord-ouest des Pyrénées, il se dessine un large réseau de circulation de matériaux pour le Paléolithique moyen récent. L'importante diversité des ressources 
régionales et extrarégionales documentées dans ces cavités implique une certaine articulation avec les zones de piémont et de plaine. Bien que représentant de faibles proportions ( $11 \%$ à Gatzarria et entre 7 et $14 \%$ au Noisetier), l'apport de ces silex documente une importante diversité, car ils proviennent de la plupart de ressources régionales connues, voire même extrarégionales. Dans les deux cavités, ils sont le résultat d'une importation sélective aux modalités similaires: de rares nucléus à exhaustion et des éclats peu volumineux, principalement des supports retouchés et des éclats liés à la gestion de l'outillage. Ils documentent ainsi des occupations qui se rapprochent du type provisioning of individuals (Kuhn 1994).

En l'état actuel des données, il reste encore délicat de proposer des hypothèses concernant la mobilité des groupes. La question de la saisonnalité des occupations montagnardes sera également particulièrement intéressante à explorer dans l'avenir. Cette question a déjà été abordée par d'autres travaux, au sein desquels ont été décrits des modèles de mobilité distincts selon les technocomplexes, comme cela a notamment été proposé pour le nord de l'Aquitaine (Delagnes et Rendu 2011). Ces associations sont contestées, et d'autres travaux ont insisté sur la diversité des choix techniques et l'importance des conditions environnementales qui prévalent dans les stratégies territoriales (Thiébaut 2013). D'autres recherches ont aussi évoqué une mobilité qui s'organiserait différemment, de manière saisonnière. Selon cette dernière hypothèse, des stratégies de mobilité hivernales et estivales se complètent et s'adaptent en fonction de l'accès aux différents types de ressources (Richter 2006).

Ainsi, ces différents modèles de gestion des territoires nous donnent d'importantes pistes de réflexion pour interpréter la mobilité des groupes néandertaliens au sein de l'espace nord-occidental des Pyrénées. En effet, la répartition géographique inégale des ressources minérales, les variations climatiques saisonnières particulièrement intenses et la topographie escarpée du versant nord-pyrénéen nous permettent d'envisager une planification complexe de l'organisation des groupes dans ce type de milieu.

\section{BIBLIOGRAPHIE}

AZAMbre B., CROUZEl F., DEBROAS E.-J., SOULÉ J.-C., TERnET Y., 1989, Carte géologique de France à 1/50 000. Feuille Bagnères-de-Bigorre (1053). Notice explicative, Orléans, Éditions du BRGM.

BARRAGUÉ J., BARRAGUÉ É., JARRY M., FOUCHER P., SIMONNET R., 2001, « Le silex du flysch de Montgaillard et son exploitation sur les ateliers du Paléolithique supérieur à Hibarette (HautesPyrénées) », Paleo, n 13, p. 29-52.

BARSHAY-SZMIDT C., EIZENBERG L., DESCHAMPS M., 2012, « Radiocarbon (AMS) dating the classic Aurignacian, Proto-Aurignacian and Vasconian Mousterian at Gatzarria cave (PyrénéesAtlantiques, France) », Paleo, n ${ }^{\circ} 23$, p. 11-38.

BON F., CHAUVAUd D., DARTIGUEPEYROU S., GARDÈRE P., KLARIC L., MENSAN R., 2002, « Les ressources en silex de la Chalosse centrale : gîtes et ateliers du dôme diapir de Bastennes-Gaujacq et de l'anticlinal d'Audignon ", dans Cazals N. (dir.), Comportements techniques et économiques des sociétés 
du Paléolithique supérieur dans le contexte pyrénéen, rapport de PCR, Toulouse, Service régional de l'archéologie Midi-Pyrénées, p. 47-58.

BRUXELLES L., JARRY M., SERVELLE C., 2012, « Ressources lithiques des formations alluviales du Midi toulousain : méthodologie, résultats et premières applications aux séries paléolithiques », dans Marchand G. et Querré G. (dir.), Roches et sociétés de la Préhistoire : entre massifs cristallins et bassins sédimentaires, Presses universitaires de Rennes, p. 31-49.

CANÉROT J., 2008, Les Pyrénées, vol. 2 : Itinéraires de découverte, Biarritz, Atlantica.

CAPDEVILLE J.-P., 1997, Carte géologique de France à 1/50 000. Feuille Hagetmau (978). Notice explicative, Orléans, Éditions du BRGM.

CHALARD P., BON F., BRUXELles L., DUCASSE S., TEYSSANDIER N., RENARD C., GARDÈre P., GUILLERMin P., LACOMBE S., LANGLAIS M., MENSAN R., NORMAND C., SIMONNET R., TARRIÑo A., 2010, « Chalosse type flint: exploitation and distribution of a lithologic marker during the Upper Paleolithic, Southern France ", dans Brewer-LaPorta M., Burke A.-L., Field D. (dir.), Prehistoric mines and quarries: a transatlantic perspective. Actes des sessions posters présentées au colloque de la SAA (Porto-Rico, avril 2006), Oxford, Oxbow, p. 13-22.

COLONGE D. et MOURRE V., 2009, « Quartzite et quartzites : aspects pétrographiques, économiques et technologiques des matériaux majoritaires du Paléolithique ancien et moyen du sud-ouest de la France ", dans Grimaldi S. et Cura S. (dir.), Technical analysis on quartzite exploitation, Oxford, Palaeopress (BAR International Series, 1998), p. 3-12.

COlOnge D., ChalaRd P., BilOtTe M., DuCASSE S., Platel J.-P., 2011, « Nouvelle découverte d'un gîte à silex à Lepidorbitoides dans le sud-ouest de la France (Saint-Aubin, Gers) et implications archéologiques ", Bulletin de la Société préhistorique française, $n^{\circ}$ 108, p. 561-563.

COLONGE D., LELOUVIER L.-A., MOURRE V., NORMAND C., 2012, « Matières premières dans l'Acheuléen du piémont pyrénéen », dans Marchand G. et Querré G. (dir.), Roches et sociétés de la Préhistoire : entre massifs cristallins et bassins sédimentaires, Rennes, Presses universitaires de Rennes, p. 53-65.

COSTAMAGNO S., ROBERT I., LAROULANDIE V., MOURRE V., THIÉBAUT C., 2008, « Rôle du gypà̀te barbu (Gypaetus barbutus) dans la constitution de l'assemblage osseux de la grotte du Noisetier (FréchetAure, Hautes-Pyrénées, France) », Annales de paléontologie, nº 94, p. 245-265.

CUVILLIER J., 1951, Corrélations stratigraphiques par microfaciès en Aquitaine occidentale, Leyden, Brill.

DELAGNES A. et RENDU W., 2011, « Shifts in Neandertal mobility, technology and subsistence strategies », Journal of Archaeological Science, n 38, p. 1771-1783.

DESCHAMPS M., 2014, « La diversité culturelle au Paléolithique moyen récent : le Vasconien et sa signification au sein des faciès moustériens ", thèse de doctorat, université Toulouse II - Le Mirail.

DESCHAMPS M., 2017, « Late Middle Palaeolithic assemblages with flake cleavers in the western Pyrenees: The Vasconian reconsidered ", Quaternary International, $\mathrm{n}^{\circ} 433$, p. 33-49.

DESCHAMPS M., soumis, « Middle Palaeolithic industries from Gatzarria cave (Northwestern Pyrenees): new insights into stratigraphy, taphonomy and lithic technocomplexes », Comptes Rendus Palevol.

DESCHAMPS M. et FLAS D. (dir.), 2018, La grotte Gatzarria à Ossas-Suhare (Pyrénées-Atlantiques), rapport d'opération annuel 2017, Bordeaux, Service régional de l'archéologie Nouvelle-Aquitaine.

DESCHAMPS M. et FLAS D., 2019, Paléolithique moyen récent et Paléolithique supérieur initial en contexte montagnard : les industries lithiques de Gatzarria et leurs implications régionales, dans Deschamps M., 
Costamagno S., Milcent P.-Y., Pétillon J.-M., Renard C., Valdeyron N. (dir.), La conquête de la montagne : des premières occupations humaines à l'anthropisation du milieu. Actes du $142^{2}$ congrès national des sociétés historiques et scientifiques, 24-28 avril 2017, Paris, Éditions du CTHS.

DESCHAMPS M., SERVELLE C., COLONGE D., MOURRE V., 2010, «Étude des ressources minérales dans l'environnement de la grotte du Noisetier », dans Mourre V. (dir.), Le site moustérien de la grotte du Noisetier à Fréchet-Aure (Hautes-Pyrénées), fouille programmée pluriannuelle 2008-2010 : rapport final, Toulouse, Service régional de l'archéologie Midi-Pyrénées, p. 84-92.

DESCHAMPS M., SERVELLE C., COLONGE D., MOURRE V., 2011, « Étude des ressources minérales dans l'environnement de la grotte du Noisetier », dans Mourre V. (dir.), Le site moustérien de la grotte du Noisetier à Fréchet-Aure (Hautes-Pyrénées), fouille programmée pluriannuelle 2008-2010, rapport final, Toulouse, service régional de l'archéologie Midi-Pyrénées, p. 68-77.

FERNANDes P., RAYNAL J.-P., TALlet P., TUfFery C., PIBOUle M., SÉRONIE-VIVIEN M., SÉRONIE-VIVIEN M.-R., TURQ A., MORALA A., AFFOLTER J., Millet D., MILlet F., BAZILE F., SCHMidT P., FOUCHER P., DELVIGNE V., LIAGRE J., GAILLOT S., MORIN A., MONCEL M.-H., GARNIER J.-F., LÉANDRI-BRESSY C., 2013, « Une carte et une base de données pour les formations à silex du sud de la France : un outil pour la pétroarchéologie ", Paleo, n 24, p. 219- 228.

FOUCHER P., 2015, «Flint economy in the Pyrenees: A general view of siliceous raw material sources and their use in the Pyrenean Gravettian ", Journal of Lithic Studies, vol. 2, n 1, p. 111-129.

FOUCHER P., SAN JUAN-FOUCHER C., VERCOUTÈRE C., FERRIER C., SÉRONIE-VIVIEN M.-R., DE LA PEÑA P., FERNANDES P., SERVELLE C., COLONGE D., 2016, « Raw material procurement and use at Gargas Cave (Hautes-Pyrénées, France): a Pyrenean-foothill economy during the Gravettian period », Munibe, série Antropologia-Arkeologia, $\mathrm{n}^{\circ}$ 67, p. 253-268.

HENRY J., zOLNAÏ G., LE POCHAT G., MONDEILH C., 1989, Carte géologique de France à 1/50 000. Feuille Orthez (1003). Notice explicative, Orléans, Éditions du BRGM.

KIEKEN M. et THIBAULT C., 1975a, Carte géologique de France à 1/50 000. Feuille Hasparren (1002). Notice explicative, Orléans, Éditions du BRGM.

KIEKEN M. et THIBAULT C., 1975b, Carte géologique de France à 1/50 000. Feuille Saint-Vincent-de-Tyrosse (975-976). Notice explicative, Orléans, Éditions du BRGM.

KUHN S., 1994, « A formal approach to the design and assembly of mobile toolkits », American Antiquity, $\mathrm{n}^{\circ}$ 59, p. 426-442.

LACOMBE S., 1998, « Préhistoire des groupes culturels au Tardiglaciaire dans les Pyrénées centrales : apports de la technologie lithique », thèse de doctorat, université Toulouse II - Le Mirail.

LAPLACE G. et SAENZ DE BURUAGA A., 2002-2003, « Typologie analytique et structurale des complexes du Moustérien de la grotte de Gatzarria (Ossas-Suhare, pays Basque) et de leurs relations avec ceux de l'abri Olha 2 (Cambo, pays Basque) ", Pyrenae, $\mathrm{n}^{\circ}$ 33-34, p. 81-163.

LE POCHAT G. et THIBAULt C., 1977, Carte géologique de France à 1/50 000. Feuille Dax (977). Notice explicative, Orléans, Éditions du BRGM.

LE POCHAT G., BOISSONNAS J., THIBAUlT C., BERNATZKY M., 1974, Carte géologique de France à 1/50 000. Feuille Iholdy (1027). Notice explicative, Orléans, Éditions du BRGM.

MALlye J.-B., COSTAMAgno S., BOUdAdi-MALigne M., PRUCCA M., LAROUlandie V., THiÉBAUT C., MOURRE V., 2012, « Dhole (Cuon Alpinus) as a bone acumulator and new taphonomic agent: The case of the Noisetier cave (French Pyrenees) », Journal of taphonomy, vol. 10, nº 3-4, p. 305-338. 
MINET T., 2013, « L'exploitation des silex au Paléolithique ancien et moyen dans l'avant-pays nordpyrénéen : approche gîtologique, pétroarchéologique et techno-économique », mémoire de master 2, Toulouse, université Toulouse II - Le Mirail.

MINET T., 2015, « Exploitation des silex au Paléolithique ancien et moyen dans l'avant-pays nordpyrénéen : Armagnac, bassin de l'Adour », dans Bilan scientifique de la région Midi-Pyrénées 2013, Toulouse, Service régional de l'archéologie Midi-Pyrénées, p. 233-234.

MOURRE V. et THIÉBAUT C., 2009, « L'industrie lithique du Moustérien final de la grotte du Noisetier (Fréchet-Aure, Hautes-Pyrénées) dans le contexte des Pyrénées centrales françaises », Treballs d'Arqueologia, $\mathrm{n}^{\circ}$ 14, p. 89-106.

MOURRE V., COSTAMAgno S., ThiÉBAUt C., ALlARD M., BRUXElles L., COlONGE D., CRAVinho S., JEANNET M., JUILLARD F., LAROULANDIE V., MAUREILLE B., 2008, « Le site moustérien de la grotte du Noisetier à Fréchet-Aure (Hautes-Pyrénées) : premiers résultats des nouvelles fouilles », dans Jaubert J., Bordes J.-G., Ortega I. (dir.), Les sociétés du Paléolithique dans un grand sud-ouest de la France : nouveaux gisements, nouveaux résultats, nouvelles méthodes. Actes des Journées SPF, Talence, 24-25 novembre 2006, Paris, Société préhistorique française (Mémoires de la Société préhistorique française, 47) / Talence, laboratoire PACEA, p. 189-202.

NORMAND C., 1986, « Inventaire des gîtes à silex de la Chalosse (1984-1985) », dans Arambourou R., Strauss L.-G., Normand C., Recherche de préhistoire dans les Landes en 1985, Dax, Société de Borda (Bulletin de la Société de Borda, $\mathrm{n}^{\circ}$ 402), p. 133-140.

NORMAND C., 2002, «Les ressources en matières premières siliceuses dans la basse vallée de l'Adour et de ses affluents : quelques données sur leur utilisation au Paléolithique supérieur », dans Cazals N. (dir.), Comportements techniques et économiques des sociétés du Paléolithique supérieur dans le contexte pyrénéen : rapport de PCR, Toulouse, Service régional de l'archéologie MidiPyrénées, p. 26-44.

NORMAND C., 2003, « Du bloc à l'outil au Paléolithique : Harria eta Herria / Pierre et pays », Bulletin du Musée basque, hors série, p. 313-338.

ODIN G.-S., 2008, « Description et illustration de quarante-quatre gilianelles (microproblematica) et de dix autres microproblematica du Crétacé de la coupe stratotypique de Tercis (limite CampanienMaastrichtien), sud-ouest France », Carnets de géologie/Notebooks on Geology, CG2008_M01.

ODIN G.-S., 2010, « Traces de volcanisme explosif dans le Campanien pyrénéen aux alentours du stratotype de limite Campanien-Maastrichtien à Tercis (SO France, N Espagne) : repérage biostratigraphique avec une étude particulière du foraminifère Radotruncana calcarata », Carnets de géologie/Notebooks on Geology, CG2010_A02.

READY E. et MORIN E., 2013, « Revisiting the Middle to Upper Paleolithic transition at Gatzarria Cave », poster présenté au Palaeoanthropology Society Meeting, DOI : 10.12853/POSTER.NESPOS. 0058.

RICHTER J., 2006. « Neanderthals in their landscape », dans Demarsin B. et Otte M. (dir.), Neanderthals in Europe, Liège, université de Liège (ERAUL, 117), p. 51-66.

ROUQUEROL N., 2000, « Des ateliers de taille du silex à Lespugue (Haute-Garonne) », Revue de Comminges, $\mathrm{n}^{\circ} 1$, p. $15-20$.

ROY SUNYER M., MORA TORCAL R., PLASENCIA FIGUEROA F. J., MARTÍNEZ-MORENO J., BENITO-CALVO A., 2017, "Quartzite selection in fluvial deposits: The N12 level of Roca dels Bous (Middle Palaeolithic, southeastern Pyrenees) », Quaternary International, n 435, p. 49-60. 
SAENZ De BURUaGa A., 1991, El Paleolítico superior de la cueva de Gatzarria (Zuberoa, Pais Vasco), Bilbao, Universidad del País Vasco.

SÁNCHEZ DE LA TORRE M. et MANGADO LLACH X., 2016, « A new territorial marker in the Pyrenees: cherts from the Agua-Salenz formation », Munibe, série Antropologia-Arkeologia, n 67, p. 219-226.

SÁNCHEZ DE LA TORRE M., REY M., RODRÍGUEZ N., CASADO A., MEDINA B., MANGADO LLACH X., 2014, « The LithicUB project: A virtual lithotheque of siliceous rocks at the University of Barcelona », Journal of Lithic Studies, vol. 1, n 1 , p. 281-292.

SÁNCHEZ DE LA TORRE M., LE BOURDONNEC F.-X., GRATUZE B., 2019, « Reconsidering prehistoric chert catchment sources: new data from the Central Pyrenees (Western Europe) », Archaeological and Anthropological Sciences, vol. 11, $\mathrm{n}^{\circ}$ 3, p. 947-957.

SÉRONIE-VIVIEN M., SÉRONIE-VIVIEN M.-R., FOUCHER P., 2006, « L'économie du silex au Paléolithique supérieur dans le bassin d'Aquitaine : le cas des silex à lépidorbitoïdes des Pyrénées centrales. Caractérisation et implications méthodologiques ", Paleo, nº 18, p. 196-216.

SÉRONIE-VIVIEN M.-R., SÉRONIE-VIVIEN M., FOUCHER P., MILLET D., MILLET F., 2012, « Entre l'Adour et la Baïse (partie occidentale du département du Gers, France) : une importante source de matières premières siliceuses du Sénonien ", Paleo, n² 23, p. 357-366.

SIMONNET R., 1981, «Carte des gîtes à silex des Pré-Pyrénées », dans La Préhistoire en Quercy dans le contexte de Midi-Pyrénées, actes du XXI e Congrès préhistorique de France (Cahors-Montauban, 3-9 septembre 1979), vol. 1, Paris, Société préhistorique française, p. 308-323.

SIMONNET R., 1999, « De la géologie à la préhistoire : le silex des Prépyrénées, résultats et réflexions sur les perspectives et les limites de l'étude des matières premières lithiques ", Paleo, $\mathrm{n}^{\circ} 11$, p. $71-88$.

SIMONNET R., 2002, « Le silex dans le bassin sous-pyrénéen de la Garonne : compléments », Préhistoire, art et sociétés, bulletin de la Société préhistorique Ariège-Pyrénées, n 57, p. 113-170.

TARRIÑo A., 2006, El sílex en la cuenca vasco-cantábrica y Pirineo navarro: Caracterización y su aprovechamiento en la Prehistoria, Madrid, Museo Nacional y Centro de Investigación de Altamira (Monografías, 21).

TARRIÑo A., 2007, « Disponibilidad de sílex coma materia prima en la Prehistoria del Pirineo occidental », dans Cazals N., González Urquijo J., Terradas X. (dir.), Frontières naturelles et frontières culturelles dans les Pyrénées préhistoriques : actes de la table-ronde de Tarascon-sur-Ariège (mars 2004), Santander, Publican Ediciones, p. 103-123.

TARRiÑo A., OLIVARES M., ETXEBARRIA N., BACETA J. I., LARRASOAÑA J. C., YUSTA I., PIZARRo J. L., CAVA A., BARANDIARÁN I., MURELAGA X., 2007, « El sílex de tipo “Urbasa”: Caracterización petrológica y geoquímica de un marcador litológico en yacimientos arqueológicos del Suroeste europeo durante el Pleistoceno superior y Holoceno inicial », Geogaceta, nº 43, p. 127-130.

TARRIÑo A., ELORRIETA I., GARCÍA-ROJAS M., 2015, « Flint as raw material in prehistoric times: Cantabrian Mountain and Western Pyrenees data », Quaternary International, $n^{\circ} 364$, p. 94-108. THIÉBAUt C., MOURRE V., CHALARD P., COLONGE D., COUdENNEAU A., DESCHAMPS M., SACCO-SONADOR A., 2012, " Lithic technology of the final Mousterian on both sides of the Pyrenees ", Quaternary International, $\mathrm{n}^{\circ} 247$, p. 182-198.

THIÉBAUT C., 2013, « Le débitage Discoïde stricto sensu : une méthode adaptée à la grande mobilité des groupes humains du Paléolithique moyen?», P@lethnologie (Dossier varia), p. 4-21. 


\section{RÉSUMÉS}

Les recherches sur le Paléolithique moyen récent du versant nord des Pyrénées bénéficient depuis plusieurs années du dynamisme des fouilles de la grotte du Noisetier (Fréchet-Aure, Hautes-Pyrénées). Celle-ci a livré des ensembles lithiques essentiellement réalisés aux dépens de matériaux locaux, complétés par des apports en silex. Des échantillonnages réalisés en différents points des formations alluviales de la Neste et d'affluents ont été comparés avec le matériel archéologique et mettent en évidence un haut degré de sélection dans l'environnement local, témoignage de connaissances fines du milieu montagnard. L'étude pétroarchéologique des silex permet de dessiner un vaste territoire connu ou parcouru. Les études en cours à la grotte Gatzarria (Ossas-Suhare, Pyrénées-Atlantiques) permettent également d'envisager de nouveaux parcours transpyrénéens.

For several years, Late Middle Paleolithic research on the Northern side of the Pyrenees has benefited from the dynamism of Le Noisetier Cave excavations (Fréchet-Aure, Hautes-Pyrénées). There, the lithic component is essentially made of local raw materials, completed by imported flint. Samples taken at different points of the alluvial formations of the Neste River and tributaries were compared with artifacts and highlight a high degree of selection in the local environment, evidence of fine knowledge of the mountain context. The petroarcheological study of flint also demonstrates a vast known or traveled territory. Ongoing studies at Gatzarria cave (Ossas-Suhare, Pyrénées-Atlantiques) also allow considering new trans-Pyrenean contacts.

\section{INDEX}

Keywords : petroarchaeology, techno-economics, territory

Mots-clés : matière première, pétroarchéologie, techno-économie, territoire

Index géographique : grotte de Gatzarria, grotte du Noisetier

\section{AUTEURS}

\section{MARIANNE DESCHAMPS}

Chercheuse, Centro de Arqueologia da Universidade de Lisboa (UNIARQ), membre associée du laboratoire Travaux et recherches archéologiques sur les cultures, les espaces et les sociétés (TRACES, UMR 5608, université Toulouse - Jean-Jaurès/CNRS)

\section{THÉO MINET}

Doctorant, laboratoire Travaux et recherches archéologiques sur les cultures, les espaces et les sociétés (TRACES, UMR 5608, université Toulouse - Jean-Jaurès/CNRS)

\section{PIERRE CHALARD}

Service régional de l'archéologie Occitanie et laboratoire Travaux et recherches archéologiques sur les cultures, les espaces et les sociétés (TRACES, UMR 5608, université Toulouse - Jean-Jaurès/ CNRS)

\section{DAVID COLONGE}

Institut national de recherches préventives (INRAP) Grand Sud-Ouest et laboratoire Travaux et recherches archéologiques sur les cultures, les espaces et les sociétés (TRACES, UMR 5608, université Toulouse - Jean-Jaurès/CNRS) 


\section{VINCENT MOURRE}

Institut national de recherches préventives (INRAP) Méditerranée et laboratoire Travaux et recherches archéologiques sur les cultures, les espaces et les sociétés (TRACES, UMR 5608,

université Toulouse - Jean-Jaurès/CNRS) ; membre de la section Préhistoire et protohistoire du CTHS

\section{CHRISTIAN SERVELLE}

Laboratoire Travaux et recherches archéologiques sur les cultures, les espaces et les sociétés (TRACES, UMR 5608, université Toulouse - Jean-Jaurès/CNRS)

\section{MARC THOMAS}

Doctorant, laboratoire Travaux et recherches archéologiques sur les cultures, les espaces et les sociétés (TRACES, UMR 5608, université Toulouse - Jean-Jaurès/CNRS) 


\title{
Montlleó (Prats i Sansor, Lérida, Espagne) : le passage du symbolisme à travers les montagnes
}

\author{
Montlleó: symbolism passing through mountains \\ Juan Luis Fernández-Marchena, Gala García-Argudo, Xavier Mangado, \\ Oriol Mercadal et Josep Maria Fullola
}

En hommage à Oriol Mercadal

Les auteurs adressent leurs remerciements à Andreu Ollé pour son soutien pendant la réalisation de ce travail, son avis à propos de certains des matériaux analysés et son aide pour l'utilisation des équipements d'analyse microscopique. Nous voulons aussi remercier le Servei de Recursos Científics $i$ Tècnics de la Universitat Rovira $i$ Virgili, ainsi que tout spécialement les chercheurs et étudiants qui rendent possible les travaux sur le terrain et l'étude des matériaux. Ce travail fait partie du projet du SERP/Université de Barcelone « La conca mitja i alta del Segre durant la Prehistòria » (2014/100479), financé par la Generalitat de Catalunya. Les travaux ont reçu aussi l'aide économique des projets du SERP HAR2017-86509 du MINECO espagnol et SGR2017-00011 de la Generalitat de Catalunya, et des projets de l'IPHES PGC2018-093925-B-C32 (MICINN-FEDER) et 2017 SGR 1040. Juan Luis Fernández-Marchena bénéficie d'un contrat pré-doctoral FPI MINECO/ FSE (BES-2015-074931) lié au projet HAR2014-55131. Gala García-Argudo bénéficie d'un contrat pré-doctoral APIF2017 de l'Universitat de Barcelona.

1 Le gisement de Montlleó a livré une grande variété d'objets singuliers. Nous avons donc décidé d'ouvrir un axe de recherche sur leurs caractéristiques et les problèmes que pose chaque catégorie de ces objets. Il s'agit d'éléments manufacturés ou naturels, d'utilisation quotidienne, avec une finalité ornementale et/ou symbolique; certains semblent avoir été ramassés uniquement parce qu'ils étaient rares. L'étude de tous ces objets dans le contexte global du territoire aide à mieux comprendre la fonctionnalité de ces anciennes occupations humaines des Pyrénées. 
2 Ce travail est une première approche de l'étude de trois groupes d'éléments qu'on peut mettre en relation avec le monde symbolique des sociétés de chasseurs-cueilleurs : la parure, les quartz et prismes, et enfin les pigments.

\section{Les objets symboliques et culturels}

3 Pendant les deux dernières décennies, le site de Montlleó a fourni un grand nombre de vestiges archéologiques en provenance d'occupations du Dernier Maximum glaciaire. La révision menée récemment sur ces matériaux a mis en évidence la présence en nombre important d'éléments de la culture matérielle liés à l'univers symbolique de ces communautés.

4 Ces vestiges peuvent être classés selon trois grands groupes : la parure, les matières colorantes et une collection de matériaux lithiques à caractère non utilitaire (Moncel et al. 2012). La parure présente un ensemble remarquable de malacofaune d'origine marine, atlantique et méditerranéenne. Les éléments lithiques à caractère non utilitaire deviennent beaucoup plus complexes si on les envisage comme des éléments symboliques de la culture matérielle. Dans la plupart des cas, il s'agit de cristaux de quartz, mais d'autres minéraux insolites sont aussi présents, tous allochtones. Tous ces éléments ont été utilisés dans le domaine symbolique par des populations documentées ethnographiquement (Levi 1978) et par des groupes humains préhistoriques (Barge et Carry 1986). Enfin, les matières colorantes figurent parmi les éléments archéologiques les plus controversés. D'un côté, elles sont associées à tout un ensemble de comportements sociaux et symboliques et culturels très complexes dans presque la totalité des sociétés humaines étudiées ethnographiquement; de l'autre, on leur reconnaît tout un ensemble d'usages fonctionnels dans le domaine médical et celui des activités de la vie quotidienne (Rifkin 2015a, Rosso 2017).

\section{Le gisement de Montlleó}

5 Montlleó est un gisement de plein air, dans la commune de Prats i Sansor (Lérida, Espagne), sur une petite colline connue (Coll de Saig), sur un petit affleurement rocheux de conglomérats d'âge plio-pléistocène associés à un paléocanal lié à un éventail alluvial. Le site se trouve à 1144 mètres d'altitude, soit environ 920 mètres audessus de la rivière du Sègre, et à quelque 110 kilomètres en ligne droite de la côte méditerranéenne actuelle la plus proche (Mangado et al. 2009a).

6 L'emplacement du site est stratégique, puisqu'il se situe sur le chemin transpyrénéen empruntant le col de la Perxe (alt. $1581 \mathrm{~m}$ ), qui met en liaison le bassin de l'Èbre avec le golfe du Lion, par la vallée du Sègre et de la Têt (fig. 1). Selon les données actuellement connues, il s'agirait du passage le plus occidental accessible depuis la Méditerranée pendant le Dernier Maximum glaciaire. C'est justement cette position de passage transpyrénéen du site qui donne à l'étude du matériel symbolique en provenance de Montlleó une valeur particulière. 
Fig. 1. - Localisation du site de Montlleó (Prats i Sansor, Lérida, Espagne).

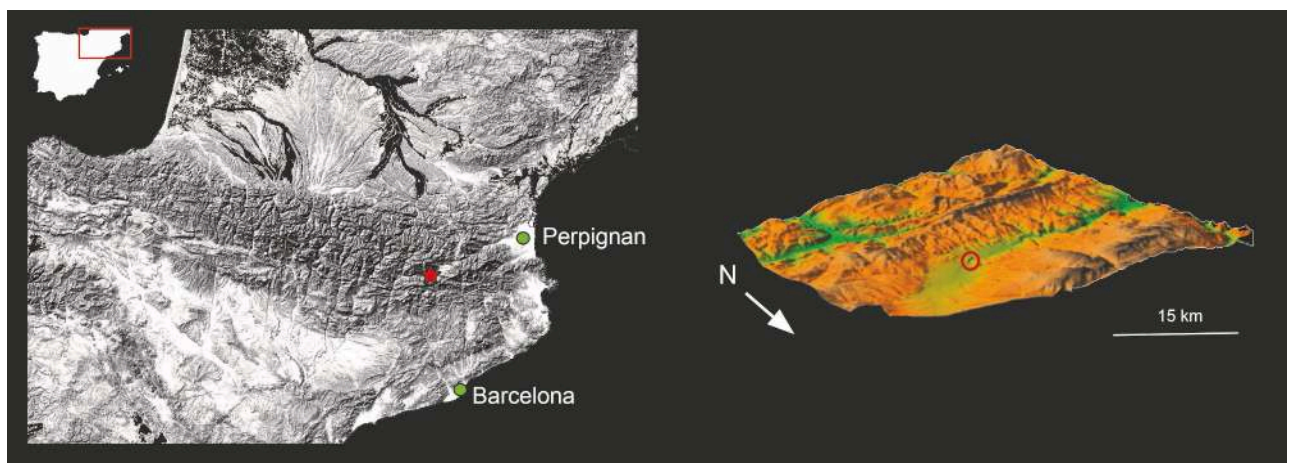

D’après Fernández-Marchena et al. 2016.

7 La séquence chronostratigraphique du site (tabl.1) commence au début du Magdalénien moyen (Mangado et al. 2005). Elle est caractérisée par la présence de quelques triangles scalènes. Pour cette première phase, nous disposons de deux dates ${ }^{14} \mathrm{C}$ : $18704 \pm 89$ cal. BP (Fullola 2001) et $18710 \pm 80$ cal. BP (Mangado et al. 2009b) cohérentes du point de vue chronologique avec cette même période dans la région pyrénéenne centre-occidentale (Pétillon et al. 2016). La plupart des matériaux ont été attribués au Magdalénien inférieur; ils sont datés d'environ $20320 \pm 120 \mathrm{cal}$. BP (Mangado et al. 2009b) et se caractérisent par l'abondance des microlamelles à dos. Ces dernières années, une occupation plus ancienne a été repérée. Elle est en cours de fouille ; toutefois, nous avons déjà une date (22 $700 \pm 233$ cal. BP) attribuable aux phases finales du Solutréen, voire du Badegoulien (Mangado et al. 2015). Cette séquence fait de Montlleó une des plus anciennes occupations humaines du Paléolithique supérieur sur le versant sud des Pyrénées orientales.

Tabl. 1. - Site de Montlleó (Prats i Sansor, Lérida, Espagne) : datations ${ }^{14} \mathrm{C}$ calibrées avec le programme OxCal v4.3.2 Bronk Ramsey (2017).

\begin{tabular}{ccc} 
Référence & Matière & Années cal. BP \pm écart type \\
\hline OxA-9017 & Equus sp., molaire & $18704 \pm 89$ \\
OxA-14034 & Charbon & $18710 \pm 80$ \\
OxA-X2234-52 & Equus sp., molaire & $20320 \pm 120$ \\
OxA-23973 & Charbon & $22700 \pm 233$ \\
\hline
\end{tabular}

Le site a été divisé en trois secteurs de fouille, A, B et C, chacun d'entre eux ayant sa propre séquence stratigraphique. Le secteur A est considéré comme stérile du point de vue archéologique à cause du haut degré d'altération par des processus de lessivage du sédiment. C'est donc dans les secteurs $B$ et $C$, avec respectivement 38 et 11 mètres carrés fouillés, que nous avons collecté les matériaux analysés dans cette étude.

\section{Matériaux et méthodes}

Les matériaux analysés dans ce travail ont été récoltés sur le site pendant les fouilles comprises entre 1999 et 2015. Les éléments de parure sont pour la plupart composés à partir de la malacofaune et comprennent quelques craches de cervidés. Concernant les matières colorantes, nous avons ajouté à la collection identifiée pendant les travaux sur le terrain d'autres éléments plus ambigus, récoltés par prévention, qui ont été par la suite identifiés avec certitude comme des matières colorantes en laboratoire. 

de ces matériaux comme éléments dotés d'une valeur symbolique, en particulier dans le cas des cristaux de quartz, nous ont obligés à faire une description précise de leurs caractéristiques.

\section{Méthodologie}

Nous avons réalisé des analyses avec différents équipements optiques, macroscopiques et microscopiques (fig. 2). Les matériaux ont subi une première évaluation de visu et ont été ensuite étudiés de façon complémentaire par d'autres moyens plus précis, selon leurs caractéristiques spécifiques (Borel et al. 2014, Ollé et al. 2016).

Dans le cas de la malacofaune et des craches de cervidés, nous avons utilisé pour l'observation macroscopique un stéréomicroscope. Pour des pièces qui demandaient une analyse plus approfondie, nous avons travaillé avec un microscope numérique, qui nous a permis d'effectuer des analyses mixtes à fort et à faible grossissement ainsi que d'élaborer des modèles en trois dimensions.

Dans le cas des minéraux, nous en avons choisi un certain nombre susceptibles de porter des vestiges de résidus, pour en faire l'analyse au microscope optique à lumière réfléchie et arriver à une première caractérisation. Enfin, dans plusieurs cas - comme ceux de certains ocres - nous avons utilisé le microscope électronique à balayage environnemental pour une première caractérisation élémentaire.

Fig. 2. - Équipements optiques, macroscopiques et microscopiques utilisés dans cette étude.

A
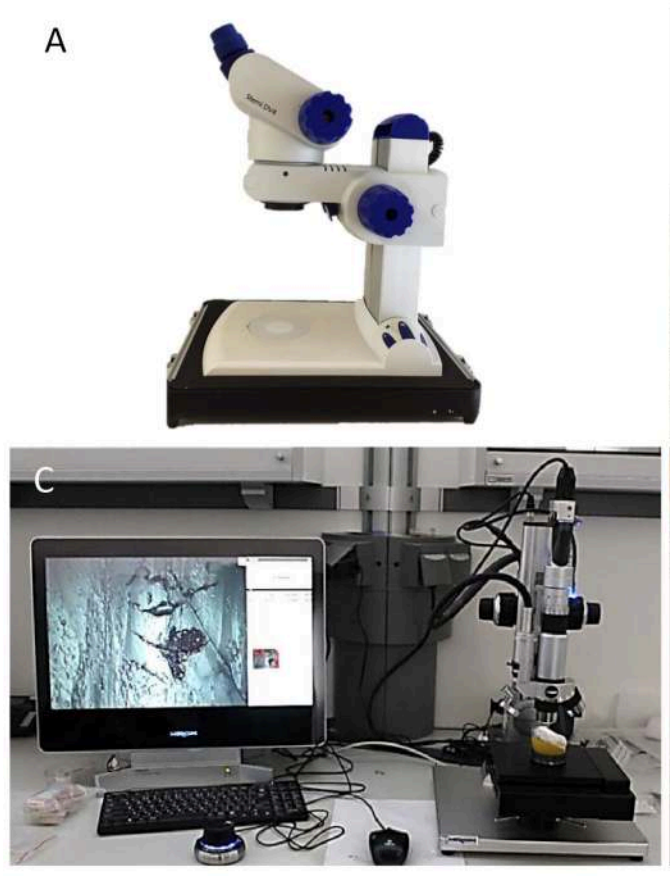
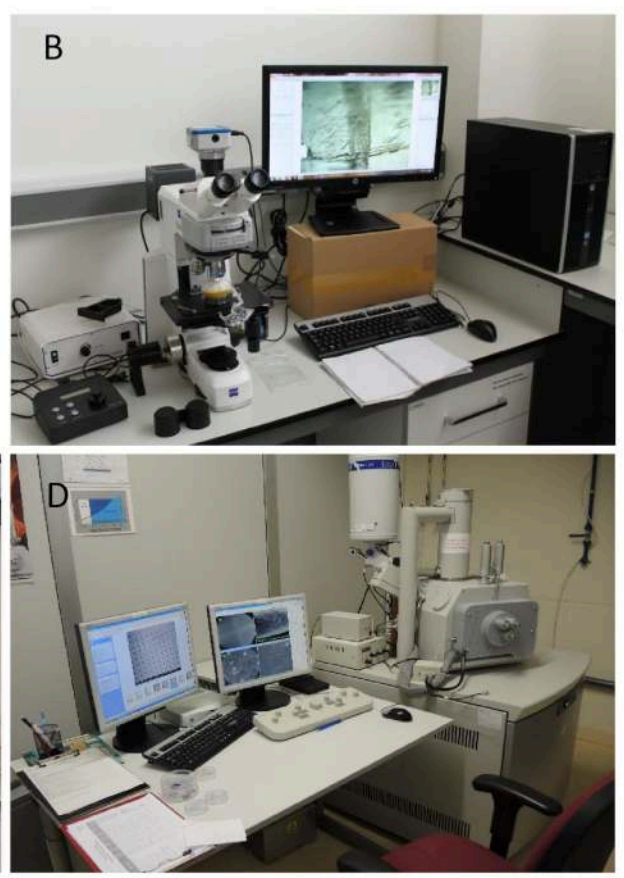

A : Stéréomicroscope (Zeiss Stemi DV4/DR). B : Microscope optique à lumière réfléchie (Zeiss Axioscope A1). c : Microscope numérique (Hirox KH-8700). D : Microscope électronique à balayage environnemental (FEl Quanta 600).

Photos Juan Luis Fernández-Marchena. 


\section{La parure}

14 aux objets de parure découverts au sein de gisements préhistoriques (Shaw et Langley 2017, Sprague 2004, Then-Obluska 2015, Wiessner 1997, Vanhaeren 2002). À travers ces approches, les préhistoriens ont accordé à ces parures plusieurs fonctions. L'interprétation la plus commune est qu'elles jouent le rôle d'éléments de transmission de l'identité sociale, ethnique et personnelle (Joyce 2005, Vanhaeren 2005, Wobst 1977). La présentation visuelle de ce type d'information serait orientée vers des individus rencontrés en dehors du groupe, mais appartenant au même contexte culturel. De façon complémentaire, les parures renvoient aux contextes socio-économiques dans lesquels les réseaux d'interaction sur des longues distances - et avec un nombre chaque fois plus élevé d'individus - deviennent nécessaires (Kuhn et al. 2001).

15 L'ensemble des objets de parure récoltés à ce jour est constitué de 58 éléments: 55 mollusques marins et trois craches de Cervus elaphus. Bien que cet ensemble ne soit pas quantitativement important, il faut souligner sa diversité taxonomique, avec 8 espèces marines différentes au total (tabl. 2). Les mollusques utilisés appartiennent à deux grandes familles : Scaphopoda et Gastropoda. Les scaphopodes sont représentés par le genre Antalis. Pour les gastéropodes, qui constituent la majorité de la collection, sept espèces ont été identifiées : Homolopoma sanguineum, Tritia neritea, Tritia incrassata, Tritia reticulata, Tritia heynemanni, Trivia sp. et Littorina obtusata (fig. 3).

Tabl. 2. - Site de Montlleó (Prats i Sansor, Lérida, Espagne) : décompte des espèces de mollusques utilisées dans les objets de parure.

\begin{tabular}{|c|c|c|c|c|c|c|c|c|c|}
\hline $\begin{array}{l}\text { Antalis } \\
\text { sp. }\end{array}$ & $\begin{array}{l}\text { Homalopoma } \\
\text { sanguineum }\end{array}$ & $\begin{array}{c}\text { Tritia } \\
\text { incrassata }\end{array}$ & $\begin{array}{l}\text { Tritia } \\
\text { reticulata }\end{array}$ & $\begin{array}{c}\text { Tritia } \\
\text { neritea }\end{array}$ & Trivia sp. & $\begin{array}{c}\text { Tritia } \\
\text { heynemanni }\end{array}$ & $\begin{array}{l}\text { Littorina } \\
\text { obtusata }\end{array}$ & $\begin{array}{l}\text { Cervus } \\
\text { elaphus, } \\
\text { (craches) }\end{array}$ & Total \\
\hline 8 & 8 & 3 & 2 & 29 & 2 & 2 & 1 & 3 & 58 \\
\hline
\end{tabular}

Fig. 3. - Site de Montlleó (Prats i Sansor, Lérida, Espagne) : exemples d'éléments de parures.

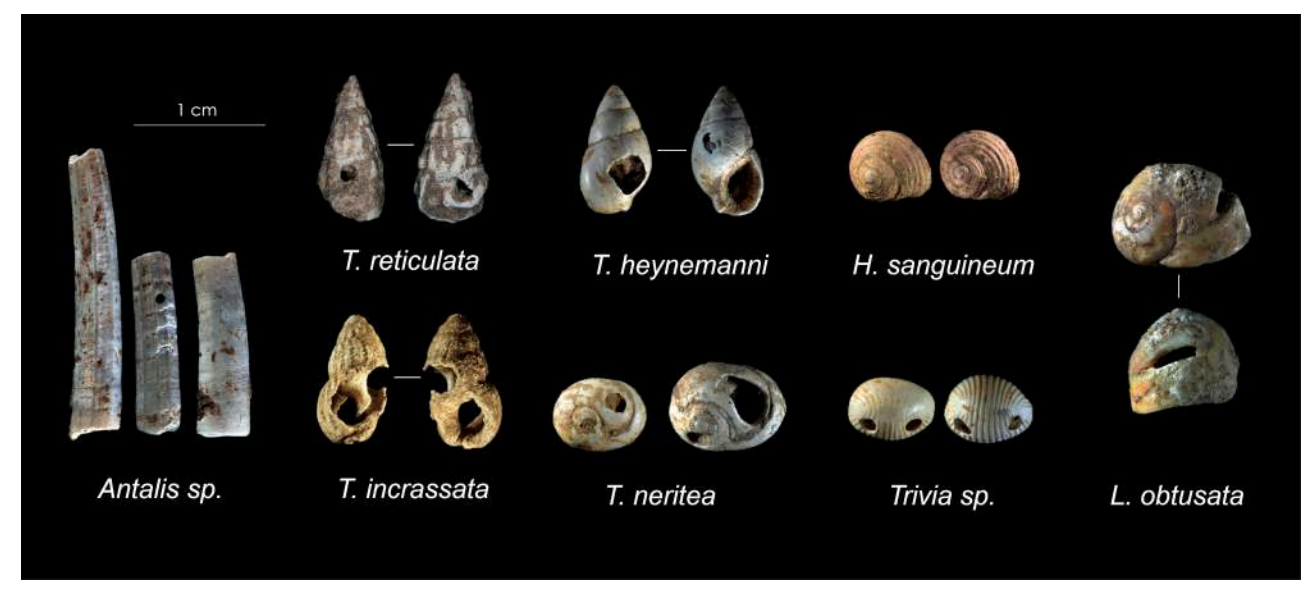

Photos Gala García-Argudo.

Tritia neritea est l'espèce dominante, avec plus de $50 \%$ de l'ensemble. Ce fait met en évidence une nette préférence pour des objets de parure à morphologie globuleuse et de petite taille. Toutes les coquilles récupérées jusqu'à maintenant à Montlleó 
appartiennent à des mollusques d'origine méditerranéenne, à l'exception de deux espèces : Littorina obstusata et Tritia heynemanni, strictement atlantiques (Eriksen 2002, Poppe et Goto 1991).

L'état de préservation des coquilles a été affecté par des processus de déshydratation et par la précipitation du carbonate de calcium $\left(\mathrm{CaCO}_{3}\right)$, qui ont pu masquer ou même effacer une partie des stigmates techniques. Trois exemplaires de T. neritea montrent une perforation non anthropique, ou début de perforation causée par des prédateurs (Muricidae ou Naticidae; Farinati et al. 2006).

18 Malgré l'action de ces agents taphonomiques, l'analyse des perforations des coquillages a mis en évidence que les techniques les plus utilisées sont la fracturation, la percussion indirecte et la pression, effectuées à la fois depuis l'intérieur et l'extérieur de la coquille (García-Argudo 2017). Les deux exemplaires de Trivia sp. montrent une double perforation. Il faut souligner aussi l'emploi de la technique du sciage, utilisée pour créer un trou au dos de l'exemplaire de L.obtusata. C'est la première fois que nous identifions ce type de technique d'usure pour perforer des coquilles de cette espèce (fig. 4).

Fig. 4. - Site de Montlleó (Prats i Sansor, Lérida, Espagne) : exemples de perforations.

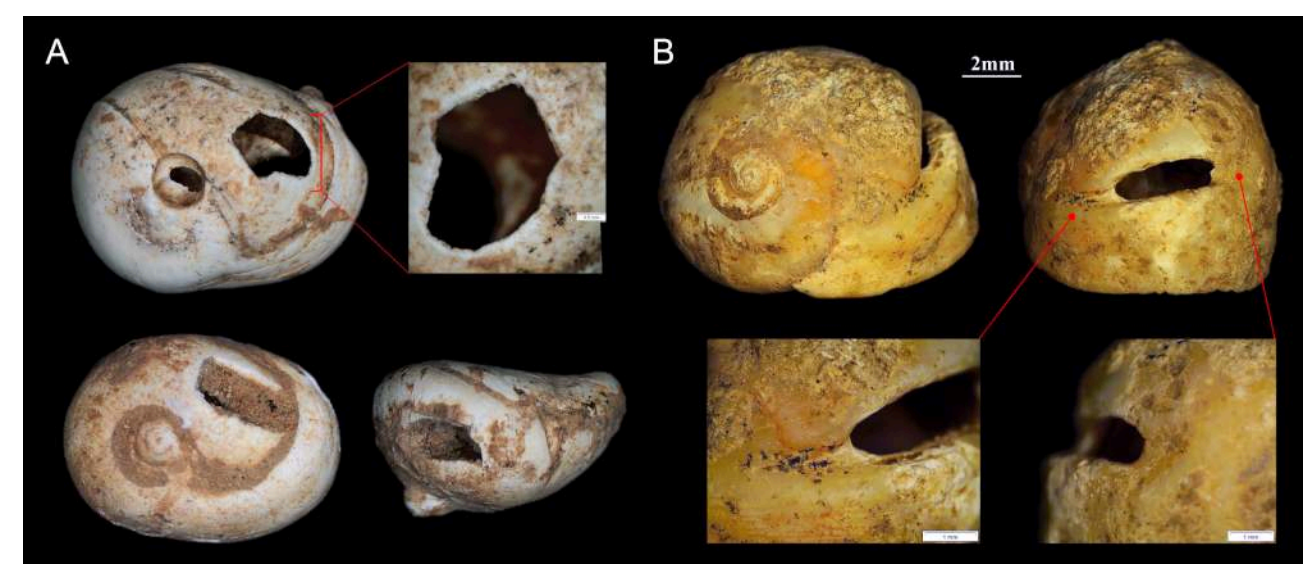

A : Tritia neritea. B : Littorina obtusata.

Photos Gala García-Argudo.

19 Pour les scaphopodes, nous avons pu identifier uniquement un système de fracturation en coche, sur les extrémités antérieures de la plupart des exemplaires (Perlès 2018). Ces casses peuvent répondre au processus de fracture pour l'élaboration des perles, mais peuvent aussi être le résultat de l'usure de ces éléments en suspension (Vanhaeren et D’Errico 2001).

20 L'étude des polissages étudiés sur les bords des perforations et sur le labre externe des gastéropodes nous a fourni dans certains cas des indications sur le moyen de suspension. L'utilisation de plusieurs types de suspension semble être conditionnée par le taxon, c'est-à-dire qu'il existe une sélection différentielle du moyen de suspension en fonction des caractéristiques physiques et morphologiques de chaque espèce.

21 La découverte d'exemplaires sans perforation parmi les espèces les plus représentées, T. neritea et $H$. sanguineum, nous permet de prendre en considération l'accumulation de matière première, soit destinée à être perforée sur le site, soit à être échangée avec d'autres groupes en tant que support brut. 


\section{Les quartz et prismes}

\section{Classification et formation du quartz} chercheurs comme un matériau local, souvent exploité par des groupes humains qui ont peu accès à d'autres matières premières pour le débitage ou à des matériaux de meilleure qualité. Par conséquent, les sites recélant des quantités importantes de quartz sont localisés dans des zones géographiques où les matières premières permettant une bonne standardisation du débitage sont peu accessibles (Knutsson et al. 2016).

d'approvisionnement et de ramassage de la matière première, il faut prendre en compte les processus de formation du quartz. Le quartz apparaît en veines et filons, soit en position primaire, soit dans des éboulis. Les filons sont le résultat du remplissage des fissures de la croûte terrestre par stress, pression ou température (Bons et al. 2012). La pression peut provoquer l'ascension des fluides à haute température, qui se solidifient en filons quand la température baisse (Bons 2001). Le quartz se forme quand la pression et la température font surgir des eaux thermales riches en tectosilicates SiO2, généralement à moyenne température $\left(350-400^{\circ}\right)$. Ces processus peuvent se produire dans n'importe quel contexte géologique, autant sédimentaire que rocheux : roches sédimentaires, métamorphiques ou ignées (Bons 2001). Comme les filons peuvent apparaitre dans tout type de contexte, les variétés de quartz filonien sont très diverses, étant donné que pendant l'ascension des fluides par la fissure, les filons incorporent plusieurs inclusions de l'environnement géologique immédiat. Pendant le refroidissement $\mathrm{du}$ fluide, celui-ci devient un agrégat polycristallin formé par les tectosilicates avec une multiplicité d'inclusions minérales, liquides ou gazeuses apportées par le milieu. Ces éléments apportés sont habituellement ceux qui donnent au quartz sa couleur.

Malgré tout, le quartz est un minéral de composition assez homogène, mais hétérogène en structure et morphologie (Lombera Hermida 2008) à cause des inclusions, spécialement sur les parois de la fissure, mais aussi à cause des différences de température dans les diverses parties du filon pendant le processus de refroidissement (Collina-Girard 1997). Ces différences sont à l'origine de l'hétérogénéité de la granulométrie de l'agrégat (fig. 5). 
Fig. 5. - Schéma du support de formation des différents types de quartz traités dans le texte.

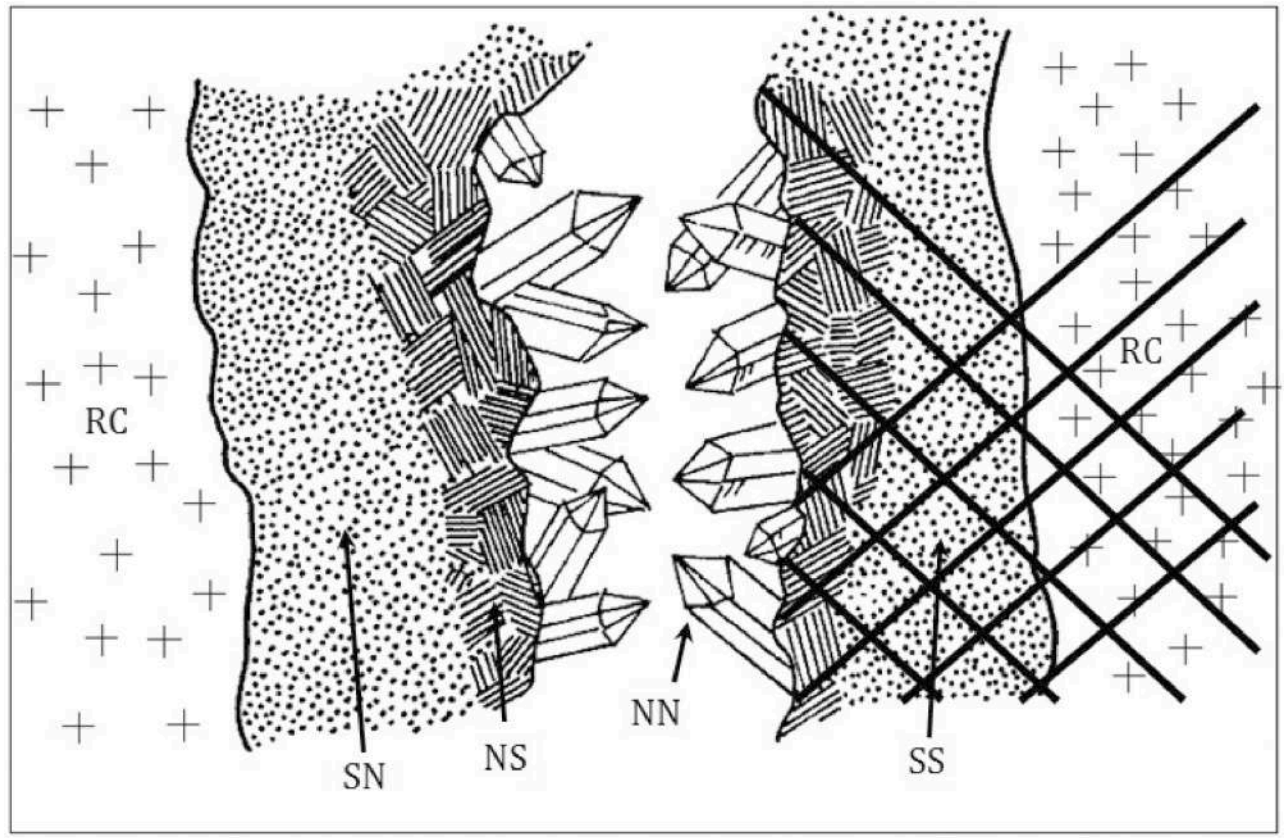

ss : présence de granulométrie et de fissures. sN : présence de granulométrie, absence de fissures. Ns : absence de granulométrie et présence de fissures. NN : absence de granulométrie et de fissures. RC : roche encaissante.

D’après Collina-Girard 1997 et Lombera Hermida 2008.

Les quartz de ce groupe sont appelés xénomorphes en raison de leur hétérogénéité (Mourre 1996), puisqu'ils peuvent être classés par leur structure morphologique (Martínez Cortizas et Llana Rodríguez 1996). Cette nouvelle division est très utile pour définir les qualités du matériel au débitage, parce qu'elle prend en compte séparément la granulométrie et la présence de fissures (S) ou leur absence $(\mathrm{N})$. Les quartz les plus homogènes (NN) peuvent être filoniens, c'est-à-dire xénomorphes, mais le plus souvent ils appartiennent au groupe des quartz automorphes (Mourre 1996).

Les quartz automorphes sont formés d'un cristal unique, développé sous des conditions stables de haute température et de pression à travers la nucléation des tétraèdres de silice (Dibble 2002). Leur formation a lieu en général dans des géodes, très souvent dans les mêmes filons de quartz, même s'ils peuvent aussi apparaître dans d'autres variétés de quartz, comme du quartz cryptocristallin sédimentaire (chert). Même s'ils peuvent croître en partant de la surface de la géode, dans certains cas ils affleurent de la cristallisation même, sous forme de druses. Les prismes formés dans ces milieux sont les plus fréquents ; comme ils se développent en partant de la paroi, ils possèdent un seul apex (Dibble 2002).

Les quartz automorphes peuvent aussi prendre la forme d'éléments "flottants " (Dibble 2002) quand ils se développent à l'intérieur des sédiments; dans ce cas, ils présentent deux apex. Ces cristaux existent uniquement dans des milieux géologiques très précis, et ce fait permet de localiser facilement les points d'affleurement.

\section{Quelques remarques sur les quartz récupérés à Montlleó}

L'approvisionnement en quartz à Montlleó est varié, et il répond à des stratégies de ramassage diverses. Malgré le fait que la localisation des points de ramassage du quartz 
est a priori locale, nous n'avons pas encore défini toutes les zones d'affleurement possibles. Globalement, il y a deux grands groupes de quartz xénomorphes de bonne aptitude à la taille (fig. 6). Le meilleur est un quartz gris bleuté à grain moyen/gros et sans fissures (SN) ; l'autre est connu comme quartz laiteux, beaucoup plus varié sur le plan morphostructurel, avec certains vestiges très aptes à la taille (NN).

Fig. 6. - Site de Montlleó (Prats i Sansor, Lérida, Espagne) : exemples de quartz xénomorphes et automorphe.

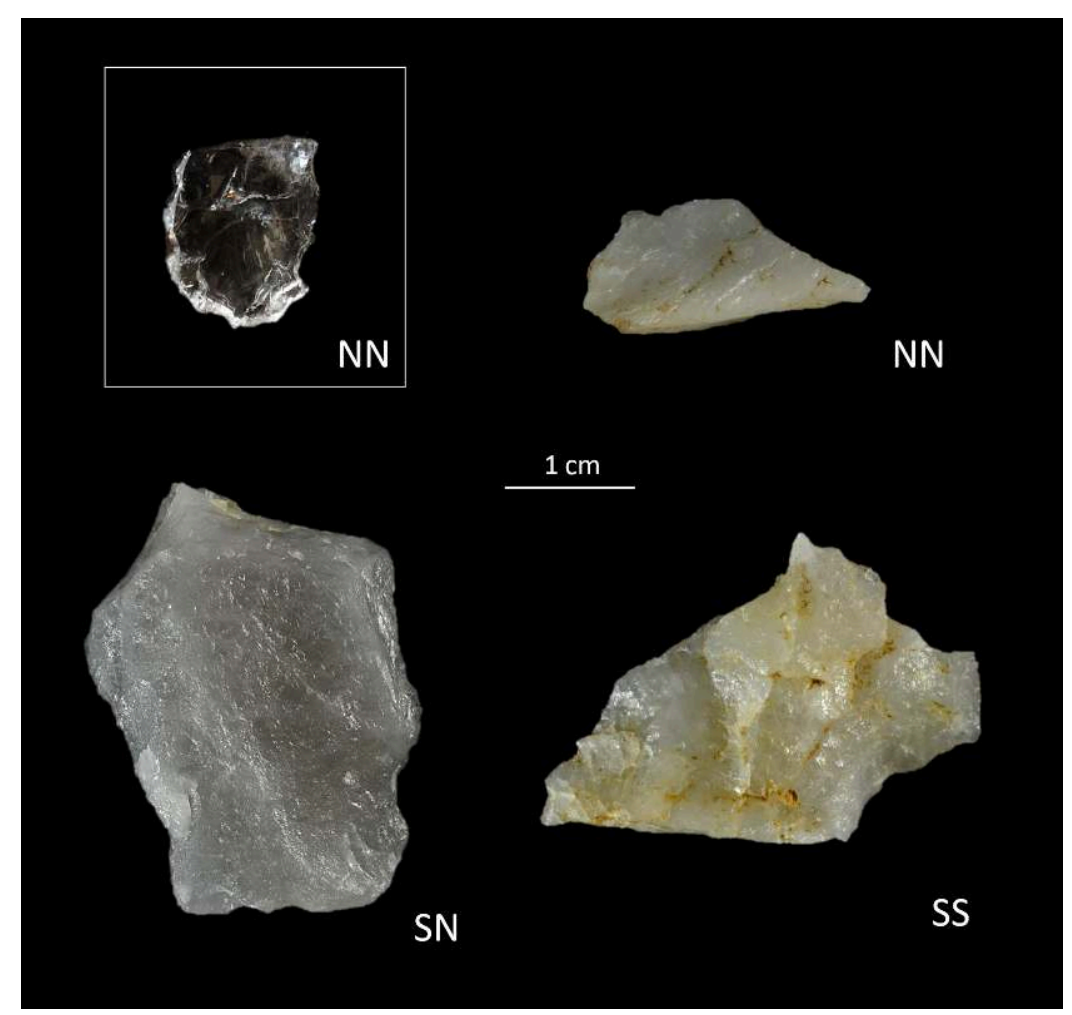

ENCADRÉ : quartz automorphe. ss : présence de granulométrie et de fissures. SN : présence de granulométrie, absence de fissures. Ns : absence de granulométrie et présence de fissures. NN absence de granulométrie et de fissures.

Photos Juan Luis Fernández-Marchena.

L'analyse au niveau macroscopique et microscopique du quartz automorphe de Montlleó a abouti à la définition de trois types de support et matériaux différents au minimum. Les supports les mieux représentés sur le site sont les prismes, même si les druses et des plaquettes cristallines sont aussi présentes dans la collection; ces plaquettes pourraient être des fragments de gros cristaux, mais nous n'avons pas encore récupéré de fragment d'apex de taille suffisante pour valider cette hypothèse.

31 La présence d'un quartz appelé « jacynthe de Compostelle » ouvre une nouvelle voie de recherche à propos de la provenance des quartz du site (fig. 7). Ce type de prisme se développe uniquement dans des sédiments du Keuper (Gil Marco 2013), qui n'existent pas en Cerdagne. Ceux qui sont bipyramidaux sont aussi appelés hématoïdes à cause de leur teinte rouge, mais ils peuvent se développer sans aucune couleur, ou avec d'autres teintes que le rouge (Gil Marco 2013). Pour cette raison, quelques prismes de cristal de roche de Montlleó, définis jusqu'à présent comme d'origine locale, pourraient être en réalité allochtones, du fait de la présence d'un double apex (fig. $7 b$ ). 
Fig. 7. - Site de Montlleó (Prats i Sansor, Lérida, Espagne) : prismes allochtones.

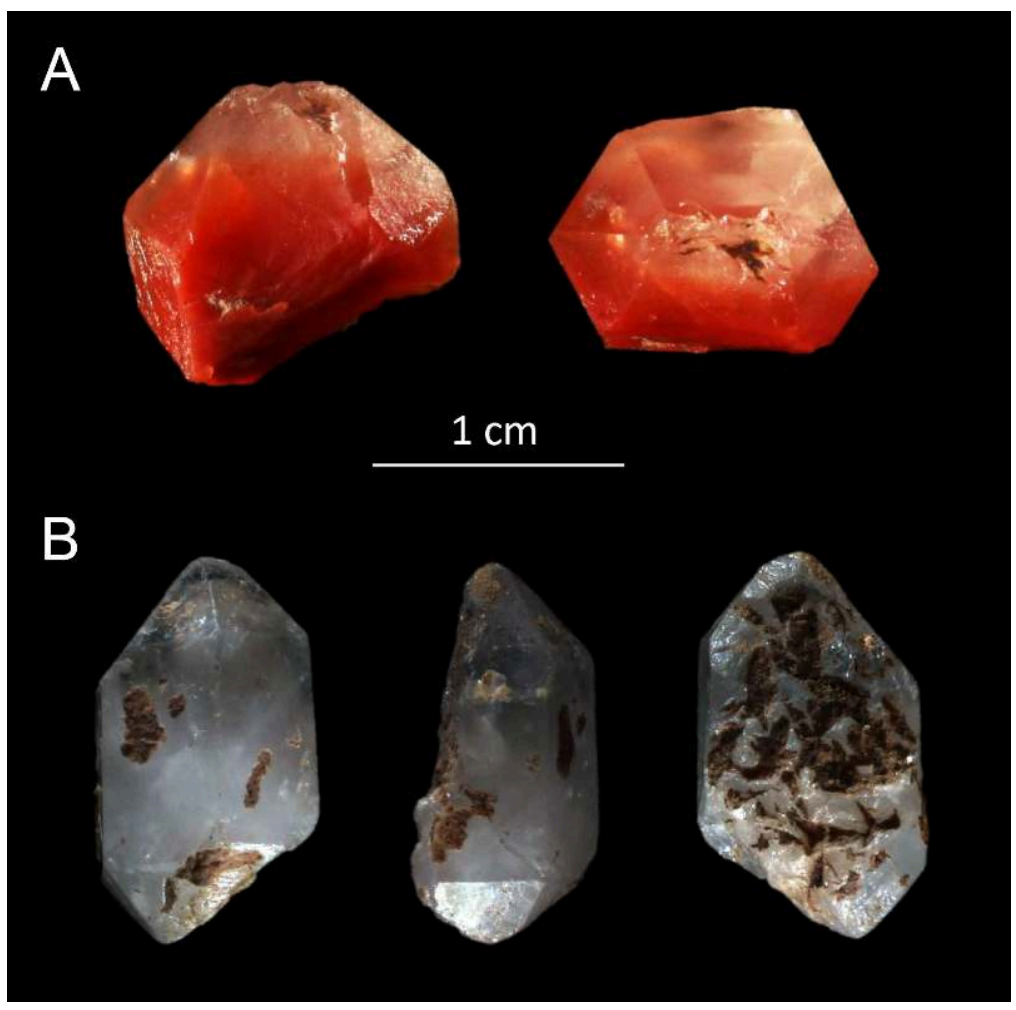

A : jacinthe de Compostelle rouge. $\mathbf{B}$ : jacinthe de Compostelle transparent.

Photos Gala García-Argudo.

32 Ces supports permettent, de plus, de démontrer un ramassage sélectif à deux niveaux ; l'un, tout à fait utilitaire et orienté vers le débitage, et l'autre non utilitaire. Ce deuxième niveau comprendrait tous les prismes et microprismes allochtones de la vallée de la Cerdagne.

\section{Les pigments}

\section{L'ocre et les substances colorantes}

Les substances colorantes, réunies génériquement sous le terme "ocre », sont un des matériaux les plus controversés en archéologie préhistorique. La caractérisation de la composition de la matière ainsi que la terminologie sont à la base de difficultés dans la détermination de leurs propriétés et de leur emploi. Une partie de ces difficultés repose sur leur attribution à la sphère magique et symbolique dans les débuts de l'archéologie préhistorique. Avec l'apparition de la New Archaeology dans les années 1960, ces matériaux seront laissés de côté jusqu'à pouvoir être analysés de la manière la plus scientifique possible (Audouin et Plisson 1982). Des analyses ont commencé à être publiées régulièrement depuis deux décennies à peine, et aujourd'hui ces publications sont extrêmement nombreuses.

La dichotomie fonctionnalité/comportement symbolique et culturel est un autre des problèmes qui affectent encore l'analyse de ces matériaux, bien que les deux interprétations ne soient pas exclusives, sauf dans un nombre réduit de cas. Un exemple en est l'utilisation de l'ocre comme enduit corporel chez les Himbas (Namibie), 
autant comme moyen d'identité tribal que pour protéger la peau (Rifkin 2015a). Les études ethnographiques et ethnoarchéologiques ont permis de mettre en évidence un grand nombre d'usages de ces matériaux, aussi bien pour des activités du quotidien qu'avec des finalités symboliques et culturelles (Rosso 2017). Plusieurs de ces usages, protection pour la peau, répulsif contre les insectes, cautérisant, imperméabilisant, etc., ont été compilés par Audouin et Plisson (1982), bien qu'ils n'aient pas été vérifiés expérimentalement.

Les propriétés et la couleur des pigments élaborés à partir d'oxydes de fer peuvent être modifiées au fur et à mesure des besoins. La couleur de l'ocre peut être changée par traitement thermique du jaune au rouge, du rouge au pourpre et du pourpre au noir, par augmentation progressive de la température (Audouin et Plisson 1982). Cette procédure modifie aussi les caractéristiques physicochimiques de l'ocre. Il a été démontré expérimentalement que l'application d'ocre jaune et d'ocre rouge (un ocre jaune traité thermiquement) en cours de tannage sur deux zones différentes d'une même peau entraîne une bonne conservation de la peau traitée avec l'ocre rouge seulement (Audouin et Plisson 1982), du fait du caractère asséchant de ce matériau, qui de plus est antiseptique et inhibiteur de la collagénase, empêchant ainsi la putréfaction des restes organiques (Audouin et Plisson 1982, Rifkin 2011).

Par conséquent, l'ocre utilisé pour des activités quotidiennes - traitement des peaux, anti-moustiques (Rifkin 2015b), fabrication d'adhésifs (Wadley 2005) ou même écran solaire (Rifkin et al. 2015) - serait tout à fait utilisable pour la peinture corporelle symbolico-culturelle (Fiore 2005, Rifkin et al. 2015), l'art rupestre (Clottes et al. 1990) ou l'art mobilier (Henshilwood et al. 2009).

\section{Les substances colorantes à Montlleó}

37 Une très grande quantité de minéraux colorants a été mise au jour à Montlleó, avec un éventail chromatique très diversifié (fig. 8). Nous n'avons pas pu déterminer avec certitude s'il existait un ramassage différentiel des variétés d'oxydes de fer, ou s'il y a aussi d'autres matières colorantes utilisées pendant la Préhistoire, comme le dioxyde de manganèse, le lignite, etc. 
Fig. 8. - Site de Montlleó (Prats i Sansor, Lérida, Espagne) : exemples de la diversité chromatique des pigments.

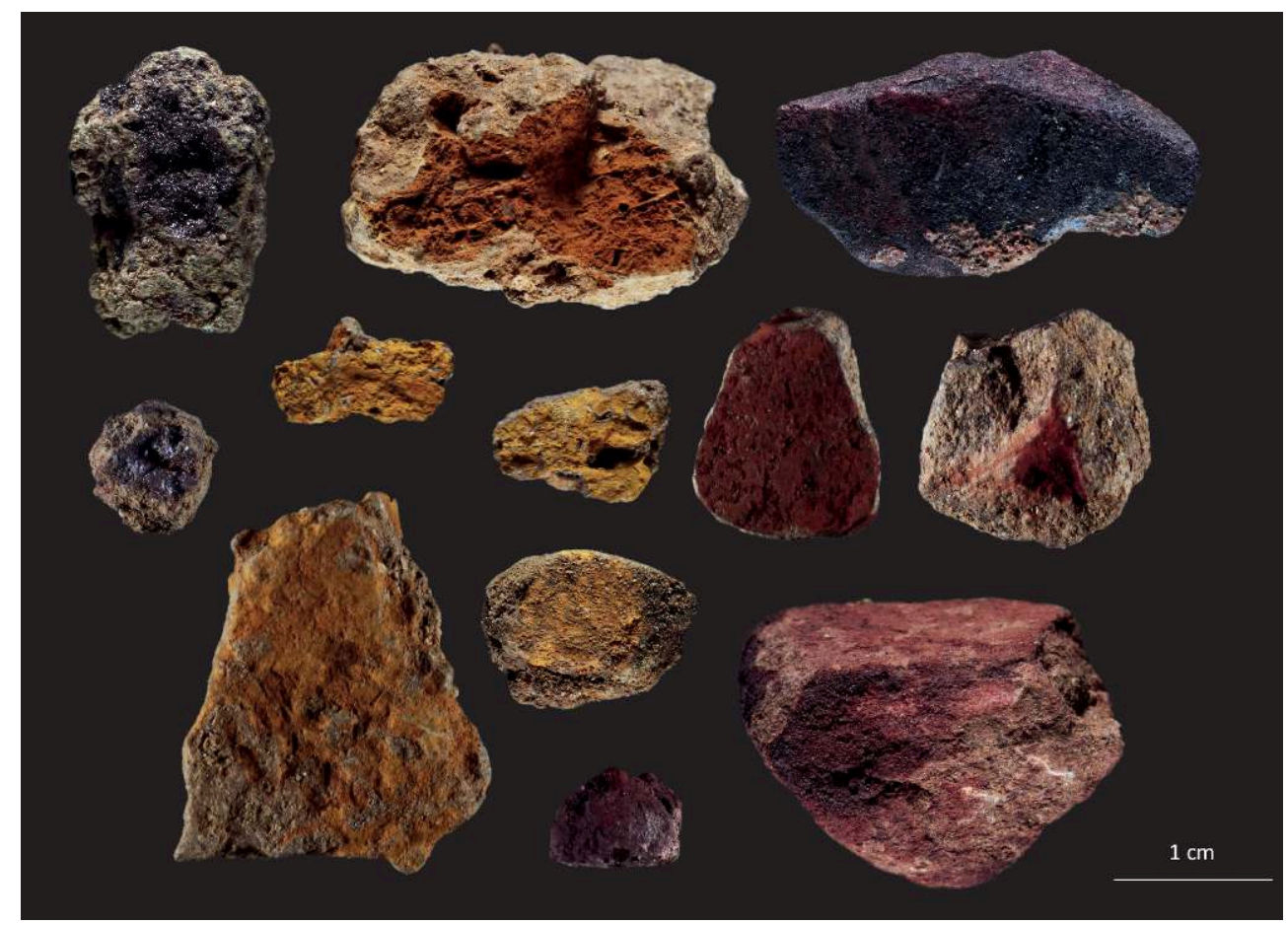

Photos Gala García-Argudo.

38 L'état de préservation de ces vestiges est médiocre, mais dans certains cas il a été possible de déterminer des surfaces légèrement polies, vraisemblablement par une utilisation en tant que crayon. Il faut souligner la présence d'un bloc d'ocre rouge portant sur l'un de ses bords une série d'incisions parallèles soignées (fig. 9). 
Fig. 9. - Site de Montlleó (Prats i Sansor, Lérida, Espagne) : bloc d'ocre rouge portant des stries.

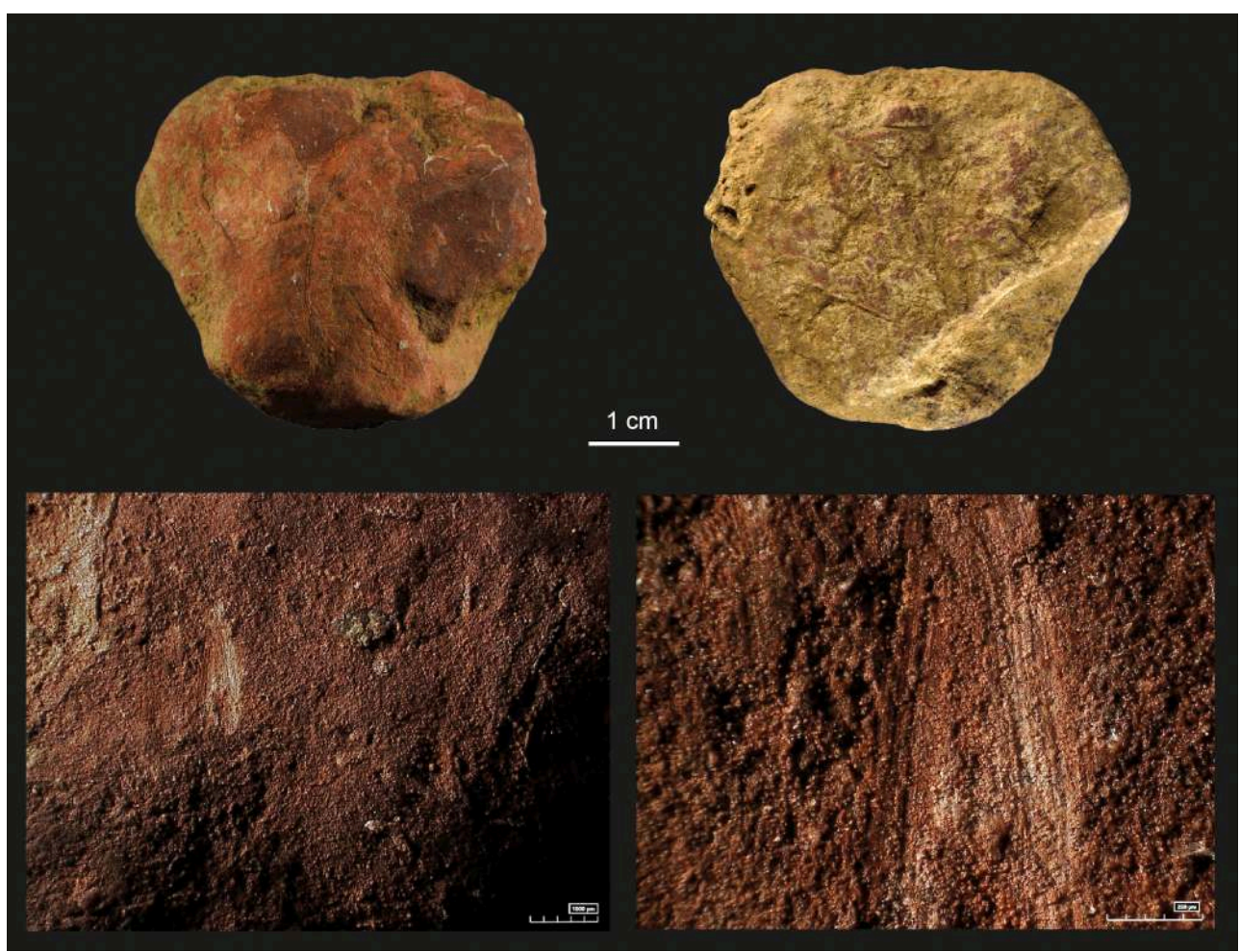

Photos Gala García-Argudo.

La fonction des ocres à Montlleó demeure encore inconnue, mais la présence d'une telle diversité chromatique semble indiquer des fonctions symboliques et culturelles. Pour l'instant, les seuls éléments sur lesquels nous avons pu identifier la présence d'ocre rouge sont des supports macrolithiques utilisés pour broyer l'ocre et le convertir en poudre (fig. 10), ainsi que sur certains grattoirs portant des taches, et sur les vestiges d'emmanchement d'un projectile. Ces faits nous indiquent que l'ocre rouge apparaitrait spécialement liée à des activités du quotidien. L'utilisation des autres variétés chromatiques n'a en revanche pas pu être précisée. 
Fig. 10. - Site de Montlleó (Prats i Sansor, Lérida, Espagne) : présence d'ocre rouge sur un support macrolithique.

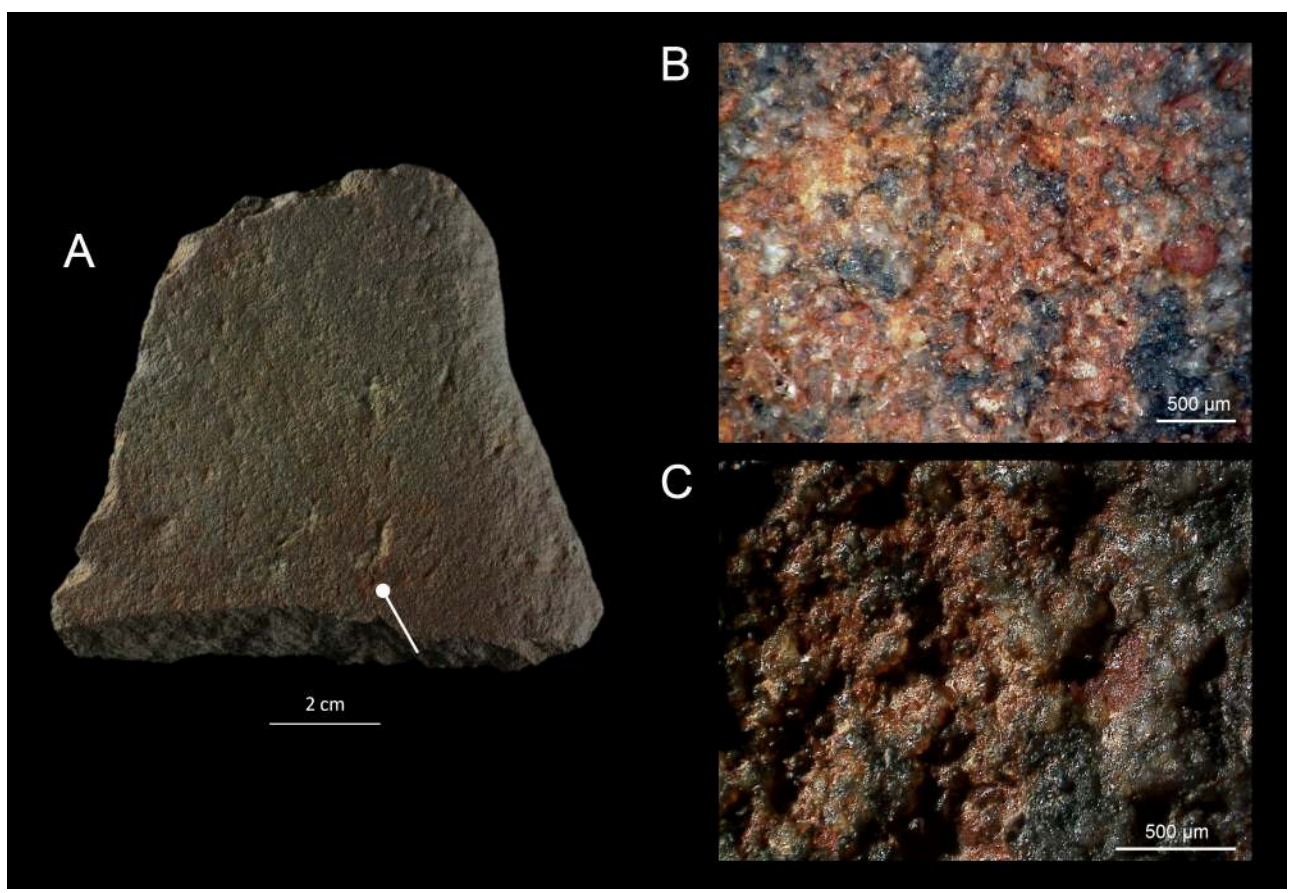

A : plaquette utilisée comme socle pour broyer de l'ocre. B : détail au microscope numérique. c : le même détail avec lumière oblique.

Photos Gala García-Argudo.

\section{Conclusions}

Le développement de cette étude ouvre la porte à une approche alternative de certains matériaux du site de Montlleó. L'étude des parures, minéraux insolites et pigments apporte des données supplémentaires pour tenter de comprendre le comportement culturel de ces communautés.

41 Concernant l'ensemble de la parure, des normes techniques de perforation et de systèmes de suspension ont été identifiées sur les espèces les mieux représentées (T.neritea et H.sanguineum). Ce fait pourrait montrer que ces communautés appréciaient l'élaboration et l'usage d'objets standardisés selon certaines normes culturelles (Stiner 2003 et 2014). La présence d'exemplaires sans perforation nous montre qu'une partie de ces matériaux exogènes arrivaient sur le site non comme parures, mais comme matière première brute. La collection de parures de Montlleó présente une diversité taxinomique plus grande que celle habituellement rencontrée sur des sites éloignés de la côte dans des chronologies comparables (García-Argudo 2017). Cela pourrait être lié à l'emplacement stratégique du site sur une voie transpyrénéenne. La présence de parures utilisant des espèces d'origine atlantique pourrait renforcer l'hypothèse selon laquelle le site s'intégrait dans un réseau d'échanges à longue distance depuis le Dernier Maximum glaciaire (Fuentes et al. 2017).

42 La collecte de prismes de quartz bipyramidaux de très petite taille, et par conséquent non aptes à la réalisation d'outillage lithique, nous permet de déduire l'existence d'un vrai choix et du transport d'éléments à caractère non utilitaire. Le transport de ce type 
d'éléments non originaires de la vallée de la Cerdagne, associé au fait qu'ils soient mis en évidence comme des éléments à valeur symbolique et culturelle chez plusieurs groupes humains, va au-delà du simple ramassage de curiosités (Soressi et D’Errico 2007) et nous fournit une information précieuse sur la pensée abstraite de ces communautés.

D'autre part, la découverte d'une grande diversité colorimétrique de pigments, ainsi que la mise en évidence de leur valeur fonctionnelle uniquement pour les ocres rouges, nous indique un usage différentiel des matières colorantes. Le manque d'indices à propos des propriétés des autres couleurs mises au jour sur le site nous amène à les considérer, dans l'état actuel des connaissances, comme des éléments à caractère symbolique.

Le site de Montlleó, à cheval entre la péninsule Ibérique et le reste du continent européen, et localisé dans la seule vallée non englacée de cette zone pendant le Dernier Maximum glaciaire, était sans doute un point de repère important pour les groupes humains qui traversaient la chaîne pyrénéenne (Sánchez de la Torre 2015). La présence de plusieurs éléments de culture matérielle liés à l'univers symbolique et culturel des groupes de chasseurs-cueilleurs en provenance de l'Atlantique et de la Méditerranée nous permet d'envisager un degré de mobilité très élevé, ainsi que l'existence de réseaux à longue distance.

\section{BIBLIOGRAPHIE}

AUDOUIN F. et PLISSON H., 1982. «Les ocres et leurs témoins au Paléolithique en France : enquête et expériences sur leur validité archéologique ", Cahiers du Centre de recherches préhistoriques, $\mathrm{n}^{\circ} 8$, p. 33-80.

BALLIN T. B., 2008, Quartz technology in Scottish prehistory, Edimburg, Society of Antiquaries of Scotland (Scottish Archaeological Internet Report, 26).

BARGE H. et CARRY A., 1986, «Les parures en quartz hyalin du Midi de la France », Bulletin du Musée d'anthropologie préhistorique de Monaco, nº 29, p. 65-80.

BONS P. D., 2001, « The formation of large quartz veins by rapid ascent of mobile hidrofractures », Tectonophysics, $\mathrm{n}^{\mathrm{o}} 336$, p. 1-17.

BONS P. D., ELBURG M. A., GOMEZ RIVAS E., 2012, « A review of the formation of tectonic veins and their microstructures ", Journal of Structural Geology, no 43, p. 33-62.

BOREL A., OLLÉ A., VERGÈS J. M., SALA R., 2014, « Scanning Electron and Optical Light Microscopy: two complementary approaches for the understanding and interpretation of usewear and residues on stone tools ", Journal of Archaeological Science, no 48, p. 46-59.

BRONK RAMSEY C., PETTITT P. B., HEDGES R. E. M., HARDGINGS G. W. L., OWEN D. C., 2000, « Radiocarbon dates from the Oxford AMS system: Archaeometry datelist $30 »$, Archaeometry, vol. 42, n 2, p. 459-479. 
CLOTTES J., MENU M., WALTER P., 1990, « La préparation des peintures magdaléniennes des cavernes ariégeoises ", Bulletin de la Société préhistorique française, vol. 87, nำ6, p. 170-192.

COLLINA-GIRARD J., 1997 « Les outillages sommaires sur supports naturels tenaces (quartz et quartzites) : technomorphologie et évolution psychique », Préhistoire anthropologie méditerranéennes, vol. 6, p. 210-226.

DIBBLE H. L., 2002, Quartz: An Introduction to Crystalline Quartz, New York, Dibble Trust Fund.

ERIKSEN B. V., 2002, « Fossil mollusks and exotic raw materials in Late glacial and early Postglacial find contexts: a complement to lithic studies ", dans Fisher L. E. et Eriksen B. V. (dir.), Lithic raw material economies in Late Glacial and Early Postglacial Europe, Oxford, Archaeopress (BAR International Series, 1093), p. 27-52.

FARINATI E., SPAGNUOLO J., ALIOTTA S., 2006, « Bioerosión en micromoluscos holocenos del estuario de Bahía Blanca, Argentina », Ameghiniana, nº 43, p. 45-54.

FERNÁNDEZ-MARCHENA J. L., GARCÍA-ARGUDO G., MANGADO X., SÁNCHEZ DE LA TORRE M., MAS B., FULLOLA J. M., 2016, « Crossing the Pyrenees: Material evidences of symbolic behaviour of LGM human groups in a stop along the way ", dans Proceedings of the 5th Meeting of the European Society for the Study of Human Evolution (PESHE 5) : abstracts, Leipzig, European Society for the Study of Human Evolution, p. 93.

FIORE D., 2005, « Pinturas corporales en el fin del mundo: Una introducción al arte visual Selk'nam y Yamana », Chungara, vol. 37, nº 2, p. 109-127.

FUENTES O., LUCAS C., ROBERT E., 2017, « An approach to Palaeolithic networks: The question of symbolic territories and their interpretation through Magdalenian art ", Quaternary International, vol. 503B, p. 233-247.

FULlola J. M., 2001, « Recherches sur le Paléolithique supérieur dans le nord-est ibérique : la Catalogne (1996-2001) », dans Noiret P. (dir.), Le Paléolithique supérieur européen : bilan quinquennal 1996-2001. UISPP, commission 8 (XIV e congrès, Liège, septembre 2001), Liège, Service de préhistoire de l'université de Liège (ERAUL, 97), p. 141-148.

GARCÍA-ARGUDO G., 2017, « Los ornamentos en concha durante el Magdaleniense: El caso de la Cova del Parco (Alòs de Balaguer, Lleida) », mémoire de master, Tarragona, Departament d'Història i Història de l'Art, Universitat Rovira i Virgili.

GIL MARCo J., 2013, « Los Jacintos de Compostela del Keuper de la Cuenca Mijares-Palancia: Canales-Andilla (Castellón-Valencia), España », Acopios, nº 4, p. 93-347.

HENSHILWOOD C., D'ERRICO F., WATTS I., 2009, « Engraved ochres from the Middle Stone Age levels at Blombos Cave, South Africa ", Journal of Human Evolution, no 57, p. 27-47.

JOYCE R. A., 2005. « Archaeology of the body », Annual Review of Anthropology, n 34, p. 139-158.

KNUTSSON H., KNUTSSON K., MOLIN F., ZETTERLUND P., 2016, « From flint to quartz: Organization of lithic technology in relation to raw material availability during the pioneer process of Scandinavia », Quaternary International, no 424, p. 32-57.

KUHN S. L., STINER M. C., REESE D. S., GÜLEÇ E., 2001, « Ornaments of the earliest Upper Paleolithic: New insights from the Levant ", Proceedings of the National Academy of Sciences, nำ 98, p. 7641-7646. LEVI J. M., 1978, «Wii'ipay: the living rocks. Ethnographic notes on crystal magic among some California Yumans », Journal of California Anthropology, vol. 5, no 1, p. 42-52. 
LOMBERA HERMIDA A. de, 2008, « Quartz morphostructural groups and their mechanical implications », Museologia Scientifica e Naturalistica speciali, p. 101-105.

MANGADO X., MERCADAL O., FULLOLA J. M., ESTEVE X., LANGLAIS M., NADAL J., ESTRADA A., BERGADÀ M. M., 2005, « Montlleó (La Cerdanya, Lleida): un yacimiento magdaleniense de alta montaña al aire libre en los Pirineos catalanes », dans Bicho N. et Corchón S. (dir.), o Paleolítico: actas do IV Congresso de Arqueologia Peninsular, Faro, Universidade do Algarve, p. 471-480.

MANGADO X., FULlOLA J. M., MERCADAL O., BERGADÀ M. M., LANGLAIS M., ESTEVE X., ESTRADA A., NADAL J., TEJERO J. M., GRIMAO J., 2009a, « Montlleó: El primer poblament del Pirineu català », dans Cicle de Conferències Patrimoni Arqueològic i Arquitectònic a les Terres de Lleida, Departament de Cultura i Mitjans de Comunicació, Lleida, Generalitat de Catalunya, p. 49-61.

MANGADO X., MERCADAL O., FULLOLA J. M., GRIMAO J., 2009b, « Montlleó: Un punt clau en la travessa humana del Pirineu », dans Fullola J. M., Valdeyron N., Langlais M. (dir.), XIV Col·loqui Internacional d'Arqueologia de Puigcerdà : Els Pirineus i les àrees circumdants durant el Tardiglacial, Mutacions $i$ Filiacions Tecnoculturals, Evolució Paleoambiental (16000-10000 BP). Homenatge al Professor George Laplace, Puigcerdà, Institut d'Estudis Ceretans, p. 549-564.

MANGADO X., FUllola J. M., MERCADAL O., 2015, « Montlleó (Prats i Sansor, la Cerdanya) i les evidències de les ocupacions paleolítiques a Cerdanya: un abans i un després en la recerca », dans Actes de les Primeres Jornades d'Arqueología i Paleontologia del Pirineu i Aran, Barcelone, Generalitat de Catalunya (Publicacions d'Arqueologia i Paleontologia, 11), p. 88-95.

MARTÍNEZ CORTIZAS A. et LLANA RODRÍGUEZ C., 1996, « Morphostructural variables and the analysis of their effect on quartz blank characteristics », dans Moloney M., Raposo L., Santonja M. (dir.), Nonflint stone tools and the palaeolithic occupation of the Iberian Peninsula, Oxford, Archaeopress (BAR International Series, 646), p. 49-53.

MONCEL M.-H., CHIOTTI L., GAILLARD C., ONORATINI G., PLEURDEAU D., 2012, « Non-utilitarian lithic objects from the European Paleolithics ", Archaeology, Ethnonology \& Anthropology of Eurasia, vol. 40, p. 24-40.

MOURRE V., 1996, « Les industries en quartz au Paléolithique : terminologie, méthodologie et technologie », Paleo, no 8, p. 205-223.

OLLÉ A., PEDERGNANA A., FERNÁNDEZ-MARCHENA J. L., MARTIN S., BOREL A., ARANDA V., 2016, « Microwear features on vein quartz, rock crystal and quartzite: A study combining Optical Light and Scanning Electron Microscopy », Quaternary International, no 424, p. 154-170.

PERLÈS C., 2018, Ornaments and Other Ambiguous Artifacts from Franchthi, vol. 1 : The Palaeolithic and the Mesolithic, Bloomington, Indiana University Press.

PÉTILLON J. M., LAROULANDIE V., COSTAMAGNO S., LANGLAIS M., 2016, « Testing environmental determinants in the cultural evolution of hunter-gatherers: a three-year multidisciplinary project on the occupation of the western Aquitaine basin during the Middle and Upper Magdalenian (19-14 kyr cal BP) », Quaternary International, nº 414, p. 1-8.

POPPE G. T. et GOTO Y., 1991, European seashells, vol. 1, Wiesbaden, Christa Hemmen Verlag.

RIFKIN R. F., 2011, « Assessing the efficacy of red ochre as a prehistoric hide tanning Ingredient », Journal of African Archaeology, vol. 9, n 2, p. 131-158.

RIFKIN R. F., 2015a, « Ethnographic insight into the prehistoric significance of red ochre », The Digging Stick, vol. 32 nº 2, p. 7-10. 
RIFKIN R. F., 2015b, « Ethnographic and experimental perspectives on the efficacy of ochre as a mosquito repellent », South African Archaeological Bulletin, vol. 70, ํํ201, p. 64-75.

RIFKIN R. F., DAYET L., QUEFFELEC A., SUMMERS B., LATEGAN M., D’ERRICO F., 2015, « Evaluating the photoprotective effects of ochre on human skin by in vivo SPF assessment: implications for human evolution, adaptation and dispersal », PloS One, vol. 10, ํㅜ 9, e0136090.

Rosso D. E., 2017, « Aproximación etnoarqueológica al uso de colorantes para el tratamiento del cabello: el caso de los Hamar (Etiopía) », Pyrenae, vol. 48, nº 2, p. 123-149.

SÁNCHEZ DE LA TORRE M., 2015, Las sociedades cazadoras-recolectoras del Paleolítico superior final pirenaico: territorios económicos y sociales, Barcelona, Universidad de Barcelona (Monografies del SERP, 11).

SHAW B. et LANGLEY M., 2017, «Investigating the development of prehistoric cultural practices in the Massim región of Eastern Papua New Guinea: Insights from the manufacture and use of shell objects in the Louisiade Archipielago ", Journal of Anthropological Archaeology, no 48, p. 149-165.

SORESSI M. et D’ERRICO F., 2007, « Pigments, gravures, parures : les comportements symboliques controversés des Néandertaliens ", dans Vandermeersch B. et Maureille B. (dir.), Les Néandertaliens : biologie et cultures, Paris, Éditions du CTHS, p. 297-309.

SPRAGUE R., 2004. «Incised Dentalium shell beads in the Plateau Culture Area », Beads, Journal of the Society of Bead Researchers, no 16, p. 51-68.

STINER M., 2003, " "Standardization" in Upper Paleolithic ornaments at the coastal sites of Riparo Mochi and Üçagizli Cave », Trabalhos de Arqueologia, n 33, p. 49-59.

STINER M., 2014, «Finding a common bandwidth: Causes of convergence and diversity in paleolithic beads ", Biological Theory, no 9, p. 51-64.

THEN-OBLUSKA J., 2015. « Beads and pendants from Sedeinga, Nubia », Beads, Journal of the Society of Bead Researchers, nำ 27, p. 29-45.

VANHAEREN M., 2002, « Les fonctions de la parure au Paléolithique supérieur : de l'individu à l'unité culturelle », thèse de doctorat en géosciences et sciences de l'environnement, Pessac, université Bordeaux I.

VANHAEREN M., 2005, « Speaking with beads: The evolutionary significance of personal ornaments ", dans D’Errico F. et Blackwell L. (dir.), From tools to symbols: From early hominids to modern humans, Johannesburg, Witwatersrand University Press, p. 525-553.

VANHAEREN M. et D'ERRICO F., 2001, « La parure de l'enfant de La Madeleine (fouilles Peyrony) : un nouveau regard sur l'enfance au Paléolithique supérieur », Paleo, nº 13, p. 1-55.

WADLEY L., 2005, « Putting ochre to the test: replication studies of adhesives that may have been used for hafting tools in the Middle Stone Age ", Journal of Human Evolution, no 49, p. 587-601.

WIESSNER P., 1997, « Seeking guidelines through an evolutionary approach: style revisited among the ¡Kung San (Ju/ hoansi) of the 1990s », Archaeological Papers of the American Anthropological Association, no 7, p. 157-176.

WOBST H. M., 1977, « Stylistic behaviour and information exchange », dans Cleland C. (dir.), Papers for the Director: Research essays in honor of James B. Griffin, Ann Arbor, University of Michigan, Museum of Anthropology (Anthropological Papers, 61), p. 317-342. 


\section{RÉSUMÉS}

Le site de plein air de Montlleó (Prats i Sansor, Lérida, Espagne) est situé sur une petite colline de la haute vallée du Sègre, au cœur de la plaine de la Cerdagne, sur un axe stratégique de communication - ou couloir - qui connecte les deux versants des Pyrénées. Les caractéristiques culturelles des industries lithiques et les dates radiocarbone nous démontrent l'âge ancien des occupations humaines sur cette partie méridionale des Pyrénées orientales. Le site de Montlleó se caractérise par la quantité et la variété des éléments culturels, que nous pouvons mettre en relation avec l'univers symbolique de ces populations de chasseurs-cueilleurs. Ces évidences matérielles sont exploitées dans cet article pour étudier le comportement symbolique des populations de la fin du Paléolithique supérieur. Les marqueurs sont répartis en trois types : la parure, dans le sens traditionnel du terme, les minéraux rares apportés sur le site, et enfin les matières colorantes.

The open-air site of Montlleó (Prats i Sansor, Lérida, Spain) is located on a small hill in the upper valley of the Segre River, in the center of the Cerdanya plain, on a strategic axis of communication -or corridor- connecting both sides of the Pyrenees. The cultural features of the lithic industries and the radiocarbon dates are indicating the old age of the human occupations in this southern part of the eastern Pyrenees. The site is characterized by the quantity and variety of cultural elements that can be related to the symbolic sphere of these hunter-gatherer populations. In the present research we analyze this material evidence in relation to the symbolic behavior of the late Upper Paleolithic populations. In this regard, we study three types of markers: ornaments, in the traditional meaning of the term; rare minerals brought to the site; and dyestuffs of several hues.

\section{INDEX}

Mots-clés : fin du Paléolithique supérieur, parure, pigment, quartz, symbolisme

Keywords : ornament, pigment, quartz, symbolism

\section{AUTEURS}

\section{JUAN LUIS FERNÁNDEZ-MARCHENA}

Seminari d'Estudis i Recerques Prehistòriques (SERP), Secció de Prehistòria i Arqueologia, Departament d'Història i Arqueologia, Universitat de Barcelona

\section{GALA GARCÍA-ARGUDO}

Seminari d'Estudis i Recerques Prehistòriques (SERP), Secció de Prehistòria i Arqueologia, Departament d'Història i Arqueologia, Universitat de Barcelona

\section{XAVIER MANGADO}

Seminari d'Estudis i Recerques Prehistòriques (SERP), Secció de Prehistòria i Arqueologia, Departament d'Història i Arqueologia, Universitat de Barcelona

\section{ORIOL MERCADAL}

† Museu Cerdà 


\section{JOSEP MARIA FULLOLA}

Seminari d'Estudis i Recerques Prehistòriques (SERP), Secció de Prehistòria i Arqueologia, Departament d'Història i Arqueologia, Universitat de Barcelona 
Les Pyrénées, une frontière préhistoriographique pour le Magdalénien ? Réflexions à partir du Magdalénien moyen récent de la grotte Tastet (Sainte-Colome, Pyrénées-Atlantiques)

The Pyrenees, a pre-historiographical border for the Magdalenian? Reflections from the Late Middle Magdalenian of Tastet Cave (SainteColome, Pyrénées-Atlantiques, France)

Mathieu Langlais et Jean-Marc Pétillon

Nous tenons à remercier le CTHS et en particulier S. Brunet, L. Lemaitre et P. Chareyre pour l'organisation de ce congrès; les membres de la section de préhistoire et protohistoire, spécialement C. Mordant; ainsi que M. Deschamps, S. Costamagno, P.-Y. Milcent, C. Renard et $N$. Valdeyron pour l'organisation de la session dans laquelle s'inscrit cette communication. Merci également aux deux rapporteurs, dont les commentaires ont permis d'améliorer le manuscrit, et à Isabelle Tarier pour le travail éditorial. Les fouilles à Sainte-Colome ont lieu grâce à l'autorisation et à l'aide du propriétaire du site, M. Pierre Tastet, et grâce à l'implication de la mairie de Sainte-Colome, de la famille Augareils, des associations GAPO et Archéologies et des fouilleurs bénévoles; que toutes et tous en soient ici remerciés. Ces recherches ont été financées par le ministère de la Culture (DRAC Nouvelle-Aquitaine) et par les projets Magdatis (ANR 2011 BSH3 0005) et Magdaqui (région Nouvelle-Aquitaine).

1 Dix ans après la publication des actes de la table ronde de Tarascon-sur-Ariège consacrée à la question des frontières dans les Pyrénées préhistoriques (Cazals et al. 2007), le congrès 2017 du Comité des travaux historiques et scientifiques fut l'occasion de redynamiser la réflexion sur ce sujet. La notion de frontière en préhistoire peut être abordée sous différents aspects (Cazals et Bon 2007). Pour l'ouest de l'Europe, des 
espaces comme la vallée du Rhône, le sable des Landes, la vallée de la Garonne ou le massif pyrénéen sont parfois interprétés comme des barrières géographiques correspondant à de véritables frontières culturelles (Bruxelles et Jarry 2011, Bertran et al. 2013). Mais bien que ces espaces contraignants structurent le territoire des chasseurs-collecteurs, ils ne sont jamais totalement imperméables à la diffusion d'objets et d'idées, ni à la circulation des groupes humains (Cazals et al. 2007, Langlais 2007, Bazile 2011, Gourc et al. 2016, Langlais et al. 2016). Ainsi, autour du massif pyrénéen - depuis le Bassin aquitain jusqu'au bassin de l'Èbre et à la corniche bascocantabrique - les relations entretenues au cours du Magdalénien sont bien connues, tant à travers la diffusion d'objets particuliers (Buisson et al. 1996, Utrilla et Mazo 1996, Pétillon 2006, Sauvet et al. 2014) qu'à travers la circulation des matières premières siliceuses (Corchón et al. 2009, Langlais 2010, Mangado et al. 2010, Sánchez de la Torre 2015, Pétillon et al. 2015, Fontes 2016, Langlais et al. 2016, Pétillon et al. 2017). Toutefois, malgré ces liens évidents, la régionalisation des recherches et la diversité des traditions universitaires et méthodologiques ont abouti à la mise en place d'autres types de frontières, terminologiques cette fois: des frontières "pré-historiographiques » (Langlais et Mangado 2007).

2 Ainsi, au sud de la chaîne pyrénéenne (pré-Pyrénées et vallée de l'Èbre) et à l'ouest de celle-ci (Pays basque et corniche cantabrique), la sériation suivante est proposée par plusieurs auteurs: Magdaleniense inferior, Magdaleniense medio, puis Magdaleniense superior-final (Utrilla 2004, Aura et al. 2012, Fontes 2016). Parallèlement, dans le sudouest de la France, le Magdalénien est subdivisé en trois grandes phases, inférieure, moyenne et supérieure, présentant chacune ses traits distinctifs (Langlais 2010, Langlais et al. 2012). Dans le cadre du projet Magdatis (projet ANR 2011 BSH3 0005, « Le Magdalénien de la façade atlantique face aux changements environnementaux»), nous avons pu préciser la chronologie de l'évolution technoéconomique des chasseurscollecteurs du Magdalénien moyen et supérieur dans cette région, ce qui a abouti à la proposition d'une sériation en quatre temps selon plusieurs critères technotypologiques au sein des équipements lithiques et osseux :

- Magdalénien moyen ancien (MMA) ;

- Magdalénien moyen récent (MMR) ;

- Magdalénien supérieur ancien (MSA) ;

- Magdalénien supérieur récent (MSR).

3 Nous ne détaillerons pas ici ces critères de sériation et renvoyons aux publications pour plus de détails (Langlais et al. 2016, Pétillon 2016, Pétillon et al. 2016b, Laroulandie et al. 2017).

4 L'objectif de cet article est de questionner le rôle de la chaîne pyrénéo-cantabrique comme axe de diffusion ou obstacle à la circulation durant cette période, et de rediscuter en conséquence la pertinence de ces distinctions "pré-historiographiques » - apportant ainsi à un débat ancien une contribution nourrie de travaux et de résultats récents. Nous nous focaliserons essentiellement sur le Magdalénien moyen récent (daté entre 17,5 et $16 \mathrm{ka}$ cal. BP), à la lumière des recherches menées depuis quelques années dans le bassin d'Arudy, en basse vallée d'Ossau, dans les Pyrénées-Atlantiques. En effet, dans cette microrégion à l'ombre du massif pyrénéen, la documentation sur le Magdalénien a été récemment renouvelée, d'abord dans le cadre du projet Magdatis (Pétillon et al. 2015), puis via la fouille de la grotte de Laa 2 (Pétillon et al. 2017) et de la grotte Tastet, à Sainte-Colome (Pétillon et al. 2014 ; opération en cours), et aujourd'hui 
du projet collectif de recherche Pavo (coordination J.-M. Pétillon). Les résultats obtenus font du bassin d'Arudy une référence pour l'étude des relations trans- et circumpyrénéennes au Magdalénien.

\section{Caractéristiques du Magdalénien moyen récent (MMR)}

5 Le projet Magdatis a permis de réaliser, pour le Magdalénien moyen et supérieur du Bassin aquitain, une série de nouvelles datations ${ }^{14} \mathrm{C}$, pour lesquelles les échantillons ont été sélectionnés selon un protocole rigoureux (Barshay-Szmidt et al. 2016). Les résultats montrent un peuplement continu du versant nord des Pyrénées au Magdalénien, tandis que pour le nord de l'Aquitaine (département de la Gironde), un hiatus est visible pour toute la période 17,5-15,5 ka cal. BP : aucun site girondin n'est aujourd'hui attribuable à cette fourchette chronologique, alors même que la sélection des échantillons datés a été en partie orientée explicitement dans le but de rechercher des traces d'occupation humaine à cette période. Ce hiatus s'accorde avec l'absence, dans ce secteur, d'ensembles archéologiques clairement attribuables au MMR sur des bases technotypologiques. Il semble donc qu'on assiste, entre 17,5 et 15,5 ka cal. BP, à un dépeuplement $d u$ nord-ouest du bassin aquitain. Ce phénomène est sans doute conditionné, au moins en partie, par l'impact environnemental de l'événement climatique Heinrich 1, qui se matérialise en plaine par un pergélisol sporadique (Andrieux et al. 2016, Naughton et al. 2016, Pétillon et al. 2016a, Laroulandie et al. 2017). Les données archéologiques et radiocarbone suggèrent que le même hiatus de peuplement pourrait se retrouver dans les régions au nord de la Gironde (Charente et Vienne). Quoi qu'il en soit, le piémont nord des Pyrénées n'est pas affecté par cette contraction de l'aire de peuplement magdalénien ; il présente au contraire au MMR une forte densité d'occupation, qui permet une caractérisation fine appuyée sur un riche corpus archéologique. Nous ne présenterons pas ici les données de la faune (voir notamment Pétillon et al. 2015 et 2017, Costamagno et al. 2016) ni celles de la parure (Peschaux 2017) et rappellerons seulement les principaux caractères des équipements lithiques et osseux.

6 Les industries lithiques du MMR se caractérisent, en continuité sur ce point avec le Magdalénien moyen ancien (MMA), par la mise en œuvre de deux chaînes de production autonomes : d'une part des lames pour l'outillage domestique, d'autre part des lamelles destinées à la confection des armatures de projectiles (Langlais et al. 2016). La production laminaire du MMR est organisée à partir de volumes mis en forme de manière élaborée (aménagement transversaux à partir de crêtes postérieure et antérieure), exploités au percuteur tendre organique sur une table cintrée. Ce débitage unipolaire fournit des supports calibrés et vise à optimiser la longueur obtenue. On assiste par ailleurs à une véritable "valorisation sociale » de la grande lame (Langlais 2007, Angevin et Langlais 2009). Cette valorisation se marque par la haute technicité des débitages, normalisés et productifs (et l'apprentissage des savoir-faire nécessaires); par la circulation des lames sur de grandes distances; par leur utilisation comme tranchant, fréquemment repris en support d'outil d'extrémité à longue durée de vie ou en nucléus à lamelles; mais aussi, en dehors de leur cycle fonctionnel normal, par leur dépôt à l'abri des regards en fond de grotte, dans des anfractuosités à proximité de parois ornées, comme à Labastide, dans les Hautes-Pyrénées, ou à Enlène, en Ariège (Bégouën 1933, Simonnet 1982, Angevin et Langlais 2009). La circulation des matières 
premières siliceuses sous la forme de supports laminaires et de volumes à débiter témoigne également de la planification des besoins, qui plus est dans une région relativement dépourvue en silex aptes au débitage de grandes lames (Langlais et al. 2016 : fig. 9-2).

$7 \mathrm{Au}$ MMR, comme précédemment au MMA, le bois de renne et l'os sont exploités par rainurage longitudinal multiple, avec des débitages à forte productivité permettant de produire en grande quantité des supports d'objets sur baguette. Au sein d'un outillage très diversifié, les catégories majoritaires sont, dans l'industrie en os, les aiguilles à chas, et dans l'industrie en bois de cervidé, les pointes de projectiles (Pétillon 2016). Ces dernières sont soit des pointes «monobloc» tirées de bois de gros module, soit des pointes bivalves, composées de deux baguettes demi-rondes accolées par leur face plane (Rigaud 2006) et souvent façonnées à partir de bois de module moyen (Lefebvre 2016). Les os de grands cétacés sont également utilisés pour la fabrication de pointes de projectiles. Les armatures osseuses du MMR, souvent longues, présentent une base en biseau simple ou une base pleine, et fréquemment une ou deux rainures longitudinales pour l'insertion de microlithes.

Le MMR est une période de fort développement de la gravure et de la sculpture sur matières osseuses. On voit l'apparition de nouvelles parures en os (contours découpés sur os hyoïde, rondelles percées sur scapula) qui se diffusent notamment dans les Pyrénées aquitaines et la corniche basco-cantabrique (Buisson et al. 1996, Cattelain et Bellier 2014). On voit aussi les décors gravés et sculptés envahir les équipements osseux - avec notamment des pièces célèbres, telles les baguettes demi-rondes gravées d'une façon parfois très virtuose, ou les crochets de propulseurs sculptés de figurations animales en ronde bosse (Cattelain 2017).

\section{Le MMR dans le bassin d'Arudy : la grotte Tastet}

Situé sur le versant nord-ouest des Pyrénées, au débouché de la vallée d'Ossau, le bassin d'Arudy est un petit bassin glaciaire situé à environ 400 mètres d'altitude, entouré de collines qui le dominent d'environ 150 mètres. Il correspond à une concentration de sites du Magdalénien moyen et supérieur: dans un rayon de moins de 2 kilomètres autour de la ville d'Arudy, on connait au moins huit gisements en grotte et en abri, en général entre 400 et 500 mètres d'altitude (fig. 1), ayant livré un matériel parfois très abondant attribué à cette période (Marsan 1979 et 1996). La plupart de ces sites sont connus et étudiés depuis longtemps. 
Fig. 1. - Localisation des sites mentionnés dans le texte.

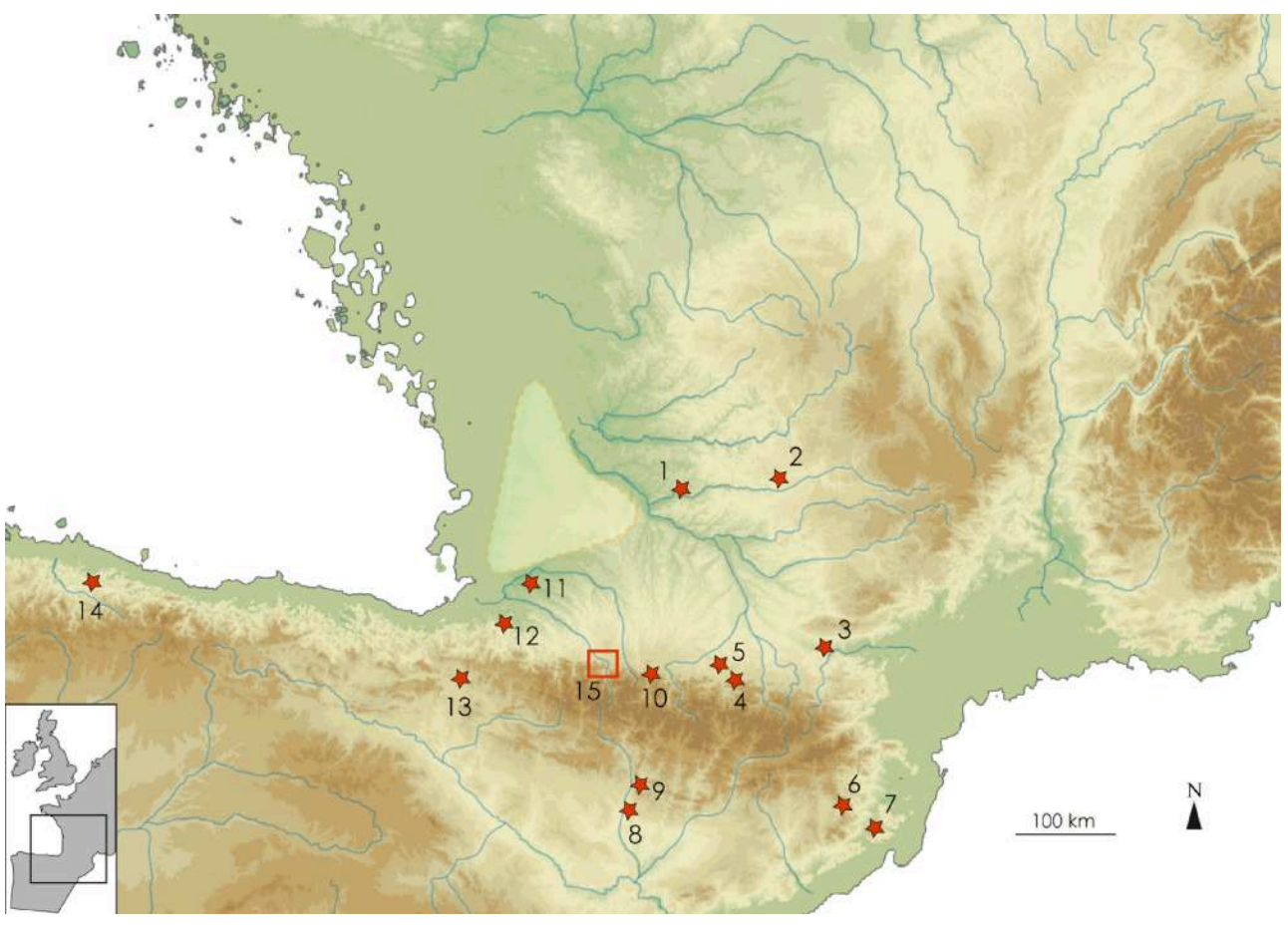

Trait de côte -120 m; pointillés : sable des Landes. 1 : La Roche (Castelmoron-sur-Lot, Lot-et-Garonne). 2 : Les Peyrugues (Orniac, Lot). 3 : Gazel (Sallèles-Cabardès, Aude). 4 : Le Tuc d'Audoubert (Montesquieu-Avantès, Ariège). 5 : Peyre Blanque (Fabas, Ariège). $\mathbf{6}$ : Coma d'Infern (Les Planes d'Hostoles, Gerona, Espagne). 7 : Sant Benet (San Feliu de Guíxol, Gerona, Espagne). 8 : Forcas (Graus, Huesca, Espagne). 9 : Cova Alonsé (Estadilla, Huesca, Espagne). 10 : Labastide (Hautes-Pyrénées). 11 Duruthy (Sorde-l'Abbaye, Landes). 12 : Isturitz (Pyrénées-Atlantiques). 13 : Legintxiki (Etxauri, Navarra, Espagne). 14 : Las Caldas (Asturias, Espagne). 15 : bassin d'Arudy, dans les Pyrénées-Atlantiques (grotte Tastet, Saint-Michel, Espalungue, Le Poeymaü, Malarode 1, Laa 2, Le Bignalats).

PAO Mathieu Langlais; fond de carte Géoatlas.

Schématiquement, pour le Magdalénien, on peut distinguer trois générations de travaux de terrain : une pendant la seconde moitié du $\mathrm{XIX}^{\mathrm{e}}$ siècle et le début $\mathrm{du} \mathrm{Xx}^{\mathrm{e}}$, avec en particulier les fouilles d'É. Piette à Espalungue et celles de F. Mascaraux à SaintMichel; une autre de la fin des années 1940 aux années 1980, avec les fouilles de G. Laplace, M. Livache et G. Marsan (Magdalénien d'Espalungue, du Poeymaü, du Bignalats et de Malarode 1); et une troisième depuis une dizaine d'années, avec une révision générale des collections dans le cadre du projet Magdatis (Pétillon et al. 2015), mais également de nouvelles opérations de terrain. Les fouilles dirigées de 2006 à 2010 par P. Dumontier dans la grotte de Laa 2 ont en effet permis de mettre au jour dans le sondage 4 une séquence du Magdalénien inférieur (?), moyen et supérieur, avec notamment un ensemble du MMR dans la couche C3 (Pétillon et al. 2017). Et dans la grotte Tastet, à Sainte-Colome, les fouilles dirigées depuis 2012 par l'un d'entre nous (J.-M.P.) ont permis de découvrir une séquence du MMR dont nous présentons ici les principales caractéristiques.

La grotte Tastet s'ouvre à environ 512 mètres d'altitude sur le versant est du bassin d'Arudy, dans une barre calcaire orientée NO-SE qui affleure à cet endroit sur environ 2,5 mètres de haut et plusieurs dizaines de mètres de long, au milieu de formations de marnes schisteuses. Son entrée se présente aujourd'hui sous la forme d'une ouverture d'environ 0,5 mètre de haut pour 1 mètre de large. Elle donne accès à une salle d'environ 10 mètres carrés, entièrement mais chichement éclairée par la lumière du 
jour, dont la voûte atteint à peine 2 mètres de hauteur maximale et qui est prolongée au sud-est par une étroite galerie rectiligne, longue d'une quinzaine de mètres (fig. 2).

Fig. 2. - Grotte Tastet (Sainte-Colome, Pyrénées-Atlantiques) : plan et coupe de la grotte et du talus extérieur, avec indication des deux secteurs de fouille (extérieur à l'ouest, intérieur à l'est).

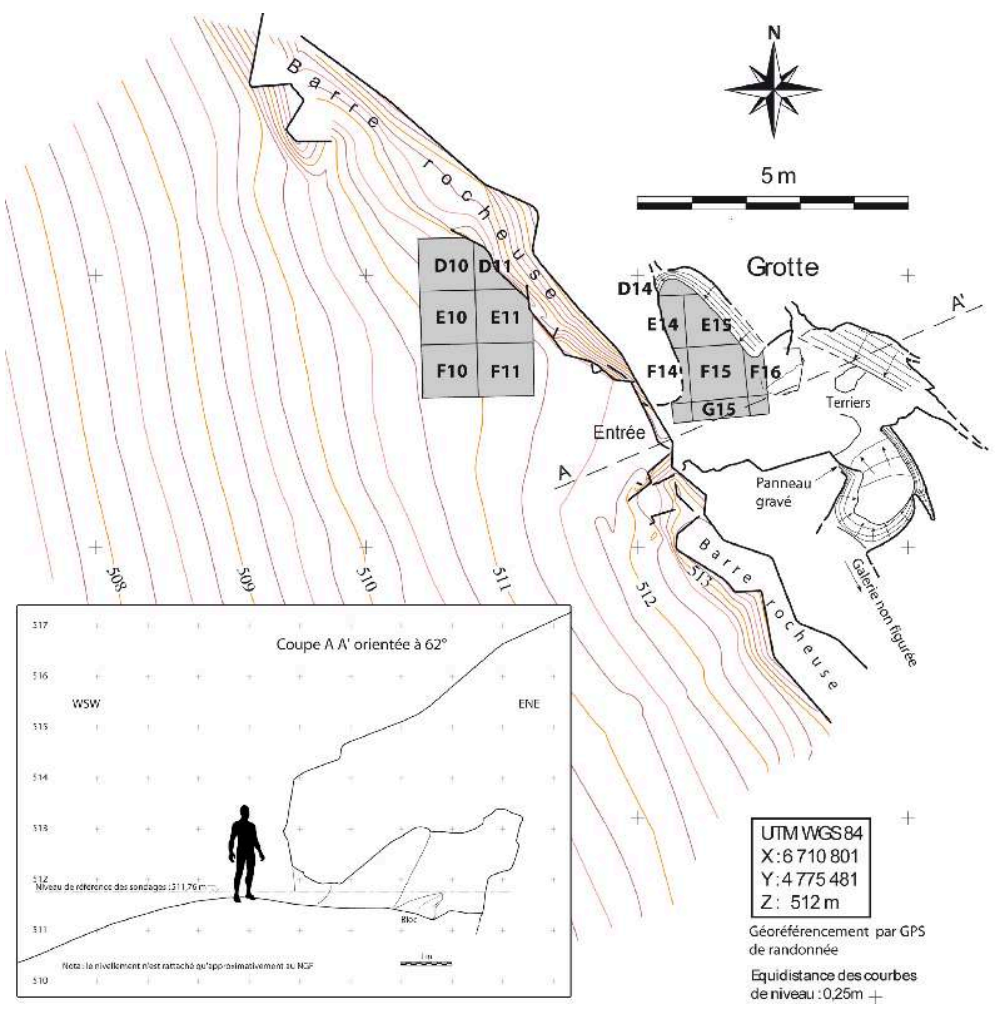

La galerie sud-est n'est pas figurée.

PAO Jean-Marc Pétillon ; relevé topographique Gilles Parent, 2012.

Les résultats de la fouille montrent que la partie sous abri devait être un peu plus avancée vers l'ouest au moment de l'occupation magdalénienne, de 2 à 3 mètres au maximum (existence probable d'un ancien auvent aujourd'hui disparu). La grotte Tastet est l'unique grotte ornée des Pyrénées béarnaises (Omnès 1983, Blanc et Marsan 1984). Les figurations - deux bisons, deux chevaux et une série de traits gravés - se concentrent sur un panneau d'environ 1 mètre carré sur la paroi sud de la petite salle; elles ont été récemment réétudiées et attribuées stylistiquement au Magdalénien moyen (Garate et al. 2013).

La fouille concerne une dizaine de mètres carrés répartis en deux secteurs : 3,5 mètres carrés à l'intérieur de la petite salle ornée et 6 mètres carrés sur le talus, devant l'entrée de la cavité actuelle, c'est-à-dire sous l'ancien auvent. Le bedrock n'a été atteint en aucun point de ces deux secteurs. Très homogène sur le plan sédimentaire, le remplissage est partout très caillouteux et dominé par les clastes calcaires issus du massif. Toutefois, l'impossibilité pratique de réaliser un raccord entre les deux secteurs de fouille nous a obligés à utiliser une nomenclature stratigraphique distincte pour chacun de ces secteurs.

14 Le remplissage du secteur intérieur a été fouillé sur une épaisseur maximale d'environ 1 mètre. Le niveau le plus ancien atteint pour le moment (US 310-311) est un ensemble magdalénien qui a livré une date ${ }^{14} \mathrm{C}$ autour de $18-17,8 \mathrm{ka}$ cal. BP, mais qui reste mal 
caractérisé et dont nous ne parlerons pas ici. Il est surmonté par un ensemble du MMR (US 305-309) épais de 20 à 30 centimètres et daté entre environ 17,8 et 16,8 ka cal. BP. Le sommet du remplissage (US 301-303) est fortement bioturbé par des terriers sur une épaisseur de 30 à 50 centimètres, voire localement plus.

Dans le secteur extérieur, la fouille a également atteint une profondeur maximale d'environ 1 mètre. Sa base est constituée d'un ensemble presque stérile du point de vue archéologique, épais de plus de 40 centimètres (US 208-211). Cet ensemble est surmonté d'un niveau daté du tout début du Magdalénien moyen (US 207, vers 19 ka cal. BP), encore peu fouillé et qui ne sera pas non plus évoqué dans cet article. Enfin, la partie supérieure du remplissage extérieur, épaisse de 30 à 60 centimètres, est de lecture stratigraphique délicate car elle a vraisemblablement été tronquée par l'érosion avant d'être en partie remaniée par des creusements récents (fouille archéologique du XIX siècle ?). L'ensemble le plus riche et probablement le mieux conservé (US 206a), fouillé seulement en 2017, a livré du mobilier attribuable au MMR et deux dates ${ }^{14} \mathrm{C}$ autour de $17,5 \mathrm{ka}$ cal. BP. Les zones remaniées (US 205-206 et 206v) ont également livré du matériel attribuable au MMR et plusieurs dates ${ }^{14} \mathrm{C}$ groupées entre environ 17,5 et $17 \mathrm{ka}$ cal. BP.

16 L'industrie osseuse découverte à la grotte Tastet comprend 74 pièces, dont 33 proviennent des niveaux les mieux conservés attribuées au MMR (US 305-309 et 206a). Le matériel issu du secteur intérieur est en très bon état de préservation, alors que celui du secteur extérieur a souffert de conditions de dépôt plus défavorables (surfaces altérées, cassures, etc.). Des fragments de déchets et de supports témoignent de l'exploitation de l'os et du bois de renne par double rainurage longitudinal. L'équipement en os est constitué de lissoirs et d'aiguilles à chas (fig. $3, \mathrm{n}^{\text {os }} 1$ à 3 ). Les objets en bois de renne comprennent des outils intermédiaires de type coin/ciseau (fig. $3, \mathrm{n}^{\circ} 4$ ) ainsi qu'une majorité de pièces relevant de l'équipement de chasse. On compte ainsi plusieurs pointes de projectiles, exclusivement à biseau simple (fig. $3, \mathrm{n}^{\text {os }} 5$ et 6), et plusieurs fragments de baguettes demi-rondes dont deux, de calibre identique et retrouvées à proximité immédiate l'une de l'autre dans l'US 206a, constituent peutêtre les deux éléments d'une même pointe bivalve à base pleine (fig. $3, n^{\text {os }} 7$ et 8 ). Le faible effectif de cette série n'autorise pour l'instant pas de comparaisons très poussées, et la suite de la discussion portera donc uniquement sur l'industrie lithique. 
Fig. 3. - Grotte Tastet (Sainte-Colome, Pyrénées-Atlantiques) : échantillons d'industrie osseuse des US 206a ( $\left.{ }^{\circ s} 2,3,4,7,8\right), 306\left(n^{\circ s} 1,6\right)$ et $309\left(n^{\circ} 5\right)$.

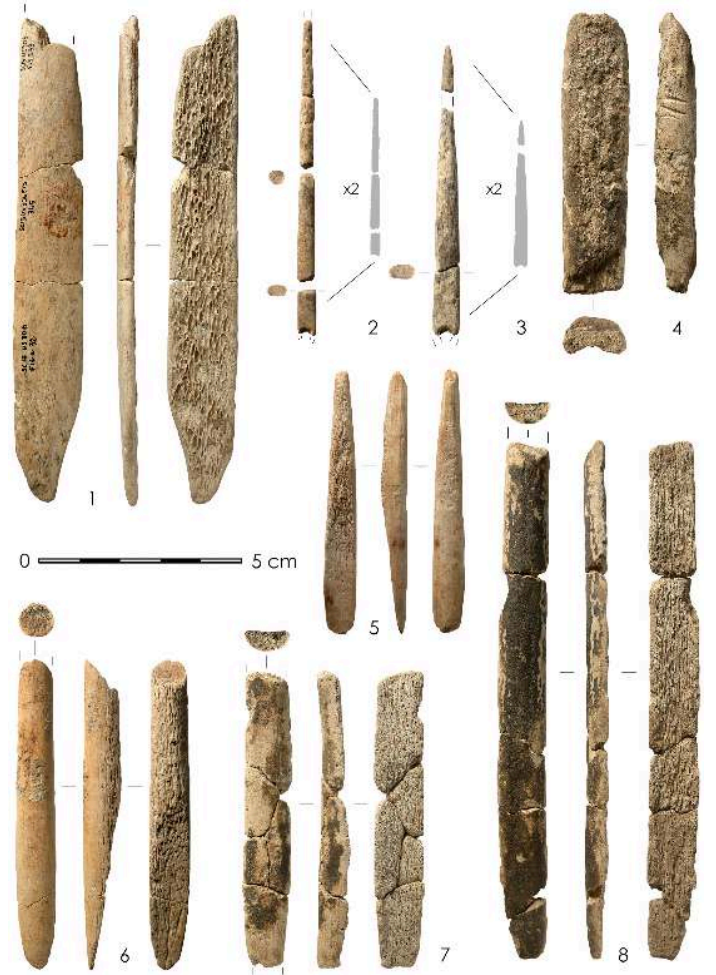

INDUSTRIE EN OS : 1 : lissoir. 2 ET 3 : aiguilles à chas. INDUSTRIE EN BOIS DE CERVIDÉ : 4 : outil intermédiaire. $\mathbf{5}$ Eт $\mathbf{6}$ : pointes à biseau simple. $\mathbf{7}$ ET $\mathbf{8}$ : baguettes demi-rondes (appariées ?).

PAO et photos Jean-Marc Pétillon.

Dans les niveaux du MMR (US 305-309 et 206a), les caractères les plus marquants de l'industrie en silex sont :

- Un outillage sur lames régulières extraites au percuteur tendre organique (fig. 4);

- La présence de près d'une dizaine de fragments de lames robustes en silex du Bergeracois (fig. 5), retrouvées à l'intérieur de la cavité ;

- Une production de supports de microlithes selon un schéma enveloppant unipolaire convergent à partir de blocs ou d'éclats (fig. 6) ;

- Parmi les microlithes, une proportion non négligeable (près d'une centaine d'exemplaires) de lamelles à dos tronquées de type triangle scalène (fig. 7, $\mathrm{n}^{\text {os }} 40$ à 66). 
Fig. 4. - Grotte Tastet (Sainte-Colome, Pyrénées-Atlantiques), percussion tendre organique : exemples de lames brutes et outils retouchés avec vue des talons.

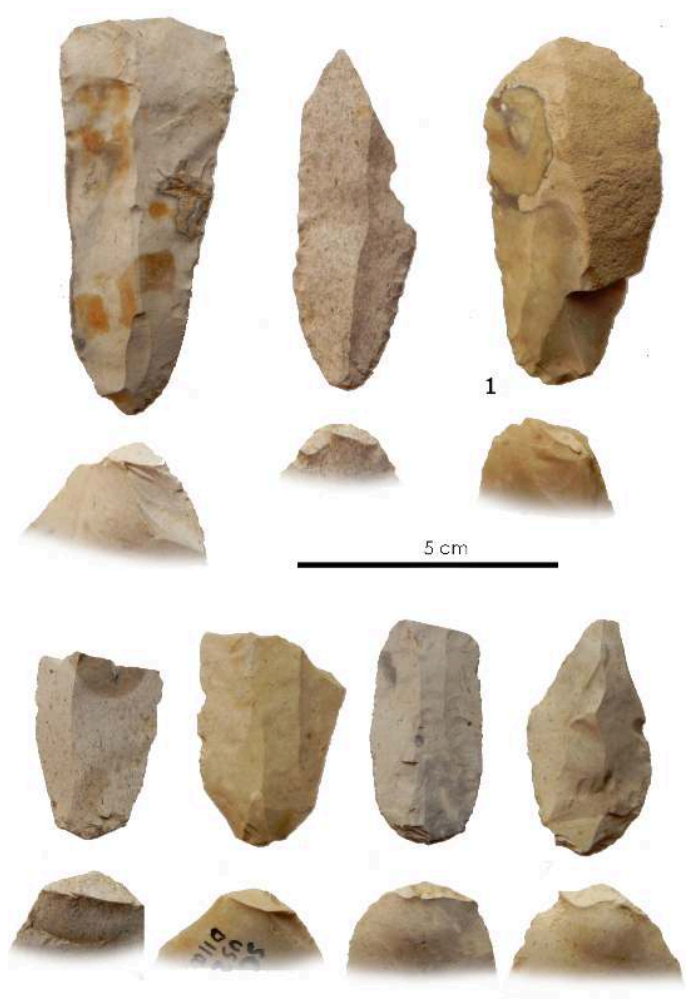

La lame 1 est latérale, d'où un talon déjeté.

PAO et photos Mathieu Langlais. 
Fig. 5. - Grotte Tastet (Sainte-Colome, Pyrénées-Atlantiques) : fragments de lames en silex du Bergeracois (US 305 et 306 ).

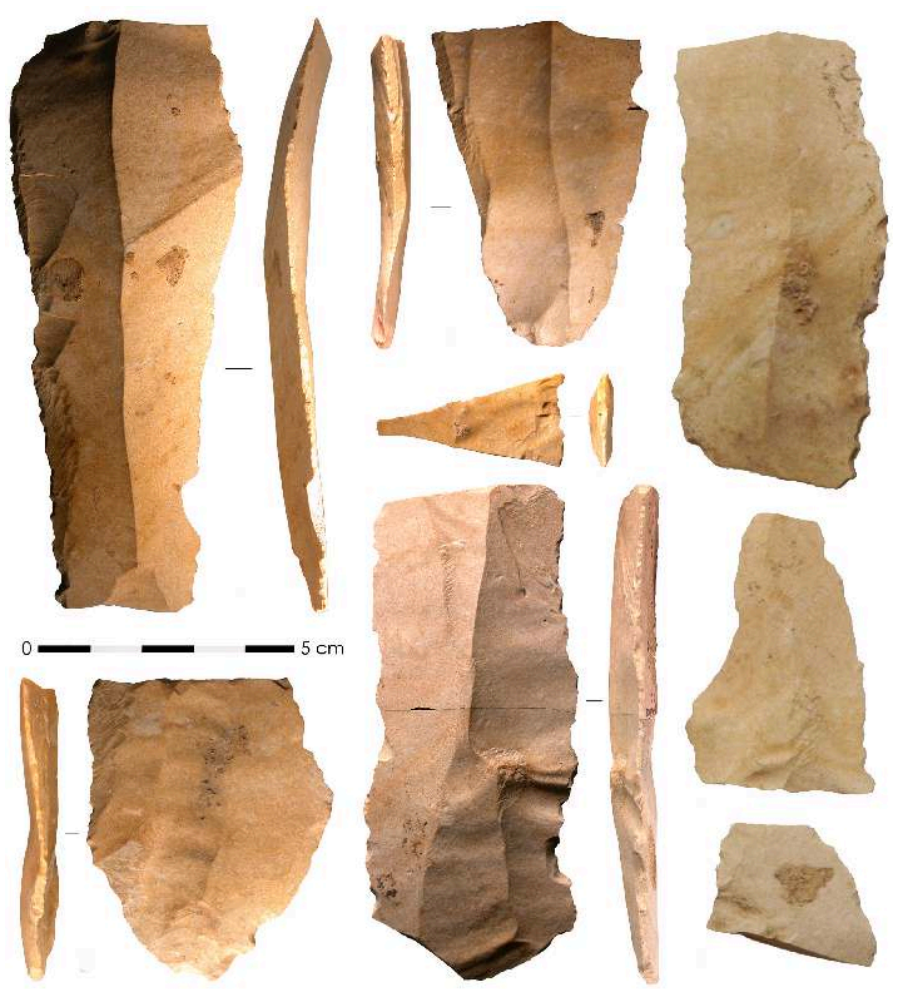

PAO Jean-Marc Pétillon. Photos Mathieu Langlais et Jean-Marc Pétillon. 
Fig. 6. - Grotte Tastet (Sainte-Colome, Pyrénées-Atlantiques), débitage unipolaire convergent : exemples de nucléus à lamelles.

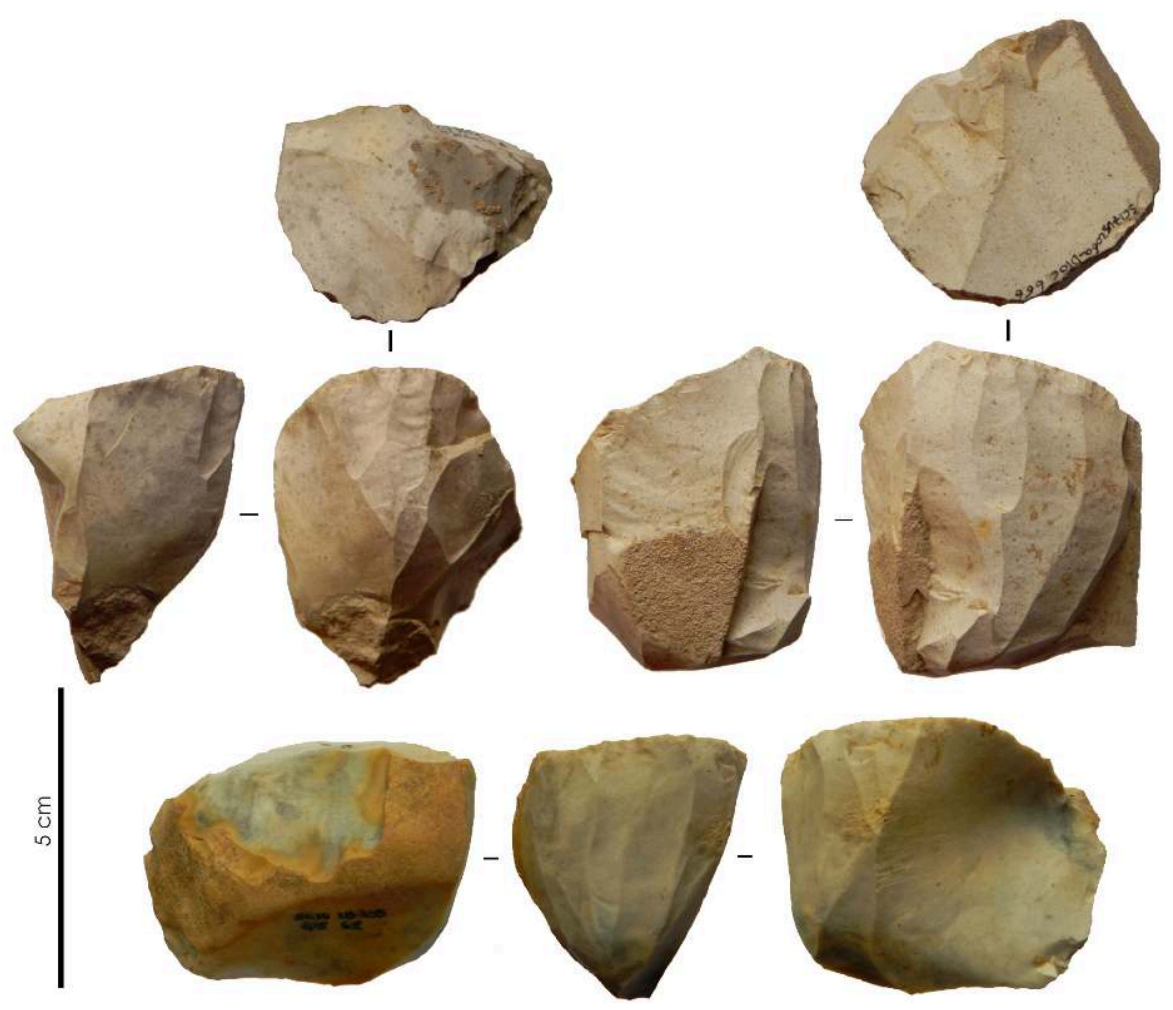

PAO et photos Mathieu Langlais.

Fig. 7. - Exemples de triangles scalènes.

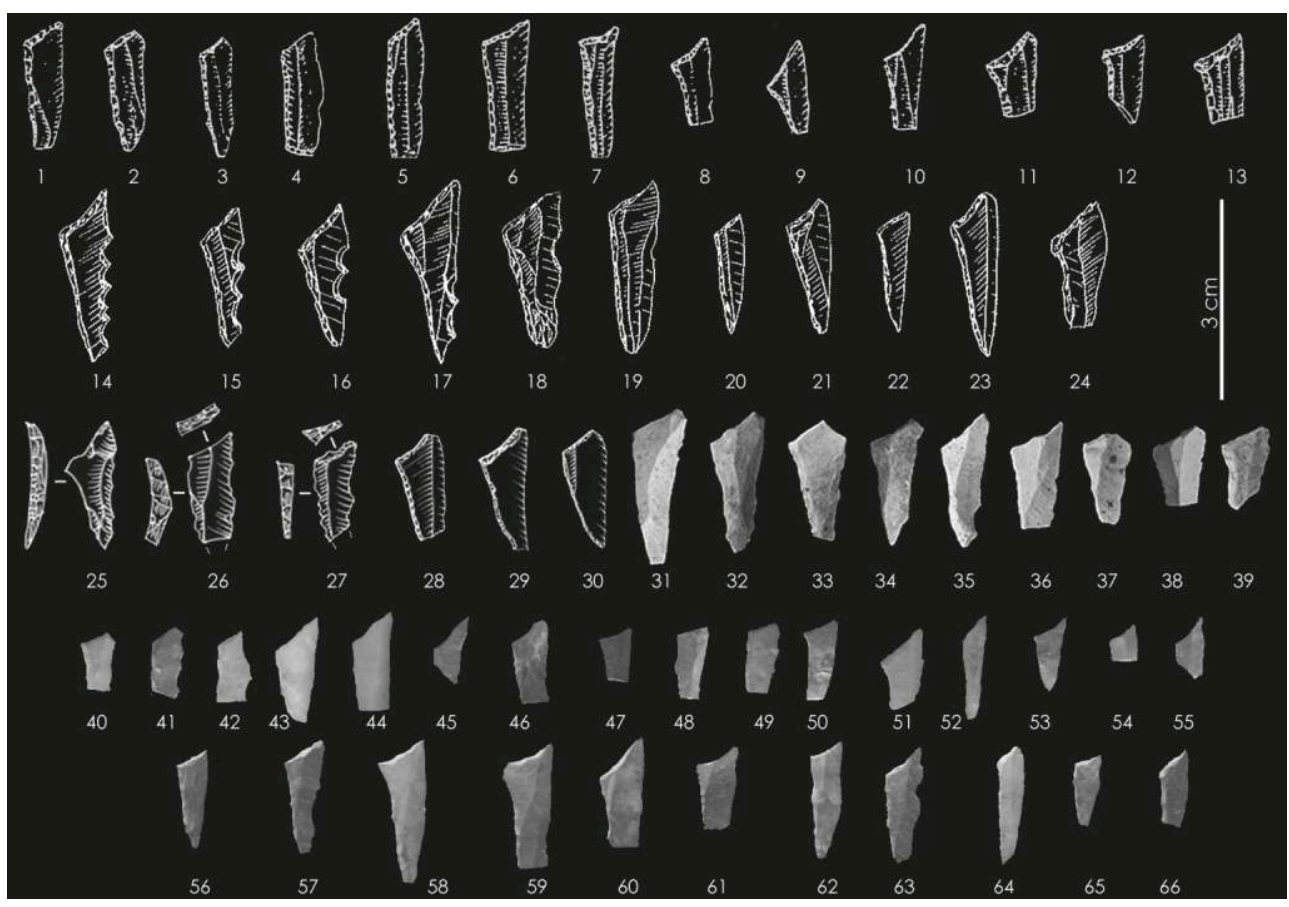

1 À 13 : Las Caldas C. XI-XIII (Asturias, Espagne). 14 À 24 : La Roche (Castelmoron-sur-Lot, Lot-etGaronne). 25 À 39 : Peyre Blanque (Fabas, Ariège). 40 À 66 : Grotte Tastet.

PAO Mathieu Langlais. 1 à 13 : extraits de Corchón $1994 ; 14$ à 24 : extraits de Le Tensorer $1981 ; 25$ à 39 : extraits de Lacombe et al. $2015 ; 40$ à 66 : photos Mathieu Langlais. 
Bien que proches morphologiquement, les lamelles à dos tronquées de type triangle scalène de la grotte Tastet ne doivent pas être confondues avec les lamelles scalènes du MMA (Langlais 2008 et 2010, Sécher 2017). En effet, si comme ces dernières, les triangles du MMR sont réalisés sur des lamelles normalisées et présentent une latéralisation préférentielle des dos et troncatures obliques (à $90 \%$ : troncature proximale et dos dextre ou troncature distale et dos senestre), l'angle dos-troncature et la délinéation des troncatures sont moins normalisées (fig. 7) que pour les lamelles. D'une longueur moyenne de 13 à $15 \mathrm{~mm}$, ces pièces présentent un gabarit autour de 4 à $5 \mathrm{~mm}$ de large pour $1,5 \mathrm{~mm}$ d'épaisseur. Pour le moment, l'utilisation de la technique du microburin n'est pas documentée à Tastet. Jusqu'à récemment, dans le domaine pyrénéen, les microlithes triangulaires de dimension réduite étaient connus surtout dans le Magdalénien supérieur, et ce des deux côtés des Pyrénées, comme par exemple à La Cauna (Belvis, Aude) ; la grotte du Moulin (Troubat, Hautes-Pyrénées) ; la grotte du Parco (Alòs de Balaguer, Lérida, Espagne) (Sacchi 1986, Barbaza 1996, Langlais 2008). La grotte Tastet est un des rares sites de cette région où ce type d'armature lithique a pu être identifié dans un contexte renvoyant clairement au MMR, sans risque de mélange en particulier avec le Magdalénien supérieur, ce dernier étant totalement absent sur le site. Cette découverte permet donc de rediscuter de la variabilité interne du MMR à partir des productions lamellaires et des microlithes.

\section{La variabilité du MMR}

\section{Un MMR à triangles}

Des objets identiques aux triangles scalènes de la grotte Tastet ont été identifiés dans d'autres gisements pyrénéens : Le Bignalats, également situé dans le bassin d'Arudy, et qui a livré du matériel du MMR et du Magdalénien supérieur (Pétillon et al. 2015), et surtout Peyre Blanque (Fabas, Ariège) (fig. $7, \mathrm{n}^{\text {os }} 25$ à 39), en cours de fouille et récemment publié avec une attribution au "Magdalénien ancien-moyen " (Lacombe et al. 2015). Au nord-est de la chaîne pyrénéenne, la grotte Gazel (Sallèles-Cabardès, Aude) témoigne d'occupations datées du MMR livrant une association de lamelles et triangles scalènes fabriqués avec la méthode du microburin (Langlais 2010). Ces objets rappellent fortement les «benets" définis par N.Soler (également obtenus avec l'emploi de la technique du microburin) à partir de deux sites de plein air malheureusement non datés (Soler 1995, Langlais 2010). La grotte des Peyrugues (Orniac, Lot) livre un ensemble à lamelles scalènes également daté du MMR (Langlais 2010), ce qui suggère donc, comme pour Gazel, une possible perduration des lamelles scalènes depuis le MMA, parallèlement aux triangles scalènes. Enfin, le site de La Roche (Castelmoron-sur-Lot, Lot-et-Garonne) (Le Tensorer 1981) livre des triangles scalènes en contexte de MMR aquitain (fig. 7, $\mathrm{n}^{\mathrm{os}} 14$ à 24 ).

20 À l'ouest des Pyrénées, ces triangles rappellent morphologiquement (latéralisation préférentielle des dos et troncatures et délinéation des troncatures) deux séries attribuées pourtant au Magdaleniense inferior cantábrico : Las Caldas (couches XI à XIII ; fig. 7, $\mathrm{n}^{\text {os }} 1$ à 13), dans les Cantabres, et Legintxiki en Pays basque (Corchón 1994, Montes et Domingo 2013, Corchón etal. 2015). On peut également noter des rapprochements avec Ekain couche VII (à Deva, Guipuscoa, Espagne), qui livre des lamelles et triangles, mais dans un ensemble mélangé avec du Magdalénien inférieur 
(Cazals et Langlais 2006). En revanche, comme nous l'avons vu plus haut pour les Peyrugues, ces ensembles à triangles se distinguent de séries à lamelles scalènes comme celles d'Abauntz (Arraitz-Orkin, Navarra, Espagne) attribué selon la date ${ }^{14} \mathrm{C}$ au Magdaleniense medio (Utrilla et Mazo 1996).

\section{Un autre Magdalénien moyen récent}

21 D'autres sites datés de la même période, mais dans lesquels aucun triangle scalène n'a été découvert, livrent en revanche des armatures lithiques bien différentes. Dans le bassin d'Arudy, des sites pourtant voisins de la grotte Tastet ou du Bignalats - comme Saint-Michel, Laa 2 C3 ou le Poeymaü BI - montrent, parallèlement à un apport de lames transportées sur plus de 200 kilomètres (notamment en silex du Bergeracois), la mise en œuvre de débitages frontaux sur tranche d'éclats et de lames permettant la production de lamelles fines et étroites ( 2 à $4 \mathrm{~mm}$ de large pour $1 \mathrm{~mm}$ d'épaisseur) transformées en microlithes à dos, parfois appointées (Langlais 2010, Pétillon et al. 2015 et 2017, Langlais et al. 2016). Au Tuc d'Audoubert (Montesquieu-Avantès, Ariège), on retrouve ces mêmes débitages et armatures à dos étroites, ainsi qu'une grande lame importée (Bégouën et al. 2009). Il en est de même à Labastide (Hautes-Pyrénées), où de grandes lames en silex du Bergeracois ont été déposées dans une anfractuosité de la paroi (Simonnet 1982); le débitage lamellaire, sur tranche d'éclats, est en revanche réalisé sur des silex locaux du flysch (Lesage 2008, Langlais 2010). À Duruthy C4 (Landes) et à Isturitz (Pyrénées-Atlantiques) - notamment dans le MMR du Grand Diverticule, fouillé sous la direction de C.Normand -, on trouve également ces productions lamellaires et des morphotypes d'armatures identiques (Langlais 2010) (fig. 8). 
Fig. 8. - Isturitz, Grand Diverticule : exemples de nucléus à lamelles sur tranche et de lamelles à dos étroites.
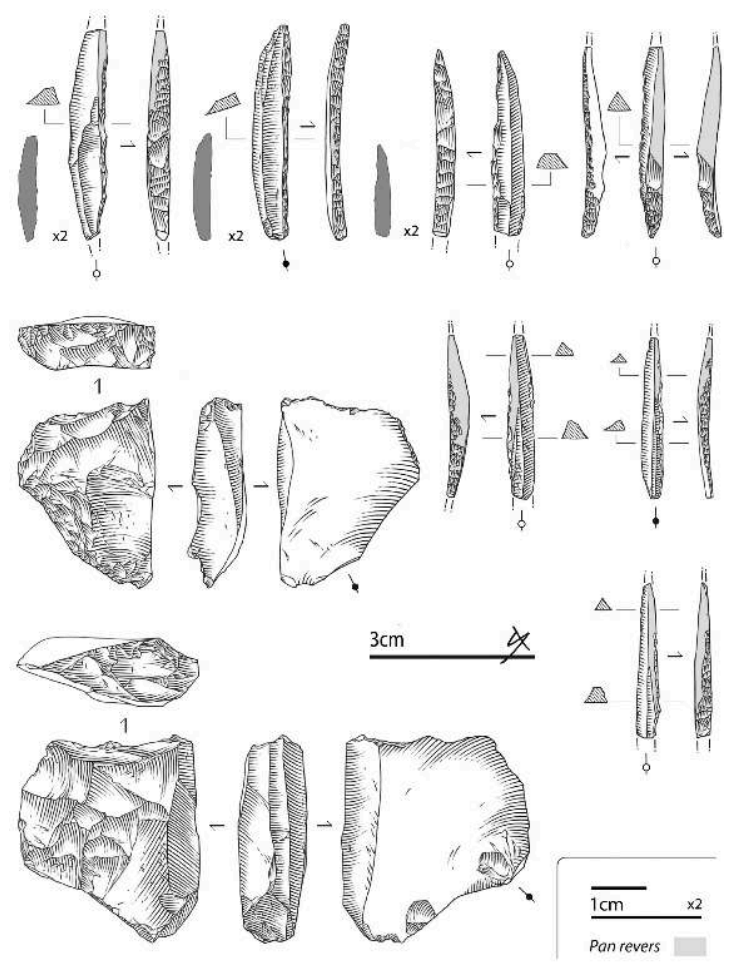

Dessins Sylvain Ducasse.

La couche C4 de Laa 2, datée du MMA, bien que pauvre numériquement, livre également un débitage sur tranche pour des lamelles à dos étroites. Elle pourrait témoigner d'une précocité de ces choix techniques. Ceci nous renvoie aux deux séries d'Espagne où ce comportement a pu être diagnostiqué : l'abri Forcas, couches XIII à XVI (Langlais 2014), et Cova Alonsé (Langlais 2013). En effet, ces deux sites sont attribués pro parte au Magdaleniense inferior cantábrico (Montes et Domingo 2013, Utrilla et Mazo 2014).

\section{Discussion}

En l'absence de cas d'interstratification entre ces deux morphotypes d'armatures lithiques, il est difficile de se prononcer définitivement sur la relation chronologique (diachronie ou synchronie) entretenue par les sites à triangles scalènes et ceux à lamelles à dos étroites. En l'état actuel des données radiocarbone, les triangles scalènes se concentrent plutôt vers la toute fin du MMA/Magdaleniense inferior et les débuts du MMR, entre 18,5 et $17 \mathrm{ka}$ cal. BP, tandis que les lamelles à dos étroites occupent tout l'espace chronologique entre 18,5 et 16 ka cal. BP (fig. 9 et tabl. 1). En l'état des données, triangles scalènes et lamelles à dos étroites apparaissent donc plutôt synchrones au sein du MMR. 
Fig. 9. - Graphique des dates calibrées du MMR.

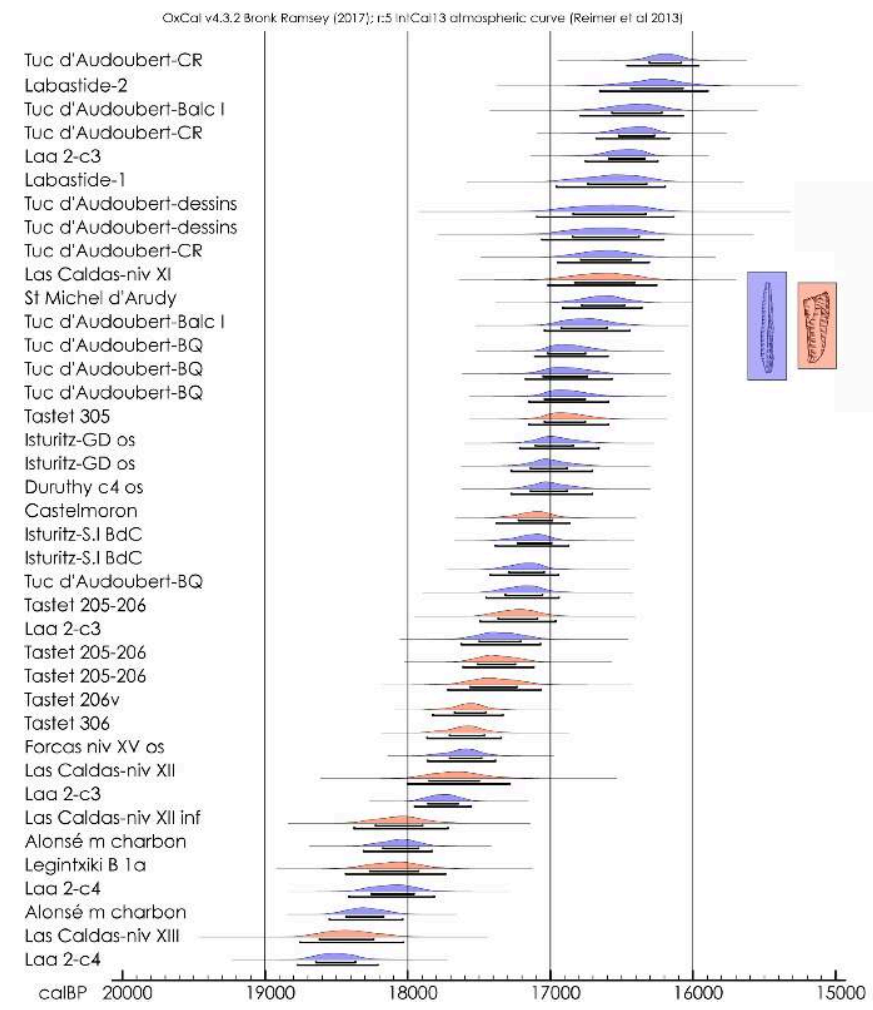

EN BLEU : séries à lamelles à dos étroites. EN ROUgE : séries à triangles scalènes.

PAO Mathieu Langlais.

Tabl. 1. - Liste des dates calibrées du MMR de la figure 9.

\begin{tabular}{|c|c|c|c|}
\hline Sites & Date BP & $\begin{array}{l}\text { Référence } \\
\text { de lanalyse }\end{array}$ & $\begin{array}{c}\text { Référence } \\
\text { bibliographique }\end{array}$ \\
\hline Tuc d'Audoubert CR & $13460 \pm 70$ & Poz-8432 & Bégouên et al. 2009 \\
\hline Labastide 2 & $13500 \pm 120$ & Gif-6612 & Djindjian 2000 \\
\hline Tuc d'Audoubert balc.। & $13600 \pm 110$ & GifA-102391 & Bégouén et $a$. 2009 \\
\hline Tuc d'Audoubert CR & $13610 \pm 70$ & Poz-8435 & Bégouên et af. 2009 \\
\hline $\operatorname{Laa} 2 \mathrm{C}_{3}$ & $13665 \pm 60$ & OXA-26673 & Pétillon et al. 2017 \\
\hline Labastide 1 & $13700 \pm 120$ & Gif-6611 & Djindjian 2000 \\
\hline Tuc d'Audoubert dessins & $13730 \pm 160$ & GifA-102390 & Bégouën et af. 2009 \\
\hline Tuc d'Audoubert CR & $13750 \pm 90$ & Poz-8433 & Bégouën et at. 2009 \\
\hline Tuc d'Audoubert dessins & $13750 \pm 140$ & GifA-102389 & Bégouên er at. 2009 \\
\hline Las Caldas niv. XI & $13755 \pm 120$ & Ua-2734 & Corchón et al. 2015 \\
\hline Saint Michel d'Arudy & $13760 \pm 65$ & $O \times A-28123$ & Barshay-Szmidt et al. 2016 \\
\hline Tuc d'Audoubert balc.I & $13840 \pm 80$ & Poz-8335 & Bégouên et al. 2009 \\
\hline Tuc d'Audoubert BQ & $13920 \pm 60$ & Poz-17513 & Bégouën et â. 2009 \\
\hline Tastet 305 & $13930 \pm 70$ & $L y-10029$ & Pétillon et al. 2014 \\
\hline Tuc d'Audoubert BQ & $13930 \pm 70$ & Poz-17511 & Bégoueuen et at. 2009 \\
\hline Tuc d'Audoubert BQ & $13930 \pm 80$ & Poz-17512 & Bégouèn et al. 2009 \\
\hline Isturitz $G D$ os & $13980 \pm 65$ & OXA-26679 & Barshay-Szmidt et al. 2016 \\
\hline Duruthy c4 os & $14005 \pm 65$ & OXA-28118 & Barshay-5zmidt et af. 2016 \\
\hline Isturitz GD os & $14005 \pm 65$ & $\mathrm{O} \times \mathrm{A}-\mathrm{X} 2503-23$ & Barshay-Szmidt et af. 2016 \\
\hline Castelmoron & $14070 \pm 60$ & Ly-7904 & Langlais 2010 \\
\hline Isturitz SI BdC & $14075 \pm 60$ & OXA-19832 & Szmidt et al. 2009 \\
\hline Isturitz SI BdC & $14110 \pm 60$ & OXA-19831 & Szmidt et al. 2009 \\
\hline Tuc d'Audoubert BQ & $14120 \pm 70$ & Poz-17523 & Bégouën et al. 2009 \\
\hline Tastet 205-206 & $14150 \pm 80$ & $L y-11729$ & Pétillon et al. 2014 \\
\hline $\operatorname{Laa} 2 \mathrm{C}_{3}$ & $14252 \pm 94$ & Er-11113 & Pétillon et al. 2017 \\
\hline Tastet 205-206 & $14270 \pm 80$ & $\lfloor y-10027$ & Pétillon et ol. 2014 \\
\hline Tastet 205-206 & $14290 \pm 110$ & $L y-11705$ & Pétillon et al. 2014 \\
\hline Tastet 206v & $14410 \pm 70$ & Poz-84488 & Inédit(Pétillon) \\
\hline Tastet 306 & $14430 \pm 80$ & Ly-11992 & Pétillon et al. 2014 \\
\hline Forcas niv. XV os & $14440 \pm 70$ & GrA-25979 & Utrilla et Mazo 2014 \\
\hline Las Caldas niv. X\|I & $14495 \pm 140$ & Ua-2735 & Corchón et al. 2015 \\
\hline Laa 2-C3 & $14570 \pm 65$ & $0 \times A-26672$ & Pétillon et al. 2017 \\
\hline Las Caldas niv. XII inf. & $14835 \pm 130$ & Ua -4300 & Corchón et al. 2015 \\
\hline Alonsé $m$ charbon & $14840 \pm 90$ & GrA-21536 & Montes et Domingo 2013 \\
\hline Legintriki B la & $14865 \pm 140$ & Ua-3397 & Montes et Domingo 2013 \\
\hline Laa 2-C4 & $14880 \pm 120$ & $L y-11706$ & Pétillon et al. 2017 \\
\hline Alonsé $m$ charbon & $15060 \pm 90$ & GrA-21537 & Montes et Domingo 2013 \\
\hline Las Caldas niv. XIII & $15165 \pm 160$ & Ua-4301 & Corchón et al. 2015 \\
\hline Laa $2 \mathrm{C}_{4}$ & $15240 \pm 120$ & $L y-11707$ & Pétillon et ol. 2017 \\
\hline
\end{tabular}



limite notre réflexion. Côté français, la couche $\mathrm{C} 4$ de La 2 , datée du MMA, livre une petite série très proche de la couche sus-jacente, attribuée au MMR à lamelles à dos étroites. En Espagne, très peu de séries à lamelles à dos étroites ou triangles ont jusqu'ici été identifiées, et il est difficile d'estimer la longévité chronologique de ces morphotypes. Les ensembles d'Alonsé niveau m, Forcas c. XV, Las Caldas Sala II (c. XIII et XII inf.) et Legintxiki livrent des dates ${ }^{14} \mathrm{C}$ compatibles avec du MMA, qui pourraient donc suggérer une précocité des deux morphotypes au sein même du MMA ou un recul des limites chronologiques du MMR. En revanche, si les couches XII et XI de Las Caldas présentent également des dates proches du MMR, les couches XIII et XIV de Forcas livrent des dates du Magdalénien supérieur... Il faut donc rester prudent quant à la caractérisation chronologique de ces morphotypes d'armatures sans révision archéostratigraphique des séquences en amont.

Ceci nous amène aux différences terminologiques dans la dénomination des premiers temps du Magdalénien entre le sud-ouest de la France et la péninsule Ibérique - ce que nous avons appelé plus haut "frontière pré-historiographique» (fig. 10). Nous ne discuterons pas ici de la phase «archaïque » ou «initiale» du Magdalénien, ni du Badegoulien ibérique. Nous soulignerons en revanche que plusieurs zones d'ombre persistent sur la variabilité des équipements lithiques et osseux regroupées au sein du Magdaleniense inferior cantábrico. Au regard de la chronologie française, cette phase regrouperait deux temps qui sont pourtant bien distingués du point de vue de la typotechnologie lithique et osseuse: le Magdalénien inférieur, tel qu'il a été redéfini par N. Cazals (2000) puis par l'un d'entre nous (Langlais 2007), et le MMA (sensu Langlais et al. 2016 et 2017, Pétillon 2016, Sécher 2017). En revanche, le MMR, tel qu'il est aujourd'hui caractérisé dans le sud-ouest de la France, apparaît bien synchrone avec le Magdaleniense medio cantabrique, réunifiant en quelque sorte l'espace francocantabrique autour d'une même définition du Magdalénien moyen. 
Fig. 10. - Diagramme comparatif des modèles évolutifs du Magdalénien entre Espagne cantabrique et France.

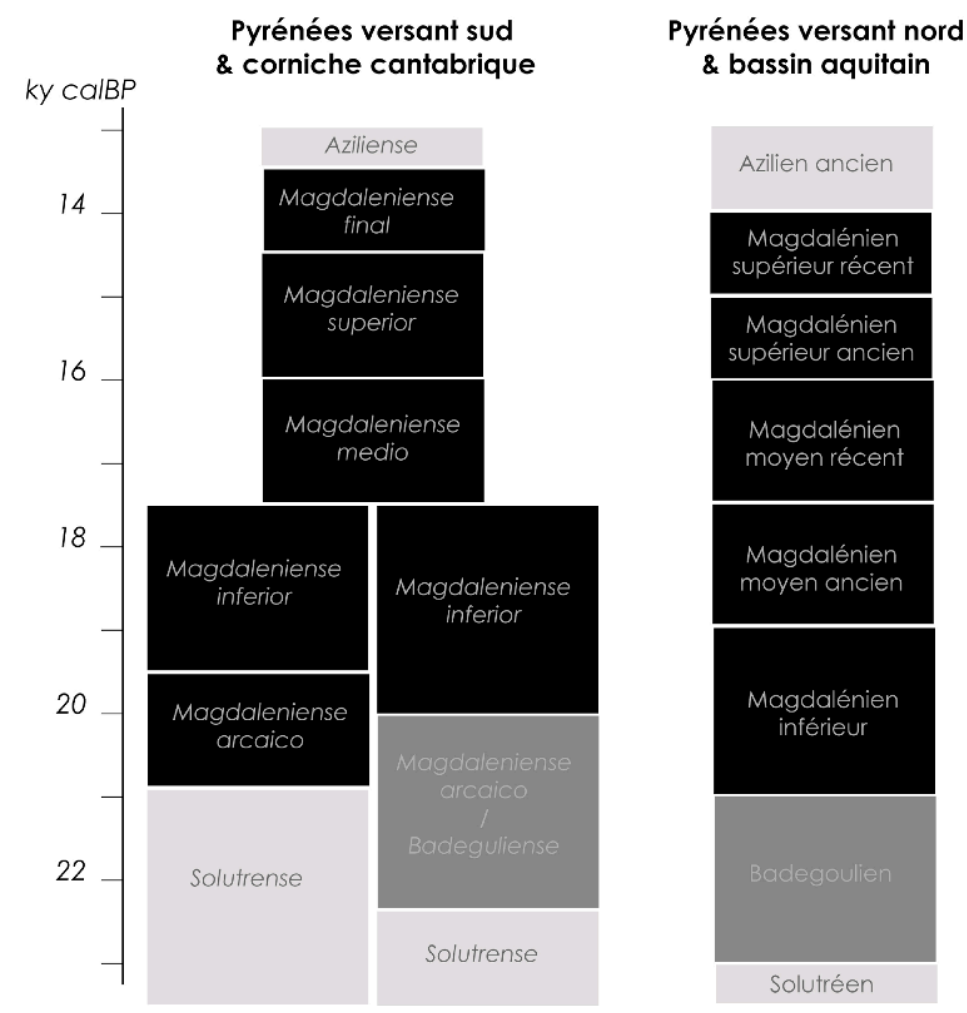

Espagne d'après Utrilla 2004, Aura et al. 2012, Fontes 2016 ; France d'après Renard et Ducasse 2015, Barshay-Szmidt et al. 2016, Langlais et al. 2016, Pétillon 2016.

Dans les Pyrénées et sur la corniche basco-cantabrique, la présence de traditions techniques similaires (ensembles à armatures triangulaires versus ensembles à lamelles à dos étroites) est une illustration supplémentaire des relations étroites entretenues à cette période entre groupes de chasseurs-collecteurs tout au long de la chaîne pyrénéocantabrique. À la même époque, durant le MMR, la circulation des matières premières siliceuses témoigne également de relations transpyrénéennes (Corchón et al. 2009, Langlais 2010, Sánchez de la Torre 2015, Fontes 2016, Langlais et al. 2016, Pétillon et al. 2017). Cette absence de frontière culturelle relativise un peu plus la pertinence des frontières pré-historiographiques, et souligne à nouveau la nécessité d'un travail approfondi de confrontation archéologique entre les assemblages pyrénéens et bascocantabriques.

\section{BIBLIOGRAPHIE}

ANDRIEUX E., BERTRAN P., SAITO K., 2016, « Spatial analysis of the French Pleistocene permafrost by a GIS database », Permafrost and Periglacial Processes, vol. 27, $n^{\circ}$ 1, p. 17-30. 
ANGEVIN R. et LANGLAIS M., 2009, « Où sont les lames ? Enquête sur les "caches" et "dépôts" de lames du Magdalénien moyen (15000-13500 BP) », dans Bonnardin S., Hamon C., Lauwers M., Quilliec B. (dir.), Du matériel au spirituel : réalités archéologiques et historiques des " dépôts » de la Préhistoire à nos jours, actes des $29^{\circ}$ Rencontres internationales d'archéologie et d'histoire, Antibes, APDCA, p. 223-242.

AURA J. E., TIFFAGOM M., JORDÁ PARDO J. F., DUARTE E., FERNÁNDEZ DE LA VEGA J., SANTAMARIA D., RASILLA M. de la, VADILLO M., PEREZ RIPOLL M., 2012, « The Solutrean-Magdalenian transition: A view from Iberia », Quaternary International, $\mathrm{n}^{\circ} 272-273$, p. 120-133.

BARBAZA M., 1996, « Le Magdalénien supérieur final et l'Azilien dans les Pyrénées centrales : la grotte-abri du Moulin à Troubat (Hautes-Pyrénées) et son contexte », dans Delporte H. et Clottes J. (dir.), Pyrénées préhistoriques, arts et sociétés : actes du $118^{e}$ congrès des sociétés historiques et scientifiques (Pau, 1993), Paris, Éditions du CTHS, p. 311-326.

BARSHAY-SZMIDT C., COSTAMAGNO S., HENRY-GAMBIER D., LAROULANDIE V., PÉTILLON J.-M., BOUDADI-MALIGNE M., KUNTZ D., LANGLAIS M., MALLYE J.-B., 2016, « New extensive focused AMS ${ }^{14} \mathrm{C}$ dating of the Middle and Upper Magdalenian of the western Aquitaine/Pyrenean region of France (ca. 19-14 ka cal BP): Proposing a new model for its chronological phases and for the timing of occupation ", Quaternary International, n 414 , p. 62-91.

BAZILE F., 2011, « De l'Épigravettien à l'ouest du Rhône ? », Paleo, nº 22, p. 27-52.

BÉGOUËN H., 1933, « Trouvaille de grandes lames de silex en Ariège », Bulletin de la Société préhistorique française, $n^{\circ} 30$, p. 641-643.

BÉGOUËN R., FRITZ C., TOSELLO G., CLOTTES J., PASTOORS A., FAIST F., BOURGES F. de, FOSSE P., LACOMBE S., LANGLAIS M., 2009, Le sanctuaire secret des bisons : il y a 14000 ans dans la caverne du Tuc d'Audoubert, Paris, Somogy.

BERTRAN P., SITZIA L., BANKS W., BATEMAN M. D., DEMARS P.-Y., HERNANDEZ M., LENOIR M., PRODEO F., 2013, « The Landes de Gascogne (southwest France): periglacial desert and cultural frontier during the Palaeolithic », Journal of Archaeological Science, vol. 40, n 5, p. 2274-2285.

BLANC C. et MARSAN G., 1984, « Grotte de Sainte-Colome », dans Leroi-Gourhan A. (dir.), L'Art des cavernes : atlas des grottes ornées paléolithiques françaises, Paris, Imprimerie nationale, p. 287-288.

BRUXELLES L. et JARRY M., 2011, « Climatic conditions, settlement patterns and cultures in the Paleolithic: the example of the Garonne Valley (southwest France) », Journal of Human Evolution, vol. $61, \mathrm{n}^{\circ} 5$, p. 538-548.

BUISSON D., FRITZ C., KANDEL D., PINÇON G., SAUVET G., 1996, « Les contours découpés de têtes de chevaux et leur contribution à la connaissance du Magdalénien moyen ", Antiquités nationales, $\mathrm{n}^{\circ} 28$, p. 99-128.

CATTELAIN P., 2017, « Les propulseurs d'Isturitz », dans Normand C. et Cattelain P. (dir.), La grotte d'Isturitz : fouilles anciennes et récentes, Treignes, CEDARC (Artefacts, 13), p. 35-56.

CATTElain P. et Bellier C., 2014, « Objets décorés pris sur stylohyoïde », dans Mons L., Péan S., Pigeaud R. (dir.), Matières d'art : représentations préhistoriques et supports osseux, relations et contraintes, Paris, Errance, p. 91-104.

CAZALS N., 2000, « Constantes et variations des traits techniques et économiques entre le Magdalénien inférieur et moyen : analyse des productions lithiques du nord de la péninsule Ibérique ", thèse de doctorat, Paris, université Paris I. 
CAZALS N. et BON F., 2007, « Des frontières préhistoriques : oui, mais en fonction de quelles limites? ", dans Cazals N., González Urquijo J., Terradas X. (dir.), Frontières naturelles et frontières culturelles dans les Pyrénées préhistoriques, Santander, PubliCan, Ediciones de la universidad de Cantabria, p. 21-25.

CAZALS N. et LANGLAIS M., 2006, « La place d'Ekain (couche VII) au sein du Magdalénien bascocantabrique : nouvelles contributions sur l'organisation des productions lithiques », Munibe, vol. 57, nº 2 (Homenaje a Jesus Altuna), p. 177-191.

CAZALS N., GONZÁLEZ URQUIJO J., TERRADAS X. (dir.), 2007, Frontières naturelles et frontières culturelles dans les Pyrénées préhistoriques, Santander, Publican, Ediciones de la universidad de Cantabria.

CORCHÓN M. S., 1994, « El Magdaleniense con triángulos de Las Caldas (Asturias, España): Nuevos datos para la definición del Magdaleniense inferior cantábrico », Zephyrus, n 47, p. 77-94.

CORCHÓN M. S., TARRIÑO A., MARTINEZ X., 2009, « Mobilité, territoires et relations culturelles au début du Magdalénien moyen cantabrique : nouvelles perspectives ", dans Djindjian F., Kozłowski J., Bicho N. (dir.), Le concept de territoire dans le Paléolithique supérieur européen : actes du $15^{e}$ congrès de l'UISPP (Lisbonne, 2006), Oxford, Archaeopress (BAR International Series, 1938), p. 217-230.

CORChÓN M. S., ORTEGA MARTINEZ P., VinCENTE SANTOS F. J., 2015, « El origen del Magdaleniense: una cuestión controvertida. La cueva de Las Caldas y los yacimientos del Nalón (Asturias, Norte de España)», Munibe, $n^{\circ}$ 66, p. 63-75.

COSTAMAGNO S., BARSHAY-SZMIDT C., KUNTZ D., LAROULANDIE V., PÉTILLON J.-M., BOUDADI-MALIGNE M. LANGLAIS M., MALLYE J.-B., CHEVALLIER A., 2016, « Reexamining the timing of reindeer disappearance in southwestern France in the larger context of the late glacial faunal turnover », Quaternary International, $\mathrm{n}^{\circ}$ 414, p. 34-61.

DJINDJIAN F., 2000, Identité, chronologie et territoires du Magdalénien en Europe occidentale : questions posées, dans G. Pion (dir.), Le Paléolithique supérieur récent : nouvelles données sur le peuplement et l'environnement, Table ronde de Chambéry, 1999, Paris, Société préhistorique française (Mémoires de la Société préhistorique française, 28), p. 95-112.

FONTES L. M., 2016, « The Initial Magdalenian mosaic: New evidence from Urtiaga cave, Guipúzcoa, Spain », Journal of Anthropological Archaeology, nº 41, p. 109-131.

GARATE MAIDAGAN D., RIVERO O., BOURRILLON R., PÉTILLON J.-M., 2013, « L'art pariétal de la grotte Tastet (Sainte-Colome, Pyrénées-Atlantiques) : au carrefour des traditions artistiques tardiglaciaires », Paleo, $\mathrm{n}^{\circ}$ 24, p. 103-120.

GOURC L., LANGLAIS M., SITZIA L., CAUX S., BELBEOC'H G., LENOIR M., 2016, « La Honteyre (Le Tuzan, Gironde) : une occupation de chasseurs-collecteurs magdaléniens en contexte de désert sableux », Bulletin de la Société préhistorique française, vol. 113, nº 4, p. 713-735.

LACOMBE S., STERLING K., CONKEY M., DIETRICH W., 2015, « Le site de plein air de Peyre Blanque (Fabas, Ariège) : un jalon original du Magdalénien dans le sud-ouest de la France », Bulletin de la Société préhistorique française, vol. 112, $\mathrm{n}^{\circ}$ 2, p. 235-268.

LANGLAIS M., 2007, « Dynamiques culturelles des sociétés magdaléniennes dans leurs cadres environnementaux : enquête sur 7000 ans d'évolution de leurs industries lithiques entre Rhône et Èbre », thèse de doctorat, université Toulouse II - Le Mirail et Universitat de Barcelona.

LANGLAIS M., 2008, « Magdalenian chronology and territories between the Rhone and the Ebro: the case of the lithic weapon elements ", dans Pétillon J.-M., Dias-Meirinho M.-H., Cattelain P., Honegger M., Normand C., Valdeyron N. (dir.), Recherches sur les armatures de projectile du 
Paléolithique supérieur au Néolithique : actes du colloque C $83 d u 15^{e}$ congrès de l'UISPP, Lisbonne, septembre 2006, Toulouse, Presses universitaires du Midi (P@lethnologie, $\mathrm{n}^{\circ}$ 1), p. 220-249.

LANGLAIS M., 2010, Les sociétés magdaléniennes de l'isthme pyrénéen, Paris, Éditions du CTHS (Documents préhistoriques, 26).

LANGLAIS M., 2013, "Productions et équipements lithiques de la cova Alonsé », dans Montes L. et Domingo R. (dir.), El asentamiento magdaleniense de la Cova Alonsé (Estadilla, Huesca), Zaragoza, Universidad de Zaragoza (Monografías Arqueológicas, 48), p. 79-89.

LANGLAIS M., 2014, « Les productions lithiques de l'abri Forcas I (niv 14-16) : diagnostic sur les productions lamellaires ", dans Utrilla P. et Mazo C. (dir.), La Peña de las Forcas (Graus, Huesca): Un asentamiento estratégico en la confluencia del Ésera y el Isábena, Zaragoza, Universidad de Zaragoza (Monografías Arqueológicas, 46), p. 113-124.

LANGLAIS M. et MANGADO J., 2007, «Le Magdalénien entre le Rhône et l'Èbre : des frontières naturelles et culturelles vécues par les préhistoriques et perçues par les préhistoriens ? ", dans Cazals N., González Urquijo J., Terradas X. (dir.), Frontières naturelles et frontières culturelles dans les Pyrénées préhistoriques, Santander, PubliCan, Ediciones de la Universidad de Cantabria, p. 143-163.

LANGLAIS M., COSTAMAGNO S., LAROULANDIE V., PÉTILLON J.-M., DISCAMPS E., MALLYE J.-B., COCHARD D., KUNTZ D., 2012, « The evolution of Magdalenian societies in South-West France between 18000 and 14000 cal BP: changing environments, changing tool kits ", Quaternary International, $n^{\circ} 272-273$, p. 138-149.

LANGLAIS M., SÉCHER A., CAUX S., DELVIGNE V., GOURC L., NORMAND C., SÁNCHEZ DE LA TORRE M., 2016, « Lithic tool kits: A metronome of the evolution of the Magdalenian in Southwest France $(19,000-14,000$ cal BP) », Quaternary International, $\mathrm{n}^{\circ}$ 414, p. 92-107.

LANGLAIS M., PÉTILLON J.-M., SÉCHER A., 2017, « Les débuts du Magdalénien dans le Sud-Ouest français : témoignages croisés des équipements lithiques et osseux », dans Bourdier C., Chehmana L., Malgarini R., Poltowicz-Bobak M. (dir.), L'essor du Magdalénien : aspects culturels, symboliques et techniques des faciès à navettes et à Lussac-Angles. Actes de la séance de la SPF de Besançon, 17-19 octobre 2013, Paris, Société préhistorique française, p. 209-234.

LAROULANDIE V., COSTAMAGNO S., LANGLAIS M., PÉTILLON J.-M., 2017, « L'œuf ou la poule ? Retour sur le projet Magdatis, "Le Magdalénien de la façade atlantique face aux changements environnementaux" ", Quaternaire, vol. 28, n² 2, p. 277-283.

LE TENSORER J.-M., 1981, Le Paléolithique de l'Agenais, Paris, CNRS éditions (Cahiers du Quaternaire, 3).

LEFEBVRE A., 2016, « Les stratégies d'adaptation des sociétés pyrénéennes entre 19 et 14 ka cal BP : étude biométrique et techno-économique comparée sur l'exploitation du bois de cerf et du bois de renne autour des Pyrénées au Magdalénien moyen et supérieur ", thèse de doctorat, Pessac, université de Bordeaux.

LESAGE T., 2008, « Une production lithique d'individus du Magdalénien moyen en contexte de grotte profonde ornée : l'exemple de la grotte de Labastide (Hautes-Pyrénées) », mémoire de master 1, université Toulouse II - Le Mirail.

MANGADO J., BERGADA M. M., LANGLAIS M., ESTEVE X., TEJERO J. M., ESTRADA A., NADAL J., MERCADAL O., FULLOLA J. M., 2010, « Montlleo : un gisement de chasseurs magdaléniens dans la plaine de Cerdagne. L'occupation d'un espace montagnard dans les Pyrénées de la Catalogne ", dans Tzortzis S. et Delestre X. (dir.), Archéologie de la montagne européenne : actes de la table ronde 
internationale de Gap, septembre 2008, Paris, Errance/Aix-en-Provence, Centre Camille Jullian (Bibliothèque d'archéologie méditerranéenne et africaine, 4), p. 137-144.

MARSAN G., 1979, « L'occupation humaine à Arudy (Pyrénées-Atlantiques) pendant la Préhistoire et le début de la Protohistoire ", dans $7^{e}$ Rencontres d'historiens sur la Gascogne méridionale et les Pyrénées occidentales, Pau, $1^{\text {er }}$ octobre 1977, Pau, université de Pau et des pays de l'Adour, p. 51-98. MARSAN G., 1996, «Préhistoire de la vallée d'Ossau : éléments de réflexion et de discussion sur l'occupation de la montagne ouest-pyrénéenne au Tardiglaciaire et au début du Postglaciaire », dans Delporte H. et Clottes J. (dir.), Pyrénées préhistoriques, arts et sociétés : actes du $118^{e}$ congrès des sociétés historiques et scientifiques (Pau, 1993), Paris, Éditions du CTHS, p. 473-486.

MONTES L. et DOMINGo R. (dir.), 2013, El asentamiento magdaleniense de la Cova Alonsé (Estadilla, Huesca), Zaragoza, Universidad de Zaragoza (Monografías Arqueologicas, 48).

NAUGHTON F., SANCHEZ GOÑI M. F., RODRIGUES T., SALGUEIRO E., COSTAS S., DESPRAT S., DUPRAT J., MICHEL E., ROSSIGNOL L., ZARAGOSI S., VOELKER A. H. L., ABRANTES F., 2016, « Climate variability across the last deglaciation in NW Iberia and its margin ", Quaternary International, $\mathrm{n}^{\circ} 414$, p. 9-22.

OMNÈs J., 1983, « La petite grotte ornée de Sainte-Colome (Pyrénées-Atlantiques) », Revue de Comminges, vol. 96, $\mathrm{n}^{\circ} 1, \mathrm{p} .3-13$.

PESCHAUX C., 2017, « La parure des sociétés du Dernier Maximum glaciaire : évolution des pratiques et traditions ornementales entre la fin du Solutréen, le Badegoulien et le début du Magdalénien dans les bassins parisien, ligérien et aquitain » thèse de doctorat, université Paris Nanterre.

PÉTILLON J.-M., 2006, Des Magdaléniens en armes : technologie des armatures de projectiles en bois de cervidé du Magdalénien supérieur de la grotte d'Isturitz (Pyrénées-Atlantiques), Treignes, CEDARC (Artefacts, 10).

PÉTILLON J.-M., 2016, « Technological Evolution of Hunting Implements among Pleistocene HunterGatherers: Osseous Projectile Points in the Middle and Upper Magdalenian (19-14 ky cal. BP) », Quaternary International, $\mathrm{n}^{\circ} 414$, p. 108-134.

PÉTILLON J.-M., BOUDADI-MALIGNE M., GARDÈRE P., KUNTZ D., LANGLAIS M., LAROULANDIE V., LIARD M., MALLYE J.-B., MISTROT V., NORMAND C., PESCHAUX C., 2014, « La grotte Tastet à Sainte-Colome (canton d'Arudy, Pyrénées-Atlantiques) : occupations du Magdalénien moyen ", rapport de fouille programmée, Bordeaux, Service régional de l'archéologie Aquitaine.

PÉTILLON J.-M., LANGLAIS M., KUNTZ D., NORMAND C., BARSHAY-SZMIDT C., COSTAMAGNO S., DELMAS M., LAROULANDIE V., MARSAN G., 2015, « The human occupation of the northwestern Pyrenees in the Late Glacial: new data from the Arudy basin, lower Ossau valley », Quaternary International, $\mathrm{n}^{\circ} 364$, p. 126-143.

PÉTILLON J.-M., LAROULANDIE V., COSTAMAGNO S., LANGLAIS M., 2016a, « Testing environmental determinants in the cultural evolution of hunter-gatherers: a three-year multidisciplinary project on the occupation of the western Aquitaine basin during the Middle and Upper Magdalenian (19-14 kyr cal BP) », Quaternary International, n 414, p. 1-8.

PÉTILLON J.-M., BOUDADI-MALIGNE M., GARDÈRE P., KUNTZ D., LANGLAIS M., LAROULANDIE V., MALLYE J.-B., MISTROT V., NORMAND C., 2016b, « La grotte Tastet à Sainte-Colome (canton d'Arudy, PyrénéesAtlantiques) : première année d'autorisation triennale », rapport de fouilles programmées, Bordeaux, Service régional de l'archéologie Nouvelle-Aquitaine.

PÉTILLON J.-M., LAROULANDIE V., BOUDADI-MALIGNE M., DUMONTIER P., FERRIER C., KUNTZ D., LANGLAIS M., MALLYE J.-B., MISTROT V., NORMAND C., RIVERO VILÁ O., SÁNCHEZ DE LA TORRE M., 2017, « Occupations 
magdaléniennes entre 20000 et 15000 cal BP dans le piémont pyrénéen : la séquence paléolithique du sondage 4 de la grotte de Laa 2 (Arudy, Pyrénées-Atlantiques) », Gallia préhistoire, n 57 , p. 65-126.

RENARD C. et DUCASSE S., 2015, « De la rupture typologique à la fracture socio-économique : implications sur les systèmes de mobilité entre Solutréen récent et Badegoulien dans le SudOuest français (24-21 ka cal BP) ", dans Naudinot N., Meignen L., Binder D., Querré G. (dir.), Les systèmes de mobilité de la Préhistoire au Moyen Âge : XXXVe Rencontres internationales d'archéologie et d'histoire d'Antibes, Antibes, Éditions APDCA, p. 193-208.

RIGAUD A., 2006, «Étude technologique des baguettes demi-rondes de Labastide (HautesPyrénées) », Archéologie des Pyrénées occidentales et des Landes, n² 25, p. 229-246.

SACCHI D., 1986, Le Paléolithique supérieur du Languedoc occidental et du Roussillon, Paris, Éditions du CNRS (Gallia préhistoire, supplément 21).

SÁNCHEZ DE LA TORRE M., 2015, « Las sociedades cazadoras-recolectoras del Paleolítico Superior final pirenaico: territorios económicos y sociales ", thèse de doctorat, Barcelona, Universitat de Barcelona.

SAUVET G., FRITZ C., FORTEA PEREZ J., TOSELLO G., 2014, « Fluctuations des échanges symboliques au Paléolithique supérieur en France et dans le nord de l'Espagne », dans Jaubert J., Fourment N. et Depaepe P. (dir.), Transitions, ruptures et continuités en Préhistoire : actes du $27^{\circ}$ Congrès préhistorique de France, Bordeaux-Les Eyzies, juin 2010, Paris, Société préhistorique française, p. 403-415.

SÉCHER A., 2017, « Traditions techniques et paléogéographie du Magdalénien moyen ancien dans le sud-ouest de la France (19000-17500 cal. BP) : des groupes humains à plusieurs visages ? ", thèse de doctorat, Pessac, université de Bordeaux.

SIMONNET R., 1982, « Grandes lames de silex dans le Paléolithique supérieur des Pyrénées centrales », Bulletin de la Société préhistorique Ariège Pyrénées, n 37, p. 61-105.

SOLER N., 1995, « El jaciment magdalenià de Sant Benet (Sant Feliu de Guixols) », Estudi del Baix Emporda, $\mathrm{n}^{\circ} 14$, p. 55-66.

SZMidT C., LAROUlANDIE V., DACHARY M., LANGLAis M., COSTAMAGNo S. (2009), Harfang, Renne et Cerf : nouvelles dates ${ }^{14} \mathrm{C}$ du Magdalénien supérieur du Bassin aquitain au Morin (Gironde) et Bourrouilla (Pyrénées-Atlantiques), Bulletin de la Société préhistorique française, vol. 106, nº 3 , p. 583-601.

UTRILLA P., 2004, « Evolución histórica de las sociedades cantábricas durante el Tardiglacial: El Magdaleniense inicial, inferior y medio (16.500-13.000 BP) », dans Fano M. (dir.), Las Sociedades del Paleolítico en la Región Cantábrica, Bilbao, Diputación Foral de Bizkaia (Kobie, 8), p. 243-274.

UTRILla P. et MAZo C., 1996, « Le Paléolithique supérieur dans le versant sud des Pyrénées : communications et influences avec le monde pyrénéen français », dans Delporte H. et Clottes J. (dir.), Pyrénées préhistoriques, arts et sociétés : actes du $118^{e}$ congrès des sociétés historiques et scientifiques (Pau, 1993), Paris, Éditions du CTHS, p. 243-262.

UTRILla P. et MAZo C. (dir.), 2014, La Peña de las Forcas (Graus, Huesca): Un asentamiento estratégico en la confluencia del Ésera y el Isábena, Zaragoza, Universidad de Zaragoza (Monografías Arqueológicas, 46). 


\section{RÉSUMÉS}

Pour le Magdalénien, le massif pyrénéen est une frontière " pré-historiographique ", les diverses phases de cette culture n'étant pas définies de la même façon des côtés français et espagnol. Notre objectif est de rediscuter la pertinence de ces distinctions en questionnant le rôle des Pyrénées comme axe de diffusion ou obstacle à la circulation durant cette période. Nous nous focalisons sur le Magdalénien moyen récent (17,5-16 ka cal. BP), envisagé à la lumière des travaux actuels dans le bassin d'Arudy, où la grotte Tastet a livré une industrie du Magdalénien moyen récent originale, à nombreux microlithes de type triangle scalène. Ces derniers permettent d'établir des parallèles avec d'autres séries pyrénéo-cantabriques et d'évoquer l'existence de plusieurs variantes du Magdalénien moyen récent, distinguées notamment par leurs armatures lithiques. La diffusion de ces traditions techniques illustre les relations existant tout au long de la chaîne pyrénéo-cantabrique. Cette absence de frontière culturelle relativise la pertinence des frontières pré-historiographiques.

For the Magdalenian, the Pyrenees are a "pre-historiographical border": the definition of the different phases of this culture are not similar on the French and Spanish sides. Our aim is to reevaluate the relevance of this dissimilarity by questioning the role of the Pyrenees as a diffusion route or as an obstacle to movement at that period. We focus on the Late Middle Magdalenian (LMM, ca. 17.5-16 ka cal BP), considered from the point of view of recent research in the Arudy Basin, where the excavation of Tastet cave yielded an original LMM industry with abundant microliths of the "scalene triangle" type. These microliths have parallels in other assemblages from the Pyrenean and Cantabrian area, and hint at the existence of different variants of the LMM, distinguished, among others, by their lithic armatures. The diffusion of these technical traditions illustrates the relationships existing all along the Pyreneo-Cantabrian range. This absence of cultural border further puts into perspective the relevance of prehistoriographical borders.

\section{INDEX}

Mots-clés : peuplement, Magdalénien moyen récent, triangle scalène

Keywords : scalene triangle, Late Middle Magdalenian, settlement

Index géographique : grotte Tastet, Pyrénées, Arudy

\section{AUTEURS}

\section{MATHIEU LANGLAIS}

Laboratoire De la Préhistoire à l'actuel : culture, environnement et anthropologie (PACEA, UMR 5199, université de Bordeaux/CNRS)

\section{JEAN-MARC PÉTILLON}

Laboratoire Travaux et recherches archéologiques sur les cultures, les espaces et les sociétés (TRACES, UMR 5608, université Toulouse - Jean-Jaurès/CNRS) 


\section{Circulation à longue distance des matières premières lithiques et des objets de parure au Magdalénien moyen en Auvergne : exemple du site d'Enval-Moliard (Vic-le-Comte, Puy-de-Dôme)}

Long distance circulation of lithic raw materials and ornaments in the Middle Magdalenian in the Auvergne region: the case of the EnvalMoliard site (Vic-le-Comte, Puy-de-Dôme)

Frédéric Surmely, Sandrine Costamagno, Jay Franklin, Raphaël Angevin, François Chevrier, Stéphane Madelaine et Maureen Hays

La circulation à longue distance des matières premières lithiques entre l'Auvergne et le sud du Bassin parisien est attestée depuis le Gravettien ancien, autour de 30000 BP (Surmely et al. 2008a). Elle concerne une large gamme de silex du Turonien inférieur et supérieur, ainsi que des silex filoniens de l'Infralias. Au Protomagdalénien, sur le site du Blot (Cerzat, Haute-Loire), dans la haute vallée de l'Allier, la proportion de silex importés depuis le sud du Bassin parisien est de $99 \%$. Ce phénomène se poursuit au cours des stades culturels ultérieurs, notamment au Magdalénien moyen (Masson 1981, 1982a et 1982b, Surmely et al. 1998 et 2008, Delvigne 2016, Pasty et al. 2017, Delvigne et al. 2018). Ce faciès culturel est connu par plusieurs sites, localisés principalement autour de la vallée de l'Allier (Angevin et Surmely 2012 et 2014, Surmely 2013). La découverte récente du site d'Enval-Molliard apporte un éclairage nouveau à cette question, avec la mise en évidence de nouveaux circuits de circulation concernant des matières premières lithiques, mais aussi des objets de parure. 


\section{Le site d'Enval-Moliard}

Enval (commune de Vic-le-Comte, Puy-de-Dôme) est un village installé sur un escarpement gréseux, à moins de 2 kilomètres à vol d'oiseau du val d'Allier, couloir naturel de circulation nord-sud (fig.1). La falaise, haute de plus de 40 mètres, comprend plusieurs lignes étagées de petits abris-sous-roche sur plus d'un kilomètre de long.

Fig. 1. - Localisation du site d'Enval-Moliard (Vic-le-Comte, Puy-de-Dôme).

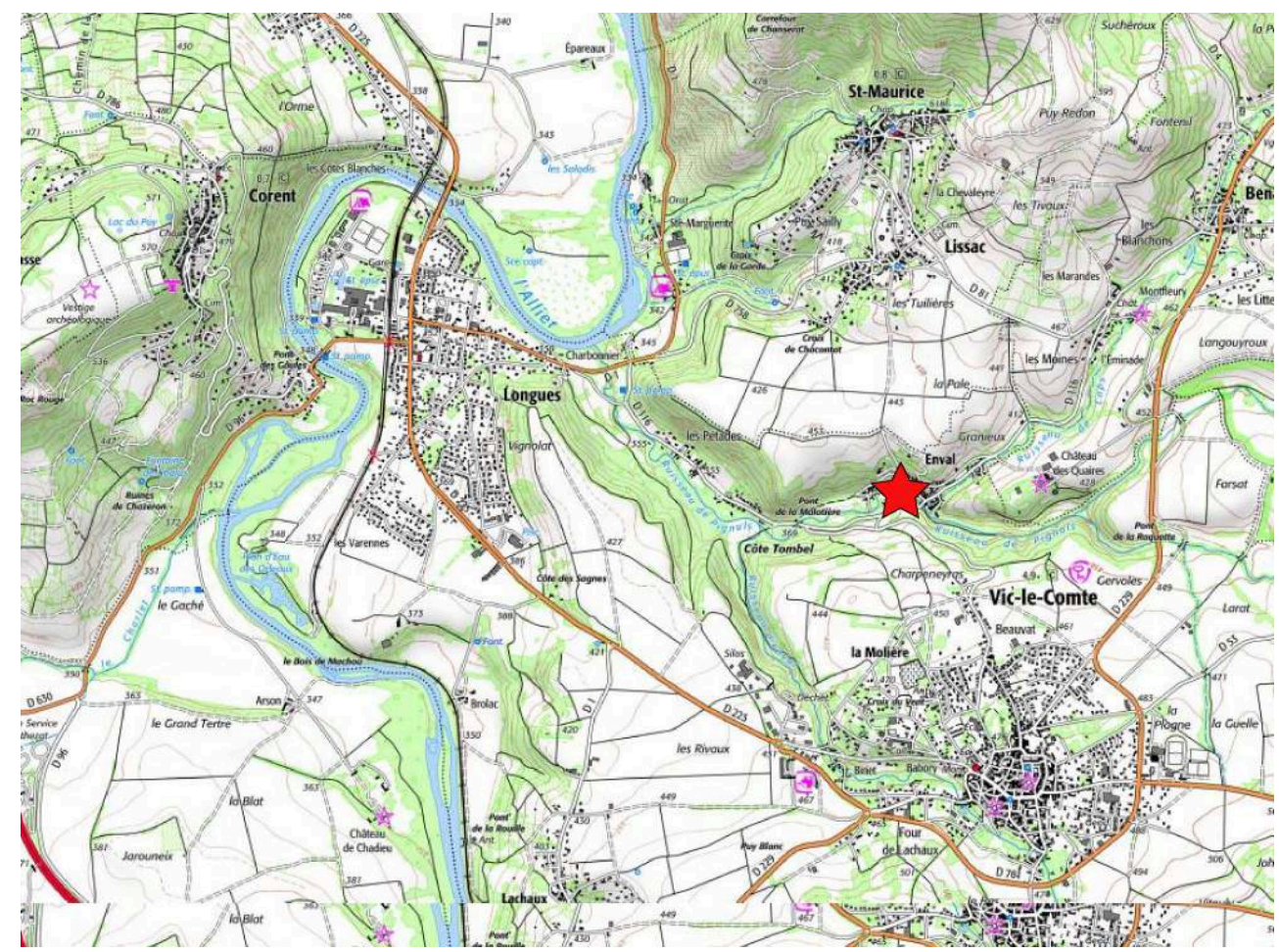

PAO Frédéric Surmely. Fond de carte IGN 1/25 000.

La première mention de découverte de vestiges préhistoriques date de 1877. Vers 1925, en 1929, puis de nouveau en 1968, des travaux d'aménagement en différents points du village conduisirent à la mise au jour de niveaux d'occupation préhistorique, malheureusement tronqués par l'urbanisation ultérieure. La dernière découverte, localisée dans le fond d'un ancien abri-sous-roche appelé abri Durif, amputé par la construction d'une grange, fit l'objet d'une fouille programmée sous la direction d'Y.Bourdelle (Bourdelle et Merlet 1991). Deux séquences sédimentaires furent reconnues: le «Fond de l'abri » et le «Sol de la grange». En 2009, l'un d'entre nous entreprit un programme de recherche destiné à permettre l'étude complète du mobilier issu des fouilles Bourdelle et à évaluer le potentiel du lieu. L'ensemble des occupations a ainsi pu être rattaché au Magdalénien moyen (Surmely 2013, Merlet et al. 2017), sur la base de l'étude du mobilier lithique et des objets d'art et de parure. Des sondages ont révélé l'existence de petites poches de remplissage témoignant d'une occupation magdalénienne le long de l'escarpement principal.

4 En mars 2016, D. Moliard, au cours de travaux, a mis au jour des vestiges préhistoriques emballés dans un sédiment argilo-sableux rougeâtre, à une centaine de mètres au nord 
de l'abri Durif, sur la même ligne d'abri. Grâce à son accord, une opération de nettoyage et d'expertise du site d'Enval-Moliard a pu rapidement se mettre en place (Surmely 2016). À cette occasion, nous avons redressé la coupe frontale, tamisé les déblais et réalisé un petit sondage profond.

Le site correspond à un ancien abri-sous-roche s'ouvrant à la base d'un banc rocheux gréseux. La présence de gros blocs dans le remplissage témoigne de l'effondrement du toit rocheux et donc de son recul depuis l'époque magdalénienne. Au moins en un endroit, le surplomb a été partiellement retaillé à une époque historique indéterminée. S'y ajoutent les perturbations à l'avant, notamment lors de l'aménagement de la plateforme par le propriétaire. L'ampleur de la surface couverte par le surplomb rocheux à l'époque des occupations préhistoriques reste donc difficile à déterminer.

Ledressement de la coupe frontale principale a permis de montrer que la puissance des niveaux archéologiques avoisine les 140 centimètres à cet endroit, avec au moins quatre niveaux sédimentaires distincts (US $40,70,80$ et 100), renfermant de très nombreux vestiges en lien avec une occupation magdalénienne (fig. 2). La présence de connexions osseuses atteste d'une absence de remaniement post-dépositionnel important du remplissage. Ces premières observations devront toutefois être confirmées par l'étude micromorphologique encore en cours.

Fig. 2. - Site d'Enval-Moliard (Vic-le-Comte, Puy-de-Dôme) : vue partielle de la coupe frontale après nettoyage et redressement, montrant les 4 niveaux d'occupation et l'extrême abondance des restes lithiques et surtout osseux.

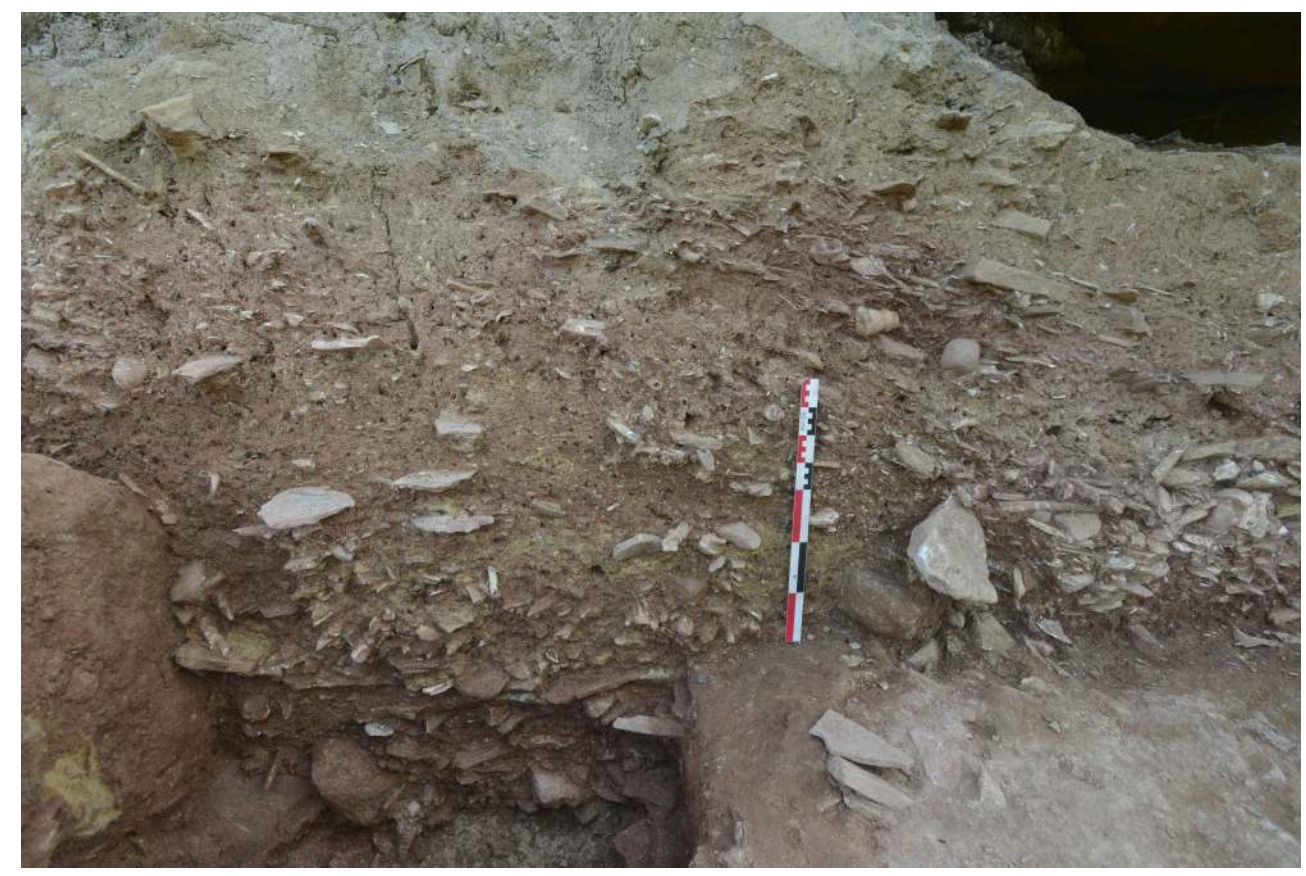

Échelle photo : 0,5 m.

Photo Frédéric Surmely, 2016.

Chaque niveau a fait l'objet d'une ou plusieurs mesures d'âge par le radiocarbone sur ossements, par l'intermédiaire de deux laboratoires différents (tabl. 1). 
Tabl. 1 : Site d'Enval-Moliard (Vic-le-Comte, Puy-de-Dôme) : datations ${ }^{14} \mathrm{C}$ réalisées à ce jour (calibration : intcal13. ${ }^{14} \mathrm{C}$ ).

\begin{tabular}{ccccc} 
Localisation & Référence échantillon & Date BP & Date calibrée & Référence datation \\
\hline US 40, C23 & $N^{\circ} 8387$ & $13580 \pm 70$ & 14691 à 14186 av. J.-C. & Sac-A48177 \\
US 40, C23 & - & $13851 \pm 63$ & 15070 à 14549 av. J.-C. & D-AMS 020378 \\
US 70, C23 & - & $13810 \pm 70$ & 15036 à 14476 av. J.-C. & Sac-A46130 \\
US 70, C23 & $N^{\circ} 8386$ & $13960 \pm 70$ & 15241 à 14675 av. J.-C. & Sac-A48176 \\
US $80, C 23$ & - & $13779 \pm 40$ & 14953 à 14481 av. J.-C. & D-AMS-018147 \\
US $80, C 23$ & - & $14010 \pm 60$ & 15317 à 14476 av. J.-C. & SacA-50658 \\
US 100, C22 & - & $13851 \pm 40$ & 15037 à 14594 av. J.-C. & D-AMS-018788 \\
\hline
\end{tabular}

8 Ces résultats placent l'occupation du site dans une fourchette assez restreinte, au Magdalénien moyen récent, selon la chronologie établie par Langlais et al. (2016). Ces dates sont très proches de celles obtenues pour l'abri Durif. En dehors des 5 datations réalisées anciennement par Y. Bourdelle sur les deux séquences de cet abri, nous avons effectué de 2010 à 2013, dans le cadre d'un programme de recherches, 18 nouvelles mesures d'âge (Surmely 2013). 14 n'ont pas donné de résultat, du fait de la mauvaise conservation du collagène ; 2 ont livré des résultats aberrants ; 2 , enfin, sont proches de celles obtenues sur le site d'Enval-Moliard : $13980 \pm 70$ BP et $14520 \pm 80$ BP (la fiabilité de la seconde date a été jugée médiocre par le laboratoire).

Les niveaux archéologiques se caractérisent par une très forte densité de vestiges, notamment de fragments osseux, comparable à celle du célèbre « magma » des niveaux gravettiens de Solutré (Combier et Montet-White 2002). Le spectre faunique est relativement homogène sur toute la séquence, avec quatre taxons prédominants : renne (Rangifer tarandus), bovinés, cheval (Equus caballus) et lagomorphes. Le renne, espèce majoritaire dans toutes les unités stratigraphiques, représente entre 50 et $89,4 \%$ des restes déterminés. À l'exception de l'US 50, viennent ensuite les lagormorphes (Repus sp.), avec 9,1 à 27,7\% des restes. Ce taxon, présent sous forme d'ossements complets ou presque complets, semble avoir une origine naturelle, ce qui n'est pas le cas des ongulés, qui présentent de nombreuses traces anthropiques: stries de boucherie, traces de percussion, traces de feu. L'impact des carnivores sur les ossements est limité.

10 En ce qui concerne les profils squelettiques, il est remarquable de constater que tous les éléments sont présents, y compris les vertèbres, ce qui pourrait témoigner de l'introduction de carcasses entières, en particulier pour le renne. Un fragment de crâne d'un renne mâle dépourvu de bois indique que l'animal a été abattu au cours de la mauvaise saison. La présence de quelques restes de fotus évoque également l'hiver. Ces indices témoignent d'une occupation au moins durant la mauvaise saison (Surmely 2016).

11 Pour le renne, on note la présence de nombreux fragments de bois, dont certains correspondent à des déchets d'extraction de baguettes et d'autres à des produits finis, principalement des fragments de baguettes. Quelques fragments osseux portent des traces de rainurage, et un fragment de diaphyse d'ongulé de grande taille a été utilisé comme retouchoir. Les objets de parure, relativement abondants $(n=47)$, ont été réalisés sur des coquillages et des restes dentaires. À signaler également, deux fragments de plaquettes rocheuses gravées de figurations animales, semblables à celles découvertes à l'abri Durif.

12 L'industrie lithique est également très abondante. L'outillage est dominé de façon écrasante par les burins. Sont aussi présents les armatures microlithiques (lamelles à dos simple), les grattoirs et les pièces esquillées, mais selon des proportions moindres, 
et qui varient selon les niveaux. La faible proportion d'armatures microlithiques est tout à fait remarquable, car elle se démarque des chiffres obtenus sur l'abri Durif (Surmely 2010) et des autres sites magdaléniens du val d'Allier. Quoiqu'il en soit, on peut observer que, à nouveau, les quatre niveaux individualisés présentent des caractéristiques assez proches, qui semblent indiquer une étroite proximité fonctionnelle et chronologique.

13 L'abondance extraordinaire des vestiges osseux ou lithiques et la présence d'objets de parure et de plaquettes gravées indiquent une occupation durable et importante du site.

\section{Circulation des matières premières lithiques}

Dans l'ensemble de l'Auvergne centrale, au cours du Magdalénien moyen, les matières premières allochtones sont une composante importante de l'approvisionnement, de l'ordre de 25 à $30 \%$ (en poids) selon les sites (Surmely et al. 2008a) Le reste est composé de silex tertiaires d'origine régionale.

L'identification des matériaux a été faite par examen macroscopique, en nous basant sur la lithothèque constituée de 1996 à 2009 pour les régions Auvergne, Centre et Bourgogne, et les analyses microfaciologiques et géochimiques antérieures (Surmely et al. 2008a). Une tentative de caractérisation géochimique de certains types particuliers, comme le silex de Fontmaure, est en cours. Les matériaux importés sont composés de plusieurs types (tabl. 2 et fig. 3 ).

Tabl. 2 : Site d'Enval-Moliard (Vic-le-Comte, Puy-de-Dôme) : répartition par niveaux des grands types de matières premières utilisées sur le site.

\begin{tabular}{lrrrr}
\hline \multicolumn{1}{c}{ Niveaux } & US 40 & US 70 & US 80 & US 100 \\
& & & & \\
\hline Types de matières premières & $28 \%$ & $36 \%$ & $41 \%$ & $31 \%$ \\
\hline Tertiaire local & $54 \%$ & $31 \%$ & $33 \%$ & $52 \%$ \\
Turonien inférieur & $2 \%$ & $7 \%$ & $5 \%$ & $7 \%$ \\
Turonien inférieur à dendrites rouges & $12 \%$ & $7 \%$ & $6,5 \%$ & $2 \%$ \\
Turonien inférieur à dendrites noires & $0,5 \%$ & $3 \%$ & $0,5 \%$ & 0 \\
Turonien moyen & $1 \%$ & $3 \%$ & $6,5 \%$ & 0 \\
Turonien supérieur & $0,5 \%$ & $1 \%$ & $1 \%$ & $0,5 \%$ \\
Hettangien & $1,5 \%$ & $0,5 \%$ & $0,5 \%$ & 0 \\
Cristal & $0,5 \%$ & $12,5 \%$ & $6 \%$ & $7,5 \%$ \\
Divers et indéterminés & $208 \mathrm{~g}$ & $749 \mathrm{~g}$ & $1659 \mathrm{~g}$ & $796 \mathrm{~g}$ \\
Poids total & & & & \\
\hline
\end{tabular}

Ce tableau n'inclut pas les nombreuses pièces trouvées hors stratigraphie, du fait des bouleversements dus aux travaux. 
Fig. 3. - Site d'Enval-Moliard (Vic-le-Comte, Puy-de-Dôme) : différents types de silex du Turonien (inférieur et supérieur) découverts sur le site.

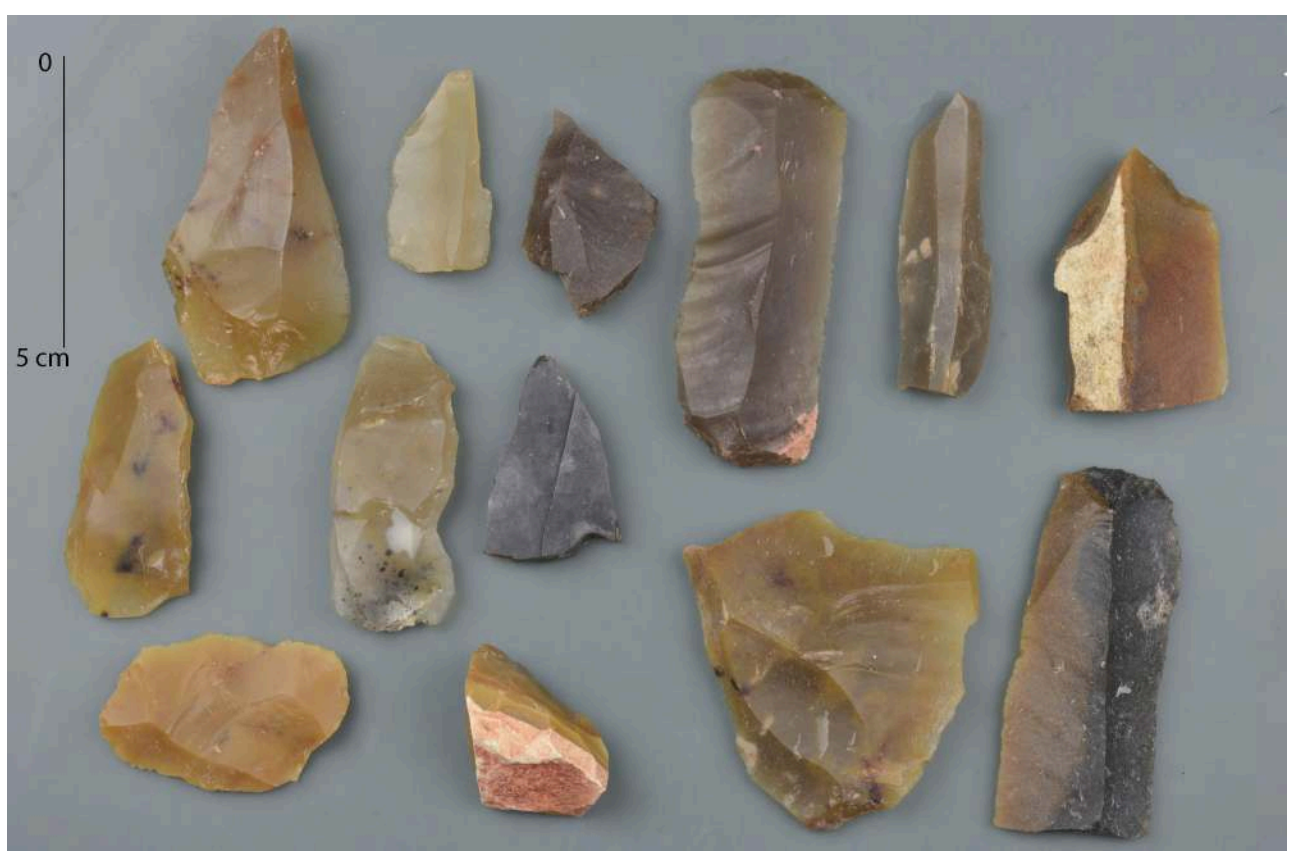

Photo Frédéric Surmely.

La fraction dominante est celle des silex de la craie du Turonien inférieur (Masson 1981, Surmely et al. 1998). La variété de type blond est la plus abondamment utilisée, ce qui est le cas dans la totalité des gisements du Paléolithique supérieur d'Auvergne que nous avons pu étudier, à l'exception de certains niveaux protomagdaléniens du site du Blot (Surmely et al. 1997, 2008a et 2008b). À l'issue de notre prospection-inventaire des gîtes à silex des régions Centre et Bourgogne et de notre étude basée sur la géochimie, nous avons pu rapprocher ce matériau des gîtes de la basse vallée du Cher (Aubry 1991, Surmely et al. 2008a). Ce type de silex présente parfois, au sein d'un même rognon, des plages plus opaques et de teinte plus sombre (couleur miel), souvent localisées en périphérie du nodule. La variété blonde à dendrites et taches rouges se rencontre uniquement dans certains gîtes du nord de l'Indre et du Cher. Le gîte le plus représentatif est celui de Thenioux (Surmely et al. 2008a : $\mathrm{n}^{\circ} 80$ ).

Contrairement à d'autres chercheurs, comme M. Piboule (Pasty et al. 2017), nous distinguons la variété blonde à dendrites noires, qui a une aire de répartition spécifique, restreinte à notre connaissance à la vallée du Fouzon (limite Cher-Indre). Seuls deux gîtes ont été reconnus, à Orville (Cher) et Lye (Indre). L'étude géochimique a confirmé la pertinence de ce rapprochement (Surmely et al. 2008a). Il est à noter que ce type particulier de matériau a été découvert dans un niveau du Solutréen supérieur de l'abri des Peyrugues, à Orniac, dans le Lot (Allard 2016), mais aussi dans le Solutréen ancien de La Baume d'Oullins, en Ardèche (Guégan 2013). Il semble également présent dans les séries de La Vigne Brun, dans la Loire (Pesesse 2008) et dans bien d'autres sites du Paléolithique supérieur. Il faut également considérer le fait que sa représentativité est assurément sous-estimée, car les dendrites noires, signes distinctifs du matériau, ne sont souvent pas visibles sur les petites pièces, qui sont alors comptabilisées parmi les silex blonds « ordinaires ». 


$$
\text { du Magdalénien moyen d'Auvergne } \cdot \text { des silex tertiaires à grain fin très différents des }
$$
roches tertiaires de Limagne et d'origine indéterminée, et des silex colorés en jaune, orange, vert foncé ou marron foncé. Ces derniers matériaux sont caractéristiques des silex d'origine hydrothermale de l'Hettangien, appelés «silexites », « jaspoïdes » ou "jaspéroïdes» par d'autres chercheurs (Demars 2015, Pasty et al. 2017, Piboule et al. 2018). Les gîtes potentiels, situés à égale distance du site (environ 130 kilomètres) sont Le Bois du Pérou, à Saint-Jeanvrin, dans le Cher (Piboule et al. 2018) et la Corrèze (Séronie et Séronie-Vivien 1987, Demars 2015). Une tentative de caractérisation chimique a été faite par le biais d'un appareil à fluorescence $\mathrm{X}$ portable, dans le cadre de l'étude d'un site néolithique (Surmely et Caillat 2016). Cette analyse n'a pas permis de différencier les gîtes de Corrèze de ceux du Cher, qui présentent des caractéristiques chimiques similaires. De fait, la provenance des matériaux retrouvés à Enval reste incertaine, mais assurément allochtone.

Ce schéma d'approvisionnement combinant ressources locales et matériaux d'importation se retrouve sur le site d'Enval-Moliard. Mais ce dernier se distingue toutefois des autres gisements par plusieurs caractères. D'abord, les matières premières allochtones y sont plus fortement représentées, dans une proportion toujours supérieure à la moitié du poids total de l'industrie lithique taillée, et qui atteint $73 \%$ dans l'US 40. La proportion de silex blond à dendrites noires est de 5,5\% dans l'US 80 et même de $7 \%$ dans l'US 70, alors qu'elle est à peine de $2 \%$ dans tous les autres sites, y compris l'abri Durif voisin. Mais surtout, le site a livré des types de matériaux jusqu'alors inconnus dans les autres sites du secteur. C'est le cas de silex provenant des séries du Turonien moyen de la partie nord-est de l'actuel département de l'Indre (secteur d'Azay-le-Ferron) et de silex bariolés bien particuliers, identifiables macroscopiquement comme des silex de Fontmaure, souvent appelés «jaspe de Fontmaure ", provenant des environs de Vellèche, dans le nord du département de la Vienne (Pradel 1967, Pradel et Tourenq 1967) (fig. 4). Une confirmation par l'analyse géochimique (ICP-MS) est en cours (FS). C'est la première fois qu'est observée la présence de ce matériau dans un site préhistorique d'Auvergne. Il faut souligner que c'est aussi le gîte attesté le plus éloigné d'Enval, avec une distance linéaire de 260 kilomètres ! 
Fig. 4. - Vue montrant la similitude entre un burin provenant de l'abri Enval-Moliard (à gauche) et un échantillon de silex du gîte de Fontmaure (Véllèches, Vienne ; à droite).

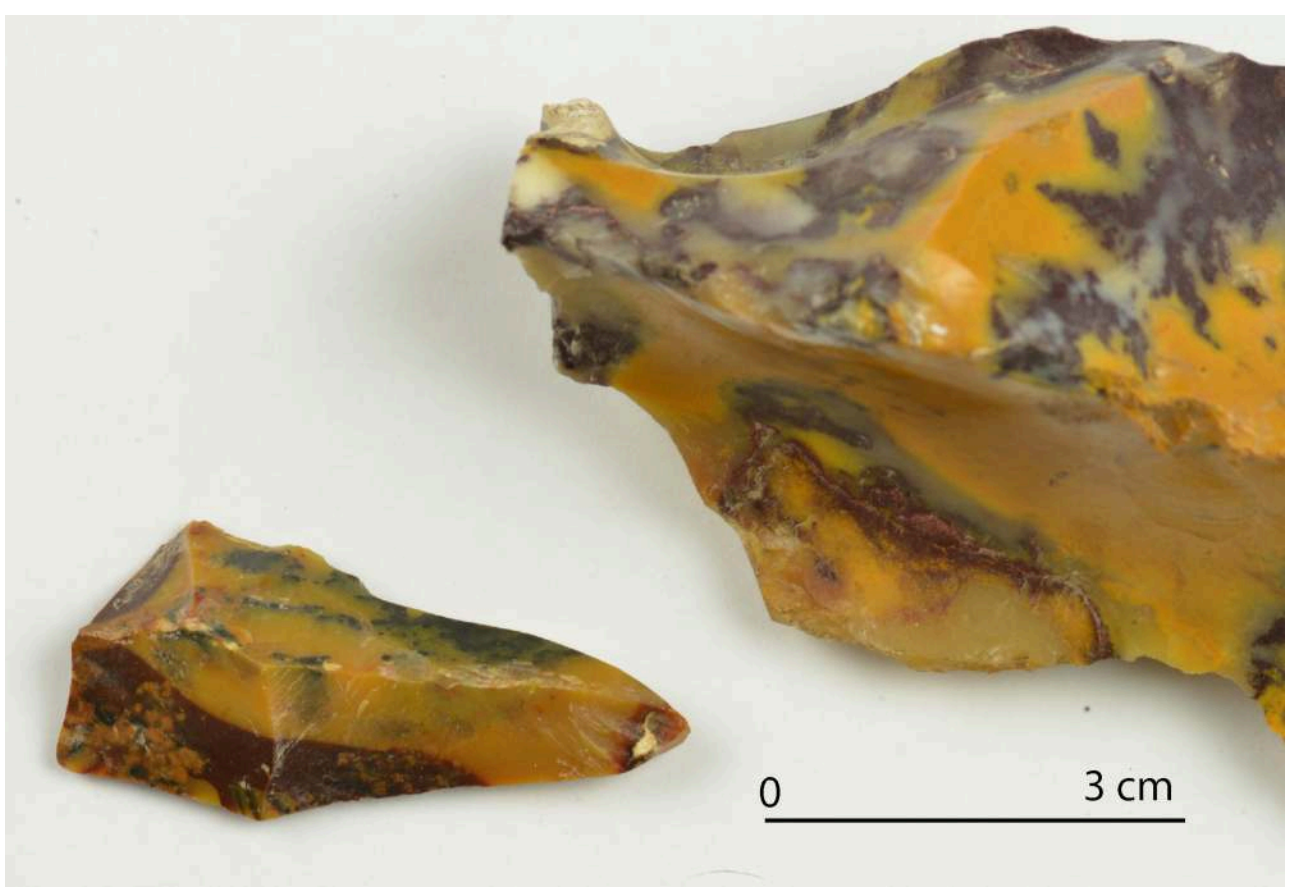

Photo Frédéric Surmely.

Les deux sites d'Enval ont également livré quelques petits éclats de cristal de roche (quartz hyalin : fig. 5-3), parfaitement transparent. De manière générale, il s'agit d'une matière première très peu abondante dans les séries du Paléolithique supérieur français, qui n'a pas attiré l'attention des chercheurs, mais que l'on retrouve toutefois dans de nombreux sites de toute la France.

Fig. 5. - Site d'Enval-Moliard (Vic-le-Comte, Puy-de-Dôme) : pièces de parure et « curiosité ».

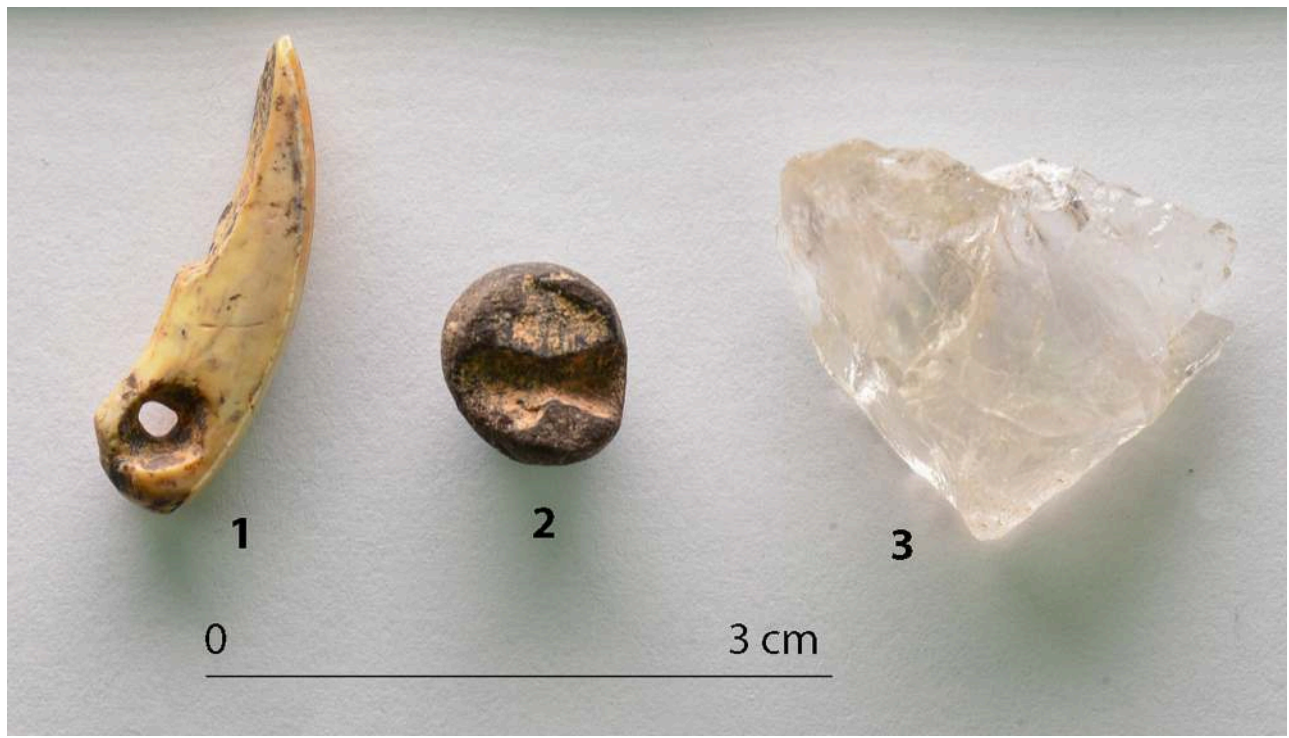

1 : incisive de marmotte sciée et perforée. 2 : fragment de perle en lignite. 3 : éclat de cristal de roche. Photo Frédéric Surmely. 

magdaléniens (Givenchy 1923, Daniel 1969). Les pièces mentionnées correspondent à des outils finis, mais il est possible que des éclats et déchets de façonnage aient été présents dans les séries et non décrits par les chercheurs sus-cités ; à noter qu'un gros bloc brut a été découvert à Solutré, malheureusement hors contexte. Si les filons de quartz sont nombreux en Auvergne et tout particulièrement dans le Puy-de-Dôme (Rudel 1966), la plupart sont constitués d'un matériau plus ou moins coloré et/ou opaque, et jamais totalement transparent. C'est le cas du plus connu d'entre eux, situé à Roche-d'Agoux, dans le Puy-de-Dôme (Hottin et al. 1989). Ajoutons que le quartz hyalin est très rare dans les sites néolithiques de cette région. Le quartz hyalin constitue 1,6 \% des lamelles sur le site du Néolithique moyen de Champ-Madame (Beaumont, Puy-deDôme: Saintot 2016). Une origine extrarégionale de ce matériau semble donc très probable. Il se trouve à l'état naturel dans les Pyrénées, en bordure orientale du Massif armoricain (Hinguant et al. 2012), et surtout dans les Alpes, où des gîtes d'un matériau de grande qualité (Meisser et Meisser-Issenring 1997, Rostan 2005) ont été exploités intensément à partir de l'Azilien (Ginestet et al. 1984, Guerreschi 2002, Mezzena et Perrini 2002) et surtout au Néolithique ancien (Gallay et al. 1987, Rostan et Thirault 2016). Sur la base de la proximité géographique et de la pureté de la roche, une origine alpine nous semble la plus plausible, mais une confirmation par l'analyse chimique reste à effectuer. On peut penser que les pièces façonnées dans ce type de matériau avaient une valeur particulière.

Les matières premières importées ont fait l'objet d'une gestion totalement différente de celle des silex locaux. Les silex allochtones ont été introduits sous la forme de préformes. La gestion de ces matériaux a été orientée vers la production de supports allongés, mais en y ajoutant, à la différence des matériaux locaux, la recherche d'une rentabilité maximale, ce qui se traduit par un très fort taux de transformation des supports bruts, et des ravivages d'outils menés jusqu'à exhaustion totale. Nombreux sont les outils dont la longueur avoisine les 2 centimètres (fig. 6). Les nucléus sont rares et réduits à des exemplaires de petite taille. C'est assurément de ce même souci d'économie que découlent certaines caractéristiques "typologiques» de l'industrie lithique des séries d'Enval, notamment l'assez fort taux d'outils mixtes et multiples (fig. 6) et la morphologie des burins. Les burins sont en effet largement dominés par des formes dièdres à biseau assez large, résultant de ravivages multiples ou même d'autres outils. Les pièces esquillées sont pour la plupart des grattoirs sur lame inutilisables et recyclés. 
Fig. 6. - Site d'Enval-Moliard (Vic-le-Comte, Puy-de-Dôme) : quelques exemples de grattoirs-burins, illustrant le ravivage extrême des outils.
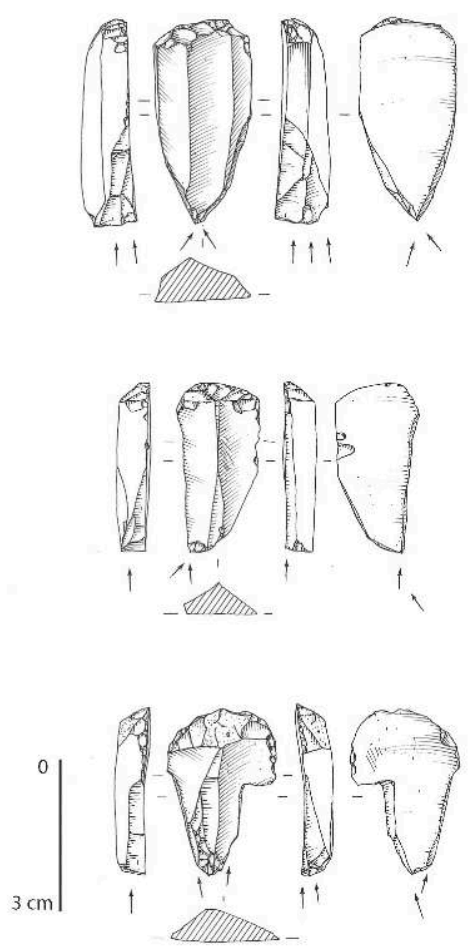

Dessins Philippe Alix.

En revanche, la production lamellaire a été effectuée sur des nucléus véritables et on n'observe pas de mise en œuvre de procédés de détachement sur supports ou fragments de supports.

\section{Objets de parure}

Les objets de parure sont rares dans la grande majorité des sites d'Auvergne (Taborin 1998), pour des raisons encore indéterminées, mais qui peuvent être multiples, notamment fonctionnelles et/ou taphonomiques (non-conservation des restes organiques dans la majorité des sites).

Les sites d'Enval se démarquent du lot, notamment celui d'Enval-Moliard, qui a livré une large gamme de pièces de parure, comprenant des dents et coquillages percés, des perles en lignite et des "objets de curiosité ». 49 objets ont été recueillis lors de l'opération de nettoyage/expertise du site. Si certaines de ces pièces ont été très probablement façonnées sur des matériaux locaux, comme les dents percées de rennes et de bovinés, animaux chassés sur le site, d'autres sont indiscutablement d'origine allochtone et même lointaine. L'analyse complète des objets reste à effectuer.

\section{La parure sur coquillages}

2714 coquillages ont été découverts à Enval-Moliard (Surmely et al. 2017). Leur étude archéologique détaillée reste à faire. La plupart sont des mollusques: gaspérodes terrestres (Helix), gastéropodes marins (Natica, Turitella subangulata) et bivalves marins 
(Gryphea arcuata, Anadara Turonica, Cardium et indéterminés). Il y a aussi un brachipode (Terebratula). Tous sont des coquillages fossiles (tabl. 3 et fig. 7).

Tabl. 3. - Site d'Enval-Moliard (Vic-le-Comte, Puy-de-Dôme) : répartition des objets de parure en coquillage par niveaux.

\begin{tabular}{|c|c|c|c|c|c|c|c|c|}
\hline & Helix & Natica & Anadara & Bivalve & Turitella & Terebratula & Gryphea & Total \\
\hline US 40 & & & & 2 & & & & 2 \\
\hline US 70 & 2 & & 1 & & & & & 3 \\
\hline US 80 & 1 & 3 & & 2 & 1 & & & 7 \\
\hline US 100 & & & & & & 1 & 1 & 2 \\
\hline Total & 3 & 3 & 1 & 4 & 1 & 1 & 1 & 14 \\
\hline
\end{tabular}

Fig. 7. - Site d'Enval-Moliard (Vic-le-Comte, Puy-de-Dôme) : coquillages.

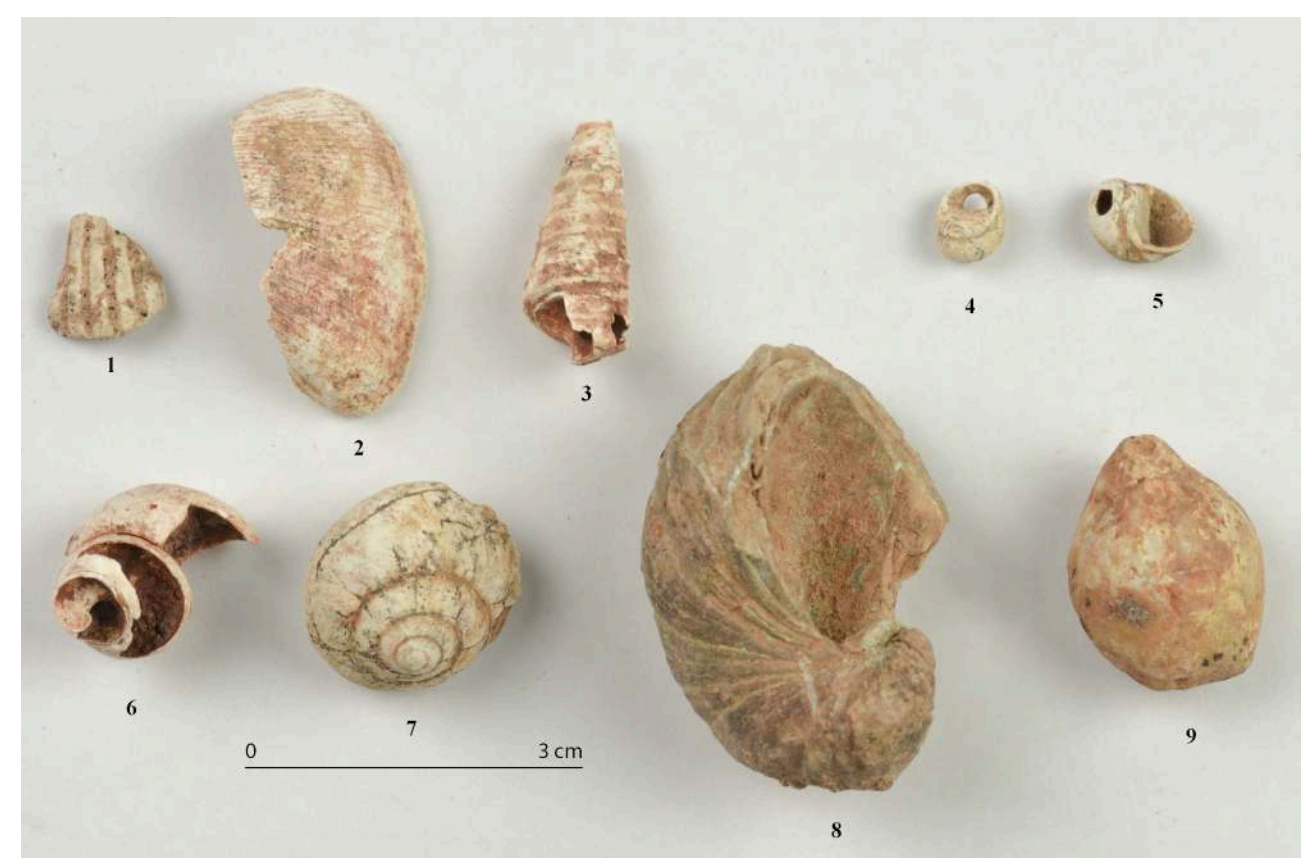

1 : US $80, n^{\circ} 13$, fragment de coquille fossile de bivalve. $\mathbf{2}$ : US 80, n 12, Anadara Turonica. $\mathbf{3}$ : US 80, n 18, Turritella subangulata. 4 : US 80, n², Natica, percée. 5 : US 80, n³7, gastéropode de type Natica, percé. $\mathbf{6}$ : US 70, n² 2, Helix sp. 7 : US 80, n 16, Helix sp. 8 : US 100, n 19, Gryphaea arcuata. 9 : US 100, $n^{\circ} 21$, Terebretula.

Photos Frédéric Surmely.

Ils appartiennent à des horizons chronologiques initiaux divers (Miocène, Jurassique), mais on les trouve mélangés dans les faluns qui bordent le Massif central, notamment les faluns de Touraine, dont la localisation est voisine des principaux gîtes de matières premières lithiques ayant alimenté le site. Il est donc fortement probable que les mollusques ont été collectés dans ce contexte. Dans ces formations, les espèces représentées sur le site ne sont pas rares et même, pour certaines, extrêmement communes. Certaines portent des traces d'usure importante, témoignant probablement d'un port prolongé en tant qu'ornement. Pour la plupart, la fonction d'objet de parure est attestée par une perforation. Mais ce n'est pas le cas pour d'autres objets, et même improbable pour la gryphée (fig. 7-8). On ne peut donc pas exclure un autre usage pour ces dernières pièces : objets de curiosité, jouets, bibelots... L'abri Durif a fourni un seul coquillage, une ammonite percée, dont il ne reste malheureusement que le moulage 
(Surmely 2013, Merlet et al. 2017). Trois coquillages fossiles ont également été signalés au Rond-du-Barry, à Polignac, en Haute-Loire (Taborin 1998 et 2004).

\section{Les dents}

Le site d'Enval-Moliard a livré de nombreuses dents percées $(\mathrm{n}=22)$, alors que ces objets sont très rares dans l'abri Durif (Merlet et al. 2017). Elles proviennent d'animaux variés (cheval, renne, cerf, bouquetin, marmotte, boviné), avec une prédominance du renne $(n=8)$ et du cheval $(n=8)$. Le choix s'est porté exclusivement sur des incisives, ce qui est habituel pour le Paléolithique supérieur (Alvarez-Fernandez 2009), mais dans le cas d'Enval, ce sont toutes des dents permanentes, issues pour la plupart d'individus âgés, voire très âgés.

Les pièces présentent de grandes similitudes entre elles (fig. 8). La technique utilisée est celle du perçage bifacial, après rainurage et parfois amincissement de la racine, ce qui était également la norme (Alvarez-Fernandez 2009).

Fig. 8. - Site d'Enval-Moliard (Vic-le-Comte, Puy-de-Dôme) : dents percées.

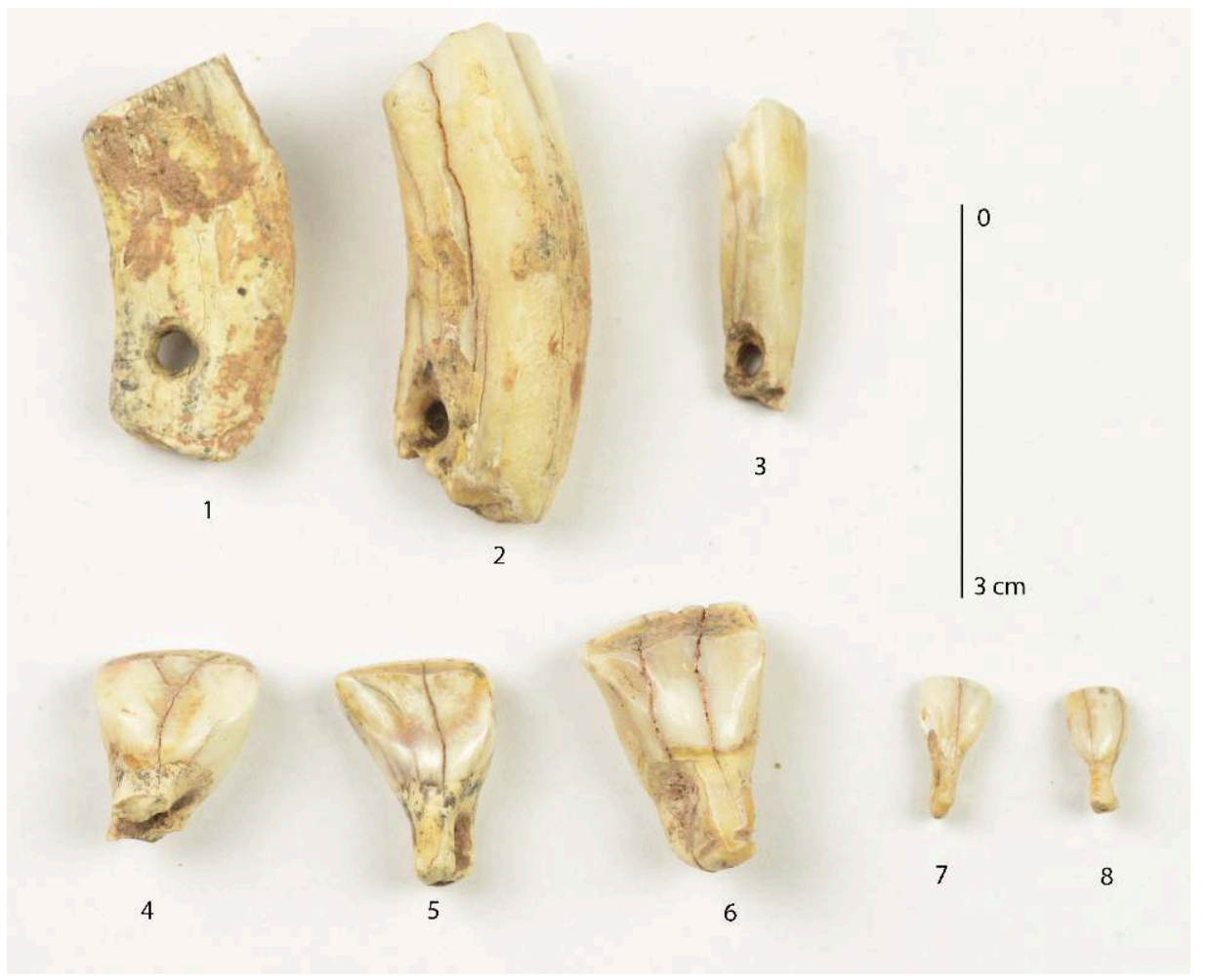

1 : HS, $n^{\circ}$ 28, incisive centrale de cheval (ITG) tronquée et percée. $\mathbf{2}$ : US 80, n 11, incisive de cheval (linfG) tronquée et percée. $\mathbf{3}$ : HS, $n^{\circ} 27$, incisive de bouquetin tronquée et percée. $\mathbf{4}$ : US 80, nº 14, incisive de boviné tronquée et percée. $\mathbf{5}$ : US 80, n 17, incisive de cerf ( $11 \mathrm{G}$ adulte) tronquée et percée. 6 : US 70, nº, incisive de boviné tronquée et percée. 7 : US 70, $n^{\circ} 4$, incisive de renne tronquée et percée. 8 : HS, n 26, incisive de renne tronquée et percée.

Photos Frédéric Surmely.

31 En parallèle, on observe un sectionnement quasiment systématique au niveau de la partie distale de la racine, qui affecte 12 des 14 dents non brisées, soit $85 \%$ des pièces. Seules deux dents de cheval (US 40 et US 70) échappent à cette règle. Le sectionnement est obtenu par sciage. Ce dernier enlevant la partie apicale de la racine (cerf, renne, 
boviné) ou de la couronne (cheval, bouquetin, marmotte), la perforation est présente à proximité du collet ou assez haut sur la couronne. C'est le cas notamment des dents $\mathrm{n}^{\circ} 6$ (incisive de boviné, US 70 : fig. 8-6) et $\mathrm{n}^{\circ} 17$ (incisive de cerf, US 80 : fig. 8-5).

Les dents sciées sont fréquentes au Magdalénien, en particulier durant le Magdalénien supérieur, de l'Espagne à l'Allemagne (Poplin 1983a et 1983b, Méreau 2012, Kuntz et al. 2015, Vanhaeren et D'Errico 2003, Alvarez-Fernandez 2001 et 2009, Büllinger 2005, Büllinger et Müller 2006, Costamagno et al. 2018), mais certains sites du Magdalénien moyen peuvent également en livrer (Peschaux 2017). Selon F. Poplin (1983a) cette technique permettrait la récupération de la rangée complète d'incisives, qui peut être utilisée ensuite dans son entier comme ornementation. À Enval-Moliard, la présence d'une perforation associée au sciage témoigne d'une technique différente, puisque le sciage apparait ici comme un moyen de modifier la forme de la racine des incisives récupérées de manière isolée. Selon C. Peschaux, à l'exclusion de la couche II du Taillis des Coteaux (Antigny, Vendée), cette parure serait caractéristique du Magdalénien moyen à lamelles scalènes. Principalement identifié dans les sites du sud-ouest de la France, comme Combe-Cullier (Lacave, Lot : Rigaud, comm. pers.), Saint-Germain-laRivière ensemble supérieur (Gironde), La Plantade (Bort-les-Orgues, Corrèze), Lafaye (Bruniquel, Tarn-et-Garonne), Le Petit Cloup Barrat (Pech-Merle, Lot) et Les Peyrugues c. 3 (Orniac, Lot) (Peschaux 2017), ce type de parure a également été signalé en Espagne, dans le niveau E d'Abauntz (Navarra, Espagne), ainsi que dans le Jura, à la grotte Grappin (Arlay), qui a livré une incisive de boviné aménagé selon cette modalité (Welté et Cupillard 2006).

Cheval, renne, bovinés et caprinés font partie des animaux chassés et rapportés sur le site, ce qui indique que les dents ont pu être acquises dans l'environnement local. La présence notamment d'un apex scié de racine d'une incisive de cheval pourrait indiquer une production sur place d'une partie de la parure. La présence dans le carré C 23 US 70/80 de 22 incisives de renne, dont une sciée, pourrait évoquer une réserve de dents non utilisées, initialement destinées à la confection d'éléments de parure. D'autres animaux (cerf et marmotte) sont absents du spectre faunique, ce qui semble indiquer une acquisition des dents plus lointaine et peut-être indirecte. C'est le cas en particulier de la marmotte, qui est absente des sites de basse Auvergne et caractéristique du milieu alpin. Plusieurs sites magdaléniens ont livré des incisives de cette espèce utilisées comme parure, sciées comme à la grotte des Romains (Virignin, Ain) et Petersfels, dans le Bade-Wurtemberg, en Allemagne (Poplin 1983b) ; à Monruz (Affolter et al. 1994) et Champréveyres (Neuchâtel, Suisse), Kesslerloch (Thayngen, Schaffhouse, Suisse), Chênelaz (Hostias, Ain) : (Büllinger et Müller 2006) - ou, plus rarement, perforées (abri Campalou, à Saint-Nazaire-en-Royans, Drôme). Aucun exemplaire ne présente à la fois une racine sciée et une perforation (fig. 5-1). Bien qu'importées, ces dents sont tout à fait comparables aux autres parures trouvées sur le site.

\section{Perles en lignite}

Trois perles circulaires en lignite ont été découvertes (fig. 5-2), ainsi qu'un déchet de façonnage. Ces objets étaient également nombreux dans le site voisin de l'abri Durif (Merlet et al. 2017). Le lignite est présent dans le Massif central, mais on ne peut exclure l'idée d'une importation de nodules d'origine lointaine, mis en forme sur le site. Les 
perles en lignite sont en effet caractéristiques des sites magdaléniens du domaine alpin (Büllinger et Müller 2006).

\section{Objets de curiosité et divers}

Parmi les objets de curiosité (fig. 9), le site a livré plusieurs petits rognons de silex et pisolithes dont la provenance est assurément allochtone (formations sédimentaires du Crétacé supérieur) et pourrait être identique à celle des matériaux utilisés pour l'industrie lithique. On trouve peu de références à de tels objets dans les autres sites d'Europe. La pièce $n^{\circ} 20$ présente un trou naturel, qui a pu être utilisé pour la suspension, mais sans traces d'usure apparente (fig. 9-2). L'objet $\mathrm{n}^{\circ} 24$ a une forme qui évoque grossièrement une silhouette féminine (fig. 9-4), sur le modèle des figures féminines schématiques (FFS) découvertes sur les parois de certaines cavités ornées ou dans l'art mobilier (Delluc et Delluc 1995, Bosinski 2011, Rémy 2013). Les objets ${ }^{\text {os }} 32$ et 42 ne portent également aucune trace de transformation (fig. 9-1 et 9-3).

Ces pièces ne présentent aucun stigmate visible d'utilisation et on peut donc supposer qu'elles n'ont pas eu de rôle fonctionnel (ornementation corporelle). Il pourrait donc s'agir, comme certains coquillages non percés, d'objets de curiosité, voire de jouets.

Fig. 9. - Site d'Enval-Moliard (Vic-le-Comte, Puy-de-Dôme) : objets insolites, rognons de silex et pisolithes.

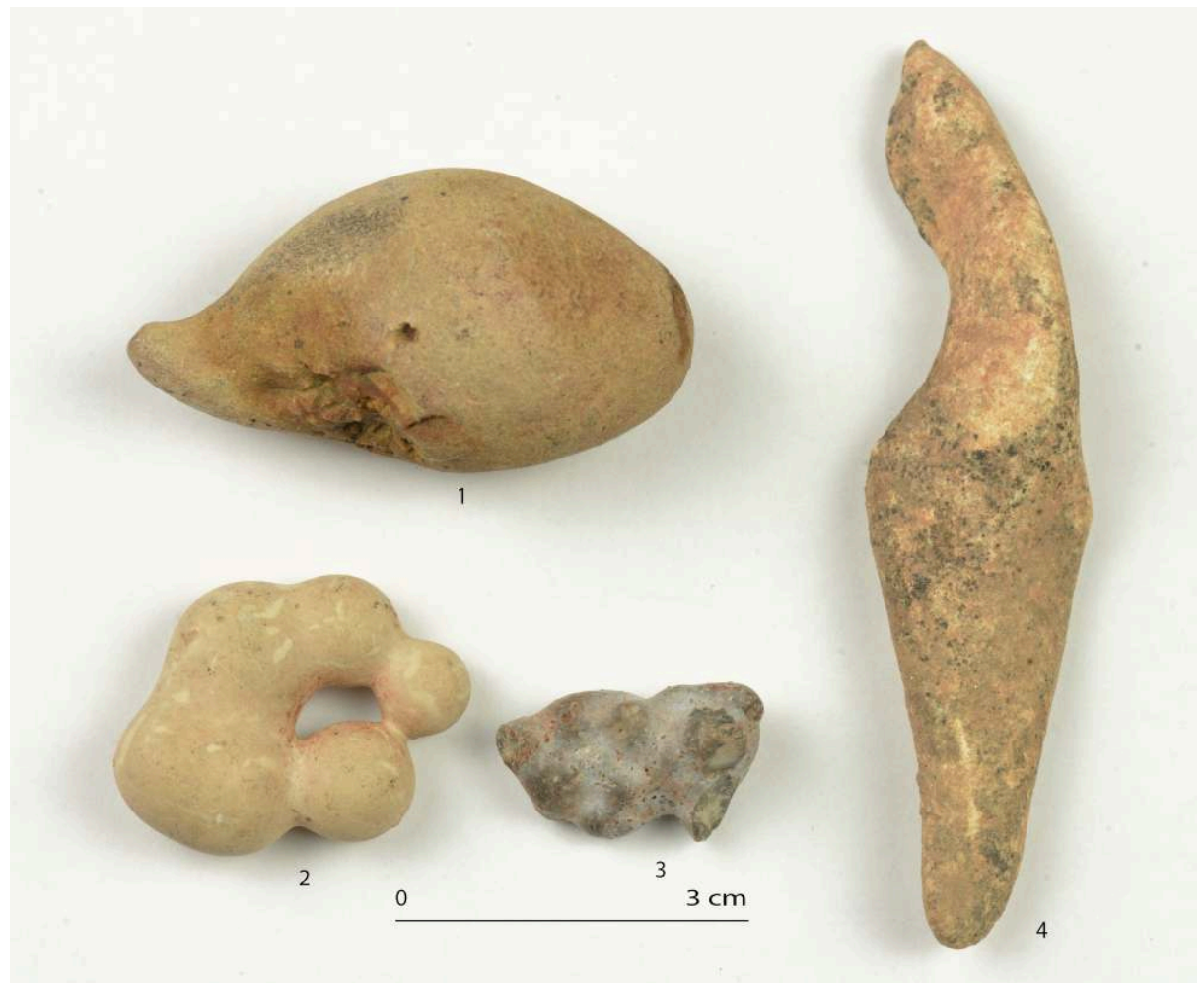

La perforation du no 2 est naturelle. Le n 4 , bien que totalement naturel, évoque une silhouette féminine (FFS).

Photo Frédéric Surmely. 


\section{Discussion}

37 Le Magdalénien moyen de l'Auvergne s'inscrit dans la lignée des cultures antérieures, avec le recours à des matériaux d'importation qui ont eu un rôle important dans l'outillage des groupes humains. La proportion atteint $73 \%$ dans un niveau du site d'Enval-Moliard. Ce phénomène concerne toute la gamme de l'outillage commun.

Comme nous l'avons souligné à maintes reprises, les raisons du recours à des matériaux d'origine lointaine pour le façonnage d'outils de la vie quotidienne restent obscures (Surmely et al. 2008a). Des expérimentations ont montré que les critères d'ordre fonctionnel et qualitatif semblent à exclure (Surmely et Murat 2003). Il reste donc l'hypothèse d'une recherche esthétique, voire symbolique (rareté...). Les sites d'Enval se démarquent des autres gisements magdaléniens de basse Auvergne par l'importation d'objets de parure et de curiosité.

L'hypothèse d'un "courant alpin ", basée sur la provenance présumée de quelques objets (lignite, quartz, dents de marmotte), nous paraît plausible, mais doit être confirmée par des analyses complémentaires.

Les modalités d'introduction de ces pièces dans les sites, notamment dans celui d'EnvalMoliard, sont également difficiles à déterminer. Un approvisionnement direct pour tous les objets nous paraît fortement improbable, compte tenu de l'éloignement et de la multiplicité des sources d'approvisionnement (fig. 10), et il faut sans doute imaginer un système d'échanges (Whallon 2006) pour une partie au moins des objets d'origine lointaine. On peut envisager l'existence de modalités d'introduction différenciées selon les types de biens et leurs origines géographiques, basées sur les déplacements ordinaires des groupes humains ou des expéditions spécialisées, issues des échanges entre groupes voisins dans le cadre d'une "économie multicentrique " (Bohannan et Dalton 1962, Perlès 2007)... À noter enfin que la diffusion des silex crétacés du Bassin parisien au Paléolithique supérieur n'a pas été limitée à l'Auvergne, mais s'est étendue au moins à l'Aquitaine (Delvigne et al. 2018) et au Forez (site de La Goutte Roffat: Surmely et Alix, à paraître). 
Fig. 10. - Site d'Enval-Moliard (Vic-le-Comte, Puy-de-Dôme) : schéma de provenance des biens d'origine lointaine.

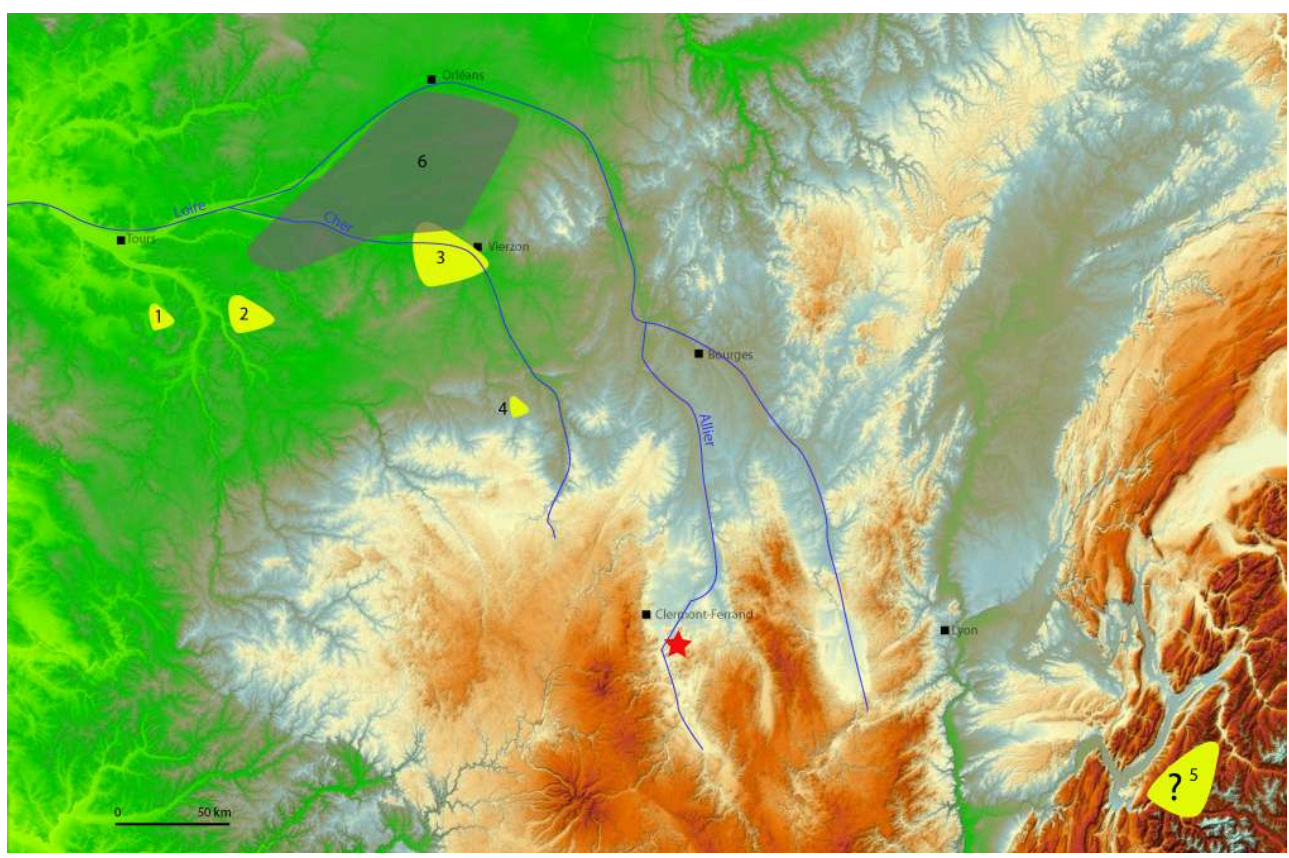

Étoile rouge : site d'Enval. 1 : zone de provenance du silex de Fontmaure. $\mathbf{2}$ : zone de provenance des silex du Turonien moyen et supérieur. $\mathbf{3}$ : zone de provenance présumée des silex du Turonien inférieur. $\mathbf{4}$ : zone de provenance des silex de l'Hettangien. $\mathbf{5}$ : zone de provenance possible des quartz et incisives de marmotte. $\mathbf{6}$ : zone de provenance des coquillages fossiles.

PAO Frédéric Surmely.

Dans tous les cas, ces transports d'objets, quelles qu'en aient été les modalités, témoignent de la circulation des biens dans le Massif central au cours du Magdalénien moyen, à une échelle qui dépasse les 200 kilomètres et qui est, de plus, multidirectionnelle. Cette mobilité a été observée dans d'autres régions, à des échelles parfois encore plus grandes (Aubry et al. 2012, Cattin 2015, Langlais et al. 2016). L'apparente banalité de certains objets découverts sur le site d'Enval-Moliard, comme ces petits nodules de silex inexploitables pour la taille, mais aussi l'utilisation des silex allochtones pour la fabrication de l'outillage ordinaire, renforcent l'hypothèse d'une circulation aisée, non limitée à des objets durables et à forte valeur ajoutée.

\section{Conclusion}

L'étude de l'origine de l'équipement technique et des objets de parure des groupes humains en Auvergne au cours du Magdalénien moyen montre l'ampleur et la complexité des liens qu'ils ont entretenus avec les régions environnantes, à des échelles qui dépassent les 200 kilomètres à vol d'oiseau. Le site d'Enval-Moliard, récemment découvert, est sur ce point particulièrement représentatif. Les objets retrouvés sur ce site témoignent en effet de contacts directs ou indirects avec plusieurs aires géographiques, qui seraient en outre éloignées entre elles de plus de 500 kilomètres si l'hypothèse d'importation de produits venus du domaine alpin venait à être confirmée. Il y avait bien sûr des relations privilégiées et sans doute régulières avec le centre de la France, d'où sont importés plusieurs types de silex, mais aussi très probablement des coquillages et des objets de curiosité. Ces liens existaient depuis le Gravettien ancien et 
ont été mis en évidence sur tous les sites (Surmely et al. 2008a). L'approvisionnement en silex du site d'Enval-Moliard est ainsi proche de celui du site de La Garenne (SaintMarcel, Indre : Despriées et al. 2009, Paillet et al. 2016). Le site d'Enval-Moliard pourrait témoigner de relations également avec les régions alpines, au travers de l'introduction de quartz hyalin et de certains objets de parure, en particulier les incisives de marmotte.

C'est pour nous une confirmation du caractère complexe et multiforme des transports d'objets à longue distance au cours du Magdalénien. Ajoutons que l'importance de ces mouvements est très probablement sous-estimée, car nos observations ne portent que sur les témoins en matières non périssable. Comment s'étonner dès lors de l'homogénéité culturelle des groupes humains à l'échelle de l'Europe ? La poursuite des recherches sur le site d'Enval-Moliard et l'achèvement des études sur le site récemment fouillé à Solutré (Lajoux et al. 2016) devraient permettre de préciser les hypothèses formulées ici.

\section{BIBLIOGRAPHIE}

AFFOLTER J., CATTIN M., LEESCH D., 1994, « Monruz, une nouvelle station magdalénienne sur les rives du lac de Neuchâtel », Archéologie suisse, vol. 17, n³ 3, p. 94-104.

ALLARD M., 2016, « Le Solutréen de l'abri des Peyrugues (Orniac, Lot, France) », https://

hal.archives-ouvertes.fr/hal-01233216.

ALVAREZ-FERNANDEZ E., 2001, «L'axe Rhin-Rhône au Paléolithique supérieur récent : l'exemple des mollusques utilisés comme objets de parure ", L’Anthropologie, vol. 105, nº 4, p. 547-564.

ALVAREZ-FERNANDEZ E., 2009, « Magdalenian personal ornaments on the move: a review of the current evidence in the Central Europe », Zephyrus, vol. 63, p. 45-59.

ANGEVIN R. et SURMELY F., 2012, « Le Magdalénien moyen et la trajectoire historique des sociétés du $\mathrm{XVI}^{\mathrm{e}}$ millénaire av. J.-C. en France centrale », Palevol, vol. 12, nº 1, p. 57-68.

ANGEVIN R. et SURMELY F., 2014, «Les temps du Magdalénien dans le Massif central et ses marges septentrionales : structure paléohistorique, mutations culturelles et expressions techniques entre 15000 BP et 11500 BP », dans Jaubert J. et al. (dir.), Transitions, ruptures et continuité en préhistoire, Paris, Société préhistorique française, p. 449-462.

AUBRY T., 1991, «L'exploitation des ressources en matières premières lithiques dans les gisements solutréens et badegouliens du bassin versant de la Creuse (France) », thèse, Pessac, université Bordeaux I.

AUBRY T., LUIS L., MANGADO LLACH J., MATIAS H., 2012, « We will be known by the tracks we leave behind: exotic lithic raw materials, mobility, and social networking among the Côa Valley foragers (Portugal) », Journal of Anthropological Archaeology, vol. 31, nº 4, p. 528-550.

BOHANNAN P. et DALTON G., 1962, « Markets in Africa », Chicago, Northwestern University Press. 
BOSINSKI G., 2011, Femmes sans tête : une icône culturelle dans l'Europe de la fin de l'époque glaciaire, Paris, Errance.

BOURDELLE Y., 1987, « Rapport de synthèse des fouilles d'Enval de 1969 à 1987 », Clermont-Ferrand, Direction des antiquités d'Auvergne, dact.

BOURDELLE Y. et MERLET J.-C., 1991, « Le site d'Enval, commune de Vic-le-Comte (Puy-de-Dôme) », Bulletin de la Société préhistorique française, vol. 88, p. 109-113.

BÜLLINGER J., 2005, « Nouvelles découvertes d'incisives de marmotte sciées dans des sites magdaléniens de l'arc jurassien », dans Dujardin V. (dir.), Industries osseuses et parures du Solutréen au Magdalénien en Europe, Paris, Société préhistorique française, p. 347-351.

BÜLLINGER J. et MÜLLER V., 2006, «Les éléments de parure », dans Büllinger J. et al. (dir.), Le site magdalénien de Monruz, 1 : Premiers éléments pour l'analyse d'un habitat de plein air, Hauterive, Service et musée cantonal d'archéologie de Neuchâtel (Archéologie neuchâteloise, 38), p. 149-165.

CATTIN M.-I., 2015, « Ça bouge au Magdalénien : mobilité et circulation à travers l'exemple des campements de Monruz et Champréveyres (Suisse) », dans Naudinot N., Meignen L., Querré G. (dir.), Les systèmes de mobilité de la Préhistoire au Moyen Âge, $\mathrm{XXXV}^{e}$ Rencontres internationales d'archéologie et d'histoire d'Antibes, Antibes, APDCA, p. 209-222.

COMBIER J. et MONTET-WHITE A., 2002, Solutré 1968-1998, Paris, Société préhistorique française.

Costamagno S., PÉTILLON J.-M., RigAud S., KUNTZ D., LAROUlANDiE V., LANGLAIS M., 2018, « Le Renne (Rangifer tarandus), pilier de l'économie des Magdaléniens de Peyrazet (Lot) », dans Costamagno S., Dupont C., Dutour O., Gourichon L., Vialou D. (dir.). Animal symbolisé, animal exploité : du Paléolithique à la protohistoire. Actes du $141^{e}$ Congrès du CTHS, 11-16 avril 2013, Rouen, Paris, Éditions du CTHS, p. 68-88.

DANIEL R., 1969, « Quelques précisions sur le remplissage archéologique de la grotte de Liveyre, commune de Tursac (Dordogne) », Bulletin de la Société préhistorique française, vol. 4, p. 112-116.

DELLUC B. et DELLUC G., 1995, « Les figures féminines schématiques du Périgord », L'Anthropologie, vol. 99, p. 236-257.

DELVIGNE V., 2016, « Géoressources et expressions technoculturelles dans le sud du Massif central au Paléolithique supérieur : des déterminismes et des choix », thèse, Pessac, université de Bordeaux.

DelVigne V., Piboule M., Fernandes P., LAfARge A., AUbry T., MANGADO Llach J., PRIMAUlt J., RAYNAL J.-P., 2018, « Principales matières premières lithiques disponibles au Paléolithique entre l'Auvergne et le Bassin parisien, partie 2, Loir-et-Cher, Indre-et-Loire : le cas du Turonien inférieur et supérieur ", dans Troubat O. (dir.), Préhistoire de la France centrale, Montluçon, Cercle d'archéologie de Montluçon et de la région, p. 27-48.

DEMARS P.-Y., 2015, « Le bassin de Brive dans le Paléolithique supérieur », Travaux d'archéologie limousine, vol. 35, p. 13-32.

DESPRIÉES J., TYMULA S., RIGAUD A., 2009, Données récentes sur le Magdalénien de La Garenne (SaintMarcel, Indre) et la place du Magdalénien à navettes en Europe, Argenton-sur-Creuse, Association pour la sauvegarde du site d'Argentomagus et Amis du musée (Bulletin de l'Association pour la sauvegarde du site d'Argentomagus, numéro spécial 2).

GALLAY A., CARAZETTI R., BRUNIER C., 1987, Le Néolithique ancien des Alpes centrales (fin du $5^{e}$ millénaire) et ses relations avec la Méditerranée, Paris, CNRS éditions. 
GINESTET J.-P., BITNZ P., CHAIX L., EVIN J., OLIVE C., 1984, « L'abri-sous-roche de La Vieille-Église, La Balme-de-Thuy (Haute-Savoie) : premiers résultats ", Bulletin de la Société préhistorique française, vol. 81, nº 10-12, p. 320-342.

GIVENCHY P. de, 1923, « Pointes paléolithiques en cristal de roche limpide (quartz hyalin) », Bulletin de la Société préhistorique française, vol. 20, p. 166-170.

GUÉGAN S., 2013, « Le Solutréen ancien en vallée du Rhône », Bulletin de la Société préhistorique française, vol. 110, $\mathrm{n}^{\circ} 4$, p. 623-644.

GUERRESCHI A., 2002, « Alpe Veglia : des chasseurs mésolithiques près du Simplon », dans Curdy P. et Praz J.-C. (dir.), Premiers hommes dans les Alpes, de 50000 à 5000 avant Jésus-Christ, Sion, Musées cantonaux du Valais, p. 174-177.

HINGUANDT M., BIARD M., BODINIER B., LENORMAND A., TSOGBOU AHOUPÉ R., 2012, « Les matières premières lithiques du Solutréen de la vallée de l'Erve (Mayenne) », dans Marchand G. et Querré G. (dir.), Roches et sociétés de la préhistoire, Rennes, Presses universitaires de Rennes, p. 423-438.

HOTTIN A.-M, PÉRICHAUD J.-J., BOIS J.-P., ARCY D. d', 1989, « Notice explicative de la feuille SaintGervais-d'Auvergne au 1/50 000 ", Orléans, BRGM.

KuntZ D., SÉCher A., COSTAMAgno S., MALlye J.-B., PÉTIlLON J.-M., PESChAUX C., PUbERT E., RENDU W., BOUDADI-MALIGNE M., LAROULANDIE V., BARSHAY-SZLMIDT C., LANGLAIS M., 2015, « Le Roc de Marcamps 2 (Prignac-et-Marcamps, Gironde) : nouvelles données sur la subsistance et les traditions techniques au début du Magdalénien moyen ", Bulletin de la Société préhistorique française, vol. 112, $\mathrm{n}^{\circ}$ 3, p. 475-516.

LAJOUX J.-B., MALGARINI R., BEMILLI C., BAYLE G., 2016, « Retour à Solutré », Bulletin de la Société préhistorique française, vol. 113, $\mathrm{n}^{\circ} 4$, p. 824-826.

LANGLAIS M., SÉCHER A., CAUX S., DELVIGNE V., GOURC L., NORMAND C., SANCHEZ DE LA TORRE M., 2016, « Lithic tool kit: A Metronome of the evolution of the Magdalenian in southwest France (19,000-14,000 BP) », Quaternary International, vol. 30, p. 1-16.

MASSON A., 1981, « Pétroarchéologie des roches siliceuses : intérêt en préhistoire ", thèse de $3^{\mathrm{e}}$ cycle, Villeurbanne, université Claude-Bernard - Lyon I.

MASSON A., 1982a, "Circulations paléolithiques : une question de longueur », Bulletin de la Société préhistorique française, vol. 79, $\mathrm{n}^{\circ}$ 7, p. 197.

MASSON A., 1982b, «Échanges et approvisionnement en silex à l'époque magdalénienne ", dans Gog A. et Spier F. (dir.), Le Mésolithique entre Rhin et Meuse : actes du colloque sur le Paléolithique supérieur final et le Mésolithique dans le Grand-Duché de Luxembourg et dans les régions voisines (Ardenne, Eifel, Lorraine), Luxembourg, 18-19 mai 1981, Luxembourg, Société préhistorique luxembourgeoise, p. 51-72.

MÉREAU A.-L., 2012, « Les dents animales perforées au Magdalénien : nouvelles perspectives fonctionnelles. Étude de quatre sites pyrénéens ", thèse, Paris, université Paris I.

MEISSER N. et MEISSER-INSENRING P., 1997, Cristal de roche, Lausanne, Musée cantonal de géologie.

MERLET J.-C., PLASSARD F., CHAUVIÈRE F.-X., 2017, « L'art mobilier et la parure du gisement magdalénien d'Enval (Vic-le-Comte, Puy-de-Dôme) », dans Cleyet-Merle J.-J., Geneste J.-M., ManEstier E. (dir.), L'art au quotidien : objets ornés du Paléolithique supérieur, Les Eyzies-de-Tayac, Musée national de préhistoire (Paleo, numéro spécial), p. 401-423. 
MEZZENA F. et PERRINI L., 2002, « Mont Fallère : des trouvailles mésolithiques en Val d'Aoste », dans Curdy P. et Praz J.-C. (dir.), Premiers hommes dans les Alpes, de 50000 à 5000 avant Jésus-Christ, Sion, Musées cantonaux du Valais, p. 186-188.

PAILLET P., PINÇON G., BOURDIER C., 2016, « Historique des recherches sur les faciès à Lussac-Angles et à navettes ", dans Bourdier C. et al. (dir.), L'essor du Magdalénien : aspects culturels, symboliques et techniques des faciès à navettes et à Lussac-Angles, Paris, Société préhistorique française, p. 19-32.

PASTY J.-F., PIBOULE M., ALIX P., 2017, « Le site magdalénien de plein air des Hauts de Buffon à Montluçon (Allier, France) », Gallia préhistoire, p. 125-224.

PERLÈS C., 2007, «Échanges et technologie : l'exemple du Néolithique », dans Evin J. (dir.), Un siècle de construction du discours scientifique en préhistoire, vol. 3, Paris, Société préhistorique française, p. 53-62.

PESCHAUX C., 2017, « La parure des sociétés du Dernier Maximum Glaciaire : évolution des pratiques et traditions ornementales entre la fin du Solutréen, le Badegoulien et le début du Magdalénien dans les Bassins parisien, ligérien et aquitain », thèse, Paris, université Paris I Panthéon-Sorbonne.

PESESSE D., 2008, « Les premières sociétés gravetiennes », thèse, Aix-en-Provence, université de Provence.

PIBOULE M., DELVIGNE V., FERNANDES P., LAFARGE A., RAYNAL J.-P., 2018, « Principales matières premières lithiques disponibles entre le Bassin parisien et l'Auvergne. Partie 1 : Allier, Cher et Indre », dans Troubat O. (dir.). Préhistoire de la France centrale, Montluçon, Cercle d'archéologie de Montluçon et de la région, p. 9-25.

POPLIN F., 1983a, « Incisives de renne sciées du Magdalénien d'Europe occidentale », dans Poplin F. (dir.), La faune et l'homme préhistorique, Paris, Société préhistorique française (Mémoires, 16), p. 55-67.

POPLIN F., 1983b, « Les dents travaillées de renne et autres animaux du Petersfels », dans Albrecht G., Berke H., Poplin F. (dir.), Recherches scientifiques sur les inventaires magdaléniens de Petersfels, fouilles 1974-1976, Tübingen, Archaeologica Venatoria, p. 133-153.

PRADEL L., 1967, Les gisements de Fontmaure : Paléolithique inférieur, Moustérien de tradition acheuléenne, Moustérien final à lames, Toulouse, Institut d'art préhistorique de la faculté des lettres et sciences humaines de Toulouse (Travaux de l'Institut d'art préhistorique).

PRADEL L. et TOURENQ C., 1967, « Les matériaux de Fontmaure : choix des Paléolithiques et mesures des caractères physiques ", Bulletin de la Société préhistorique française, vol. 64, n 3, p. 81-85.

PRIMAULT J., 2003, «Exploitation et diffusion des silex de la région du Grand-Pressigny au Paléolithique », thèse, Paris, université Paris X.

RÉMY D., 2013, « Caractérisation techno-économique d'industries en bois de cervidés du Badegoulien et du Magdalénien : le cas du Rond-du-Barry (Haute-Loire) et de Rochereil (Dordogne) », thèse, Montpellier, université de Montpellier.

ROSTAN P., 2005, « Les ressources en cristaux de quartz hyalin du sud-est de la France et leurs potentialités archéologiques », Bulletin du musée d'anthropologie préhistorique de Monaco, vol. 45, p. 3-13.

ROSTAN P. et THIRAULT É., 2016, « L'usage du quartz hyalin dans les Alpes durant la Préhistoire : une vue d'ensemble. Nouvelles données en Oisans (Isère et Hautes-Alpes) », dans Tomasso A. et 
Binder D. (dir.), Ressources lithiques, productions et transferts entre Alpes et Méditerranée, Paris, Société préhistorique française, p. 97-136.

RUDEL A., 1966, Richesses minéralogiques en Auvergne, Clermont-Ferrand, Volcano.

SAINTOT S., 2016, Un habitat chasséen en Auvergne : Champ Madame à Beaumont (Puy-de-Dôme) au Néolithique moyen II, Paris, CNRS éditions.

SÉRONIE-VIVIEN M.-R. et SÉRONIE-VIVIEN M., 1987, Les silex du Mésozoïque nord-aquitain : approche géologique de l'étude du silex pour servir à la recherche préhistorique, Bordeaux, Société linnéenne de Bordeaux (Bulletin de la Société linnéenne de Bordeaux, 15).

SURMELY F., 2010, « Rapport sur le programme de recherches sur le site magdalénien d'Enval », Service régional de l'archéologie d'Auvergne, dact.

SURMELY F., 2013, « Rapport sur le programme de recherches sur le site magdalénien d'Enval », Service régional de l'archéologie d'Auvergne, dact.

SURMELY F., 2016, « Le site d'Enval-Moliard (Vic-le-Comte, Puy-de-Dôme), rapport de sondage et d'expertise », Service régional de l'archéologie d'Auvergne, dact.

SURMELY F. et ALIX P., à paraître, «L'approvisionnement en matières premières lithiques des occupants du site magdalénien de La Goutte Roffat (Villerest, Loire) », Préhistoire du Sud-Ouest.

SURMELY F. et CAILlAT P., 2016, « Sondages dans les abris-sous-roche de Pranal (BromontLamothe) », Préhistoire du Sud-Ouest, vol. 24, p. 197-205.

SURMELY F. et MURAT R., 2003, «Études comparatives sur la résistance mécanique de divers silex lacustres et marins français", dans Actes de la Table ronde internationale d'Aurillac "Les matières premières lithiques en préhistoire",( Préhistoire du Sud-Ouest, supplément), p. 337-342.

SURMELY F., FONTANA L., LIABEUF R., BOURDELLE Y., 1997, « Nouveaux éléments apportés à l'étude du site d'Enval et du peuplement magdalénien en Limagne », Bulletin de la Société préhistorique française, vol. $94, \mathrm{n}^{\circ} 2, \mathrm{p} .172-181$.

SURMELY F., BARRIER P., BRACCO J.-P., CHARLY N., LIABEUF R., 1998, « Caractérisation des matières premières siliceuses par l'étude des micro-faciès et application à la connaissance du peuplement préhistorique de l'Auvergne ", Comptes rendus de l'Académie des sciences de Paris, vol. 326, p. 595-601.

SURMELY F., BOUDON P., PIN C., BRIOT D., 2008a, « La diffusion des silex crétacés dans le centre du Massif central durant la préhistoire (Paléolithique, Mésolithique, Néolithique) », Paleo, vol. 20, p. 115-144.

SURMELY F., HAYS M., COSTAMAGNO S., 2008b, « Le Gravettien et le Protomagdalénien en Auvergne », Paleo, vol. 20, p. 73-98.

SURMELY F., COSTAMAGNO S., FRANKLIN J., HAYS M., 2017, « Découverte d'un nouveau gisement du Magdalénien moyen à Enval (Vic-le-Comte, Puy-de-Dôme) », Bulletin de la Société préhistorique française, vol. 114, $\mathrm{n}^{\circ} 1$, p. 173-176.

TABORIN Y., 1998, La parure en coquillages au Paléolithique, Paris, CNRS éditions.

TABORIN Y., 2004, Langage sans parole : la parure aux temps préhistoriques, Paris, La Maison des roches. VANHAEREN M. et D'ERRICO F., 2003, « Le mobilier funéraire de la dame de Saint-Germain-la-Rivière (Gironde) et l'origine des inégalités », Paleo, vol. 15, p. 195-238. 
WELTÉ A.-M. et CUPILLARD C., 2006, « Le Magdalénien à navettes de la grotte Grappin à Arlay (Jura) : nouveaux regards ", L'Anthropologie, vol. 110, p. 624-663.

WHALLON R., 2006, « Social networks and information: Non-“utilitarian” mobility among huntergatherers », Journal of Anthropological Archaeology, vol. 25, p. 259-270.

\section{RÉSUMÉS}

L'étude de l'origine de l'équipement technique et des objets de parure des groupes humains en Auvergne au cours du Magdalénien moyen montre l'ampleur et la complexité des liens entretenus avec les régions environnantes, à des échelles qui dépassent les 200 kilomètres à vol d'oiseau. Les objets retrouvés sur le site d'Enval-Moliard, récemment découvert, témoignent de contacts directs ou indirects avec plusieurs aires géographiques éloignées entre elles de plus de 500 kilomètres : des relations privilégiées et sans doute régulières avec le centre de la France, d'où ont été importés plusieurs types de silex, mais aussi très probablement des coquillages et des objets de curiosité, et également avec le domaine alpin, au travers de l'introduction de quartz hyalin et de certains objets de parure, en particulier des incisives de marmotte. C'est pour nous une confirmation du caractère complexe et multiforme des transports d'objets à longue distance au Magdalénien moyen.

The study of the origin of technological materials and ornaments objects of human groups in the Auvergne during the Middle Magdalenian shows the extent and complexity of the links that people maintained with surrounding regions, often on distances exceeding $200 \mathrm{~km}$ as the crow flies. The recently discovered site of Enval-Moliard is particularly representative of this fact. objects found at this site indeed show direct or indirect contacts with several geographical areas located over $500 \mathrm{~km}$ away. There were certainly privileged and likely regular relationships with central France, from where several types of flint were imported, but also very probably shells and objects of curiosity. The site of Enval-Moliard also seems to show connections with the Alps region through the introduction of hyaline quartz and certain ornament objects, in particular perforated marmot incisors. In our view, it confirms the complex and heterogeneous characteristic of long-distance exchanges of objects in the Middle Magdalenian.

\section{INDEX}

Mots-clés : Magdalénien, silex

Keywords : flint, Magdalenian

Index géographique : Auvergne

\section{AUTEURS}

\section{FRÉDÉRIC SURMELY}

Service régional d'archéologie Auvergne - Rhône-Alpes (Direction régionale des affaires culturelles, ministère de la Culture) 


\section{SANDRINE COSTAMAGNO}

Laboratoire Travaux et recherches archéologiques sur les cultures, les espaces et les sociétés (TRACES, UMR 5608, université Toulouse - Jean-Jaurès/CNRS), secrétaire de la section Préhistoire et protohistoire du CTHS

\section{JAY FRANKLIN}

EcoPlan Associates, INC (Mesa, Arizona, USA)

\section{RAPHAËL ANGEVIN}

Service régional d'archéologie Auvergne - Rhône-Alpes (Direction régionale des affaires culturelles, ministère de la Culture)

\section{FRANÇOIS CHEVRIER}

Musée d'histoire naturelle d'Orléans

\section{STÉPHANE MADELAINE}

Musée national de préhistoire des Eyzies-de-Tayac

\section{MAUREEN HAYS}

University of Charleston (USA) 


\section{Les montagnes du Jura : entre} contrainte topographique et vecteur de diffusion à la fin du Paléolithique supérieur (15 000-12 000 avant le présent)

The Jura Mountains: between topographic constraint and diffusion area at the end of the Upper Paleolithic (15,000-12,000 Before Present)

\section{Gérald Béreiziat}

1 Au cœur de l'Europe occidentale, le Jura a entretenu une histoire singulière avec les premières occupations humaines. Longtemps repoussé vers les marges, le peuplement s'est animé au sortir de la dernière glaciation, sous l'effet des changements climatiques et environnementaux, en maîtrisant peu à peu les caractéristiques géomorphologiques de ce massif. Les différentes dynamiques observées durant le Tardiglaciaire, du Magdalénien moyen à l'Azilien, s'accompagnent d'une importante mosaïque culturelle. Cette dernière révèle des pénétrations multiples et des origines diverses, dont il est parfois difficile de dresser un cadre précis.

2 L'orientation sud-ouest/nord-est (fig. 1) de la chaîne montagneuse et la présence de grands cours d'eau en périphérie ont joué un rôle décisif dans le développement des unités de peuplement. Ce contexte a notamment conditionné les déplacements, la circulation des objets et des techniques, et favorisé les contacts entre les groupes. Souhaitant discuter cette réalité, la présente étude s'appuie sur les données chronologiques et matérielles d'une cinquantaine de sites répartis sur l'ensemble du pourtour jurassien, en mobilisant les sphères spatiale (paléogéographie et approvisionnement en matières premières lithiques), chronologique (datations ${ }^{14} \mathrm{C}$ ), technique (projectiles en matière dure animale et armatures lithiques) et symbolique (incisives de marmotte et statuettes féminines de type Gönnersdorf). 
Fig. 1. - Cadre géomorphologique de l'arc jurassien.

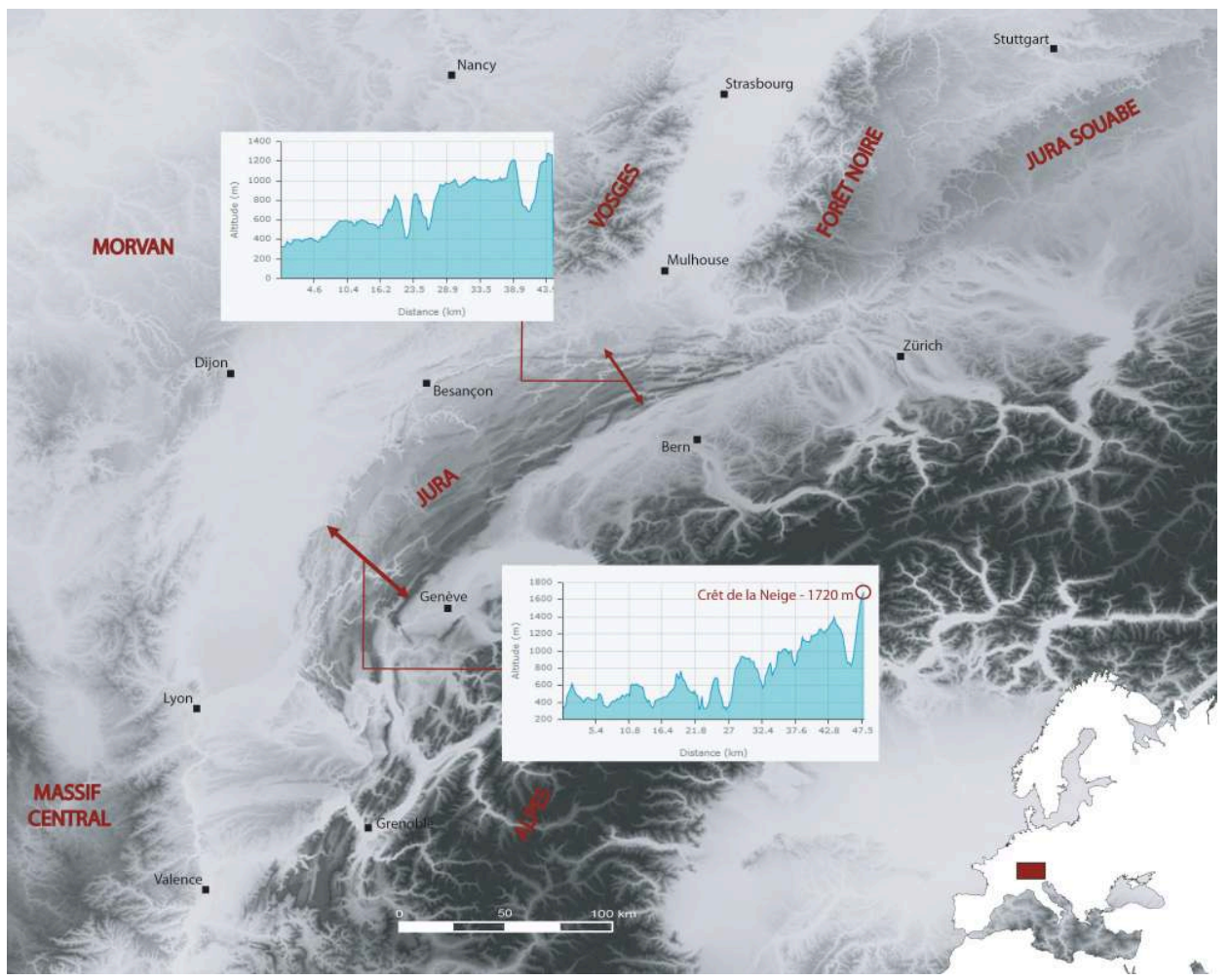

Les graphiques représentent les profils altimétriques relevés sur deux points de la chaîne montagneuse.

PAO Gérald Béreiziat, fond de carte IGN 2018.

\section{Le massif du Jura}

\section{Présentation}

3 L'arc que forme le massif du Jura s'étend sur près de 350 kilomètres entre le lac de Constance et le nord des Alpes françaises. Cependant, en tant qu'entité géologique, il s'impose au-delà des limites formées par le Rhin puisqu'il s'étire le long du Danube et englobe le Jura souabe et une partie du Bade-Wurtemberg. Dans sa globalité, le Jura occupe un espace de près de 700 kilomètres de long. La topographie et le jeu des plis montrent des pans plus abrupts sur le versant oriental, côté suisse, alors que les versants français et du sud-ouest de l'Allemagne se caractérisent par un dénivelé plus doux, qui s'estompe par étages sur les 50 à 60 kilomètres de largeur de la chaîne montagneuse (fig. 1). Les reliefs ne sont pas très élevés, ne dépassant qu'à deux reprises 1700 mètres d'altitude en France, dans la partie méridionale (département de l'Ain), au Crêt de la Neige (alt. 1720 m) et au Reculet (alt. 1718 m).

4 Ce territoire comprend trois cours d'eau importants, le Rhône, la Saône et le Rhin, qui sont autant d'axes naturels ayant facilité la mobilité des sociétés nomades et les relations entre plusieurs espaces. Le sud de la Suisse et celui de la Méditerranée sont ainsi joints par le Rhône, favorisant également une pénétration à plus longue distance vers le sud-ouest de la France. En prolongation de la vallée rhodanienne, la Saône rattache les Vosges à la plaine de la Bresse et ouvre un accès vers le centre-est de la 
France et le Bassin parisien. Enfin, le Rhin, qui prend sa source dans les Alpes suisses, permet de relier l'Europe septentrionale. Ce cadre hydrographique a joué un rôle très important dans l'organisation territoriale des populations et des activités durant le Paléolithique supérieur, comme l'ont déjà démontré des travaux réalisés depuis une vingtaine d'années, notamment sur l'approvisionnement en matières premières lithiques et la diffusion des coquillages marins comme éléments de parure (Djindjian 1995 et 2016, Floss 2000 et 2014, Alvarez Fernandes 2001 et 2009, Béreiziat 2011 et 2012, Terberger et al. 2013, Hussain et Floss 2014, Béreiziat et Floss 2016).

\section{Paléogéographie humaine}

\section{Perspective diachronique}

Les premiers millénaires du Paléolithique supérieur sont signalés dans quelques rares sites du pourtour jurassien, essentiellement en Franche-Comté, dans le département du Jura, dans les grottes des Gorges, à Amange, et celle de la Mère Clochette, à Rochefortsur-Nenon, ainsi qu'en Saône-et-Loire, à la grotte des Balmes, à Cuiseaux (FornageBontemps 2011, Cupillard et al. 2013, David et al. 2014). Des traces plus prégnantes s'observent en marge, sur la rive droite de la Saône, toujours en Saône-et-Loire, sur les sites de Germolles, à Mellecey, d'Azé, de Saint-Martin-sous-Montaigu, de Senozan et de Solutré (Combier et Montet-White 2002, Floss et al. 2013 et 2015).

Le Dernier Maximum glaciaire est marqué par de discrètes pénétrations dans le nord de la Suisse, à Kastelhöhle nord, Kohlerhöhle et Y-Höhle (fig. 2) (Leesch et al. 2012).

Fig. 2. - Répartition géographique des sites mentionnés (sur fond blanc) dans le cadre de l'ensemble des sites tardiglaciaires répertoriés entre les Alpes du nord et le Jura souabe.

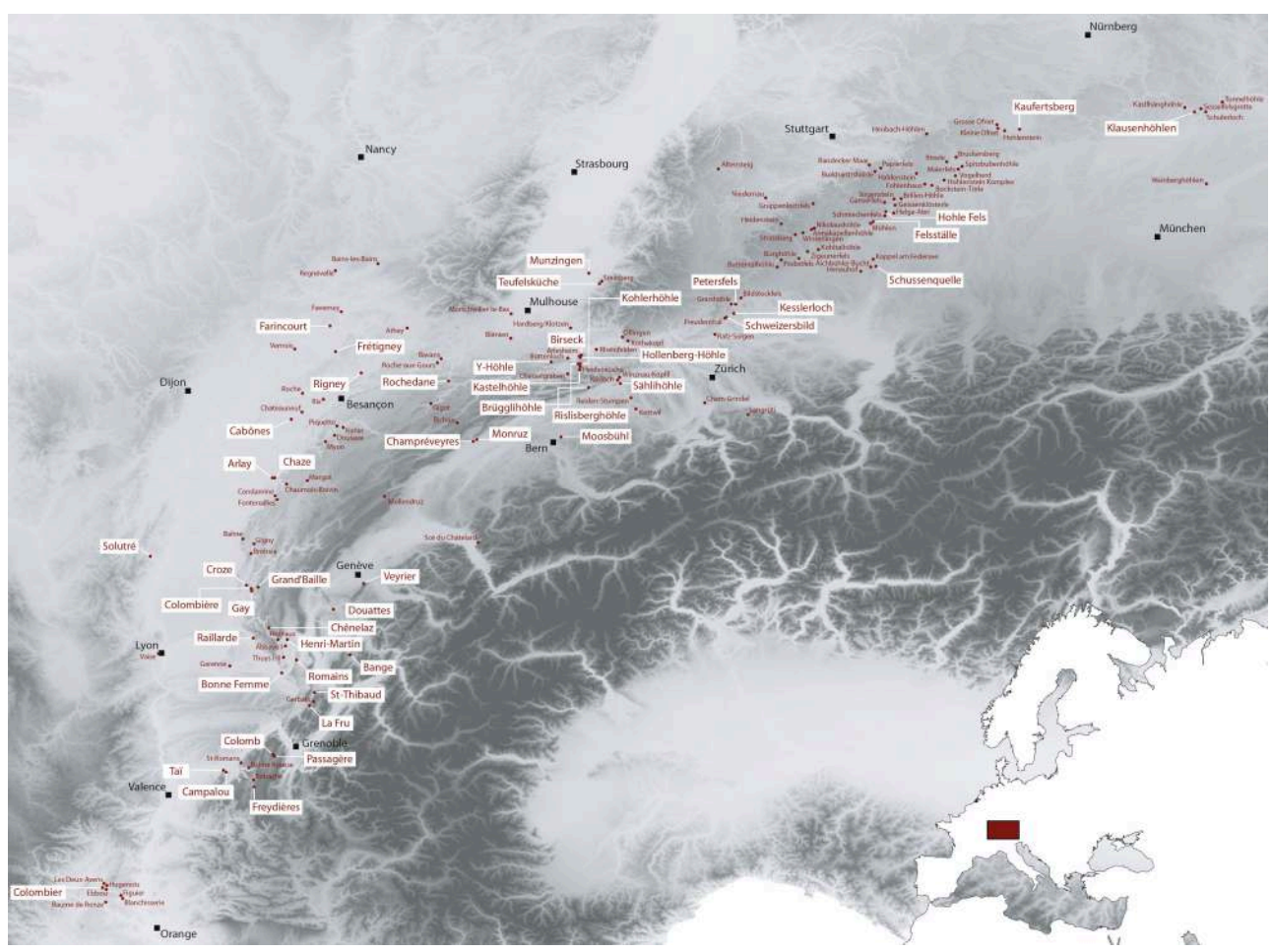

PAO Gérald Béreiziat, fond de carte IGN 2018. 
Les datations pour le site de Kastelhöhle (18 $530 \pm 150 \mathrm{BP}$, soit $22746-21975$ cal. BP ; $19200 \pm 150 \mathrm{BP}$, soit $23550-22730 \mathrm{cal}$. BP ; $19620 \pm 140 \mathrm{BP}$, soit 24 016-23 $230 \mathrm{cal}$. BP) pourraient caractériser une présence badegoulienne relativement ancienne (Leesch et Müller 2012). Cette attribution reste toutefois fragile en raison de la discrétion des informations matérielles. Il est à noter qu'en France, dans l'espace géographique dont il est question ici, deux dates sur renne (19 $310 \pm 80 \mathrm{BP}$, soit 23 528-22 984 cal. BP et 18070 $\pm 80 \mathrm{BP}$, soit $22180-21631$ cal. BP) provenant des niveaux M4 et M5 de Fretigney, en Haute-Saône, se calent dans cet horizon chronologique (Drucker et al. 2012, Cupillard et al. 2014).

Plusieurs dates AMS obtenues sur les sites d'Arlay (16 840 \pm 110 BP - 20 596-20 021 cal. BP) et de Gigny (17 $645 \pm 110$ BP, soit 21 700-20 984 cal. BP), dans le Jura, de Rigney, dans le Doubs (16 $680 \pm 80 \mathrm{BP}$, soit 20 383-19 889 cal. BP), et de Kohlerhöhle, à Brislach, en Suisse (16 $205 \pm 55 \mathrm{BP}$, soit $19779-19365$ cal. BP) documentent une phase de peuplement contemporaine de la fin du Pléniglaciaire supérieur (fig. 3) (Cupillard et Welté 2006, Drucker et al. 2012, Leesch 2014).

Fig. 3. - Datations AMS de gisements tardiglaciaires, du nord de la vallée rhodanienne à la Bavière (calibration OxCAL 4.3).
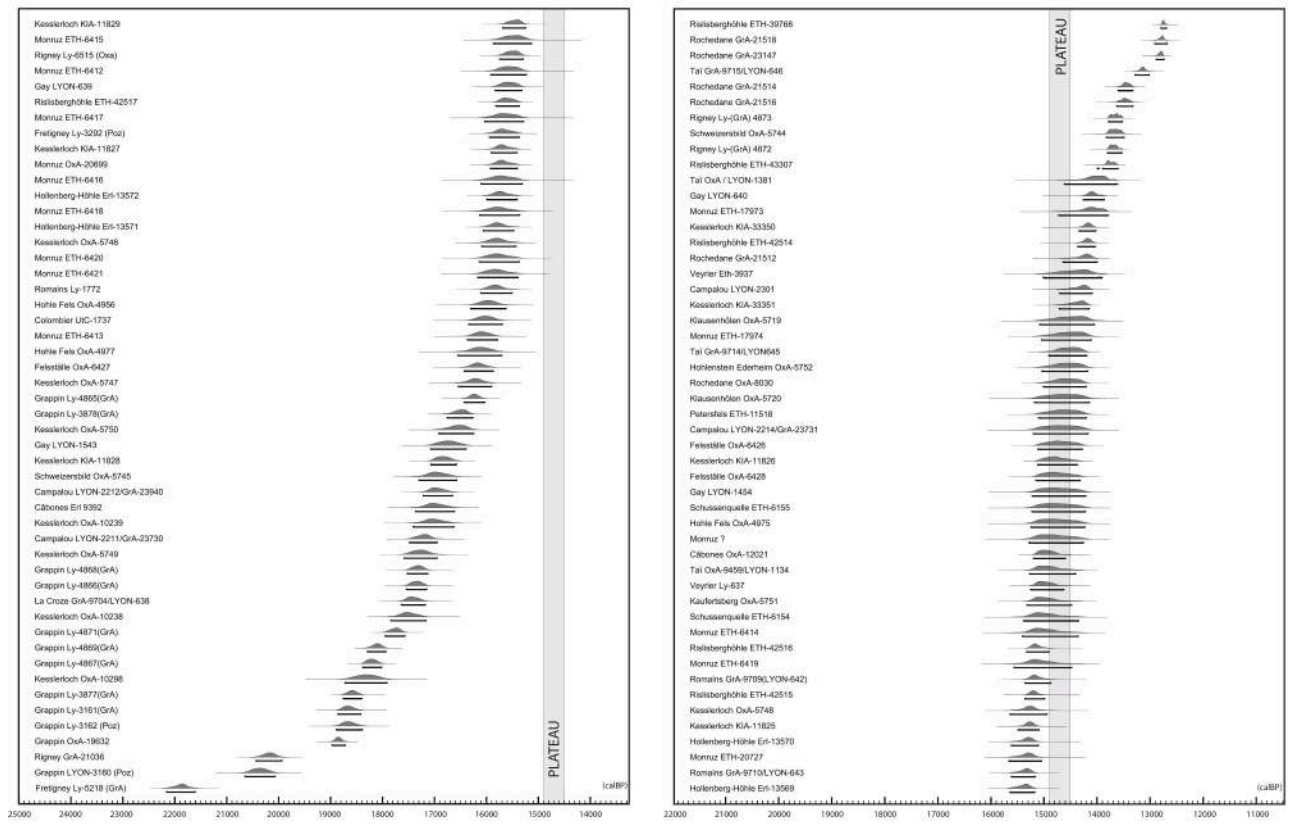

PAO Gérald Béreiziat.

La rareté des éléments lithiques et osseux associés à ces dates rend toutefois difficile de préciser leur attribution chronoculturelle. À Rigney, les vestiges de production lamellaire (Malgarini et al. 2017), caractérisés par de nombreux burins-nucléus, dont certains de type La Marche ou Rocher de La Caille, et d'une pièce typologiquement située entre des nucléus de type Orville et les nucléus de type Bertonne, tendraient à rapprocher une partie de la série soit à l'une des phases du Badegoulien, soit à un épisode du Magdalénien inférieur ou du Magdalénien moyen ancien.

Les dates obtenues sur ces quatre sites s'isolent à l'évidence de la dizaine de gisements reconnus ou attribués à la phase moyenne du Magdalénien et du premier stade du Dryas ancien (15 500-14 000 BP, soit 18 700-17 000 cal. BP) (fig. 3). Certains de ces sites 
abritent des indices d'appartenance à l'un des deux grands faciès présents durant cette phase chronoculturelle : le Magdalénien «à navettes".

11 Entre 14000 et $13200 \mathrm{BP}$ (17000 BP, soit $15500 \mathrm{cal}$. BP), intervalle durant lequel moins de mesures radiocarbone sont enregistrées, une rupture s'observe sur une grande partie de l'arc jurassien. Cette baisse de la fréquentation du territoire coïncide-t-elle avec un dépeuplement temporaire de cet espace ou résulte-t-elle d'un biais de la recherche (Leesch 2014) ? Le pourtour jurassien montre en tout cas une dynamique différente de ce que l'on observe durant cette période dans les Alpes du nord, la Drôme et l'Ardèche, où des groupes du Magdalénien supérieur ancien se développent : à La Fru (Saint-Christophe, Savoie) et à Campalou (Saint-Nazaire-en-Royans, Drôme). Cette situation pourrait s'expliquer par la présence des lacs glaciaires dans le sud du Jura, qui auraient ralenti la pénétration des groupes dans cette région et en Suisse (Mevel 2010, Béreiziat 2011, Mevel et al. 2014).

12 Marqué par le net réchauffement climatique du Bølling (12 700-12 000 BP, soit 15 000-14 000 cal. BP), les occupations de la phase finale du Magdalénien se multiplient et témoignent d'une riche diversité, concernant par exemple les morphotypes de pointes lithiques. Cette phase peut être, dans certains contextes, concomitante de la mise en place de l'Azilien, présent sous sa forme ancienne entre 12400 et $12000 \mathrm{BP}$ (14 500 BP, soit 14000 cal. BP) sur le site suisse de Champréveyres, à Hauterive (Leesch 1997), à l'abri Gay à Poncin, dans l'Ain (Béreiziat 2013), à La Fru (Mevel 2010) et à SaintThibaud-de-Couz, en Savoie (Pion 2004).

\section{Occupation de l'espace : l'exemple de l'approvisionnement en matières premières lithiques}

13 Le pourtour jurassien a fait l'objet de nombreuses prospections conduites dans le cadre de plusieurs projets de recherches, soulignant ainsi une très grande richesse et diversité des matières premières siliceuses disponibles sur ce vaste territoire (fig. 4 et fig. 5) (Floss 1994, Cupillard et al. 1995, Grünwald et Affolter 1995, Burkert 1998, Rué 2001, Féblot-Augustins 2002, 2005 et 2009, Affolter 2003, Bressy 2003, Aubry et al. 2003, Burkert et Floss 2005, Floss et al. 2005, Bressy et Floss 2006, Jacottey et Milleville 2009). 
Fig. 4. Répartition des matières premières siliceuses présentes sur le massif jurassien et son pourtour.

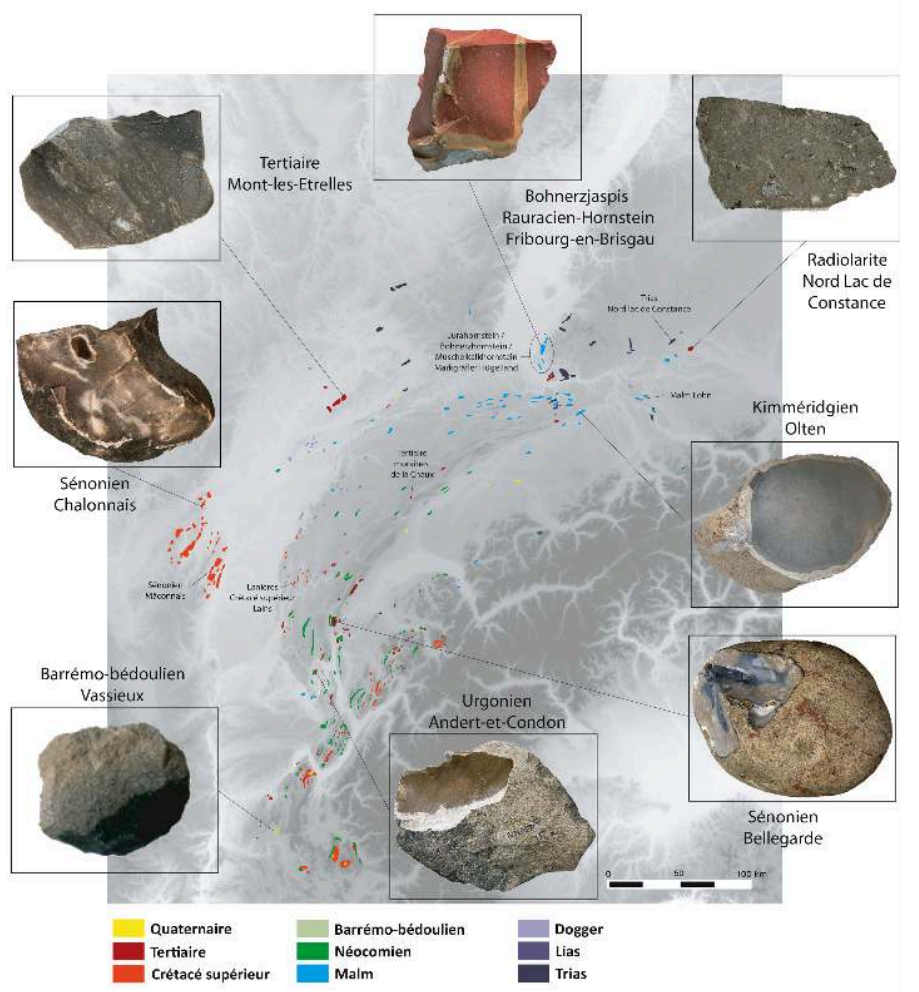

Les différentes couleurs correspondent aux faciès géologiques. 
Fig. 5. - Perspective diachronique des stratégies d'approvisionnement en matières premières lithiques de quelques sites de l'arc jurassien du Magdalénien moyen au Magdalénien final/Azilien ancien.
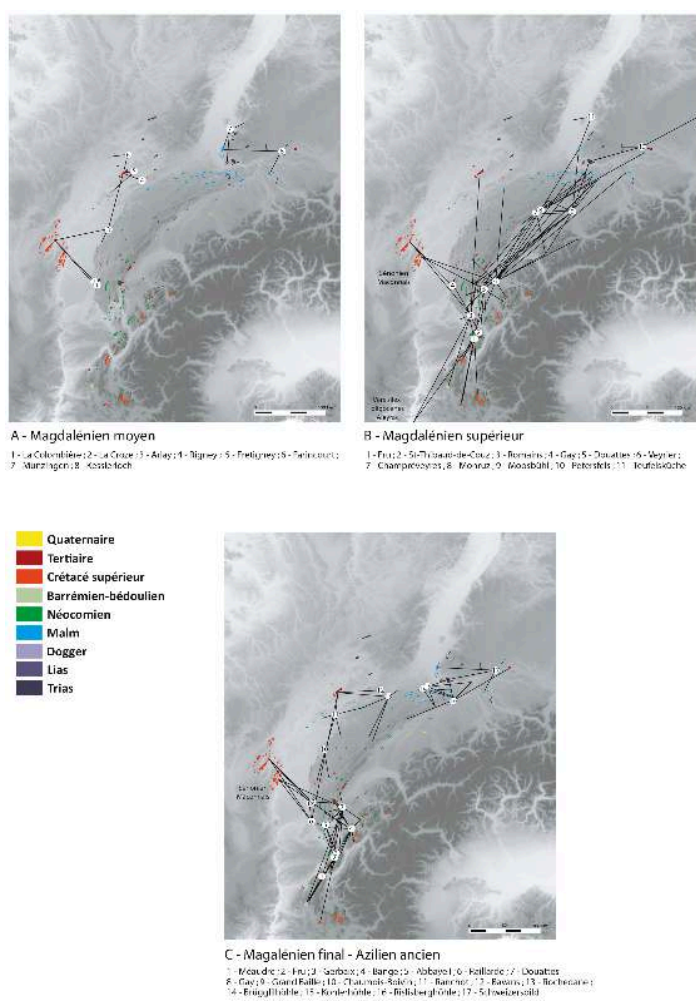

A - MAgdalÉnien moyen. $\mathbf{1}$ : La Colombière (Neuville-sur-Ain, Ain). $\mathbf{2}$ : La Croze (Saint-Martin-du-Mont, Ain). 3 : Arlay (Jura). 4 : Rigney (Doubs). 5 : Fretigney (Haute-Saône). 6 : Farincourt (Haute-Marne). $\mathbf{7}$ : Munzingen (Allemagne). 8 : Kesslerloch (Suisse). B - MAgDALÉNIEN SUPÉRIEUR. 1 : La Fru (SaintChristophe, Savoie). $\mathbf{2}$ : Saint-Thibaud-de-Couz (Savoie). $\mathbf{3}$ : Grotte des Romains (Virignin, Ain). 4 : abri Gay (Poncin, Ain). 5 : Les Douattes (Musièges, Haute-Savoie). 6 : Veyrier (Suisse). 7 : Champréveyres (Suisse). 8 : Monruz (Suisse). 9 : Moosbühl (Suisse). 10 : Petersfels (Allemagne). 11 : Teufelküche (Allemagne). c - MAgdaléNien finAL/AZILIEN ANCIEN. 1 : Méaudre (Isère). 2 : La Fru. 3 : Gerbaix (Saint-Christophe, Savoie). 4 : Bange (Allève, Haute-Savoie). $\mathbf{5}$ : Abbaye I (Chazey-Bons, Ain). $\mathbf{6}$ La Raillarde (Sault-Brénaz, Ain). $\mathbf{7}$ : Les Douattes. 8 : abri Gay. 9 : Grand'Baille (Pugieu, Ain). 10 Chaumois-Boivin (Blois-sur-Seille, Jura). 11 : Ranchot (Jura). 12 : Bavans (Doubs). 13 : Rochedane (Pont-de-Roides, Doubs). 14 : Brügglilhöhle (Suisse). 15 : Kohlerhöhle (Suisse). 16 : Schweizersbild (Suisse).

PAO Gérald Béreiziat, fond de carte IGN 2018.

14 L'approche présentée ici permet de proposer une première cartographie de l'espace occupé par les groupes paléolithiques et de caractériser leurs systèmes de mobilité ; approche qui restera largement à compléter dans les prochaines années.

Les matériaux exploités durant le Magdalénien moyen ne sont pas très diversifiés mais induisent un approvisionnement particulier (fig. 5A). Les silex allochtones de bonne qualité ont ainsi été préférés aux silex locaux de qualité moindre, comme nous le constatons à La Croze (Saint-Martin-du-Mont, Ain), La Colombière (Neuville-sur-Ain, Ain) et Arlay (Jura). Dans ces sites, les assemblages lithiques possèdent une proportion significative de matières premières provenant des sources sénoniennes chalonnaises (Saône-et-Loire), ce qui représente une distance d'environ 80 kilomètres. Cette distance sépare également Arlay des gîtes originaires de Mont-Les-Étrelles, en Haute-Saône (Bourgeois 1995, Féblot-Augustins 2002, Cupillard et Welté 2006, Béreiziat 2011). Ce silex lacustre tertiaire des bassins oligocènes est très caractéristique. Auréolé, à la zonation irrégulière, gris, opaque et à grain fin, il se présente sous la forme de 
plaquettes pouvant atteindre une trentaine de centimètres d'épaisseur (fig. 4). Les gîtes de Mont-Les-Étrelles ont été presque exclusivement exploités par les occupants de Fretigney (Haute-Saône), Rigney (Doubs) et Farincourt (Haute-Marne). Ils étaient complétés par un approvisionnement de matières premières trouvées dans l'environnement proche : silex bajociens à Fretigney et Farincourt, chailles grises de l'Argovien à Rigney (David 1996).

Dans le sud-ouest de l'Allemagne, le « rauracien-hornstein » et le «jurahornstein », qui affleurent au sud de la ville de Fribourg-en-Brisgau (fig. 4 et 5A), à l'Isteiner Klotz, à Auggen et à Schliengen (Floss 1994), composent l'essentiel des matières premières présentes sur le site de plein air de Munzingen (Pasda 1998). Elles se retrouvent, en faible quantité, à Kesslerloch, au nord-est de la Suisse, où les occupants ont préférentiellement exploité les poches de silex de Lohn (fig. 4 et $5 \mathrm{~A}$ ) et les galets alluvionnaires proches, localisés à moins de 5 kilomètres (Affolter 2003).

Durant le Magdalénien supérieur (fig. 5B), les sites de Teufelsküche et Petersfels, dans le sud-ouest de l'Allemagne, reprennent une partie du schéma d'approvisionnement constaté sur les sites du Magdalénien moyen de Munzingen et Kesslerloch. Le «jurahornstein» $(29,4 \%)$, le «bohnerzhornstein» $(37,6 \%)$ et le «muschelkalkhornstein » $(26,9 \%)$, dont les sources sont localisées au sud de la région de Markgräfler Hügelland, composent chacun un tiers de la totalité des matériaux lithiques exploités à Teufelsküche. À Petersfels, les sources du Trias, distantes de moins de 10 kilomètres, au nord du lac de Constance (fig. 4 et 5B), ont fourni le matériau de l'écrasante majorité $(89 \%)$ des 7949 pièces composant cette collection. Quelques pièces, présentes souvent à l'unité, évoquent un apport de matières premières diverses: quartz, quartzite, radiolarite, "plattenhornstein ", " tonstein », « kieselschiefer » (Pasda 1998).

En Suisse, les sites de Champréveyres (Hauterives), Monruz (Neuchâtel) et Moosbühl (Moosseedorf) montrent une exploitation de diverses sources le long de l'arc jurassien, signalant un axe préférentiel nord-est/sud-ouest, du sud du Jura à la région d'olten (fig. 5B) (Leesch 1997, Cattin 2002, Affolter 2003). Sur la vingtaine de matières premières recensées, trois dominent nettement le corpus: les silex hauteriviens d'origine locale (39\%), les silex allochtones sénoniens (19\%) de la région de Bellegarde, en France (à $120 \mathrm{~km})$, et kimméridgiens $(17 \%)$ de la région d'Olten, en Suisse (à $80 \mathrm{~km}$ ) (fig. 4 et 5B). Cette diversité apparente des matières premières se retrouve plus au sud, à Veyrier (Suisse) et aux Douattes (Musièges, Haute-Savoie) (Affolter 2003 et 2009). À Veyrier, la cartographie des provenances dessine ainsi une vaste aire de distribution intégrant le plateau suisse, les Préalpes, la vallée du Rhône, ainsi que certains éléments suggérant une origine beaucoup plus lointaine, le Bassin parisien ou le Loir-et-Cher (Stahl-Gretsch 2006). Dans le Jura méridional (fig. 5B), l'omniprésence des matériaux locaux ( $80 \%$ des ressources) sur le site de la grotte des Romains (Virignin, Ain) est à relever; mais des secteurs plus lointains et multiples ont été mis à profit: le sud du Vercors (sources barrémo-bédouliennes: 5,5\%), Bellegarde (sources du Crétacé supérieur : 4,6\%), les bords du Rhône, mais aussi le Sénonien chalonnais, distant de 200 kilomètres, et Mont-Les-Étrelles, à 280 kilomètres (Béreiziat 2011). Dans le nord des Alpes, le site de La Fru (fig. 5B) montre des relations privilégiées avec la vallée du Rhône par la présence des silex barrémo-bédouliens du Vercors et oligocènes de la région d'Aleyrac, à 130 kilomètres (Mevel 2010). 
19 À la fin du Magdalénien et durant la phase ancienne de l'Azilien, on observe une restriction du territoire d'approvisionnement, bien que la présence de matériaux allochtones indique une permanence des contacts ou déplacements évoqués précédemment (fig. 5C).

20 Dans plusieurs sites du Jura méridional, la présence d'un silex patiné à grain fin, très homogène, à la surface porcelanée et de couleur bleue dans la zone sous-corticale, renvoie une nouvelle fois à la piste chalonnaise. Ce silex sénonien se retrouve à La Raillarde (Sault-Brénaz, Ain), à l'abri Gay et surtout à La Grand'Baille (Poncin, Ain), où il représente $15 \%$ de l'ensemble (Féblot-Augustins 2002, Béreiziat 2011).

21 Une origine mâconnaise (fig. 4 et $5 \mathrm{C}$ ) de certaines pièces qui se composent, à la différence des silex sénoniens de Chalon-sur-Saône, de nombreux bryozoaires, s'observe aussi dans plusieurs assemblages du Jura méridional (La Raillarde) et du nord des Alpes, en Haute-Savoie: grotte de Bange, à Allève et abri des Douattes. Cette présence, sporadique, établit une nouvelle fois un contact avec cette partie de l'axe Rhin-Rhône.

22 Au sud du lac Léman et dans les Alpes du Nord, l'orientation méridionale est favorisée (fig. 6C) bien que dans la couche 3 de l'aire 1 (Azilien ancien) de La Fru, où dominent les matières premières locales, une dichotomie s'observe entre les silex barrémobédouliens provenant du sud du Vercors (à $80 \mathrm{~km}$ ) et les silex hauteriviens provenant du Nord, des environs de Belley (à 40 km) (Mevel 2010).

Le long du Rhin, l'approvisionnement montre une nouvelle fois l'importance de l'axe est-ouest (fig. $5 \mathrm{C}$ ). Le silex kimméridgien de la région d'olten domine nettement les assemblages dans les sites suisses de Brügglihöhle, à Nenzlingen, et de Kohlerhöhle et Rislisberghöhle, à Oensingen, distants de seulement quelques kilomètres des gîtes d'extraction (Affolter, 2003).

Dans le nord de la Franche-Comté et en Haute-Saône, l'exploitation se concentre sur les gîtes du bassin oligocène de Mont-Les-Étrelles. Certaines matières premières comme le silex du Crétacé inférieur/Tertiaire des moraines de La Chaux, présent dans le site de Rochedane (Pont-de-Roides, Doubs), et les lanières du Crétacé supérieur de Lains présentes à Ranchot (Jura) évoqueraient une pénétration à l'intérieur du massif jurassien (fig. 4 et 5C) (Cupillard 1998, Affolter 2003).

\section{Unité et originalité des cultures matérielles}

\section{Regard sur quelques composantes de l'industrie osseuse et lithique}

Quelques sites du Magdalénien moyen ont livré des indices d'appartenance au Magdalénien à navettes (David 1996, Cupillard et Welté 2006, Béreiziat 2011, Mevel et al. 2014, Malgarini 2014, Malgarini et al. 2017) (fig. 6). 
Fig. 6. - Répartition du Magdalénien à navettes.

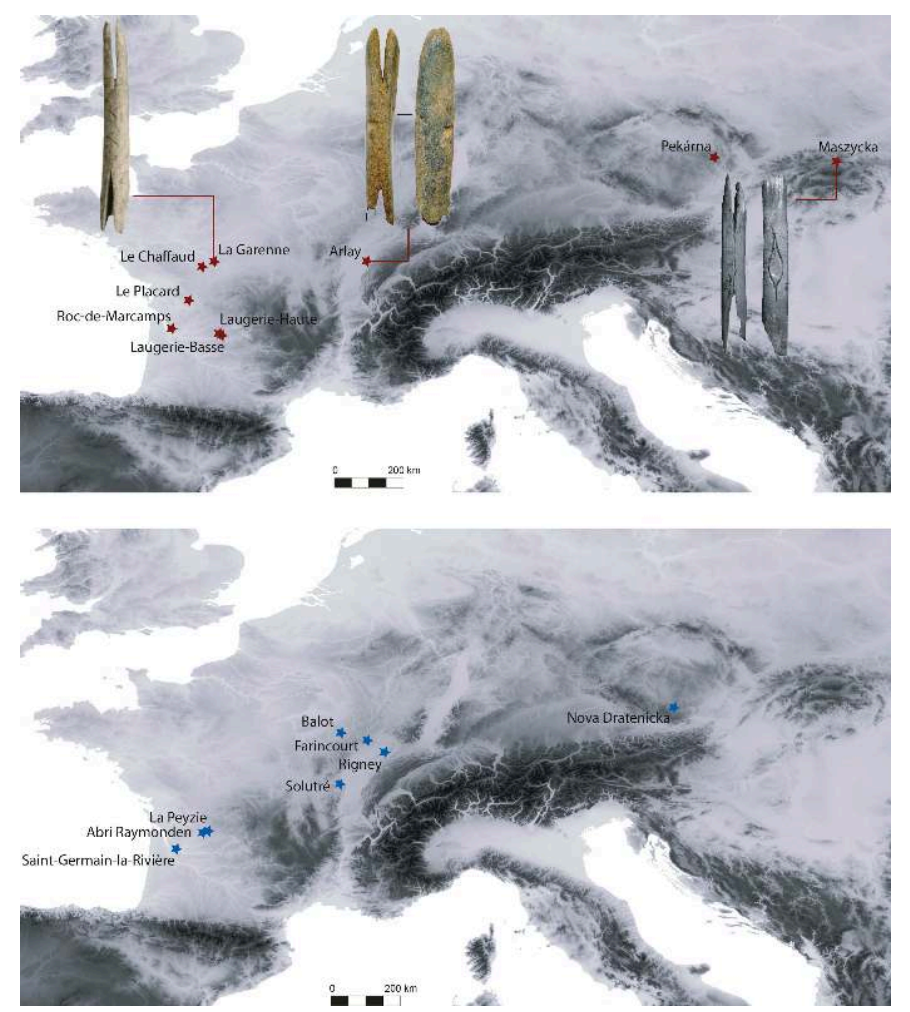

En haut, sites avec navettes; en bas, sites sans navettes mais abritant des composantes secondaires relatives à ce faciès : bâton percé phallique, figuration humaine et sagaie à double biseau de section carrée.

PAO Gérald Béreiziat, fond de carte (C) IGN 2018

Par contre, seul le site d'Arlay abrite ce type d'objet et peut être directement rattaché à ce faciès. Dans d'autres sites, même si les navettes sont absentes, des éléments secondaires laissent entrevoir un rapprochement avec cet épisode culturel : à Rigney, un bâton percé phallique; à Farincourt (Haute-Marne), un bâton percé phallique et figuration humaine ; à Solutré, un bâton percé phallique et une sagaie à double biseau de section carrée (David 1996, Combier et Montet-White 2002).

Un autre faciès central du Magdalénien moyen, caractérisé par les sagaies de type Lussac-Angles et présent dans un large quart sud-est de la France, soulève actuellement des interrogations pour la région, car aucune pointe de l'arc jurassien ne répond exactement au type décrit par G. Pinçon (1988). La Croze et Kesslerloch (Thaygen, Suisse) sont deux exemples alimentant ce débat : dans ces deux sites, un type de pointe spécifique, courte à biseau simple, est proche du type Lussac-Angles, sans toutefois en porter la rainure caractéristique (Mevel et al. 2014, Malgarini 2014, Malgarini et al. 2017). La présence la plus orientale de ce faciès se trouve dans la grotte du Trilobite, à Arcy-sur-Cure, dans l'Yonne (Bodu et Renard 2013).

Même si leur présence reste discrète sur l'ensemble du pourtour jurassien, les éléments façonnés en ivoire (pointes et fragments de pointes) retrouvés à Arlay, La Croze, Rigney, Farincourt et à la grotte de Chaze (Malgarini 2014) demeurent de meilleurs indicateurs culturels pour attribuer ces sites au Magdalénien moyen.

Concernant l'industrie lithique, on observe quelques particularités en marge de l'outillage composant le fonds commun magdalénien, telles que l'absence de lamelles à 
bord abattu à La Croze et la présence de nombreux becs dans ce même site, ainsi qu'à Rigney. Pour le gisement de Rigney, nous avons déjà évoqué la piste badegoulienne, qui pourrait expliquer le caractère particulier de cet assemblage. L'absence de supports à bord abattu à La Croze s'expliquerait davantage par une spécialisation fonctionnelle de l'occupation, tournée vers le travail des bois de cervidés (David 1996, Béreiziat 2011, Mevel et al. 2014). Complémentaires des burins, les becs argumenteraient cette hypothèse. Plusieurs études tracéologiques ont en effet montré que ces outils avaient été surtout utilisés pour percer ou aléser une matière osseuse (Schmider 1988, Beyries et al. 2005, Audouze 2006).

Parmi les faciès reconnus sur l'arc jurassien se trouve également celui à triangles scalènes, éléments présents à Farincourt et Birsek-Ermitage (Arlesheim, Suisse). L'attribution chronoculturelle pose question car ce faciès est également présent dans le Magdalénien supérieur. Selon F. Djindjian (1999), ces éléments seraient davantage caractéristiques de la fin du Dryas ancien et du début du Bølling, attribution argumentée par les datations AMS des niveaux à triangles scalènes de la Kniegrotte (Thuringe, Allemagne) datés entre 13250 et 13090 BP (Hedges et al. 1998). Toutefois, pour B. Ginter et M. Połtowicz-Bobak (2010), ce type de supports retouchés, présents dans plusieurs sites d'Europe de l'Est (Vilshofen en Allemagne, Hranice en République Tchèque, Dzierżysław en Pologne), ne peuvent avoir une valeur chronoculturelle clairement définie.

31 Un autre faciès à armature à cran, morphologiquement différent, est présent dans les sites de La Colombière et de Munzingen (Movius et Judson 1956, Pasda 1998 et 2017). La morphologie et la position de la retouche présentent des analogies avec quelques armatures à cran de plus grande dimension du Magdalénien supérieur trouvées dans le sud-ouest de la France, dans l'abri du Morin (Pessac-sur-Dordogne, Gironde) et dans la grotte de Duruthy, à Sorde-l'Abbaye, dans les Landes (Langlais 2010).

Même si des éléments de comparaison avec les sites suisses et ceux du sud-ouest allemand manquent encore, on constate par contre, sur le versant français, une relative homogénéité des modalités de production. Cette constante s'observe à travers la production lamellaire, majoritairement mise en place en continuité de celle des lames (Malgarini et al. 2017). Cette modalité de débitage diffère de celle du Magdalénien moyen du centre et du sud-ouest de la France (Langlais et al. 2017).

Parmi les traits culturels dominants, l'ensemble des sites de l'horizon chronologique 13 200-12 $800 \mathrm{BP}$ ont en commun une forte proportion de lamelles à bord abattu :

- 65 \% de l'outillage à Monruz (Bullinger 2000) ;

- $60 \%$ à Champréveyres (Cattin 2002) ;

- $60 \%$ de l'aire 1 et $80 \%$ de l'aire 2 à La Fru (Pion 2004, Mevel 2010) ;

- $63 \%$ à Bange (Pion 2004) ;

• 62,5 \% à Moosbühl (Le Tensorer 1998) ;

- 49 \% à Teufelsküche (Pasda 1998) ;

- $46 \%$ du total des outils des couches 9A et 9B de la grotte Jean-Pierre 1 à Saint-Thibaut-deCouz, en Savoie (Bintz 1995) ;

- $78 \%$ des trois niveaux de la grotte des Romains (Béreiziat 2011);

- $60 \%$ du niveau F2d de l'abri Gay (Béreiziat 2011). 
Sur la base des variations des rapports entre les types de lamelles, à dos simple ou tronquées, plusieurs faciès se distinguent (Leesch 1993, Le Tensorer 1998, Bullinger 2000, Mevel 2010, Béreiziat 2011, Mevel et al. 2014) :

- Le premier regroupe les séries où les lamelles à dos simple forment la totalité de l'outillage lamellaire. Il concerne le niveau 9A de Saint-Thibaud-de-Couz, l'aire 1 et le niveau C4 II de La Fru;

- Le deuxième correspond aux ensembles composés de moins de $10 \%$ de lamelles tronquées. Il englobe les sites de Monruz, de Champréveyres, des Douattes et les deux gisements du Jura méridional ;

- Enfin, le troisième faciès intéresse les séries où les éléments à dos tronqué dépassent $10 \%$. Peu représenté, il concerne les sites de Moosbühl, la couche $9 b$ de Saint-Thibaud-de-Couz, Sälihöhle Oben à Soleure, en Suisse (Bullinger 2000), et éventuellement Veyrier (StahlGretsch 2006).

Si ces éléments concourent à différencier les ensembles du Magdalénien supérieur du pourtour jurassien, nous devons toutefois garder à l'esprit l'extrême fragilité de ces classifications basées sur des décomptes souvent peu fiables. Une analyse technologique tendrait à être plus pertinente, car faisant abstraction de certaines contraintes comptables. Dans cette optique, la mise en œuvre d'un procédé technique singulier tel que la fragmentation volontaire des lamelles à bord abattu, constatée aux Romains et à Monruz (Haïd et Margerand 1996, Cattin 2002, Leesch et al. 2004, Béreiziat 2011), mais aussi à Gönnersdorf, en Allemagne, et à Étiolles, dans l'Essonne, section Q31 (Bosinski 1973, Olive 2004), dont plusieurs occupations sont également contemporaines de la fin du Dryas ancien, pourrait participer à une meilleure définition chronoculturelle des ensembles lithiques. 
Fig. 7. - Lamelles à bord abattu fragmentées.

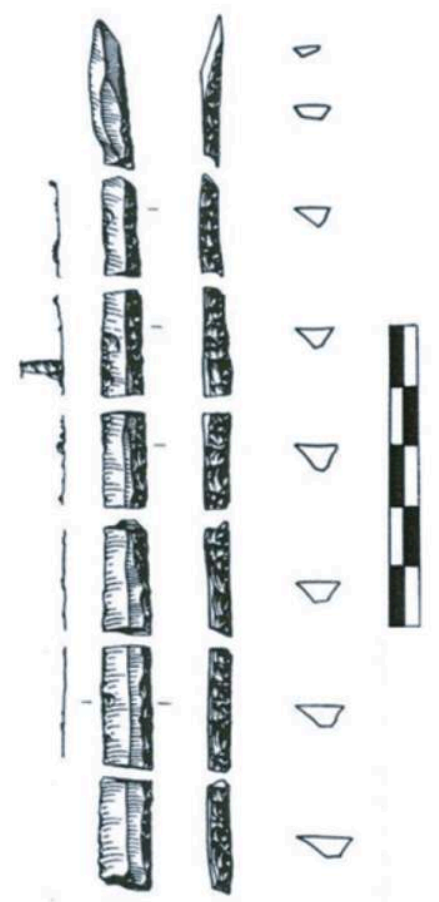

A

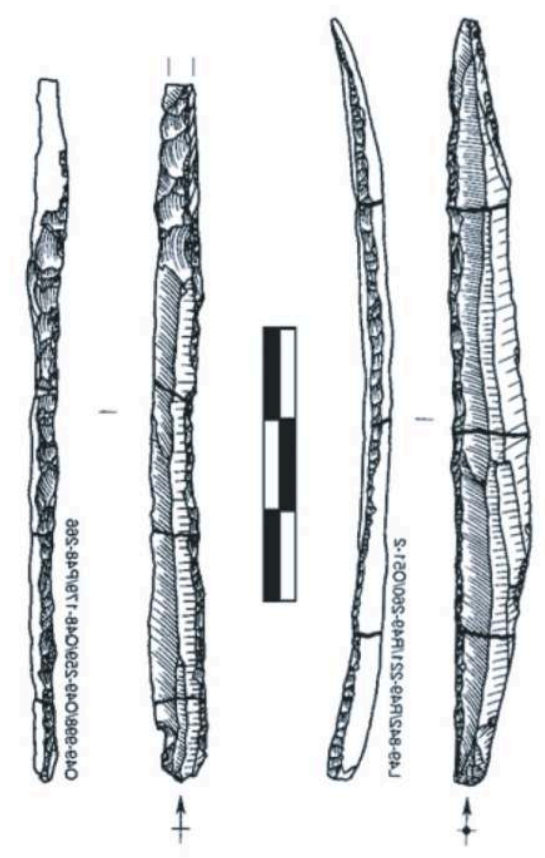

B

A : grotte des Romains (Virignin, Ain). B : grotte de Monruz (Neuchâtel, Suisse).

Extrait de Haïd et Margerand 1996 et Cattin 2002.

La phase finale du Magdalénien est marquée par une grande diversité des morphotypes de pointes lithiques (à dos anguleux, à cran, à pédoncule...) au nord de la Suisse, dans la région d'olten et de la Birse (Kohlerhöhle, Brügglihöhle, Schweizersbild à Schaffhouse) ; en Franche-Comté : abri des Cabônes à Ranchot, dans le département du Jura ; et dans le Jura méridional : site de La Grand'Baille et abri Henri-Martin (Pugieu), grotte de La Bonne-Femme (Murs-et-Gélignieux), dans l'Ain (Combier et Desbrosse 1964, David 1996, Le Tensorer 1998, Béreiziat 2011). Ces différentes pointes laissent entrevoir des influences diverses à la fin du Paléolithique supérieur. Elles sont toujours accompagnées de nombreuses lamelles à bord abattu, à retouche simple, tronquée ou bitronquée. Cette association caractérise notamment le techno-assemblage $\mathrm{E}$ de D. Leesch (1993). Ce dernier est défini par les pointes à dos anguleux, les pointes à cran ou pointes à dos courbe en pourcentage significatif à côté des lamelles à dos simples, tronquées ou bitronquées, des burins dièdres, des grattoirs sur lame et des perçoirs.

\section{Un massif montagneux au cœur des manifestations culturelles magdaléniennes}

D'une altitude moyenne de 660 mètres, le Jura n'a jamais constitué un frein à l'implantation humaine, dès qu'il fut libéré de sa gangue de glace et des masses d'eau générées par les lacs postglaciaires après le Dernier Maximum glaciaire. Des occupations d'altitude s'observent ainsi dès la fin du Dryas ancien, notamment à La Chênelaz (Hostias, Ain), dans le Jura méridional, à 900 mètres d'altitude. Cette grotte a la particularité d'avoir abrité des groupes ayant pratiqué la chasse à la marmotte 
(environ une cinquantaine d'individus exploités). Deux datations sur des ossements ont donné $12780 \pm 75 \mathrm{BP}$, soit 15 559-14 995 cal. BP ; $12610 \pm 200 \mathrm{BP}$, soit 15 573-14 132 cal. BP (Cartonnet et Naton 2000). Cette spécialisation est également reconnue dans d'autres sites d'altitude du Vercors, aux Freydières (Saint-Agnan-en-Vercors, alt. $820 \mathrm{~m}$ ) et dans les grottes Colomb et La Passagère (Méaudre, alt. $1050 \mathrm{~m}$ ). Des restes de marmotte ont notamment donné plusieurs dates comprises entre la fin du Dryas ancien et la fin du Bølling dans la grotte des Freydières (Griggo et al. 2012). Si cette espèce permettait de se fournir en fourrure et viande, elle intégrait également la sphère symbolique à travers les incisives sciées ou perforées dont nous retrouvons trace dans plusieurs sites du pourtour jurassien : Campalou, La Chênelaz, la grotte des Romains, Champréveyres, Monruz, Kesslerloch et Petersfels (Bullinger et Müller 2005). Ces éléments incorporent donc le fonds mobilier de ces populations tardiglaciaires et dessinent, par analogie, un trait identitaire singulier présent sur une large bande allant de la Drôme au nord-est de la Suisse.

Ce territoire est aussi le témoin de diffusion de manifestations culturelles plus homogènes, comme les statuettes féminines de type Lalinde-Gönnersdorf (Bosinski 1973, Otte 1992, Bosinski et al. 2001, Gaudzinski-Windheuser et Joris 2015). Davantage représentées dans une version pariétale dans le sud-ouest de la France, ces figurations se manifestent surtout sous la forme de petites statuettes entre le Massif central et la Pologne (fig. 8).

Fig. 8. - Répartition des sites abritant des statuettes féminines schématiques du type LalindeGönnersdorf du Massif central à la Pologne.

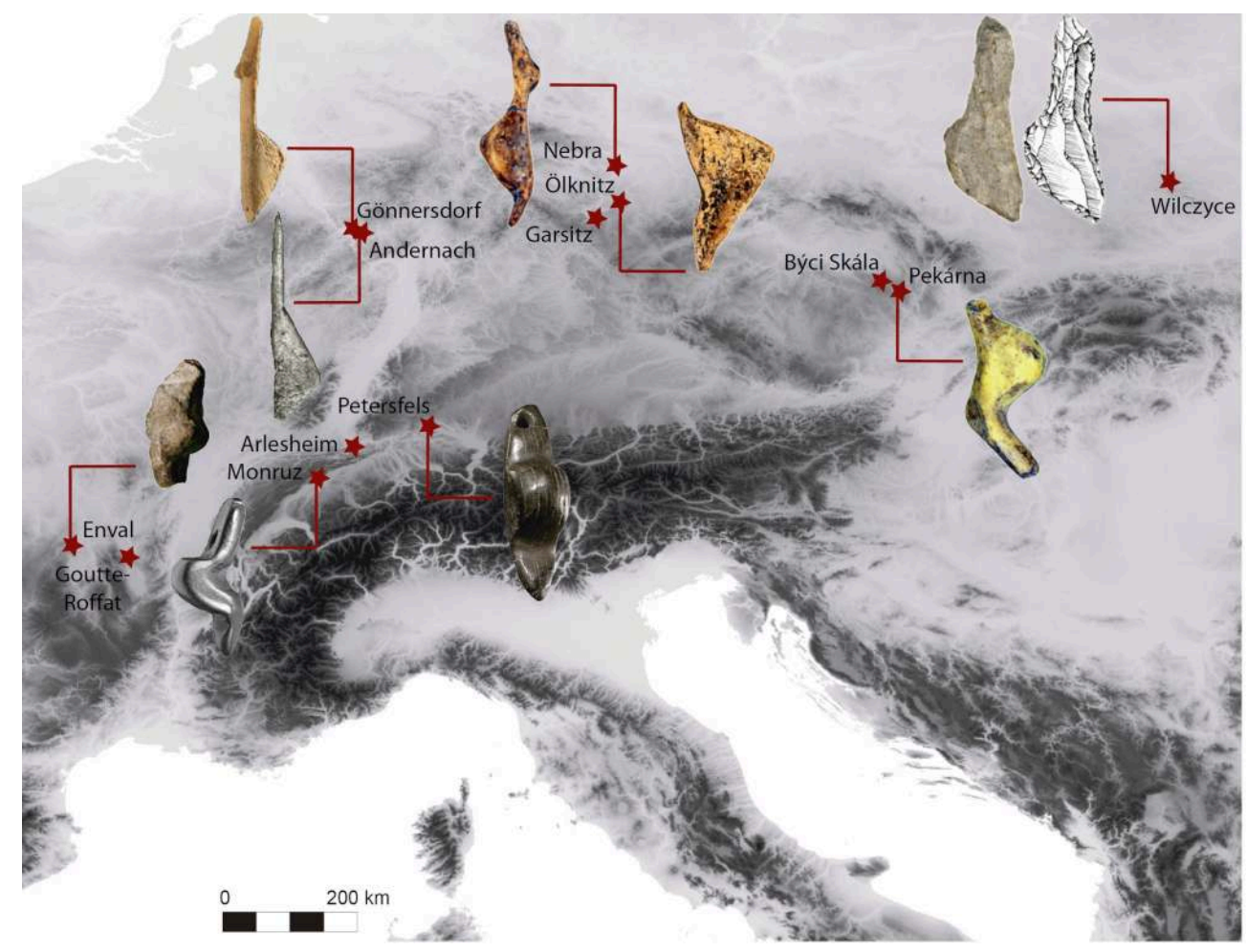

PAO Gérald Béreiziat, fond de carte IGN 2018.

Bien que les matériaux de fabrication varient (ivoire, bois de renne, lignite, silex), leurs composantes artistiques et morphologiques restent assez proches et soulignent une 
entité très cohérente. Chronologiquement, les niveaux d'occupation abritant ces objets se situent à la fin du Dryas ancien, entre 16000 et 15000 cal. BP (fig. 9).

Fig. 9. - Datations ${ }^{14} \mathrm{C}$ de plusieurs sites ayant livré des statuettes féminines schématiques du type Lalinde-Gönnersdorf entre le Massif central et la Pologne.

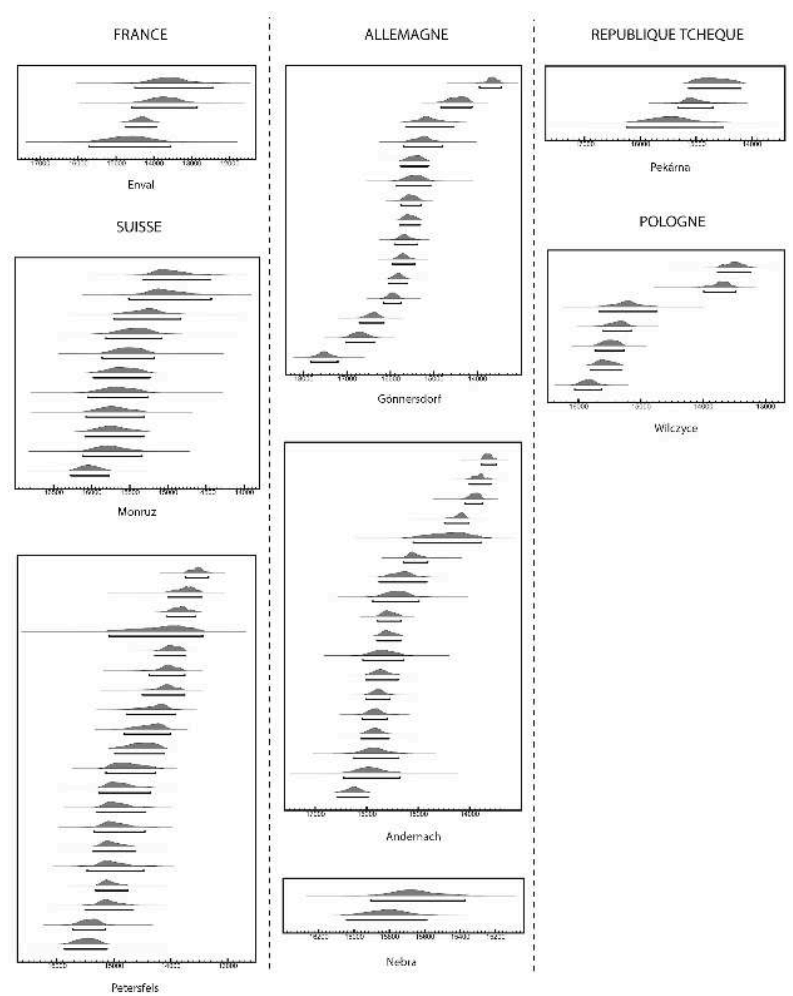

PAO Gérald Béreiziat.

\section{Conclusion et discussion}

À la croisée de divers champs d'expression de la culture magdalénienne, le pourtour jurassien a été soumis à des influences multiples, des mouvements constants contrôlés à la fois par la géomorphologie de la chaîne montagneuse mais aussi par les axes fluviatiles. L'exemple de la diffusion des coquillages marins comme éléments de parure dans les assemblages de l'arc jurassien en est une bonne illustration (fig. 10) (Alvarez Fernandes 2001 et 2009, Hussain et Floss 2014). 
Fig. 10. - Localisation des sites du pourtour jurassien ayant livré des coquillages provenant de la mer Méditerranée et du Bassin parisien, et de l'ambre originaire de la mer Baltique.

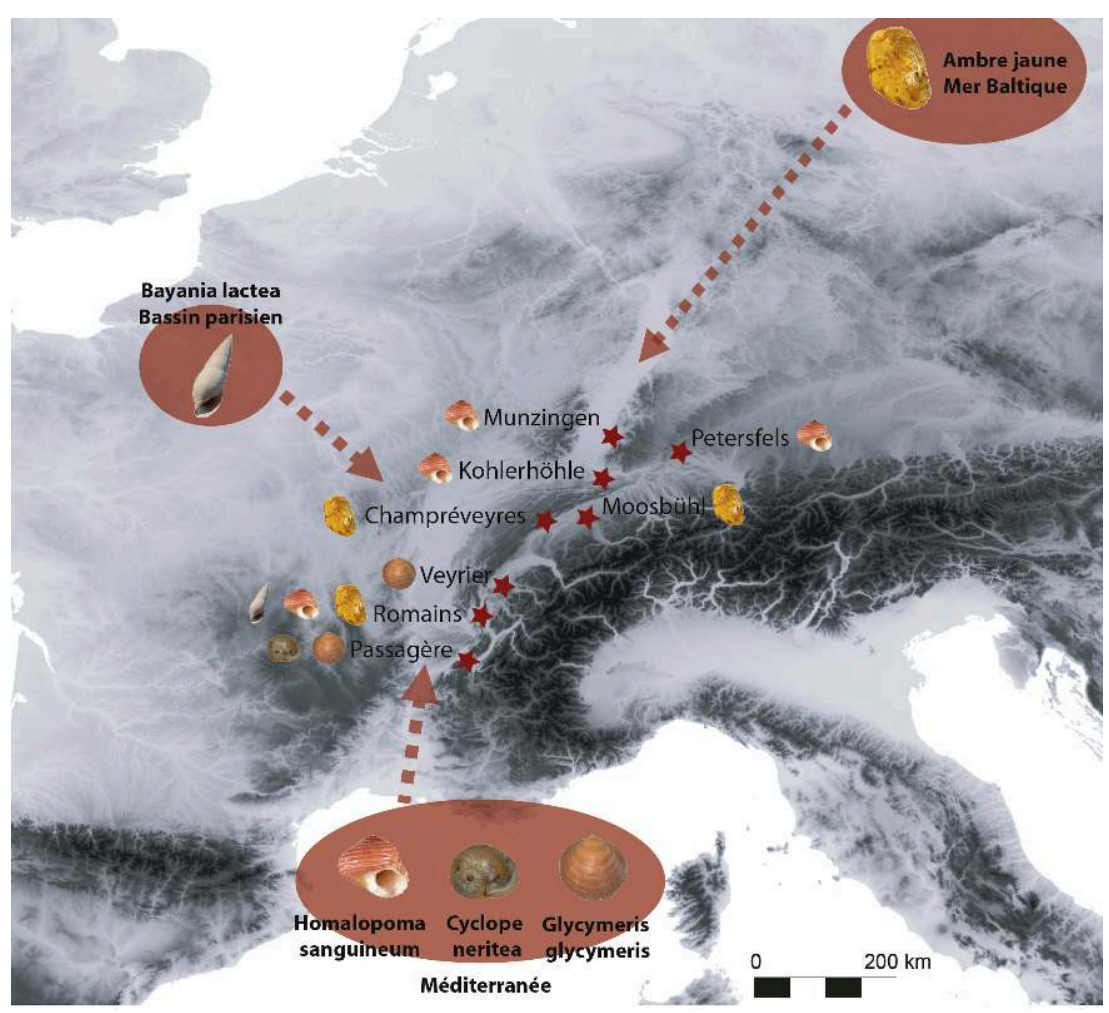

PAO Gérald Béreiziat, fond de carte IGN 2018.

Les synthèses cartographiques des approvisionnements en matières premières permettent aussi de présenter certaines stratégies et considérations spatiales en relation avec ce territoire. Des différences s'observent durant les différentes phases du Magdalénien :

- Au Magdalénien moyen, l'approvisionnement décrit souvent un apport en matières premières exogènes de très bonne qualité. Cette stratégie serait à corréler à la forte normalisation des systèmes de production, guidée par l'omniprésence du projet laminaire et la recherche de grandes lames pour alimenter l'outillage du fonds commun;

- Au Magdalénien supérieur, dans les niveaux d'occupation de la fin du Dryas ancien, les matières premières montrent une très grande variété et un vaste territoire d'approvisionnement. Alors que les systèmes de production paraissent cloisonnés durant la phase précédente, ils dénotent ici une certaine souplesse, qui dépend des intentions mais aussi de la diversité des volumes sollicités ;

- À la fin du Magdalénien, les sites proposent un schéma principal de réduction des territoires d'approvisionnement, même si la présence de matériaux allochtones décrit une permanence des contacts et/ou déplacements selon les directions déjà remarquées au cours des périodes précédentes.

Il convient toutefois de nuancer les différences inhérentes à chaque période en insistant également sur l'importance des lieux d'implantation de l'occupation et l'accessibilité des gîtes naturels. Plusieurs entités géographiques apparaissent (Béreiziat et Floss 2016) :

- l'extrémité nord-est du pourtour jurassien, le nord de la Suisse et le sud-ouest de l'Allemagne ; 
- la Franche-Comté et la Haute-Saône ;

- le versant est du Jura, en Suisse ;

- le sud de Genève ;

- le Jura méridional ;

- le nord des Alpes.

Il serait intéressant d'évaluer l'influence de ces entités sur l'équilibre ou l'éclatement des faciès culturels. Nous constatons que la sphère symbolique est celle qui retranscrit le mieux la notion de diffusion et d'unité culturelle, moins soumise à des facteurs externes, alors que les composantes industrielles lithique et osseuse décrivent une plus grande diversité et complexité. Pourtant, au sein de ces ensembles industriels souvent composites, des marqueurs technologiques tendraient à rapprocher certaines pièces de ce puzzle et à laisser entrevoir des liens, jusque-là dormants, entre certaines occupations. Nous sommes toutefois conscients que cette mosaïque reste difficile à déchiffrer, car les approches sont souvent hésitantes, contrariées par l'ancienneté de certaines fouilles et les biais dans la documentation archéostratigraphique; un contexte qu'il conviendra de mieux maîtriser par la poursuite des analyses fines des ensembles déjà existants et par un retour sur le terrain.

\section{BIBLIOGRAPHIE}

AFFOLTER J., 2003, Provenance des silex préhistoriques du Jura et des régions limitrophes, Neuchâtel, Éditions archéologie neuchâteloise (Archéologie neuchâteloise, 28).

AFFOLTER J., 2009, « Les Douattes (Musièges, Haute-Savoie) : les séries magdaléniennes et aziliennes des fouilles Jayet et Pion (1999-2002) », dans Pion G. et Mevel L. (dir.), La fin $d u$ Paléolithique supérieur dans les Alpes du nord, le Jura méridional et les régions limitrophes : approches culturelles et environnementales, Paris, Société préhistorique française (Mémoires de la Société préhistorique française, 50), p. 161-172.

ALVAREZ FERNÁNDEZ E., 2001, « L'axe Rhin-Rhône au Paléolithique supérieur récent : l'exemple des mollusques utilisés comme objets de parure ", L’Anthropologie, vol. 105, nº 4, p. 547-564.

ALVAREZ FERNÁNDEZ E., 2009, « Magdalenian personal ornaments on the move: A review of the current evidence in Central Europe », Zephyrus, t. LXII, p. 45-89.

AUBRy T., PeYRouse J.-B., WALTER B., 2003, « Les feuilles de laurier de Volgu (Saône-et-Loire) : une énigme en partie résolue? » Paleo, $\mathrm{n}^{\circ} 15$, p. 245-250.

AUDouze F., 2006, «Essai de modélisation du cycle annuel de nomadisation des Magdaléniens du Bassin parisien », dans Olive M. et Valentin B. (dir.), Variabilité des habitats tardiglaciaires dans le Bassin parisien et ses alentours : quelles significations? Actes de la table ronde-séance de la Société préhistorique française, Paris, 2005, Paris, Société préhistorique française (Bulletin de la Société préhistorique française, vol. 103, $\mathrm{n}^{\circ}$ 4), p. 683-694. 
BÉREIZIAT G., 2011, « Variabilité des comportements techniques du Dryas ancien à la fin du Bølling : analyse technoéconomique comparée du matériel lithique de cinq gisements tardiglaciaires du Jura méridional », thèse de doctorat, université Bordeaux I.

BÉREIZIAT G., 2012, « Raw material exploitation strategies from oldest Dryas to the end of Bølling in the Southern French Jura: Indicators for a differential behaviour? », Anthropologie, International Journal of the Science of Man, vol. L/4, $\mathrm{n}^{\circ}$ 2, p. 443-461.

BÉREIZIAT G., 2013, «Quoi de neuf à l'Est ? Une séquence tardiglaciaire du Jura méridional revisitée : l'abri Gay à Poncin (Ain) », L'Anthropologie, vol. 117, nº 1, p. 94-119.

BÉREIZIAT G. et FLOSS H., 2016, « De longs fleuves tranquilles ? Le rôle du couloir Rhin-Saône-Rhône dans la dynamique de peuplement à la fin du Paléolithique supérieur sur le pourtour jurassien », dans Robert S. et Sittler B. (dir.), Water as a morphogen in landscapes/L'eau comme morphogène dans les paysages, $17^{e}$ Congrès mondial de l'UISPP (Burgos, 2014), vol. 4, Session A14, p. 15-30.

BEYRIES S., JANNY F., AUDOUZE F., 2005, « Débitage, matière première et utilisations des becs sur le site de Verberie "Le Buisson Campin" (Oise), dans le nord de la France », dans Auxiette G. et Malrain F. (dir.), Hommages à Claudine Pommepuy, Amiens, Société archéologique de Picardie (Revue archéologique de Picardie, numéro spécial 22), p. 15-25.

BINTZ P. (dir.), 1995, « Les grottes Jean-Pierre 1 et 2 à Saint-Thibaud-de-Couz (Savoie) : paléoenvironnement et cultures du Tardiglaciaire à l'Holocène dans les Alpes du nord. $2^{\mathrm{e}}$ partie : La culture matérielle », Gallia préhistoire, vol. 37, p. 155-328.

BODU P. et RENARD C., 2013, « "L'ancien” Solutréen du Bassin parisien : quelques observations récentes ", dans Bodu P., Chehmana L., Klaric L., Mevel L., Soriano S., Teyssandier N. (dir.), Le Paléolithique supérieur ancien de l'Europe du nord-ouest : réflexions et synthèses à partir d'un projet collectif de recherche sur le centre et le sud du Bassin parisien. Actes du colloque de Sens (2009), Paris, Société préhistorique française (Mémoires de la Société préhistorique française, 56), p. 117-141. BOSINSKI G., 1973, « Le site magdalénien de Gönnersdorf (commune de Neuwied, vallée du Rhin moyen, RFA) », Bulletin de la Société préhistorique de l'Ariège, vol. 28, p. 25-48.

BOSINSKI G., D’ERRICO F., SCHILLER P., 2001, Die Gravierten Frauendarstellungen von Gönnersdorf, Stuttgart, Franz Steiner Verlag.

BOURGEOIS D., 1995, « Déterminations pétrographiques des industries lithiques de la grotte Grappin à Arlay (Jura) », mémoire de DESS en méthodes scientifiques et techniques en archéologie, université de Bourgogne.

BRESSY C., 2003, Caractérisation et gestion du silex des sites mésolithiques et néolithiques du nord-ouest de l'arc alpin : une approche pétrographique et géochimique, Oxford, Archaeopress (BAR International Series, 1114).

BRESSY C. et FLOSS H., 2006, « Multiparametric characterization of Southwestern Germany cherts: application to the study of circulations during the Upper Paleolithic period », dans Bressy C., Burke A., Chalard P., Martin H. (dir.), Notions de territoire et de mobilité : exemples de l'Europe et des premières nations en Amérique du Nord avant le contact européen. Actes du congrès de l'European Association of Archaeologists, 2004, Liège, Presses universitaires de Liège (ERAUL, 116), p. 131-136.

BULLINGER J., 2000, «L'industrie lithique du site magdalénien de Monruz (Neuchâtel, Suisse) et les ensembles contemporains de l'arc jurassien ", dans Pion G. et Mevel L. (dir.), La fin du Paléolithique supérieur dans les Alpes du nord, le Jura méridional et les régions limitrophes : approches culturelles et environnementales, Paris, Société préhistorique française (Mémoires de la Société préhistorique française, 50), p. 177-184. 
BULLINGER J. et MÜLLER W., 2005, « Nouvelles découvertes d'incisives de marmotte sciées dans des sites magdaléniens de l'arc jurassien », dans Dujardin V. (dir.), Industrie osseuse et parures du Solutréen au Magdalénien en Europe, Paris, Société préhistorique française (Mémoires de la Société préhistorique française, 39), p. 347-351.

BURKERT W., 1998, « Lithische Rohmaterialversorgung im Jungpaläolithikum des südöstlichen Baden-Württemberg ", thèse, Tübingen, Universität Tübingen.

BURKERT W. et FLOSS H., 2005, « Lithic exploitation areas in the Upper Paleolithic of West and Southwest Germany: a comparative study », dans Körlin G. et Weisgerber G. (dir.), Stone age mining age: Proceedings of the VIIIth Flint Symposium, Bochum, 1999, Bergbau, Freunde von Kunst und Kultur im Bergbau (Der Anschnitt, supplément 19), p. 35-49.

CARTONNET M. et NATON H.-G., 2000, « Le Magdalénien de la grotte de La Chênelaz à Hostias (Ain) », dans Pion G. (dir.), Le Paléolithique supérieur récent : nouvelles données sur le peuplement et l'environnement. Actes de la table ronde de Chambéry, 12-13 mars 1999, Paris, Société préhistorique française (Mémoires de la Société préhistorique française), p. 235-243.

CATTIN M.-I., 2002, Hauterive-Champréveyres, un campement magdalénien au bord du lac de Neuchâtel : exploitation du silex (secteur 1), Neuchâtel, Éditions archéologie neuchâteloise (Archéologie neuchâteloise, 28).

COMBIER J. et DESBROSSE R., 1964, « Magdalénien final à pointe de Teyjat dans le Jura méridional », L'Anthropologie, vol. 68, n 1-2, p. 190-194.

COMBIER J. et MONTET-WHITE A., 2002, Solutré 1968-1998, Paris, Société préhistorique française (Mémoires de la Société préhistorique française, 30).

CUPILLARD C., 1998, « Matières premières siliceuses et territoires d'approvisionnement ", dans Cupillard C. et Richard A. (dir.), Les derniers chasseurs-cueilleurs du massif jurassien et de ses marges (13 000-5 500 avant Jésus-Christ) : catalogue d'exposition, Lons-Le-Saunier, Centre jurassien du patrimoine, p. 153-156.

CUPILLARD C. et WELTÉ A.-C., 2006, « Le Magdalénien de la grotte Grappin à Arlay (Jura, France) : nouveaux regards ", L'Anthropologie, vol. 110, nº 4, p. 624-683.

CUPILLARD C., AFFOLTER J., BOURGEOIS D., 1995, Lithothèque franc-comtoise ou inventaire des ressources siliceuses de Franche-Comté : projet collectif de recherche, rapport, Besançon, Service régional de l'archéologie de Franche-Comté.

CUPILLARD C., MALGARINI R., FORNAGE S., 2013, « Le Paléolithique supérieur ancien dans le quart nord-est de la France : l'exemple de la Franche-Comté. Environnement, chronologie et faciès culturels ", dans Bodu P., Chehmana L., Klaric L., Mevel L., Soriano S., Teyssandier N. (dir.), Le Paléolithique supérieur ancien de l'Europe du nord-ouest (35000-15000 BP) : réflexions et synthèses à partir d'un projet collectif de recherche sur le Paléolithique supérieur ancien du Bassin parisien, Paris, Société préhistorique française (Mémoires de la Société préhistorique française, 56), p. 351-363.

CUPILlARD C., MAGNy M., BOCHERENS H., BRIDAUlt A., BÉGEOT C., BICHET V., BOSSUET G., DRUCKER D. G., GAUTHIER É., JOUANNIC G. MILLET L., RICHARD H., RIUS D., RUFFALDI P., WALTER-SIMONNET A.-V., 2014, "Changes in ecosystems, climate and societies in the Jura Mountains between 40 and $8 \mathrm{ka}$ cal BP », Quaternary International, vol. 378, p. 40-72.

DAVID S., 1996, « La fin du Paléolithique supérieur en Franche-Comté », Gallia préhistoire, vol. 38, p. 111-248. 
DAVID S., PIGEAUd R., ROBERT E., PETROGNANi S., D’ERRICO F., BÉREIZIAT G., CAILHOL D., GRIGGO C., JAILLET S., JEANNET M., PAITIER H., 2014, « Un site inédit à l'interface de territoires symboliques du Paléolithique supérieur ancien : la grotte des Gorges, Jura », dans Otte M. et Le Brun-Ricalens F. (dir.), Modes de déplacements et de contacts dans le Paléolithique eurasiatique : actes du colloque international de la commission 8 (Paléolithique supérieur) de l'UISPP, Université de Liège, 28-31 mai 2012, Liège, Université de Liège (ERAUL, 140) / Luxembourg, Musée national d'histoire et d'art (ArchéoLogiques, 5), p. 537-567.

DJINDJIAN F., 1995, «L'influence des frontières naturelles dans les déplacements des chasseurscueilleurs au Würm récent », Prehistoria alpina, vol. 28, nº 2, p. 7-28.

DJINDJIAN F., 1999, « J.-M. Le Tensorer, Le Paléolithique en Suisse : compte rendu », Bulletin de la Société préhistorique française, vol. $96, \mathrm{n}^{\circ} 1, \mathrm{p} .79$.

DJINDJIAN F., 2016, « L'importance des cours d'eau dans l'orientation, les déplacements et les colonisations des groupes de chasseurs-cueilleurs du Paléolithique supérieur européen », dans Robert S. et Sittler B. (dir.), Water as a morphogen in landscapes / L'eau comme morphogène dans les paysages : $17^{e}$ Congrès mondial de l'UISPP (Burgos, 2014), vol. 4, Session A14, p. 1-14.

DRUCKER D. G., BRIDAULT A., CUPILLARD C., 2012, « Environmental context of the Magdalenian settlement in the Jura Mountains using stable isotope tracking (13C, 15N, 34S) of bone collagen from reindeer (Rangifer tarandus) », Quaternary International, vol. 272-273, p. 322-332.

FÉBLOT-AUGUSTINS J., 2002, « Exploitation des matières premières et mobilité dans le Bugey : un aperçu diachronique du Magdalénien moyen au Néolithique », dans Bailly M., Furestier R., Perrin T. (dir.), Les industries lithiques taillées holocènes du bassin Rhodanien : problèmes et actualités, Montagnac, Monique Mergoil (Préhistoires), p. 13-27.

FÉBLOT-AUGUSTINS J., 2005, Survey of flint types from Bugey, France, en ligne : http:// www.flintsource.net/flint/infF_bugey.html

FÉBLOT-AUGUSTINS J., 2009, « Les ressources siliceuses du Bugey : caractérisation pétrographique des matières premières ", dans Voruz J.-L. (dir.), La grotte du Gardon (Ain), vol. 1 : Le site et la séquence néolithique des couches 60 à 47, Toulouse, Archives d'écologie préhistorique, p. 167-200.

FLoss H., 1994, Rohmaterialversorgung im Paläolithikum des Mittelrheingebietes, Bonn, RömischGermanisches Zentralmuseum.

FLoss H., 2000, « Le couloir Rhin-Saône-Rhône, axe de communication au Tardiglaciaire ", dans Thévenin A. (dir.), Les derniers chasseurs-cueilleurs d'Europe occidentale (13 000-5 500 av. J.-C.), actes du colloque de Besançon, 23-25 octobre 1998, Besançon, Presses universitaires franc-comtoises (Annales littéraires), p. 313-321.

FLOSS H., 2014, « Rivers as orientation axes for migrations, raw material transport and exchange in the upper Palaeolithic of Central Europe ", dans Yamada M. et Ono A. (dir.), Lithic raw material exploitation and circulation in prehistory: A comparative perspective in diverse palaeoenvironments, actes du colloque de Tokyo, Meiji University, 27-28 octobre 2012, Université de Liège (ERAUL, 138), p. 11-22.

FLOSS H., LINGNAU M., NAPIERALA H., PASIANOTTO N., WISSING C., 2005, « Prospections systématiques aux alentours des sites paléolithiques de Rizerolles à Azé », dans Groupement archéologique du Mâconnais (dir.), 1954-2004, Résultats des dernières recherches archéologiques en Mâconnais, Mâcon, GAM, p. 16-21.

FLOSS H., DUTKIEWICZ E., FRICK J., HOYER C., 2013, « Le Paléolithique supérieur ancien en Bourgogne du sud », dans dans Bodu P., Chehmana L., Klaric L., Mevel L., Soriano S., Teyssandier N. (dir.), Le Paléolithique supérieur ancien de l'Europe du nord-ouest : réflexions et synthèses à partir d'un projet 
collectif de recherche sur le centre et le sud du Bassin parisien, actes du colloque de Sens (2009), Paris, Société préhistorique française (Mémoires de la Société préhistorique française, 56), p. 331-350.

FLOSS H., HOYER C. T., HECKEL C. E., TARTAR É., 2015, « L'Aurignacien en Bourgogne méridionale », dans White R. et Bourrillon R. (dir.), Aurignacian Genius : art, technologie et société des premiers hommes modernes en Europe, actes du symposium international, 8-10 avril 2013, New York University, Toulouse, Presses universitaires du Midi (P@lethnologie, 7), p. 167-190.

FORNAGE-BONTEMPS S., 2011, « La grotte de La Balme (Cuiseaux, Saône-et-Loire, France) : une industrie à becs du Gravettien moyen ", dans Goutas N., Klaric K., Pesesse D., Guillermin P. (dir.), À la recherche des identités gravettiennes : actualités, questionnements et perspectives, actes de la table ronde d'Aix-en-Provence, 2008, Paris, Société préhistorique française (Mémoires de la Société préhistorique française, 52), p. 99-109.

GAUDZINSKI-WINDHEUSER S. et JÖRIS O., 2015, « Contextualising the female image: symbols for common ideas and communal identity in Upper Palaeolithic societies », dans Coward F., Hosfield R., Pope M., Wenban-Smith F. (dir.), Settlement, society and cognition in human evolution: Landscapes in mind, Cambridge, Cambridge University Press, p. 288-314.

GINTER B. et POLTOWICZ-BOBAK M., 2010, « Magdalenian with triangles in Central Europe », dans Połtowicz-Boba M. et Bobak D. (dir.), The Magdalenian in Central Europe: New Finds and Concepts, Rzeszow, Fundacja Rzeszowskiego Ośrodka Archeologicznego, p. 23-34.

GRIGGO C., GAY I., MONIN G., 2012, « Populations de marmotte, fluctuations climatiques et activités cynégétiques au Tardiglaciaire dans le Vercors ", dans $8^{\text {es }}$ Rencontres du patrimoine naturel en Rhône-Alpes, octobre 2010, Grenoble, Muséum d'histoire naturelle de Grenoble, p. 110-119. GRÜNWALD C. et AFFOLTER J., 1995, « Les ressources en matière première siliceuse dans le Vercors », dans Épipaléolithique et Mésolithique en Europe, livret-guide de l'excursion Préhistoire et Quaternaire en Vercors, $5^{\mathrm{e}}$ Congrès international de l'UISPP, $12^{\mathrm{e}}$ commission, p. 41-43. HAID N. et MARGERAND I., 1996, « Les lamelles à bord abattu magdaléniennes de la grotte des Romains à Pierre-Châtel (Virignin, Ain, France) ", L'Anthropologie, vol. 100, nº 1, p. 42-54. HEDGes R. E. M., BRONK C. R., VAN KLINKEN G. J., PETTITT P. B., NIELSEN-MARSH C., ETCHEGOYen A., FERNANDEZ NIELLO J. O., BOSCHIN M. T., LLAMAZARES A. M., 1998, « Methodological issues in the radiocarbon dating of rock paintings ", Radiocarbon, vol. 40, p. 35-44.

HUSSAIN S. T. et FLOSS H., 2014, "The role of river courses in organizing the cultural space of the Upper Paleolithic: examples from the Rhine, Rhône, Danube and Garonne », dans Otte M. (dir.), Modes de contact et déplacements au Paléolithique eurasiatique : colloque UISPP, Liège 2012, Liège, université de Liège, p. 307-320.

JACOTTEY L. et MILLEVILLE A., 2009, Gestion des matières premières et implantation humaine autour du massif de la Serre (39), rapport final 2007-2009 du projet collectif de recherche, Service régional de l'archéologie de Franche-Comté, inédit.

LANGLAIS M., 2010, Les sociétés magdaléniennes de l'isthme pyrénéen, Paris, Éditions du CTHS (Documents préhistoriques, 26).

LANGLAIS M., PÉTILLON J.-M., SECHER A., 2017, « Les débuts du Magdalénien moyen dans le sud-ouest français : témoignages croisés des équipements lithiques et osseux », dans Bourdier C., Chehmana L., Malgarini R., Połtowics-Bobak M. (dir.), L'essor du Magdalénien : aspects culturels, symboliques et techniques des faciès à navettes et à Lussac-Angles. Actes de la séance de la Société préhistorique française (Besançon, 17-19 octobre 2013), Paris, Société préhistorique française, p. 209-234. 
LE TENSORER J.-M., 1998, Le Paléolithique en Suisse, Grenoble, Jérôme Million.

LEESCH D., 1993, « Le Paléolithique supérieur récent », dans Le Tensorer J.-M. et Niffeler U. (dir.), Paléolithique et Mésolithique (La Suisse du Paléolithique à l'aube du Moyen Âge, vol. SPM I), Bâle, Archéologie suisse, p. 153-164.

LEESCH D., 1997, Hauterive-Champréveyres, 10 : Un campement magdalénien au bord du lac de Neuchâtel. Cadre chronologique et culturel, mobilier et structures, analyse spatiale (secteur 1), Neuchâtel, Archéologie neuchâteloise (Archéologie neuchâteloise, 28).

LEESCH D., 2014, « Suisse 1983/2013 : chronologie, habitat et territoire », dans Noiret P. et Leesch D. (dir.), Le Paléolithique supérieur d'Eurasie : bilan 2014. Actes du Congrès UISPP, commission VIII, Liège, université de Liège (ERAUL, 142), p. 93-135.

LEESCH D. et MÜLLER W., 2012, « Neue Radiokarbondaten an Knochen, Zähnen und Geweih aus einigen Magdalénien-Fundstellen der Schweiz und ihre Bedeutung für die Stellung des Magdalénien innerhalb des Spätglazials ", Jahrbuch Archäologie Schweiz, n 95, p. 117-126. LEESCH D., CATTIN M.-I., MÜLLER W. (dir.), 2004, Hauterive-Champréveyres et Neuchâtel-Monruz : témoins d'implantations magdaléniennes et aziliennes sur la rive nord du lac de Neuchâtel, Neuchâtel, Archéologie neuchâteloise (Archéologie neuchâteloise, 31).

LEESCH D., MÜLLER W., NIELSEN E., BULLINGER J., 2012, « The Magdalenian in Switzerland: Recolonization of a newly accessible landscape », Quaternary International, vol. 30, p. 1-18.

MALGARINI R., 2014, « Les gisements magdaléniens dans le Jura et les Alpes du nord et leurs industries osseuses ", thèse de doctorat, Besançon, université de Franche-Comté.

MALGARINI R., MEVEL L., BÉREIZIAT G., BODU P., DEBOUt G., CUPILlARD C., CARQUIGNY N., 2017, « Les faciès du Magdalénien moyen dans l'est de la France : confrontation et discussion des industries osseuses et lithiques ", dans Bourdier C., Chehmana L., Malgarini R., Połtowics-Bobak M. (dir.), L'essor du Magdalénien : aspects culturels, symboliques et techniques des faciès à navettes et à LussacAngles. Actes de la séance de la Société préhistorique française, Besançon, 17-19 octobre 2013, Paris, Société préhistorique française, p. 139-156.

MEVEL L., 2010, « Des sociétés en mouvement : nouvelles données sur l'évolution des comportements techno-économiques des sociétés magdaléniennes et aziliennes des Alpes du nord françaises (14 000-11 000 BP) », thèse de doctorat, université Paris -Nanterre, 655 p.

MEVEL L., BÉREIZIAT G., MALGARINI R., 2014, « Les sociétés magdaléniennes des Alpes du nord françaises et du Jura méridional (15 000-12 000 BP) : perspectives culturelles », dans Jaubert J., Fourment N., Depaepe P. (dir.), Transitions, ruptures et continuités en Préhistoire : actes du $27^{e}$ congrès préhistorique de France, Bordeaux-Les Eyzies, 31 mai-5 juin 2010, vol 2 : Paléolithique et Mésolithique, Paris, Société préhistorique française, p. 463-485.

MOVIUS H. L. et JUDSON S., 1956, The Rockshelter of La Colombière, Cambridge, Harvard University, Peabody Museum (American School of Prehistoric Research Bulletin, 19).

OLIVE M., 2004, « À propos du gisement magdalénien d'Étiolles (Essonne) : réflexion sur la fonction d'un site paléolithique ", Bulletin de la Société préhistorique française, vol. 10, n 4, p. 249-258.

OTTE M., 1992, « Processus de diffusion à long terme au Magdalénien », dans J.-P. Rigaud, H. Laville, B. Vandermeersch (dir.), Le peuplement magdalénien : paléogéographie physique et humaine. Actes du colloque de Chancelade, octobre 1988, Paris, Éditions du CTHS (Documents préhistoriques, 2), p. 399-416. 
PASDA C., 1998, Wildbeuter im archäologischen Kontext: das Paläolithikum in Südbaden, Taschenbuch, Folio-Vlg (Archäologie im Südwesten, 2).

PASDA C., 2017, « Munzingen: a Magdalenian site in the Southern Upper Rhine plain (Germany) », dans Bourdier C., Chehmana L., Malgarini R., Połtowics-Bobak M. (dir.), L'essor du Magdalénien : aspects culturels, symboliques et techniques des faciès à navettes et à Lussac-Angles. Actes de la séance de la Société préhistorique française, Besançon, 17-19 octobre 2013, Paris, Société préhistorique française, p. 157-174.

PINçon G., 1988, « Sagaie de Lussac-Angles », dans Camps-Fabrer H. (dir.), Fiches typologiques de l'industrie osseuse préhistorique, cahier 1 : Sagaies, Aix-en-Provence, université de Provence, 1988.

PION G., 2004, « Magdalénien, Épipaléolithique et Mésolithique ancien dans les deux Savoie et le Jura méridional », thèse de doctorat, Besançon, université de Franche-Comté.

RUÉ M., 2001, Caractérisation des matériaux siliceux en Saône-et-Loire : constitution d'une lithothèque. Rapport de prospection, thématique 200, Dijon, Service régional de l'archéologie de Bourgogne/ Groupe de recherche archéologique de Tournus.

SCHMIDER B., 1988, «Les industries du centre du Bassin parisien au Paléolithique récent : essai de chronologie ", dans Otte M., De la Loire à l'Oder : les civilisations du Paléolithique final dans le nordouest européen, actes du colloque de Liège, décembre 1985, Oxford, Archaeopress (BAR International Series), p. 1-11.

STAHL-GRETSCH L.-I., 2006, Les occupations magdaléniennes de Veyrier : histoire et préhistoire des abrissous-blocs, Paris, Éditions du CTHS (Documents préhistoriques, 20) / Lausanne, Cahiers d'archéologie romande (Cahiers d'archéologie romande, 105).

TERBERGER T., Floss H., HEINZELMANN P., KOtUla A, SERANGELI J., 2013, « Down the river Rhine ca. 16,000 years ago: New evidence from the site Dreieich-Götzenhain, Hesse », dans Pastoors A. et Auffermann B. (dir.), Pleistocene foragers: Their culture and environment, Mettmann, Wissenschaftliche Schriften des Neanderthal Museums, p. 101-115.

\section{RÉSUMÉS}

De par sa situation géographique, sa topographie et les axes naturels qui l'encadrent, le massif jurassien occupe une position clé dans l'aire d'expression de la culture magdalénienne. Plusieurs dynamiques de peuplement s'observent en diachronie et en synchronie, montrant que ce territoire se trouvait, à la fin du Paléolithique supérieur, au carrefour de plusieurs expressions, et formait un réseau social fortement entrecroisé du Jura méridional au lac de Constance. Cet article souhaite documenter cette réalité sous le prisme de l'approvisionnement en matières premières lithiques et des orientations techniques, par une présentation de certaines composantes industrielles lithiques et osseuses, ainsi qu'à travers quelques tendances de l'art mobilier et des objets de parure. Ces différentes approches mettent ainsi en lumière des situations contrastées à partir des traits culturels des populations venues occuper cet espace.

Due to its geographic location, topography and shaping by a natural axis, the Jura massif holds a key position within the zone of expression of the Magdalenian culture. Several settlement dynamics have been observed, showing that at the end of the upper Paleolithic, this territory was situated at the crossroads of numerous characteristics and shaped a close-meshed social network between the Southern Jura and the Lake of Constance. This article documents these complex conditions from a diachronic and a synchronic perspective, considering the procurement of raw material, the technical orientations of the lithic and bone industries, and finally some tendencies 
concerning the portable art and body ornaments. These different approaches thus illuminate a deep dichotomy between aspects of unity and signs of diversity in the cultural patterns of the populations in this region.

INDEX

Mots-clés : approvisionnement, art mobilier, Tardiglaciaire, datation, industrie lithique, industrie osseuse, matière première, paléogéographie, parure

Keywords : body ornament, bone industry, dating, lithic industry, paleogeography, portable art, provision supply, raw material

Index géographique : Arc jurassien

\section{AUTEUR}

\section{GÉRALD BÉREIZIAT}

Collaborateur du laboratoire De la préhistoire à l'actuel : culture, environnement et anthropologie (PACEA, UMR 5199, université de Bordeaux/CNRS) 


\section{Le Néolithique dans les Pyrénées} nord-occidentales : circulation et complémentarité entre le piémont et la moyenne montagne

The Neolithic of the northwestern Pyrenees: circulation and complementarity between foothills and mid-mountain

Patrice Dumontier

Nous remercions vivement Geneviève Marsan pour ses informations et pour nous avoir permis d'examiner le mobilier provenant de ses fouilles; Karim Gernigon pour avoir examiné le vase de Sasiziloaga et nous avoir conseillé ; Claude Blanc, Serge Cassen, Pablo Marticorena et Pierre Pétrequin pour avoir donné leur accord à la reproduction de figures qu'ils avaient publiées; ainsi que la rédaction du CTHS et les deux rapporteurs pour leurs commentaires, qui ont permis d'améliorer cet article.

1 Les Pyrénées nord-occidentales ont été jusqu'ici peu présentes dans les études régionales sur le Néolithique. S’il est vrai que les données restent peu nombreuses, nous sommes loin du désert archéologique que l'on pouvait imaginer à partir de la cartographie réalisée il n'y a pas si longtemps par S. Cassen (1993a et 1993b).

2 La présente contribution a donc pour objectif de présenter les découvertes archéologiques de ce vaste secteur. À partir de l'évocation des données paléoenvironnementales, on s'interrogera sur les rythmes d'anthropisation des espaces de montagne, sur l'expansion agropastorale des différents étages altitudinaux, ainsi que sur les formes de complémentarité et les schémas d'occupation (mobilité/sédentarité) que la documentation recueillie permet d'envisager entre les différents espaces. La culture matérielle sera abordée à partir de données récentes et, pour certaines, inédites.

3 La présentation des sites n'est pas exhaustive, elle est centrée sur la documentation provenant du département des Pyrénées-Atlantiques, complétée par des sites des 
Hautes-Pyrénées, de l'Aragon et de la Navarre. Nous n'avons pas retenu les sites pour lesquels nous n'avons pas de données chronologiques. La documentation du nord-ouest de l'Espagne a surtout été exploitée pour le Néolithique ancien; les données sont plus rares pour les périodes suivantes, et les éléments de la culture matérielle, notamment la céramique, sont très différents de ce qui est observé sur le versant nord.

4 Après les premières analyses polliniques réalisées par G. Jalut (Jalut et al. 1988) et Bui Thi Maï (Blanc et Bui Thi Maï 2003) en vallée d'Ossau, ce sont les études palynologiques des tourbières réparties sur de nombreux secteurs des Pyrénées, réalisées par D. Galop et son équipe, qui illustrent le mieux l'anthropisation progressive de la montagne et du piémont au Néolithique (Galop 2006, Galop et al. 2007, Rius et al. 2009).

5 Ces données permettent d'aborder les rythmes d'anthropisation, donnant un éclairage large, complété par les fouilles archéologiques qui nous renseignent plus directement sur les Hommes concernés, les traits culturels qui les caractérisent et qui les relient aux différentes cultures encadrant les Pyrénées occidentales.

6 Quels sont les sites archéologiques connus à ce jour qui documentent cette grande période?

\section{Les premières implantations du Néolithique ancien : entre $5800 / 5300$ et 4500 avant notre ère}

7 Les plus anciens pollens de céréales sont enregistrés dans les analyses polliniques de la tourbière du Gabarn, à Ogeu (Pyrénées-Atlantiques), en basse vallée d'Ossau, à 300 mètres d'altitude. La présence d'activités agropastorales y est enregistrée vers 5750, puis vers 5400 avant notre ère (Galop 2006). Ces résultats confirment l'implantation d'agriculteurs/pasteurs sur le piémont, en basse vallée d'Ossau, au début de la deuxième moitié, voire dans la première moitié du vi millénaire avant notre ère (fig. 1). 
Fig. 1. - Localisation des sites du Néolithique ancien des Pyrénées nord-occidentales.

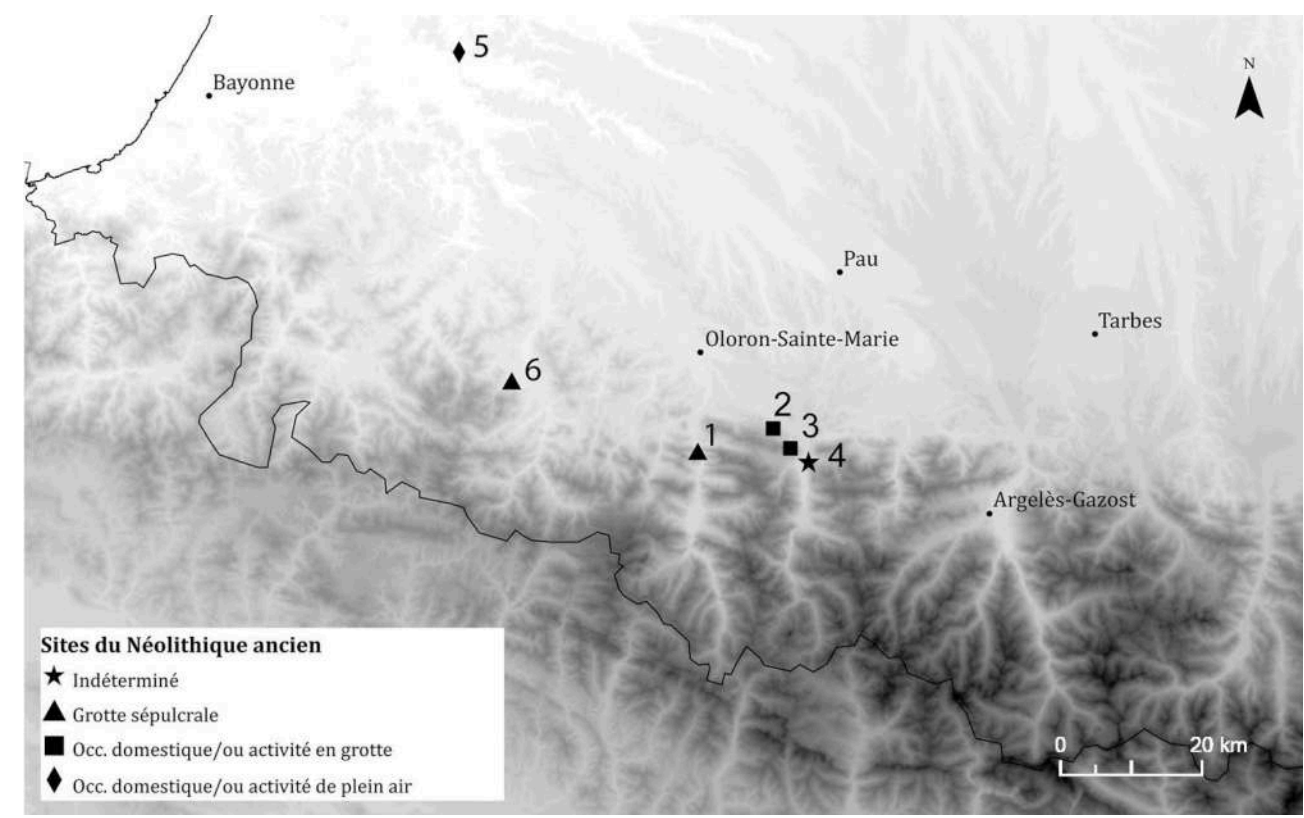

1 : Apons (Sarrance, Pyrénées-Atlantiques). 2 : Malarode 1 (Arudy, Pyrénées-Atlantiques). 3 : Poeymaü (Arudy, Pyrénées-Atlantiques). 4 : Espalungue (Arudy, Pyrénées-Atlantiques). $\mathbf{5}$ : Lamothe (Labatut, Landes). 6 : Haispea (Aussurucq, Pyrénées-Atlantiques).

Données Patrice Dumontier, cartographie Benoît Pace et Mélanie Le Couédic.

$\mathrm{Au}$ débouché de la vallée d'Ossau, à Arudy (Pyrénées-Atlantiques), nos connaissances reposent sur des occupations en grottes (Poeymaü, Malarode 1 et Espalungue) installées sous les porches ou à proximité des entrées. Dans la grotte du Poeymaü (couche alsh), ces occupations sont caractérisées par la présence de 5 structures de combustion (foyers), certaines à pierres chauffées. Les restes de consommation sont représentés par un véritable tas de coquilles d'escargots qui s'élevait entre deux foyers et des restes de faune (non publiés). La datation de la couche alsh (tabl. 1) réalisée sur charbons de bois couvre le $\mathrm{VI}^{\mathrm{e}}$ millénaire avant notre ère, malheureusement avec un écart type très important (Livache et al. 1984). Le mobilier lithique ne se distingue pas nettement de celui des chasseurs-cueilleurs sauveterriens des niveaux archéologiques sous-jacents. La céramique est représentée par quelques tessons de céramique inornée, non décrits par les auteurs, et que nous n'avons pas retrouvés dans les collections déposées au Musée national de préhistoire. Des réserves ont été formulées sur la lecture difficile des niveaux du Mésolithique final et du Néolithique ancien de ce site par G. Marchand (1999 et 2000) et par J. Roussot-Larroque (2001), mais cela ne remet pas en cause la présence de foyers datés du Néolithique ancien. 
Tabl. 1. - Datations radiométriques évoquées dans l'article.

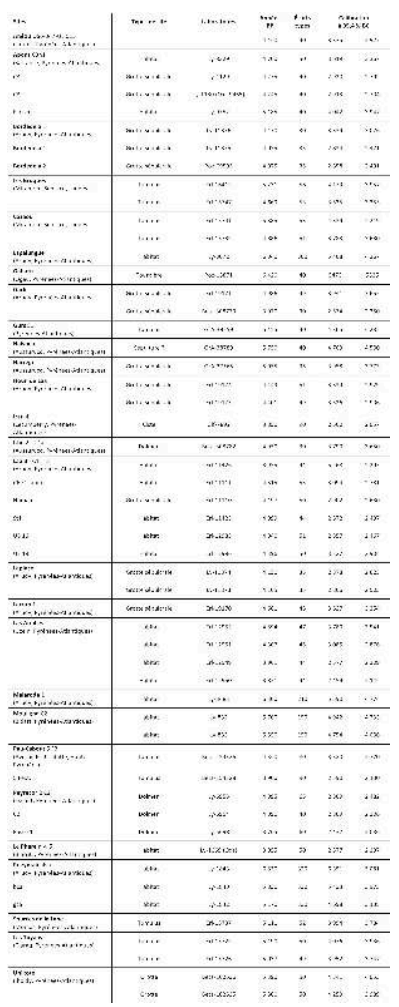

9 Deux autres sites ont montré des occupations de cette période à Arudy. La grotte de Malarode 1, fouillée par G. Marsan et inédite, a livré, dans la couche 4 inférieure, des tessons inornés, notamment dans une lentille sédimentaire (carré $4 \mathrm{E}$ ) qui n'a pas encore été datée. Ces tessons sont comparables à une poterie mise au jour dans la grotte d'Apons, en vallée d'Aspe (Sarrance, Pyrénées-Atlantiques). La couche 4 inférieure de Malarode est par endroits lessivée et a livré d'autres tessons du type d'Apons, mélangés à d'autres fragments plus récents de céramique. Ces données sont difficilement exploitables, mais une datation réalisée sur charbons place entre 5600 et 4700 avant notre ère une occupation de cette cavité.

10 Enfin, la grotte d'Espalungue (Arudy) a livré, dans un petit diverticule, une dent humaine datée entre 5445 et 4420 avant notre ère, sans structure ou mobilier associé (Marsan 1987 : p. 8).

11 En vallée d'Aspe, à 15 kilomètres d'Arudy, dans la grotte d'Apons (Dumontier et al. 2016a), le niveau C3n1b a livré les restes d'une occupation domestique. L'industrie lithique, comportant un segment du Bétey, est répartie en majorité près d'une structure de pierres interprétée comme l'entourage d'un foyer, qui se trouve à l'aplomb du porche actuel. La céramique est représentée par un seul vase brisé, de forme sphérique, au fond épais et légèrement conique. Nous n'avons pas pu réaliser de datation radiométrique fiable.

12 À Apons, les données environnementales esquissent pour ce niveau un paysage partiellement anthropisé où ne subsistent que des pins et de rares feuillus, avec la présence de plantes témoins du piétinement du sol par le bétail (Dumontier et al. 2016a : p. 117).

13 Trois de ces sites, et notamment Apons et Poeymaü, évoquent des occupations de faible intensité, de type campement sous abri, avec des fréquentations éventuellement 
répétitives (Poeymaü) dans le cadre de déplacements qui pourraient être associés ou non au pastoralisme. En l'absence de datation pour la grotte d'Apons, et à partir du mobilier, ces occupations s'inscrivent dans la deuxième moitié $\mathrm{du} \mathrm{vI}^{\mathrm{e}}$ millénaire avant notre ère.

Si plusieurs indices démontrent la mise en place progressive d'une économie de production, quels sont les porteurs de ces nouvelles pratiques (élevage, agriculture, céramique, hache polie) et quel chemin ont-ils emprunté pour parvenir dans les Pyrénées nord-occidentales?

Toute tentative pour répondre à cette question repose sur l'analyse des datations des sites les plus anciens et du mobilier archéologique disponible. Devant la faiblesse de la documentation et le fait que les fouilles du Poeymaü et de Malarode n'ont pas encore fait l'objet d'une publication complète, la phase la plus ancienne connue à ce jour est documentée par la grotte d'Apons (fig. 2).

Fig. 2. - Mobilier céramique du Néolithique ancien des Pyrénées-Atlantiques.
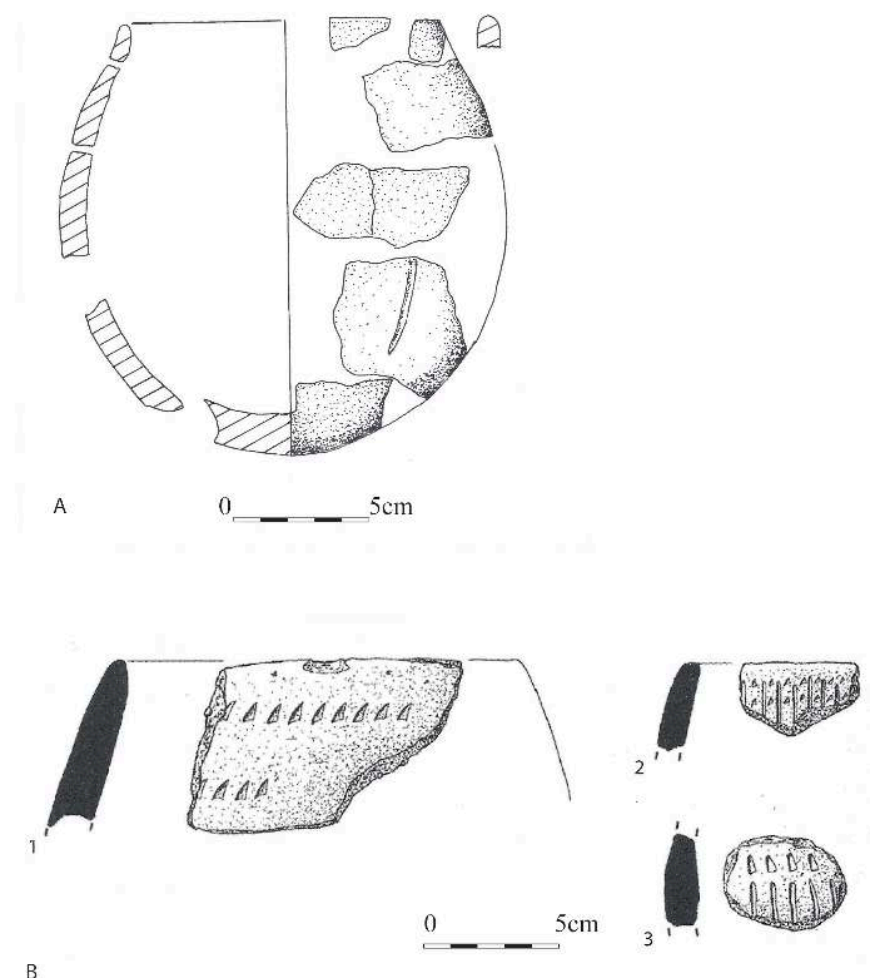

A : grotte d'Apons (Sarrance, Pyrénées-Atlantiques). B : site de plein air de Lamothe (Labatut, Landes).

A : dessin Patrice Dumontier. B : extrait de Cassen et Cassen 1989.

16 Pour ce site, l'analyse pétrographique de la pâte de la céramique réalisée par F. Convertini et la morphologie de ce vase évoquent un Néolithique ancien. Les techniques utilisées, notamment les inclusions de calcite pilée, rappellent les traditions de groupes culturels orientaux proches des mondes méditerranéens et méridionaux (ibériques).

17 Sur le versant sud des Pyrénées, en Aragon et en Navarre, plusieurs sites datés entre 5800 et 5300 avant notre ère témoignent de la présence de céramique inornée attribuée à la phase ancienne du Néolithique, associée à des segments du Bétey ou pièces à double 
biseau. Nous nous intéresserons ici à l'abri d'Aizpea, en Navarre, avec un niveau daté dans la seconde moitié du vi millénaire avant notre ère (Barandiarán et Cava 2001 : p. 543), mais aussi à la grotte de Chaves, en Aragon (Bastarás, Huesca, Espagne), où le niveau 1 (également nommé 1a) a livré des céramiques correspondant au Cardial récent, montées avec des argiles contenant des inclusions de calcite (Gallart Martí et López Aguayo 1988, Ramón Fernández 2006 : p. 294). Dans ce niveau, de même que dans le précédent, où les dégraissants sont majoritairement constitués de grains de quartz, la céramique ornée du Cardial côtoie des vases inornés avec des fonds épais, souvent coniques, proches du vase d'Apons.

En Aragon, selon V.Baldellou, le Néolithique initial serait représenté par des établissements colonisateurs, avec des groupes porteurs de la céramique cardiale, parfaitement néolithisés, autant techniquement qu'économiquement. "La grotte de Chaves, modèle certain d'un établissement colonisateur " (Baldellou et Utrilla 1999: p. 228), aurait un rôle déterminant dans le processus de néolithisation des territoires prépyrénéens de Huesca. Autour de Chaves, la phase d'acculturation paraît se produire pendant la phase pionnière.

Pour la façade atlantique, l'hypothèse d'une diffusion par le sud, le long des affluents de l'Èbre, a déjà été évoquée (Roussot-Laroque 2001, Marchand et Manen 2006 : p. 229). Les cols pyrénéens ne constituant pas une barrière infranchissable, une relation entre Apons et l'Aragon par la vallée d'Aspe est tout à fait envisageable. Les données techniques et morphologiques concernant la céramique de la grotte de Chaves et de la grotte d'Apons, ainsi qu'une exploitation possible pour le montage du vase d'Apons des argiles du secteur de Droundak, à la Pierre Saint-Martin, c'est-à-dire sur l'un des points de passage entre les deux versants des Pyrénées, sont des indices qui viennent renforcer cette proposition.

Les sites étudiés en haut Béarn (Poeymaü, Malarode et Espalungue en vallée d'Ossau, et la grotte d'Apons en vallée d'Aspe) témoignent d'une fréquentation des vallées d'Aspe et d'Ossau dans la deuxième moitié $d u v^{e}$ millénaire avant notre ère. Les données environnementales montrent qu'il ne s'agit pas de simples intrusions, mais qu'un début d'agriculture est enregistré dans le piémont, sur le Gabarn, et que la fréquentation du défilé d'Escot par des troupeaux est perceptible en vallée d'Aspe, à Apons. Qu'en est-il de l'occupation en moyenne et en haute montagne? Nous manquons de données pour le moment, mais si les premières diffusions de l'économie agropastorale ont pour origine le sud de la chaîne, comme nous l'avons évoqué pour les grottes de Chaves et d'Apons, nous sommes déjà devant un espace montagnard parcouru entre les deux versants.

21 Par la suite, au début $d u v^{e}$ millénaire avant notre ère, trois sites montrent une présence répartie en moyenne montagne et dans la vallée de l'Adour: Haispea (Aussurucq, Pyrénées-Atlantiques), Lamothe (Labatut, Landes) et Mouligna (Bidart, Pyrénées-Atlantiques).

Un squelette a été découvert par les spéléologues de la Société spéléologique et préhistorique des Pyrénées occidentales dans la grotte d'Haispea (alt. $800 \mathrm{~m}$ ). La datation réalisée sur os place ces vestiges entre 4703 et 4500 avant notre ère, sans que les conditions de découverte et d'étude aient été développées dans la publication de cette datation (Ebrard 2013 : p. 155). Nous ne savons donc pas s'il s'agit d'une sépulture ou d'un défunt laissé dans la cavité. 
Les données fournies par les analyses polliniques montrent une augmentation de la pression anthropique sur la moyenne et haute montagne et son piémont entre $4200 / 4000$ et 3700/3600 avant notre ère. Cette pression n'est pas particulière aux Pyrénées mais concerne l'ensemble des milieux montagnards européens. L'essor de l'élevage est à l'origine de cette phase de conquête (Galop 2006). Comment se traduit cette pression à partir des sites archéologiques connus et étudiés (fig. 3) ?

Fig. 3. - Localisation des principaux sites du Néolithique moyen et récent des Pyrénées nordoccidentales.

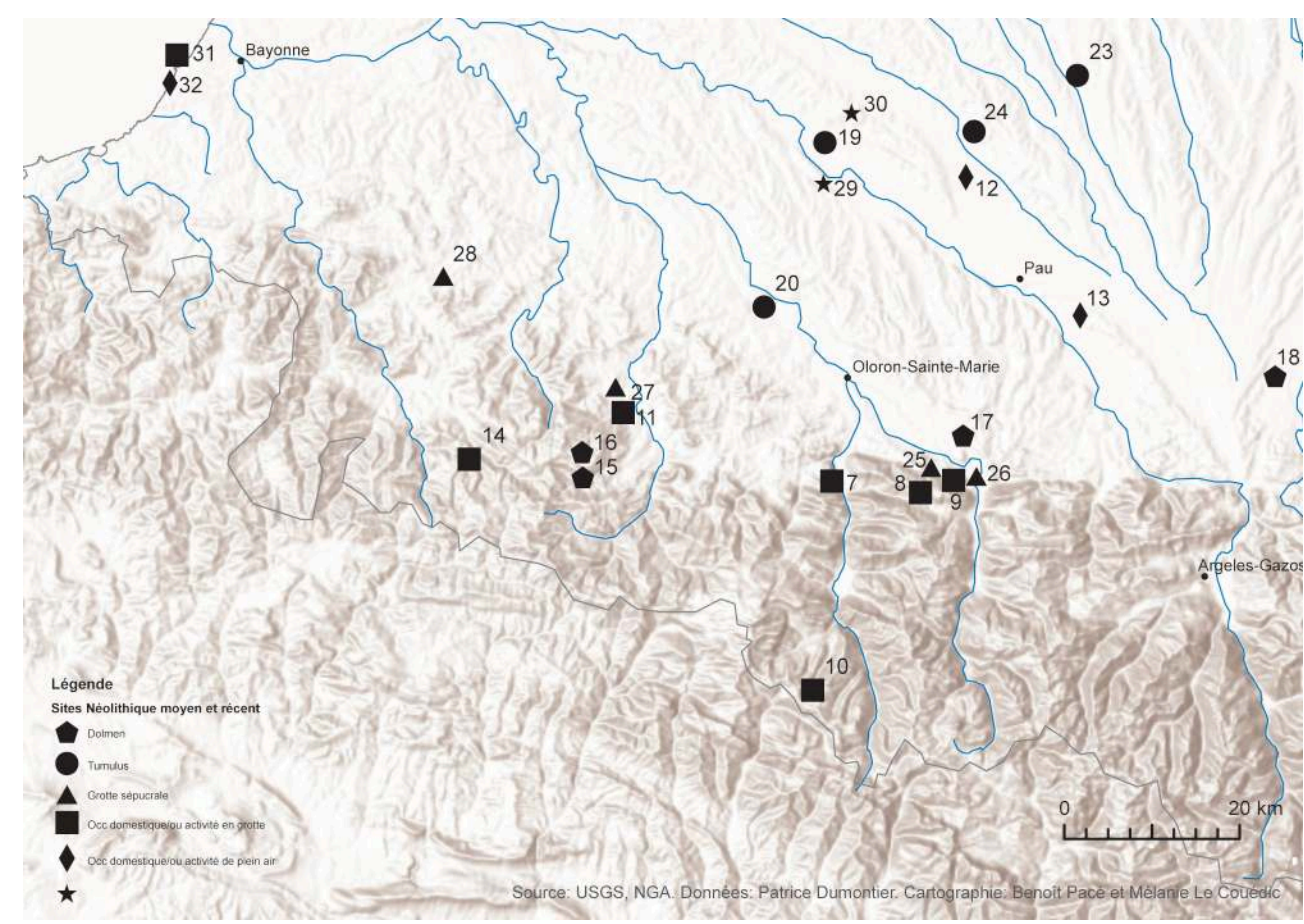

7 : Apons (Sarrance). 8 : Malarode 1 (Arudy). 9 : Poeymaü (Arudy). 10 : Caillau (Accous). 11 : Sasiziloaga (Aussurucq). 12 : Las Areilles (Uzein). 13 : Colline 312 (Assat). 14 : Mikelauen-Zilo (Lecumberry). 15 et 16 : Ithé 1 et Ithé 2 (Aussurucq). 17 : Téberne (Buzy). 18 : Marque-Dessus (Azereix, Hautes-Pyrénées). 19 : tumulus T1 (Mont). 20 : tumulus (Gurs). 21 : tumulus Les Bruques (Miramont-Sensacq). 22 tumulus Cazaou de Luc (Miramont-Sensacq). $\mathbf{2 3}$ : tumulus chemin des Tuyaas (Claracq). $\mathbf{2 4}$ : tumulus source de la Lane (Momas). 25 : Garli (Arudy). 26 : Larrun 1 (Arudy). $\mathbf{2 7}$ : Harregi (Aussurucq). 28 Unikote (Iholdy). 29 : Lagor. $\mathbf{3 0}$ : Arthez de Béarn. $\mathbf{3 1}$ : Le Phare (Biarritz). $\mathbf{3 2}$ : Mouligna (Bidart). Les sites se trouvent dans le département des Pyrénées-Atlantiques, sauf les nos 21 et 22 (Landes).

Données Patrice Dumontier, cartographie Benoît Pace et Mélanie Le Couédic. 


\section{L'habitat}

26 comme cela a pu être étudié, par exemple, dans la région de Bergerac (Fouéré 2011 : p. 365). Dans les Pyrénées nord-occidentales, les habitats étudiés correspondent tous, à ce jour, à des occupations en grottes ou sous abri naturel et à des structures de combustion qui, en l'état actuel de la recherche, évoquent des campements sur le plateau du Pont Long (fig. 3).

27 La grotte du Poeymaü contient trois niveaux d'occupation, bca, gca et asln, attribués au Néolithique moyen à partir de datations radiométriques, avec malheureusement un écart type très important. Nous évoquerons plus particulièrement le niveau bca, qui contenait des foyers appareillés, des tessons de poterie, une industrie lithique très pauvre, des restes osseux et des escargots (Cepaea Nemoralis) nombreux (Livache et al. 1984). La céramique provenant de ce niveau, que nous avons examinée au Musée national de préhistoire, nous a semblé intrusive, avec des éléments appartenant à l'âge du Fer. Nous n'avons pas pu dégager de ce lot des morphologies appartenant au Néolithique moyen. La présence de dépôts lenticulaires au fond de la cavité pour cette couche, évoquée par les auteurs, pourrait expliquer ce mélange.

L'économie pastorale est documentée dans la grotte d'Apons, en vallée d'Aspe, par des restes de petit bœuf, qui se trouvaient sur un foyer à pierres chauffées daté entre 4042 et 3947 avant notre ère (Dumontier et al. 2016a) et dans la grotte de Mikelauen-Zilo, à Lecumberry (Pyrénées-Atlantiques - alt. $450 \mathrm{~m}$ ), en basse Navarre, par un niveau de litière qui atteste une activité de bergerie autour de 3800 avant notre ère (tabl.1) (Galop 2006 : p. 281).

En Soule, dans la grotte de Sasiziloaga (Aussurucq, Pyrénées-Atlantiques), la présence d'une occupation est matérialisée par un vase qui a été trouvé cassé à l'intérieur de la cavité, à côté d'un petit lac assez éloigné de l'entrée. Ce vase est inédit. Il s'agit d'un récipient de forme ovoïde, au profil fermé, à col non différencié. L'ouverture, dans le prolongement de la panse, se termine par un petit rebord ourlé. Deux anses en oreilles percées sont placées sur le tiers supérieur de la panse (fig. 4). 
Fig. 4. - Mobilier du Néolithique moyen et récent des principaux sites des Pyrénées nordoccidentales.

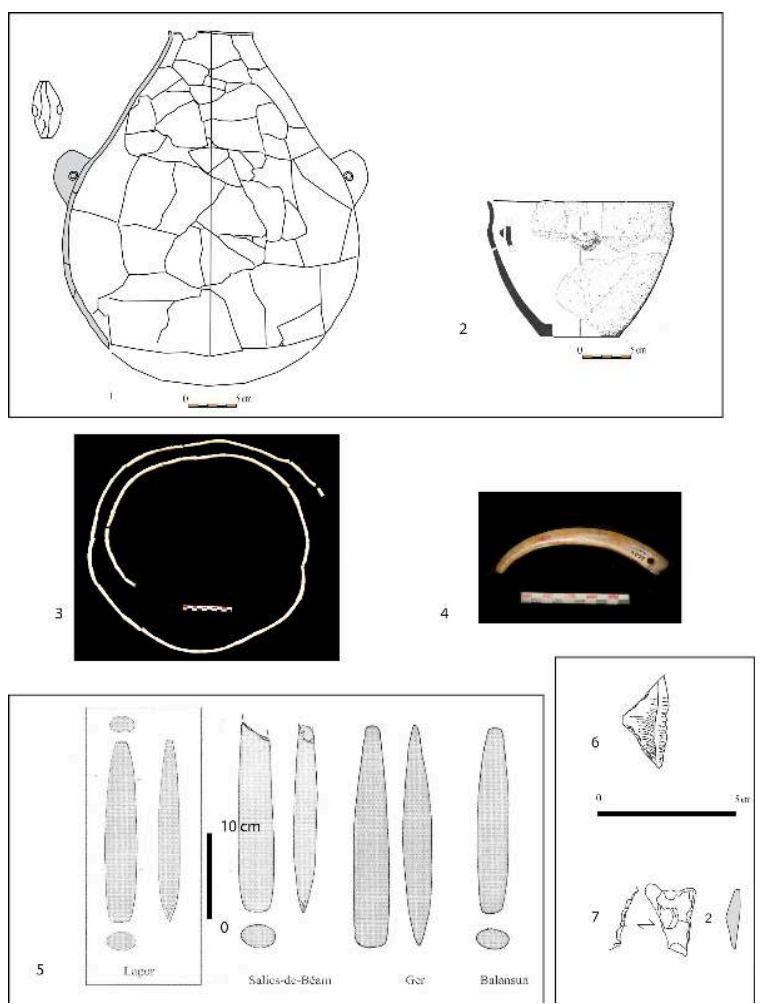

1 : Sasiziloaga (Aussurucq), bouteille. 2 : grotte du Phare (Biarritz), vase provenant du niveau 6. 3 ET 4 grotte de Garli (Arudy), pendeloque sur défense de sanglier et parure en dentales. $\mathbf{5}$ : Sites de Lagor, Salies-de-Béarn, Ger et Balansun, grandes lames de haches polies. 6 : Bious-Oumette (Laruns), armature de flèche à tranchant transversal et retouche abrupte des bords. $\mathbf{7}$ : abri du Caillaü (Accous), armature de flèche à tranchant transversal et retouche abrupte directe du bord droit et inverse du bord gauche. Tous les sites se trouvent dans le département des Pyrénées-Atlantiques.

1 et 2 : dessins Patrice Dumontier ; 3,4 et 7 : photos Patrice Dumontier ; 5 : extrait de Pétrequin et al. $2007 ; 6$ : extrait de Blanc 1994.

Sur la plage de Mouligna, à Bidart, dans un niveau de tourbière contenant des vestiges lithiques, deux datations (tabl.1) témoignent d'occupations au Néolithique moyen (Chauchat 1974 : p. 140).

Dans le piémont, des structures domestiques constituées par des foyers à pierres chauffées, présentes notamment sur le plateau du Pont Long, sur le site de Las Arreilles (Uzein, Pyrénées-Atlantiques - Elizagoyen et al. 2012), témoignent d'occupations répétitives sans structures bâties reconnues. Ces structures légères sur le plateau du Pont Long et dans les grottes et abris pourraient traduire une relative mobilité découlant d'activités privilégiées telles que l'élevage, par exemple.

$\mathrm{Au}$ niveau cartographique, nous avons retenu les grandes haches ciseau (fig. 4.5) découvertes fortuitement à Lagor, Arthez de Béarn, Salies de Béarn, Ger et Balansun et qui, bien que n'étant pas en roche alpine, appartiennent très probablement au Néolithique moyen (Pétrequin et al. 2007). Enfin, malgré l'absence de datations radiométriques et de céramiques, on notera la présence d'armatures de flèche à tranchant transversal dans les cercles de pierres de Bious-Oumette (Gabas, PyrénéesAtlantiques), à 1310 mètres d'altitude (Blanc 1994) et de Bious-Artigue, à 1400 mètres d'altitude (Laplace 1953), ainsi que dans un niveau remanié de l'abri-sous-roche det 
Caillaü (Accous, Pyrénées-Atlantiques) (fig. 4.6), à 1450 mètres d'altitude (Dumontier $2006:$ p. 12).

\section{Rituels funéraires et espaces cultuels associés}

33 Au Néolithique moyen et dans la région, trois types de sites sont associés aux mondes des morts et aux cultes associés : les dolmens, les tumulus et les dépôts des corps dans des grottes naturelles (fig. 3).

\section{Dolmens}

34 Cette période voit dans les Pyrénées occidentales l'apparition de la construction des dolmens d'Ithé 1 et 2 (alt. 702 et $696 \mathrm{~m}$ ), à Aussurucq, dans le massif des Arbailles. La première phase d'utilisation du dolmen d'Ithé 2 est datée entre 3790 et 3650 avant notre ère (tabl. 1) (Ebrard 2013). En basse vallée d'Ossau, le dolmen de Buzy (PyrénéesAtlantiques), fouillé à la fin du xix siècle, pourrait, par son architecture, appartenir à cette période. Il en est de même pour plusieurs dolmens basques et du plateau de Ger, pour lesquels nous n'avons pas d'éléments de datation. On évoquera notamment le dolmen à couloir de Marque-Dessus (Azereix, Hautes-Pyrénées) (Pothier 1892), qui, par son architecture, évoque le Néolithique moyen. Les travaux engagés dans le cadre d'un projet collectif de recherche (PCR Structures dolméniques et territoires dans les Pyrénées nord-occidentales), dirigé par P. Marticorena, devrait apporter de nouvelles données prochainement sur ce point.

Tumulus sans structure mégalithique

On voit également apparaître les premiers tumulus « simples » dans le piémont et sur le plateau du Pont Long. Pour ceux qui ont fait l'objet d'une fouille complète, ces tertres recouvrent des structures fossoyées (fosses, fossés circulaires avec palissade, structure de galets). Pour le Néolithique moyen, ces tertres sont documentés par les tumulus de Mont (Pyrénées-Atlantiques) (Marsan 1985), de Gurs (Préchacq, Pyrénées-Atlantiques) (Ebrard 2013), et par ceux fouillés par J.-F. Chopin sur le chantier de l'A65 : Les Bruques et Cazaou de Luc (Miramont-Sensacq, Landes), Chemin des Tuyaas (Claraq, PyrénéesAtlantiques) et Sources de la Lane (Momas, Pyrénées-Atlantiques) (Marticorena 2014 : p. 37). Ces tumulus sont généralement considérés comme recouvrant des éléments de structures sépulcrales. Cependant les sépultures sont difficiles à mettre en évidence ici, car dans cette région les sols ne conservent pas les vestiges osseux en dehors de ceux provenant d'une crémation. Pour nous, cependant, cela ne remet pas en cause le parallèle qui peut être fait avec les monuments présents dans des secteurs où les sols sont plus propices à la conservation des vestiges osseux, ce qui n'exclut pas l'existence de pratiques cultuelles, comme nous l'aborderons pour le Néolithique final avec le tumulus de Pau-Cabout 5. Nous attendons avec impatience la publication des tumulus fouillés sur le tracé de l'autoroute A65, qui devrait apporter des éléments de réflexion sur ce point.

\section{Grottes sépulcrales}

37 En vallée d'Ossau, quatre défunts avaient été déposés dans la petite grotte de Garli, à Arudy (alt. $454 \mathrm{~m}$ ). Le mobilier associé était constitué d'une ou plusieurs parures de dentales (87 éléments) et d'une pendeloque réalisée sur une lame détachée d'une 
canine de sanglier (fig.4). Une datation réalisée sur os (tabl.1) place l'une de ces sépultures au Néolithique moyen (Dumontier et al. 2014). Une autre datation, également réalisée sur os dans des conditions imprécises, daterait un autre de ces individus du Néolithique final (Ebrard 2013: p. 155). Toujours à Arudy, la grotte sépulcrale de Larrun 1, également nommée grotte du Turon d'Espalungue, contenait les restes de deux enfants. Une datation réalisée sur os place l'une de ces sépultures entre 3627 et 3354 avant notre ère (tabl. 1), au Néolithique récent (Dumontier et al. 2014).

Dans le massif des Arbailles, la grotte Harregi, à Aussurucq (alt. $211 \mathrm{~m}$ ), présentait de nombreux vestiges humains, appartenant à huit individus, dans un niveau remanié. Ce dépôt funéraire a été attribué au Néolithique moyen par D. Ebrard à partir d'une seule datation réalisée sur os (Ebrard 2013: p.149). Une hache polie et une céramique accompagnaient ces dépôts.

39 À Iholdy (Pyrénées-Atlantiques), dans la grotte d'Unikoté, des restes partiels de deux individus, une femme adulte et un enfant d'environ 10 ans, ont été mis au jour. Ils ont été datés du dernier tiers du v $v^{\mathrm{e}}$ millénaire avant notre ère. Les vestiges osseux ont été extrêmement perturbés, ce qui rend impossible la reconstitution du mode de dépôt. Ces vestiges présentent des traces de découpe et de raclage. Plusieurs hypothèses ont été envisagées par les auteurs: une pratique du cannibalisme ou une pratique funéraire sans cannibalisme, mais avec découpe du cadavre, ou encore un traitement plus spécifique de la tête : préparation d'un trophée ou d'une relique (Boulestin et al. 2013).

Au-delà du nombre de sites, nous remarquerons que la culture matérielle est très faiblement représentée. L'industrie lithique est indigente, de même que la céramique. On notera que le seul vase presque complet trouvé dans la grotte de Sasaziloaga (Aussurucq, Pyrénées-Atlantiques), si son attribution au Néolithique moyen semble très probable (comm. pers. K. Gernigon), n'appartient pas à la culture chasséenne.

41 Enfin, au Néolithique récent, le niveau 6 de la grotte du Phare, à Biarritz (fouilles Marembert-Dumontier) a livré un petit vase tronconique très proche de formes appartenant à un environnement Matignons (fig. 4). Cette couche est en attente de datation radiométrique.

\section{Le Néolithique final et le Chalcolithique (entre 3400/3200 et 2200 avant notre ère)}

À partir de 3300 avant notre ère, l'affirmation des activités humaines est attestée à la fois par les données polliniques et par les paléo-incendies. L'espace montagnard est désormais totalement anthropisé (Galop 2006). Les données archéologiques sont ici plus nombreuses et concernent aussi bien l'habitat que les sépultures (fig. 5) ${ }^{1}$. 
Fig. 5. - Répartition des principaux sites du Néolithique final des Pyrénées nord-occidentales.

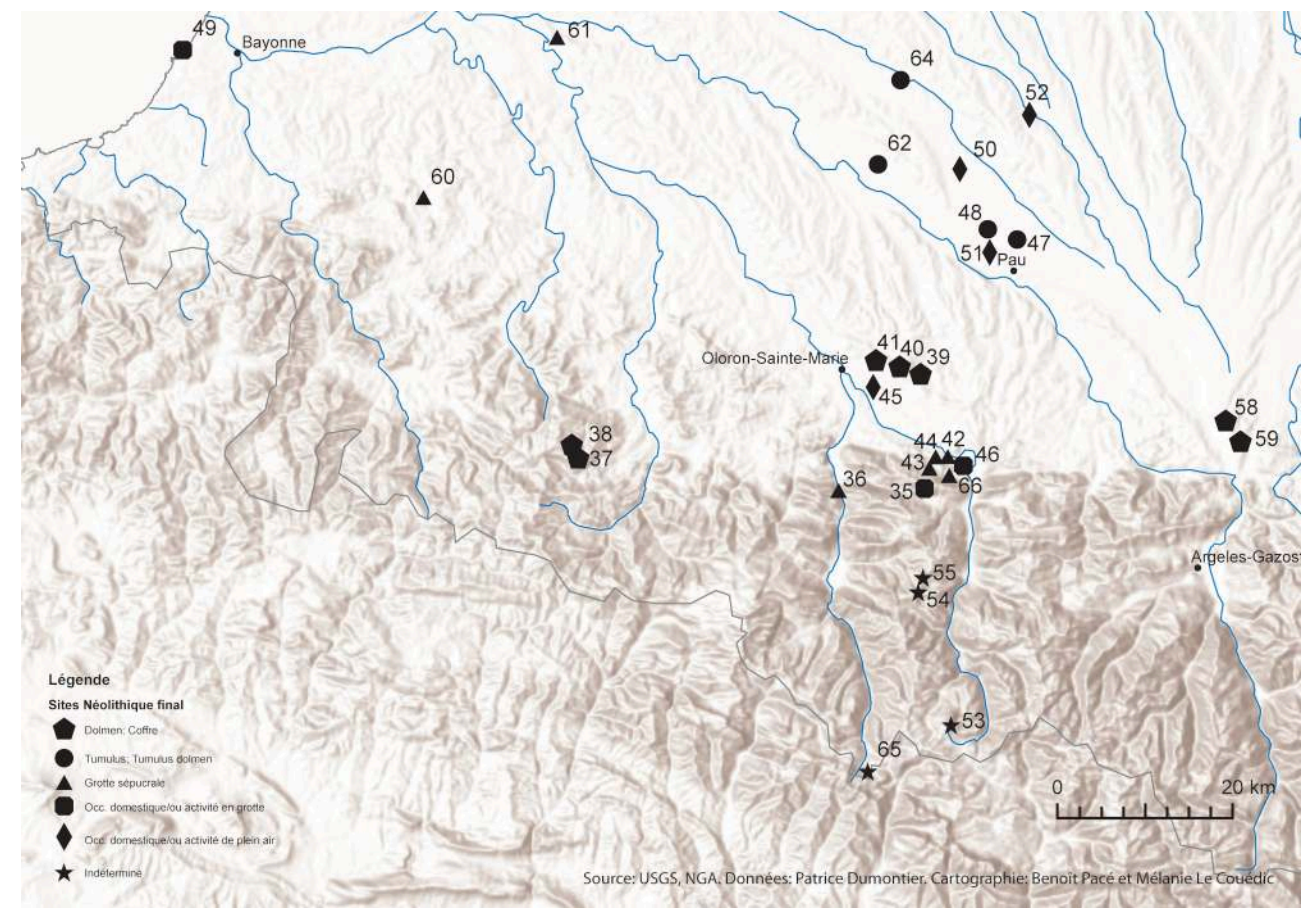

35 : Malarode 1 (Arudy). 36 : Apons (Sarrance). 37 Eт 38 : Ithé 2 et Ithé 1 (Aussurucq). 39 Eт 40 Peyrecor 1 et 2 (Escout). 41 : Darre La Peyre (Precilhon). 42, 43 Eт 44 : Houn de Laa, Laa 2 et Laplace (Arudy). $\mathbf{4 5}$ : Gabarn H1 (Escout). $\mathbf{4 6}$ : Poeymaü (Arudy). $\mathbf{4 7}$ : Cabout 5 (Pau). $\mathbf{4 8}$ : tumulus T6 (Lescar). $\mathbf{4 9}$ : le Phare (Biarritz). $\mathbf{5 0}$ : Las Areilles (Uzein). $\mathbf{5 1}$ : Mirassou (Lons). $\mathbf{5 2}$ : Labarthe 2 (Argelos). $\mathbf{5 3}, \mathbf{5 4}$ ET 55 : Peyreget, La Taillandère et Arrioutort (Laruns). 58 Eт 59: Puey Mayou et La Halliade (Bartrès, Hautes-Pyrénées). 60 : Isturitz (Saint-Martin-d'Arberoue). 61 : Duruthy (Sorde-l'Abbaye, Landes). 62 tumulus (Artix). $\mathbf{6 3}$ : Lestaque 2 (Avezac-Prat-Lahitte, Hautes-Pyrénées). 64 : tumulus T1 (Pomps). 65 Causiat (Urdos). 66 : Garli (Arudy). 67 : L'Espiet (Souès, Hautes-Pyrénées). 68 Eт 69 : Les Brucques et Cazaou de Luc (Miramont-Sensacq, Landes). Les sites se trouvent dans le département des PyrénéesAtlantiques, sauf indication d'un autre département.

Données Patrice Dumontier, cartographie Benoît Pace et Mélanie Le Couédic.

\section{L'habitat}

Des indices d'habitations ont été observés lors d'une surveillance de travaux au Gabarn d'Escout (Pyrénées-Atlantiques), sur un rebord de plateau dominant la vallée d'Ossau, où nous avons reconnu la présence de structures fossoyées: fosses, trous de poteaux, probable sablière en bois (Dumontier et Bordenave 2006) associées à du mobilier attribué au Néolithique final. Il en est de même sur le site de Pont de Peyre (Poey-deLescar, Pyrénées-Atlantiques). Ce site partiellement fouillé par J.-F. Chopin a livré un mobilier céramique et lithique associé à six structures en creux, possibles silos, et deux structures en galets (Chopin 2008a : p. 2).

Au-delà de ces deux sites, les structures domestiques (habitats ou zones d'activités) étudiées, comme pour le Néolithique moyen, correspondent toutes à des occupations en grottes ou sous abri-sous-roche et à de nombreuses structures de combustion (foyers) mises au jour sur le plateau du Pont Long (Mirassou, à Lons : Chopin 2008b ; Las Areilles, à Uzein : Elizagoyen et al. 2012) ou en pied de versant, dans la vallée du Luy-deFrance (Labarthe, à Argelos: Thirault et al. 2012), interprétées comme lieu de campement, habitats temporaires mais répétitifs dans un même secteur. La cartographie de ces sites peut être complétée par celle réalisée par P. Marticorena à 
partir de son étude récente des lames de haches polies (fig. 6), ce qui permet d'avoir une vue de la large répartition des sites et indices de sites connus, même si, pour la majorité d'entre eux, l'information repose sur des documents issus de prospections réalisées par différents chercheurs, sans qu'il y ait eu de fouille et sans élément suffisant de datation (Marticorena 2014). Cependant, les concentrations importantes de mobilier récolté ont vocation à signaler la présence d'habitats plus pérennes que les campements que nous connaissons.

Fig. 6. - Localisation des sites à lames polies des Pyrénées nord-occidentales.

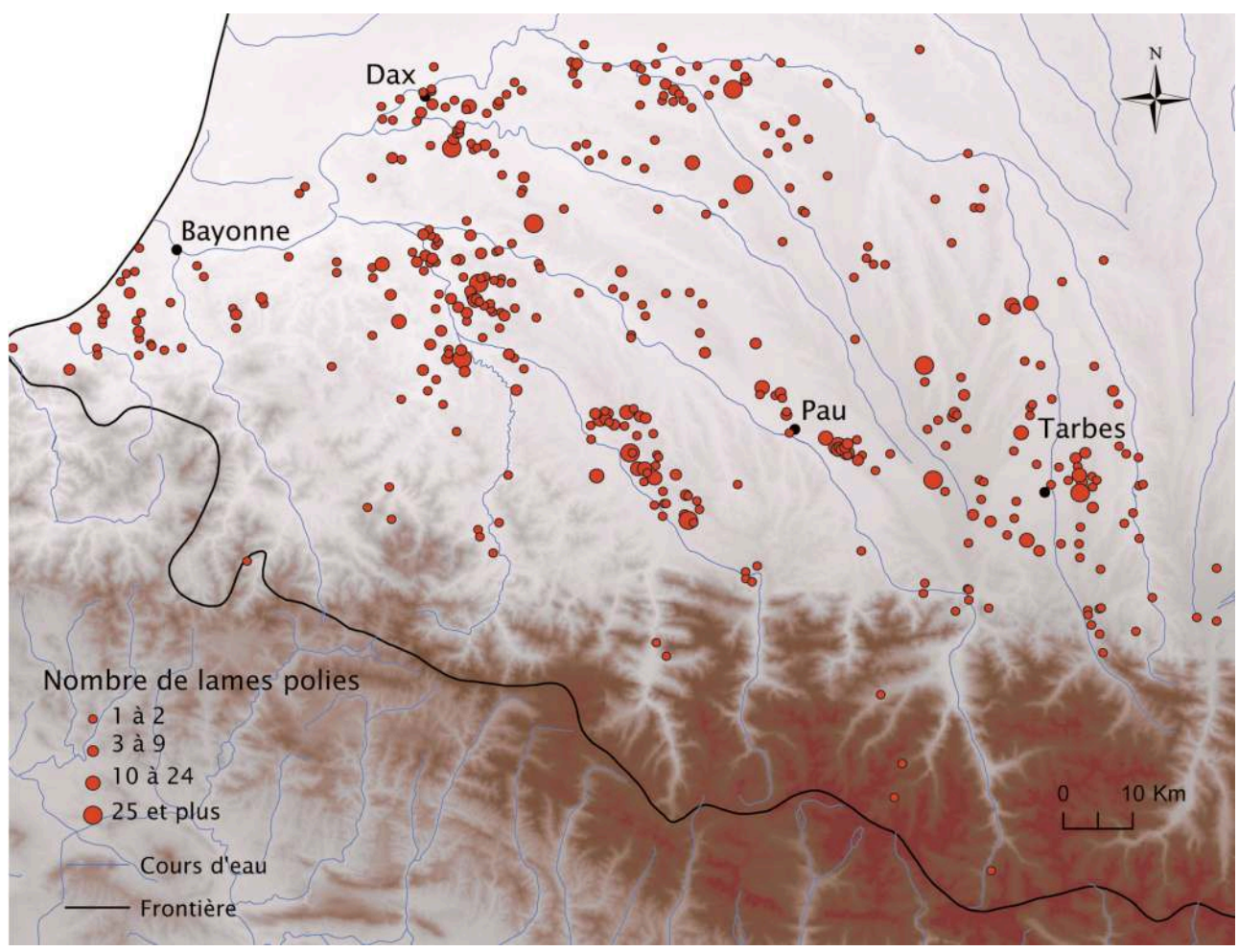

DAO Mélanie Le Couédic, d'après Marticorena 2014.

En vallée d'Ossau, dans les collines calcaires d'Arudy, les porches des grottes du Poeymaü, de Malarode 1 et 2, de Laa 3 et l'abri du Bignalats, à Arudy, montrent des successions d'occupations ponctuelles de type campement sous abri : foyer, industrie lithique, céramique et restes de faune.

Si nous n'avons que peu d'information sur l'organisation, l'importance des occupations et le mobilier de Poeymaü et de Malarode 1 et 2, la grotte de Laa 3 a fait l'objet d'une fouille récente, dont la publication est en cours de rédaction (Dumontier et al. 2009). Laa 3 correspond à la petite salle d'entrée sud-est de Laa 2, une cavité assez grande (40 m de longueur pour 7 à $10 \mathrm{~m}$ de largeur) dont l'entrée principale se trouve orientée au nordest. Les dimensions de Laa 3 sont modestes $(4 \mathrm{~m} \times 4 \mathrm{~m})$. Elle a pourtant été occupée à plusieurs reprises au Mésolithique, puis au Néolithique final, avant un effondrement de la falaise qui a colmaté en grande partie l'accès.

47 Les occupations du Néolithique final sont documentées par des structures de combustion et du mobilier céramique. L'industrie lithique est indigente (9 documents). 

(Pyrénées-Atlantiques), les découvertes de pointes de flèches en silex à ailerons et pédoncule au col de Peyreget (alt. $2208 \mathrm{~m}$ ) (Dumontier 2016b: p. 182) et au col d'Arrioutort (alt. $1701 \mathrm{~m}$ ) (Marsan et Utrilla 1996) et celle d'une pointe de flèche foliacée en silex mise au jour à coté d'un polissoir au col de La Taillandère (alt. $1890 \mathrm{~m}$ ) (Blanc et Bui Thi Maï 2003). Ces deux derniers cols mettent en communication les vallées d'Aspe et d'Ossau.

\section{Le monde des morts et les sites cultuels associés}

Dans la basse vallée d'Ossau, le dolmen de Peyrecor 2 (Escout, Pyrénées-Atlantiques) (fig. 7) a été érigé entre 2869 et 2306 avant notre ère (Dumontier et al. 1997). À proximité, sur la même ligne de crête, les dolmens de Peyrecor 1, à Escout (Dumontier 1997) et de Darre La Peyre, à Précilhon (Dumontier et al. 2008) présentent des caractéristiques architecturales très proches : chambres semi enterrées pour les trois, choix des matériaux (grès du flysch), tumulus circulaire parementé (muret constitué de plusieurs assises de dalles de grès) pour Peyrecor 1 et 2 . Bien que les niveaux de construction de ces deux structures mégalithiques n'aient pas pu faire l'objet d'une datation radiométrique, il est probable qu'ils appartiennent à la même période chronologique. Ils témoignent de la poursuite de la construction de ces monuments au Néolithique final. 
Fig. 7. - Dolmen de Peyrecor 2 (Escout, Pyrénées-Atlantiques).

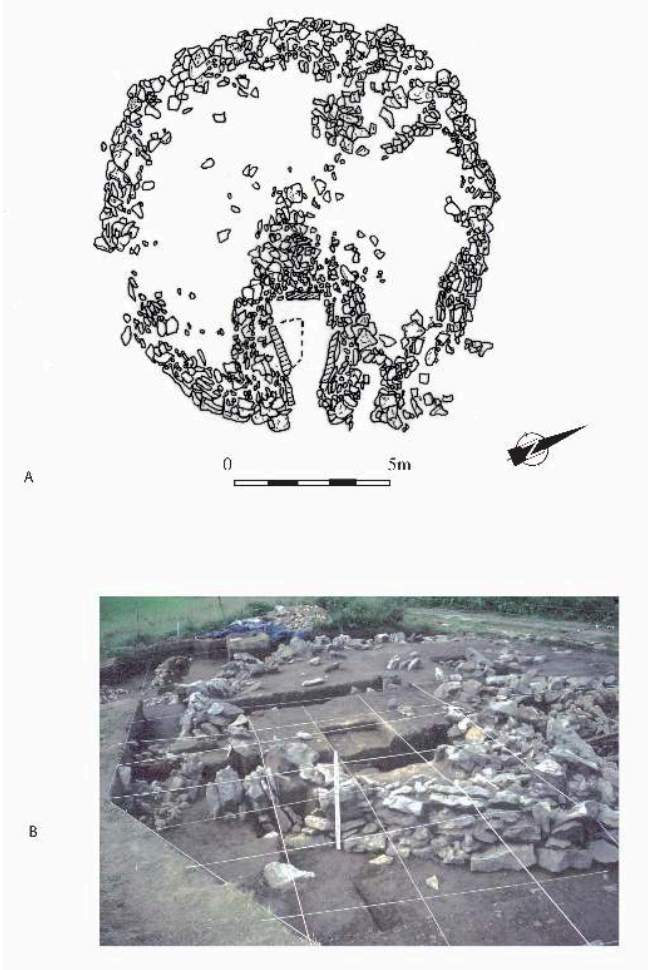

Relevé et photo Patrice Dumontier.

55 Les dolmens plus anciens, érigés au Néolithique moyen, ont été réutilisés pour déposer des défunts (Ithé 1 et Ithé 2 ). On notera que dans le dolmen d'Ithé 1 , des vestiges osseux incinérés ont été datés du Néolithique final (Ebrard 2013 : p. 175).

Plusieurs de ces dolmens ont été encore utilisés au Campaniforme (Ithé 1 et 2, Peyrecor 2 et Darre La Peyre) et au-delà, à l'âge du Bronze.

On évoquera également, sur le plateau de Ger, les mégalithes de Bartrès (HautesPyrénées): le Puey Mayou - vaste chambre de $7 \mathrm{~m}$ sur 4 environ, de forme rectangulaire - et La Halliade - allée couverte avec des dépôts campaniformes, réutilisée par la suite à l'âge du Bronze (Piette 1881, Mohen 1978). Dans les deux cas, il s'agit probablement de réutilisations de monuments plus anciens.

58 À la même époque, des cavités naturelles, souvent de simples boyaux, à l'exception de la grotte d'Isturitz (Saint-Martin d'Arberoue, Pyrénées-Atlantiques - Dumontier et al. 2015) et de l'abri Duruthy (Sorde-l'Abbaye, Landes) ont également été utilisées pour recevoir les défunts (Lartet et Chaplain-Duparc 1874, Marticorena et al. 2016). Il s'agit des sépultures collectives de Garli, Houn de Laa, Laa 3, Laplace, Bordedela 1 et 2, toutes localisées à Arudy, dans les Pyrénées-Atlantiques, contenant un nombre variable d'individus, de 2 à plus de 30.

En vallée d'Aspe, à Sarrance, le niveau C3sup de la grotte d'Apons a fait l'objet d'un aménagement mégalithique - coffre de $2 \times 1 \mathrm{~m}$ et blocs dressés (stèles aniconiques ?) destiné à recevoir des sépultures collectives dans un espace ouvert sur l'extérieur. Ici, la présence de trois blocs dressés et la configuration de la cavité pourraient indiquer l'existence de cérémonies associées aux défunts (fig. 8). 
Fig. 8. - Grotte d'Apons (Sarrance, Pyrénées-Atlantiques) : aménagement sépulcral mégalithique dans l'abri-sous-roche, niveau C3sup.

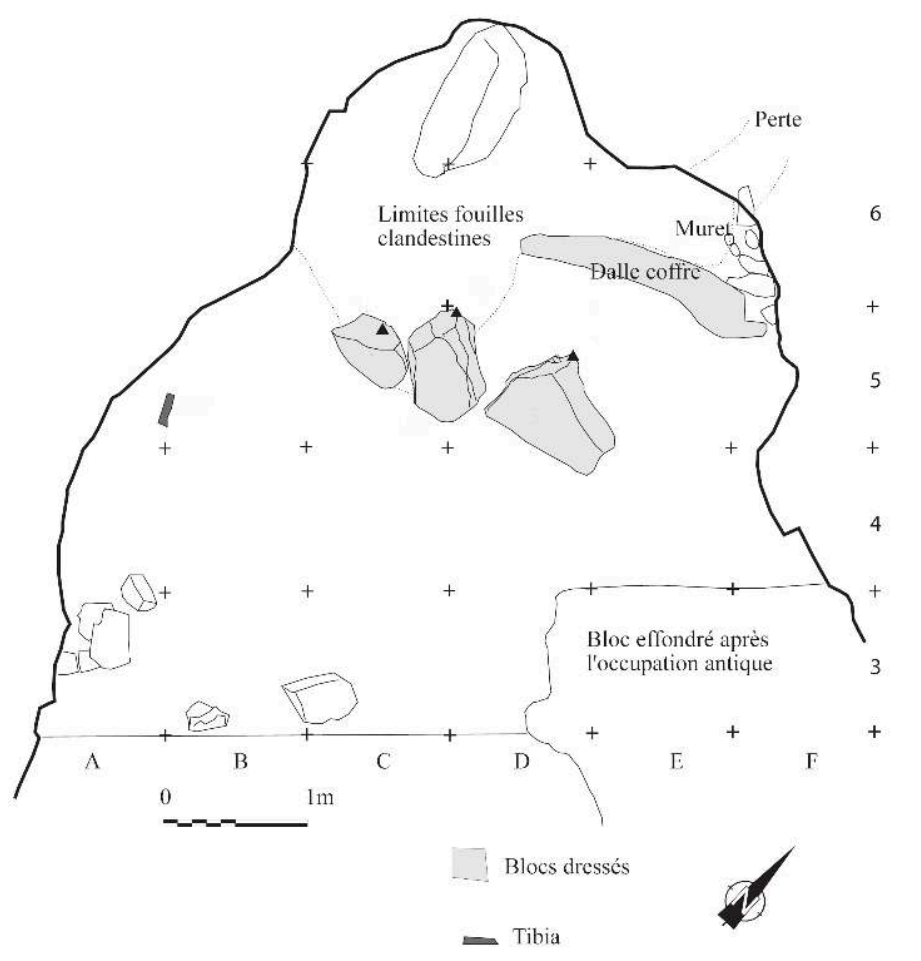

Relevé et PAO Patrice Dumontier.

Sur les plateaux du Pont Long, de nombreux tumulus ont été datés du III ${ }^{\mathrm{e}}$ millénaire avant notre ère. Le tumulus d'Artix (Pyrénées-Atlantiques - fouilles de Laverny) recouvrait une sépulture en coffre du Néolithique final, reprise au Campaniforme. Les tumulus de Lons $\mathrm{T} 3, \mathrm{~T} 5$ et $\mathrm{T} 6$, de Lescar T1 et TII ont livré quelques tessons d'une céramique de couleur brun-rouge contenant un dégraissant grossier et abondant, associé à une industrie lithique sur silex avec un macro-outillage sur galets de quartzite abondant, tout à fait comparable au mobilier lithique et céramique des " campements " évoqués plus haut (Dumontier et al. 2016b : p. 183). Le tumulus de Pomps T1 (PyrénéesAtlantiques) recouvrait un pavement rectangulaire de galets de $1,2 \mathrm{~m} \times 0,6 \mathrm{~m}$, sur lequel reposaient les vestiges osseux brûlés de deux individus (Blanc et Bui Thi Maï 1988). La conservation de connexions et de proximités anatomiques implique une crémation " par le dessus ", probablement à partir d'une structure en bois (maison funéraire ou coffre : Dumontier et al. 2016b : p. 181). Pour la deuxième moitié du III millénaire, les fouilles des tumulus Pau-Cabout 5 (Marembert et al. 2008) et de l'Estaque 2, à AvezacPrat-Lahitte, dans les Hautes-Pyrénées (Tchérémissinoff et al. 2008), ont livré un mobilier céramique et lithique qui illustre bien la transition entre le Néolithique final/ Chalcolithique et le début de l'âge du Bronze, et qui démontre également la continuité de ces pratiques funéraires.

61 La fouille de Pau-Cabout 5 apporte des informations importantes sur son fonctionnement. Ce petit tertre de 20 mètres de diamètre recouvrait deux structures circulaires concentriques : un fossé palissadé et une élévation en terre crue. Près du centre, un poteau en bois était fiché dans une des fosses mises au jour. Ces données sont proches de ce qui a été observé à l'Enclos des Terriers, à Avrillé (Vendée), où deux 
fossés concentriques entouraient un monolithe dressé (Beneteau et al. 1992). Le remplissage du fossé extérieur montrait des caractéristiques interprétées comme le blocage d'une palissade. La fonction du fossé intérieur, profond de 10 à 15 centimètres, restait floue. La datation obtenue et le mobilier évoquaient le Campaniforme, comme pour Pau-Cabout 5.

62 Nous avons ici un ensemble particulier, délimité et sanctuarisé, qui a fonctionné de façon ouverte (culte symbolisé par un poteau) avec des dépôts d'offrandes représentés par les vases brisés ou non dans les fosses et les fossés. Dans un deuxième temps, toujours au Néolithique final, la palissade a brûlé. Dans un troisième temps, on note le dépôt d'un vase au Bronze moyen, dans un point du fossé extérieur. Ce fossé était-il encore visible à ce moment-là ? En effet, le tumulus de terre qui a recouvert l'ensemble peut suivre la phase d'incendie et être antérieur au dépôt du Bronze moyen. Dans ce cas, le dépôt de ce vase aurait été réalisé en bordure du tumulus. Une autre hypothèse serait l'élévation du tumulus au Bronze moyen.

63 Ce site a fonctionné sans tumulus pendant une certaine durée et si une utilisation funéraire est possible, nous avons ici un témoin très probable de pratiques cultuelles à la fin du Néolithique final.

\section{Quel Néolithique final ?}

En vallée d'Ossau, à Arudy, le mobilier céramique des US 10 et 16 (fig. 9) de Laa 3, centré respectivement sur la première et la deuxième moitié du $\mathrm{III}^{\mathrm{e}}$ millénaire avant notre ère (tabl. 1), comporte des gobelets à lèvres amincies, avec des ouvertures convergentes. L'un d'eux présente un bouton sous le rebord.

Ces formes sont proches de plusieurs gobelets du niveau 5 de la grotte du Phare, à Biarritz (Marembert et al. 2000 : p. 103). À Laa 3 toujours, une jatte à carène haute et fond probablement rond, associée à une structure de combustion, est nouvelle pour le sud de l'Aquitaine dans un environnement du Néolithique final. Elle montre des affinités avec le Vérazien d'Ouveillan, Aude (Guilaine et al. 1980) ou de Mailhac, Aude (Montecinos 2005). Pour les autres morphologies, les deux pots cylindriques à bords amincis et aux fonds arrondis sont proches de la céramique mise au jour dans une fosse de la Zac du Parc de l'Adour, à Souès, dans les Hautes-Pyrénées (Pons et al. 2013), mais aussi de Loupiac, dans le Lot (Prodeo 2003). Les traits dominants de ce mobilier montrent des influences du Vérazien de la région toulousaine. 
Fig. 9. - Grotte de Laa 3 (Arudy, Pyrénées-Atlantiques), unités stratigraphiques 10 et $16:$ mobilier céramique du Néolithique final.

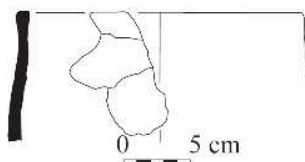

A
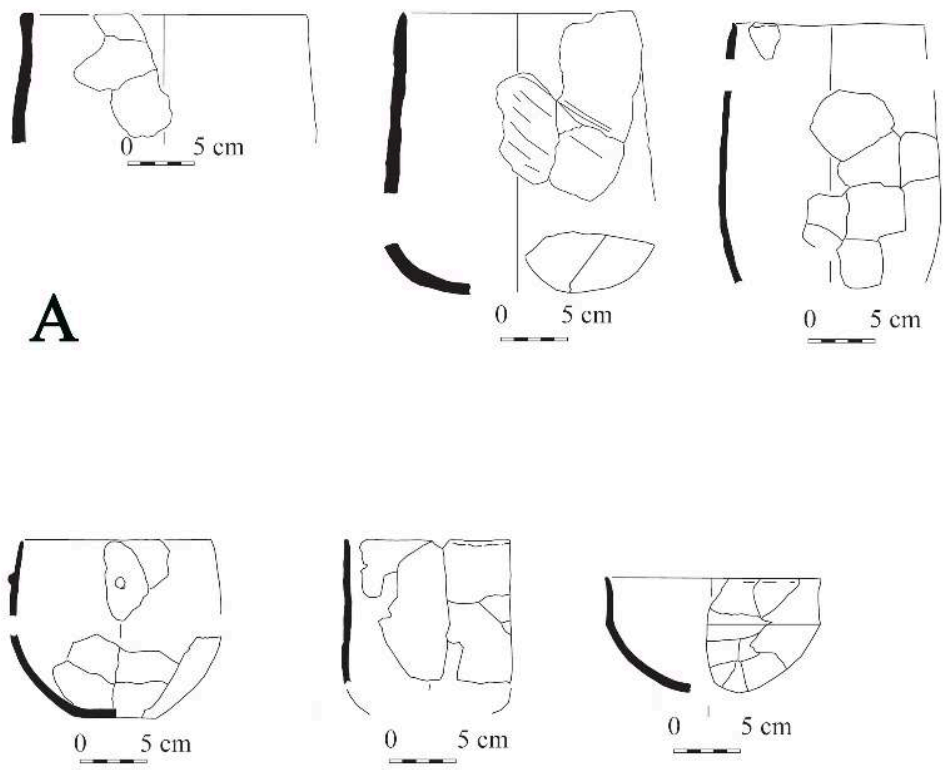

B
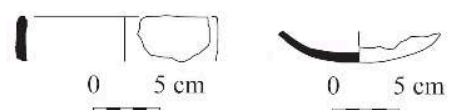

A : $x x v I^{e}-x x I I I^{e}$ siècle avant notre ère. $\mathbf{B}: x x \mid x^{e}-x x v^{e}$ siècle avant notre ère

Dessins Patrice Dumontier.

Sur la côte atlantique, dans la grotte du Phare, le mobilier céramique est composé de 13 récipients (fig. 10) qui ont une fragmentation peu dispersée et se trouvent tous à proximité des foyers. La céramique fine regroupe des gobelets hémisphériques ou à fonds plats. Les décors sont constitués d'un bouton sous le bord et de cannelures sur la moitié supérieure d'un vase. Cette petite série est complétée par des vases à provision et à cuire, avec une pâte épaisse, mal cuite, des formes cylindriques ou tronconiques et un exemplaire présentant une forte carène. 
Fig. 10. - Grotte du Phare (Biarritz, Pyrénées-Atlantiques), niveau 5 : mobilier céramique du Néolithique final.
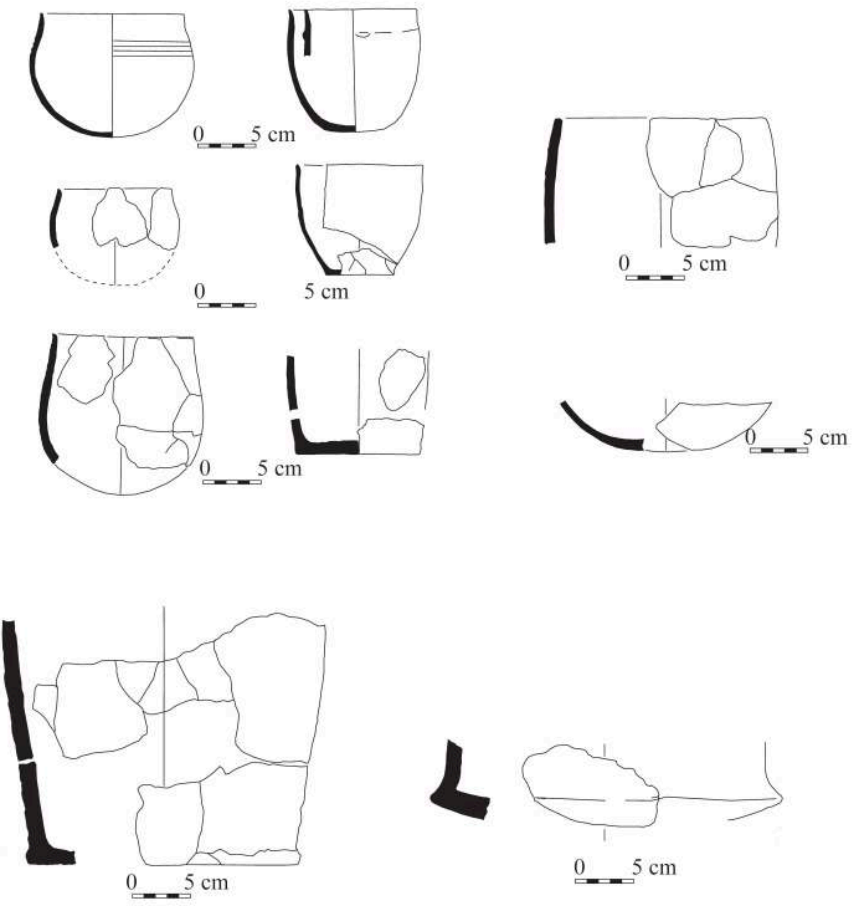

Dessins Patrice Dumontier.

La parure est abondante (fig. 11), avec 228 perles discoïdes en calcite et calcaire et des coquillages percés ( 5 nasses, dont 4 en connexion, 2 murex, 2 dentales). Le matériel osseux et lithique est plus pauvre: 2 pointes de flèche à ailerons et pédoncule, 1 poinçon sur métatarsien d'ovicapriné, 1 pointe bifide/lissoir sur os long de grand mammifère. 
Fig. 11. - Grotte du Phare (Biarritz, Pyrénées-Atlantiques), niveau 5 : industrie lithique et osseuse et parure du Néolithique final.

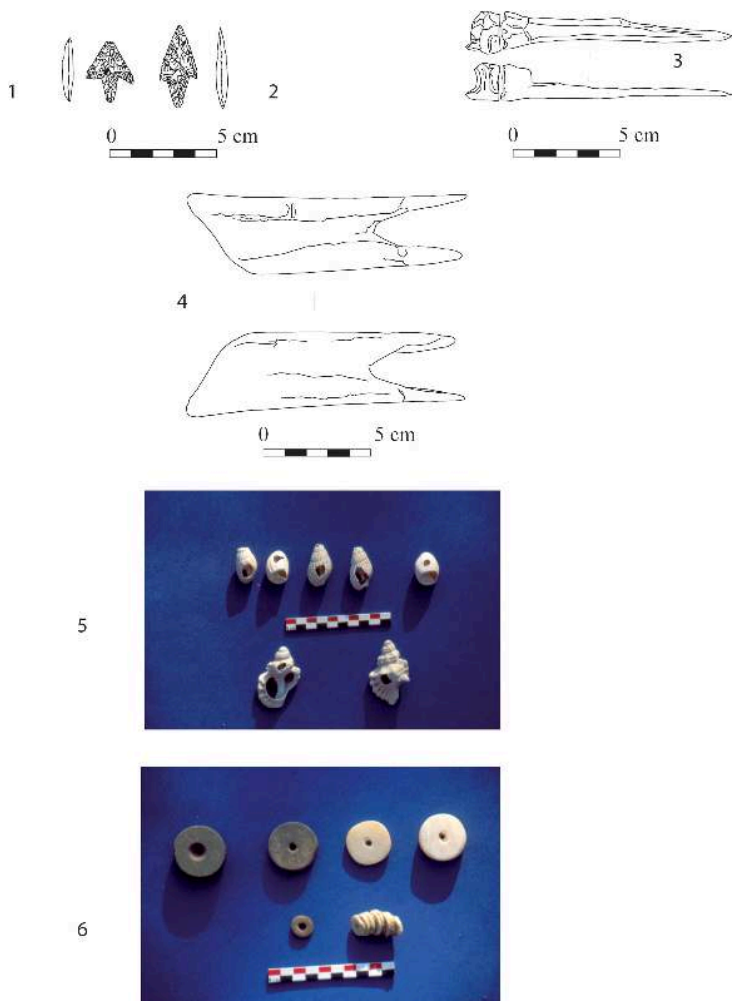

1 Eт 2 : pointes de flèches à ailerons et pédoncules. 3 : poinçon sur métatarsien d'ovicapriné. 4 : pointe bifide/lissoir sur os long de grand mammifère. $\mathbf{5}$ : parure en coquillages (Nasse et Murex). $\mathbf{6}$ : perles discoïdes en calcaire et calcite.

Dessins et photos Patrice Dumontier.

Le niveau d'occupation présente une répartition des vestiges et des recollages qui démontrent une grande homogénéité. La finesse du niveau s'oppose à une occupation de longue durée, mais on ne peut exclure deux occupations successives, assez proches dans le temps (niveaux $5 \mathrm{a}$ et $5 \mathrm{~b}$ ). Malgré cela, le fait que nous n'ayons qu'une seule datation radiométrique nous semble insuffisant et il y aura lieu d'envisager la datation de tous les foyers.

À ce jour, l'approche chronologique peut se faire à partir de deux sources : la datation du foyer 1 , qui se situe autour du milieu du III $^{\mathrm{e}}$ millénaire, et l'étude du mobilier. Les vases décorés de cannelures sont présents dans la céramique pré-artenacienne de Diconche dans la première moitié du III millénaire (Burnez et Fouéré 1999 : p. 523) et à la Perte du Cros, dans une fourchette de 3360 et 2923 avant notre ère (US 1017 et niveau inférieur à l'US 9004 : Galan 1967, Gernigon et Fouéré 2004, Gernigon et al. 2008). Les grands récipients tronconiques et cylindriques sont proches de plusieurs de formes de Combe Nègre, dans un niveau (N3) daté de 2655 à 2350 et 2468 à 2205 avant notre ère (Prodeo 2003), mais aussi du chantier 3 de Diconche, dans une plage chronologique un peu plus ancienne (Burnez et Fouéré 1999 : p. 501).

70 La parure couvre le Néolithique final et le Chalcolithique, notamment à Abauntz, entre 3293 et 2783 avant notre ère (Utrilla Miranda 1982). En l'état actuel, les données fournies notamment par la céramique fine suggèrent plutôt une occupation dans la première moitié du $\mathrm{III}^{\mathrm{e}}$ millénaire et probablement au début de cette période. 
71 Dans la région de Pau, dans les tumulus datés du $\mathrm{III}^{\mathrm{e}}$ millénaire, la présence d'éléments sableux fins associés à des graviers ou quartz broyés est une constante pour tous les tessons de céramique mis au jour. Nous évoquerons deux des datations obtenues pour ces sites, malheureusement avec un écart type très important (tabl.1) :

- Tumulus Lons Lescar T6: un vase découvert sur une structure de galets chauffés; les charbons ont fourni un résultat situé entre 3355 et 2440 avant notre ère (Blanc et Dumontier 1986 : p. 93).

- Tumulus 1 de Pomps : céramique associée à une double crémation datée entre 2775 et 1950 avant notre ère (Blanc et Bui Thi Maï 1988).

À Uzein, les occupations domestiques ont livré des céramiques avec des pâtes contenant des inclusions fines assez abondantes, avec de nombreux graviers grossiers. Le nombre minimum d'individus (NMI) est de 19 récipients. Si cette céramique semble homogène, les analyses réalisées par F. Convertini (Elizagoyen et al. 2012: p. 413) montrent qu'elle recouvre en fait deux populations distinctes : l'une sans introduction de la chamotte dans la pâte, alors que la seconde voit apparaitre ces inclusions. Une phase précoce, de transition, pourrait correspondre à l'apparition des inclusions de chamotte avec un apport sableux grossier. Une série de datations ${ }^{14} \mathrm{C}$ par AMS recouvre deux plages, centrées l'une sur la période 3300/3000, l'autre sur la période 2800/2140 avant notre ère (Elizagoyen et al. 2012). Ces gestes techniques (inclusions de chamotte) semblent avoir une forte connotation culturelle, qui pourrait aussi témoigner d'un changement chronologique.

Toujours à Uzein, pour la céramique fine, nous n'avons qu'une forme partiellement restituée et des fragments de panse appartenant à trois vases proches de la céramique fine du niveau 5 de la grotte du Phare, à Biarritz et de l'US 10 de la grotte de Laa 3, à Arudy.

Pour la céramique plus grossière, cette population comprend des gobelets, des formes tronconiques (jattes), des bols et des jarres. Le montage est essentiellement au colombin et les traitements de surface montrent de grands lissages obliques qui peuvent aller jusqu'à des traînées digitées, destinés à régulariser les collages. Les fonds à notre disposition sont plats, légèrement débordants. Les décors et moyens de préhension ou de fixation comprennent des cordons lisses horizontaux placés sous le bord, une perforation sous le bord (qui pourrait faire partie d'une ligne de perforations), des boutons, des languettes (dont l'une conserve de chaque côté le négatif du collage d'un cordon), des languettes doubles pour deux documents, et des impressions digitées. Plusieurs de ces éléments (cordons lisses et perforations sous le bord parfois associés) sont assez largement présents en France sur la céramique d'accompagnement du Campaniforme (Besse 1996). Nous les trouvons également en contexte chalcolithique non campaniforme.

L'ensemble de ces composantes se retrouve également à Cassagna 1 et 2 à Blagnac, en Haute-Garonne (Tchérémissinoff 2008), dans des contextes du Néolithique final/ Chalcolithique et sur le site campaniforme de Lapeyrère, à Muret, en Haute-Garonne (Jolibert 1988). Bien sûr, plusieurs des ces éléments sont présents dans une assez grande fourchette chronologique. C'est ainsi que les cordons lisses sous le bord peuvent se rencontrer au Bronze ancien, par exemple au Roc d'en Gabit (Carcassonne, Aude) (Vaquer et al. 2004). Il en est de même pour les boutons et languettes, avec une dispersion chronologique plus vaste encore. Cependant, dans le sud de l'Aquitaine, l'association des ces éléments avec le type de pâte rappelé ci-dessus nous oriente sur 
une fourchette chronologique et culturelle dans le $\mathrm{III}^{\mathrm{e}}$ millénaire avant notre ère. Cette fourchette pourrait recouvrir deux phases, l'une correspondant à un Néolithique final antérieur à 2600/2500 avant notre ère et la seconde se situant après, dans un Néolithique final contemporain du Campaniforme.

Trois documents sont assez exceptionnels pour le sud de l'Aquitaine pour que nous y revenions; il s'agit des languettes doubles superposées trouvées en deux exemplaires à Uzein (Elizagoyen et al. 2012) et d'un autre vase comportant ce type de préhension, mis au jour lors d'un diagnostic réalisé sur le tracé de l'autoroute A65 à Cazères-sur-Adour, dans les Landes (fig. 12) (Dumontier et al. 2018). Ces doubles languettes nous orientent elles aussi vers la céramique de tradition Véraza.

Fig. 12. -Cazères-sur-l'Adour (Landes) : jarre à double languette.

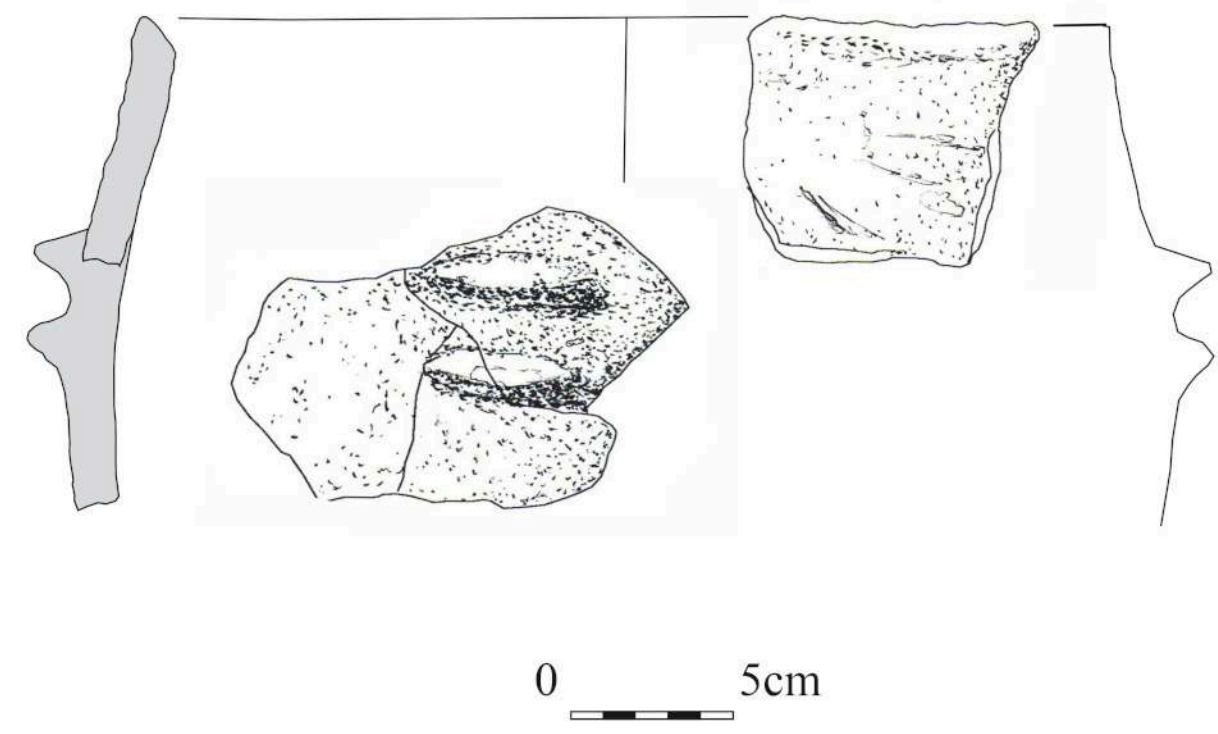

Dessin Patrice Dumontier.

Sur le site de Muret, en Haute-Garonne, des tessons de type Véraza appartenant à trois vases différents ont été découverts associés aux éléments campaniformes dans la couche d'habitat de Lapeyrère (Jolibert $1988:$ p. 55 et 123). Sur le site de Cassagna 2, à Blagnac, en Haute-Garonne, un fragment de panse présente deux languettes superposées. Pour l'auteur, ce tesson appartient probablement à une jarre en tonnelet associant ces deux languettes à une série de perforations sous le bord, très représentative de la céramique d'accompagnement campaniforme, et un fond plat (Tchérémissinoff 2008 : p. 468, Convertini 2008 : p. 475).

Si les deux languettes superposées évoquent des affinités avec la céramique vérazienne, la présence exclusive des fonds plats à Uzein, comme pour le vase de Cassagna 2, montre que nous sommes devant des influences mixtes.

L'analyse pétrographique des vases à doubles languettes d'Uzein (Elizagoyen et al. 2012) et de Cazères-sur-Adour (Dumontier et al. 2018), réalisée par F. Convertini, montre la présence de chamotte dans la pâte. L'ensemble des données nous a conduit à proposer un positionnement chronologique dans un Néolithique final contemporain du Campaniforme. 
80 À Uzein, bien que les vases à languettes superposées ne soient pas associés directement à ces résultats, on notera les datations obtenues pour les US 1036 de l'ensemble 1 (entre 2577 et 2309 avant notre ère) et US 1081 de l'ensemble 11 (entre 2459 et 2142 avant notre ère : Elizagoyen et al. 2012).

81 En l'état actuel des données, nous avons ici trois vases (2 à Uzein, 1 à Cazères-surAdour) qui proviennent sans doute d'une fabrication locale, avec une morphologie influencée par le courant Véraza. On notera également la présence d'un vase à deux languettes superposées dans le niveau 2 de Santimamiñe, dans le sud du Pays basque (Apellaniz 1973 : p. 40).

82 De même, sans association directe avec les vases, on note également la présence de macro-outils réalisés sur galets, bien connus en Béarn et dans les Hautes-Pyrénées par les fouilles de plusieurs tumulus et prospections de sites d'habitats.

83 La mise en évidence de chamotte dans la céramique que nous dénommerons « vérazoïde » du Néolithique final de Cazères et d'Uzein est extrêmement intéressante, car elle indique la mise en œuvre d'une tradition que l'on ne retrouve pas dans la région toulousaine à la même période pour le Vérazien, la seule exception étant le vase mixte ou hybride campaniforme/vérazien avec perforations préorales et languettes superposées de Cassagna 2, à Blagnac, évoqué ci-dessus. Dans ce dernier cas, la présence de chamotte est plutôt à relier au phénomène campaniforme, car la céramique décorée et commune de l'Europe occidentale en renferme souvent une fraction. Plus à l'est, dans son secteur le plus riche en sites (Aude, Pyrénées-Orientales), la céramique du Vérazien n'est pas dégraissée, non plus, avec de la chamotte (Convertini $2008:$ p. 475).

84 Nous pouvons également évoquer le mobilier mis au jour dans le quartier Mirassou, à Lons (Chopin 2008b) et sur le site de Labarthe 2, à Argelos, dans les PyrénéesAtlantiques (Thirault et al. 2012) où deux datations ${ }^{14} \mathrm{C}$ recouvrent la période de 2831 à 2350 avant notre ère. Malgré les nombreux points communs, les décors (impressions sur le rebord des vases, boutons bifides) sont différents de la céramique d'Uzein. S'il y a des variations dans le registre décoratif et dans l'association de fonds plats et de fonds ronds - qui peuvent reposer également sur une évolution chronologique - ces céramiques sont très proches, techniquement, de celle d'Uzein.

Pour le Béarn, les éléments à notre disposition, céramique et industrie lithique sur galets, que l'on retrouve sur tout le piémont pyrénéen, démontrent l'existence d'un courant d'échanges ou d'influence est-ouest au sud de la Garonne, notamment avec la région toulousaine, au cours du $\mathrm{III}^{\mathrm{e}}$ millénaire. Pour la côte atlantique, le mobilier de la grotte du Phare montre des influences venant du nord et du nord-est : Artenac (SaintMary, Charente), Perte du Cros (Saillac, Lot) et Combe Nègre (Frayssinet-le-Gélat, Lot). Il est bien sûr évident qu'au-delà de ce constat, nous manquons de données pour le moment pour envisager une éventuelle partition entre la façade atlantique et l'intérieur des terres.

86 Pour conclure sur le Néolithique final, les analyses polliniques nous confirment le développement d'activités agricoles sur le piémont, dans les basses vallées et sur le plateau du Pont-Long. Les structures d'habitation qui pourraient être associées à ce type d'activité n'ont pas fait l'objet de fouilles extensives (Gabarn d'Escout et Pont de Peyre, à Poey-de-Lescar). Cependant les prospections pédestres dans les labours démontrent l'existence d'un grand nombre d'indices de sites, avec un mobilier parfois 
abondant, où les herminettes et meules dormantes sont bien représentées. Ces implantations et les monuments funéraires collectifs tels que les dolmens, marqueurs de territoire, recouvrent assez largement l'ensemble des collines du piémont et des plateaux pré-pyrénéens. Cette structuration va sans aucun doute de pair avec des activités sédentaires, notamment agricoles.

Comment s'insèrent dans le paysage les structures foyères associées aux nappes de mobilier, souvent interprétées comme des campements, étudiées sur le Pont-Long? Nous nous sommes interrogés sur le fait qu'elles pouvaient être associées à des habitats construits non reconnus à la fouille ou situés à proximité, en dehors de la surface étudiée. On ne peut l'exclure, mais devant le nombre d'opérations réalisées, sondages compris, sur les tracés des autoroutes A64 et A65, il nous semble peu probable que les éventuelles structures bâties soient passées inaperçues des différents chercheurs impliqués. Ajoutons que les mobiliers associés (lithique, céramique) sont modestes en nombre et ne traduisent donc pas des occupations de longue durée. Il en est de même pour les niveaux d'occupation étudiés dans la majorité des grottes.

L'ensemble de ces éléments pourrait évoquer des groupes mobiles, empruntant souvent les mêmes trajets, avec les mêmes zones de campement. Cette mobilité pourrait s'inscrire dans le cadre d'une exploitation complémentaire des ressources des terroirs : pâturage, chasse ou pêche dans les espaces humides et habitat sur les coteaux; elle pourrait aussi être, en partie, associée à un pastoralisme qui couvrirait l'ensemble du territoire du sud Adour (piémont, moyenne et haute montagne) et serait complémentaire d'activités agricoles pour lesquelles les structures d'habitat n'ont pas été étudiées à ce jour. Le pastoralisme est attesté par différents marqueurs: palynologie, restes de faune domestique en grotte. Pour autant, c'est un constat qui n'implique pas l'adhésion au dogme d'un pastoralisme transhumant (Merlet 2007) tel qu'il existera au Moyen Âge ou à l'Époque moderne.

89 Si l'agriculture et le pastoralisme correspondent aux activités dominantes, la chasse est toujours présente, notamment en montagne. La prospection de roches particulières et l'extraction du minerai de cuivre se développent également, comme en témoigne la mine de Causiat, à Urdos, en haute vallée d'Aspe, où la chalcopyrite a été exploitée autour de 2500 ans avant notre ère (Beyrie 2010 : p. 216).

90 N'oublions pas la production et l'échange de haches polies en roche dure qui viennent compléter les activités pratiquées (Marticorena 2014), ainsi que d'autres, la pêche par exemple, n'ayant pas laissé de traces perçues à ce jour.

91 À la fin du Néolithique, la montagne est largement occupée. Le haut Ossau et les vallées du versant espagnol (Aragon, Tena) ont livré une documentation archéologique assez riche: des découvertes isolées (armatures de flèches) témoignant d'activités cynégétiques à plus de 2000 mètres d'altitude, quand l'édification de dolmens sur le versant sud, à proximité d'Anéou, évoque une occupation plus pérenne des territoires.

\section{Conclusions}

Le Néolithique ancien reste peu documenté. Cependant les données fournies par le site d'Apons permettent d'appuyer l'hypothèse d'une avancée des premiers agriculteurs/ éleveurs par les vallées pyrénéennes, à partir de l'Aragon et de la Navarre, dès le $\mathrm{VI}^{\mathrm{e}}$ millénaire avant notre ère. L'utilisation d'argiles provenant du massif de la Pierre 
Saint-Martin pour le montage du vase d'Apons atteste a minima d'une circulation entre les cols et le piémont.

Les données fournies par les analyses polliniques montrent une augmentation de la pression anthropique sur la moyenne et haute montagne et son piémont entre $4200 / 4000$ et 3700/3600 avant notre ère. Si sa présence est confirmée notamment par la présence de dolmens, qui sont également des marqueurs de territoire, les occupations domestiques étudiées évoquent surtout des populations mobiles. Nous n'avons pas, à ce jour, trouvé d'habitat pérenne. Le mobilier correspondant à cette période est particulièrement indigent. La céramique de Sasiziloaga évoque un Néolithique moyen non chasséen et celle du niveau 6 de la grotte du Phare, à Biarritz, une influence Matignons au Néolithique récent.

$\mathrm{Au}$ Néolithique final, une occupation large de tout le territoire, montagne comprise, est attestée aussi bien par les analyses polliniques que par les sites archéologiques fouillés.

Les occupations domestiques étudiées jusqu'ici (structures de combustion sur le plateau $\mathrm{du}$ Pont-Long, campements sous abris-sous-roche et porches de cavités) pourraient évoquer des groupes mobiles, empruntant souvent les mêmes trajets, avec les mêmes zones de campement. Cette mobilité pourrait être, en partie, associée à un pastoralisme qui couvrirait l'ensemble du territoire du sud Adour (piémont, moyenne et haute montagne) et serait complémentaire d'activités agricoles pour lesquelles les structures d'habitat n'ont pas été étudiées à ce jour. Elle pourrait aussi s'inscrire dans le cadre d'une exploitation complémentaire des ressources des terroirs. À la fin du Néolithique, la montagne est largement occupée.

Les perspectives de la recherche archéologique de la prochaine décennie sont multiples. La priorité nous semble devoir porter sur la recherche des habitats pérennes.

\section{BIBLIOGRAPHIE}

APELLANIZ J. M., 1973, Corpus de materiales de las culturas prehistóricas con cerámica de la población de las cavernas del País Vasco meridional, San Sebastián, Sociedad de ciencias naturales Aranzadi (Munibe, suppl. 1).

BALDELlou V. et UtRILla P., 1999, « Le Néolithique en Aragon », dans Vaquer J. (dir.), Le Néolithique du nord-ouest méditerranéen : actes du Colloque international de Carcassonne, 26-30 septembre 1994, XXIV ${ }^{e}$ Congrès préhistorique de France, Paris, Société préhistorique française, p. 225-237.

BARANDIARÁN I. et CAVA A (dir.), 2001, Cazadores-recolectores en el Pirineo navarro: El sitio de Aizpea entre 8000 y 6000 años antes de ahora, Vitoria-Gasteiz, Universidad del País Vasco/Euskal Herriko Unibertsitatea (Veleia, Series Maior, 10).

BENETEAU G., CROS J.-P., GILBERT J.-M., 1992, « L'enclos campaniforme à monolithes des Terriers à Avrillé (Vendée) », Gallia préhistoire, ${ }^{\circ}$ 34, p. 259-288. 
BESSE M., 1996, «Types et origines potentielles de la céramique du Campaniforme en France », dans Mordant C. et Gaiffe O. (dir.), Cultures et sociétés du Bronze ancien en Europe : actes du $117^{e}$ Congrès national des sociétés savantes, Paris, Éditions du CTHS, p. 165-180.

BEYRIE A., 2010, « La mine du Somport, une mine de cuivre exploitée au III millénaire avant J.-C. », dans Mistrot V. (dir.), De Néandertal à l'Homme moderne : l'Aquitaine préhistorique, vingt ans de découvertes (1990-2010), Bordeaux, Confluences, p. 216-219.

BLANC C., 1994, « Résultats de la fouille du cercle de pierre de Bious-Oumettes (Laruns, P.-A.) », Archéologie des Pyrénées occidentales et des Landes, $\mathrm{n}^{\circ}$ 22, p. 23-31.

BLANC C. et BUI THI MAÏ, 1988, « Une double sépulture chalcolithique sous tumulus et son paléoenvironnement (Pomps, Pyrénées-Atlantiques) », Munibe, nº 40, p. 71-82.

BLANC C. et BUI THI MAÏ, 2003, « L'affûtoir-polissoir du col de la Taillandère (vallée d'Ossau, Laruns, P.-A.) : résultats du sondage (1995) et des analyses polliniques ", Archéologie des Pyrénées occidentales et des Landes, $\mathrm{n}^{\circ} 22$, p. 45-59.

BLANC C. et DUMONTIER P., 1986, « Sauvetage d'un groupe de tumulus à Lons/Lescar (P.-A.) », Archéologie des Pyrénées occidentales, n 6, p. 75-95.

BOULESTIN B., HENRY-GAMBIER D., MALlye B., MICHEL P., 2013, « Modifications anthropiques sur des restes humains mésolithiques et néolithiques de la grotte d'Unikoté (Iholdy, PyrénéesAtlantiques) ", Bulletin de la Société préhistorique française, vol. 110, n² 2, p. 281-297.

BURNEZ C. et FOUÉRÉ P. (dir.), 1999, Les enceintes néolithiques de Diconche à Saintes (Charente-Maritime) : une périodisation de l'Artenac, Paris, Société préhistorique française, (Mémoires de la Société préhistorique française, 25).

CASSEN S., 1993a, «Le Néolithique le plus ancien de la façade atlantique de la France », Munibe, $\mathrm{n}^{\circ}$ 45, p. $119-129$.

CASSEN S., 1993b, « Le Néolithique récent sur la façade atlantique de la France : la différenciation stylistique des groupes céramiques ", Zephyrus, n XLIV-XLV (1991-1992), p. 176-182.

CASSEN S. et CASSEN A., 1989, « Préhistoire et Protohistoire à Labatut (Landes) et Bayonne (Pyrénées-Atlantiques) : l'apport de la prospection spontanée ", Bulletin de la Société de Borda, ${ }^{\circ}$ 416, p. 515-522.

CHAUCHAT C., 1974, « Datations C14 concernant le site de Mouligna, Bidart (PyrénéesAtlantiques) », Bulletin de la Société préhistorique française, vol. 71, nº 5, p. 140.

CHOPIN J.-F., 2008a, « A65 : d'Uzein à Poey-de-Lescar (section 5b) », ADLFI-archéologie de la Franceinformations [en ligne], http://journals.openedition.org/adlfi/2718.

CHOPIN J.-F., 2008b, « Les tertres du quartier Mirassou (Lons) et le site du vallon de Mohédan (Billère) », dans Barraud D., Réchin F. (dir.), Lescar-Beneharnum, ville antique entre Pyrénées et Aquitaine, Pau, FAPOL (Archéologie des Pyrénées occidentales et des Landes, numéro hors série 3), p. 73-88.

CONVERTINI F., 2008, « Analyses de pâtes de quelques vases de Cassagna 2 (Blagnac, HauteGaronne) », Bulletin de la société préhistorique française, vol. 105, nº 3, p. 475-477.

DUMONTIER P., 1997, « Les dolmens sous tumulus 1 et 2 de Peyrecor à Escout (PyrénéesAtlantiques) », dans Fabre G. (dir.), Archéologie en Béarn : actes du $4^{e}$ Colloque d’Arzacq, Pau, Ségur, p. 77-121. 
DUMONTIER P., 2006, Abri det Caillaü, commune d'Accous (Pyrénées-Atlantiques), rapport de sondage diagnostic, Bordeaux, Service régional de l'archéologie Aquitaine.

DUMONTIER P. et BORDENAVE J., 2006, Le Gabarn : secteur Peyrelade et parcelle 263, commune d'Escout (64), rapport de surveillance de travaux, Bordeaux, Service régional de l'archéologie Aquitaine.

DUMONTIER P., BUI THI MAÏ, HEINZ C., 1997, « Le dolmen sous tumulus $\mathrm{n}^{\circ} 2$ de Peyrecor et son paléoenvironnement à Escout (Pyrénées-Atlantiques) », Bulletin de la Société préhistorique française, vol. $94, \mathrm{n}^{\circ} 4$, p. 527-550.

DUMONTIER P., BUI THI MAÏ, CONVERTINI F., COURTAUd P., DARDEY G., FERRIER C., GRATUZE B., RÉCHIN F., ORTÉGA D., 2008, « La structure funéraire mégalithique de Darre La Peyre, commune de Précilon (Pyrénées-Atlantiques) », Archéologie des Pyrénées occidentales et des Landes, n² 27, p. 43-76.

DUMONTIER P., ARMAND D., BUI THI MAÏ, CALLEGARIN L., COSTAMAGNO S., COURTAUd P., DOUAT M., FERRIER C., GIRARD M., LANGLAIS M., MARTICORÉNA P., PÉTILLON J.-M., MISTROT V., NORMAND C., RÉCHIN F. VERGEOT H., VALDEYRON N., 2009, Grotte de Laa 2, commune d'Arudy (Pyrénées-Atlantiques), rapport de synthèse 2007-2009, Bordeaux, Service régional de l'archéologie Aquitaine.

DUMONTIER P., COURTAUD P., ARMAND D., CONVERTINI F., FERRIER C., 2014, La grotte de Bordedela et les cavités sépulcrales d'Arudy, Pyrénées-Atlantiques : rapport de fouille programmée annuelle 2014, Bordeaux, Service régional de l'archéologie Aquitaine.

DUMONTIER P., COURTAUD P., NORMAND C., ARMAND D., BEDECARRATS S., CONVERTINI F., FERRIER C., PARENT G., PÉTILLON J.-M., QUEFFELEC A., VANHAEREN M., VERGEOT H., 2015, Grotte d'Isturitz, commune de SaintMartin-d'Arberoue (Pyrénées-Atlantiques) : rapport de synthèse des fouilles 2009 et 2015, Bordeaux, Service régional de l'archéologie Aquitaine.

DUMONTIER P., COURTAUd P., FERRIER C., ARMAND D., BUI THI MAÏ, CONVERTINI F., VALDEYRON N., 2016a, La grotte d'Apons à Sarrance (Pyrénées-Atlantiques) : des derniers chasseurs-cueilleurs aux premières sociétés agro-pastorales en vallée d'Aspe ( $8^{e}$ au $2^{e}$ millénaire avant notre ère), Cabrerets, association Préhistoire du Sud-Ouest (Préhistoire du Sud-Ouest, supplément 14).

DUMONTIER P., COURTAUd P., ARMAND D., CONVERTINI F., FERRIER C., 2016b, « Entre montagne et piémont, témoignages agropastoraux du Néolithique à l'âge du Fer », dans Rendu C., Calastrenc C., Le Couédic M., Berdoy A. (dir.), Estives d'Ossau : 7000 ans de pastoralisme dans les Pyrénées, Toulouse, Le Pas d'Oiseau, p. 175-203.

DUMONTIER P., CONVERTINI F., DEFAYE S., 2018, « Une trace d'occupation du Néolithique final dans la vallée de l'Adour, sur le tracé de l'A65, à Cazères-sur-Adour (Landes) », Archéologie des Pyrénées occidentales et des Landes, vol. 31, p. 99-105.

EBRARD D., 2013, 50 ans d'archéologie en Soule : hommage à Pierre Boucher (1909-1997), Mauléon, Ikerzaleak.

ELIZAGoyen V., DUMONTIER P., CONVERTINI F., CLAUd É., FOURloubey C., VIGIER S., 2012, « Uzein Las Areilles : des occupations humaines sur le piémont des Pyrénées occidentales au Néolithique et à l'âge du Bronze », dans Perrin T., Sénépart I., Cauliez J., Thirault E., Bonnardin S. (dir.), Dynamismes et rythmes évolutifs des sociétés de la Préhistoire récente : actes des $9^{e}$ Rencontres méridionales de préhistoire récente, Saint-Georges-de-Didonne (17), 8 et 9 octobre 2010, Toulouse, Archives d'écologie préhistorique, p. 393-421.

FOUÉRÉ P., 2011, « Les Vaures à Bergerac, Dordogne : premier témoignage d'un village structuré pour le Néolithique récent du sud-ouest de la France ", dans Sénépart I., Perrin T., Thirault E., Bonnardin S. (dir.), Marges, frontières et transgressions : actualité de la recherche. Actes des $8^{e}$ 
Rencontres méridionales de préhistoire récente, Marseille (13), 7 et 8 novembre 2008, Toulouse, Archives d'écologie préhistorique, p. 365-386.

GALAN A., 1967, « La station néolithique de la Perte du Cros à Saillac (Lot) », Gallia préhistoire, vol. $10, \mathrm{n}^{\circ} 1$, p. 1-60.

GALLART MARTí M. D. et LóPEZ AGUAYO F., 1988, « Análisis mineralógico de las cerámicas neolíticas de la cueva de Chaves (Casba, Huesca) », Bolskan, $n^{\circ}$ 5, p. 5-19.

GALOP D., 2006, « La conquête de la montagne pyrénéenne au Néolithique : chronologie, rythmes et transformations des paysages à partir des données polliniques », dans Guilaine J. (dir.), Populations néolithiques et environnement, Paris, Errance, p. 279-295.

GALOP D., CAROZZA L., MAREMBERT F., BAL M.-C., 2007, « Activités agropastorales et climat durant l'âge du Bronze dans les Pyrénées : l'état de la question à la lumière des données environnementales et archéologiques ", dans Mordant C., Richard H., Magny M. (dir.), Environnement et cultures à l'âge du Bronze en Europe occidentale, Paris, Éditions du CTHS (Documents préhistoriques, 21), p. 107-119.

GERNIGON K., 2013, Bilan scientifique 2011 des recherches sur la Préhistoire récente en Aquitaine : potentiel avéré, connaissance renouvelées, une programmation à développer, Bordeaux, Service régional de l'archéologie Aquitaine, p. 11-48.

GERNIGON K. et FOUÉRÉ P., 2004, « Révision de la stratigraphie néolithique de la Perte du Cros (Saillac, Lot) », dans Dartevelle H. (dir.), Auvergne et Midi : actualité de la recherche. Actes des $5^{e}$ Rencontres méridionales de préhistoire récente, Cabrerets, association Préhistoire du Sud-Ouest, p. 337-352.

GERNIGON K., FOUÉRÉ P., SAINT-SEVER G., VERGNAUd L., 2008, « La Perte du Cros (Saillac, Lot) et les termes de passage du Néolithique final à l'âge du Bronze en bordure occidentale du Massif central », Bulletin de la Société préhistorique française, vol. 105, n 3, p. 479-499.

GUILAINE J., VAQUER J., BOUISSET P., 1980, « Les stations véraziennes d'Ouveillan (Aude) », dans Guilaine J. (dir.), Le groupe de Véraza et la fin des temps néolithiques dans le sud de la France et la Catalogne : actes du colloque de Narbonne, 1977, Paris, CNRS Éditions, p. 22-32.

JALUT G., ANDRIEU V., DELIBRIAS G., FONTUGNE M., PAGES P., 1988, « Paleoenvironment of the valley of Ossau (western French Pyrenees) during the last 27000 years ", Pollens et spores, $n^{\circ} 30$, p. 357-394. JOLIBERT B., 1988, Le gisement campaniforme de Muret, Toulouse, Archives d'écologie préhistorique. LAPLACE G., 1953, « Les couches à escargots des cavernes pyrénéennes et le problème de l'Arisien de Piette », Bulletin de la Société préhistorique française, vol. 50, nº 4, p. 199-211.

LARTET L. et CHAPLAIN-DUPARC G., 1874, « Sur une sépulture des anciens Troglodytes des Pyrénées, superposée à un foyer contenant des débris humains associés à des dents sculptées de lions et d'ours ", Matériaux pour l'histoire primitive et naturelle de l'Homme, $10^{\mathrm{e}}$ année, $2^{\mathrm{e}}$ série, vol. $5, \mathrm{n}^{\mathrm{o}} 3-4$, p. 101-167.

LIVACHE M., LAPLACE G., EVIN J., PASTOR G., 1984, « Stratigraphie et datations par le radiocarbone des charbons, os et coquilles de la grotte du Poeymaü à Arudy, Pyrénées-Atlantiques ", L'Anthropologie , vol. 88, n 3, p. 367-375.

MARCHAND G., 1999, La néolithisation de l'ouest de la France : caractérisation des industries lithiques, Oxford, Archaeopress (BAR International Series, 748). 
MARCHAND G., 2000, « La néolithisation de l'ouest de la France : aires culturelles et transferts techniques dans l'industrie lithique », Bulletin de la Société préhistorique française, vol. 97, $\mathrm{n}^{\circ} 3$, p. 377-403.

MARCHAND G. et MANEN C., 2006, «Le rôle du Néolithique ancien méditerranéen dans la néolithisation de l'Europe atlantique » dans Fouéré P., Chevillo C., Courtaud P., Ferullo O., Leroyer C. (dir.), Paysages et peuplements : aspects culturels et chronologiques en France méridionale, actualité de la recherche. Actes des $6^{e}$ Rencontres méridionales de préhistoire récente, Périgueux, 14-16 octobre 2004, Périgueux, Association pour le développement de la recherche archéologique et historique en Périgord/Cabrerets, Préhistoire du Sud-Ouest, p. 213-232.

MAREMBERT F., DUMONTIER P., Delfour G., 2000, « Biarritz, grotte du Phare », Dans Bilan scientifique de la région Aquitaine 1999, Bordeaux, Service régional de l'archéologie Aquitaine, p. 103-104.

MAREMBERT F., DUMONTIER P., DAVASSE B., WATTEZ J., 2008, « Transition Néolithique final/Bronze ancien sud aquitaine à travers les tumulus Cabout 4 et 5 de Pau, Pyrénées-Atlantiques ", Archéologie des Pyrénées occidentales et des Landes, $\mathrm{n}^{\circ}$ 27, p. 77-112.

MARSAN G., 1985, « Le tumulus néolithique T1 de Mont (Pyrénées-Atlantiques) », Archéologie des Pyrénées occidentales, $\mathrm{n}^{\circ}$ 7, p. 17-53.

MARSAN G., 1987, « Découverte isolée d'âge néolithique à la grotte d'Espalungue à Arudy (P.-A.) », Archéologie des Pyrénées occidentales, $\mathrm{n}^{\circ} 7$ (Les hommes et leurs sépultures dans les Pyrénées occidentales depuis la préhistoire), p. 8.

MARSAN G. et UTRILLA P., 1996, «L'implantation du mégalithisme dans les passages des Pyrénées centrales : comparaison des vallées d'Ossau et Tena-Canfranc », dans Delporte H. et Clottes J. (dir.), Pyrénées préhistoriques : arts et sociétés. Actes du $118^{e}$ Congrès national des sociétés historiques et scientifiques, Pau, Paris, Éditions du CTHS, p. 521-532.

MARTICORENA P., 2014, Les premiers paysans de l'ouest des Pyrénées : synthèse régionale à la lumière des haches de pierre polie, Bayonne, Université populaire du Pays basque.

MARTICoRena P., CAULE B., DÉMANGeot C., VAqUeR J., MAREMBERT F., 2016, « Duruthy, une sépulture oubliée : d'un site original à l'organisation territoriale des Pyrénées nord-occidentales au Néolithique final », dans Cauliez J., Sénépart I., Jallot L., La Briffe P.-A. de, Gilabert C., Gutherz X. (dir.), De la tombe au territoire et actualité de la recherche : actes des $11^{e}$ Rencontres méridionales de préhistoire récente, Montpellier (Hérault) 25-27 septembre 2014, Toulouse, Archives d'écologie préhistorique, p. 537-549.

MERLET J.-C., 2007, « La place du pastoralisme transhumant dans l'économie des populations du sud de l'Aquitaine aux âges du Bronze et du Fer : dogme ou réalité ? ", dans Gomez de Soto J. (dir.), La notion de mobilité dans les sociétés préhistoriques, actes $d u 130^{\circ}$ congrès des sociétés historiques et scientifiques, La Rochelle, 2005, Paris, Éditions du CTHS, p. 69-78.

MOHEN J.-P., 1978, « Tumulus des Pyrénées françaises », dans Els pobles pre-romans del Pirineu, actes du $2 e$ Col-loqui Internacional d'Arqueología de Puigcerdà, 1976, Puigcerdà, Institut d'Estudis ceretans, p. 97-108.

MONTECINOS A., 2005, La céramique vérazienne de Mailhac (Aude), Toulouse, Archives d'écologie préhistorique.

PASSEMARD E., 1920, «L'industrie des tourbes de Mouligna (Basses-Pyrénées) », Bulletin de la Société préhistorique française, vol. 17, $\mathrm{n}^{\circ}$ 11, p. 263-268. 
PÉTREQUIN P., CASSEN S., ERRERA M., PAILLER Y., GAUTHIER E., 2007, « La hache polie de Lagor (Pyrénées-Atlantiques) : une production du $5^{\mathrm{e}}$ millénaire », Archéologie des Pyrénées occidentales et des Landes, $\mathrm{n}^{\circ} 26$, p. 7-20.

PIETTE E., 1881, « Note sur les tumulus de Bartrès et d'Ossun », Matériaux pour l'histoire primitive et naturelle de l'Homme, $17^{\mathrm{e}}$ année, $2^{\mathrm{e}}$ série, $\mathrm{n}^{\circ} 16, \mathrm{p} .522-532$.

PONS F., PANCIN S., GANDELIN M., 2013, « Des traces d'occupation du Néolithique final dans la vallée de l'Adour à Souès (Hautes-Pyrénées) », Archéologie des Pyrénées occidentales et des Landes, $\mathrm{n}^{\circ} 30$, p. 161-168.

POTHIER E., 1892, « Tumulus-dolmen de Marque-Dessus (commune d'Azereix, Hautes-Pyrénées) », L'Anthropologie, $\mathrm{n}^{\circ}$ 3, p. 37-42.

PRODEO F., 2003, «La céramique des occupations du Néolithique final de Combe Nègre et de Combe Fages à Loupiac (Lot) ", dans Gascó J., Gutherz X., Labriffe P.-A. de (dir.), Temps et espaces culturels du $6^{e}$ au $2^{e}$ millénaire en France du sud: actes des $4^{e}$ Rencontres méridionales de préhistoire récente, Lattes, Association pour le développement de l'archéologie en Languedoc-Roussillon, p. 219-234. RAMÓN FERNÁNDEZ N., 2006, La cerámica del Neolítico antiguo en Aragón, Zaragoza, Institución Fernando el Católico (Caesaraugusta, 77).

RIUS D., VANNIÈRE B., GALOP D., 2009, « Fire frequency and landscape management in the northwestern Pyrenean piedmont (France) since early Neolithic (8000 cal BP) », The Holocene, vol. 19, $\mathrm{n}^{\circ}$ 6, p. 1-13.

ROUSSOT-LARROQUE J., 2001, « Le sud-ouest aquitain entre sud et ouest, du $8^{\mathrm{e}}$ au $5^{\mathrm{e}}$ millénaire avant notre ère ", dans Jaubert J. et Barbaza M. (dir.), Territoires, déplacements, mobilité, échanges durant la préhistoire: terres et hommes du Sud. Actes des congrès nationaux des sociétés historiques et scientifiques, Toulouse 2001, Paris, Éditions du CTHS, p. 471-497.

TCHÉRÉMISSINOFF Y., 2008, « Le site de Cassagna 2 (Blagnac, Haute-Garonne), une petite série problématique : rappel des faits en forme d'introduction », Bulletin de la Société préhistorique française, vol. 105, $\mathrm{n}^{\circ}$ 3, p. 467-473.

TCHÉRÉMISSINOFF Y., BRUXELLES L., LAGARRIGUE A., LELOUVIER L.-A., LEROY F., 2008, « Le tumulus de l'Estaque 2, commune d'Avezac-Prat-Lahitte (Hautes-Pyrénées) : résultats de fouille préventive », Archéologie des Pyrénées occidentales et des Landes, n² 27, p. 187-220.

THIRAULT E., DUMONTIER P., MORIN-RIVAT J., REMiCOURT M., RUÉ M., 2012, « Le site Néolithique final de Labarthe 2 à Argelos (Pyrénées-Atlantiques : une occupation temporaire ? » dans Perrin T., Sénépart I., Cauliez J., Thirault E., Bonnardin S. (dir.), Dynamismes et rythmes évolutifs des sociétés de la préhistoire récente, actes des $9^{e}$ Rencontres méridionales de préhistoire récente, Saint-Georges-deDidonne (17), 8 et 9 octobre 2010, Toulouse, Archives d'écologie préhistorique, p. 423-450.

UTRILlA MIRANDA P., 1982, « El Yacimiento de la Cueva de Abaúntz (Arraiz, Navarra) », Trabajos de Arqueología Navarra, $\mathrm{n}^{\circ}$ 3, p. 201-345.

VAQUER J., GANDELIN M., MARSAC R., 2004, « Le site de Roc d'en Gabit, Carcassonne (Aude) », dans Dartevelle H. (dir.) Auvergne et Midi : actualité de la recherche, actes des $5^{e}$ Rencontres méridionales de préhistoire récente, Cabrerets, association Préhistoire du Sud-Ouest, p. 475-484. 


\section{NOTES}

1. Devant l'obligation de limiter le nombre de figures, celles-ci ne concerneront que des documents inédits ou particuliers en lien avec l'article ou difficiles d'accès. C'est ainsi que malgré leur intérêt, les mobiliers de Pau-Cabout 5, L'Estaque, Uzein et Argelos, déjà publiés, ne seront pas repris ici.

\section{RÉSUMÉS}

Cet article a pour objectif de présenter les connaissances acquises sur les types d'occupations du Néolithique dans les Pyrénées nord-occidentales. La cartographie intègre les derniers résultats obtenus lors des fouilles récentes. Cette présentation, essentiellement factuelle, évoque les résultats obtenus par les analyses polliniques, les types d'habitats et de sépultures et les éléments représentatifs de la culture matérielle. Le questionnement concernant l'origine du Néolithique ancien est abordé à partir de données récentes (grotte d'Apons, à Sarrance, PyrénéesAtlantiques); pour le Néolithique moyen, l'importance de l'occupation du territoire, supposée à partir des données polliniques, reste peu documentée; pour le Néolithique final, une présence plus importante est enregistrée. Un accent est mis sur les données inédites (fouilles de la grotte de Laa 3, à Arudy, Pyrénées-Atlantiques, et du site du Phare, à Biarritz, Pyrénées-Atlantiques) ou difficilement accessibles (grottes de Garli, à Arudy) ainsi que sur les résultats des analyses radiométriques.

The purpose of this article is to present the knowledge acquired about the Neolithic occupation types found in the northwestern Pyrenees. The mapping incorporates the latest results from the recent excavations. This presentation, which is essentially factual, refers to the results obtained by pollen analyses, settlements and burial types and the representative elements of material culture. Questions about the origin of the Early Neolithic are addressed on the basis of recent data (d'Apons cave in Sarrance); for the Middle Neolithic, the importance of the territory occupation, inferred from pollen analyzes, remains poorly documented; for the Final Neolithic, a more significant presence is recorded. Emphasis is placed on unpublished (excavations of the Laa 3 cave in Arudy, of Le Phare in Biarritz) or difficult to access (Garli caves in Arudy) data and on the results of radiometric analyses.

\section{INDEX}

Mots-clés : culture matérielle, type d'occupation

Keywords : material culture, occupation type

Index géographique : Pyrénées nord-occidentales 
AUTEUR

PATRICE DUMONTIER

Responsable bénévole d'opérations archéologiques 
Vestiges graphiques, culture matérielle et matières premières : circulations du Néolithique aux âges des métaux dans les Alpes du sud. Les exemples de l'abri Faravel (Freissinières, Hautes-Alpes), de l'abri des Oullas (Saint-Paul-surUbaye, Alpes-de-Haute-Provence) et du tertre des Sagnes (Jausiers, Alpes-de-Haute-Provence)

Graphic remains, material culture and raw materials: circulations from the Neolithic to the Metal Ages in the French Southern Alps. Faravel (Freissinières, Hautes-Alpes), Oullas (Saint-Paul-sur-Ubaye, Alpes-deHaute-Provence) and tertre des Sagnes (Jausiers, Alpes-de-HauteProvence)

Claudia Defrasne, Florence Mocci, Kevin Walsh, Stéfan Tzortzis, Brigitte Talon, Thibault Lachenal et Vincent Dumas

Les vestiges archéologiques découverts sur trois sites alpins, l'abri Faravel (Freissinières, Hautes-Alpes), au cœur du parc national des Écrins, la paroi des Oullas (Saint-Paul-sur-Ubaye, Alpes-de-Haute-Provence) et le tertre des Sagnes, dans la haute Ubaye (Jausiers, Alpes-de-Haute-Provence), situés entre 1900 et 2390 mètres d'altitude, attestent, dès le Mésolithique, d'une circulation des hommes et des idées au 
sein des massifs alpins méridionaux (Garcia et al. 2007, Mocci et al. 2009, Margarit et al. 2014, Walsh et Mocci 2011 et 2016, Walsh et al. 2010, 2014 et 2016) (fig. 1).

Fig. 1. - Localisation des principaux sites et vallées cités dans le texte.

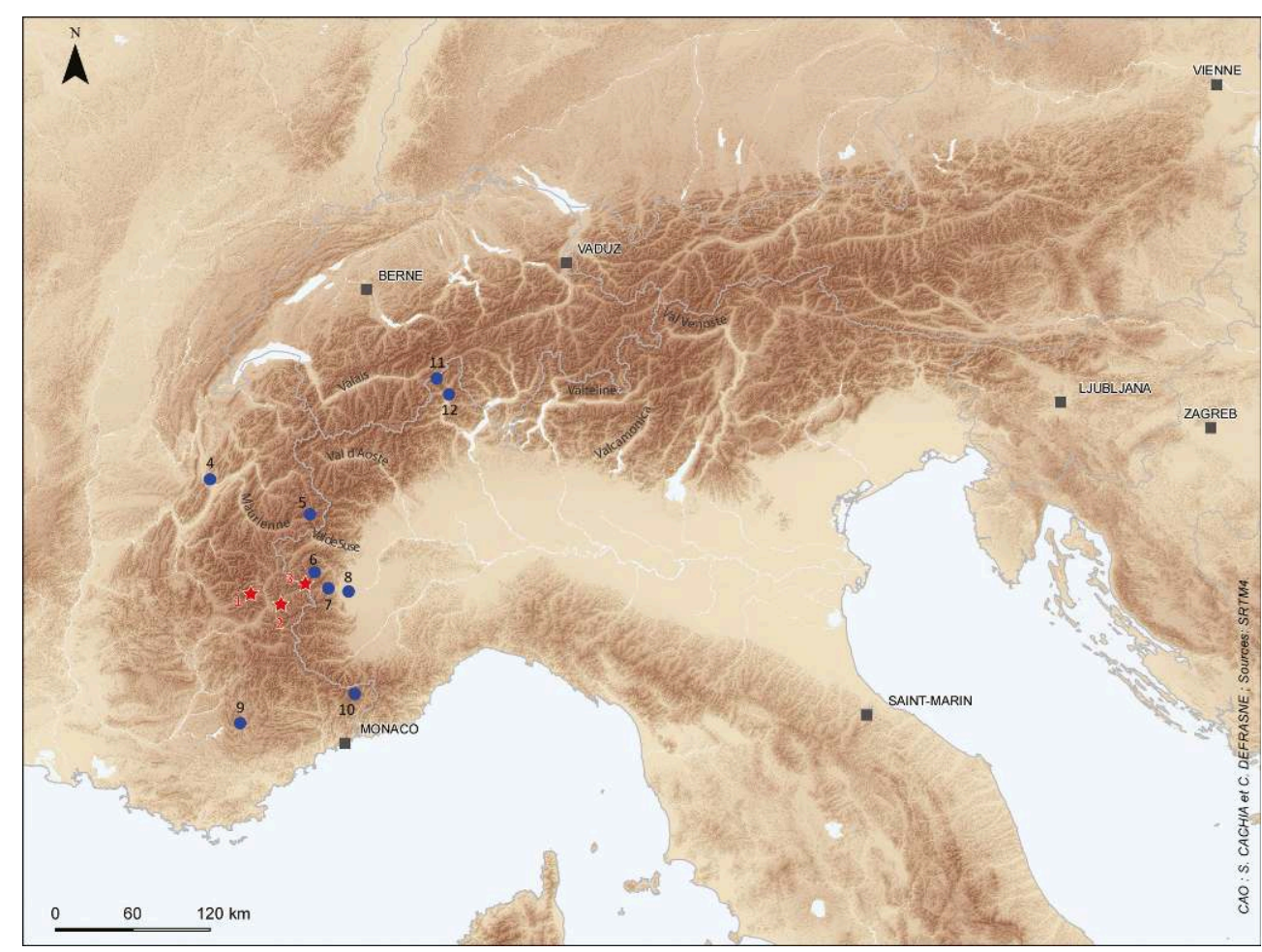

1 : abri Faravel (Freissinières, Hautes-Alpes). 2 : tertre des Sagnes (Jausiers, Alpes-de-Haute-

Provence). $\mathbf{3}$ : abri des Oullas (Saint-Paul-sur-Ubaye, Alpes-de-Haute-Provence). 4 : abri du Trou de La Féclaz (Saint-Jean-d'Arvey, Savoie). 5 : Rocher du Château (Bessans, Savoie). 6 : Roccio d'la Fantino (Val Germanesca, Piemonte, Italie). 7 : Balma di Mondon (Val Pellice, Piemonte, Italie). 8 : Rocca di Cavour (Cavour, Piemonte, Italie). $\mathbf{9}$ : Pierre Escrite (Castellane, Alpes-de-Haute-Provence). 10 : mont Bego et vallée des Merveilles (Tende, Alpes-Maritimes). 11 : Balm d'la Vardaiola (Alpe Veglia, Piemonte, Italie). 12 : Balma dei Cervi (Crodo, Piemonte, Italie).

(c) Sylvain Cachia et Claudia Defrasne, fond de carte NASA, SRTM4.

2 La fonction des sites, les graphismes pariétaux et la culture matérielle témoignent, par les structures archéologiques présentes, les matières premières employées, la technique ou le choix des expressions graphiques, d'affinités culturelles à plus ou moins longue distance. Il apparaît ainsi que ces zones de montagne, loin de constituer des barrières infranchissables, témoignent de circulations intervallées et transalpines ainsi que d'interactions culturelles nombreuses. Celles-ci mettent en lumière une problématique importante: celle des modalités de pénétration en haute montagne consécutivement à la fin des temps glaciaires. Les données relatives aux fluctuations et reflux des masses glaciaires en haute Durance apparaissent compatibles avec l'idée d'une arrivée jusqu'en montagne de groupes humains depuis les régions méridionales dès le Tardiglaciaire (Le Roy 2012). En reculant, les glaciers ont libéré d'importants espaces permettant la mise en place progressive de niches écologiques spécifiques et ont procuré ainsi des territoires nouveaux (Jorda 1988). «Les Alpes ne sont pas des confins ni un territoire extérieur en perpétuel retard sur l'évolution générale, mais à plein titre un pôle original et actif de mouvement et de contact, que ses richesses 
placent au cœur des changements culturels d'Europe occidentale» (Beeching 2003 : p. 184).

\section{Une circulation en altitude entre la préhistoire et l'âge du Fer: les sites de l'abri Faravel, des Sagnes et des Oullas}

\section{L'abri Faravel (Freissinières, Hautes-Alpes)}

Découvert en 2010 et fouillé entre 2011 et 2015 sous la direction de F. Mocci (codirection K. Walsh, C. Defrasne et V. Dumas), l'abri Faravel est un surplomb ouvert au sud-est, à 2133 mètres d'altitude, dans la partie septentrionale d'une ligne d'escarpement peu élevée de grès du Champsaur. Celle-ci constitue l'un des nombreux ressauts du plateau de la Grande Cabane de Faravel, vaste espace dénué de végétation ligneuse situé au sein du parc national des Écrins (Walsh et al. 2016), en aval du col du Fond de la Cabane (alt. $2928 \mathrm{~m}$ ) surplombant la vallée du haut Champsaur (fig. 2).

Fig. 2. - Abri Faravel (Freissinières, Hautes-Alpes) : vue depuis le nord-est.

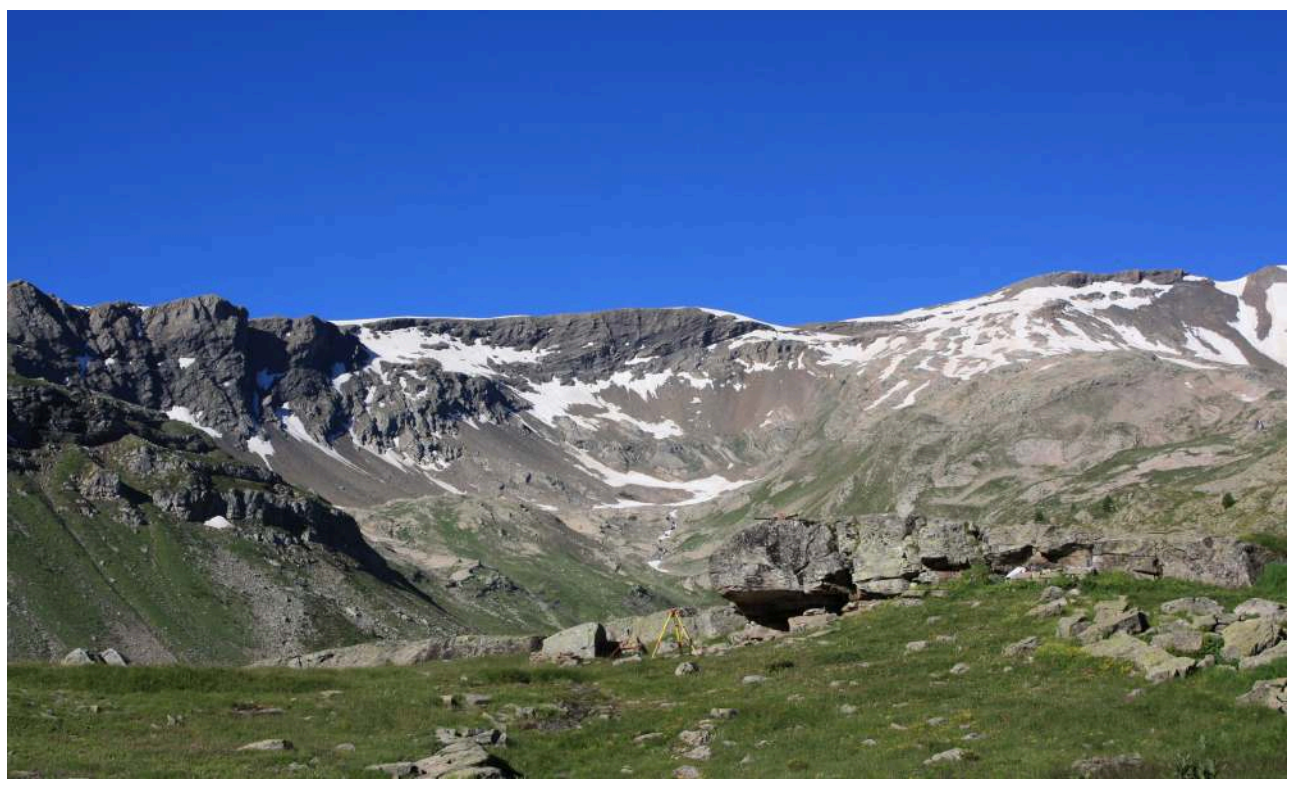

Photo Kevin Walsh, 2014

Le plafond de l'abri couvre une surface d'environ 13 mètres carrés, où sont conservés les niveaux sédimentaires les mieux préservés de tous les sites de haute altitude fouillés jusqu'à présent dans les Alpes méridionales. Les dynamiques naturelles et anthropiques locales ont contribué à l'évolution de la topographie. Lors des premières implantations, l'abri donnait sur un petit replat surplombant une petite dépression humide, entièrement comblée au début de l'âge du Bronze ; le passage depuis le plateau de la Grande Cabane de Faravel vers les vallées du Champsaur via ce col pouvait être possible grâce à la présence de zones englacées, aujourd'hui disparues. Actuellement, l'accès vers le haut Champsaur emprunte le col des Terres Blanches (alt. $2720 \mathrm{~m}$ ), qui évite le plateau de la Grande Cabane de Faravel. 
Vingt-trois phases d'occupation humaine et de processus naturels, regroupées en huit états distincts, ont été identifiées dans la chronostratigraphie de l'abri. Sur la base du mobilier archéologique et de datations radiocarbone, onze périodes sont représentées : le Mésolithique, le Néolithique ancien, le Néolithique moyen, le Néolithique récent/ final, l'âge du Bronze ancien, l'âge du Fer II, le début de la période gallo-romaine ( $\mathrm{I}^{\mathrm{er}} \mathrm{s}$.), la fin du Haut Empire/début de l'Antiquité tardive, l'Antiquité tardive, le haut Moyen Âge et le Moyen Âge classique, ainsi que l'époque contemporaine.

Le caractère exceptionnel de cet établissement de haute montagne réside pour une bonne part dans la conservation, sur le plafond de l'abri, de peintures pariétales réalisées à l'aide d'une argile rouge chargée en oxydes de fer sur des dépôts de calcite, après préparation du support par piquetage. Il s'agit à ce jour de l'unique cas recensé dans le parc national des Écrins. Au sein du mobilier archéologique, constitué de plus de 3000 objets lithiques, d'une centaine de fragments de céramique non tournée et d'objets métalliques (clous de chaussure, éléments de ferronnerie), se distingue une pièce remarquable à une telle altitude : une fibule de type Aucissa en fer, datée entre 30 et 90 av. J.-C., d'influence italique (artefacts FIB 4643 ; Feugère 1985, Riha 1994) (fig. 3).

Fig. 3. - Abri Faravel (Freissinières, Hautes-Alpes) : fibule d'Aucissa en fer (Ier siècle avant J.-C.) recueillie sur le site.

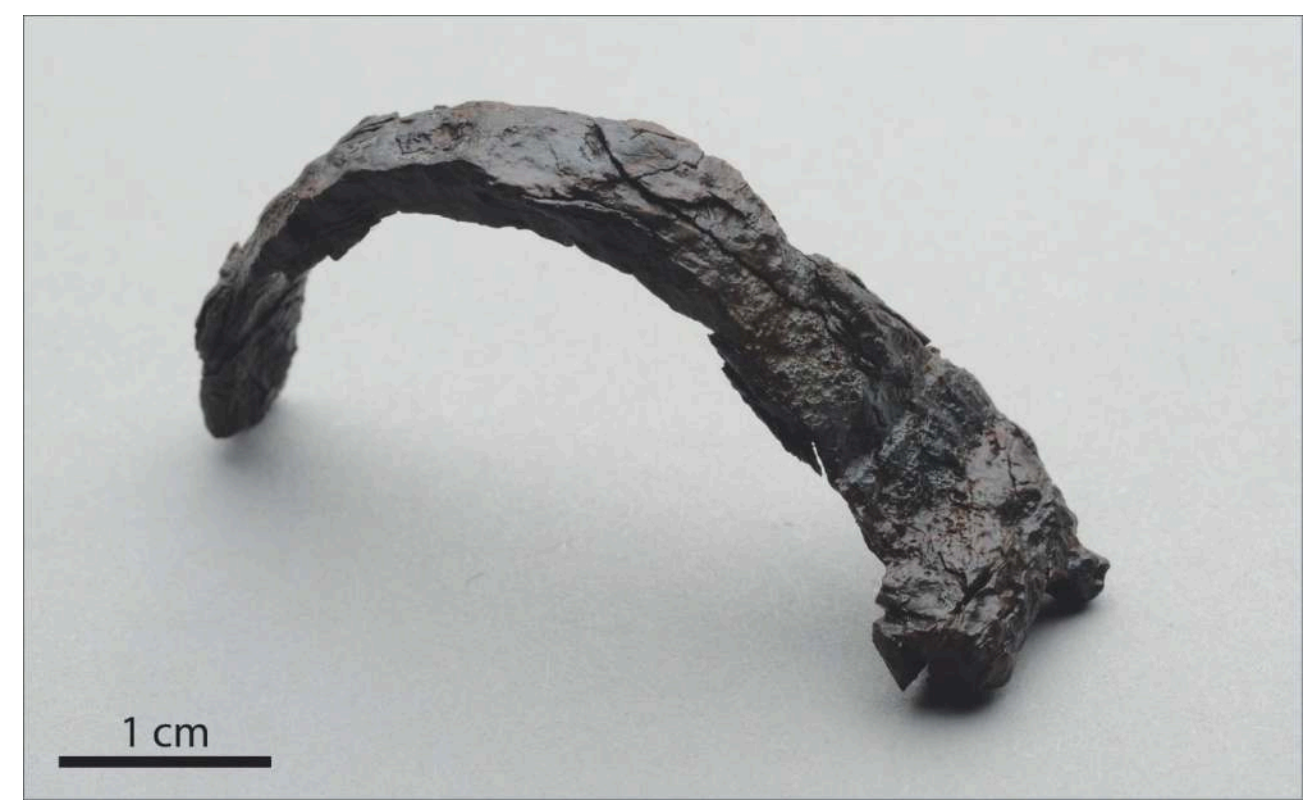

Photo Loïc Damelet.

Halte de chasse, campement temporaire, installation associée à une économie de ressources spécifiques et/ou à un itinéraire alpin (via le col du Fond de la Cabane), l'abri Faravel s'inscrit dans un environnement d'altitude régulièrement fréquenté par l'Homme depuis au moins le Mésolithique (une pointe à cran atypique attribuée au Paléolithique supérieur récent a été découverte sur le site de Faravel XIX, à 2303 mètres d'altitude, attestant d'une fréquentation antérieure) et modelé par les activités anthropiques depuis le début de l'âge du Bronze (Tzortzis et al. 2019, Walsh et al. 2014).

8 Les études paléoenvironnementales menées sur et autour du site apportent, pour les périodes préhistorique et protohistorique, des données sur l'accessibilité et 
l'occupation des zones d'altitude. L'étude pédoanthracologique réalisée sur le plateau de Faravel par B. Talon apporte une première analyse des charbons de bois conservés dans les sols hors contexte d'habitat (feux de végétation d'origine naturelle et anthropique). L'étude des charbons de bois prélevés dans les unités stratigraphiques de l'abri par C. Cenzon-Salvayre et N. Martin a permis de déterminer les taxons présents dans les contextes d'occupation et de proposer une première image de l'usage du bois comme combustible. Des carottages palynologiques conduits par J.-L. de Beaulieu ont été réalisés en aval de l'abri Faravel, dans la tourbière de Fangeas (alt. 1990 m).

Entre 16000 et 8500 avant notre ère, le milieu reste très ouvert et donc favorable aux incursions humaines. Seuls les genévriers (Juniperus) forment des peuplements arbustifs nains durant les deux phases d'amélioration climatique, vers 13000 puis vers 11000 avant notre ère, sans doute accompagnés d'un modeste développement du bouleau près des zones humides. Ce n'est que vers 8 000-6 900 avant notre ère que les boulaies claires s'installent. Au cours du Néolithique, un paysage forestier au caractère semi-ouvert à ouvert se distingue, avec une limite supérieure de la végétation forestière s'élevant jusqu'à 2300 mètres d'altitude environ. Cette végétation est constituée principalement de pin cembro (Pinus cembra) avec, en mosaïque dans le peuplement, des mélèzes (Larix decidua), des bouleaux (Betula) et des genévriers. Au Bronze ancien, le milieu boisé est caractérisé par une dominance du pin cembro et dans une moindre mesure du mélèze d'Europe et/ou de l'épicéa (Picea). La présence du bouleau, du saule (Salix) et du genévrier, tous trois héliophiles, indique que le milieu forestier est très ouvert. L'identification d'essences présentes actuellement à une altitude inférieure (érable, pin de type sylvestre) conduit à envisager l'éventualité de transport de bois de feu ou de construction depuis les altitudes inférieures vers les sites d'altitude. Entre la seconde moitié du III $^{\mathrm{e}}$ millénaire avant notre ère et le second âge du Fer, la présence croissante, dans les diagrammes polliniques, de Poaceae, des herbacées stepporudérales et nitrophiles liées à l'élevage, et de particules carbonisées (charbons) indique localement un accroissement de cette activité et l'utilisation du feu pastoral pour l'entretien des alpages. Ces signaux sont associés à une quasi-disparition de la forêt ouverte de Pinus cembra, favorisant l'expansion de Larix liée à la constitution des alpages supraforestiers locaux (Mocci et al. 2009 ; Talon 2010 ; Walsh et al. 2014 ; Tzortzis et al. 2019).

\section{Le site des Oullas (Saint-Paul-sur-Ubaye, Alpes-de-Haute-Provence)}

Le site des Oullas, ou Roche des Poignards, se situe à 2390 mètres d'altitude, dans la haute vallée du Longet, en rive gauche de l'Ubaye (Müller et Jorda 1990, Müller et al. 2004 : p. 96, Arcà et Fossati 1995 : p. 32, Arcà 2004, Trustram-Eve 2005, Defrasne et Bailly 2014). Il est situé dans un talweg orienté nord-est/sud-ouest, bordé de part et d'autre par de hautes parois schisteuses (fig. 4). 
Fig. 4. - Abri des Oullas (Saint-Paul-sur-Ubaye, Alpes-de-Haute-Provence) : vue depuis le sudouest.

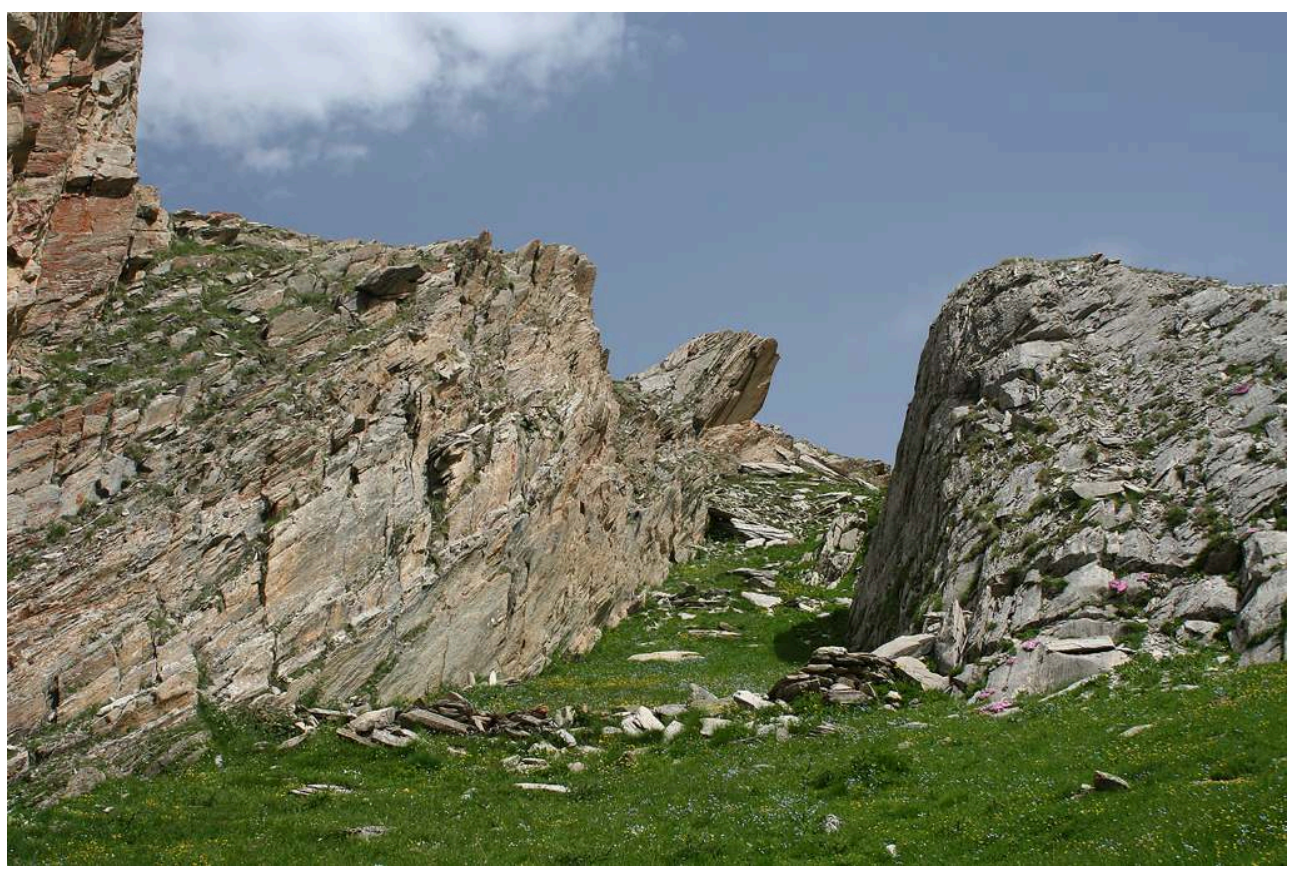

Photo Claudia Defrasne.

11 Cette configuration topographique participe à la particularité du site, véritable corridor naturel, passage sur une importante voie de communication empruntée depuis le Néolithique. En effet, la haute vallée du Longet relie l'étroite vallée de Maljasset/ Maurin (alt. $1910 \mathrm{~m}$ ) (Saint-Paul-sur-Ubaye) au col du Longet (alt.2660 m) et au piémont italien. L'une des parois faisant face au sud-est forme dans la partie aval un petit abri-sous-roche et porte un nombre considérable de peintures et gravures pariétales datées du Néolithique jusqu'à l'époque moderne (campagnes de relevés effectuées en 2010 et 2014 sous la direction de C. Defrasne). Les vestiges d'une structure rectangulaire en pierres témoignent de la récente vocation pastorale du lieu. Les sondages réalisés en 2006 sous la direction de F. Mocci (co-direction K. Walsh) à l'intérieur de la structure ont permis d'identifier trois phases :

- Des niveaux d'occupation d'époque moderne, contemporains de la structure pastorale ;

- Deux foyers successifs et des vestiges d'incendies médiévaux (1 020-1 260 cal. BC, Pa 2445);

- Une structure ovoïde, peut-être antérieure au XI ${ }^{\mathrm{e}}$ siècle avant notre ère.

12 La présence d'un important chaos rocheux sous les niveaux médiévaux a empêché la poursuite de la fouille archéologique et la recherche de niveaux contemporains des plus anciennes figurations pariétales (Mocci et Walsh 2007). La fréquentation néolithique du secteur est néanmoins attestée par la découverte de cinq haches polies lors de prospections menées dans la haute vallée au XIX ${ }^{\mathrm{e}}$ siècle, ainsi que d'une lame avec grattoir du Néolithique moyen (alt. $2521 \mathrm{~m}$ ) et d'un tranchant de hache polie en roche verte (alt. $2536 \mathrm{~m}$ ) identifiés lors de prospections en 2005 dans le cadre du programme collectif de recherche "L'Ubaye de la fin de la Préhistoire aux Temps modernes » (2001-2005). 


\section{Le site des Sagnes (Jausiers, Alpes-de-Haute-Provence)}

Découvert en 2002 et fouillé en 2003, le site des Sagnes se trouve à 1900 mètres d'altitude, dans la haute vallée de l'Ubaye (Jausiers, Alpes-de-Haute-Provence), au sein d'un environnement topographique et paysager remarquable, en bordure du parc national du Mercantour (Isoardi 2006, Garcia et al. 2007, Golosetti 2016 : p. 171) (fig. 5).

Fig. 5. - Le tertre des Sagnes (Jausiers, Alpes-de-Haute-Provence) en cours de fouille, vu depuis le nord.

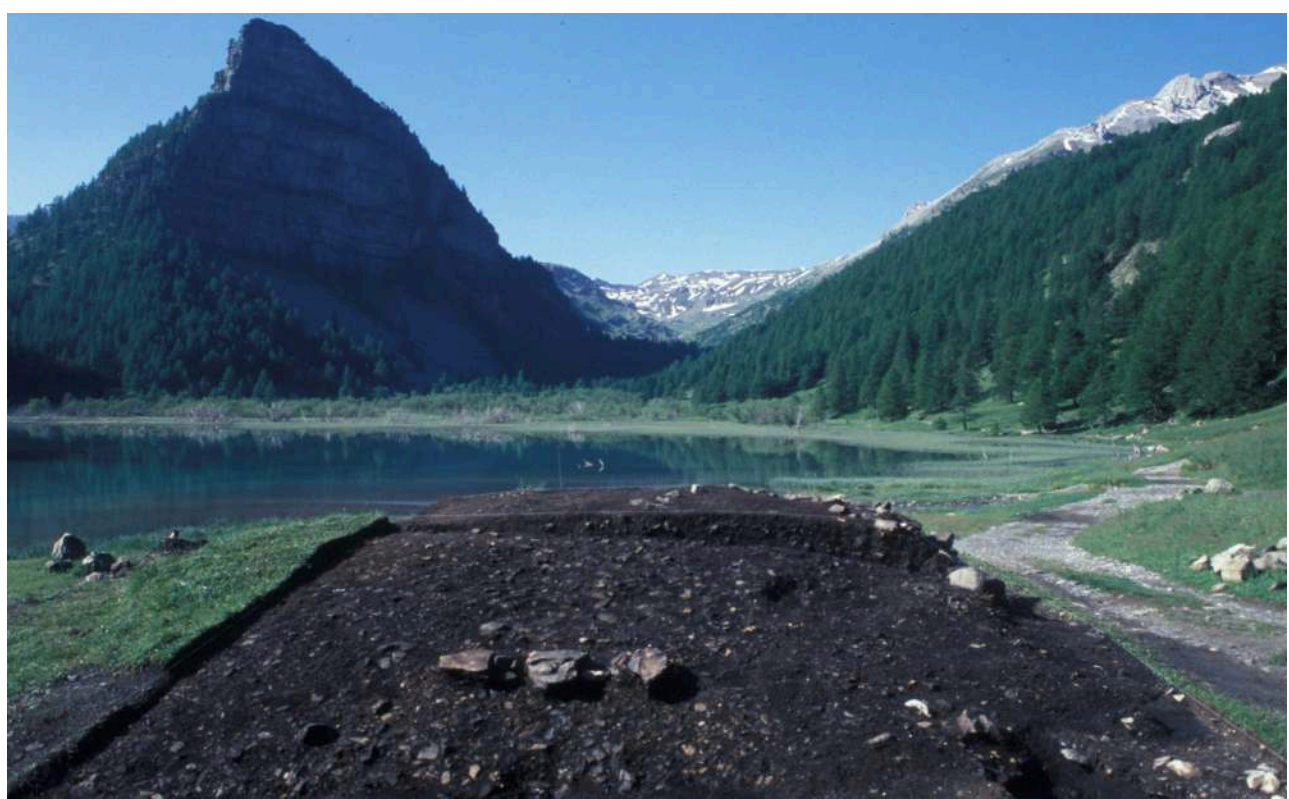

Photo Florence Mocci

Placé au pied du massif de la Tour des Sagnes (alt. $2365 \mathrm{~m}$ ), en aval des cols de Restefond et de Pelouse, voies de passage les plus directes vers les Alpes-Maritimes, le tertre des Sagnes borde une grande tourbière transformée en retenue artificielle en 1975, au débouché du torrent du Caïre. Il s'agit d'un tertre artificiel de 14 mètres de diamètre et d'une hauteur de 1,40 mètre constitué au cours de l'âge du Fer par une succession de lits de plaquettes de schiste et de charbons de bois mêlés à plus de 6000 fragments de céramiques et de restes fauniques. La base du tertre est datée, par datation ${ }^{14} \mathrm{C}$, entre 550 et $350 \mathrm{cal} . \mathrm{BC}$ ( $\mathrm{Pa} 2288$ ) et $430-170 \mathrm{cal} . \mathrm{BC}$ pour le sommet (Pa 2210). Cet amoncellement recouvrait trois fosses et un coffre constitué de deux couronnes de plaquettes plantées sur chant. Le résidu charbonneux d'une des fosses a été daté par ${ }^{14} \mathrm{C}$ entre 800 et 500 cal. BC (Pa 2289).

Ce tertre, interprété comme un aménagement cultuel résultant de la tenue d'un important banquet (Brandopferplätze), est implanté sur le sommet du cône de déjection du torrent, espace hors zone humide et hors pentes instables environnantes, propice à une installation humaine. Il succède ainsi à une occupation de la fin de l'âge du Bronze/ début de l'âge du Fer, dont témoigne une fosse de combustion au comblement riche en charbons de bois (essences variées : aulne, épicéa, hêtre ; 797-541 cal. BC, Pa 2289). Cette dernière s'implante elle-même sur une occupation du Néolithique ancien marquée, sur environ 58 mètres carrés, par la présence d'objets lithiques qui en constituent les uniques témoins. 


\section{Vestiges graphiques et culture matérielle : territoires en jeu et circulation des idées au cœur des massifs alpins}

Les vestiges matériels issus des milieux d'altitude, qu'il s'agisse de peintures et gravures ou d'objets, révèlent des interactions culturelles à différentes échelles, et des connexions à des territoires situés hors des secteurs de montagne. Ils sont les témoins de l'intégration des zones alpines à une géographie culturelle en perpétuelle évolution. Ces influences culturelles se retrouvent également au tertre des Sagnes, dont la constitution en dépôts successifs peut être comparée aux Brandopferplätze mis au jour dans les Alpes orientales et centrales, entre 800 et 2500 mètres d'altitude (Mahlknecht 2005, Pernet et Schmid-Sikimik 2007, Steiner 2010).

\section{Les graphismes pariétaux, témoins d'interactions culturelles}

Les interactions culturelles et la circulation des idées qui en est le corollaire ont été inscrites sur et dans la pierre. Les parois rocheuses et affleurements des Alpes ont livré des vestiges graphiques qui mettent en images et matérialisent des connexions entre régions européennes dès le $v^{e}$ millénaire avant notre ère. Des gravures pariétales du Val d'Aoste, du Valais suisse et probablement du mont Bégo (Alpes-Maritimes) attestent ainsi des fondements idéels unissant les Alpes au golfe du Morbihan dans le contexte de la circulation des grandes haches en roches alpines (Cassen 2017a et 2017b, Cassen et al. 2017a et 2017b). Des correspondances, non seulement de formes mais aussi d'associations de formes, entre ces régions géographiquement éloignées témoignent ainsi de l'existence d'une trame idéelle commune qui transcende la diversité culturelle.

\section{Les Alpes occidentales et l'expression schématique méditerranéenne ( $\mathrm{V}^{\mathrm{e}}-\mathrm{III} \mathrm{e}^{\mathrm{e}}$ millénaire avant notre ère)}

Peut-être dès le $\mathrm{V}^{\mathrm{e}}$ millénaire, mais probablement davantage aux $\mathrm{IV}^{\mathrm{e}}$ et $\mathrm{III}^{\mathrm{e}}$ millénaires avant notre ère (Hameau 2002), des peintures schématiques investissent des abris-sousroche d'altitude. Neuf sites en ont livré, exclusivement situés dans les Alpes occidentales (fig. 1). Le site des Oullas et l'abri Faravel en font partie. Les vestiges les plus anciens visibles sur la paroi des Oullas sont des ramiformes peints à la base du panneau rocheux (fig. 6). 
Fig. 6. - Abri des Oullas (Saint-Paul-sur-Ubaye, Alpes-de-Haute-Provence) : relevé des ramiformes peints sur la paroi.

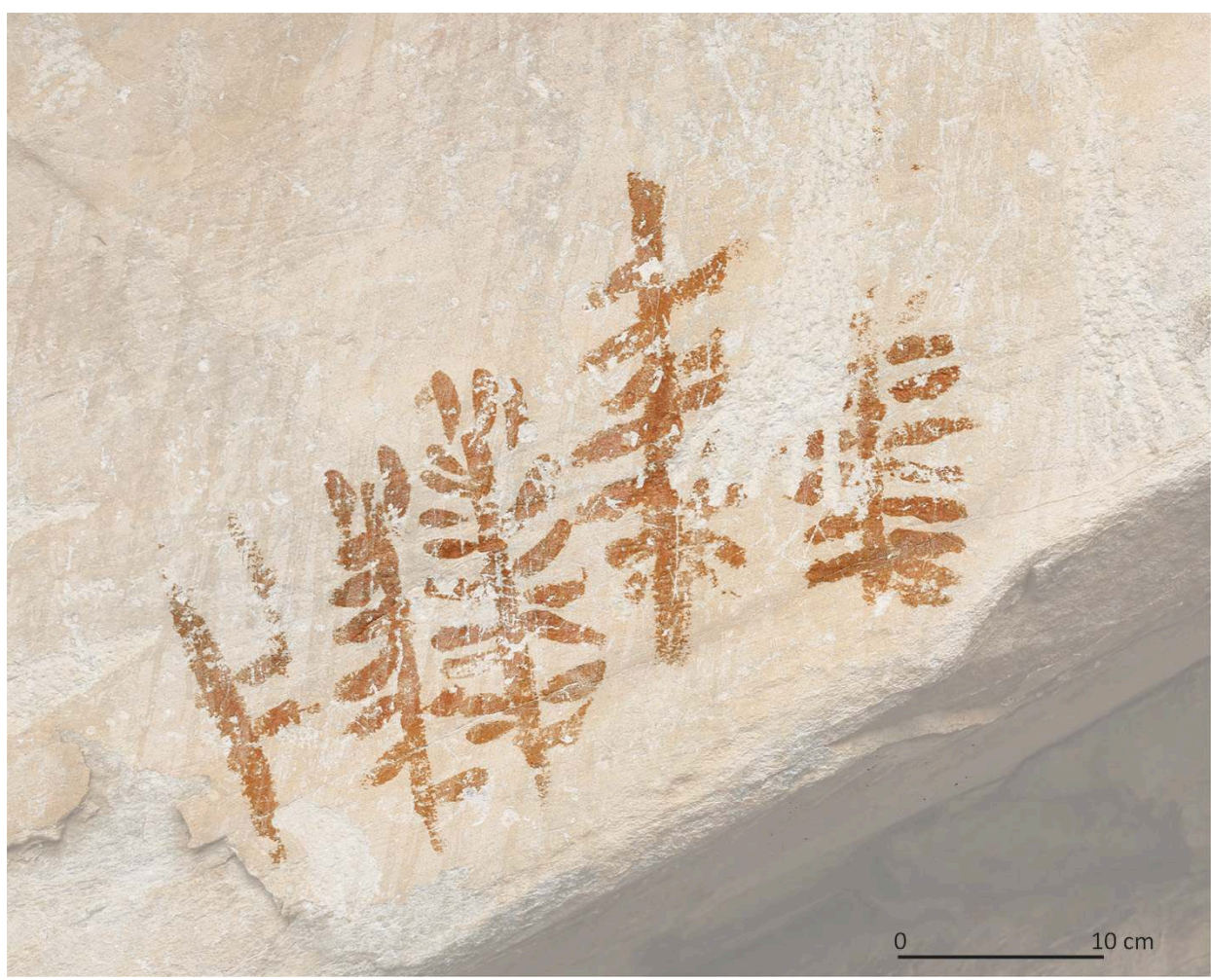

Photo Claudia Defrasne.

La technique de réalisation et la nature de ces figures permettent de les rattacher à l'expression schématique méditerranéenne, connue de la péninsule Ibérique au piémont italien. Cette expression se caractérise par la réalisation de peintures schématiques majoritairement dans des abris-sous-roche, parfois en grotte. Il semblerait que le choix des abris peints ait répondu à des critères de sélection préférentiels: une orientation méridionale, la présence d'une paroi orangée et d'écoulements périodiques d'eau sur ou aux abords du site, ainsi qu'une position dominante et/ou repérable dans l'environnement (Hameau 2002 et 2009). Le corpus de formes conjugue caractéristiques communes à l'ensemble des régions concernées et variabilité régionale. Il comprend essentiellement des ramiformes, soléiformes, lignes brisées, ponctuations, anthropomorphes et grilles, ainsi que des figurations animales, notamment des cervidés et caprinés. Les figures, d'exécution rapide, sont réduites à leur plus simple structure.

Le site des Oullas répond en tous points à ces critères, tout en étant le site à peintures situé le plus haut en altitude. L'insertion chronologique de ce phénomène demeure très imprécise en l'absence de datations absolues. Toutefois, l'ensemble des indices chronologiques issus de l'environnement des sites, des superpositions de vestiges graphiques, des comparaisons entre peintures et culture matérielle et du contexte archéologique des abris lorsqu'il est présent, situent le schématisme méditerranéen dans une période comprise entre le $\mathrm{v}^{\mathrm{e}}$ et le $\mathrm{III}^{\mathrm{e}}$ millénaire avant notre ère (Defrasne, inédit, recherche post-doctorale en cours). La paroi des Oullas a ainsi livré un terminus ante quem essentiel, les peintures schématiques étant recouvertes de gravures de 
poignards de type Remedello caractéristiques de la première moitié du $\mathrm{III}^{\mathrm{e}}$ millénaire avant notre ère.

21 Cette infiltration des massifs alpins par l'expression schématique est probablement également visible sur le site de l'abri Faravel. Son plafond a en effet livré deux groupes de tracés parallèles voisinant avec deux animaux affrontés, dont un probable cerf (fig. 7).

Fig. 7. - Abri Faravel (Freissinières, Hautes-Alpes) : peintures du plafond.

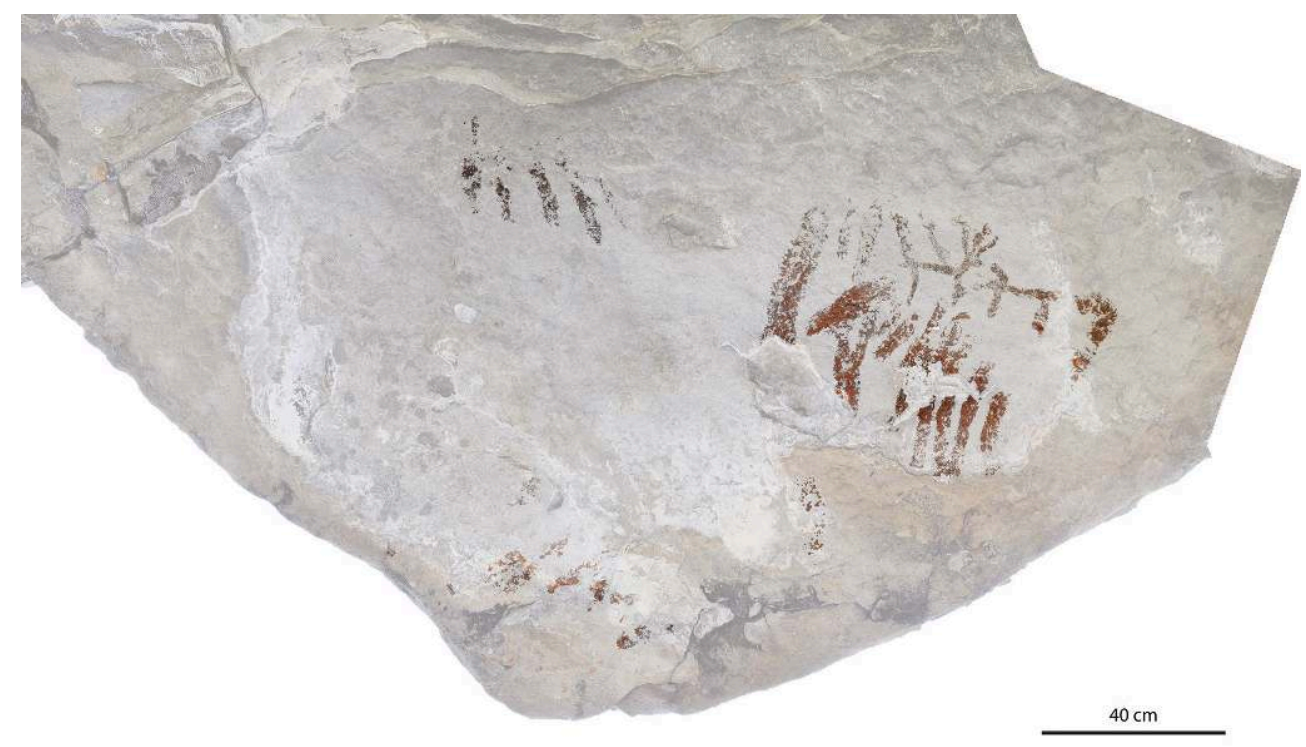

Photo Claudia Defrasne.

D'autres vestiges de peintures ne sont plus identifiables, tandis que des taches colorées sont visibles sur la paroi verticale du fond de l'abri. L'animal que nous interprétons comme un cerf présente des bois rayonnants identiques à ceux de la paroi piémontaise de la Balm d'la Vardaiola (Gambari 1994 et 2007, Crosa Lenz 2001, Poletti Ecclesia 2011, Walsh etal. 2016), ainsi qu'un projectile figuré au milieu du dos. La fouille archéologique de l'abri Faravel n'a pas permis de préciser davantage la chronologie des figurations. Celles-ci sont réalisées sur le négatif d'une dalle découverte en stratigraphie, qui se serait détachée sur les niveaux du Néolithique ancien (5 295-5 045 cal. BC $-6200 \pm 40$ BP, Poz 76773, 95,4\%) constituant de fait un terminus post quem pour la réalisation des peintures.

Ainsi, les sites des Oullas et de l'abri Faravel, deux sites de haute montagne, n'en sont pas moins pleinement intégrés à un phénomène idéel d'ampleur européenne, qui rassemble les sociétés de la péninsule Ibérique au piémont italien. La construction graphique associant cerf et projectile et véhiculant l'idée de chasse invite à évoquer des affinités à plus large échelle. Un tel schéma figuratif est documenté dans le schématisme méditerranéen (Chasteuil, gorges du Verdon ; Castellane, Alpes-de-HauteProvence), mais également dans des régions plus méridionales. Des cerfs présentant des caractéristiques et associations semblables sont peints sur les parois de la Grotta dei Cervi, à Porto Badisco (Lecce, Italie) (Graziosi 1996). Une même solution iconographique apparaît ainsi indépendante du contexte environnemental et culturel. Tout en restant prudents sur le sens à prêter à ces comparaisons entre régions très éloignées, nous pouvons interroger l'existence d'idées communes à différentes régions du Néolithique 
européen et leur circulation sur de grandes distances. Sont-elles l'indice d'un système idéel commun? Quelles sont les interactions de ces graphismes à la géographie culturelle des régions concernées et aux dynamiques culturelles identifiées par ailleurs? Ces problématiques constituent des axes de recherche essentiels, qu'il conviendra de développer ultérieurement.

\section{Le III millénaire et l'influence nord-apennine}

$\mathrm{Au} \mathrm{III}^{\mathrm{e}}$ millénaire avant notre ère, ce sont d'autres connexions culturelles et idéelles qui peuvent être identifiées sur la paroi des Oullas. Les gravures de poignards en cuivre de type Remedello qui recouvrent les peintures schématiques figurent des objets bien connus des contextes archéologiques, et particulièrement des nécropoles de la première moitié du III ${ }^{\mathrm{e}}$ millénaire avant notre ère de la plaine padane (fig. 8).

Fig. 8. - Abri des Oullas (Saint-Paul-sur-Ubaye, Alpes-de-Haute-Provence) : gravures de poignards Remedello sur la paroi.

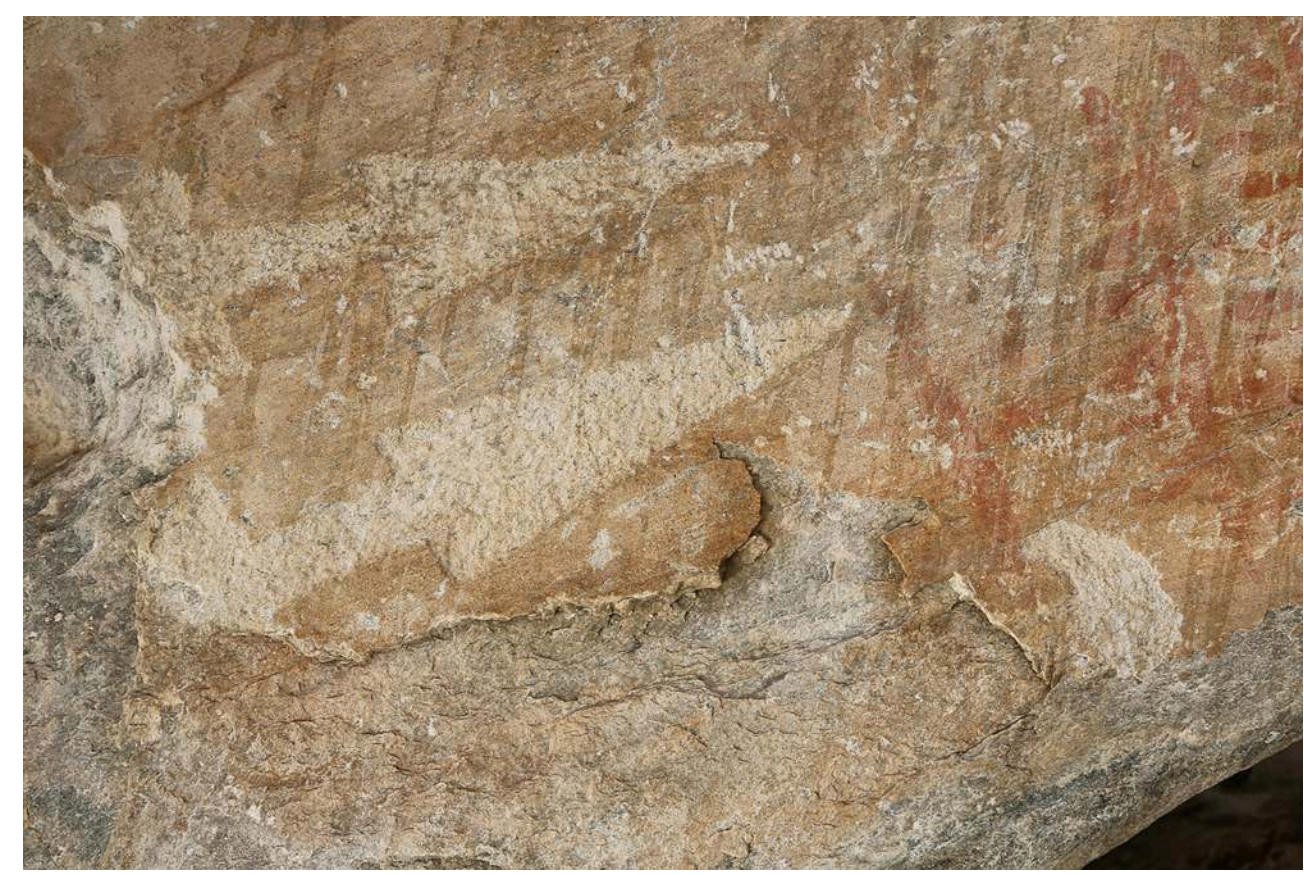

Photo Claudia Defrasne.

Ces objets en cuivre ont été investis d'une forte valeur idéelle. Leur image apparaît alors comme un dénominateur commun à nombre de régions alpines. Elles apparaissent tant sur les stèles des sites funéraires du Petit-Chasseur à Sion, en Valais suisse, que sur celles de Saint-Martin-de-Corléans, en Val d'Aoste (Mezzena 1997, Corboud 2009). Leur nombre est décuplé sur les statues-menhirs et les affleurements rocheux des Alpes centrales italiennes (Val Venosta, Valcamonica, Valtellina), témoignant d'un investissement social et idéel de l'objet. Ces images de poignards en cuivre ornent ainsi des corps de pierre érigés en contexte cérémoniel et/ou funéraire et matérialisent une communauté d'idées propre aux régions alpines au Néolithique final/ Chalcolithique. En dehors de ces secteurs, l'image du poignard Remedello se retrouve exclusivement sur la paroi des Oullas, et son absence dans le secteur du mont Bégo est notable et significative (Huet 2012: p. 286). Elle témoigne en effet de discontinuités culturelles entre certains secteurs des Alpes du sud. Quant aux gravures de poignards 
documentées à Chastel-Arnaud, dans la Drôme (Morin et al. 2005), elles présentent d'importantes différences morphologiques avec les exemples italiens, qui invitent à les considérer avec prudence. Les exemplaires ubayens, identiques aux objets réels et dont l'organisation sur la paroi évoque les statues-menhirs centre-alpines, attestent donc d'une influence culturelle nord-apennine dans la vallée de l'Ubaye au III $^{\mathrm{e}}$ millénaire avant notre ère. Cette influence est perceptible jusqu'en France méridionale, avec la découverte d'un poignard de type Remedello dans le dolmen d'Orgon, dans les Bouchesdu-Rhône (Courtin et Sauzade 1975).

\section{Le guerrier de l'âge du Fer : une image transalpine}

Cette insertion de la paroi du site d'altitude des Oullas au cœur des phénomènes culturels qui ont animé l'Europe est également valable pour l'âge du Fer. Les sites funéraires de cette période sont très bien attestés en Ubaye et témoignent d'influences transalpines (Isoardi et Mocci 2019). La paroi des Oullas offre dès lors un argument supplémentaire en faveur de connexions avec le nord de la péninsule apennine à cette période.

Une gravure de guerrier, située nettement plus haut en altitude que les sites de la même époque connus et peut-être contemporaine de la première phase du tertre des Sagnes, évoque en tous points, comme les autres pôles de l'iconographie rupestre que sont la haute Maurienne, la Valcenischia et le val de Suse, les gravures du Valcamonica, dans les Alpes centrales italiennes. Sa morphologie tend en effet à le rattacher aux $\mathrm{VI}^{\mathrm{e}}$ $\mathrm{V}^{\mathrm{e}}$ siècles avant notre ère (Fossati 1991) (fig. 9).

Fig. 9. - Abri des Oullas (Saint-Paul-sur-Ubaye, Alpes-de-Haute-Provence) : relevé de la gravure du guerrier de l'âge du Fer.

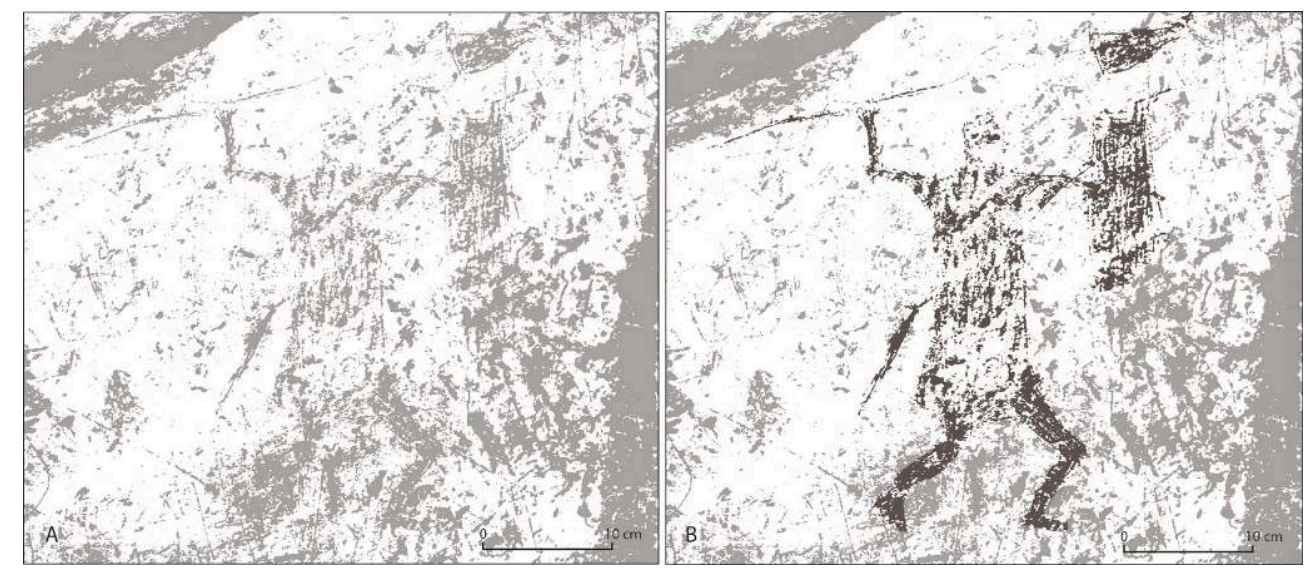

(c) Claudia Defrasne.

Du Néolithique à l'âge du Fer, les vestiges graphiques des parois d'altitude des Oullas et de Faravel attestent non seulement d'une circulation des hommes au cœur des reliefs alpins, mais également d'une circulation des idées et d'une intégration de la haute Ubaye et des Écrins dans des phénomènes culturels et idéels d'ampleur européenne. 


\section{La circulation des matières premières lithiques}

\section{L'abri Faravel}

29 Avec 3365 artefacts, l'assemblage lithique représente la majeure part des témoins archéologiques mobiliers présents sur le site de l'abri Faravel. Il faut cependant nuancer cette donnée quantitative en indiquant que la série ne représente qu'un volume et une masse pondérale limités, étant donné l'écrasante majorité des petits modules la constituant. Elle provient pour partie d'unités stratigraphiques issues de colluvionnement et se retrouve de fait fréquemment en position stratigraphique secondaire, parfois associée à des témoins plus récents. Toutefois, une partie conséquente de cet assemblage lithique a été mise au jour dans des niveaux en place correspondant aux premiers états d'occupation de l'abri. L'étude de la série est en cours et les données sont donc encore à approfondir. Les remontages, en particulier, n'ont pour l'heure pas encore été tentés. Un certain nombre de traits généraux peuvent toutefois d'ores et déjà être établis.

En dépit d'une bonne quantité de pièces non diagnostiques, la majeure partie de cette série présente une relative homogénéité technologique et peut être assignée au premier Mésolithique (Sauveterrien ou épigones). On note ainsi la présence de plusieurs dizaines d'armatures microlithiques entières ou fragmentaires, réalisées généralement sur lamelles étroites. Parmi elles sont notamment bien représentés les scalènes. Par ailleurs, une infime quantité de pièces évoque davantage le second Mésolithique (Castelnovien). La série se caractérise de plus par une production d'éclats lamellaires et de lamelles de petit module, à partir de nucléus souvent aménagés sur éclats épais. L'outillage du fonds commun, peu représenté, est constitué principalement d'éclats retouchés et de denticulés.

31 Il existe enfin une petite quantité de pièces qui se distinguent assez nettement au sein de la série et qui proviennent très probablement d'un faciès chronoculturel postérieur, en l'occurrence le Néolithique moyen. Il s'agit de fragments de lames manifestement issues d'une tout autre chaîne opératoire que celle caractérisant la production mésolithique observée par ailleurs. Il est à noter dans ce contexte que la fouille n'a livré aucun objet poli en roche tenace. Face à une quantité aussi modeste de pièces assignées à cette période, il reste difficile d'interpréter ce fait. Il pourrait en effet témoigner de la non-utilité perçue par les porteurs de cette culture matérielle de tels artefacts dans ce contexte précis (territoire investi et activités qui y sont projetées), et par conséquent de l'absence de tels objets dans le bagage des Néolithiques. Toutefois, il pourrait tout aussi bien être la conséquence d'un soin particulier accordé à la conservation de telles pièces et donc à leur transport au moment où les hommes quittent l'abri.

Du point de vue des roches utilisées, il faut signaler d'emblée que le plateau de Faravel ne recèle pas de gîtes à silex. Les formations siliceuses repérées les plus proches ne se situent pas à moins de 10 kilomètres. Il s'agit de ressources peu intéressantes, du fait de la difficulté à les extraire de leur encaissant, d'une accessibilité à leurs gîtes également difficile et surtout de leur mauvaise aptitude au débitage. Elles n'ont pas été utilisées. À l'abri Faravel, les matières premières siliceuses sont essentiellement allochtones et leurs aires d'acquisition sont situées à plus de 50 kilomètres à vol d'oiseau, au sud-sudouest. L'assemblage lithique est ainsi très largement dominé par l'association des silex hauteriviens et des silex barrémo-bédouliens. La provenance de ces matériaux est localisée sur une aire située entre le sud-ouest du département des Hautes-Alpes et le 
nord-ouest du département des Alpes-de-Haute-Provence (ouest de Montclus, secteur de la montagne de Céüze/Barcillonette, alentours de Sisteron). Est également représenté, mais dans une faible proportion, le silex bédoulien blond, dont des gîtes sont relativement connus dans la région du mont Ventoux et des monts du Vaucluse. C'est de ce matériau que sont tirées en particulier les quelques pièces attribuées au Néolithique moyen. De façon plus modeste encore est représenté le silex rubané oligocène du bassin d'Apt-Forcalquier, à la limite du Vaucluse et des Alpes-de-HauteProvence.

On rencontre enfin, là encore en moindre proportion, d'autres matières premières lithiques: du quartz hyalin (d'origine très probablement alpine), de la chaille et quelques autres types de silex, en particulier une variété noire et diaclasée dont la provenance exacte n'est pas encore établie. En fin de compte, on retrouve à l'abri Faravel la plupart des matières premières lithiques rencontrées par ailleurs sur les stations préhistoriques repérées et/ou fouillées depuis une vingtaine d'années sur le plateau et la montagne de Faravel, et plus généralement dans les massifs de l'Argentiérois/Vallouise (Tzortzis et al. 2006 et 2019, Mocci et al. 2009).

\section{Le site du tertre des Sagnes}

La série lithique constituée sur le site des Sagnes est bien modeste, avec un total de 112 pièces seulement, pour une masse limitée quant à elle à environ 160 grammes. 66 d'entre elles ont été mises au jour en stratigraphie (niveau d'occupation préhistorique et horizons protohistoriques sub-jacents), les 46 autres étant le fruit d'une collecte effectuée sur les abords immédiats du tertre, ce dernier ayant été malheureusement tronqué à au moins deux reprises au cours des temps par l'aménagement d'un chemin communal puis d'une station de pompage. L'analyse de la série a révélé des traits technologiques qui nous ont conduits à la situer sans trop de difficulté parmi les industries lithiques holocènes. La présence d'une flèche tranchante de type flèche de Montclus (armature réalisée sur lamelle par bitroncature inverse et retouche rasante directe, Orliac 1988) ainsi que l'usage avéré de la technique du microburin, avec 3 exemplaires sur lamelles de modules analogues à celui dont est tirée l'armature tranchante, nous incitent à rapprocher cet assemblage lithique des séries provenant d'horizons du Néolithique ancien de plusieurs gisements de moyenne et haute montagne des territoires alpins ou de leurs marges. Nous citerons en particulier, dans l'arrière-pays méditerranéen, l'abri Pendimoun, à Castellar (Alpes-Maritimes, Binder et al. 1993) et dans les Alpes occidentales, l'abri de La Grande Rivoire, à Sassenage, dans l'Isère (Nicod et Picavet 2013), ou bien encore le site de L'Aulp-duSeuil, à Saint-Bernard-du-Touvet, en Isère (Bintz et al. 2004). Une attribution chronoculturelle plus précise nous semble difficile sur la seule base des données technologiques et typomorphologiques disponibles, en l'absence de céramique associée comme de datation radiocarbone du niveau d'occupation préhistorique. De par sa situation géographique, le site du tertre des Sagnes pourrait se trouver dans l'aire d'influence de plusieurs ensembles culturels du Néolithique ancien : Cardial provençal et rhodanien, Impressa ligure, voire même groupe padan de Vhò (Perrin 2004).

L'assemblage lithique des Sagnes présente une palette relativement diversifiée de matériaux utilisés. Leur reconnaissance se fonde à ce jour sur un examen macroscopique. Elle demeure ainsi très générale et méritera bien entendu d'être complétée et précisée à l'issue d'une étude spécifique d'identification de nature 
pétrographique et de provenance. 25 pièces sont ainsi issues des silex barrémobédouliens mentionnés précédemment au sujet de l'abri Faravel. De même, le silex hauterivien, très présent à l'abri Faravel et plus généralement sur les sites d'altitude des Écrins, est représenté aux Sagnes par 18 objets. 7 artefacts sont issus du silex oligocène du bassin d'Apt-Forcalquier. Une courte majorité d'objets, soit un nombre de 26 , sont issus d'un silex zoné de couleur beige-blanc dont l'origine gîtologique reste à déterminer. 23 pièces ont été tirées de matériaux variés et apparemment distincts de ceux décrits précédemment, ou bien présentent une patine blanchâtre très marquée modifiant leur aspect initial. Enfin il faut noter la part des pièces, 13 au total, ayant subi une altération thermique (coloration grisâtre, aspect faïencé, cupules) ne permettant aucune reconnaissance fiable.

36 Ainsi, malgré les incertitudes pesant d'une part sur la nature exacte et l'origine des matériaux altérés et d'autre part sur celles du silex zoné, le plus représenté en nombre d'artefacts, on constate que près de la moitié de la série provient de silex allochtones. Bien évidemment, ces données sont à relativiser du fait même de la petitesse de la série et de l'impossibilité d'évaluer la représentativité d'une telle documentation vis-à-vis du site dans son état initial.

\section{Synthèse : assemblages lithiques, longues distances et exploitation des écosystèmes d'altitude}

Sur les deux sites, la forte représentation des matières premières lithiques allochtones, en provenance de sources lointaines, hors des hautes vallées et massifs centraux alpins, atteste de circuits d'acquisition à longue distance, très probablement dans le cadre d'une fréquentation et d'une exploitation saisonnière de ces territoires de haute altitude (fig. 10). 
Fig. 10. - Abri Faravel (Freissinières, Hautes-Alpes) et tertre des Sagnes (Jausiers, Alpes-de-HauteProvence) : secteurs de provenance des silex allochtones reconnus sur les sites.

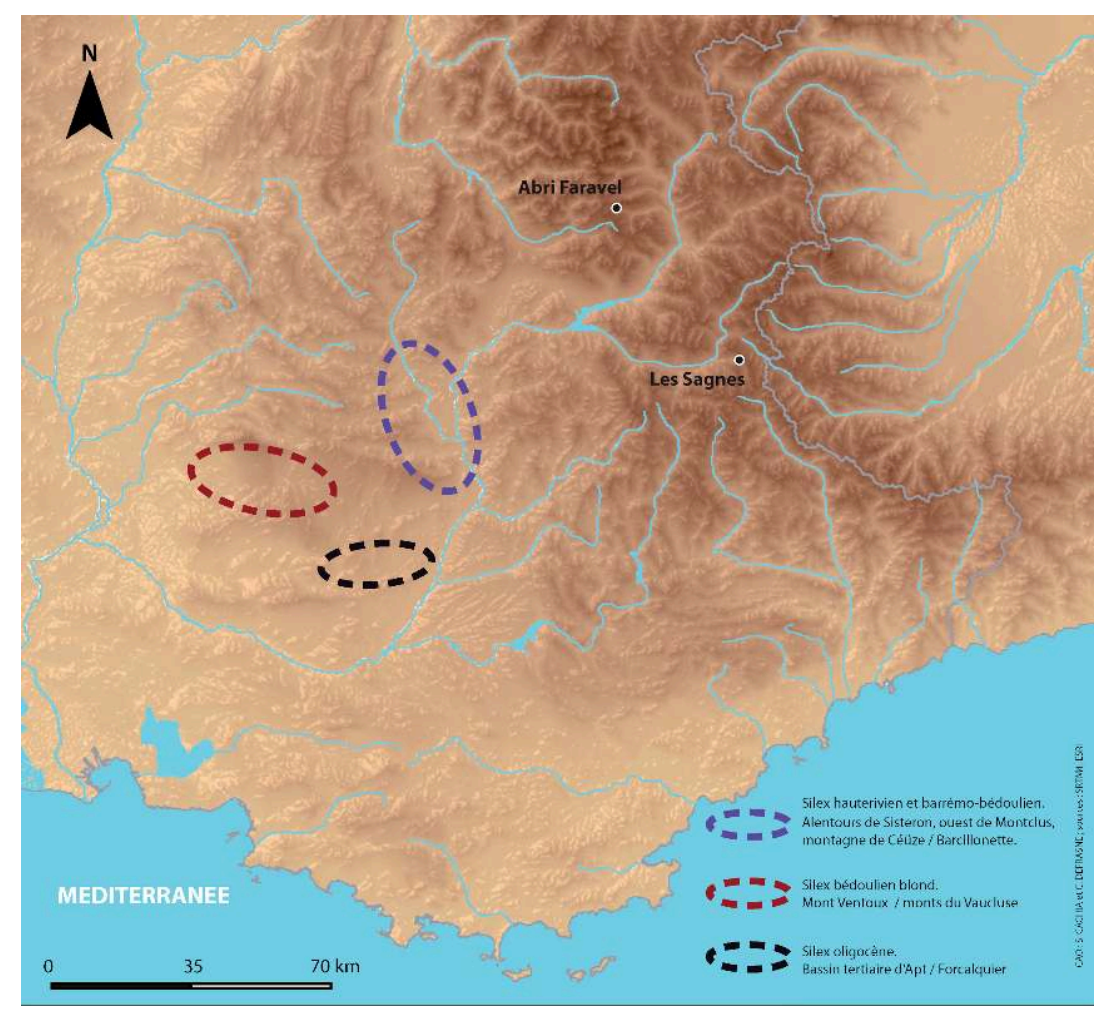

(c) Sylvain Cachia et Stéfan Tzortzis. Fond de carte NASA, SRTM4, ESRI 2017.

ganent sans doute aussi de ces trans temporaire la masse et le volume modestes des deux séries. Pour l'abri Faravel, où le nombre d'artefacts est toutefois sensiblement plus élevé, et en mettant de côté certains traits technologiques et culturels propres au premier Mésolithique en général (production de petits supports pour confectionner des armatures microlithiques), cette nette prédominance de la fraction fine au sein de l'assemblage lithique peut être aussi, en l'occurrence, la conséquence de deux pratiques non exclusives. Nous pensons ici, d'une part, au fait de limiter la quantité de matière première emportée sur le secteur afin de faciliter les déplacements depuis ses lointains gîtes. Ceci amenuise d'autant les activités de débitage et de façonnage sur le site, bien que la plupart des différents produits et sous-produits de la chaîne opératoire soient représentés dans la série, ce qui n'est toutefois pas le cas dans le petit lot de pièces assignées au Néolithique moyen, produites vraisemblablement ailleurs. Nous pensons aussi, d'autre part, au fait de conserver avec soi (de faire durer) autant que possible un grand nombre d'artefacts lithiques, qui ne seront donc pas laissés sur le site.

Comme à l'abri Faravel, beaucoup d'indices semblent indiquer que la matière première lithique n'a été introduite sur le site des Sagnes qu'en quantité restreinte. Là encore, cette donnée est sans doute à mettre en lien d'une part avec son origine lointaine (du moins dans une proportion très importante), et d'autre part avec les conditions particulières qu'engendrent les longues distances et l'altitude en ce qui concerne les déplacements. Pour être davantage nourrie, cette problématique nécessite toutefois qu'un travail plus approfondi, notamment de prospection, soit mené sur la nature et l'origine précise de certains matériaux présents dans la série. 
40 Au sein de l'assemblage lithique, le silex beige-blanc est celui qui présente le plus d'éléments d'une chaîne opératoire de débitage, avec ses produits intentionnels et ses sous-produits, en particulier l'unique nucléus décompté. Il s'agit du seul témoignage allant dans le sens d'un débitage sur place. Aucun remontage n'a pu toutefois être opéré, ce qui peut laisser supposer qu'une partie de cette production a été récupérée et emportée ailleurs.

41 Les autres matériaux sont surtout représentés par les supports, parmi lesquels se dégage une assez forte proportion de produits élancés de plein débitage, en l'occurrence des lamelles. Un tel fait peut signifier que cette partie de l'assemblage lithique a été produite ailleurs, puis conduite sur place, comme nous le pensons pour les pièces attribuées au Néolithique moyen de l'abri Faravel. Aux Sagnes, en contexte néolithique, si la retouche des supports est dans l'ensemble assez peu développée, la production ou du moins la possession d'armatures géométriques est en revanche attestée, ce qui sous-entend l'usage de l'arc et des flèches. En tenant compte notamment des spécificités de l'environnement du site, avec, en premier lieu, la proximité immédiate d'un point d'eau important, il nous semble tout à fait fondé d'associer cette occupation préhistorique à des motivations analogues à celles ayant prévalu à l'installation de groupes humains à l'abri Faravel et plus généralement sur le plateau du même nom. Ces motivations renvoient à des activités saisonnières pouvant ne mettre en œuvre qu'un groupe restreint d'individus qui évoluent dans les espaces montagnard et subalpin : chasse et collecte spécialisées, ciblées sur des niches écologiques spécifiques ; pastoralisme à compter du Néolithique, une pratique qui implique très probablement encore une part de chasse pour assurer l'ordinaire des pasteurs ainsi que le souci de préserver les troupeaux des prédateurs éventuels, loups, ours, félins.

\section{La céramique : des caractéristiques alpines?}

42 Fait inédit en contexte d'altitude dans la région, les fouilles réalisées à l'abri Faravel ont également permis la découverte de mobilier céramique. Seuls quelques cas comparables sont connus sur des sites des Alpes orientales (Reitmaer 2012 : p. 30).

Les 121 tessons récoltés correspondent à seulement 3 - éventuellement 5 - vases différents, présentant une homogénéité manifeste. Cette production se caractérise par l'utilisation d'une argile contenant naturellement des inclusions de muscovite, dans laquelle ont été adjointes des fibres d'amiante. Les surfaces, bien que sensiblement érodées, montrent les traces d'un brunissage sommaire, et ces récipients ont été cuits dans une atmosphère réductrice leur conférant des teintes noirâtres. Ces vases bénéficient de morphologies relativement simples, aux lèvres aplaties: elles correspondent à deux gobelets et un pot aux parois presque parallèles, de délinéation convexe ou légèrement sinueuse (fig. 11). 
Fig. 11. - Abri Faravel (Freissinières, Hautes-Alpes) : pot et gobelets en céramique non tournée.

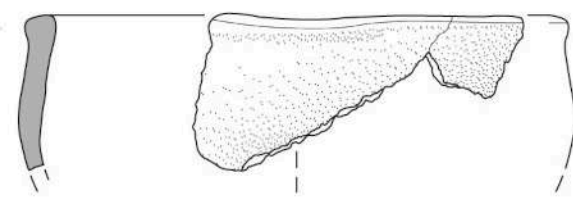

US $118 / 118 G$

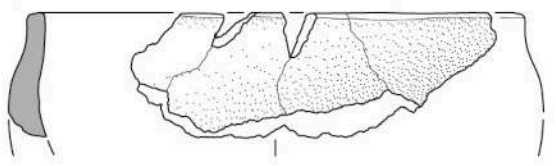

US $117 / 118 / 145$

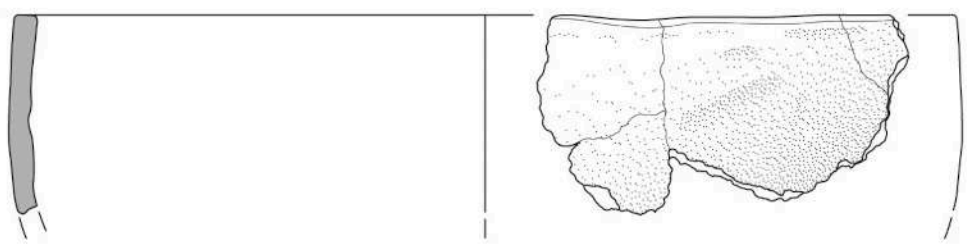

US 106/118/118G/145

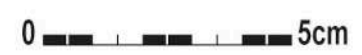

Dessin Thibaut Lachenal. dégraissant utilisé pourrait notamment provenir du gisement d'amiante du vallon de Péas, à Château-Ville-Vieille, dans le Queyras, exploité au début du $\mathrm{xx}^{\mathrm{e}}$ siècle et localisé à une trentaine de kilomètres à vol d'oiseau du site. L'intérêt de son incorporation dans l'argile est probablement technique. En effet, l'amiante offre une très bonne résistance aux chocs mécaniques et thermiques, de par son caractère réfractaire et son élasticité. Elle permet en outre de confectionner des vases aux parois fines et faiblement poreuses (Istria 2007, Paolini-Saez 2012, Peche-Quilichini et Chapon 2012). Son utilisation pourrait ainsi être dédiée à une catégorie de vaisselle servant à la cuisson de 
préparations liquides. Cette proposition n'est pas incompatible avec les analyses des résidus organiques extraits de ces tessons, lesquelles indiquent la présence de graisses animales issues de ruminants et de non-ruminants (identification biomoléculaire des marqueurs chimiques réalisée en 2014 par F. Carrer et A. Lucquin au laboratoire BioArCh, université de York).

Le mobilier céramique de l'abri Faravel, et par extension celui du tertre des Sagnes, peut ainsi être interprété comme une production spécifique aux Alpes méridionales, dont le caractère régional est confirmé par l'emploi de la technique du modelage et d'un dégraissant local. Son répertoire se distingue par ailleurs nettement des productions plus méridionales de la région provençale. Ainsi les affinités stylistiques dont il témoigne renvoient-elles plutôt au domaine continental plutôt que méditerranéen (Garcia et al. 2007 : p. 42). En l'état actuel des recherches, l'utilisation de cette céramique n'est illustrée que sur deux sites, mais cette production demeure aisément reconnaissable, en particulier par la présence d'amiante dans la pâte, ce qui devrait permettre à l'avenir de définir plus précisément son aire de diffusion.

\section{Conclusion}

Les données archéologiques issues des travaux réalisés dans les Alpes méridionales depuis une vingtaine d'années, et plus particulièrement dans les massifs des Écrins et de l'Ubaye, documentent ainsi des circulations montagnardes et transalpines dès le Néolithique. Au Mésolithique et Néolithique, les matières premières lithiques employées par les groupes fréquentant ces secteurs de montagne proviennent essentiellement, à ce jour, des zones pré-alpines, dans les secteurs de Sisteron (Céüze et Barcillonette), du mont Ventoux et des monts de Vaucluse, et dans une moindre mesure du bassin de Forcalquier. L'origine de ces matières premières implique des circulations montagnardes par des vallées pénétrant les massifs alpins des Écrins et de l'Ubaye jusqu'aux zones d'altitude où elles sont découvertes. Les sites « intermédiaires » font encore défaut pour restituer les circuits effectifs de ces groupes qui explorent des territoires sur de longues distances. Nous pouvons émettre l'hypothèse que la seule fréquentation récurrente de ces territoires pourrait être un facteur favorisant l'avènement des itinéraires transalpins parcourus aux périodes plus récentes. Des circulations transalpines à proprement parler sont, en revanche, attestées par les peintures et gravures rupestres. Au Néolithique moyen et récent/final, l'expression schématique méditerranéenne présente dans l'ensemble de la péninsule Ibérique et en France méridionale est en effet attestée dans les massifs alpins occidentaux jusqu'en Piémont. Au III $^{\mathrm{e}}$ millénaire avant notre ère, la charge sociale et idéelle prêtée à l'objet "poignard en cuivre » dans les Alpes centrales italiennes se diffuse jusque dans la haute Ubaye, où il est gravé sur une paroi bordant une importante voie de circulation reliant la vallée de la Durance et le Piémont. Ces circulations transalpines sont également attestées pour l'âge du Fer par la présence en Ubaye d'une gravure témoignant de connexions à la sphère italique ainsi que d'un Brandopferplatz, lieu cultuel largement documenté dans les Alpes centrales et orientales. Tous ces vestiges mettent en évidence l'intégration de ces secteurs d'altitude dans les phénomènes culturels et idéels qui ont animé l'Europe pré- et protohistorique et l'articulation entre circulations montagnardes et circulations européennes propres à chaque période (Hafner 2012, Jennings 2017, Lachenal 2008, Petrequin et al. 2006). 


\section{BIBLIOGRAPHIE}

ARCÀ A., 2004, « Ubaye St. Paul (Hautes-Alpes, France): the daggers Rock », dans Casini S. et Fossati A. E. (dir.), Le pietre degli dei: statue-stele dell'Età del Rame in Europa, Bergame, Civico Museo Archeologico (Notizie Archeologiche Bergomensi, 12), p. 371-373.

ARCÀ A. et FOSSATI A., 1995, Sui sentieri dell'arte rupestre: le rocce incise delle Alpi. Storia, ricerche, escursioni, Turin, Gruppo Ricerca Montana/Cooperativa Archeologica Le Orme dell'Uomo.

BEECHING A., 2003, « Mobilités et sociétés néolithiques dans les Alpes occidentales et la France méridionale », Preistoria alpina, n³9, p. 157-187.

BINDER D., BROCHIER J.-É., DUDAY H., HELMER D., MARINVAL P., THIÉBAULt S., WATTEZ J., 1993, « L'abri Pendimoun à Castellar (Alpes-Maritimes) : nouvelles données sur le complexe culturel de la céramique imprimée méditerranéenne dans son contexte stratigraphique », Gallia préhistoire, $\mathrm{n}^{\circ} 35, \mathrm{p} .177-251$.

BINTZ P., MORIN A., PELLETIER D., 2004, « Un site mésolithique et néolithique : l'abri no 1 de l'Aulp du Seuil à Saint-Bernard-du-Touvet ", dans Jourdain-Annequin C. (dir.), Atlas culturel des Alpes occidentales : de la Préhistoire à la fin du Moyen Âge, Paris, Picard, p. 37.

CASSEN S., 2017a, « Introduction », dans Pétrequin P., Gauthier É., Pétrequin A.-M. (dir.), Objetssignes et interprétations sociales des jades alpins dans l'Europe néolithique, Besançon, Presses universitaires de Franche-Comté/Centre de recherche archéologique de la vallée de l'Ain, p. 759.

CASSEN S., 2017b, «D'un signe l'autre, des Alpes à l'Atlantique : représentant et représenté », dans Pétrequin P., Gauthier É., Pétrequin A.-M. (dir.), Objets-signes et interprétations sociales des jades alpins dans l'Europe néolithique, Besançon, Presses universitaires de Franche-Comté/Centre de recherche archéologique de la vallée de l'Ain, p. 883-909.

CASSEN S., GRIMAUD V., LESCOP L., VALOIS L., 2017a, « Les compositions gravées en Beauce et Gâtinais », dans Pétrequin P., Gauthier É., Pétrequin A.-M. (dir.), Objets-signes et interprétations sociales des jades alpins dans l'Europe néolithique, Besançon, Presses universitaires de FrancheComté/Centre de recherche archéologique de la vallée de l'Ain, p. 761-846.

CASSEN S., GRIMAUD V., LESCOP L., LAGROST L., 2017b, « Les compositions gravées en Bourgogne », dans Pétrequin P., Gauthier É., Pétrequin A.-M. (dir.), Objets-signes et interprétations sociales des jades alpins dans l'Europe néolithique, Besançon, Presses universitaires de Franche-Comté/Centre de recherche archéologique de la vallée de l'Ain, p. 847-882.

CORBOUd P., 2009, « Les stèles anthropomorphes de la nécropole néolithique du Petit-Chasseur à Sion (Valais, Suisse) », Bulletin d'études préhistoriques et archéologiques alpines, nº 20, p. 9-97.

COURTIN J. et SAUZADE G., 1975, « Un poignard de type Remedello en Provence », Bulletin de la Société préhistorique française, $\mathrm{n}^{\circ} 72$, p. 184-190.

CROSA LENZ P., 2001, « Il Balm d'la Vardaiola », dans Crosa-Lenz P. (dir.), I cacciatori preistorici dell'Alpe Veglia, Turin, Edizioni Regione Piemonte/Ente Parco Vegia Devero, p. 51-52.

DEFRASNE C. et BAILly M., 2014, « Les Oullas: An Image Bearing Rockshelter on a Neolithic Alpine Path? », dans Besse M. (dir.), Around the Petit-Chasseur Site in Sion (Valais, Switzerland) and New Approaches to the Bell Beaker Culture, actes du colloque international de Sion, 27-30 octobre 2010, Oxford, Archaeopress, p. 101-110. 
FEUGÈrE M., 1985, Les fibules en Gaule méridionale, de la conquête à la fin du ve siècle ap. J.-C., Montpellier, Presses universitaires de la Méditerranée (Revue archéologique de Narbonnaise, supplément 12).

FOSSATI A., 1991, «L'eta del Ferro nelle incisioni rupestri della Valcamonica », dans La Guardia R. (dir.), Immagini di una aristocrazia dell'eta del Ferro nell'arte rupestre camuna, contributi in occasione della mostra Castello Sforzesco, 1991-1992, Milan, Comune di Milano, p. 11-71.

GAMBARI F. M., 1994, «Varzo, loc. Alpe Veglia: Scavi in insediamenti stagionali del Mesolitico e dell'età dei metallic », QuadAPiem, $\mathrm{n}^{\circ}$ 12, p. 310-311.

GAMBARI F. M., 2007, «Balm d'la Vardaiola: la pittura Neolitica », dans Di Maio P. (dir.), Prime Impronte dell'uomo nella regione Sempione-Arbola, Turin, Celid, p. 24-25.

GARCIA D., MOCCI F., TZORTZIS S., WALSH K., DUMAS V., 2007, « Archéologie de la vallée de l'Ubaye (Alpes-de-Haute-Provence, France) : premiers résultats d'un projet collectif de recherche », dans Della Casa P. et Walsh K. (dir.), Interpretation of sites and material culture from mid-high altitude moutain environments, actes du colloque international de l'European Archaeological Association, Lyon, septembre 2004, Trente, Museo Tridento di scienze naturali (Preistoria Alpina, 42), p. 23-48.

GOLOSETTI R., 2016, Archéologie d'un paysage religieux : sanctuaires et cultes du sud-est de la Gaule ( $v^{e}$ siècle av. J.-C.-IVe s. ap. J.-C.), Venosa, Osanna Edizioni.

GRAZIOSI P., 1996, The prehistoric paintings of the Porto Badisco cave, Florence, Istituto Italiano di Preistoria e Protostoria.

HAFNER A., 2012, « Archaeological Discoveries on Schnidejoch and at Other Ice Sites in the European Alps », Arctic, nº 65, p. 189-202.

HAMEAU P., 2002, Passage, transformation et art schématique : l'exemple des peintures néolithiques du sud de la France, Oxford, Archaeopress (BAR International Series, 1044).

HAMEAU P., 2009, « Site, support et signe : une cohérence de sens. L'expression graphique picturale au Néolithique ", L'Anthropologie, $n^{\circ} 113$, p. 861-881.

HUET T., 2012, « Organisation spatiale et sériation des gravures piquetées du mont Bego », thèse de doctorat, Nice, université Nice - Sophia-Antipolis.

ISOARDI D., 2006, « Histoire de la recherche archéologique en Ubaye : des antiquaires du XVI ${ }^{\mathrm{e}} \mathrm{s}$. à l'archéologie contemporaine en haute Provence », Chroniques de Haute-Provence, n 356, p. 67-129.

ISOARDI D. et MOCCI F., 2019, « Spécificité des pratiques funéraires de l'Ubaye durant l'âge du Fer : réflexion sur le genre et la place des armes dans une vallée intra-alpine », dans Bintz P., Griggo C., Martin L., Picavet R. (dir.), L'Homme dans les Alpes, de la pierre au métal, Le Bourget-duLac, Éditions de l'université Savoie - Mont-Blanc (Edytem), p. 335-343.

ISTRIA D., 2007, « L'utilisation de l'amiante en Corse du XIVe au XIX s. », Médiévales, nº 53, p. 39-50.

JENNINGS B. R., 2017, « Late Bronze Age exchange and interaction in the northern Circum-Alpine region: not only across the Alps ", dans Trefny M. et Jennings B. (dir.), Inter-regional contacts during the first millenium B. C. in Europe, $19^{e}$ Congrès de l'EAA, Pilsen, 5-9 septembre 2013, Hradec Králové, University of Hradec Králové, p. 24-45.

JORDA M., 1988, « Modalités paléoclimatiques et chronologiques de la déglaciation würmienne dans les Alpes françaises du sud (bassin durancien et Alpes-de-Haute-Provence) », Bulletin de l'Association française pour l'étude du Quaternaire, $n^{\circ}$ 2/3, p. 111-122. 
LACHENAL T., 2008, «Relations transalpines à l'âge du Bronze : état des données pour la Provence ", dans Archéologies transfrontalières, Alpes du sud, Côte d'Azur, Piémont et Ligurie, bilan et perspectives de recherche, Nice, Musée d'anthropologie préhistorique de Monaco (Bulletin du Musée d'anthropologie préhistorique de Monaco, supplément 1), p. 81-93.

LE ROY M., 2012, « Reconstitution des fluctuations glaciaires holocènes dans les Alpes occidentales : apports de la dendrochronologie et de la datation par isotopes cosmogéniques produits in situ ", thèse de doctorat en sciences de la Terre, université Joseph-Fourier Grenoble I.

MAHLKNECHT M., 2005, « Der alpine Brandopferpatz am Grubensee im Maneid-Tal », Der Schlern, $\mathrm{n}^{\circ}$ 79, p. 4-21.

MARGARIT X., MOCCI F., TZORTZIS S., WALSH K., VOYEZ C., DUMAS V., DEFRASNE C., TALON B., 2014, « Une décennie de modification des approches d'archéologie programmée et préventive en Préhistoire récente : l'exemple du département des Hautes-Alpes (1998-2012) ", dans Thirault E., Praud I., Bostyn F., Billard C., Sénépart I. (dir.), Méthodologie des recherches de terrain de la Préhistoire récente en France : nouveaux acquis, nouveaux outils, 1987-2012. Actes des Rencontres méridionales de Préhistoire récente INTERNEO, Marseille, 23 mai 2012, Toulouse, Archives d'écologie préhistorique, p. 57-72.

MEZZENA F., 1997, « La valle d'Aosta nel Neolitico e nell'Eneolitico », dans La valle d'Aosta nel quadro della preistoria e protostoria dell'arco alpino centro-occidentale, Florence/Pise, Istituti editoriali e poligrafici internazionali, p. 17-138.

MOCCI F. et WALSH K., 2007, « Saint-Paul-sur-Ubaye, Cornascle I/Les Oullas », dans Bilan scientifique 2006, Aix-en-Provence, Service régional de l'archéologie PACA, p. 39-40.

MOCCI F., WALSH K., RICHER S., BRESSY C., COURT-PICON M., TZORTZIS S., PALET-MARTINEZ J. M., BEAULIEU J.-L. de, DUMAS V., ÉDOUARD J.-L., PY V., 2009, « Archéologie et paléoenvironnement dans les Alpes méridionales françaises : hauts massifs de l'Argentiérois, du Champsaur et de l'Ubaye (HautesAlpes et Alpes-de-Haute-Provence, Néolithique final-début de l'Antiquité) », dans Desmet M., Magny M. et Mocci F. (dir.), Du climat à l'Homme : dynamique holocène de l'environnement dans le Jura et les Alpes, actes du colloque du GDR JurAlp, Aix-en-Provence, 15-16 novembre 2007, Chambéry, Université de Savoie (Cahiers de paléoenvironnement/Edytem, 6), p. 53-272.

MORIN A., PICAVET R., CARLES J., BERNARD C., 2005, « Étude préliminaire sur des poignards gravés de type Remedello découverts dans les Préalpes du sud (Chastel-Arnaud, Drôme, France) et réflexions sur leur insertion dans le Néolithique final régional ", Bulletin de la Société préhistorique française, $\mathrm{n}^{\circ} 102$, p. 345-359.

MÜLLER A. et JORDA M., 1990, Prospections et inventaire archéologique de la vallée de l'Ubaye de 1987 à 1989, rapport, Aix-en-Provence, Service régional de l'archéologie PACA.

MÜLLER A., JORDA M., GASSEND J.-M., 2004, «L'occupation humaine de la vallée de l'Ubaye et les modalités du peuplement de la zone intra-alpine », Méditerranée, nº 1-2, p. 95-108.

NICOD P-Y. et PICAVET R., 2013, « La Grande Rivoire à Sassenage (Isère) : derniers chasseurs et premiers pasteurs aux portes du Vercors ", dans Bintz P. et Millet J.-J. (dir.), Vercors, terre de préhistoire, Grenoble, Glénat, p. 168-171.

ORLIAC M., 1998, « Montclus (flèche de) », dans Leroi-Gourhan A. (dir.), Dictionnaire de la Préhistoire, Paris, Presses universitaires de France, p. 707.

PAOLINI-SAEZ H., 2012, « Les productions à pâtes amiantées à l'âge du Fer : origines et évolution », dans Peche-Quilichini K. (dir.), L'âge du Fer en Corse : acquis et perspectives, actes de la table-ronde de Serra-di-Scopamène, août 2009, Serra-di-Scopamena, Associu Cuciurpula, p. 76-86. 
PECHE-QUILICHINI K. et CHAPON P., 2012, « La céramique non tournée de la fin du deuxième âge du Fer d'I Palazzi (Venzolasca, Haute-Corse) », Documents d'archéologie méridionale, nº 35, p. 285-300. PECHE-QUILICHINI K. et PICCARDI E., 2013, « Domestic uses, trading and afterwards functions of pottery in the 2nd Iron Age northern Tyrrhenian sea: potential identity evidences ", dans Bombardieri L., D’Agostino A., Guarducci G., Orsi V., Valentini S. (dir.), SOMA 2012: Identity and connectivity, actes du $16^{e}$ Symposium Mediterranean Archaeology, Florence, mars 2012, Oxford, Archaeopress (BAR International Series, 2581), p. 705-714.

PERNET L. et SCHMID-SIKIMIC B., 2007, « Le Brandopferplatz de Wartau Ochsenberg (canton de SaintGall) dans son contexte régional », dans Barral P., Daubigney A., Dunning C., Kaenel G., RoulièreLambert M.-J. (dir.), L'âge du Fer dans l'arc jurassien et ses marges : dépôts, lieux sacrés et territorialité à l'âge du Fer. Actes du XXIX Colloque de l'AFEAF, Besançon, Presses universitaires de Franche-Comté (Annales littéraires de l'université de Franche-Comté, série Environnement, sociétés et archéologie), vol. 2, p. 819-834.

PERRIN T., 2004, « Les processus de néolithisation en Italie septentrionale », Bulletin de la Société préhistorique française, $\mathrm{n}^{\circ} 101$, p. 887-891.

PÉTREQUin P., ERRERA M., PÉTREQUin A.-M., ALLARD P., 2006, « The Neolithic Quarries of Mont Viso, Piedmont, Italy: Initial Radiocarbon Dates », Preistoria Alpina, n 35, p. 7-30.

POLETTI ECCLESIA E., 2011, « Parco Naturale Veglia Devero », dans Guida breve al museo e al territorio, Varzo, Archeomuseo multimediale del Parco Veglia Devero, p. 12-13.

REITMAIER T., 2012, Letzte Jäger, erste Hirten : Hochalpine Archäologie in der Silvretta, Chur, Somedia (Archäologie in Graubünden, numéro spécial 1).

RIHA E., 1994, Die römischen Fibeln aus Augst und Kaiseraugst, vol. 2 : Die Neufunde seit 1975, Augst, Römermuseum (Forsch. in Augst, 18).

STEINER H., 2010, Alpine Brandopferplatze: Archaologische und naturwissenschaftliche Untersuchungen, Trente, Temi.

TALON B., 2010, « Reconstruction of Holocene high-altitude vegetation cover in the French southern Alps: evidence from soil charcoal », The Holocene, $n^{\circ}$ 20, p. 35-44.

TRUSTRAM-EVE N., 2005, « A geo-spatial analysis of alpine rock art », mémoire de master, Department of Archaeology, University of York.

TZORTZIS S., MOCCI F., WALSH K., TALON B., COURT-PICON M., DUMAS V., PY V., RICHER S., 2006, « Les massifs de l'Argentiérois du Mésolithique au début de l'Antiquité : au croisement des données archéologiques et paléoenvironnementales en haute montagne (Hautes-Alpes, parc national des Écrins) », dans Garcia D. et Richard H. (dir.), Le peuplement de l'arc alpin, actes du $131^{e}$ Congrès national des sociétés historiques et scientifiques, Grenoble, 2006, Paris, Éditions du CTHS, p. 123-148.

TZORTZIS S., MOCCI F., WALSH K., DEFRASNE C., TALON B., LACHENAL T., DUMAS V., CENZON-SALVAYRE C., 2019, «L'abri Faravel et la fréquentation préhistorique de la moyenne et de la haute montagne dans le parc national des Écrins (Hautes-Alpes, France) », dans Bintz P., Griggo C., Martin L., Picavet R. (dir.), L'Homme dans les Alpes, de la pierre au métal, Le Bourget-du-Lac, Éditions de l'université Savoie - Mont-Blanc (Edytem), p. 161-176.

WALSH K. et MOCCI F., 2011, « Mobility in the Mountains: Late Third and Second Millennia Alpine Societies' Engagements with the High-Altitude Zones in the Southern French Alps ", European Journal of Archaeology, $\mathrm{n}^{\circ}$ 14, p. 88-115. 
WALSH K. et MOCCI F., 2016, « Driving forces and variability in the exploitation of a high-altitude landscape from the Neolithic to Medieval Periods in the Southern French Alps », dans Collis J., Pearce M., Nicolis F. (dir.), Summer farms: Seasonal exploitation of the uplands from prehistory to the present, Sheffield, J. R. Collis Publications (Sheffield Archaeological Monographs, 16), p. 183-201.

WALSH K., MOCCI F., TZORTZIS S., BRESSY C., TALON B., RICHER S., COURT-PICON M., DUMAS V., PALET-

MARTINEZ J. M., 2010, « Les Écrins, un territoire d'altitude dans le contexte des Alpes occidentales de la Préhistoire récente jusqu'à l'âge du Bronze », dans Tzortzis S., Delestre X., Greck J. (dir.), Archéologie de la montagne européenne, actes du colloque international de Gap, musée-museum départemental, 29 sept.- $1^{\text {er }}$ oct. 2008, Aix-en-Provence, Errance/Centre Camille Jullian (Bibliothèque d'archéologie méditerranéenne et africaine, 4), p. 211-225.

WALSH K., COURT-PICON M., BEAULIEU J.-L. de, GUITER F., MOCCI F., RICHER S., SINET R., TALON B., TZORTZIS S., 2014, «A historical Ecology of the Ecrins (Southern French Alps): Archaeology and Palaecology of the Mesolithic to the Medieval Period », Quaternary International, $n^{\circ} 353$, p. 52-73. WALSH K., MOCCI F., DEFRASNE C., DUMAS V., MASINTON A., 2016, « Interpreting the Rock Paintings of Abri Faravel: laser and white-light scanning at 2,133 $\mathrm{m}$ in the southern French Alps ", Internet Archaeology [en ligne], vol. 42, https://doi.org/10.11141/ia.42.1.

\section{RÉSUMÉS}

Les recherches menées depuis plusieurs années dans les Alpes du sud ont mis en évidence la présence et l'intense circulation des hommes au cœur des reliefs alpins dès la Préhistoire. Les sites et indices de sites en milieu d'altitude y sont en effet nombreux. L'étude des matières siliceuses et céramiques permet d'identifier des connexions à d'autres territoires et attestent d'échanges et de circulation à plus ou moins longue distance. Il en va de même de la fonction de certains sites à vocation rituelle. S'y ajoute l'image rupestre qui, par le choix des formes et des techniques, invite à considérer des circulations à l'échelle européenne dès le Néolithique. Trois sites emblématiques ont été choisis pour illustrer le propos : l'abri Faravel (Freissinières, HautesAlpes, alt. $2133 \mathrm{~m}$ ) dans le parc national des Écrins, l'abri des Oullas (Saint-Paul-sur-Ubaye, Alpes-de-Haute-Provence, alt. $2390 \mathrm{~m}$ ) et le tertre des Sagnes (Jausiers, Alpes-de-HauteProvence, alt. $1900 \mathrm{~m}$ ), dans la haute Ubaye.

Research conducted for over twenty years in the Southern French Alps has highlighted the presence and intensity of human mobility in the core of this region since prehistoric times. Surveyed and excavated sites are numerous in the sub-alpine zone $(1,500-2,300 \mathrm{~m})$. The study of lithic and ceramic material allows us to consider connections with other territories and infer exchange and circulation networks over a range of distances. The same is true for certain types of ritual sites. The study of rock art, based on the assessment of the similar forms and techniques apparent at a number of sites, allows us to consider the question of the mobility of ideas at the European scale from the Neolithic onwards. Three emblematic sites have been chosen to illustrate this subject: the Faravel rock shelter (Freissinières, Hautes-Alpes, 2,133 m) in Les Écrins National Park, the Oullas shelter (Saint-Paul-sur-Ubaye, Alpes-de-Haute-Provence, 2,390 m) and the Sagnes burnt-mound (Jausiers, Alpes-de-Haute-Provence, 1,900 m) in the Upper Ubaye. 
INDEX

Mots-clés : abri-sous-roche, céramique, circulation, industrie lithique, Brandopferplätze, peinture rupestre, Préhistoire, Protohistoire

Keywords : ceramic material, human mobility, lithic industry, Brandopferplätze, rock art, Prehistory, rockshelter, Protohistory

Index géographique : Alpes

\section{AUTEURS}

\section{CLAUDIA DEFRASNE}

Aix-Marseille Université, CNRS, LaMPEA, Aix-en-Provence, France

\section{FLORENCE MOCCI}

Aix-Marseille Université, CNRS, Centre Camille Jullian, Aix-en-Provence, France

\section{KEVIN WALSH}

University of York, Department of Archaeology

\section{STÉFAN TZORTZIS}

Ministère de la Culture, direction régionale des affaires culturelles de PACA, service régional de l'archéologie et Aix-Marseille Université, CNRS, EFS, Anthropologie bioculturelle, droit, éthique, santé (ADES), Marseille, France.

\section{BRIGITTE TALON}

Aix-Marseille Université, CNRS, Centre Camille Jullian, Aix-en-Provence, France ; Institut de recherche pour le développement ; Avignon université, Institut méditerranéen de biodiversité et d'écologie marine et continentale (IMBE)

\section{THIBAULT LACHENAL}

ASM - Archéologie des sociétés méditerranéennes, UMR 5140, Univ Paul-Valéry Montpellier, CNRS, MCC, F-34000 Montpellier, France

\section{VINCENT DUMAS}

Aix-Marseille Université, CNRS, Centre Camille Jullian, Aix-en-Provence, France 
Nouvelle lecture des rapports interculturels entre les communautés aux marges de l'Apennin méridional (régions Campania et Puglia, Italie) à partir de découvertes récentes

New reading of intercultural relationships between communities on the margins of the southern Apennine (Campania and Puglia regions, Italy) from recent discoveries

Claude Albore Livadie, Anna Maria Tunzi, Elena Soriano, Nicola Gasperi et Francesco Matteo Martino

1 Le territoire considéré dans cet article comprend un vaste secteur de la Campanie centrale et méridionale et la partie occidentale du Tavoliere delle Puglie, une plaine située dans le nord des Pouilles. Les divers cours d'eau qui proviennent de la chaîne de l'Apennin samnite et traversent la plaine du Tavoliere constituent aujourd'hui, comme jadis, une voie naturelle de pénétration vers la côte adriatique (fig. 1). 
Fig. 1. - Localisations des vallées fluviales entre la Campanie et la région des Pouilles.

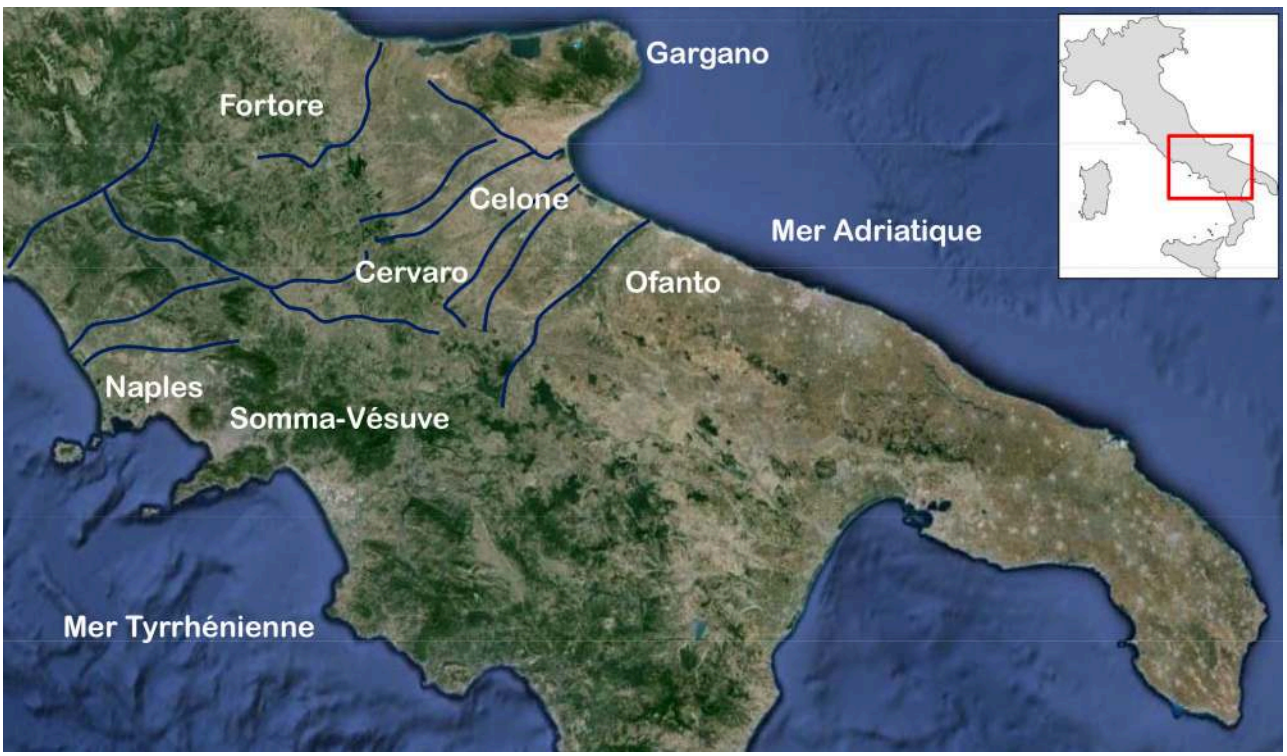

PAO Francesco Matteo Martino

2 L'Apennin samnite, formé de montagnes aux sommets plus ou moins arrondis et de cols de faible altitude, sépare le versant adriatique de la plaine campanienne, sans toutefois constituer une réelle frontière. En effet, au niveau de la culture matérielle, de la circulation et de la diffusion des modèles, la plaine campanienne semble avoir eu précocement un rôle central dans les contacts avec les zones limitrophes de la région des Pouilles.

\section{Chronologie, faciès culturel et impact volcanique}

3 Au cours de sa longue histoire éruptive, le complexe volcanique Somma-Vésuve a profondément marqué le paysage et l'histoire du peuplement, et ce depuis les périodes les plus anciennes et jusqu'à nos jours, déterminant l'aspect actuel d'une grande partie de la Campanie interne, qui lui doit la fertilité de ses sols et sa vocation principalement agricole. Les manifestations éruptives, qu'il s'agisse d'éruptions pliniennes, subpliniennes ou d'épisodes à caractère secondaire, se sont succédé cycliquement durant des milliers d'années.

L'éruption plinienne des ponces d'Avellino, qu'un grand nombre d'analyses radiométriques a datée de $3550 \pm 20 \mathrm{BP}$, soit 1951-1 $773 \mathrm{cal}$. BC $2 \sigma$ (Passariello et al. 2009), a frappé de nombreux villages, localisés principalement dans le secteur nordouest de la plaine campanienne. Les produits pyroclastiques ont rejoint les provinces d'Avellino et de Bénévent, plus à l'est, et ont même atteint le secteur septentrional de la région des Pouilles (fig. 2). 
Fig. 2. -Distribution des ponces d'Avellino dans la région du Vésuve.

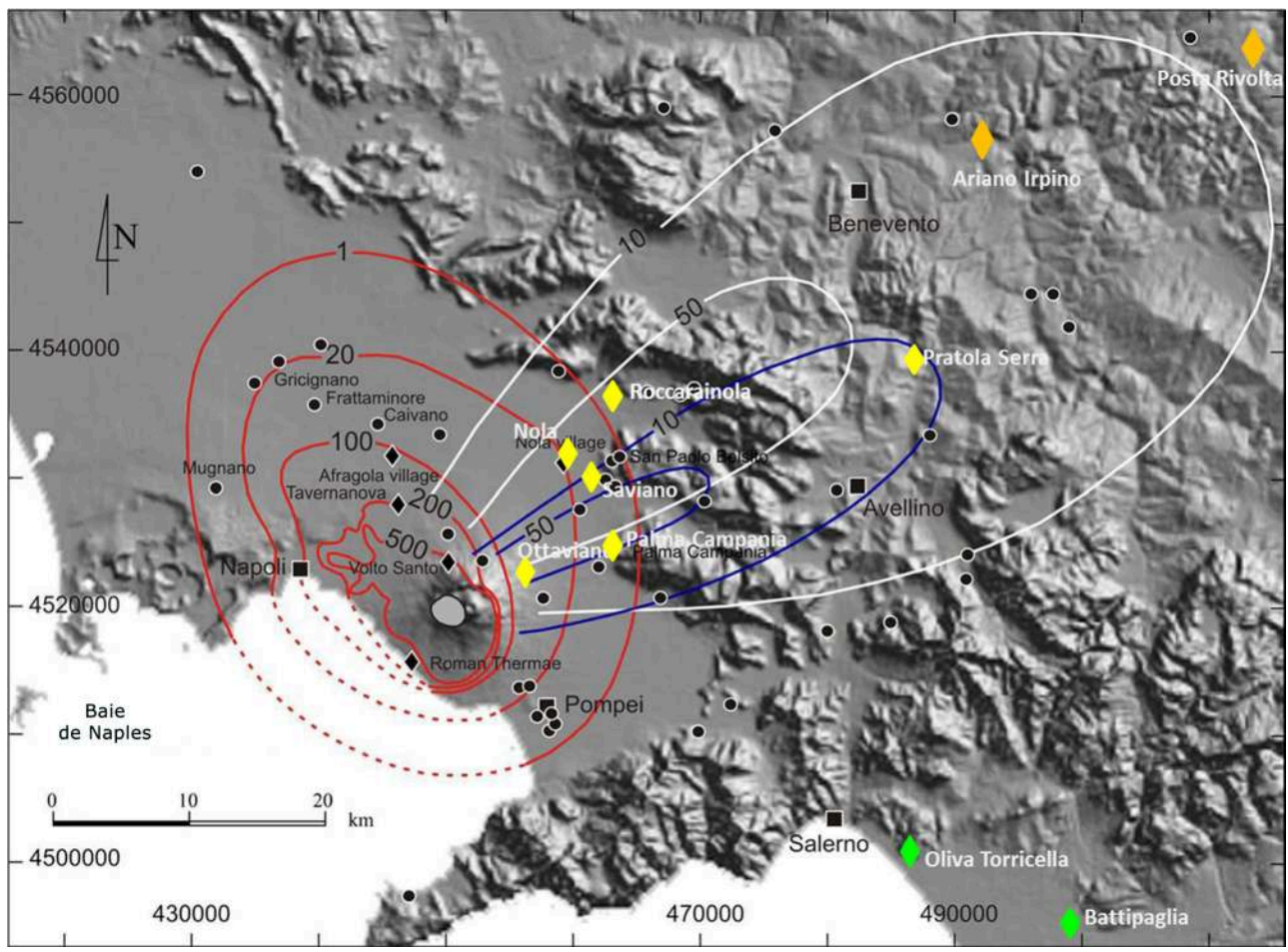

Les isochrones des retombées des ponces d'Avellino sont en centimètres. EN BLEU : EU2 (ponces blanches). EN BLANC : EU3/EU4 (ponces grises). EN ROUgE : coulées pyroclastiques (EU5). Les points se rapportent aux sites archéologiques de l'âge du Bronze ancien trouvés jusqu'à présent sous les dépôts. Les losanges jaunes, orangés et verts correspondent aux sites mentionnés dans le texte.

D'après Di Vito et al. 2009, PAO Elena Soriano.

Selon la typologie du matériel éjecté, l'impact de l'éruption a produit une brutale interruption, plus ou moins durable, de la vie des villages situés dans le secteur des retombées principales. Cette catastrophe constitue donc un terminus ante quem pour la formation des aspects spécifiques qui ont fortement caractérisé la culture dite de Palma Campania dès les premières découvertes (Albore Livadie 1980 et 2007). Les villages détruits et recouverts par les produits volcaniques peuvent donc être considérés comme des contextes clos, contemporains dans leur ultime phase de vie. L'éruption devient de ce fait une importante borne chronologique de référence pour le développement des cultures de l'Italie méridionale tyrrhénienne (Albore Livadie 2011).

La culture de Palma Campania, du nom du site éponyme découvert en 1972 à Naples (Albore Livadie 1980), semble être caractérisée par une grande homogénéité, tant par sa production céramique que par le choix de la localisation des habitats. Certaines formes peuvent être considérées comme de véritables fossiles directeurs de cette culture (Soriano et Livadie, sous presse). On les retrouve en effet aux marges de la plaine campanienne et de l'aire de retombée des produits éruptifs, sur les hauteurs qui constituent l'appendice méridional de l'Apennin campanien, mais aussi dans plusieurs sites des Pouilles, établis dans les vallées fluviales reliant les Apennins à la mer Adriatique. Le village du Bronze ancien final/Bronze moyen initial de Posta Rivolta (Foggia) en fait partie. Récemment fouillé, il documente divers aspects de l'influence de la culture propre à la Campanie (Tunzi et al. 2012, 2017a et 2017b) (fig. 3 et fig. 4). 
Fig. 3. - Posta Rivolta (Foggia) : planimétrie de la fouille.

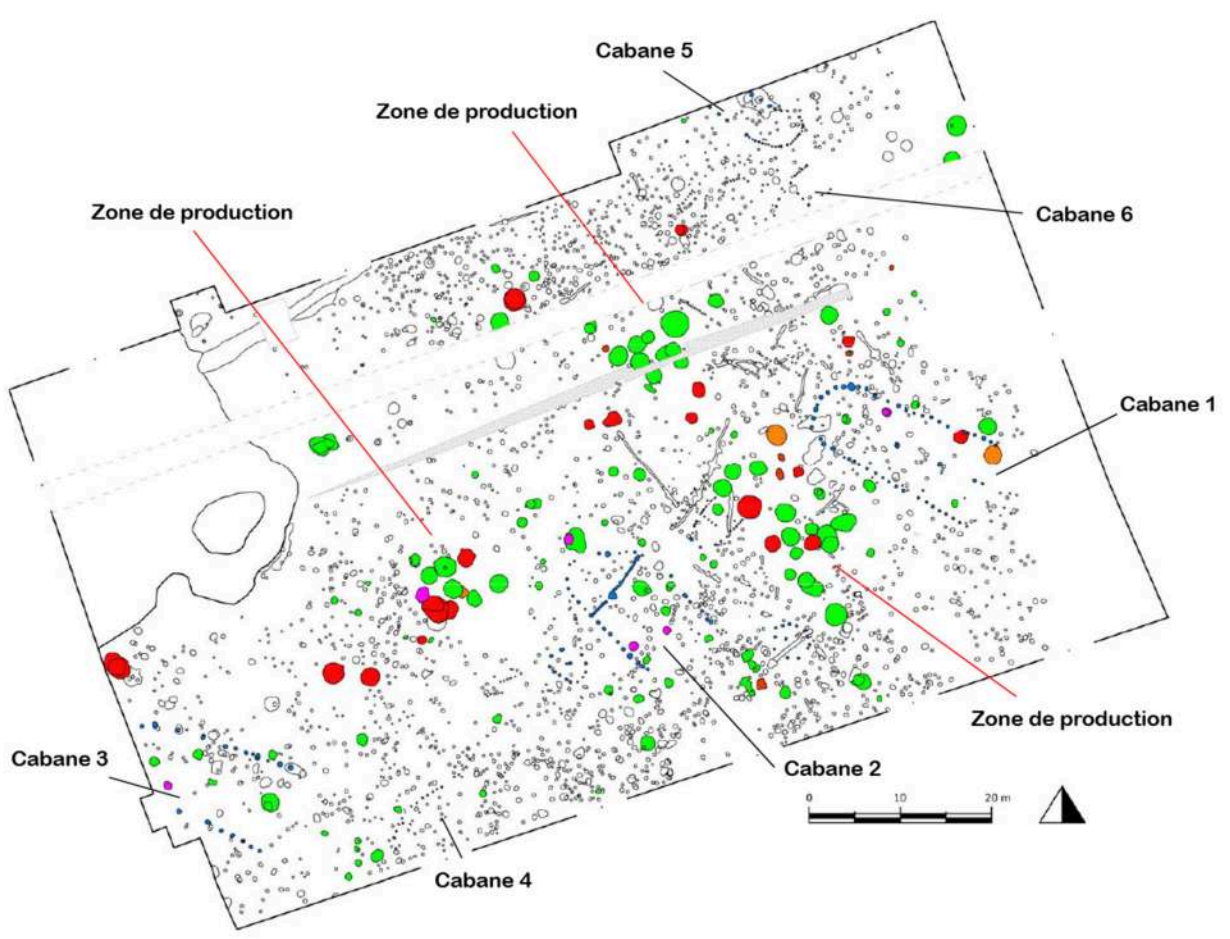

PAO Nicola Gasperi. 
Fig. 4. - Posta Rivolta (Foggia) : témoignages de la culture propre à la Campanie.
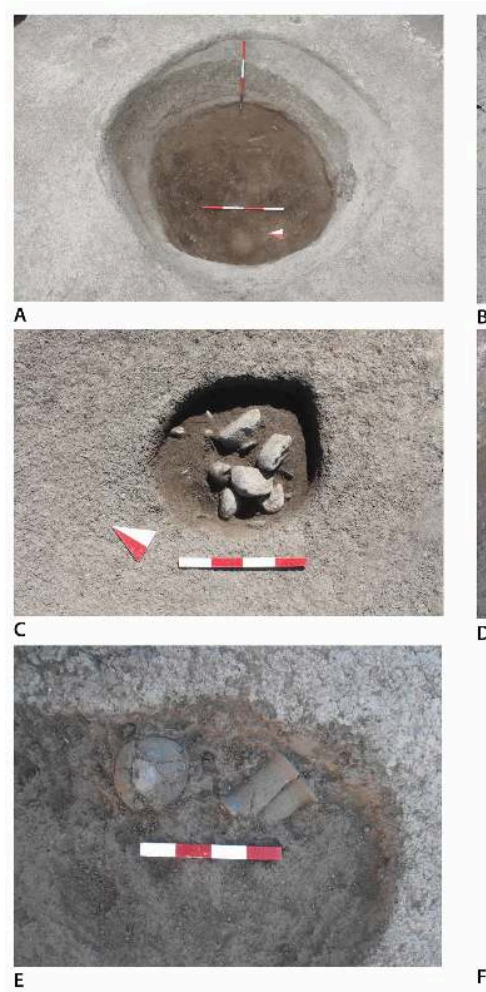
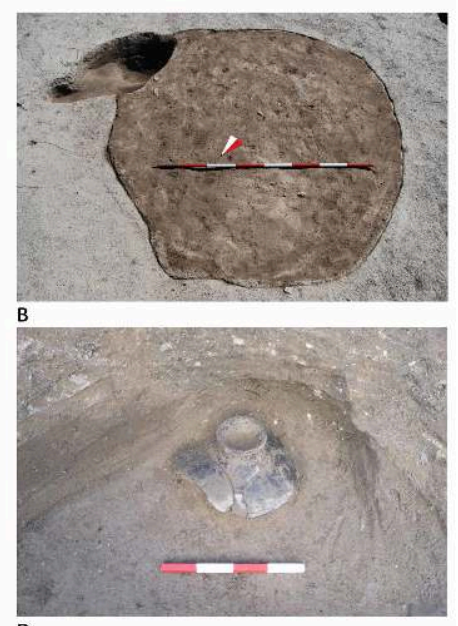

D
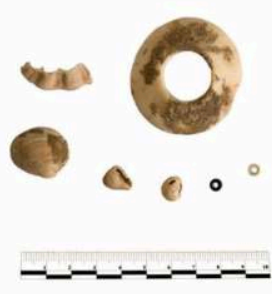

A : niveau de combustion du four T. B : couche d'oblitération de la fosse 90 . c : oblitération de la fosse 104 avec galets et détail d'une écuelle mono-ansée. D : vase sur pied de la fosse 97 . E : fosse 82, mise au jour d'un vase mono-ansé et d'un support. $\mathbf{F}$ : coquillages utilisés pour le collier de la tombe 3 (à enchytrismos).

Photos Nicola Gasperi.

7 Du côté campanien, le site de La Starza (Ariano Irpino) présente de fortes similitudes avec celui de Posta Rivolta (Albore Livadie 1992, 1995a, 1995b et 1996). En position stratégique sur les collines pré-apenniniques, cet habitat de longue durée - sa séquence stratigraphique va du Néolithique ancien jusqu'au premier âge du Fer, presque sans solution de continuité - offre une clé de lecture d'importance fondamentale pour cette période complexe de la Protohistoire campanienne. Mais c'est la richesse des matériaux céramiques provenant des couches post-éruptives qui permet d'appréhender le mieux l'importance des contacts. Ces niveaux appartiennent à la période finale du Bronze ancien campanien et à la phase de passage au Proto-Apenninique, qui précède directement la période apenninique. La stratigraphie relative à la période postérieure à l'éruption des ponces d'Avellino à La Starza et à Posta Rivolta, quoiqu'en l'absence sur ce dernier site de dépôts pyroclastiques, permet d'évaluer le phénomène protoapenninique et sa formation dans une région de frontière entre la Campanie et les Pouilles. Les indices rassemblés laborieusement, principalement grâce aux fouilles récentes, offrent un éclairage nouveau qui souligne l'interdépendance de ces deux régions.

Il est fort vraisemblable que la force dévastatrice de l'éruption des ponces d'Avellino a eu des conséquences sur la dynamique du peuplement; elle conditionne sans aucun doute la lecture des données relatives aux aspects propres du faciès de Palma Campania et celle des aspects liés à la période proto-apenninique qui a suivi. 
On sait que la culture apenninique, définie par Ugo Rellini dans les années 1930 et décrite par Salvatore Puglisi en 1959 comme une expression des communautés pastorales en Italie, a été précédée par une période dite proto-apenninique, succédant au Bronze ancien (Lo Porto 1962-63, Peroni 1996 : p. 202-204, Soriano et Albore Livadie 2016). La découverte en 1972 à Palma Campania (Naples) d'une maison qui faisait certainement partie d'un village plus vaste s'est avérée essentielle pour l'élaboration des séquences culturelles de l'âge du Bronze en Italie méridionale. Recouverte par une épaisse couche de pyroclastites attribuées à l'éruption des ponces d'Avellino (Albore Livadie 1980), cette maison contenait plus d'une centaine de vases de types fort différents de ceux que l'on connaissait jusqu'alors dans la région. Cette riche documentation posait les bases de la définition d'un nouvel aspect culturel, dit de Palma Campania, propre au Bronze ancien en Italie méridionale tyrrhénienne.

Mais quel est le rapport de ce nouveau faciès avec les cultures qui l'ont précédé ? Sa genèse n'est pas encore pleinement acquise, bien que des études récentes semblent rapporter à la culture transadriatique de Cetina une partie du patrimoine décoratif, en particulier le motif des files de triangles opposés (fig. 5).

Fig. 5. - Céramiques de type Cetina (site de Fossa Aimone, Atena Lucana) et Palma Campania (site de Croce del Papa, Nola).
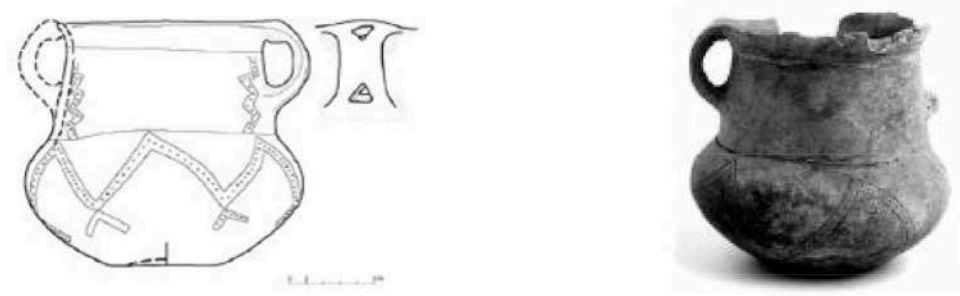

facies Cetina - Musée Archéologique National de Naples (MANN)

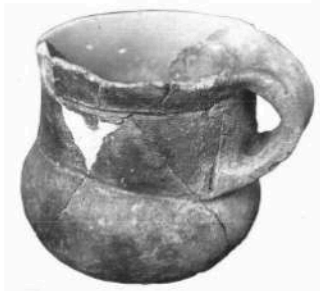

facies Cetina - Fossa Aimone Atena Lucana
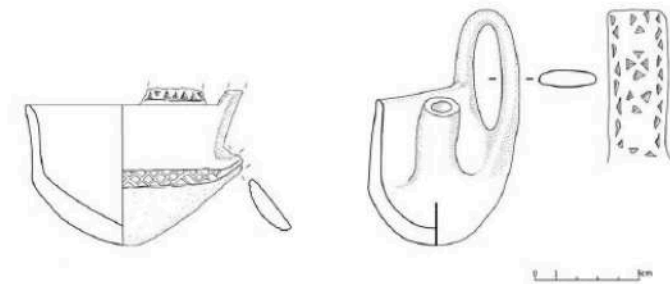

facies Palma Campania - Nola Croce del Papa

Extrait de Soriano et Albore Livadie 2016

11 La présence du faciès Cetina est documentée d'ailleurs dans un certain nombre de sites campaniens (Arcuri et al. 2016), dont l'habitat d'oliva Torricella (Salerno) qui appartient à un moment ancien de la culture de Palma Campania (Di Maio et Scala 2012, Albore Livadie 2012). Cependant, le manque de publications concernant des fouilles plus récentes ne permet pas de clarifier les éventuels rapports avec les séquences énéolithiques de l'Italie méridionale. 
12 À cette incertitude concernant les phases initiales de la culture de Palma Campania s'ajoute une méconnaissance des phases finales, principalement de leurs rapports avec le Proto-Apenninique. Une meilleure connaissance de cette période paraît désormais nécessaire à la compréhension des phénomènes liés aux modifications, à partir de ce moment central du Bronze ancien profondément marqué par l'éruption, de l'occupation du territoire, de l'organisation et de l'évolution de l'espace rural, de l'exploitation des ressources (production agricole et élevage), de la façon d'habiter et de construire, de la structuration des rapports sociaux, mais aussi des formes d'échange et de contact.

\section{Stratégies d'implantation et formes de l'habitat}

13 En ce qui concerne le secteur nord-ouest de la plaine campanienne et les villages du Bronze ancien qui y étaient installés au moment de leur destruction par l'éruption, on peut poser l'hypothèse (que seule une enquête territoriale systématique et une étude typologique des habitats pourront confirmer) de vastes agglomérations qui s'étendaient sur plusieurs hectares. Situés à proximité de cours d'eau, ces villages avaient une économie de subsistance mixte qui prévoyait une agriculture intensive, comme cela a été démontré dans une récente étude sur les traces de labour (Saccoccio et al. 2013). Les sols demeuraient fertiles sans que soit nécessaire le recours à l'alternance des cultures, vu le processus de régénération naturelle et de fertilisation dû aux produits volcaniques. L'agriculture côtoyait l'élevage du bétail (ovicaprins et bovins), dont on trouve les témoignages à l'intérieur des villages et à proximité : clôtures et empreintes d'animaux (Albore Livadie et al. 2007, Laforgia et al. 2007).

14 En ce qui concerne les habitats, qui occupaient les collines ou la ceinture montagneuse pré-apenninique aux marges de la plaine campanienne, berceau et épicentre de la culture de Palma Campania, on peut supposer aussi une vocation liée à l'activité pastorale saisonnière. La montée dans les pâturages d'altitude liée à la transhumance estivale est bien attestée dans les massifs montagneux de Campanie, principalement durant le Bronze ancien. Dans la région d'Avellino, le massif du Taburno-Camposauro témoigne de fréquentations régulières (Albore Livadie 1980, Talamo 1996). Il en est de même des sites de Fraconia et de Palombaio (Taurano, Campanie), situés à une altitude de 600 mètres environ, ou de Visciano (sur le mont Donico, Campanie) à une altitude encore supérieure. Dans la zone de Solofra-Serino (Albore Livadie 1999), diverses localités s'égrènent sur le parcours qui conduit aux stations fréquentées comme estives. La vocation pastorale propre à ces lieux de hauteur délimitant la plaine campanienne n'exclut pas, comme nous l'avons déjà souligné, la transformation du lait et la production de fromages, fonction qui avait un rôle d'une certaine importance également dans les communautés villageoises de la plaine (Citro, sous presse).

Caractéristique d'une économie mixte, le village de Croce del Papa (Nola) restitue des récipients de céramique et des seaux réalisés en lattes de bois, dont l'un d'entre eux devait être accroché à l'enceinte d'un enclos près de la cabane 2 (Albore Livadie 2002 et 2011, Albore Livadie et Vecchio 2005). Ils devaient être utilisés pour la traite. L'usage d'ustensiles liés au filtrage des produits laitiers est documenté à Roccarainola (Calcara Pagliara) par des tasses mono-ansées dont le fond est percé d'un trou circulaire (Albore Livadie 1999), au mont Castello (Savignano Irpino, Campanie) et bien sûr à La Starza (Ariano Irpino), où sont présents des couvercles de bouilloire et des vases avec un bord 
interne, retrouvés aussi à Croce del Papa (cabane 4), à Roccarainola et à Posta Rivolta (fig. 6).

Fig. 6. - Sites de Croce del Papa (Nola), Pratola Serra, Roccarainola (Naples), Posta Rivolta (Naples), La Starza (Ariano Irpino), Frattaminore (Naples) : ustensiles divers destinés aux produits laitiers.

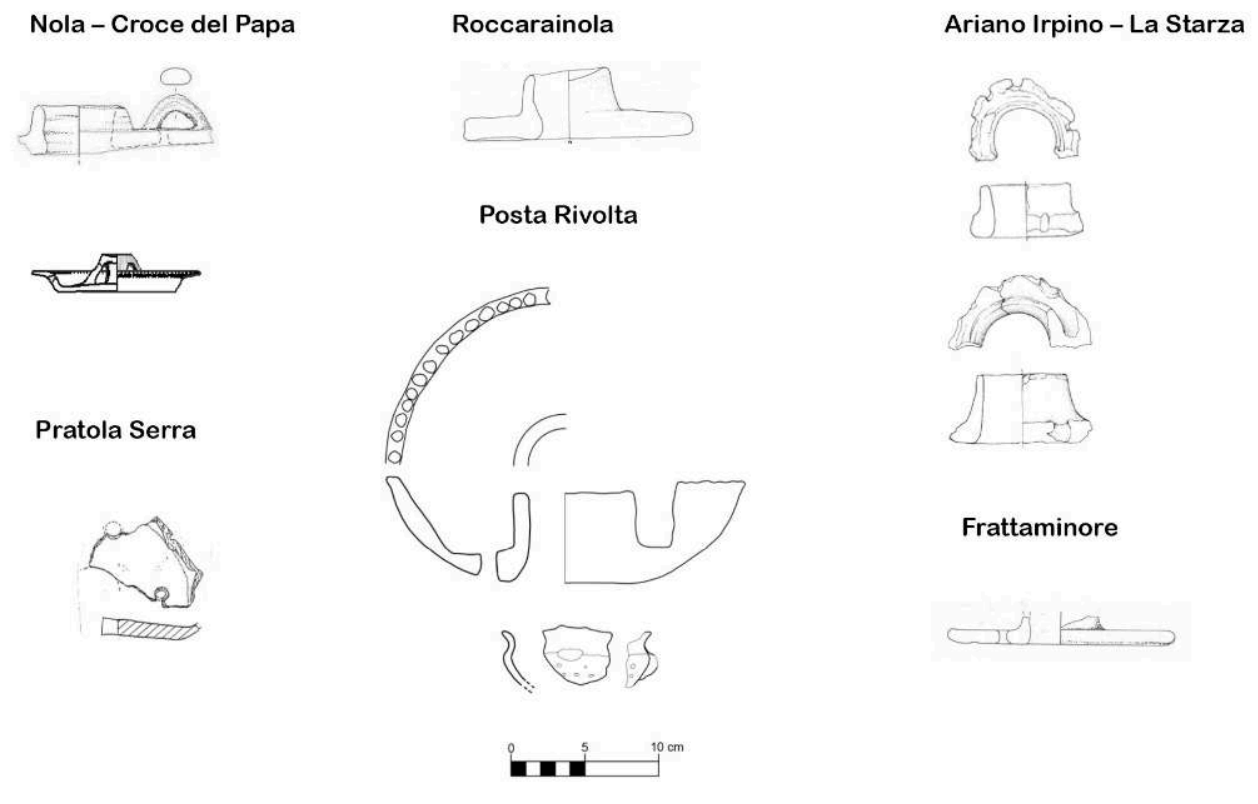

Extrait de Soriano et Albore Livadie 2016

Des correspondances étroites dans la production céramique sont indéniables une fois encore à Ariano Irpino et à Posta Rivolta. Elles s'affirment de la fin du Bronze ancien au tout début du Bronze moyen (Proto-Apenninique) et sous-entendent clairement la circulation de modèles et/ou de personnes entre les deux régions. Ces deux sites, peu distants l'un de l'autre, occupent des positions topographiques diverses: La Starza d'Ariano Irpino est établie en position dominante sur une colline qui contrôle le torrent Cupido et la rivière Miscano, tandis que Posta Rivolta est localisée là où la faible altitude des reliefs délimitant la vallée du Cervaro commence à diminuer pour se raccorder à la plaine du Tavoliere. Le site de La Starza, qui connaît une séquence quasi continue depuis le Néolithique ancien, documente une réoccupation immédiatement successive à l'éruption des ponces d'Avellino (Albore Livadie 1995a). Le site de Posta Rivolta, qui n'a pas été touché par les dépôts de produits pyroclastiques, montre une continuité entre les deux périodes, ainsi que le confirment les datations radiométriques (Fossa 104 US 9880, Lyon 14191: $3600 \pm 30 \mathrm{BP}$, soit 2031-1 888 cal. BC $2 \sigma$ et Fossa 98 US 9382, Lyon 14188 : $3425 \pm 30$ BP, $1876-1639$ cal. BC 2б). Le matériel de type Palma Campania à Posta Rivolta est donc présent, même à une époque antérieure à l'éruption, et il est contemporain des villages de la plaine campanienne détruits par celle-ci. On peut remarquer que des similitudes majeures dans le répertoire céramique se retrouvent dans les niveaux post-éruption d'Ariano Irpino. 


\section{Mobilier}

17 La proximité entre les deux sites (40 kilomètres environ à vol d'oiseau), leur position sur d'importantes voies de communication utilisées à des époques plus anciennes, au Néolithique ancien et moyen, avec la diffusion de la céramique impressa et de la céramique Masseria La Quercia tout le long de la vallée du Cervaro, mais aussi durant l'Énéolithique (Talamo 2015, Tunzi 1994, Tunzi et al. 2018) à Savignano Irpino (Albore Livadie 1995b) (fig. 6) et à Bovino, ainsi que le rôle de jonction entre l'Hirpinie et le Tavoliere de la vallée de Bovino en particulier ont déjà été soulignés (Tunzi et al. 2012 : p. 139).

Rappelons aussi la présence en Hirpinie et dans le Subapennin daunien de vastes nécropoles à crémation secondaire, comme celles de San Martino de Taurasi (Talamo 2004 et 2008), de Giardinetto (Orsara di Puglia) et Risega (Deliceto) (Tunzi et al. 2014 et 2018, Tunzi 2015 : p. 213). Ces éléments communs s'expliquent par l'existence de relations précoces et vraisemblablement par l'acquisition à Posta Rivolta de modèles céramiques propres au faciès de Palma Campania, en particulier les formes ouvertes, tasses, tasses-louches et écuelles, supports en forme de clepsydre, tasses et coupes sur pied (fig. 7 et fig. 8), considérées par ailleurs comme des fossiles directeurs de cette culture.

Fig. 7. - Sites de Croce del Papa (Nola), Posta Rivolta (Foggia), La Starza (Ariano Irpino) : tasses, tasses-louches, écuelles et bols.

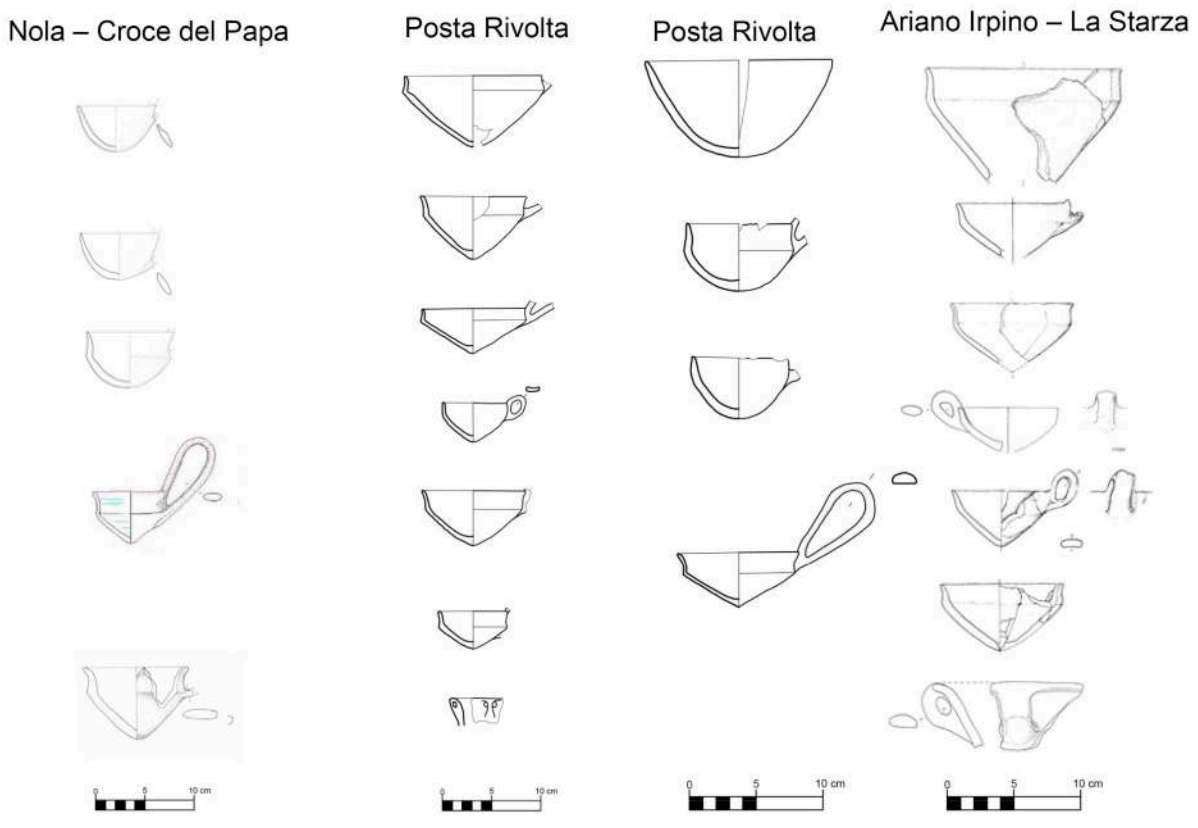


Fig. 8. - Sites de Oliva Torricella (Salerno), Posta Rivolta (Foggia), Croce del Papa (Nola), La Starza (Ariano Irpino) : supports en forme de clepsydre et coupes sur pied.

Oliva Torricella
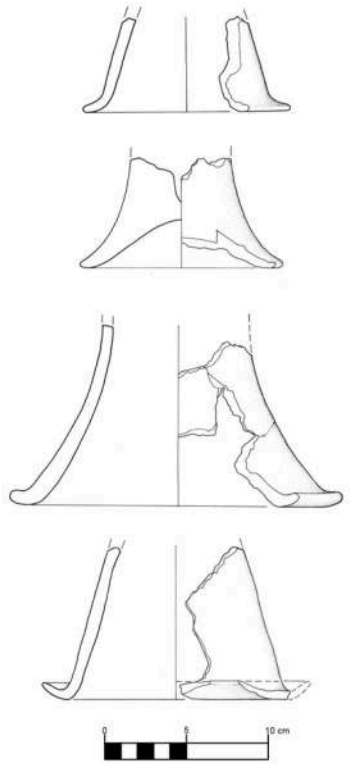

Posta Rivolta
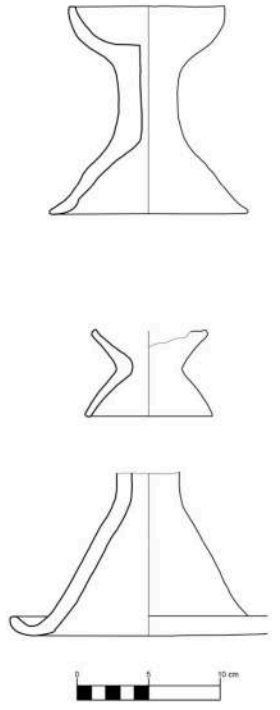

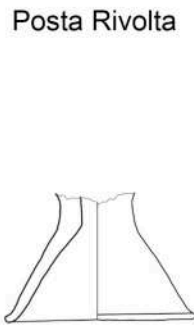

Nola - Croce del Papa
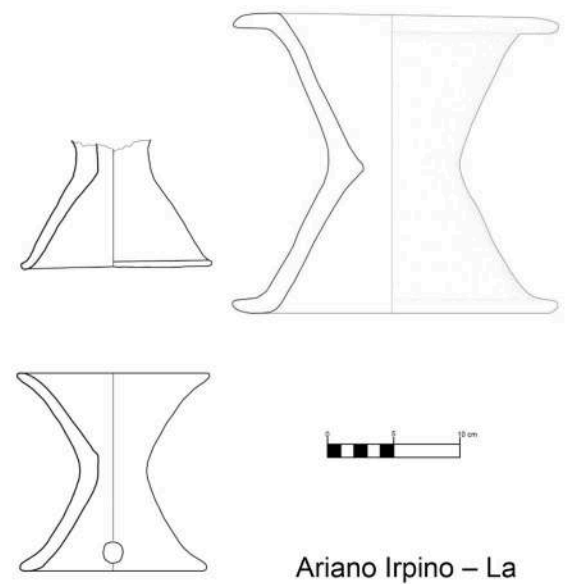

Ariano Irpino - La

Starza

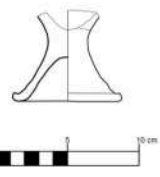

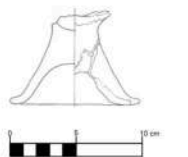

Extrait de Soriano et Albore Livadie 2016.

Pouilles ne se limite pas à Posta Rivolta mais est bien attestée, une fois encore, dans la vallée du Cervaro, en particulier à Giardinetto (Orsara di Puglia), un village du Bronze ancien mal conservé en raison de fréquentations plus récentes (Tunzi et al. 2017b). Comme Posta Rivolta, il est proche du Cervaro qui, provenant de l'étroite gorge du Valico di Bovino, conflue dans une vaste vallée, et de ce fait placé en relation avec les nombreuses voies de communication utilisées depuis le Néolithique ancien jusqu'à l'époque romaine.

Des situations semblables ont été reconnues ailleurs grâce à des prospections de surface et des découvertes sporadiques dans les vallées contiguës : sur le site de Costa Palomba, à Calaggio, Anzano di Puglia (Gravina 2001) ; sur celui de Romano, à Celone (Recchia 2006) ; dans la vallée du Carapelle, à Ordona (Iker 1995 : p. 38) ; sur les sites de la vallée du Candelaro, à Apricena : sites de Mezzana della Quercia (Gravina 2014 : fig. 1.7) et de La Murgetta (inédit), celui de Grotta delle Carrozze, à San Giovanni Rotondo (Gravina 2017), celui de Cupola Beccarini, à Manfredonia (Nava 1999 : p. 46) ; et dans la vallée du Fortore: celui de Mulino Dabbasso, à Celenza Valfortore (Gravina 2003), celui de Masseria Faralla, à Lucera (Gravina 1996), confirmant une fois encore l'importance des 
fleuves comme axes privilégiés à la base des flux d'échanges de différentes natures entre les deux régions (fig. 9).

Fig. 9. - Distribution des types Palma Campania et des formes influencées par les types Palma Campania dans des sites des deux côtés des Apennins.

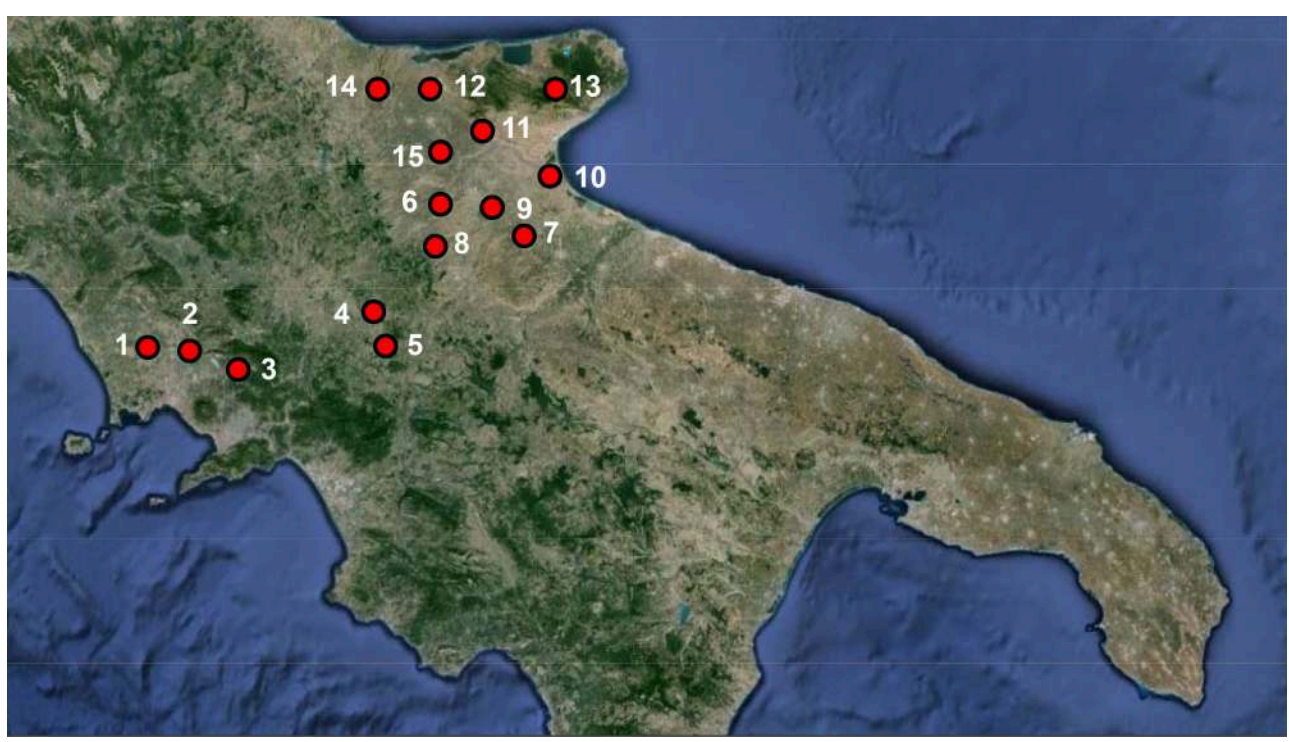

1 : Gricignano di Aversa (Caserte). 2 : Frattaminore (Naples). 3 : Nola (Naples). 4 : La Starza (Ariano Irpino). $\mathbf{5}$ : Costa Palomba (Anzano di Puglia). $\mathbf{6}$ : Valle del Celone. $\mathbf{7}$ : Ordona (Foggia). 8 : Giardinetto (Orsara di Puglia). 9 : Posta Rivolta (Foggia). 10 : Cupola Beccarini (Manfredonia). 11 : Mezzana La Quercia (Apricena). 12 : La Murgetta (Apricena). 13 : Le Carrozze (San Giovanni Rotondo). 14 : Mulino Dabbasso (Celenza Valfortore). 15 : Masseria Faralla (Lucera).

PAO Nicola Gasperi.

22 Les sites occupent des terrasses fluviales ou des fonds de vallées, c'est-à-dire des secteurs où les défenses naturelles sont quasi absentes. La proximité des cours d'eau est essentielle au choix du contexte environnemental, selon un modèle déjà connu à cette époque en Campanie et dans l'Hirpinie (Talamo et Ruggini 2005).

En ce qui concerne les formes que l'on peut considérer comme spécifiques de la phase proto-apenninique, les caractéristiques tasses à anse en ruban et robuste prise surélevée en forme de hache sont bien présentes à Posta Rivolta et à Ariano Irpino, ainsi que dans d'autres sites de la région de Bénévent et de la vallée de la Solofrana. On les retrouve également dans la province de Salerne, en particulier sur le site de Castelluccia, à Battipaglia (Scarano 2012), en dehors de l'aire de retombée des pyroclastites (fig. 10). 
Fig. 10. - Céramiques proto-apenniniques.
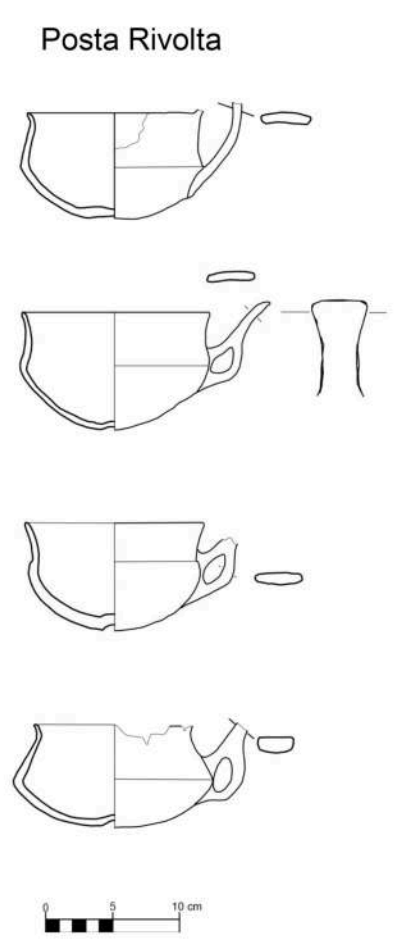

Extrait de Soriano et Albore Livadie 2016

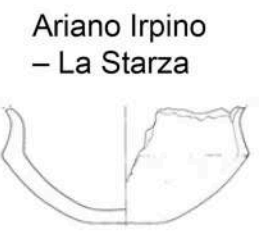

San Paolo

Belsito
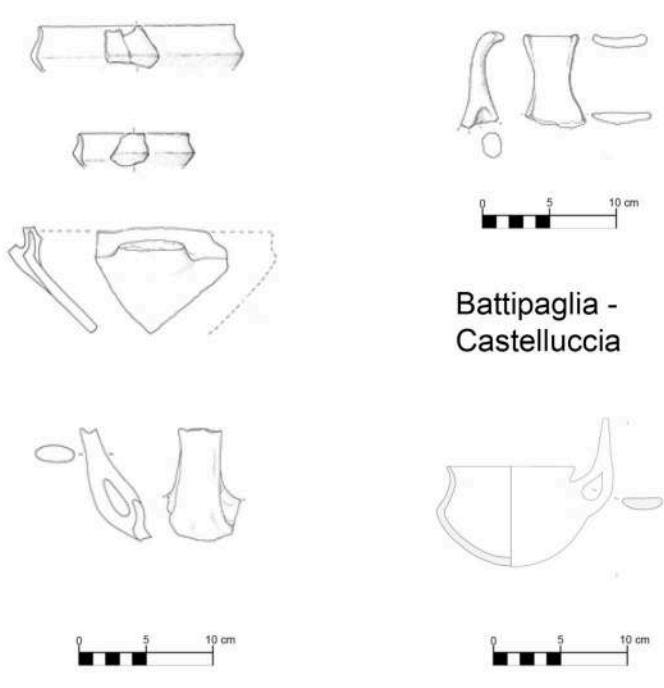

Battipaglia Castelluccia
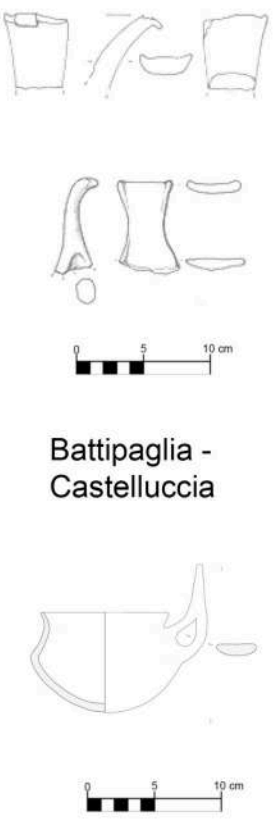

\section{Conclusion}

La récente découverte de nouveaux habitats contribue à révéler pour le Bronze ancien un système de contacts qui, jusqu'à ces dernières années, était difficile à imaginer. Seule la période du Bronze moyen le suggérait sur la base de la présence, aisément identifiable, de la céramique à décor incisé, propre au faciès apenninique. La culture apenninique a été, dès sa première définition (Puglisi 1959), considérée comme caractéristique des communautés spécialisées dans l'élevage, accoutumées à un certain degré de mobilité liée au déplacement saisonnier des hommes et des animaux, depuis les pâturages de hauteur en été et de plaine en hiver (Puglisi 1959, Cazzella et Recchia 2008 : p. 138, Copat et Ruggini 2013).

Bien que l'on ne puisse pas parler, même pour le Bronze moyen, d'une transhumance au sens propre, c'est-à-dire d'un phénomène massif de déplacement des troupeaux de la montagne à la vallée et vice-versa, ainsi que cela apparaîtra à l'époque romaine et persistera jusqu'à nos jours (Peroni 1996), il est fort vraisemblable qu'une mobilité des populations à travers les vallées fluviales de l'Apennin jusqu'aux plaines existait pour les périodes plus anciennes, et très certainement au moins depuis le début de l'âge du Bronze.

Le schéma que nous proposons dément formellement la vision de l'Apennin comme une barrière entre les populations tyrrhéniennes et celles des régions de l'intérieur ou de la zone adriatique. Bien au contraire, la chaîne des Apennins campaniens a eu un rôle central dans l'écosystème interrégional, tout à l'avantage de l'économie de la plaine, au sein d'un phénomène complexe de réciprocité et d'interdépendance. 
Un nouvel élément renforce cette idée. En effet, la découverte de quatre sépultures en jarre à Posta Rivolta (Tunzi et al. 2017b : p. 114) constitue un élément probant qui s'insère dans un cadre d'attestations renvoyant cette fois encore aux contextes contemporains déjà cités : Nola, San Pietro Torre d'Elia, Frattaminore (Marzocchella et al. 1999), Gricignano (Albore Livadie et Marzocchella 1999). Par ailleurs, à Posta Rivolta, comme à Nola et à Frattaminore, les enchytrismoi sont utilisés pour des enfants en bas âge ou des fœtus et sont proches des habitations, soulignant ainsi un partage des pratiques funéraires, de leur portée idéologique et de la fonction sociale qu'elles sousentendent.

\section{BIBLIOGRAPHIE}

ALBORE LIVAdIE C., 1980, « Palma Campania (Napoli) : Resti di abitato dell'età del Bronzo antico », Notizie degli Scavi di Antichità, t. XXXIV, p. 59-101.

AlBore LIVADIE C., 1992, « Nuovi scavi alla Starza di Ariano Irpino (Avellino, Campania) », dans Atti del Congresso Nazionale sul Bronzo Medio in Italia, Viareggio 1989, Sesto Fiorentino, All'Insegna del Giglio (Rassegna di Archeologia, 10), p. 481-491.

ALBORE LIVADIE C., 1995a, « Preistoria : La Starza », dans AA.VV. (dir.), Insediamenti antichi nell'Arianese: Mostra Permanente, Palazzo Anzani 16 marzo 1995, Pratola Serra, Mezzogiorno, p. 1-5.

ALBORE LIVADIE C., 1995b, « La più antica frequentazione della Valle del Miscano », dans L'uomo, l'abitato, il territorio, Progetto Itinerari Turistici Campania Interna : la Valle del fiume Miscano, vol. 2 , Avellino, Poligrafica Ruggiero, p. 13-28.

ALBORE LIVAdIE C., 1996, « La Starza di Ariano Irpino : Un sito millenario », dans Colucci Pescatori G. (dir.), Storia illustrata di Avellino e dell'Irpinia, Pratola Serra, Sellino \& Barra, p. 17-32.

ALBORE LIVADIE C., 1999, " Territorio ed insediamenti nell'agro Nolano durante il Bronzo antico : nota preliminare ", dans Albore Livadie C. (dir.), L'eruzione vesuviana delle "Pomici di Avellino" e la facies di Palma Campania (Bronzo antico), Bari, Edipuglia, p. 203-246.

ALBORE LIVAdIE C., 2002, « Nola, la Pompéi de la préhistoire : recherches en cours sur un site du bronze ancien détruit par l'éruption des Ponces d'Avellino (3 500 BP) », dans Raynal J.-P., Albore Livadie C., Piperno M. (dir.), Hommes et volcans : de l'éruption à l'objet. Actes du $14^{e}$ Congrès UISPP (université de Liège), Clermont-Ferrand, Archéo-logis CDERAD (Dossiers de l'Archéo-logis, 2), p. 57-65.

ALBORE LIVADIE C., 2007, «L'età del Bronzo antico e medio nella Campania nord-occidentale », dans XL Riunione Scientifica IIPP (Naples-Rome, 2005), Florence, Istituto Italiano di Preistoria e Protostoria, p. 231-240.

ALbORE LIVAdIE C., 2011, « Nola, une Pompéi du Bronze ancien, 1800-1700 environ avant J.-C. », dans Garcia D. (dir.), L'âge du Bronze en Méditerranée : recherches récentes, Paris, Errances, p. 65-82.

AlBoRE LIVADIE C., 2012, « La facies di Palma Campania : l'aspetto di Oliva Torricella », dans Campanelli A. (dir.), Dopo lo Tsunami: Salerno antica, Naples, Art'em, p. 122-137. 
ALBORE LIVADIE C. et MARZOCCHELLA A., 1999, « Riflessioni sulla tipologia funeraria in Campania fra il Bronzo antico e il Bronzo medio ", dans $39^{\circ}$ Convegno Nazionale sulla Preistoria, Protostoria e Storia della Daunia (San Severo, 27-29 nov. 1998), San Severo, Archeoclub d'Italia, p. 117-134.

ALBore LIVAdie C. et VecCHIo G., 2005, « Un villaggio del Bronzo antico a Nola-Croce del Papa (Campania)», dans

Albore LiVAdie C., VeCChio G., Delle donNe M., PIZZANo N., 2007, « Un paysage fossilisé sous les cendres du Vésuve (Nola, Naples, Italie) », dans Studer J., David-Elbiali M., Besse M. (dir.), Paysage/Landschaft/Paesaggio : l'impact des activités humaines sur l'environnement du Paléolithique à la période romaine. Actes du colloque du Groupe de travail pour les recherches préhistoriques en Suisse (15-16 mars 2007, Genève), Lausanne, Cahiers d'archéologie romande, p. 159-174.

ARCURI F., ALBORE LIVADIE C., DI MAIO G., ESPOSITO E., NAPOLI G., SCALA S., SORIANO E., 2016, « Influssi balcanici e genesi del Bronzo antico in Italia meridionale: la koinè Cetina e la facies di Palma Campania », Rivista di Scienze Preistoriche, t. LXVI, p. 77-95.

CAZZella A. et RECCHIA G., 2008, "A view from the Apennines : the role of the inland sites in Southern Italy during the Bronze Age », dans Grimaldi S., Perrin T., Guilaine J. (dir.), Mountain Environments in Prehistoric Europe : Settlement and Mobility Strategies from Paleolithic to the Early Bronze Age, Oxford, Archaeopress (BAR International Series, 1885) p. 137-143.

CITRO D., sous presse, « La pastorizia e l'attività casearia », dans Albore Livadie C. et Vecchio G. (dir.), Il villaggio di Croce del Papa (Nola): un insediamento del Bronzo antico sepolto dall'eruzione pliniana delle "Pomici di Avellino", Centre Jean Bérard, Naples.

COPAT V. et RUGGINI C., 2013, « The mountains during the Bronze Age, Southern and Central Italy: space becoming places ", dans Gheorghiu D. et Nash G. (dir.), Place as material culture: objects, geographies and the construction of times, Newcastle, Cambridge Scholar Publishing, p. 183-212.

DI MAIO G. et SCALA S., 2012, « Le evidenze di paleotsunami della costa di Salerno », dans Campanelli A. (dir.), Dopo lo Tsunami: Salerno antica, Naples, Art'em, p. p. 62-83.

DI VITO M. A., ZANELLA E., GURIOLI L., LANZA R., SULPIZIO R., BISHOP J., TEMA E., BOENZI G., LAFORGIA E., 2009, « The Afragola settlement near Vesuvius, Italy: The destruction and abandonment of a Bronze Age village revealed by archaeology, volcanology and rock magnetism », Earth and Planetary Science Letters, $\mathrm{n}^{\circ} 277$, p. 408-421.

GRAVINA A., 1996, « La Daunia Nord-Occidentale: Note di Topografia », dans Cocchi Genick D. (dir.), L'antica età del Bronzo in Italia, Florence, Octavo Cantini, p. 580-581.

GRAVINA A., 2001, « Nuovi dati sulla frequentazione preistorica nel territorio di Anzano di Puglia (Foggia) », dans $21^{\circ}$ Convegno Nazionale sulla Preistoria, Protostoria e Storia della Daunia, San Severo, Archeoclub d'Italia, p. 139-152.

GRAVINA A., 2003, « Gli insediamenti preistorici di Mulino Dabbasso: Valle del medio Fortore (Celenza Valfortore - FG) », dans $23^{\circ}$ Convegno Nazionale sulla Preistoria, Protostoria e Storia della Daunia, San Severo, Archeoclub d'Italia, p. 177-200.

GRAVINA A., 2014, «L'eneolitico e l'età del Bronzo nel Gargano meridionale: la frequentazione nell'area centro-occidentale ", dans $34^{\circ}$ Convegno Nazionale sulla Preistoria, Protostoria e Storia della Daunia, San Severo, Archeoclub d'Italia, p. 165-186.

GRAVINA A., 2017, « Grotta delle Carrozze (San Giovanni Rotondo - FG) », Preistoria e Protostoria in Etruria : notiziaro, $\mathrm{n}^{\circ}$ 4.II, p. 68-70. 
IKER R., 1995, « Dalla preistoria alla protostoria », dans Mertens J. (dir.), Herdonia, Scoperta di una città, Bari, Edipuglia, p. 35-46.

LAFORGIA E., BISHOP J., BOENZI G., DE FILIPPIS A., MOSCATO F., MAZZOCCHI A., DI VITO M., ISAIA R., 2007, « Afragola (NA): un insediamento del Bronzo Antico distrutto dall'eruzione delle Pomici di Avellino ", dans Strategie di insediamento fra Lazio e Campania in età preistorica e protostorica: Atti XL Riunione Scientifica, Florence, Istituto Italiano di Preistoria e Protostoria, p. 932-935.

LO PORTO FELICE G., 1962-1963, « La tomba di Cellino San Marco e l'inizio della civiltà del Bronzo in Puglia », Bullettino di Paletnologia Italiana, p. 191-225.

MARZOCCHELLA A., CALDERONI G., NISBET R., 1999, « Sarno e Frattaminore : evidenze dagli abitati », dans Albore Livadie C. (dir.), L'eruzione vesuviana delle "Pomici di Avellino" e la facies di Palma Campania (Bronzo antico), Bari, Edipuglia, p. 157-202.

NAVA M. L., 1999, « I precedenti insediativi : l'area di Cupola-Beccarini », dans Mazzei M. (dir.), Siponto Antica, Foggia, Grenzi Editore, p. 45-69.

PASSARIELlo I., ALBORE LIVADIE C., TALAMO P. F., LUBRITTO C., D'ONOFRIO A., TERRASI F., 2009, « ${ }^{14}$ C chronology of Avellino pumices eruption and timing of human reoccupation of the devasted region », Radiocarbon, vol. 51, n 2, p. 803-816.

PERONI R., 1996, L'Italia alle soglie della Storia, Rome/Bari, Editori Laterza, p. 202-204.

PUGLISI S. M., 1959, La civiltà appenninica : Origine delle comunità pastorali in Italia, Florence, Sansoni. ROMANO V. et RECCHIA G., 2006, «L'età del Bronzo nel Tavoliere interno : nuovi dati dalle ricognizioni nella valle del Celone ", dans $26^{\circ}$ Convegno Nazionale sulla Preistoria, Protostoria e Storia della Daunia, San Severo, Archeoclub d'Italia, p. 205-252.

SACCOCCIO F., MARZOCCHELla A., VANZETTI A., 2013, « The field system of Gricignano d'Aversa (Southern Italy) and the agrarian impact in the Piana Campana, ca. 3900 cal. BP », Quaternary International, $\mathrm{n}^{\circ}$ 303, p. 82-92.

SCARANO G., 2012, « L'abitato di Castelluccia », dans Campanelli A. (dir.), Dopo lo Tsunami : Salerno antica, Naples, Art'em, p. 126-133.

SORIANO E. et ALBORE LIVADIE C., 2016, « La facies di Palma Campania e i suoi rapporti con le facies coeve dell'Italia medio-tirrenica e dell'Italia meridionale: considerazioni alla luce delle recenti scoperte ", dans Scafuro M. et Pontrandolfo A. (dir.), Dialoghi sull'Archeologia della Magna Grecia e del Mediterraneo, Paestum, Pandemos, p. 101-112.

SORIANO E. et ALBORE LIVADIE C., sous presse, « La facies di Palma Campania: omogeneità culturale interna e circolazione dei modelli ceramici », dans Facies e culture nell'età del Bronzo italiana, Academia Belgica, Rome.

TALAMo P., 1996, « Camposauro (Vitulano-Benevento) », dans Cocchi Genick D. (dir.), L'antica età del Bronzo in Italia, Florence, Octavo Cantini, p. 576-577.

TALAMo P. 2004, Taurasi : Un nuovo aspetto dell'Eneolitico in Campania, Salerno, Ministero per i Beni e le Attività Culturali/Comune di Taurasi.

TALAMO P., 2008, « Dinamiche culturali nelle aree interne della Campania centro-settentrionale durante le prime fasi dell'Eneolitico », Rivista di Scienze Preitoriche, t. LVIII, p. 125-164.

talamo P., 2015, « Tra Puglia e Campania », dans Tunzi A. M. (dir.), Venti del Neolitico: Uomini del Rame. Preistoria della Puglia settentrionale, Foggia, C. Grenzi, p. 90-95. 
TALAMO P. et RUGGINI C., 2005, « Il territorio campano al confine con la Puglia nell'età del Bronzo ", dans $25^{\circ}$ Convegno nazionale sulla Preistoria-Protostoria-Storia della Daunia, San Severo, Archeoclub d'Italia, p. 171-185.

TUNZI A. M., 1994, « L'Età dei Metalli », dans Mazzei M. (dir.), Bovino: Studi per la storia della città antica. La colezione museale, Taranto, La Colomba, p. 61-86.

TUNZI A. M. (dir.), 2015, Venti del Neolitico: Uomini del Rame. Preistoria della Puglia settentrionale, Foggia, C. Grenzi.

TUNZI A. M., LO ZUPONE M., GASPERI N., BUBBA D., 2012, « Area produttiva e insediamento di facies Palma Campania a Posta Rivolta (Foggia) », dans $32^{\circ}$ Convegno Nazionale Preistoria-Protostoria-Storia della Daunia, San Severo, Archeoclub d'Italia, p. 127-154.

TUNZI A. M., BUBBA D., GASPERI N., MARTINO F. M., LOPEZ DE ARMENTIA ITURRALDE M., LILO K., LO ZUPONE M., 2014, « La necropoli eneolitica a cremazione di Giardinetto (Orsara di Puglia) », dans $34^{\circ}$ Convegno di Preistoria, Protostoria e Storia della Daunia, San Severo, Archeoclub d'Italia, p. 141-164.

TUNZI A. M., LO ZUPONE M., BUBBA D., GASPERI N., MARTINO F. M., LOPEZ DE ARMENTIA ITURRALDE M., 2017a, « Il Campo del Vasaio: Un sito del Bronzo Antico a Posta Rivolta (FG)», dans Radina F. (dir.), Preistoria e Protostoria della Puglia, Florence, Istituto Italiano di Preistoria e Protostoria (Studi di Preistoria e Protostoria, 4), p. 457-463.

TUNZI A. M., GASPERI N., LO ZUPONE M., MARTINO F. M., 2017b, « Il campo del vasaio: influssi delle culture campane nella preistoria della Puglia nordoccidentale », dans Dialoghi sull'Archeologia della Magna Grecia e del Mediterraneo, Paestum, p. 113-120.

TUNZI A. M., GASPERI N., MARTINO F. M., QUERO T., 2018, « Uomini o Dei: Gli armati nelle tombe eneolitiche ", dans $13^{\circ}$ Convegno Preistoria e Protostoria in Etruria, Valentano, Milan, Centro Studi di Preistoria e Archeologia, vol. 1, p. 135-146.

\section{RÉSUMÉS}

L'étude en cours sur la culture matérielle de Palma Campania (Bronze ancien) suggère de nouvelles réflexions concernant sa chronologie et son extension territoriale. Des données inédites obtenues lors de fouilles en Campanie et dans les régions limitrophes, en particulier à Posta Rivolta (Foggia, Italie) documentent des liens étroits avec le Bronze ancien campanien. La typologie de la céramique se rapproche de celle de la culture de Palma Campania, et les datations ${ }^{14} \mathrm{C}$ confirment la contemporanéité du site foggien avec les villages détruits par l'éruption des

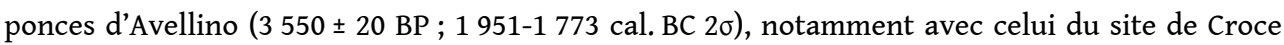
del Papa (Nola, Italie). Les indices de contact se basent principalement sur les correspondances culturelles et sont dus aux échanges qui se sont développés au cours du temps entre la Campanie et le Tavoliere des Pouilles. L'hypothèse traditionnelle d'une mobilité pastorale est ici développée et renforcée.

The current study of the Palma Campania facies (Early Bronze Age) leads to a redefinition of the facies itself in terms of chronology and geographical extension. Some excavations of the neighboring areas, especially the Posta Rivolta site (northern Puglia), give cultural features indicating substantial links with the Campania region during the height of the Early Bronze Age. At Posta Rivolta, the ceramic artifacts belong to the cultural context of the Palma Campania facies. The chronological data provided by $14 \mathrm{C}$ dating confirm the contemporaneity of this occurrence with some villages of the Piana Campana destroyed by the Avellino eruption $(3,550 \pm 20$ BP; $1,951-1,773$ cal. BC $2 \sigma)$, like Croce del Papa (Nola). These features are mainly based 
on cultural similarities due to the relationships between Campania and the Tavoliere plain. The relationships are the result of the pastoral exploitation of these areas, which is confirmed by the latest discoveries discussed here.

INDEX

Keywords : eruption of Avellino Pomices, Early Bronze Age, facies of Palma Campania Mots-clés : culture de Palma Campania, Bronze ancien, éruption des ponces d'Avellino Index géographique : Campanie, Pouilles, Tavoliere, Somma-Vésuve

\section{AUTEURS}

\section{CLAUDE ALBORE LIVADIE}

Directrice de recherche émérite, Aix Marseille Université, CNRS, Centre Camille Jullian, Aix-enProvence, France

\section{ANNA MARIA TUNZI}

Soprintendenza Archeologia, Belle Arti e Paesaggio per le province di Barletta-Andria-Trani e Foggia

\section{ELENA SORIANO}

Doctorante, Aix Marseille Université, Centre Camille Jullian, Aix-en-Provence, France

\section{NICOLA GASPERI}

Collaborateur externe de la Soprintendenza Archeologia, Belle Arti e Paesaggio per le province di Barletta-Andria-Trani e Foggia

\section{FRANCESCO MATTEO MARTINO}

Collaborateur externe de la Soprintendenza Archeologia, Belle Arti e Paesaggio per le province di Barletta-Andria-Trani e Foggia 


\title{
Essai de modélisation des échanges et des réseaux de circulation dans les Alpes centrales au premier âge du Fer
}

\author{
Attempt at modeling exchanges and circulation networks in the Central \\ Alps in the Early Iron Age
}

Veronica Cicolani et Thomas Huet

1 Dans l'Antiquité, les Alpes ont été le plus souvent perçues comme un milieu hostile à l'implantation humaine "[...] tecta informia imposita rupibus [...] animalia inanimaque omnia rigentia gelu [...] », peuplées par des communautés de sauvages, «homines intonsi et inculti » (Tite-Live: Histoire romaine, XXI, 32, 7), s'adonnant souvent au brigandage (Strabon: Géographie, Les peuples des Alpes, IV, 6), mais malgré tout constamment habitées, traversées et parcourues autant par les populations autochtones qu'allochtones (Gallay 2006). Barrière perméable entre Italie et Europe continentale, les Alpes ont constitué l'un des enjeux majeurs des politiques de contrôle du commerce européen. Mais qu'en est-il de leur rôle pour les périodes plus reculées? Dans quelle mesure ce milieu favorable à l'isolement, notamment culturel, mais aussi au transit contrôlé des personnes et des biens, a-t-il participé au façonnement des identités et des interactions culturelles? Ce sera le sujet de ce travail, qui a bénéficié du soutien du LabEx ARCHIMEDE au titre $\mathrm{du}$ programme Investissement d'avenir (ANR-11LABX-0032-01).

2 À l'âge du Fer ( VIII $^{\mathrm{e}}-\mathrm{V}^{\mathrm{e}}$ siècle av. J.-C.), les Alpes centrales se trouvent au contact de deux grands domaines à la fois culturels et géographiques: le domaine sud-alpin, et plus spécifiquement celui de Golasecca, et le domaine nord-alpin, peuplé par les communautés celtiques. Au sein des massifs, dans les vallées périalpines et intraalpines, les communautés indigènes composent ce que l'on définit stricto sensu comme le domaine alpin : un espace composé d'entités culturelles diversifiées (Della Casa 2009). Dans cet espace, les nombreux cols et vallées offrent différents points d'accès et de 
transit, dont le degré de difficulté demeure encore difficile à saisir et à modéliser pour les époques pré- et protohistoriques (Della Casa 2009, Salac 2013, Migliavacca 2013).

Sur le plan archéologique, les contacts entre domaines alpin et sud-alpin, et surtout avec l'Italie du nord et la côte méditerranéenne, sont connus depuis la Préhistoire et sont principalement liés à la recherche de matières premières : les roches vertes, le corail ou bien les coquillages marins (Pétrequin et al. 2005, Borrello 2015). Cette ouverture est particulièrement bien attestée au cours du Campaniforme; à titre d'exemple, on peut citer les nombreuses parures en coquillage issues des sépultures à ciste mégalithique du Petit Chasseur, à Sion, dans le canton du Valais (Gallay 2006). Elle se maintient jusqu'à l'âge du Bronze, du moins dans le Valais et dans la zone des Alpes bernoises. Vers la fin de l'âge du Bronze (XIII $-\mathrm{X}^{\mathrm{e}}$ siècle av. J.-C.), des contacts plus spécifiques avec le domaine de Golasecca sont matérialisés par la présence dans les sépultures d'éléments de parure identiques (De Marinis et Gambari 2005). La distribution d'épingles caractéristiques des palafittes suisses, puis de fibules à arc simple sud-italiques et de celles de type Mörigen suggère en effet l'existence de contacts personnels entre communautés alpines et sud-alpines (David-Elbiali et Dunning 2005, Casini 2011).

4 Mais c'est surtout entre le $\mathrm{VII}^{\mathrm{e}}$ et la fin du $\mathrm{v}^{\mathrm{e}}$ siècle av. J.-C. que les interactions entre communautés alpines, sud-alpines et nord-alpines s'intensifient et se diversifient. C'est en effet au cours de cette période que ce secteur des Alpes se retrouve impliqué dans un vaste réseau européen d'échanges, structuré à plusieurs niveaux (Verger et Pernet 2013) et dont les communautés sud-alpines et alpines ont été des acteurs importants (Pauli 1980 et 1991, Lorre et Cicolani 2009, Cicolani 2013 et 2017). Dans ce contexte d'intensification des interactions, celles qui se font jour entre le domaine alpin et celui de Golasecca sont particulièrement significatives. En effet, au cours du premier âge du Fer, plus de 300 parures sont documentées dans l'ensemble du domaine alpin et du plateau suisse, réparties sur 70 sites de statuts et fonctions différents: habitats, sépultures et dépôts. Ces accessoires vestimentaires sont généralement les seuls ou les rares éléments étrangers au costume local (Cicolani 2017) (fig. 1). 
Fig. 1. - Carte de distribution du petit mobilier de Golasecca et hallstattien en Europe occidentale entre 670 et 380 av. J.-C.

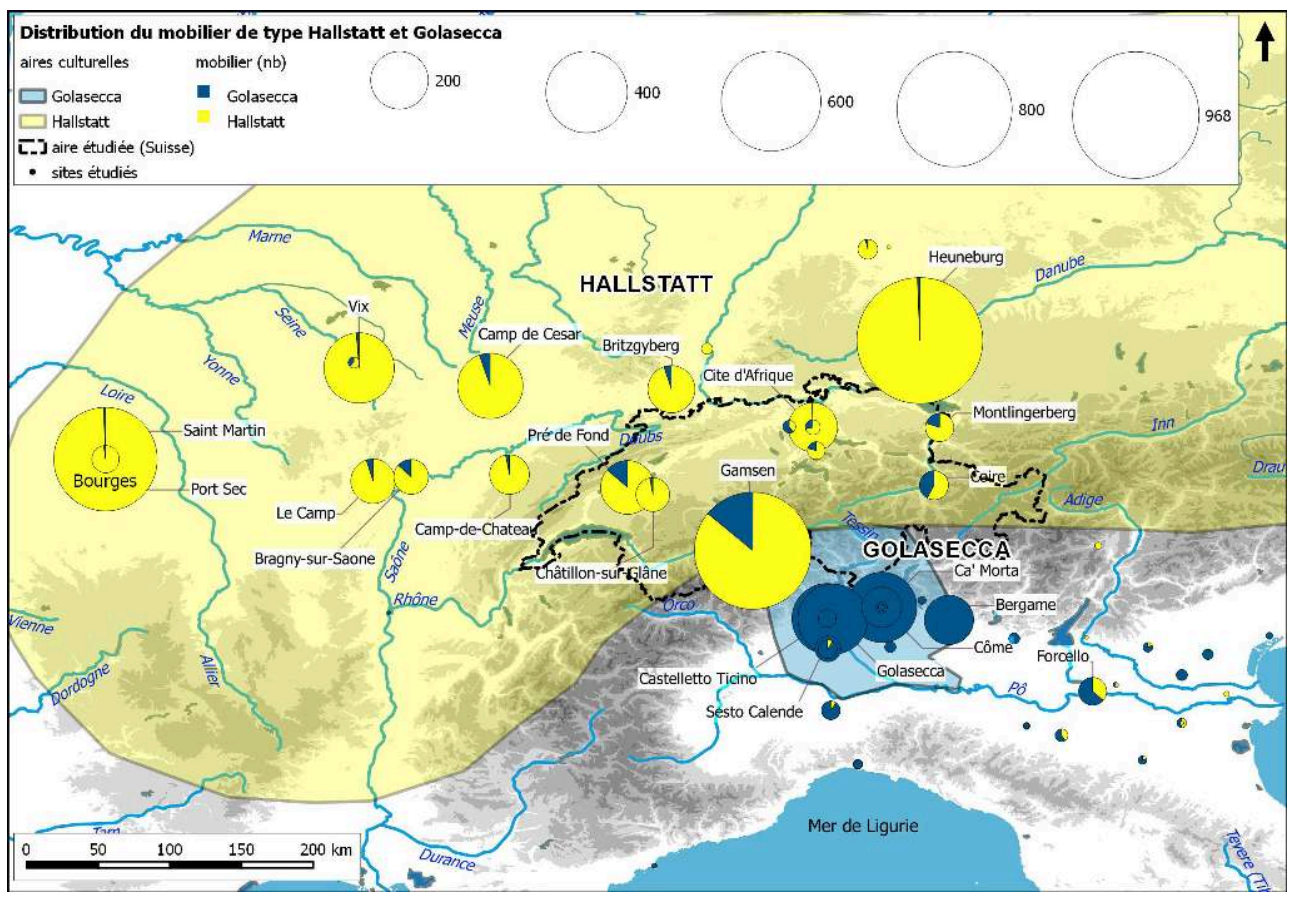

Les diagrammes circulaires soulignent le ratio entre productions métalliques indigènes et de type Golasecca. NMI : 5000.

PAO Thomas Huet, données Veronica Cicolani et Dubreucq 2013.

La culture italique et celtophone de Golasecca se développe dans un vaste territoire compris entre la plaine du Pô au sud et les Alpes au nord. Les cours de la Doire Baltée et de la rivière Oglio marquent respectivement les frontières occidentale et orientale (De Marinis 1988, Lorre et Cicolani 2009, Cicolani 2017, Gambari et Cicolani à paraître).

Depuis le milieu du $\mathrm{IX}^{\mathrm{e}}$ siècle av. J.-C., la culture de Golasecca se structure progressivement autour des deux principaux axes de communication fluviolacustres de la région, le Tessin et le lac Majeur à l'ouest, le lac de Côme à l'est. Par un processus de concentration territoriale, deux grands pôles finissent par émerger. Le premier est Castelletto Ticino, un petit promontoire naturellement protégé par une boucle du Tessin, en lien avec un point naturel de rupture de charge, localisé à l'exutoire du lac Majeur (Gambari 2004). Le second pôle est celui de Côme, implanté aux abords et au sud du lac homonyme (De Marinis 2001). Cette bipolarisation se reconnait sur le plan archéologique par l'apparition au sein de la même matrice culturelle de deux sousentités: une occidentale, gravitant autour de Castelletto Ticino, et une orientale, autour de Côme. Vers le milieu du $\mathrm{vl}^{\mathrm{e}}$ siècle av. J.-C., un troisième faciès devient perceptible, le faciès alpin ou septentrional, documenté surtout par une riche série de nécropoles disséminées dans les vallées des Alpes lépontines (De Marinis et Biaggio Simona 2000).

7 La possibilité de contrôler et d'exploiter les axes de communication fluviolacustres les plus importants du nord-ouest de l'Italie a joué un rôle majeur, non seulement dans le développement local, mais aussi dans l'intégration du domaine de Golasecca dans un plus vaste réseau de contacts reliant les mondes italique et étrusque aux domaines alpin et transalpin (De Marinis 2008, Gambari 2004, Cicolani 2017). Les contacts directs 
avec les Étrusques sont lisibles depuis le milieu du viII siècle av. J.-C.: on cite par exemple le mobilier de la tombe de La Vigna di Mezzo, près de Côme (deuxième moitié du viII siècle av. J.-C.), avec ses importations métalliques issues de Véies et Vetulonia, ou bien celui de la tombe de Fontanili, à Castelletto Ticino (VII siècle av. J.-C.), avec son bassin orientalisant des ateliers de Vetulonia (Lorre et Cicolani 2009). À ces contacts avec les Étrusques font suite, vers le milieu du vi siècle av. J.-C. et surtout vers la fin de ce dernier, ceux avec le monde grec, par l'intermédiaire de nombreux comptoirs fluviaux et emporia. Ces derniers, depuis la fondation d'Adria et de Spina, s'activent le long du Pô et de ses principaux affluents, densifiant ainsi les réseaux d'échanges internes et externes à la péninsule (Bonomi et Güggisberg 2015, Sacchetti 2013, De Marinis et Rapi 2007, Tarditi 2007).

8 Pour tâcher de restituer une partie de ces échanges dans le secteur central des Alpes (Alpes et Préalpes suisses) au cours du premier âge du Fer ( $d u \mathrm{VII}^{\mathrm{e}}$ au début du IV siècle av.J.-C.), nous nous intéresserons à la distribution de deux catégories d'objets, différentes mais complémentaires : le petit mobilier métallique de type Golasecca et les importations céramiques et métalliques étrusco-italiques et méditerranéennes. La distribution spatiale et chronologique de ces objets et de leurs contextes archéologiques permet de jalonner des voies autour desquelles se sont probablement nouées les interactions, et de réfléchir aux échanges à la fois de biens, de personnes et d'idées.

9 Les Alpes et Préalpes suisses offrent un vaste panel de points d'accès où les déplacements sont contraints et donc plus susceptibles de marquer des régularités. Pour comprendre la distribution spatiale de ces objets dans l'espace alpin, nous nous servirons d'un référentiel théorique pour les déplacements, le réseau des plus courts chemins. Pour modéliser les relations entre les sites et les domaines culturels, nous utiliserons le tracé de graphes (théorie des graphes). Ces modélisations seront proposées selon les différentes sous-périodes de la culture de Golasecca.

\section{Les Alpes centrales : au carrefour de domaines culturels et géographiques différents}

Les Alpes centrales se développent d'est en ouest, formant une ligne de partage entre trois grands bassins versants : le Pô au sud, le Rhin au nord, le Danube à l'est (fig. 2). 
Fig. 2. - Principaux bassins versants et cols des Alpes centrales ; limites entre le domaine de Golasecca (au sud) et de Hallstatt (au nord).

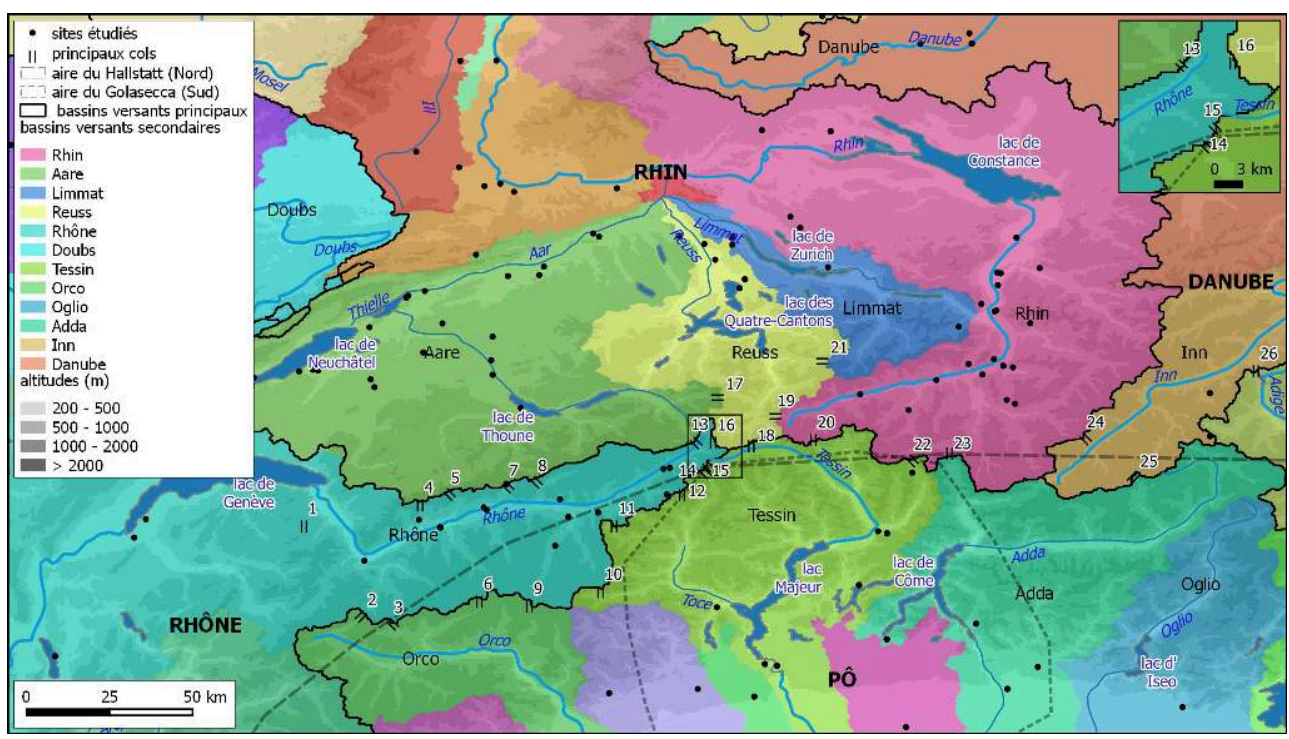

1 : Pas de Morgin (1 371 m). 2 : col du Petit Ferret (2 490 m). 3 : col du Grand Saint-Bernard (2 469 m). 4 : col de Sanetsch (2 $252 \mathrm{~m}) . \mathbf{5}$ : col de Schnidejoch $(2756 \mathrm{~m}) . \mathbf{N}^{\circ} \mathbf{6}$ : col Collon (3 $\left.074 \mathrm{~m}\right) . \mathbf{7}$ : col de la Gemmi $(2314$ m). 8 : col de Lötschen $(2690$ m). $\mathbf{9}$ : col de Théodule (3 316 m). 10 : col de Monte-Moro (2 853 m). 11 : col de Simplon (2 008 m). 12 : col d'Albrun (2 409 m). 13 : col du Grimsel (2 165 m). 14 : col de Gries (2 479 m). 15 : col de Nufenen (2 480 m). 16 : col de Furka (2 429 m). 17 : col de Susten (2 224 m). 18 : col de Saint-Gothard (2 108 m). 19 : col de l'Oberalp (2 044 m). $\mathbf{2 0}$ : col de Lucomagno (1 914 m). 21 : col de Klausen (1 948 m). 22 : col de San Bernardino $(2065$ m). $2 \mathbf{3}$ : col de Splügen (2 115 m). $\mathbf{2 4}$ : col de l'Albula (2 312 m). $\mathbf{2 5}$ : col de Livigno (2 315 m). 26 : col de Reschen (1 504 m). PAO Thomas Huet. Données Centre national d'études spatiales (CNES), Swisstopo, National Point of Contact (NPOC)/Office fédéral de l'environnement (OFEV).

11 Au sein du massif, les sillons formés par les hautes vallées du Rhône et du Rhin, orientées d'est en ouest, forment les principaux axes de circulation interne. La ligne de partage entre le domaine de Golasecca, au sud, et le domaine nord-alpin se fait le long d'une ligne de crête jalonnée par de nombreux cols la traversant, orientés nord-sud. Cette ligne de crête passe, d'ouest en est, par les cols du Grand Saint-Bernard (fig. 2, $\mathrm{n}^{\circ}$ 3), du Simplon ( $\left.n^{\circ} 11\right)$, de l'Albrun ( $\left.n^{\circ} 12\right)$, du Nufenen $\left(n^{\circ} 15\right)$, du Saint-Gothard $\left(n^{\circ} 18\right)$, du San Bernardino $\left(n^{\circ} 22\right)$ et du Splügen $\left(n^{\circ} 23\right)$, pour les principaux. Elle marque ainsi la séparation entre le bassin versant du Pô, au sud, qui ouvre sur l'Adriatique à travers le Tessin, et ceux du Rhône et du Rhin, au nord, avec pour le premier un débouché sur la Méditerranée, et pour le second une ouverture sur la mer du Nord.

La région alpine du domaine du Golasecca correspond au bassin versant du Tessin. Le fleuve, avec ses deux sources situées au col du Nufenen $\left(n^{\circ} 15\right)$ et au col du SaintGothard ( $\left.n^{\circ} 18\right)$, est alimenté par le Brenno, la Moesa et la Morobbia et traverse en direction nord-sud les Alpes lépontines avant de se jeter dans le lac Majeur, au cœur du domaine de Golasecca. À la sortie du lac, depuis Castelletto Ticino, le cours d'eau poursuit son trajet vers le sud, à travers la plaine padane, pour se jeter dans le Pô, reliant ainsi le domaine alpin à celui de Golasecca et - à travers le Pô - aux mondes étrusque et méditerranéen. Un peu plus à l'ouest, la rivière Toce, dans le val d'Ossola, assure une autre jonction nord-sud entre les Alpes centro-occidentales suisses et le domaine de Golasecca.

$13 \mathrm{Au}$ sein des Alpes centrales, le passage entre les bassins versants du Rhône et du Pô se fait par de nombreux cols, dont celui du Grand Saint-Bernard (fig. 2, $\mathrm{n}^{\circ}$ 3), de Théodule 
$\left(n^{\circ} 9\right)$, du Simplon ( $\left.n^{\circ} 11\right)$, de l'Albrun $\left(n^{\circ} 12\right)$ et de Nufenen $\left(n^{\circ} 15\right)$. Plus au nord, les voies de communications entre les bassins versants du Rhône et de l'Aar empruntent les cols de Sanetsch $\left(n^{\circ} 4\right)$, de Schnidejoch $\left(n^{\circ} 5\right)$, de la Gemmi $\left(n^{\circ} 7\right)$, de Lötschen $\left(n^{\circ} 8\right)$ et de Furka $\left(n^{\circ} 16\right)$. Au sein de ces chapelets de cols, ceux de Grimsel $\left(n^{\circ} 13\right)$ et de SaintGothard ( $\left.n^{\circ} 18\right)$, les plus centraux, donnent à la fois accès aux vallées du Rhône et du Rhin. À l'est, les cols de Saint-Gothard ( $\left.n^{\circ} 18\right)$, de Lucomagno ( $\left.n^{\circ} 20\right)$, du San Bernardino $\left(n^{\circ} 22\right)$, du Splügen $\left(n^{\circ} 23\right)$ et d'Albula $\left(n^{\circ} 24\right)$ donnent accès aux vallées du Rhin et de l'Inn. Enfin, en bordure du plateau suisse (moyen pays), un dense système fluviolacustre, organisé autour des bassins fluviaux de la Reuss, de l'Aar et de la Limmat, dans un relief peu accidenté, offre plusieurs axes de circulation dans les domaines périalpin et nord-alpin, aussi bien vers le nord que d'est en ouest.

\section{Le corpus : productions ordinaires sud-alpines et importations méditerranéennes}

14 Afin de mieux étudier les échanges entre communautés alpines, sud-alpines et nordalpines, un corpus spécifique a été retenu, qui réunit 2187 objets et de 289 sites répartis dans les domaines alpin et nord-alpin occidental. Le découpage chronologique de la période de Golasecca utilisé ici a été réalisé en regroupant les différentes sous-phases en quatre grands horizons chronologiques, afin d'obtenir un nombre statistiquement suffisant de données pour chaque horizon (fig. 3).

Fig. 3. -Nombre d'objets étudiés en NMI par phase (NMI = 2 187).

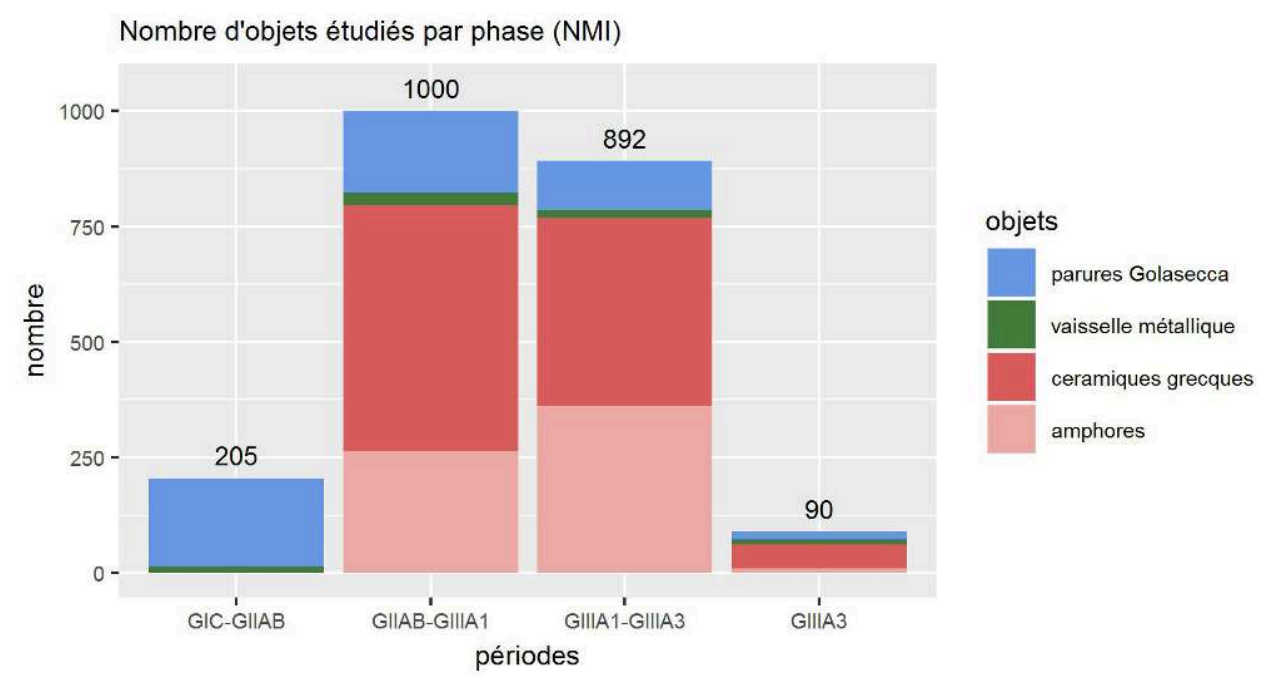

Le corpus se compose de deux grandes catégories de mobilier. La première réunit l'ensemble des éléments vestimentaires caractéristiques du costume du domaine de Golasecca documentés au nord des Alpes: 564 NMI répartis sur 189 sites, dont 340 objets et 75 sites attestés dans le domaine alpin (Cicolani 2017). Il s'agit principalement de fibules, de pendeloques, d'éléments liés au soin du corps (trousses et instruments de toilette isolés), de bracelets et d'agrafes de ceinture (fig. 4). 
Fig. 4. - Objets de type Golasecca attestés en Europe nord-occidentale au premier âge du Fer.

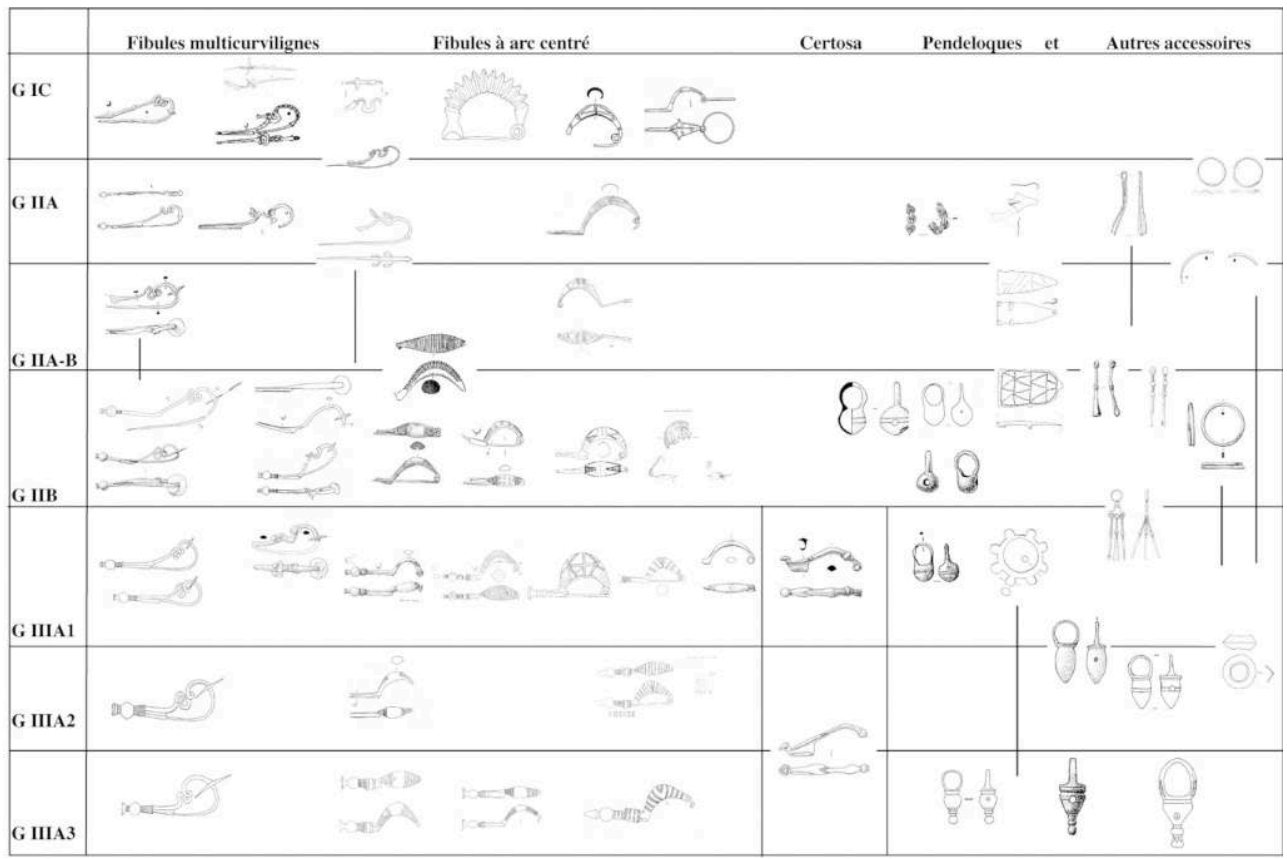

Extrait de Cicolani 2017, p. 175, fig. 150.

16 Ces éléments vestimentaires ordinaires, relevant du domaine personnel et à faible valeur marchande, sont des marqueurs identitaires de premier choix pour identifier en dehors de leur foyer de production, sinon leurs porteurs, du moins les domaines culturels et/ou technologiques de provenance. La présence de ces objets dans des contextes archéologiques variés (habitats, nécropoles, dépôts métalliques) va permettre de réfléchir sur les déplacements de biens et de personnes à courte et moyenne distance. Ces données ont été par ailleurs complétées par les quelques céramiques originaires du domaine de Golasecca, ponctuellement attestées dans le domaine alpin et nord-alpin, ainsi que dans la péninsule italienne (Lorre et Cicolani 2009).

17 La deuxième classe rassemble les objets appelés ici " extra-ordinaires » (1 698 objets, répartis sur 100 sites) en raison de leur forte valeur marchande, culturelle et symbolique. Il s'agit de vaisselles métalliques étrusco-italiques et de Grande Grèce, attestées dans la zone d'étude depuis une phase avancée du viI siècle av. J.-C., mais aussi de céramiques et d'amphores à vin grecques et gréco-italiques parvenues dans le domaine nord-alpin et celui de Golasecca surtout vers la fin du vi ${ }^{e}$ siècle av. J.-C. et tout au long du siècle suivant (Lüscher 1998, De Marinis et Rapi 2007, Sacchetti 2013, Bonomi et Güggisberg 2015, Ruffieux et Mauvilly 2014, Müller et al. 1999). En raison de l'origine plus lointaine de leurs ateliers de production et de la valeur particulière qu'elles détiennent (facture, fonction, rareté et contenu), ces productions sont des marqueurs d'échanges à longue distance en mesure d'identifier des réseaux de plus vaste portée et aux fonctionnements plus complexes impliquant, voire stimulant, l'intervention de plusieurs intermédiaires et/ou bénéficiaires.

Bien que l'étude comparée de la diffusion de ces deux catégories d'objets soit ici focalisée sur le milieu alpin, la fenêtre d'observation a été élargie au domaine nordalpin occidental afin de mieux comprendre les dynamiques spatiales subjacentes. La 
quasi-absence de mobilier de type Golasecca dans le Midi français explique l'exclusion de ce territoire dans cette étude exploratoire.

\section{Méthodologie}

19 À partir de ce corpus contextualisé et quantifié, l'étude a été développée suivant deux approches : l'analyse spatiale et le tracé de graphes. La première méthode s'appuie sur le réseau des plus courts chemins entre les sites et permet de modéliser les voies de déplacements les plus probables. La deuxième approche permet de mettre en évidence, visuellement, les liens entre les sites et les différents domaines culturels.

\section{Le réseau théorique des déplacements d'individus et d'objets}

20 Les transports forment l'un des trois principes du modèle géographique dit des « lieux centraux ", avec les deux autres principes : celui de marché et celui d'administration (Christaller 1933). C'est donc un facteur important de la hiérarchisation des sites, et nous savons que dans les sociétés traditionnelles, les coûts de transport sont élevés. Dans les Alpes, où les itinéraires sont contraints (pentes, talwegs, cols), la minimisation supposée de ces coûts (en temps ou en énergie) devait être un élément déterminant des structures d'échanges. Actuellement, entre les sites, nœuds potentiels des réseaux d'échange, la praticabilité des chemins est trop difficile à approcher quantitativement. Une approximation de la structure du réseau d'échange peut être établie à partir du calcul des plus courts chemins. Cette modélisation est nécessairement schématique en l'état de nos données.

21 Pour calculer les itinéraires, nous nous sommes servi de l'algorithme Shortestpath $d u$ logiciel R, lui-même basé sur l'algorithme de Dijkstra (1959). Le réseau des plus courts chemins a été établi entre tous les sites considérés comme contemporains (c'est-à-dire appartenant à la même période) suivant le découpage chronologique présenté sur la figure 3. Si deux sites étaient en relation, c'est probablement par certains segments de ces chemins que les échanges devaient s'effectuer.

22 La jonction de deux chemins définit un carrefour. Un carrefour est compté dans le système d'information géographique (SIG) dès lors que des chemins se touchent, se croisent ou se superposent partiellement. Les carrefours sont figurés par la densité de chemins qui les composent, à l'aide de l'outil Heatmap de QGIS (analyse du noyau) : le nombre total de chemins de chaque carrefour permet d'estimer son aire d'influence, selon un principe probabiliste. Dans cette modélisation, le rayon de recherche est fixé à 2 kilomètres autour des carrefours et correspond approximativement à une aire moyenne (environ 12,5 $\mathrm{km}^{2}$ ) pour l'ensellure d'un col ou d'une confluence.

Le modèle numérique de terrain (MNT) qui sert de référentiel au calcul des plus courts chemins est le SRTM3 de la NASA (résolution à l'équateur $90 \mathrm{~m}$, précision $\pm 20 \mathrm{~m}$ en plan et $\pm 16 \mathrm{~m}$ en altitude). L'unité de terrain dans l'aire étudiée est un carré d'environ 90 mètres de côté. La couverture des terrains (rivières, forêts, sol dénudé, etc.) n'entre pas dans le calcul de la carte des coûts. Les difficultés de franchissement sont uniquement calculées à partir de la carte des pentes extraite du MNT. Les unités de terrain de moins de $5 \%$ de pente sont considérées comme ayant un coût de franchissement de 1; au-delà de $15 \%$ de pente, les difficultés de franchissement deviennent exponentiellement élevées. 

simplification, dans notre modèle, ces difficultés sont considérées isotropes, c'est-àdire qu'il est identiquement coûteux de monter, de descendre ou de traverser à altitude constante une pente. Après un algèbre de carte croisant l'emprise des lacs à la carte des coûts, les unités de terrains recouvertes par les lacs ont chacune une difficulté de franchissement de 5. Ce coût est arbitrairement fixé car, à notre connaissance, il n'existe pas de consensus sur les difficultés de franchissement des pièces d'eau. Cela dit, ce coût prend en compte le coût des deux ruptures de charge qui se font sur les rives (embarquement et débarquement). Les cours d'eau ne sont pas pris en compte dans les calculs.

\section{Les correspondances matérielles entre les domaines culturels et les sites}

La théorie des graphes (ou analyse des réseaux) offre un cadre conceptuel et divers indices statistiques pour traiter les notions de réseaux et de voisinage. L'ensemble d'un système est représenté par des nœuds et des liens mettant ces nœuds en relation. La grande plasticité conceptuelle de cette modélisation a permis de l'adapter à des sujets aussi divers que l'étude des visibilités intersites (Brughmans et al. 2015) ou la distribution des signes sur des céramiques décorées (Huet 2018). Dans cette étude, les nœuds appartiennent à deux catégories : les sites et les types d'objets. Un lien existe entre ces catégories quand un site a livré tel ou tel type de mobilier. La spatialisation des nœuds utilise l'algorithme de Fruchterman-Reingold. Les nœuds sont situés conformément aux différentes «forces » qui s'exercent sur eux, c'est-à-dire qu'ils sont positionnés en fonction du nombre et de l'origine de leurs liens. Les nœuds au centre du graphe sont aussi ceux qui ont le plus de liens, les types de mobilier seront d'autant plus proches qu'ils apparaissent dans des sites communs, etc. Le tracé de graphe, en jouant sur la sémiologie des nœuds et des liens (forme, taille, couleur, transparence, etc.) permet également de mettre en évidence certaines caractéristiques topologiques du graphe.

des indices peuvent être calculés localement, pour chaque nœud du graphe (degrés, excentricité, etc.) ou pour le réseau entier (connectivité, répartition des degrés, etc.). C'est un aspect important de la théorie des graphes, car il permet de comparer différents éléments (nœuds, liens) ou des graphes entre eux : évolution au cours du temps, organisation des sous-réseaux, etc.

Dans cette étude semi quantitative - le nombre de liens est compté, mais pas le nombre d'objets associés à ces liens - c'est surtout l'heuristique visuelle du tracé de graphe qui servira à modéliser les relations entre les sites et les types de mobilier.

\section{Les communautés alpines et sud-alpines au prisme des échanges protohistoriques}

Dans l'analyse des chemins potentiellement empruntés depuis l'aire de Golasecca, il a été fait le choix de considérer Castelletto Ticino comme référentiel pour la diffusion des parures depuis le viI siècle av. J.-C. jusqu'à la fin du siècle suivant. C'est en effet au cours de cette période que l'agglomération proto-urbaine s'épanouit, pour ensuite être 
délaissée progressivement pendant le $\mathrm{v}^{\mathrm{e}}$ siècle av. J.-C. C'est à partir de ce moment que l'agglomération de Côme prend le relais et vit son plein essor (De Marinis 2001, Lorre et Cicolani 2009). Cette alternance dans la source de diffusion des parures, bien qu'artificielle, reprend celle mise en évidence par les données archéologiques sans exclure, dans le traitement des données, les voies qui auraient pu être empruntées depuis le pôle oriental de Côme.

Le réseau de communication entre les sites est analysé par grandes phases, en décrivant les indices archéologiques (sites, carrefours, cols) du sud (domaine de Golasecca) vers le nord (domaine alpin et nord-alpin suisse), en prenant en compte la distribution du mobilier (objets personnels et de prestige) et les contextes archéologiques.

\section{Du VII vers la fin vie siècle av. J.-C. : mise en place du réseau et consolidation}

30 La première phase couvre une longue période allant du premier quart du VII $^{\mathrm{e}}$ siècle av. J.-C. au troisième quart du siècle suivant. Elle correspond à l'émergence du domaine de Golasecca et en particulier de l'agglomération proto-urbaine de Castelletto Ticino (Gambari 2004). Au cours de cette période, les éléments typiques du domaine de Golasecca apparaissent dans les mêmes territoires caractérisés, depuis l'âge du Bronze, par des échanges à longue et courte distance : principalement les vallées suisses du Rhône et du Rhin. La modélisation des plus courts chemins indique que l'accès au domaine alpin se faisait le long de deux voies principales : l'une, occidentale, par les vallées de Toce, à l'ouest, et du Tessin, à l'est ; l'autre, orientale, par la vallée du Tessin et le val de Breno (fig. 5). 
Fig. 5. - Plus courts chemins et carrefours intersites théoriques pour la période Golasecca IC-IIAB, entre 670 et 530 av. J.-C.

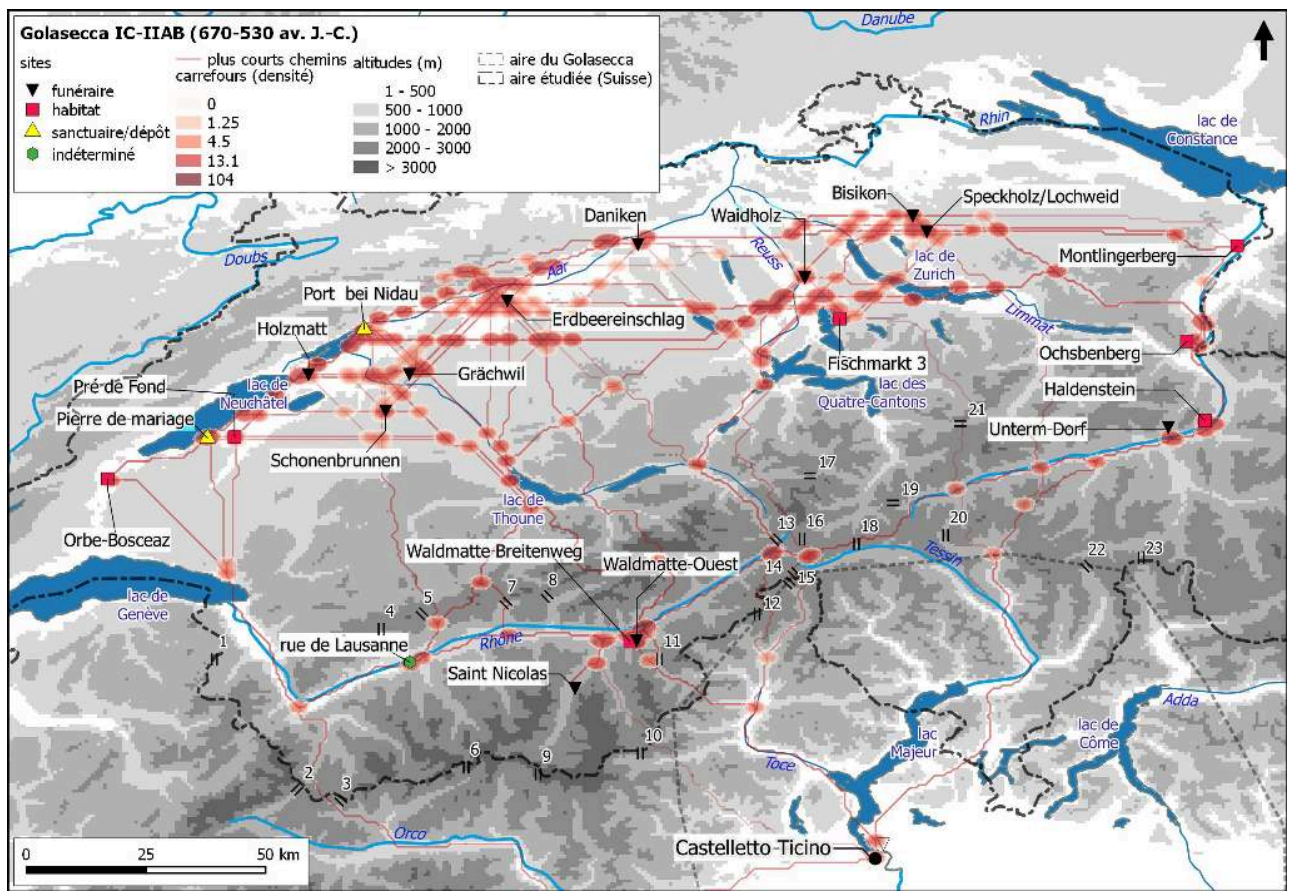

Les numéros des cols renvoient à la fig. 2 .

PAO Thomas Huet. Données Veronica Cicolani.

La voie occidentale conduit à une série de cols tels le Simplon ( $\left.n^{\circ} 11\right)$, l'Albrun ( $\left.n^{\circ} 12\right)$, le Gries ( $\left.n^{\circ} 14\right)$ et le Nufenen $\left(n^{\circ} 15\right)$ qui ouvrent sur la haute vallée du Rhône. Cette voie est probablement la plus fréquentée, comme l'indique la densité de carrefours présents tant autour de l'habitat de Gamsen-Waldmatte (Brigue-Gliss, canton du Valais), situé au débouché du Simplon, qu'au pied du col du Grimsel, ouvert sur la vallée de l'Aare. Depuis Gamsen, le chemin le plus direct vers le domaine nord-alpin passe par la haute et moyenne vallée de l'Aar. Les cols du Lötschen $\left(n^{\circ} 8\right)$, de Schnidejoch $\left(n^{\circ} 5\right)$ et de la Gemmi $\left(n^{\circ} 7\right)$ ont pu jouer un rôle important. Une fois les Préalpes franchies, les parures de type Golasecca se concentrent dans la région des Trois Lacs (lacs de Neuchâtel, de Bienne et de Morat). Ces objets sont trouvés dans des dépôts, des habitats et des nécropoles. Cependant, l'absence de sites au cœur de la vallée de l'Aar ne permet pas de distinguer clairement le ou les chemins empruntés pour y parvenir.

Une voie orientale remonte aussi dans le domaine alpin, atteignant la haute vallée du Rhin par la vallée du Ticino, puis du Breno. Le premier site relié à l'aire Golasecca est la nécropole d'Uterm Dorf (Tamins, canton des Grisons), suivie, le long de la haute vallée du Rhin, par une série de trois habitats distribués le long de la vallée en direction du lac de Zürich : Haldenstein (canton des Grisons), Ochsbenberg (Wartau, canton de SaintGall) et Montlingerberg (Oberriet, canton de Saint Gall). Ici, les données archéologiques mettent encore une fois l'accent sur une distribution centrée autour des lacs, ceux de Zürich et de Zoug. Le cadre qui se dégage au cours de cette première phase est celui d'un réseau qui commence à se structurer à l'appui des principales voies de communication intra-alpines et fluviolacustres permettant la jonction puis l'ouverture, à l'est comme à l'ouest, du domaine de Golasecca vers l'ensemble du secteur nord-alpin occidental. La présence du même type de mobilier de type Golasecca dans les habitats 
(Gamsen, canton du Valais), les sépultures, pour la plupart féminines (Saint-Nicolas, canton du Valais) et dans les dépôts aquatiques, comme à Port-près-Nidau (canton de Berne), ou bien à Font, Pierre de Mariage (canton de Fribourg), souligne dès cette phase l'intégration de parures exogènes au sein des principales activités humaines: domestique, funéraire et cultuelle.

Les rares importations à forte valeur ajoutée documentées pour cette période montrent que les liens nord-sud ne sont attestés que par l'entremise du site de Grächwil (canton de Berne), sépulture ayant livré la fameuse hydrie originaire de Grande Grèce (Güggisberg 2004), associée à du petit mobilier nord-italique (fig. 6).

Fig. 6. - Distribution en Suisse de la parure Golasecca et de la vaisselle métallique (étrusque et de Grande Grèce) par type de site pour la période Golasecca IC-IIAB, entre 670 et 530 avant J.-C.

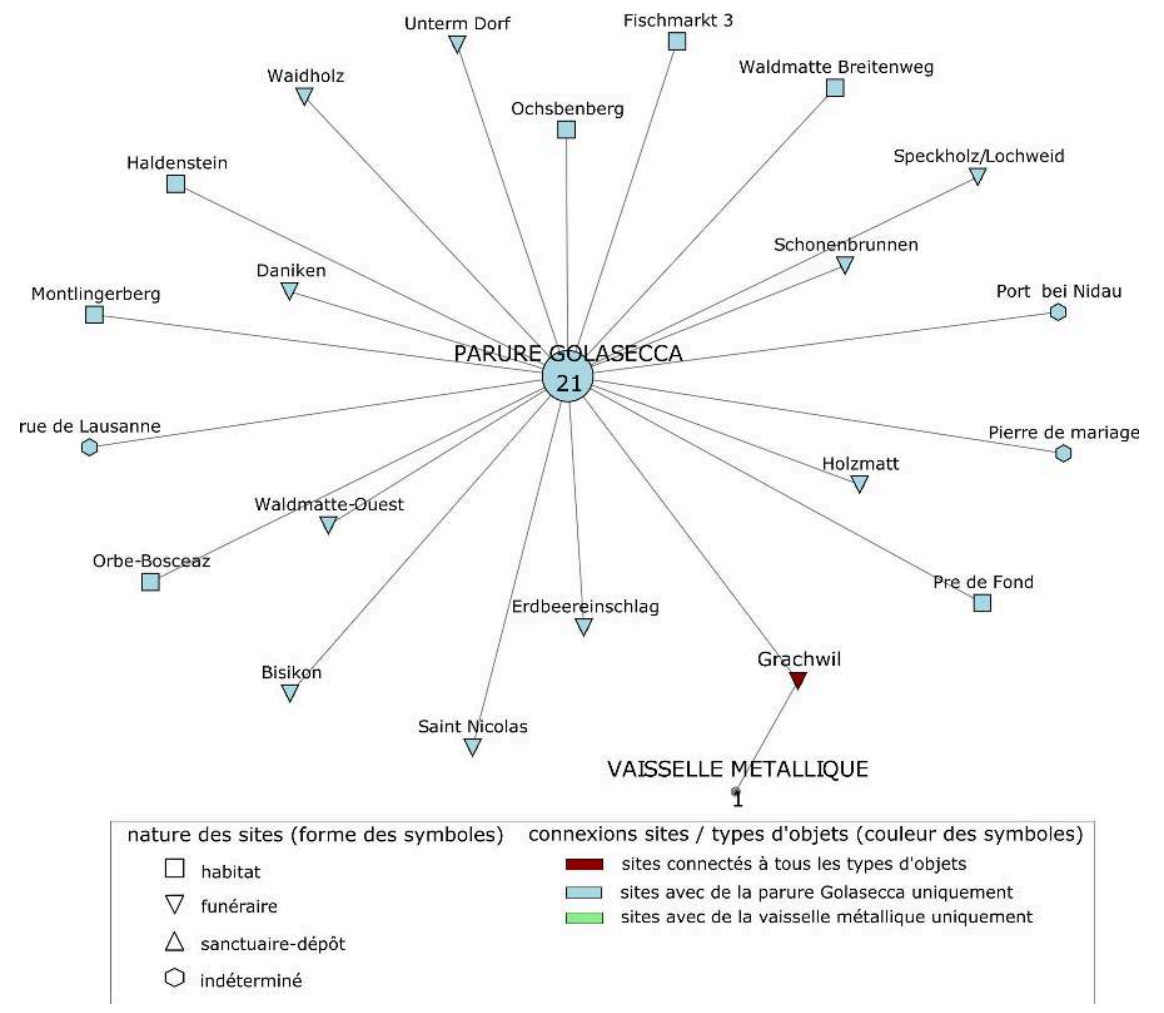

PAO Thomas Huet. Données Veronica Cicolani.

$\mathrm{Au}$ vu des données, les associations entre mobilier de type hallstattien, Golasecca et villanovien ne sont visibles que dans les dépôts humides découverts dans la région des Trois Lacs comme à Port, ou bien à Orpund (canton de Berne), composés exclusivement d'éléments de parure enfouis en l'état d'utilisation (Cicolani et al. 2015). Il est donc envisageable que l'arrivée dans cette région de l'hydrie se soit réalisée à l'appui du réseau préexistant, ici esquissé par la distribution spatiale du petit mobilier (Schindler 2004).

\section{Du milieu du $\mathrm{Vl}^{\mathrm{e}}$ au milieu du $\mathrm{V}^{\mathrm{e}}$ siècle av. J.-C. : essor et diversification du réseau}

Dès le milieu $d u \mathrm{VI}^{\mathrm{e}}$ siècle av.J.-C., le cadre change sensiblement. On assiste non seulement au doublement du nombre de sites concernés (40), mais aussi à une 
diversification et à une augmentation du nombre d'objets. La conjonction de ces deux paramètres explique pourquoi le modèle montre une densification significative du réseau intersites (fig. 7).

Fig. 7. - Plus courts chemins et carrefours intersites théoriques pour la période Golasecca IIBIIIA1, entre 530 et 450 av. J.-C.

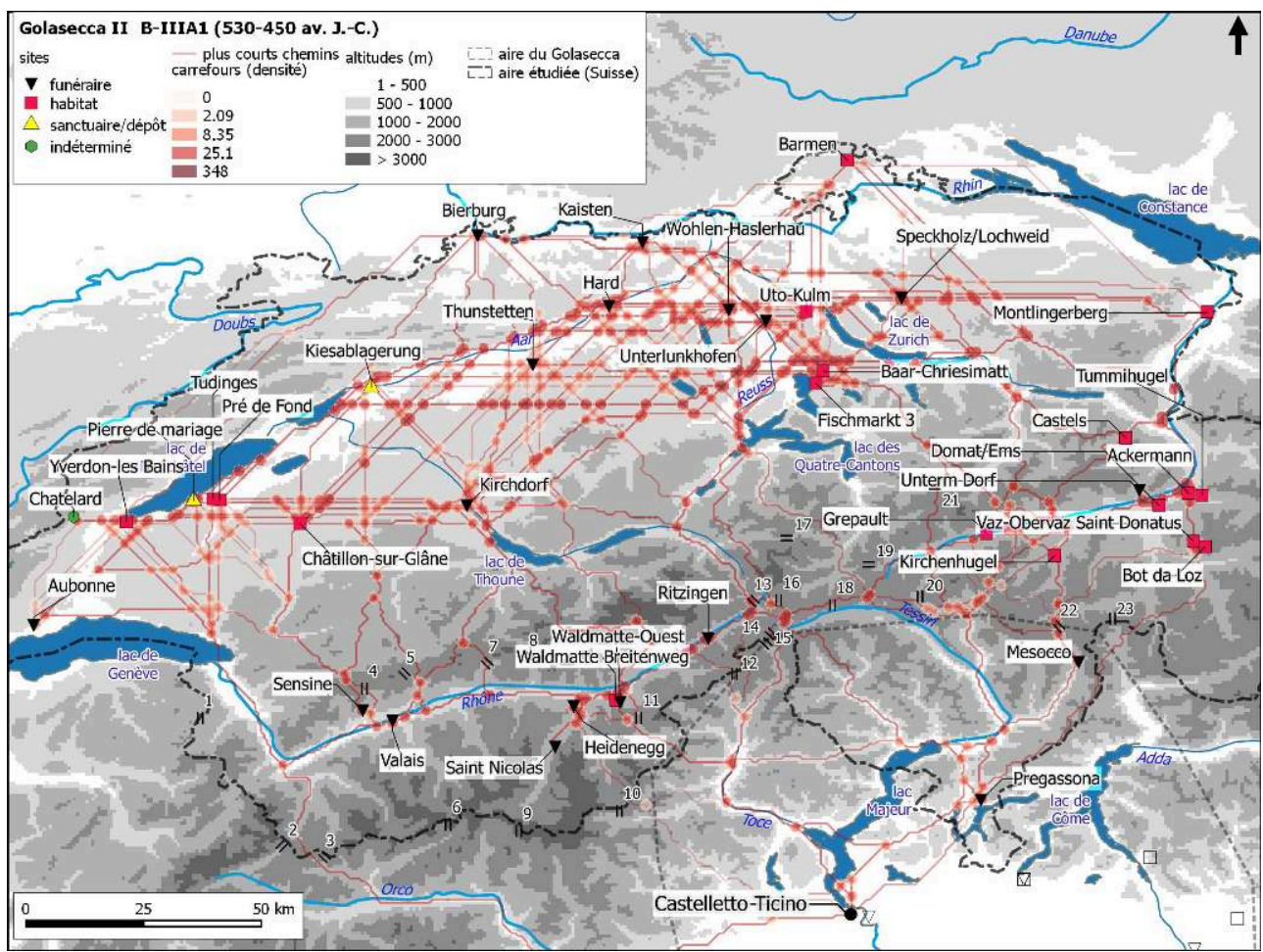

Les numéros des cols renvoient à la fig. 2.

PAO Thomas Huet. Données Veronica Cicolani.

Les parures de type Golasecca se repartissent à l'ouest du col de Saint-Gothard ( $\left.\mathrm{n}^{\circ} 18\right)$, principalement dans les sépultures alpines distribuées le long de la vallée du Rhône et de ses vallées latérales, alors qu'à l'est, dans le bassin versant du Rhin, ces mêmes objets figurent surtout dans les habitats, ici mieux documentés. D'ouest en est, la ligne de cols Simplon ( $\left.\mathrm{n}^{\circ} 11\right)$ - Nufenen ( $\left.\mathrm{n}^{\circ} 15\right)$ - Saint-Gothard $\left(\mathrm{n}^{\circ} 18\right)$ - San Bernardino $\left(\mathrm{n}^{\circ} 22\right)$ montre une répartition assez uniforme des concentrations des carrefours, qui témoigne d'un probable équilibre entre ces lieux de franchissement. Au sud de ces cols, le réseau intersites montre la stabilisation et la densification des connexions établies durant la phase précédente. Au nord, dans les vallées du Rhône et du Rhin, le nombre des carrefours témoigne également d'une circulation plus intense et ramifiée qu'à la période précédente.

La voie occidentale, qui joint Castelletto Ticino à l'habitat de Gamsen, est encore la plus susceptible d'avoir été employée, d'après la documentation archéologique. En amont de ce site, dans la haute vallée du Rhône et sur les voies des cols de Grimsel $\left(n^{\circ} 13\right)$ et de Saint-Gothard $\left(\mathrm{n}^{\circ} 18\right)$, la fréquentation est attestée par la découverte funéraire de Riztingen; en aval, dans la «basse " vallée du Rhône, c'est encore dans les vallées latérales, comme dans celle de la Vispa ou à Conthey, que l'on retrouve des sépultures alpines aux parures mixtes, mêlant des éléments indigènes et de type Golasecca. Ces faits confirment la fréquentation du couloir rhodanien suisse entre la fin $\mathrm{du} \mathrm{vI}^{\mathrm{e}}$ et le 
milieu du ve siècle av. J.-C. par les gens de Golasecca. Plus à l'ouest, les pendeloques provenant d'Aubonne indiquent l'emprunt du Rhône et le contournement du lac de Genève au début $d u v^{e}$ siècle av. J.-C. C'est encore dans la région des Trois Lacs que les carrefours indiquent une fréquentation dense, appuyée sur plusieurs habitats d'envergure aux associations mixtes de mobilier: Pré de Fond (Bussy, canton de Fribourg) puis Châtillon-sur-Glâne (canton de Fribourg). La plupart des sites inscrits dans cette phase jalonnent les principales voies qui conduisent à la vallée de l'Aar, comme le documentent une fibule de La Certosa à Spiez/Schonegg (canton de Berne) et la pendeloque de la nécropole tumulaire de Jaberg-Kirchdorf (canton de Berne), en aval du lac de Thoune. Ce site est par ailleurs installé à un important croisement de chemins qui, partant de Fribourg, s'engouffrent ensuite dans le domaine alpin.

D'autre part, la voie orientale, franchissant le col du San Bernardino ( $\left.n^{\circ} 22\right)$, met en relation le faciès septentrional de Golasecca avec le bassin hydrographique du Rhin, où est implanté l'habitat de Domat/Ems (Kirschenhungel, Grisons). À l'exception de la nécropole d'Unterm Dorf, dans l'ensemble du bassin versant du Rhin, ce sont encore une fois les habitats qui marquent une fréquentation assidue de la haute vallée du Rhin en direction des lacs de Zürich et de Zoug, au nord et nord-ouest. C'est ici que les carrefours intersites sont particulièrement nombreux, comme l'indiquent les découvertes issues des habitats de Zoug-Fischmarkt 3 et de Baar (canton de Zoug) puis, dans la basse vallée de l'Aar, suivant une ligne est-ouest, entre les nécropoles tumulaires de Wohlen-Haslerhau et de Thunstetten. Comme dans les habitats, ces ensembles funéraires livrent des associations mêlant parures de type Golasecca (en particulier des séries de pendeloques) à des parures locales, et dans le cas de WholenHaslerhau, à une situle en bronze issue d'ateliers tessinois.

C'est aussi à partir de cette seconde phase, et surtout vers la fin du vi siècle av. J.-C., qu'apparaissent pour la première fois les vaisselles métalliques issues d'ateliers tessinois, dans la sépulture de Wohlen-Haslerhau et dans l'habitat de Baar-Baarbourg, dans la vallée de la Reuss (Schmid-Sikimic et Bigler 2005, p. 7), mais aussi les rares importations méditerranéennes: amphores, céramiques grecques et corail brut. Ces découvertes, bien que mieux documentées en Suisse occidentale, où l'activité archéologique a été plus intense, s'étendent également vers l'est. Les tessons de céramiques grecques des habitats d'Uto Kulm et de Baar-Baarburg et la branche de corail brut de l'inhumation féminine de Trüllikon (canton de Zurich) représentent les présences méditerranéennes les plus orientales à ce jour connues (Schmid-Sikimic et Bigler 2005).

La modélisation de l'information par le graphe réunissant les objets personnels et à valeur ajoutée du domaine de Golasecca aux importations grecques et étrusques souligne l'importance de Châtillon-sur-Glâne et du canton de Zoug (Zug-Fischmarkt et Baar-Baarburg) dans les échanges interculturels, les deux habitats étant associés à au moins trois classes de mobilier (fig. 8). 
Fig. 8. - Distribution en Suisse des parures de type Golasecca, des vaisselles métalliques (ateliers de Golasecca), des céramiques grecques et des amphores pour la période Golasecca IIB-IIIA1, entre 530 et 450 avant J.-C.

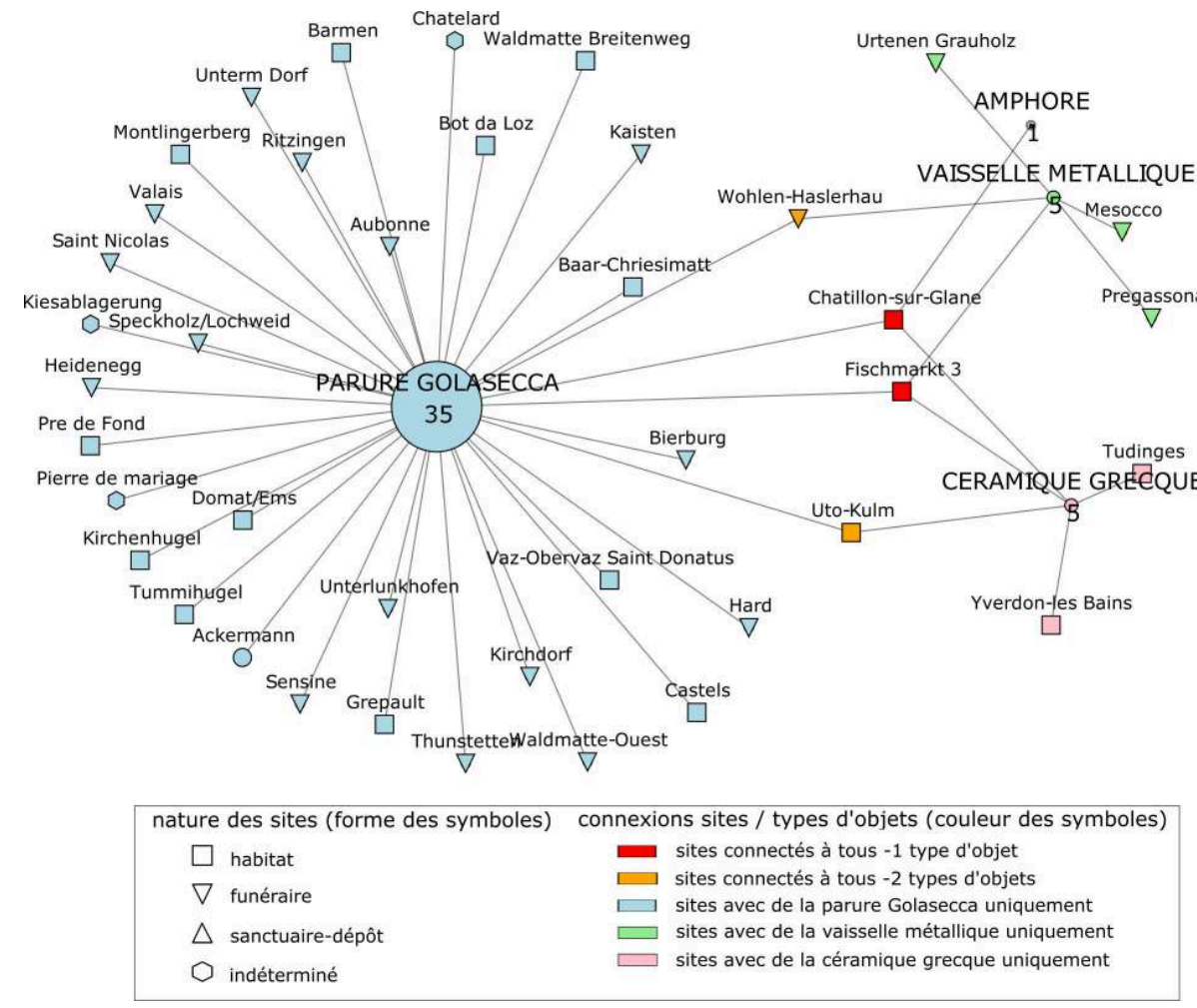

PAO Thomas Huet. Données Veronica Cicolani.

41 La vaisselle métallique produite dans les ateliers tessinois et alpins orientaux, en particulier les situles, ne s'associe jamais directement aux importations méditerranéennes, hormis dans le cas de l'habitat de Baar (canton de Zoug), d'où proviennent un tesson de coupe attique et un fragment d'attache d'anse de situle tessinoise. Le même cas de figure est valable pour les cistes à cordons à poignées fixes, rattachables à une variante du type La Certosa découvertes à Pregassona, à Molinazzo et à Urtenen-Grauholz, attribuées à des ateliers alpins orientaux (De Marinis 2000, p. 369). Une situation bien différente est illustrée par la distribution des amphores et de la céramique grecque, faiblement attestées dans l'ensemble du domaine alpin. Elles ne sont associées que dans l'habitat fortifié de Châtillon-sur-Glâne, où on comptabilise environ une dizaine de céramiques grecques et une vingtaine d'amphores, dont trois massaliètes et dix-sept réparties entre italiques et grecques (Lüscher 1998). Des dolia se rapprochant de ceux découverts à Breisach, de la céramique grise, de la céramique pseudo-ionienne ainsi que de la parures de type Golasecca et des Alpes orientales complètent la liste des importations documentées sur le site (Lüscher 1998). L'estimation du nombre d'amphores serait toutefois à revoir à la baisse, tout comme celui des céramiques grecques (Ruffieux et Mauvilly 2015). La diversité de leurs provenances fait entrevoir la mise en œuvre d'un système complexe et imbriqué de voies, et des réseaux de distribution dont Châtillon-sur-Glâne a été l'un de maillons. Le nombre extrêmement réduit d'éléments de parure de type Golasecca ici présent (deux fragments de fibules) ne permet pas de relier étroitement ce circuit de distribution des céramiques grecques et des amphores au circuit sud-alpin, mais simplement de 
constater que ces apports se produisent en même temps, entre la fin du $\mathrm{VI}^{\mathrm{e}}$ siècle av. J.-C. et le milieu du siècle suivant.

Il est en revanche possible d'envisager que l'arrivée de céramiques grecques à l'est, dans la vallée de la Reuss, soit en partie à lier aux réseaux internes alpin et sud-alpin, très actifs à ce moment. En effet, l'occupation de la part du faciès alpin de Golasecca des vallées alpines du Misox, de la Léventine et de l'Engadine, ouvertes vers le plateau oriental et l'Allemagne, constitue un atout indéniable pour une gestion directe des réseaux montagnards. C'est le cas du moins pour l'aire de Zoug (habitats et stations alpines de Zoug et Baar), d'où proviennent plusieurs éléments de parure de type Golasecca : une attache d'anse de situle tessinoise et un fragment de céramique attique. Par l'entremise de stations alpines qui s'égrènent le long de la vallée du Rhin (SchmidSikimic et Bigler 2005), on peut alors expliquer la présence de fibules de type Golasecca et peut-être celle de tessons de céramique attique dans l'habitat de Uetliberg (Uto Kulm), dont un fragment de cratère à colonnettes à figures noires, daté vers la fin du $\mathrm{VI}^{\mathrm{e}}$ siècle av. J.-C. Il est intéressant de remarquer que ces habitats se situent également le long de la route du Gothard, axe de communication important entre les deux versant des Alpes. La présence de céramiques grecques dans l'habitat artisanal de Sévaz (une coupe, un cratère en calice et un tesson probablement issu d'un autre cratère) et le tesson isolé découvert à Yverdon-les-Bains (un tesson à figures rouges d'un probable cratère en calice) demeurent en revanche difficiles à expliquer dans une perspective sud-alpine (Ruffieux et Mauvilly 2015). En effet, à Sévaz, habitat occupé essentiellement au cours du $v^{e}$ siècle av. J.-C., aucun élément sud-alpin n'a été mis au jour, bien que l'habitat s'inscrive dans une zone où les liens intrasites sont denses. La chronologie du site explique en partie cette absence, car il correspond à un moment où les témoignages sud-alpins dans les habitats diminuent d'une façon accrue.

La faiblesse des données, la particularité des formes céramiques découvertes et le décalage chronologique entre productions à figures noires et rouges rendent difficile la compréhension de la présence de ces vases grecs au sein de l'ensemble des habitats suisses ici examinés. Bien qu'une partie d'entre eux puisse être plus directement reliée à l'action du réseau sud-alpin (Baar, Zoug, Uto Kulm), les données disponibles ne sont pas pour autant suffisantes pour considérer le domaine de Golasecca comme l'intermédiaire exclusif du commerce méditerranéen au sein du milieu alpin.

\section{Du milieu du $v^{\mathrm{e}}$ au début du IV ${ }^{\mathrm{e}}$ siècle av. J.-C. : une contraction progressive du réseau}

Au cours du v viècle av. J.-C., Castelletto Ticino, actif jusqu'à 450 av. J.-C., est secondé puis remplacé par l'agglomération proto-urbaine de Côme, pôle de référence du secteur oriental du domaine de Golasecca. En dépit de ce basculement des activités de Castelletto vers Côme, c'est encore la voie occidentale, remontant la vallée du Toce et conduisant du col de Nufenen ( $\left.\mathrm{n}^{\circ} 15\right)$ à l'habitat de Gamsen (Waldmatte-Breitenweg), dans la haute vallée du Rhône, qui demeure la mieux documentée. C'est ce dont témoigne la concentration de carrefours (fig. 9) et les découvertes encore nombreuses de Gamsen. 
Fig. 9. - Plus courts chemins et carrefours intersites théoriques pour la période Golasecca IIIA2IIIA3, entre 450 et 380 av. J.-C.

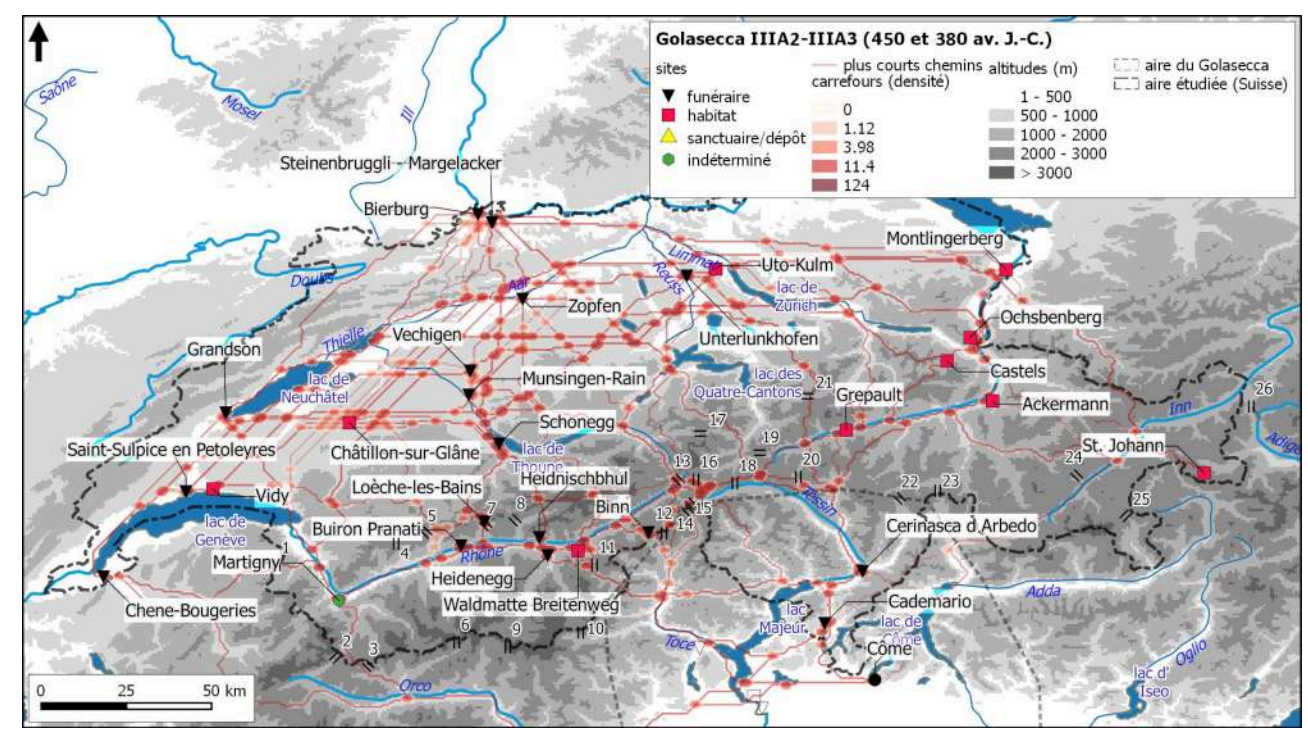

Les numéros des cols renvoient à la fig. 2.

PAO Thomas Huet. Données Veronica Cicolani.

On constate cependant une réduction du nombre de sites intégrés dans le réseau par rapport à la phase précédente, passant ainsi de 28 à seulement 14 au début du IV siècle av. J.-C. Ces derniers sont maintenant principalement concentrés en Suisse occidentale, dans la haute vallée du Rhône et la haute vallée de l'Aar, et moins nombreux en Suisse orientale, le long des hautes vallées du Rhin et de la Reuss. La concentration de carrefours à l'est et à l'ouest du col de Saint-Gothard ( $\left.\mathrm{n}^{\circ} 18\right)$ témoigne probablement de son rôle encore important dans les échanges intra-alpins, assurant une liaison entre les vallées du Rhin et du Rhône. Le col de la Gemmi ( $\left.{ }^{\circ} 7\right)$, qui met en connexion la haute vallée du Rhône et vallée de l'Aar, est potentiellement fréquemment emprunté, comme l'indiquent la concentration de carrefours et les découvertes funéraires de Loèche-lesBains, à proximité immédiate du col. Au nord du col, la succession des nécropoles de Schonegg, Münsingen-Rain, Vechigen et Zopfen, ayant toutes livré des fibules de La Certosa de type tessinois (450-380 av. J.-C.), documente une dernière fréquentation du couloir de la vallée de l'Aar dans un secteur à forte densité de carrefours.

Vers la fin $d u v^{e}$ siècle av. J.-C. et le début du siècle suivant, le réseau est davantage contracté et recentré sur le domaine alpin proprement dit. Les carrefours les plus denses se font maintenant dans l'aire même du domaine de Golasecca (fig. 10). 
Fig. 10. - Plus courts chemins et carrefours inter-sites théoriques pour la période Golasecca IIIA3, 420-380 av. J.-C.

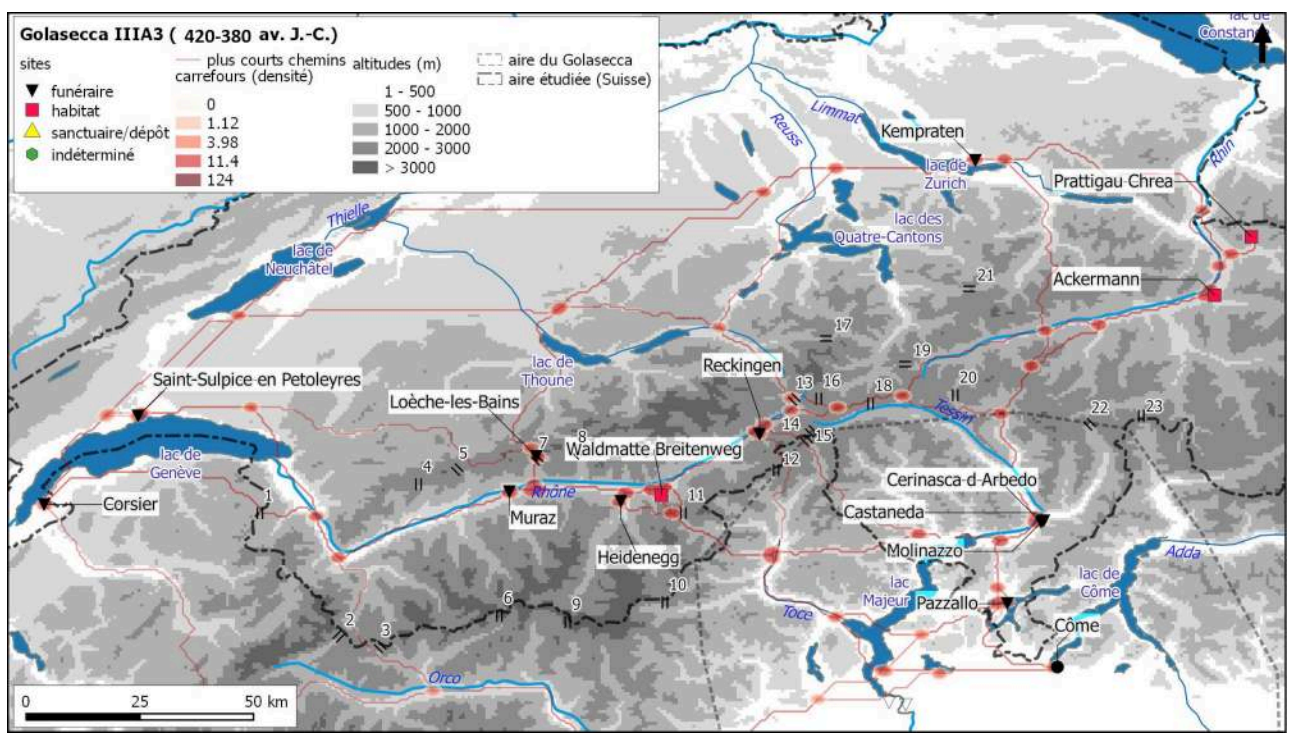

Les numéros des cols renvoient à la fig. 2.

PAO Thomas Huet. Données Veronica Cicolani.

Seules les vallées du Rhône et du Rhin nous restituent les derniers témoignages d'une fréquentation plus sporadique et documentée de préférence dans le domaine funéraire, notamment par des fibules d'apanage féminin. Depuis Côme, la voie occidentale, passant par le col du Simplon ( $\left.{ }^{\circ} 11\right)$ se maintient, alors que l'enfilade des sites de Pazzallo, Molinazzo, Castaneda et Cerinasca, dans les vallées de Vedeggio et de Ticino, trace une voie vers les habitats de la vallée du Rhin (Coire-Ackerman, Prattigau Chrea) par le col de Ceneri, bien qu'aucun site ne soit recensé autour de la ligne de crête entre le San Bernardino ( $\left.\mathrm{n}^{\circ} 22\right)$ et le Saint-Gothard ( $\left.\mathrm{n}^{\circ} 18\right)$.

\section{Discussion}

L'analyse de la distribution spatiale et contextuelle des parures de type Golasecca dans le réseau des plus courts chemins confirme le rôle structurant des Alpes centrales dans l'orientation des déplacements et l'organisation des réseaux d'échanges entre domaines alpin, sud-alpin et nord-alpin. Tout au long de la période ici examinée (entre 670 et 380 av. J.-C. environ), plusieurs cols, au-delà de ceux plus communément pris en compte, ont été franchis avec une fréquence majeure, comme par exemple ceux de Simplon ( $\left.{ }^{\circ} 11\right)$, de Grimsel $\left(n^{\circ} 13\right)$ et de Nufenen $\left(n^{\circ} 15\right)$. Le séquençage chronologique des données en quatre grandes phases a également permis d'observer le comportement spatial du réseau depuis sa structuration (Golasecca IC-IIAB) jusqu'à sa contraction progressive (Golasecca IIIA2-IIIA3), marquée par des changements dans le choix des

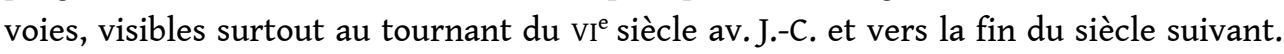
Les concentrations de carrefours individualisés au sein des massifs et sur l'ensemble du Moyen Pays ont par ailleurs complété l'information en suggérant l'existence d'autres itinéraires possibles, en dépit parfois de l'absence de données archéologiques. Ceci a ainsi contribué à mettre en exergue le dynamisme et la densité des réseaux de circulation interne au domaine alpin, jusque-là peu perçus dans leur complexité. En intégrant d'autres informations d'ordre géomorphologique (unités de terrain de type 
lac, rivière, forêt, sol dénudé, visibilité, temps de franchissement, etc.) et archéologique (architecture, position géographique et typologie plus fine des sites, quantification précise de l'ensemble de productions découvertes), cette approche pourra davantage acquérir un potentiel explicatif dans l'identification et la compréhension de la structuration des réseaux de communication et donc des territoires impliqués dans les échanges interculturels.

La présence d'importations dans le milieu alpin est un phénomène plus complexe à évaluer. La vaisselle métallique entre dans les réseaux d'échanges tout au long des phases examinées et elle est attestée dans la zone où les densités de carrefours sont les plus élevées. Documentée en plus étroite association avec les productions ordinaires (parures et fibules), sa présence dans les ensembles funéraires et plus rarement dans les habitats témoigne du maintien des relations à moyenne et longue distance entre le domaine de Golasecca et les communautés alpines. Au ve siècle av. J.-C., son aire de distribution est limitée, et elle finit par concerner seulement les nécropoles du faciès septentrional de Golasecca (De Marinis et Biaggio Simona 2000), alors qu'au nord des Alpes la répartition spatiale des situles et des cistes à cordons de type tessinois couvre une aire géographique étendue, depuis les côtes de la Bretagne (Le Bono) jusqu'à l'est du Rhin, en débordant largement du périmètre défini par la répartition du petit mobilier de Golasecca à la même période (Cicolani 2017).

Les importations méditerranéennes (vin en amphores et céramiques grecques) apparaissent dans les registres archéologiques alpins au cours du ve siècle av. J.-C. Moins étroitement liées aux marqueurs individuels, elles se concentrent majoritairement dans le plateau suisse occidental, uniquement dans les habitats. Ces éléments témoignent de réseaux d'échanges établis autour de l'axe rhodanien français et prolongés au sein du milieu alpin à l'appui de réseaux fluviaux et terrestres internes très ramifiés. Au vu de données disponibles, ces importations, faiblement représentées, ne semblent pas avoir fait l'objet d'un commerce spécifique dans les Alpes centrales, ni avoir débouché sur l'émergence de centres de redistribution desservant le domaine alpin. La composition de la vaisselle méditerranéenne restituable à partir des découvertes publiées $(5$ coupes à boire, 4 cratères à colonnettes et 2 ou 3 cratères en calice à figures rouges) suggère une adhésion partielle aux pratiques de commensalité de type "banquet", comme cela a pu être mis en évidence dans le domaine de Golasecca (Ruffieux et Mauvilly 2015, Casini 2015). Par ailleurs, les cratères à colonnettes à figures noires de Châtillon-sur-Glâne et d'Uto Kulm, comme ceux plus tardifs en calice et à figures rouges de Sévaz-Tudinges, et probablement d'Yverdon, sont des productions rarement attestées en Europe continentale tout comme dans l'ensemble de la Gaule méditerranéenne et en Italie du nord (Bonomi et Güggisberg 2015). Si on peut envisager qu'une partie de ces importations a pu être aussi transportée à travers les Alpes par l'entremise du domaine de Golasecca, en particulier dans le secteur oriental (habitats fortifiés de Baar-Baarburg et de Uto Kulm), la probabilité que ces productions soient parvenues à Châtillon-sur-Glâne par ce même réseau ne paraît pas envisageable $a u \quad v u d u$ faible nombre de témoignages archéologiques disponibles à ce jour. Il serait plus judicieux d'expliquer la présence de parures sud-alpines et de céramiques méditerranéennes dans les Alpes centrales par l'action et l'imbrication de plusieurs réseaux de distribution, l'un animé par Marseille, Lyon et Bragny-sur-Saône, l'autre par Golasecca et les stations et habitats alpins garantissant entre la fin $\mathrm{du} \mathrm{vl}^{\mathrm{e}}$ et le $\mathrm{v}^{\mathrm{e}}$ siècle av.J.-C. la diffusion de productions 
ordinaires et d'autres plus exotiques. Cette interprétation semble être l'explication la plus probable pour comprendre la diffusion des productions méditerranéennes dans l'ensemble du domaine alpin, voire du domaine nord-alpin, où elles constituent une présence bien sûr significative sur le plan socioculturel, mais tout de même marginale sur le plan quantitatif.

\section{BIBLIOGRAPHIE}

BONOMI S. et GUGGISBERG M. (dir.), 2015, Griechische Keramik nördlich von Etrurien : Mediterrane Importe und archäologischer Kontext, Wiesbaden, Reichert Verlag.

BORRELLO M. A., 2015, « Le parures in conchiglie, Beni di prestigio, segni d'identità sociale e indicatori di contatti a lunga distanza nel Neolitico ", dans Girod A. (dir.), Appunti di Archeomalacologia, Florence, All'Insegna del Giglio, p. 137-145.

BRUGHMANS T., KEAY S., EARL G. P., 2015, « Understanding inter-settlement visibility in Iron Age and Roman Southern Spain with exponential random graph models for visibility networks ", Journal of Archaeological Method and Theory, vol. 22, $\mathrm{n}^{\circ}$ 1, p. 58-143.

CASINI S., 2011, « Le fibule a coste rinvenute a Bologna : Nuovi spunti di riflessione », Notizie Archeologiche Bergomensi, $\mathrm{n}^{\circ}$ 19, p. 257-270.

CASINI S., 2015, « La circolazione della ceramica attica nell'Italia settentrionale », dans Bonomi S. et Guggisberg M. (dir.), Griechische Keramik nördlich von Etrurien : Mediterrane Importe und archäologischer Kontext, Wiesbaden, Reichert Verlag, p. 19-33.

CHRISTALLER C., 1933, Die zentralen Orte in Süddeutschland, Jena, Gustav Fischer.

CICOLANI V., 2013, « Les petits objets métalliques de la culture de Golasecca : des marqueurs culturels et anthropologiques pour l'étude de relations transalpines au premier âge du Fer ", dans Colin A. et Verdin F. (dir.), L'âge du Fer en Aquitaine et sur ses marges : mobilité des hommes, diffusion des idées, circulation des biens dans l'espace européen à l'âge du Fer, vol. 2 : Actes du XXXV colloque international de l'AFEAF, Bordeaux 2011, Bordeaux, Fédération Aquitania (Aquitania, supplément 30), p. 459-478.

CICOLANI V., 2017, Passeurs des Alpes : la culture de Golasecca entre Méditerranée et Europe continentale à l'âge du Fer, Paris, Hermann (Histoire et archéologie).

CICOLANI V., DUBREUCQ É., MÉLIN M., MILCENT P.-Y., 2015, « Aux sources de la Douix : objets et dépôts métalliques en milieu humide au Premier âge du Fer à partir de l'exemple d'un site remarquable ", dans Olmer F. et Roure R. (dir.), Les Gaulois au fil de l'eau, $37^{e}$ colloque international de L'AFEAF, Montpellier, 8-11 mai 2013, Bordeaux, Ausonius (Mémoires d'histoire et d'archéologie médiévales de l'Institut Ausonius, 39), p. 719-756

DAVID-ELBIALI M. et DUNNING C., 2005, « Il quadro cronologico relativo e assoluto nell'ambito nordalpino tra 1000 e 700 a. C. ", dans Bartoloni G. et Delpino F. (dir.), Oriente e Occidente: metodi e discipline a confronto: riflessioni sulla cronologia dell'età del Ferro in Italia. Atti dell'incontro di studi, Roma, 30-31 ottobre 2003, Pise/Rome, Ist. Editoriali e Poligrafici, p. 145-197. 
DE MARINIS R. C., 1988, « La cultura di Golasecca : Insubri, Orobi e Leponzi », dans Pugliese Carratelli G., Italia : omnium terrarum alumna, Milan, Credito Italiano, p. 159-247.

DE MARINIS R. C., 2000, « Il vasellame bronzeo nell'area alpina della cultura di Golasecca », dans De Marinis R. C. et Biaggio Simona S. (dir.), I Leponti tra mito e realtà, vol. 1, Locarno, Armando Dadò, p. 341-406.

DE MARINIS R. C., 2001, «L'età del Ferro in Lombardia: stato attuale delle conoscenze e problemi aperti », dans De Marinis R., Como e la Lombardia nell'età del Ferro, Como, Società Archeologica Comense, p. 27-76.

DE MARINIS R. C., 2008, « Aspetti degli influssi dell'espansione etrusca in val padana verso la civiltà di Golasecca », dans Della Fina G. M. (dir.), La colonizzazione etrusca in Italia: atti del XV convegno internazionale di studi sulla Storia e l'Archeologia dell'Etruria, Orvieto, 2008, Rome, Quasar (Annali della fondazione per il museo "Claudio Faina", XV), p. 115-146.

DE MARINIS R. C. et BIAGGIO SIMONA S. (dir.), 2000, I Leponti tra mito e realtà, Locarno, Armando Dadò.

DE MARINIS R. C. et GAMBARI F. M., 2005, « La cultura di Golasecca dal X agli inizi del VII secolo a. C.: cronologia relativa e correlazioni con altre aree culturali », dans Bartoloni G. et Delpino F. (dir.), Oriente e Occidente: metodi e discipline a confronto. Riflessioni sulla cronologia dell'età del Ferro italiana. Atti dell'incontro di studi, Roma, 30-31 ottobre 2003, Rome, Ist. Editoriali e Poligrafici, p. 198-226.

DE MARINIS R. C. et RAPI M., 2007, L'abitato etrusco del Forcello di Bagnolo San Vito-Mantova : Le fasi di età arcaica, $2^{\mathrm{e}}$ éd., Florence, Tipografia Latini.

Della CASA P., 2009, « La Préhistoire des Alpes : enjeux scientifiques, méthodes et perspectives de la recherche ", Le Globe, $\mathrm{n}^{\circ} 149$, p. 7-28.

DIJKSTRA E. W., 1959, « A Note on Two Problems in Connexion with Graphs », Numerische Mathematik, vol. 1, nº 1, p. 269-271.

DUBREUCQ É., 2013, Métal des premiers Celtes : productions métalliques sur les habitats dans les provinces du Hallstatt centre-occidental, Dijon, Éditions universitaires de Dijon (Arts, archéologie et patrimoine).

GALLAY A. (dir.), 2006, Des Alpes au Léman : images de la préhistoire, Gollion, Infolio.

GAMBARI F. M., 2004, « I signori del commercio sulle vie d'acqua : il ruolo degli scambi nella cultura di Golasecca », dans Marzatico F. et Gleirscher P. (dir.), Guerrieri Principi ed Eroi fra il Danubio e il Po, dalla preistoria all'Alto Medioevo, Trente, Provincia Autonoma di Trento, p. 305-313.

GAMBARI F. M. et CICOLANI V., à paraître, « De chefs guerriers aux seigneurs de terres et commerces : les "princes" de la zone occidentale de la culture de Golasecca entre viI et $\mathrm{V}^{\mathrm{e}}$ siècle av. J.-C. ", dans Brun P., Chaume B., Sacchetti F. (dir.), Vix et le phénomène princier, colloque international 27-28 octobre 2016, Châtillon-sur-Seine.

GÜGGISBERG M., 2004, Die Hydria von Grächwil zur Funktion und Rezeption mediterraner Importe in Mitteleuropa im 6. und 5. Jahrhundert V. Chr, Akten Internationales Kolloquium, 12.-13. Oktober 2001, Berne, Bernisches Historisches Museum (Schriften des Bernischen historischen Museums, 5). HUET T., 2018, « Geometric graphs to study ceramic decoration », dans Mieko M. et Uleberg E. (dir.), Exploring Oceans of Data : Proceedings of the 42nd Annual Conference on Computer Applications and quantitative Methods in Archaeology 2016, Oxford, Archaeopress. 
LORRE C. et CICOLANI V., 2009 (dir.), Golasecca : du commerce et des hommes à l'âge du Fer, VIII ${ }^{e}-V^{e}$ siècle av. J.-C. : catalogue d'exposition, Musée d'archéologie nationale, château de Saint-Germain-en-Laye, 27 novembre 2009-26 avril 2010, Paris, Réunion des musées nationaux.

LÜSCHER G., 1998, « Die Importkeramik », dans Dietrich-Weibel B., Lüscher G., Kilka T. (dir.), Posieux/Châtillon-sur-Glâne : Keramik (6.-5. Jh. v. Chr.) = Céramiques ( $\mathrm{VI}^{e}-\mathrm{V}^{e}$ siècles av. J.-C.), Fribourg, Éditions universitaires (Archéologie fribourgoise, 12), p. 119-210.

MigLIAVACCA M., 2013, « Le Prealpi venete nell'età del Ferro: analisi e interpretazione di un paesaggio polisemico », Preistoria Alpina, $\mathrm{n}^{\circ}$ 47, p. 17-30.

MÜLLER F., KAENEL G., LÜSCHER G. (dir.), 1999, La Suisse du Paléolithique à l'aube du Moyen Âge. SPM IV : Âge du Fer, Bâle, Archéologie suisse.

PAULI L., 1980, Die Alpen in Frühzeit und Mittelalter : Die archäologische Entdeckung einer Kulturlandschaft, Munich, Beck.

PAULI L., 1991, "Les Alpes centrales et orientales à l'âge du Fer », dans Duval A. (dir.), Les Alpes à l'âge du Fer, actes du $10^{e}$ colloque sur l'âge du Fer, Yenne-Chambéry, Paris, CNRS éditions (Revue archéologique de Narbonnaise, supplément 22), p. 291-311.

PÉTREQUin P., PÉTREQUiN A.-M., ERRERA M., CASSEN S., CROUTSCH C., KLASSEN L., ROSSY M., GARIBALDi P., ISETTI E., ROSSI G., 2005, « Beigua, Monviso e Valais : All'origine delle grandi asce levigate di origine alpina in Europa occidentale durante il V millennio », Rivista di Scienze Preistoriche, t. LV, p. 265-322.

RUFFIEUX M. et MAUVILly M., 2015, « Des forgerons qui vivaient comme des princes ? Réflexion sur la céramique attique découverte dans l'atelier de Sévaz/Tudinges (canton de Fribourg) ", dans Bonomi S. et Guggisberg M. (dir.), Griechische Keramik nördlich von Etrurien : Mediterrane Importe und archäologischer Kontext, Wiesbaden, Reichert Verlag, p. 169-178.

SACCHETTI F., 2013, Les amphores grecques dans le nord de l'Italie, Paris, Errance/Aix-en-Provence, Centre Camille Jullian (BIAMA, 10).

SALAC V., 2013, « De la vitesse des transports à l'âge du Fer » dans Colin A. et Verdin F. (dir.), L'âge du Fer en Aquitaine et sur ses marges : mobilité des hommes, diffusion des idées, circulation des biens dans l'espace européen à l'âge du Fer, vol. 2 : Actes du XXXVe colloque international de l'AFEAF, Bordeaux 2011, Bordeaux, Fédération Aquitania (Aquitania, supplément 30), p. 451-474.

SCHINDLER M. P., 2004, «Von Süd nach Nord : Transalpiner Handel und Sidelung im Alpenraum », dans Guggisberg M. (dir.), Die Hydria von Grächwil : zur Funktion und Rezeption mediterraner Importe in Mitteleuropa im 6. und 5. Jahrhundert v. Chr., Akten Internationales Kolloquium anlässlich des 150. Jahrestages der Entdeckung der Hydria von Grächwil durch das Institut für Archäologie des Mittelmeerraumes der Universität Bern, 12.-13. Oktober 2001, Bern, Verlag Bernisches Historisches Museum, p. 71-78.

SCHMID-SIKIMIC B. et BIGLER B., 2005, « Von Süden in den Norden und wieder zurück : Wege über die Alpen - Aktuelles zur Eisenzeitforschung im Kanton Zug », Archéologie suisse, vol. 28, n 1, p. 6-19. TARDITI C., 2007, Dalla Grecia all'Europa. La circolazione di beni di lusso e di modelli culturali nel VI e V secolo a. C., Milan, Vita e Pensiero.

VERGER S. et PERNET L. (dir.), 2013, Une odyssée gauloise : parures féminines à l'origine des premiers échanges entre la Grèce et la Gaule, Arles, Errance. 


\section{RÉSUMÉS}

Au premier âge du Fer, à la marge des domaines nord-alpin et sud-alpin, les Alpes centrales (Suisse actuelle) jouent le rôle de trait d'union. Des produits de diverses origines y parviennent ou y transitent par l'action de réseaux intermédiaires. Pour étudier la formation et le fonctionnement de ces réseaux, nous avons retenu deux classes d'objets: les parures norditaliques de type Golasecca, objets ordinaires et personnels issus d'interactions à courte et moyenne distance, et les importations méditerranéennes, objets à valeur ajoutée liés à des réseaux collectifs agissant à plus longue distance. Le corpus (289 sites et 2187 objets) est étudié dans le cadre d'un réseau de déplacements théoriques - les plus courts chemins - et par la modélisation des relations entre les sites, les domaines culturels et les différentes classes de mobilier fournissant le cadre conceptuel et les outils pour mesurer les différentes formes d'intégration et d'exclusion des sites dans les réseaux de distribution des objets.

During the Early Iron Age, on the margins of the north-alpine and south-alpine domains, the Central Alps (modern Switzerland) act as an exchange area. Products of various origins reach or pass there through different intermediate networks. In order to study the formation and operating of these networks, we selected two classes of objects: the Golasecca ornaments, ordinary and personal objects from short- and medium-distance interactions, and the Mediterranean imports, value-added objects from long-distance collective networks. The corpus (289 settlements and 2,187 objects) was studied in the context of a theoretical circulation network -the shorter routes- and through the modeling of relationships between archeological sites, cultural domains and classes of artifacts. These approaches provide the conceptual framework and tools to measure various forms of site integration and exclusion in the object distribution networks.

INDEX

Mots-clés : âge du Fer, importation méditerranéenne, modélisation, objet de type Golasecca, réseau

Keywords : Iron Age, Mediterranean import, modelling, network Index géographique : Alpes centrales

\section{AUTEURS}

\section{VERONICA CICOLANI}

Laboratoire Archéologie et histoire de la Méditerranée et de l'Égypte ancienne (LabEx Archimede) et laboratoire Archéologie des sociétés méditerranéennes (ASM, UMR 5140, université Paul-Valéry - Montpellier III/CNRS)

\section{THOMAS HUET}

Laboratoire Archéologie et histoire de la Méditerranée et de l'Égypte ancienne (LabEx Archimede) et laboratoire Archéologie des sociétés méditerranéennes (ASM, UMR 5140, université Paul-Valéry - Montpellier III/CNRS) 


\section{Mobilité des individus et des biens dans la vallée de l'Ubaye (Alpes-de- Haute-Provence) et le Guillestrois (Hautes-Alpes) à l'âge du Fer}

Mobility of individuals and goods in the Ubaye valley (Alpes de HauteProvence) and the Guillestrois area (Hautes-Alpes) in the Iron Age

Delphine Isoardi et Laurie Tremblay Cormier

1 La vallée de l'Ubaye est située dans le département des Alpes-de-Haute-Provence, dans la partie sud du massif alpin français (fig.1). Particulièrement enclavée, elle est entourée de plusieurs sommets dépassant les 3000 mètres d'altitude, tandis que son fond va de 771 à 2655 mètres, du lac de Serre-Ponçon au col du Longet. De nombreuses vallées secondaires débouchent sur un col offrant un passage vers les régions voisines, parmi lesquels : les cols de Larche et du Longet, vers le Piémont italien; ceux d'Allos et de la Bonette, débouchant sur la vallée du Verdon et le Mercantour en direction de la côte ligure ; le col de Vars, menant à l'Embrunais et aux vallées rejoignant les Alpes du nord. Cependant, plusieurs de ces cols sont à plus de 2000 mètres d'altitude et subissent de ce fait un fort enneigement, qui ne les rend praticables que durant la saison estivale. Exception faite de son accès ouest, avec sa jonction avec la Durance (aujourd'hui submergée par le lac artificiel de Serre-Ponçon), cette vallée d'altitude se trouve ainsi dans un relatif isolement topographique, dont l'impact sur l'occupation humaine et les circulations est indéniable. 
Fig. 1. - Localisation de la vallée de l'Ubaye (Alpes-de-Haute-Provence) et du Guillestrois (HautesAlpes).

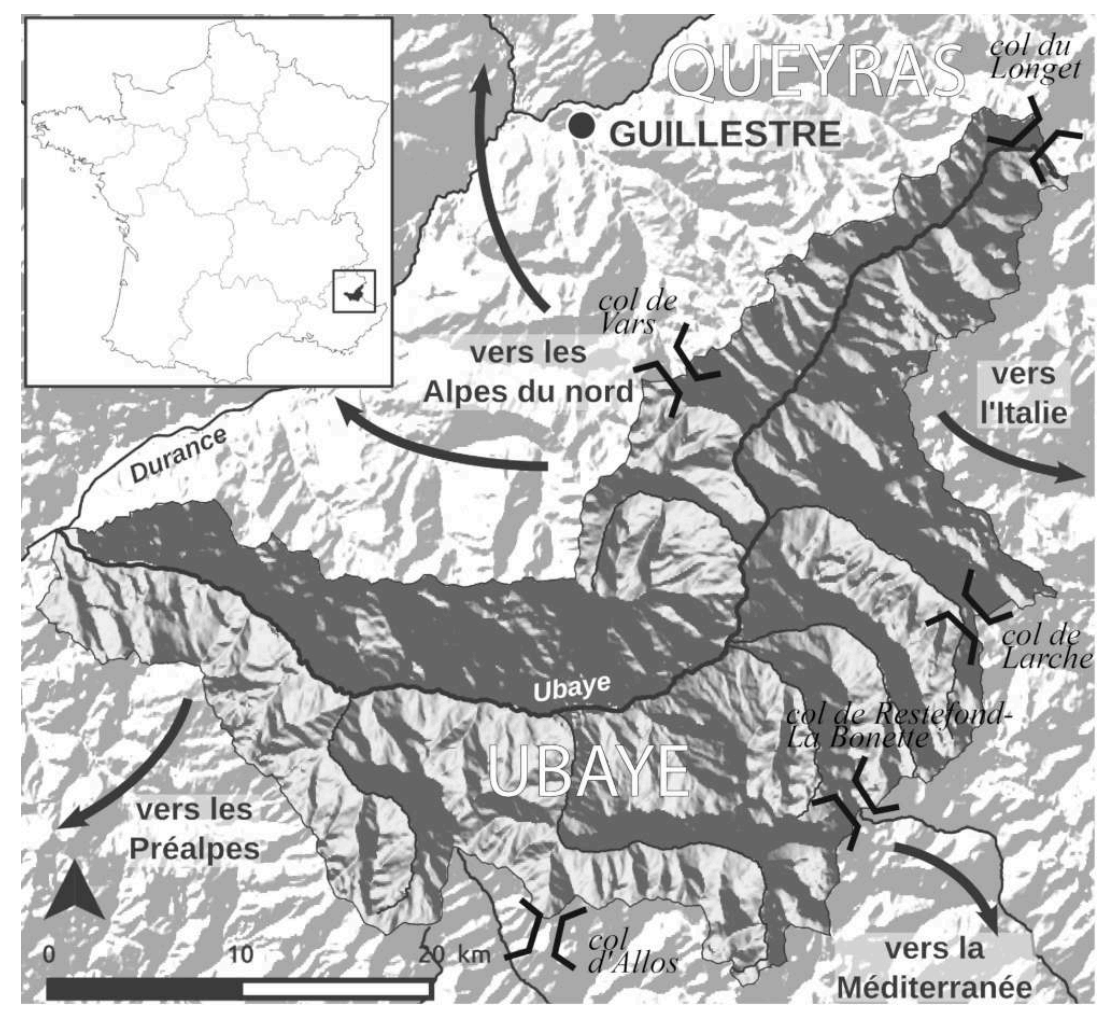

Le lac artificiel de Serre-Ponçon n'est pas représenté, afin de respecter la topographie ancienne de la confluence de la Durance et de l'Ubaye.

PAO et cartographie Laurie Tremblay Cormier.

2 Le Guillestrois est principalement relié à la vallée de l'Ubaye par le col de Vars. Il est idéalement situé dans la haute vallée de la Durance, à l'entrée du massif du Queyras et sur l'axe menant aux cols franco-italiens, dont le Montgenèvre. Bien qu'appartenant à la vallée de la Durance, le Guillestrois a été intégré à cette étude en raison de sa culture matérielle et de ses pratiques funéraires similaires à celle de la vallée de l'Ubaye. Son altitude est comparable, son point le plus bas étant à 867 mètres. Cette situation place la vallée de l'Ubaye et le Guillestrois sous l'influence d'importantes contraintes topographiques.

3 L'étude présentée ici revient sur l'une des principales caractéristiques de cette zone à l'âge du Fer: le développement d'une parure en bronze découverte en contexte funéraire, composée d'une grande quantité d'éléments, et qui a fait la renommée scientifique de cette région dès la fin du XIX ${ }^{e}$ siècle. Malgré de lourds handicaps dus à un contexte archéologique documenté de manière lacunaire, nous proposons ici quelques hypothèses quant à l'identité des porteurs de ces parures, aux relations entretenues avec les régions voisines et à la place de la vallée de l'Ubaye et du Guillestrois dans le monde celtique.

\section{Cadre historiographique et méthodologique}

4 La fenêtre chronologique retenue s'étend $\mathrm{du}_{\mathrm{VII}}^{\mathrm{e}}$ au $\mathrm{I}^{\mathrm{er}}$ siècle avant notre ère. Le domaine funéraire (fig. 2) est pratiquement le seul témoin pour caractériser le 
peuplement de la vallée de l'Ubaye et du Guillestrois à l'âge du Fer. Bien que documenté de manière plus ou moins précise selon les sites, c'est à partir de ce support que la réflexion sera conduite, suivant deux approches complémentaires :

- Le genre des personnes déposées dans la tombe, basé sur une première approche via la parure ;

- Les relations avec les autres régions européennes, par l'identification et la quantification des objets importés ainsi que des imitations.

Fig. 2. - Localisation des sites funéraires de la vallée de l'Ubaye (Alpes-de Haute-Provence) et du Guillestrois (Hautes-Alpes) à l'âge du Fer.

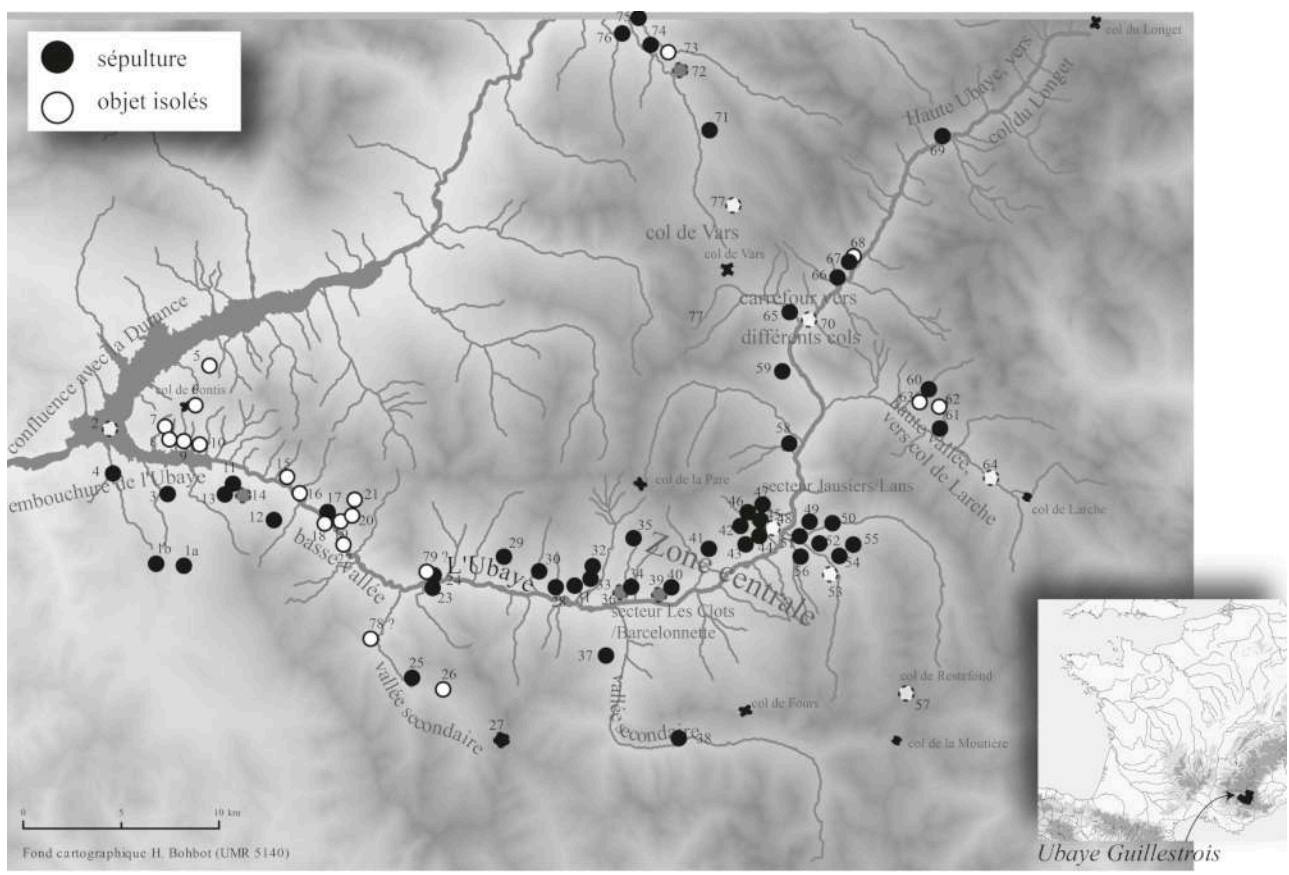

1A : « Saint-Jean » (hameau). 1B : Saint-Léger (Saint-Jean). $\mathbf{2}$ : « Bords du lac de Serre-Ponçon ». LA BRÉole : 3 La Bréole village ; 4 Les Grands Champs. Pontis : 5 Pontis village ; 6 col de Pontis/L'Auche. LE LAUZET : $\mathbf{7}$ La Cime des Travers ; 8 Le Bouas ; 9 La Noyrée ; 10 Champinassou. SAINT-VINCENT : 11 Le Fort ; 12 Clot-du-Dou ; 13 Le Pré-Tiron ; 14 Saint-Vincent (sans précision). LE LAUZET : 15 SaintMartin ; $1 \mathbf{6}$ Champ Contier, « Champubas »; $\mathbf{1 7}$ Clots-des-Doux ; 18 Le Lauzet (village) ; 19 Dramonasc ; 20 La Lauze ; 21 La Gourette ; 22 La Buissière. MÉolans-ReVel : 23 Méolans ; 24 Revel ; 25 Clarionds/ Ronda ; 26 Laverq ; $\mathbf{2 7}$ « Sources du Verdon ». LES THUILES : 28 Le Bérardon ; 29 Les Prats ; 30 Miraval. SAINT-PoNS : 31 Les Cordeils ; 32 La Frâche-les Clots ; 33 Le Tanquet ; 34 La Vigne-Malpasset " au-dessus de Saint-Pons »; $\mathbf{3 5}$ Les Chalanches ; $\mathbf{3 6}$ Saint-Pons (sans précision). UVERNET-FouRS 37 Les Martels/Les Molanès ; 38 Villars d'Abas. BARCELONNETTE : 39 Barcelonnette (sans précision) ; $\mathbf{4 0}$ « Au pied de la montagne » (Ville-Vieille ?). JAussiers : 41 Bouzoulières (Faucon) ; 42 Saint-Flavi-Les Fontanins ; $\mathbf{4 3}$ Les Argiles (Faucon) ; $\mathbf{4 4}$ Les Sanières ; $\mathbf{4 5}$ Les Charniers-La Rochette ; $\mathbf{4 6}$ Les Rouitas ; $\mathbf{4 7}$ Chanenc; $\mathbf{4 8}$ Jausiers (sans précision). LANs : $\mathbf{4 9}$ Les Payans/Le Serre des Bérauds/Le Guénier/ Buissonas/Les Mâts ; $\mathbf{5 0}$ L'Ubac ; $\mathbf{5 1}$ La Murette ; $\mathbf{5 2}$ Hameau de Lans-Les Buissons ; $\mathbf{5 3}$ Lans (sans précision); $\mathbf{5 4}$ Les Gréoux/Le Château ; $5 \mathbf{5}$ Les Tourets-Le Coulet; $\mathbf{5 6}$ La Frâche ; $\mathbf{5 7}$ "Les environs d'un col au-dessus de Jausiers, vers 2800 m d'altitude ». Restefond ?; 58 Le Châtelard (CondamineChâtelard) ; 59 plateau de Tournoux (Les Gleizolles). MEYRONNEs : 60 Saint-Ours ; 61 Les Gravettes ; 62 La Fontette/la Fouenteta ; 63 Crot Mandile. LARCHE : 64 col de Larche/lac de la Madeleine ? ; 65 L'Auche/L'Arche-Riou Mounal. SAINT-PAUL-SUR-UBAYE : 66 La Grande Serenne ; $\mathbf{6 7}$ Le Châtelet ; 68 « champ du Pommier »; 699 Maurin ; 70 Saint-Paul (sans précision) ; 71 Sainte-Catherine (Vars). GUILLESTRE : $\mathbf{7 2}$ «Fontaine de Sidi-Brahim »; 73 La Moureisse ; 74 Peyre-Haute ; 75 Champ-Chevallier 76 : Risoul (église ?) ; $\mathbf{7 7}$ Vars (sans précision). REVEL-MÉoLANS : 78 Saint-Barthélemy ; 79 promontoire Saint-Jacques? Les points contenant une étoile signalent les sites de localisation imprécise. Les sites sont dans les Alpes-de-Haute-Provence, sauf les nos 71 à 77 (Hautes-Alpes).

PAO Delphine Isoardi, fond de carte Hervé Bohbot. 

diachronique des évolutions locales, qui peut être mise en parallèle avec celles ayant cours à une échelle plus petite.

Le corpus documentaire est intimement lié à l'histoire de la recherche archéologique régionale, où l'on observe au minimum deux temps principaux. Au xix siècle et au début $\mathrm{du} \mathrm{xx}^{\mathrm{e}}$, les érudits locaux ont été particulièrement actifs, tels le Dr A. Ollivier, médecin, né à Saint-Ours, et F. Arnaud, notaire de Barcelonnette, de même que des archéologues au rayonnement plus large comme E. Chantre, H. Müller et C. Chappuis. Mandaté par l'empereur Napoléon III, ce dernier espérait d'ailleurs retrouver dans la vallée de l'Ubaye les traces du passage d'Hannibal (Millotte 1991). Si l'activité scientifique fut intense à cette époque, retenons toutefois les limites de cette approche ancienne, avec en exergue un attrait évident pour le bel objet, délaissant le plus souvent son contexte et occasionnant une collecte sélective du mobilier, voire éventuellement des mélanges ou encore de potentielles recompositions douteuses d'ensembles. Certes, quelques "fouilles» ont été conduites par les savants cités cidessus (dans le secteur de Jausiers et Lans, vers Saint-Paul et à Peyre-Haute), mais la majorité des découvertes reste fortuite, faisant suite à des travaux agricoles. Le témoignage d'échanges épistolaires avec les grands archéologues de l'époque, comme entre F. Arnaud et J. Déchelette, à propos de la tombe des Mâts (Jausiers, Alpes-deHaute-Provence), montre cependant que ces érudits se tenaient au fait des connaissances du moment.

$7 \quad$ Aux $\mathrm{Xx}^{\mathrm{e}}$ et $\mathrm{XXI}^{\mathrm{e}}$ siècles, des opérations de prospection à petite échelle conduites par différentes instances scientifiques ont pris la suite de ces premières recherches : le projet collectif de recherches d'A. Müller, dans les années 1980 en haute Ubaye (Müller et al. 2004), puis celui du Centre Camille Jullian, dirigé par D. Garcia et F. Mocci de 2001 à 2006 sur toute la vallée (PCR «L'Ubaye de la fin de la Préhistoire aux Temps modernes "- Garcia et al. 2007). Or, si les apports ont été fructueux pour certaines périodes et types de structures, cela ne fut pas le cas pour les habitats de l'âge du Fer. Parallèlement, deux fouilles récentes ont permis de compléter les données funéraires anciennes (fig. 2 et 3) avec la découverte de la sépulture protohistorique des Grands Champs (La Bréole, Alpes-de-Haute-Provence) (Dufraigne et Richier 2000), et de la tombe de Saint-Léger (Montclar, Alpes-de-Haute-Provence) (Rouzeau 2011). 
Fig. 3. - Répartition des structures funéraires dans la vallée de l'Ubaye (Alpes-de Haute-Provence) et le Guillestrois (Hautes-Alpes) à l'âge du Fer.

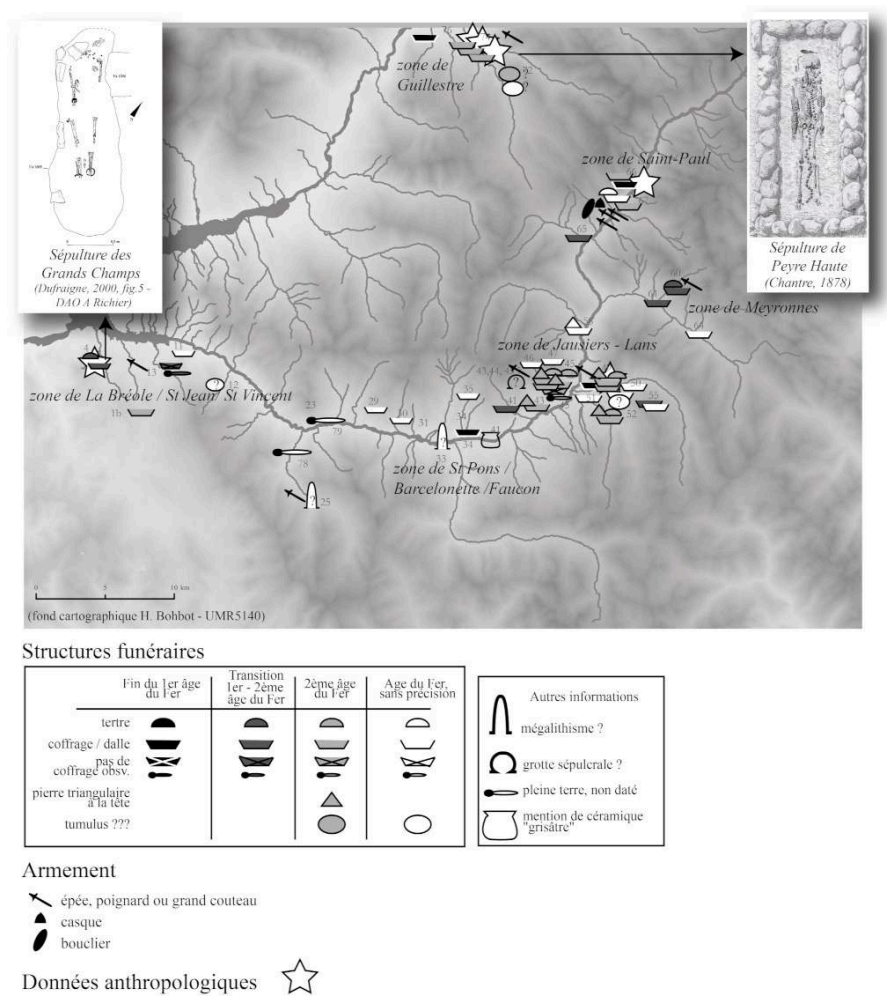

PAO Delphine Isoardi. Fond de carte Hervé Bohbot. Sépulture des Grands Champs : extrait de Dufraigne et Richier 2000. Sépulture de Peyre Haute : extrait de Chantre 1878.

\section{État de la documentation archéologique : des sépultures peu documentées, mais un costume funéraire objet de toutes les attentions}

Les vallées des Hautes-Alpes et du nord des Alpes-de-Haute-Provence se distinguent du reste du Sud de la France par la pérennité de l'inhumation face à la généralisation progressive de l'incinération, depuis le Bronze final jusqu'à la fin de l'âge du Fer (Dedet 2004 : fig. 6). Dans le détail, les pratiques ubayennes et du Guillestrois sont peu connues avant la fin du premier âge du Fer, en raison du manque de vestiges. Puis, à partir de ce moment et pour les deux âges du Fer (fig. 3), l'inhumation individuelle sur le dos, bras le long du corps et jambes en extension, avec parfois les mains posées à hauteur ou sur la région pubienne, est la pratique la plus fréquente. Un contenant funéraire est souvent signalé, constitué d'un coffrage ou d'un muret de pierres, recouvert d'une ou plusieurs dalles. Parfois il est fait mention d'une dalle sous le corps ou, en complément du coffrage, d'une dalle de forme triangulaire derrière la tête (ou d'un muret triangulaire). La présence d'un marquage en surface demeure une question délicate: même si un "tertre" est parfois mentionné (dont nous n'avons aucun dessin, ni description détaillée, ni encore moins d'indication sur les dimensions), aucune des descriptions ne semble correspondre à un véritable tumulus, hormis pour le site de Sidi Brahim (fig. 2, $\mathrm{n}^{\circ}$ 72), à Guillestre (Courtois 1960b). Cependant, il reste possible que l'intensité des activités agricoles de la fin du XIX et du début du $\mathrm{Xx}^{\mathrm{e}}$ siècle ait conduit à 
la destruction de pierriers sur des tombes, nous privant ainsi de précieuses informations sur les superstructures.

9 Finalement, les cas de sépultures multiples sont anecdotiques, voire douteux, à l'image d'une grotte sépulcrale à Jausiers et de deux cas supposés de mégalithisme avec inhumation, l'un près d'une pierre dressée, l'autre en lien avec un cercle de pierres (pour une présentation plus détaillée des structures funéraires : Isoardi et Mocci 2019).

La vallée de l'Ubaye se caractériserait ainsi par des tombes " plates ", peut-être avec un mode de signalisation individuel (mais le plus souvent non conservé ?), sans volonté de monumentaliser la sépulture, comme en témoigne l'érection d'un tumulus dans les vallées voisines de la Durance et du Buëch (Mahieu et Boisseau 2000). Le tableau des structures funéraires, au vu de la qualité des sources, reste donc forcément succinct.

11 Concernant maintenant le mobilier issu de ces tombes, il appartient principalement à la parure et est majoritairement en bronze. Malheureusement, une grande partie a aujourd'hui disparu, suite aux ventes et aux échanges. Prenant la suite des premières publications du Dr Ollivier (1883, 1884 et 1889) et d'E. Chantre (1875-1876, 1878 et 1880), de nombreuses études se sont attachées à leur caractérisation (Eles-Masi 1967-1968, Courtois 1960a, 1960b, 1961, 1976a et 1976b, Bocquet 1969, 1986 et 1991, Sabatier 1985, Isoardi 2001). Récemment, la redécouverte d'une partie de la collection du Dr Ollivier, tout d'abord par une série de photographies d'époque dans les archives départementales des Alpes-de-Hautes-Provence, à Digne (Bourvéau 2011), puis par un lot d'objets conservé chez un particulier (Fossati 2012), a permis de combler quelques lacunes documentaires.

Malgré ces reprises successives, l'ancienneté et la dispersion des découvertes sont la cause de lacunes et de biais évidents, à commencer par la sélection probable des plus belles pièces, ce qui n'offre aucune garantie quant à l'intégrité des ensembles funéraires. Il y a, au final, peu d'ensembles clos fiables disponibles pour l'étude des associations : seulement 34 , pour un total de 114 sites et objets isolés. De plus, les études anthropologiques des restes osseux sont très rares et anciennes, au nombre de six seulement.

13 L'état actuel du corpus permet de dégager deux grands types de costumes funéraires, composés d'éléments de parure et d'accessoires de vêtements, se succédant dans le temps. C'est une vision malheureusement assez tranchée, qui ne peut guère être nuancée.

14 Les inhumé(e)s du premier âge du Fer portent régulièrement aux jambes des anneaux (pleins ou creux, décorés d'incisions ou non) et des armilles aux poignets, en nombre variable (fig. 4A). Le bracelet creux en tôle de bronze enroulée et orné de stries, porté aux jambes ou aux poignets, est aussi classique de cette période dans cette vallée. On rencontre également divers bracelets massifs striés, certains présents aussi en moyenne Durance, dans la région de Gap à Sisteron. Quelques fibules sont attestées, de types assez divers et en exemplaire unique; ce sont surtout des importations ou des imitations, supposées locales, de modèles étrangers.

15 Au second âge du Fer (fig. 4B), la parure du défunt est plus riche et fournie, avec une augmentation du nombre et de la variabilité de la parure. De nouvelles matières sont introduites en plus de l'ambre et du verre : le corail et l'émail. La parure se démarque surtout par un ensemble de productions régionales associées à des importations ou des éléments inspirés de productions exogènes, ces derniers ayant justement permis de 
dater ces sépultures. Les parures régionales (fig. 4B) comportent des brassards d'anneaux de volume tronconique, composés de 20 à 40 bracelets pour chaque avantbras, formant une « gaine " parfaitement assemblée grâce à leur forme et leur diamètre décroissant, à laquelle s'ajoutent parfois un ou des bracelets à oves creuses. Sur l'inhumé(e) a également été retrouvé un très grand nombre d'appliques décoratives coniques en forme de violon et de crotales piriformes, ces dernières parfois retrouvées sur les côtés du crâne.

Fig. 4. - Exemples de parures dans la vallée de l'Ubaye (Alpes-de Haute-Provence) et le Guillestrois (Hautes-Alpes) au premier et au deuxième âge du Fer.

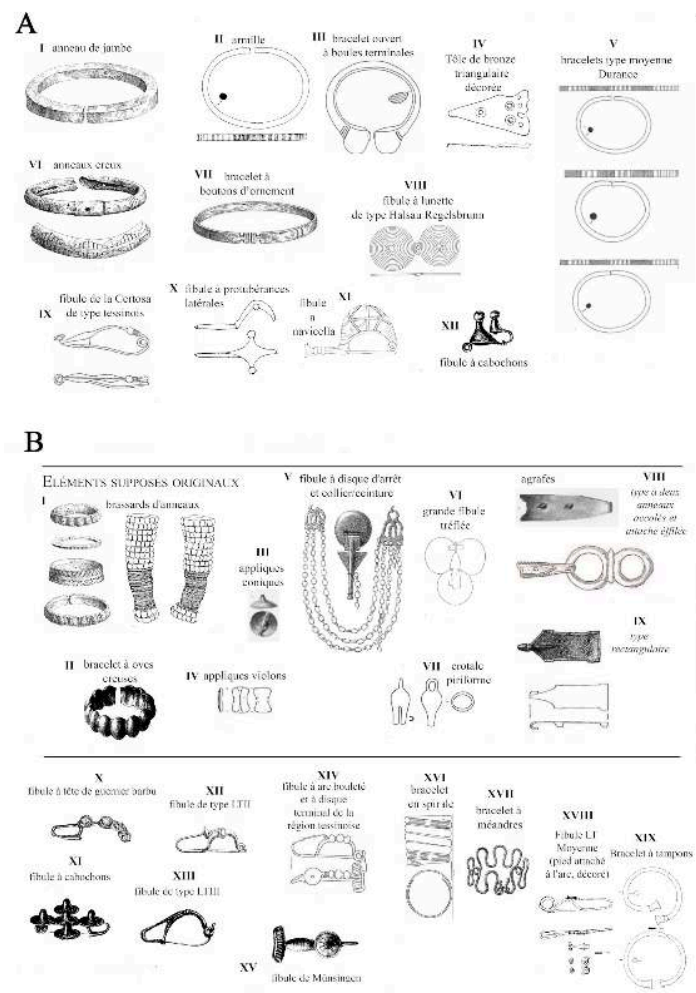

A : premier âge du Fer et transition vers le deuxième âge du Fer. B : deuxième âge du Fer (400 avant notre ère). Les échelles sont différentes pour chaque objet.

PAO Delphine Isoardi. A I, VI, VII : extraits de Chappuis 1862 ; II, III, V : extraits de Bocquet 1991 ; IV : extrait de Millotte 2011 ; VIII, IX, X, XI : extraits de Eles Masi 1967-1968; $\mathbf{x I I}$ : extrait de Chantre 1880. B $\mathbf{I}$ : extrait de Chappuis 1862 et Millotte $1991 ; \mathbf{I I}, \mathbf{V}, \mathbf{X I}, \mathbf{x I I I}, \mathbf{x V I I}$ : extraits de Chantre 1880 ; IV, VI, VII, $\mathbf{x I V}$, XVI : extraits de Eles Masi 1967-1968; VIII : extrait de Chantre 1878 et Sabatier 1985 ; IX : extrait de Chantre 1880 et Eles Masi 1967-1968; III, X, XII : extraits de Chantre 1878; xv : extrait de Chappuis 1862 ; XVIII, XIX : extraits de Guillaumet et Maranski 1991.

Plusieurs chaînes reliées à deux pendeloques ajourées, posées sur le corps, peuvent avoir été portées comme parures pectorales ou comme ceintures. Les boucles de ceintures spécifiques à la vallée sont de deux types : formées de deux anneaux accolés à une agrafe allongée, ou rectangulaires et accolées à un crochet en triangle. Le costume est complété de nombreuses spirales tubulaires de fil de bronze, de perles en verre et en ambre, et de bagues en spirale. Les fibules sont nombreuses et variées, et relèvent souvent de modèles connus ailleurs dans le monde laténien, comme le type à pied attaché à l'arc et les fibules à masque. Plus locale, la fibule à grand disque d'arrêt se retrouve fréquemment au-dessus de la tête, et peut donc avoir servi à fermer un tissu funéraire. 
17 La figure 5 présente la répartition de ces éléments de parure principaux au fil du temps au sein de la zone d'étude, tandis que la figure 6 recense l'ensemble des parures caractéristiques découvertes en dehors de celle-ci.

Fig. 5. - Localisation et décompte des éléments de parure les plus caractéristiques aux premier et deuxième âge du Fer dans la vallée de l'Ubaye (Alpes-de Haute-Provence) et le Guillestrois (HautesAlpes).

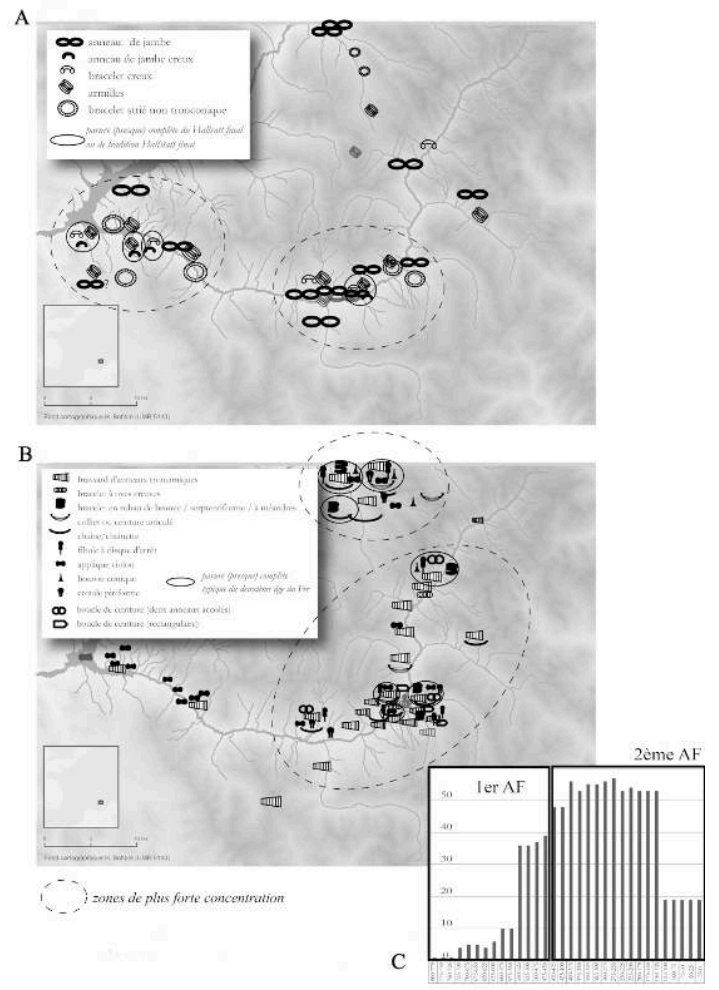

A : premier âge du Fer. B : deuxième âge du Fer. C : décompte de toutes les découvertes de nature funéraire (sépultures et objets isolés).

PAO Delphine Isoardi. 
Fig. 6. - Parures typiques de la vallée de l'Ubaye (Alpes-de Haute-Provence) et du Guillestrois (Hautes-Alpes) à l'âge du Fer découvertes hors de la zone de production (premier état des lieux).

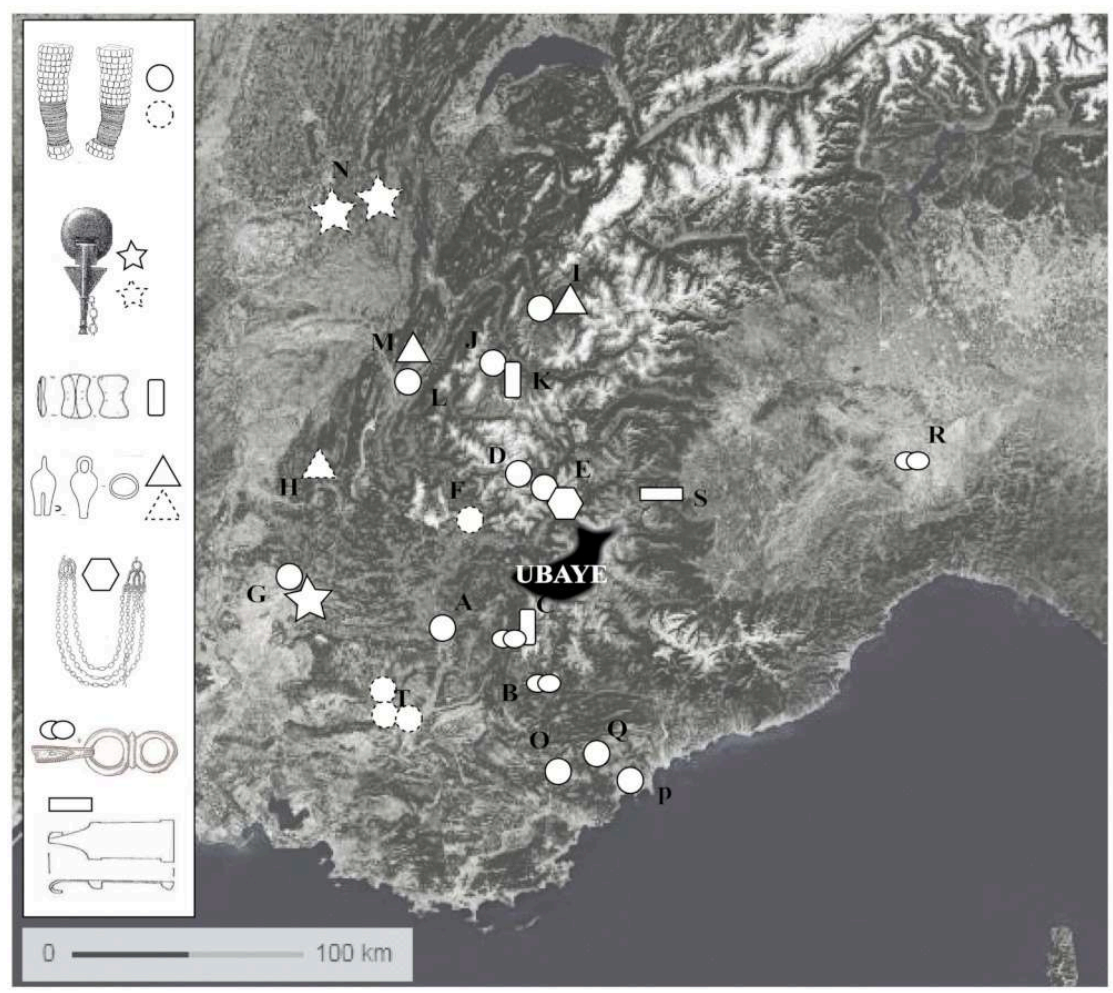

A : Sisteron (Alpes-de-Haute-Provence) : Sabatier 1985, Bocquet 1991. B : Méouilles (Saint-André-lesAlpes, Alpes-de-Haute-Provence). c : Chastelas (Beaujeu, Alpes-de-Haute-Provence). D : Dormillouse (Freissinières, Hautes-Alpes). E : Pallon (Freissinières, Hautes-Alpes). F : « Dans le Champsaur », (Hautes-Alpes). G : Nyons (Drôme). H : «Dans le Dauphiné ». I : Saint-Jean-de-Helleville (Savoie). J Albiez-le-Vieux (Savoie, « en Maurienne ») (musée d'Annecy). $\mathbf{k}$ : Saint-Sorlin-d'Arves (Savoie). L : La Tronche (Isère). $\mathbf{M}$ : Meylan, (Isère). $\mathbf{N}:$ « pays des Allobroges ». $\mathbf{0}:$ grotte de Lioure (Claviers, Var). $\mathbf{P}$ aven Bernard (Vallauris, Alpes-Maritimes). a : dépôt de la Coumbo (Saint-Vallier-de-Thiey, AlpesMaritimes). R : Alessandria (Piemonte, Italie). s : Crissolo (Piemonte, Italie) (Faudino et al. 2014). T "Basses-Alpes ».

PAO Delphine Isoardi ; fond de carte Google Maps.

Quant à l'armement, il ne peut être caractérisé, ni même confirmé : supposé appartenir à l'âge du Fer, il n'est connu que par sept mentions d'épées, de poignards ou de couteaux, en fer ou en bronze, ainsi que par un casque et un bouclier (fig. 3). Seuls deux ou trois éléments peuvent être rattachés, par association avec le restant du mobilier, à la fin du premier ou au tout début du second âge du Fer, et deux autres au second âge du Fer: ils proviennent respectivement de la sépulture de Saint-Ours (Meyronnes, Alpes-de-Haute-Provence) (fig. $2, \mathrm{n}^{\circ} 60$ ), et de celles des Payans (Jausier, Alpes-deHaute-Provence) (fig. 2, $n^{\circ} 49$ ) et de La Bréole (fig. 2, $n^{\circ}$ 3).

\section{Une première approche du genre des inhumés de l'âge du Fer en Ubaye-Guillestrois}

19 L'étude du genre à partir des parures de la zone d'étude a déjà fait l'objet d'une communication (Isoardi et Mocci 2019). La démarche et ses résultats seront simplement résumés ici. 
20 Les six tombes ayant fait l'objet d'une étude anthropologique plus ou moins satisfaisante ont servi de référence à notre démarche (fig. 3).

- La tombe des Grands Champs, datée du ve siècle avant notre ère $\left(n^{\circ} 4\right)$;

- La tombe des Mâts, datée de 350-120 avant notre ère ( $\left.n^{\circ} 49\right)$;

- La tombe de Peyre-Haute, de la collection Bisch, avec la même datation ( $\left.n^{\circ} 74\right)$;

- La sépulture III de Peyre-Haute, datée de 350-120 avant notre ère elle aussi (enfant potentiel, $\left.\mathrm{n}^{\circ} 74\right)$;

- La sépulture du Chatelet, également de 250-150 avant notre ère $\left(\mathrm{n}^{\circ} 67\right)$;

- Et enfin, la sépulture I de Peyre-Haute, datée de 250-120 avant notre ère ( $\left.n^{\circ} 74\right)$.

21 La réserve est bien sûr de mise, car la qualité des expertises anthropologiques est extrêmement variable : si aux Grands Champs, celle-ci a été du ressort d'un anthropologue (Dufraigne et Richier 2000), pour les Mâts comme pour les tombes de Peyre-Haute (Chantre $1878:$ p. 6) et du Châtelet (Chappuis 1862), fouillées entre la fin du XIX ${ }^{e}$ et le tout début $d u X X^{e}$ siècle, ce sont des médecins qui ont œuvré, voire même un dentiste, comme l'indique une lettre manuscrite du Dr Hellion, dentiste à Paris, qui a travaillé à partir de trois dents pour les Mâts (Isoardi 2006). Autant dire que le doute ne peut être levé sur la fiabilité des résultats, mais en l'état actuel, il est impossible d'affiner ces expertises anthropologiques.

Retenons que sur ces six cas, quatre femmes auraient été identifiées (le sexe du cinquième adulte et celui de l'enfant n'étant pas clairement déterminé), dans les sépultures des Grands Champs, des Mâts, la sépulture I de Peyre-Haute et celle du Châtelet. Ces tombes ont été décrites suivant le même protocole (protocole issu de Bélard 2014) afin d'en tirer le maximum d'informations et de pouvoir les comparer, en notant leurs similitudes, les marqueurs chronologiques et les éléments qui, au contraire, ne sont pas systématiquement portés. En résultent de possibles marqueurs du genre féminin : le port de parures à plusieurs endroits du corps simultanément (cou, oreilles, bras, jambe, tronc), le port d'anneaux de jambes, les brassards composés d'armilles, les brassards d'anneaux tronconiques du deuxième âge du Fer (et de manière générale un grand nombre de bracelets), le port de plusieurs fibules simultanément, des colliers d'ambre et autres matières, des appliques de vêtements, et une diversité des matières utilisées (fig. 7A, première colonne). 
Fig. 7. - Marqueurs supposés du genre dans la vallée de l'Ubaye (Alpes-de Haute-Provence) et en Europe à l'âge du Fer.

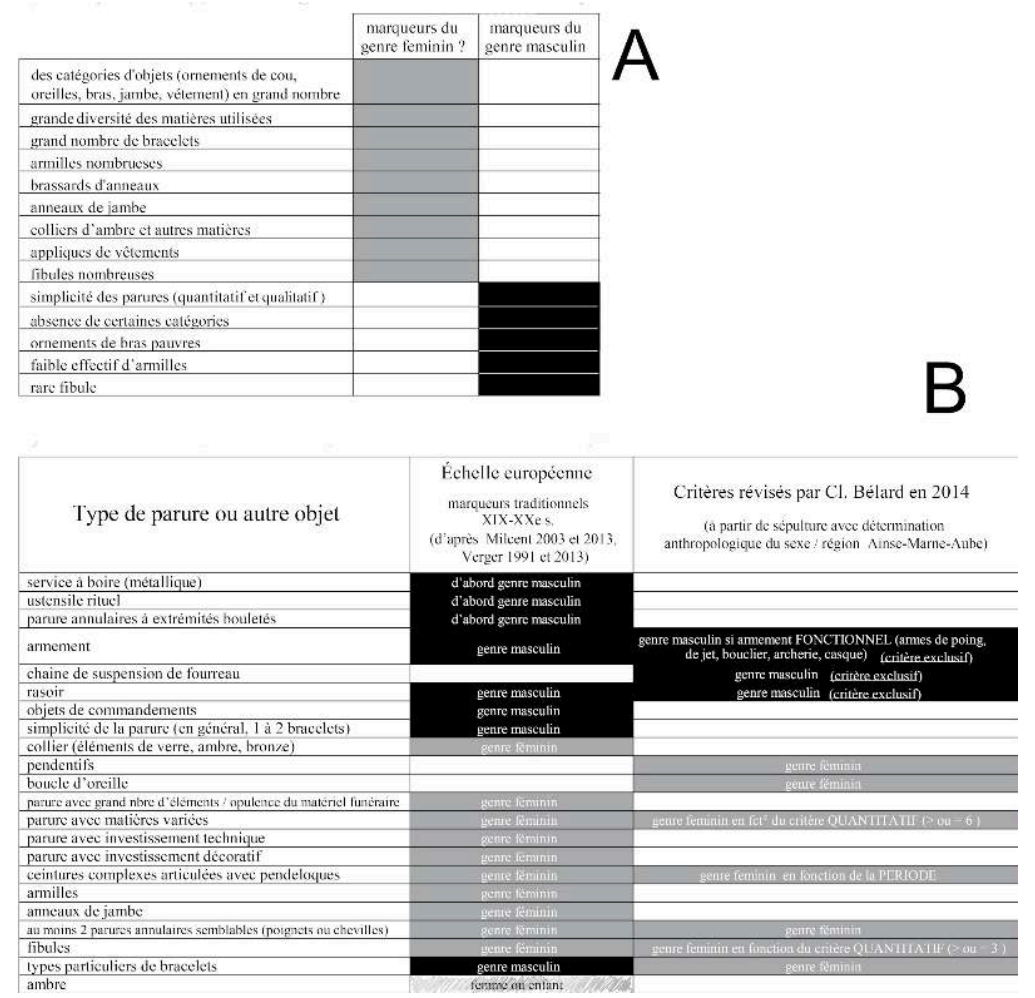

A: marqueurs supposés du genre sur la parure dans la vallée de l'Ubaye. B : marqueurs du genre sur la parure funéraire en Europe.

PAO Delphine Isoardi, d'après Milcent 2003 et 2013b, Verger 1991 et 2013b, Bélard 2014

23 Cependant, d'autres paramètres ont pu jouer sur ces différences en qualité et quantité, notamment la classe d'âge, le statut marital, le statut social, l'origine ethnique, la cause de la mort... (Boissinot 2008). Et, surtout, cette première approche du genre dans la vallée de l'Ubaye est entravée par l'absence d'identification anthropologique d'individus de sexe masculin. Aussi, un regard sur les marqueurs du genre à échelle européenne est indispensable (fig. 7B).

La synthèse sur ce sujet a été élaborée principalement à partir des travaux de P.-Y. Milcent (2003a, 2013a, 2006, 2013b), S. Verger (1991, 2013a, 2013b) et C. Bélard (2014 et 2015), dont le travail de doctorat s'est basé sur les sépultures avec détermination anthropologique du sexe dans la région Aisne-Marne, afin de revoir plus objectivement les éléments de distinction traditionnels du genre. Il apparaît alors que les données obtenues sur la vallée de l'Ubaye et le Guillestrois (en tenant compte, rappelons-le encore une fois, des problèmes inhérents à ce corpus), pourraient rejoindre les résultats des travaux européens mentionnés plus haut sur certains points : on y retrouve les armilles, anneaux de jambe, brassards d'anneaux, fibules en grand nombre, colliers et ceintures-colliers, associés au genre féminin. De ce tableau, il serait également tentant de retenir pour la vallée de l'Ubaye les caractéristiques suivantes pour les dépôts funéraires associés au genre masculin (fig. 7A, deuxième colonne) : d'abord, la simplicité des parures du point de vue quantitatif et qualitatif : types plus simples, moins de matières. Mais surtout l'absence d'anneau de jambe, d'armille (du moins en grand nombre), de brassard d'anneaux et, de manière générale, le présence d'ornements de bras modestes: un ou deux bracelets; pas de fibules en 
grand nombre, et absence également de collier-ceinture, collier, boucle d'oreille, bague, agrafe de ceinture...

Il n'est en revanche pas possible de retenir les armes ici comme critères exclusivement masculins, voire même comme critères indicatifs, car dans les tombes ubayennes on les trouve associées à différents marqueurs supposés féminins, tels que des anneaux de jambe pour les sépultures $\mathrm{n}^{\circ} 66$ et 60 , des brassards et des perles de verre pour la tombe $\mathrm{n}^{\circ} 60$, des brassards et un collier pour la tombe $\mathrm{n}^{\circ} 49$, et un grand nombre de bracelets ainsi que de l'ambre sur le site $n^{\circ} 3$. En outre, il semblerait que les armes soient plutôt courtes, en bronze, à lame épaisse : d'où la question de leur réelle fonction utilitaire ou simplement d'une vocation symbolique. C. Bélard a montré que seules les armes fonctionnelles sont des marqueurs du genre masculin (2014: p. 106, 134 et 154). Sur cette base, nous avons pu travailler sur l'ensemble des 34 associations de mobilier plus ou moins complètes et effectuer un tri selon le genre supposé (fig. 8).

Fig. 8. - Approche chronologique du genre d'après les sépultures de la vallée de l'Ubaye (Alpes-de Haute-Provence) à l'âge du Fer.

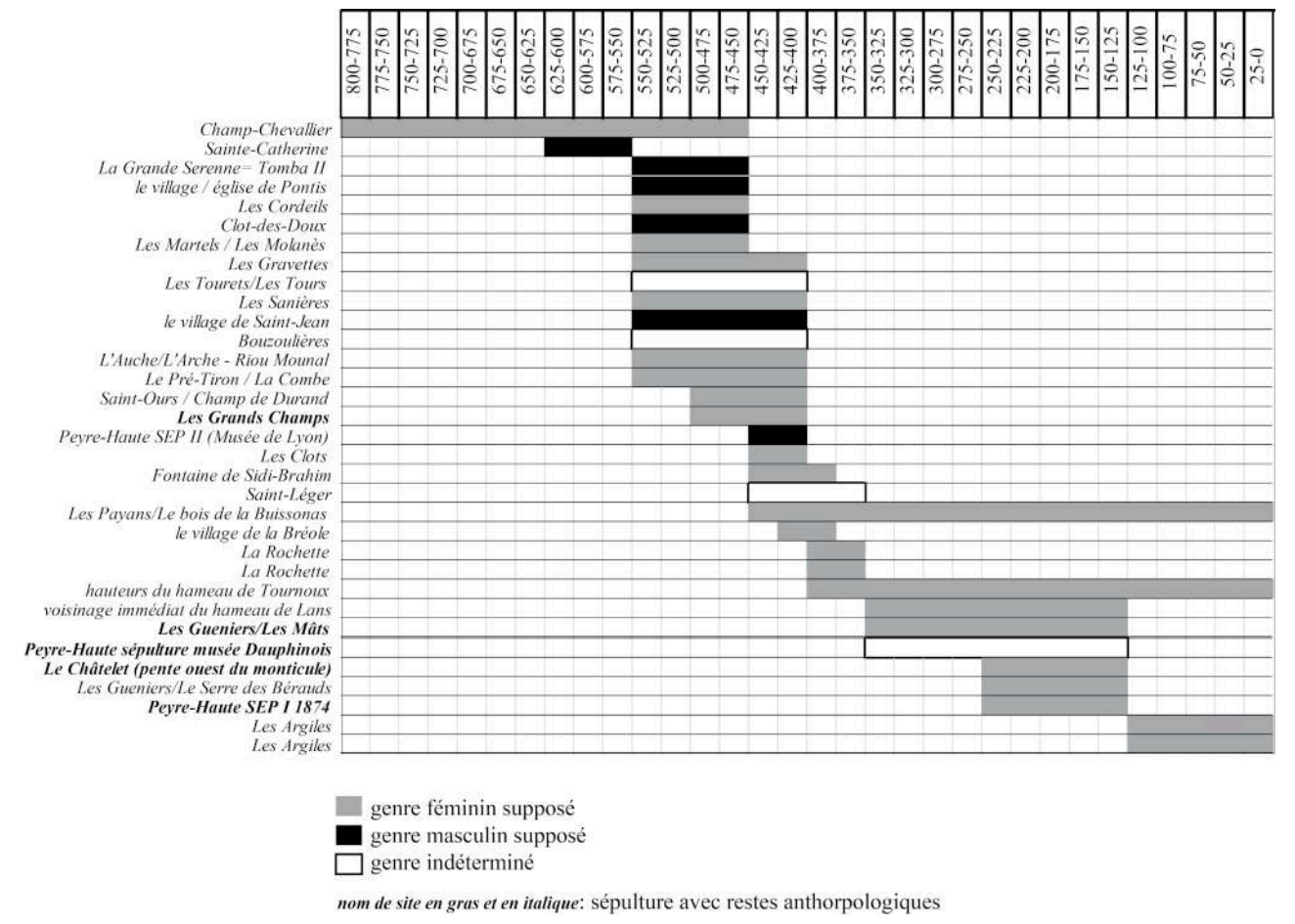

PAO Delphine Isoardi.

Bien entendu, compte tenu du mode de constitution de ce corpus, il ne sera jamais possible de savoir si ces ensembles sont réellement complets : par exemple, il reste possible d'interpréter une tombe modestement pourvue comme une tombe masculine, alors qu'il pourrait s'agit d'une tombe de femme incomplète. Toutefois, ce tri pourrait bien s'avérer instructif dans une perspective chronologique, car il semblerait que l'on puisse distinguer une première période où coexistent des tombes d'hommes et de femmes avec mobilier métallique (globalement jusqu'en 425/400 avant notre ère), tandis qu'à partir du $\mathrm{IV}^{\mathrm{e}}$ siècle avant notre ère, les tombes à mobilier découvertes seraient essentiellement des tombes de femmes (Isoardi et Mocci 2019). 
Ainsi, la destination de ces pratiques funéraires avec dépôts de mobilier semble évoluer au fil du temps, témoignant d'un glissement vers une valorisation de la figure féminine. Bien sûr, il reste possible que les hommes du second âge du Fer soient eux aussi mis en avant, mais selon des pratiques funéraires ou lors de cérémonies ne laissant pas de traces en termes de mobilier archéologique. Du corpus archéologique étudiable aujourd'hui, retenons que la richesse des parures, en quantité et qualité, est très majoritairement associée aux femmes pour le second âge du Fer dans la vallée.

\section{Les interactions extrarégionales au travers de la parure funéraire}

\section{Choix méthodologiques}

La place de la vallée de l'Ubaye et du Guillestrois dans les réseaux d'échanges peut être mesurée par le mobilier importé ou imitant des modèles étrangers, traduisant des interactions avec les régions voisines ou plus lointaines. Il est cependant nécessaire de nuancer l'intégration, dans l'analyse, des influences externes visibles dans les productions locales. Certaines pièces peuvent, sans trop de risque, être considérées comme des imitations puisque leurs formes, atypiques pour la vallée de l'Ubaye, reprennent celles bien connues dans d'autres régions. Cependant, leur représentation reste anecdotique, signe que cet apport externe n'a pas donné lieu à une intégration durable dans la production locale. L'exemple le plus parlant est certainement le bracelet à tampons sphériques de Jausiers (fig. 11a: XV), qui reprend la forme et les dimensions du type Bade-Alsace et reste, à l'heure actuelle, un unicum à l'échelle européenne. À l'inverse, les grosses fibules laténiennes à nodosités montrent elles aussi une parenté indéniable avec les exemplaires du domaine celtique; toutefois, leur présence régulière dans les sépultures en fait des éléments typiques de la culture matérielle de la vallée de l'Ubaye, signes de l'appropriation locale de ces influences externes et de l'intégration de la vallée à un fonds culturel commun (de fait, suivant notre protocole, elles sont écartées de l'analyse ci-dessous).

La frontière entre les imitations conservant une nature exogène pour les populations et les objets intégrant des apports externes mais qui sont entrés dans les traditions locales est mince et subjective. Dès lors, leur emploi dans l'analyse des influences externes, et donc des interactions extrarégionales, dépend du seuil d'« exotisme " de l'objet, luimême défini par le chercheur! À quel moment passe-t-on de l'imitation d'une production étrangère à l'assimilation de caractères étrangers dans la production locale? Sans entrer dans la discussion de ces problématiques, nous avons fixé cette limite comme suit: lorsque les apports exogènes ont mené à la création de véritables types locaux, comme dans le cas des fibules à nodosités, ils ont été considérés comme suffisamment assimilés pour ne plus être considérés comme des apports externes.

31 Cet article n'ayant pas pour vocation de fournir une étude détaillée de chaque pièce, la description des objets utilisés comme marqueurs des interactions extrarégionales (donc importations et imitations) restera succincte. De plus, l'analyse proposée repose pour l'instant sur les publications disponibles au moment de cette étude, et donc sur une documentation graphique datant majoritairement de la fin du XIX ${ }^{e}$ siècle. Aussi ce n'est là qu'une approche préliminaire, une première image qui demandera à être précisée par la reprise des collections. 


\begin{abstract}
mêmes (commerce, cadeaux, butin...), des idées (imitation, transmission), ou des individus (migrations, mariages exogamiques, mercenariat...).
\end{abstract}

biais d'intermédiaires, et pour des raisons diverses liées à la circulation des objets eux-

Fig. 9. - Décompte et répartition des éléments de parure de la vallée de l'Ubaye (Alpes-de HauteProvence) et du Guillestrois (Hautes-Alpes) selon l'influence, la provenance, et une production peut-être locale.

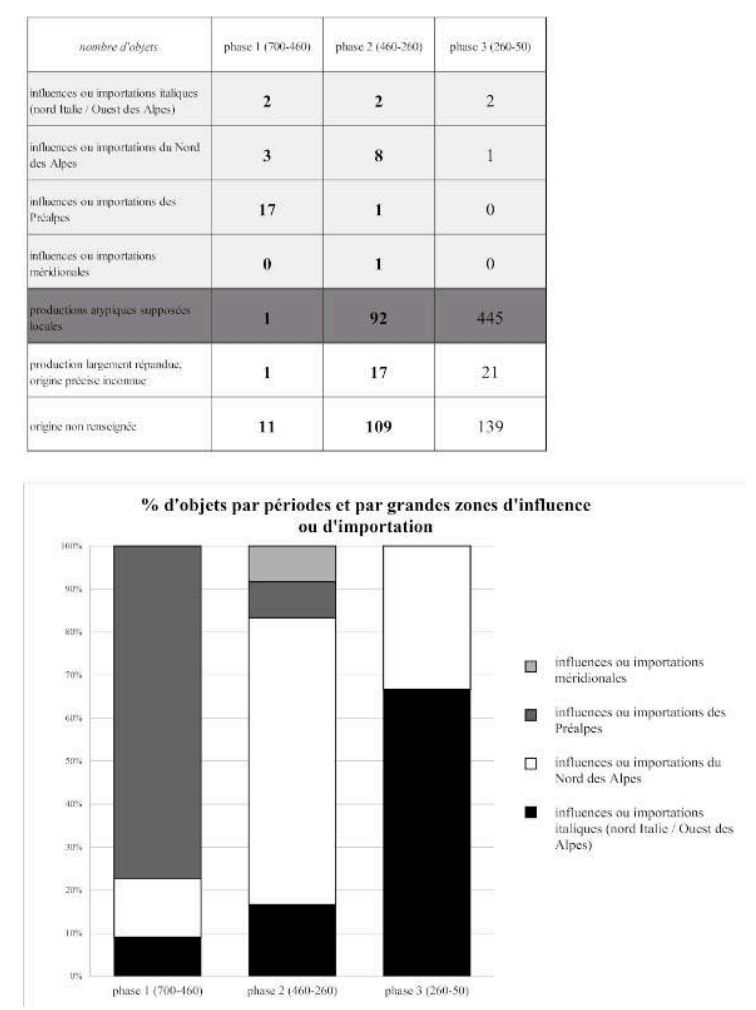

PAO Laurie Tremblay Cormier.

En second lieu, une modélisation des données récoltées a été réalisée à l'aide de projections linéaires, une méthode synthétisant visuellement la distribution d'un semis de points dans une zone définie (fig. 10).

Ce mode de représentation permet de résumer des lots d'informations de taille variable sans occulter les distributions marginales (Tremblay Cormier 2014: p. 297). L'adaptation de cette méthode à l'archéologie fut développée pour la modélisation de la circulation et de la consommation du bronze, par la répartition des masses de métal (Gauthier 2004: p. 355, 2005 : p. 119-120, 2009 : p. 154; Mordant et al. 2004). Elle fut ensuite testée en incorporant des critères qualitatifs, pour distinguer la distribution du mobilier en fonction de sa provenance (Tremblay Cormier 2014 et 2016), approche retenue ici.

Visuellement, le principe se rapproche de l'histogramme (fig. 10) : la distribution spatiale des objets est reportée le long d'un axe divisé en tronçons (fig. 10A), représentant l'aire d'étude, dont l'épaisseur varie selon la quantité qui s'y rapporte 
(fig. 10B) ; grâce à son enclavement géographique, cet axe possède une forte cohérence topographique. Des tronçons de 5 kilomètres ont été déterminés de façon empirique, correspondant à un seuil idéal de regroupement des points. La provenance des objets exogènes est matérialisée par l'utilisation de teintes correspondant à quatre grandes régions : le domaine hallstattien nord-occidental puis laténien, la moyenne Durance et les Préalpes, le golfe du Lion et l'Italie du nord (fig. 10C).

Fig. 10. - Décompte et répartition des éléments de parure de la vallée de l'Ubaye (Alpes-de HauteProvence) et du Guillestrois (Hautes-Alpes) selon la méthode de la projection linéaire.

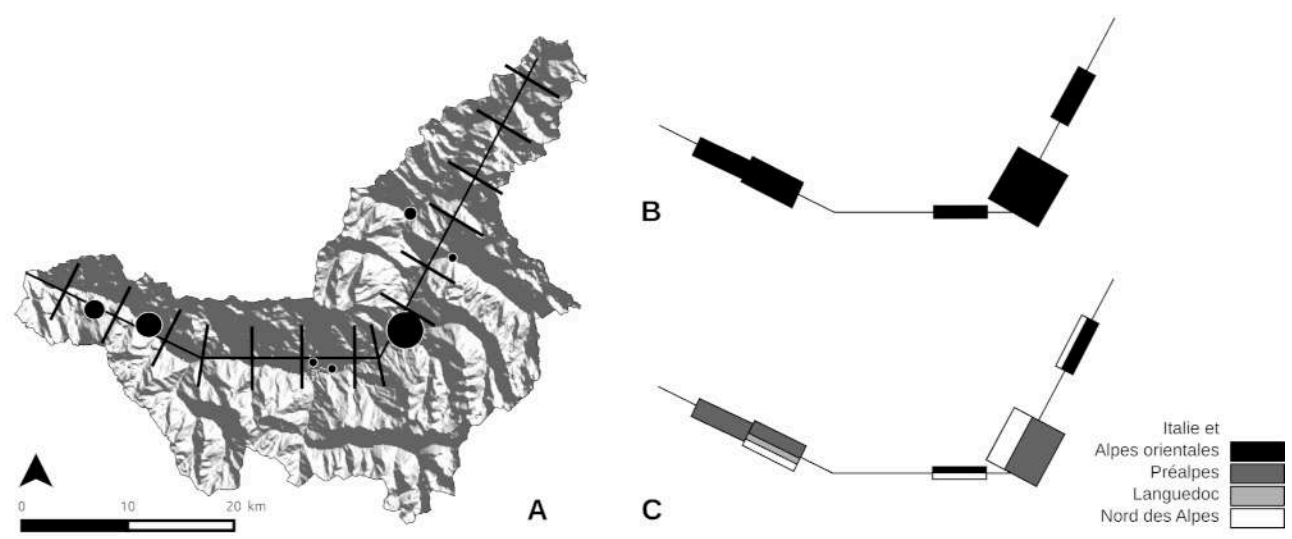

PAO Laurie Tremblay Cormier.

37 Le site de Guillestre n'a pas été inclus à la projection malgré son poids dans le corpus (plus de 300 objets) : son intégration aurait en effet faussé la cohérence topographique de la projection, en raison de sa situation dans une autre vallée. Il est donc représenté à part, sous une forme graphique aux mêmes teintes que la projection linéaire, afin de permettre les comparaisons.

\section{Résultats}

Afin de montrer l'évolution des interactions selon un seuil statistique suffisant, le corpus a été divisé en trois étapes (fig. 9 et fig. 11) :

- Phase $1:$ du début du viI ${ }^{\mathrm{e}}$ siècle à 460 avant notre ère (premier âge du Fer) ;

- Phase $2:$ de 460 à 260 avant notre ère (début du second âge du Fer);

- Phase $3: \mathrm{du} \mathrm{III}^{\mathrm{e}}$ siècle au milieu du $\mathrm{I}^{\mathrm{er}}$ siècle avant notre ère (milieu et fin du second âge du Fer). 
Fig. 11. - Projection linéaire et mobilier exogène de la vallée de l'Ubaye (Alpes-de Haute-Provence) et du Guillestrois (Hautes-Alpes) des phases 1 à 3 à l'âge du Fer.

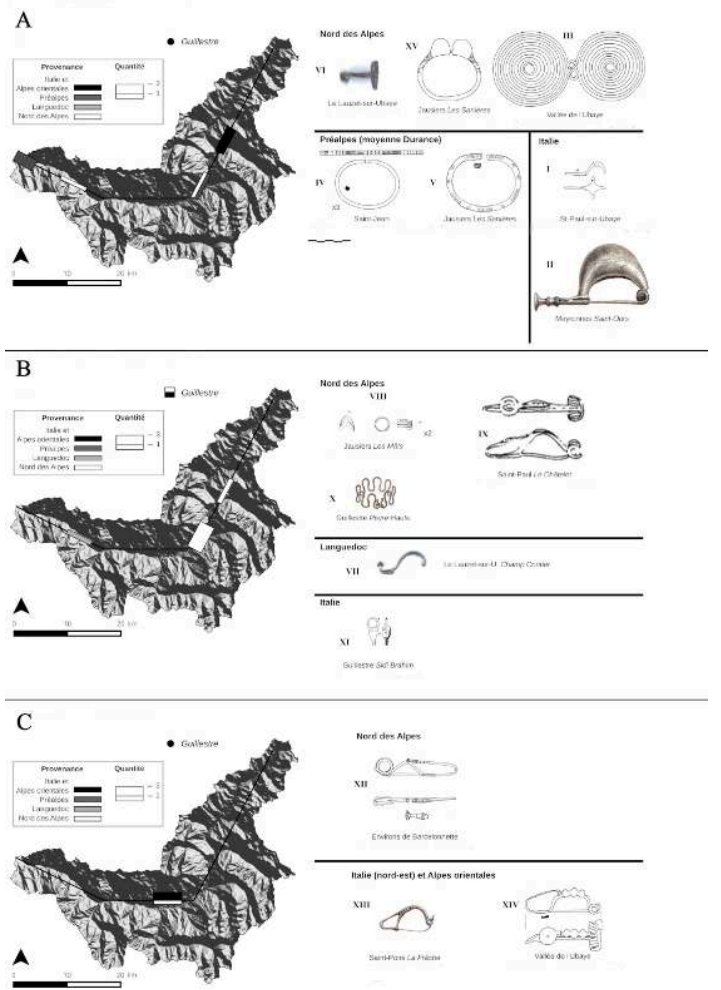

A : phase 1, premier âge du Fer, 700-460 avant notre ère. B : phase 2, début du second âge du Fer, 460-260 avant notre ère. c : phase 3, milieu et fin du second âge du Fer, 260-50 avant notre ère.

PAO Laurie Tremblay Cormier. A : I, III : extraits de Eles Masi 1967-68; II : extrait de Chantre 1880 ; Iv extrait de Eles Masi 1967-68 et Sabatier 1985 ; vı : extrait de Isoardi 2001 ; xv : extrait de Sabatier 1985. B : vilI : extrait de Campolo 2005 ; IX : extrait de Eles Masi 1967-68; $\mathbf{x}$ : extrait de Chantre 1880 ; VII : extrait de Isoardi 2001 ; $\mathbf{x I}$ : extrait de Courtois 1960b. C : xII : extrait de Guillaumet et Maranski 1991 ; XIII : extrait de Chantre 1880 ; xIV : extrait de Eles Masi 1967-68.

\section{Phase $1: 700$ à 460 avant notre ère, premier âge du Fer}

Le premier âge du Fer (fig. 11A) est surtout représenté par des objets isolés ou sans contexte; les importations, peu nombreuses, n'échappent pas à la règle. Aucun ensemble n'est actuellement identifié, y compris à Guillestre. Le nord de la péninsule Italique est représenté par une fibule à arc plein orné de boutons latéraux, découverte à Saint-Paul-sur-Ubaye (fig. $11 \mathrm{~A}, \mathrm{n}^{\circ} \mathrm{I}$ ). Ce type possède de nombreuses variantes; dans les nécropoles de Chiavari et d'Este, les exemplaires apparentés appartiennent à la seconde moitié $d u v^{e}{ }^{e}$ siècle et au début $d u v^{e}$ siècle avant notre ère (Eles Masi 1986: p. 155, Paltineri 2010 : p. 70). La fibule de Meyronnes est plus problématique (fig. 11A, $\mathrm{n}^{\circ} \mathrm{II}$ ) : d'un type à navicella typique du nord de l'Italie aux $\mathrm{VII}^{\mathrm{e}}$ et $\mathrm{VI}^{\mathrm{e}}$ siècles avant notre ère (Eles Masi 1986 : p. 105), elle serait associée à du mobilier plus récent (chaînette, parures annulaires; Chappuis $1862:$ p. 55). Il s'agirait soit d'un objet exogène plus ancien, conservé dans une tombe laténienne, soit d'un mélange de mobilier dont on connaît de fréquents exemples au xIX ${ }^{\mathrm{e}}$ siècle. Par prudence, cet objet est donc intégré à la modélisation de l'étape 1.

Des bracelets de section quadrangulaire à ovale, aux extrémités droites et décorés de groupes variables de stries transversales, ont été découverts à Saint-Jean et dans la 
nécropole de Jausiers-Les Sanières (fig. 11A, $\mathrm{n}^{\text {os }} \mathrm{IV}$ et V), attestant son utilisation ancienne. Ils peuvent être mis en relation avec une production concentrée en Provence et dans les Préalpes, qui apparaît au $\mathrm{VII}^{\mathrm{e}}$ siècle et perdure durant la première moitié du $\mathrm{VI}^{\mathrm{e}}$ siècle avant notre ère (Arcelin 1976 : p. 659).

41 Les régions au nord et à l'ouest des Alpes sont représentées par deux objets, à l'embouchure et dans la zone centrale de la vallée. Un bracelet à gros tampons sphériques et jonc massif de section planoconvexe, sans association, provient des Sanières (fig. $11 \mathrm{~A}, \mathrm{n}^{\circ} \mathrm{XV}$ ou fig. $4 \mathrm{~A}, \mathrm{n}^{\circ} \mathrm{III}$ ). Sa morphologie rappelle les productions $\mathrm{du}$ Rhin supérieur des $\mathrm{VII}^{\mathrm{e}}$ et $\mathrm{VI}^{\mathrm{e}}$ siècles avant notre ère, mais sans en partager le décor. Il pourrait s'agir d'une production locale, mais ce serait alors une imitation d'un modèle clairement étranger, ce qui permet de l'intégrer à l'analyse. S'y ajoute une fibule à timbale du Lauzet-sur-Ubaye (fig. 11A, $\mathrm{n}^{\circ} \mathrm{VI}$ ), découverte lors de prospections clandestines à La Noyrée (Isoardi 2001 : p. 69) : elle se rattache au type F4 A2, originaire du centre-est de la France, qui perdure et est largement diffusé au La Tène A1 (Mansfeld 1973 : p. 41, Carrara et al. 2013). Sa datation à la fin du premier âge du Fer est justifiée par la présence de parures similaires dans la vallée du Rhône, sur l'oppidum de Crest (Treffort 2002 : fig. 6) ; cette datation est corroborée à Chabestan (Hautes-Alpes) par son association avec un poignard à antennes bouletées (Courtois $1961:$ p. 196), et avec de la céramique attique au Pègue, dans la Drôme (Lagrand 1987 : p. 60).

\section{Phase $2: 460$ à 260 avant notre ère}

42 La seconde étape (fig. 11B) est la période la mieux représentée, avec le début de l'utilisation des nécropoles de Jausiers et de Guillestre. La pendeloque en panier profilé $\mathrm{du}$ tumulus de Guillestre-Sidi-Brahim (fig. 11B, ${ }^{\circ} \mathrm{XI}$ ) est l'objet le plus ancien. Originaire de la région de Golasecca et de la plaine du Pô, elle est datée du début du second âge du Fer au sud (?) des Alpes (De Marinis 1981 : p. 232, Chaume $2001:$ p. 150). Sans provenance, donc comptée dans le tableau de la figure 9 mais non représentée dans la modélisation de la figure 11, la fibule de type Certosa (fig. 4B, $n^{\circ}$ IX) constitue une variante probablement produite dans le Tessin entre la fin $d u v^{e}$ et le $\mathrm{IV}^{\mathrm{e}}$ siècle avant notre ère (Primas 1967 : p. 113, Stöckli 1975 : p. 13).

Une fibule sans contexte (fig. 11B, $\mathrm{n}^{\circ} \mathrm{VII}$ ) provient de prospections clandestines au Champ Contier (Lauzet-Ubaye, Alpes-de-Haute-Provence) (Isoardi 2001 : p. 68). Elle peut être rattachée au type du golfe du Lion de par son pied relevé, terminé par un bouton conique. Provenant du nord-ouest du bassin méditerranéen, ces fibules datent de la première moitié $d u v^{e} e t$, ponctuellement, $d u$ début $d u{ }^{2} v^{e}$ siècle avant notre ère (Tendille $1978:$ p. 84).

44 La bague coudée de la tombe des Mâts (fig. 11B, $n^{\circ}$ VIII), à Jausiers, est d'un type concentré en Haute-Savoie et en Suisse, dont la répartition s'étend jusqu'à la Bohême et à Lattes (Kaenel 1990 : p. 243, Feugère 1993 : p. 52). En raison de la rareté de ces parures dans toutes les Alpes du sud, dont elle est l'unique exemplaire, elle peut ainsi constituer un marqueur des interactions avec les régions nord-alpines. De même, les deux bagues en spirale des Mâts (fig. 11B, $\mathrm{n}^{\circ}$ VIII) ont des correspondances en Suisse, dont plusieurs à Vevey et Münsingen (Hodson 1968 : p. 40, Kaenel 1990 : p. 249), et dans la nécropole italique d'Ornavasso (Déchelette $1914:$ p. 1096, Campolo 2005), où le caractère mixte du mobilier (Déchelette 1914 : p. 1093) peut soutenir une origine nord-alpine. La forme du bracelet en méandres de la sépulture 3 de Guillestre (fig. 11B, $n^{\circ} \mathrm{X}$ ) permet de le 
rattacher au type 2, connu dans une large zone allant de la Champagne à la Suisse et de la plaine padane à la Bohême (Delnef 2003 : p. 280). Comme pour la bague coudée des Mâts, il s'agit ici de l'unique exemplaire connu à l'heure actuelle dans les Alpes du sud : pour la même raison, il sera donc intégré à l'analyse.

Une fibule trouvée sur un col au-dessus de Lans pourrait finalement correspondre au type Münsingen-Andelfingen (fig. $4 \mathrm{~B}, \mathrm{n}^{\circ} \mathrm{XV}$ ), par son pied replié sur l'arc décoré d'un disque émaillé (Kaenel 1990 : p. 239). La fibule découverte au Châtelet (Saint-Paul-surUbaye, Alpes-de-Haute-Provence) (fig. 11B, $n^{\circ}$ IX), constitue une variante de ce même type et pourrait correspondre à une imitation. L'aspect anecdotique de ces fibules dans la vallée de l'Ubaye et leur absence des ensembles funéraires justifient leur intégration dans les marqueurs d'interactions externes.

Les perles en verre sont par contre exclues de l'analyse: en l'absence d'étude des matériaux, il est impossible de leur attribuer une provenance sur la seule base de leur forme ou de l'aspect du verre. Présentes de manière régulière dans la vallée, elles peuvent tout aussi bien être locales, ou provenir d'une ou de plusieurs autres régions, qu'il s'agisse de Gaule méridionale, du nord de l'Italie ou des régions au nord et à l'ouest des Alpes (Feugère 1992).

\section{Phase $3: 260$ à 50 avant notre ère}

47 L'utilisation de certaines nécropoles se poursuit aux $\mathrm{III}^{\mathrm{e}}$ et $\mathrm{II}^{\mathrm{e}}$ siècles avant notre ère, avec cependant une chute brutale à la fin $\mathrm{du}_{\mathrm{II}}^{\mathrm{e}}$ siècle avant notre ère. Une fibule des environs de Barcelonnette, sans association, se rattache à cette période par son pied parallèle au porte-ardillon touchant l'arc (fig. 11, $\mathrm{n}^{\circ} \mathrm{XII}$ ) ; le décor du pied, fait d'un esse et de cercles oculés, rappelle les motifs végétaux laténiens.

Par contre, comme nous l'avons spécifié ci-dessus, plutôt qu'un apport exogène, les autres grandes fibules à pied accolé à l'arc de la vallée de l'Ubaye et de Guillestre semblent constituer une variante régionale des types laténiens. L'emploi du bronze les différencie en effet des productions en fer de Manching (Gebhard 1991) et du Tessin (Stöckli 1975 : p. 33). De plus, la grande taille du pied, en sphère aplatie, son tracé parallèle au porte-ardillon et ses dimensions très allongées ne permettent pas de comparaison avec les exemplaires suisses, ceux du piémont italien ou même de Gaule méridionale. Une comparaison directe, probablement originaire de la vallée de l'Ubaye, provient de la nécropole savoyarde de Saint-Sorlin-d'Arves (Willigens 1991 : pl. XXIII/ 383).

Les Alpes orientales et leur piémont italien sont l'autre lieu d'influence ou de provenance des objets exogènes. Une fibule à arc à nodules sphériques et pied à disque (fig. 11C, $\mathrm{n}^{\circ} \mathrm{XIV}$ ), sans contexte, se rattache au type XXIV du Trentin-haut-Adige (Adam 1996 : p. 184). Plus tardive, la fibule isolée de La Frâche correspond au type Almgren 65a (fig. 11, $\mathrm{n}^{\circ}$ XIII). Ce type, daté en Italie du deuxième quart du $\mathrm{I}^{\mathrm{er}}$ siècle avant notre ère, se concentre dans le nord du Frioul-Vénétie julienne et les Alpes orientales (Demetz 1999 : p. 37 et cartes 2-3). L'absence totale de ces types dans les Alpes du sud permet de les intégrer à l'analyse comme marqueurs des interactions extrarégionales. 


\section{Synthèse et conclusion}

50 Quelques points méritent d'être soulignés. Les importations et imitations ne concernent que la parure, un état de fait qui incombe à la surreprésentation de cette catégorie dans les sépultures. On remarque toutefois qu'elles sont toujours associées à des productions locales, et qu'il n'existe aucun ensemble exclusivement constitué d'objets exogènes. Au niveau des régions représentées, certaines brillent par leur absence : l'Étrurie et la Grande Grèce, dont les productions font pourtant l'objet d'un commerce à grande échelle - mais il est vrai qu'il porte principalement sur des vases et leur contenu.

51 Finalement, à l'issue des projections présentées ci-dessus, le faible nombre d'objets sélectionnés ne permet pas de voir une distribution préférentielle des marqueurs d'interactions en fonction des régions, bien que certaines tendances semblent se dessiner, comme la présence du mobilier italique dans la partie supérieure de la vallée et de celui des Préalpes dans sa partie inférieure.

52 En croisant les hypothèses sur le genre des inhumés et les résultats de l'étude sur les provenances des éléments exogènes du costume funéraire, apparaissent ainsi des situations sensiblement différentes. Pour le premier âge du Fer, dans les tombes, les parures sont majoritairement influencées ou issues des régions préalpines proches ainsi que de la zone italique, et peuvent avoir été destinées autant à des hommes qu'à des femmes. Au second âge du Fer, ce sont surtout a priori des femmes qui ont été distinguées par le très riche costume local, auquel se sont greffés des éléments importés, ou imitant des modèles typiques du nord des Alpes. Cependant, il n'est pas exclu que ces mêmes parures proviennent en fait de l'Italie du nord voisine, en raison de la présence, à ce moment, de types d'objets similaires (Déchelette 1927: p. 593, Bocquet 1991 : p. 134 et 143, Vitali 2001).

53 Quant aux modalités de circulation d'objets importés, il reste difficile de trancher entre les circulations d'individus et l'échange d'objets. Nous aimerions toutefois proposer certaines pistes de réflexion en lien avec notre corpus. La circulation d'objets peut être le fait d'échanges ponctuels, dont la finalité nous échappe : échange marchand non monétaire, don et contre-don, etc. On peut cependant exclure le fait que ces parures étrangères aient fait l'objet d'un commerce de masse, en raison de leur nature anecdotique et de la grande diversité des types et des provenances représentées, exception faite des perles de verre, pour lesquelles la provenance n'a pu être établie, faute d'analyse des matériaux.

54 Concernant la circulation d'individus, on peut également exclure la possibilité d'une migration de communautés étrangères, en raison du petit nombre d'objets exogènes à chaque phase. On resterait donc dans le domaine des déplacements individuels, ou du moins d'un nombre restreint de personnes, pour l'échange de biens ou pour la création et le maintien d'alliances entre les élites, notamment par le biais de liens matrimoniaux.

Bien que connus surtout, dans la communauté scientifique, pour leur riche parure funéraire atypique du second âge du Fer, la vallée de l'Ubaye et le Guillestrois témoignent en réalité, tout au long de l'âge du Fer, d'interactions variées avec les diverses communautés sises de part et d'autre de leur lignes de crêtes selon les phases, et cela mesuré ici par le seul vecteur de la parure métallique. En outre, l'enrichissement 
dont témoigne cette riche parure à lourds brassards de bronze du second âge du Fer alimente l'idée d'une période faste pour ces communautés montagnardes.

Bien que nous ne puissions résoudre dès aujourd'hui la question des modalités de déplacements des populations, ubayennes comme extérieures à la vallée, on peut ainsi toutefois proposer que les populations de la vallée de l'Ubaye et du Guillestrois ont pleinement profité des mouvements qui agitèrent l'Europe aux $\mathrm{IV}^{\mathrm{e}}$ et $\mathrm{III}^{\mathrm{e}}$ siècles avant notre ère. Plutôt qu'un cul-de-sac géographique, ces régions ont pu être le témoin de déplacements de part et d'autre des Alpes et peuvent, par exemple, avoir profité du contrôle de ces axes de circulation. En effet, en zone de montagne, une voie de passage est un élément fort qui confère un pouvoir à celui qui la gère: la topographie particulière n'offrant guère d'autres alternatives de passage, c'est un point que l'on peut obstruer ou ouvrir selon les besoins. Tantôt barrière, tantôt passage protégé, la voie de passage alpine donne donc une supériorité, un ascendant, aux populations montagnardes autochtones.

Sans vouloir faire une analyse régressive, rappelons que c'est une possibilité qui est avérée pour le $\mathrm{I}^{\mathrm{er}}$ siècle avant notre ère. À l'époque d'Auguste, dans ce secteur alpin occidental, au moins trois embranchements permettaient de relier l'Italie à l'Espagne par voie terrestre : la route du mont Cenis, celle du mont Genèvre depuis Suse, et celle du col du Lautaret depuis Briançon (Artru 2013 : p. 239). F. Artru propose d'y rajouter la route du col de Larche. Or tout ce secteur correspondait au royaume de Cottius (le Regnum Cottii, qui s'étendait de la Maurienne à la haute Vésubie), dont faisait partie la vallée de l'Ubaye (Barruol 1969). Après la pacification des Alpes par les armées romaines dans les années 9-8 avant notre ère, le royaume de Cottius est devenu un royaume fédéré à Rome (Barruol 1969 : p. 29), mais a conservé une grande autonomie. Et justement, concernant les voies partant de Suse (capitale de l'ancien royaume de Cottius), par les cols du Montgenèvre et du mont Cenis, sous Auguste, la protection comme la restauration de ces routes furent confiées à cet ancien roi indigène, Cottius (Ammien Marcellin, Res Gestae: XV, 10, 2 et 7 et Strabon, Géographie: IV, 1, 3 et V, 1; voir aussi Leveau 2003 : p. 37). Ainsi, dans un premier temps, pour la gestion des cols, les Romains ont préféré s'entendre avec les reguli et chefs locaux, quitte à payer le passage (Leveau et Segard 2006 : p. 158). Il est donc avéré, pour les périodes tout juste postérieures à notre étude, que les populations locales avaient un bénéfice politique, militaire et/ou économique à tirer de ces atouts topographiques, comme l'hypothèse de péages sur le transport de marchandises. Une situation qui, si elle s'appliquait aux siècles antérieurs, pourrait fournir une partie de la réponse quant à l'enrichissement du costume funéraire féminin et à l'intégration des influences étrangères dans la création de productions régionales atypiques. Cependant, c'est là une hypothèse qui ne peut se contenter de ces seuls éléments funéraires pour être soutenue. 


\section{BIBLIOGRAPHIE}

ADAM A.-M., 1996, Le fibule di tipo celtico nel Trentino, Trente, Ufficio Beni archeologici (Patrimonio storico artistico del Trentino, 19).

ARCELIN P., 1976, « Les civilisations de l'âge du Fer en Provence », dans Guilaine J. (dir.), La Préhistoire française, Paris, CNRS éditions, p. 657-675.

ARTRU F., 2013, « La circulation dans les Alpes à l'époque romaine : l'exemple des Alpes cottiennes ", Dialogues d'histoire ancienne, vol. 39, n 1, p. 237-263.

BARRUOL G., 1969, Les peuples préromains du sud-est de la Gaule : étude de géographie historique, Paris, De Boccard (Revue archéologique de Narbonnaise, 1).

BÉLARD C., 2014, « Les femmes en Champagne pendant l'âge du Fer (dernier tiers VI ${ }^{\mathrm{e}}$ - III ${ }^{\mathrm{e}}$ siècle av. J.-C.) et la notion de genre en archéologie funéraire ", thèse de doctorat, Paris, École pratique des hautes études.

BÉLARD C., 2015, « La notion de genre ou comment problématiser l'archéologie funéraire », Nouvelles de l'archéologie, $\mathrm{n}^{\circ}$ 140, p. 23-27.

BETZLER P., 1974, Die Fibeln in Süddeutschland, Österreich und der Schweiz I, München, Beck (Prähistorische Bronzefunde, XIV/3).

BOCQUET A., 1969, Catalogue des collections préhistoriques et protohistoriques du musée Dauphinois, Grenoble, Musée dauphinois.

BOCQUET A., 1986, «L'archéologie de l'âge du Fer dans les Alpes du nord », dans Bocquet A. et Ballet F. (dir.), Les Celtes et les Alpes : catalogue d'exposition, Chambéry, Musée savoisien, p. 13-50. BOCQUET A., 1991, «L'archéologie de l'âge du Fer dans les Alpes occidentales françaises », dans Duval A. (dir.), Les Alpes à l'âge du Fer : actes du $10^{e}$ Colloque de l'AFEAF, Yenne-Chambéry, 1986, Paris, CNRS éditions (Revue archéologique de Narbonnaise, 22), p. 91-155.

BoIsSinOT P., 2008, « Genres et identités au risque de l'archéologie : le cas de la Protohistoire », Pallas, $\mathrm{n}^{\circ}$ 76, p. 137-149.

BOURVÉAU J., 2011, « La collection archéologique du docteur Ollivier d'après les photographies de Saint-Marcel Eysseric, 1890 : essai de détermination », Chroniques de Haute-Provence, $\mathrm{n}^{\circ}$ 367, p. 4-78.

CAMPolo S., 2005, « Nouvelle approche du matériel de la tombe du IIème âge du Fer des Mâts à Jausiers (décembre 2005, Alpes-de-Haute-Provence) », dans Garcia D. et Mocci F. (dir.), Histoire d'une vallée alpine : l'Ubaye des âges des Métaux aux Temps modernes, document final de synthèse, AixEn-Provence, Service régional de l'archéologie PACA, p. 165-205.

CARRARA S., DUBREUCQ É., PESCHER B. , « La fabrication des fibules à timbale comme marqueur des contacts et des transferts technologiques au cours du Ha D-LT A1 : nouvelles données d'après les sites de Bourges, Lyon et Plombières-les-Dijon ", dans Colin A. et Verdin F. (dir.), L'âge du Fer en Aquitaine et sur ses marges : mobilité des hommes, diffusion des idées, circulation des biens dans l'espace européen à l'âge du Fer, Bordeaux, Fédération Aquitania (Aquitania, supplément 30), p. 595-608.

CHANTRE E., 1875-1876, Études paléoethnologiques dans le bassin du Rhône : âge du Bronze. Recherches sur l'origine de la métallurgie en France, III : Statistiques, Paris, libr. J. Baudry. 
CHANTRE E., 1878, « Les nécropoles du premier âge du Fer dans les Alpes », Matériaux, $2^{\mathrm{e}}$ série, $\mathrm{n}^{\circ}$ IX, p. 1-15.

CHANTRE E., 1880, Études paléoethnologiques dans le Bassin du Rhône : premier âge du Fer. Nécropoles et tumulus, Paris, libr. J. Baudry.

CHAPPUIS C., 1862, Étude archéologique et géographique sur la vallée de Barcelonnette à l'époque celtique, Besançon, impr. de Valluet Jeune.

CHAUME B., 2001, Vix et son territoire à l'Âge du Fer : fouilles du mont Lassois et environnement du site princier, Montagnac, M. Mergoil (Protohistoire européenne, 6).

COURTOIS J.-C., 1960a, « Une nouvelle parure de la fin de l'âge du Bronze découverte dans les Hautes-Alpes (canton de Guillestre) », Bulletin de la Société préhistorique française, nº 57, p. 164-168. COURTOIS J.-C., 1960b, « Une sépulture à inhumation sous tumulus du Hallstatt récent récemment détruite à Guillestre (Hautes-Alpes) », Bulletin de la Société préhistorique française, nº 57, p. 168-171. COURTOIS J.-C., 1961, « Essai sur la Protohistoire des Alpes du Dauphiné », Revue archéologique de l'Est, vol. XII, n 4 , p. 287-303.

COURTOIs J.-C., 1976a, « Nécropoles de l'âge du Fer », dans Bocquet A. et Lagrand C. (dir.), Néolithique et âges des métaux dans les Alpes françaises : livret-guide de l'excursion A9, 5-10 septembre 1976, $9^{e}$ congrès de l'UISPP, Nice, p. 110-112.

COURTOIS J.-C., 1976b, « Les civilisations de l'âge du Fer dans les Alpes », dans Guilaine J. (dir.), La Préhistoire française, Paris, CNRS éditions, p. 708-723.

DE MARINIS R., 1981, « Il periodo Golasecca III A in Lombardia », Studi Archeologici, vol. I, p. 41-300.

DÉCHELETTE J., 1914, Manuel d'archéologie celtique préhistorique et gallo-romaine, t. II : Archéologie celtique ou protohistorique, $3^{\mathrm{e}}$ partie : Second âge du Fer ou époque de La Tène, Paris, Picard.

DÉCHELETTE J., 1927, Manuel d'archéologie celtique préhistorique et gallo-romaine, t. III : Premier âge du Fer ou époque de Hallstatt, Paris, Picard, $2^{\mathrm{e}}$ éd. augm.

DEDET B., 2004, «Variabilité des pratiques funéraires protohistoriques dans le sud de la France : défunts incinérés, défunts non brûlés ", Gallia, n 61, p. 193-222.

DELNEF H., 2003, « Les bracelets méandriformes en Europe (IV ${ }^{\mathrm{e}}-\mathrm{III}$ e s. av. J.-C.) », Archaeologia Mosellana, $\mathrm{n}^{\circ}$ 5, p. 271-300.

DEMETZ S., 1999, Fibeln der spätlatène und frühen römischen Kaiserzeit in den Alpenländern, Rahden, Marie Leidorf (Frühgeschichtliche und provinzialrömische Archäologie, 4).

DUFRAIGNE J.-J. et RICHIER A., 2000, La Bréole (Alpes-de-Haute-Provence) : les Grands Champs. Document final de synthèse, sauvetage urgent du 13 septembre 2000 au 27 septembre 2000, Aix-en-Provence, AFAN. ELES MASI P. von, 1967-1968, « L'Età del Ferro nelle Alpi Occidentali francesi », Cahiers rhodaniens, $\mathrm{n}^{\circ} 14$, p. 11-222.

ELES MASI P. von, 1986, Le fibule dell'Italia settentrionale, München, Beck (Prähistorische Bronzefunde, XIV/5).

FEUGÈRE M., 1992, « Le verre préromain en Gaule méridionale : acquis récents et questions ouvertes ", Revue archéologique de Narbonnaise, vol. 25, $n^{\circ}$ 1, p. 151-176.

FEUGÈRE M., 1993, « Des parures et des hommes : économie et société en Gaule méridionale à travers l'exemple des parures celtiques du Midi », dans Daubigney A. (dir.), Fonctionnement social 
de l'âge du Fer : opérateurs et hypothèses pour la France, Lons-le-Saunier, Centre jurassien du patrimoine, p. 43-55.

FOSSATI E., 2012, « Les bronzes du Docteur Gleize », mémoire de master II, Aix-en-Provence, AixMarseille université.

GARCIA D., MOCCI F., TZORTZIS S., WALSH K., 2007, « Archéologie de la vallée de l'Ubaye (Alpes-deHaute-Provence, France) : premiers résultats d'un projet collectif de recherche », Preistoria Alpina, $\mathrm{n}^{\circ} 42$, p. 23-48.

GAUTHIER É., 2004, « L'évolution de la consommation du métal à l'âge du Bronze, en France orientale et en Transdanubie ", Histoire \& mesure, vol. XIX, n³/4, p. 345-376.

GAUTHIER É., 2005, « La consommation du métal en France orientale et en Transdanubie du XVII ${ }^{\mathrm{e}}$ au $\mathrm{IX}^{\mathrm{e}} \mathrm{s}$. avant notre ère : analyse spatiale et modélisation des systèmes socio-économiques de l'âge du Bronze ", thèse de doctorat en archéologie, Dijon, Université de Bourgogne.

GAUTHIER É., 2009, « La consommation et la circulation du métal à l'âge du Bronze dans le Jura et les plaines de la Saône ", dans Barral P., Daubigney A., Richard A. (dir.), L'isthme européen RhinSaône-Rhône dans la Protohistoire : approches nouvelles. En hommage à Jacques-Pierre Millotte, Besançon, Presses universitaires de Franche-Comté (Annales littéraires de l'université de Besançon, 860), p. $145-159$.

GEBHARD R., 1991, Die Fibeln aus dem Oppidum von Manching, Stuttgart, Franz Steiner (Die Ausgrabungen in Manching, 14).

GUILLAUMET J.-P. et MARANSKI D., 1991, « À propos de quelques objets célèbres des Alpes », dans Duval A. (dir.), Les Alpes à l'âge du Fer, Paris, CNRS éditions (Revue archéologique de Narbonnaise, 22), p. 233-238.

HODSON F. R., 1968, The La Tène Cemetery at Münsingen-Rain : Catalogue and Relative Chronology, Bern, Stämpfli (Acta Bernensia, 5).

HOMPS-BROUSSE H., 2014, « Ancienne collection du docteur Antoine Ollivier (1823-1907) », Revue des musées de France - revue du Louvre, vol. 2, p. 4.

ISOARDI D., 2001, « La Protohistoire de l'Ubaye : bilan bibliographique », mémoire de maîtrise d'archéologie, Aix-en-Provence, Aix-Marseille université.

ISOARDI D., 2006, « Histoire de la recherche archéologique en Ubaye : des antiquaires du XVI e s. à l'archéologie contemporaine en haute Provence », Chroniques de Haute-Provence, bulletin de la société scientifique et littéraire des Alpes-de-Haute-Provence, $\mathrm{n}^{\circ}$ 356, p. 67-129.

ISOARDI D. et MOCCI F., 2019, «Spécificité des pratiques funéraires de la vallée de l'Ubaye et du Guillestrois durant l'âge du Fer : réflexion sur le genre et les parures dans le domaine funéraire, solutions pour mesurer l'implication d'une vallée intra-alpine des Alpes du sud dans les mouvements socio-économiques européens ? ", dans Bintz P., Griggo C., Martin L., Picavet R. (dir.), L'Homme dans les Alpes de la pierre au métal : actes de la table ronde AVDPA, Villard-de-Lans, 13-15 octobre 2016, Annecy, Éditions de l'université Savoie - Mont-Blanc (Edytem), p. 343-376.

KAENEL G., 1990, Recherches sur la période de La Tène en Suisse occidentale : analyse des sépultures, Lausanne, Bibliothèque historique vaudoise (Cahiers d'archéologie romande, 50).

LAGRAND C., 1987, « Die frühe Eisenzeit im Südosten Frankreichs », dans Fischer F., Bouloumié B., Lagrand C. (dir.), Hallstatt-Studien/Études hallstattiennes, Tübinger Kolloquium zur westeuropäischen Hallstatt-Zeit, Tübingen, Acta humanoria (Quellen und Forschungen zur prähistorischen und provinzialrömischen Archäologie), p. 56-88. 
LEVEAU P., 2003, «La période romaine dans les Alpes occidentales : un bilan des recherches », dans Boetsch G., Devriendt W., Piguel A. (dir.), Permanences et changements dans les sociétés alpines, Aixen-Provence, Edisud, p. 31-56.

LEVEAU P. et SEGARD M., 2006, « Le pastoralisme antique autour du col du Petit-Saint-Bernard », dans Apollonia L., Ballet F., Feuillet M.-P., Herrero D. (dir.), Alpis Graia : archéologie sans frontières au col du Petit-Saint-Bernard. Séminaire de clôture, Aoste, 2-4 mars 2006. Italia-Frania (Alpi), Projet Interreg IIIA Alcotra 2000-2006, Aoste, Alpes latines coopération transfrontalière Italie-France, p. 153-161.

MAHIEU E. et BoISSEAU B., 2000, « La nécropole de Ventavon (Hautes-Alpes) », Documents d'archéologie méridionale, vol. 23, p. 6-68.

MANSFELD G., 1973, Die Fibeln der Heuneburg 1950-1970: ein Beitrag zur Geschichte der Späthallstattfibeln, Berlin, Walter de Gruyter (Heuneburgstudien, 2).

MILCENT P.-Y., 2003, «Statut et fonctions d'un personnage féminin hors norme », dans Rolley C. (dir.,), La tombe de Vix dans l'histoire de la recherche, Paris, Picard, p. 312-327.

MILCENT P.-Y., 2006, « Les importations italiques au nord-ouest du midi gaulois (milieu du Xé-début du IV s. av. J.-C.) : inventaire et perspectives d'interprétation », dans Gori S. et Bettini M. C. (dir.), Gli Etruschi da Genova ad Ampurias, atti del convegno di studi etruschi ed italici, Pise/Rome, Istituti editoialie poligrafici internazionali, p. 319-355.

MILCENT P.-Y., 2013a, « Le contexte historique », dans Rolley C. (dir.), La tombe de Vix dans l'histoire de la recherche, Paris, Picard, p. 327-366.

MILCENT P.-Y., 2013b, « La nouvelle place des femmes dans l'espace funéraire en Gaule : des tombes à épée hallstattienne aux tombes à riche parure féminine ", dans Verger S. et Pernet L. (dir.), Une Odyssée gauloise : parures de femmes à l'origine des premiers échanges entre la Grèce et la Gaule, Paris, Errance, p. 136-141.

MILLOTTE J.-P., 1991, « Contribution à l'histoire de la recherche archéologique dans les Alpes françaises : le rapport Charles Chappuis ", dans Duval A. (dir.), Les Alpes à l'âge du Fer : actes du $10^{e}$ colloque de l'AFEAF, Yenne-Chambéry, 1986, Paris, CNRS éditions (Revue archéologique de Narbonnaise, 22), p. 255-270.

MORDANT C., KROLIKOWSKY F., SALIGNY L., GABILLOT M., 2004, « Approches de la notion de flux de métal au sein des sociétés européennes de l'âge du Bronze », dans Lehoërff A. (dir.), L'artisanat métallurgique dans les sociétés anciennes en Méditerranée occidentale: techniques, lieux et formes de production, Rome, École française de Rome, p. 264-285.

MÜLLER A., JORDA C., GASSEND J.-M., 2004, « L'occupation humaine de la vallée de l'Ubaye et les modalités du peuplement de la zone intra-alpine », Méditerranée, vol. 102, nº 1/2, p. 95-108.

OLLIVIER A., 1883, Vallée de Barcelonnette : simple relation sur quelques monuments celtiques découverts dans cette vallée, Digne, Barbaroux, Chaspoul et Constans.

OLLIVIER A., 1884, « Âge préhistorique dans les Basses-Alpes : période du Bronze », Annales des Basses-Alpes, vol. II, $\mathrm{n}^{\circ}$ 12, p. 25-29.

OLLIVIER A., 1889, Une voie gallo-romaine dans la vallée de l'Ubaye et passage d'Annibal dans les Alpes: étude historique, Digne, impr. F. Giraud.

PALTINERI S., 2010, La necropoli di Chiavari: scavi Lamboglia (1959-1969), Bordighera, Isituto internazionale di studi liguri (Monografie preistoriche ed archeologiche, 17). 
PRIMAS M., 1967, « Zur Verbreitung und Zeitstellung der Certosafibeln », Jahrbuch des RömischGermanischen Zentralmuseums Mainz, $\mathrm{n}^{\circ}$ 14, p. 99-133.

ROUZEAU N., 2011, « Montclar, Saint-Léger », dans Bilan scientifique de la région Provence-Alpes-Côted'Azur, Aix-en-Provence, Service régional de l'archéologie PACA, p. 32-33.

SABATIER M., 1985, Les vallées de la Haute-Durance et de l'Ubaye à l'époque protohistorique, Paris, École du Louvre (Mémoires de l'École du Louvre).

STÖCKLI W. E., 1975, Chronologie der jüngeren Eisenzeit im Tessin, Basel, Verlag Schweizerische Gesellschaft für Ur- und Frühgeschichte (Antiqua, 2).

TENDILLE C., 1978, « Fibules protohistoriques de la région nîmoise », Documents d'archéologie méridionale, $\mathrm{n}^{\circ} 1$, p. 77-112.

TREFFORT J.-M., 2002, «L'habitat du Hallstatt final de Crest-Bourbousson 1 (Drôme) », dans Archéologie du TGV Méditerranée, t. 2 : La Protohistoire, Lattes, Association pour la recherche archéologique en Languedoc oriental (Monographies d'archéologie méditerranéenne, 9), p. 3/3-396.

TREMBLAY CORMIER L., 2014, « Le mobilier métallique méditerranéen comme témoin des échanges à longue distance entre Rhin et Rhône, du $10^{\text {ème }}$ au $5^{\text {ème }}$ siècle avant notre ère ", dans Barral P., Guillaumet J.-P., Roulière-Lambert M.-J., Saracino M., Vitali D. (dir.), Les Celtes et le nord de l'Italie, Dijon, Association archéologique de l'Est (Revue archéologique de l'Est, supplément 36), p. 297-309. TREMBLAY CORMIER L., 2016, Identités culturelles et échanges entre Rhin et Rhône du $10^{e}$ au $5^{e}$ siècle avant notre ère, Dijon, Éditions universitaires de Dijon (Art, archéologie \& patrimoine).

VERGER S., 1991, «L'utilisation du répertoire figuratif dans l'art celtique ancien », Histoire de l'art, vol. 16, p. 3-17.

VERGER S., 2013a, « Les dépôts launaciens », dans Verger S. et Pernet L. (dir.), Une Odyssée gauloise : parures de femmes à l'origine des premiers échanges entre la Grèce et la Gaule, Paris, Errance, p. 100-107.

VERGER S., 2013b, « La défunte de la tombe de Vix, descendante des femmes gauloises exceptionnelles du début du $\mathrm{VI}^{\mathrm{e}}$ siècle ? ", dans Verger S. et Pernet L. (dir.), Une Odyssée gauloise : parures de femmes à l'origine des premiers échanges entre la Grèce et la Gaule, Paris, Errance, p. 368-373.

VITALI D., 2001, « I Celti a sud del Po », dans Cuscito G. (dir.), I Celti nell'alto Adriatico, Trieste, Centro di Antichità altoadritiche (Antichità altoadritiche, XLVIII), p. 227-239.

WiLligens M.-P., 1991, «L'âge du Fer en Savoie et Haute-Savoie », dans Duval A. (dir.), Les Alpes à

l'âge du Fer, Paris, CNRS éditions (Revue archéologique de Narbonnaise, 22), p. 157-226.

\section{RÉSUMÉS}

Les sites de l'Ubaye (Alpes-de-Haute-Provence), une vallée de haute montagne isolée témoignant durant l'âge du Fer d'une production de parures en bronze originale et d'une grande richesse, permettent ici de tester de nouvelles approches sur le costume funéraire. Notre démarche a consisté à reprendre une documentation mise au jour principalement au XIX siècle pour réfléchir au genre des inhumés et à l'évolution au cours de l'âge du Fer des personnes mises en avant dans le domaine funéraire. On s'intéressera ensuite à l'identification des objets exogènes ou d'influence exogène, et surtout à la manière de les quantifier, afin d'apprécier les relations de la vallée avec les autres régions européennes. À partir de ces premiers résultats, on proposera de nouvelles hypothèses quant aux modalités de circulation de ces biens, voire des individus: 
hypothèses ouvrant de nouvelles perspectives sur le rôle de cette petite vallée reculée au sein des mouvements européens contemporains.

As a high mountain valley topographically isolated from the main north-south roads (such as the Durance's axis), but showing, during the Iron Age, a production of original and rich bronze ornament, the Ubaye valley is a perfect study ground to test new approaches about funeral costume. Firstly, we have re-studied old documentation (mainly gathered in the 19th century), to reflect on the gender of the buried people and the evolution of the special funerary treatment of persons. In a second phase, we have re-examined the identification of exogenous objects, and above all, of how to quantify them, in order to appreciate the valley's relationships with other European regions. From these first results (which will undoubtedly evolve during the ongoing studies), we are now able to propose news hypotheses concerning the modalities of circulation of these particular goods; and even, maybe, of the individuals themselves. These hypotheses open up new perspectives on the role of this remote little valley within the contemporary European movements.

\section{INDEX}

Mots-clés : âge du Fer, bronze, circulation, costume funéraire, genre, mobilité, parure, projection linéaire, quantification

Index géographique : Alpes du sud, vallée de l'Ubaye

Keywords : funerary costume, gender, Bronze, circulation, mobility, ornament, quantification

\section{AUTEURS}

\section{DELPHINE ISOARDI}

Aix-Marseille Université, CNRS, Centre Camille Jullian, Aix-en-Provence, France

\section{LAURIE TREMBLAY CORMIER}

Chercheuse associée au laboratoire Archéologie et histoire ancienne : Méditerranée-Europe

(Archimède, UMR 7044, université de Strasbourg/université de Haute-Alsace/CNRS) 